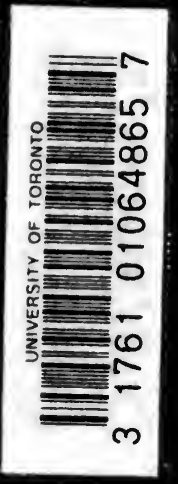




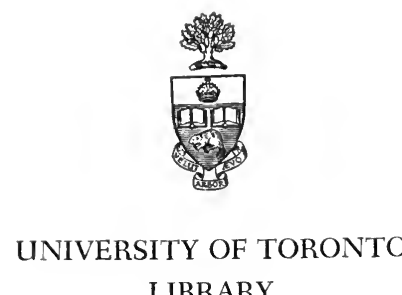

LIBRARY

WILLIAM H. DONNER

COLLECTION

purchased from

a gift by

THE DONNER CANADIAN

FOUNDATION 

Digitized by the Internet Archive in 2007 with funding from Microsoft Corporation 



\section{INDEX VERBORUM}

TO THE

\section{Published Text of the Atharva-Veda.}

BY

\section{WILLIAM DWIGH'T WHITNEY,} PROFESSOR IN YALE COLLEGE.

[Yol. XiI. of the Journal of the A Merican Oriextal Society.]

NEW HA V E N :

FOR THE AMERICAN ORIENTAL SOCIETY,

Printed by Tuttle, Morehovse axi Taylor, Printers to Yale College. MDCCCLXXXI.

SOLD BY THE SOCIETY'S AGENTS:

NEW YORK:B. WESTERMAN \& CO., 838 BROA IN WAY; LONDON: TRÜBNER \& CO.; LEIPZIG: F. A. BROCKHAUS;

PARIS: E. LEROUX. 


$$
\begin{aligned}
& P_{k} \\
& 3409 \\
& w_{5} \\
& 1881
\end{aligned}
$$

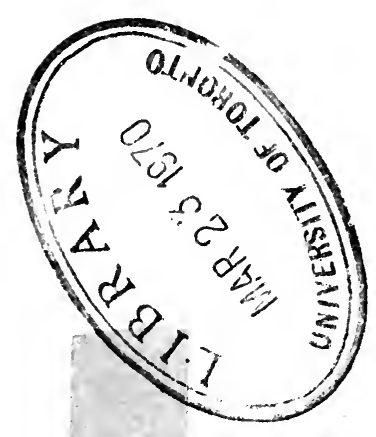




\section{INDEX VERBORUM}

TO THE

\section{PUBLISHED TEX'T OF 'THE A'THARVA-VEDA.}

\section{INTRODUCTION.}

The work here made public was begun in 1851, when the Atharvan manuscripts at Berlin were first taken in hand by me, in a way which led later to the publication of the text of that Veda by the joint care of Professor Roth of Tübingen and myself.* Its collection and arrangement occupied more or less of my time until the end of 1875 , having been in considerable part so carried on that the material should be furnished in instalments for use by the editors of the St. Petersburg Sanskrit Lexicon. Our original intention was that it should form part of the second volume of our publication, along with other indexes, notes, translation, etc. But the appearance of that volume is still indefinitely delayed by the collection of needed material, as well as by the absorption of Professor Roth in other labors; and, on the other hand, it has not appeared possible to get such a work as this produced in the ordinary way of business, without the aid of some learned association. Hence, with the full approbation of Professor Roth, the Index, as a work of independent character and value, has been offered to the American Oriental Society, and accepted for publication in the Society's Journal, in which had already been brought out, some years ago, the Prătiçakkhya belonging to the same text. $\dagger$

As stated in the title, the Index is that to the published text of the Atharvan. By this is meant, in the first place, that it has no

* Atharva-Veda Sanhita, herausgegeben von R. Roth und W. D. Whitney. Erster Band, Text. Berlin, 1856. roy. 8vo.

† Atharva-Veda-Prātiçākhya, or Çāunakīyā Caturādhyāyikā, Text, Translation and Notes. By W. D. Whituey. From Journ. Am. Or. Soc'y, Vol. VII., 1862. 
reference to the other, the so-called Päippaläda text, ${ }^{*}$ hunted up a few years ago in Cashmir at the instance of Professor Roth, $\nmid$ and thus far represented by a single inaccurate and mostly unaccented manuscript on strips of birch-bark, now in his hands. The latter text is too different from the other, and at present too imperfect, to allow of the two being worked up and presented together in Index form. It will in due time perbaps require to have its peculiar material cast into such form independently. In the second place, it is meant that due account is taken of such readings of our edition as do not rest on manuscript authority. It dil not seem fossible to the editors to let the text pass through their hands without some amendment of its numerous and obvious false readings, and some attempts to bring sense out of the utter nonsense which constitutes part of the last two books. There will, of course, be differences of opinion as to whether this was well-advised-whether they should not have contented themselves with giving just what the manuscripts gave them, keeping suggested alterations for their notes; and, yet more, as to the acceptableness of part of the alterations made, and the desirableness of others which might with equal reason have been made. No attempt is here made to amend the text further; nor, again, to criticize the amendments made: for either of these things an Index is no suitable place. It is sought simply to call attention to all cases in which a published reading differs from that of the manuscripts, as well as to those comparatively infrequent ones where the manuscripts are at variance, and to furnish the means (in books xix. and xx., partly with the aid of the variants reported at the foot of the page) for determining in any particular case what the manuscripts actually read. Not every unintelligible complex of letters in the last two books, to be sure, is given; and, on the other hand, a printed word which has absolutely no manuscript authority (as shown by the foot-notes to the text) is ocsasionally ignored.

There are, however, parts of the text of which the material is not included in the Index. Thus, especially, most of the twentieth book, it being made up of extracts taken bodily (both in their samhita- and their pada-form) from the established text of the Rig-Veda: these obviously constitute in no proper sense a part of the Atharvan, and it were useless labor to duplicate their material from the Rig-Veda Index. The parts of this book which are peculiar to the Atharvan, and therefore included in the Index, are as follows: the kuntāpa-süktāni, or hymns 127-136; the single hymns 2 (in prose), 48, and 49 ; and of hymn 34 the three verses 12,16 , and 17. Of all these the text is in a sad condition; in part, it is nonsense, or even worse. But further, a considerable number of verses (fifty-two), scattered everywhere through the text, are given in all the manuscripts only by their first words with ity eka, iti dve, etc., added, as being repetitions without

* The title of tlie Cashmir text to this name is not beyond question.

† See Der Atharva-Veda in Kaschmir, von R. Roth. Tübingen, 1875. 4to. 
variant of verses already given; and these have not been indexed in their second occurrence. The list of them is as follows:

\begin{tabular}{|c|c|c|c|c|c|}
\hline 17.3 & 283 & $x$ & 3.5 & vi. & 85.1 \\
\hline 6. 1 & 1.1 & ג. & 5. $46-7$ & vii. & $\begin{array}{l}\text { 8. } 1 \\
89,1,2\end{array}$ \\
\hline 2 & 7.7 & & $48-9$ & viii. & 3. $12-3$ \\
\hline $23.10-2$ & $32.3-5$ & xi. & 10.17 & v. & 8.6 \\
\hline 58.3 & 39.3 & xiii. & 1.41 & ix. & 9.17 \\
\hline 84.4 & 63.3 & & 2.38 & $\mathrm{x}$. & 8.18 \\
\hline 94. 1,2 & 8. 5,6 & xiv. & 1. $23-4$ & vii. & 81. 1, 2 \\
\hline 95. 1. 2 & v. $4.3,4$ & & 2.45 & & 112.1 \\
\hline 101.3 & 4. 7 & xviii. & 1. $27-8$ & & $82.4,5$ \\
\hline vii. 23.1 & 17.5 & & 3.57 & xii. & 2.31 \\
\hline 75.1 & 21.7 & & 4.25 & xviii. & 3. 68 \\
\hline 112.2 & 96.2 & & 43 & & 69 \\
\hline viii. 3.18 & 29.11 & & $45-7$ & & $1.41-3$ \\
\hline 22 & 71.1 & & 69 & vii. & 83.3 \\
\hline 9.11 & 10.4 & xix. & 13.6 & vi. & 97.3 \\
\hline 1.15 & 89.2 & & 23. 20 & xix. & 22.21 \\
\hline 3. 23 & 12.9 & & 24.4 & ii. & 13.2 \\
\hline 10.4 & 73.7 & & $27.14-5$ & xix. & 16. 1,2 \\
\hline 20 & 11 & & 37.4 & v. & 28.13 \\
\hline 22 & 22.1 & & 58.5 & ii. & 35.5 \\
\hline 1.4 & 18.5 & & & & \\
\hline
\end{tabular}

Moreover, xiii. 3.18 is the same with ix. 9. 2, save for the added refrain; and ix. 10.5 has but a single variant from vii. 73.8 ; and I have omitted them (excent the variant) in indexing.

With the exceptions thus stated, the Index is intended to be a complete one, giving every word and form, even down to $c a$ and the cases of the demonstrative and relative pronouns, in every instance of its occurrence.

As regards the form in which the references are made, certain explanations require to be given.

First: as no inconsiderable amount (about one seventh of the metrical part) of the Atharvan is found also, with more or less differences of reading, in the Rig-Veda, the Index has due regard to the fact, and endeavors to show at a glance, respecting any given word or form, not only what occurrences it has in the Atharvan, but which of these are additional to its Rik occurrences. To this end, every occurrence which is also a Rik occurrence, the word or form being found identically in a Rig-Veda passage to which the Atharva-Veda passage corresponds, is marked by an added asterisk (*). And further, one to which the Rig-Veda offers a variant, of any kind or degree, is similarly marked by an added dagger $(\dagger)$. It would, of course, be of interest also to exhibit in like manner the relation of the Atharvan material to that of other texts, Veda or Brāhmana or Sūtra; and, unquestionably, better and more original readings are sometimes given in those other texts than in the corresponding passages of the Atharvan. But it would be impossible to accomplish all this without embarrassing the Index with a burdensome variety of signs. And, again, the Atharva-Veda is certainly in general entitled to rank next after the Rig.Veda; and the indexes of the 
other texts, when they are made, may suitably be subordinated to this, as this is subordinated to that of the Rig-Veda.

secont: the form given to each vocable by the pada-text is everywhere inclieated, as regarls the two items of division by the avrigraher-sign into component parts and restoration (samapatti: Prät. iv. $73 \mathrm{ff}$.) of more normal form by removal of Vedic irregularities etc. For avagraha-sign is used a small eircle, that being its usual form in the Atharvan pada-manuscripts;* and, wherever seen, this is the indicator of pada-text division; the hyphen is employed for purposes like our own, or as sign of the omission of part of a word. For brevity's sake, in the case of declined stems, the pada-division is shown only in the stem at the head of the series, unless its place is ehanged by the further addition of a separable ending. The $i t i$ which is added after a pragrhya or uncombinable form is always reported. In other respects, of no practical importance, the word-form or pada-form, as determined by the rules of external sandhi, is not servilely adhered to. Thus, final $s$ and $r$ are always written instead of $h$; an etymological sonant is often written instead of a surd, both as final and before the avagraha-sign; and in the latter situation the anusvära or $\dot{m}$ is sometimes read instead of the $m$ which (with avasāna-sign added) is regularly given by the manuscripts. $\nmid$ In short, the intention is to render the publication of a pada-text unnecessary, by giving any one at all acquainted with such things the means of readily and accurately determining the pada-reading of every item of the Atharvan vocabulary.

To illustrate: ançuománt having been given at the head, the inflected forms exhibiting this division-as ançuomántam, ançu॰mátīs-are written without the sign of separation; while the loe. pl., if it occurred, would be written as ançumátosu, and the dat.-abl. pl. as ançumádıbhyas (instead of ançumáto bhyah, the precise pada-form). A pragrhya word has its final repeated in parenthesis with íti appended: thus, asmé (p. -é iti); and one that is both pragrhya and avagrhya, and which the pada-text (Prãt. iv.74, note) gives undivided before iti and divided after it, has etc. added to the íti: thus, the padareading adhipatì íty ádhiopatī is indicated, under the heading ádhiopati, by ádhipatī (p. -ī íty etc.). In any ease where special eircumstances require it, more than this is done; and, in general, more regard is had to brevity and distinctness than to eousistency in all such matters.

It must be borne in mind that no pacla-text for the kuntapahymns has come to light, nor any of any value for the other peculiar parts of the last book, and that that for the nineteenth book is of inferior character and insufficiently established (virtually on a single manmseript only). Also, that the division of a word which would otherwise be made is now and then prevented by the occurrence of the word only before the enclitic iva (since

* This sign is used in all the pada-texts, even of book xx., excepting in the Munich text of xviii. and $x x$.

t The agreement of the manuseripts in writing $m$ with avcesana as final is not complete, but this mode is much more usual than the other. 
this has always the avayrahr before it, and excludes any other division).

Third: it is sought (after Grassmann's example) to exhibit the metrical form of each word, so far as this can be done with a tolerable degree of confidence. There are not a few doubtfiul cases, even in the Rig-Veda, and they are much more numerous in the Atharvan, on account of the greater irregularity of its metrical form-the very frequent occurrence of pädas which are defective or redundant by a syllable, if nothing worse. Hence I have limited the restoration to the more obvious and unquestionable cases: the resolution of the semivowels $y$ and $v$ into the vowels $i$ and $u$, and that of the (gen. pl.) ending $a m$ into aam.

To illustrate: under the stem aghnya (the stems are always written in the form required by the later rules, and their alphabetic arrangement is in accordance with this), the forms are written with ya or with ia aceording to their estimated value in the metre; and so. under the root sā, either syămi or siãmi in composition with prefixes, either vioácanti or vy àcasva; and in other cases, as of compound words, the same difference is shown by other intelligible methodsoftenest, by putting the metrical reading in parenthesis, with $l$. (lege) before it.

It is to be noted that, as in the Rig-Veda (see Professor Lanman in Proceedings Am. Or. Soc. for May, 1880), the great majority of the resolutions of the endings bhyas, bhyām, and àm into the dissyllabic forms bhias, bhiàm, and aam are made at the end of anustubh pãdas, where, if we admit catalectic pãdas of seven syllables (Lanman, as above), the resolution is unnecessary. This is true of 51 out of the 69 occurrences of bhias; of 6 out of 10 of those of bhiam; and of 29 out of 33 of those of aam. It is also true of 7 out of the 10 cases in which the lost $a$ of the endings an, man, van requires to be restored.

The instances in which $r$ is with more or less probability to be read as a sylla. - ble ( $r$ or $a r)$ are reported here rather than in the Index below. They are: stem indra, vii.24.1; 84.2 : viii.5.2 1 : xix.15.2;-stem rudra, vii.87.l : xi. 2.3 : xviii.1.40 : xix.9.11; 10.6 ;-stem vajra, x.9.1 : xi.10.12, 13,27 : xii.2.9;-stem mitra, i.3.2 : xiii.3.13;-stem hotı $\overline{\mathbf{a}}_{\text {; }}$ xi.6.14; 7.19;-stem prāṇa, ix.1.2: xi.2.3;-stem candra, i.3.4;--stem tantra x. 7.42 :- -stem rāṣțra, x.10.8;-stem pātra, x.10.9;-pitros, xx.34.16;-çaçre, iv.18.6: v.31.11;--dadhre, xviii.3.63;--kran, viii.6.25 :-pra, ii. $1.2 ; 34.2$ : vii. 18.1 .

For a more complete and detailed statement of this elass of phenomena, this is not the fitting place.

A noteworthy amount of the Atharvan text, however, is in prose; and in this part of its material, of course, no restoration of the kinds here referred to has been attempted.

It may be convenient to have here for reference a compact list of the prose passages. It is this:

Books: $x \nabla .$, and most of xvi. (except verses $1.10,12,13 ; 4.2,6 ; 6.1-4,11$; 9.1, 2).

Hymns: ii.11; 16-24: iii.26; 27 : iv. $9 ; 10 ; 16 ; 24 ; 26$ (with metrical matter intermixed); 27 (do.): vi.10; 48: vii.88: viii.10: ix.6 (except verses 1, 2); 7 : x.5 (except verses $22-4,42-3,45-50$, and parts of verses $7-14,36-41,44$ ): xi.3 
(except verses 19-22): xii.5 (except verses $15-7,47-53,55-70):$ xix.17; $18 ; 19$; $21 ; 22$ (except last verse); 23 (do.); $51 ; 60 ; 61 ; 69 ; 70:$ xx.2.

Parts of hymns: iv.39.1-8: v.6.9-14: vi.46.1, $2 ; 123.3,4$ : vii.81.4, 5; 97.5-8: viii.8.22-4 : ix.1.21-4; 3.25-31; 5.16, 20-2, 31-6 : xii.3.55-60 (in part): xiii.4.14$5,22-6,46-56$ : xvii.20-3: xviii.3.25-8 (in part), 30-5 (do.), 36-7; 4.27, 67-8, 71$4,76-8 i$ : xix.44.4, $5 ; 45.6-10 ; 57.2-4,6$.

Single verses: iii.29.7: v.21.12: vi.44.3; 79.3; 83.4: vii.89.4: viii.1.14: ix. $2.13 ; 10.24$ : xii.2.42: xix.9.14; 31.12 .

It is not, however, possible to draw everywhere a sharp line between metrical and non-metrical matter; prose and loose verse slide into one another sometimes in a perplexing manner, or are mixed up in the same stanza. . here.

Two or three more points call for a few words of explanation

Cases of identical form in the same number are not distinguished from one another: thus, for example, the nominatives and accusatives neuter (nor, in adjective-stems in $a$, is the accus. masc. sing. separated from the neuter), the genitive and ablative singular, the dative and ablative plural, and so on. But the homophonous cases of different numbers are always given separately; and vocatives are distinguished from nominatives and accusatives in all numbers.

The treatment of prepositions in connection with roots is not a simple matter: the plan here adopted is as follows. The normal cases, of a verb-form with immediately preceding preposition, are given under the root as combined with that preposition; and so also when more than one preposition precedes, provided those before the last lose their independent accent, testifying thus to the unity of the combination. A verb-form that has belonging to it a single preposition standing before it with the intervention of other words, or standing after it, is entered along with the preposition (the two being separated by interposed dots) ; but the latter, as not so fully subordinated to the verb, is entered also as a separate word, under the head of the preposition itself-as are, of course, all its other more independent occurrences.

To illustrate: pári yanti and parioyánti are found under $/ \mathbf{i}+$ pari; $\mathbf{a}$ ca párā ca yánti appears as á... yánti and párā... yánti under $d^{\mathbf{i}}+\overline{\mathbf{a}}$ and $\mathcal{l}_{\mathbf{i}}$ + parā, and the á and párā have their references also under those prepositions; sampráyacha is given only under $\sqrt{ }$ yach + sampra, but the á of á prá drava is quoted under $\overline{\mathbf{a}}$, while the rest is given under $\sqrt{ } \mathbf{d r u}+$ pra-and so on. In all such combinations, where verb-form and prefix are contiguous, the metrical form of their combination, as two syllables or one, is indicated, as pointed out above.

This nethod has been preferred to the one followed by Grassmann in his Rig-Veda Index, because for exegetical purposes it is important to have all the combinations of a root with a given preposition or congeries of prepositions together under one's hand; and it is far more difficult to assemble them from Grassmann's Index, than to assemble from this one the aceordant forms from under the different prepositional sub-headings when the investigation of forms is the object had in view. 
Under each preposition, then, are given references to all the passages in which that preposition occurs otherwise than immediately before a verb-form and constituting an accentual unity with it. Further are mentioned all the roots with whose forms it occurs in combination, or from whose combination with it derivatives oceur; and finally, all its own derivatives and eompounds not rehearsed under the roots.

Under each root is given the list of all its primary derivatives found to occur or implied in secondary derivatives that occur; and, under each root + a preposition, such derivatives from this combination. Further, under each stem is given the list of all immediate derivatives from it, and of all compounds into which it enters as a member.

Gerundives, simple or compounded, are given in their alphabetic place, and not along with the more proper verb-forms and verbal adjectives and nouns, under the roots.

The method of giving the cases of pronouns under the head of the form recognized by the Hindu grammarians as stem-thus, aham etc. under mat, ayam and anena and asmāi etc. under idam, and so on--has seemed to me too artificial to be retained, and such cases will be found under the actual pronominal roots or stems to which they are to be referred; isolated forms, like aham and adas etc., being put in their own alphabetic place.

No stem or form is accentuated unless it occurs in the Atharvan text with the accent marked. Stems given as the basis of compounds or further derivatives are also left without accent.

The root-sign $(\sqrt{ })$ is set not only before actual roots, but also before any derivative or denominative quasi-root. It merely indicates an element from which verb-forms are made.

In giving verse-numbers, a dash is used (e. g., under asmāi, in 10. 5. 7-14) only when the same phrase is repeated in a number of successive verses; otherwise, each verse is separately mentioned. A superior figure added to a verse-number indicates (after F. M. Müller's example in the Index of Rig-Veda padas) how many occurrences of the given word are found in that verse.

The mode of construction of the reversed Index of roots and stems will be explained at the beginning of that Index.

A small extra edition of the work is printed, on large paper, so as to admit of being bound up with, or in a manner to mateh, the Atharvan text itself, as also in order to furnish more roomy margins for annotations. 


\section{SIGNS AND ABBREVIATIONS.}

\section{[For further explanations, see the Introduction, above.]}

* marks an occurrence found also in a corresponding Rig-Veda passage; $\dagger$ marks a variation from the reading of a corresponding Rig-Veda passage; - represents the avagraha or division-mark of the pada-text; p. signifies 'pada-text;' mss. signifies 'the manuscripts ;'

s. mss. signifies 'some of the manuscripts ;'

m. mss. signifies 'most of the manuscripts ;'

ed. signifies 'edition' (published text). 


\section{N D E X}

a (pron. root) : enă. 4. $8.7 ; 30.8^{\circ}$. 5. II. $5^{2}, 6^{2}$. 9. 9. $6^{*}, 17^{*}, 18^{*}, 22^{\dagger}$; I0. $25^{*}$. I2. 3.33 I4. I. $2 I^{*}$. 18. I. $50^{*}, 60^{*}$.

ayă. 7. 3. I. 19. I2. I".

asmāí. $\quad$ I. $30.3,4$. 2. $29.1,2^{3}, 5$. 3. $8.4 ; 17.5^{\dagger} ; 28.3$. 4. $22.2,4 ; 31$. 3 (ed. * asmé). 5. I. 3 (m. mss. asmé); $3.3^{\dagger} ; 4.7 ; 26.9 ; 30.12$. 6. 40. 2 ; 54. $2^{2}$; 80.2. 7. 78.2; 97.3. 8. 2.6, $8 ; 5$. IO; $7.6,23,24,27$. I0. 5. 7-I4. 12. 2.45 . I4. I. $33^{2} ; 2.24,31 . \quad 18$. I. $55^{*} ; 4.34$. I9. $30.2 ; 38.2 ; 55$. I. asmāi. 2. $5.6^{*} ; 28.5 ; 29.5^{2}$. 3. 3 . 2. 4 . $6.3 ; 22$ I. 5. I. $9 ; 14.4 ;$ I 7 . I7; I9. I5. 6. 78.1 ; I23. 2 ; 12 S. I. 7. 14. $3^{2}$; I8. 2 . 8. 2.5 , IO; Iо. I6. 9. $5.24,25,26$. I0. $2.15^{2} ; 5.50$; 6. 6-II, I3, I5. II. $2.8, \mathrm{I} 8,22$. I2. 4. I8, I9, $35^{2}$. I8. I. IO*, $55^{*} ; 2.12^{*}$, $\mathrm{I}^{2+}, 37 ; 3.5 \mathrm{O}^{*}, 5 \mathrm{I}^{*}$. I9. $4 \mathrm{I}$. I $; 52.3$. 20. 135 . 12.

asyāí. 2. 36. I. 6. 60. I, 3. II. I. 3, II. I2. 3. II. I4. I. 3I, 59; 2. 9, I3, $21,27,28^{\dagger}, 29,73,74$. I5. I3. 8 .

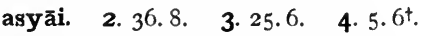
6. $78.3 ; 8$ I. 3. 8. 6.3. 14. I. 39 . asmát. 8. 1. $4 ; 7.5$. 9. 2. 17, I8. 12. 5.38 . 18. $2.28 ; 4.49$.

asyá. I. $9.2 ; 32.2$. 2. 5. 2 . 4. 2. I"; $4.6 ; 22.2 ; 28.6$. 5. I2. II*; $23.2 ; 27.10 ; 29.2,3,4$. 6. 28. 3 ; 31. $2^{*} ; 34.5^{\dagger} ; 48.1-3 ; 52.3 ; 54.1$; 68. 3 ; 73. I; IOI. 2. 7.95. I. 9. 9. I $^{*}, 5^{*}$; IO. IO*. I0. 8.9. I I. 4. 23, 24. I8. I. $5^{*}, 7^{*}, 48^{*} ; 4.89^{*}$. I9. 6 . $3^{\dagger} ; 49.5$ (mss. açva-).

asya. I. 2.1 ; I2. 3 . 2. I. 2 ; 9.3 ; 32. 2, 5. 3. 7.2; II. 6 . 4. I. I, 3, 6; II. $4^{2}, 5,8$, I2; I4. $8^{2} ;$ I6. 4,$5 ; 2$ I. $2^{*}$; 22. I, 3 ; 24. I ; 28 . I ; 30. $7^{*} ; 34 . \mathrm{I}^{3}$.
5. $8.3,4 ;$ I $3.3 ;$ I 7. I 2, I 4, I5, I6, I 8 ; I8. $6^{2} ; 22.5^{2} ; 23.9 ; 27.1,5,7 ; 29.5$, IO, I2, I5; 30. 13. 6. $3.2 ; 6.2$; I4. 2 ; 20. I; 76.3; 134. I; 138.2, 3. 7 . I4. 4 ; I5. I ; 20. $3 ; 26.4^{*} ; 45.2 ; 47$. $2 ; 56.5 ; 57.2^{*}, 2^{2+} ;$ 7O. I, $2^{2} ; 9^{\circ} .2^{*}$; 95. I, 3. 8. 4. II ; IO. $3,5,6,7, I 8$, 2I, 33. 9. I. $23 ; 4.4,7,16 ; 5.23$, $24 ; 9 . \mathrm{I}^{*}, 5^{*}, \mathbf{I} 8^{*}$. I0. $2.5^{2}, 8, \mathrm{I} 5^{2}$, $26 ; 3.16 ; 4.7 ; 5.50 ; 7 . I^{4}, 2,3,9$; 8. $7,8,12,13,18,24 ; 9.4$. I I. 2.28 ; 3. $7^{2}, 8,22 ; 4.22,25 ; 8.3$ I. I2. 3 . $45 ; 4.3, \mathrm{I} 3,27^{2}, 38 ; 5.42,43,68^{2}$, $69^{2}, 70^{2}, 7$ I. I3. 2. I, I4, I8* 32,45 ; 3. I4, $24^{*}$. I5. I. 7 ; 3. II ; 5. I-7; I2. 6,7 , IO, II; I3. $9 ;$ I5.3-9; I6. I -7 : 17. I-7; I8. $2^{2}, 3^{2}$. I 8. I. $5^{*}, 33^{*}$, $36^{*} ; 2.4^{*} ; 3.71 ; 4.34,44$. 19.6.2*, $3^{2 *}, 5^{*}, 6^{2 *}, 10^{*}, 15^{*} ; 32.2 ; 53.2$.

asia. $7 \cdot 89 \cdot 2^{*}$ (s. mss. asyá).

asy $\bar{a}$ (p. asya). I. I2. 2.

asyấs. 5. 12. $4^{*} ; 25.10-3.6$ 6. 60. 2. 7. 8. I ; I2. 3 ; IO3. I. 8. 6.9, I5. 9. IO. $5^{*}$. I2. $3.40 . \quad$ I $4.1 .48 ; 2.25$, 68,69 .

asyās. I. I4. I. 5. I7. 3*, I7; I9. $5^{2}$. 7. 20.5. 8. $6.5 ; 9.10^{3}$. 9. I. 2 , $3,6,7$; I0. $23^{\dagger}$. Io. I0. $5,23,24,3$ I. I2. $4.5,6,7,8,15,18^{2}, 27,28$. I4. I. $10^{*}, 26^{*}, 57 ; 2.2^{*}$. I 8. 4.32 . 20. $\mathrm{I} 36 . \mathrm{I}^{2}, 2$ (mss. asyằs).

asiās. 12. 4.9 .

asmín. I. 9. I ; II. I ; I5.2 ; 20. I ; 30. I; 35.3. 2. 26. I. 3. I4. 3 ; I8. 3*. 4. 4. 4,8 ; 6.3 ; 22.3. 5. 3. 8*; 24. I-I ${ }^{2} ; 26.2,3,7,8-I I ; 28.4 .6$. 47. 2 ; 85. I; II7.3. 7. 43. I; 47.I; 58. $2^{*}$; 97.1". 8. 5. 21 ; 7.II. 9. 4 . $23^{\dagger} ; 5 \cdot 2,7$, II ; 9. I $7^{\dagger}$. IO. 3. I9, 20, 23,$24 ; 4.8$. I2. 2 . I3. I4. I. $2 \mathrm{I}^{*}$; 2. 48,49 I 5. I2. 7 , II. I8. I. $42^{\circ}$ 
$59^{*} ; 3.20,67^{*} . \quad$ I9. $27.10 ; 46.5,5$ (mss. asmin).

asmin. 5. 19.3. 9. I.6. I0. 2. II, $12^{2}, 13^{2}, 14^{2}, 17^{2}$, I9; 3. I 7; 8.24. II. 8. $16,17,32$. 12. 3.3 . I3. 4 . 13, 21 . asyăm. 3.26. 1-6. 5. 24. I-1 $7^{6}$. 19 . 47.2 .

asyām. 3. IO.4. I0. 10. 3, 33. 12. 5. I3, I4. I4. 2. I4.

ābhis. 2. 2.3.

ebhyás. 8. 8.24.

ebhyas. 2. $35 \cdot 4$. 3. $27.1-6.6 .93$. 2. I0. $6.16 ; 9.7$. II. I. 26,32 .

ābhyás. 3. 3.3.

[I7.

ābhyas. 6. 5 I. $2^{*}$; I 4 I. I. 10. 6. I4, eșấm. I. $29.6^{*}$. 3. 19. $2,5^{4}$. 6. 84 . I II2. I, 2. 7. I2. 3. I2. 2. $25^{*}$. I4. I. $2^{*}$. I9. 28.4 .

eșām. x. $7.7 ; 8.4^{2} ; 9.4$. 2. 26.2 ; 32. 4 ; 35. 4. 3. I. $2,4^{\dagger} ; 2.4^{3}, 6$; 19 . 8. 4. I6. I; 33. $3^{*} ; 34.2^{2} ; 36.4 .5$. 3. $2^{*}$. 6. $47.2 ; 64.2^{*} ; 66.1,3^{2}$; I04. I. 7. 108. I. 8. $3 \cdot 6^{*} ; 4 \cdot 3^{\dagger} ; 8.6,20^{2}$. 9. I0. $26^{*}$. I0. 1. $17 ; 8.5,8,28^{3}, 36^{2}$. I1. $6.9 ; 9.13^{2}, 23$; I0. $16^{2}, 2$ I. 12. 2. $23^{*}, 46 ; 3.16$. I4. 2. 27 . I5. I7. Io (m. mss. éşām). 18. 1. $6^{*} ; 3.62$. 19. $13.9^{\dagger} ; 45.5 ; 53.4$. 20. I27. 5 (mss. eșấm): I 32. 8, 9 .

āsām. 1. 32.2. 2.2.3; I4. 6 (āsaam). 3. 13.6. 4. $21 \cdot 3^{*}$. 7. 74. $2^{2}$. 8. 7. $12^{2}$. 12. 4 . 45. 20. I 27. I3 (mss. àsắm), I3 eșú. 14. 2. 9 .

eșu. 6. $35.3 ; 67.3$. 10. 3.25 .

āsú. 3. I0.4. 7. III. I.

ăsu. 18. $3 \cdot 8^{+}$.

asmắn. I. I. 4 ; I9. $3 ; 2$ I. $2^{*} ; 29 . I^{*}$. 2. II. 3 ; I9. I-23. 5 ; 35.4 . 3. I. 3 ; 2. 6 ; $27.1-6.4$. I0. 5 ; I9. 5 ; 40. I8. 5. 6.8, 9, 10; I4. 2. 6. 6. I ; I5. I $^{*} 2$; I9. $3^{\dagger} ; 27.3^{*} ; 47.1,2 ; 5$ I. $2^{*}$; 54. 3 ; 66. I; II6. 3. 7. 9. $2^{*} ; 27.1$; 66. I ; 75. $2 ; 8$ I. 5,6 ; I09. $4^{2}$. 8. 4 . $23^{*} ; 5.4$ 9. $2.25 ; 4.7$. 1 1. I. 7 , 2 I ; 5. 15-2I, 25-35. I2. I. 25 ; 2. I , 33. I6. I. $5 ; 7.5$. I8. $3.45^{*} ; 4.87$. I9. $4.4 ; \mathrm{I} 3 . \mathrm{II}^{*} ; 2 \mathrm{OI}, 3 ; 35.4 ; 45$. $5 ; 49.3 ; 50.4,6 ; 58.2 ; 64.2$. asmăbhis. 6. I22. I. 12. 3.42 . asmábhyam. I. I6. I; I8. $2 ; 26.2$. 2. 6.5 . 3. $5.3 ; 8.1$; I2.5. 4. I8.6; 3I. $7^{*}$. 5. 3I.II. 6. $92.3^{*}$; 110.1*; I28. 3. 7. 14. $3 ; 24.1 ; 50.4^{*} ; 78.2$; I 1 5. 3. 8. 4. $14^{*}$. 9. $2.3 ; 4.6,22$; 5. 12. 12. 1. 62 . I4. I. 62 . 18. 2. $13^{*} ; 3.14 ; 4.62$. 19. I1. $6^{*}$.

asmát. I. $2.3 ; 9.2,4 ; 18.4 ;$ I9. I, 2 ; 20. 2 ; 26. I. 3. 7.7. 4. I7. 5 (s. mss. asmín). 6. 20. I; 26. $3 ; 45.2^{*}$; 73. $3 ; 84.3 ; 93.2 ; 97.2^{*} ;$ I 2I. $\mathbf{I}^{2}$; I24. 3. 7. $4^{2} . \mathrm{I}^{*}, 2^{*}, 2^{\dagger} ; 53 . \mathrm{I} ; 60.4$, $6 ; 77.3 ; 83.3^{*}, 4^{2} ; 92 . I^{\dagger} ;$ II 5. 2 . 8. 7. I4. IO. I. I6;5.24 2 . II. 2.19 , 26. I2. I. 49,$50 ; 3 \cdot 40,43$. I3. I. 3I. I4. 2. 48. I6. I. IO, II. I8. I. $40^{*} ; 4.70 . \quad$ I9. 3 I. II ; 33.3. 20. 34. I6 (ed. ásthāt).

asmákam. 2. I2. 2,$3 ; 26.4,5 ; 31$. 5. 3. IO. I3. 4. 3I. $5^{*}$. 5. 3. II. 6. I5. I*; 93. I; I26. 3. 7. 4I. $2 ; 50.4^{*}$. 10. $5 \cdot 36^{2}$. $12.3 \cdot 55-60$. 16.8 . I$27^{10}$; 9. $I^{2}$. 18. 4.68. I9. 13. $7^{*}, 8^{*}$, $\mathrm{II}^{3^{*}}$; 34. I ; 57.6. -and see asmáka. asmáka. I. 7.6. 3. $24 \cdot 4 \cdot$ 7. 77. $\mathrm{I}^{\dagger}$. asmấsu. $4.32 .4^{*}$. 5.6.8. 6. 84.2 . 7. $5.2 ; 52.1 ; 76.6^{*} ; 82.1^{*}$. 7-I4. II 5.25 . I2. 2.46 . I9. 3 . $3 ; 3$ I. $13 ; 45.2 ; 57.2,5 ; 64.4$. asmé (p. -é íti). 4. 2 I. I* ${ }^{*} 31.3^{*}$ (mss. asmāí). 5. I. 3 (s. mss. ed. asmāí). 18. I. $3^{*}, 42^{*}$. 19. $40.4^{*}$ (mss. asmāí). (cf. asmátsakhi ; átas, átra, átha, adás, ádha, ât.)

á ṅ ç a : -am. 7. 50. $4^{*}$.

áṅçān. II. I. 5 .

(n. pr.): ánç̧as. 6. 4. 2.

áņçam. Ir. 6.2.

a ṅ çú: -ús. 5. 29. I2, I3.

an̉çúm. 7. 81.6.

anço (p. -o íti). 7. 81.3 .

ançávas. 9. 6. I4. II. I. I8. I9.6. I6. an̉çứn. 5. 20. 10. 6. 49.2. II. I

9. 12. 3. 20.

(cf. an̉çumánt, upān̉çú.)

a ṅ çu mánt: -mắn. 8. I. 2.

an̉çumántam. 13.2.7. 
ançumátīs. $8 \cdot 7 \cdot 4$.

áns a: -se. 8. 6. 13 .

áṅsāu. 9. $4.8 ; 7.7$ 10. $2.5 ; 9.19$. II. $3 \cdot 9$.

áṅsābhyām. 2. 33. 2".

(cf. ańsadhrí.)

a ́̀ s a dhrî: -dhrím. II. I. 23 (mss. -dhrím, -ddhrím, -drím, -ddrím).

án has: -sas. 2. 4. 3 ; 28. I. 4. IO. I, $3 ; 23.1-29.7$. 6. $45 \cdot 3^{*} ; 9^{6 .} I^{*} .7$ 7. 64. I； II2. I. 8. 2. I8; 4. 23*; 7. I3. 10. 5.22 II. $6.1-6,8$, I0-2I. I9. 44. 8, 9 .

án̉hasahıañh-. I. 3 I. 2.

ánhhặosu (mss. ed., -a॰su). 6. 35. 2. (cf. an̉homúc.)

a nh $\mathbf{h}$ in an̉hubhéda, an̉hurá, an̉hūraná.

a nh u bhé d a : -diās. 20. I36. I.

a ṅhurá: -ás. 5. 1. 6".

a ṅ hū r a ṇá: -ṇatt. 6. 99. I.

an̉hūrañâ. 9. 2.3.

a ṅ hom úc (p. -hah॰m-): -cam.

42. 4 .

an̉homúce. I9. 42.3.

ákalyāna: -ṇi. 20. I28.8.

akavacá: -ás. II. IO. 22.

a kāmá : -ás. I0. 8.44.

akāmấs. 6. II $4 \cdot 3$.

ákupyant: -ntas. 20. 130. 8 .

ákūpāra: -as. 5. I7. $\mathrm{I}^{*}$.

a kr ta in krtākrtá.

akrttaoruc; ákṛttaruk. 4. 3I. $4^{*}$. akṛștaopacyá: -cyé. 5. 29. 7.

akta in abhyakta, ākta.

a ktú : -tún. I8. I. $35^{*}$.

aktúobhis. 13.2.17*, 22*. I7.9. I8. I. $55^{*}$.

a kratú: -ús. $4 \cdot 32.5^{*}$.

akratúm. 3. 25.6.

a kravyãd (p. -yaoad): 12. 2.3, 42. Vakṣ: + nis: níh ... akṣṇuhi. 4 . 22. I.

akṣá: -ṣấs. 6. 70. I. 7. Iog.6. 14. I. 36 .

ákșās. 7. 50. 9.

akșân. 4. 16.5. 7. 109.7.

akșāís. 7. 50. I. akșébhyas. 7.109. 2.

akşănăm. 6. 118.1. 7. 109.5.

akșéșu. 4. $3^{8} .4$. 5.31.6. 6. 38.3.

7. IOg. I. I2. 3.52 . I 4. I. 35 .

(cf. akşákāma, akşádrugdha, akșávŗtta, akșaparājayá).

Iákşa: -as. 9. 9. II". I4. I. I2*.

I9. 53. 2 .

ákşāt. 2. I4. 2.

ákşa, a kşán, ákşi, akșî: ákșam. 4. 9. I (s. mss. ákşyam, akșyàm).

akșṇ6s. I 9. 60. I (mss. akşós, akṣyós, akșṇós).

ákși. 1. 8.3. 15. 18. $2^{2}$.

ákşiṇī (p. -i íti). I0. 9. I4. I I. 3.2. ákșiṇi. 4. $5 \cdot 5^{\dagger}$.

akşyāù. I. 27. I. 4. 3.3. 5. 23.3; 29.4. 6. 9. $\mathrm{I}^{2}$. 7.36. I. $19.50 . \mathrm{I}$ (mss. -yāú).

akșibhyăm. 2. $33 . I^{*}$. II. $3 \cdot 34^{2}$.

akșyós. 6. 24. 2.

akșiós. 5. 4. Io (mss. ed. -ṣós). 6. 127.3.

(cf. ádhyakșa, àktākșa, ánāktākșa, caturakṣá, dhūmākṣá, parókșa, paryastākșá, pratyákșa, sanisrasākșá, samakṣá, sahasrākșá, sãkṣá, akșaṇvánt, akṣibhû́).

akșá $\mathrm{k}$ āma: -mās. 2. 2. 5 .

a kṣa ṇ०vánt: -vắn. 9.9. $5^{*}$.

ákșata: -as. I2. I. II.

akșá。drugdha: -as. 5. I8.2.

akṣán: see 2 ákșa.

akșa $\circ$ parājayá: -ám. 4. I7.7.

akșára: -rena. 9. 10. 2*. I 8. 3. $40^{*}$.

akșáre. 9. I0. 18 *.

akṣárās. I3. 3.6 (mss. -rā).

(ef. uṣṇihākșará, ekākșará, sahásrākșara.)

akṣá vṛtta: -am. 6. II8.2.

ákși: see 2 ákșa.

ákşita: -as. 4.5.7. 6. I42.2. 9. I. 6. II. I. 20.

ákșitam. 3. $24 \cdot 4^{2}, 7 ; 29.4,5 . \quad 4$. 27.2. 7. 81.6. I8. 4. 36 . I9. 54.4 . ákșitām. 7. I7.2; 80.2. I8. 4.32. ákșitasya. 7. 76.4. 
ákssitāu. 9. I, 7 .

áksitās. 1. $15 \cdot 3.6 .1+2 \cdot 3^{4} \cdot 7 \cdot 81$. 6. I0. 6. I4.

ákşiti: -is. Ir. $7.25 ; 8.4,26$.

ákșitim. I8. 4.27.

a ksibhù : -bhúvas. 20. I36. 4 .

aksit: see 2 ákșa.

ákșiy a mạna: -am. 7. 20.3.

ákşu: -um. 9.3.8.

(cf. akşujālá.)

a kșu०jālá: -lâbhyām. 8. 8. I8.

akșu dhy ý: -yấs. 7.60. 4 (-dhiấs ?), 6.

a ks y à : -șíam. 4. 9. I (? mss. ákşam, ákşyam, akșyàm).

ákhāta: -am. 5. I3.I.

ágata: -asya. II. IO. I6. I4.2.74. a g a dá: -ás. 4. I 7.8. 5. 29.6-9.

agadám. 5. 4.6. 6. $95 \cdot 3$. I8. 3. $55^{*}$. agást1: -im. 4. 29.3.

(cf. agástya.)

a gás ty a: -tias. 4. 37. I. I8. 3. I5. agástiasya. 2. 32.3.

a go in

agót ā: -tām. 4. I 7.6.

a gnấy $\mathbf{1}: 7 \cdot 49 \cdot 2^{*}$.

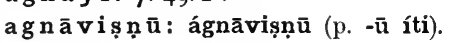
7. $29.1,2$.

agní: -ís. I. $7.4 ; 9.1,2 ;$ I6. I, 2 ; 25. I; 28. I; 33. I. 2. I. 4 ; IO. 2 ; I2. $8 ; 25.4 ; 28.2 ; 29.1 ; 34.3 .3$. I. I, $2,3,6 ; 2 . \mathbf{I}, 2 ; 4.3 ; 8 . \mathbf{I}, 3 ;$ II. $4^{\dagger} ;$ I $5.6 ; 2$ I. 0, IO; 26.1 I 27. I; 31 . 6. 4. II. 7; I5. IO; 3I. $2^{*} ; 36 . \mathrm{I}$; 39. 2,9 . 5. 3. $3^{*} ; 8.3$; I2. $\mathrm{IO}^{*}, \mathrm{II}^{*}$; I4. I3; I7. $2^{*}:$ I $8.4,6$, I4: 22. I, 2 ; $23.1 ; 24.2 ; 25.4 ; 26.1 ; 27.3 .5,11$; 28. 2,$5 ; 3$ O. II ; 3I. I2. 6. 3.2; 27. $2^{*} ; 34.2^{\dagger}, 5^{*} ; 35.1,2 ; 36.3 ; 37.2$; 39. $3 ; 45.2^{*} ; 47.1$; 53. I ; 7I.I, 2 ; 73. I; 76. I; 86. $2 ; 88.2^{*} ; 94.3 ; 97$. I ; IO6. 3 ; III. 2 ; I 20. I ; I2I. 2.7 . I 7.4;2O.I ; 24. I ; $33 . \mathrm{I} ; 53.2,3,6$; 62. I; 63. I; 64. 2 ; 73. I, $2 ; 82.4,5$; II 4. 2. 8. 3. I* $24^{*}, 26^{*} ; 5.5$, IO, I8; 8. $23 ; 9.6$. 9. 2. I $3,20,24 ; 3.21,22$; 4. $3 ; 5.6,7 ; 7.1,19$. Io. $3.14 ; 4$. $26 ; 6.6 ; 7.2,4,12 ; 8.39 ; 9.26$; I0.
7. I I. I. $2^{*}, 33 ; 2.8 ; 7.1 ; 8.8,9$ 9. 25 . I 2. I. $19^{3}, 20,53 ; 2.4,7^{*}$, I I, I2, I 5, I $6,33,35,38,44,50,52 ; 3.2$, $24,25,43 ; 5.4 I, 6 I, 72$. I3. I. II, I 7, 20, 27, 28 $, 48,53^{2} ; 2.46^{*} ; 3.5$, I3; 4. 5, 36. I 4. I. $8^{*}, 48,49 ; 2.2^{*}$, $3^{*}, 4^{*}, 59-62$. I5. 4. $5 ; 6.1$; IO. 7 ; 14. $8 ;$ I $5.3 ;$ I8. 3 . I6. I. 7,$8 ; 4.4$, $7 ; 9.2$. I7. 30. I $8.1 .39^{*} ; 2.28$, $54^{*}$; 3. I I, $55^{*}, 65^{*} ; 4.8,9$, I5, 64. I9. 4. I ; 6. $7^{*}$; 10. $4^{*} ;$ I 7.1 ; $24.8 ; 31.2$; 33. I ; 37. I; 43. I' $; 45.6 ; 55.3 .4$; 59. $2^{*}, 3^{*}$. 20. 2. 2 .

ágne. I. 7.2 . 2. I6. 4 ; I9. I-5. 3. $3.1 ; 15.5 ; 20.2^{*} ; 22.3$ 4. I4. 5 ; 33. $I^{*}$. 5. 3. $2^{*} ; 8 . \mathrm{I} ; \mathrm{I} 4.8 ; 27 . \mathrm{I} 2$; 29. I, 4 , I3. 6. $5.1 ; 63.4^{*} ;$ 108. 4 ; I30. 4. 7. 34. I; 6I. 2 ; 73. IO* ; I Iо. I. 8. $3 \cdot 4^{*}, 7^{*}, 20^{*}, 23^{*}$. 9. $2.4,9$. I0. 6. 35 . I I. I. I, 3,6, I6, 36 (mss. agne). I2. 2. 42. I3. I. 3I. I8. I. $34^{*} ; 2.36 ; 3.5 ; 4.30$. I9. 3. 2, 3 ; $27.5 ; 64$. I (ed. ágre).

agne. $\quad$ I. $7.1,3 ; 6.7 ; 8.4^{2} ; 9.3,4$. 2. $6 . \mathrm{I}, 2^{2}, 3^{3}, 4^{3}, 5 ; \mathrm{I} 3 . \mathrm{I}^{2} ; 28.5 ; 36$. I, 3. 3. I5. $3^{*}, 4^{*}, 8 ; 20 . I^{*}, 5^{*} ; 3 I$ I. I. 4. $4.6 ; 33.4^{*}$. 5. 3. $\mathrm{I}^{*} ; 6.10 ; \mathrm{I} 2.3^{*}$; $25.7 ; 28.4 ; 29.2,3,5$, IO, II $I^{*}, I 4$, I 5 ; 30. I4. 6. $5.3 ; 32 . \mathrm{I} ; 49 . \mathrm{I} ;$ IO3. 2, 3 ; IO4. 2 ; IIO. I* ; III.I ; II2. I, 2; II 7. I, 2 ; II $9 . \mathrm{I}$; I22.4; I24. I. 7. 53. I; 6I. I; 7 I. I* ; 73. $9^{*} ; 78 . \mathbf{I}$, $2 ; 82.3^{2}, 6^{2} ; 84.1 ; 89.1,2^{*} ; 97.3$; I06. I; I08. $1^{2} ;$ I09. 2 . 8. $3.3^{\dagger}, 5^{*}$, $6^{*}, 8^{*}, 9^{*}, \mathbf{1 0}^{*}, \mathbf{I I}^{*}$ (mss. ágne), $12^{*}$, $\mathrm{I} 3^{*}, \mathrm{I} 5^{*}, \mathrm{I} 7^{*}, \mathrm{I} 9^{*}, 2 \mathrm{O}^{\dagger}, 2 \mathrm{I}^{*} ; 4.1 \mathrm{O}^{*}, \mathrm{I} 4^{*}$. 9. I. I4; 5. I7, I9; 9. I $3^{*}$. II. I. 4. I 2. $2.3,5,6,17,18,45,46$. I3. 3 . 2I, 23. I 4. 2. I* (m. mss. ágne), 69 . I6. 6. II. I8. I. $22^{*}, 24^{*}, 25^{*}, 26^{*}$; 2. $4^{*}$, IO $^{*}, 34 ; 3.6^{*}, 21^{*}, 42^{*}, 47^{*}, 48^{*}$, $53^{*} ; 4.9$, IO, I I, $88^{*}$. I 9. 3. 4; 7.2 (ed. me); 8. 3; 11. $6^{*} ; 55.1,2,7,7$ (not in mss.); 59. $\mathrm{r}^{*} ; 64.3^{*}, 4$.

agním. I. $6.2^{*} ; 33.1-3$. 3. I6. I*; 20. $4^{*} ; 21.8^{2} ; 30.6$ 4. $23.3,4,7$; 40. I. 5. I8. 5 ; 30. I2. 6. I8. I; 28 . $2^{*}$. 7. $45.2 ; 50.3^{*} ; 63.1 ; 82.2^{2}$; 
IIO. 2. 8. 2. 4, 9 ; S. 2.9 .3$. I4; Iо. $28^{2 *}$. I0. $2.20,21 ; 7.33 ; 8$. I 7. II 6. I. I2. 1. $6,19,20 ; 2.8^{*}, 9,10,54$. I3. I. $25,40,52,57$. 14. 1. $39 ; 2$. I 8 , $20,23,24,25 . \quad 15.4 .5 ; 10.9 . \quad 18$. I. $20^{*}, 2 I^{*} ; 3.22^{*}, 60^{*} ; 4.14,40$. 19. 18. $1 ; 27.7$.

agnínā. 3.12.9. 4. 14. 2 ; 23. 5 ; 39.2. 5. 23.13. 6. 85.3 . 8.8.17. 9. 5.5 . I I. 2.26 . I3. I. 29 . I9. 37 . I; 45.6 .

agnáye. 4. 39. $\mathrm{I}^{2}$. 6. I0. $\mathrm{I} ; 34 \cdot \mathrm{I}^{*}$. 7. 87 . I. 9. 3. 12 . II. 8.3 I. I2. 3 . $55 ; 4.34^{2}$. 14. $2.4^{*}$. I8. 4.7 I. I9. 4. I ; 43. I; 55. 5 .

agnés. 3.1.5; 2.3; 19.4. 4. 14. I; 23. I ; 33. $5^{*}$; 36. 2. 5. 27. I, 5, 8, 9 ; 28.6. 6. 20. I; 76.2, 4. 7. 45.2; 70. 4, 5. 8. 1. $4 ; 2.13,27,28 ; 7.8$, 15, 16. 9. I. I, 3 , 10; $2.6 ; 5.6,13$. 10. 5.7 II. I. $25 ; 3.36 ; 8.9$. 12 . I. $20 ; 2.40 ; 3.34$. I3. I. $30 ; 2.35^{*}$; 4. 36. I5. 6. I. I8. $2.58^{*} ; 4.8$. I9. $26.1 ; 27.5 ; 45.3$.

agnāú. 4. 39.9. 5. 31.9. 6. 29. I*; 38. I ; 122.3. 7. 72. $3^{*} ; 87.1$. 9. 5. 5. IO. I. I8; 4. 22 . II. I. $29 ; 5.13$. 12. $2.13,19: 3.7,54$. I7. 13 . agní (p. -í íti). I I. 5.11. I 3. I. 46 , $47,49,49-5 \mathrm{r}$.

agnáyas. 2. 35.1. 3. 2 I. I. 7. 67. I. 8. I. II. 9. 4. I8. I0. 5. 2 I. I2. I. 19, 37; 3. 50. I3. 2. $18^{*}$. I6. I. I. 18. 4. I2, I3. I9. 9. II, I2; I6. 2. agnin. I2. 2.4. I6. I. I3.

agníobhis. 3. 20. $5^{*}$.

agníobhyas. 3. 2 1. 1-7.

agnísu. I5. I2. I.

(cf. indrāgnî, dakșināangní, pūrvāgní, jamádagni, agnấyī, agnāvișṇū, agnijă-agnyādhéya.) a gniojá (or -já): -ấs. Io. 4.23. a gni ojihvá: -vấs. II. 9. I9. agniotaptá: -tébhis. 8. 4. $5^{*}$. agníotejas: -jās. I0. 5.25. a gniodagdhá: -dhấs. I8. 2. $35^{*}$. agníodūta: -as. 2. I2.7. I8. 2. I*. a gniodhắna: -nāt. I2. 3. 35 . agnidhẳne. 6. $27 \cdot 3^{\circ}$. a gnimánt: -mắn. 8.4 .2 a gníomũ ḍ ha: -ḍhānām. 6. 67.2. a gní orūpa: -pãs. 4. 3I. I". a gní ovās a s: -sãs. I2. I.21. agnioçăla: -am. 9.3. 7 .

a gni ş ț o má (p. -niost-): -ás. II. 7.7. agnișțomám. I0. 9. 8 . agnișțoména. 9. 6.40. agnişțomãís. 12. 3.33.

agnişvātt a (p. -niosv-): ágnișvāttãs. I 8. 3. $44^{*}$.

a gniohotrá: -ám. Ir. 7.9. agnihotré. 10. 3.22. I5. 12. I. (cf. agnihotrahút.) agní ohotra: -rās. 6. 97. I. agnihotra ohút: -tām. 3. 28.6. agniș 6 ma: -māu. 3. 13.5. 8. 9. 14 . agníșómā. 6. 93.3.

agnișomāu. 6. 5 †. 2 .

ágnīṣomā. I. 8.2. I 8. 2. 53 . agníșómābhyām. I2. 4. 26 . (cf. agnīṣomíya.)

agnīṣomá: -māú. 6. 6r. 3. agniṣomíy a: -as. 9.6.6. agnyādhéya (p. -nioādh-): -am. II. 7.8 .

ágra: -am. 2. 26. 2 . 4. I. 5 ; 19. 3 ; 32. $7^{*}$. 6. I37.3. 7. I. I; 3. I ; SI. $2^{*} ; 82.4,5$. 8. 7.3 , 12. 10.8.8. 12. 3. 10. I6. I. 6.

ágre. I. 34.2 . 2. $29.7 ; 34.3,4$. 3. $4.4 ; 9.6 ;$ 1 $2.5 ; 22.3$ 4. 1.2 ; 2. $6^{\dagger}, 7^{*}, 8 ;$ I4. $\mathrm{I}^{2} ;$ I9. $4 ; 28.4$. 5 . 12. $4^{*}$; 28.11. 6. I16.1. 7. 82.2 ; I I0. 2. 8. IO. I. 9. $4.2 ; 5.20 ; 9.8^{*}$, $2 I^{*}$. I0. $7.28 ; 8.2 I^{2}$. II. I. 23 ; IO. I5. I2. I. 8,$24 ; 2.31^{*} ; 3.1,6 ; 4$. 24. I3. 2.39. I4. 2. $\mathrm{I}^{*}, 32,50$. I9. $6.9^{\dagger} ; 22.21 ; 31.9$ (m. mss. agne); 35. I ; 4I. I ; 52. I* ; 53. IO ; 56. 2 . ágrā. 8. 3. I0".

(cf. iṣvagrá, jyótiragra, tápuragra, sámagra, samagrá, agratás -agriyá, agrétvan.)

agratás. 4. 10.2. 5. 17.14. 19. 34.8 (mss. grasate).

agraoçás. I2. 4. 33. I9. 6. I $^{\dagger}$. 
a gri yá: -ás. 5.2.8*. agriyám. II. 6.3.

ágru, a grú : -rúvāi. 6. 60. I, 3 . ágravas. I 4. 2. 72 . I 8. 2.47.

a grétvan (p. -raoít-): -varì. I2. I. 57 .

a ghá: -ám. I. 28.3. 4. 33. I*, I-8*. 8. $4.2^{*} ; 6.26$. I0. I. 5 . I2. 3.14 ; 5.22. I4. 2. 59, 60, 6r, 62 . aghăt. I2. $5 \cdot 59$.

(cf. tārșțāghá [?], aghakṛtaghāy, aghāçvá.)

a g ha०kṛt: -te. Io. I. 5 . aghakṛ́dobhis. I4.2.62.

a ghá odvișța: -țā. 2. 7. I.

a gha omārá: -ás. 6. 93. I.

a gha $\circ$ rúd: -das. 8. I. I9. II. 2. II. a gha lá: -lấs. 8. 8. 10.

aghá ○viṣa: -șā. $\quad$ 5. IS. 3 . I2. 5 . I2, 26, 59 .

aghávișās. 6. 93.2.

aghávișābhias. 6.93.3.

a ghá ○çañsa: -sas. 4.21. $7^{*}$. I9. 47.6 .

agháçañsam. 8. 3.19*; 4. 2. agháçañsāya. 8. 4. $4^{*}$.

a gha çańs $a \circ d u h c ̧ a n ̃ s a ́:$

-sâbhyām. 12. 2. 2.

a gha hāará: -ás. 6. 66. I.

$\checkmark$ a ghāy: -yántam (p. -gha॰y-). I 0. 4. 10.

aghāyatấm (p. -gha॰y-). I O. 9. I.

+ abhi: abhyaghãyáti (p. abhioa-). 7. 70.3 (mss. -yánti). 19. 50.4 (m. mss. -yánti).

abhyaghāyánti (p. abhioa-). 5.6.9. (cf. aghāyú.)

a ghāyú (p. aghaoy-): -yús. 4. 3. 2. 5. 6. IO; IO. I-7. I9. 47.8 ; 49.9. aghāyós. I. 27. I. 7.5I. I*. aghāyávas. I. 27.2, 3. I9. I8. I-IO. aghāyutnām. I. 20.2 .

a ghārín: -rínīs. Ir. 9. ì4.

a g hã çvá (p. -gha॰a-): -çvásya. I 0. 4. IO.

áthora: -rena. 7.60. I. I4. 2.12. (cf. ághoracakșus.)

ághora॰cakşus: 14. 2. $17^{*}$. a ghnyá: -niás. 9. 4. I7.

aghnyāú. 14. 2. 16*.

aghniāú. I8. 4. 49.

aghnyâ. I9. 16. 2.

aghniá. 3. 30. I. 6. 9r. $2^{*}$. 7. 73. $8^{*}$. ághnie. $12.5 .58,60$.

aghnye. ro. 9. II.

aghnie. 6. 70. I-3. 7. 73. 11*. 10. 9. 3,24 ; IO. I. I2. $5.63,65$. I8. 3. 4 . aghnyấyās. 8. 3.15*.

aghniấs. 7. 83.2. 8. 7.25. 19. 44.9. aghniânām. 9.4.2, 4, I9 (-naam).

a ñká: -kéna. 7. II 5 . I.

añkấn. I. I2. 2.

(cf. bāhvañká, saman̄ká, añkín.) an̄kín: -nas. I9. 66. I.

an ku çá: -ás. 6.82 .3 .

añgá. I. I6.2. 5. II. 5, 7. 9.9. $5^{*}$. II. 4. $2 \mathrm{I}$. I3. 3. $2 \mathrm{I}$.

añgá (p. -gá). 2. 3.2 2 .

añgó (p. -ó íti). 6. 60. 2.

I áñg a : -am. 5. I7. 5*. 6. 72. I. I0.

$7.2,9,25,26$. I4. I. $27^{*}$. I 8. 2.26 ; 4. 64 .

áñgam॰añgam. 4.9.4* 9. 3. I0.

áñgena. 6. 72. I.

áñgāt. I0. $7 \cdot \mathrm{I}^{3}$.

áñgătoañgāt. 5.25. 1. 8. 7.3. ro.

4. 25. I4. 2.69.

ánge. ro. $7 \cdot 1^{3}, 3^{4}, 13,27$.

áñgeoañge. I. I2.2. 2. $33 \cdot 7^{\dagger}$. 6 . II 2. 3 .

áñgāni. 3. 2. $5^{*}$; 11.6. 4. 5.4; 12. 7. 6. 90. 2. 9. 4. Ir; 8. I9. I0. 5. 50 ; 7.6. I I. 7.6. 20. I36. 8 (not mss.). áñgā. 6.66.3. II. 8. I2. I2. 5.42, 7I. áñgāis. 4. 14.9. 6. 120.3. 7. 5.5. 8. 2.3 .

áñgebhyas. I. 12. 4. 2. 34.5. 3. 7.3. 5. 30.8. 6. 90. I. 9. 8. 7-9, II. 2. 6. I9. 44.2.

áñgānām. I 8. 2.24.

(cf. trinçádañga, yathāñgá, yāvadañgína, viçvān̄gá, vīụvànga, vyàñga, sámañga, sárvāñga, sāñgá, añgajvará, an̄gabhedá, añgeșțhâ, áñgya.)

2 áñga: -gebhyas. 5. 22 . I4. 
añga०jvará: -ás. 5.30.9. añgajvarám. 5.30.8. 9.8.5. añg a०bhedá: -ás. $\quad$ 5. 30.9. 19 44. 2 .

añgabhedám. 9. 8. 5, 22.

áñ giras: -rās. I9. 34.6; 54. 5 . añgiras. 20. 135.9 (mss. -rás).

án̄girasam. 4.29.3.

án̄girasas. 3. 21 .8. 8.8.13. 9. 5 . I6. I0. 6. $20 ; 7.18,34$ I I. 6. 13 . I 2. $3.43,45$. 4 8. I. $5^{8}, 61 ; 3.20$; 4. 3 .

án̄girasas. 2. 12.5 .

áñgirobhis (p. -raḥobh-). 2. 12.4 . I 8. I. $47^{*}, 59^{*}, 60^{*}$.

áñgirobhyas (p. -raḥobh-). I 2.3 . 44. I9. $22.18 ; 39.5$ (mss. -reyebhyas). 20. 135.6. án̄girasām. 6. 35.3. I6. 8. I I. I8. 4. 8.

(cf. atharvāñgirás, āñgirasá.)

añ gúri, añgúli : -rim. 4. I8.6. 5 . 31. II. 20. 136. I3 (not mss.).

añgúlīs. I0. 2. I.

añgúliobhis. 4. 14.7.

an̄gúliobhyas. 2. 33.6.

(cf. anañgurí, daçāñgulá, páñcān̄guri, svan̄gurí.)

a ñ gula in daçān̄gulá.

añgușthá : -ám. 20. I36. I6.

a ñ geșt thă (p. -geosth-): -ăs. 6. I4. I. áñg y : -gias. 6. 127.3.

$\checkmark$ ac, see añc.

ac in vyac.

a cas in vyácas.

á c a kṛvàn s: -kruṣe. 5. 14.9.

ácikitvāns: -vān. 9. 9. $7^{*}$.

acít: -tam. 8. 3. $2 \mathrm{I}^{*}$.

acítas. 8. 4. I*

á citti: -tyā. 6. 5 I. $3^{\dagger}$.

ácittiā. 5.17.12-7; 30.3; 31. I0.

I2. $4.5 \mathrm{I}, 52$.

ácittis. 2. 6.5 .

ácyuta:-as. 6. 88.3. I9. 33. 2.

ácyutam. 5. 28. I4. I2. 3.35.

ácyutā. 9. 2. I5.

(cf. acyutacyút.)

acyuta。cyút: 5. 20. I2. I3. $2.46^{\prime \prime}$.

áchā (p. -a). 6. 39. 2.

(cf. acha $+\sqrt[V]{ } \mathbf{i}, \overline{\mathbf{a}}+\mathbf{i}, \mathbf{v a d}, \mathbf{a}+$ vad.)

á ch idy a măn a: -nă. 8. 2. I. áchidyamānaȳa. 7. 43. I".

áchinna: -as. I9. $5^{8}$. I.

áchinnam. 6. I22. I.

áchinnās. I 9. 58.1 ,

(cf. achinnaparná.)

a chinnaoparṇá: -néna. I9. 32.2.

Vaj: ája. 4. 37.2.

ajatu. 8.6.19.

ajantu. $8.5 \cdot 5,6$.

(cf. áj, ajá [?], ajani, ajirá, ájman, ājí.)

$+\bar{a}$ : ấ 'jāmi. 3. $25 \cdot 5$.

â 'jatu. 7.9.4".

à 'jat. 3. 8.4

(cf. ájani.)

+ u d : úd ajantu. I4. I. 39 .

úd ājata. I2. 4.24.

+ upa: úpā 'je. 5.11. 2.

+ nis: nír ajāmasi. I2. 2.2.

níh ... ajāmasi. 2. I4.2. I2. 2.3 nír ajatu. 2. 14.4.

$\sqrt{ } \mathbf{a j}, \mathbf{a} \tilde{\mathbf{n}} \mathbf{j}$ : see $\mathbf{a n ̃ j}$.

áj: ájam. I9. 50. 5 .

a já: -ás. 4. I4. I. 9. 5. I, $3,7^{2}$, IO, I I, I $3, \mathrm{I} 6, \mathrm{I} 8,2 \mathrm{O}, 2 \mathrm{I}, 3 \mathrm{I}-6$. I $7.3 \mathrm{I}$; 8. 4 I. I3. I. 6. I8. $2.8^{*}$. I9. II. $3^{*}$ ája. 9. 5.9, I6.

aja. 9. 5. I5 (m. mss. ája).

ajám. 4. I4.6, 9. 9. 5. $7^{2}$, I I, 12 , $22,24-6,27,28,31-6,37$. I 8. 2. 9 . ajéna. I 8. 2. 22.

ajásya. 4. 4.8; I4. 7,8. 9. 5.19; 9. $7^{*}$.

ajé. 5. 3I. 2.

(cf. caramãja, ajagará, ajababhru, ajayâna, ajaçṛnga, ajấ, ajāví, ajína.j

a j a g a rá : -ás. 20. I29. I7 (not mss.). ajagarấs. $4.15 .7,9$. II. 2.25.

ájagd ha $\mathbf{a}$ pāpma n: -mā. 9.6.26.

ajani in ájani.

aja॰babhru: ájababhru. 5. 5.8. 
aja oyấna: -nāis. I 8.2 .53 (m. mss. ajoy-).

ajára: -as. 8. 3. $20^{*}$. I9. 24.8 ; 53. I. ajáram. 3. I9. I, 5. 6. 98.2. 9.9. $2^{*}, 4^{*}$. I0. 8.44 . I $8.4 .98^{*}$.

ajárā. I0. 8. 26.

ajárām. 2. 29.7. 12. 2.32.

ajáre (p. -e íti). 8. 3. $25 ; 9.12$.

ajárāsas. 8. 3.19*.

ajárebhis. $8.4 \cdot 5^{*}$.

ajárant: -ntīm. 7.6.2.

aja oç r ñ̄g a: -gí. 4. 37.6.

ájaçrñgi. 4. 37.2.

ájasra: -as. 7.78. I. r9. 3.2.

ájasram. 6. 36. I. I3. 2.36. I6. 2. 5. ájasrā. I 8 . I. $35^{*}$.

ajă: -ầm. 6. 7I. I.

áj āta: -tās. II. 8.5.

ájātān. 6. 136.2. 7.34. 1; 35. I.

ajăni: -naye. 6. 60. I.

ájā mi : I8. I. IO*, II*.

ajāví (p. aja॰av-): ajāváyas. 5. 21 . 5. 7.60.5. 8. 7.25. II. 2.9. I9. 6. $12 *$.

ajāvíobhis. I0. 6.23.

ajāvíṣu. II. 2.2I. I2. 2 I5.

ajína: -am. 6.67.3.

ajínena. 5. 21.7.

ajínāis. 4. 7.6.

(cf. kṛ̣ṇājiná.)

ajirá: -ás. 3. $4 \cdot 3$.

ajirám. 8. 8.3 (mss. -ram; p. khadiraoaj-).

(cf. ajirādhirājá.)

ajirādhirājá (p. -raoadh-): -jāú. 7. 70.3 .

ájit a: -as. I2. I. II.

ájītā. I. 27.4. "n

ájívana: -as. I8. 2. 30 .

ajuryá: -ám. 5. I. 4.

ájușța: -țā. 7. II5.2.

ájușțām. ro. 3.6.

ájușțāni. 6. 45.2*.

áj ñ ãta : -as. I0. I. 8 .

ájñătam. 6. $127 \cdot 3$.

ájñāte. Io. I. 20.

ájñātās. 8. 7. I 8 .

(cf. ajñātayakșmá.) ajñ̃ât a $\circ$ y kṣmá: -mát 3. II. I*.

ájman : -ma. 6. 97. 3*.

ájmanā. II. IQ. 22.

ájmani. Ir. IO. 22.

ájyāni: -nim. 6. 55. I.

$\checkmark$ a ñ c, ac: cf. an̄ká, añkuçá, ac, acas, añc, añcana.

$+\overline{\mathbf{a}}$ : ấ 'ñcatu. II. Io. I6.

ácyā (p. āoácya). I8. I. 52*.

+ u d : úd acāmi. I4. I. 38 .

úd acati. I0. 8. 29

úd aca. 4. 15.16t.

+ ni: cf. nyáñcana.

+ vi : vioácanti. 4. 27. 2.

vy àcasva. 3. 3. I.

ví ... acyase. 6. 49. 2.

vioacyámānam. I8. 4.36.

(cf. Vvyac, vyác, vyácas.)

+sam: sám ... acyase. 6. 49. 2.

(cf. saman̄ká.)

a ñc in adharăñc, anváñc, ápāñc, apyañc, arvấñc, ávāñc, údañc, upāñc, ưvañc, ghṛtâñ̃, tiryáñc, narāñc, nyàñ̃, párāñc, purvañc, pratyáñc, prâño, víșvañc, sadhryàño, samyáñc.

a ñ cana in nyáñcana.

$\checkmark a \tilde{n j}$, aj: anajmi. 4. I4. 6.

anakti. 5. 27.2.

añjáte. 18. 3. $18^{*}$.

anáktu. 5. 28. 3 .

añtam. 6. 69.2. 9. I. I9.

áñjantu. I8. 3. 101.

añjantu. 3. 22. 2 .

(cf. añjana, áñjas, añji, akta, aktú, ájya.)

+ abhi: abhí añjate. 18. 3.18*.

abhíoaktā. I0. I. 25.

(cf. abhyakta, abhyáñjana.)

+ à: à 'ñkșva. I9. $45 \cdot 5$ (mss. àkșva).

àoaktā. I0. I. 25.

(cf. ālkta, ăjya, ăñjan.a)

+ ni: nioañjánti. 9. I. I7.

ní anaktu. 18. 3. II, I2.

níoaktām. 14. 2. $33^{\dagger}$.

+ pra: cf. prăñjana.

+ vi: ví añjate. I8. 3. $18^{*}$.

ví ajyate (or $\sqrt{ }$ aj). I4. I. $26^{*}$. 
víoaktas. 20. 34 . 16 (mss. vyàktás). víoaktam. I8. 1. $55^{*}$.

+ s a m: sám añdhi. 3.12.8. 4. 15. 6. 12. 3. 45. 19. 3 I. 13 (m. mss. sám indhi).

sám anaktu. I0. 3.17-25. I4. 2. 40*. I8. 3. II.

sám ... anaktu. 13. 1. 8.

samoantté. 8. 3. $15^{*}$. 12. 3.13.

sám añjate. 18. 3.18*.

samoañján. 5. 12. $2^{*}, 10^{*}$.

sámoaktas. 7.74.4. I8. 3. I4.

sámoaktam. 5. 28. I4.

sám... aktám. 7.98. $\mathrm{I}^{2}$.

sám。aktā. 3. 17.9.

(cf. samáñjana.)

añj an a in abhyáñjana, ãñana, devāñjana, prấñjana, samáñjana.

á ñ j a s : 2. $5 \cdot 6^{*}$.

$a \tilde{\mathbf{n}} \mathbf{j} \mathbf{i}$ in

a ñji ○ vá: -ám. 8. 6.9.

áṇi (?): áṇāu. 20. 136. 2.

aniy as in

a ṇīy aská (p. -aḥok-): -ám. ro. 7 . a ṇ ú: anứni. Ir. 7. ro.

(cf. aniyas.)

át andra: -as. II. 4. 24. I3. 2. 28,42 . át apta: -as. 9. 5.6 (? s. 1 tap + pari). átas. 5. 2. 6"; 22. I1. 6. I11. I (mss. atás). 8. I.4. 9.5.6. I5. 10.3, 5. 18. I. $32^{*}, 55^{*}$.

a t askará: -ám. 12. 1. 47 .

áti. 2. $6.5^{4}$; II I-5; I $2.6^{*}$. 3. II. $3^{\dagger}$. 4. $16.6 ; 33.7^{*} ; 34.4 ; 35.2$. 6. 34. I-5* ; 5 I. I ; 75. $3^{2}$; I IO. 2. 7. 4 I. $1^{2} ; 63 . I^{2} ; I I 7 . I^{*}$. 8. 5.9. 9. 5.9. I0.' I. I6. II. I. I2, 2 I. I2. 2 . II ; 3. I8. I3. 2.34. I6. 1.7. I8. 1. 24", $33^{*}, 38^{*} ; 3.23^{\dagger}$. 19. 50. 2. 20. 127.7. (cf. ati $+V V^{\prime}$ I as, āp, i, $\bar{a}+\mathbf{i}, \mathbf{e s s}$, kram, kṣam, khyā, cṛt, ji, tap, tṛ, tṛd, dãç, dĩv, dru, Idhā, dhãv, nī, nud, paç, 2 pr, bhā, man, yā, ric, ruc, vad, I vā, vyadh, saj, sṛ, sṛj, abhi + srrj, sṛp, sthā, han ; and atijîvá, atimātrá, atirātrá, atiçarvará.)

a ti॰ghny à: -nías. I1. 7.16. a ti̊jívá: -ás. 8. 2.26.

átithi: -is. 7.21.1; 73.9. 9. 6. 21, 37. I0. 6.4. I5. IO. I; II. I; 12. 1 ; $13.1-5,6$.

átithes. 9. 6.3 $3 \mathfrak{- 6}$.

átithāu. 9.6.38.

átithayas. 9.6.23.

átithīn. 9.6.3,48,53.

átithInām. 9. 6.30.

(cf. médhātithi, átithipati.)

átithi०pati: -is. 9. 6. $3,18,53$.

áti̊dívan: -vā. 7.50.6

a ti॰paçyá: -ám. II. 2. I7.

atiomãtrá: -ám. 5. I9. I. 8.6. I3.

atiorātrá: -ám. ro. 9.9.

atirātréna. 9.6.4I.

(cf. sāhnātirātrá.)

ativyādhya in anativyãdhyà.

atividdha $\circ$ bheşajá: -jí. 6. rog. I.

ati̊çarvará: -ré. 4.5.4.

atiçarvaréşu. 7. 80.4 .

a tiș ț $\mathbf{h} \overline{\mathbf{a}}$ in

a tișt hăv ant (p. -sthấov-): -vān. 3 . 22. 6.

a tiosará: -rấs. 5 .8. 2.

atisarās. $5 \cdot 8.4$.

atisarăn. 5. 8.7.

a tis ṛș ța in ánatisrșțta.

átura: -rānām. 7.50. 2 (1. -ṇaam). atṛṣyá: -yấs. 7.60.4,6 (l. -șiầs ?). atejás: -sam. 2. 19-23. 5 .

áttu : see $V$ ad.

attṛ́: -tấras. 6. $\mathrm{r}+2.3$.

átyāpti (p. átioā-): -is. I I. 7.22.

a tya yá (p. atioã-): -yám. Io. 8. 3* (1. atiā-).

[21. a trá (attrá): -rấs. 9. 7. 16. I0. 10. átra. 3. 23.2. 4. 7.7. 5. 8. $9^{2}$. 6. $37.2 ; 53.3$; 104. 2 ; 123. 2 . 8. I.9. 9. 4. $24 ; 9 . \mathrm{I}^{*}, 7^{*}, 13^{*}, 2^{*} ;$ IO. $12^{*}$. II. I. 33. I2. 2. I, IO, I 8 ; 3. I 7, 45 , 48, 55-60. I4. I. $5^{8}$. I7. 8 . I8. I. 13, $26^{*}, 3 \mathrm{I}^{*}, 34^{*}, 36^{*}, 39^{\dagger}, 43^{*} ; 2.30,59^{*}$; $3 \cdot 6^{*}, 5 \mathrm{I}^{*}, 73 ; 4 \cdot 7,33,49,86^{2}$. I9. $7 \cdot 3$. átrā (p. -ra). 5. I. 3, 5. 9. IO. 12*. 12. $2.26^{*}, 27$.

á tri (áttri) : -is. 13. 2. $4,12,36 ; 3$. I5. I8. 3. 15,16 . 
átrim. 4. 29. 3, 4. átrayas. 18. 3. 20 . (cf. atrivát.)

atrín (attrín): -ínas. 1. 7.3; I6. I, 3. 2. 4.3. 4. I0. $2 . \quad 6.32 .3$. 8 . 4. $1^{*}, 5^{*}$.

atríṇām. I. 8.4.

atriovát. 2.32.3.

átha. I. $7.3 ;$ I 8.1 . 2. 6.5 . 3. 3 . $6 ;$ S. I ; I 2. $5 ; 25.6$ 4. I. 5 ; 4. 8 ; $7.2 ; 17.8$. 6. 50. I; 66. 3 ; II6. I ; II9. 2 ; I2I. I; I38. 2 . 7. 8. I; I4. $3 ; 56.6 ; 83.4$ 8. 1. $6 ; 8.20 ; 9$. 24. 9. $5.27 ; 9.12^{*}$. IO. I. $28 ; 4$. I. II. I. 8 ; 4 I4; 8.3 I. I2. 2. 30 ; 3. 55-60; 4. 22, 23, 25, 28, 36, 52. I4. I. $\mathrm{I}^{*}, 2 \mathrm{I}^{\dagger} ; 2.29^{*}$. I5. I2. 8 ; I3. 6 . I8. $2.4^{*}, 5^{*}, 5^{\dagger}, 9 ;$ 3. 7 I. I9. 52.5 ; 68. I. 20, I36. 7 (?), 8 (?).

átho (p. -0 íti). ' I. I4. $2^{2} ; 22.2,4^{*}$. 2. $4.6^{2} ; 9.1 ; 31.2,4 ; 32.5 ; 36.7$. 3. $2.4^{2} ; 18.5^{\dagger} ; 21.9 ; 24.1 ; 25.5$. $4 \cdot 3 \cdot 4^{2} ; 4.5 ; 6.6 ; 9.3^{2} ; 13.5^{*}: 17$. 7 ; $19.3 ; 20.5 ; 36.1$. 5. I4. $2 ; 21$. 4-6; 22. 10; 30. 13. 6. I3. I; 14. $3 ;$ 19. $2 ; 21.3 ; 69.3^{2} ; 74.2^{2} ; 96$. $2^{2 *} ;$ 103. $2 ;$ IO9. $3 ;$ I28. 4 ; I33. 4 ; I38. 2 ; I39. $2^{3}, 4 ;$ I $40.2^{2}$. 7. 56.2 , $5 ; 60.5 ; 74.3 ; 76.2 ; 95.3$. 8. 2 . $28 ; 5.12^{3} ; 7.5,10,22,28^{2}$. 9. 3.1 ; $4.4,20 ; 8.7 ;$ 10. $28^{*}$. I0. $2.27 ; 3$. 7 ; $8.22 .3^{8} ; 9.12-24 ;$ IO. I7, 33. II. I. $29 ;+3,9,17 ; 6.2,6,7 ; 7.8 ; 8$. $5,14,15,23 ; 9.10,22 ;$ IO. 3 . I2. I. 7,$9 ; 2.19 ; 4$. $18,30,39,40,46$. I4 I. $2^{*}, 28^{*} ; 2.4^{*}$. I9. $4.3^{2} ; 6.9^{*} ; 34$. $4^{2}, 8 ; 39.2-4 ; 46.3 ; 48.1 ; 49.3$; 50. 5 . 20. I 28.5 ; I30. I 7, I 8 , I9.

átharvan: -vā. 5. 2. $9^{*}$. Io. 2.26 ; I0. 12, I7. I 8. 3.54. I9. 4. I ; 54.5 . atharvan. 5. II. 2 (mss. áth-).

átharvāṇam. 4. I. 7. 5. II. II.

7. 2. 1 .

átharvane. 7. 104. I.

átharvanas. I0. 2.27.

átharvāṇas. 4. 37. I. I0. 6.20.

II. 6.13. I 8. 1. $58^{*}$.

átharvaṇām. I6. 8. I3. (cf. atharvavát, atharvāñgirás, ātharvaná.)

atharva०vát. 8. 3. $21^{*}$.

a th arvāñ girás (p. - vaoañg-): -ásas.

I0. 7.20.

Va d: ádmi. 6. 71. I, 3 .

admi. 5. 18.7. I4. I. 57 .

átti. 9. 9. $20^{*}$.

atti. 4. 30. $4^{*}$. I2. 5.4 I. I5. I4.

I-I 2.

adánti. $7.56 .7 . \quad$ 8.6.23.

adyāt. 5. 18. 2.

addhí. 7. 73. $11^{*}$. I $8.3 \cdot 42^{*} ; 4$. $65^{*}$. 20. I 36 . I I-3 (?).

addhi. 4.22.7. 5.22.8. 6. 63. I. 1 2. 2. 3 (mss. ádhi; ed. addhí).

attu. I. $28.3,4$. I $8.3 .46^{*}$.

attam. 6. 140. $2^{2}$.

attó (p. -ó íti). I 8. 3. $44^{\dagger}$.

atta. 2. $24.1-8^{3}$.

adantu. 5. I2. II. 8. 3. $7^{*}$. II. IO. $23,24,26$.

adat. ro. 8. 22.

ádān. 6. 50. I.

áttum. I8. 4.63.

áttave. I. II. 4. 5. I8. I. I2. 2. 37. I4. I. $29^{*}$. I8. I. $56^{*}, 57 ;$ 2. 34 . (cf. attŕ, atrá, átri, atrín, ad, ada, adant, adya, advan, ánna, ādyà.) $+\overline{\mathbf{a}}$ : â. .. admasi. 6. I6. I.

a d in ahutâd, āṇ̣âa, āmấd, ubhayấd, kravyầd, purușấd, madhvád, viçvấd, sūyavasâd, havirád.

a d a in annādá, avakādá, garbhādá, haviradá.

ádatta: -as. 5.11.9, Io.

ádattā. 12. 4: 13 .

ádattvā. I2. 4. 19, 23, 45. [34. ád a dat: r2. 4. 20, 2 I (mss. ad-), 26, ád a di vāñs:-dușe. 12. 4. 39.

ádadușas. 12. 4. 48 .

a dant in ánadant.

ádabdha: -as. 6. 53.2. I7. 12.

ádabdhena. I7. 12.

ádabdhebhis. I7. 9 .

(cf. ádabdhacakșus, ádabdhāsu.)

áda bdha०cakșus: 13. 2.44.

á d a bdhāsu (p. -dhaoas-) : -us. 5. I. I. 
a da y á: -ás. 19. 13. $7^{\circ}$ (mss. adāyás). á d g a : -gās. 1. 27.3.

adás. 2. 3.1. 3. 7.3 ; 13. 1. 4. 2. a d dhā in

4; 19.4. 5. 2. $3^{\circ}$. 6. 18.3. 10. 9. a ddhătí: -ís. 6. 76.2.

5. I1. $8.33^{2}$. 12. 1. 55. 14.7.9 addhătáyas. I1. 8.7. 14.1.16\%.

(adáḥoad-). 19. 52.4. 20. 128.12. ádbhuta: -as. 2.12.1. 5. 27.10.

ád āna: -nāya. 12. 4.51.

(cf. adānyá.)

a dāny á: -niấn. 2. 35. 3 .

ádābhya: -bhias. 3. 21.4 . 7. 26 . 5*. 18. 1. $18^{*}$.

ádābhiam. 8. 4.20".

ádāraosṛt: I. 20. I.

ádāçuri: -is. 20. 128.4 .

ádāsyant: -yan. 6. 71.3; II9.1. áditi: -is. 3. 22. I. 5. 26.6. 6. 3 .

I $; 4.1,2 ; 7.1 ; 68.2 ; 8$ I. $3 ; 120$.

2. 7. $6 . \mathrm{I}^{6^{*}} ; \mathrm{I} 7.3$. 8. 9.2I. 9. 7 .

IO. II. I. I, II ; 3.4. I2. I. $6 \mathrm{I}$.

I5. $6.7 ; 18.4$. I8. I. $19^{*}, 36^{*} ; 3.27$. 19. $10.9^{*}$.

adite. 2. 28.5 . I2. 3. I1. [30. áditim. 3. 8. 2. 7. 6. $2,3^{*}, 4$. I8. 4 . áditaye. 5.12. $4^{*}$. 7. $34.1 ; 83.3^{*}$. 8. 3. $16^{*}$.

ádites. 2. 28. 4. 3.16.2\% 7.7.1. II. I. 24. I3. 2.9. I5. 6. 7. I8. I. I8*. ádityās. 3.22.1. 5. 1.9. 13.1. $38 ; 2.37$.

(cf. ādityá.)

áditsant: -ntam. 3. 20.8 .

ádipsant: -satas. 4. 36. 2.

ádivyant: -yan. 6. IIg. I.

ádurmañgal a: -lī. I4. $2.40^{\dagger}$.

áduṣkr t t (p. -uḥok-) : -tāu. 14. 2. 16 *

ádūna: -nās. 2. 3I. 3 .

ádṛçy amāna: -as. I0. 8.13.

a dŕṣt a : -as. 5. 23. 7 .

adŕşțam. 2. 31.2.

adŕ̛sț̄ās. 6. $52.2^{*}$.

adṛ́ștān. 5. 23.6*. 6. 52.3. 8. 8. 15 . (cf. adṛștahán.)

a dṛșța ohán: -hă. 5. $23.6^{*}$. 6. 52 . ádeva: -as. 6. 6. I.

ádevis. 8. 3. $24^{*}$.

a devá: -ás. 5. 8.3 .

ádevṛ०han: -vṛghnī. I4. 2 I 8.

a dom a dá: -ám. 6. 63. I.

a dom adhá: -dhāú. 8. 2. I8.

a d y a in annădya, pāútrădya.

a d yá. I. 1. 1; 20.2 ; 32.3. 3.2.4; 22. 3. 4. 3. $5 ;$ 4.6. 5. 7.5.6; 12. 1., $9^{*} ;$ 18.2. 6. 66.2; 67.1: 90. $1 ; 99.2 ; 108.4 ; 118.1 ; 138.1 .7$. 20. I; $31.1^{\circ} ; 47.2 ; 48.2^{\circ} ; 50.1 ; 8.4$. I; 97.1.' 8. 3. 1 $2^{\circ}, 1^{\circ}$. 10. 7.23 ; $8.23,29 ; \quad$ IO. I I (1. adiá ?). II. 4 . $21 ; 8.3,16$; 10. 20. 12. $2.22^{\circ}$. 13. I. 58 . I6. $4.6 ; 6.1^{\circ}, \mathrm{I}^{\dagger}$. I8. I. $6^{\circ}$, $46^{*} ;$ 2. $13^{*} ; 3.59^{\dagger}$. 19. 11. $5^{*} ; 47$. 5,$6 ; 49.9 ; 50.2$.

adyấ (p. -yá). 7.82.6. 8.4.15". 9. 10. $9^{*}$. 19. 50.6 (p. adyá, à).

ádri: -is. 5. 20. 10. 9. 4. 5. 19. 10. 3 ". a drúh: -has. 6. 7. I.

ádrogha०vāc: -cam. 6. I. 2.

ádroghāvita (p. -ghaoav-): -tās. II. I. $2^{\dagger}$.

a dvan in vyádvan.

ádha. I8. I. $2 \mathrm{I}^{2^{*}}$; 3. I7.

ádhā (p. -dha). $\quad$ I. 28.4 . 3. 4.4; 20. $I^{\dagger}$. 4. 32. $7^{*}$. 5.22. $2^{2}$. 6.65. I. 7. $73.11^{\dagger} ; 83 \cdot 3^{\dagger}$. 8. 4. $15^{*}$. I0. 2. 7; 4. 25 . I2. 3. 2, 9. I3. I. 30. I4. 2. 20. I8. I. $16^{*}, 5 \mathrm{I}^{\dagger} ; 2 . \mathrm{II}^{\dagger}, 23 ; 3$. $2 \mathrm{I}^{*} ; 4.48,63,70$.

a dhamá: -ás. 8. 4. 16*.

adhamám. 1. $21.2^{\dagger}$. 2. 8 . I. 3. 7. 4. 7. $83 \cdot 3^{*}$. 8. 2. $24 . \quad 9.2 .17,18$. 10. 3. 9 . 13. 1. 32 .

adhamăs. 6. 121. т. 7.83.4.

adhamá. 9. 2. 4, 9.

ádhara: -as. 6. 134.2 (ádharaḥ。 adh-). 7. 31. I*. 19. 46.5 .

ádharā. 3. 18.4 .

ádharāt. 7. 5 I. I*.

ádharasyās. 8. 2.15.

ádharāu. I0. 2. 2.

ádhare. I. 9.2, 4. 3. 19.3. 4. 22. 6. I3. I. 31 .

ádharān. 2. 29.3. 3.6.6. 5.8. $8 ; 28$. 14. 6.88.3. 10. $3.3 ; 6.19$, 
30. I3. I. 3I. I9. 33. 2.

ádharābhias. 3. 18.4 .

(ef. adharahanú, adharăñc, adharăt.)

a dharaohanú: -ús. 9.7.2.

a dharācyà : -cíam. 4.7.2 (m. mss, -răcyam).

a d h a rẫn c: -rần. 5. 22. 2. I2. 2. I. adharāk. 20. I28.2 (mss. ádharāk); 134. I-6 (mss. adhárāk).

adharâñoam. 5. 22.3,4. 6. 127. 3. I 0. 5. 36 . I6. $8.1-27$. I9. 39. I0. adharăñcas. 3. 6.7. 9. 2.12.

(cf. adharācyà.)

a dh arăt. 2. 14.3 . 6. 40.3. 8. 3 . I9*; 4. 19*; 5. I7. II. 2. 4. I2. I. 31,32 ; 2.41 I 8.4 .11 I 9.15 .5 ; 48. 4 .

adhás. 3. $18.4^{\dagger}$. 6. 42.2 . 8. $4.1 \mathrm{I}^{*}$. (cf. adhamá, ádhara, adhástāt, adhaspadá, adhóvacas.)

a dhástāt. 4. 40. 5 .

a dh a spa dá (p. -aḥıp-) : -dám. 2 7.2. 5. 8. 5,8. 7.34. I; 62. I. II I. I. 12,21 .

adhaspadéna. Io. 4. 24.

ádhi. I. 9.2, 4. 2. 9. $3^{2} ; 27.7 .4$. 27. I ; 28. 7. 5. 6. $4^{\dagger}$; 12. $6^{*} ; 30.6$. 9. $9.3^{*}$ I I. 2.20 I2. 3.3. I9. 33. 5 (?) ; 49.2 (mss. ávi).

(with abl.) I. $3.9 ;$ I4. I; 24. 4; 34 . I. 2. $3.1,4,5 ; 7.1,3 ; 9.1$; 10.8 ; 30. I; 33. $1^{*}, 4^{*}$. 3. 6. I. 4. 6.4 ; 10. 2,6; I9. 4, 7; 34.1. 5. 4.7; 21.4. 6. 2 I. I; 73. $3 ; 76.1 ; 87.1^{*} ;$ I09. 2 ; III. I； I2I. I； I24. 3 ; I33.4. 7. 8 . I; 53. I; 65. I; II 5.3. 8. 2. 27;6. $24 ; 7.2,7,14,16,19 ; 9 \cdot 4^{2}, 5$. 9. 5 . $6^{2} ; 8.12 ; 9.18^{*} ;$ IO. $21^{*}$. I0. 2.26 ; 7. 2 ; 10. 19, 2 I. II. I. $26 ; 5.15 ; 8$. I, 34 I 2.3 .26 . I3. I. 25,$42 ; 3.2$; 4. 33. I4. 2. 43 . I9. 3. I; 6. $9^{*}, 16$; $45.3 ; 56.1,2,3,5$.

(with loc.) I. $3.6 ; 32.4 ; 35.3 .2$. I. $5 ; 9.4$ 3. 7. I. 4. 2.6* 4. $7 ; 7$. I; 8.4. 6. 30. I; 70. I-3, 3; I36. I ; 138. 4, 5. 8.6.24; 7.1 $3 ; 9$. I9. 9. I. IO, I6, I $7 ; 3.20 ; 5.4,5,8$, I $5 ; 9$.
$6^{*}, 21^{*} ; \quad$ IO. $1^{*}, 7^{*}, 18^{*}$. $\quad$ Io. $2.5,14$; 7. I, I $2,15^{2}, 29,30: 43^{*} ; 8.19,41 ; 9$. I 2 ; I. 5 . I I. I. 24,$36 ; 4.4$; 5. I I, $24 ; 7.8,9,14,18 ; 8.30,34 ; 9.10$. I2. I. $8,52,56 ; 2.41 ; 3 \cdot 36,47$. I3 I. II, I4, $37^{2} ; 3.6$. I 4. I. I* 2. 23 , 48, 49. I8. I. I $^{*} ; 2.14^{\dagger}, 32,47 ; 4.3$, 4. I9. $5.1^{*} ; 24.2,3 ; 26.1$; 27. 10; 3 I. I $2 ; 34.6 ; 48.6 ; 53.3 ; 54.5$.

(cf. adhi $+V^{\prime}$ ah, i, I ūh, ci, vi + I kṛt, kram, I kși, gam, I gā, dīv, I dhā, ni + dhā, dhṛ, nṛt, I pā, brū, ruh, vac, I çî, çri, su, skand, sthã ; and adhigavá, ádhyalsșa, ádhipati, ádhipatni, adhirājá, ádhirajju, ádhyardha.)

a dhi og a vá: -ám. 9.6.39.

a dhi ocañkra má:-măm. II. 9. I6. a dhiodévana: -ne. 5. 3I.6. 6 . 70. I.

ádhi ○pati : -is. 3. $27.1-6 . \quad$ 4. 8 . I ; 35.6. 5. 24. I, 2, 4, 7, 8-14; 30 . I5. 7. 5.2. I2. 5.4. I3. 2. 25,4 I ádhipataye. 6. 10. I-3. I2. 3.55-60. ádhipati (p. -i íti etc.). 5. 24. 5 . ádhipatayas. 5. 24.6.

ádhipatiobhyas. 3. 27. I-6. (cf. ădhipatya.)

ádhiopatni (p. -i íti etc.): 5.24. 3 . a dhiopẫ: -ấs. 4.15.10;3I. $5^{*}$. 6. I I9. I. 7. 53. 2 . IO. I. 22 . I2. 3. 9. I9. 31. 2, 6, I I ; 56.6 .

ádhi $\circ$ rajju: -us. 6. II8. 2.

a dhi orājá: -ás. 6. 98. I, 2. 9. 10. 24. I9. 46.4 .

ádhirāja. 19. 20. 3 (mss.).

adhirājám. 5. 3. 10*.

a d hi ovāká: -ás. I 9. 32.9 (not mss.). adhivākăya. 6. I3. 2.

adhiovikártana: -am. I4. I. 28*. a dhiṣáva na a (p. -iosávan-): -ṇe. 5 . 20. 10 .

$[\mathrm{I}$. a dhiṣṭ̂a tṛ (p. -iosthā-): -tá. 4. I6. a dhiṣt hấna (p. -iosthā-) : -nāt. I2.

$4.4,5$. adhișțắne. I2. 4.23.

ádhīti (p. -ioit-): -tīs. 2. 9.3.

ádhĩra: -as. 5. 31. 10. 
ádhỉrās. II. 9.22.

á d hṛ șța : -țās. r9. $5^{8.4^{*}}$.

ádhenu: -nave. 6. 59. I.

ädhóvacas (p. -dháḥ๐v-) : -sas. 5 . 11. 6 (ed. -varcasas).

ádhyaksa (p. -dhioa-) : -as. 9. 2. 7. I0. 1. 6.

adhyakşẹ̣a. 5. 3. $\mathrm{I}^{\circ}$.

ádhyakşebhyas. 1. 31 . 1. [mss.). ádhy ardha: -as. 20. 131. 22 (not a dhva०gát: -tas. I3. 1. 36,43 .

ádhvan: -vã. I3. 2.14.

ádhvānam. 3. 15.4 *.

ádhvanas. 7.72.2*

ádhvanas (pl.). 4. I I. 2.

ádhvaobhis. I. $4 \cdot I^{*}$.

(cf. abhyadhvá, vyadhvá, adhvagát.)

a dhvará: -ás. 4. 24.3. 7. $58 . \mathrm{I}^{\dagger}$.

I I. 7. 7. I8. 2. 32 .

adhvarám. I. 4. 2*. 5. I 2. 2"; 27. 8, 9. I4. I. $46^{\dagger}$.

adhvarăya. 3. $16.6^{*}$.

adhvaré. 8. 4. I8*. I 8. I. $2 \mathrm{I}^{*}, 4 \mathrm{I}^{*}$.

19. 33. 3 .

adhvarằn. 19. 59. 3*.

adhvarănăăm. I9. 42.4 .

adhvaréşu. 5. 27.5. 6. I IO. I*. I4.

I. $37^{*}$.

(cf. vítatādhvara, vyadhvará ?, svadhvará, Vadhvariy, adhvaryú.)

Vadhvariy : -ríyatăm (p. -rioy-).

I. 4 . I*.

a dhvaryú: -ús. 7.73.5. I8. 4 . I5. I9. 42. I.

ádhvaryo. 20. 135.4 (mss. ádhvaryóh).

adhvaryo (p. -o íti). II. I. 3 I. (cf. camasădhvaryu.)

$\checkmark$ an: ánati. 4. 4.3.

anát. 9. 10. $8^{*}$.

(cf. anant, āna.)

+ a pa : ápă 'nati. II. 4. 14.

apănaté. II. 4.8 .

apãnatás. 6. 3 I. $2^{\dagger}$.

(cf. apãná.)

+ u d: úd ānişus. 3. 13. 4 . (cf. udāná.)

+ pra : pră 'ṇati (p. an-). I0. 8. I9.

II. 4.14 .

prá... ánati. 7.25.2.

prānáti. 4. 30. $4^{+}$. 11. 4. 10; 7.23.

I3. 4. II, 19 [3.3.

prănáanti. I. 32. I. I0. 10. 5. I3.

prầ 'ṇa (p. ana). 3. 3I. g.

prānát. I0. $8.2,6,11$. II. 2. 10 .

12. I. 3,4 .

prănaté. I I. 4. 3 .

prānatás. 4. 2. 2".

prānatăm. 3. 31. 9 .

prănatînăm. 8. 9.9.

prāṇáyati. 1 3. 3.3.

(cf. prāná, áprāṇant.)

+ vi : vianát (p. vioa-). 5. 2.2*.

(cf. vyāná, ávyanant.)

+ s a m: sám ăna. 9. 10. $9^{*}$.

(cf. samāná.)

a n a (pron. stem): anéna. I. 16.3. 3. I9. 2. 5. 28.2. 6.65.2. 8. 5. $3^{4}$. 10. 5. $15-21^{2}$. 18. 4.50 .

anáyā. 4. IS.5. 6. 133.3. I0. 5 .

I5-2I. II. IO, I2, 2 I.

ánagg na: -nās. 12. 3. $5 \mathrm{I}$.

án a gni $\mathrm{n}$ d a g d h a : -dhās. 1 8. 2. $35^{*}$. an añgurí (p. anam॰g-): -rés. 8. 6 . 22.

a n a ḍváh: -văn. 4. 11. I4, 2, 4, 10.

5. I7. I8. 8. 5. II. 9. I. 22 . II.

4. I3; 5.I8. I2. 3.49 . I9. 39. 4 .

anaḍ̂ăham. 9. 5.29. $12.2 .4^{8}$.

anadúh 4 as. 4 II. 3, 8, 9, II.

anadúhi. 4. II. 7.

anaḍ̂ăhău. 3. II. 5. 7. 53. 5. I4.

I. IO*.

anaḍăhas. I9. 50. 2.

anadúdobhyas. 6. 59. I. [I6. an atiov yādhy à: -dhíam. 9. 2. ánatiosrsț a: -as. I5. I2.8, 11 .

a n a tyudyá (p. -tioud-): -ám. Io. 7. 28 .

ána d ant : -ntas. 6. 50. 2.

a n a $\mathbf{t}$ in áprāṇant, ávyanant.

an antá: -ám. 8. 4. 17 $7^{\dagger}$ I0. 8.12².

a n a p aty á: -ám. I2. 4. 25.

ánapatyaovant: -ntas. I8. 2.47. 
anapaod yátā: -tām. 4. 17.6. anapa。vācaná: -nă. 8. 8. 9 . ánapaosprę: -rik. I3. I. 27. ánapaosphurant: -ran. IO. IO. 27 ánapasphurantam. $\quad$ 8. 4.36 (mss. ed. anapasphú-). ánapasphurantāu. 9. I. 7 . ánapasphurantĩ. I2. I. 45 . ánapasphurantīs. I 8. 4.34 (mss. ed. anapasphú-).

ánabhyakta: -tas. 20. 128.6 (mss. an ... tás).

ána bhy ārū ḍha (p. -bhioār-) : -am. II. 5.23 .

an a bhrí: -ráyas. I9. 2.3. a n a mitrá: -ám. 6. 40. $3^{4}$. I2. I. 47. anamitrắm. I2. I. I0.

a n a mĩvá: -ás. 2. 29.6. anamīvám. I 8 2.12*. anamivắ. II. I. 22 (p. -văḥ). anamivăs. 2. 30.3. 3.14.3. I. $62 ; 2.31^{*}$. I 8. I. $42^{*}$. anamivắn. I2. 2. $26^{\dagger}$.

án arpaṇa: -am. I2. 4.33. a n a rmán: -ánām. 7. 7. I. a narvá: -ám. 9. 9. 2*.

ánava。glāyant: -yatā. 4. 4.7. an ava dyá: -yăbhis. 2. 2.3. anavaodrāná : -ás. 8. I. I3. a navaodharșy à : -șíam. 7. 2. 10. an ava०bravá: -ás. 4. 31.5*. a navāyá: -ám. 8. 4.2*. a n a ç an a in açanānaçaná. ánaçnant: -an. 9.9.20*. a n a çrú : -rávas. I2. 2. $3 \mathrm{I}^{*}$. ánaṣt $\mathbf{a} \circ \mathrm{paçu:} \mathrm{-us.}$ I8. 2. $54^{*}$. ánas: 14. I. $10^{*}, 12 *$.

ánasas. I2. I. 47 . I4. I. $4 \mathrm{I}^{*}$.

(cf. anaḍváh, ánasvant, upānasá.) an asthá: -sthă. 9.9.4*. anasthấs. 4. 34. 2.

ánasvant: -vatī. IO. I. I5.

án $\mathbf{k}$ tākṣa : -as. 20. 128.6 (mss. anālztấ-).

ánāgamiṣy ant: -yatas. I6. 6. Io. a nā gás, ánā g as, á nā g a : anāgấs. 6. $27.2^{*}$.

anāgásam. 2. 10. 1-8. I0. I. I8. ánāgasam. I9. 44. 3 .

ánāgasas. $7 \cdot 6 \cdot 3^{\dagger} ; 34.1 ; 83 \cdot 3^{*} .9$ 5. 2. I6. 6. $\mathrm{I}^{*}$.

anāgásas. I0. 1. 7 . 19. 50. 7 . ánāgān. I8. เ. $36^{*}$.

(cf. anāgohatyâ.)

a nā goh a tyà (p. -gahoh-) : I0. I. 29 ánājānant: -nan. 6. II9.3.

ánātata: -am. 20. 132. 7 .

án ātu ra: -rān. I2. 2. 49 .

a nāthá: -ám. I8. I. I2*.

ánā diṣṭa: -țām. I5. 6.6.

an ā y ý : -diám. 8. 2. I9.

anādiâ. $5 \cdot 18.3$.

anādiăm. 5. I8. I.

ánādhṛṣ: -şas. 6. 2 I. 3 .

a nādhṛ șá: -ás. 7. 84. I.

anādhṛş̧yâs. 18. 2. 16*.

ánāpt a : -tā. 4. 7. 7 .

a n $\overline{\mathbf{a}}$ b a y u : ánābayo (p. -o íti). 6. I6.

a nām aná: -năt. I2. 4. 5, 8 .

a nām a yá: -yta 20. 129. 20.

anāmayấs. 9. 8.13-8.

(cf. anāmayatvá.)

a n ām a y a tuá: -ám. I 9.45 .2 (mss. ánāmagas, tvám).

$\left[7^{*}\right.$.

a ñ̄ ma yitnú : -núobhyām. 4. I3.

a ñ̄y a ta ná : -ás. Ir. 3. 49 .

a ñ̄ rambha ṇá: -ṇé. 8. 4. $3^{*}$.

ánārşeya: -yānām. II. I. 33 .

án āva yā: -yās. 7.90.3.

ánāvṛtta: -tãm. I 5. 6.7.

a nāvyādhá: -dhấm. I4. I.64.

anāvraská: -ás. 12. 4.47.

a nā çú: -ús. 20. I2S. Io (mss. anāçus).

a ñ̄smāká: -ás. 19.57.5. anāsmākám. I9. 57.4.

a nāsrāvá : -ám. 2. 3.2.

anidhmá : -ás. I4. I. $37^{*}$.

ánindā: -ās. II. 8.22.

a niopády a māna: -am. 9. Io. II $^{\dagger}$.

ánibhṛșța: -as. I9. 60.2 (mss. átiopṛșthā).

aniomiṣá: -ás. I9. I3.2*.

animișéna. I9. I3.3".

ániomeșa: -am. 9. 9.22*.

ánirā: -ām. 20. 135. I3. 
ánirāhita (p. -iȟāh-): -tas. I2. 2. 35,36 .

ánişțṛta (p. -ih̨ost-): -tas. 7. 82.3. ániohatya. I2. 3.4.

ánika: -am. 4. 27.7. 6. $125 \cdot 3^{\prime \prime}$.

7. 36.1 . 13. $2.34,35^{\circ}$.

(cf. jyótiranīka, çatănìka, anikaçás.)

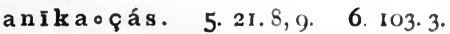
ánİ̧̧ a ra: -rās. I2. 3.42.

ánu. I. 22. 1. 2. $5.5^{*} ; 12.5^{2} ; 34.3$. 3. $7.2 ; 8.6 ; 9.6 ; 13.2 ; 18.6^{*} ; 21$. 7. 4. $15.4,7-9,12 ; 21.4^{*} ; 38.5 \cdot 5$. I. $3 ; 2.1^{*} ; 8.9 ; 27.7$. 6. 17. I-4; $26.2 ; 29.3 ; 39.1 ; 48 . \mathrm{I}-3 ; 53 . \mathrm{I}$, $3 ; 69.2 ; 72.1 ; 73.3 ; 90.2 ; 97.3^{*}$; 105. 1, 2, 3; II3. $2^{2}$; I22. I, 2 ; 13I. 2 . 7. $20.1,2,6 ; 43.1 ; 57.1 ; 82.4^{5} ; 97$. 4 ; 118. I*. 8. 9. $8,12,13^{2}, 15^{2}, 16,17$. 9. I. I(), $24^{3} ; 4.24 ; 5.2 ; 9.9^{*}$. 10 . 4. $6 ; 5.25-35,37,45 ;$ IO. $7^{2}$. II. I. 31 ; 2. 10; 5. 12; 8. II, I9-22, 24, 27. I2. $2.2 I^{*}: 3.17 ; 4$. I. I3. I. IO; 2 . I4, $18^{*}, 2 \mathrm{r}^{*}, 40 ; 3 . \mathrm{I}, 20 ; 4.26$. I4. J. $15^{*}, 46^{*}, 60 ; 2.10^{*}, 74$. I5. $2.1-4$; 6. I-7. $8^{2}, 9 ; 9.1 ;$ I4. I-I2. I 8. I. $20^{*}, 32^{*}, 50^{*} ; 2.9,13^{*} ; 4.28^{4^{*}}, 75,76$, 86,87 . I9. 6. $2^{\dagger} ; 26.3 ; 32.9$ (not mss.); 44. Io (mss. anu); 49. 2 (not mss.), 5 (mss. anu), 6 (mss. anu). 20. 34. 16 (not mss.) ; 135. 5 (?).

(cf. anu $+\sqrt{ } \sqrt{ }$ art, I aç, i, pari + i, pra $+i$, sam $+i$, ich, idh, iks, I kr, 2 kr, kram, vi + kram, sam + kram, I kṣi, khyā, gach, gam, $\bar{a}+$ gam, I gā, ghrā, car, vi + car, sam + car, 2 ci, chā, jā, jñā, tan, $\bar{a}+$ tan, tap, tṛ, tṛd, dṛc, dah, nis + dah, sam + dah, I dā, sam + diç, dhāv, dhī, nikş, nī, pat, pad, paç, pālay, bandh, budh, bhṛ, mad, man, I mā, mrj, mruc, yaj, sam + pra + yā,pra + yuj, rabh, $\overline{\mathbf{a}}+\mathbf{r a b h}, \mathbf{s a m}+\mathbf{r a b h}, \mathrm{rādh}, \mathbf{r u d h}$, ruh, $\overline{\mathbf{a}}+$ ruh, 2 vap, vac, 2 vas, vah, pra + vah, sam + vah, vã, I vid, sam + vid, 2 vid, pra + viç, sam + viç, vṛj, vṛt, $\bar{a}+$ vṛt, vi + vṛt, çās, I çì, ā + çì, q̧uc, çuş, çru, sac, sic, vi + sic, sṛp, stubh, sthā, sphur, hã, hũ, hṛş; and anupūrvá, anupalāla, ánvāntrya, anukúla, ánuvartman, ánuvrata, anusúrya.)

anuokará: -réna. I2. 2. 2.

anukúla: -am. 5.14.13 (-iva).

anuojighrá: -ám. 8.6.6.

ánudita: -tãm. 5. 1. 2.

anuodéya: -yĩ. I4. I. $7^{\prime \prime}$.

anuodhyấ: -ấs. 7. 11 4. 2 .

ánun madit a (p.-utom-) : -as. 6. III. I, $2,3,4$.

ánupaokșita: -tāu. 6. 78. 2.

ánupaodasvant: -vatas. 4. II. 9. 12.

$\begin{array}{lll}\text { ánupadasvatim. } & \text { 2. 36. 5. } & \text { 7. 80. } 2 .\end{array}$ a nupalāla in palălănupalālá.

a nupaosecaná: -ás. II. 3.24.

a nu०pūrvá: -ám. $\quad$ I2. $2.24^{*}, 25^{*}$.

(cf. anupūrvávatsa.)

a nu pūrváovatsa : -sām. 9. 5. 29. anuprayạ na (p. -uoprayắn-) : -am.

7. $73.6^{\dagger}$.

ánuomati: -is. 1. I8.2. 6. 11.3.

7. $20.1,5,6 ; 24.1$.

ánumate. 6. I31.2. 7. 18. 4,6 .

anumate. 2. 26.2. 7. 20.2.

ánumatim. 5.7.4.

ánumatyās. 9.4.12.

a nu०mầ dy a: -diā. I 4. I. 47.

anuoméy a: -yās. 6. 137. 2.

anuomroka: ánumroka. 2.24. 3.

an u०yājá: -jấs. I. 30. 4 .

a nuorā dhá: -dhă. 19. 7.3.

(cf. anūrādhá.)

anuoródhana: -am. 6. IO2.3.

ánuovartman:-mānas. 3. 8.6 .

a nu०vāká: -kāís. I9. 22. I.

ánuovrata: -as. 3. 30. 2.

ánuvratā. 3.25.4. I3. I.22. 14. I. 42 .

an ușțúbh (p. anuostú-): -úp. 8. 9. 20. I9. 2 I. I.

anușțúbham. 8. 9. I4.

a nuṣt țā tṛ́ (p. anuosthā-) : -tấ. I5. 5. $1-7$. 
anusthātằram. I 5. 5: I-7.

anuṣṭhātắrāu. $15 \cdot+1$ I-6.

anust thú. I2. $4 \cdot 45$.

anuosarpa: ánusarpa. 2. 24. 4 .

anuosturya: -riam. I9. 49.5 (ed. ánv ásūryám).

a nuosphurá: -ám. I. 2.3 . a nu०h avá : -ám. I9. 8.4.

án ū ka: -am. 4. I4. 8 .

ánūkāt. 9. 8.21.

(ef. anūkyà.)

a n $\bar{u} \mathbf{k}$ y à : -kíam. 9.6. I.

anūkíāt. 2. 33. 2*.

anūkyè (p. -è íti). II. 3. 9.

a nū c y à : -yè (p. -è íti). I 5. 3.5.

án ūna: -as. 7. 81.3.

ámūnam. 7.81.3. 12. 3.48.

a $\bar{u}$ pa in

a nū p y à : -píâs. I 9. 2. 2.

a nū rā dhá (p. anuor-): -ám. I9. I5. an ū ṿ̛́j (p. anuov-) : -jāu. 9. 4. I2. a n ṛ kṣa rá : -rắ. 18. 2.19*.

anṛkșarắs. 14. I. $34^{*}$.

a n ṛ̣̣á : -ás. 6. I I 7. I, 2.

anṛnăs. 6. 117. $3^{4}$.

ánṛt a: -am. I. IO. 3. 2. I5.5. 4 . 9. 7 ; 16.6. 6. 6I. 2, 3. 7. 89. $3^{\dagger}$. 9. IO. $23^{*}$ IO. $2.14 ; 5.22$ I 2.3 .52 . I8. I. $4^{*}$. I9. 44.8 .

ánṛtena. 6. 7 I. 3. 7. 70.2. 8. 3. $\mathrm{II}^{*}$. ánṛtebhis. 8. $4.8^{*}$.

(ef. satyānṛtá, ánṛtadeva, anṛtavắc.)

ánrtaodeva: -as. 8. $4.14^{*}$.

an rutaovắc: -âk. 4. I6. 7 .

áneva. I6.7.4.

a nehás: -hắ. 6. 84.3.

anehásam. 7.6.3*

ánta: -as. 9. 10. $14^{*}$.

ántam. 9. 10. $13^{*}$. I0. 7.42. I2. 3.34. I5. 7. I.

ántāt. I8. $3.65^{\dagger}$.

ántāu. 6. S9.3. I3. 2.6, I3.

ántās. I. I7.3. I 4. 2. $5 \mathrm{I}$.

ántān. I4. I. 45 .

(ef. anantá, dūréanta, sáminhitānta, sámanta, samantá, ántaka, antatás, ántavant.) a nt a ḥokoçá: -ám. I. 14. 4.

a nt a ḥ opātrá: -tré. II. 9. 15.

ántaka: -as. 6. 46.2. 8. 10.23.

I6. 5. I-6. I9. 9.7.

ántakāya. 8. I. I.

antatás. I4. I. 64

antár. I. $4.4^{*} ; 6.2^{*} ; 13.3 ; 30.3$.

2. $10.5 ; 31.5 ; 32.1$ 3. 6.3 ; 10.

$4 ; 20.8 ; 21.1,2^{2}, 7^{2} ; 22.3 .{ }^{\cdot} 4.8$.

7 ; 10. 7 ; I1. $3 ; 26.5 ; 28.5 ; 30.7^{*}$. 5. I1. 8 , 9. 6. I. $2 ; 73.2 ; 8$ o. 3 ; 132 . I-5. 7. 43. I ; 87. I. 8. I. II; 4 . $3^{*}$. 9. 3.6, 14, $22 ; 8.7,9 ; 9 \cdot 9^{*} ; 10$. $\mathrm{IO}^{*}, \mathrm{II}^{*}, \mathrm{I}^{*}$. I0. $2.7 ;$ 5. I5-2I; 7 . I0; $8.13,28 ;$ I0. 25,28 . II. 2. II , $24 ; 4.20 ; 5.3 ; 7.1,6 ; 8.2,6$. 12. I. $19,37,60 ; 2.33$. I3. I. I, $2 ; 2$. $30 ; 3.15,20$ I4. I. $37^{*}$. I7. 8, I3. I8. $4.89^{*}$. 19.3 .2 : $27.10 ; 42$. I (mss. antáh̆ohite); 48. I; 6I. I (not mss.); 72. I. 20. 34.12 ; 133.6 .

(cf. antar $+V \mathcal{V}$ I kr, gam, car, chad, 2 dī, I dhā, paç, bhū, vad, sthā; and ántara, antară, antárvant, āntrá, antardeçá, antardāvá, antaḥpātrá, antaḥkoçá, antarhastá.)

ántara: -am. I. I9. $4^{*}$. 2. $30.4^{2}$. 7. 100. 1 .

antará. 3. 15.2. 4. 16.5. 5. 20. 7. 6. 55.1. 7. 109.3. 8.6.3. 9. $3.15 ; 8.9$ I0. $7.28 ; 8.39$. II. 4 . I4; 5.1 I ; $8.34^{2}$. I2. 2. 44 . I3. I. 57,$58 ; 3.6$. 14. 2. 34 I9. 56.4 . antárikșa : -am. 2. I2. $I^{2}$. 3. 21 . 7 ; 29.8. 4. 2.4; II. I; I4. 3 ; 20. I; 35.3; 39.4. 5. 3. $3^{*} ; 9.7 ; 28$. 2. 6. 40. I; I20. I, 2 . 7. I. 2 ; 6. I*, 4. 8. I. $12 ; 4.23^{*} ; 8.5,21,22$. 9 . I. 21 ； $3.15 ; 5.20 ; 7.5$; I0. 24.10. 2. 24,$25 ; 5.26 ; 7.3,12,32,35 ; 8$. 36 ; 9. 10. I I. 2. 10, $27 ; 5.4 ; 6.6$; 9. +. I2. I. 20,$53 ; 3.20,26$ I3. I. $7,9,16,33 ; 2.32,35^{*}, 45 ; 4 \cdot 31$. I4. 2. 69 . 15. 17. 2 . I7. 13. I8. 2. 9, $49 ; 3.59 ; 4.5,6$. I9. $6.8^{*} ;$ 9. I, I4; 10. $5^{*}$; $15.5 ; 32.9 ; 58.2$. 20. 49. I. 
antarikşa. 6. 130.4.

antárikşeṇa. 4. 20.9; 38.5-7. 6. ántiosumna: -ne (p. -ne íti etc.). 80. I". II. 3.39. I3. 3. 13. r9. 17. 2 ; 19. 2.

7. II2. $\mathrm{I}$.

a ndhá: -ás. 6. 129.3. 9.9.15*. Ir.

antárikșāya. 5.9.3, 4. 6. 10. 2. 7. 102. I. Ir. 2. 4 .

antárikșăt. 4. IO. I; I4. 3; 40.6. 5. I0.8. 6. I24. I, 2. 7. 26.8. 9. I. I. I0. I. $13 ; 5.26$. 12. 5.72. I3. 4. 31 I6. $4.4 ; 7.6$. I8. 4.9 . I9. 3. I ; 9.7 (?); 35.4 .

antárikşasya. $5 \cdot 24.8$.

antárikşe. I. $30.3 ; \quad 32.2 ; 33.3$. 2. 10. 3 . 4. 8. 5 ; $14.8 ; 25.2 ; 39$. $3^{2}$. 7.66. $1 ; 97.8$. 8. $3.3^{*}, 5^{*} ; 10$. 8. 9. 4.10; 6. $56^{2}$. II. 2.23 ; 10. 2,8. 13. $2.30 ; 3.22$. 15. 13.2. I7. I2. 18. 3.63 (s. mss. -şeṇa). I9. 8. I; 27.12.

antárikșāṇi. 19. 27.3.

(cf. pārthivāntarikșá, antárikșa-

vant-antarikşasád.)

antárikşa০vant: -ntam. rg. I8. antárikşaosamçita: -tas. ro. 5. 26.

antarikşa०sád: -das. ro. 9. I2. II. 6. I2.

antarikṣasádobhyas. 18. 4. 79 .

a ntardāvá (p. -tahod-): -vé. 6. 32. I.

a ntardeçá (p. -taḥıd-): -çát. I 5 . antardeçấs. 8. 8.22. 10. 6. r9. antardeçắn. I 5. 6.9; I4. I 2 . antardeçébhyas. 4. 40.8. 5. I0. 7. 5 . $5 \cdot 7^{2}$. (cf. sắntardeça.) 3. 34 . andhám. 9.8.4. 19. 47.8 (mss. ándha); 50. I (do.). andhéna. 18. 3.3. andhă. 9. 2. 10 .

ánd h a s: 7. 58. 2 ". ándhasas. 6. 2. 2.

ánna: -am. 3. 27. 3. 4. 30.4*. 5. 18. 4, 7. 6. 63. I; 71. I, $3^{2}$; II6. I. 7 . IOI. I. 8. 2. 19; 7. I2. 9. 6. 24, 25 , 26. ro. $2.27 ; 5.45 ; 6.5$ (ánnam。 an-), 33 (do.); 8.22 ; 10.8 . I I. 5 . 25. I2. I. $3,4,42 ; 5$ I0. 13. 4 . 14 . 22. I5. $7.4,5 ; 8.2 ;$ I4. I-I2. I9. 7.4 .

ánnena. 10. 6.23. 12. I. 22.

ánnāya. 12. 3.57.

ánnasya. 5.28.3. 7.60.5. 15 . 8. 3. rg. 3 I. $8 ; 55.5$ (p. -dagdhá。 ann-).

ánne. ro. 5.44 .

ánnāni. r9. 31. 4 .

ánnānām. r 8. 4.54.

(cf. ukşănna, vaçănna, viçvānná, ánnatejas-annădya.)

ánn a ot ej a s : -jās. ro. 5.34.

ánna०pati: -is. 13. 3.7.

ánnapataye. 19. 55.5.

a nn a b bāa gá : -ás. 3. 30. 6.

annabhāgám. I2. 1. 29.

ánna०vant: -vān. r 8. 4.21.

anna०víd: -das. 6. II6. I.

antardhí (p. -tah̆odh-): -ís. r2. 2. a ntárvant (p. -táh̆ov-): -vān. 9. 4. 3. antarhastá (p. -taḥoh-): -tám. 7 . 50.2.

ánta。vant: -vat. ro. 8. r2.

ánti. 6. 4.2 (mss. ántitam). 8.5. I I (do.). ro. 4.9 (mss. anti); 8. $32^{2}$. 18 . 3. $23^{*}$.

(cf. antiká-ántisumna.)

antiká: -ám. 3. II. $2^{*}$.

antikăt. 4. 16. I. 12. $2 \cdot 38,50,52$. ántita (?): -tam. 6. 4.2 (ed. ánti

a nnā dá (p. -na॰ad-): -ás. I3. 3. 7 .

annādám. I5. I4. I, 2, 7-I2.

annādéna. 15.14.1, 2, 7-12.

annādáya. r 9.55 .5 (mss. anna。 adáyas).

annădím. I5. 14.4, 5 .

annădyă. $15 \cdot 14.4,5$.

annādís. $15 \cdot 14 \cdot 3,6$.

annādîbhis. I5. 14.3,6.

a nnă d y a (p. -na॰ád-): -am. I2. 5 .

IO. I3. $4.14,22$. I 5. $7.4,5 ; 8.2$. annădyena. r $3 \cdot 4 \cdot 49,56$. 
annăadyasya. I5. 8.3.

án y a:-yena. I9. $6.4^{\dagger}$ (? mss. ányena, anyéna).

ánye. I2. I. 4.

ányebhyas. 12. 2. I6.

ányeșu. II. 4. 23.

a nyá: -yás. 2. 4. $5^{2}$. 3. 2.6 ; 30. I, 5. 4. 13. $2^{2 *}$. 5. 11. 4. 7. 79. $4 ; 8$ o. $3^{*} ; 8$ I. I $^{2 *}$. 8. 9. I9. 9. 9. $20^{2 *}$; Io. $26^{+}$. I0. 8.23. II 4. $26 ; 5 . \mathrm{IO}^{2}, \mathrm{II}^{2}$. I2. 3.50 I 3. I. $50^{2} ; 2 . \mathrm{II}^{*}$. I8. I. $16^{\dagger}, 16^{*}$.

anyă. I0. $7 \cdot 42^{2}$. I 8 . I. 15 .

anyám. 3. 2.6; 30.1. 4.18.36. 20. I ; 26. 2. 9. 5.27; 10. $16^{2 *}$. I 2 . 3. 50. I3. 2. IIt. I8. I. II $4 \mathrm{I}^{*}$.

anyầm. I. 32.4 . I2. 4 13.

anyát. 5. II. 5, 6. 6. I2. I. I0. 2. 22,23 ; 7.31. II. 8.23. I3. $2.43^{2}$. I8. 2. 3I, 5 I. I9. 53.4.

anyéna. II. 3. 32, 35, 39-43. I 8 . I. $9^{*}, 13^{*}$. I9. $6.4($ (?)

anyáyā. I I. $3 \cdot 36,49$.

anyásmāi. 3. 30.5. I2. 3.46.

anyásya. 10. 8.23.

anyásmin. 8. 9. I9. I2. 4. 15.

anyásyām. I. 32. 4 .

anyăbhyām. Ir. $3 \cdot 33,34,44-8$.

anyé. 2.6.2; 28. I. 3. II. 5, 7. 9.

9. $12^{*}$. I $2.3 .42,51 ; 4.22$.

anyắs. 6. 60. 2 . 10. $8.3^{*}$.

anyắn. 1. 10. $2 ; 30.3$. 2. 29.3. 4. $5.7 ; 36.3$. 7. 35. I. I2. I. 58 . I9. 33.5 (not mss.).

anyấ. 6. 30. 2 .

anyébhis. 8. 5.9.

anyãís. II. $3 \cdot 37,38$.

anyébhyas. I2. 4.23.

anyéșām. I2. 2. 5 I (1. -șaam). I4. 2. anyầsām. 6. 60.2. 7.37.1; 38.4. (cf. anyakşetrá-anyedyús.) [9. anyaokṣetrá: -ré. 3. 3. 4. 5. 22. anyakṣetrăni. $5,22.8$.

anyátas. I3. 3.1 $2^{2}$.

a nyátra. 3. 23. I. 6. II. $3 ; 26.3 ; 40$.

2 ; 93. 2 ; I40.3. 7. III.I; II5. 2.

9. 2.25. I0. I. I6. II. 2. I9, $21,26$. a nyá onābhi: -is. I. 30 . I. a n yá varna: -nām. I2. 3. 54 . any e dyús. I. 25.4 . 7. II6. 2. án y okas (p. ánioo-): -kās. I2. 2.4 . a nváñ c: -ñcam. 6. 134. 3.

antucas. 3. I. $4^{t}$.

anứci. IO. IO. IO.

(cf. ánūka, anūcyà.)

$\left[2^{*}\right.$.

a nvartitṛ́ (p. anuoar-) : -ta. 5. I7.

a nvāgantṛ́ (p. anuoā-) : -tâ. 6. 123. I, 2.

[3I. 4 .

ánvāntrya (p. ánuoā-): -riam. 2. á p: ápas. I. $5 \cdot \mathrm{I}^{*} ; 6 . \mathrm{I}^{*}, 4^{2} ; 33 . \mathrm{I}-4$. 2. $5.6^{*} ; 7.1 ; 29.5 .3 .7 \cdot 5^{3 *} ; 13$. $5^{3} ; 21.10 ; 26.3 ; 31.3$ (mss. āpas). 4. $2.6 * 8 ; 8.4-6$; I5. I, 5, 9. 5. I 7. $\mathrm{I}^{*} ; 28.2$. 6. $23.2 ; 24 . \mathrm{I}, 2$; 5 I. $2^{*}$; 58. $2 ; 6$ I. I; 68. $2 ; 9$ I. $3^{3^{*}} ;$ I24. 2 7. I8. $2 ; 40.1 ; 64.1 ; 83.2 ; 107$ I; II2. I. 8. I. $5 ; 2.14 ; 4.8^{*} ; 7.3$. 9. $1.9 ; 2.20 ; 3.22 ; 6.5$, 16. го. $5.22,24 ; 6.3,14 ; 7.6,1 \mathbf{1}, 37 ;$ Io. 4,29 . II. I. I7; 2. $24 ; 5.13 ; 7.2$, $20 ; 8.29,30$. I2. I. $3,9,19,23,30$ $53 ; 2.40$ I3. $3.6 ; 4.37$ I4. I. $39,40^{2}$. I5. $2.3 ; 7.2,3 ;$ I 5.7 I6 I. I0. I8. I. I7; 3. II; $4.39^{2}$. I9. 2. $\mathrm{I}^{2}, 2^{2}, 5^{3}$ (mss. apás); $9 . \mathrm{I}, \mathrm{I} 4 ; 10$. $8^{*}$; $7.6 ; 27.9 ; 43.7 ; 44.9 ; 54 . \mathrm{r}$. -(accus.) I. 25.1 . 3. I2. 9. 4. I5. II. 6. 85.3 . 9. I. 9. IO. 2. II, I6; 7. IO. II. 2.8 I2. 3. 4. I3. I. 45 . I9. $2.3 ; 27.3$.

ăpas (voc.). I. $5 \cdot 3^{*} ; 6.3^{*}$. 2. 23 . I-5. I 4. $2.16^{*}$. I8. 4.40 .

āpas. I. 33.4 . 3. I3. 2, 7; 31.3 (ed. ăpas). 7.89 .3 (m. mss. ăpas). Io. 5. 6, 7-14, I5-2I. I I. 6.23 (mss. ed. ăpas). I2. 3. I3, 29. I6. I. 8, I2; 4 . 6. I9. 40.2 (mss. ăpas); 44. r (do.). apás. I. $4 \cdot 3^{*} ; 5 \cdot 4^{*}$. 2. $5 \cdot 5^{*}$. 4 . I5. 12*, I $; 2$ I. $7^{*} ; 27.4$. 6. $22.1^{*}$, 2 ; 23. I. 7. 4 I. I; 89. It; rog. 2.8 . 9. 23 ; Iо. $x_{5}, x_{7}$ 9.6.4. Io. 2.7 ; $5.33 ; 9.27 ;$ IO. 8 . II. I. I5, I8; 5 . 7 ; 6. II; 8. 28. I3. I. $2,2 \mathrm{I}^{*} ; 3.9^{*}$. I4. I. $37^{*} ; 2.69$. I5. II. $4 ;$ I4. 3 . I8. $2.7^{*}$ 19. I8.6. 20. 128. 14. (nom.) 2. 3.6. 6. 23. 3. I9. 2. $5^{3}$ (mss.). 
adobhís. 2. 10. $2 . \quad 4.27 .4,5 . \quad 12$. 3. 30. I5. 14.3 . I8. I. $55^{*}$. adobhyás. 3.3.3. 10. 5.33. I3. 4. 37. I5. 2.3. 19. 43.7.

apắm. I. $4.4^{*} ; 35.3 .4 .4 .5 ; 8.5$; I5. 2, 3, IO, I2; 37.3. 5. 5. 7; I9. I3, 14; $24.4 ; 28.6$ : 29.8. 6. 106. $2^{*}$; I24. I; 125.2*. 7. 39. I*; 49. I*. 8. 7.8. 9. $4.2,5$. 10. 5.7-14, 15-2I, $50 ; 8.34,35$. II. I. I $3 ; 4$. 26. I 5 . 2. 3. I6. I. I, 6. I 8. 3. $5,56^{*}, 65^{*}$. I9. $2.4^{3} ;$ II. $3^{*} ; 33$. I $; 42.4 ; 45.3$. ápām. 6. 3. I, 3. I 4. I. $37^{*}$.

aposú. I. $4.4^{2 *} ; 6.2^{*} ; 30.3 .2 .31 .5$. 3. 21.1 ; 22.3. 4. 8.7 ; 10. 7 ; 30. $7^{*}$; 37. 10. 6. $38.2 ; 80.3 ; 132.1-5.7$. 83. I; 87.1. 8. I. II. I0. 5. I5-2I; 8. 4 O. II. $2.24 ; 3.43 ; 5.13 ; 6.23$; 8. 34 I2. I. 37 I3. I. I, 2,$50 ; 2$. 30 ; 3. 15. 14. 1. $37^{*}$. 16. 1. 7. I7. 8, 13. I8. I. $4^{*} ; 3 \cdot 60^{\dagger} ; 4.89^{*}$. I 9. $3.2^{2} ; 8.1 ; 27.10$.

(cf. ápavant, ápya, āptyá, udāpyà, apsujá-apsúsamçita.)

ápa. I. 2. 2 ; $21.4^{2 *} ; 28$. I. 2.8.2, $2-5 ; 35.2$. 3. $7 \cdot 7^{2} ; 23.1$. 4. I8. $7^{2}, 8 ; 25 \cdot 4^{2} ; 31.7^{*} ; 32.5^{*} ; 33.1^{*}$, $\mathrm{I}-8^{*} ; 35.7$. 5. 3. $\mathrm{IO}^{*} ; 6.7$; 22. I. 6. $4.2 ; 6.3^{\dagger} ; 45.2^{*} ; 81.1 ; 119.3$. 8. $1.2 \mathrm{I}^{3} ; 4.17^{*}$. $\quad$ I0. $5.24 ; 7.40$. I2. I. $37 ; 3.19,49$. $3.2 .17^{*}$. I4. I. $59 ; 2.6^{*}, 48,68^{2}, 69$. I6. I. เo; 6 . $2^{*}$. I8. $2.27,40,57 ; 4.49$. I9. 8 . 5 (mss. apa); 12. I* (mss. ápas); 20. I ; $34.3 ; 50.5$ (mss. apá).

(cf. apa $+\sqrt[V]{ } V$ an, $i$, abhi ...i, ud $+\mathbf{i}$, Ikș, uch, ubh, I ūh, kaș, I kr, kram, abhi ... kram, krī, gam, I gā, guh, ci, cit, cyu, ji, takș, tṛ, dah, 2 dā, drā, I dhā, dhāv, dhvas, nah, nī, nud, pad, bādh, brū, bhū, bhṛ, I mā, mṛj, yā, rādh, rudh, lup, likh, vac, 2 vap, I vas, vah, I vā, vic, viç, a pa rā p pa ra ṇá: -ás. I2. 5.45. I vṛ, vṛj, ā + vṛt, ven, vyā, çat, á pa r ā h hat a: -as. I8. 4.38. [46. çuc, çuș, çri, sidh, sū, slrambh, a pa rāhṇ á (p. -ra॰ahn-): -ás. 9. 6. sprę, sphur, han, hã; and ápatya, á pari o para: -reṇa. 18. 2.46.

apamá, ápara, ápodaka, apartú, á pariomita: -as. 9. 5.21. I5. 15.9. apakămá, áparūpa, ápavrata.) a paokām á: -ám. 3. 13.3. apakāmásya. 2. 12.5 . apakămăt. 9.8.8.

a pakşá: -şắs. II. 5.2I.

ápa。ga: -gã. I. 34.5 . 2. 30. I. 6. S. $1-3$.

apacítas. $7 \cdot 76.2^{2}$.

ápacitas. 6.83. I.

apacítām. 6. 25 I-3. 7.74. I.

ápati: -is. 8.6.16.

á pati oh an: -tighni. 14. 2. $17^{*}, 18$. ápatighnīm. 14. 1.62.

ápatya: -am. 7. 108. I.

(cf. ápatyavant, anapatyá.)

á patya。vant: -vat. I2. 4. I. (cf. ánapatyavant.)

á patha: -am. 6. 73.3. I0. I. I6. ápathena. 5. 31. 10.

a pád: -pấd. 9. 10. $23^{*}$. I0. 8.2I.

ápa d a: -am. 6. 29. 2.

a padya (apatya?) in anapadyátā. a pa $\circ \mathrm{dhv}$ às á: -séna. 4. 3.5. ápapi vãñs: -pușas. 6. 139.4 . á pa०bhūti: -taye. 5. 8.5. a pa omá: -má. Io. 4. I. apa 0 mítya: -am. 6. II7. I (2?). ápara: -as. 9.5.28. I0. I. $27^{2} ; 4$ I. I2. $2.23^{*}, 25^{*}$. 13. 2. I4. $14.2 .3^{\dagger}$. áparam. 9. 5.27. I3. I. 56, 57. I4. I. 64 . I8. 2. $38-45,50,5 \mathrm{I}^{2} ; 4.44$. I9. 50. 4 (mss. apavắn, p. apaovăn). áparām. 6. 18. I. ápareṇa. I0. $4 \cdot 3$. ápare. 9.6.5I. I8. 3. 72. áparās. I0. 10. 8. áparāsas. I 8. I. $46^{+}$. áparān. 10. 3.13-5. [ṇá.)

(cf. pūrvāpará, çivāpará, aparāháparāojita: -as. 5.30.17. 8. 5 . 22. I0. 4. I5.

áparājitām. I 0.2 .33 a pa॰cít: 6.83.3. 
áparimitam. 9. 5.22².

áparimitās. I5. 13. $5^{2}$. á pa॰rū pa: -am. I2. 4.9. a partú (p. apaoṛt-) : -ús. 3. 28. I. ápalita: -tās. Ig. 60. I. a paovaktṛ́: -tăras. 5. I5. I-II. a pavācana in anapavācaná. ápa。va nt: -văn. I8. 4.24. a pa०vāsá: -sé. 3. 7. $7^{2}$. ápaovrata: -tena. 3. 2.6. ápą̧u०han: -çughnim. I4. I.62. á paçcādaghvan: -vā. I9. 55.5 (mss. ápaçcā dagdhấ-).

a pa०çrayá: -ás. I5. 3.8. a pás: -sas. 6. 23. I. I9. 2.3 (not ed.). ápas: 7. 48. I*. I8. I. $31^{*}$.

(cf. "vidmanăpas, svápas.) a pa。skambhá: -ásya. 4.6. 4 . a p a prẹ in ánapasprę. a pas phurant in ánapasphurant. a pāka in āpākesthă.

a pāktás. 8. 4. I9 $9^{\dagger}$.

a pãctina: -am. 6. 9I. I.

áp āĩ c: -āñ. 9. 10. 16*.

ápāk. 20. 128.4; 134. 1-6.

ápāñcam. 3. 3.6.

ápāñcāu. 7.70.4.

ápāñcas. 5. 3. $2^{\dagger}$.

ápācīm. I 8. 3.3.

(cf. apāka-apācína.)

a pāná: -ás. 2.28.3. 5. 30. 15. 7. 53. 3,4 . II. 4. I3. I2. 5. 9. I5. I6. I-7. I6. 4. 3. I8. 2. 26, 46. I9. 5 I. I. apānám. I0. 2. I3. I9. 27.6.

apānéna. I3. 3.4.

apānăya. 6. 4I.2. I9. 45.6-10. apānăs. 6. IO4. I. 8. I. I. II. 3. 29. I5. I5. 2.

(cf. prāṇāpāná.)

a pāmārgá: -ás. 4. I7.8; I8.7; 19. ápămārga. 4. 17.6,7; I8.8. 7. 65. I (mss. ap-), $2,3$.

apālá: -lấm. I4. I. 4I*.

a pā̧⿻ țhá: -țăt. 4.6.5.

(cf. çatấpāșțha, apāșțhávant.)

a pașțhá。vant: -vat. I4. I. 29*.

ápi. I. 7.7. 2. 2.3. 4. 12.3. 5. 2. $3^{*}$. 6. $45 \cdot 3^{\dagger} ; 50.1 ; 55 \cdot 3^{*} ; 77.2^{*}$.
7. 49. $1^{*} ; 92.1^{*} .9 .4 .2 ; 5.14 ; 9$. $7^{*}$. I0. 4.26 ; IO. 33 . II. 1. $33 ; 7$. 3, I2, I4. I2. 1. 4, 25; 2. 4, 9, 53; 3 . 22 ; $4.38,39$. I3. 4. I6, I7, I8. I4. 2. 29 . I8. I. $33^{*}, 58^{*}$. I 9.38 .2 ; 59 . $3^{*}$ 20. I27.12; I30. 14 (mss. api, abhi).

(cf. api $+V \sqrt{ } 1$ as, $i, 2 \overline{u h}, I \mathbf{k r}$, I kụt, kșā, gach, gam, I gã, car, 2 dā, I dhā, nah, pṛc, bhū, yă, ruh, vat, 2 vap, vyā, vraçc, çr, sthā.) api。dhăna: -am. 7.35.3. II. 3 . II. 18.4 .53 . apihit a in apūpápihita.

a p I c y à : -cíe. I8. I. $36^{*}$.

ápunardĩyamāna (p. -naḥod-): -nā. I2. 5.44.

á purog a va: -vāsas. 20. I 35.7 (mss. -vãsas, -vāmas).

a p ū pa in páñcāpūpa, apūpánābhi--apūpápihita.

a pũ pá onābhi: -im. I0. 9.5.

a pūpáovant: -vān. I8. 4. It -24. a pūpấpihit a (p. -pá。ap-): -tān. I8. 3. 68.

a pūrvá: -véna. Io. 8.33. [II. ápodaka (p. ápaoud-): -kas. 5. I6. ápodakam. 5. 13.2.

ápodakasya. 5. I3. 6.

á pya: -piā. I8. I. $4^{*}$, I9*.

ápyās. I9. II. 2*.

a py a ñ c in apícyà.

ápra॰cañka ça: -çās. 8. 6. I6.

ápracetas: -tās. 20. 128.2 (mss. apr-).

áprajas: -sam. 7.35.3. 12. 5. 45. (cf. aprajástā, aprajāstvá.)

a prajás tã: -tām. 9.2.3. [26. a prajāstvá (p. -jāḥ̆ot-) : -ám. 8. 6. aprajāstvấya. I0. I. I7.

apratí: 7. 50. $1^{2}$; 93.I; IIO.I. [3. ápratibruvant: -vadobhis. 3. 8 . ápratiomany ū y māna: -nãs. I3. I. 31 .

a pratișțhāná (p. -tiosthā-): -ás. II. $3 \cdot 49$.

ápratíta (p. -tioit-): -tāu. 7.25. I. ápratitta:-am. 6. II7.I. 
ápradadi: -is. 20. I28. 8 (?). a prapāná: -ṇă. 20. I28.8. ápraomā da: -am. 12. I. 7, 9, 18. 13. I. 23 ; 3. II. 19. 46.2 .

ápraomāyuka: -am. I9. 4 . 3 . ápra。yāva: -am. 3. 5. I (mss. ed. -van). I9. 55. I (mss. -yātam).

ápra。yuchant: -an. 2.6.3. 6. 4. 3. 7. $9 \cdot 2^{*}$. I 8. I. $34^{*}$.

ápra。hita: -tāu. 6. 29. 2.

a prāṇá: -ṇấ. 8. 9.9.

áprāṇant: -ṇat. I0. 8. Ir.

ápriya: -as. 8. 10.18. 19.45 .2 (mss. priyás).

ápriyam. 8. 10. 33. I5. I. 8.

ápriyasya. 9.5.31, 32-62.

ápriye. 8.6.26. I2. I. 30. I9. $57 \cdot \mathrm{I}^{\dagger}$. ápriyās. 9. 6.23.

(cf. priyāpriyá.)

á pl a va: -vãs. I 9. 50.3.

a pvà̃: apue. 3.2. $5^{*}$.

apuắm. 9. 8.9.

a psarás: -sãu. 6. II8. I.

ápsarasāu. 6. II8.3.

apsarásas. 4. 37.2, 3, I2. 6. I I I. 4. 7. 109.3. 8. 5. 13. 9. 7. IO. II. 9. I5. I2. I. 23,50 . I4. 2. $9,34,35$.

apsarasas. $4 \cdot 37 \cdot 3$.

apsarásām. 6. I30. I.

(cf. gandharvãpsarás, apsarâ.)

a ps a ră: -ằm. $4 \cdot 3^{8} \cdot 1^{2}, 2^{2}, 4$. apsarăbhyas. 2.2.5. 7. I09. 2. apsarấsu. 2. 2. 3 .

(cf. apsarāpatí.)

a ps arāopatí: -tés. 4. 37.7.

ápsas: 6. 49. 2.

ápsasā. 6. 49. 2.

a psuojá (or -já): -jâs. Io. 4.23.

a psu०y०gá: -gãís. I0. 5.5.

a psuṣád (p. -suosá-) : -das. I2. 2.4 . I6. I. 13 .

apsú osamçita: -as. ro. 5.33.

a phalá: -lấs. 8. 7.27.

abandhú: 6. I2ن.2.

ábandhuokrt: 4. I9. I.

abandhrá: -ás. 4. 16. 7.

abalá: -léna. 3. 29. 3.

abalấn. 3. 19.7. (cf. abaládhanvan.)

abalá $d h a n v a n:$-nas. 3. 19.7. a balāsá: -sāú. 8. 2. 18.

ábibhīvāns: -bhyuşis. 3.14.3.

ábibhyat: 19. 65. I (mss. bíbhyat).

ábrahman: -mā. 20. 128.6.

ábrahmaṇas. 20. 128.6 (mss. bráh-).

ábrāhmaṇa: -as. I2. $4.43,44,46$.

ábrāhmaṇãs. 5. 17.8. II. I. 32 .

abhagá: -ás. 5. 3I. II.

ábhaya: -am. 4. $21.4^{*}$ 6. 6. 32.3 ; 40. $\mathrm{I}^{4}, 2$; 50. I. 7.91. $\mathrm{I}^{*}$. 8. I. 10. II. 2.3 I. I3. I. 5 . I8. 3.6I. I9. $3.4 ; 8.7$; 9.I 3 ; I $4 . \mathrm{I} ;$ I $5 . \mathrm{I}^{*}, 4^{*}, 5^{5}$, $6^{5}, 6$ (mss. -ye) ; I6. I ; 44. I.

ábhayās. I $9.45 \cdot 4$.

(cf. abhayamkará, ábhayatama.) a bha y a mokará: -ás. I. 21, I". 8. 5. 22.

ábhaya otama: -mena. 7.9. 2*.

a bhāgá: -ás. 4. 32.5".

abhí. I. I. $3 ; 29.1^{*}, 2^{3^{*}}, 3^{3^{*}}$. 2. I0. 4.3 . I. 2,$3 ; 2.5^{*}, 6 ;$ II. $8 ; 18.6^{\dagger} ; 2$ I. 5 . 4. I. 3,$5 ; 8.2,6$; I4. 6,$9 ;$ 21. $4^{*}$; 27. $4 ; 32.6^{*}, 7^{*} ;$ 36. 10. 5. I. $5,6^{*}$; 4. 2 ; II. 7 ; I9.4, 9. 6. $25.1-3 ; 34$. $4^{*} ; 4$ I. $3 ; 47.3 ; 78.2 ; 97.1$; 99. I ; IO2. I; I 26. 3. 7. 9. I* I4. $\mathrm{I}^{2} ; 37$. I ; 84. $2^{*}$. 8. $2.4,15 ; 3 \cdot 3^{*}, 9^{*} ; 4$. $2^{*}, 21^{2 *} ; 6.22 ; 7.26 ; 8.6 ; 9.6,15$, 21. 9. I. $8^{*} ; 4.24 ; 5.6$, I2; $9.3^{*}$; 10. $6^{\dagger}$. I0. $2.18 ; 5.43$. I I. I. 6,37 . I2. I. $12,29,33,34 ;$ 2. $26^{*}, 27 ; 3.4$, $8^{2}$, I $2, I_{5}$, I $7,26,30,42,52 ; 4$. I 5 . I 3 . I. $20 ; 2.9,42,43$. I4. 2. 34,35 . 18 . 2. $50^{*}, 5 \mathrm{I}, 52 ; 3 \cdot 2^{2 *}, 4 \mathrm{O}^{\dagger}, 5 \mathrm{O}^{*}, 73 ; 4$. IO, I3, 62, 66. I9. I3. $7^{*} ; 3$ I. I2. 20. 48. $\mathrm{I}^{2} ;$ I 27. I0.

(cf. abhi $+\sqrt[V]{ }$ aghāy, añj, arc, I aç, I as, $i$, apa $+i, \bar{a}+\mathbf{i}$, ud + $\overline{\mathbf{a}}+\mathbf{i}, \mathrm{ud}+\mathbf{i}, \operatorname{sam}+\mathbf{i}, \mathrm{ich}, \mathrm{idh}$, pra + iṣ, iç, ūrṇu, kāę, I kṛ, nis + $\mathbf{k r}, \mathbf{h i n}+\mathbf{k r}$, lkrand, apa + kram, ã + kram, kruç, kṣar, gach, gam, sam + gam, I gā, $\bar{a}+g \bar{a}$, I gr, gāh, ghar, cakș, car, ã + car, prati...car, jambh, jā, ji, ava + tan, tap, sam + tap, trp, 
das, dih, dīp, du, druh, I dhā, dhāv, dhṛș, nakṣ, nand, 2 naç, ava + nij, ni, nu, pat, nis + pat, paç, pū, bhañj, bhā, bhū, sam + bhū, man, pra + man, manasy, mih, mud, mṛç, yā, yuj, yudh, rakș, riș, ru, rud, $\bar{a}+$ ruh, lap, vad, valg, 2 vas, vah, I vā, sam + viç, I vṛ, vṛj, vṛt, $\bar{a}+$ vṛt, pari $+\overline{\mathbf{a}}+$ vrrt, ni + vṛt, vṛdh, vrs, vyadh, çańs, çuc, çri, çriș, çru, sac, sah, sā, sic, su, sruj, ati + srj, ava + srj, sṛp, svar, skand, stan, stu, sthā, ud + sthā, sphūrj, syand, sru, han, har, has, hr, pra + hi, hu, hvṛ; and abhítas, abhichāyá, abhipūrvá, abhyadhvá, abhīpatás, abhísatvan, abhírāștra, abhírūpa, abhívīra, abhíșți.)

abhikaraṇa in svapnābhikáraṇa.

a bhiokŕtvan:-varis. 2.8.2.

abhiocákșaṇa: -am. 6. 127.2.

abhicákṣaṇās. 9.2.21.

a bhi०cārá: -ás. II. I. 22.

abhicārăt. 8.2.26. I0. 3.7.

abhicārắs. I9. 9.9.

abhi॰cārín: -ínas. Io. I. 9 . abhiochāyá: -ám. I3. I. 57.

abhiojít: II. 7. I2. I9.7.4.

abhítas. I. $27 \cdot 3$. 3. 5.6, 7; 30.6.

4. 5. $6^{*}$. I0. $8.3^{*}$, 1 7. I2. 3. 42 . I3.

I. 35. I4. I. 45 . I9. I6.2. 20. I36. 15 (not mss.).

abhiodrohá: -ám. 6. 5 I. $3^{*}$.

abhiodhănī: 8. IO. I2.

(cf. açvābhidhănī.)

abhioniṣkārín: -ínas. IO. I. 3I. abhinná: -né. 4. 2 I. $2^{\dagger}$.

abhíopūrta: -am. 9.5. 33 .

a bhiop ū rvá: -ám. II. 2.22.

a bhi。bhavá: -ás. I. 29. 4.

abhi。bhàa: -ằs. I. 20. I. 5. 3.6.

abhibhăm. 4. 28.4. [44.7.

abhibhăs. II. 2. II. I 8. 4.49. I9. abhi॰bhú: -úm. I0.6.29.

abhi。bhút: -ús. 2. 27. 1. 6. 97. $1^{4}$.

9. 5.36. II. I. 6. I4. 2. I9. abhibhúvam. 9.5.36.

abhíbhūti: -is. 6. 98.2.

(cf. abhíbhūtyojas.)

a bhíbhūti॰ojas: -jās. 4. 32. $4^{*}$.

abhiobhútya: -yāya. 19.37.3.

abhimarçan a in çivábhimarçana.

abhíomāti:-im. 4. 3I. 3*. I9. 32.6.

abhímātayas. 2. 7.4.

abhímātis. 18. 2. $59^{*}$.

(cf. abhimātijít, abhimātișāhá.)

abhimātiojit: 2.6.3.

abhimātiṣāhá (p. -tiosah-): -ás. 4. 32. $4^{*}$. 5. 3. $9^{\dagger} ; 20.2$, II.

abhi॰yúj: -jas. 7.73. $9^{*}$.

abhíorāṣța: -as. I. 29. 6*.

abhíorūpa: -pām. 8.9.9.

abhiororudá: -ám. 7. 38. I.

a b hivāsin in bastābhivāsín.

abhíovĩra: -as. I9. I3. $5^{*}$.

abhiovyādhín: -nas. I. I9. I.

abhíoçasti: -im. 3.I.I; 2.I. abhíçastiä. 6. I20.2. I2. 5.58 . abhíçastes. 7.53. I.

(cf. abhiçastipâ.)

abhiçastiopă : -ấs. 2. 13.3. 4 . 39.9. 5. 18.6. 8. 7. 14. 19. 24. 5, 6 . abhi॰çoká: -ás. I. 25.3.

abhi。çocá: -cấn. 4. 37. Io.

abhi॰çócana: -am. 4.9.5. abhiçócanāt. 2. 4. 2.

abhi॰çocayiṣnú: -ús. 6. 20.3.

abhi。çrāvá: -vé. I8. I. $29^{*}$.

abhi。çríṣ: -șas. 14. 2.47*.

abhi。çrí: -çríyāu. 8. 2. I4.

a bhișáva ṇ a (p. -iosávan-): -ṇis. 9. 6. 16.

abhiṣấc (p. -iosắ): -cas. I8. 4.44 (mss. -çắc-). I9. II. $2^{*}$.

abhíșți: -țaye. I. 6.1*. 6.3.2.

abhíosatvan: -vā. I9. I3. $5^{*}$.

abhioskánda: -am. 5. I4. II.

abhiosvará: -ré. I 3. 3. $25^{*}$.

a bhihat a in ulkábhihata.

abhi。hásya: -ám. 6. 30.2.

abhiohrút: -tas. 6. 4.2. [3.3.

ábhiohruti: -tī (p. -tī íty etc.). 6.

abhi॰hvārá: -ré. 6. 76.3.

abhipatás. 7.39. I* $^{*}$. 
a bhi modamúd (p. abhimoda॰m-): -das. II. $7.26 ; 8.24$.

abhîruna a: -am. 7.89.3.

a bhIl ãpaláp (p. abhilāpaol-): -pas. II. 8.25 .

a bhivargá (p. abhiov-): -găt. I I. abhivargé. $3 \cdot 5 \cdot 2$. 6. 54.2. $\left[3^{*}, 4\right.$.

abhívartá (p. abhiov-): -ás. I. 29. abhivarténa. I. 29. I".

abhivắra (p. abhiov-): $\quad$ I. 32.4 (abhí, iva, āra?).

abhiçu: -unā. 6. 137.2. [mss.). abhíçavas. 8. 8.22. 20. 131. 4 (not abhiṣ̂́h: -şăț. 12. I. 54. I3. I. 28. ábhujișțha: -as. 20. 128. 4 (not mss.).

ábhūti: -is. II. 8.21. I2. 5. 35 . ábhūtyā. 16. 7. I.

ábhūtyās. 7. 100. I (1. -tiās). I6. $5.3 ; 8.3$.

[akta.

a bhy a kta in ánabhyakta, suàbhya bhyáñ jan a (p. abhioá-): -am. 6. 124. 3. 14. 1. 6* (1. abhiáñj-).

(cf. āñjanābhyañjaná.) [28.2. abhyadhvá (p. abhioa-): -vé. 4 . abhyākrắma (p. abhioā-): -am. I0. 7.42 . a b h y ācārá (p. abhioā-): -ám. Io. a bhy $\mathbf{a} \mathbf{r} \bar{u}$ ḍha in ánabhyārūụha. abhrá: -ás. 9.6.47.

abhrám. 4. I5.9. 8.6. I9; IO. I2. 9. 7. I8. I0. I. 13. II. 3. 6 . abhrăt. 12. 3.25.

abhré. II. 5. 13 .

abhrâni. 4. 15. I. II. 7.21. (cf. abhrajâ, abhriya.)

$\mathrm{abhra} \circ$ jă: -ấs. I. 12.3. abhrătṛ: -taras. r. I7. I. ábhrātṛohan: -rghnim. I4. I. 62. ábhri: -iobhis. ro. 4.14.

(cf. anabhrí, abhrikhāta.) $[5,6$. abhri。khāta: ábhrikhāte. 4. 7 . abhriya: ábhriye. 2.2. 4 . a bhvà: -àm. 4. I 7.5. I 3. 4. 25. Vam: āmamat. 6.57.3. I0. 5.23. āmáyat. 9. 8. 10.

(cf. I áma, ámati, ámīvā, āmá, āmana, āmaya, āmayitnu.)

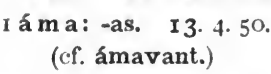

ámānuṣa: -am. 20. 128.12 (mss. mănușam).

a mā 0 vā s y à: -yà. 7. 79. 2. I 5. 2. 2 ; 16.3 .

ámāvāsye. 7. 79. I, $4^{\dagger}$. amāvāsyàm. I5. 17.9.

amāvāsíām. I. 16. I.

amāvāsyàyāi. $\quad 7 \cdot 79 \cdot 3$.

amāvāsíe. 4. 36.3.

ámita: -am. I0. 7.39.

ámitā. 4. 26. I.

(cf. amitavīrya.)

a mit a"ovĩ rya: ámitaviria. I9. 34. a mítra: -as. 4.22.2. 6.67.3. II. 9. 19 ; 10. 22, 26. amítrasya. 1. 21. $3^{*}$.

amítrāt. I9. 15.6. amítrās. 2. 28.3. 5. 21.2,8. 6. IO4. 2. 8. 8.2. II. IO. $2 \mathrm{I}, 23$. [19. amitrās. 6. 67.2 (mss. -mít-). 8. 8 . 
amítrān. I. I9. 2, 3. 3. 2.5 ; I9. $3, S^{*}$. 4. 22. I. 5. 20. $8 ; 21.4^{-6,7}$, 12. 6. IO4. I. II. 9. $12^{2}, 18,21,23$; I0. I, 3, I 3, I 8, I9. I9. I $3.8^{*}, 8^{\dagger}$.

amítrebhyas. 5.21.3. 6. 104.3. I I. 9. I, I 5, 22, 24 ; IO. 6 .

amítrāṇām. 3. I. 5. 5. 21.9. 6. 67. I. 8. 8. I. I I. 9. $3,5,18,20,23$; Io. $16,20^{2}$.

amítreșu. 5. $21 . \mathrm{I}^{2}$. I I. 9.9, II, 25. (cf. anamitrá, āmitrá, viçvămitra, amitrayú-amitrāy.)

a mitrayú:-ús. 20. I27. I3. [20.4t. a mitrasāhá (p. -raosah-): -ás. I. a mitraosenă : -ăm. 3. r. 3 (s. mss. ed. -sénām). 5. 20.6.

a mitra。hán: -hắ. 4. 32. 3*. vamitrāy: -yántam (p. -tra॰y-). 7. $84.2^{\dagger}$.

a mì (pron.): amí (p. -î́íti). 3. 8. 5 ; 29. 1. 5. $8.5 ; 21.8 .6 .103$ 3. 7. 8o. 4. 8. 8. I0, 24. 9. Io. I8t. I3. 2. 13.

amíbhyas. 8. 8.24.

amíṣām. 3. 2. $5^{*}$; I9. $8^{*}$. 8. 8. I9. II. 9. 2O; IO. I9. I2. 2.55. I9. 52.4 .

a mivaocătana: -as. I. 28 . I. 8 . 2. 28 . I9. 44.7 .

amìvacătaniss. $\quad 3 \cdot 7 \cdot 5^{*}$. 6. $91 \cdot 3^{*}$.

á m I vā: 7. 42. I*.

ámīvām. 4. 10. 3 .

ámīvās. 7.84.1. 8.7.14. I9.

$34.9 ; 44.7$.

(cf. anamīvá, amīvacátana.)

a m G (pron.): -úm. 2. I2.4. 3. 3. I. 5. 8. 7 ; 22. I2. 6. 75. I; 135.2, 3 . 8.6. I2. 9.6.6I. I0. 5.44. I6. 8. I $-27^{2}$. I 9. 53. 5. 20. I 28. I (not mss.). amúm. $\quad 4.30 .7^{*}$. 6. 9.3; 139.3. 7. II3. I. 8. 8. 2, I 4, I 5, I7, I8. II. IO. 13 .

amúṣmāi. 7. I13. I. I6. 6. 7, I1.

amúșmāt. I2. $5 \cdot 38$.

amúșyās. 6. 138.4, 5. 8. 8.16. Io. 5. 36, 44. I6. $7.8 ; 8 . I-27$.

amuṣyās. 4. 16.9.

amúsya. 6. I 30. 3; I 35. I-3. 9. 9. 10*. amúșmin. II. 4. I8. I2. 5.57.

amú (p. - -ú íti). 3. 7.4.

amús. I. $4.2^{*} ;$ I7. I; 27. J. 6. 67. I. 9. 4.6. II. 9.18 ; IO. $20^{2} .20$. I28. I (not ed.); I29. 7 .

amú. I3. $4 \cdot 28$.

amún. 5.8.8. 6. 29. I ; 84. 2 ; 126. 3. 8. 8. $3^{2}, 4,8,9$, IO, II, 24. Iо. I. 6 , 3I. II. I. 20.

(cf. āmuṣyãyaṇá, amútas-amuyâ.) á muc İ: -cyās. . I6. 6. ro.

amútas. I. 20. 3. 5. 3. II; 8. 3. 7. II5. I. 8. 9.6 . II. ro. 9,14 . I4. I. I $7,18^{2 *}$. $8.3 \cdot 38$.

[39. amútra. 8. I. I8. 9. 3. Io. I3. I. (cf. amutrabhúya.)

amutra॰bhtíy a: -yāt. 7. 53. r.

amuyâ. 5.22. I. 7. 56.6; 99. I. I4. I. $27^{*}$.

amura: 5. I. 9 ; I I. 5 .

ámușita: -tā. r. 27.4 .

a mū lá: -lấyām. 5. 3I.4.

amŕta: -as. 8.2. I3, 26. I0. 8.44. I2. 2. 33. I3. I. 43. I6. 4. 2 .

amítā. Io. 8. 26.

amŕtam. I. $4.4^{*}$ 2. I. $5 . \quad 3.30$. 7. 4. $2.2^{*} ;$ I5. $10 ; 23.6 ; 26.4 ; 35$. 6. $5.6 .8 ; 28.11$. 7. 17.3. 8. I. $6 ; 7.20$. 9. I. I, 2. I0. $2.14 ; 3.25$; 6. I4; 7. 5; I0. 26,29 . I I. I. $28 ; 6$. $23 ;$ 7. I3. I2. I. 8,$15 ; 3.4$. 13. I. 7,$34 ; 4.25$. I8. I. $32^{*} ; 3.4 I^{*}, 62$; 4. 39. I9. 6. $3^{*} ; 26.1$; 3I. I I (not ed.); 43. 7 ; 53. 2 .

amṛ́tām. I8. 2. $38^{*}$.

amŕtena. 3. 12.8,9. 5. 28.8. 7. II8. I*. I . 2. 29. II. 5. 5, 23. I 8 . 4. 4. I9. I9. IO.

amŕtenā (p. -na). 3. 12.8 .

amŕtāya. I4. I. 42.

amŕtāt. 8.2.13.

amŕttasya. 2. 1. 2. 3. I3.6. 4. 7. I; $9.3 ; 11.6 .5 .4 .3,4 ; 28.7 ; 30$. I4. 6. $44.3 ;$ I21. 3. 7. 47.2 . 8. I. I; 2.I; 7.I2,22. 9. I. 4 ; 9. $22^{*}$. II. 5.7 I I. 3.4 I. I3. $2.15 ; 3.20$. I4. I. $61^{*}$ I8. I. $25^{*}, 34^{*}$. 19.39 . 
amṛ́te. I0. 8.4 I. II 7 II I. amṛ̂tāu. 9. 3. 19. amṛ́tās. 3. 3I.I1. 4. $2.6^{\dagger}$. I3. I. 24. I8. $3.53^{\circ}$. I9. $11.5^{\circ}$.

amṛtăsas. 7.73.3. I2. 3.27. 18. I. $3^{*} ; 3.39^{\dagger}$.

amṛ́tãni. 4. 8. $3^{*}$. 5. 1.3. 6. 1.3. 8. I. 5 . amṛ́tebhias. I. 3I. I.

(cf. amṛtagarbhá-amṛ́tāsu.) a m rִ t a g a rbhá: -ás. 6. 46.1 . a mṛtaotvá: -ám. 7. 106.1 . I0. 1*. 15. 17. io. 18. 4.37 . amŗtatvásya. I9. 6. 4". amṛtatvé. I 8. 3.62. I9. 64.4 (mss. -tvám).

(cf. prajāmṛtatvá.)

a mớt $\mathbf{a} \mathbf{s} u$ (p. -taoas-): -us. a mení: -náyas. 5.6.9. amenín. 5. 6. 10.

a moky á: -kiāís. 3. 6. 5 .

a motá (p. amāou-): -ám. 9. 5.14. r2. 3.51 .

amnás. 8. 6. r9.

a m bí: -báyas. I. $4 \cdot \mathrm{I}^{*}$.

ámbhas : I 3. 4. 14, 22, 50, 51 .

á y a: -yāis. 4. 38.3.

a y a in anavāyá, atyāyá, prāyá, samayá.

a y a kṣmá: -ám. 5. 29.13.

ayakṣmấs. 3. 12. 9. I2. 1. 62 . ayakṣmăn. 6. 59. 2 .

(cf. ayakșmamkárana, ayakṣmátāti.)

a y akșmamokár a ṇa: -ṇīs. I 9. a y a kșmáot āti: -im. 4. 25. 5 .

a y ajñiyá: -ás. 12. 2. 37 .

áyajvan: -nas. 3.24. 2. áyajvanas (pl). II. 2. 23.

áyana: -am. 5. 30.7. I0. 1. 8; 10. 21. I8. $4.8^{3}$, I5. I9. 7. 2.

áyanā. Io. I. 16 .

(cf. âyana, udáyana, upāyana, janấyana, nyáyana, parâyaṇa, prāyạ̣a, svastyáyana, rāmāyaṇá ?.)

á y a b h y a: -yā. 20. I28. 8.

a y á $\mathbf{m}$, see $\mathbf{i}$ (pron.). áy as: II. 3. 7. 18. 3. 22". áyasā. 5.28.5.

áyasi. 5. 28. I.

(cf. áyasa, ayaspātrá, ayasmáya, áyojāla, áyodañşţra, áyomukha.) a y a spātrá (p. ayaḥop-): -ám. 8. 10. 22.

a y a s má y a: -am. $\quad 5.28 .9$ ayasmáyena. 7.115.1.

ayasmáye. 6.63.3.

ayasmáyān. 6.63.2;84.3.

ayasmáyăis. 19. 66. I.

ayasmáyis. 4. 37.8.

áyăta: -am. ro. 8.8.

á y ãtu: -um. 8. 4. 16".

áyāmin: -mi. 20. 128. 10 (?).

[7. a y ā çú: -çávas. 8. 6. I 5 .

áyuta: -as. I9. 5 I. I $^{6}$.

áyutam. 19. $5 \mathrm{I} \cdot \mathrm{I}^{2}$.

ayút a: -am. 8. 2. $21 ; 8.7$. 10. 8. 24 .

áy udhimg ama: -as. 20. 128. Io (mss. yudhímgamás). [I. á yojāla' (p. áyaḥoj-): -lās. I9. 66 . áyod añ ștra (p. áyahod-): -as. 8. 3. $2^{*}$.

$\left[7^{\dagger}\right.$.

a yodhyá: -ás. 5. 20. 12. I9. 13. ayodhiâ. 10. 2. 31 .

ayodhyéna. 19. $13.3^{\dagger}$.

á yomukha (p. áyaḥom-): -khās. I I. ro. 3 .

a rá: -rấs. 3. 30.6. Io. 8.34.

(cf. trinçádara, tryàra, dvădaçāra, páñoāra, șáḍara.)

a r a in udára, samará.

a ra gárāṭa: -țeșu. 6. 6g. I. [ [ ${ }^{*}$. áramokṛta: -as. 2. 12.7. 18.2. áramkrtam. I2. I. 22.

(cf. svàramkrta.)

a r a mo g a má: -ás. 3. 13.5.

aramgamâsas. I3. 2.33.

a r a m g a rá: -ás. 20. 135. 13.

a ramogh uṣá: -ás. Io. 4.4 .

áraț u parna: -as. 20. 13 3 I. I 8 (mss.

áraduparamas). [I08. I.

árana: -as. I. I9. 3* 5. 30.2. 7.

áranam. 5. 22 . I 2.

árạāya. 6. 43. I.

árạ̣ebhis. 7. 52. I. 
áranī. 7. 108. I.

áraṇi: -im. I. 18.2.

a ráṇi: -ṇĩ (p. -1 íti). ro. 8. 20.

áraṇya: -am. I2. I. II, 56 (-ṇiam ?). áranyāt. 2. 4. 5 .

(cf. āraṇyá, araṇyānì.)

a r a ṇ y ānì: -niấs. 12. 2. 53 .

aratní: -nin. I9. 57.6.

a rathá: -thăs. II. IO. 24 .

arapás: -pầs. I. 22.2. 4. 13.4*.

arapás. I8. I. $5 I^{*}$.

áram, álam: áram. I. 5. 3*.

álam. 6. rog. I.

(cf. áramkṛta-aramighușá.)

árarivāǹs: -rușīs. I9. I5. 2.

arár.u: -us. 6. 46. I.

a rasá: -ás. 4. 6.6. 5. I6. I-10; 22. 2. arasám. $\quad 4.6 .1,6^{2} ; 7.2^{2}$. 5. 4.9; 8. 6 ; I3. 8 , 10, II. 6. 29.3 ; 100. 3 ; 138. 3. 7. $56.3,7$. $10.4 \cdot 3,4$. 9. $34 \cdot 3$.

árasa. 6. 138.3 .

arasa. 4.6 .6 .

arasásya. 4.6.6. 7. 56.5 .

arasă. I0. 4.8 .

arasấs. 2. 31.3. 4. 18. 1. 9. 2. 10. I9. 34.3 .

árasās. 5.13 .7$.

arasăsas. 10. 4.9 .

arasắn. 2. $27.1-6$.

$[35.5$.

arasáotarās. 7.76.1.

arasáotamam. 5.13.9.

aräț a kî: $4 \cdot 37.6$.

árāti: -is. 2. $7 \cdot 4$.

[3. 17

árāte. $5 \cdot 7 \cdot 8$.

arāte. $5.7 \cdot \mathrm{I}, 2,7 . \quad$ I 4. 2. I9.

árātim. I. I8. $1^{2}$. 2. IO. 7 . 3. I.

I ; 2. I ; I5. I. 5. 7.3,6. 8. 2. I 2 .

12. $2.3,45$. I9. 3I. II.

árātiā. 3. 31. I.

árātyāi. 5. 7. 10.

árātaye. 5. 7. I, 3.

árātyās. I0. 3.7 (-tiās ?). I3. 4 .

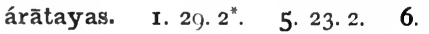

I29. I- 3. II. 8.2I. I3. I. $59^{*}$. I 4. 2. II". I9. 50.3 .

árātīs. I. 2.2. I0. 5.36. I3. I.

20. I6. 9. I. (cf. arātidúșaṇa-arātīyú.)

arātiodúșaṇa: -as. r9. 34. 4 .

arātiodúṣi: -is. 2. 4.6.

arātiohá: -ám. I9. 35.2.

Varātiy: -tioyât. 4. 36. I

arātiyú (p. -tioy-): -yós. Io. 6. I.

arādhás: -sam. 5. I1. 7, 8 .

arādhásas. 12. 5.60, 65 .

a rấy a: -am. 2. 25. 3 .

arâyās. 12. I. 50.

[6. 7 .

arăyān. 8. 6.4, 5, 6, I2. I1. 6. I6. I6.

arâyyebhyas. 8. 2. 20.

(cf. arāyakșáyaṇa, arāyacătana, arãyí.) •

arāy aokşáy aṇa: -am. 2. 18. 3 . arāya ocátana: -am. 2. 18.3.

a $\mathbf{a} \mathbf{y}$ í: -yías. I. 28. 4. 2. 14. 3. 4 17. 5 ; 18. 7.6 .

ári: -is. 7. $88.1^{2}$. I3. I. 29.

a rí: -ís. 20. 127. II.

aryás. I 8.3 .23 *.

áritra: -trāṇi. 5. 4. 5.

(cf. çatăritra, svaritrá.)

ari prá: -ré (p. -é íti). 5. 2. $9^{\dagger}$.

ariprắs. 10. 5.24 . I6. I. 10.

árișța: -as. $\quad 4 \cdot 5 \cdot 7 . \quad 7 \cdot 53 \cdot 5 . \quad 8.2$. 8. 10. 3. 10.

arișța. 8. 2. 24 .

árișțam. 19. 7.3 (mss. -ța).

árișțās. 5.3. $5^{*}$. $10.5 \cdot 23$.

árișțāsas. 7. 50.7. 19. 47.2.

árișțāni. 19. 60.2 (mss. arișțăni). (cf. árișțagu--árișțāsu.)

árișța॰gu: -us. I0.3. Io.

arișțáotãti: -taye. 3.5.5. 5 . 30.12. 6. 19. $2 ; 80.2$. 8. $2.6 ; 5$. $20 ; 7.6,27$. I9. 38.2.

arișțátātiobhis. 4. 13. $5^{*}$.

árișțaonemi: -im. 7. $85 . \mathrm{I}^{*}$.

árișțaovīra: -rās. 3. 12. 1. [2.72.

áriṣțāsu: -sū (p. -ū íty -țaoa-). r4.

árișyant: -ntas. 2. 4. I. I9. 50. 3 .

aru ḥosrắna: -am. 2. 3. 3, 5 (samh.

mss. arusr-).

a ru ṇá: -ás. 5. 22.3. II. 5. I2. [5I. arunám. I2. I. 52 . I3. $2.36 ; 4$. aruṇéna. I9. 56.4 (? ed. vár-, mss. áruṇena). 
aruṇăya. 6. 20.3. aruṇăs. I0. 2. II. II IO. 7. aruṇāís. II. 10. 2. aruṇis. I8. $3.21^{*}$. arụ̣inām. I8. 3. $43^{*}$.

arundhánt: -atî. 6. 59.2. [59.1. arundhati. 4. 12.1. 5.5.5.9. 6. arundhatím. 8. 7.6.

a rụsá: -ṣấsas. 3. 3. 2.

árus: $5 \cdot 5 \cdot 4$.

(cf. aruhsrănạa.)

árūkş ṇa: -am. 8. 2. 16 (? mss. áḍū-, ádrū-).

arepás: -ásas. 7.22. 2.

árog a na a: -am. 2. 3.2. [13. 3. 23. arká: -ás. 4. $15.5 ; 24.5$. 6. 72.1 . arkám. 3. 3.2. 9. 10. $2^{*}$. 10. 8 . $3^{*}$. I2. 2. 55 . I3. 1. 33 . I 8. $3 \cdot 40^{\dagger}$; 4. $29^{*}$.

arkéṇa. 9. 10. 2".

arkāís. I 8. 3.47".

(cf. bṛhadarká, svarká, arkāęvamedhá.)

arkāȩvamedhá (p. arka॰aç-): -dhāú. II. 7.7.

a $\mathbf{g} \mathbf{h}$ a in sahasrārghá.

Varc: árcāmi. I8. I. $31^{*}$.

árcanti. 1. 2. 3. 12. 1. 38 .

arcāma. 6. 27. I".

arcata. I8. $3.63 ; 4.54$.

(cf. arká, arcanănas, arcí, arcís, ŗ̣van, ṛ́c, ŗca.)

+ abhi: abhí... árcāmi. 7. 14. 1. abhí arcanti. 13. I. 33 .

abhy àrcata. 7.82. $1^{\dagger}$.

abhy àrcan. 13. 3. 23.

+ u d: úd ānṛcús. I2. 1. 39 .

(cf. udṛ́c.)

+ prati: práty arca. 2. 19-22.3. práty arcata. 2. 23.3.

a rca ntănas: -nās. I8. 3. 15 .

arcí: -cíobhis. 8. 3. $23^{\dagger}$.

arcís: 1. 25.2. 2.19-23.3. I2. I. 51. I8. 2. $8^{*}$.

arcíșā. 5. 29. 15. 6.32.3. 8. 3. 2*, $\mathrm{II}^{*}, 13^{*}, 17^{*}, 25$. I3. 2.2. I9. $65 . \mathrm{I}^{2}$. arcínși. II. 5. I3.

$f^{\prime}$ arch, see r.ch. árjuna: -as. 13. 3. 26.

árjunam. 2. 32.2. 5. 23.9; 28.5, 9 árjunās. $4 \cdot 37 \cdot 4$.

árjuni. 2. 24. 7.

árjunyās. 20. 130. 3 (mss. arjunyăs). (cf. árjunakăṇạa.)

á rjunaokāṇ ḍa: -asya. 2.8. 3.

a rṇavá: -ám. 7.81. $\mathrm{I}^{\dagger}$ 13.1.36 ; 2. $11^{\dagger}$. I8. I. $1^{\circ}$. arṇavéna. $5 \cdot 6.4^{\dagger}$.

arnavat. I. 10. 4. I3. 1. 26.

arṇavé. $\quad 3 \cdot 6.3 . \quad$ II. $8.2,6 . \quad$ I2.

I. 8,60 . I3. 1. $40 ; 2.2$.

vart (= vṛt): cf. artitr.

+ a nu: ánv artişye. I 4. I. 56.

(cf. anvartitṛ́.)

a rtit r in anvartitŕ.

ártha: -am. I2. 2. $23^{\prime \prime}$ I5. 17.8. árthāya. I. 7.6.

(cf. prărtha.)

$\checkmark$ ard: rdantu. 8. 4. 2.4"

ardati. 12. 4.3 .

ardáya. 4. 15.6.

ardaya. 6. 65.1.

ardayāti. 4. 15.11.

ardáyan. 6. 49.2.

$\checkmark$ ardh, see rdh.

árdha: -as. 8. 9. I.

árdham. 9. 9.17*.

árdhe. 4. 1. 6*. 9. 9.12".

ardhá: -ám. 5. I.9. I0. 8.7, I3.

II. 4. 22 [4. 22 .

ardhéna. 5.1. $9^{2}$. I0. $8.7,13$. II.

(cf. ádhyardha, ardhaka--ardhin.)

ardhaka in

a rahaka。ghātín: -nā. II. 2. 7.

ardhaogarbhá: -bhăs. 9. 10. $17^{*}$.

a rdhaobhấj: -ấk. 6. 86.3.

ard ha 0 māsá: -sé. 8. 10. $20^{2}$. [6.6. ardhamāsâs. I0. 7.5. I I. 7.20. 15. ardhamāsânām. 15. 6.6. I6. S. 20. ardharcá (p. -dhaoṛc-): -céna. 9 Io. 19.

(cf. ardharcaças.)

a rdhärcaças. 20. 135.5 .

a rid $h$ in in svardhín.

árpa ṇ a: -ṇena. I2. 3. 22. 
(cf. ánarpana.) |arşaṇit: -ís. 10. 8. 13, I6, 2 I. a rbud a in nyàrbuda. (ef. árbudi.) Varh: arhati. I0. I. 26. 14. 1. $29^{*}$. árbudi: -is. Ir. 9. 4, 23.

árbude. II. 9.5 ; I0. 5 . I9. $22.21 ; 26.1$. (cf. argha.) arbude. II. 9. I, 2, 3, 7-I I, I3-5, I5, I $8,20,22,24,25$; 10. 23. (cf. nyàrbudi.)

arbhá: -ásya. 7. 56.3. (cf. arbhaká.)

a rbhaká: -ám. 7. 56.6. II. 2. $29^{*}$. arbhakấs. I. 27.3 . I9. 36.3 . arman in anarmán, durarmaṇi. aryá: -ás. 6.63.4*.

ary a mán: -mă. I. I I. I ; I8. 2.3 . I4. 2 ; 20. $3^{*}$. 5. $5.1 ; 28.12$. 6. 4 . 2 ; 60. I; 103.1. 9.7.7. II. 6.4 . I3. 4. 4. I 4. I. $50^{*} ; 2.13,40^{*}$. I9. 9. $6^{*} ;$ 10. $2^{*}$.

aryaman. 6. 60. $2^{2}$.

aryamáṇam. 3. 20. $7^{*}$. I4. I. I7. aryamṇă. 2. 36. 2. I 4. I. 34 . aryamṇás. 3. 5.5 . I 4. I. $39 ; 2.5^{*}$. a rva in anarva.

árvan: -vā. 4. 21. 4*. 20. I29. I I (?). arvānas. 18.3 .19$.

árvant: arvan. 6. 92. 2.

árvatas. I0. 4.7 . 19. 50.5 .

árvantas. I9. II. I*.

árvatām. 4. 9. 2;27.3. 20. 127.3. árvatis. I0. 4.21 .

(cf. árvan, arva.)

arvācîna: -am. I0. 5.22.

a rvācīná: -ám. 3. 16. 6*.

a rvã̃ c: $-\mathbf{a} \bar{n}$. 3. 2. 3. 4. $15.11^{*}$; 32. $6^{*} ; 38.6$ 5. $22.11 ; 26.12 .8$. I. 9 ; 2. 2. I0. 8 . 19. I3. $2.31 ; 3$. I6. I7. I7. I8. $2.60 ; 3.48^{*}$. 19. 53. 2 (not mss.).

arvăk. 4. 25.6. 5. I1.6. 8. I. Iо. I0. I. I6; 8.17 (p. arvắn). I I. 5 . IO, II. I8. I. $5 \mathrm{I}^{*}$. I9. $5 \cdot \mathrm{I}^{*}$.

arvăñcam. 5. 3. II. II. 3. 32-49. arvâñoāu. 5.26. 12.

arvăñã. 9. 9.19*.

arvắcas. 9. 9.19*.

arvấci. 3. 17. $8^{*}$. 6. 67.3.

(cf. arvācína, arvācinná.)

al ají: -jés. 9. 8. 20.

ál a pant: -pan. 8. 2. 3 .

á 1 a m, see áram.

a lasầ 1 à: 6. 16. 4 .

a lăn ḍu: -ḍun. 2. 31.2, 3 .

a lăbu: -unā. 8. 10. 30 .

alấbūni. 20. 134. I (mss. álā-).

(cf. alâbuka, alābupātrá.) [álā-). a lăbuka: -am. 20. 132. I, 2 (mss. a lābu०pātrá: -ám. 8. 10. 29:

a línça: -as. 8. 6. I.

a líklava: -vãs. II. 9. 9.

alíklavebhyas. II. 2.2.

a li ka: álīkās. 5. 13. 5 .

álubhyant: -yatas. 3. IO. II.

a $1 \mathbf{k a}$ a $a$ in vyàlkaça.

álpa: -as. II. 3.24.

álpe. 4. 16.3.

(cf. álpapaçu--alpikă.)

álpa $\circ$ paçù: -um. 12. 4. 25 .

ál p a ç a y u: -yūn. 4. 36.9 (iva).

a lpikầ: 20. I36. 3 (mss. álpikā).

(cf. svalpikâ.)

Vav: ávati. 8. 7.21.

avati. 8. 4. $12 *$.

ávathas. 4. 29. $3^{2}, 4^{2}, 5^{2}, 6^{2}$.

ávatas. $4 \cdot 2 \cdot 3^{*}$.

ávanti. I8. 3. $24^{*}$.

avatu. 2. 12.4. 5. $24.1,2,4,7-14$.

7. 20. 5. I9. 45. 6-9.

avatam. I4. I. 35,36 .

avatām. $\quad 5.24 \cdot 3,5 ; 27.8$. 7. I2. I. 18. $3 \cdot 38$.

avata. I9. I. 2; 72. I.

avatā (p. -ta). I9. I3. II*.

ăvantu. I8. 3. 15.

avantu. 2. 13.5. 3. 19.5. 5. 24. 6, I5, I6, I7. 7. 49. I*. I 8. I. $44^{*}, 47$; 3. $45^{*}$. I9. 45 . 10.

āvan. 4. 2. $6^{+}$.

āvitha. 5. 2. $6^{*}$.

âvayas. 6. I6. 2.

āvayat. 4. 6.3. 5. I9. 2.

(cf. ávas, ávi ?, avita, avitṛ́, avisyú, suprāvî ?, ūtí, úma, oman.) 
+ u d: úd avā (p. -va). 3. 16. 3". 7. 50. $4^{*}$.

udoávantãu. 7.95.2.

+ upa: úpā 'vati. I. I6. 2.

+pra: prá... ávathas. 4. 29.1, 2. prầ 'va. I3 I. 43 .

prá ... avatu. I9. $13.7^{\circ}$.

prấ 'vatam. 6. 4.3. [49. I'. prấ 'vantu. 3.23.6. 4.15.9. 7 . prá ... avantu. 4. 27. 1 .

prá... áviṣus. 20. 136.4 (mss. ãv-). (cf. prăvī.)

+s am: sám... avantu. 4. 15.7, 9. áva. I. II. 3, 4-6. 4. I. 7 ; 15. 12 . 5. $6.6 ; 13.6 ; 14.1,2 ; 21.1 .6 .16$. $3 ; 26.1 ; 42.1,2 ; 65.1^{3} ; 134.1 .7$. 7. I; 55. I; 83. $3^{*} ; 9$ o. $3 ; 94 . \mathrm{I}^{\dagger}$; 107. I. 8. +. $17^{*} ;$ 6.16. I0. 4.3 . 12. I. $5^{8}$. I3. I. $32^{2}$. I4. 2. 52 . 16. 7. 4 . $8.4 .6 \mathrm{I}^{*}$. I9. $3.4 ; 36.4,5$; 65. I. 20. 133.6 .

(cf. ava $+v \mathfrak{l}^{\prime} \mathbf{i}$, upa ...i, il, r, kāạ, kram, kșam, kșip, gach, gam, I gā, guh, 2 gṛ, grah, glā, car, tan, abhi ...tan, tap, tṛ, day, 2 drā, I dhā, dhāv, dhu, dhrss, dhvas, nah, nij, abhi... nij, nī, pad, paç, bādh, brū, bhid, bhraņ̣, bhṛ, muc, mŗ̣, yaj, yā, rādh, ruc, rudh, ruh, çañs, 2 çì, çrath, çvas, sā, ut ... sāa, sṛj, abhi ... srrj, upa ... sṛj, sṛp, sku, sthā, han, hā; and avața ?, avatká, ávattara, avamá, ávara, avás, ávatoka, avakeçá, ávāñc.)

a v a kā in

a vakādá (p. -kāoad-): -dân. 4 . $37.8,9$, 10. and a vákolba (p. -kāoul-): -bās. 8. 7 . a va oke ȩáa: -ás. 6. 30. 2. avaokrāmá: -mí. 5. 14. 10. áva०kșāma: -am. 6. 37.3. avaocarantikat: 5. 13.9. a v a ț a in pipilikăvațá. áva otoka: -kām. 8. 6. 9 . avatoká: -ám. 2. 3. I. ávatotara: -as. 18. 3. 5 . avadyá: -ám. 7.89.3. I 8. 3. $5^{*}$ (inss. ávadyam).

$\left[47,4^{8}\right.$. avadyăt. 2. 10.6. 5.6.8. 12.2. avadyăni. 5. 11. 7.

(ef. anavadyá, avadyávant.) a vadyá ovant: -vatyăs. 7.103. I. a v a drāṇa in anavadrāná. $\mathrm{a} v \mathrm{adh} \mathrm{ars} \mathrm{y} \mathrm{a}$ in anavadharşyà. a va dhvańsá: -ás. 5.22 .3 (iva). a vanejana in hastãvanéjana. a vabrava in anavabravá.

ava $\circ$ bhṛtha: -am. 9. 6.53.

a v a má: -má. 18.2. 4 S.

avamám. 5.13.2. 10. 7.8 .

avamâs. 19. 47.5 .

avamấn. 6. 103. 2.

a va y ā in ánāvayã (?).

a va॰ yấj (or -yâ): -ăs. 2. 35. I.

a va०y ātṛ́: -tấ. 2. 2.2.

a va०yắna: -am. 8. 1.6.

ávara: -as. I8. 2. 32 .

avare. I. 17.2.

ávaram. I. 8.3. 5. 1 I. 5. 7. 7.35.3. 8. 3 . $3^{*}$. I0. 8.8 .

ávareṇa. 9. 9. $17^{*}, 18^{*}$; 10. $25^{*}$.

- ávarāya. I. 12.4 .

ávare. 5. 2.6.

ávare (pl.). 5. 24. 16. 10. 7.21. 18.

ávarā. 7. 4I. I.

ávarăn. I2. 2.29.

(cf. avarapará.)

a vara opará: -ám. II. 3. 20.

a varcás: -ásam. 4. 22.3.

á va rjivāins: -júşiṇām. 7. 50. 2 (1. -naam).

avartsyánt: -án. I 5. 6. 7 (so p.: read āv-). [5.37.

ávarti: -is. $4 \cdot 3+3$. 10. 2. 10. 12. ávartim. 9. $2.3,4 ;$ 4. 17 . 9.3 I. I I (mss. amŕtam).

ávartiā. 12. 2.35.

a varmán: -mânas. II. 10. 23.

a v a çá: -ás. 6. $42.3 ; 43.3$.

a va ○ çás: -sã. 6. $45 \cdot 2^{\dagger}$.

ávaçā: I 2. 4.42.

ávaçām. I2. 4. 17 .

a va०çvasá: -ám. 4. 37.3. [51". ávas: -sā. 5.2.6*. 6.7. 1. 18.1 . ávase. 3. 20. $4^{*}$. 5.25.2. 6. 108. 
2. 7.6.2; 40. I. 8. 7.23, 24. áviçva०vinna: -nām. 9. 9. 10t. ávobhis (p. ávaḥobh-). 7.9I. I*. a viṣá: -ám. 8. 2. 19.

I9. 10. I*. $\quad$ a viṣ yú: -yávas. 3. 26. 2. II. 2.2.

(cf. svávas, ávasvant.)

avás. 9. 9. $17^{*}, 18^{\dagger}, 18^{\prime \prime}$.

avaosárjana: -nāya. 6. 84 . I.

avaostâna: -am. I8. 1. $55^{*} ;$ 2. 37 .

I9. I4. I (p. avasă-).

(cf. avasānadarçá.)

avas̄ānaod arçá: -ás. 7. 4r. r.

a vaskavá: -ám. 2. 3 I. 4.

a vasthá: -ásya. 7. 90. 3 .

ávasvant: -ntas. 3. 26.6 .

a vācína: -am. I0. 4.25.

avācínān. I3. I. 30 .

á vāñ c: ávācīs. I0. 2. I I

(cf. avācína.)

a vāy a in anavāyá.

a vāstú: -úm. I2. 5.45.

ávi: -is. 3. 29. I, 2. 5. I9.2. Io. 8. 31. 12. 2. 53 .

ávim. 3. $17.3 ; 29.3-5.5 .1 .9 ; 8$. 4. 6. 71. I. 7. 50. 5 .

ávyām. 5. 31.2. 12. 2. I9 (áviām ?), ávinām. I9. 47.6 .

(cf. ajāví, ávika, ávimant.)

á vika: -kās. 20. I29. I 7 (mss. víkā). áviocācala: -lās. ro. 8.4.

áviocācalat: $6.87 .1^{\dagger}, 2^{\dagger}$.

a vi ceta ná: -năni. 20. 135.7 (mss. avícetán-).

ávi cheda: -dāya. 9.6.38.

ávi॰jānaint: -nan. $9.96^{*}$.

ávijñāta。g a da: -dā. I2. 4. I6.

a vita in ádroghāvita.

a vitṛ́: -tâ. I9. 13. $8^{*}$.

avităram. 7.86. $\mathrm{I}^{*}$.

ávitti: -tes. I6. 6. Io.

ávid y ā: -ās. II. 8. 23.

ávidvāns: -dușas. 4. I8. 2.

ávidvāñsas. 6. II5. I.

ávidușțarāsas. I 9. 59. 2* (p. ávi॰d-). ávi॰dviṣ: -ṣe. I. 34.5 .

áviodveșa: -am. 3. 30. I.

avidhavá: -vâs. I2. 2. $3 I^{*}$.

ávi om ant: -matas. 6. 37. I.

a vi॰mokjyá: -kiám. 6.63. I.

ávi $\mathbf{r} \overline{\mathbf{a}} \mathrm{d} \mathbf{h}$ a y a n t: -ntī. 2. 36. 4 .

ávi॰hrut a: -am. 6. 26. I.

a vi in suprāví (?).

áviraohan: -hā. I. I6.4. 6. 14. 3 .

áviraghnis. 6.83.2. I4. I. 39 .

a vṛká: -kăs. I8. I. $44^{*}$.

avāiraohatyá: -yâya. 6. 29. 3.

ávy a ca s: -sas. I9. 68. I (mss. ávyasas; p. ávioas-).

ávy a n a t: ávioanat. 5. 2. 2*. [IO. ávyṛddhi (p. ávioṛ-): -is. Io. 2. ávy eṣy ant (p. ávioe-): -at. 12. 4.9. avratá: -ás. 6. 20. I. 7. II6.2.

ávrāty a: -as. I5. 13.6.

$\checkmark$ I a ç: açnutás. I4. 2.9.

açnuve. 9. IO. $15^{*}$.

açnuté. I9. 38 . I.

[38, 1 .

açnute. 4 . $9.5 ; 21.4^{*}$. 9. 5.26. I 9 .

açnávāmahāi. 6. Iog. $2^{*}$.

açnutām. 8. 2.8.

ānánça. 6. 49. I.

ānaçus. 9. IO. $1^{*}$.

ānaçé. 6. II3. I, 3. [56.3.

ānaçānăs. 2. I. 5. 6. 47.3. I9.

āșța. 4. 1. 5 (mss. āșțra).

açīya. I6. 4.6. I9. 6I. I.

açìmáhi. I9. $11.6 *$

açìmahi. I3. I. $60^{\dagger}$. I4. $2 \cdot 5^{*}$. I8. 3. $67^{*}$. 19. $47.2^{2}$.

(cf. açáni, áçman, áçva, áșți, áṣțrā, ăçā, āçú, āçyà.)

+ an u: anu॰ānaçé. 4. 25. 2.

+ abhi: abhí açnavātāi. I2. 3.34.

+ ud: ud ānaț, see $/$ naç. [-vat).

+ vi: ví açnavam. I9. 55.6 (mss. ví açnutam. I4. I. 22*.

ví açnutām. I4. 2.64 .

vi॰ānaçé. 3. 7.6. 5.7.9.

ví ānaçe. I3. I. 16.

+ s a m: samoaçnuté. 3. 22. 5.

sám açnute. I0. 10. 33 .

samoānaçé. ro. $7 \cdot 36$.

V2 a ç: açnắmi. 6. 135. 1. 7. IOI. I. açnăsi. 8. 2. I9.

açnăti. 9. 6.3I-6.

açnāti. 9. 6.31-6. I4. I. $3^{*}, 5^{*}$. 
açnánti. 9. 6.25, 26. I I. 10. I4. a ç Irşán: -şănạam. I 9. 47.8; 50. I. açniyatat. 4. II. 3 . açirģănas. 6.67 .2$.

açniyāt. 9. 6.24 (s. mss. -yăt), 24. $37,3^{8,39}$. I2. $4.43,44,46$.

āçît. 8. 3. $17^{\dagger}$ (açit ?).

açită. I2. $5 \cdot 37,3^{8}$.

açyámānā. 12. 5.38.

(cf. aç, áçana, açităvant, açitṛ, áçna, açnant.)

+ pra: prāo'çnánti. 8. 7. 25.

pră 'çāna. I. 7.2.

prầ 'çnantu. I2.3. 32 .

prāo'çnatî. 6. I33.2.

prắçnan (p. pra॰ăę-). I r. 3.32-49. prấ "çişam. II . 3. 32-49.

prắçis (p. pra॰ă-). I I. $3 \cdot 28,29,32-$ prầ "Çîs. II. 3.26, 27. pră "çit. II. 3. 31.

(cf. prăç, prāçitŕ.)

+ vi: ví āçnāt. 2. 27.4.

a ç in prấç.

açatrú: 6. 40. 2.

áçana: -ne. 5.29.6, 7 .

(cf. açanakị́t, açanānaçaná.)

a ç a n a $\circ \mathbf{k r ̣ ́ t : ~}$-tam. 9. 6. I3.

a ç a nān a ça ná: -né. I $9.6,2^{\dagger}$ (mss. açanắn açané).

a çáni: -is. 3.27.4. 6. 37.2; I 42 . I. 7. 50. 1. 8. $3 \cdot 4^{*}$.

açánim. 8. 4. 20*, $25^{*}$.

açányā. 7. I09. 4.

açányāi. 12. 3. 54 .

açániobhis. 8. 3. $6^{*}$.

áça pant: -patas. 6.37.3. 7.59. I. á ç a s t a: -tāni. 6. 45. I.

áças ti: -is. I. 20. I. 5.3.6.

áçastim. 8. 2.2. $17.8,17$.

áçastiās. I2. 2. I 2.

áçastayas. 7. II4. 2.

$\mathrm{a}$ çit a in açităvant.

a çitṛ in prāçitṛ́.

a çităvant (p. -tá。v-): -vati. 9. 6 . á çi va: -vās. 7. 43. r. 12.2.27. [mss.) áçiçlikṣu: -um. 20. I34. 6 (not á ç i ș ț a : -țān. 2. 3I. 3. [mss. açítis). açītí: -ís. 5. I5.8. I9. 47.3 (m. açitáyas. II. 3.21. açitíobhis. 2. I2.4.

áçun a: -am. I4. 2. $16^{\dagger}$.

á ço nุa : -ṇās. I 9. 60. I (not mks.).

áçn a : -as. 9. 9. I*.

a ç $\mathbf{n} \mathbf{a} \mathbf{t}$ in ánaçnant.

á çm a n: -mă. I. 26.1. 2. 13.4. 4 . I 2. 7. I0. 5. 20. I2. 1. 26. I 8. 4. 54 . áçmănam. I. 2.2. 2. 13. 4. 7. 35 . 3. 8. $4.19^{\circ}$ I 3.4 .41 I 4.1 .47$. áçmană. $\quad 5.23 .13 .6 .138 .5 .7$. 35. 2. I3. I. 32 .

áçmane. I. I3. I.

áçmanas. 6. 42.2 .

áçmānas. 4.18.3. I I. 7.2 I.

áçmaosu. 3.2I. I. I2. I. 10.

(cf. áçmanvant-áçmahanman.) áçm a n。vant: -vati. I2. 2. $26^{\circ}, 27$. a çm a $\circ \mathbf{v}$ armán: -má. 5. 10. $1-7$. á çm a ha n m a $n$ : -maobhis. 8. $4.5^{\circ}$. a çra d d há: -dhấs. I2. 2. $5 \mathrm{I}$. áç ra d d hā: I I. 8.22.

áçrāta: -am. 7.72. I*.

áçrānta: -tasya. I9. 25. I.

a çrīrá: -ám. 4. 2 r. 6*.

açlīâ. I4. I. $27^{\dagger}$.

á ç ru: -rūṇi. 5. I9. 3 .

(cf. anaçrú, açrumukhá.) açru०mukhá: -khí. Ir. 9.7. a çreșmá n: -mănas. 3.9.2.

a çlīlá, see açrīrá.

áçlo ṇa: -as. I. 3 I. 3 . áçloṇās. 6. 120.3.

á çv a: -as. $\quad$ 2. 30. 5. 5. 5.8. 8. 2 . 25. 9. $9.2^{*}$. IO. I. I9; IO. I6. II. 5. I8. I2. I. $57 ; 2.50$ I9. $53 . \mathrm{I}$ : $57 \cdot 4^{2}$. 20. I 28 . IO (?), I I (?) ; I 36.5 (not mss.). [I 5 (mss. áç-). açva. I 9. $49 \cdot 5$ (ed. asyá). 20. I 28. áçvam. I. I6.4. 4.9. $7^{*} ; 36.10$. 5. I4. 6 ; $29 . \mathrm{I} ; 7$ I. I. 8. 7. II. Io. I. I 7, 29 .

áçvāya. 3. I 5.8. I9. 55. I, 7. áçvasya. $4.4 \cdot 8$; I 5. I I * $5 \cdot 5 \cdot 9$. 6. $38.4 ; 72.3$. 9. IO. I 3 (1. açua-?), I4". IO. 4.2. II. 2.22. I9. 49.4 . 20. 129. I8.

áçvā. 8. 4. 6*. 
áçvās. 2. 26.3. 3. 16.6* 9. 9. $3^{*}$. II. $2.9 ; 3.5$. I3. I. $24 ; 2.6,7$. I8. 4. Io (s. mss. áçvas). I $9.6 .12^{*} ; 38$. 2 (mss.). 20. I 29. I; I30. I9 (mss. çvâ); I3I. 5 .

áçvās (voc.). I. $4.4^{\dagger}$. I9. 2.4 . açvās. 20. 127. I2 (mss. açvăs).

áçvān. 6. 77. I. áçvãis. 3. 16. $3^{*}$. 7. $81.4,5$. 18 . áçvebhis. 6. I08. I.

áçvebhyas. 19. 47. 10.

[I6.

áçvebhias. 3. 28.3. 9. 3. 13. 12. 2. áçvānām. 4. 9.2. 8. 4. IO*. I2. I. 5. I9. 47.7.

áçveșu. 4. 22. 2. 9. I. I8. I2. I. I9, 25 (áçue-?); 2 . I 5.

(cf. aghāçvá, rãjāçvá, vadhryaçvá, çyãvăçva, háryaçva, açvakșabhá-áçvya.)

a çvaokşabhá: -bhà. I 9.49 . I (? ed. viçvávyacās).

a çvaojít: 5. 3. II. 7. 50.8 .

a çvat a rá: -rásya. 4. 4. 8.

açvataryàs. 8. 8.22.

a çvatthá: -ás. 3.6. I. 5. 4.3. 6. II. I. 8. 7.20. I9. 39.6. 20. 13I. 17. áçvattha. 3.6.5.

açvattha. 3. 6. 2, 3, 4, 6. 8. 8. 3 .

açvatthăt. $5 \cdot 5 \cdot 5$.

açvatthásya. 3.6.8.

açvatthăs. $4 \cdot 37 \cdot 4$.

(cf. açvatthapalāçá.)

a çva t tha pal āçá: -ám. 20. I34. 3 (mss. áçvatthapálāçam).

á ç v a o p a r ṇ a: -ṇās. 6. I26. 3 .

a çv a medha in arkāçvamedhá.

aç va०yúj: -jāu. I9. 7.5.

á çva०vant, açvāvant (p. -va。 v-): -avān. 6. 68.3.

áçvavat. I8. 3.61.

áçvāvatĩ. 3. I2. 2.

áçvāvatīm. I 8. 2.3 $\mathrm{I}$.

áçvāvatīs. 3. $16.7^{*}$.

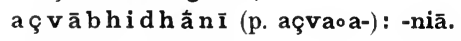
4. 36. 10. 5. 14. 6.

açvín: -nā. $3.3 .4 ; 4.4$; 16. I $^{*}$; 22. 4. 4. 30. $1^{*}$. 5. 3. $9^{*} ; 25 \cdot 3^{\dagger}$. 6. 3. 3 ; 82.2 ; I03. I; 141. 2 . 7.53. I.
9. 7. I9. II. $6.4 ; 8.5$. I4. I. $8^{*}, 9^{*}$, $20^{*}, 54 ; 2.13$. I 9. 10. $4^{*} ; 20.1$.

áçvinā. 5.26.12. 6. 69.2. 9. I. I9. I4. I. 36.

açvinā. 2. 30. 2. 6. 4.3 ; 50. I (mss. áçV-); IO2. I; I4I. 3. 7. 52. I; 73. I, $2,4,5$. 9. I. II, I6, I7. I4. I. 14*, 35 (mss. açví-), $55 ; 2.5^{*}$. I9. 40. 4 ; 42. 4 (mss. açví-).

açvínāu. I0. 6. 12. I2. I. I0. 18. 2. $33^{*}$. I9. I6. 2.

açvíobhyām. 7.73. * $^{*}$.

açvínos. 2. 29.6. 7.73.3. 9. I. II ; 4.8 . II. 3.46 . I9. 5 I. 2 .

açvíni. 7.49. $2^{*}$ (cf. àçvina.) áçvya: -yena. 8. 3. $15^{*}$.

așạ̄hhá: -ḍhăs. I9. 7.4. [29.

așțá: 5. I5.8. 8. 9. $2 \mathrm{I}^{2}, 23$. II. 8.

așțāú. 2. 12.7. I9. 47.3.

(cf. açīí, áșțakā--aṣțāvinç̧á.)

áṣt a kā: I5. I6. 2.

(cf. ekāșțaká.)

așt a okṛ́tvas. II. 2. 9.

așțaodhă. I3. 3. I9.

așțá putra: -rā. 8. 9. 2 I.

aș ț a má: -ás. I3. 4. I8.

așțamím. 8. 9.2I.

(cf. saptamāșțamá.)

așțá yoni: -is. 8. 9. 2 I. [23.5. aș ța rcá (p. -țaoṛc-): -cébhyas. I9. aṣțaovṛṣá: -ás. 5. I6. 8.

așțáocakra: -am. II. 4. 22. aștấcakrā. I0. 2. 3 I.

așțà d aça in

aṣțādaçarcá (p. -çaoṛc-): -cébhyas. I9. 23. I5.

a șt à $\circ$ p a kṣa: -șām. 9.3.21.

aṣt á o p a d: -dì. 5. 19.7. 9. 10. $21^{*}$. I0. I. 24 . I3. I. $42^{*}$.

așțà y ogá: -gāís. 6. 9I. I.

a ș țā ovi ṅ çá: -ám. I9. 7. I (not mss.). așțāvinçăni. I9. 8.2.

áṣ ți : țaye. 6. 54. I.

(cf. jarádașți.)

á șt r $\mathbf{a}$ : -ām. 3. 17.6.

aș țîvánt: -ntāu. 9. 4.12; 7. 10. I0. $2.2 ; 9.21$. II. 8 . I 4 . $\left[45^{2}\right.$. aṣṭhivádobhyām. 2.33. $5^{*}$. II. 3 . 
V I a s: ásmi. 3. Ig. I, 4. 5. II. 10. 6. II7. I ; 123. 3 ; 133.3. 8. 4. $14^{\dagger}, 15^{*}$. 9. IO. $15^{*}$.

asmi. I. $7.4 ; 34.4$. 3. $18.5^{*}$. 4 . 32. $5^{*}, 6^{*} ; 36.6$ 5. 9.7 ; II. 3 , Iо. 6. $39.3 ; 123.3$. 7. 79.2. 8. $4.16^{*}$; 9. 22. II. I. I9. I2. I. $54^{2}, 58$. I4. 2. $7 \mathrm{I}^{2}$. I6. 3.6. I8. I. I3. I9. 32.5 . ási. I. $25 \cdot 2,3.4 .9 .10 ; 33.6^{*}$. 5. $5.2 ;$ II. $9 ; 14.7$; I6. I-II. 6. I6. 2 (mss. asi); 46. I, I (s. mss. ed. asi). 7. 38. 5 ; 46. I*, 3. 9. 3. 9. ro. I. 29. II. 4. I8. I3. 4.45 . I7. $20,2 \mathrm{I}$. I8. I. $38^{*}$. 19. 38.2 (mss. āsi, p. ā॰ási); 57.4 (mss. asi).

asi. I. I3. $3 ; 20.4^{*} ; 23 . \mathrm{I}, 3 ; 25.2$, 3 ; 34. I. 2. 3.2 ; II. $\mathrm{I}^{3}, 2^{3}, 4^{3}, 5^{4}$; I7. I-7; I8. I-5; 27. I. 3. 5.8 ; IO. I3; I2. 3,5 ; $18.5^{*} ; 20.2^{*}$. 4. 3. 7 ; 4. $5^{2} ; 6.8 ; 7.6 ; 9.1,2,3^{2}$; 10. $6^{2}$; I2. I ; I9. $\mathrm{I}^{2}, 2,3^{2} ; \quad 20.3,7 ; 3$ I. $4^{*}$. 5. 4. $7^{2}, 9 ; 5 \cdot I^{2}, 3,4,6,7,8 ; 6.4,9$, II-4; IO. I-7; II. 2, 9, II ; I2. I*, $3^{*}$; I3. IO, II ; I6. I-II ; 20. IO; 22. $5 ; 25.7,8 ; 29$. I. 6. I5. I $^{*}$ I6. $4^{2}$; 2I. $2 ; 44.3^{2} ; 46$. I, I (mss. ási), $2^{3}$; 48. I, 2, 3;8r. I; 86. $3^{2} ; 95.3 ; 9^{8}$. $3^{2}$; I0O. $3^{2}$; IO8. I ; I25. I* ; 26. $2^{*}$; I33. $2^{2} ;$ I36. I; I38. I. 7. I2. $2 ; 38.3 ; 8$ I. $3,4^{3} ; 88$. I $^{2} ; 89.4^{3}$; III. I ; II3. $2^{2}$. 8. 2. $28^{2}$; 5. II. 9 . 2. 19-24, $23^{2} ;$ 3. 7 ; 5. IO, I6 $6^{2}$ Io. 4. $24^{2} ; 5.25-35,44 ; 8.27$. II. I. 35 . I2. I. 6 I. I3. $2.19^{*}, 29^{3 *}, 30 ; 4.46$, 47. I4. I. 5 I ; 2. I5. I6. I. $6 ; 2$. $6 ; 4.2 ; 5 . \mathrm{I}^{3}$. I I. I I. I $2,2 \mathrm{O}^{2}, 2 \mathrm{I}^{2}$. I8. I. $15^{*}, 22^{*} ; 3.5,36^{3}, 37^{3} ; 4.68$. I9. $3 \mathrm{I}$. II, I2 ${ }^{3}, \mathrm{I} 3 ; \quad 32.3,5 ; 34 . \mathrm{I}^{2}$; $35.3 ; 39.4,9 ; 44 . \mathrm{I}, 5 ; 48.6 ; 49.8$; 52. $2 ; 59 . \mathrm{I}^{*}$.

ásti. I. 18.3. 4. I2. 2 ; I9. 2.5 . 6. II-4; II. 5 (s. mss. ed. asti). 7 . 5. 4 (mss. ásthi); 97. 2*. I0. 7.3I. I I. ro. 27 . I2. $3.4^{8}$ (s. mss. asti). I4. 2. I2. I9. 5. I*

asti. 3.6.7. 7.7. I ; 56.6. 8. 9. 22. 9. 2. I $2 ; 9 . I^{*}$. II. I. 33 ; 2. 25 . I2. 2.3 6. I9. 53.4 . 20. I 35.4 (ed.). smasi. $7.9 .3^{*}$. 19.48 .4 .

smas. 18.4 .87$.

sthá. I. $5 \cdot I^{*}$ (sțhâa); 30.3. 2. 12 . $2 ; 14.5^{2} ; 24.1-8 ; 26.1-6.6$ 6. 2 I. 3 ; 50.3. I0. 1. 30. I2. $2.2 i^{\dagger}$. I 8 . 3. $20,25-35$; 4. I6-24. I9. 27. I I-3. stha. 3. I. 2 ; I3. I. 7.75.2. I0. 5. I-5 $5^{5}, 6^{6}, 7-14$. I6. $2.2 ; 4.7 . \quad$ I 8 . 4. 86 (8. mss. sthá). I9. $69.1-4$

sthána. I. 31.2. 3.8.5. 6.24.3. sthana. 3. 13.2. 6.66.2.

sánti. 6. IO4. 2 ; II 2.3. 7.5. I". II. 2. 28. I9. 47.3 (inss. santi).

santi. 5. 6. $3^{*}$. IO. I. 20.

ásāni. I. 29.5 . 3. 5.5 ; 8.2. 7 . 38.2. 8. 5. 19. 19. 31.6.

ásasi. I. 29. $3^{*}$. 2. 3. I. 6. III. 2, 4. 7. I13.2. [ás-). I4. I. I $8^{*}$. ásati. 6. 64. $3^{*}$; III. I, 3. 7. 36. I (p. asātha. 3. 8.4. I 4. I. 32 .

ásas. I. I6. $4 ; 34 \cdot 2,5^{2}$. 2. $30 . I^{2}$. 3. I $7.8^{\dagger} ; 25.5$. 4. I. $7 ; 8.6$. 6. 8 . I-3 $3^{2} ; 9.2$. 7. 37. I; 38. 4 ; II $3 . \mathrm{I}$. 8. 2. I3. I4. I. $20^{*}, 50^{*} ;$ 2.75. I9. 46. 7 .

asas. 3. I2.5. 6. I3I.3. I8. 2.30. I9. 46.7 (mss. asat).

ásat. r. 22.2. 2. 28.5. 3. 20. $6^{*}$; 23. 5. 4. $13.4^{*}$. 6. $75 \cdot 3.7 \cdot 42.2^{\dagger}$; 90.3. 8. $5.21 ; 7.22$. I6. 6. II. I8. 2. 30. I9. 3I. 2 .

asat. I. 26. I. 2. I. 2 . 3. I7. $2^{\dagger}$. 6. 5. 2. 7. 56.8 . 9. $9.15^{*}$. I0. 4. I8. I4. 2. I5, 21. I8. I. I2*

ásāt. 6. I28. I.

ásāma. I9. 49.6.

ásan. II. I. I3. I2. 2. $26^{*}, 27$.

syām. 6. 58. I. 19. 49.3 (ed. syās). syās. 8. I. I6. I8. I. $25^{*}$.

syàt. I 2. 4. I3, 40 (1. siât).

syāt. ro. 8.23.

siāt. 3. 28.2. I 0. 7.24. I I. 4. 21\% siăma. 5.8.9.

syāma. 5.3.5*. 6.79.3. 18. 3. 17 . siāma. 3. I0. 5. 7; I6. $3^{*}, 4^{2 *}, 5^{*}$. 6 . $39.2 ; 47.1,2 ; 55.2,3 ; 55.2 ; 62$. 2 ; 93.3; II 7.3. 7.20.3,6; 34. I ; $68.2 ; 73$. II $^{*} ; 79.4^{*} ; 80.3^{*} ; 83.3^{*}$; 
9I. I*; 92. I*; I09.6. I0. 9.27. I2. I. $62 ; 3.17$. I3. 2. 37. I4. 2. 36 . I7. 8, II. I 8. I. $58^{*}$.

syus. $4.2 \mathrm{I} . \mathrm{I}^{*}$.

edhi. 3. 28.3 . 4. 31. $2^{*}, 6^{*}$. 5. 30. 6. 6. $87.2^{*} ; 142.2$. 7. 78. I. II. I. 7 , 22. I2. 2 . I0, 49 . I4. I. $43,44^{2+}$; 2. I8. I $8.3 .7^{*} ; 4.38^{2}$. $19.13 \cdot 8^{*}$; 55. 3,4 .

ástu. I9. 7.2.

astu. I. I. 2,3 ; $3 . \mathrm{I}-5 ; 9.2$; IO. 2 ; I $2.4^{2} ; \mathrm{I}_{3} \mathrm{I}^{2}, 3,4 ; 25.4 ; 26 . \mathrm{I}, 2 ; 3$ I. $4^{2}$. 2. 2.1 ; 10. $2 ; 35.4 ; 36.1,4$. 3 . IO. 2,6 ; I4. 4 ; I5. I' $4^{2}$; I6. $5^{*}$; I9. I, 5 ; 2I. I-7; 27. I-6; 30. 7. 4. 22. $2,3^{2} ; 34.8 ; 33.6$. 5. 3. $\mathrm{I}^{*}, 3^{*}, 4^{*}, 5^{*}$; 7. 1, 3 ; 20. 7 ; 28.6; 29.6-9; 30. 12. 6. I2. 3 ; I3.I; I5. I* $; 20.1,2 ; 27$. $\mathrm{I}^{*}, 2^{*}, 3^{*} ; 28.3 ; 29.2 ; 32.3 ; 40 . \mathrm{I}^{3} ;$ $56.2 ; 57.3^{2} ; 63.2^{2} ; 64.3^{*} ; 66.1$; 68.3；71.3；73.2.3；84.3; 97.2; 98. 2 ; II6. I, 3 ; I28. $2^{2}$; I4I. 2 . 7 . 8. I; 4I. $2 ; 79.4^{*} ; 80.3^{*} ; 82.3 ; 87$. I ; IOI. I : IO6.I. 8.I.I, I8; 2. I, 7: $16 ; 4 \cdot 3^{*}, 8^{*}, \mathrm{II}^{2^{*}}$. 9. $4.20^{2} ; 5.12$. I0. I. $5 ; 3.2$ I I. I. I5; $2.8,1_{5}^{2}$, I8, $22 ; 4.7^{2}, 8,23$; IO. 4 . I2. I. II, $42 ; 3 . \mathrm{II}^{2}, 32,39 ; 4.45$. I3. I. I 7-9, $27 ; 4.48,55$. I4. I. $19,52,60 ; 2.63$. I5. II. $2^{3}, 6,8$, IO. I6. 2.6. I8. I. $46^{*} ; 2.3 \mathrm{I}, 36^{2} ; 3.6 \mathrm{I}, 7 \mathrm{I} ; 4 . \mathrm{I} 5,48$. I9. $3.4 ; 4.2^{2} ; 7.3 ; 8.2,3,7^{3} ; 9.2^{2}$, $3,4,5,9, \mathbf{I} 3^{2}, \mathbf{I} 4$; то. $2^{2 *}, 3^{*}, 4^{*}, 5^{2 *}, 6^{*}$, $7^{*}, 9^{2 *}$, IO; II. $2^{*}, 3^{2 *}, 6^{2^{*}} ;$ I4. I ; I5. 3,$5 ; 46.5 ; 49.5 ; 58.1 ; 64.3$. 20. I28. $14 ; 135$. IO $^{2}$.

stam. 3. II.6. 5. 9. $8^{2}$. I4. I. $22^{*}$. stăm. 6. 78. 2.

stām. 2. IO. I-8. 3. 4.5. 7. 53. 2. 8. 2. I4, I8. 9. 4. Iо. I0. 9. 25.

sta. 6. $73.3 .7 .60 .4,6,7$.

santu. I. $6.4^{2}$. 2. $6.2 ; 12.6^{*} ; 14$. 3. 3. 19. $7^{*}$. 4. I8. I. 5.3. $3^{*} ; 6$. $9 ;$ I4. 5 . 6. 66. $3 ; 77.3 ;$ I42. $3^{3}$. 7 . I2. 2 ; 73. I0*. 8. $2.15 ; 6.16 ; 7.8$, 17. 9. 2. 10; 4. 6,20 I0. 9.3. II. $6.9,22 ; 9.2$; IO. 7 I2. I. $62 ; 3$. 42. I4. I. $34^{*}, 4$ O. I8. $2.20 ; 3.5 I^{*}$,
68,$69 ; 4.26,34,42$. I9. 2. $\mathbf{I}^{2}, 2 ; 8$. I ; 9. I, 9 ; 10. $2^{*}, 3^{*}, 4^{*}, 7^{*}, 8^{*}$; I I. I* I6. 2 ; 20. $2 ; 40.3$ (not mss.); 42.3 sán. 4. II.3; 32.5* 5.8.3; 22. 9. 6. 26. I. 8.2.7. II. 7.3. I3 I. $39^{2}$. I7. I2. I8. $4.59^{*}$ I9. 53 4. 20. $135 \cdot 7^{2}$ (mss. ?).

sát. 5. 19.9. 9. I0. $28^{*}$. I0. 2.22, $23 ; 7.21 ; 8.6$.

sántam. 3. 3. 2. 9. 10. 9*. ro. 1. 18; 8. $32^{2}$. I3. I. 33. I9. 53.3 (not mss.). sántas. 2. 34.4. 6. I I7. 2.

satás. 8. 4. $2 \mathrm{I}^{*}$.

satăm. I. 8.4 .

satî. II. 8. I7. I2. 4. I6.

satyắs. 12. 4.8 .

satís. 9. 9. $15^{*}$. I2. 3. 26 .

às. 14. 1. $6^{2 *}$.

ăsīt. 4. 2.6 (m. inss. āsīt). 8. 9 . I4; IO. I2, 22-9. II. 8.7 I2. I. 8 ; 5. 50 (ăsî3t). I3. 3. I2. I8. 2. 33*; 3.3. I9. $52 . \mathrm{I}^{*} ; 53.8$.

āsît. 4. 2. $7^{*}, 8$. 5. 17. $2^{*}$. 6. 30. I. 7. 80. 4. 8. 8.5,8; IO. I. 9. 4. I3, I5; 9. $9^{*}$. I0. $8.39,40$. I4. I. $6^{*}$. $7^{*}, 8^{*}, \mathrm{IO}^{2 *}, \mathrm{I}^{*}$. I5. I. I. I8. 2.27. 19. $6.6^{*}, 8^{*}, 10^{*}$. 20. I28. 12 .

ầstām. 8. IO. I3. II. 8.2 (so p.), 6 (do.). I 5. 3. 4, 5. [II*. āstām. 9. 4. 12 $2^{2}$ 13. I4. 1. $9^{*}, 10^{*}$, âsan. 5. 18. 10. 6. I12.2. Ix. 8. 10. 12. I. 37 . I5. 3. 10.

āsan. 3. 13.5 . 5. 4. $5^{2}$. 6. 30. I ; 137.2. 7. 5. I* 9. 4.14 ; $10.25^{*}$. I0. $2.4 ; 8.35,40$. II. $5.14 ; 8.1,2$, 5. I3. I. 46 . I4. I. $8^{*}$. I9. $6.15^{*}$. ăsa. 7. 66. I.

āsa. 4. $32.2^{*}$. 5.2. $\mathrm{I}^{*}$.

äsitha. I. 24. I.

āsimá. 7.65.3.

(cf. ásu ?, ásta, asti, 2 āsa, sát, satyá, sátvan ?, sti ?.)

+ ati: áti ... syāma. II. I. I2, 2 I. + a pi: ápi ... ásti. I8. I. $33^{*}$.

ápi ... astu. 12. 2.9.

ápi ... āsīt. 2. 2.3.

+ abhi: abhí ... asi. II. I.6. [22. abhí șyāma (p. sy-). 7. 93. I. I3. I. 
abhí ... ásāni. 6. 97. I. $\checkmark 2$ a s: ásyasi. I. I3. I. II. 2. 25. asyati. I 3. 4.41 .

asyatas. 12. 4.17 . ásyatha. I. 26. I. 6.65.2. ásyanti. 5. 18.9. asyanti. 12. 3. 29 . asyatam. 8. 4.25". asyatām. I0. I. 23 . ásyantam. II. 2. 17. ásyate. 6. 90. 3 . ásyantas. 6. 66. 2 . àsyat. 4.6.4. 6. 90. I. âsyan. 4.6.7. asyate. 5. 19. 5 . astấm. 6. $59 \cdot 3$. 12. 2. 47 . astáyā. 5. 31. I 2.

astâs. I. I9. 2 .

(cf. as, ásana, así ?, ásișțha, asta, ástṛ, astrá, I ăsa, āsin, I āsyà.) + upa: úpā 'syāmasi. 6. 42. 2. + ni: nioásyatha. I4. 2. 22.

+ nis: nírastam. 7. 76.3 (? mss. ed. nireâstam).

+ parā: párā "syas. 20. I29. 6.

+ pari: paryásyantī (p. parioá-). I2. 5.21 . pári ... asyate. I3. 2. 43 .

(cf. paryastākșá.)

a sán, ás ŗj : áş̣k. 4. 12.4, 5. 9. 9.4". asnă. $4 \cdot 5 \cdot 8$ (p. āsnă). asnás. 5. 5. 9; 19.3.

(cf. âsneya, asṛ̣̂păvan, áş̣ñmuá s a n a: -nāya. I. 13.4.

ás a n t: -an. 8. 4.8. II. 7.3. [25. ásat. 4. 19.6. 8. 4. $12 \%$ I0. 7. I0, âsat (p. ás-). 8. 4. $12^{\circ}, 13^{\circ}$.

ásatas. 4. I. I. 10. 7.25. 18.4. 55 . âsatas (p. ás-). 8. 4. $8^{\circ}$. ásati. 17.19. ásatíbhyas. 7. 76. I. asatotarās. 7. 76. I.

(cf._asacchākhá, asanmantrá.)

a s a mỏ tāpá: -ám. I6 3.6. asamiāpé (p. -é íty etc.). 4. 26. 3. 8. 2. 14 [ [9.6.
[9.

a s a nm antrá (p. asatom-) : -răt. 4 . a sa patná: -ás. I. 29.5. I0.6.30. I9. 46.7 . asapatnám. 8.5.17 $7^{3} \cdot$ 9.2.7,8. I2. I. 4I. I9. I6. I. asapatnắs. I9. I4. I.

ás a p atn a: -as. I. I9. 4 .

ás abandhu: -us. 6. I5. 2;54. 3 .

ás a ma: -as. 12. 3.3\%.

á s a măti : -im. 6. 79. I.

á s a mo ̣̣̂ d dh a: -dhās. I. 27. 2, 3.

ás a moṛ d dhi: asamrddhe. 5.7.7.

+ prati: práty asyāmi. 5. 8.5. 6.

+ vi: ví asya. 12. 3. I8.

ví asyatāt. I0. 4. 6 .

ví... asyatam. 3. 25.6 .

ví āsias. 20. 128. I3.

ví āsthan ( $/$ sthā ?). I3. I. 5.

(cf. vyastakeçá.)

+ s a m: samoásyati. I2. 4.9. sám asyatām. 6. 89.3.

as in hṛtsvás.

ás a moy ant: -yat. I8. I. I4 (s. mss. ed. asaminyát).

as a ms ù kt a ogilá: -lébhias. Ir. ásamosthita: -am. 6. 50. 2.

a s a mokh yāt a: -tās. I2. 3.28.

as a mokhyeyá: -ám. ro. 8.24. a sa cchākhà (p. asatoçā-): -ấm. I0. 7.21 .

á s a moj $\circ \tilde{\text { ña }}$ I2. $5 \cdot 34$.

ásamṛddhayas. I4. 2. 49.

a s a mobā dhá: -ám. I2. I. 2. asambādhé. I 8. 2.20. a s a m०bhavyá: -ám. 5. 18. 12; 19. ás arva०vira: -as. 9.2.14. a s a çcát: -átas. 5.6.3*. a sā dá: -dâs. II. IO. 24 .

a sí: -ínā. 9. 5.4. asáyas. I0. I. 20. asîn. II. 9. I.

ásikni: I. 23.3. ásikni. I. 23. I. ásikniā. $5 \cdot 13.8$. ásiknyās. 20. I30. 2 (mss. asidyăs). ásikniām. I2. 2. 20. ásiknis. 8. 7. I.

ásita: -am. I. $23 \cdot 3^{2}$. II. 2.18 . ásitasya (n. pr.). I. I4.4. 6. I37. I. 
ásitās. 6. 137. 2 (mss. asitấs), 3 (do.). (cf. asūsút.)

(ef. ásilknī, asitá, asitajñú.) [13. a sú tikā: 6.83.3.

a sitá: -ás. 3. 27. I. 6. 72. I. I0. 4.5, as úrta: -am. I0. 3.9.

asităya. 6. 56.2. 12.3.55. as ū sú: -súas. I0. 10. 23.

asităt. 7.56 .1 .

asitásya. 5. 13.6.

ásitās. 5. I3. 5 .

asita $\circ$ j̃̃ú: -ñû́s. I2. I. 2 r.

ás ișt tha: -țäu. 4.2S.2. [9.9.4*. a ș̣ kopátvan: -vānam. 2. 25.3.

á s ṛñ $\mathbf{n} u \mathbf{k h}$ a (p. ásṛk॰m-): -ān. II.

9. 17.

á s ṛj, see asán.

ásu: -us. 5. I. 7. 6.53.2. 8. I. 3. áso (p. -o íti). I 9. 44.4 .

ásum. 2. 12.8. 5. 29.5; 30.1. 7. 2. I. 8. I. I5; 2. I. I8. I. $29^{*}, 44^{*}$; 2. $13^{*}$.

ásunā. 6. I04. I. 8. I. I.

ásave. I9. 44.4 .

ásos. II. 7. I6. I8. 2. $24^{*}$.

ásavas. 8.2.26. I 8. 3.62. [27.

ásūn. 6. 104. X. 12. 2.55. 18. 2.

(ef. ádabdhāsu, amṛ́tāsu, áriṣțāsu, gatấsu, naṣțăsu, asutị́p-ásura.)

a suotṛ́p: -pāu. $\quad$ r8. 2. $13^{\dagger}$. asutŕppas. 8. 3. $13^{*}$.

ásu०nīta: -tāya. I8. 2. 56 .

ásuoniti: -is. I8. 3. $59^{\dagger}$.

ásunītim. I8. I. $3 \mathrm{I}^{*} ; 2.5^{*}$.

ásura: -as. I. IO. I. 4. I5. 12* 5 . 27. I. 8. 6.5. I8. I. $23^{*}$.

ásurāya. 5. II. I. I3. 4.42.

ásurasya. 4.8.3* 6. 72. I. I8. r. $2^{*}$. I9. 56 . I.

ásurās. $\quad 2.3 .3 . \quad 6.108 .3 ; 109.3$. 8. IO. $22^{2}$. I O. 10. 26 . II. IO. I5. I9. 66. $\mathrm{x}$.

ásurān. 4. I9.4. 6. 7.2. 8. 5.3; 9. 24 ; 10.22. 9. $2.17,18$. 10.3 . II. II. 5.7. I2. I. 5 .

ásurebhyas. 2. $27.3,4$. 6.65.3 (1. -bhias). r9. 56.3.

ásurānāam. $\quad 4 \cdot 23 \cdot 5 . \quad 6.7 \cdot 3 ; 86$. 3 ; 100.3. I0. 3. 2 ; 6. I0. I9. I3. I. (cf. āsurá, devāsurá, asurakșáyaṇa-asuramāyâ.) [12, I3 .

as uraokṣáy aṇa: -am. II. IO. IO, ásuraokșiti: -im. ro. 6.22-8. a sura॰māyấ: -yáyā. 3. 9.4. as ú : asúam. 7. 35.3.

as âú (pron.): I. 26. I, $2 ; 29.5^{*}$. 2. I4. 3. 3. 2.6 4. $2.3,4 ; 16.3$. 5. 8 . 3, 7. 6. 130. $1-4,2,3$; 131. I, 2 . 7 . 7O. I, 2. II. IO. II. I2. 3.20 (mss. asāu). I3. I. 23. I5. I0. 7; 15.4, 5 ; 18. $2^{2}$. I6. 8. I-27. I8. 4.66 . asāu. 4. 16.9. 5.6.5-7. I8. 4. 33 . ásta: -am. 4. 15.6. I0. 8. 16. I4. I. $43 ; 2.13,29^{*}$. $18.3 .5^{*}$.

(cf. astaminyánt-astameșyánt.) a s t a in vyastakeçá, paryastākşá. a s t a moyánt: -yán. 9.6.46. astamyaté. I7. 23.

ástaka: -am. 2. 26. 5 . (cf. svastaká.)

ástamoit a: -tāya. I7. 23. (cf. svastamitá.)

a s t a moeṣy ánt: -yaté. I7. 23. a s ti in nyastika, svastí.

á stṛ: -tã. 6. 93. I (mss. ástrā). 8. 3. $5^{*}$. I $9.13 \cdot 4^{*}$ (mss. ástāt); 34. 3. 20. I 27.6 (not mss.).

ástrā. II. 2. 7.

ástre. 6. 93. 2.

ástṛta: -as. 19. 46: 1-7.

astṛta. I 9. 46.2 (mss. ástṛta).

ástṛtam. I9. 46. I.

ástṛte. I9. 46. 5 .

a stṛtá: -ás. I. 20. $4^{\dagger}$. 5. 9.7.

astrá: -ám. II. 10. 16.

as trāiṇá: -năâs. 8.6. 16.

asthán, ásthi: ásthi. 4. ro. 7 ; I2. $3,4,5$. 7. 5. 4. I0. 9. I8. II.

8. II, 29 .

asthnás. 4. 12. $\mathrm{x}$ [70.

ásthīni. 9. 5.23. II. 8. I2. I2. 5 . asthíobhyas. 2. 33.6 .

(cf. anasthá, purușāsthá, asthanvánt, asthijá, ásthibhūyas, asthisrañsá, așţhīvánt.) 
a sthanovánt: -ntam. 9.9.4* ásthi, asthí, seo asthán. asthiojá: -ásya. I. 23.4. ásthi obhūyas: -yān. 5. I8. I3. ásthira: -as. 20. 130. r9 (not ed.). asthiosransá: -ám. 6. I4. I. asthūrí: 20. I3O. I9 (not mss.). a s m a (pron. stem), see a pron.

a smátosakhi: -khā. 6. 125. I*. a s mă ka : -kam, -ka, see a pron. asmăkāsas. $4 \cdot 33 \cdot 3^{*}$. (cf. anāsmāká.)

ásmṛti: 7. 106: 1 .

ásravant: -ntim. 7.6. $3^{*}$.

ás rāma: -as. I. 3I. 3 .

ásvaga: -am. 12. 5.45 .

(cf. asvagátā.)

a svagátã: 12.5 .40 .

asvagátām. 9.2.3.

asvapná: -ás. 5. 30. 10. 8. I. I3. asvapnéna. I 9. 56.5 (mss. asvápnena; ed. svápnena).

asvapnấs. I2. I. 7 .

$\checkmark$ ah: âha. 3. $16.2^{*}$. 8. 4. $15^{*}, 16^{2 *}$ 9. 6. 19. 12. 4. I7. I5. II. $3-6,8$, IO. ahha. $\quad 3 \cdot 4 \cdot 5 \cdot \quad 8.5 \cdot 5^{2}$. II. 3.28 , 29, 32-49. I6. 9. 22. I9. $24.8^{2} ; 44.8$. āhús. 3. II. 5,$7 ; 2$ I. $4^{2}$. 4. 2. $5^{*}$. 5. 17.4. 9. $2.5 ; 9.2 \mathrm{I}^{\dagger}$. I0. $7.19^{2}$; I0. 23 . I1. 6.7 . I2. $3.4 ; 4.52(\mathrm{~m}$. mss. āhus). I3. 2. 36 .

ãhus. I. 25. I. 2. $2.3 ; 35.2$. 4 . II. II. 5. $28.6 .8 .9 .7,16,17.9$. I. $2 ; 4.7,8,9 ; 5 \cdot 7^{2} ; 9.12^{2 *}, 15^{*}, 16^{*}$, $19^{2 *} ;$ 10. $3^{*}, 28^{2 *}$. I0. $7.25 ; 8.23$, 33 ; 10. 26. II. 4.12, I 5 I I. 2.53 ; 4. I0, 33,36 I8. I. I4*. I9. 27.3 ; 30. $3^{2} ; 53.3$. 20. 128.2.

+ adhi: ádhy āha. I. I6. 2.

+ prati: práti ... ăha. I8. 2. 37 .

áha. I. 34.2. 4. 18.7. 7.38.4. I9. 2. $4^{2}$. 20. I28. 4 (mss. ahám); I 29. 6 (mss. áhá); I35. I3 (mss. aha).

a ha, see under áhan.

áh at a: -as. I2. I. II.

áhan, áhar, áhas: áhar. 2. I5.2. 4. I. 5. 6. 3 I. $3^{\dagger}$. 8. 5.6, I8. 9. 2 . I0. I0. 2. I6. II. 4.2 I. I3. $2.22^{\dagger}$;
4. 29. I5 2. I-4, 3. I7. $25,26.19$. 20. $4 ; 48.2 ; 50.7$.

áhaḥoahah. 16. 7.11. 19. 55.7.

áhnă. 4. 18.1. 15. 18.5.

áhne. 8. 2.20. 19. 48. $2 ; 50.7$.

áhnas. 8. 9.6. 13.4.29. I6. 4 . 4. I8. 1. $7^{*}$.

áhni. 6. IIO. 3. I9. 56.2

áhani. 7. 52.2.

áhani ( $\mu$. -1 íti). I3. 2.3.

áhnos. I6. 8.22.

áhāni. 7. 69. I; 82.4, 5. I2. 2. $25^{\circ}$. 19. 7.1 .

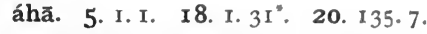
áhobhis (p. áhaḥobh-). I8. I. $55^{\circ}$. áhaobhis. 18. 1. 10".

áhnām. 3. 16. 4". 5.12. 4". 6. 128 . 2. $7.80 .4 ; 8$ I. $2^{*}$. I $8.4 .5^{8 t}$.

(cf. dvādaçāhá, bhadrāhá, şaḍahá, aparāhṇá, nyáhna, sāhna, sahasrāhṇyá, áharjāta, áhardivi, ahorātrá.)

a há m (pron.). I. 9. 4 ; 10. $3 ; 29.5,6$ ". 2. I0. $2-8 ; 25.2 ; 27.5 ; 30.5^{2} ; 32$. 3. 3. $5.2,5 ; 6 . \mathrm{I}, 3,5 ; 7.6 ; 8.3$ (?), 6 ; I5. I; I8. $4^{*}, 5^{*} ;$ I9. $2^{2}, 3,5 ; 22$. 6 ; 24. I, 2 ; 29. 8 ; 3I. I-II. 4. 4. 7 ; $5.7 ; 6.4,5 ; 9.7^{\dagger} ; 14.3^{2} ; 18.5 ; 20$. $2,4,8 ; 26.3 ; 28.3$; 30. $1^{5^{*}}, 2^{*}, 3^{*}, 5^{3^{*}}$, $6^{3 *}, 7^{*}, 8^{*} ; 32.5^{*} ; \quad 36.7,9 . \quad 5 \cdot 3 \cdot 4^{*}$; 7. 5,$7 ; 8.8,9 ; 9.7$ II. $3^{2}$, IO; I3. 3,6 ; 30.8. 6. 15. 2,3 ; 21.1 ; 23.1 ; 39. $3 ; 61.2^{4}, 3^{3} ; 65.2 ; 71.1 ; 76.2$; 84. I; 97. I ; IO2. 2 ; IOS. 2 ; II7. 2 : II9. I ; I 22. 5 ; I24. I I I27. 2 ; 130. 3 ; $133.3^{2}$. 7. I2. 3 ; I5. I; 35.2 ; 38. 2,$4 ; 4^{8}$. I* ; 50. I; 74. I, $3 ; 79$. 2 ; 95.2 ; IOO. I; IIO. 2 ; II\}.I. 8 . 2. 3,$6 ; 4 . \mathrm{I}^{*} ; 7.6, \mathrm{I} 8 ; 8.8 ; 9.16$ (mss.), 22. 9. 2. 2 ; 3.2, $15 ; 8.10-2$, I9, 20. 10. I. $32 ; 3.10 ; 4.21 ; 5$. $25-35,36 ; 7.43 ; 8.16,3^{8^{2} ; 9.27}$; IO. $3^{2}$. II. I. I9, 27; 3. 30, 32-49; 9 . 4 : 10. 9, I3. I2. I. I I, I 2, $54: 2.32^{2}$, $33 ; 3 \cdot 47^{2}$. I3. I. 19, $38 ; 2.44,45$. I4. I. $38,5 \mathrm{I}, 57 ; 2.19,7 \mathrm{I}^{3}$. I6. 3 . I ; 4. I; 7.8. I 7. $6,20,2 \mathrm{I}, 24^{*}, 27,28$, 29. I8. I. I $3,45^{*} ; \quad 3 \cdot 52^{*}$. I9. 9. 
I4 (not mss.); 3I. 4, 5, 6, I3; 32.4, 5,$7 ; 36.6 ; 40.2 ; 5$ I. I $;$ 70. I.

(cf. ahamuttará.)

ah amouttará: -ré. I2. 4. 50. ahamuttaréșu. 4. 22. I.

(cf. ahamuttaratvá.)

ah a muttaratvá: -vé. 3. 8.3 (mss. ed. ahám uttaraotvé).

áh ar, see áhan.

áharita: -as. I. 22. 2.

áharjāta (p. áhạ̣oj-): -asya. 3 .

I4. I. 5. 28.12.

áhardivi (p. áhaḥod-). 5. 2I. 6.

a h a la: áhala. 20. 131.9 (mss. áhala, áhara, etc.).

áhas, see áhan.

[I9. II. $3^{*}$.

áhi: -is. 4. 9.8. 6. 56. I. I0. 4. 26.

áhe. 5. I3. 4 (mss. áhes). ro. 4. 2 I.

ahe. 6. 56.3 . Io. 4.18 .

áhim. 2. $5 \cdot 5^{*}, 6^{*}$. 4. 3. $4 ; 24.6$. 6 .

I39. 5. 7. 88. I. I0. 4.9, IO $^{2}$, I6, I7.

19. $47.8 ; 5$ O. I.

áhaye. 8. $4.9^{*}$.

áhes. I 0. 4. I9, 26.

áhāu. 3. I3. I.

áhī (p. -ĩ íti). I0. 4. 8 .

áhayas. 6. 67.2 . 10. 4.9.

áhīn. I0. 4.6.

áhīnām. 2. 5. $7^{*}$. 6. I2. I. IO 4 .

I, $3,4,20,23$.

(cf. ahighní.)

áhinsant: -ntas. 6. 50.2. I2. 3 .

áhinsantīm. 9.3.22.

áhinssantīs. 9. 8. I3-8.

ahi॰ghnî: -nyás. I0. 4.7.

áhiraṇyavant: -vān. 20. 128.6 (mss. -vas).

á huta: -am. 6. 7I. 2. I5. I2. IO(mss. ed. ahutám).

áhutām. I2. $4 \cdot 53$.

áhutebhyas. 7.97.7.

(cf. ahutăd.)

ahutăd (p. -taoád-): -das. I. 30.4 . I8. 2.28 .

$[74 \cdot 3$.

áh ṛṇīyamāna: -as. 5. I7.2* 6 . áhṛnīyamānās. $\quad$ I. 35.4 . 6. 74.3. 8. 2. 21 . I8. 4.6 .

áhotṛ: -tā. 9.6.52. ahorātrá: -ré (p. -é íti). I0. 7.6; 8. 23. II. $5.20 ; 6.5,7 ; 7.14$. I2 I. $9,36,52 ; 2.49$. I3. $2.5,32$. I5 $6.6 ; 18.4$.

ahorātrăbhyām. 6. I28.3. I3.2. 43. I4. 2. $40^{\dagger}$. I9. 8.2, 7 .

ahorātráyos. I5.6.6. I6.8.21.

ahorātră. 4. 35. 4 .

ahorātrāís. I3. 3.8.

a hn a, see under áhan.

ahnya, see under áhan.

áhruta: -as. 6. 92. $3^{*}$.

áhrutās. 6. 120.3.

ấ (prep.). I. 9. 4; I4. $3 ; 23.2 ; 3$ I. 3 . 2. $2.3 ; 5.4^{3}, 7^{*} ;$ I $2.4 ; 26 . \mathrm{I}, 2,5$; 30. $5 ; 35.5 ; 36 . \mathrm{I}, 8$. 3. 3. I, $4 ; 4$. I. $5 ; 5.1,5 ;$ IO. 7,8 ; I $2.3^{3}, 7^{4} ;$ I3. I, 5,$6 ; 23.2^{2}, 5 ; 3$ I. II. 4. 4. $7 ; 8$. $3^{*} ;$ II. 4 ; I3. $2^{2 *}, 3^{*}, 5^{*} ;$ I 4.4 ; I 5 . II ; 2I. I* ; 22. 2; 33. I* ; 36.4 (not in mss.); 37.5 . 5. I. $2^{2}$; 7. I ; II. 9 ; I2. $\mathrm{I}^{*}, 6^{*}, 8^{2 *} ;$ 13. $5 ; 25.7 ; 26.6$; $27.8,9 ; 28 . \mathrm{I}^{3}, \mathbf{I} 4$. 6.2. I, 2 ; I6. I ; 26. I ; 3 I. I* $^{*}$ 33. I, 3 ; 35. I, 3 ; 5 I. $2^{*} ; 55.2^{2} ; 63.4^{*} ; 67.3 ; 68.1 ; 73$. $\mathrm{I}^{2} ; 79.2^{2} ; 87 . \mathrm{I}^{*} ; 92 . \mathrm{I} ;$ IO2. 2 ; IO4. 3 ; I37.3. 7. 8. I; 9. I* ; I5. I ; 20. 5 ; 22. I ; 26.8; 39. I ; 40. 2 ; 49. $2^{*}$; 53. 3,$6 ; 59 . \mathrm{I} ; 73.6 ; 76 . \mathbf{I} ; 8 \mathbf{I . 5}$; II4. $\mathrm{I}^{3}$; II 7. I*. 8. I. 6, 8, I6 (jihvá à b-); 2.2; 3. $2^{*} ; 4.9^{*} ; 5.20 ; 9$, 6. 9. 9. $\mathrm{I}^{*} ;$ IO. $8^{*}, \mathrm{II}^{*}, 23^{*}$. I0. 4 . I 5 ; IO. II, I2. II. I. IO, I4 ; 7. I4. I2. I. $55 ; 2 . \mathrm{I} 7,42,46 ; 3 . \mathrm{I} 3,55-60$; 4. 6, I2, I6;5.63. I3. I. $3,5,15^{4} ; 3$. 22. I4. I. $25^{*}, 39,62 ; 2.5^{*}, 8,40^{*}, 70$. I5. 2. I- $4^{2} ; 7 \cdot 3^{3}, 5^{5}$; IO. 8 , IO; II. 7,9, I2 ; I2. IO. I6. 4.2. I8. I. II*, $23^{*}, 24^{*}, 25^{*}, 45^{*}, 46^{*}, 59^{*}, 60^{2 *} ;$ 3. 14 , $23^{*}, 44^{*}, 47^{*}, 48^{*}, 62,65^{*} ; 4$. I6-24, 49 , 50, $52,88^{*}, 89$. $\quad$ 9. $7 \cdot 5^{4} ; \quad 3$ I. 7, I0; $42.3 ; 47.1^{2}, 9$ (not mss.); 49.2 (not mss.); 5O. I (not mss.); 52. $2^{\dagger}, 3$; 59 . $\mathrm{I}^{2 *}, 3^{*} ; \quad 64 \cdot 3^{*}$. 20. $48 . \mathrm{I} ; \quad$ I $27 . \mathrm{I}$; I35. Io (not mss.).

ó (p. ó íti). 7. 72.2*. I8. I. I*. 
(cf. $\overline{\mathbf{a}}+\sqrt[V]{ }$ ac, aj, añj, ad, $\mathbf{i}$, acha ... i, ati ....i, abhi ... i, ud ... $i$, abhyud ...i, upod ...i, upa ...i, nis ...i, pra ...i, sam"... i, idh, İr, îrts, u, r, ŗch, kū, I krr, ud ... krr, upa ...kr, pari ... $\mathbf{k r q}$, vi ... krṛ, sam ... krṛ, 2 kṛ, krand, kram, abhi . . . kram, krī, I kși, khan, khid, khud, gach, gam, anu ... gam, upa ... gam, ni ... gam, r gā, abhi ... gãa, ud ... gã, sam ... gā, gur, grah, sam ... grabh, ghaț, ghṛ, ghră, car, abhi ... car, ud ... car, carany, ci, sam ... ci, cit, crt, cyu, chad, chid, jan, jā, jñā, tan, anu... tan, tap, tud, dah, I dā, prati ... dā, vi ... dāa, sam ... dā, 2 dāa, diç, dṛç, dyut, I dhã, nis ... dhā, pari ... dhā, sam ... dhā, dhāv, dhi, dhṛ, dhṛs, nand, nah, pari ... nah, ni, ni ... nī, nṛt, pat, pad, paç, piṣ, I pr, pṛn, pyā, prā, prī, plu, bandh, I bhaj, bhā, bhū, bhūş, bhṛ, sam ... bhr̆, mad, mantray, I mã, mi, yach, ud . . . yach, nis... yach, pra +yach, yaj, yat, yam, vi ... yam, yā, I yu, yuj, yudh, rabh, anu... rabh, ric, rih, ru, ruc, ruj, rudh, ruh, anu ... ruh, abhi ... ruh, ud ... ruh, lap, labh, lup, vad, acha... vad, 2 vap, 3 vas, vah, upa ... vah, nis ... vah, sam ... vah, I vā, 2 vā, sam . . v vā, 3 vā, I vid, viç, vișt, I vṛ, pra ... vṛ, 2 vṛ, vṛj, vṛt, anu ... vṛt, apa ... vṛt, abhi ... vrrt, upa . . . vṛt, pari ... vrrt, abhipari ... vrrt, vi . . vṛt, vṛs, vrșāy, vṛh, vyadh, vraçc, çan̉s, ças, çā, çāas, çī, anu . . . çì, çuc, çr, çri, çriş, çru, prati ... çru, çliş, saj, sad, san, sic, su, sū, srr, sku, stṛ, sthā, prati ... sthā, snā, syand, sru, han, prati ... han, hu, hū, hṛ, upa ...hṛ, sam ...hṛ, hvṛ; and āvát, ătura?, ămanas, āmíkșā, ãgará ?, áliga, āvyuşá, otsūryá.) ā ku $\mathbf{t} \mathbf{a}$ in cittākútá.

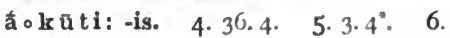
$64.3^{\circ} ; 73.2$. II. 7.18.

aknute. 6. I31.2. [4.2, 4 .

âkuntim. $5.7 .8 ; 8.2$. II. 8.4. I9.

ákūtyā. 5.6.10. 19. $4 \cdot 3^{9}$.

ăkūtiā. 3.2.3.

àkūtaye. 6. 4 r. I.

âkūtyām. 5.24. I-17.

ākūtayas. 3.2.4.

ákūisis. 3. 8. 5; 20. 9.

(cf. ākūtiprá.)

ākūtioprá: -ás. 3.29.2.

à $\circ$ rṛti: -is. I4. 1. $4^{\circ}$.

(cf. dvădaçākṛ̂ti.)

a kt a in svăkta and

ấktākşa: -as. 20. 128. 7 (mss. āktă-). (cf. ánāktākşa.)

à $\circ k r$ a ndá: -ás. I2. I. 4 I. [4.

ã॰krám a ṇ a: -am. 5.30.7. I3. I.

āokrayá: -yé. I9. 52.3 (mss.

âkșaye).

ā $\circ \mathbf{k}$ ará: -ás. 2. 36.4.

alkharé. 6. $49 \cdot 3^{*}$

ā khú : -úm. 6. 50. I.

$\bar{a} \mathbf{g} \mathrm{a}$, in ánāga, see anāgas.

à॰g a ma: -me. 6.81.2.

à $\circ$ g a miṣt th a: -ṭhās. r 8 . I. $45^{*}$.

ā॰gará: -ré. 4.36.3.

á gas: 4. I3. I*. I3. 3. I-25. I 8. I. 52*. ăgasas. I2. 4.50 (m. mss. āgasás). (cf. ánāgas, anāgás, kṛ̂tăgas.)

āgārá: -ám. 20. 132. I 2 (mss. -ram).

ăgnídhra: -rāt. 20. 2.2 (mss. à gni-).

ā g hāțá: -țầs. 4. 37.4.

ághṛni: -is. 7.9.2*

āñgirasá: -ás. 6. $45 \cdot 3^{*}$. 8. I0. 25. IO. I.6. II. IO. IO, I2, I3. I9. $4 \cdot 4$. ān̄girasám. 5.19.2.

ān̄ girasắnām. I6. 8. 12. I9. 22. I. ān̄girasi. I2. 5.52. [I6. ān̄girasîs.s. 8. 5.9; 7.17,24. II. 4 . ã $0 \mathrm{c}$ ā $\mathbf{y}$ à : -yàs. II. 5. I 4, I 5, I 7 . ācārías. Ir. 5. 3, 8, I6. ācāríam. I r. 5. I. ācāryà̀ya. I9. 64.4 (mss.). 
āchád。vidhāna: -nāis. I4. I. $5^{*}$. ăj a ni (p. ā॰áj-): -niā. 3. 25.5. [4, 5 . ājí: -ím. 6. 92.2. 7.82. I*. I3. 2. àjin. 2. 14.6 .

ăjya: -am. 6. II5.3. 7. 70. 2, 3. 9. 4 . $7 ; 5.38 ; 6$. II. II. 5.13. I3. I. 53. I9. 6. $10^{*}$.

àjiam. 5. 8. I. 9. 2.8. I o. 6.6. I I. 8. 29. I2. 4.34 .

ăjyena. 2. 26.4. I3. I. 52 . I9. àjiena. 5. 21.3. 9.2. I. I0. 9. 25. 12. 3.23 .

ăjyāya. II. I.3I.

ăjiasya. I. 7.2.

ăjie. . 5. 21. 2. I I. 9.6.

ájiāni. 6. II4.3. 8. 9.18. [jya.) (cf. prșadājyá, mășājya, varșầẵ̃jan a (p. āoáñj-): -am. 4. 9.9. I9. $44.2,3 ; 45.3,4$.

āñjana. 4. 9.3,4,5,6,7, Io. I9. 44 . I, IO; 45. I.

ăñjanena. 12. 2. $31^{*}$.

áñjanasya. 4.9.8. 6. 102.3.

âñanyām. 20. I33. 5 (mss. āñjanyằn).

(cf. uttarāñjant, āñjanābhyañjaná.)

ā ñja nā bh y añjaná(p. -naoabhy-); -ám. 9. 6. II.

āṇ ḍá: -ḍatt. I4. 2.44.

ānḍ̂áu. 9. 7.13.

(cf. āṇdăd, āṇdít.)

ān ḍă d (p. -ḍaoá-): -ấdas. 8. 6.25. āṇ ḍ̂t: -ḍíâu. 6. 138.2.

(cf. āṇtîka.)

āndîka: -am. 4. 34.5. 5. 17. 16 .

àt. 2.3.2. 3.13.2,6; 21. 10. 4. 3. 3,$4 ; 9.8 ;$ 20. I. 5. 13.2,3. 6. 22. I*. 7.70.2. 8.6.26. 9. I0. $15^{*}$. I0. IO. IO. II. $5.24 ; 9.8$ I2. 2 . 5I. I3. 2. 4I. 20. I32. I.

àta ta in ánātata.

àtura: -am. 6. IOI. 2. (cf. ánātura.)

ãotṛ́ d: -das. I4. 2. $47^{*}$. à otodín: -nāu. 7.95. 3 .

ātmaodáa: -ấs. 4.2. I*. I 3. 3. $24^{*}$. ātma odùtsi: -is. I6. I. 3 . ātmán: -mă. 5. 1. $7 ; 5.7 ; 9.7 .6$ 53.2. 7. 67. x; III. I. 9. 4. I0;9. 4*. I3. 2. $35^{*}$. I6. $3.5 ; 7.5$. 19. 5 I. I àtmănam. $\quad 4.9 .7^{*} ; 20.5$. 5.9.7. 6. 16.2. 8.6.13. 9. 5.30. I0. 8. 44. II. 8.3 I. I2. $3.30,5$ I ; 4.30 . I6. 7.5. I9. I7. I-IO.

ātmánā. 3. 29.8. 5. 29.6-9. 8. 2. 8. 9. 5. 3I-6. I8. 2. $7^{\dagger}$. I9. 33.5 . ātmáne. 4. 18.6. I2. I. 10; 2.34. àtmánas. 5. 29.5. 9.8.9. II. 5 . I5. I5. I0. 2.

àtmáni. I. 18.3. 4. 12.2. 7. 53. 3 ; 57 . I. 9. I. II-3, I6.

àtmán. 9. 6.21. I2. 3.54. I5. I. 2. ātmáosu. 3. I5. 7. II. 5.22. I9. 48. 5 . (cf. tmánā, tmányā, udákātman, sárvātman, sātmatvá, ātmadă, ātmadúși, ātmanvánt--ātmasád.) ātman॰vánt: -vát. 4. I0. 7; 25. I. I0. $2.32 ; 8.2,43$. II. 2. IO. I3. I. 52.

ātmanvátām. I9. 27.8 (mss, ātma。 tvátām).

ätmanvátī. 14. 2. I4.

ātma parājitá: -ás. 5. 18.2.

àtma osád: -dāu. 5. 9.8.

ātharvaṇá: ātharvana. 6. I. I (mss. atth-).

àtharvaṇám. 4. 3. 7.

ātharvanăs. I0. 6. 20.

ātharvanănām. I6. 8. 12. I9. 23. I. ātharvaṇis.s. II. 4. I6.

āodáhana: -am. I2. 5.48.

āodàna: -am. 6. 104.2,3.

ādănena. 6. I04. I.

(cf. ādānasamidāná.)

[9. 3 . ād āna os a māan á: -năbhiām. II. ādityá: -ás. 2. 32. 1. 4. 39.6. 6. 52. I*. 9. 2.15 . II. 9.25 ; IO. II, I6. I5. 4.6 ; 10. 7 ; $5.4 ;$ I8. 2 . I7. $24^{*}$. I9. 9. Io.

ăditya. 5. 21. 10. I I. I0. 4. I7. 25. āditya. $7.83 \cdot 3^{*}$ (1. -tia). 9. 8. 22. I3. $2.3,28,29^{*}, 29^{\dagger}$. ādityám. 3.20. $4^{\dagger}$. I0. 8. I7. I5. 4. 6 ; IO. II; I7. 9 . ādityéna. 4. 39.6 . 
ădityấya. $439.5^{2}$. 12.3 .55 . àdityé. 10. 3. 18 .

ādityāú. 8. 2.15.

ãdityâs. I. 9.1. 3. 27. I. 5.3. $9^{\dagger}$, 10*. 6. 68. I; 74.3. 8. I. 16. 10. 7. $22 ; 9.8$. I1. 6. 13. I2. $2.6 ; 3$. 43. I4. I. I", $2^{\prime \prime}$ I5. 2. I. I8. 3. I2; 4.3. I9. 9. II; II. $4^{*}$; I6. 2. 20. 135.6 (mss. ădityās), 9. [sas). ădityăsas. I9. 56.4 (mss. ădityāădityās. 6. II4. I.

ădityās. I. 30. I. 5. 28. 4. 6. I I4. 2. àdityằn. 3.8.3. I0. 9. IO. II. 6. 5 (1. -tiăn?). I3. 3. 17. ādityāís. 4. 30. I". 8. 8. I2. I0. I0. 9. I8. 3. 27 . I9. I7. 4 . ãdityébhis. 2.12.4. 19. 10.6". ădityébhyas. I2. 3.44. I 5. 2. I. I9. 39.5 (1. -bhias). ãdityănām. 9.1.4; 4.13. I5. 2. I. I8. 4.8. I9. 13.10*.

(cf. ādityávant.)

ãdityáovant: -ntam. r9. I8.4. ā dion a vá: -ám. 7. I09.4.

ā d y à : -àm. 8. 2. I9. (cf. anādyá.)

ādyá: -yāís. r9. 22. I. $\overline{\mathbf{a}} \mathbf{d} \mathbf{h}$ arș a in durădhárșa. āodhārá: -ás. r2. 3.48. ā०dhí: -is. 5. 17. 3*. âdhi $\circ$ patya: -am. 18. 4. 54. I9. ă dh h̀: :-dhiâ. 6. I32. I-5. ädhias. 6. I3I. I.

(cf. vyàdhī, ādhíparna.)

ā dhî $\circ$ parn a : -ṇām. 3.25. 2.

āodhṛ́ṣ: -șe. $\quad$ 6. $33.2^{2} \quad$ (mss. ed. ādhṛșe).

(cf. ánādhrṣ.)

ā dhṛṣa in anādhṛșyá.

à dhe ya in agnyādhéya.

ādhrá: -ás. 3. 16.2*.

ā $\mathbf{n}$ a in apāná, udāna, prāṇá, vyāná, samāná.

āon andá: -ás. 9. 7.23.

ānandăs. I I. 7.26;8.24.

ănandấn. I 0. 2. 9 .

à on andín: -ínim. 4. 38. 4 .

ānandínis. 4. 15. 16. āna a in upānasá.

ānuşák. 4.32. r".

āntrá: -ám. I0. 9. 16.

āntrăni. 9.7.16;8.17. II. 3.10. āntrébhyas. 2. $33.4^{\circ}$. 10.10 .21 āntrés̨u. I. 3.6.

(cf. ánvāntrya.)

$\checkmark$ āp: āpnóti. 9. 5.22;6.612.

āpnoti. 4. I1.9. 9.2.24. 10.2 . 2O, 2 I; 9. IO.

āpnuhí. 2. I 6 I-5.

āpnotu. 4. 38.3.

āpnot. 3. 13.2

āpús. 4. 35. 4 .

àpus. 9. 2. 19. I7. 12

ipsan. 9. 5 I 2 .

(cf. ápas, apás, āpí, ánāpta, āpti.) + a ti: cf. átyāpti.

+ pra: prāpnóṣi (p. -a॰āp-). 4. I9. 2. prấ "pnoti. 4. 9.5.

pră "pam. I2. 3. 45 .

prâa "pat. I. 3O. I. II. I.22. 14. 2. $69^{4}$. I7. 29. I9. 20.4 .

prà "pan. I7. 28.

prấ 'peyam (p. prá áp-). 3. 20.9. prăptas (p. praoâp-). 9. 7. 22.

prépsan (p. praolip-). 10. $7.4^{2}$.

prépsantī (p. -īíti praoì-). I0. 7.6. prépsantīs (p. -a०1̀-). I0. $7.4,6,37$. (cf. prăpti.)

+ vi: ví āpa. 8. 9.20. I2. 3.5.

ví āpitha. 13. 2. 30.

vioâpitha. I7. 13 (mss. vioāpitha, -thá).

ví āpus. I2. 3. 28.

vyàptas. 20. I 3 I. 20 (not mss.). (cf. vyà̀ti.)

+ s a m: sám āpnoti. 9. 5. I4. Io. 9. 6 . I3. 2.15 .

samoấpa. I2. 3. 45 .

samoāpiàs. Ir. 3. I9.

(cf. sámāpti.)

à $p$, see áp.

āpa hoçíkșant: -ntis. I2. 3.27. āpāka in

a pākeosthă (or -sthá): -ầs. 8. 6. I4.

à pí: -pés. 4. 32. 6".

(cf. āpitvá.) 
āpiotvá: -ám. 10. 8.5 . āpta in ánāpta. ā pti in átyāpti, prấpti, vyàpti, sámà pty á: -tiám. 5. 2. $7^{*}$ (mss. ed. -tám). āptié. I9. 56.4 .

āptiănām. 5.2. 7".

āpy a in udāpyà.

āprî: -ríyas. II. 7. I9.

ā॰bád h: -dhe. 5. 28. I1.

àbayu: -yo (p. -oíti). 6. I6. I. ábayo (do.). 6. I6, I. (cf. anābayu.)

ā b arh a in muṣkābarhá. à。bhaga: -am. 4.23.3. ābhtuka: -am. 6. 29.3. ă obhūti: -tiā. 4. 31.6*. āmá: -ám. 8.6.23.

āmé. 4. I7. $4^{2}$. 5.29.6; 3I. I ${ }^{2}$. (cf. āmapātrá, āmăd.)

ā ma in vyāmá, samāmá.

ã $m$ an a in anāmaná.

ầm an a s: -sam. 2. 36.6 .

āomántraṇa: -am. 8. I0. 7 . āmántraṇe. 8. 10.7.

(cf. ãmantraṇîya.)

à $\circ$ mantraṇiya: -as. 8. 10.7. āma $\circ \mathrm{p} \bar{t}$ trá: -ám. 8. Io. $2 \hat{\text {. }}$

āmaya in anāmayá, pṛștyāmayá, çīrșāmayá, hṛdayāmayá.

ām a y itnu in anāmayitnú. [10.8.

āmă d (p. ãma॰á-): -das. 8. 3. $7^{*}$. II.

āmíkṣā: 9.4.4.

āmíkșām. I0. 9. I3-24.

āmitrá: -ás. 4. 2 I. $3^{*}$.

āmitrí. 5. 20.5. I I. IO. 25.

āmuṣ y ãy aṇá: -ṇa. 4. 16.9. [1-27. āmușyāyạám. I0. 5.44. I6. 8 . āmuṣyāyaṇásya. I 0. 5.36. āmuşyāyaṇé. I6. 7.8.

à y a in atyāyá, prāyá.

ā॰yátana: -am. I5. I2. 7, II. (cf. anāyataná.)

āy ád ○vasu: -us. I3. 4.54.

ăyana (p. āoáy-): -nena. 6. I22.2. áyane. 6. I06. $I^{*}$.

ăy ant in āyádvasu.

ā॰yávana: -am. 9.6.17. Ir. 3 . I6. I2. $3 \cdot 36$. äyávanena. 20. I3I.II. [sīs). á y a sa : -sīs. 19. $58.4^{*}$ (mss. mầ 'ya(cf. svāyasá.)

ā y in in paryāyín.

ā y ú: -yós. 5. 1. 6*. 18. 3. $23^{*}$.

(cf. dīrghāyutvá.)

ā॰yúj: -jas. II. 8.25. [II. 9. I.

台y udha: -am. 6. I33.2. I0. I0. I8.

âyudhāni. 5.20.8. 8.8.20.

âyudhā. 3.19.5. 4. 3I. I* 5. 2. $5^{*}$. (cf. iṣvāyudhá, ugrăyudha, tigmăyudha, yajñāyudhá.)

ā y u rdá d (p. -uḥıd-): -dam. 6. 52.3. ā y urdấ (p. -uḥod-): -ấs. 2. I3. I.

à y uṣa in tryāyușá.

[9.8.

ā y uṣ k ̣̂́t (p. -uḥok-): áyuşkṛt. 5 . ãyuṣkị̂tām. 3. 31.8. I9. 27.8 .

ā y uṣpatnì : áyuṣpatnī (p. -nī íty ăyuḥop-). 5. 9.8.

ā y uṣpratára ̣̣a (p. -uḥ॰pr-): -as. 4. 10. 4 (m. mss. āyuhpro-).

á y ușmant: -mān. 8. 5. I9, 21 . Io. 3. IO, I2. I7. I. I8. 2. 45 . I9. 26. $2 ; 27.8$.

ayușmat. 6. 98.2.

àyuṣmatas. 8.2.13.

áyușmantas. 6. 47. 1, 2. 7. 6I. I, 2. àyuşmatām. 3.31.8.

áyușmatī. I 4. I. 45 (p. mss. -tī, -ti). áyuṣmatīm. 3. 10. 3,8 .

āyu şy à: -àm. 2. 29. I (s. mss. -úșyam). I9. 26.4 (1. -şíam).

àyus: $\quad$ I. $30.3 ; 35.2$. 2. 13.2, 4 ; I 7. $4^{2} ;$ 29. 2 . 4. 39. 2, 4, 6, 8. 5. 9 . 8. 6. 4I. $3 ; 78.3 .7 .32 . \mathrm{I} ; 33 . \mathrm{I}$; 53. 3,$6 ; 8$ I. $2^{*} ; 82.2 ;$ IO3. I. 8. I. $3,2 \mathrm{O}^{*} ; 2 . \mathrm{I}, 2,7$, II, I 7 ; $4 . \mathrm{I}^{*}$. 9. 4 . 22. I0. $2.15 ; 5.36$. II. I. $34 ; 4$. 6. I2. I. 22,$62 ; 2.24^{2 *}, 30^{*}, 45 ; 4$. 28 ; 5. 9 . I3. 2.37. I4. I. $22^{*}, 47$; 2. $36^{*}, 39,64,75$. I6. 8. I-27. I 8 . 2. $3^{*}, 10^{*}, 23,29,46,55^{*} ; 3$. I 7 (m.mss. āyuh); $4.48,53,62$. I9. $32.3 ; 55$. $6 ; 56.5 ; 61.1 ; 63.1 ; 64.4 ; 69.1-4$; 70. I; 7I. I. 20. 48.3 .

ăyușā. 3. 5.3; 3I. I-II, IO 2 . 7 . 89. $2^{*}$ I2. $2.32,55$. I3. I. I7, I8, I9. I4. $2.2^{*}$. I9. $27.8 ; 33.1$. 
áyuşe. I. 35.1 2. 28.5. 4. 10.7. 5. 28.6, 13. 6. 63. 1; 76.2,4. I8. 2. 23 . I 9. 24. 2,$3 ; 26.3 ; 32.1 ; 40$. $3 ; 45.6-10 ; 46.1$.

âyuşas. 10. 3.16 .19 .44 .1 ; 58.1 . âyūṇṣi. 2. 4.6. 4. 10.6. 5.28.7. 6. 78.3 . 7. 14.4 . 12. $2.13,25^{*}$, 14. 2. 67. 19. 34.4 .

(cf. kṣitấyus, tryāyuşá, dirghăyus, viçvấyus, çatăyus, sahásrāyus, āyurdád-āyuşyà.)

ā r a in udārá.

ārá: -răt. I. I9. I. 2. 3.6. 6. 30. 2 ; 32. I. 7.92. I*. 8. I.12; 2.9, I2. 9. 10. $25^{*}$. IO. I. I, 2. I 9. 3I. II ; 56.6 .

āré. I. $26 . I^{2}$. 6. $45.2^{*}$. $\quad$ ro. 4.26. (cf. ārâttāt, āréçatru.)

āra ṇyá: -yấs. 5. 21. 4. 6. 50. 3. II. 2. $24 ; 5.21 ; 6.8$. I2. 1. 49. I9. 6. $14^{\dagger}$. āraṇyāís. 3.31.3.

ārăttāt. I9. 8.4 (not mss.).

$\bar{a} \mathbf{r} u \mathbf{j}$ in çaphārúj.

à $\circ \mathbf{r} \mathbf{h}$ : -has. I3. I. 9 .

āré ॰çatru: -um. 7. 8. I.

āoréh a ṇa: -am. 6. 9.3.

āoróhạ̣a: -am. 5. 30. 7 .

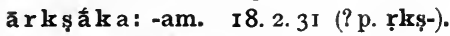

ārtavá: -vắs. 5.28.2. ro. 6. I 8 ; 7.5. I1. 3. I7;7. 20. I5. 6.6 ; 17.6 . ärtavấn. 3. 10. 9. II. 6. I7. ārtavāís. 5. 28. 13 .

ārtavébhias. 3. 10. 10. ārtavănām. I5. 6.6. I6. 8. I9.

ărti: -is. 8. 8.9. I0. 2. 10.

ârtim. I2. 2. 38 .

àrtiā. 3. 3I. 2.

ấrtni: -ñ (p. -ííty etc.). I. I. 3 .

ârtvijya: -yena. II. 3. I4.

ārtvyá: -ás. 8. I0. 22.

ārdrá: -ám. I. 32.3 .

ārdră. I9. 7.2.

(cf. ārdrádānu-ārdráhasta.)

ārdrá。dānu: -us. I6. 3.4.

ārdrá opavi: -is. I6. 3.4.

ārdráopavitra: -as. 9.6.27.

ārdráohasta: -tā. 12. 3. I3.

ărya: -rias. 4. 20.4. 5. 11.3 . âriam. 4. 20.8; 32. I"

âriāya. 19. 32.8.

ărie. 19.62. 1 .

âriās. I8, 1.2 $1^{\circ}$.

ārçá: -ám. 4. 4. 5 .

ārşeyá: -yấs. II. I. I $6,25,32$.

ärseyătn. I I. I. 26, 35 .

ārşeyébhyas. 12. 4.2, I2.

ārseyănăm. 16. 8. 10.

ārşeyéşu. I I. I. 33.

(cf. ánārşeya.)

Vāl: +nis: nír āla. 6. 16. 3 (?).

(cf. vyāla.)

à la in vyāla (?).

āolāpá: -pầs. II. 8.25.

à。liga: -gĩ. 5. 12.7 .

$\bar{a} \circ \mathbf{v a ́} t$ : -tas. 5. 30. $1^{3}$.

à vápana: -nī. I2. I.6I.

ā०vapantikă: 14.2.63.

ā०va yá: -ám. 8. 6.26.

à várta na: -am. 6. 77. 2*.

(cf. vyãvártana.)

ã。va sathá: -thắn. 9.6.7.

āvís. 4. 20.5. 6. 123.2. 7. I08. I.

8. 3. $24^{*}$. 10. 8.6. 12. 1. $60 ; 4.29,30$. ā $\mathbf{r} \mathbf{j}$ in svấvṛj.

$\bar{a} \circ \mathbf{v}$ ṛt: -tam. I0. $5 \cdot 37^{2}$.

ãvị́tas. 6. $77 \cdot 3$. 10. 7.4 .

(cf. upāvŕ̛t.)

ãvṛtta in ánāvṛtta.

ăv yādha in anāvyādhá.

āov yuşá: -ám. 4. 5.7.

ā vraska in anāvraská.

à०çarīka: -am. r9. 34. I0.

āoçás: -sā. 7.57. I. [I 4. 1. 28*.

āoçás an a: -am. 5. 19.5. 12.5 .39$.

à ç ā: âçāmoāçām. 4. I 5. 8. 12. I. 43, 54 .

âçās. 5.7.9. 6. 62.2. 7.9.2*. 9 .

2. 2 I. I0. $5.29 ; 8.36$. I I. 6.6 . I9.

I $5.6 ; 52.3$.

ăçābhyas. ro. 5.29.

àçānām. I. 31. I, 2, 3.

(cf. āçāpālá, âçāsameçita.)

āoçằ: -ầm. 6. 119.3. I9. 4. 2.

āçā॰pālá: -ás. I. 3 I. 3 .

āçāpālàs. I. 3I. 2.

āçāpālébhyas. I. 3I. I.

ā çā rāișín (p. -raoeṣ-): -ștí. 4. 15.6. 


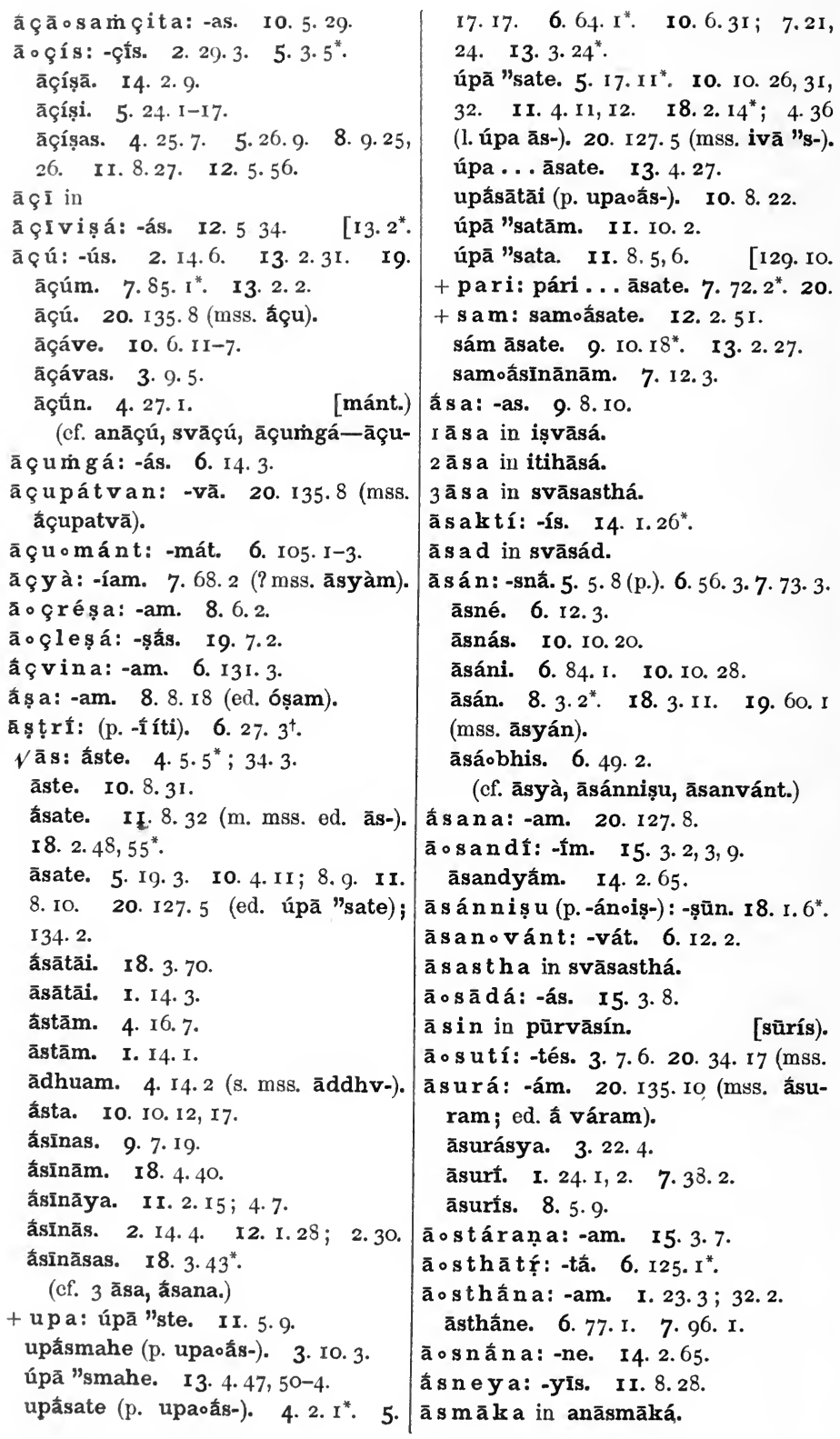


1 ā s y à : -síās. I. I 9. 2.

2 às y à : -síam. 6. $56.3 ; 139.2,4$. 7 . 68.2 (mss.); 70. 4, 5. I0. 7. 33 .

āsíena. 7. 56.8 .

āsíāy a. I I. 2.6.

ăsyè. 7. 56.8 .

āsíāni. 4. 39. 10 (p. âsyāni). (cf. dáçāsya, dvyà̀sy a, mahăsya, lóhitāsya, çúş̧āssya, āsyatás.)

ās yatás. 6. 76.2. 9.8.3.

āosrāvá: -ám. I. 2.4 .

āsrāvásya. 2. 3. 3-5.

(cf. anāsrāvá, āsrāvabheșajá.)

āsrāva。bheşajá: -ám. 6. 44. 2.

āohánana: -am. I2. 5.39.

āhánane. I2. 5.47.

āhánanābhyām. 20. 133. I (mss. āhananābhyấm).

āh a nás: āhanas. I 8 . I. $7^{*}, 9^{*}$.

āhanásam. 4. 30.6".

ā。h a vá: -véșu. I8. I. $48^{*}$.

$\bar{a} \mathbf{h}$ ava $\mathbf{a}$ in

āohavanty a: -as. 9.6. 30. I 5. 6. 5 . āhavaníyasya. I5.6. 5 .

āhavanitye. 8. ro. 3 .

ā hā (?) in durâhā, svâhā.

ā。h ā ry à: -àm. 9. 1. 23.

āhāryàni. 9. 6. I8.

āhuta in ghṛtăhuta, bráhmāhuta. à०huti: -is. Io. 5.43. II. IO. 5, I5. I5. I7. 10.

âhutim. 6. 83.4. 7.70. I. Io. 8. 35. I I. IO. I4, 26. I 5. I4. 4. I9. 4. I. áhutyā. I I. IO. I2 (-tiā). I5. I4.4. áhutes. 3.22. 4

âhutiās. I2. I. I3. (cf. āhutīvŕdh.)

[32. $\mathrm{I}^{*}$.

āhutivvŕdh (p. -tiov-): -dham. 7 .

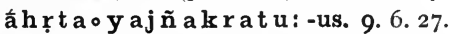
āhrutabheșajá: -jís. I9. 2. 5 (mss. àdu-, âhu-; p. át utá bh-).

āh v a in paruṣāhvá.

i (pron. root): ayám. I. $7.4 ; 8.2$; IO. 1,$2 ; 22.2$ 2. $4.3^{3}, 6 ; 9.2,3$; 28. I; 29. 2,$3 ; \quad 36.7 .3 .2 .2 ; 4$. $5^{2}, 6 ; 5.1 ; 8.3$ I0. 8 ; I3. 7 ; 4 .
$6 ; 20.1^{*} \cdot 4 \cdot 5 \cdot 6^{*} ; 13.4^{*}, 6^{* *} ; 22.2$, $3^{2}, 4 ; 32.6^{*} ; 38.7^{2}$. 5. 9. 7 ; 22. 2 ; $26.12 ; 27.4 ; 28.9 ; 20.6-1), 12,13$; 30. $11,17.6 .5 .3 ; 16.3 ; 20.3 ; 31$. $I^{*} ; 43 . I^{2}, 2 ; 44.1 ; 60.1 ; 65.1,3$; 72. $1 ; 74.1 ; 78.1 ; 70.1 ; 81.1 ; 85$. I ; 86. I; 87. $3^{\dagger} ; 88 . I^{*} ; 102.1$; I II. I; II2. I; I2O.I; I2I. 2 ; I3O.I; I34. I. 7. 22.1 ; 30. I; 33. I; 53. 5,$6 ; 56.4 ;$ 62. I ; 73.4. 8. I. I, I $8^{2} ; 2.5,8 ; \quad$ 5. I, 2, 4, I6 ; $8.8, \mathbf{I} 7$ 9. $4.2 \mathrm{I}^{2} ; \quad$ 10. $7^{*}, 14^{3 *}$. 1 O. I. $8, \mathrm{I} 5$ 3. I, $3,4^{3}, 6,8$, IO, II; 4 I5; 6. 2 , $4,22-8,3 I^{2}, 32$. II. I $2 *, 15 ; 2$. I I ; IO. 5. I2. 2. $8^{*}, 43$; 3. I4. I 3 I. $16^{3} ;$ 3. 15 . I4. I. 33 . 15. 10.7 15. 3,$6 ; 18.3^{2}$. I7. $24^{*}$. 18. 1. $4^{8^{* \prime}}$ 3. $4, I_{4}, I_{5}, 53^{\dagger} ;$ 4. I5, 37. I9. 27.10 ; 31. IO, I4; 32. 9, 10; 33. I; 34. 4 ; 36. $5 ; 39.2-4 ; 54.5$ (mss. kāleyám) 20. I29. II (not mss.); 136. Io (ed vayám).

idám. I. $7 \cdot 3,5 ; 8.1^{2} ;$ I6. $3^{2} ; 23$. I ; $24.2^{2}, 3,4 ; 29.5^{\dagger} ; 30.2 ; 31.1$; 32. I. 2. I. I; $3.3,5 ; 12.2^{2}, 3^{2} ; 13$ 3 ; 26.5 ; 30. $1 ; 36.7$. 3. $4.5 ; 8.2$; 13. $7^{2} ; 15.4 ; \quad 19.1 ; 23.1 ; 24.4$ 29. 7,$8 ; 31.5^{*}$. 4. $4.2 ; 5.5^{*} ; 6.8$; 7. I, $2 ; 8.1 ; 9.7 ;$ I2. I; I6. I, $4 ; 23$ $7 ; 26.7 ; 27.6 ; 28.1 ; 30.3^{*} ; 36.8$; 38. 3. 5. 8.2; I $2.8^{*} ; 26.12 ; 27.9$ I $; 28.6 ; 29.1$. 6. I3. 2,$3 ; 27.1^{*}$ 29. $2,3^{2} ; 33.1 ; 44.1 ; 47.3 ; 51.3^{*}$ 53. I; 54. I; 57. $\mathrm{I}^{2} ; 68.3 ; 77 . \mathrm{I}$ 83. 4 ; 88. I* ; 89. I; 90. I ; 94. 3 ; 97. I ; IOO. 2 ; IO4. 2 ; IO6. $2^{*} ;$ II 6 3 ; II7. I, 2 ; 122. 5 ; I 28. 1; I 3I. $2^{2}$; I36. 3. 7. I. 2 ; I. I. I I. 4 ; 18. I 20.6; 25. $2 ; 26.4^{*} ; 35.1 ; 33.1$; $58.2^{*} ; 64.1,2 ; 68.2^{2} ; 74.2 ; 75.2$ 77. I*; 89. 3 ; IOg. I, $5^{2}$. 8. 2. 25

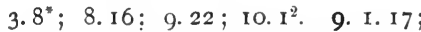
2,$8 ; 3.5 ; 5.20,23$ (idámoidam), 24 (do.), $38 ; 6.18,18$ (idấ3m); 10 I5. IO. I. $9 ; 2.22,23,24,25 ; 4$ $7^{2}$, I0; 5. I5-21, $36^{2} ; 6.13 ; 7.35$; $8.2,5,6 ; 9.27 ; 10 . \mathbf{I}, 26,34$. I I I. II, $27^{2}, 28^{2} ; \quad$ 2. $10^{2}, 30 ; 3.24$; 
4. I, 8, I8; 5. I4; 6.5, 9, II, I9, $20 ; 8.16,32$. I2. I. $3.53 ;$ 2. I ; $3.44,45 ; 5.5$ O. I3. I. $I^{2}, 20,23,54$, $55^{2} ; 2.44,45 ; 3.15 ; 4.12,20$. I4. I. $38,45,46^{*}, 56 ; 2.9$, I9, $46^{*}, 74$. I6. I. $4 ; 7.8 ; 8.1-27^{2}$. I8. I. $46^{*}, 52^{\dagger}$, $53^{*} ; 2.2^{*}, 50,5 \mathrm{I} ; 3 \cdot 2^{*}, 7^{*}, 64 ; 4 \cdot 35$, $37,4+, 51,52,56$. I9. $6.4^{*} ; 9 . \mathbf{I}, 4$; II. $4^{*}, 6^{*} ; 14.1 ; 24.6 ; 27.11-3 ; 37$. I ; 42.3 (mss. imám); 44. 7, 8; 48. $3^{2} ; 50.6 ; 52.5 ; 56.2,4$ (ed. tám). 20. I27. I; I3I. I3; $135.9^{3}$.

iyám. I. 34 . I. 2. 8. $2 ; 25.2 ; 30$. $5 ; 36.3,4$ 3. 10.4. 4. 1. $2 ; 4.3$; I6. $3 ; 37.6 ; 38.6$. 5. $25.2 ; 26.6$; 3о. 16. 6. I7. I-4; 60. 2 ; Iog. I. 7 . $3^{8.5} 5 ; 56.1,2 ; 73.8^{*}$. 8. $4.6^{*}$; Iо. I. 9. 9. $2.15 ; 4.8 ; 5.20 ; 6.17 ;$ I0. I $2^{*}, I_{4}^{*}$. I0. $2.24 ; 5.43 ; 8.26$. II. I. I, 6,8 , II；3. II； $5.4 ; 9.4$; 10. 4 , 6. 12. $2.27 ; 3.9$, II ; 4.42 (iyă 3m). I4. I. $18^{*}, 52 ; 2$. I $3, I_{4}, 20,28^{*}, 60,63$, 74. I5. I0.6; I7. I. I8. 3. I; 4. 50. 19. 9. 3. 20. 130. $17^{2}$ (mss. iyánn), I 8 (do.).

(cf. ítara, itás, íti, itthám, itthă, íd, idā, ima, iyant, iva, ihá, ī, evá, evám.)

$\checkmark$ i: émi. I9. 4.2 (mss. emi). emi. 4. 28.3 (p. nemi). 5. 1. 7. éși. I3. 2. 5 .

eși. 4. I9.2. 6. 98.3. 7. $81.2^{\dagger}$. I3. 2. 12. I7. I7.

éti. 4. 24. I. 9. 4. II; 8. 7. II. 2. 22. I2. 3. 48 . I9. 8. I.

eti. I. I2. I. 4. I9. 6. 5. I7.9, I4. 6. 20. I. 8. 5.2 ; 9.9. 9. 9. $14^{*}$; I0. I6" $23^{*}$. II. 5. $6^{2}$. I 3. 4 . I, $2,8,9$. I4. I. $7^{*}$. I8. 4. I $3, \mathrm{I} 5,37$.

yánti. I. I7. I. 4. 3. I. 5.21.8. 6. 7. I; 98.3. 7. 40. 1. 8. 6. I4; 10. $3,5,6,7$. $10.2 .6 ; 7.5 ; 9.4$. 2 . $2.25^{*} ; 3.25$. I3. I. $35 ; 3.17$. I4. I. $34^{*}$; 2. $10^{*}$. I $8.4 .2,3,7$.

yanti. I. $4 . I^{*}$. 2. I. $3^{*}$. 8. 2.24 ; 8. I2. 9. 5.29. I0. 7.5. I3. I. I3. ayas. 7. $97 . \mathrm{I}^{\dagger}$.

áyās. 2. 12. 7 ( $\sqrt{ }$ yā?). áyati. I3. I. 58 . I9. 49. IO.

ayat. 4. 3.6.

áyāt. I2. 5.64.

ayan. I8. 3. $2 \mathrm{I}^{*}$.

ihi. 2. 25.4 . I0. I. 28 . I2. 3. I.

étu. 6. $75 \cdot 3$.

etu. I. $27.2,4 . \quad$ 2. $7.5 ; 34$. I. 3 I. 6 4. I. $2 ; 3.2,5 ;$ 15.6. 5. 14 I3; 22. 4. 7. IOS. I. 8. 3. II*, $14^{*}$; 4. IO"; 7. I 5. IO. I. I, 2, I9; 4. 25. II. I. I7. I2. I. 40. I8. $3.72 ; 4.57$. ita. $7 \cdot 97 \cdot 7.8 .7 .16$.

eta. II. I. I8.

yántu. 8. 4. $5^{*}$.

yantu. 2. 24. I-8. 3. Ig.6. 4. I4. $5 ; 37.3 .5 \cdot 3 \cdot 2^{*} ; 20.3,7.8 .3 \cdot 14^{*}$; 8. $13^{2}$. 9. 2. 4 . IO. 3.9. II. 2. II ; 9. 19. I2. 3. 49. 13. 1. 32. I9. 13.9*. yán. I8. I. $29^{*}$.

yántam. 6. 122.4. I8. 2.9.

yatás. I8. 4.56.

yántas. 4. 14.4. 5.7.4.

yati. 6. 60. 2.

yatís. 2. $5.3^{\dagger}$. 3. 13.2. 5. 21.9 . 6. 85.3 .

yatis. I4. I. $32 ; 2.52$ (ed. yatís).

ấs. I0. IO. I0.

āít. ro. 8.39.

āítam. I 8. 3. $38^{*}$ (mss. ed. āitám). āitām. I4. I. IIt.

áyan. 3. 22. 3 (mss. āyan், p. āyam). 5. 28.8. I 8. I. $3 \mathrm{I}^{\dagger}$.

āyan. 4. I4. I (p. āyam). 10. 8. $3^{\dagger}$. imahe. 4. 23. I. 6. $36 . \mathrm{I}$. I8. $4.6 \mathrm{I}^{\dagger}$. iyase. 4. $13.3^{*}$

iyase. 5. 6. $4^{*}$.

íyate. 12. 1. 5 I.

iyate. 4. 34.4 . I9. $53.2 ; 54.6$.

Iyante. I I. 8.26.

íyamānas. I5. I. I.

iyamãnam. II. 2. I7.

iyátha. 8. I. IO.

iyāya. 10. 7. 31 .

Iyús. I8. I. $44^{*}, 46^{*} ; 2.55^{\dagger}$.

iyus. 9.9. $8^{*}$.

étave. 6.23.2.

(cf. /ich, /inv, áya, āya, áya na, ãyana, āyin, āyú, ãyus, ita, 
iti, itvan, ina, inva, etŗ, étu, eșyant, yant.)

+ ach a: ácha...eti. 5. 27.4.

ácha... yantu. 3.4.3.

+ ati: atioéşi. r3. 1. 57 (l. aty).

áti eși. 18. 1. $39^{\dagger}$. 19.33.3.

áty eti. 10.8.16.

áti ... eti. I2. 2. 1 I.

áti yanti. I8. 3. 17.

áti ... ayāma. 12. 3. 18 .

áti... ihi. 7. 117. $\mathrm{I}^{*}$. 10. I. 16.

áti ...etu. 6. $75 \cdot 3^{2}$.

átī 'tām. r4. 2. II".

(cf. atyāyá.)

[14. I. 30.

+ adhi: adhioéti (l. adhy). 7.60.3. ádhi .... ihi. 5.30.6.

ádhi 'tam. 6. 118.3 .

(cf. ádhīti.)

+ an u: ánu emi. Ir. 9.4.

ánu eși. 12. 2.49. 17. 16.

ánv eti. ro. 2. 19.

ánv etu. 6. 89.2. r9. 4. 4 .

ánu yantu. 3. $17.5^{\dagger}$.

ánv āyan. II. 5.2.

ánu āitat. r8. 3.40 (s. mss. āitát).

+ a pa: ápa ... yanti. 13. 2. $17^{*}$.

apấyati. 19. 50.6 (mss. anuopāyási).

ápā 'yati. 4.3.5. 6.6.2; 20. I.

ro. I. I3. I9. 49.10², Io (p. suoáp-), Io (mss. apaoáyatas).

apấyātāi (p. apaoáy-). 7. 90. 3 .

ápe 'hi. 5.7.7. 6. I6. 3; 45. I.

7. 88. I.

ápāi 'tu. ro. I. Iо.

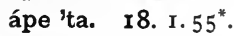

ápe 'tana. 6. 83.2.

+ abhy apa: abhyápehi (p. abhi。 áp-). 7. 88. I.

+ a pi : ápy eti. 5. 18. 13. 10. 10. 6. ápi yanti. 4. 34. 2.

ápī'hi. 18. 2. $\mathrm{II}^{\dagger}$.

ápi etu. 2. 34. 2.

ápi 'tam. 12. 3.44.

ápi 'tana. I0. 5. 23.

+ abhi: abhioéti. r. 25.4 (1. abhy). 7. I 6.2 (do.). 9. I. 8.

abhí eti. 8. 9.9. I3. 2. $27^{*} ; 3.25^{*}$. abhí ... eti. 8. 9.21. I3. 2.43 . abhioyánti. 10. $7 \cdot 4,6$.

abhí... yanti. 5. 4.2.

abhì 'hi. 4. 32. 3 ".

abhí etu. 5.13.4 (1. abhy). 7. I16.

2. I3. I. 10.

abhí... etu. 8. 4.21'.

abhioyántāu. 5. 1. 5 .

abhi॰yánti. 7.46.3.

abhioấyata (l. abhy). 4. 24.6.

+ ava: ávāi 'tu. I. I1.4.

ávā 'yantām. r I. 10.8.

(cf. avāya.)

[6. 53.

+ upāva: upăvāiti (p. upa॰áv-). 9.

+ ã: āí 'mi. 7. 60. r.

- â...emi. 6. 5 I. $2^{*}$.

ãíti (p. āoé-). 3. 2.6. 9. I. 2.

āí 'ti. I3. 2. 25.

etás (p. āoit-). 6. 29. 2.

emási (p. ā॰im-). ro. 4.6.

é 'masi. ro. 4.6 .

ā॰yánti. 6. 66. I; 103.3. I2. 4 II. ầ yanti. 12. 3.26. 20. 130. 15 .

á... yánti. 2. 2.3.

â... yanti. 8. 9.6.

é 'hi. I. I. 2 . 2. 5.4 ; 13.4. 3. 4 . 5. 4. 9. I; $15.1 \mathrm{I}^{*} ; 32.5^{*}, 6^{*} ; 38.6$. 5. 4. I； 5.5,9; 30.7. 6.68. I. 8 .

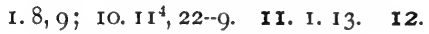
2. I. I3. I. 2O. I8. $2.21,60 ; 3.2^{*}$, $58^{*}$. 19. 3. I, 2.

āí 'tu. I. I5.2. 3. I5. I. 4. 15.6; $38.3,5$. 5. 30. $13^{3}$. 6. 38 . I-4; 53 . 2". 7.67. 1. 9. 4. 7. 10. 4. 22. 12. 3 . I 7. I 8. 3.62. I9. 39. I (p. āítu); 52. 4 .

[79. 2.

á... etu. 3. 23.2. 5. 12. $8^{*}$. 6 .

é 'tam. r8. 4.49 .

à ... itām. 7.53.3.

é 'ta. 3. $8.6^{2}$; 13. 7 ; 30.5. 7. 75 . 2. Ix. 6. 18. I2. 2. $30^{\dagger}$. 18.4 .37$. é 'tana. 3. 14. 4. 5.8.3.

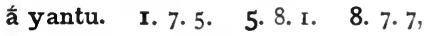
I0. 9. 2.7. x2. 3.20.

ă ... yantu. 2. 26. I ; 35.5. 5. I1.9. á 'yasi. 6. I3I. 3 (p. à॰áy-). á... áyas. I9. 50.6 (?). áyati (p. āoáy-). 4. 3.5. 6. 60.2 ; 75. 2, 3. I9. 49.9 . 
á 'yat. 6. II 8. 2 .

à 'ya. I9. 8.3 (p. ắya or à ?).

ā॰yán. 6. 81.2*.

ā॰yántam. 7.13. 2.

ā॰yát. I2. 3. 49 .

ā॰yaté. II. $2.15 ; 4.7$.

ā॰yatás. 6. 82. I. 7.38. I.

ã॰yatás (acc. pl.). 7. 60. 2, 3 .

āoyatím. 13. 2. $46^{*}$.

ā॰yatís. 6. I09. 2. I9. 58.3 .

āís. 5. 22. I I (p. à éḥ).

eyátha (p. ā॰iy-). Io. I. $24,28$.

āí 'șyāmi. 7.60.7.

étia (p. āoítya). I. 7.4. I0. 6.5. I9. (cf. àyana.)

+ a chā: achaoấyanti. 12. 4. I4, 15 .

+ a tyă: atyấyanti (p. atioấy-). II. ro. I4.

atyăyantu (p. -i॰ă-). I I. IO. I5.

+ abhyā: abhi॰āími. 6. II8. 3 .

abhioéhi. 8 2. 2.

+ udā: utoéhi. 5. 30. II. II. I. 2 I. I3. I. I (1. udă-ihi ?).

udoéta. II. 6. I8.

udoāyaté. I7. 22.

udoétia. I2. 4. 4I.

+ abhyudã: abhyudétya (p. abhio ud-). I5. II. 2 ; I2. 2 [6.53.

+ upodã: upodáíti (p. upaoud-). 9.

+ upā: upāími (p. upaoāí-). 6. II8. 3 . upáyasi (p. upaoây-). $\quad$ I. 34. 2. 3 . 25.5. 6. $9.2 ; 42.3 ; 43.3$. upāítu (p. upaoāí-). 7. 66. I. upétana (p. upaoét-). 3. 14. 3. upāyatî́m (p. upaoāy-). 3. 10. 2. upeyimá (p. upa॰ey-). IO. I. IO.

+ nir ā: nirāítu (p. nị̣॰aí-). Io. 4 . 21, 22.

+ prā: prāyán (p. pra॰āyán). 4. 25. 2 (prāyám ?).

+ s a mā: sam॰āíti. 6. IO2. I.

samoétas. II. 5. II.

samoấyān. I2. 3. 40.

sam॰āítu. 3. 22. 5. 6. IO2. I. 7 samoétam. I2. 3.3.

samoéta. 7.21. I. I4. 2. $28^{*}$.

samoeyáthus. 12. 3. I.

samoétya. I I. 6. I8 (1. -tia). I2. 3. 4 .
+ ud: úd eși. I 3. $2.20^{*}$.

udoéti. I0. 8. I6. I3. 4.7.

úd eti. I9. 54. I.

út... eti. 5. 23. $6^{*}$. 6. 52. I.

út ... yanti. 8. 9. 6 .

udoáyat. 8. 4. $3^{*}$.

úd ihi. 3. 4. 1. 17. $6^{2}, 7^{2}$.

úd etu. 5. I3. 3 ; 30. II. 6. 76. I.

19. 10. $8^{*}$.

út ... etu. 3. I9.6. 8. 2.8.

úd āitām. 8. 9. I.

ud॰ấyan. II. I. 37 .

udoyán. 2. 32.1. 7. 13.1, 2. 9. 2.

I $5 ; 5.35 ; 6.46 ; 8.22$. I2. I. I5.

13. 1. 32 ; 2. 10, 28, 34; 3.13. I7.

30. I9. 28.4 .

ud॰yántam. 6. 76.2. 9. 35.5.

udoyaté. I7. 22.

udyatímoudyatīm. 9. 5. 35 .

údoayatām. I. 22. I.

údoitāya. I7. 22.

údoite. $4 \cdot 25 \cdot 3$.

udoítya. 18. 2.47 .

(cf. udáyana, úditi.) [50. 2.
[5

+ a pod: apódita (p. apaoúd-). 6.

+ abhyud: abhioúdihi. 3. 20. 10.

I7. 6,7 .

[7. 3. I.

+ praty u d: pratyúdāit (p. -tioúd-).

+ upa: úpāi 'ti. 9. 6.4.

úpa yanti. 4. 2I. $4^{*}$.

upáyati (p. upaoáy-). I9. 49. 10.

úpa yantu. 4.34.5-7. 6. 32.3. 8.

8. 2 I. 9. 5. I5.

(cf. upăyana.)

+ ni: ní eti. 12. 4. 20, 2 I.

ni॰yánti. 6. $49 \cdot 3^{\dagger}$.

ní etu. 6. 29. I.

nìtas (p. níoit-). 3. I1. $2^{*}$.

nítia (p. nioítya). 12. 2. 38 .

(cf, nyáyana, nyăyana.)

+ parā: párā ... yánti. 2. 2.3.

páre 'hi. 3. 2. $5^{*} ;$ 4.6. 5. 22.2. 6.

45. I. I0. I. 7 ; $16,20,24,25,26$. I I.

I. I3. I2. 2. $1,21^{*}$. I4. 2. 34,35 .

párāi 'tu. 6. I40. 3. I8. 3.62.

páre 'ta. 4. 37:3-5.

párã yantu. 8. 5.9.

parāoyaté. I I. 2. I 5; 4. 7. 
parā॰yatás. 7.38.1. [2.47. + anupra: anu॰prémas. 5.7.3.

pareyús (p. -rāoîy-). 2. 26. I. I8. anu॰préyatus. r9. 44. ro (ed.-u pr-). pareyiovấnam. I 8. I. 49*. +u p a pra: upaopráyanti. 12. 4.3I. páretas (p. -rāoit-). 3. II. 2*. 4. + sampra: samoprayatís. 3. I3.I. 32. $5^{*}$. I 8. 2. 26.

páretam (do.). 18. 4. 5I, 52. [4. 44 . páretās (do.). 12. 2. 29. I 8. I. $50^{\dagger}, 54^{\dagger}$; parétia (p. -rāoítya). 5. 22.8. 10. 4. I9. I4. I. 43.

(cf. parăyaṇa, parāparāitŕ.) $\left[29^{\dagger}\right.$. + vi parā: viopáretana. I4. 2. $28^{\dagger}$,

+ pari: páry emi. 6. 8. 3 .

pári eși. 17.15.

paryéti (p.-rioé-). 4. 38.5. 6. 8.3. parioyánti. I. I. I.

pári yanti. 12. 4.52. I5. 17.8.

pári etu. I4. I. 39.

parioyántas. 4. 35.4.

pári ... āyam. 2. I. 4, 5 .

páry āit. I5. I. 5. I9. 53.4.

pári ... āyan. 8. 9. I8 (mss. āyam). (cf. paryāyín, paryāyiká.)

+ a n u pari : anuopáriyanti. I 5. I7. 8.

+ purás: purá etu. I. 2I. I* 7 . 9. 2*. 14. 1. 59. I9. 13. 9*.

(cf. puraetŕ.)

+ pra: prāí'mi. 9. 3. 22. I9. I 7. I-IO. prá ... eti. I $8.4 .60^{\dagger}$.

prá ... yánti. 4. 33. $5^{*}$.

pré 'hi. 3. 2. $5^{*}$. 4.8.2; 12.6; I4. $5 ; 3$ I. $3^{*} ; 32.7^{*}$. 7.8. I. 9.5.8. 10. $4.6 ; 9.3$, I. I I. I0. I8. I8. r. $54^{2 *} ; 3.8,73$.

prāí 'tu. 6. I2I. 3 .

prá... etu. 2. I0. 5. 3. I. $4^{*}$.

pré 'tam. I. 27.4 .

pré 'ta. 3. I. 2 (1. prái-). I 2. 2. 34. pré 'tā (p. -ta). 3. r9. 7 (l. prá i-).

prá yantu. 4. 3I. I*.

prá... yantu. 7. II 4.2.

pra॰yán. 6. 31 . $1^{*}$.

praoyatí. 7.97. $1^{*}$.

praoyatí. I4. I. 12*.

preyăya (p. praoiy-). 18. 3.13.

preyús (p. praoīy-). 5. 8.6.

prāiṣyán (p. pra॰eș-). 5. 22.14.

prétam (p. práoit-). I8. 3. I.

(cf. prãyá, prăyaṇa.)

+prati: práti 'mas. II. 2. 18 .

pratioétu. 3. I. 2.

práti etu. 3. I. I; 2. I (mss. pratioétu).

práty āyan. 20. 135. 62.

pratitia (p. -tioítya). I9. 49.9.

(cf. ápratita.)

+ vi : ví ... eşi. 13. 2. $22^{*}$.

ví... eti. I $8.3 .39^{\dagger}$.

vi॰yánti. 3. 30. 4 .

vì 'ta. I 8. I. $55^{\text {*. }}$

ví... ita. 3. 2. 4 .

ví... yantu. 3. II. 5,7 .

vioyántā. 9. 10. 16 *.

(cf. ávyeșyant.)

+ s a m: sám eti. 4. 34. 4. 18. I. $53^{*}$. samْyánti. 4. 11.12. 6. 25. I-3. sám yantu. 4. 15.8. II. 9. 1 I.

sám ... yantu. 4. 15. I.

sam̉oyán. 9.5.33.

sam̉oyántam. 9. 5.33.

sam.yatós. I6. 8.22.

samyatímosamyatīm. 9. 5.33.

(cf. samayá, sámiti, ásamyant.) + anus am: anuosámyanti. II. 5. 2.

+ a b h is a m: abhiosámyanti. Ir.5. 3 .

+ upas a m: upaosámyantu. 3. 8.4.

ikşú: -únā. I. 34.5.

íkşvāku: -kos. 19. 39. 9 (mss. -ko, íșāko). [īng-).

$\sqrt{ } \mathbf{i} \bar{n}$ g: iñgayanti. 9. 10. $27^{*}$ (s. mss.

+ ud: úd ingaya. 3. 17.6".

Vich: ichămi. 4. 21. $5^{*}$.

ichasi. IO. I. 20. 20. $129.4,14$.

ichatas. 4. 15.15 . 8.6.4.

ichate. II. 5. I7.

ichante. I0. 8. 5 .

ichă (p. -á). I8. 1. 16*.

icha. 5. 22.6,7. I4. 2. $33^{*}$.

ichatu. 6. 20. I. 8.4. $18^{*}$.

ichasva. I8. I. II".

ichatām. 8.6.4.

icheta. 12. 4. 13.

ichas. I0. I. 7 .

ichāt. 4. $21.5^{\dagger}$. 6. 133. I. 


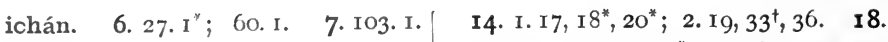
I9. 56.3 .

ichántas. I9. 4 I. I.

ichántī. 7. 73. 8*. II. 9. 8. I4. 2. I9. ichámānas. $3 \cdot 15 \cdot 3^{*}, 5,6$. I9. 7. I. āíchat. II. 5. I5.

āíchāma. 8. 5. II.

+ anu: ánv icha. 6. I34.3. anvichán (p. anuoi-). 6. 37. I. anvāíchat (p. anuoaí-). 12. 1.60. + abhi: abhì 'chāt. I2. 3.34, 4r. abhí ... ichāt. I2. 3.42.

ij in ritvíj.

It a: -as. 6. 14.3.

ítasya. 9. 3. 18.

í ḍ: -dás. 6.63.4* I 8. I. $43^{*}$. (cf. ídā.)

Í ḍa : 5. I 2. $8^{*} ; 27.9 . \quad 7.27 .1$. II. 7. 18.15 .6 .7$.

iḍe. 14. 2. 19.

Ị́̂ām. I 8. 4. 30.

ídayā. 3. Io. II. 6. 62.3.

ídāyās. 3. ro.6. I5. 6.7. (cf. írā.)

it, see íd.

it a in ástamita, duritá, ápratīta, suvitá, svitá.

ítara: -ras. 12. 2. $8^{*}, 2 \mathrm{I}^{*}$.

ítaram. II. 8.3I. I2. 2. $7^{*}$.

ítarās. II. I. I3.

ítarān. 3. II. 5, 7.

ítarābhis. I8. 2.9.

ítarāsu. 3. 10. 4 . (cf. itarajaná.)

it a ra oja ná: -năs. 8. Io. $28^{2}$. 9. 7 . I7. I I. 9. I6.

ítarajanās. II. IO. I.

itarajanăn. 8. 10. 28.

itás. I. $20.3 ; 23.2,3 . \quad$ 2. I4. 4,5 , 6. 3. II. $6 ; 3$ I. 4. 4. 3. I; 6. 2 ; I4. $9 ;$ I7. $2 ; 25.4 ; 37$. II. 5. 4. I, 3 ; 22. I; 3I. IO. 6. I4. 3 ; 23. $2 ; 25$. I-3; S3. 3 ; I $26.2^{*}$. 7. $26.5^{\dagger} ; 65$. I; $83.2 ; 95.3 ;$ II $4.2 ;$ II $5 . I^{2}, 2,3$. 8. I. I $8 ; 2.8 ; 6.7$, II, I4 $, 23,25 ; 8$. $24^{2}$; 9.6. I o. I. I $4,17,20,24,30$. I I 2. I $2, I_{4}, 27 ; 5 . \mathrm{II} ; 8.7$; IO. 9, I4. I2. I. $49 ; 2.2,3$. I3. I. $39^{2} ; 2$. I3. I. $6 \mathrm{I} ; 2.27,5 \mathrm{I}, 54^{*} ; 3.38$. 19.34 . $3 ; 39.6 ; 44.7$.

íti. I. $3 \cdot 1-5,6-9 ; 7 \cdot 4$ 3. $13 \cdot 4 ; 16$. $2^{*} ; 31.5^{*}$. 4.17.2; 20.6. 5. 17. $3^{*}$, 4; I8.7; 19.9; 23. I. 6.81.3;82. $2 ; 84 . \mathrm{I}^{2} ;$ I $28 . \mathrm{I} ;$ I30. $2^{2}$. 7. 74. I; $83.2^{2}$; 109. 6. 8. 4. $15^{*}, 16^{2 *} ; 9.18$; IO. I, 9, II, 22-9, 3I. 9. I. 24 ; 4. I2; 6. 18,$19 ; 9.16^{*}$. 10. I. 7,$15 ; 2.5$, I 7; IO. 23 . II. I. 7 ; 2. 28 ; 3. $24^{3}$, $26,27,28,29,32-49 ; 6.7 ; 8.22^{2}, 32$. I2. $4 . \mathrm{I}, 6,42^{2}, 48,49,52 ; 5.50$. I3. 4. $47,50-4$. I5. I. 8 ; 3. I, 2 ; I0. 3 , 4 II. 2, 3-6, 8, I0; I2. 2; 13. 8 ; I 7. IO. I8. I. $49^{\dagger} ; 2.22,48^{2} ; 4$. 7. 19. $34.6 ; 44.9^{2}$. 20. 128.2, 4 ; 129. I3 (ed. iva), I5, I6; I30. I7, I8; I3I. I3 (not ed.), 2 I (ed. ít); I32. 5, I4 (not mss.); I35. I-3 (mss. iti); I 36.6 (not mss.), 7 (do.).

(cf. itihāsá.)

i ti in ádhīti, úditi, sámiti.

itihāsá (p. -haoās-): -ás. I5. 6.4. itihāsásya. I 5. 6.4.

itthám. 3. 13.7. 6. 135. I. 8.9. 22. 20. 136.9 .

itthă. 1. 20. $4^{*}$. 4. I.6. 20. 134. I-6 (mss. -thá).

it va $\mathbf{n}$ in agrétvan.

íd. I. $2.4 ; 17.2,3 ; 34.2,4$. 2. 2.4 3. $7.5^{*} ; 8.4 ;$ I $3.5^{2}, 6 ;$ I $5.8 ;$ I6. $5^{*} ; 17.2^{*}, 3 ; 184^{*} ; 20.6^{*}$. 4. 2. $5^{+}$; I 7. $8 ; 21.2^{2^{*}}, 3^{*} ; 24.1 ; 27.6 ; 37$. 12. 5. I. $6^{*} ; 2 . \mathrm{I}^{*} ;$ I3. IO, II ; I 4.9 . 6. $22 . \mathrm{I}^{*} ; 26.3$; I. $2^{*} ; 55.2$; 57.1 ; $63.2,4^{*} ; 84.3 ; 9$ I. $3^{*}$; IOI. I; II 9 . I ; I2O. I ; I2I. 2 ; I34. 3. 7. 18. $2^{2}$; 20. $2 ; 2$ I. I; 36. I; 38.4; 50. $6^{*}$; 57. $2^{*} ;$ 88. I. 8. 4. $\mathrm{I2}^{*}, 2 \mathrm{I}^{*} ;$ 5. 12 , 16. 9. 2.19-24; 4. $21 ; 6.2 ; 9.8^{*}$, $16^{*}$; IO. $\mathrm{I}^{*}$. $10^{*}, 15^{*}, 18^{*}, 2 \mathrm{I}^{\dagger}$. I0. 4 . I ; 6. 7--9, 10, I4-7; I0. 24 . II. I. 6,$34 ; 8.7$. I2. $3.9,47$. I4. I. $5^{*}, 7^{*}$, I6*, 29*, 30, 32, 57; 2. 4I. I7. 6-I9, 24. I8. $2.6^{*}, 50,5 \mathrm{I} ; 3.2 \mathrm{I}^{*}$. I9. 26. I; $32.7 ; 34.9 ; 45.3 ; 55.7 ; 59.3^{*}$; 64. 4 (ed. tăbhir), 4 (mss. samíd). 
20. $127.11^{2}$; I29. I2; I3I. 2 I (mss. İtyằn); I $35.4 ;$ I36. I.

(cf. céd [p. ca ít], néd [p. ná ít], svid.)

i d a ty in

id ád ov a s u : -us. I3. 4. 54 .

i dá m, see i pron.

i d $\bar{a}$ in

idầñm. 3. I6. $4^{*}$. 8. 3. $5^{*}$. and idāvatsará: -rấya. 6. 55.3.

id dha in bráhmeddha.

$\checkmark \mathrm{idh}$ : indháte. 4. 23. I. 8. I. I. indhate. 12. I. 20. 13. I. 40.

inddhām. 12. $2.7^{\dagger}$.

índhānās. 5.3. I*. I9. 55.3, 4.

idhīmahi. I8. I. $56^{\dagger}, 57$.

iddhás. 3. 8.3.

[édhas.)

(cf. iddha, idh, idhmá, idhra, + anu: ánv āinddha. 10. 2. I6. [18. + a bhi: abhì' 'ndhe ('nddhe ?). II. 3 . abhìddhas (p. abhíoid-). 7.73. $7^{*}$. $+\bar{a}$ : â... idhīmahi. I8. 4.88*.

+ pari: pári ... inddhām. 12. 3. 25. + sampra: samopréddhas. 6. 76. I.

+ vi: cf. vīdhrá (?).

+ s a m: sám inddhe. 7. 82.6. sám ... inddhe. 5. 18.5.

sám indhate. I1. 3. I7. I2.2. II. I8. 4 . $4 \mathrm{I}$.

sám idhĩmahi. I8. I. 56*, 57 .

samoidhānás. I3. I. 28.

sámoiddhas. 5. I2. I* 7. 73. I, 2.8. 3. I $^{*} 2^{*} ; 8$. I 7. II. I. $4 ; 5.6$. I2 2. II, I8. I3. I. $28 ; 3.23$.

sámoiddham. 7.74. 4 .

sámoiddhe. 2. I2.8. I0. 6.35.

sámoiddhās. I8. 4. I2.

sám idhyase. 6. 63. $4^{*}$.

sám idhyate, I3. I. 48, 50 .

sám idhyasva. Ir. I. 4 .

sám ... idhyásva. 2. 6.2. (cf. samídh.)

i d h in samídh.

idhmá: -ás. 19. 6. IO".

idhmám. ro. 6.35 . I2. 2.54 .

idhména. 3. 15.3*. 5. 8. I. 19.64. 2. (cf. anidhmá.)

i dhra (?) in ăgnīdhra, vĩdhrá. in a in

ináot a ma: -am. 5. 2. $7^{\circ}$.

índu: -us. $18.3 .54 ; 4.60^{\circ}$.

índave. 18.3.39*.

índavas. 6. 2. 2.

indavas. 7. I09. 6

índra: -as. I. 7.3, 4, 7; 9. I; 16. 2 ; 2 I. I"; 26. 2 ; 29. I". 2. 5. 3; I4. $4^{2} ; 27.3,4,5 ; 29.7$. 3. 1.6 (mss. índra); $3.3 ; 8.2 ; 11.3^{\dagger}, 4^{\dagger} ; 12.4$; I $3.2,3 ; 14.2 ; 15.6 ; 17.4^{\circ} ; 22.2$; 27.2. 4.3.5; 5.7; II. $2,3,7$; I9. 8 ; 2 I. $2^{*}, 5^{2 *} ; 23.5 ; 3$ I. $5^{*} ; 32.2^{*}$. 5. 8.8; I8. $5,6,14 ; 2$ I. 8, II ; 23.I; 24. II ; 25.4, 6; 26.3, II ; 29. IO; 3I. I2. 6. 30. I; 33. $3 ; 39.3 ; 40$. $2 ; 47.2 ; 58.1,2 ; 65.3 ; 66.2 ; 67$. I, $2 ; 75.1,2 ; 87.3^{*} ; 88.2^{*} ; 94.3$; 97. I; 98. I ; 103.2, 3; 104. 3 ; 111.4 ; I22. 5 ; I38. 2 ; I4I. I. 7. 24.1 ; 44. I* 5 I. I* $; 8$ I.6; 86. I* $; 89.2^{*} ; 9$ I. $I^{*} ; 92 I^{*} ; 94 . I^{*} ;$ IIO. I. 8. I. I5; 4. $16^{*}, 2 \mathrm{I}^{*}, 25^{*} ; \quad 5.3,5, \mathrm{IO}, 14, \mathrm{I} 8,2 \mathrm{I}$, 22 ; 8. I, I8, 23 ; IO. I2, 26. 9. 2. I3, I 7, I8; 4. II, 2I ; 7. I, 20; 9. I9". I0. $3.11 ; 4.10,12,16,17,18 ; 6.7 ; 8$. $42^{*} ;$ I0.9. II. I. $27 ; 5.7$, I6, I9; $6.23 ; 7.1$; 8.8,9;9.20, 25 ; IO. II, I6, 27. I2. I. IO, I8, 40; $2.54 ; 3$. 24. I3. I. $27,5 \mathrm{I} ; 3 . \mathrm{I} 3 ; 4.46 . \quad$ I 4 . I. $37^{*} ; 2.42$. I 5. IO. 6 ; I4. 2 . I 7 . I8. I 8. 3. I2, $22^{*}, 25 ; 4$. I5. I9. 5 . I* $^{*} 6.7^{*} ; 9.6^{*}, 12 ;$ 10. $6^{*} ; 13.2^{*}, 4^{*}$, $7^{*}, 9^{*}, \mathrm{II}^{*} ; \mathrm{I5.3}$; 17.8 ; 19.9; 20.3; $24.7^{*}, 8$; 26. 4 ; 27. I, 9 (mss. indra); $28.3 ; 34.8$ (m. mss. úpendras), 9 ; $43.6^{2} ; 45.7 ; 46.2,3$. 20. $2.3 ; 34$. I2, I6, I7; I27. II; I28. 14.

índra. 2. $5.1,2 . \quad 3.1 .5 ; 2.3 ; 4$. 6 (índraoin-). 4.22.2. 5. 3.8*; 8. $2,5,9$. 6. $5 \cdot 2 ; 40.3 ; 87.2^{*}$. 7. $3 \mathrm{r}$. $1^{*} ; 84.2^{*}$; IIO. 3. 8. $4.24^{*} ; 5.17$; 6. I3. I3. I. 30. I4. I. 62. I8. 3.67". 19. 55.6 (mss. índrā; p. -ra; ed. íd găh); 70.1. 20. I27.13.

indra. I. 2.3 ; I9. I; $21.2^{*}, 3^{*}, 4^{*}$. 2. $5.4^{2} ;$ I $2.3 ; 27.7 ; 29.3 .3 .1$. $3,4^{*} ; 3.6 . \quad 4.4 .4$; 22. I, 3. 5. 8 . 
$7,9^{2} ; 23.2 ; 28.4$. 6. 45. $3^{*} ; 66.1$, $3 ; 82.3 ; 98.2,3$; 99. I ; 126. 3. 7. I $2.3 ; 50.4^{*} ; 72.2^{*}, 3^{*} ; 76.6^{*} ; 84.3^{*}$; 97. $2^{*}$; II 7. I*. 8. 4. $8^{*}$, I $^{*}, 22^{*} ; 5$. I5; $8.7 ; 9.21 .9 .4 .23^{*}$. II. 9.23. I3. I. $59^{*} ; 4.46,47$. I4. I. $18^{*}, 4 \mathrm{I}^{*}$; 2.64. I7. 9. IO, $\mathrm{II}^{3}, \mathrm{I}_{2}, \mathrm{I}^{4}, \mathrm{I} 4$. I9. 8.6; I3. $5^{*} ;$ I5. I*, $2,4^{*} ; 42.3$. 20. I27. I3 ; I 28.12 , I4; : $35 . \mathrm{II}, \mathrm{I} 2$. índram. 3. 3.2 ; 10.12 ; 15.1 ; 16. $\mathrm{I}^{*} ; 20.7^{*} ; 21.8 .4$ 4. 21. $5^{*} ; 22.5$; 24. 7. 5. 2.9* ; 3. II. 6. 38. I-4; 39 . 2 ; $54.1 ; 97.3^{*}$. 7.38.2; 46.3; 86. $\mathrm{I}^{4 *} ; 98.1$; I IO. 2. 8. 4. $20^{*}$. 9. 4. 9 ; I0. $25^{*}$. I0. 7.30 ; 10. IO. II. 6. I. I2. I. $37 ; 2.47$ I 5. 10. 4.5 , II. I7. I-5. I8. I. $48^{*}$. I9. I5.2; I8. 8 ; 24. 2. 20. I28. I5, I6 (mss. indra).

índreṇa. 2. 29.4. 3. 5.4; 6.2 : $2 \mathrm{I}$. 3. 5. I4. 7; 2O. I 2 ; 2I.II. 6. 65. 3; 104. 2; 126. I* ; I29. I. 7. 4I. I; 90. $2^{*} ;$ 93. I: 98. I. 9. 3.3. I0. 4 . I 2 ; 9. I. II. IO. 9. I2. 4. 5O. I3. I. 3. I8. $3.4^{*}$. I9. I3. $3^{*}$; 3I. 7 ; 42. 4 (not mss.).

indrāya. I. 9.3. 4. 21. I*. 5. 2. $8^{*}$; 27. 12. 6. 2. I, $3^{*}$. 8. 9.24. 9 . 4. 3 ; 5.2. I2. I. $38 ; 3.56$. I8. I. $37^{*} ; 3.54$. I9. 43.6 .

índrāt. I I. 8. 9.

índrasya. 2. 3.6; 5. $5^{*} ; 3$ I. I. 3 . I9.4. 4. 22. 4; 24. I; 37.8, 9. 5. 6. 4 , II-4; 8. 4. 6. 33. I, 2 ; 5I. I ; 82. I; 85.2; 86. I; 92. I; 99.2, 3; I25. $2^{*}, 3^{*} ;$ I 26. $2^{*}$. 7. $26.6^{*} ; 52.2$; 72. I* ; III.I. 8. 4. I3* ; 9.23. 9. $2.6 ; 4.7,8$. I0. 4 . I ; 5. I-6, 8 . I2. 4. 5 I. I6. I. 9. I8. $4.58^{*}, 60^{*}$. I9. I3. I, IU* $; 30.3 ; 35 . \mathrm{I} ; 46.4$. índre. I. $35 \cdot 3$. I $7.29,30^{3}$.

(cf. mahendrá, āindrá, índragupta-índreșita.)

índra॰gupta: -tām. I2. I. II. in d $\mathrm{ra} \circ \mathrm{j}$ â: -ấs. 4. 3.7.

indraojālá: -léna. 8. 8.8. índra。jūta: -am. 6. 39. 1, 2. [79.2. índra。jyeșțha: -țhās. 3. I9.6.7. indra。dhanús: I 5. I. 6.

indra oputra: índraputre. 3. I0. 13. índra omedin: -di. 5. 20. 8. índramedināu. II. 9. 18. índramediobhyām. II. 9. 4. indra y ogá: -gãís. ro. 5.3. índrarșabha: -bhā (p. -draoṛş-; s. mss. índrar-). 12. I. 6.

índra०vant: -ntas. 5.3.3*. indra vāy ú: -yú. 3. 20. 6*.

índra.os a khi: -khā. 4. 5. 2; 22.6, 7 . indraos a m dhă: -dháyā. II. Io.9. in drā gn ń: -ní (p. -1̂́ti). I. 35.4. 3. 3.5. 4. 30. I*. 5.7.6. 6. 104. 3 ; I32.4. 8. I. 2 , I6; 2. 2 I. 9. $2.9 ; 3$. I9. IO. I. 2 I. II. 8. 5. I4. I. 54 . I9. IO. $I^{*} ;$ I6. 2 ; $20 . \mathrm{I}$.

índrāgnī (p. -Ĩ íti). I 3. I. 3 I.

indrāgni (do.). 3. II. I*. 9. I. I2. indrāgníobhyām. 5. 3.10* indrāgnyós. 9. I. I2. I6. 8.24. (cf. āindrāgná.)

indrāṇt: r. 27.4. 6. 132.3. 7. 49. $2^{*}$. 9. 7.8. I4. 2. 3I. I5. 6. 7 . indrāṇăâs. 15. 6.7.

índrāpūṣánā: I9. IO. I*. indrāpūșañā. 6. 3. I.

índrāvárunā: I9. IO. I*. índrāvarunā. 7. 58. $1^{*}, 2^{*}$.

índrāsómā: I9. IO. I* índrāsomā. 8. 4. $1-7^{*}$.

indriyá: -ám. 3. 22.5. 5. 9.8. 6. 133.4. 7.67. I. I2. 5.7. I5. Io. Io. 19. 42.4 20. 48.3 (not mss.). indriyéna. 6. 124.1. 16. 1.9. I9. 33. $2 ; 42.4$ (ed. índrena); 45.7.

indriyấya. 19. 37.2.

indriyấṇi. 1. 35.3. I. 9. 9.5.

indriyāís. I9.27. I. (cf. nírindriya, indriyávant.)

indriyá ovant: -vān. I5. IO. IO. índreșita (p. -raoiș-): -tās. 7. 70. 2. $\checkmark$ inv: ínvatha. $4 \cdot 27 \cdot 3$.

invata. $5.2 .6^{t}$.

in v a in viçvaminva.

i má (pron.): imám. I. 8. $2 ; 9.1,2,3$, 4 ; IO. I; I5.I, 2 ; 30. $\mathrm{I}^{3}$. 2. 6.2; 9 . I ; I3. I, $2 ; 26.2 ; 28.1,3^{2}, 5 ; 35.5$. 
3. $3.4,6 ; 2$ I. $8.4 .13 .4^{\dagger} ; 22 . I^{2}, 2$; 27. I ; $34.8 ; 38.5$. 5. 3. II $4.6 \% 5$. $4 ; 27.8 ; 28.4^{3} ; 30.14 .6 .5 .2 ; 30$. I; $35.2 ; 54.2 ; 63.3 ; 9$ I.I; 95.3; $97.3^{*}$; III. I; I38. I. 7. 2. I; 5. 5 ; 8. I; 20. $5^{2} ; 28.1$; 53. $4 ; 58 . \mathrm{I}^{*} ; 73$. $9^{*} ; 75.2 ; 78.2 ; 82.1^{*} ; 97.8 ;$ I I6. 2. 8. I. $6, \mathrm{I} 8 ; 2.5,7,8,10,20 ; 5.12$, I3, 20, 2I; 7.2, 5, 7, 19, 22 . 9. 2. 7 ; 5. I 7 ; 6.6I; 9. $3^{*}$. I0. $2.2 \mathrm{O}^{2}, 2 \mathrm{I}^{2}$; 3. I $2 ; 6.17,29$. II. I. 4, I6, I $8 ; 9$. 26. 12. $2.4,7^{*}, 23^{*}, 43,47 ; 3.4,32$, 37. I4. I. 32,$33 ; 2.8,13,18,23,25$, $40^{\dagger}, 70,73$. I7. I1. I8. 1."60"; 2 . $4^{\dagger}, 5^{\dagger}, 27 ; 3 \cdot 52^{*}, 53^{*}, 60^{*} ; 4 \cdot 28^{*}, 40$, 54. I9. I. I, $2^{3}, 3 ; 24.1,2,3 ; 28$. I ; 30. $1 ; 46.2 ; 54.5 ; 58.6$.

imằm. I. I8. 2. 2. 7.4 (s. mss. măm); 36. I. 3. 12. $4,7^{2} ; 15.3^{*}, 4^{*} ;$ I6. $3^{*}$; 17. $7^{*} ;$ 18. $1^{*}$. 6. $125.3^{*}$; 133. I. 8. 2. I; 6.9, I6; I0.9. 9.3. I5. I0. 2. 18 ; 6.12; 8.36. II. I. 5,9, I I ; 5.9 ; IO. 14,26 . I 4. I. $35,36,53,54$, 55,$59 ; \quad 2.4^{*}, 28^{*}, 53-8$. I 5. 13. $8^{3}$. 18. $2.38-44$. 20. 127.6 .

imāú. 4. 13. $2^{*}$. 6. 78.2 . I0. 2.6. I4. 2.64. I8. 2. 56 .

imâ. I9. I3. I.

imé (p. -é íti). 3. 31.4. 5. 12. $9^{*}$; 20. 7. 6. 8.3 ; 58.1. 8. 5.3. Iо. 7.35 ; 8.2. II. 5.8 , II. I3. 3. I. 19. 15.5 .

imé. 2.6.3. 3. I. $2 . \quad 4.24 .1 ; 38$. 6. 5. 8.2. 6. $28.2^{*}, 2^{\dagger} ; 88.1^{*} ; 126$. 3. 7.60. $2 ; 79.2$. 8. 8. 16, $24 ; 9$. 7. 9.9.12*. 10. $4.11 ; 6.31 ; 7$. $44^{*} ; 8.31$; 9. I2. II. I. I8； 2. 9. I2. I. $15 ; 2.21,22^{*}$. I3. 4 . $10,27$. 14. 2.59. I5. 15.8. I8. 3.61. I9. 3I. II. 20. 135.4 .

imăs. 1. 17. 3. 2. I0. 4 . $33.3 ; 4$. 2 ; 12. 9 ; 24. 3. 4. 2. $5^{*}$; 20. 2 ; 21 . $5^{*}$. 5. 13.9; 28 . 10. 6. $21.1 ; 85$. 3 ; 98.2 ; 122. 5. 7. 9. $2^{*}$; 19. I; 35 . 2. 8. 7.13. 9. 4.6. I0. I. II; 6.9; $8.37,38$; IO. 4 . II. I. $14,17,27 ; 4$. I9. I2. I. $42 ; 2.3 I^{*} ; 3.30$. I 4.2 . 52. I5. 15.7, $9 ;$ 16.7. 18. 4. 39 .
I 9. $8.6 ; 32.4 ; 45.4 ; 53.5,7.20$. 127. I3 (mss. -âs); I36. I I.

imăni. 7.68.2. 10.4.7. I3.1. I4. I9. 9.5.

ima. 3. 20.8. 5.2.8"; 22.8. 7 . 87. I. 8. $4.6^{*}$. 9. $9.2^{*}, 7^{*}$. $\quad$ II. 2. I I. I7. 16. I8. I. $5 \mathrm{I}^{*}$. I9. 53.2 , 3. 20. I30. I (not mss.).

imăn. 3. 1 2.8 (mss. -ằm). 6. I7. 2 ; $28.2^{\prime \prime} ; 50.2 ; 74.3 ; 84.2$. I2. 2 . 32,55 . I 4. I. $56 ; 2.26$. I 8. 2.2 I (mss. -ắm); $3.62 ; 4.50$.

$\checkmark$ iy aksa, see $\sqrt{\text { yaj. }}$

iy at tikat: 20. 130.20 (not mss.).

i y á m, see i pron.

írā': 3. 29.6. 5. I3. I. 9. 7. 12. I5. 2. 3 (m. mss. ed. iră). 20. 130. I6 (?). írām. 4. II. IO (mss. -ān). Ig. 3I. 3. 20. 135.13 .

(cf. ánirā, írākṣīra, írāvant.)

írāokşira: -rã. Io. Io. 6.

írā。vant: -ntas. 7.60.6.

Íāvati. 8. IO. II, 24. (cf. āirāvatá.)

íriṇa: -ṇā. 4. 15. 12.

írya: -as. 3.8.4. I2. 3. II.

Vil: ilayati. 10. 7.37 .

ilayanti. ro. $7 \cdot 37$.

iláyatā (p. -ta). I. $17 \cdot 4^{*}$.

+ ava: áve 'laya. 6. I6.3.

áva ... āilayīt. 6. I6.3.

iv a (p. oiva). I. I. $3 ; 3.7,8 ; 5.2^{*}$; 8. I; II. $4^{2} ;$ I 4.1 I $27.2,3 ; 32.2,3$; 35.3. 2. I. $4 ; 5.6^{*} ;$ I $2.3,6^{+}$; I3. I ; I4. 6 ; $25.2 ; 27.5 ; 28.1,5$; 3 I. I ; 32. 5. 3. $6.4,7 ; 7.3 ; 9.2,5$; II. 5 , 8 ; $14.4,5 ;$ 15. 8 ; $16.6^{*} ; 18.6^{2 *}$; $23.2 ; 24.3 ; 29.6^{2} ;$ 30. I, 6,7. 4 . $4.3,7 ; 7.5 ; 9.4^{*} ;$ I2. 7 ; I6. I ; I9. 2,3 ; 20. 3 ; 22. 4 ; 27.1 ; 30. $8^{*}$; 33 . $7^{*}, 8^{*} ; 36.6^{2}, 9^{2} ; 37.11^{3}$. 5. I. I $; 5$. 3 I I3. I, $6^{2} ; \mathrm{I} 4.3, \mathrm{II}^{2}, \mathrm{I} 3 ;$ I 8.3 .6 , I5 ; I9. I, 8 ; 20. 2, 3, IO, II ; 22. 2, 3, $7 ; 23.8 ; 25.1 ; 26.5 ; 29 .{ }^{4} 13.6 .6$. $3^{*}$; I2. I; I4. 2 ; I5.2, 3; I8. $3 ; 20$. I; 22. $3^{2} ; 25.1-3 ; 30.3 ; 37.2$ (ivā); 42. I ; 49. I; 50. $2 ; 67.2 ; 69.3 ; 7$ I. 2 ; 80. 2 ; 83. I; 92. $3^{*}$; 1O2. 2 ; II5. 
$2,3^{3} ; 134.1$ I $35.1,2,3 ; 142.2 .7$. 13. $2 ; 26.7^{*} ; 38.5 ; 45.2^{2} ; 50.3^{*}$, $9^{2} ; 53.5 ; 56.4 ; 62.1 ; 70.3 ; 74$. 2 ; 90. I* ${ }^{*}$ 95. I, $2^{3}$; II 3.2 ; II 5 . 2 (p. -naḩoiva), 4 ; I1 7. $1^{*}$. 8. $4 \cdot 2^{*}$, $6^{*}, 8^{*}, 17^{*}, 21^{*}, 22^{*} ;$. 5. $8, \mathrm{Ir}^{2} ; 6.7,8$, II, $17,19,24,26 ; 7.15^{2}, 27$. 9. 2.6 , I $2 ; 3.3 .17^{2}, 24 ; 4.2$, II ; ro. $15^{*}$. I 0. I. I, 3,8 , I4, I5, 25; 26. 30, 32 ; 3. II ; $4.3,4,19,2 \mathrm{I}^{2} ; 6.5 ; 7.38,43 ; 8 . \mathrm{I}_{4}$, $25,34,39,41,42^{*}$. II. 2. 13,$22 ; 4$. I0; 8. 32. I2. I. I 8,$45 ; 2.52 ; 3.12$, $23,27,29,33,37$ I3. I. 38 ; 2. I3, $46^{2^{*}}$. I $4.1 .53 ; 2.31,32,44,64$. I 8 . 1. $8^{2 *}, 9^{*}, 15^{2 *}, 16^{*}, 22^{*} ; \quad 3.23^{*}, 25-35$, $38^{*}, 39^{*} ; \quad 4.60^{*}$. I 9. $34.3 ; 35.2$; $38.2 ; 39.4^{2} ; 45.4 ; 49.2,6 ; 50.3$; 55. I, $7 ; 57.4^{2} ; 58$. I (not mss.). 20. I 27. $4,5,5^{2}$ (not mss.), ro; I 29. I3 (not mss.), I 7 (do.); I3I. ro (not ed.); 19; r32. I6 (not ed.); r33.6; r36. I, 2 (mss. eva), 3, I6 (not mss.).

(irregularly monosyllabic) I. I4. x, 4; I7. I. 2. 7.1 ; 25.4; 30.3. 3. 9. $4^{2} ; 16.6 ; 29.6 .4 .4 .6$ (s. mss. ivã), $7 ; 5.7 ; 7.4^{2}, 5 ;$ I6. 5,$7 ;$ 18.2; I9. I; 20. 7; $31.2^{*}, 5^{*} ; 36.10 .5 .8 .4$; I3. $3 ;$ I $4.3,5,6,10^{3}, 12,13^{2} ;$ I 8.4 , $15 ; 20.1,2 ; 22.14 ; 29.12 ; 30.9$. 6. 12. I; I4. 3 ;20. I; $21.2 ; 37 . \mathrm{I}$, 2,$3 ; 42 . \mathrm{I}, 2 ; 49.2 ; 54 . \mathrm{I} ; 87.2^{*}$; 89. 2 ; IOI. 2 ; I 2 I. 4 ; $137.2,3$; I 42 . 2. 7. 50. $6^{\dagger} ; 59.1$; IO9. 4 ; II5.2(?). 8. $2.4,12 ; 4.6^{*} ; 5.7 ; 8.3,4$. 9.3. 2, 21. I0. I. 17,$19 ; 7.2$ I. II. 2.8 ; 4. $26 ; 7.4,6$ I2. I. $57 ; 2.50 ; 3$. II, 2 I. I4. I. I 7 ; 2. I 5, 37. I8. 2. II; 4. 66. I9. $28.2 ; 3^{2}, 4 ; 33.5 ; 45$. I ; 46. $2 ; 57.5$. 20. I $28.5 ;$ I 36.3 . V I, 2 i ș: iṣnāmi. 8. 8. I4, I5.

ișnán. II. 5. I.

ișyati. I 8 I. $23^{*}$.

İșiré. 5. I9. 3. I9. 26.2 (m. mss. iṣ-). ișitás. $5 \cdot 12 \cdot 3^{*}, 9$ 6. $27 \cdot \mathrm{I}^{*}, 2$. 10. 8. 35. I2. 2. 9 . I8. 4. I.

ișitám. 6. II6. 2. I9. 53. 5, 9.

ișităs. I0. 8.33 .

(cf. Vich, $\sqrt{ }$ Ị̇, Veș, ís, ișá, ișita, ișirá, ișíkā, ișu, iṣțí, eșa, eșaṇa, eșin, eșyà.)

+ pra: pré 'ṣyatam. I8. 2.53 (mss. ișyantam).

préșitā (p. práoịș-). II. 3. I4.

préșitāu (do.). 8. I. 9.

préșitās (do.). 3. 13. 2.

(cf. prāișá.)

+ a b hipra: abhiopréşyāmi. I6. 7.2.

ís : íșam. 3. Io. 7. 4. 39. 2, 4, 6, 8. 5. 20. II. 6. 28. I*. 9. I. $20 ; 5.24$. I8. I. $24^{*}$; 4. $4,88^{*}$. 19. +o. $4^{*}$ (inss. íṣum).

ișâ. 3. I5.8. 7. 80. I. I9. 55. I, 2. ișé. 7. 73. I.

íșas. I8. I. $42^{*}$.

ișá: -șâya. 20. 127.3 (ed. ŕșaye).

ișita in índreșita, devéșita, púrușeșita.

[ro. $4^{*}$.

ișirá: -ás. 6. 62. I. I8. I. $21^{\dagger}$. I9. ișiră. 19. 49. I.

ișirám. 5. I. 9.

ișirăs. 6. $49 \cdot 3^{*}$.

ișîtkā: -ãm. 7. 56.4. I2. 2.54 .

íșu: -us. 3. $25.1,3$. 5. 18. $15^{2}$. 7 . 52. 2. II. 2. I2. I9. 55.2 (ed. iștís). ișo (p. -o íti). 4. 6.6.

ísum. I. I3.4. 3. 25.2 . 6. 57.1 ; 90. I. 8. 8. 20. II. IO. I6. I2. 4 . I7. I9. 34. 3. 20. 127. 6 (not mss.). íșuā. 5.5.4. I0. I. 27.

íșvās. 5. 14. I 2.

íșavas. 2. 3.6. 3. $26 . \mathrm{I}-6$; $27 . \mathrm{I}-6$. 8. 8. 20. II. 9. I. I7. 28. I9. I3. II*. íșūs. 8. 3. $6^{*}$. II. 6.9. íṣuobhyas. 3. 27. I-6.

(cf. āsánniṣu, tigméṣu, tīkṣṇéșu, manuṣyeșu, iṣukà - íṣuhasta, ișvagrá-iṣvāsá.)

ișukà: I. 3.9.

iṣ uodhí: -ím. 3. 23. 2. ișudhāú. 4. Io. 6.

iṣ u०b hṛ̂t: -tām. 4. 28. 2.

íșu 0 m a nt: -ntam. 4. 24. 5.

íșumate. I2. 3. 55-7, 60 .

íșumatyāi. 12. 3. 58 .

ișumatibhyas. 12.3 .59 .

íș $\mathrm{o} \circ \mathrm{h}$ as ta: -tena. I9. I3. $3^{*}$. íṣuhastāis. 19. 13. $4^{*}$. 
ișt t a in ișțāpūrtá, ișțăvant.

iháokratu: -us. 18.4. 38 .

ișțāpūrtá: -ám. 2.12.4. 3. I2. iháocitta: -as. I8. 4.38.

8. 6. 123.2. I8. 2. 57 .

ișțāpūrténa. 18. 3. $58^{*}$.

işțāpūrtásya. 3. 29. I.

iș ța va ant (p. -țáov-): -ntas. I8. 3. 20. I (pron. root) in Idŗ̛́, Im.

işți: -ís. I9. 55.2 (not mss.).

ișțáye. 7. 4. I.

(ef. gávișți.)

iș ți : -țayas. I 1. 7. 19 (mss. tád iṣț-). (cf. dúrișți, svìșți.)

ișu o a grá: -râni. II. Io. I6.

işu

işvãsá (p. -șu०ã-): -ás. I 5. 5. I-7. ișvăsám. I5. 5. I-7.

ihá. I. I. $3 ; 5.2^{*} ; 7.7 ; 8.1 ; 9.3$; I0. $4 ; 15.2^{3} ; 31.3 . \quad$ 2. $5.1,4 ; 6$. 4 ; I2. I; 26. I. 3. 3. I, $6 ; 4$. I, $7 ; 8$. 4 ; II. 6 ; I2. I, 2 ; I3. 7 ; I4. $4^{2}, 5,6$; I6. $5^{*} ;$ 1 7. $2^{*}, 7^{\dagger} ; 20.2^{*}, 6^{*}, 6^{\dagger} ; 24.3$, 5,$7 ; 28.3,4^{3} ; 3$ I. 9. 4. 2I. I* $; 25$. $5 ; 31.5^{*} ; 38$. I. $2,4,6^{2}, 7^{2}$. 5. 3. $4^{\dagger}$, $6^{*}$; 6. 5-7; 8. I; II. I; I2. $8^{*}, 9^{*}$; 20. II; 25. 7 ; 26. I, 4, $5 ; 28.3 ; 30$. I, 6, II, I7. 6. II. $3 ; 27.3^{*} ; 32.3$; 40. I ; $55.1 ; 58.1 ; 62.3 ; 63.3 ; 73$. $1^{2}, 3 ; 74.3 ; 87.2^{3 *} ; 88.3 ; 97.2 ; 98$. I ; $114.2 ; \operatorname{II7.2;~I21.3.~7.2.~} \mathrm{I}^{2}$; 4. I; $5.5 ; 9.3^{*} ;$ IO. $\mathrm{I}^{*} ;$ I $2.4^{2} ; 40$. 2 ; 50. $3^{*}$; 52. I; 53.2, 5 ; 60. 5,7 ; $67.1 ; 73.2 ; 74.4 ; 78.1,2 ; 82.3$; 84. I; 85. I* ; 97. I* ; III. I ${ }^{2}$. 8. I. $I^{2}, 3^{4}, 7,18 ; 2.6,7 ; 3.8^{*} ; 7.6,7$, Io. 9. $2.8 ; 4.6,23^{\dagger} ; 9.5^{*}, \mathrm{I} 8^{*}$. IO. I. $20 ; 4.9$. II. I. I, 4 , IO ; 8.33 ; IO. 9. I2. $2.8^{*}, 2 \mathrm{I} ; 3.12^{2}, \mathrm{I} 3,43$. 13 . I. $2,4,5^{2}, 10,17-9,39$. I4. I. $21^{*}, 22^{*}$, $32^{2} ; 2.15, \mathrm{I}^{\dagger}, \mathrm{I} 9,24,25,29,3 \mathrm{I}, 32$, $37,39,64,7$ I, 74 . I 8. I. $7^{*}, 9^{*}, 25^{*}$, $39^{\dagger}, 45^{*}, 59^{*}, 59^{\dagger} ; \quad$ 2. $13^{*}, 2 \mathrm{r}, 24,29$, $37^{2}, 57,59^{*}$; $\quad 3.1,14,25-35,43^{*}, 44^{*}$, $45^{*}, 6 \mathbf{1}, 73 ;$ 4. I2, 13, I6-24 $34^{2}, 66$, $87^{2}$. 19. 6. $2^{*} ; 9.14^{3} ;$ 10. $6^{*} ; 48.4$; 49. $3 ; 52.4 ; 56.6 ; 72$. I. 20. 127 . I $2^{3}$; I 29. I I (not mss.); I 34 . I-6. ihă (p. ihá). I 9. 56.6.

ihó (p. -ó íti). 3. 14. 4. 20. I27. I2. (cf. ihákratu-ihábhojana.)

VI kş: Ikşe. I2. I. $5^{8}$.

ikşamānas. 9.7.23.

Ikşamānā. I2. 5.20.

ákșata. I3. 3.6.

$[3+3$.

+ an u: anvāíkşanta (p. anuoāí-). 2 .

+ a pa: apékşamănă (p. apao1-). I2.

5. I9.

ápe "kșante. 4. I4. 4 .

+ pra: prékşate (p. pra॰1-). 9.6. I8. pré "kşate. 9.6.3.

+ prati: prátī "kşante. I 4. I. 39

+ s a m: sám îkșayasva. 4. 15.3.

sám ìkşayantu. 4. I5.2.

sam॰īkşáyan. II . 9. 6, 9, I I , 25.

$\sqrt{ } \overline{\mathbf{I}} \overline{\mathbf{n}} \mathbf{k} \mathbf{h}:+$ pari: parioīnkháyātāi (s. mss. ed. párīñkha-). I8. 2. 58.

+ pra: ef. preñkhá.

V $\mathbf{1}$ d: ide.e. 7. 50. $3^{*}$.

ide.e. 4. 23.3. 5. I. 8.

Ị̇āmahe. I4. 2. 33".

iduate. I4. I. $37^{*}$.

Idate. 4. 32.2*. 20. 135.9 (mss.

Ị́̂anas. $5 \cdot 27 \cdot 4$.

Iḍitás. I $8 \cdot 3 \cdot 42^{*}$.

(cf. ị̣itṛ́, iḍ̂ya.)

I dụ ị̂̂: -tấ. 4. 3I. $4^{\dagger}$.

îdya: -dias. 2. 2. I. 5. 12. $3^{*}$. 6. 98. I ; I IO. I*. 8. 3. $26^{*}$. I 9. 59. I* $^{*}$. Idyam. I7. I -5 .

i dṛ́ç: -ŕ̛k. 4. 27.6. Idr̂́çe. 3. I. 2.7 . I0g. 1, 7.

im. 4. 30. $4^{*}$. 9. 9. $5^{*}, \mathrm{IO}^{*}, \mathrm{I}^{*}$; IO. IO ${ }^{2 *}$. I8. I. $7^{*}, 2 \mathrm{O}^{*}$. 20. 135.8 .

$\sqrt{ } \mathbf{I} \mathbf{r}:$ trate. I9. 8.6 .

irate. 19. 38.2.

iráyan. 4. I5. II.

ãírayas. 7.55. I.

ãírayat. 7.3.1 ( m. mss. -ata).

āírayanta. 2. I. 5. 6. 47.3.

(cf. îrmá.)

$+\bar{a}$ : é "rayāmas. 5.29.5.

é "rayasva. I4. 2. $38^{*}$. I7. I I. 
é "rayethām. 5. 1.4.

é "rayantām. 5. I.3. 6. 6I. I.

+ u d: udoirate. I. 20.2. 6. 99. 2.

út... Irate. I3. 2. I.

úd irșva. I $8.3 \cdot 2^{*}$.

úd îratām. 3. I9.6. I8. I. 44*.

udoîrānās. I2. I. 28.

úd iraya. I8. I. 23*.

úd irayata. 4. 15. 5.

+ pra: pré "rate. 4. 25.3.

prá ... irate. 20. 127.5.

pré "raya. 7.97.3.

prá ....ìraya. 6. $34 \cdot \mathrm{I}^{*}$.

prāí "rayat. Io. 2. 26.

+ vi: ví... āirayethām. 7. 44. I.

+ s a m: samoiriré. I4. I. $46^{\dagger}$.

sám İrayāmasi. 8. 2.5.

sám İraya. 5. 30. I4.

sám āirayat. 8. 5. I4. I5. I. I.

sám āirayan. I. II. 2. 3. 3r. 7. 4 .

2.8. 7. 22.2. I9. 54.4 .

Irmá: -mábhyām. Io. IO. 2I.

$\bar{i} \mathbf{t} s \bar{a}$ in vīrtsă.

$\sqrt{\mathbf{1}} \mathbf{r} \mathbf{y}$ in îșyă, irșyú.

[74. 3.

îsṣy ă: -ăm. 6. I8. 3. 7. 45. 2 (-șiām); irșyầyās. 6. I8. I. 7. +5. I.

ĩrşyú: -yós. 6. 18. 2.

$\checkmark$ I ç: Içișe. 2. 28.3. 6. 79.3.

içe. 2. 34. I. 3. I5.3. 4. 2. I*; II. $5^{2}$. 6. $28.3^{*}$. II. $4.23,24$. I3. 3. $24^{*}$. Içe. 6. $86.2^{2}$. 8. $2.23^{2}$. I I. 2.27. içãthe (p. -e íti). 4. 28. I, 6.

içmahe. 4. 39.7.

Içidhve. 4. 27.6.

Içate. 5. 21.7.

$[127,13$.

içata. 4. $21.7^{*}$. I9. $47 \cdot 6^{3}$. 20.

içānas. 3. I5. I. 6. 2.3. 7. I7. I ;

I8. I. 9. 2.3. II. $7.16 ; 9.4$ I5. I. $5 ; 5 . \mathrm{I}-7,7 ;$ I4. I0.

Içānam. I5. $5 \cdot 7$.

İ̧ānām. 4. I 7. I.

Içānās. I. 5. $4^{*} \cdot 4 \cdot 27 \cdot 4,5 \cdot$ II. 9. 26. (cf. içă, iç̧u, içvará.)

$+\mathbf{a b h i}$ in abhíçu.

Içấ: II. 8. I7.

içằm. II. 9. $25^{3}$; I0. 2 . I5. I. 5 . $\mathbf{I} c ̧ \mathbf{u}$ in abhiçu.

I çvará: -ás. II. 4. I, Io. I9. $6.4^{\dagger}$; içvarắs. 7. I02. I.

(cf. ánīçvara.)

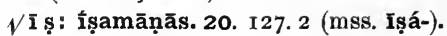

+ u d: úd ișatu. Ir. 9.2I.

îșâ: 8. 8.23.

Ișé (p. -éíti). II. 3.9 (s. mss. Içé). (cf. ișãyugá.)

īṣā y u gá: -gébhias. 2. 8. 4 .

$\sqrt{ } \mathbf{i} \mathbf{h}$ in ehá, anehás.

u (p. ūñ íti). I. $6.4^{2}$; II. I ; I4.3. 2. $2.3 ; 3.3-5 ; 9.2 ;$ I $3.2,3 ; 26.3$; 30. 2. 3. $4.6 ; 7.5^{*}$; II. $4^{*} ; 2$ I. 4 ; 23. 5. 4. 3. 4,$6 ; 4.2$; 12. 3 ; 16. 9 ; 30. $5^{*} ; 36$. I0; 39.9. 5. 4.6 ; II. II ; I2. $4^{*}$; I3. 2, 3; I4. 2, 6; 22. 9 . 6. I. 2 ; II. $3 ; 2$ I. I ; $26.2,3 ; 56.3^{2}$; 57. I; 74. I; 85. I; 87. $2^{*} ; 91.3^{*}$; I24. 2,$3 ;$ I33. ${ }^{2}$; I36.2. 7.5.2; 20. 6 ; 31. $1^{2 *} ; 56.8 ; 70.2 ; 73.3,7^{*}$; 74. $3 ; 84.2^{*}$; 103. I. 8. 2. 13; 4. 13 ${ }^{*}$, $20^{*}, 21^{*} ; 5.5,9 ; 9.10,16,17,23,25$. 9. I. 6,$7 ; 4.4,7 ; 5.7 ; 6.39 ; 9.6^{*}$, I $5^{*}$, I $^{2 *} ;$ 10. $6^{*}$. 10. $2.2,3,7,13 ; 4$. I8; $7.3^{8} ; 8.4,16,28$; Iо. $13,14,15$. II. I. II；4. $20 ; 8$ I. I2. I. I2; 2. $3^{2} ; 3.3,26,47$. I3. 2. $16^{*}, 25 ; 4 \cdot 5^{2}$, 4I. I4. I. $40^{2}$. I5. I0. 6,7 . I6. 9. 2. I8. เ. $7^{*}, \mathrm{I} 2^{*}, \mathrm{I} 4^{*}, \mathrm{I} 6^{*}, 50^{*} ; 2.8^{*}$, $26,30,33^{*}, 50,5 \mathrm{I} ; 3 \cdot 6^{*}, 20,38^{*}, 7 \mathrm{I}$, 73 ; 4. II, 44. I9. $2 . \mathrm{I}^{2}$; 9. $9^{2}$; IO. $2^{2 *}, 3^{*}, 7^{2^{*}}, 8^{*}, 9^{2 *} ;$ I I. $1^{*}, 2^{*} ;$ 24. 5,6 , $8 ; 34.6 ; 53.9$. 20. $135.6,7$.

u. I. 24.4 . 5. I. $5 ; 6.4^{*}$. 7.6.2; 85. I*. I8. I. 16*, $37^{*} ; 3.7^{*}$. and in añgó, attó, átho, ihó, utó, úpo, evó, ó, téno, dattó, doșó, nó, pró, mó, yadó, yó, vidmó, só. (cf. utá.) [6. 94. 3. $\checkmark$ u (?): $+\overline{\mathbf{a}}:$ ótā (p. àout-). 5. 23. r. ótāu (do.). 5. 23. r. 6. 94. 3. [94. 3. óte (p. óte íty ấute). 5. 23. I. 6. ótās (p. ăout-). 6. 23. 2.

(cf. $/ 2$ vā.)

ukt a in sūktá.

ukthá: -ám. 6. 35.3.

ukthăni. 2. I2. 2. 
ukthãís. 7.63. I. I8. I. $+3^{\dagger}$. ukthéşu. 6. 35.2 .

(cf. ukthaçás-ukthyà.)

ukth a •çás: -çăsas. I 8. 3. $2 \mathrm{I}^{\dagger}$. [26.3. u k thām a dá (p. -thaom-): -dăni. 5 . u k th y à: -thías. I I. 7. IO. I 8. I. $22^{\dagger}$. ukthíam. 7. 47. I; 48. I ${ }^{*}$. I2. 2. IO. V ukş: ukșatu. I2. I, 7, 9.

ukșántu. 3. I2. 4 (mss. ed. uchántu). ukşantu. I8. 2.22.

ukșámānāa. 3. I2. I.

ukșită. $5 \cdot 5 \cdot 8$.

(cf. ukșaṇa, ukșán ?.)

+ pra: prāú "kşan. I9. 6. II".

prokșántí (p. praouk-). I0. 9. II. (cf. prókșanaa.)

+ s a m: sám ukṣāmi. I9. 27. 5 .

sám ukșatu. I0. 3. 17-25.

sám ukşata. 5.28.4. 7. 75.2.

u kṣa a ̣ a in prókșaṇa.

ukṣán: -șânam. 9. 10. $25^{*}$.

ukșánam. 3.11.8. 18.3.18*.

ukșánạas. 4. 24. 4 . (cf. āukșá, ukșấnna.)

u kṣănn a (p. -şáoan-): -nāya. 3.21. 6*. u kh á: -ám. II. 3. I8.

ukhă. 12. 3.23.

(cf. úkhya.)

ú khy a: -yān. 4. I4. 2.

ugrá: -ás. 2. 29.4. 3. 4.2, 3, 4, 7; I2. $6.4 .8 .2 ; 9.4^{*} ;$ I9.8. 5. 2. I* $^{*}$ 8.9; I9.6. 6. I6. I. 8. 5. 2. 9. 2 . 3, 7, I4. I0. 2.9 . II. I. I5. I2. 5. 21. I3.3.19. I5. 5.4. I9. I3. $5^{*}$, $7^{\dagger} ; 32 . \mathrm{I} ; 34.7,9 ; 52.2 ; 65 . \mathrm{I}$ (mss. ugras).

ugrám. 3. $5.4 ;$ I6. 2* 4. I3. $5^{\dagger}$; $27.7 ; 30.3^{*} ; 31.3^{*} ; 36.8$. 5. 3 . 10* ; $7.1^{\dagger}$. 6. $57.2 ; 97.3^{\dagger} ; 99$. I. 8. 5. I9. I0. $4.3,4 ; 6.6$-IO. I2. I. I. I5. 5.4. I8. I. $40^{*}$. I9. I3. IO"; 33. 4. 20. I32. 6.

ugra. I. IO. 2, 4. II. 2. IO, 2I. I 8. 3. $23^{*}$. I9. 34.8 (mss. -râ).

ugrắ. 2. 25. I. 8. 8. 9. 9. I. 3, IO. ugréna. $5.13 .3 ; 23.2$.

ugráya. 7. Iọ. I. 20.48.3 (not mss.). ugrásya. I. IO. I. 6. 73. I. 20. I 27. I I. ugrãú. 4.28.3. 8.6.20. II. 2.14. ugrău. 4. 23, 6, 7 .

ugră. I9. I5.4.

ugrầs. 3.1. 2 ; 19. $7^{\circ}$. 5. 21 111. 6 74. 3. 8. 7.4 , I0. 13.1.3.

ugrāís. 5.13.1.

ugrînām. 4. 2ł. 2.

(cf. ugrajit-ugrăyudha.)

ugraojít: -tāu. 6. II8. I. [13.4* ugráodhanvan: -vã. 8. 6. 18. I 9.

ugrá。băhu: -us. 4.24.2.

ugrábāhavas. 3. I9.7.

u g ram opaç y á: -yé (p. -é íty etc.). 6. II8. I.

úgrampaçye (p. -e íty etc.). 6. I I 8. 2. ugrampaçyấs. 7. 109.6. [19.7. u grắy u d ha (p. -ráoāy-): -dhās. 3. $\checkmark$ u c: cf. ókas, ocana, ocara.

+ ni: ní ucyatu. 2. 14.3. 6. 26.3.

(cf. ányokas, nyócana, nyocará.) u c cá : -cấ. I3. 2. 36.

uccāís. 4. I. 3.

(cf. uccāírghoșa, uccāiḥçravas.) u c cāi ḥ ç ravas in āuccāihçravasá. u ccāírghoṣa (p. -āíḥogh-): -ṣas. 5. 20. I. uccāírghoșā. 9. I. 8. $\checkmark$ uch, see $/$ I vas.

u c hó c a na (p. utoçó-): -nāu. 7. 95 . I. (cf. uchocanapraçocaná.) [95.I. uchocana opraçocaná: -nāú. 7 . u ch l a k há (p. utoçl-): -khāú. Io. 2. I. u ch hāsá (p. ut॰çv-) : -sé. I 8. 3. I 8 *. ujjeşa (p. utoj-): újjeşe. 4. I 7.I. út, see úd.

utá. I. $4.4^{\text {" } ; 8.3 ; 9 . ~ I, ~} 2,4^{2} ; 11.2$; I2. $3 ;$ I $5.2 ;$ I $7.2 ;$ I $8.4 ;$ I $9.3 ; 22$. $3 ; 28.4 ; 3$ O. I' 4 ; 3I. $4 ; 35.3 .2$. x. $3^{\dagger} ; 9.3,4 ; 12.1 ; 28.3 ; 29.3 ; 32$. 4; 34. I. 3. 5. 5; 6.8; 7.7; 10.9; II. I" $; 3.6 ;$ I $4.4,5 ; 16.1^{*}, 4^{4 *} ;$ I9. $4 ; 20.3^{*}, 8 ; 21.3 ; 28.2 ; 30.3 .4$. 2. $7^{*}, 8 ; 3.2 ; 4.5^{2} ; 6.3,5,6 ; 7.6$; $8.5 ; 9.3^{2}, 6 ;$ IO. 3 ; II. I ; I $3.1^{2^{* *}}$; I4. $5 ;$ 15. 7, $9 ;$ 16. $3^{3}, 4 ; 19.3 ; 20$. $4,8^{2} ; 21 . I^{*} ; 22.5 ; 25.5 ; 28.2,5$; 29. 5,$6 ; 3$ O. $.^{*}, 3^{*}, 6^{*}, 7^{*} ; 32.6^{*} ; 37$. 4. 5. 1. $7^{2}, 8 ; 7.8 ;$ I $2.2^{x} ;$ I $3.1,2$; 
I7. $8 ; 18.9$, I0; 21. II；22.13；23. 7,8 ; 30. I 2 ; 3I. 5. 6. 3. I, 3 ; I8. I, 2 ; 20. I ; 2I. 3 ; 27. $3^{+} ; 38.1$; 4I. I ; 59. 2 ; 6o. I, 3 ; 6I. I, 2, 3; 7I. I, 3; $92.2 ; 93.2 ; 95.3 ; 96.2^{*} ; 98.3$; IO9. I ; II3. 2 ; II9. I ; I2O. I ; I26. I* I III. 3. 7. 5. $5^{2}$; II. I ; 26. $8^{2}$; $35.2,3 ; 38.3 ; 49.2^{*} ; 50.5,6^{*} ; 5$ I. $\mathrm{I}^{2 *} ; 56.6 ; 73.7^{*} ; 74.2 ; 80 . \mathrm{I} ; 95$. 3 ; III. I. 8. $3 \cdot 3^{*}, 5^{*}, 5^{\dagger}, 7^{*}, 7^{\dagger}, 19^{*}$, $20^{\dagger} ; 4.22^{2 *}, 24^{*} ; 5.6^{2} ; 6.1,5,6,17$, $2 \mathrm{I} ;$ 7. I, 27, 28；8. I4；9.24. 9. I. 2 ; $2.14,24 ; 3 . \mathrm{I} ; 5.15$. I0. $1.27^{2}$; 3. $13-5 ; 4.5 ; 7.19,32 ; 8.12,17,23$ $25,27,28^{4}$; IO. I, 34 . II. I. 18,34 ; 2. $4, I_{5}, 29^{2 *} ; 4.7,16 ; 5.4 ; 6 . \mathrm{I}, 3,8$, I 7, 2I ; 9. I 5, 2I, 24 . I2. I. $3,25,28$, 32 ; 2. I7; 3.II, I2, I6, $27^{3} ; 4.18$, 50. I3. I. 15,$38 ; 2.26^{2 *} ; 3.7$. I 4 . I. IO $^{*}, 28^{\dagger}, 44^{2+} ; 2.48,69$. I7. I $2,29$. I8. I. $5^{*}, 48^{2 *} ; 2.33^{*}, 49 ; 3.53^{*}, 55^{*}$. I9. I. $2 ; 6.4^{*} ;$ II. $4^{*}, 6^{*} ;$ I $5.3 ; 22$. 2I (ed. ha); $32.4 ; 35.4 ; 44.6 ; 48$. $4 ; 50.5 ; 53.5 ; 56.4 ; 62 . I^{2}$. 20. I $27.5^{2}$ (not mss.); $135.8^{2}$. ută (p. utá). 7.97. $\mathbf{I}^{\dagger}$.

utó (p. -6́ íti). 4. I6.3; I9. I $^{3}$. 10. 7. 21 ; 8.29. I8. I. $48^{*}$. I9. 35.5 ; 47. 3. 20. I 35.8 (mss. utá).

u t a in amotá.

[lam).

u tokúu la: -am. I9. 25. I (mss. útkūutotamá: -ás. 3.5.2. 5.4. $9^{2}$. 6. I5. $I^{\dagger}, 2,3^{2}$. 8. 5. II. I9. 39.4. 20. I27. 8 (mss. támas).

uttamă. 6. 2 I. I.

uttamám. 1. 9.2, 4. 2. 3.2; 8. I. 3. 7.4. 4. 14. 6,$9 ; 22.5$. 5. I3. 2. 6. $63 \cdot 3.7 \cdot 53 \cdot 7^{+}, 7^{*} ; 83 \cdot 3^{*}$. II. I. $4,30,37$. I2. $3 \cdot 45$. I8. 3. 64 . [64. uttamăm. 9.5.29. I5. 6.3. I8. 3. uttaména. I. 9.3.

uttamé. II. 4. II, I8. I2. I. 8 .

uttamăs. 6. I2I. I. 7. 83. 4 .

uttamăni. 5. 4.8. 7. 73. 10*" uttamébhyas. I 9. 22. I 2.

(cf. upottamá, uttamāñjanī.)

u t t a m ã ñj a ñi (?), see uttarāñjaní. úttara: -as. 3. 5.5 (mss. uttarás).
4. 22. 6. 5. 28. 10. I I. 8. I8. 12. I. 54 útotaras. I9. 46.7 (mss. uttarás). úttarā. 6. I6. 4.

útotarā. 3. $18.4^{2 *}$. I0. $2.24,25$.

utotare. 3. 18.4 .

úttaram. 4. I4. 8. I I. 5.6. I2.3. I0. útotaram. 2. 27. 7. 4. 31. 6*. 6. 54 . I, 2. 7. $26 . I^{*}$. I0. 6. $3 I$; 7.3, II. I8. $4.5 \mathrm{I}$.

úttarām. 6. I18. 3. 8. 2. 15. úttarāmouttarām. 3. ro. $\mathrm{r}^{*} ; 17.4^{*}$. 12. I. 33 .

úttarena. ro. $8.4 \mathrm{I}$.

útotarasmāt. 7. $5 \mathrm{I}$. I*.

úttarasmin. II. 2.25.

útotarasmin. I. 9. I.

úttarasyām. 4. 14.8.

útotarāu. I0. 2. 2.

útotare. I9. $7.4 ; \mathrm{I}_{3} . \mathrm{II}^{*}$.

útotarā. I8. I. I I*.

úttarebhyas. 6. 134.2. [taré-). útotarebhyas. 19. 22.13 (mss. utútotarābhyas. 3. 18.4 .

(cf. ahamuttará, caturuttará, uttaratás-uttarấvant.)

uttaratás. 4. 40.4. I8. 4. 9.

uttara otvá: -vé. 3. 8.3 (mss.).

u tta ra odrá (-drú ?): -rāú. 6. 49. 2.

ut otarám. 6. 5. I.

uttara॰hanú: -ús. 9.7.2.

uttarāñ janî: -ním. 20. 133. 5 (mss. úttamāmọ jánim), 6 (mss. úttamām jánīn).

uttartat. 6. 4 O. 3. 8. 3. $20^{\dagger}$; 5. I7. I0. 9. 8 . II. 2.4 ; 6. I 8. I2. I. 32 ; 3. 24 . I8. 4. II. I9. 15.5 (p. utot-); I6. I ; 48.4 (p. utot-).

u tt a rávant (p. -rá。v-): -ntam. 4. 22. 5. I0. 8. 22.

uttarắvat. I2. 3. 10, 47 .

uttāná: -năyām. 9. 9. 14 *. 20. 133 . 4 (mss. úttānầyāi).

uttānáyos. 9. I0. 12 *.

uttānăs. I2. I. 34 .

(cf. uttānaparṇa, uttānaçî́van.)

uttā na $\circ$ parṇa: úttānaparṇe. 3 I 8. 2*.

uttānaoçîvan: -variss. 3. 2I. Io. 
utotirá: -ás. I 9. 32. I (ed. úttaras). utotudá: -ás. 3. 25. I.

ut thātṛ: -túr. 9. 4. I4.

ut •păt a: -tās. I 9. 9. 7 (s. mss. -ātăs). ut。părạ̣a: -ṇasya. 5. 30. I2.

Gtsa: -as. 6. 106. $\mathrm{I}^{\dagger}$.

útsam. 3. 24. 4. 4. 27. $2 ; 31.5^{*}$. I7. I5. I8. $4.35,36$.

útsās. 4. 15. 7, 9.

Ǵtsāsas. I. 15:3.

(cf. utsyà.)

u t s y à : -síās. I9. 2. I.

úd. I. IO. I ; 29. $5^{2 *}$. 2.6.2. 3. 9 . 5 ; I7. 3 ; I9. $6 ; 24.4 ; 3$ I. IO $^{2}$. 4 . 3. I; $4.2^{3}, 4.5 .9 .8^{6}$; I4. II ; I9. I; 23. $6^{*}$. 6. 5.1 ; 5I. $2^{*} ; 52 . \mathrm{I}^{\dagger} ; 71.2$; II9. I ; I2O. I; I2I. 2 ; I3O. 4.7. 53. $7^{*} ; 80.1 ; 83.3^{*} ; 95.1$; II3. I. 8. I. $2^{4}, 3,16^{2}, 17^{4}, 19 ; 2.8,9,15 ; 7$. 28 ; 9.6. 9. 2.2. I2. I. 39. I3. I. $2,36,43$; 2. I, $9,16^{*}$. I4. 2. $16^{*}, 36$. I8. I. $44^{2 *}, 6$ I ; 2. 22,$43 ; 3.52^{*}$. I9. I4. I (mss. utoçréyas).

(cf. ud $+\sqrt[V]{ }$ /añc, I aj, an, arc, av, I aç, $\mathbf{i}, \overline{\mathbf{a}}+\mathbf{i}$, abhi $\ldots \overline{\mathbf{a}}+\mathbf{i}$, upa $\ldots \bar{a}+\mathbf{i}$, apa ... i, abhi ... i, prati ... i, ing , ir, iș, ubj, uș, I ūh,

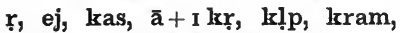
khid, gam, I gā, $\bar{a}+$ gā, 2 gāa, grath, grabh, grah, car, ā + car, carany, chid, ji, takș, tan, tud, tṛ, dịp, I dhā, 2 naç, nī, pat, sam . . pat, pad, 3 pā, pū, 2 pr, bharts, bhid, bhū, bhṛ, majj, mathāy, mad, I mā, muc, mrj, yam, yach, $\overline{\mathbf{a}}+$ yach, yā, I yu, yuj, yudh, rañj, ruc, ruh, $\bar{a}+$ ruh, lup, vac, vad, 2 vap, 3 vas, vah, vij, vip, vi, çiș, çuc, çrath, çri, çvañc, çvas, sad, sā, ava + sā, sṛ, sṛj, sṛp, stambh, sthā, abhi ... sthā, spŗ̣, han, hā, hū, hṛ, hṛș ; and uttarám, údañc, uttamá, úttara, udvát, utkúla, uchlakhá.)

$\checkmark$ u d, und: undáte. 5. I9. 14. undantu. 6. 68. r, 2. [odaná ?.) (cf. útsa, udán, udaká, udra, + vi: vioundatí. I8. $3.72 ; 4.57$. ví ūdus. 6. $22,1^{\dagger}$

u d a ká: -ám. 3. 13. 4. 5.14.13; I0). 8. 6. $100.2 ; 139.4$. 7.73.11\%9. 9. $5.5 ; 6.4,44^{2}, 48 ; 9.5^{\circ}$ I0.8. I 4 . I 2. 3. 30. I 5. I I. 2, 4; 13.8. udakéna. 4.34.6,7. 6.68.1. udakásya. I. 15.4.

udaké. 4. I6.3. udakéşu. 9.2.6.

(cf. ápodalka, súrodaka, udákātu dákātman (p. -kaoăt-) : -mănas. 8. 7.9 .

u da ktás. 8. $3 \cdot 19^{\dagger} ; 4 \cdot 19^{\dagger}$.

ú d a ñ c: -añ. $\quad 5 \cdot 4 \cdot 8.9 \cdot 7 \cdot 21$.

údak. 20. 128.3 (mss. u tád); I 34. I-6 (ed. udák).

údīcí. 3. 27.4. I2. 3. IO.

údīcìm. I 5. 2. 4 ; I4. 4 .

údīcyāi. I 2. 3. $5^{8}$.

údicyās. 4. 40.4. 5. 10.4. 6. $9^{8}$. 3. 9. 3. 28 . I 5. $4.4^{2} ; 5.4^{2}$. I 8.3 . 28. I9. $17.7 ;$ I8.7. [3.33. údīcyām. 3.26.4. I 5.2.4. I8. údīcīs. I2. I. 31 ; 2. 4I. [cyà.) (cf. uccá, udaktás, udīcína, udīu daodhí: -ím. 4. I5.6, II.

udadhés. I. 3.8 .

udán: udnă. 3. I2. 4 (mss. utnă, өd. unnâ). 7. 45.2 (mss. utnâ). [nás). udnás. 7. I8. I (mss. utnás, ed. ūdhudábhis. 20. 134. I (not mss.).

(cf. udaká, udadhí, udanvántudaplutá, udavāhá, udahāra.)

u d a n०vá n t: -átī. I 8.2 .48 (m. mss. ed. -vatí).

udanvátīs. I9. 9. I.

uda $\mathbf{a}$ ú: -ús. I8. 3.37.

uda。prút: -tas. 6. 22.3. I 8. 2. 22. u da plutá: -ám. Io. 4.3,4 (oiva). udoáy a na: -am. 5. 30. 7.

udára: -am. 4. I6.7; 34. I. 9. 3. I $5 ; 7.16$ IO. 7.32 ; IO. 22 . II. 5 . 25. I5. I. 7 .

udáreṇa. II. $3 \cdot 42^{2}$.

udárāya. II. 2.6.

udárāt. 2. 33. $4^{\dagger}$. 9. 8.9, I I, I2. I O. udáre. I I. 5.3.

(cf. udaradārá.) 
u da ra odārá: -ás. II. 8.42. u da $\circ$ vāhá: -hăs. I 8.2.22.

uda ohārá: -ríam. Io. 8. I 4. u d āna in vyānodāná.

u doāp y à : -píam. I0. I. 7 .

udoārá: -ré. 4. II. 3.

udārắs. II. 9. I6.

údārās. II. IO. I.

udārăn. 6. II 3. 2. I I. 9. I, I 5, 22, 2 4. udārănạām. IIr. 9. 6.

udārathí: -ím. 4. 7.3.

u dit a in ánudita.

údoiti : -tāu. 3. 16. $4^{\dagger}$. 7. $5 \cdot 3$.

úditayas. I0. 2. I0.

u dĩcîna: -nāis. I2. 2. 29.

u dīc y à: -cíam. 4. 7.2.

[14.

u du mbára, -bála: -ras. 20. 136. udumbálam. 8.6.17. and

u dumba lá: -lāú. I8. 2. I3*.

(cf. āúdumbara.)

u doṛ́c: -ci. 6. 48. I-3.

u dogíthá: -ás. II. 7.5. I5.3.8. uddharṣín (p. utoha-): -ínam. 8.

6. I7.

uddhí: -ís. 8. 8. 22.

udobhíd: 5. 20. II.

ud॰bhú: 9.2. 6 .

udbhvís. I8. 4.26.

u d ○bh y a sá: -sấs. II. 9. I 7 .

u d y a in anatyudyá, ritódya.

ud॰ yầna: -am. 8. I. 6.

u doy ugá: -ám. 5. 22. II.

udra in samudrá.

udovát: -tas. I2. I. 2.

udovahá: -ás. I9. 25. I.

udovà̀can a: -am. 5. 8.8.

$\checkmark$ und, see $1 /$ ud.

un māna in mahónmāna.

unmocan a in

unmocana opramocaná: -né (p. -é íty etc.). 5. 30. 2-4.

ú pa. I. I. $4 ; 4.2^{*} ; 7.5 ; 28.1 .2$. 5.2. 3. $4.5 ; 8.4$; IO. II ; I $2.1,9$; I4. $6 ; 15.7 ;$ I8.6 $6^{\dagger}$. 4. II. II 2 I. $2^{*} ; 24 . \mathrm{I} ; 25.7 ; 31 . \mathrm{I}^{\dagger} ; 32.6^{*} ; 34$. 5-7. 6. 35. I, $2 ; 37.1 ; 49.3^{*}$. 7. I2. I; $27.1 ; 32 . I^{*} ; 75.2$ IIO. 3 . 8. 10. 21 . 9. $4.23^{3 *} ; 7.26$. 10.4 .
I4. II. I. 34 I2. $3.3,34,40$. I3. I. I4; 4.27. I4. I. I $5^{*}$. I8. $2.4^{\dagger}$, $2 \mathrm{I}, 53,60 ; 3 . \mathrm{I}, 5^{2}, 5 \mathrm{I}^{*}, 66^{*} ; 4 \cdot 4 \mathrm{O}^{2}, 65$ (s. mss. upao). I9. 4. $3 ; 3$ I. $7 ; 34$. $8 ; 52.4$ (mss. upao); $56.3 ; 58.2^{2}$. 20. I27. I4.

úpo (p. -oíti). I3. 4. 44, 45.

(cf. upa $+\sqrt[V]{ } \sqrt{ }$ aj, av, 2 as, ās, $i$, ava $+\mathbf{i}, \operatorname{ud} \bar{a}+i, \bar{a}+i$, pra $+i$, sam $+\mathbf{i}$, I $\overline{\mathbf{u}}$, r, r, rs, eș, $\overline{\mathbf{a}}+\mathrm{I} \mathbf{k r}$, I $\mathbf{k s ̦ i}$, 2 kși, gach, gam, ā + gam, I gā, 2 gā, grabh, ghrā, jīv, jñā, tap, tas, pra + tṛ, das, I dā, diç, dṛç, dru, I dhā, sam + nam, nī, samparā + nī, nu, pat, pad, prc, bandh, brị, brū, bhṛ, mi, yach, yā, sam + yā, yuj, labh, vac, vad, pra+vad, vadh, 2 vas, $\overline{\mathbf{a}}+\mathbf{v a h}$, I vā, viç, $\bar{a}+$ vṛt, vyā, sam + vyā, çak, çī, çrỉ, çru, çvas, sac, sad, ni + sad, sic, srjj, ava + srjj, srpp, stambh, stu, stṛ, sthā, spṛç, han, hā, hṛ, $\overline{\mathbf{a}}+\mathbf{h r ̣}$; and upamá, úpara, upāñc, upakvasa, upajika, upatṛnya, upapakșyà, úpamāsya, upānçú, upānasá, upastí, upajíhvikā.)

u paokvasa: úpakvasa. 6. 50. 2.

upaojấ: II. I. Ig.

upajíhvikā: 20. I29. 20 (mss. úpajihvíkā).

upa ○jîka: -kās. 2. 3.4.

upajīkās. 6. тоO. 2 (ed. -jík-). [j-). upa ojivá: -văs. I9. 69. 2 (mss. úpa upaojívanitya: -as. 8. IO. 22-9. upaotṛnya: úpatṛnya. 5. I3. 5. u pa。d eç y à : -çíam. II. 8.23. upaodrașț̣́: -țấ. II. 3. 54 . u paodhăna: -ne. I4. 2.65. upaodhí: -ís. 6. 70. 3 . u paodhmâtna: -ni. 8. 8.2. upa०nāhá: -ás. 9. 4.5. up a opakṣ y à: -șíās. 7. 76. 2. upa p parcana: 9.4. $23^{\dagger}$. upaobárhana : -am. 9. 5.29. I4. I. 6 . I5. 3. 7 .

upabárhạ̣e. I2. 2. I9, 20.

(cf. kaçipūpabarhaṇá.) u pa b dá: -dāís. 8. 4. I $7^{*}$. 
u pabdi: úpabde. 2. 24.6.

upaobhŕt: I8. 4.5.

upabhṛt. I8. 4.6 (mss. -bhṛ̂t).

u pa má: -mấm. I $8.3 .65^{\dagger}(\mathrm{s}$. mss. úpa mắm; p. upaom-). upamásya. 5. I. $6^{\dagger}$ (mss. ed. úpama-). upamás. 4. I. I (p. upaom-). úpaomāsya: -am. 8. 10. I9. u paomít: -tām. 9. 3. I.

úpara: -as. 6. 49.2.

úparasya. 6. $49 \cdot 3^{*}$. 18. $3 \cdot 23^{*} ; 4.4$. úpare. 9. 9. $12^{*}$.

upári. 8. 9.6. I8. 3.25-35.

(cf. upariçayaná-uparispứç.) u pari॰ç a y a ná: -ám. 9. 6.9. upárișțāt. 4. 40.7. 8.8.13. u pariospŗ̧̣: -ças. 5. 3.10†. u pavañ cana in sūpavañcaná. u pa०vâa: -ấm. I2. I. 5 I. u pa॰vāká: -ám. 9.9. 8*. upaovásana: -ne. I4. 2. 49, 65 . upavita in prācīnopavítá. ú pa॰çruti: -is. I6. 2.5. úpaçrutyā. 2. I6.2. upa॰çvasá: -sé. II. I. I2. upaos at tṛ́: -tá. 7.82.3. upasattáras. 2. 6.2. 3. 12.6 . upaosád: -das. 6. I42.3. 9. 7.6. I5. 3. IO, II.

upasarga in deçopasargá. u pa s arpaṇa in sūpasarpaná. upaosécana: -am. II. 3. I3. (cf. anupasecaná.)

upaostára: -re. I4. 2. 2 f. upaostáraṇa: -am. 5. 19. I2. upaostít: -ís. 6. I5. $\mathrm{I}^{\dagger}$. upastáyas. 6. $15 \cdot \mathrm{I}^{\dagger}$. upastín. 3. 5.6,7. upaosthá: -thâs. 12. I. 62 . upáostha: -as. 7.6.4. upástham. I3. I.4. upásthāt. 3. II.2* 7. 53.3. I4.2.25. upásthe. 2. 28. I, 4 ; 29.4. 8. 4 . $9^{*}$. I3. I. 38 . I 4. I. $2^{*}, 47$. 18.3 . $43^{*}, 65^{*}$. 20. 34 . I6.

(cf. upasthá, rathopasthá.)

u paspṛ́ç: -ças. 20. 127.2. u paohatnú: -úm. I8. I. 40*. upaoh a tyã: -ằm. 5. 4. 10.

upaohávya: -am. II. 7.15 (8. 148s. -havyám).

u pảnçú (p. upa॰a-): 4. 32. $7^{*}$.

upaka:-ke (p. -e íti). 5. 1 2.64; 27.8. upã̃ c in upăka.

u pānasá (p. upaoān-): -săt. 2, 1 f. 2.

upānáh: -hì. 20. 133.t (mss. upânáhi).

upāy a na in sūpāyaná.

u pãvị́t (p. upaoãv-): -tas. 6. 77.3. upott amá (p. upaout-): -mébhyas. I9. $22.1 \mathrm{r}$.

upohá (p. upaoũh-): -ás. 324.7

1 ubj: ubjátam. 8. 4. I".

ubjántas. 8. 8. I3.

$+\mathrm{u}$ : : úd ubja. II. I. 7.

+ ni: ní ubja. 8. 8.6. II. I.6.

+ vi: ví ubjatu. 9. 3. I8. [2.27.

+ sam: sámoubjitas. 9.3.20. Io. sámoubjitām. 9. 3.18.

$\checkmark \mathrm{ubh}, \mathrm{umbh}$ : + apa: ápo 'mbhata. 8. 8. II.

ubhá: -bhāú. 3.20.6 $6^{\dagger} \cdot 4 \cdot 32 \cdot 7^{\dagger}$. 5. 7.6. 6.89.3. 7.70.4. 8. 4. I3". 9. 3.9. I0. 4.8. I I. $2.14 ; 7.3$; 10. II. I2. 4. I7. I3. 2.6, I3. I9. 32.5 . ubhà. 3. 4. 4. 4. 30. $1^{2 *}$. 5. 3.9"; 25. $3^{\text {t. }}$ 7. $44.4^{*} ;$ I IO. I. 8. 2. I5; 3. $3^{*} ; 6.4$ I0. 4. I6. II. 6.5. I3. 2. IO, 30. I4. I. $9^{*}, 5+$; 2. I3. I8. I. $54^{*}$. ubhé (p. -é íti). I. I. 3. 2. IO. I-S. 3. 4. $5 ; 18.5^{*}$. 4. 9. 10. 5. I8. $5 ; 30$. 2-4. 6. I. $3 ; 58$. I; I3S. 2 . 7. 9. I" ; 57. $2^{2 *}, 2^{2 \dagger}$. 8. 5.3. 9. 4. I0. 10. 7. 35. II. 5. I, 8. I2. 3. 5.6. I9. I5. 5 . ubhăbhyām. 6. I9. $3^{*}$. 7. 56.8. 8 . 2. 20. II. 2. 16. [38. 2 . ubháyos. 7. 76. 4. 10. 4. 10, I5. 19. (cf. ubháya.)

u bháya: -as. II. 7. II.

ubháyam. 4. 3r. 7".

ubháyena. I2. 4 . I8.

ubháye. 7. 79.2. 8. I0. 9. I2. I. 47. ubháyāni. 7. I09. 2.

ubháyān. I2. 2. 44; 3.6. I8.4.39. ubháyīs. 8.5.9.

(cf. ubhayadyús-ubhayāvín.) 
ubhaya॰dyús. I. 25.4. 7. II6. 2 . 8. I0. 2 I.

u bhay ă d: -dam (-dan?). 5. I9. 2. u bh a yấda t: -dati. 5. 3I. 3 .

ubhayădatas. I9. 6. I2*.

ubhayāvín: ubhayāvin. 8. 3. $3^{*}$. ubhayāvínam. 5.25.9.

úras: 9. 5.20. I0. 2. 4. II. 9. I4. úrasā. II. $3 \cdot 4 \mathrm{I}^{2}$.

úrasi. I0. 3 . II ; 8. I8. I2. 5.48. I3. 3. 14. I9. 32.2.

u rú : -ús. 7. 3. I. II. I. I9; 2. II. I2. $3 \cdot 38$. 13. $4 \cdot 52$.

urú. 2. I2. $\mathrm{I}^{2}$. 4. 2.4 ; II. I. 5. 3 . 6*. 6. 40. I; 49. 2. 7.6. $4 ; 26.3^{2}$. I0. 7.35 I I. $2.10,27 . \quad$ I2. I. 20. I4. 2. 69. I8. 2. 49 ; 3. 59. I9. 9. I. ưúm. 6. 33.3. 7. $84.2^{*}$. 9. 2. II. I2. I. I. I4. I. 58 . I9. I5. $4^{*}$.

urós. 7. 26. 8 ; II $8 . I^{*}$.

urāú. I 8. 2.20.

urúșu. 7. 26. 3*.

urvi. 4. 2. 4 . I6. 3.6 .

urui. I9. 47.2.

urvím. I 8. 3. $22^{\dagger}$.

[18. I. $32 *$.

ưví (p. -ííti). 4. 26.3. II. 5.8. urvis. 3. 20.9. 4. II. I. 8. 9. I6. 9. 2. II. I0. 7.35 . I3. I. 4,$46 ; 3$. I, 6. I8. 2. $6^{*}$.

urvías. II. 7.18.

urvis. 5. 3.6*.

urvíbhis. 12. 2. 48 .

(ef. urúkşaya--urujman, urúloka --urūṇasá, urvañc-urviyâ.)

urú Ł ks a y a: -yās. 7.77.3.

u ru॰gāyá: -ás. 2. I2. I. 7. 26. I*. urugāyám. 4. 21. $4^{*}$. 5. 17.11*. 19. II. $5^{*}$.

uru०gùula: -lāyās. 5. I3. 8. uru॰grāhá: -hāís. I I. 9. I2 (ūr-?). uruocákṣas: -șās. I9. Io. $8^{*}$.

uruojman: 6. 4.3.

úrụ̣ ḍa: -ḍas. 8. 6. I5.

urú。loka: -am. 5.3.3*

uru॰vyác: -ce. 6. 4I. 2.

uruovyác as: -cās. 5. 3. $8^{*}$.

uruvyácasam. I 8. 3. $49^{*}$.

uruvyácasā. 5. 27.8.
Vuruṣy: -șyă (p. -șyá). 6. 4.3. uruṣyatām. 6. 3. 3. [I3* urū ṇasá (p. uruona-): -sāú. I8. 2. urvá: -ás. r6. 3.3.

urva ñ c: urūcî. I9. 10. $3^{*}$ (mss. ūr-). urūcím. 7.6.2.

ưūcî (p. -ííti). 3. 3. I.

urūci (p. -ĩ íti). 4. 26. 2.

urvárā: I4. 2. 14 .

urvárāyām. 10. 6. 33 .

urvárās. I0. I0. 8.

urvári: -iss. ro. 4.21.

u rváçĩ: -is. I 8. 3.23*.

urvārú: -ruăs. 6. I4. 2.

(cf. urvāruká.)

urvāruká: -ám. I4. I. I7.

urviyấ. 5. I2. $5^{*}$. I8. 1. $2^{*}$.

ulá: -ám. I2. I. 49.

úlapa: -peșu. 7.66. I.

ululí: -láyas. 3. 19.6.

úlū ka: -as. 6. 29. I.

(cf. kapotolūká, úlūkayātu.)

úlūka॰y ātu: -um. 8. 4.22*.

ultúkhala: -am. II. 3. 3. I2. 3. I3. 20. I36. 6.

ulúkhhale. ro. 9. 26.

(cf. ulūkhalamusalá.)

u lū kha la omu sa lá: -lấni. 9. 6. I5.

ulkấ: I9. 9.8 (not ed.), 9 (-âs ?).

ulkănirhata: -am. I9. 9.8 (mss. ulkấ níro). [ulkầ 'bhíoh-)

ulkăbhihata: -am. r9. 9.9 (mss. ulkuși in

ulkuștomant: -mān. 5. 17.4.

úlba: -ás. 4. 2.8. (cf. avákolba.)

u çán ā: -ām. 4. 29.6.

$\checkmark$ uṣ: óṣa. I9. 29. $7^{4}$.

óṣantĩ. I2. 5.54 .

(cf. VI vas, uṣná, oṣá.)

+ ud: úd oșatu. I2. 5.72.

+ ni: ní oșa. 8. 3. $21^{*}$.

ny òșatu. 12. 5.73.

ní oşatam. 8. 4. ${ }^{*}$.

+ s a m: samoóșantī. I2. $5 \cdot 54$.

uş: uṣás. I6. 6. $6^{2}$. (cf. vyúș.)

uṣás: -şắs. 4. 4.2. 7.69.1. 9.6. 45. II. 6. 7. I5. 2.2. I6. 6. 5. I8. I. $20^{*}$. I9. I $2 . I^{*} ; 48.2 ; 50.7$. 
úṣas. I6. 6. 2*.

uşásam. I0. 2.16 .

ușâsam (p. uṣás-). I 3. $2.46^{\circ}$.

ușăm. I2. 2. 45 (ușấmouṣăm).

ușásā. I6. 6. 5 .

uşáse. I9. 48.2; 50.7. [7.31.

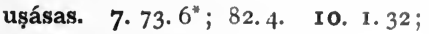

ușásã. 8. 9. 12.

ușắsas (p. ușás-). 3. 16. 7".

ușásas. 3. I6. 6". 4. 21. I". 7. 22. 2. I0. 8. 30. 14. $2.3 \mathrm{I}, 43,44$. 16. 4. 6. I7. 30. I8. 3. 24 ". I9. 10. 10"; 49.6 (p. anuouş-).

[18. $4.58^{\dagger}$.

uşásām. 3. 7.7. 7. 81.2* ; 82.4, 5. (cf. sūşás, uṣâsānáktã.)

uşăsānáktā (p. uşás-): 5.12.6"; 27.8. 6. 3.3.

ușți in vyùșț.

ú ș ț a: -asya. 20. I32. I3 (mss. ușțrá-). úșțrās. 20. 127.2.

uṣṇá: -ṇéna. 6. 68. I.

uṣnée. 20. 134.5 (not mss.).

uş̣̂ăn. 8. 9. 17.

uṣn ṇ̂h: -ṇik. I9. 21 . I.

(cf. ușníhā.)

uş ṇi ha ã: -ās. 6. I34. I (p. -hā). [10. 20. uşṇ́hābhyas. 2. 33.2*. 9. 8.21. 10. (cf. ușṇihākșará.)

[I. 15. u sụihā kşará (p. -hã॰ak-): -ás. I 3 . uṣnt is a: -am. I5. 2. I-4.

ú şy a l a : -lāni. I4. I. 60.

(cf. samușyalá.)

usrá: -ră. 12. 3.37. (cf. usríya.)

usríy a: -as. I. I2. I. 9. 4. I.

usríyāyãs. 7. 73. 5,6. 8. 3.17*. usiríyās. 4. 26.5. I4. I. 32.

usríyābhis. 3. 8. I. 5. 20. I; 21.3. usríyāsu. 7. 73.4.

ũtí: -tit. 7. 77. I". I8. I. $5 \mathrm{I}^{*}$. ūtáye. 4. $18.1 ; 25.6 ; 27.1$. 6. 35 . I ; 80.2. I9. 24. 7".

ütíobhis. 7.3I. I". I7. I0. I9. I5. I*. údhan, túdhas: tudhas. 4. II. 4 . 8. 10. 12. 9. 7. 14. I0. 7.19;9.22; I0. 7 . I2. 4.18 .

údhani. 7. 72. $3^{\prime \prime}$. (ớ. kỉaàlodhan.)

ū ná: -ás. I0. 8.44 (m. ms8. ed. Q́nas). ūnám. 12. 1.61.

ūnéna. 10.8.15. (cf. ậūna, ekona.)

ábadhy a: -am. 9. 4. 16;7.17. II. 3. I2. 12. 5. 39.

úm a: -ãs. 5. 2. $1^{\circ}, 3^{\circ}$

ū rú: -úm. 14.2.39.

ūrú (p. -á íti). 8.6.3. 9. 7.9; 8.

7. I0. $2.3 ; 9.2$ I. II. $3.44 ; 8.14$. I4. 2. $38^{\circ}$. 19. $6.5^{\circ}$.

ūrú。bhyām. $2.33 \cdot 5^{\circ}$ I I. $3 \cdot 44^{2}$. ūrvós. I9. 60. 2.

t̂́ $\mathbf{r j : ~ - j a m . ~ 2 . ~ 2 9 . 3 , ~} 5^{3}$. 3. 10.7. 4 . 39. $2,4,6,8$. 5. I7. II". 6. $22.2 ; 28$. $I^{*} ; 40.2 ; 79.2 .7 .60 .1 ; 79.3^{2} .8$. 9. I3. 9. I. $7,9,20 ; 5.24$. I2. I. 29 ; 2. 46 . I 8. $3.43^{*} ; 4.4,30,34,36,40$. 19. 7.4 .

ūrjé. I. 5. I". I8. $4.8 \mathrm{I}$. 19.37 .3 . ūrjás. II. I. 15. I8.4. 53, 54. 19.45. 3 . úrjas. I2. I. 12.

$\overline{\mathbf{u}} \mathbf{r j a s}$ in

ťr rjasvant: -vān. I9. 46.6 . úrjasvantas. 7. 60.2.

úrjasvatĩ. 3. 12.2; I 7.9. 9. 3. I6. ūrjasvatī (p. -īíti). 2. 29. 5 .

ū rjấ: II. 7.13. I6. 2. I.

úrje. 8. Io. II, 26.

ūrjấm. 2. 29.7. 8. 10. $26^{2}$. 9.6.33. ūrjáyā. 4. 25.4. 5. 1.7. 9. 6. 45. I0. 6. 26.

ūrna in [úrṇamom- ${ }^{-}$).

úr rṇ a mra d a s: -dās. I $8.3 \cdot 49^{*}$ (p.

ū rdhvá: -ás. 4. 12.6; 35.3. 7. IO2.

I. 9. 9. 10*. I0. $2.26,28 ; 7.4 ; 8$. I9; IO. I9. II. I. 7 ; $4.25 ; 9.2$ I. I3. I. II. I5. 3. I ; 15.3. I9. 46.2. ūrdhvă. 3.27.6. 7.14.2 (p. -văs). ūrdhvám. 5.27.9. Io. $2.3,24,25$; 8. I4. I I. I. 9. I8. 3. 29.

ūrdhvắm. I 5. 6.2; I4. 9 .

ūrdhvâyāi. I2. 3.60.

ūrdhvâyās. 4. 40.7. 5. 10.6. 9.3. 30. I5. $4.6^{2} ; 5.6^{2}$. I9. I7. 10; 18. I0. ūrdhvặyām. 3. 26.6. 4. I4.8. I 8. 3. 35 [13. 13. 3. 16 . ūrdhvấs. 5. 27. I. I0. 2. II. I2. I. 
ūrdhvă. 5. 27. I.

ūrdhvấn. I3. I. 53,54. [svapna.) (cf. ūrdhvábudhna -- ūrdhváūrdhvá。budhna: -as. I0.8.9. $\overline{\mathrm{u}} \mathrm{rdhvá} \circ \mathrm{māy}$ u: -us. 5. 20.4. ū rdhvá osvapna: -nās. 6. 44. I.

ū rmí: -ís. I0. 5. I6. I4. 2. 16*.

ūrmáyas. 6. 52. $3^{\dagger}$.

ū ṣmán: -mănạam. 6.18.3. l' $^{\prime}$ ū h: ohatām. I9. 44. Io (mss. ohatu, rohatu; p. roh-). (cf. ūha.)

+ a dhi: ádhy āuhat. I0. 2. 17.

+ a pa: ápo "hämi. I4. I. 38. ápa ... ūha. I8.2.57.

+ ud: úd ūha. II. I. 9 .

+ upa: ef. upohá.

$+\mathrm{n}$ is: niroúhan. 8. 2.9.

+ pari: pári ūhāmi. I9. 37.3.

+ prati: práty āuhatām. 7.53. I. práty āuhan. 5.28.8. I2.2.29. práti ... āuhata. 9. I0. $7^{*}$.

+ s a m: samoúhasi. I. I3.2. (cf. samūhá.)

$\sqrt{ } 2 \overrightarrow{\mathrm{u}} \mathrm{h}:$ ohate. 20. I3I. IO. + api: apioūhé. 8.4. $14^{*}$.

ūha in upohá, samūhá.

$\checkmark$ r: iyarta. 6. 22.3. armavat (?). $5.2 .8^{\dagger}$.

àra. 4. 27.6.

ārat. I0.4. I.

ṛtvâ. 4. 40. I-8. 6. 120.2. I2. 4. 53 . arpaya. I0. 9. $\mathrm{r}$.

áxpayan. 5. 19. 2.

arpipam. I2. I. 35

árpitam. 9. 9. $12^{*}$.

(cf. \/rch, ará, ara, áraṇa, áritra, árpana, arman, arva, árvan, árvant, āra, r̂́ti, ṛtha, rátha.)

+ ava: cf. ávarti.

+ ã : ấ 'ratām. I4. 2. 16*'

ârpitas. 6. II2.3. I0. 7. 14. árpitam. I0.8.6; 10. 33 . árpitās. 10. 7. 12. I3. 3. ro. árpitāni. 8. 9. I9 d. 18. I. I7. ărpitāni (p. ằar-). 8. 9. Ig b. árpitā. I I. 5.9. I 8. 2. 6๋. (cf. árti.)
+ u d : cf. udārá.

+ u pa: upārimá (p. upaoār-). 6. 45 . $2^{*}$; 96.3. 7. ro6. I.

úpā 'rāma. II. 2. I7.

+ ni: ní arpaya. 10. 3. 5.

ní arpayatam. 8. 4. I*.

níoarpitās. 10. 3.15.

+ nis: niroŕtya. 10. 2. 2 .

(cf. nírṛti, nirṛthá.)

+ prati: pratioarpayitvá. 12. 2. 55 .

+ s a m: sám arāmahi. I I. 2. 7, 20.

sám ṛ̣̣vatām. I 8. 2.9.

sámoṛteșu. I9. I3. II*.

sám arpaya. 5.22.6. 6.66. I. (cf. samará.)

ŕ kvan: -vaobhis. I8. I. $47^{*}$.

$\mathbf{r} \mathbf{s} \mathbf{a}$ in

ŕkșaogriva: -am. 8. 6.2.

ṛ kṣa ra in anṛkșará.

ṛ kșáka: -am. I8. 2. 3 I (mss.).

r kşî́kā: -ām. I2. I. 49 .

ŕk०s a m çita: -as. I0. 5.30.

ṛkosāmá: -măbhyām. I4. I. II*

ṛ́c: ṛ́k. II. 7.5. I4. 2.7I.

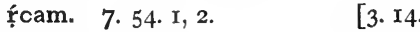
ŗcă. 6. $28 . \mathrm{I}^{*}$. 9.5 .5 ; 10. $18^{*}$. I I ṛcás. 9. 10. $18^{*}, 19$.

ŕcas. 9.6.1. I0. $5.30 ; 7.14,20$; IO. I4. II. $6.14 ; 7.24 ; 8.23$. I2. 4. 27,28 . I3. 4.38 . I5. 3.6; 6. 3 . 19. $6.13^{*} ; 54.3$.

rgobhís. I0. I. I2. I2. I. $38 ; 4.49$ rg॰bhyás. I0. 5.30. I3. 4. 38 .

ŗcăm. I0. 8. ro. I5. 6.3.

(cf. udṛ́c, ṛca, ṛ́kvan, ṛ̂ksamçita, riksāmá.)

r c a in ardharcá, așțarcá, așțādaçarcá, ekarcá, ekādaçarcá, ekānṛcá, caturṛcá, caturdaçarcá, tṛcá, trayodaçarcá, daçarcá, dvādaçarcá, navarcá, pañcarcá, pañcadaçarcá, şaḍrcá, șoḍaçarcá, saptarcá, saptadaçarcá.

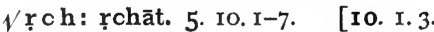
rrchatu. 4. I9.6. 5. r4. II. 6.26.3. richantu. 8. 3. $14^{*}$. I9. I8. I--10.

$+\overline{\mathrm{a}}$ : à rchatu. 2. 12. 5 .

+ nis: nír rrchati. 12. 4.53 . 
ŗchárā: -răs. 10. 9. 23

rjilka in bhặjika.

f́jiy as: 5. 14. 12. 8. 4. 12*.

ṛjı̣̂ă: 9. 6. I6.

r.jú: -jávas. I4. I. 34 ".

(cf. ŗjugá, rijūraçmi.)

ŗju॰gá: -ás. I. I2. I.

rjú $\mathbf{r}$ açmi: -is. $\quad 4.29 .7$.

ṛ̣̣á: -ám. 6. 46. 3"; II8. 1, 2, 3; 119.

I, 2. I 9 45. I (p. riṇ-, ran-); 5I. I"

(s. mss. -ṇăm).

[raṇ-).

ṛnatat. 6. II 8. 2. I9. 45. I (mss. riṇ-, ṛ̣ắni. I9. 57.2 (p. sáh mṛnăạni). (cf. anṛná.)

ŗ́tá: -ám. 2. Io. 8 (mss.1). 7. 72. 3". 8. 3. II". 9. 5.21 ; IO. $23^{*}$. IO. 7. I, II, 29, 30; I0. 33 . I I. $3.13 ; 7.17$. I2. I. II ; 5. IO. I4. I. 3 I. I5. 6. 2. I6. 8. I-27. I8. I. $4^{\dagger} ; 3.2 I^{*}, 24^{*}$. ŗténa. 3. I2. 6.6 .47 .3 ; I I 4. I, 2. I0. 8.3 I. II. I. 23 . I4. I. I". I7. 29. I8. I. $29^{*}, 30^{*}$.

rrtásya. 2. I. 4,5 4. 35. I. 5. I2. $2^{*}$, II* ; I7. I'. 6. 22. I* ; 36. I ; II4. I, 2 ; I22. I; I34. I. 7.6.2. 8. 9. I3, I6, 2I. 9.3. 22 ; 9. I3*; I0. $15^{*}$. II. 3. 48. I2. I. 6 I. I3. 3. $9^{*}$, I9. I4. I. $19^{*}$. I5. 6.2. I7. 16. I8. 1. 6"; 3. $40^{*}$; 4. 3. 20. 34. 12 (not mss.). rté. 9. $9.8^{*}$. I2. 5. I.

ṛtăni. 7. I. I ; 57.2 $2^{\dagger}$.

(cf. ánṛta, yajñárta, ṛté ?, ṛtájāta 一ṛ̂̄vị́dh, rrtódya.)

ṛtá ○jāt a: ṛ্tajāte. 5. I5. I-II.

ṛtájātās. I 8. 2. I $5^{\dagger}$. [44*. I 9. I I. $5^{*}$.

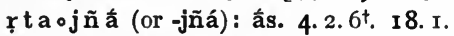
r tá prajāta: -tā. I. II. I. ṛtáosāta: -tās. I8. 2. $15^{\dagger}$.

r taosthấ: -ấs. 4. I. 4 . ṛtăva n (p. ṛtáov-) : -vānam. 6. 36. I. ŕtāvari. 5. I5. I-II. 6. 30.3.

ṛtāvari. I0. 10. $9,16$.

ṛtăvarī (p. -i íti). 6. 62. I.

ṛtāvarīs. 3. 13.7.

[29. I.

ṛtāṿ̛́dh (p. ŗtåv-): -ṿ̛dhāu. 4 .

ṛtāvị́dhas. II. 6. I9, 20. I8. 2. I5". ti: -is. I2. 5. 25 .

(cf. ávarti, ărti, nírṛti.)

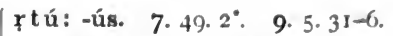

rtúm. 8.9.17. 9.5.31-6.

rtúnā. 14.2. 34 (not mss.). 20. 2. 1-4.

ŗtāú. II 4.4 .

ŗtávas. 2.6. I. 8. 8.22; 9.15, 18 . I0. $6.18 ; 7.5$. II. $3.17 ; 6.22 ; 8$. 5. I2. 1. $36 ; 2.25^{\circ}$. I3. 1. I 3 . I5. $6.6 ; 17.5,8$. 18. 4.2 .

ṛtún. 3. 10.9. 6. 36. $2 ; 61.2,3.7$. 8I. I". 8. 9. IO. II. 6. I7. I8. I. $18^{\circ}$. I9. $59.3^{\prime \prime}$.

ŗtúobhis. I. 35.4 . 3.8. I. 5. 28. 2, I3. II. I. IC ; 3. $37 ; 5.20 ; 7.20$. 12. $2.25^{*} ; 3.32$. 17. 29 .

ṛtúobhyas. 3. I0. IO.

ŗtūnăm. I5. 6.6. I6.8. I7.

(cf. apartú, ekartú, gandharvar-

tú, ārtavá, ārtvyá, ŗtuthă--rtuçás, r̊tvíj-ṛ́tviya.)

ṛtuathá. 5. 12. 10*. 9. 10. 26*. 13. 3. 2. I4. I. $16^{*}$.

ṛtuopáti: -tín. 3.10.9. Ir.6. I7. ŗtuoçás. 9. 5. I3 (s. mss. -çàs).

ruté. 4. 26.6. I4. 2. $47^{*}$. 20. I33. 2 (ed. dṛ́tis ; mss. rite).

ṛtó d y a: ŗtaoúdieșu. I4. I. 3 I.

ṛtvíj: -jas. 8. 9.2I. 9.6.23. Io. 9. 4. I2. I. 38. I9. II. $5^{\dagger} ; 42.2 ; 58.6$. ritvijas. 6. 2. I. (cf. ărtvijya.) r tvíya: -yas. 3. 20. $\mathrm{I}^{*}$. rqtvíyam. 7.72. I". [yāya). ŗ́tviya: -yā. 12. 3.29 (mss. ŕ্tvir̂tviye (p. -e íti). I 4. 2.37.

ŗth a in nirrthá.

$\checkmark \mathbf{r} \mathrm{d}$, see $v$ ard.

r ddh a in ásamrrddha, súsamṛddha. r. ddhi in vyṛ̀ddhi, sámṛddhi.

V ṛdh: ṛnáahat. 18. 1. 6".

ṛndhán. 5. I2.2*.

ärdhnot. 4. 39. I, 3, 5, 7.

ānṛdhús. 2. 35.1 .

ṛdhyām. 7. 50. $3^{*}$ (m. mss. ṛndh-). ṛdhyăsma. 6. 94.3.

rdhema. I9. 55.4.

ardháyanti. 7.80 .4 .

(cf. ardhá, árdha, Irtsā, ūrdhvá, ŗddha, ŗddhi, ŗdh, 1 vrrdh.)

$+\bar{a}$ : értsamānas. 6. I18.2. 
+ vi : vîrtsantī (p. vioîrt-). 5. 7.8. [6. ví "rtsīs (s. mss. vì-; p. ví îr-). 5.7. (cf. vyì̀ddhi, vīrtsâ.)

+ s am: sám ridhyante. I2. 4. I9. sám ṛdhyatām. 8. 2. I3. I4. I. 2 I $^{*}$. I9. 52.5 .

sám ... ṛdhyatām. 4. 36. 4 . sámoṛddham. 14. I. 3I. [dhi.) (cf. samị́dh, sámṛddha, sámṛd$\mathbf{r} \mathbf{d h}$ in samṛ́dh.

rdhak in

[I. I.

彳́ dhañmantra (p. -akom-) : -as. 5 .

ŗbhú: -ús. 4. 12.7. 6. 48.2. 10. 1. 8. rbhúm. I. 2. 3 .

ṛbhávas. 6. IO8. 3. I9. II. I*.

rbhavas. 9. I. I3.

ŗbhūnatam. 9. I. I3.

ṛ́bhvan: -vāṇam. 5.2. $7^{\dagger}$. [iva). ṛça: -as. 4. 4.7 (p. kráma svárçaḥ。 (cf. ārçá, ŕçya.)

ŕç y a: -asya. 5. I4. 3 (s. mss. ed. riç-). ŕ̛çyās. 19. 38.2 (mss. áçvās). (cf. ríçya.)

V I, 2 r̦ș: rssati. 9. 4. I7.

arșanti. 20. 48. 2.

arşatu. 4. 3.2. 19. 47.8.

arșat. Io. 4 . I (s. mss. -rișat).

(cf. arșaṇî, rșțí.)

+ upa: uparṣánti (s. mss. upaṛs-, upariș-; p. upaorş-). 9. 8. I4, I5, I6.

+ pari: pári ... arșata (s. mss. -riș-). 6. $28.2^{\dagger}$.

[ta), 9 .

+ vi: ví ŗșatu. 4. 37.6, 8 (s. mss. -șaví rșantu. 8. 7.9.

+ s a m: sám arșasi. I3. 2. I3.

sám arșase. I 8. 4. $60^{\dagger}$.

ŗ̣abhá: -ás. 3.6.4. 4.38.5. 5 . 20.2. 9. 4. I, 3,7 . IO. IO. IO. I9. 27.1 ; 36.5 .

ŗ̧̣abhám. 9. 2. I ; 4. 9, I4, I5, I8, I9. rșabhásya. 4. 4.8. 6. 38.3. 7. I13. 2. 9. $4 . \mathrm{II}, 23^{*}$. 14.2 . I4.

r̦șabhắs. 323.4 .

rșabhăsas. 4. 24.4 .

ṛșabhănāām. 4. 4.4. [ṛ̣abhadāyín.)

(cf. Índrarșabhá, maharşabhá, r șabhaodāyín: -ne. 9. 4. 20.

ṛ̛ i: -is. II. 8.14 . I 8. $3.4 \mathrm{I}^{\dagger}$. ṛ́sim. 4. 30. $3^{*}$.

ṛ̛ṣināa. 8. 5.8 . I3. I. 55 .

ŕșaye. 20. 127.3 (not mss.).

ŕ̛ṣi (p. -i íti). 5. 30. Io.

ŕșayas. 2.6. I; 35.2,4. 4. 23.5. 6. 4 I. 3 ; 108. 3 , 4 ; 133. 5 . 8. 5 . 10; 9. 7,14 9. 9. $16^{*}$. 10. $7.14 ; 8.9$; Io. 26 . I I. $3.32-49 ; 9.25$; I0. IO. I2. I. $39 ; 2.29$. I7. I4. I9. 33.3 ; 35. I; 4I. I.

ŕșayas (voc.). I8. 3.64.

r̦ayas. 8. 9.8.

[18*.

ŕșin. 8. 9. 24. I I. I. 26,35 . I 8. 2. I $^{\dagger}$, ŕșiobhis. 6. 12.2. 7. 89.2*. I8. 3 . $47^{\dagger}$ (m. mss. rșí-), $48^{\dagger}$ (do.).

ŕş̧iobhyas. I8. 2. $2^{*}$. I9. 22.14 (m. mss. rșí-).

ŕṣin̄ām. 4. 39.9. 6. I33. 2, 4. 8. 9.23. I0. I. I2. I6. $2.6 ; 8.9$ ( mss. ṛșinăăm).

(cf. ārșeyá, ekarșí, maharșí, saptarșí, ŕșipraçișța, ŕṣișțuta.)

ṛ̣́i०praçiṣt ta: -țā. II. I. I5.

ŕs s ișt u t a (p. ŕşiostu-) : -tām. 6. I08. 2. ŗștí: -țís. 4. 37. 8, 9

rștíobhis. 8. 3. $7^{*}$.

ṛșvá: -ás. 7. II. I (m. mss. rị̣-). ŗ̧va. I8. I. $34^{*}$.

é ka : -as. 2. I. $3^{*}$; 2. I, 2. 3. I3. 4 . 4. 2. $2^{*}, 7^{*} ;$ 10. $6 ;$ I $7.8 ; 3$ I. $4^{*} ; 37$. $\mathrm{II}^{2}$. 6. 36.3. 7. 2 I. I. 8. $4.3^{*} ; 8$. I $;$ 9. $26^{2}$. 9. 9. $2^{*}$, IO $^{*}$; Io. $26^{*}$. Io. 2. $14 ; 8.5^{2}, 28,36^{2}$; 10. $24^{2}$. I3. 2 . $3,26^{*} ; 4 . \mathrm{I2}^{2}, 2 \mathrm{O}^{2}$. I 8. 4. I I.

ékam. I. I2. I. 5. II. $6 ;$ I 7. $5^{*} ; 28$. $6^{3}$. 7. 21. I. 8. 8. $12^{3} ; 9.3^{2}$, I5, 26. 9. $9.7^{*}$; I0. $28^{*}$. I0. $7 \cdot 9,25,26 ; 8$. 4 , II, $25^{2}$. II. 2.22 ; 4. 2 I. I2. 3. 39 . I3. I. $45 ; 3.17$. I4. I. $14^{*}, 16^{*}$. I5. I. 3 ; I 7. Io. I8. $2.6^{*} ; 3.7^{2 *} ; 4.64$. 19. $45 \cdot 5^{3}$.

ékā. 5. 15. I. 6. $83 \cdot 2^{3}$. 7. 43. 1. 8. 9. $13^{3}$. 9. 5. 10. 20. 129.3.

ékām. 5. I. $6^{*}$. I5. I3. I.

ékena. 5. II.6. 10. 8. 30 (ékena॰ek-). I I. $8.33^{3}$. I9. 45.5 . 
ékayā. 7.4.1. 17. 17. ékasya. 9. 10. $26^{*}$. I 8. I. $3^{*}$. ékasmin. 12. 3. 36. I 8. I. 17. éke. I9. 56.2 (p. réke). éke (p. -e íti). I 0.7 .42$. éke. 6. 122. $2^{2}$. $10.7 .27 ; 8.36$; I0. $32^{2}$. I8. 2. $14^{*}$. 20. I32. I4 (ed. ékam).

ékās. $7 \cdot 43 \cdot I^{2}$.

ékebhyas. 18. 2. 14 ".

(cf. ékaka-ekonaviņçatí.)

ékaka : -am. 20. 132. I.

éka०cakra: -am. 9. 9. $2^{*}$. I0. 8.7. ekaojá: -ás. ro. $8.5^{2}$.

elraja. 4. 3I. $3^{*}$.

ekajám. 6. 99. 1. 9. 9. 16*.

éka ○tejana: -nām. 6. 57. I.

eka。dhâ. 5. I7.8. 8.9.26. I0. I0. 5. ékaonemi: I0.8.7. II. 4.22.

é ka ० p a tñ I: -is. 10. 8. 39. [II. $3^{*}$.

é ka ० p a d: -păd. I3.2. $27^{*} ; 3.25^{*}$. I9.

ékapadas. I3. 2.27 .

ékapadi. 9. I0. $21^{*}$. I3. 1. $42^{*}$.

é $\mathbf{k} \mathrm{a} \circ \mathrm{p} \overline{\mathrm{ada}} \mathrm{a}$-as. I3. r. 6 .

éka०mukha: -khās. 9. 4. 9.

éka $\mathbf{m} \bar{u} \mathbf{r d h}$ an: -dhnis. 8. 9. I5.

eka $\mathbf{a} \mathbf{a} \mathbf{j}$ : -âț. 3. 4. I.

eka。rātrá: -ás. II. 7. Io.

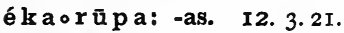

ékarūpam. 2. I. I.

ékarūpās. 2. 34. 4 .

[23. 20.

ekarcá (p. ekaoṛc-): -cébhyas. I9.

ekartú (p. ekaoṛt-): -ús. 8. 9. 25, 26.

e karṣí (p. ekaorsṣ): -ís. 8. 9. 25 (mss.

ekaṛş-; l. ekarș-), 26 (mss. ekaṛș-).

I0. 7. 14 .

eka $\circ \mathbf{v}$ d yá : -yăm. 2. I4. I.

eka०vińçá: -ás. 8. 9., 20.

eka。vĩrá: -ás. I9. 13.2*. 20.34. I7.

eka。vŕt: 8. 9.25, 26. I3. 4. 12, 20.

ekavị́tàm. I3. 4. 15, 24.

ekavf́tas. I3. 4. I3, 21 .

eka०ṿ̛ṣá: -ás. 4. 22.6, 7. 5. I6. I. 6. $86 . \mathrm{I}-3$.

ekavrṣám. 4. 22. I, 5.

eka०vrātyá: -ás. I 5. r. 6.

éka॰çata: -am. 3. 9.6. 5. I8. I2. 7. II5.3. 8. 2. 27. II. 6. I6. I9. 46. 5. éka॰ ६ a pha: -phe. 5. 31. 3. éka ० ६ Irşa n: -şănas. I 3.4.6.

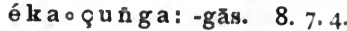

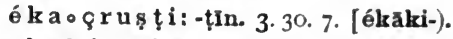
ekākín: -ínā. I9. 56 . I (m. mss. ed. ekā kşa rá (p.eka॰ak-); -ám. 5.28.8. ékādạ̧a: I9. 27. II, I2, 13；47.5. (cf. ekādaçá, ekãdaçarcá.)

e kã da çá: -ás. 5. I6. II. [19.23.8. e kă d a ç a rcá (p. -ça॰ṛc-): -cébhyas. ekăn ṛcá (p. ekaoan-): cébhyas (ed. ekadvyrc-). I9. 23. 22.

e kã șt ț ká (p. ekaoaş-): -kă. 3. IO. I 2. ékāșțake. 3. I0. 5 . ekāșțake. 3. 10. 8 .

ékāika (p. éka॰ek-): -kayã. 3.28. I. ekona in [mss. -çátis). ek on avin çatí: -ís. I9. 23. I6 (m. Vej: éjati. 7. 20.6. 8. 9.8. I0. 8 . II. I2. I. 46 . I9. 47.2 .

ejatas. 20. 136 . 1 .

éjathā (p. -tha). 6.22.2.

éjāti. 6. 22. 3.

éjat. 4. 5.4 (éjatoej-). 9. 10. $8^{*}$, I9. I0. 8.6 . I2. I. 3,4 I3. 2.3 I.

(cf. ejáthu, ejant.)

+ ud: úd ejatu. 4. 4.2.

eja toká: -kăs. 5.23.7.

ejáthu: -us. I2. I. I8.

ejant in ejatká.

eñi: 5. I4. II.

etá (pron.): -ám. I. 30.2. 2. 29.6. 3. I2. 8. 4. I. $2 ;$ I4. 7. 6. $87.3^{\dagger}$; 122. I, 3 ; I23. I. 8. I. Iо. 9. $4.8,24 ; 5$. I, 6, I $2,37,38$. I0. $6.35 ; 9$. I. I I. I. 29 ; 3. 32-49. I2. 2. $23^{*} ; 3.7$, I9, $34,38,44,46,53,55-60$. I3. 4. I5, 24. I8. I. $55^{*} ; 3.2^{*}$, I3. I9. 56.4 (mss. etấm). 20. I30. 5 .

etát. I. 35.2 . 2. I3.2. 3. II. I*; 2I. I-7; 22. I；29.7. 4. 7.7; 11.8. 5. $3.5^{\dagger}$; IO. I-7; 19. 10. 6. 29. ${ }^{*}$; 32. I ; II 3. I; II 8.2 ; I23. 5. 8. I. IO. 9. $5.11 ; 6.18,39 ; 7.25 ; 9.4^{*}$. I0. I. $28 ; 8.24$ II. I. 3 I ; $3.50 ; 5.23$. I2. $3.8,30,37,48 ; 4$ I 4 , I5, 48. I 3 . 2. I $3 ; 3.1-25$. I $4.1 .29^{2 *} ; 2.21,4 I$, 69. I5. I7.8. I6. I. 8. I 8. I. 2*, 3*, 
I2*, I3*, I4; $2.37^{2}, 57^{2} ; 3 \cdot 39^{\dagger}, 73$; 4. 3 I, 64, 75, 76, 77. I9. 33.4 ; 50. 6 . etăm. 2. 29. 7. 5.11. 2 ; 18. I. 7 . $45.2 ; 73.7^{*}$. 9. 5.4. I I. I. $24 ; 2$. 26. I2. $2.48 ; 3.2 \mathrm{I} ; 4.24$. I4. I. 3I. I7. 8. I8. 2. $5^{*} ; 3 \cdot 49^{*}, 52^{*}$. I9. 4. I, 4 .

eténa. 4. I5. II*. 5. 6.5-7.

etásya. 7. 45. 2. 9.6.28. I9. 52. 5 . etásyās. I 9. I 7. 2, 4, 6, 8; 18. 2, 4, 6, 8 . etásmăt. II. 3. 52 .

etásyām. 5.17.6*.

etăú. 7.81. I*. 8. 2.18 II. 1.9. I2. 2. 32. I3. I. 46 ; 2. II*. eté (p. -é íti). 7. 54. r.

eté. 2. 36.7. 5. 1. 4 ; 2. $3^{*}$. 7. 99. I. 8. $4.20^{*} \cdot 9 \cdot 6.23$. I3. 4. I3. $\mathrm{I} 8$. I. $9 * 61$.

etáni. 5. 22.8. 7. 42. $2^{*} ; 79.4 ; 80$. $3^{*}$. I9. 8.1 .

etăs. 4. II. II ; 34. 5-7. 5. 2I. 12 ; 29. I4. 7. II5.4. 9. 5. I5. II. I. I5. I8. 4. 33. I9. 64. 4. 20. I29. I. [I. 53 . etăn. I. 19. 3. 5.22. I1. 6. II9.2. I3. etāís. II. I. 36. I2. 3. 29.

etâbhis. 12. 4. 49 .

etébhyas. I 8. 2.54*.

etăsu. 5. 13. 2.

(cf. eșá, etắvant.)

e ta, see éni.

et tâvant: -vat. 4. II. 8.

etăvatas. 5. II. 7 .

etấvati. 4. 30. $8^{*}$.

ét $u$, see $\sqrt{i}$, and āítu.

etṛ in párāparāitṛ, puraetŕ.

Vedh: edhate. 20. I27. Io (not mss.). édhante. I4. I. $26^{*}$.

édhasva. 18. 2. 25.

edhișiyá. 7. 89.4.

(cf. edhatú.)

+ s a m: sám edhișīya. 7. 89.4. sám ... edhişīmahi. I4. 2.17.

e deh a tú: -ús. IrI. 7.22 (mss. -us). edhatúm. 9. 2. II.

[endh-).

edhána: -nyām. 19. 33.5 (mss.: or

édhas: 7. 89.4. I2. 3.2.

en a (pron.): -am. I. 9. 3; 12. 3; 30 . 2 ; 35. 2. 2. $5.7^{*} ; 9 . I^{2} ; 28 . I, 2$. 3 .
II. $1^{2 *}, 2^{*}, 3^{*}, 3^{\dagger}, 4^{\dagger} .4 .9 .5^{2}$; II. 4 ; I6. 7. 5. $2 . \mathrm{I}^{\dagger} ; 18.5^{2}$, 9. 6. $5 . \mathrm{I}^{2} ; 75$. I; 76. I, 4 ; 110. $2^{2} ; \mathbf{1 1 2 . 1 ; ~ 1 1 3 . 1 ~ ; ~}$ I23. 2 ; 133. 3 . 7. $14.4 ; 16 . \mathbf{I}^{3} ; 35$. I ; $53.4^{2} ; 56.5$. 8. I. $2^{3} ; 3.4^{*}, 4^{\dagger}$, $8^{*}, \mathrm{II}^{*}, \mathrm{I}^{*}$; 5. I3. 9. I. $24 ;$ 2. I3, 19; 3.10; 4.18; $5.4^{2}, 5,23,24$; 7. 26 . I0. $3.16 ; 5.36 ; 8.23$. II. I. I6, 24, 30; $3.28^{2}, 29^{2}, 32-49^{4}, 56$; 5. 2. I2. 3. $34,36,38,42,43^{2} ; 4$. 19, $48 ; 5.45,72,73$. I3. 3. II. I5. 2. $\mathrm{I}-4$; $4 . \mathrm{I}-6 ; 5 . \mathrm{I}-7^{2} ; 7 \cdot 3^{3}, 5^{5} ;$ IO. 2 , 8, IO; II. 2, 3-6, 7, 8, 9, I0, II ; 12. 2 ; $13.7^{2}, 8$. I6. $7 . \mathrm{I}^{6}, 2,3,1 \mathrm{I} ; 8$. I-27. I 8. 2. $4^{2 *}, 5^{*}, 8^{*}, \mathrm{I2} 2^{*}, 5 \mathrm{O}^{*}, 5 \mathrm{I}$; $3.4,50^{*}, 71 ; 4.1^{2}, 66$. I9. I. $3 ; 24$. 2,3 ; 26. I; $36.2 ; 38.1$; 72. I.

enām. 3. $12.8 ; 25.6$; 28.2. 5. 3I. Io. 7.73. $7^{*}$. 8. 9. 9 . IO. I. I, 2 ; IO. 32. II. I. $7,2 \mathrm{I}^{2}, 22^{2}$. I2. 4 . I, $\mathrm{II}^{2}, \mathrm{I} 7,22,25,50$. I4. 2. 37 . I8. 3 . 3. 19. 4. 2.

enat. 6. II 7. $2^{2}$. 8. 9.3. ro. $7 \cdot 43^{\dagger}$. I6. 6. 4. I9. 26.1 .

enena. 9. 6.40-3. I2. 2. 37 .

enāu. 7.95.2. I4. 2. 64 .

ene (p. -e íti). 5. $2.9^{\dagger}$.

enayos. $7.44 . \mathrm{I}^{\dagger}$.

enān. 2. $25.4,5$. 3. $6.5,8^{2}$. 4. 34 . 3,$4 ; 40.1-8$. 5. 3. IO $^{+} ; 8 \cdot 9^{2} ;$ 12. $3^{*}$; 21. I. 6. 104 3. 7. 7. I (mss. enām). 8. 3. $16^{+} ; 8.3,4$, IO, II, 21 ; 9. 2,5 , IO, I6. IO. 3. 2. II. I. $20,25$. 12. $3.30 ; 4$. 15. I3. I. 29,32 .

enās. 5. 29. I4. 6. I4I. I. 7. II5. 4. énas: 2. $35 \cdot 3$. 5. 3. $4^{*}$. 6. $97 \cdot 2^{*}$; II3. I II5. $2 ;$ II6. 2, 3; II9. 3. 7 . 42. $I^{*}, 2^{*}$. I0. $3.8 ; 5.24$. I2. 2.11 . I6. I. II. 20. I30. II (mss.).

énasā. 2. 35.2.

énasas. 2. 10.8. 5. 30. 4. 6. 5 I. $3^{*}$; 84. 2 ; II5.3. 7.64. 2 ; 77. 3. I2. 2. 12 ; 4. 9. I4. $2.44,59-62$.

énāṅsi. 6. II5. I.

(cf. vyènas, enasa, enasyà.) e n a s a in devāinasá, manuṣyāinasá.) en a s y à : -sías. 6. II5. 2. enasíam. 8. $7 \cdot 3$. 
éni: 6.83.2. I8. I. $32^{*}$. 20. 130. I I (not inss.).

énis. 8. 3. $7^{*}$. I $8.4 .33,34$.

éru: -um. 6. 22.3.

év a: -vāis. 8. $4 \cdot 7^{*}, 9^{*}$. (cf. duréva.)

evá. I. 1. $2,3^{2} ; 13.3 ;$ I $5.2 ; 31.4$. 2. I. $3^{*}$; 2. I, $2 ; 4.1 ; 9.5^{2} ;$ 10. $2-8$; 28. 1. 3. 8.3 ; 10. 4 ; I1. $2^{*}, 6$; I2. I, 2 ; 14. $4^{2}, 5 ; 16.5^{*} ; 18.3^{*} ; 24.4$; 25.6 ; 31.9. 4. 30. $3^{*}, 8^{*} ; 32.2$. 5 . 2. $9^{*} ; 6.3^{\dagger} ; 8.3,9 ; 17.3^{*}, 8,9 ; 18$. 4 , II ; I9. II ; 25. 2; 30.1. 6. 18.2; 29. 3 ; 71. 1; 73. 3 ; 87. $2^{*}, 2^{\dagger} ; 89.2$; 117. 2; 122. 2; 124.2, 3. 7. 27. I ; 50.1; 60.7; 67. 1; 78.1; 79.2; ลิ2. 3 ; 88. I ; 1 10. 2. 8. 1. 18; 2. 7; 10. I, 9, I4, 16, 22, 23, 26-9, 32, 33. 9. I. $24 ; 2.7,8 ; 5.22,24,3 \mathrm{I}-6 ; 6.5^{2}$, $6^{2}, 7-15,17,19: 39,49,50,51,53,54$; 9. II*. IO. I. 20,$32 ; 7.4-7$, I0--16, I 8-20, 22, 39; 8. I I I I , I 7, 24, 30, 44; Io. 26 . II. I. 20 ; 3. II, 30, 3I, 32$49 ; 4.21 ; 8.2,6$. I2. 2 . 10, I 8,39 , $49 ; 3.20,26,49 ; 4$. I, I5, I6, I8. I3. I. $17-9 ; 4.5,12,20,25$. I4. 1. 22". I5. I. I, 6, 8; 3. II ; IO. $4,5,6$; II. 3-6, 8, I0 ; I3. I-5, 5, 9; I 7.9, 10. 16. 7.4. I7. 20,21 . I8. I. $15^{*} ; 2$. $14^{*}, 16^{*}, 17^{*}, 59^{*} ; 4$. 38. I9. $2.5 ; 6$. $4^{*} ; 7.4 ; 9.2,3^{2}, 4^{2}, 5^{2}, 14 ; 34.4$; 53. $4^{2}$. 20. 133. 5 ; I35. I0; I36. 6 (not mss.), 7 (do.).

evấ (p. -vá). I. 2.4 ; 3.6-9; II. 6. 2. $15.1-6 ; 30.1 ; 36.4$. 3. $6.3,6.4$. 23. 2 ; 39. I, 3, 5, 7. 5.2. $9^{*} ; 2$ I. 4-6. 6. $8.1-3 ; 17.1-4 ; 46.3^{*} ; 58.2 ; 70$. I-3;.72. I; 74. 3;85.3;97. I; IO2. I; IO5. I- 3 ; I38. 5 ; I39. 4, 5 ; I4I. 3. 7. 13.1 ; 50.5. 9. $1.11-3,16,17$. I0. I. I $3 ; 3.13-5,17-25 ; 6.33$. I I. 4. I9. I2. $2.25^{*} ; 4.34 ; 5.65$. I 4 . I. 43. I8. 4. 55. I9. 3 I. $9 ; 50.4$ (not mss.); 57. I*.

evó (p. -ó íti). 6. 84.3.

(cf. áneva.)

evám. 8. 10. 2-7, I 7, 18-29, 30, 33. 9. I. 23,$24 ; 6.24,40-4,44-8,62 ; 7.26$.
10. 10. 27,32 . I I. $3.32-49,5$ I, 54 . I2. 4. 22,$23 ; 5.46$. I 3. 3. I-25. I5. 2. $1-4^{2}, \mathrm{I}-4$ (not mss.); 3.11 ; 4. I-6; 5. $\mathrm{I}-7 ; 6 . \mathrm{I}-9 ; 7.3,5 ; .8 .3 ; 9.3$; IO. I ; II. I, 7, 9, I1 ; 12. I, 4. 7, 8, II ; I 3. I-5, 9; I4. I-I 2 .

Vess: éşatu. 6.67.3.

(cf. eşa, eşaṇa, eşin, eşyà.)

+ ati: áti ... eşas. 9. 5.9.

+ upa: úpe 'șatu (p. -a eş-). 6.67.3. upéşantam (p. upaoéş-). 8. 6. I7.

eșá (pron.): -ás. 2. 1. $4^{2} ; 29.4 ; 35$. 3 ; 36.4. 4. 1. 6 ; 11. 8 ; 34. 5. 6. 84. 2 ; I 40. 2. 7. 54.2 ; 97.6. 8. I. Io. 9. $4.5 ; 5.21,3 \mathrm{I}-6 ; 9.25,26$, $27,29,31-6,37$. I0. $8.24 ; 9.2$. I I. 3. 32-49. I2. $2.21^{\dagger} ; 3.45$. I 3. 4 . 8, 12, 20. 14. 2. $24^{2}, 68$. I6. I. 8. I8 2. $37^{2}$; 3. 70. I9. 53.2. 20. 127.3. eșâ. I. I4. 2, 3. 2. 29.7. 3. 28.1 , 2. 5. 11. 10; 17. $3^{*}, 4 ;$ 18. 3. I0. 8 . $30^{2} ;$ 9.2. II. 1. 23,28 . I2. 3. 22 5I ; 4. IO, 39, 42 ; 5. I 2. I 3. I. 27. I4. I. $25^{*}$. I 8. I. $26^{*}, 50^{*} ; 3.49^{*}$. I9. 55.2 e ș a in prāișá, çunyāișá.

eșa ṇ a in gavéșaṇa.

e şi in in āçārāişín, durṇihitāișín, çakalyeșín.

e ș yà : -șías. I2. 2. 39 .

eșíās. 12. 4. 16.

e ș y a n t in astameşyánt, ávyeșyant. e há: -hâs. I2. 3. 33 .

eh as in anehás.

ãít u (p. áoet-): -tos. I 2. 3. 55-6o.

āindrá: -ás. 5. 20.2. 9. 4. 22.

āindrấs. 5. 8.2.

āindrāgná: -ám. 8. 5. I9. I I. 7.6. āirāovatá: -ás. 8. I0. 29.

āilabá: -ás. 6. I6. 3.

āilabám. I 2. 5. 47, 48, 49 .

(cf. āilabakārá, vyāìlaba.)

āila ba $\circ \mathbf{k a ̄}$ á: -rébhyas. I I. 2. 30 .

$6 \mathrm{kas}: 5.22 .5^{2}$. 18.3 .8$.

ókasas. 3.2.2. 6. 75.1 . 
(ef. ányokas, yathāukasá.)

o c an a in nyócana.

o cara in nyocará.

ójas: I. I2. I; $35.2,3$. 2. I7. $I^{2}$. 3.

5. I; I9. 2 . 4. $24.5 ; 31.2^{*} ; 32.1^{*}$, $4^{*}$ 6. $125.2^{*}, 3^{\dagger} ;$ 1 $26.2^{*}$. 7. 54.2 ; 84. $2^{*}$;. 90. I*. 9. I. I 7 ; 4.8. I0. 3 . I $2 ; 5.1-6$ II. $7.18 ; 8.20$ I2. 5 . 7. I8. 4.53 . I9. $33.4 ; 34.5 ; 37$. I, 2 ; 4I. I ; 42. $4 ; 52.2 ; 60.2$ (mss. ója). 20. 34. I6 (not ed.).

ójasā. 3. 1. 6 ; 2.6. 6. 97. 3*. 7. 25. I. 8. 8. I2, I3. I0. $3.13 ; 6$. I. II. Io. I3. I9. $33.3 ; 34.5$.

ójase. 8. 5.20. I0. 6.6-IO, 7. II. Io. II. I9. 26. $3 ; 37.3 ; 45.6-10 ; 46$. I. ójasas. I9. $45 \cdot 3$.

6jānisi. 6. 7.3.

(cf. abhíbhūtyojas, bhúryojas, satyāújas, ójasvant.)

ójas va nt: -vān. 8. 5.4, 16.

ójīyas. 5.2.4*. 7. 5.4.

ójiyasas. I0. 3.7.

ojmán: -mănam. 4. I9.8. 6. 125. $2^{*}$. I9. 34.9 .

oṇí: -ṇíos. 7. I4. I.

ótu: ótavāí, see $\sqrt{ } 2$ vā.

ótavas. I4. $2.5 \mathrm{I}$.

ọtsūryá (p. āout-): -ám. 4. 5.7.

óthā. 20. I35. I, 5 (mss.).

od aná: -ás. IO. IO.25. II. 3.27 (-nầ3s), 30, 3I, 32-49, 50. I2. 3. 5 .

odana. II. I. 33 .

odanám. 4. I4. $7 ; 34.3,4,8 ; 35$. I. II. I. $23 ; 3.26,27,30,3$ I. I 2. 3. 4. I2, 27. I8. 2. $30 ; 4.42$. 20. I36. II 3 (not mss.).

odanéna. 4. 35. I-6. II. 3. I9.

odanâya. I2. 3.32.

odanăt. II. $3 \cdot 52$.

odanásya. 4. 34. I. II. I. 17, 24 ; 3. I, II, 22, 23. I2. $3.5 \mathrm{I}$.

odanắn. 9. 5.37.

odanănām. 9.5. I9. [çatāúdana.) (cf. páñoāudana, brahmāudaná, op a çá: -ás. I4. I. 8 *

opaçám. 9.3.8.

(cf. opaçín.) opaçín: -ínam. 6. 138. I, 2. o $m$ a $n$ in vyòman.

oṣá: -ám. 2. 36. I. 7. 73.6. I2.3.31. (cf. vyòșa.)

óșadhi, óṣadhĩ: -dhis. 4. 4.3. 6. 59.2. 7. 38.5. I9. 32. I.

oșadhe. I. $23.1,3 ; 24.3 . \quad 2.27$. I-6; 30. $4 ; 36.8$. 4. 6.8; 7.6; 12 . 5 ; I7. I; 19. 2,4 ; 20. 2,6 ; 37. I, IO. 5. I4. I, 2 ; I5. I-1I. 6. I27. I; I36. I ; I37.3; I38. I. 8. 6.9, I0. I9. 32 . $3 ; 34.9$.

óșadhim. 3. I8. I*. 4. 4.I. I4. I. 3*. óșadhīm. 8. 2.6;7.6.

óṣadhiā. 4. I8. 5 .

óșadhayas. 2. 3. $6.3 .23 .6 ; 24 . I^{*}$. 4. I5. $2,16.6$ 6. $96 . \mathrm{I}^{\dagger}$. 8. I. $17 ; 2$. I5; 7.3, 9. I6. 9.7. 15. II. 4.6, I6, I $7 ; 5.14,20 ; 7.21$. I2. I. 23. I4. 2.7. I5. 6. I. I8. I. $17 ; 3.56^{*}$. I9. 9. $14 ; 34.7 ; 44.6$.

óșadhīs. 3. I 7. 5 ; 2 I. I; 26. 5.4 . I 7. $2 ; 23.6 .6 .222 ; 23.3 .7 .87$. I. 8. $2.22 ; 7 . \mathrm{I}, 4$, IO, I3 (mss. oș-), I 7, I9, 24, 25; 8. I4; 9. 23 ; IO. I4, I6. 9. 4. I3. IO. I. II; 5.32. II. 4 . 3,$4 ; 6 . I ; 9.24$. I2. I. $2 ; 3.3$ I, 5 O. I3. I. $2 ; 4.43$. I5. I4. 6 . I9. 9. I ; I0. $5^{*}$.

oșadhīs. 8. 7. 5, 2 I.

óṣadhībhis. 2. 10. 2.4 15.2. 12. 3. 28 . I5. I4. 6 . I9. I9. $5 ; 27.2$.

óșadhībhyas. 6. 20. 2 . I0. 5.32 . I2. 3. 59. I9. 3. I.

óșadhīnām. 3. 5. I; 3I. 10. 4. 4. 4 ; I5. IO； I7. 8 ; I9. $3 ; 22.4 ; 27.3$; 37.5. 5. 25.7. 6. I5. $\mathrm{I}^{\dagger}, 3 ; 95 \cdot 3.7$. 39. I*. 8. 3. $16^{*} ; 5.11 ; 7.25 .9 .4 .5$. I0. 4. 2 I. I2. I. I7, 57. I4. 2. 70. I5. 6. I. I9. 3 I. $5 ; 32$. $10 ; 39.4$.

óṣadhīṣu. 1. 30. 3. 2. 3I. 5. 4. 27.2. 6. 58.2 I0. 4.22 . I2. I. I9. I8. 2. $7^{*}$. I9. 3.2 .

(cf. oṣadhijá-óșadhīsamçita.) oṣ a dhiojá (or -jâ): -jấs. Io. 4. 23. 6 ș a dh $\mathbf{1} \circ \mathrm{m}$ ant: -matīs. I9. I7.6; I8.6. [(p. -dhiosa-). óșadhĪsamçita: -as. I0. 5.32 
6s șth a: -țhe. 20. 127. 4 (not mss.). oṣthău. ro. 9. 14 .

ā u kşá : -ás. 2. 36. 7 . (cf. āukșágandhi.)

ā ukşá g andhi: -is. 4. 37.3.

ā uccāi ḥ •çravasá: -ám. 20. 128. I 5 (mss. ãúccāiḩ̣̣ravasám), I6 (mss. ájāiçravasás).

à ú d u m bara: -as. 19. 31. 2, 6, 7, 10, āúdumbara. I9. 3I. II (mss. -ras), 13 (do.).

ăúdumbaram. I9. 31. 4 .

ắúumbarena. I9. 3I. I.

āúdumbarasya. I 9. 3I. 3 .

$\mathbf{k a}, \mathbf{k i}$ (pron.): kás. 3. 19. $8^{+} ; 29.7$. 4. $5.2 ; 25.2 ; 28.5$. 5. 19. 10. 6. 28 . 2* 7. 7. I; 70. $3 ; 76.3 ;$ 103. $\mathrm{I}^{4}$; 104. I. 8. 8. 19;9. $10^{5}, 25^{2}$. 9. 1. $6^{2} ; 6$. $52 ; 9.4^{2^{*}}, 18^{*} ;$ 10. $23^{*}$. I O. 2. I, 2,3 , $4,5^{2}, 6,7$, I I, $12^{5}, 13^{3}, 14^{3}, 15^{4}, 17^{4} ; 4$. $18 ; 7.23 ; 8.4$. II. $4.25 ; 8.1,12$, 14, I6; 9.20 ; 10. 19. I2. I. I8, 23-5; 4. 7. 14. 1. 56. I8. I. $6^{*}, 7^{3 *}, 33^{*}, 48^{*}$. I9. 22. 2 I. 20. I30. I-4; I32. 8, 9 .

kám. 6. 20. I. 9. 9. I $7^{*}$. I I. 8.5 , II. I5. 10. 3. 20. 130. 6.

kím. 4. 26.6. 5. 11. $5^{2} ;$ 13.7. 6. 45. 1; 51. $3^{*} ; 57.3 ; 7$ I. 1. 7. 56.6, 8 ; 70. I; I06. I. 8. 4. $14^{*}$; 9.25. 9. 9. $7^{*} ;$ IO. $18^{*}$. IO. I. $20 ; 5.22,23$; 7. 37 ; 8.16. II. $3.24 ; 4.4 ; 9.13$. I3. I. $55 ; 3.23$. I4. 2. I9. I5. 3. I. 18. I. $12^{2^{*}}, 33^{*} ; 2.24,32 ; 3.41^{\dagger}$. I 9 . 6. $5^{3^{*}} ; 48 \cdot 3^{3}$. 20. $129.4,14$ (not mss.). kéna. 5. II. $2^{2}$ : 10. $2.1^{6}, 16^{4}, 18^{4}$, I $9^{4}, 2 \mathrm{O}^{4}, 22^{4}, 24^{3}$. I8. I. $52^{*}$.

kásmāi. 3. 29. 7. 4. 2. I-7*, 8. I2.4. 7. kásmāt. 8. 9. I. I0. 2. 2,$9 ; 7.2^{3}$. kásyās. I2. 4.43.

[4. 14 . kásmin. I0. $7 \cdot \mathrm{I}^{3}, 3^{4}$. II. 8. I0. I2. ké. 4. 22.6. 5. 23. 5. 6. 50. 3. 7. 12. 2; II 7. I*. 10.7.38. I I.8. I $^{2}$ I9. 6. $12^{*}$. kấs. 5. 1 3.9. 8. 9.25. I I. 4. 17.

k吕i. I9. 9. 13;64. 3*. (cf. kád, kám kam ?, katamá, katará, káti, kathám, kathă, kada, ku.)

kaǹsá: -săs. ro. 10. 5 .

kakajā in

k a kajầ $\mathbf{k}$ ṛt a: -tã. II. 10. 25 .

k a ka ț a in reṇúkakāța and

ka kățikā: -ām. I0. 2.8.

kákutsa la : -am. I8. 4.66. [9. I9.

kakúd: 6.86.3. 9.4.8; 7.5. 10.

kakúdi. 3.4.2. 7.76.3.

(cf. trikakúd, kákuda, kákutsala ?, kakúbh, kakubhá.)

káku d a: -dăth I0. 10. I9.

kakúbh: I3. I.15 (cf. kakubhá.)

kakubhá: -bhấs. 8. 6. 10.

káksa: -şe. 6. 127.2. [vant.) (cf. çitikákșa, kakșyà̀, kakṣî-

kakșivant: -vān. I8. 3. I 5 .

kakșivantam. 4. 29. 5 .

kakṣ yà : -ṣía. 8. 4. 6*. I8. I. I5*. kakṣyàm. I9. 57.4 (not inss.).

$k a \bar{n} k a$ in

kañ ká oparvan: -aṇas. 7. 56. I. $\mathbf{k} \mathbf{a} \mathbf{n} \mathbf{k}$ ața in vikañkața.

káñ kūṣa: -șebhyas. 9. 8.2.

káțuka: -am. I4. I. $29^{*}$.

kána: -as. ro. 9. 26.

káñās. II. 3. 5 .

[káñkațas).

kánt taka: -as. I4. 2.68 (s. mss. ed.

ka nt tha, kaṇthaka in sahákaṇthikā.

kán va: -as. 4.37. I. 7.15. I. I8. 3. 15.

káṇvam. 2. 25.3. 4. 29. 5.

kánvena. 4. I9. 2.

káṇvasya. 6. 52.3.

káṇvān. 2. $25 \cdot 4,5$.

(cf. kaṇvajámbhana, kaṇvavát.)

ka ṇva ojám bh an a: -nī. 2. 25. I.

ka n va०vát. 2. 32.3.

k a t a má: -ás. 8. 8.6; 9. I, 25. 10. $2.8 ; 7.4-7$, 10-6, 18-20, 22, 39; 8. I3. II. 4.22.

katamát. 5.3.4* 9. 2.10.

katamá. Io. 8. Io. 12. $4 \cdot 45$.

katamásyās. 8. 9. I.

katamé. I0. $2.4 ; 8.35$. 
katará: -ás. 7. 44. I*.

katarát. 20. 127.9.

kataréna. 8. 9. r.

káti: I0. $2.4^{4}$. I2. 4.43 . (cf. katidhă.)

katiodhă. 8. 9. I0 ${ }^{2}$ I9. 6. $5^{*}$.

kathám. 5. II. I ${ }^{2}$. 7.76.5. 8. 9 . $19^{2}, 20^{4}$. 10. $7 \cdot 37^{2}$. 20. 132. 10.

kathă. 8. r. 6 .

kád. I8. I. $4^{*}, 7^{*}, 33^{*}$.

kadă. I. $20.4^{\dagger}$. $4 \cdot 34 \cdot 3$. 6. I30. 3 . 7. $9.3^{\dagger}$. $8.4 .7 . \quad$ IO. 7.37 . II. 4 . 2I. 20. 127.14 .

kadricĩ: 9. 9. $17^{*}$.

k a druka in tríkadruka.

ka náknaka: -am. Io. 4. 22.

kaniṣṭhá: -ás. I0. 8. 28 .

(cf. kanișţhikấ.)

kanișthikát: I. I7.2.

kanina: 20. 136. 5 (not mss.). (cf. kānīná, kanínikā.)

kaninikā: 4. 20.3.

kániyas: 3. 15.5. 12. 4.6.

kanyálā: $5 \cdot 5 \cdot 3$.

kanyálās. 14. 2. 52.

kany à: I4. 2.22. 20. I28. 8, 9. kanía. I. 14.2. 6.22.3. I0. 4. 24. II. 5. I8.

·kanyàyām. I 0. 3. 20 (l. -níā-). I2. kanyànām. 2. 30. 4 .

ka păla: -am. I0. 2.8 .

kapălāni. 9. 8.22.

(cf. çīrșakapālá.)

ka pí: -ís. 3. 9.4. 4. 37. II. 6. 49. I. kapóta: -as. 6. $27 . I-3^{*} ; 29 . I^{*}$.

kapótam. 6. 28. I*.

kapótāya. 20. 135.12.

(cf. kapotolūká.)

[6. 29.2.

ka potol ū ká(p. -taoul-): -kăbhyām.

k a phā u ḍá : -ḍāú. ro. 2.4 (mss. also -phed̦-, -phoḍ-).

ká b andha: -am. 9.4.3. I0. 2.3. kábru: II. 3.6.

kám. 2. I. 5 . 3. II. $\mathrm{I}^{*}$ 4. 9. I. 5. II. 2. 6. 6I. I; 84. I; IIO. $\mathrm{I}^{\dagger}$. 8. 2 . 25. 9. 3.6. I0. 6.7. I4. 1. 42,53 ; 2. 30. I8. 3. $4 \mathrm{I}^{*}$. 19. 46 . I.

kam. I. I7. $4^{*}$ 3. I3. 3. 7. 26. I*. kar ṇa॰çū lá: -ám. 9. 8. I, 2.
V k a m, k ā: cakānás. 2. 5. I.

cakamānăya. 19.52.3.

kāmáye. 4. 30. 3*.

kāmaye. 6. $45 . \mathrm{I}$.

kāmáyāmahe. I2. I. 40. 19.32.8.

kāmáyante. 4. 24. 5 .

kāmáyamānās. I9. 52.5 .

(cf. kanișțhá-kanyà̀, kắma.)

kamála: -am. 8. 6. 9 .

kamba lá: -lé. I4. 2. 66, 67 .

k a m búk k : -kān. II. I. 29.

kará: -réna. I2. 2. 2.

(cf. anukará, abhayamikará, kimnkará, divākará, púşkara pușkalá ?, vanamikará.) [3 (not mss.).

ká r a na a :-as. 6. 46. 2. I6. 5. I-6. I9. 57. (cf. abhikarana, ayakṣmamikáraṇa, garbhakáraṇa, phalīkáraṇa, sarūpamkárānạ, subhāgamkáraṇa.)

ka ra mbhá: -ám. 4. 7.3. 6. I6. r. karambhéṇa. 4. 7. 2.

$\mathbf{k}$ arişa in

karīsín: -ínīm. I9. 3I. 3 .

karīṣinịis. 3. 14.3 .

karúṇa: -ṇe. 12. 3. 47.

ka rú ma: -mās. 8. 6. ro.

karúkara: -am. II. 9.8.

karkandhu in [kárk...kâ).

ká rk a n d h ū k a :-kā. 20. 136. 3 (mss.

karkarí: -ím. 20. 132.8. [-yás). karkaryàs. 4. 37.4 (m. mss. ed. (cf. karkariká.)

karkariká: -ás. 20. 132. 3 .

karkí: 4.38 .6 .

karkím. 4. 38.6, 7 .

kárṇa: -as. I 5. 18. $\mathrm{j}^{2}$.

kárṇāu. I0. 2.6 ; 9. I3. I2. 4.6;

5. 22. I6. 2. $4^{2}$ [ [8.2.
[

kárṇābhyām. 2. $33 \cdot 1^{*}$. 9. 4. I7;

kárṇayos. 6. 14r.2. I9. 60. I.

(cf. kṛdhukarṇa, kṛ̣̣̣akárṇa, babhrúkarṇa, vikarṇá, çrútkarṇa, karṇá-kárṇya.)

karṇá: -nă. 5. 13.9.

kárṇaka: -kāu. 20. 133.3.

karnatás. 9.8.3. 
ka rṇín: -íni. Io. I. 2.

kárṇy a: -ṇias. 6. 127.3.

kartá: -ám. 4. 12.7.

kart an a in adhivikártana.

kártu in kártum, kártave : see $\mathrm{f}^{\prime} \mathrm{I}$ kṛ. (cf. kártva.)

kartrí: -tâ. 2. 12.5. 5. 29. I. $[3,25$. kartấram. 4. I9.6. 5. I4. II. IO. I. kartré. I0. I. 30. $[($ do. $)$.

kartị́n. Io. I. I4 (s. mss. -trén), I7 (cf. níşkartṛ.)

kártra: -am. Io. I. I9, 32 .

kártva: -tuam. I. $4.3^{*}$.

ka rma $\circ \mathbf{k r q t}$ : kármakṛt. 2. 27.6

karma $\circ \mathbf{k r q t}$ ya: -yāya. 4. 24. 6.

ka rm a ṇ y à : -íăs. 6. 23.2. [8.2,6.

kárman: -ma. 6. 23.3. II. 7. I7;

kármañā. I0. 5. I 5-2I.

kármaṇe. 19. 37.2.

kármaṇas. II. 8.6.

kármani. 5. 24. I-17.

kárman. 4. 23. 3 (kármanoka-). 12. kármāṇi. 4. 7. 7. 7.26.6*; 54. I. Io. 2. I8. I9. 68. I.

(cf. viçvákarman, sukárman, karmakṛt_karmabhāgá.)

karma ○bhā gá: -ám. 4. 39.9.

karmấra: -rās. 3. 5. 6 .

kárvara: -am. ro. 4. I9.

kárvarāṇi. 5.2.6t. 7.3. r.

karçaná: -ás. 4. IO. 7 (kārçanás ?). (cf. sapatnakárçana.)

karçápha: -asya. 3.9.4.

kaláça: -as. 9. J. 6 ; 4 . I 5

kaláçam. 9. 4.6. x8. 4. 30.

kaláçe. 7. 76.6*. 18. 4. 60*

kaláçān. I8. $4.58^{*}$.

kaláçāis. 3. I2.7. (cf. droṇakalaçá.)

kalấ: -ấm. 6. $46.3^{*}$. I9. $57 \cdot$ I* $^{*}$.

kalắs. x 9.57 .2$.

káli: -im. 7. I09. I.

(cf. kalí.)

kalí: -íobhis. Io. Io. I3.

kálpa: -am. 8. 9. Io.

kálpeșu. 20. I25.6-II.

(cf. samikalpá, sukálpa.)

ka lma lí : -ís. I 5. 2. I-4. k a l māşa in

ka lmăşa०grIv a: -as. 3. 27.5. kalmăş̧agrĩvāya. I2. 3.59.

ka lyā ṇa: -ṇt. $5.17 .12,18 . \quad$ I 0.8 . 26. 20. 128.9.

kályăṇi. 6. I07. 3, t; 130. 3 .

kalyānyāì. 6. 107.3.

(cf. ákalyāṇa.)

k a vaca in akavacá, kavacín, and

kavaca opàçá: -çāís. II. IO. 22.

kavacín: -ct. II. 10. 22.

kaví: -ís. 4. I. 7. 5. I. 4.5 ; $12.1^{\circ}$

I3. I. 8. 3.20". 9. 9. $15^{\circ}$. I3. I. II

I8. 3.63 .

kave. 12. 1.63.

kaváye. 19.3.4.

kaváyas. 3.17. $1^{*}$. 5.1.6". 8.9.17. 9. $2.5 ; 4.8 ; 9.6^{*}$. 13. I. 23,40 . I 8

I. I7; 2. I8*. I9. 53. I.

kavayas. 4.27.3. I8. 3. I9.

kavín. 9. 9. $7^{*}$. $\left[47^{\dagger}\right.$

kavíobhis. 4. 26.3. 9. 3. I9. I8. 3 .

kavinằm. 6. 47.3. 7.22. I. I4. I. 53 .

(cf. kăvya, kāvyá, kavíkratukavyá.)

kavíokratu: -um. 7. I4. I.

kavíotara: -as. 5. II. 4.

kavioçastá: -tấs. I8. I. $60^{*}$.

kaviçastăni. 5. I. 9. [9.18*. v'ka vīy: -yámānas (p. -vioy-). 9.

kavyá: -yāís. I8. 1. $47^{*}$.

(cf. kavyavăhana.)

kavyaovăhana: -nāya. I8. 4. 7I. kaça in prakaçá.

káçā: 9. I.2I.

káçām. 9. I. 5 .

káçãyās. 9. I. 22.

(cf. prakaçá, madhukaçă.)

kaçípu: -une. 6. 138.5.

(cf. híraṇyakaçipu, kaçipūpa-

barhaná.) [-ṇám. 9.6.10.

kaçip ū pabarhạá (p. -puoup-):

ka çó ka: -kās. 5.2. $4^{\dagger}$.

káçma ça: -am. 5.21. I.

kaçyápa: -as. 4.37. I. 8. 5. I $4^{2}$. I8. 3. I5. I9. 53. IO.

kaçyapa. 8. 9.7. I3. 3. 10.

kaçyápam. 4.29.3. 
kaçyápasya. I. I4. 4. 2.33.7. 4. 20. 7. 5. 28.7 . I7. 27,28 . kaçyápās. I3. I. 23.

f ka ș: ef. káșkașa?. + a pa: apăkasan (p. apaoák-) [7.20. káṣ kaṣa: -ṣāsas. 5. 23. 7 .

1kas: ef. kasuka.

+ ud: út kasantu. II. 9. 21 .

+ vi: ef. víkasuka.

+ s a m: cf. sámkasuka.

ka s a n nilla: -am. I0. 4. 5, I 7.

kásāmbu: I8. 4.37.

k a s ka in víkasuka, sámikasuka. kas yá: -yé. I8. 3. I7.

kāṭá: -ám. I2. 4.3.

kāṇá: -áyā. I2. 4.3.

kầṇ a: -am. I2. 3. 45 .

kănụāis. I2. 3. 42.

(cf. árjunalzāṇḍa, mahatkāṇụá, çatákāṇụa, sahásrakāṇụa, kāṇdín.)

kāṇ ḍ́n: -ínīs. 8. 7.4.

kānīná: -ás. 5. 5.8.

kānda (?) in

kāndāovișá: -ám. Io. 4. 22.

kābavá: -ám. 3. 9. 3, 5 .

kābavásya. 3.9.4.

kăma: -as. 3. $25 \cdot 2 ; 26.2 ; 29.7^{4}$. 6. 36. 3. 9. 2.7, II, I9. II. 3. 3. I8. I. $8^{*}$. I9. 4. 4; 52.1 ${ }^{*}$ 4. [kāma). kằma. 3. 29.7. 19. 52.1 (mss sá kāma. 9. 2. $3^{2}, 4^{2}, 5,9$, IO, 16, I 7, 1 8 , 19-24, 23, 25. r9. $52.2,5$ (p. yáto kāmas).

kằmam. 3.21.4. 4. 39. 2, 4, 6, 8. 9. I. 9 ; 2. I, 2,24 . I3. I. 5 . I8. 4 . 5 (kầmamokāa-).

kắmena. 3. 29.7. 5. I1.2. 6.9. I ; I39. 2, 4. II. 7. I3. I9 52. 1, 3, 4.

kămāya. 3. 8. 4 ; 29.7. 5. $33^{\dagger}$. I2. 4. 26.

kămāt. 9. 8. 8 .

kămasya. 3. 25. I , 3. 6. 139. 5. 9. 2.6. kămās. II. 7.13. I2. $3 \cdot 36 ; 4.19$. I4. 2. $5^{*}$. 19. +2. 3 .

kằmān. 3. 10. 1 3; 29.2. I2. 4.35, (cf. akāmá, aksṣákāma, apakāmá, jánikāma, dānakāma, devákāma, deṿ̛́kāma, dhánakāma, nāthákāma, nikāmá, pátikāma, putrákāma, púșțikāma, púrtikāma, pūrvakāma, prajâkāma, pratikāmá, yajñákāma, yátkāma, yatrakăma, sómakāma, kấmajyeṣtha-kāmyā.)

kấm a ojyeșțha: -jieşțhās. 9.2.8. kāma。dú gha: -as. 8. 9. 2.

kāmadúghā. 4. 34.8. 9. 5. IO. II. I. 28 . I2. I, 6 I

kāmadúghās. 9. 5.25. 18. 4. 33 .

kā ma oprá: -ás. II. 7.8 .

kāmapréna. ro. 9. 4.

kấma $\mathrm{m}$ ū t a: -tā. I8. I. I2*.

kàm a ○ça lya: -yām. 3. 252 .

kāmín: -ínā. 2. 3o. 2.

kāmínī. I. 34.5 . 2. 30. I. 6. 8. I-3. kāmínīs. 3. 8.4.

kă m y a: -am. 20. 128.3. [myà. kāmy a in kușthakāmyà, pratikākāmyā in dhanakāmyấ, putrakāmyă, vittakāmyà. [yà̀m). kāyá: -ám. I9. 57.4 (? ed. kakṣkāra in āilabakārá, namaskārá, rathakārá, vașațkārá, vātīkārá, srukkārá, svadhākārá, svāhākārá, hin̄kārá.

kārin in nikārín, abhinișkārín.

kārú : -úm. 20. 127. 11 .

kārú (p. -ú́ íti). 5. 12. $7^{*}$.

kārávas. 7. 73. I.

k ā r y à : -yàm. 20. 136.14 (not mss.). kāríasya. 3.24.5.

kărṣîva na a: -ṇās. 6. II6. I.

kărṣna: -am. II. 5.6. [yăs). kărṣ̣nyās. 20. I30. 4 (mss. kārṣṇkālá: -ás. I 3. 2.39. I9. 53. I, 22, $5^{2}$, $6,8,9,10^{2} ; 54.6$.

kālám. 19. 53.3. [54. I, $2^{2}$. kāléna. I9. 53.5 (mss. -lé ha), 7 ; kālàt. I9. 53. $\mathrm{IO}^{2} ; 54 \cdot \mathrm{I}^{2}, 3^{\mathrm{z}}$.

kālé. 7. 50. $6^{*}$. I9. $53 \cdot 3,5,6^{3}, 7^{3}$, $8^{3}$; 54. I, 2, 3 (mss. -lás), 4 (do.), 4", 5 (mss. -leyám).

kāl a kāñ já: -jấs. 6. 80.2. [kābe-). kāveraká: -ás. 8. 10. 28 (m. mss. kăvy a: -viam. 9. I0. $9^{*}$ I0. 8.32 . 
kăvyena. 8. 3. 20".

kăviena. 5. I. 5 (-nā); I I. 2, 3 .

kāv yá: -viás. 4. 1.6.

kāviám. 4. 29.6.

$\checkmark \mathbf{k}$ ă

+ a bhi: abhí cākaçîti. 9. 9.20*.

+ ava: avaocăkaçat. 6. $80.1^{*}$. I 3 .

2. $12 ; 4 . \mathrm{I}$.

+ pra: ef. ápracañkaça.

+ prati: pratiocăkaçān. 6. 29. $3^{2}$.

(cf. pratĩkāçá.)

+ vi: viocăkaçîti. I 3. 3. I.

+ s a m: sám kãçayãmi. I4. 2. 12. (cf. sámkāça.)

kā ça in pratĩkãçá, sámikāça.

kāeçí: -ínā. 8. $4 . \delta^{*}$.

kășṭ̂a: -ām. 2. 14.6 (mss. gă-).

kầ s: -âsă. 5.22. 10.

kāsás. I. 12. 3 .

(cf. kāsá, kāsā, kấsikā.)

kāsá: -ám. 5. 22. I I (kấsam ?).

kāsā: kāse. 6. 105. 1-3 (mss. kăse). (cf. kâsikinā.)

kầsikā: II. 2.22.

kấsikayā. 5.22. 12.

kăhābāha: -am. 9. 8. II.

ki (pron.): kím, see ka.

[yant.)

(cf. nákis, măkis, kimikará, kí-

ki mọ u ka in sukimọ̧uká.

kimokará: -rấs. 8. 8.22.

kitavá: -ám. 7. 109. 3.

kitavắn. 7. 50. I.

kimĩdín: -dî. 4. 28.7.

kimidínam. I. 7. I. 4.20. S. 8.3.25.

kimīdíne. 8. 4. $2^{*}$.

kimidínas. 8.6.21.

kimídínas (pl.). I. 7. 3 ; 2S. I, 2. 4 . 20. 5. 8. 4. $23^{\dagger} ; 6.25$. I2. 1.50 .

kimidinas. 2. $24, \mathrm{I}-4$.

kimīdinīs. 2. 24. 5-8.

kí y ant: kíyat. I0. 7.8, 9. kíyatā. I 0. $7.8,9^{2}$.

kíyatis. 8. 7.13.

$\sqrt{ } \mathbf{k i r}$, see $\sqrt{ } \mathbf{2} \mathbf{k r ̣}$. [raṇāu), 2 (do.).

kiráṇa: -ṇāu. 20. I33. I (mss. kikirāta in kāirāta, kāirātiká.

kíla. I. $34 \cdot 4 \cdot 4 \cdot 7 \cdot 3$. I8. I. $15^{*}, 4^{2 * *}$.

kilà sa: -am. I. $23.1,2 ; 24.2$. kilăsásya. I. 23. 4 .

(cf. kilāsanăçana, kilāsabheşajá.)

kilāsaonăçana: -am. I. 24.2.

ki lāsa०bheşajá: -ám. I. 242.

kílbişa: -am. 5. 19.5. I2. 3. 48.

kílbişāṇi. 6. 1 18. 1, 2 .

(cf. devakilbişá, nilkilbig̨á, brahmakilbişá.)

kiçorá: -rấs. 12. 4. 7.

kişka in çvakişkin. [II. 8. 15.

kitka sā: -ās. 7.76.3. 9. 7.5; 8. 14. kikasābhyas. 2. 33. $2^{*}$.

kị á: -țébhyas. 9. 4. 16.

kintą̧a: -as. 4. II. IO.

kīnăçās. 3.17. $5^{*}$. 6. 30. 2.

1/kírta y : kīrtáyās. 7. 37.1; 38.4.

kĩtí: -ís. I2. 5.9. I3. 4.14,22. I5. 2. $\mathrm{I}-4^{2}$.

kīrtím. 5. 20.9. 9. 6.35. I0. 3. I 7-25. I9. 63. I ; 7I. I. 20. 4 S. 3 (mss. -ís).

kīrtiă. I 0. 6.27 (m. mss. ed. -tyà). (cf. $\sqrt{\text { kīrtay.) }}$

kĩlâla: -as. 7.60. 5 .

kỉlálam. 4. I1. IO.

kỉlălena. $4.26 .6 ; 27.5$. I0. 6.25. kīlăle. 6. 69. I.

(cf. kīlálodhan.) [I2. I.59.

kílă lodhan (p. -laoūdh-): -dhñ.

k u (pron.) in kútas, kuvít, kúha, kvà, kucará, kunakhín, kúmuda (?). ku kú nd ha : -dhās. 8. 6. II.

ku kứ rabha: -bhās. 8. 6. II.

kukṣí: -ís. 7. III. I. 9. 7. I2.

kukșím. 20. I 30.7 (not mss.).

kukșî̀ (p. -1 íti). 2. 5.4. 4. 16.3. 9.

5. 20. I0. 9. I7.

kukșíobhiām. 2. 33. 4 . (cf. kukșilá.)

kukșilá: -lấs. 8. 6. 10.

kucará: -ás. 7.26.2*; $44 \cdot 3^{*}$.

kú ñ a pa: -am. II. I0. 4 .

kúṇape. II. 9.10; 10. 8.

(ef. sahásrakuṇapa.)

ku ụ d a in tāilakuṇụá.

kútas. 8. 9. I, 4. 9. $9.18^{*}$. 10. 2 $10^{2}, 14^{2} ; 8.44$. II. $8.8^{5}, 12^{4}$.

kútsa: -am. 4. 29. 5 . 
lrunakhín: -ínā. 7. 65.3.

1 ku p: ef. ákupyant, kupāyú.

k u pāy ú : -yávas. 20. I 30.8 (not mss.).

kupyá: -yăss. 20. I3I. 7 .

kúbera: -as. 8. 10. 28. (cf. kāveraká.)

k u mārá: -ás. 3. I2.3, 7 [10.8.27

kumārám. I. II. 5 .

kumārásya. 5. 23.2.

kumārấs. I2. 4.8.

kumārí. I0. 8.2\%. 20. 136. 16.

kumāri. 20. 133. I-62.

kumārî́m. 2. 36 . I.

kumāríam. I4. I. 63. (cf. kumāriká, kāúmāra.)

kumārikấ: I0. 4. I4. 20. I36. I4. kúmuda: -am. 4. 3.1. 5 .

kú m ba: -am. 6. I38. 3 .

kumbhá: -ás. 3. 12.7. 9. 6.17 (m. mss. kumbhyàs). I 9. 53. 3 .

kumbhám. 3. 12.8. II. I. I4.

kumbhéna. ro. 8.14.

kumbhé. I. 6.4.

kumbhắn. 4. 34. 7. I8. 3.68.

kumbhébhis. I9. 2. 2 .

kumbhí. II. 3. I I, I4. I2. 3. 23.

kumbhî̀m. 9. 5.5. 12. 2. $5 \mathrm{I}$.

(cf. riktakumbhá, kumbhámuṣka, kumbhíka.)

kumbhá。muṣka: -kās. 8. 6.15. kumbhámuṣlzān. II. 9. I7.

ku mbhìka: -kās. I6. 6.8.

kuríra: -am. 7. I38. 3. I4. I. $8^{*}$. (cf. kurīrín.)

kurīrín: -ínam. 6. I38.2. kurīríni. 5. 31. 2.

k uru in kāuravyá.

kurūtín: -ínī. IO. I. I5.

ku rúru: -um. 2. 3I. 2.

kurúravas. 9. 2. 22.

kurkurá: -rāú. 7. 95. 2.

kúla: -le. 20. I29. I4 (not mss.). (ef. kulapá.)

kula 1 p à : -ấs. I. I4. 3 . kulapấs (pl.). 7.72. 2*.

kulăya: -am. 9. 3. 20 . I4. I. 57. 20. I27. 8 (mss. kúlā-); I32. 5 .

kulăye. 9. 3. 20. kúliça: -çena. 2. I2. 3

kúlmala: -am. 2. 30.3. 5. I8.8.

kúlmalāt. 4.6.5.

(cf. samikalpákulmala.)

kulyấ: I8. 3. 72 (mss. kulyà); 4 . 57 (m. mss. do.).

kulyăyās. $5 \cdot$ 19.3.

kulyà̀: II. 3.13.

kuvít. 2.3.2.

kuçavartaka: 20. I3I. 9 (ed. kúç-). kușúm b h a: -am. 2. 32. 6 .

kúșț a: -as. 5. 4. Io. I9. 39. I, 5, 6 (m. mss. kușțhás), 7 (do.), $8^{2}$ (do.). kuṣțha. 5. 4. I, 6, 9. I9. 39. 2.

kúsțham. 5. 4.3, 4, 5 .

kúșțhasya. 5.4.8. 6. 102.3.

kúṣthās. I9. 57.2 (mss. ed. kușțhâs). (cf. kușthakāmyà, kúșthikā.)

k u ș ț h kām y à : -mías. I 9. 39. 9 (p. kușța k-). [9.23.

kú șțhikā: -ās. 9.4. I6; 7. 10. I0.

kúsindha: -am. I0.2. 3 .

kúsindhe. I0. 2.5 .

kusúl a: -lās. 8. 6. Io. [(mss. kú).

kúha. 20. I 30. 5 (mss. -am); I32. I I kúhā. 20. 130. 6 .

kuhû́: -ús. 7.47.2.

kuhứm. 7. 47. I.

$\sqrt{ } \mathbf{k} \overline{\mathbf{u}}$ in ākūta, àkūti, kaví.

V $\mathbf{k} \overline{\mathbf{u}} \mathbf{j}$ : kứjantāu. 7.95.2.

kút ț: -am. 8. 8. I6.

k ūṭá: -áyā. I2. 4.3.

k ū dî (or kūṭî): -díam. 5. I9. I2.

kú pa: -pe. 5.3I. 8 .

k ū rmá: -mébhyas. 9. 4. 16.

k $\bar{u}$ la î anukúla, utkúla, pratikúla, mádhukūla.

kúlbaja: -am. I2. 5. I2, 53 .

V I kṛ: kṛ̣ómi. 2. 36. 2. 3. 9. $2 ; 23$. 5. 4. I8. 1. 6. 9. 2 ; III. 2,$3 ;$ I19. I ; I29. I. 8. 2. 5, II; 6.3. I2. 2. 32 . I4. I. 58 .

kṛnomi. I. $25.4 ; 30.4$. 2. $2.4 ; 3$. I ; IO. I-8. 3. 8. 6 ; 30. I, 5, 7. 4. 30 . $3^{*}, 5^{*}$. 5. I. 5 ; 28 . II ; 3O. 5,8 . 6. 20. 3 ; 93. $2.7 .35 .3^{3}$. 8. 1. $6 ; 2.13$, I9; 7.5, 22. 9. 2. I9-24. I4. 2. 34 . I9. 30.4 . 
kṛnóósi. 5. 22.2. 6. 20.3; 30.2. 7 . 56. 4. I3. 4. 43 . [6.9. 9.8. $4^{2}$. krṇóti. 2.36.3. 6. 29. I". 8. 3. 8"; kṛ̣oti. 9. 6.45-8. I2. 4. 25. I 8 . I. $53^{*} ; 3.54$.

kṛṇmás. 6. $5 \cdot 3 \cdot 7 \cdot 76.5$.

kụnmas. 1. 13.3. 3. 30.4. 5. 7.2. 8. 2. 16,21 . 9. 3. I2. II. $2.3,4$. 14. 1. $63 ; 2.35$.

krṇmási. I9. 52.5 (mss. -masi).

kṛnmasi. 4. 3I. $4^{\dagger}$. 5.28. 13. 8.2. I0. kṛnutha. 4. 21. 6". 6. 22.2 . kṛnuthā (p. -tha). 4. 21. 6".

kṛ̣̣vánti. I. $33 \cdot 3$.

kṛ̣̣vé. 5. 8. 8. II. I. 28, 3 I.

kṛ̣ve. 7. 100. I. 9. 3.15.

kṛnușé. 3.6.6. 8.2. I6.

kṛnuşe. 5. I.2. 19. 49.4.

kṛnute. I. $35 \cdot 2$. 6. $27 \cdot 3^{*}$. 8. $3 \cdot 24^{*}$. 9. 4. I9. II. 5. IO, I5. I2. 4. $6,30^{2}$. I3. $2.28,42$.

kṛnmahe. I9. 68. I.

kṛ̣váte. 8.5.7.

kx̣ṇávas. I 8. 2. $5^{*}$ [-ṇávat).

kṛ̣avas. 5. 1.8. 19. 33.5 (mss.

kṛ̣ávat. 2. 9.5. 5.8.7.

kṛ̣avat. 2. 35. I. 3. I. I ; 2. I. 5 . 2. $8^{\dagger}$ 6. III. I; II6. 2. I2. 3. IO. I9. 27. 10.

kṛ̣avāt. 20. I32.5.

kṛ̣ávāma. 6. 27. I*

kṛ̣avāma. 12. 3.49.

kṛnávan. I8. I. II*.

kṛṇuhi. 3. I. $4^{*}$. 4. 22.3. 5. II. II ; 12. $2^{*} ; 27.12$. 7.8. I. II. I. 31 .

kṛnuu. 2. 19. 5 ; 20. 5; 21. 5; 22. 5 ; $27.1-6 ; 36.6^{2}$. 3. $5.6,7 ; 22.3$. 4 . 22. I. 5. 6. I0; 29. 2,3 , I3. 6. 99. 3 ; I08. 4: I2I. 4; I29. 2,3 ; I4O. I. 7. I2. 3. I2. I. 23,24 . I4. I. $6 I^{\dagger}$. I9. $31.13 ; 32.8 ; 47.8 ; 50.1 ; 62 . I^{2}$.

kṛnótu. 6.83. I. 8.6.18. 9.2.7. I 9. 44.3 .

kṛnotu. I. II. I. 3. 15.4. 4. 4.3. 6. 4 O. I, $2^{2} ; 53.3 ; 58.1^{2} ; 71.1,2$; 72. I; 73. $3 ; 78.3 ;$ I04. $3 ;$ I06. 3 . 7. 32. I; 33. I; 51. I* ; 86. I' ; 9I. I*; II8. I*. 8. 8.2, 4. 9. I0. 24 . I0. 6 .
3I; 9. 26. I I. I. 6. I2. I. I, 21, 22, 4I, 43. I 4. I. $47,49^{2} ;$ 2. I2, 39. 75 . I 8. 3. $12,52^{\dagger}, 55^{\circ}, 6$ I. I9. 3 I. I4.

kṛṇutám. 6. 54.2 ; 14 I. 3.

kṛnutam. 3. 25.6. 6. 50. I.

kṛnutām. 2. 28.2, 4. 3. 3. 4 .

kṛṇutá. II. I. $2^{\dagger}$.

kṛnuta. I. 30. 3. 2. I 3. 2; 23 5. 6. I23. 2. I8. 4.37 .

kṛṇutā (p. -ta). 6. 55.3. 12.2. 34. kṛnota. 5. 3.6".

kṛṇvántu. 2. 13. 4.

kṛvvantu. 3. 9.3. 6.23. 2, 3; 91. $3^{*}$. kṛnuşva. 3. 4.4. 4. 20.5. 7. 34. I. I0. I. I6. I2. 4. 29. I4. 2. 50. I8. I. $16^{*} ; 3.8$. 19. 45.5 .

kṛ̣utām. 7. 62. I.

kṛ̣̣vāthām. I4 2.37.39.

kṛnudhvam. I9. $58.4^{2 "}$.

kṛ̣ván. 5. I. 7. 6. 72. I. I2. I. 51 . I8. I. $29^{*}$. I9. 33.2. 20. 127.8.

kṛnvát. 5. 28. I4.

kṛ̣vántas. 3. I0. 5. 9. 2.8. I4. 2. 59 (mss. ed. -antás). I 8. 2. 22, 29 ; 4. $12,13$.

kṛ̣vatí. I 4. 2.60. kṛ̣̣vatís. I4. $2.6 \mathrm{r}$. kṛ̣̣vānás. 2. 29.3. kṛ̣nvānắm. 4. 38. I.

kṛ̣̣vānăs. I. I3.4. 5. 8.6.

ákṛ̣̣os. I 4 . I. $4 \mathrm{I}^{*}$.

akṛ̣os. 7. 84.2*. 20. I35. I 2 (mss. ák-, áttanos).

ákṛnot. I 0. 7.9. 19. 4. I. [I I. 1. 24. ákṛ̣̣van. I. 25. I. 4.23.6. 7. 79. I. akṛ̣van. I0. 2. 2. akṛṇvata. 8. 5. If. karoti. I2. 5. 45 .

kurvanti. 8. 10. 20.

kurve. 6. 135. I. I2. 4. 6.

kurute. 9. 6. I8, I9. I5. II. 5.

kurváte. 7. 54. I. 8.6. II, 14.

kurvate. I2. $5.47,49$.

karavas. I3. I. 56, 57 .

karavāt. I0. 2.5.

kuru. I I. 9. I, I5, 22, 24. I 4. 2. 20. kurvatām. 19. 7.4.

kurván. 9. 5.32. 
kurvántam. 9. 5.32. [vatìm) kurvatîm. 9. 5.32 (kurvatîmokurkurvāṇăs. I2. $5 \cdot 4^{8}$. akaros. 20. 128.13 .

[akar). akarot. I0. 2. I6. 20. 127.8 (ed. ákurvan. I5. 4. 1-6 (ed. ak-).

akurvan. I5. 5. I-7.

ákurvata. 6. I28. I.

kuruthās. 5. 22. II.

ákaram. 6. II5.2.

akaram. I. 32.4. 2. 2. 5. 5. 7.9, IO; 28. 7. 6. IO4. $2 ; \mathrm{I} 38.3^{3}$. 8. 2. 4. II 2. 16,30 . I2. 1. 26 . I4. $2.46^{*}$.

karam. I. 3. I-5. I 4. I. $18^{*}$.

akar. II. 4.6.

kar. 7. IO. I*.

ákaras. 6. I 28. 4 (mss. ak-). I2.3. 38 . akaras. I3. I. 20.

álkar. I. 8. I.

akar. 2. 25. I. 7. 30. I. I0. 6. I9, 30. 20. I27. 8 (mss. akarot).

kar. I8. I. $5^{*}$

akarat. I. 24. 2. 9. 2. II.

ákartām. 6. It1. 2 .

ákarma. I 8. 3.24*

akarma. 7. 97. 4. [ [. $55^{*} ; 3.22^{\dagger}$. akran. 2. 29.7. 3.4. 7. 4.21. I*. I 8. kran. 8. 6. 25 . I 4. I. 32 (mss. ed. krán). I9. 20. 4 (mss. krán). [49.3*. akrata. 3. I0. 5. 5. 3. 10 $0^{\dagger}$ 6.28. $2^{*}$; kárasi. I 8. 2. $4^{*}$.

karas. 5. I5. I-II.

karati. I9. I5. 5.

kárat. 4. 22. 5. 6. 59.2. 7. 94. I*. karat. 4. 8. 6. 6. IO3. I. 7. 30. I. I9 31. I ; 34. 2 , IO; $35.5 ; 45.3 ; 46.7$.

kárāma. I8. I. $52^{*}$,

karāmahe. 7.6.4.

kárși. 13. 2.3.

kṛdhi. I. $2.2 ; 13.2 ; 24.3 ; 26.4$; 34. I. 2. $27 \cdot 7 \cdot$ 3. $18 \cdot 2^{\dagger}$. 5. 4.6, 9; 8.6. 6. $5.1,2 ; 40.3 ; 67.3 ; 74.3$; 95.3 ; 106. 2 ; 128. 3 ; 136. 2 ; 138. I, $2^{2} ;$ I $39.3 ;$ I 4 I. 2.7 7. 20. $2 ; 26.3$; 50. $4^{*} ; 8$ I.3. 8.5.17. 17. 7. I8. 2. 9. I9. $8.6 ; 15.1^{*} ; 32.6 .20 .127 .6$ (not miss.).

[kártam).

kartam. 3. I 7. 5. I I. 2.2 (mss. ed karta. 20. I3I. 2 (not mss.). kṛta. I 9. 44. I (mss. kṛtám). cakartha. 6. 100. 3 .

calkăra. $2.5 \cdot 5^{*} ; 9 \cdot 5 . \quad 3.24 .2$. 4 . I8. $6^{2}$. 5. 8. 7 ; 14. 6,$9 ; 3$ I. II $^{2}$. 7 . IO9. 5. 9. IO. IO*. IO. I. $28 ; 8.26$. I3. I. 52. I9. 20. 2. [2.27. cakāra. 4.6.1. 6.65.3. 9.3.3. I8. calkráthus. 3. $17.7^{*}$. 9. $9.19^{*}$. cakṛmá. 6. I 18. 1. 7. 106. I. 12. 2. 40. cakṛmá (p. -má). 6. II4. I ; 115.1 . 10. 3. 8 . I8. I. $4^{*}$.

cakṛmā (p. -ma). I8. I. $33^{*}, 5 \mathrm{I}^{*}$. cakrús. 4 . I $7 \cdot 4^{3} ;$ I 8. 5. 5. 3 I. $1^{3}, 2^{2}$, $3^{2}, 4^{2}, 5^{2}, 6^{3}, 7^{3}, 8$, 9. 6. I.6. I ; I 4 I. 3. I4. 2.65. I9. 35. I, 2.

cakrus. I $0.7 .44^{*}$. II. 9. 25 .

cakré. 4. I7. I.

cakrssé. I8. 2. 20

cakré. 5. 8.8. I0. $7.32,33,34,36^{\circ}$. I2. I. IO. I9. 20.3 .

cakre. I. 24. I, 2. 2. 27. 3. 8. 9. 2. 9. 3.II. I3. I. II ; 3.25 . I9. 6. $14^{*}$. cakriré. 4. 7.7. 5. 8.6. 18. 2. 16*. cakṛovăn. 2. $35 \cdot 3$.

cakrúșam. 4. 13. I*.

cakrúșe. 4. I 8.4.

karișyāmi. 5. 8.2.

karișyati. 9. I0. $18^{*}$. I0. 6.2.

karişyatha. 5. 13.7 .

kártum. 4. I8.6. 5. 3I. II.

kártave. I3. 2.12.

kṛtvă. 3. 3.6; 25.6. 4. 7. 3; 18.2. 5 . I7. IIt. 6. IO3. 3. 8. 6.26. I0. I. 9 ; 9 6. I1. 8. II. I2. 2. 4, 43. 13.3. I. I5. I4. I-I 2. I 8. $2.33^{\dagger} ; 3.42^{\dagger}$. I9. 8.6 ; 30. I. kṛtuá. 3. 25.2. 4. 18. 3. 5. 22.4. 8. 9. 2. 10. $9.5,25$. I I. $5.9 ; 8.18,29^{2}$. I 2. $2.54 ; 4.20$. I3. I. $47,52^{2}$.

kṛtás. 4.6. 7. 5.20. 8. 6. 15.3. 9.3. 2. kṛtám. 3. 9. 2. 4. 26. $7 ;$ 38.3. 5. 5 . 4 ; 9.8. 6. 9. 3 ; II. I ; 72. 2 ; 97. $2^{*}$. 7. $4^{2} .1^{*}, 2^{*} ; 50.2 .3^{*}, 5,6^{*}, 8$. 9. 2 . I6. I0. I. 32 . I3. 4. 40. I4. 262,65 . 19. $9.12 ; 16.1 ; 72.1$.

kṛtă. 5. I 4. 7. I0. I. $3 ; 8.26$.

krténa. 6. 124. I.

kṛtásya. I. 23.4. 3. 24. 5. 7. 50. 9. 
krrté. 3. I7. 2".

kṛtăs. 4.6.7. I9. 6. 15 *

kṛtăni. 4. 38. 1, 2, 3.

kriyáte. 3. 29.3. 8. 2. 25. I9. 58.6.

kriyate. I8. 2. $\mathrm{I}^{\dagger} ; 3.64$ [11.4".

kriyámāṇam. 2. 12. 6*. 5.29.1. I9.

kriyámāṇāyãs. 3.7.6.

karikrati. 4.18.3.

kárikratam. I0. 4.3.

cíkIrșati. 5. 8.3. I2. 4. I9.

(cf. kará, káraṇa, karúña, kartị́,

kártra, kártva, kárman, kar-

măra, kāra, kārin, kāryà, kṛt,

kṛta, kṛti, kṛtya, kṛtyă kṛ̂tríma,

kṛ́tvas, kị́tvan, cakṛvāñs, krátu.)

+ an u : ef. anukará.

+ antar: antáh... kṛnute. II. 5. 3. antáh kṛ̣uş̧va. 7. 36. I.

+ a pa: ápa kṛ̣utā (p. -ta). 3. 9. I.

+ a pi: ápi ... kṛ̣otu. 9. 4. 2.

+ abhi: abhiocakrá. 3. 9. I.

(cf. abhikárana, abhikứtvan.)

+ à: a kṛ̣uṣva. 7.73. 10". [77.3. ấ krrdhi. I. 2.2. 5. 8.7. 6.65. I; āokṛ́tya. ro. I. 6 .

āocárikrat. Ir. 5. 6 .

(cf. âkṛti.)

+ udā: udoákuruta. I2. 4. 4I. [2.

+ up ā: upáluṛtam (p. upa。ấk-). 2. 34 .

+ paryā: paryâkrụtā (p. parioăk-). 12. $5 \cdot 33$.

$[5 \cdot 33$.

paryākriyámānāa (p. pari॰āk-). 12 .

+ vyā: vioăkaromi. I2. 2. 32.

vioăkaram. 7. 115.4 .

+ s a mā: sam॰ākurvānás. I3. I.8.

sam॰ăkarat. 6. I4I. I.

samoâkṛtam. 4. 3I. $7^{*}$.

+ tir as: tirás lkaras. 4. 20.7 .

+ ni: ní kurve. 7. 38. 2.

ní... akaram. 5.23.8.

ní kran. 7.82.3.

ní... cakăra. 9. ro. $7^{*}$.

niocakré. 7.38.2.

níokartum. ro. I. 26.

niocíkīrșati. I r. 2. I3.

(cf. nikārín, nikựtvan.)

+ nis: nís kuru. 5. 4.6.

niroákurvata. 4. 19. 4 . nís karat. 2. 9.5. 5.4. 10.

níş karan. 6. 24. 2.

níş kṛdhi. $5 \cdot 5 \cdot 4$.

(cf. níşkartṛ, niş̧kṛtá, níşkṛti.)

+ abhin is: abhioníşkŗtāt. I O. I. I2.

(cf. abhinişkărín.)

+ pari: párişkṛtăt. 9.3.10. 14.1. $7^{\circ}$.

+ pra: praocakrús. 12.2. 5 .

+ vi: viokurváte. I2. 1. 43 .

ví cakre. 12. 3.54.

viocakriré. I2. I. 5 .

víokṛtā. 12. 3.22.

víokṛtāni. 9. 9.16".

+ s a m: samiklṛtám. I I. I. 35 .

+ hiñ: hín kṛ̣̣oti. 9.6. 45-8.

hiñokṛ̣vatí. 7. 73. 8". I2. 5. 21 .

híñn akṛnot. 9. 10. 6".

hiñokárikratĩ. 9. I. 8.

(cf. hin̄kārá.)

+ abhihiñ: abhiohínkṛnota. I2. 3 .

$\sqrt{ } 2$ kṛ (kir): cf. kirána.

+ a n u: anuolírămi. I 8. 3.69; 4. 26.

+ ā: ãokirántīm. 4.38.2.

+ s a m: sám kira. 3.24.5.

$\sqrt{ } 3 \mathrm{kr}$ : carkṛdhi. 20. I27. II.

akārșam. 7. 7. I. [kứtya.)

(cf. kārú, kīrtí, 1/kīrtay, car-

kṛkavăku: -um. 20. 136. Io (mss. -kam).

kṛkavăkāu. 5. 3I. 2.

kṛkāța: -am. 9. 7.r.

kṛt in aghakṛ́t, açanakṛ́t, āyuṣkựt, karmakṛt, kṛtyākṛ́t, jāmikṛ̂t, jyotiṣkṛ́t, duṣkṛ́t, pathikṛ́t, pāpakṛ́t, purukṛ́t, bandhukṛ́t, bhūtakṛ̛t, madhukṛ́t, mūlakṛ́t, yajñakṛ́t, rājakṛ́t, lokakṛ́t, vijeșakṛ́t, viçvakṛ̂t, pravedakṛ́t, çlokakṛ́t, sakṛ́t, sarūpakṛ́t, sukṛ́t, steyakṛ́t, havișkṛ́t.

1/ kṛt: kṛntá. I9. $28.8^{4}$.

(cf. kartá, kartana, kṛtatra, kṛtta, kŕtti, 2 kṛtyă ?.)

+ a pi: ápi kartsyāmi. Io. I. 2 I.

+ pari: pariokŕtya. 5. I4.3.

pariokṛtyámānas. 4. 16. 7 .

+ pra: praokrntáti. I2. 4.7.

+ vi: viokṛtyámānā. 12. 5.29. 
+ a dhivi: ef adhivikártana.

+ s a m: cf. saminkrrtatrá.

1'2 k ṛt: kṛntatí (I kṛt ?). I. 27. 2.

ákrntan. I4. I. 45.

krta in akṛta, áramkṛta, kakajăkṛta, duṣkṛtá, devákṛta, námaskṛta, pitṛ́kṛta, mātṛ́kṛta, răjakṛta, váșațkṛta, vātíkṛta, çikyăkṛta, çūdrákṛta, sáhaskṛta, súkṛta, sukṛtá, stríkṛta, svayámkṛta, svâhākṛta, hástakṛta ; and kṛtádvișța-kṛtākṛtá.

kr t atra in samskṛtatrá.

kṛtá。dvișța: -țā. 7. II3. I.

kṛtáovirya: -as. I7. 27.

$[65$.

kṛtă g a s (p. -táoāg-): -sas. I 2. 5.60, kr t a $\circ \mathrm{v}$ y adh an a: kṛ́tavyadhani. 5. 14.9.

kṛtākṛtá (p. -taoak-): -ám. I9. 9.2. kṛti in alkṛti, níșkṛti.

k r tta in akṛttaruc.

kṛ́tti: -tīs. 8. 6. II.

(cf. kṛ́ttikã.)

kṛ̂ttikā: -ās. 9.7.3. I9. 7.2.

krty a in karmakŕtya.

krtya (gerund) in namaskŕtya.

I kṛtyă : -ấm. 5. 9.8.

kṛtyăbhis. 8. 5 . I5.

(cf. pāpakṛtyâ, sukṛtyâ.)

2 kṛtyắ: 4. 9.5. 5. I4. 5, II, I2, I3. I2. 5. I2, 39, 53. I4. I. $25^{*}, 26^{*}$.

kựtye. 5. I4. IO. II. I0.6. [29, 3 I. krtye. 10. I. 7, I5, I 7, 20, 2I, 25, 26, kṛtyăm. 4. 17.4; 18.2, 4. 5. 14.3, $4,6,8 ; 3$ I. I-7, $8^{2}$. IO. I. I $8 ; 3.4$. I4. 2.65. I9. 45 . I.

kṛtyăs. 4. I8.5. 5. 14.5. 8. 5.2, 5, $6,7,9^{3}$ (1. -tiăs ?). 10. 1. 6, 30. 14. 2. 49. I9. 9.9; 34. 2 (yầ k-: ed. akșak-; mss. jāgṛtsyás).

(cf. kṛtyākṛ́t-kṛtyādưși.)

kṛtyāokṛ́t: $\quad$ 4. 28.6.

kṛtyākṛ́tam. 5. I4. I, 2, 4, 5, IO, I2, I3; 3I. I2. IO. I. 5 .

kṛtyākựtā. IO. I. 2, 24, 32 .

kṛtyākṛ́te. 5. I 4. 3, 4, 5, 8. IO. I. 23. kṛtyākṛ́tas. 4. I9. I. IO. I. I9, 3I.

I9. 45. I.

[3I. I9. 34. 2.

kṛtyākṛ́tas (pl.). 4. I7.4. I0. I. 6, kṛtyāodúṣ̣aṇa: -as. I9. 34.4. kṛtyādúșaṇam. Io. I. 9 . kṛ̣tiādúșaṇis. 8. 7. 10.

kr ty $\mathbf{a} \circ d$ ț și: -is. 2.4 .6$.

kṛtríma: -as. I4. 2. 68.

kṛtrímam. I9. 34.3 (mss. kṛtrím).

kṛ́t v a n: -nas. I9. 35.5 (mss. kṛṣnávas).

kŕttvarîs. 4. I8. I.

(cf. abhikṛtvan, pāpakṛ́tvan, pūrvakṛtvan, pūrvakāmakṛ́tvan.)

kṛ́tvas. II. 2. 9. I2. 2. 29. (cf. așțakṛ̂tvas.)

kṛdhú: 20. I36. I. (cf. krrdhukarna.)

kr dhuokarṇa: -rṇt. II. 9. 7 ; Io. 7 .

1 krp, kra p: akrpran. I8. 3. $23^{*}$. kứpamāṇasya. 5. I9. I3. (cf. kṛpaná.)

kṛ́ p: kṛpá. I 8.4 .59 *.

k ṛpá: -pát. 7. 14. 2 (kṛpấ ?).

kṛp a ṇá: -ṇấs. II. 8.28.

k ṛ́ mi (mss. kṛ́mi, krími) : -is. 2. 32. 4. 5. 23.7. I1. 9. 10. I2. I. 46.

kŕmim. 2. 31. 4 ; 32. 2. 5. 23. I, 3, 9 . kínmes. 2. 3I. I.

kímayas. 2. 3 I. 5 ; 32. I-5. 5. 23. 5 . krmayas. 2. 32.3 . $[2,5,6$. kŕmīn. 2. 3 I. I, 2, 4 ; 32. I, 3. 5. 23. kứmīṇām. 2. 31. 3, 5; 32. 4 (1. -ṇaam). 5. 23. 8 , I3 (1. -ṇaam).

kṛminām. 5. 23. I3 (1. -ṇaam).

Vkṛ̣: cakárça. I2. 3. I6. [(do.). kṛçitám. 20. I36. I2 (not mss.): I6 (cf. karçaná, kṛ̣á, kựçana ?.)

kṛçá: -ám. 4. 21. 6*. 6. IOI. 2. (cf. kŗ̧̣águ.)

kṛçá。gu: -us. 4. I5.6.

kṛ çan a: -as. 4. IO. I, 3. kṛ́çanam. 4. I0. 7 .

VI, 2 kṛș: kárșet. I5. 13. $7^{2}$. krșáte. 12. 2. 36 .

kṛșatu. 3. 17.6.

krșté. I0. 6. 33 .

acarkrșus. 6. 30. I; 9I. I.

(cf. kṛșí, kṛṣīvan, kṛșța, kṛștí.)

+ s a m: samiokárṣantī. I 1. 9. 8. [6. I 2.

kṛ̂í:-ím. 3. I2.4. 8. 10. $24^{2}$. 10. 5.34 ; 
krşyă. I I. 3.4I. [5.34. I2. 2.37. krșyăăs. 2. 4. 5. 8. 2. I9 (1. -șiâs). I0. (ef, kṛşísamç̧ita, kṛşīvan.)

kṛşíosamçita: -as. 10. 5.34.

kṛșivan in kărșî̃vạa.

krşța in akŗșțapacyá and

$\mathbf{k r q s ̦}$ ț $\mathbf{r}$ dhi: -is. 8. 10. 24.

kṛșțí: -țáyas. 3.24.3. I2. 1. $3,4,42$. kṛ șná : -ás. 7. 64. 1, 2. 8.6.5. 12. 3.

I3. I 8. 3. $55^{*}$.

kṛşṇâ. 6. 83.2.7.74. I. I2. 2. 53 .

kứşne. I. 23. I. [1.52. I3. 3.9".

kṛṣnám. 6. 22. I". II. 2. I8. 12.

kṛșnătm. I2. I. II ; 3.54.

kṛșnaăt. 5 . 30. II.

kṛṣnăẫās. I3. 3.26.

kṛ̛̦nāú. 5.23.4.

$[4.34$.

kṛṣnăs. 5.23.5. 8. 7. I. II. 2.2. I 8. (cf. kắrşṇa, kṛ̛ṣna -kṛ̣̣nạajiná.)

kṛ́ṣna: -ṇās. 6. 49. $3^{*}$.

kṛșna a kárṇa: -as. 5. I7. I 5 .

kṛșnàodrá: -ám. 9. 7.4.

kṛṣna vortani: -ne. I. 28.2.

kṛşna oça ku ní: -nés. I9. 57. 4 (mss. -une).

kŗ̣̣̣ñãiná (p. -ṇa॰aj-): -ám. 9. 6. I7. $\checkmark$ k! p: kalpate. 5. I9. I5. 8. 9. 20. Io. 9. 4. 20. I28. I2 (mss. ká-).

kalpatām. 6. 88.3.

kálpat. I I. 5.26.

kálpamānas. 3.8. I. I3. 2. 33, 43 . I8. 4 . 13 (m. mss. ed. kalpá-).

akalpata. I3. I, 46, 53 .

ákalpanta. I I. 3. 2 I.

cäkḷpus (p. calk-). 9. IO. I9.

căḳ̣pé (do.). 7.87. I.

cākḷpat (do.). 6. 35.3.

acilklpat. 6. II.3.

kḷptás. I0. I0. 23.

kẹptắs. 8. 9. 15 .

kalpayāmi. I 8. 4.52. I9.27.4.

kalpáyasi. 4. 23. 2.

kalpáyanti. 9.6.7. I0. I. I.

kalpayanti. 9. 6.7. I8. 4.2. [59.3* kalpayāti. 7. 104. I. I8. 3.59\%. I9. kalpayāt. 3.4.6. [I2.2.25*. kalpaya. I. 24.4. 9.5.4. II. I.36. kalpayatu. 5. 25. $5^{*}$. kalpayantu. 9.5.13.

kalpayasva. 18. 1. $13^{\circ}$.

kalpayantãm. $7 \cdot 67.1$.

kalpáyantas. 8. 9. I4. 9. IO. I9. [55. akalpayat. 10.2.15 $15^{\text {2 }}$ 13. 1. 53. I4. I.

ákalpayan. 9. 4. 14 .

akalpayan. I9.6.8 20 . 128. I

ákalpayathās. I2. 1. 55 .

ákalpayanta. I 8. 4. 7.

kalpayitvâ. I3. I. 52, 54 .

(cf. lxálpa.)

+ ud: udoákalpayan. I2. 4.4I.

+ pra: prá... kralpatăm. 5.7.3.

praolralpáyan. I9. 8. I (mss. prá-

kalpa-).

[2.

+ prati : práti cākḷpe (p. calk-). 6. 36 .

+ vi: ví kalpate. 4. 7. 2.

ví... kalpayāmi. I2. 2. 32 .

ví akalpayat. I0. 6.21.

vioákalpayan. 9. 4. I5.

ví akalpayan. I9. 6. 5*.

+ s a m: sám kalpayati. I 2. 4. 3I.

sám kalpayā (p. -ya). 4. I2. $5^{2}$.

sám akalpayan. 6. I09. I.

(cf. samkalpa.)

keta in manasketá, çréyaḥketa.

ketú: -ús. 7. II. I; 8 I. 2*. I0. 8. I3. I I. 4.22. I3. 2.34.

ketúm. Io. 2. I2.

ketúnā. I3. 2.9, 3I. I8. 3.65*.

ketávas. II. 10.7. I3. $2.1,16^{*}, 18^{*}$.

ketún. 6. 103.3. I0. I. 32 .

ketúobhis. II. IO. I, 2. I3. 3. 23.

(cf. dhūmáketu, súryaketu, ketumánt.)

ketuomán t: -mắn. I3. 2.28.

ketumát. 6. I26.3.

ketumántas. 3. I9.6. I3. I. 24.

ketumátī (p. -i íti etc.). 8. 9. I 2.

lséval a: -as. 7.37. I; 38.4 .

kévalam. 3.18.2* 4.23.7. 10.

7.36 ; 8. I. II. 5 . IO, I5.

kévalāu. 9. 4. 12.

kévalī. 3. 25.4. 8. 9. 24. I9. 4. 2.

kévalīs. 7. 94. ${ }^{*}$.

ké ç a : -as. 6. 136.3 .

kéçās. 6. 9. I; 137.2, 3. I 5. 2. I-4. 19. 60. I (m. mss. keçấs). 
kéçān. 5. I9. 3. I I. 8. I I, I2. I4. I. 55. I9. 32. 2.

kéçebhyas. 6. 30. 3 ; 136. I.

kéçeșu. I. I 8.3 .

(cf. avalkeçá, múnikeçä, vikeçá, vyastakeçá, çocíş̧eça, sarvakeçaká, hírạ̣yakeça, keçaka-kéçya.)

ke çaka in sarvakeçaká.

ke ̧̧a。d ̛̣́nh a ṇa: -ṇīs. 6. 2I. 3 .

keça。vá: -văs. 8.6.23.

keça。várdhana: -nīm. 6. I37. I. keçavárdhanis. 6. 21.3 .

keça॰çm açrú: 8. 2. I7.

ke çín: -çî. 8. 6. 5 .

keçínas. II. 2. 18 .

keçínas (pl.). 9. 10. 26. I4. 2. 59.

keçínīs. 12. 5.48.

keçínībhias. II. 2.3I.

kéç y a: -çiam. I4. 2.68.

kesara in

kés ara oprābandhã: -dhāyās. 5

kāirāta: kāírāta. 5. 13.5.

(cf. kāirātiká.)

kāirātiká: -kă. ro. 4. I4.

kóka: -as. 5. 23.4.

kókam. 8. 6.2. (cf. kókayātu.)

kóka॰yātu: -um. 8.4. 22*".

kóça: -as. 4. I6. 7. 9.3.20. Io. 2.

3I. II. 2. II. I4. I. $6^{*}$.

kóçam. 4. 15. 16". I8. 4. 30.

kóçāt. I9. 72. I.

kóçe. 9. 3.20. I0. 2. 32.

kóçās. I3. 4. I0.

kóçān. Io. 7. I0.

[bilá.)

(cf. antahkłoçá, devakoçá, koça-

koçabilá: -lé. 20. I33. 2 (mss. kóçabíle).

kāúmāra: -as. I2. 3.47.

kā uramá: -mé. 20. I27. I (mss. -ma á or kāuruma â).

[kāur-).

kắravya: -as. 20. 127.8 (m. mss. ky ầ m bū: kiămbūs. I 8. 3. $6^{\dagger}$.

krátu: -us. 8. 9.22. $\left[67^{*}\right.$. krátum. 5. 2. $3^{*}$. I 8. I. 20*; 3.18*, krátvā. 4. 31. $6^{*} ; 32.5^{*}$.

krátunā. I3. 2. IO.

krátve. 6. I9.2. I8. 2.23. krátāu. I. $34 \cdot 2$. 3. 25.5. 6. 9. 2. krátuobhis. 8. 3. I*. I3. 3.23.

(cf. akratú, ihákratu, kavíkratu, yajñakratu, váreṇyakratu, çatákratu, sukrátu.) [kradat).

1/kran d: krándat. 20. 136. 5 (mss. ácikradat. 3.3. I.

acikradat. I $8.4 \cdot 5^{8^{\dagger}}$.

kánikradat. 2. 30.5 .

ákrandayat. 8. 9. I. [klandá ?.) (cf. kránda, krandana, krándas, + abhi: abhiokrándati. 8. 7.2I. II. $4 \cdot 3,4$. [4-6. abhí kranda. 4. I5.6. 5. 20.7; 21 . abhiokrándan. 5.20،2. II. 5. I2. abhyákrandat(p. abhioá-). I9.30.5. $+\overline{\mathbf{a}}$ : à krandaya. 2. 36.6. 6. I26. 2*. (cf. ākrandá.)

+ s a m: cf. samkrándana.

kránd a: -as. II. 2.22.

krándāya. II. 2. 3; 4. 2. (cf. ākrandá.)

krandan a in samkrándana.

krándas: -si (p. -I íti). 4. 2. $3^{*}$.

$\checkmark \mathbf{k r a p}$, see $/ \mathbf{k r p}$.

' kr a m: krame. I9. I7. I-Io.

kramate. 7. I4.4. [çah̆oiva). kxámasva. 4. 4.7 (p. kráma svárkrámadhvam. 4. I4. 2.

akramata. 4. II. $7^{3}$.

krāntám. I 0. $7 \cdot 38$.

(cf. kráma, kramaṇa, krāma, krāvan ?, cañkrama.)

+ a ti : áti ... krāma. 2. II. I-5. atiokrămantas. I2. 2.28, 29. atiokrắmantī. 20. 136.6 .

+ adhi: cf. adhican̄kramá.

+ a nu: ánu ... alkramít. 3. 7. 2.

+ a pa: ápa krāmati. I2. 5.6.

ápa krāmanti. I2. 5.I1.

ápa krāma. Io. I. I4.

apaokrắman. 7. 105. I.

ápa ... akramit. 8. 1.21.

ápakrāntas. 20. I35. I. [2.18.

+ abhy a pa: abhioápakramīs. I2.

+ a va: avaokrăman. 4. II. IO. 13. I. 20.

áva ... akramit. I 9. 36.5 . 
(cf. avakrāmá.)

+ ā: ầ kramasva. I8. 4.6.

à kramatām. 9.5. r, $3^{2}$.

à ... akramit. 6. $3 \mathrm{I} \cdot \mathrm{I}^{*}$.

āokran̉syámānas. 9.5.8.

āokrámya. 8.8.16.

(cf. ākrámana.)

+ a bhy ya: cf. abhyākrắma.

+ u d: út krāma. 8. I. 4. 9. 5.6.

ut ... akraman. 4.3. I. [19. I-9, II. úd akrāmat. 8. 10.2-8, 18-29. I 9. úd akrāman. I9. I9. Io.

+ ni: ny àkrāmat. 8. 10. 2-7.

(cf. nikrámana.)

+ parā: parāokrámya. I0. 7.11. párāolkrāntas. ro. 7.16.

+ pari: pariokrắman. 8.6.8. pári ... akramit. I. 17.4. pariokrámya. I 2.4 . 17.

+ pra: praokrấmantas. I2. I. 28.

+ vi : ví krame. I o. 5.25-35.

ví kramasva. 4. 8.4. 7.26.3.

ví kramatām. 9. 5.8.

ví akrāmat. I9. 6. 2".

vy àkramata. 9.5.20.

viocakramé. I. I2. I. I2. I. IO.

ví cakrame. $7.26 .4^{*}, 5^{*}$. I 0. 8.4 I.

I3. $2.27^{*}, 27 ; 3.25^{*}$.

viocalsramāṇás. 7. 26. $\mathrm{I}^{*}$.

ví... akrañsata. 20. 135.4 .

víokrāntā. 8. 10. 8 .

(ef. vikramá, vikrámaṇa.)

+ anuvi: anuovíkramate. 9.6.29.

+ s a m: sám krāmatam. 7. 53. 2. [57.

+ a nus a m: anuosámkrāma. I 8. 2.

krám a: -as. Io. 5.25-35.

krámān. 8. 9. ro.

(cf. vikramá.)

[vikrámana.

kra m a n a in ākrámana, nikrámaña, kray a in ākrayá, vikrayá.

kravișṇú: -ús. 8. 3. 4".

kravís: 8. 6.23.

kravíșā. 8. 3. $15^{*}$.

(cf. kraviṣṇú, kravya, krūrá.)

kravya in

kravyầd (p. -yaoád): 3. 21. $9 ; 2 S$.

2. 5. 29. 8, 9, I5 (1. -yaád). 8. I. I2;

3. $4^{*}$. $12.2 .4,7^{*}, 35,36,37,3^{8}, 43$,
$50,52,53 ; 3.43 ; 5.41,72$.

kravyădam. 3. 21.8, 9, 10; 219.10; 31.9. 8. 2.9 (1. -yaád-); 6.6. I2. 2. $8^{\circ}, 9$, IO, I5, I6, 39. 42, 43. | 13. 1. 29 . kravyădā. I I. IO. İ 8 I2. 2. 34, 51 . kravyăde. 8. 4.2".

$\begin{array}{llll}\text { kravyădas. } & 2.25 \cdot 5 \cdot \quad 4 \cdot 30,3 . & 5 .\end{array}$ 29. II". 8.2. I 2 (1. -yaád-); 3. $2^{\circ}$. II. 1o. 3 .

(cf. akravyād.)

krāma in abhyākrắma, avakrāmá. krāvan in dadhikrăvan.

krími, see kŕmi.

V krĩ: krītuă. 3.15.2.

(cf. kraya, krí, kríta.)

+ ap a: apaokrităs. 8. 7. Ir.

+ ā: ef. ākrayá.

+ nis: níṣkritas (p. níhok-). 2. 34. I.

+ pari: páry akrịnan. 4. 7.6.

+ pra: ef. prakrí.

+ vi: ví kriñite. I2. 4. 2.

(cf. vikrayá.)

$\mathbf{k r} \mathbf{i}$ in prakrí, sadyahkrí.

f'krī ḍ: kríḍantāu. 7.81. I". I3. 2. II". I4. I. 22".

krídantis. 9. 4.24.

+ pra: praokrídate. 5.21.8.

krīta in rathakritá.

Vkrudh: krúdhyati. 4. 36. I0.

krudhas. II. 2. I9, 20. [I3.3.6.

kruddhás. IO. IO. IO, I1. I2. 5. 36 .

kruddhă. I2. 4. 37 .

kruddhásya. I3 3. 1-25.

kruddhắs. I2. 2.5.

krodháyanti. 4. 36.9.

(cf. kródha.)

1'kruç: kroçatu. II. 9. 7; 10.7. (ef. kroça, kroșțrí)

+ abhi: abhí kroçantu. 5.21.9.

+ prati: ef. pratikroçá.

+ s a m: sám kroçatām. 8. 8.2 2 .

k rū rá: -ám. 5. 19. 5. 6. 49. I. I8. 4 . 83. I9. 9. $14: 56.5$.

krūrắni. I2. 5. I4.

krūrāís. I6. 7.2.

kroḍá: -ás. 9. 4. 15; 7.5.

kroḍāú. I0. 9.25.

kródha: -as. 9.7.13.

kródham. 4. 38.4. 
kroça in pratikroçá.

kroṣṭ̂́: -țré. II. 2. 2. kroṣțắras. II. 2. II.

kladívant (or knad-): - vatas ( $p$. -díov-). 7. 90. 3 .

kl a ndá: -dăs. 2. 2. 5 . $\checkmark \mathrm{klid}$ in viklíndu, vílklediyas. $\mathrm{k} l$ ind $\mathrm{u}$ in viklíndu.

klībá: klibba. 6. 138. 3 . klībám. 6. I38. 1, 2, 3 . klībăs. 8. 6. II. (cf. klībárūpa.)

klībá。rūpa: -pān. 8.6.7. $\mathbf{k} \mathbf{l}$ edi $\mathbf{i}$ a $\mathbf{s}$ in víklediyas.

klomán: -má. I0. 9.15.

klomnás. 2.33.3. 9.8.12.

kv à. I5. II. 2, 3 .

kúa. 9. 9. $4^{*}, 17^{*}$. I0. $2.2 ; 7.1^{2}, 4^{2}, 5^{2}$, $6 ; 8.7,39,4$ I. I4. I. $14^{2 *}$. 20. 129.6. kva $\mathbf{s}$ in upakvasa.

kṣata in ákșata, súkṣata.

kṣattṛ́: -tă. 5. 17. 14

kșattắram. 9.6.49.

kṣattărāu. 3. 24.7.

kṣatrá: -ám. 2. 15.4. 3. 5.2; 19. I, 5. 5. I. $8:$ I8.4. 6. 54. I, $2 ; 97$. $2 ; 98.2$. 7. 84.2*. 9.7.9. I0. 2 . 22,23 ; 3. I2. II. 7. I8; 8.20. I2. 5. 8. I5. I0. $3,4,5,7$, I1. I6. I. I3. kṣatréṇa. 2.6.4. 7.82.2, 3. 12. 3. 5 I. I8. 2. $60^{*}$.

kṣatrắya. I5. IO.2. I9. 24. 2.

kșatrásya. I9. 30.4.

kșatré. I9. 24. 2.

kșatrănni. $\quad 7 \cdot 78.2$.

kṣatrănām. 4. 22. 2.

(cf. tuvilsṣatrá, kșatrabhṛ́t-kṣakṣatraobhṛt: 7.84. I.

kṣatra॰yogá: -gāís. I0. 5.2.

kșatraovárdhana:-am. ro. 6. 29. kșatríy a: -as. 6. 76.4. 7. 103. I. I2. 5.46 .

kșatríyam. 4. 22. I. 8. 4.13*. kșatríyena. 6. 76.3. I2. 5.44. kșatríyasya. 5. 17. $3^{*}$. I2. 5. 5, II. $\checkmark$ kṣa d: kșadāmahe. I0. 6.5.

(cf. kșattŕ..)

V kṣ a n: kṣaṇișțhās. I o. I. 16. (cf. kṣata, kșatrá ?.)

kṣabha in açvakșabhá (?).

v kṣ a m: cf. kṣám, kṣamá, kșăman.

+ a ti: áti ... kṣấmat. 7.63. I (krâ-?). + a v a : cf. ávakșāma.

kṣá m, kṣấ: kșắm. 5. 1. 5. I 8. I. 39*. kșamâ. 6. 57.3.

kșámi. I8. I. I*. I 9. 5. I*

kșămā. I 8. I. 29*.

kṣ a má: -măm. I2. I. 29.

kṣá y a: -yāya. I. 5. $3^{*}$. 7. 26.3. (cf. urúkșaya.)

kș a y a ṇ a in arāyakșáyaṇa, asurakṣáyaṇa, piçācakșáyaṇa, bhrātṛvyakșáyaṇa, yātudhānakṣáyaṇa, sadānvākṣáyaṇa, sapatnakșáyaṇa.

V'kṣ a r: kșáranti. $4 \cdot 35 \cdot 5$. I2. I. 9. kșaranti. 7. 18.2; 57.2* . I I. 2.24 . kșarantu. 12. I. 30 .

kșárat. 5. 1.3. (cf. kșara.)

+ abhi: abhí kșara. 7. Iog. 4. abhí kșarantu. 8. 2. I4.

+ vi: viokșáranti. I3. 3. 2.

ví kșaranti. 9. 10.21*. I3. I. $42^{*}$. (cf. vikșará.)

kș a r a in akșára, vikșará. [vam). kṣáva: -am. I9. 8.5 (s. mss. chá(cf. parikșavá.)

$\sqrt{ }$ kṣā: kṣāpáya. 12. $5 \cdot 5 \mathrm{I}$. (cf. kșāma.)

+ a pi: ápi kșāpayati. I2. 5. 44. ápi kșāpaya. I2. 5.5I.

ks āma in ávakșāma.

kṣăman: -mā (p. -ma). I 8." 3. $21^{*}$.

V I kṣi: kṣayati. 5. 2. $8^{*}$.

kșáyantīs. I. $5 \cdot 4^{*}$.

kșiyati. II. 7. I6 (1. kṣyati).

kșiyánti. 13. 3. I.

kṣiyántam. I3. 2. 43.

(ma.)

(cf. kșáya, kṣit, kṣití, kșétra, kșé-

+ adhi: adhiokṣiyánti. 7. 26. 3*.

+ an u : ánu kșiyati. Io. 2.22 (1. kșyati), 23 (do.).

ánu kșiya. 6. 121. 4.

+ ā: āokṣiyáti. I o. 5.45 (1. kṣyati ?). āokșiyánti. I8. 2. 49 . 
ấ kșiyema. 6. 117.3.

ákșiyan (p. āoák-). I2. I. 57.

+ upa: úpa kşayema. I $9.15 .4^{\dagger}$. úpa kṣiyanti. 4. 30. 4".

+ pari: cf. parikşít.

V 2 kṣi: kṣinăămi. 3. 19. 3 .

kṣiṇāti. 3. 28. I.

kșeșța. 4. 34.8 .

kșìyáte. I2. 5.45.

[mānaa.)

(cf. kșayạ̣a, kșita, kșíti, kşìya+ up a : cf. ánupakșita.

+ nis: níh ... kṣinóomi. 6. I4. 2.

+ pra: prá kṣiṇāti. I2. 2. 35 . prá kșinuihi., 10. 3. I5. I3. 3. I-25. práokṣiṇās. I0. 3. I5.

+ s a m: sám kṣiṇāti. 3. 28. 2.

kṣit in parikșít.

kșita in ákșita, ánupakșita, and kșitắy us (p. -táoāy-): 3. II. $2^{*}$. kṣití: -tinắm. 6. 34. I* (1. -naam).

kṣiti: -is. II. $7.25 ; 8.4,26$. I2. 5 . 16, 33 .

(cf. ákșiti, ásurakṣiti.)

Vkşip: kṣipasi. 9. I. IO, 20.

kșiptásya. 6. Iog. 3 .

cikșipas. I 8. 2. $4^{*}$.

(cf. kșipta, kșiprá.)

+ ava: áva cikṣipan. I8. 4. I2, I3.

ksipta in

kṣipta॰bheșajá: -jí. 6. Iog. I.

kṣiprá: -ám. 8.8.4. II. I. I3. I2.

I. $35 ; 5.47-5$ O. 20. 135. 4 .

(cf. kșiprádhanvan.)

kșipráodhanvan: -ne. II. 4.23.

kṣ I y a mā ṇa in ákṣiyamāṇa.

kșirá: -ám. 2. 26.4, 5. 5. 19.5. 8. 3. I5*. 9.6. 39,$40 ; 9.5^{*}$. I0. 9. I $2-24$; Io. 8 , IO, II.

kșīéṇa. 4. 34. 6, 7.

kșīrásya. I. I5. 4.

kșiré. 5. 29.7. I 8.2.30.

(cf. írākșira, 16hitakṣira, kṣīrávant, kșīín.)

kṣirrá。vant: -vãn. I8. 4. I6.

kṣirín: -ínim. 7. 50.9.

v kşu: cf. kșáva.

+ pari: cf. parikṣavá.

kṣú: -úm. I8. 3.23 (cf. purukşú, kşumánt.)

I kşud in

kşudrá: -rébhyas. 19.22.6; 23. 2 r.

V kşudh: kşudhat. 2. 29.4.

(cf. kşúdh, kşudhā, kşudhya.)

kşú dh: 9.7. I 2.

[3I. II.

kşúdham. 7.50. $7^{\circ}$. 8.8.18. I9.

kşudhắ. $4 \cdot 7 \cdot 3$.

kşúdhas. II . 8.2I.

kş $u d \mathbf{d} \bar{a}$ (or kşúdh) in

kşu d hāomārá: -ám. 4. I 7.6, 7.

kşudh y a in akşudhyá.

1'kşubh: cf. kşóbhana.

+vi: viocukșubhé. 7. 57. I.

kṣuománt: kṣumáti. I8. 1. 20".

kṣurá: -ás. 20. I27.4.

kșurénaa. 6. 68. I, 3. 8. 2. 17.

(cf. kşurápavi, kṣurábhṛșți.)

kṣurá p p vi: -is. I2. 5. 20, 55 .

kṣurá。bhṛṣți: -ținā. I2. 5.66.

kṣull aká: -kăs. 2. 32.5 .

kṣétra: -ãya. 3.28.3.

kșétrāt. II I. I. 28.

kșétrasya. 2.8.5; I2. I. I9. IO. IO" kṣétre. 4. I8.5. 5. I7. I6; 3I.4. I0. I. I $8 ; 4.8$. II. I. 22 . I2. I. 43 .

kṣétrāṇi. 2. 29.3. I4. 2. 7. [yá.)

(cf. anyakșetrá, sukșetra, kṣetri-

kṣetri yá: -ám. 2. 8.2-5. 3. 7. I, $2,3,6^{2}, 7.4 .18 .7$.

kșetriyásya. 2.8.1. 3.7.4.

kșetriyăt. 2. 10. 1-8. 3. $7 \cdot 5^{\dagger}$.

kṣetriyắnaam. 2. I4. 5 .

(cf. kṣetriyanăçana.)

kşetriya onă çana: -ni. 2. 8.2-5.

kșém a: -as. II. 7. I3. I3. I. 27.

kṣémam. 3.3.5. 4. I. 4. I9. 8. $2^{2}$.

20. 127.8 .

kṣéme. 3. I2. I.

(cf. kșemyá.)

kș e m yá: -ás. I 2. 2. 49.

kșóbhạ̣a: -as. I9. 13. 2*.

V kṣṇu: kṣnuvānás. 5. 20. I.

kṣvín kā: -ās. 8. 3. $7^{*}$.

khá: khé. I4. I. $4^{I^{3 *}}$.

khăni. I0. 2. I, 6 . 
(cf. sukhá.)

khaḍ úra: -re. II. 9. I6.

khañvakhā: kháṇvakhắzi. 4. 15. I 5 (m. mss. khaṇ-).

kha dirá: -ás. 20. I3I. I7.

khadirám. Io. 6.6-10.

khadirât. 3.6. I. 5.5.5. (cf. khadirājira.)

khadirājira (p. -raoaj-) : -ram. 8. 8. 3 (ed. -rám).

[7. 38. I.

$\checkmark$ khan, khā: khanāmi. 3. I8. I* .

khanati. ro. 4. I4.

khanāmasi. 1. 34. I. 4. 4. I. 6. I36. I.

khananti. 2. 3.3.

khánamānās. 19. 2.3.

ákhanat. 4. 4. I. 6. I37. I. 7.24. I.

akhanat. 2.27.2. 5. I4. I.

khātám. 5. I3. I.

(cf. khá, khaná, khaní, khanitŕ, khanitríma, khara, khāta.)

+ ã : cf. ākhará (?).

+ ni: niokhánantas. 6. I16. I.

ní akhanan. 6. Iog. 3 .

niocakhnús. 5. 31.8. I0. I. I8.

níokhātam. IO. I. I9.

níokhātās. I8. 2.34. I9. 9.9 (mss.

ed. nikhătắs).

(cf. níkhātaka.)

+ vi: viokhánāmi. I2. I.35.

khaná: -ás. I6. I. 3.

kh aní: -ím. I6. I. 7 .

khanitṛ́: -tấras. 4.6.8.

kh a nitrím a: -mās. I. 6.4. 5. 13.

9. I9.2. 2 .

kh a ra in ālrhará.

khargálā: 8. 4. I $7^{*}$.

(cf. khứgala.)

$\mathbf{k h a r v a}$ in

kharva。vāsín: -ínīm. II. 9. i6.

khárvikā: -ām. II. 9. 16.

khála: -as. II. 3.9.

(cf. khalajá.)

khala。já (or -jā): -jâs. 8. 6. I5.

$\mathbf{k h a l a t i}$ in khălatya.

khálva: -luān. 2. 3r. I. 5. 23.8. / $\mathbf{k} \mathbf{h} \overline{\mathbf{a}}$, see / khan.

khāta in ákhāta, abhrikhāta, níkhātaka. $\checkmark$ khā d: khắdatas. 6. 49.2.

khădanti. .8. 6. 23 .

khăda. 8. 8.3.

khădantas. 5. I9. 3 .

(cf. khādá.)

khādá: -ám. 9.6. I2.

khălaty a: -am. II 8. I9.

Vkhid: + āa : a... khidāmi. 6. I02. 2.

â khidā (p. -da). 4. 22. 7 .

$+\mathrm{ud}$ : út khidati. II. $4.2 \mathrm{I}$.

utokhidét. I I. 4.2I.

utokhidán. 4. II. IO.

utokhidántī. I2. 5. I9.

+ nis: niḥokhídam. 5. 18.7 .

khilá: -lé. 7. II5.4.

(cf. khilyá.)

khilyá: -yé. 4. 21. 2*.

kht̂la: -lās. I0. 8. 4 .

, kh u d : ef. khódana.

$+\bar{a}$ : â khuda. 20. 136.5 (not mss.).

+ pra: prá khuda. 20. 135.4 (mss. -dasi).

khṛ́g ala: -am. 3. 9. 3 . (cf. khargálā.)

k hā i m a k hã : khāímakhăaji. 4. I 5 I 5 (s. mss. khāi-).

khód an a : -am (mss. sādhulkhodánam). 20. I36. I2, I4, I 5 .

$\checkmark$ khy ā : ákhyat. I8. I. $24^{\dagger}$.

(cf. khyāta, khyeya.)

+ ati: áty akhyat. I0. IO. 15. áti ... akhyat. I 8. $3.23^{\dagger}$.

+ anu: ánu ... akhyat. 7.82.4.

+ pari: pári khyan. 18. I. $2^{*}$.

+ prati: práti ... akhyat. 7.82.5. + vi: ví akhyat. 6. 31.2* . 13. 2.9. ví... akhyat. $7.736^{*}$. [28.

+ s a m: sámokhyātās. 4.16.5. I2.3. sáṁkhyātā. 4. 25. 2.

(cf. ásamikhyāta, asamikhyeyá.)

khy āta in ásamkhyāta.

khye ya in asamkhyeyá.

I g a , g ā , in ápagā, āçựngá, rjugá, durgá, nága, patamiá, puṇyagá, purogâ, çitimgá, sugá, svaga, svargá. 
$2 \mathrm{~g}$ a in sãmagá.

$\checkmark \mathrm{gach}$, see 1 gam.

g a ṇá: -ás. I3.4.8.

ganám. 6. II8. I (mss. gatnúm).

gaṇéna. 19. $13.4^{*}$.

gạ̦âs. 4. $13 \cdot 4^{\dagger} ; 15 \cdot 4$.

ganaãís. 19. 45. IO.

ganébhyas. I9. 22 . I6.

(cf. mahãgaṇá, vidaganá, ságaṇa, sárvagana.)

g a t in adhvagát, navagát.

$\mathrm{g}$ a t a in ágata, gatâsu.

g a tấsu (p. -táoas-): -um. I8. 3.2". gatăsos. I 8. 2. 59:

g a ti in gógati, sámgati.

g a tnú: -úm. 6. II8. I (ed. ganám). g a d a in agadá, vigada, ávijñãtagada.

$\checkmark$ g a : + vi: ví gada. 5.22.6 (vígada?)

g antṛ in anvāgantṛ́. [19. 38. I.

g andhá: -ás. II. 3. 8. I2. I. 23-5. gandhám. 8. 10. $27^{2}$. 12. I. 24. [34. gandhéna. 4. 37. 2. 8. 6. 10. 12. 5 . gandhấya. II. 2.6 .

(cf. gandhi.)

g and harvá: -ás. 2. I. $2 ; 2.1,2,3$. 4. 4. I; 37. II. I4. 2. $3^{*}, 4^{*}$. I8. I. $4^{*}$. 20. I28. 3 .

gandharva. I4. 2. 34 (p. -vaoṛtúnā). gandharvám. 2. 2.4. 14. 2. 36 .

gandharváya. 14. 2.4*.

$\begin{array}{llll}\text { gandharvásya. } & 4 \cdot 37.7 & 7 \cdot 73 \cdot 3 .\end{array}$

I4. 2. 35 .

gandharvấs. $\quad 8.5 \cdot 13 ; 7 \cdot 23.9 \cdot 7$. IO. II. 5.2. I2. I. 23,50 . I3. 1. 23 (m. mss. -vās). I4. 2.9.

gándharvās. 4. 37. I2.

gandharvắn. 4. 37. 2, 9. 8. 6. I9

* gandharvébhis. 7. 109. 5 .

gandharvāís. 4. 34.3. I0. IO. I3. gandharvănāām. 3. 24. 6.

gandharvis. I8. 1. 19*.

(cf. gandharvápatni - gandharvāpsarás.)

[2. 5 .

g a ndharvá opatni: -ỉbhyas. 2.

gandharvartú (p. -vaoṛt-): -únā.

I4. 2. 34 (-va rt-?).

gandharvāpsarás (p. -va॰ap-): -ásas. 8. 8 . I 5 ; 10. $27^{3}$. I0. 9. 9. I I $6.4 ; 7.27 ; 9.16,24$. 19. 54. 4 .

gandharvāpsarásām. I9. 36.6.

g andhări: -riobhyas. 5. 22. 14.

g andhi in ãukşágàndhi, durgán-

dhi, púnyagandhi, púruşagandhi.

g a bhi sák (p. -iosák). 7.7.1. 19. 56.2 (mss. bhiságbhyao).

gabhIrá: -ás. 5. II.3.

V g a m, g a c h: gáchati. 5.23.3. Io. 8. I6. I I. 8. 33 .

gachati. 9. 6.44. I1. 8.33 . I2. 4 . 32. I 8. 2. I"

gáchathas. 4. 29. 2.

gáchanti. 2. 25.5. I0. 8. 33 .

gachāsi. $5 \cdot 5 \cdot 6$.

gáchāti. I8. 2. $5^{*}$ [1.8.

gachema. 6. I2I. I. 7.83.4. II.

gácha. 5. 22. I 2.

gacha. 2. 34.5 . 5. $14.10^{2} ; 22.7$. 6. I13. 2. 7.97. $5^{3}$. 10. I. 8 . I1. 1. 35. I4. I. $20^{*} ; 2.75 . \quad$ 18. $2.7^{\dagger}, 7^{2 *}$, $46 ; 3.9 ; 4.6$. I9. 24.5 .

gachatāt. 2. 30.3.

gachatu. 7.98. 1. 9. 5.5. I2. 2. 8*. I 8. 2. 23 .

gachatam. I8. 2.53 (?). [tam). gáchantam. I 8. 2. 53 (mss. gachaágachat. I5. 7.1. [-āma). jagáma. I8. 4. 54 . I.9. 40. I (mss. jaganvăn. I8. I. I".

ágan. I4. 2.36, 74 .

agan. 7.25. I, $2 . \quad[3.64$.

áganma. I4. 2.36". I6. 9.3. I 8.

aganma. 16. 9.3.

gamātas. I0. 7.42.

gamātha. 3.8.4. I4. I. 32 .

gamāma. I. $5 \cdot 3^{*}$.

ajīgamam. 2. 25.5. I I. 3. 32-49.

gamisyati. 5.22.9. I0. 9. II.

gántave. 9.5.17. [8.3

gatvà. 2. 36.3 (1. -tuá ?). 4. 14. 2. 19

gatvăya. 20. 128. 5 .

gatấs. 10. 10. 32 .

gatắn. I8. 4. 4I.

gatấnām. 8. ז.8.

[(do.).

jígāñsati. I2. 4. 29 (mss. jíghā-), 30 gamayāmas. I6. 6. 4 . 
gamayāmasi. 3. $18.3^{*}$. gamayanti. 9.6.23.

gamaya. I2. 3.34.

gamayā (p. -ya). I. 2 I. $2^{*}$.

gamáyan. 18. 4. 64 .

gamayắm cakāra. I8. 2.27.

(cf. V I gā, gat, gata, gati, gatnú, gantṛ, gama, gamana, gámișțha, gamișyant, jágat, jigatnú, jman.)

+ adhi: ádhi ... agan. 2. 9.3. adhiogamyáte. 7. IOI. 1 .

+ a nu: ánu gachema. I I. I. 36 . anuogáchantī. I2. 5.27. anu॰gátya. 19. 44. Io.

+ a pa: ápa ... gamet. 6. 4. 2.

+ a pi: ápi gachati. I2. 4. 3I.

ápi gacha. 12. 3. 53 .

ápi gachatāt. I 8. 2. 14-8*. [2.4. ápi gachatu. 2. 12.8. 9.5. I. 12. ápi gachantu. I2. 2. 45 . ápi ... aganma. I9. 59. 3*.

+ abhi: abhiogáchāmi. I6. 7. II. abhí gachatas. 4. II. Io. abhyágacham (p. abhioág-). I6. 7 . 9 (mss. -chan).

abhígatas. 20. I35. I.

+ ava: áva gachati. 6. 76.4 . áva... gáchāt. 4. 1. 7. áva gachatāt. I8. 2.56. áva jagmus. 2. 5.6*. áva gamaya. 3. 3.6.

$+\overline{\mathbf{a}}$ : à ... gachati. 3. I3.6. I5. 2. I $-4^{2} ; 7 \cdot 3^{2}, 5^{5}$; 10. 8 , I0; II. 7,9 , II. à ... gachanti. I5. 7.3 (mss. -ati). à ... gachān. I8. I. II*. [13.6. ā॰gáchet. I5. IO. I; II. I ; I2. I ; à gachatāt. 9.3. 10 .

â... gachata. 18. 3. $44^{*}$.

ā॰gáchatas. 6. 82. I.

à'gachat. 8. I0. I8-29.

āojagằma. 6. 27. I*; 7I. 2.

à...jagāma. 7.20.5.

āojagántha. I4. 2. I9 (mss. -ndha). āojagmá. 7.97.4.

à jagamyāt. 7. 26. $2^{\dagger} ; 4$ I. I ; 84. $3^{\dagger}$. àojagmúșas. 2. 26. 2.

à 'gamam. 2. 30. $5^{2}$. 7.89. I. 8. 9 . 22. 9. I. I4. I9. 35.3 . à ... agamam. 4. 13. $5^{*}$.

ăgan (p. āoág-). 6. I16. 2, 3. 9. 10. I5*. 18. 2. 37 .

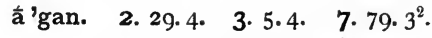
9. 4.22. I2. 3. I 5. I3. I. 2 (1. ầ agan); 2. 9. I4. 2. I3, I4. I8. I. $8^{*} ;$ 2. 57 ; 4. 53. I9. $37.1 ; 52.4$.

à... agan. 2. 30.5. 3. 5.1 ; 10. 8 . 4. 37. 5. 5. 26.6. 6. 68. I. I0. 4. I5. II. I. I4. I4. $2.5^{*}$. I8. 4. 50. I9. 3I. 7 .

à...gan. 3. 4. I.

â... agman. 4. $2 \mathrm{I} . \mathrm{I}^{*}$. [4.3. â gahi. 6. 7. I ; 108. I. I8. I. 59*. I 9. ấ gatam. 7.73.2, 4 .

à gata. I8. I. $5 \mathrm{I}^{*}$. [22-8. à 'gamat. I. 8.2. 6. 35.2 . I 0.6.2, ăgaman (p. āoág-). I4. 2.73.

à ... gamet. 2.36. 1. 3.12. 3 ; 13. 5 . à gamantu. I8. 3. $45^{*}$.

àgatas. 20. 129. I I (not mss.).

â.gatam. I0. 4.9.

áogatena. I9. 53. 7 .

à。gatasya. 6. 82. I.

à。gate. 7.52.2. II. 4.4. I9. I3. I. à。gatās. I4. 2.10*.

à... gatvă. I2. 3.13.

产 'jāgan. I9. $49 \cdot 3$ (? p. â jầ agan; ed. ájagan).

ầ gamaya. 6. 8 I.2. [syant.)

(cf. āgama, ágamișța, ánāgami-

+ u p à : upăgahi (p. upaoăg-). 7.48.2*.

+ a n vā: ef. anvāgantŕ.

+ ny ā: nioágan. $7 \cdot 73.8^{\dagger}$.

+ u d: út ... áganma. 7. 53. $7^{*}$.

+ upa: úpa ... áganma. 7. 32. $I^{*}$.

+ ni: niogáchãt. 18. 1. 12*, 14*. níogatam. I3. 4. I2, 20.

+ parā: párāogatam. 7. 12. 4 . párā॰gatās. I8. 3. 72 .

+ pari: pári ... agamam. 6. 12. I. (cf. párijman.)

+ vi: ví gachati. II. 8.33. ví...jagăma. $7 \cdot 72.2^{\dagger}$.

víogate. 5. 2 I. Io.

+ s a m: sam̊gáchāi. 7. I2. I.

sám gachasva. I8. $2.21 ; 3.58^{*}$.

sám gachatām. I8. 2. 10*; 3. $5^{8^{\dagger}}$. 
sám agachanta. 7.79.2. 10. 10.17. sám...jagmé. 9. 9.8". sám...jagme. 2. 2. 3 . samojogmānăs. 3.14. 3 . sám ... aganma. I6. 9.3. sám ... ágata. 10. 10. 13-5. sám ... áganmahi. 6. 53.3. sám... agmata. 2. 30. 2.

sám ...gamemahi. I. I.4. 7.9.4. sám ajigamat. 6. 32.2; 74. I.

sámiogatāni. 6. 44. 2.

sámogateşu. 7. 12. I.

sam̊gátya. 3.4.7. 9.4. I5. II. 6.21. I 8. 2. 26 .

sám gamayati. 9. 5.24.

[na.)

(cf. sámigati, samigamá, samgáma-

+ abhis am: abhiosamgátya. II. I. I6.

g a m a in axam̉gamá, āgama, yudhim gamá, samgamá.

g a man a in samgámana.

gámiṣṭha: -as. 5. 20. I2. (cf. àgamișțha.)

g a m i șy ant in ánāgamișyant.

g a mbhĩrá: -ám. I9. 50.3.

gambhīrât. 5. 30. II.

gambhïré. I9. 2.3 (not ed.).

gambhīé (p. -é íti). 4. 26. 3. I I. 5. 8 . gambhĩră. r 9.49 .2 (mss. -rás). gambhīrāís. I 8. 4.62,63.

(cf. gambhīrávepas.)

g a m bhírávepas: -sas. (mss. -ré apásas).

gá y a (n. pr.): -asya. I. 14. 4.

gá y a: -am. 7.42. I* ; 84 . I.

gáyasya. 6.3.3.

gáye. 2.6.3.

(cf. gáyasphāti, gayasphắna.)

gá y a s phāti: -im. I9. 31. IO (mss. páy-; p. páyaḥoph-).

gayasphắna: -as. I9. 15.3 (mss. parasph-).

g a ra in ajagará, aramgará, āgará, samigará, garagīṇá.

g a ra og İṇá: -ás. 5. I8. 13.

g a r ú tma n t: -mān. 4. 6. 3. 9. 10. $28^{*}$.

gárg a r a : -rās. 4. I5. 12.

gárgarāṇām. 9. 4. 4. garta in

g a rtaosád: -dam. 18. 1. $40^{\circ}$

g ardabhá: -bhé. 5.31.3.

gardabhăú. 20. 136. 2 (mมs. gár-

dabhãu).

gardabhi. I0. I. I4.

(cf. gărdabha, gardabhanădín.) g a r d abhaonãdín: -ínas. 8. 6. 10. gárbha: -as. $323.2 .5 \cdot 5 \cdot 25 \cdot 7^{3}$, 9. 6. 17. 1-4; $95.3^{3} ; 121.4 ; 125$. 3*. 8. 7.8. 9. 1.4. 5, $21 ; 3.21 ; 9$. $9^{*} ;$ IO. $23^{\circ}$. II. 4. 20; 5. 7; 7.6. I3. I. 4. I 9. $44.5 ; 57.3$ (mss. -bha). gárbham. I. II. $2 ; 33.1-3.3 .10$. I2. $4.2 .6^{\prime \prime}, 8.5 .25 .2^{2}, 3^{3 \circ}, 4^{4}, 5^{\circ}$, 7,8. 6. 17. I. 7. 2. I; 39.1'. 8.6. I8, 20. 9. IO. 12*. II. 4. 26; 5. 3 . I3. I. I6.

gárbhāya. 6. 8 J.2.

gárbhāt. I0. I0. 23.

gárbhasya. 5.25. I.

gárbhe. I0. 8. I3, 28. II. 4. I4. I3. 3.20. I 8. I. $5^{\circ}$.

gárbhās. 5. 17.7.

gárbhān. 8. 6.23, 25. I I. 4.3.

(cf. amṛtagarbhá, ardhagarbhá, viçvágarbha, hiraṇyagarbhá, garbhakáraṇa-garbhādá.)

g a rbha okára ṇa: -am. 5.25.6.

gárbhaorasa: -sā. 9.9. 9." [3. g a rbhā dá (p. -bhaoad-): -ám. 2. 25. g a luntá: -ás. 6.83.3.

g a v in adhigavá, purogavá, brahmagavî́, samigavá.

gá vi șți (p. góoiṣ-): -țāu. 4. $24 \cdot 5$. gavíșthira: -am. 4. 29. 5.

g a vi in brahmagaví.

g a viñi: -niós. I. 3.6. 5. 25. 10-3. (cf. gavínikā.) [8.7. gavínikā: -ke (p. -eíti). I. II. 5. 9. g a véș a ṇa (p. gooéş-): -as. 5. 20. II. $\checkmark$ g a v y: -yán. 5. 20. 3 (l. -vian?), Io (mss. -ám).

gávy a: -am. 2. I3. I. 7.82. I*. gávyām. I 8. 3. $22^{\dagger}$. gávyāni. I 9. 49.3. gá v y $\mathrm{t}$ i: -is. I6. 3.6. I 8. I. $50^{*}$. (cf. dūrégavyūti ) 
gáhvara: -am. I2. 2. 53 .

V'I gā: agām. 4. I4.3. I8. 2. 45.

ágāma. 3. 15. $4^{*}$.

agāma. 12. 2. 22* .

gās. 5. 30. I.

gāt. 5. 30. 14. 8. I. 7, I8. 12. 2. $23^{*}$.

gus. I 8.3 .62 .

geșma. 4. II. 6; I4.6. II. I. 37 .

(cf. I ga gā, gātú, gâtra, gāya.)

+ a dhi: ádhy agāt. 2. 9. 3.

+ a nu: ánv agāt. ro.4.26. 12.2. 43. ánu gās. 5. 30. J, 6. 8. I.7, 10. ánu gāta. 7.60. 7 .

ánu ... gus. 18. 1. $32^{*}$.

+ a pa: ápa gātam. 3. I I. 6. (cf. ápagā.)

+ a pi: ápy agāt. 2. 9. 2. ápy agus. 10. 3.9.

+ abhi: abhí... gāt. 5. I. 6*.

+ a v a: áva gāt. I2. 3.46.

$+\bar{a}$ : à 'gām. I9. I4. I.

à 'gās. 8. I. 20*. I4. 2. I9.

à 'gāt. 2. 9. 2.

à 'gus. 4. 24. I. 8. 9. $13^{2}$. I3. I. IO, à ... agus. 3. I2. 7. II. I. IO, I4. à gās. 12. 2. 10.

+ abhyā: abhioăgāt. 9. I0. 5 .

+ u d ā: ut॰ầgām. I 4. 2.44 .

+ s a mā: samoăgās. I2. 3. 36 .

+ u d: úd agāt. I. 29. $5^{*}$. 2. 9. 2. I3. 2. $35^{*}$. I $7.24^{*}$.

úd agātām. 2. 8. I. 6. I2I. 3 .

+ upa: úpa ... agus. 2. 5. 2.

úpa gās. 5. I9.9. 8. 2. I. I9. 27.

8 (mss. úd agās).

úpa gāt. 9. 9.4*.

úpa gus. 5.8.3. I9. I5. 2.

+ ni: ní gām. 5. 3. $4^{*}$.

ní gātām. I2. 3. I4.

+ parā: párā 'gāt. 9. 9. I7*

párā gāt. 7.53.4. I6. 4.3.

+ pari: pári ... agām. 1. 34.5 .

+ puras: cf. purogá.

+ pra: prá ... jígāti. 8. 4. I $7^{*}$.

pră 'gāt. I. 28 . I. 5. 28. 9. 6. 37 .

I. I4. I. $13^{*}$.

prá gāma. I3. I. $59^{*}$.

prá... gus. 5. I. 4 .
+ s a m: sám ... agus. I9. $57.2^{4}$.

$\mathrm{g}$ ā in ápaḡa (?), purogâa : cf. I ga.

$\sqrt{ } 2$ gã : gấyanti. I2. I. 4I.

gāya. 6. I. $I^{2}$.

gầyatas. 4. 15.3.

(cf. 2 ga, găthā, gāyatrá, gītha.)

+ u d: úd gāyati. 9. 6.45-8.

(cf. udgithá.)

+ upa: úpa gāyantu. 4. I5.4.

gătú : -ús. 7.3. I. I0. 9. 1. I3. 2.44. gātúm. 2.34.2. 7.97. $7^{2}$. 10. 2. I2. I3. I. 4. I8. I. $50^{*}$.

(cf. turágātu, sugấtu, gātuvíd.)

gātu०víd: II. I. I5.

gãtuvídam. I3. 2. 43 .

gātuvidas. 7.97 .7 .

gầtra: -rāya. I. 12. 4.

$[52$.

gâtrāṇi. 5. 29. I2. I I. I. 24. I8. 4 . gătrā. I0. 7.27. I I. I. 3I. I8. 3.9.

gầthā: -thayā. I4. I. $7^{*}$.

găthās. I0. 10. 20. I5. 6.4.

găthānām. I5. 6.4.

gādhá: -ám. I9. II.6*.

g ā y a in urugāyá.

gā y a trá: -ám. 9. Io. I*.

gāyatréna. 9. 10. $2^{*}$.

gāyatrásya. 9. 10. 3*.

gāyatré. 9. I0. I*.

gāyatrí. 8. 9. 20 ; 10. 12. I8. 2. 6*.

I9. 21.1 .

gāyatrî́m. 3. 3.2. 8. 9. I4. 10.8.41.

I3. I. Io.

gāyatryàs.s. 4. 35. 6.

gāyatryăm. I3. 3. 20.

(cf. gāyatráchandas.)

gāyatrá ochandas: -dās. 6.48. I. gà̃rabha: -am. 6. 72.3.

gāva in bṛhádgāva.

gấrh a $\circ \mathrm{p} \mathrm{at}$ y a: -as. 6. I20. I ; I2I.

2. 7.64. 2. 9.6. 30. I2. 2.44. I5.

6.5. I8. 4. 8, 9. I9. 31. 2.

gärhapatyam. I4. 2. I8, 20.

gấrhapatyena. 12. 2. 9.

gărhapatyāya. I4. I. $21^{*}, 50^{*}$.

gărhapatyasya. I5. 6.5.

gầrhapatyāt. 12. 2. 34 .

[I8.

gắrhapatye. 5.3I. 5. 8. 10. 2. I0. I.

(cf. sugārhapatyá.) 


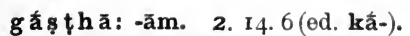
$\sqrt{ } \mathrm{g}$ à $\mathbf{~}$ cf. gabhīrá, gambhīrá, gáhvara, gādhá.

+ abhi: abhí... găhamănas. 19. 13 .

+ vi: ví găhethăm. I2. 3.36. [ag-). viágāhathās. 20. 128. I4 (mss. vyvigăhathās. 20. 128. I2 (mss. ví gã-). viojáñgahe. 5.19 .4 .

$\sqrt{ }$ iix, see $\sqrt{ } 2$ gr.

gír: -ras. 2. 5.4. 20. 48. I; I27. I4. giras. I. 15. 2. I9. I. I (ed. gíras), 2 (do.).

girbhís (p. gị̣̄obh-). 3. 20. $4^{*}$. 7 . I10. 3. I3. 1. 53,54 I9. 7. I.

gira in samgirá : cf. gila.

girí: -ís. 4. 6.8.

girím. 2. 25.4 .

girés. 5. 13.9 .

girăú. 5.4.2. 6.69. I. 20. 34. I2.

giráyas. 4. I2.3. I2. I. II.

girín. 6. 17.3 .

girin̄ăm. 10. 4.14 .

giríșu. 5. 4. J. 9. I. 18.

(cf. vișagixí, girișthắ.) girișțhă (p. -riosth-): -ấs. 7. 26. $2^{*}$; gi l a in asamsūktagilá.

gîth a in udgithá.

g I $\mathbf{x}$ a in garagīṇá.

g u in árișțagu, kŗ̧̣águ, lalămagu, vanargú, sárvagu, sugú, sumádgu. gú g gulu (s. mss. gúlg-): 2. 36. 7 . guggulu. r9. 38.2 (mss. -lú, -ló). gúggulos. r9. 38 . I (mss. ed. -lós). guggulús. $4 \cdot 37 \cdot 3$.

g u ṇá: -ṇébhis. I0. 8.43 .

gú dā: -ās. 9. 4.14;7.16;8.17. 10. 9. I6. II. 3. Iо.

gúdābhias. 2. $33 \cdot 4^{*}$.

$\checkmark$ g u p: jugupus. I9. 27.9, 10.

gopsyanti. ro. $9.7,8,9$.

guptás. 5. 20. I2. I I. IO. II. I7. $29^{2}$. guptă. 12. 5.3.

guptă (pl.). II. 9. 2.

gupitás. 2. 28.4 . I4. I. $5^{*}$.

gupitám. 5.17.3*.

gupitâs. I0. 10. 4. I8. 4. 70 .

(cf. gupta, gúpti, gópana, goptṛ.) gupta in índragupta. gúpti: -taye. 6. 122.3. $\quad$ 12. 3.7.

Vgur: + ã: à gurasva. 5.20. 4 .

gurú: -ús. 6. 42.2. 9.3.24.

(cf. gurubhŕt.)

guruobhṛ́t: I2. I. 48 .

gulphá: -phãú. I0. 2. I, 2.

guşpitá: -ám. 3.7.2. 7.90. $1^{\circ}$.

V guh: gūọhás. 6. I34.2.

(cf. gúhya, gúhă.)

+ a pa: apaogúhamānas. 19.56.2 (mss. ápa gúh-).

ápa ... gứhamănă. 8.4. $17^{\circ}$.

ápã 'gūhan. I8. 2.33".

ápa gūhathās. 4. 20. 5 .

+ a va : áva gūhati. 20. I33. 4 (mss. -asi), 5 (do.).

gúhā. I. 8.4 ; 13.3. 2. I. I, $2^{2}$. 6. 92. 2. 8. 9.2. 9. 10. $27^{*}$. I0. 8.6. II. 5 . I0; 7. 15. 12. 1. $44,46,60$. 14. I. 16*.

gúhya: -as. Io. 7.4I (mss gúhya). gúhyam. 3.5.3.

gúhiasya. 7.29. I.

gúhyăs. I I. 8.28.

gúhīa. 7. 29. 2.

g $\bar{u} l$ a in urugúla.

$V$ I g ṛ: gṛnimasi. 4. 31. $5^{*}$.

gṛ̣até. 4. 2I. $2^{\dagger}$. 5. II. II. 8. 3. II". gṛ̣ántas. 6. 62.2.

gṛ̣ānás. I7. 10.

gṛ̣ānă. I. 13.4. 5.27.9.

gṛnátā (p. -ta). 5. 27.9.

(cf. gara, gír, jaritị.)

+ abhi: abhí gṛata. 5. 27.9.

abhí gṛantu. I8. I. $52^{\dagger}$.

+ s a m: cf. samgará.

V 2 g r , gir: gírāmi. 6. I35.3.

jagāra. 9. 10. $9^{*}$.

(cf. gara, gira, gila, gīrna.)

+ ava: áva ... garat. I6. 7.4.

+ ni : ní girati. 5. I8.7.

+ s a m: samogṛ̣ămi (to I gṛ?). 6. 7 I.

3; I I9. I.

sám girāmi. 6. 135. 3 .

sám girāmas. 6. $135 \cdot 3$.

samogírya. 6. I 35.3.

(cf. samingirá.)

$\sqrt{ } 3$ g r , jā g r: jăgrati. I 9. 48.5 .

jāgrati. I $9.48 .5^{2}$ (mss. jâg-). 
jāgarat. I9. 24. 2, 3 .

jāgṛtāt. 4. 5.7.

jāgṛhí. r9. 47.9 (mss. -hi, jăgṛhhi). jāgṛhi. 2.6.3. 3. 15.7. 12. 2. I0. I3. I. 9. I4. I. $2 I^{*}$. I9. 48.6 (mss. jăgrati).

jāgṛtam. 8. 4. $25^{*}$.

jāgṛtām. 5. 30. I0.

jāgṛtá. I. 30. I.

jầgrat. 6. II5.2. I6. 7. IO.

jăgratas. 6. $45.2^{*} ; 96.3 . \quad 7.108 .2$. jâgratìm. 8. 6.8.

jāgāra. 5. I9. IO. II. 4.25. (cf. jăgṛvi, jāgrat.)

+ prati: práti jāgarāsi. I4. 2. 3 I.

$\checkmark$ g rdh: grdhas. II. 2. 2 I.

grdhat. 8. 6. I.

(cf. gŕ̛dhya, gṛ́dhra.)

gṛ́ d h y a: -yāis. I2. 2. 38 .

gṛ dhra: -as. 5. 23. 4 .

gṛ̛dhrāu. 7.95. I,

gựdhrās. II. $9.9 ;$ IO. 8,24 . I2. 5 . gŕ̛dhrebhyas. II. 2. 2.

(cf. saptagṛdhrá, gṛ́dhrayātu.)

gŕ dhraoyātu: -um. 8. 4. 22*.

$\checkmark$ g r bhāy, see $/$ grabh.

g ̣̂́ bhi: -is. I2. I. 57 .

grștí: -ís. 8. 9.24.

grștinắm. 2. 13.3. I9. 24. 5 .

gṛ̂há: -ás. 2. I 4. 3. 5. 6. 4, I I. 7.83. I. gṛhám. 4. 18.2; 21. $6^{*}$. 6. $27 \cdot 2^{\dagger}$; 29. 2 ; 37. I. II. 8. 18. I2. $2.7^{*}$. I9. 45. I.

gṛhắt. II. 8. I. I4. 2. I9.

gṛhásya. 2. I4. 4.

gṛhé. I. I4. 2. 3. $24.2 ; 30.4$. 6. 5 . $3 ; 29.3 \cdot 7 \cdot 76.5$. 8. IO. 2 I. IO. I. 20 ; 6. $4: 8.26$. I2. $4.27,48$. I4. I. $2 I^{*}$; 2. $59,60,6$ I. I5. I3. I-5. I9. 3 I. 3 ; $45.2 ; 57.5$.

[4. 3 .

gṛhăs. 6. 106.2. 7.60.2. I2. 2. 39 ; gṛhásas. I8. $3 \cdot 5 \mathrm{I}^{*}$.

ĝ̛̣hās. $7.60 .4,6$.

gṛhắn. I. 27.4. 3. 10. II ; I2.9. 7 . 6o. I, 3. 9. 6. 53. I4. I. $20^{*} ; 2.26,75$. I5. IO. I; II. I; I 2. I; I3. 6. I8. 2 . $21 ; 4.37,63$.

gṛhāís. 7. 81.4, 5. I 4. 2. I2. gṛhébhyas. 2. I4.2. 14. 2. 17. I8. 2. 27 .

gṛhébhias. 6. I37. I. I4. 2.27. gṛhănām. 3. 12.6. 6. 32. 1. 9. 6. 3I-6. I 4. 2.26 .

gṛhéșu. 6. 45. I ; 79. I, 2. 7. 60. 5 . I4. 2.62. I8. 3. I7. [-gṛharājá.) (cf. bhúmigṛha, sugṛhá, gṛhápati g r há opati : -is. 8. IO. 2. I4. I. 5 I. I9. $55 \cdot 3,4$.

gṛhápatim. I9. 3I. I3.

(cf. gấrhapatya.)

gṛhá opatni: I4. I. $20^{*} ; 2.75$. grrhápatniās. 3. 24.6. [3r.13. g r ha $\mathrm{a}$ medhín: -dht. 8. I0. 2. r 9 . g ṛhaorājá: -ásya. II. I. 29.

g ̣̂́h y a: -yãs. 5. 20. 4 .

$\mathrm{g} \mathbf{r} \mathrm{h}$ y a in hastagŕhya.

gó: gāús. 3. I8. 6*. 5. I8.3, II. 6. 3I. $\mathrm{I}^{*} ; 49 . \mathrm{I} ; 67.3$. 8. 2. $25 ; 6.17 ; 9$. 25,26 . 9. 9. $17^{*}$; 10. $6^{*}, 7^{*}, 21^{*}$. I2. 4. $39 ; 5.17$.

gắm. I. I6. 4. 3. II. 8 ; 17.3. 4. 9. 7*. 5. I8. I, 2, IO; I9. I0; 29. I. 6 . 28. I*, $2^{*}$; 7I. I. 7. 50. 9. 8. 7. II ; 9. I 5. 9. 9. 9*. I0. I. I7, 29. I2. 4. 2 , I $2 ; 5.46$. I3. I. 56 .

gós. I. 22. I. $7.5 .5 ; 22.2$. I2. 2. 37. I8. I. 32 . 19. 50.5 (p. górájas). gávi. 2. $32 \mathrm{I}$.

gấvāu. 7. 95.2. I4. I. II*.

gấvas. I. $2.3 ; 4.3^{*}, 4 ; 22.3$. 2. 26. 4. 4. 2 I. I ${ }^{*}, 4^{*}, 5^{4 *} ; 24$. 2. 6. 9. $3 ; 52$. 2*. 7. 60. $5 ; 82.6 ; 96$. I. 8. 7.25. 9 . 4. $20 ; 9.5^{*}$. II. $2.9 ; 3.5 ; 8.32$. I4 I. I $3^{*}$. I9. $6 . \mathrm{I}^{*} ; 9.8$; II. $\mathrm{I}^{*} ; 58.3$. 20. $127.5,13$.

gāvas. 3. I4. 4,6 . 4. 21.6 . I4 I. 32,33 . 20. I27. 12 (mss. gầ-).

gấs. 3. 28. I. 7. II5.4. I2. I. 39. I3. I. 2, I9. I8. 1. 6*. 20. 127.5 (not mss.); I36. II.

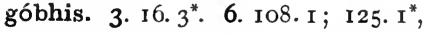
$2^{*}$. 7. $50.7^{*} ; 8$ I. 4,$5 ; 97 \cdot 2^{*}$. I0. 6 . 23. I 8. 2. $58^{*}$. I9. $27 . \mathrm{I}$

góbhyas. I. 3 I. 4. 3. 28.3 . 6. 27. $3^{*} ; 59.3$ (1. -bhias). 9. 3. 13. 12. 2 , I6. I9. 47.10. 
gónām. 20. I 27.3 (1. -naam). gávām. 2. 26. 4. 5. 3. 9.2. 4. 9.2; 22. 4. 8. 3. $16^{*} ; 4.10^{*} ; 7.15 .9 .4$. $17 ; 9.3^{*}$. I2. 1. 5 . 19. $31.8 ; 47.6$. 20. 135.4 (not mss.).

góșu. 3. 15. 7 ; 21. 2. 4. 19. 5 ; 22. 2. 6. $38.2 ; 45.1 ; 55.2 ; 69.1 .9 .1 .18$; 4. II. II. 2. 2 I. I2. I. 4, I9; 2. I, I5; 4. $27,28,39$. I4. I. $35 ; 2.53-8$. I9. $45.2 ; 57.5$.

(cf. agótā, gava-gavī, gavéșaṇa -gávyūti, gãva, gu, gógati-gópati, gopá-gopoșá, gómant-gcsáni.)

gógati : -is. 20. I29. I 3 (mss. -tĩs). góojāt a: -tãs. I9. II. $4^{*}$.

goojít: 5.3.11. 7.50.8. gojítam. 6. $97 \cdot 3^{\dagger}$. I7. I-5. gojíti. I3. I. 37.

gót a ma: I8. 3. I6. gótamam. 4.29. ó.

gotrá: -ásya. 5.2.8*. gotrăni. I9. $13 \cdot 7^{*}$. (cf. viçvágotrya.)

go०dúh: godhúk. 7.73. $7^{*}$. godhuk. 7.73.6.

godhấ: 4. 3.6.

gó ○p a ti: -is. 4.21. $3^{*}$. I2. 4. 27. I 8. 3. 4. 20. 127. I3 (mss. gópa). gopate. 5. 18.15 .

gópatim. I2. 4. 4, 22, 52. I9. 58.3. gópatinā. 3. 14.6.

gópataye. I2. 4.37, 39.

gópates. 8. 2. 23.

gópatãu. 2. 26. 4. I2. 4.8.

góp a na: -am. 12. 4. IO.

gopấ: -ấs. 3. 8.4. 5. 3.2* 6. 77. $2^{*}$. 7. $26.5^{*}$; 53.2. 9. 9. $22^{*}$. 12. I. 57 ; 3. I1. I6. 2. 3. I8. 2. $54^{*}$.

gopăm. 9. IO. II*. I3. 2.2 . gopấ (du.). 5. 9.8. I4.2. $5^{*}$. gopấs. 7. 8 r.6. 10. 8.9 .

(cf. devágopa, vătagopa, V'gopāy, V'gup.)

$\checkmark$ g०pāy: -yatas. I5. 4. I-6. gopāyánti. I8. 2. 18*.

gopāyá. I9. 48.4 (mss. ed. gopấya). gopāyatu. 19. 17. 1-5, 7-10. gopāyátam. 5.9 .8$.

gopāyata. I2. 3. 55-60.

gopāyantu. 8.1.14. 19. 17.6.

gopāyán. 8. I. I3.

gopithá ${ }^{\dagger}$ : -as. 16.2.3. gopithằya. 5.9.7.

gó。purog ava: -am. 8. 7. 12.

go०poşá: -ám. I3. I. I2.

goptṛ: -tâ. II. 1.33. I7. 30.

goptằāu. 5. 30. IO. I5 4. I-6.

goptăras. 10. 10. 5 .

goptṛ̂n. I9. 27.4 .

gó ○man t: -mān. 6. 68. 3 .

gómat. I8. 3.6r.

gómatas. 3. IO. II.

gómatām. 4. 36.6.

gómatī. 3. 12. 2.

gómatīs. 3. I6. 7".

go má y a : -yăt. 20. I 29. I 3 (not mss.).

go०rū pá: -ám. 9.7.25. 19.49 .8

(mss. góorūpam; ed. rūpám).

go०ví d: -dam. I g. I $3.5^{\dagger}$ (mss. -dan). 20. 127.6.

g O ça phá: -ás. 20. I29. 18 (not mss.); 135. 3 (mss. -phas).

goçaphé. 20. 136. I.

goșed há (p. goose-): -dhấm. I. 18.4. goșțhá (p. goosth-): -ás. 3. 14.5, 6 . II. I. I 3 .

goṣțhám. 2. 26.2. 6. 59.2. 7. 75. 2. I2. 2.4 .

goșțhéna. 3. I4. 1 .

goșțhat. 2. 14. 2.

goșthé. 2. 26. I. 3. $14.3 .4 .21 .1^{*}$. 6. $52.2^{*}$. 7. 39. I. 9. 4 . I9, $23^{\dagger}$. I I. 8. 32. I3. I. I9. I9. 3I. I.

goosáni: -im. 3. 20. 10.

gnă : -âs. $7 \cdot 49 \cdot 2^{\prime \prime}$.

gnăbhis. I9. 10. 6*.

/ grath: ef. granthí.

+ u d: úd gṛnatti (?). Io. $7 \cdot 43^{\dagger}$.

granthí: -ís. 9. 3.2.

granthés. 20. 133. 2 (mss. gránthes). granthin. 9.3.3.

I'grabh, grah, gr rbhay: grbhṇāmi. 3. 8.6. [I. $5 \mathrm{O}^{\dagger}$. gṛhṇămi. 5. 13.2. I2. 3 17. I4. gṛhṇāmi. 6. 82. I. 7.82.2. I 4. I. 48 . 
gṛhṇăti. 6. 76.4 .

gṛhṇé. 19. 3I. 4.

gṛhṇate. I 8. 3. $18^{\dagger}$.

gṛhāná. 3. 2. $5^{*}$. II. I. 10.

gṛhṇitāt. II. I. I3.

gṛhṇătu. I I. I. I I.

gṛhṇātu. 5. I4. I2. I4. I. 49.

gṛhnántas. I9. 35. I.

gṛhṇānás. 5. 20.4. 6. 8 I. I.

gṛhṇānăm. 4. 38. 2.

gṛhṇānăs. $5 \cdot 17 \cdot 10^{\dagger}$.

jagráha. 3. $18 \cdot 3^{\dagger}$ (mss. ed. jagrăha).

jagrăha. 2. 9. I. 3. II. I*. I4. I. 48 .

jagrāha. I9. 58.2.

jagṛhús. IO. I. II

jagṛhe. I8. I. $33^{*}$.

ajagrabham. 4. 5.4. [19. 38.2.

agrabham. 5. I3. I, 2, 3. 6. 83. 2.

ágrabhīt. I. I2. 2.

ágrahīt. 5.17 .8 .

agrabhīt. I0. 9.2. I8. 3.16.

agrahit. I4. I. $5 \mathrm{I}^{2}$.

gṛbhītás. 9. 10. 16*.

gṛbhītvă. 12. 3.20.

gṛhītvă. I9. $58 \cdot 3^{2}$.

gṛbhāya. 2. 30. 4 .

gṛbhāyáta. 8. 4. $18^{*}$.

(cf. gárbha, gṛ̣bhi, gṛhá, ğ̛̣hya,

gṛhya, gráha, gláha, gláhā, gra-

hana, gláhana, grábhītr, grahītṛ,

grābhá, grāha, grăhi, grāhyà.)

+ ava : áva gṛhyate. 20. I3I. I2.

$+\overline{\mathbf{a}}$ : à gṛhṇĭtam. II. 9. I I.

+ s a mā: samoấgṛbhāya. I 8. 2.60.

+ ud: udogṛhṇán. 9.6.47.

úd agrabham. 4. 20. 8.

út ... agrabhit. 8. I. 2, I 7 .

+ upa: úpa ... agrabhīt. 7. I I0.3.

+ ni: ní gṛhṇātu. 3.17.4*

nioĝ̣́hya. 20. I33.3 (mss. nígr-).

+ pari: pári gṛhṇāmi. I2. 2. 33 .

pariogṛhṇánti. I2. I. I3.

páry agṛhṇan. 12. 3. I6.

pári jagrabha. I9.3I. 5 .

páriogṛhītā. II. 3. I5.

+ pra: práogṛhītam. 12. 4.34 .

+ prati: práti gṛhṇāmi. 3. 29. 7. 9 3. $15^{2}$. I9. 37.2 . pratiog̣̣hṇăti. 9.3.9.

práti gṛhnāti. I3. 3. II.

práti gṛhṇiyāt. Io. Io. $2,27$.

práti gṛhṇāhi. 3. ro. 13. 5. 29. 15. práti gṛbhṇihi. 20. 135. 9.

práti ... gṛhāṇa. 5. 29. 14.

práti gṛhṇātu. 3. 29.8. I I. I. 8, I8.

práti gṛhṇantu. 2. 34. 5. 9. 5.37.

pratiogṛhnántam. 3. 2 I. 4.

pratiogṛhṇatás. 9. 3. 16.

práty agṛhṇāt. I0. I0. 25.

práty agṛbhṇan. 20. $135 \cdot 7^{2}$.

pratiojagráha. 6. 7I. I.

prátiogṛhitas. 9. 5. 12.

pratiog̣̣hya. 3. 29.8 .

práti ... gṛbhāya. 3. เo.6. 6. 125 .

$3^{*}$. II. I. I4. I9. 42.3 .

práti ... gṛbhāyata. 20. I35. 10.

(cf. pratigraha, pratigrahītŕ.)

+ vi: vi॰gṛ́hya. 4. I5. I4.

+ s a m: sám ... jagrabham. 6.21. I. sám ... ágrabham. ro. 4. I9.

sáṁogṛ̂hītās. 8. 4. 8*.

samogṛ́bhya. II. 5.6.

(cf. samgráhana.)

grábhitṛ: -tā. I. I2. 2.

gráha: -hās. II. 7. 18. I9. 0.7, I0. (cf. duspratigraha.)

grah aṇa in samgráhana.

grahItṛ in pratigrahītŕ.

grābhá: -ám. I4. I. 38 .

(cf. hastagrābhá.)

grầma: -am. 4.7.5;36.7,8. 5. I7.4. grấmāya. 6. 40.2.

grắmāt. I 8. 2.27.

grăme. 4. 22.2. 8. 7. II.

grămās. I2. I. 56 .

grằmān. $5 \cdot 20.3$.

(cf. samigrāmá, grāmaghoṣíngrāmyá.)

g rām a o g hoṣín: -șí. 5. 20. 9.

grāmaojít: -tam. 6. 97. $3^{\dagger}$.

grām a ṇi í (p. -maon-): -ís. 19. 31. I $2^{2}$. grāmaṇías. 3. 5.7.

grāmyá: -miás. 2. 34.4. 3. Io. 6 ; 3I. 3 (1. -myấs). I I. 5. 2 I. I9. 6. 14*. grăvan: -vā. 5. 20. IO; 22. I. 6. 3. 2. I0. 9.2. I2. 3. I4, 2 I, 
grăvāṇāu. Ir. I. 9, I0. grắva॰bhyām. 6. 1'̄ grắvāṇas. 3. 10. 5. 4. 24. 3. 8. 4 . I7*. 9. 6.15. 19. I0. $7^{*}$. grăvṇām. r 4. I. $5^{*}$.

(cf. yuktágrāvan.) [pagrāhá. g rāh a in urugrāhá, nāmagrāhá, çũrgrăhi: -is. 3. II. I*. 6. II3. I, 3. grăhim. 8. 2.12. I2. 3.18. grăhyā. 3. 2.5. 12. 2.39. 16. 7. I. grăhyās. 6. I 12. I, 2. I6. 5. 1; 8. i. 19. 45.5 .

grăhiās. 2. 9. I; 10. 6,8 .

g rāh y à: -hías. $5 \cdot 17 \cdot 3^{*}$.

grivắ: -ấs. 6. 32.2; 134. I. 9.7.3. I0. I. 2 I ; $2.4 ; 9.20$. I I. 8.15 . I9. 49. 9 .

grivăbhyas. 2. $33,2^{*}$.

grìvăsu. 6. 63. I.

(cf. ṛ̂șagriva, kalmășagrīva, nişkágriva, vígrīva, grāívya.)

g rîṣmá: -ás. 6. 55.2. I2. 1. 36. I 5 . 3. 4. I9. 6. 10*.

grīṣmăya. 8. 2. 22.

(cf. grāíșma.)

grāívya: -viās. 6. 25.2. 7.76.2.

grāíṣma: -am. 5.22. I3.

grāíșmāu. I $5 \cdot 4 \cdot 2^{2}$.

g l á h a : -hāt. 4. 38.3.

gláhe. 4. 38. I, 2.

gláhā: 6. 22.3.

gláhana: -am. 7. I09. 5 .

V $\mathrm{g} \mathbf{l} \overline{\mathbf{a}}:+\mathrm{ava}$ : áva glāpayanta (p. glap-). 9. 9. Iot. $^{\dagger}$

(cf. ánavaglāyant.)

g lāú: -āús. 6. 83.3.

gva in návagva.

gha. 5. I3. IO, II. I9. 39. 2-4 (mss. nadyá).

ghā (p. gha). 6. I. 3. I8. I. $3^{*}, I^{*}$. $\checkmark$ ghaṭ: + ā: cf. āghāțá.

ghaná: -éna. Io. 4. 9.

(cf. drughạá.)

ghan āghaná: -ás. 19. I3. $2^{*}$.

$\checkmark$ gh ar: cf. gharmá, ghārin, ghị́ṇi ?, ghṛtá.
+ abhi: abhí ghāraya. I2. 3. 37.

abhíoghăritas. 5.21.3.

abhíoghāritãu. 10. 9. 25 .

$+\bar{a}$ : a jigharmi. 8. 3. $1^{\circ}$.

(cf. ăghrñi ?.)

gh a rmá: -ás. 4. II.3. 7. 73. I, 2, 5, 7". 8.8.17. 9. 7.3 . II. 3. 18. I9. $38.2,3$.

gharmám. 4. 1. 2 ; 11. 5. 6.36.1. 7. 73. 4 ; 97.4. 9. 10. 6". I I. 5. 5. I2. 2. $7^{\circ}$.

gharmásya. 4. I I. 6.

gharmé. 7. 73.6.

gharmăs. 8. 9. 13 .

gharmăn. 9. 1. 8 .

(cf. gharmadúgha, gharmasád.)

gharma。dúgha: -ghe (p. -eíti etc.). 4. 22. 4. $\left[48^{\circ}\right.$. gh armas á d: -ádobhis. 18. 3. $47^{\circ}$, $\checkmark$ gh a s: jaghása. 6. I 17.2.

jaghăsa. $5 \cdot 29 \cdot 2,4$ ( $v$ has ?).

jakșivăn. 4.7.3.

jakșivăṅsas. $7 \cdot 97 \cdot 3$.

aghās. 20. I 29. I6 (?).

ákșan. I8. 4. 6I*.

akșan. I8. $3.42^{*} ; 4.65^{*}$.

jagdhám. 5. 29.5.

jagdhvấ. 5. 18. I0; 19. 10.

jíghatsati. 5. 19.6.

jíghatsatas. 6. I40. I.

jighatsas. 5. 18. I.

[sú.)

(cf. ghasa, ghāsá, jagdha, jighat+ vi: cf. vighasá.

g h a s a in vighasá.

g hāṭa in āghāțá.

g hātin in ardhakaghātín.

ghâtuka: -as. I2. 4.7.

g h ārin in aghārín.

ghāsá: -ás. 4. 38.7. 8.7.8.

ghāsám. I I. 5. I8. I8.2.26. I9. 55 .

I, 7 (not mss.).

ghāsăt. I 8. 2.26.

$\checkmark$ ghuṣ: cf. ghușa, ghóșa, ghoșin.

ghuṣa in aramighusá.

ghṛ́ni: -is. 7. 3. I.

(cf. ăghṛṇi.)

ghṛtá: -ám. 2. I3. I. 3. I2. I; I3. 5 ; I6. $7^{*}$. 7. I $8.2 ; 26.3 ; 29.1,2 ; 73$. 
$4 ; 82.6^{3} ;$ 109.2. 8. 7. 12. 9. 2. II; 4. 4, 7. I 0. $6.5 ; 9$. I I ; IO. 32 . I I. 5 . I5. I2. I. 29. I8. I. $32^{*}$; 2. $14^{*}$. 20. 48. 3 .

ghrrténa. I. 3I. 3. 3. I2.4; I5.2, 3*; I 7. 9. 4. I4. $6 ; 26.6 ; 27.5$. 5. I 2 . IO*; $27.2 ; 28.3 .6 .5 .1 ; 22.1^{*} ; 32$. I ; $51.2^{*} ; 73.2 ; 93.2$. 7. 57.1 ; 75 . $2 ; 82.6 ; 98.1$; IOg. I, 3, 4. 9. 2. I. I I. I. I 8,3 I. I2. $3 \cdot 37,4$ I, 44 . I 3 I. 8,33 . I8. 3. 10. I9. 27.5 .

ghṛtásya. 3.12.8. 6. 9.3. 7. 29. I, $2 ; 82.1^{*} .9 .4 .5$. I0.6.25. I8. $3.72 ; 4.57$. I9. $58 . \mathrm{I}$.

ghṛtăt. 5. 28. I4. I9. 33. 2 ; 46.6 . ghṛtă. 5. 27. 4 .

(cf. ghṛtápad-ghṛtăhuta.)

ghṛtá $\circ$ p a : -dī. 7.27. I. ghṛtaopấvan: -vā. I3. I. 24. ghṛta。pú: -púas. 6. 5 I. $2^{*}$.

ghṛtáopṛștha: -as. 2. I3. I. 9. 9. I*. I2. 3. I9, 53 .

ghṛtáprșțthās. 9.5. I5. I 8. 4. 5 . ghṛtáopratíka: -as. 2. 13. I. [4I. ghṛta。prí: -ríyam. I2. I. 20. I8. 4. ghrtaoyoni: -ne. 7.26.3.

ghṛtá ova nt: -vān. I8. 4. I9.

ghṛtávat. 3. 10.6; 17.9. 7.68.2. 9. 2.8. 12. 3. 45 . I8. 2. 3*.

ghṛtávatā. 3. IO. II.

ghṛtávantas. 4. 35.5.

ghṛtávatī. 3. 12. 2.

ghṛtávatīs. I9. 4 2.2.

ghṛtá。vṛddha: -as. I3. I. 28.

ghṛtaoçcút (s. mss. -çcyú-): -tam. I0. 6. 6-10.

ghṛtaçcútas. I. 33.4. I0. 9.27. I 8. 3. $5 \mathrm{I}^{*}, 68 ; 4.42$.

ghṛtaostàva: -as. I2. 2. I7. [I. $3 \mathrm{I}^{*}$. ghṛtaosnu: -nū (p. -ūíti etc.). I8. ghṛtá。hrada: -dās. 4. 34. 6.

ghṛtẫn c: -ấcí. 9. I. 4. I0. 4.24 I9. 48.6.

ghṛtăcīm. I3. I. 27. [12, 28. ghṛtấhuta (p. -táoāh-): -as. I3. I. ghṛ̂tăhutam. 4.23.3.

ghorá: -ám. I. 18. I. 6. I40. 3. I6. I. 8 . I8. 4.83 . I9. $9.3 .4,5, \mathrm{I} 4$;
35. 3 (mss. sámghoram), 20. 49.2 (not mss.).

ghoră. 5. 18. I5.

ghorát. 4. 9.6. I8. 4.9.

ghorásya. $7 \cdot 70.5$.

ghoré. 6. 8 +. I.

ghorâs. 2. 35.4 .

ghorăni. I2. 5.13 .

ghorāís. 16. 7.2.

(cf. ághora, ghorácakșas.)

ghoráocaksas: -se. 8. 4. 2".

ghóṣa: -as. 3. 13.6; 19.6. 5. 20. 7.

I9. I3. 10*.

ghóșam. 3. 10. 5. 4. 31. $4^{*}$. 7. 43. I.

8. 6. II.

ghóșās. 3. I9.6. 7. 52.2. II. 9. II.

(cf. uccāírghoșa, jyāghoșá, padghoșá, ghóșabuddha, ghoșín.)

ghóṣa obuddha: -dhā. 5.20.5.

ghoşín: -ínas. 4. $15 \cdot 4$.

ghoșínis. I I. 7.20.

ghoșíñ̄bhias. II. 2. 3 I.

(cf. grāmaghoșín.)

ghn $\mathbf{i}$ in sahasraghní.

ghni in ahighni, çvaghnt.

g hny a in atighnyà, aghnyá.

ghráñs: -án. 7. 18. 2.

g h r a n sá: -ás. I3. I. $48,53$.

ghrańsám. I3. I. 46, 47, 52 .

$\sqrt{ } \mathbf{g} \mathbf{h} \mathbf{r} \overline{\mathbf{a}}:$ cf. jighra.

+ anu: cf. anujighrá.

+ à: āghrăya. I9. 8.5 (not mss.).

+ upa: upaojíghrati. I2. 4. 5.

ca. I. $2 \cdot 4^{4} ; 5 \cdot 3^{*} ; 6.2^{*}, 3^{*} ; 7.3 ; 8$.

3 ; 9.1 ; IO. 4 ; II. $5^{2}$; I2. $3^{2}$; I3. 3 ;

I4. 4 ; $5.4^{2} ; 17.2 ; 19.2,4 ; 20.3^{2}$;

22. $\mathrm{I} ; 23 . \mathrm{I}^{2}, \mathbf{2}^{2}, 4 ; 29.6^{*} ;$ 30. 2,4 ; 32. $3,4^{2} ; 35.3$. 2. $2.3^{2} ; 4.5^{2} ; 6$. $2^{3} ; 7.2^{2} ; 9.2$; 10. 6 ; 13. $3^{2}$; I4. 3 , $4 ; \mathrm{I} 5 . \mathrm{I}-6^{2} ; 25.3 ; 30.2 ; 34.3 ; 35$. 4, 5. 3. I. I, $3 ; 2.1 ; 3.6 ; 5.7 ; 6$. I, $2,3.5,6 ; 9.4$; 10. $7^{2} ; 15.4^{2}$; I7. 3 ; 20. $4^{*}, 5^{*}, 6,7^{*}, 8^{2}, 9 ; 22.2^{3}, 4$; $23.3,4 ; 24.5,7^{2} ; 28.5,6 ; 30.4$. 4 . I. $1^{2}, 4,7 ; 2.4^{*}, 5^{\dagger} ; 3.3^{2} ; 4.8 ; 5$. $2^{2}, 5^{*} ; 9.9^{2} ;$ I1. $9^{2}$, เо; 16. 2,$8 ;$ I 8 . 
7; 20. 2, 4, 7, 9; 21. $2^{*}, 3^{2 *} ; \quad 22.6$; 23. 7 ; 25. I, 3, $4^{2}, 7 ; 31.7^{\prime \prime} ; 32.3^{\circ}$; $33.2^{*}, 3^{*} ; 36.1,2 ; 37.10 ; 38.4$. 5 . $2.2^{2^{*}}, 6^{*}, 9^{2^{*}} ; 3.7 ; 4.9^{2} ; 5.2 ; 6.9$,

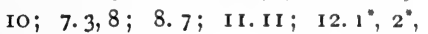
$3^{*} ; 13.6,7^{4}, 9 ; 15.1-I^{2} ; 17.7 ; 18$. 9 ; 21. 2, 7; 23. $1^{2}, 4^{3}, 5,6^{3}, 7^{2}, 13^{2}$; $25.4^{2} ; 27.6^{2} ; 28.2,14 ; 29.14 ; 30$. $4,5,9,10^{2}, 16,17 ; 3$ I.9. 6. $2 . \mathrm{I}^{2}$; 5. I, $3 ; 6.3^{*} ; 14.1 ; 15.2^{2} ; 16.3^{2}$; 19. $3^{*} ; 22.2^{2} ; 23.1 ; 24.2 ; 25.1-3^{2}$; 3I. I* $34.4^{*} ; 35.3 ; 37.3 ; 40.1$; $42.3 ; 43 . \mathrm{I}^{2} ; 44.2 ; 49.2^{3} ; 50.3 ; 5 \mathrm{I}$. $3^{*} ; 53 . \mathrm{I}^{3} ; 54 \cdot 3^{2} ; 57 \cdot 3^{3} ; 61.2 ; 66$. 2 ; 67. I ; 71. I; 72.3; 81. I; 85.2; $87.3^{\dagger} ; 88.2^{2 *} ;$ 9о. 1; 94. $3^{2} ; 96.3$; 98. I; IOI. I; IO2. $\mathrm{I}^{2}, 3$; IO4. I, 3 ; I07. I-4 $4^{2}$ I IO. $\mathrm{I}^{4^{*}} ;$ II 2.3 ; II5. 2; II 7. 3 ; I2O. 3 ; I2I. $2^{2}$; I24. 2 ; I33. 4 ; 136. 3 ; 138. $3 ; 139.3^{2}$; 140. 1, 2 , 3. $7.4 \cdot \mathrm{I}^{4} ; 9 \cdot \mathrm{I}^{2^{*}} ; \mathrm{I} 2 . \mathrm{I}^{2}, 2$; $3 . \mathrm{I}^{2}$; 20. I, 2,$6 ; 25.2^{2} ; 33 . I^{2} ; 44 . I^{*} ; 56$. $8^{2} ; 59.1 ; 67.1 ; 70 . I^{2}, 3 ; 76.3,4$; $79.2 ; 8$ I. $3^{2} ; 82.5 ; 89.3^{4} ;$ 90. 3 ; IO9. $2,3,5$; I IO. I. 8. I. $9^{2}, 12^{2} .13^{6}$, $20^{*} ; 2.20^{2} ; 3.3^{*} ; 4.10^{*}, \mathrm{II}^{2^{*}}, \mathrm{I}^{2^{2 *}}$; $25^{*} ; 5.9$, 10, I6, 18 $8^{2}, 22 ; 6.4^{2}, 7$, IU, $15,23,24^{2} ; 7.1,5,10,13,17,18^{4}$, 20,$24 ; 8.9^{3}, 17^{2}, 18 ; 9.7$; 10. $13^{4}$, $24^{4}, 25^{4}, 3$ I. 9. I. $17,22^{6} ; 2.3,15^{3}$; 3. $2,4,5,9,12^{2}, 15^{2}, 22 ; 4.22^{2}, 24$; 5. I4, I9, $21^{2}, 27,37^{2} ; 6.23^{2}, 3 \mathrm{I}-6^{2}$, $5 \mathrm{I}^{2} ; 7 \cdot \mathrm{I}^{2}, 7^{4}, 9^{2}, 10^{2} ; 8 . \mathrm{I} 7, \mathrm{I} 8,22$; 9. $13^{*}, 19^{*}, 21^{*}$; IO. $11^{2 *}$. IO. I. I3, 2I, 22, 32; 2.9, I2 ${ }^{2}, 19^{2}, 24.25,26$, $29^{2} ; 3.8, \mathrm{I}^{3}, \mathrm{I}^{2}, \mathrm{I} 6, \mathrm{I} 8 ; 4 \cdot 3^{2}, 8^{2}$, 9 , Iо, I5, I6 $6^{2}, 17 ; 5.22,23 ; 7.8,10^{4}$, $\mathrm{II}^{2}, \mathrm{I}^{2}, \mathrm{I} 7,22^{5}, 33,3^{8} ; 8 . \mathrm{I}^{4}, 2^{3}, 4$, $\mathrm{IO}^{2}, \mathbf{I}^{2}, \mathbf{1 6}, \mathbf{1 7}, 34^{2} ; 9.6,7,9, \mathbf{1 2}^{2}$, I3. I4, I6, I 7, I8, I9, 20, 21, 22, 23, 26 ; 10. $3,21,30,31$. II. I. 6,33 , 34 ; 2. $2,3,16^{2}, 29^{\dagger}, 31$; $3.24^{2}, 28$, $29^{*}, 32-49^{2}, 55,56 ; 4.4, \mathrm{IO}^{2}, \mathrm{I} 5,17$, I8; 5. I, 5, 8, 9, 2I ${ }^{2}, 23 ; 6.6,9, \mathbf{I 2}$; 7. $\mathrm{I}^{3}, 3^{3}, 5,9^{3}, \mathrm{II}^{2}, 12^{2}, 15,17^{2}, 20^{2}$, $22,23^{2}, 25^{2}, 26,27 ; 8.2^{2}, 4^{2}, 6^{2}$, I 5 , $20^{2}, 21^{5}, 22^{5}, 23^{3}, 24,25^{3}, 26^{2}, 27^{3}, 28^{3}$, 30; $9 . \mathrm{I}^{3}, 4^{2}, 7,13,15,16,17,18^{2}$,
$22^{5}, 23^{2}, 24,25^{2} ; \quad$ 10. $2,7,9,11^{8}$, I 8 . $22^{3}, 23,24$. 12. 1. $5,12,23,3 \mathrm{I}, 47$, $50,51,52,53^{4} ; 2.2^{3}, 14,18,19,36$. $40^{2} ; 3 \cdot 5^{2}, 6,9,12,25^{2}, 27,29,34,36$. 46,$50 ; 4.1,2,7,12,13,14,16,19$, $25,26,28^{2}, 38^{2}, 44.53 ; 5 \cdot 7^{8} \cdot 8^{6}, 9^{8}$, $10^{10}, 13,38^{2}, 56$. I3. I. 8 . 1 $2^{2}, 13,19$, $25,34^{6}, 37,38,46,47,55.56^{2}, 57^{4}$, $5^{8^{3}} ; 2.5^{2}, 14^{2}, 35^{\circ} ; 4.11^{3}, 14^{7}, 19^{2}$, $22^{9}, 23^{6}$. I4. I. $33,35^{2}, 39,45,4^{8}$, 53 ; $2.4^{2 *}, 9,20,22,29.34,35,37$, $41,42^{2}, 46^{\circ}, 51,59-62,66,69,74.15$. 2. $\left.1^{18}, 2^{21}, 3^{18}, 4^{18} ; 3.4^{4}, 5^{4} ; 4 \cdot \mathrm{I}^{-6}\right)^{4}$; 6. $\mathrm{I}^{12}, 2^{10}, 3^{8}, 4^{8}, 5^{12}, 6^{14}, 7^{8}, 8^{5}, 9^{8} ; 7$. $2^{6}, 4^{5} ; 8.3^{4} ; 9.2^{4}, 3^{4} ;$ 10. $3^{2} ;$ 1 $2.3^{2}$; 1 3. $7 ; 17.8,9^{2} ; 18.4^{2}$. I6. $2.5^{2} ; 3$. $2^{4}, 3^{4}, 4^{4} ; 4.6 ; 6.4$. I $7.6^{2}, 7^{2}, 21^{2}$, $24^{\dagger}, 27,28,29^{2}$. 18. 1. $4^{*}, 15^{*}, 19^{*}$, $26^{*}, 45^{2 *}, 47^{2 *}, 54^{*}, 55^{*} ; 2.2^{*}, 7^{2 *}, 12^{*}$, $34,56,5^{\prime \prime} ; 3.1,14^{2}, 19,38^{2}, 44^{\dagger}, 55^{*}$, $72 ; 4.28^{2^{*}}, 29^{\circ}, 57^{3}, 62^{2}, 75,76$. 19. 6. $3^{*}, 4^{*}, 7^{2 *}, 11^{*}, 12,12^{2 *}, 14^{*} ; 7.2$, 3. $5 ; 8.2^{2}, 5$ (mss.) ; 9. $2^{2}, 8$, 10 (not Inss.); Ig. I-II ${ }^{2}$; 20. 2 ; 24. $5^{2}, 6$; 25. I ; 26. $3^{2} ; 27.10 ; 31.3,4^{2}, 5,7^{2}$, $\mathrm{IO}^{\bar{z}}$, II, I3, I4; 32.4 (not mss.), 7. 84, 9 ; 33. 2 ; 34. $2 ; 36.3,6$ (not mss.); 37. I; 39. I, 5, 8, IO; 40. I; 4I. I ; 42. 2 (not mss.), $2 ; 44.10^{2} ; 45.2^{2}$; 46. $\mathrm{I}^{2}, 6^{4} ; 47.4^{4}, 5^{2} ; 48.3^{3}, 5 ; 49.5$; 53. $5 ; 54.3 .5^{5} ; 55.6 ; 57.5 ; 58.6$; 59. 2 (not mss.); 63. I; 64. $\mathrm{I}^{2}, 2^{2}$; 68. $\mathrm{I}^{2}$. 20. 34.12 (not mss.) 17 (do.); I27. 1 ; $128.1^{2}, 4^{2}, 5^{2}, 8^{2}, 9^{2}, 10^{2}, 1^{2}$; I29. I8 (not mss.); I3I. 22, 23 (not mss.); I35. I 2.

cā (p. ca). 7. 4. I. I0. 8. I 2.

(cf. caná, cit, céd.)

c a k r vāin in ácakṛ̂āns.

cakrá: -ám. 9. 9. $2^{*}, 13^{*}, 14^{*}$. 10. 8. 4. II. 7. 4. I4. I. $14^{*}, 16^{\circ}$.

cakré. 9. 9. II".

cakré (p. -é íti). I4. I. I I", 12", 16". cakrằ. I8. I. $8^{*}, 9^{*}$. I9. 53. I, 2 (mss. -ần).

(cf. așțăcakra, ékacakra, tricakrá, ródhacakra, saptácakra, sucakrá.) 
c akravāká: -kă. I4. 2.64 (oiva). $\checkmark$ c a kṣ: cf. cákșaṇa, cákșan, cákșas, cákșu, cákșus. $\left[26^{+}\right.$.

+ abhi: abhiocáșțe. 8. 4. 8*. 9. Io. abhí calșate. I8. 4. 29*. [66t. abhyácakșata (p. abhioác-). I3. 3 . (cf. abhicálșanaa.)

+ prati: práti cakșva. 8. $4.25^{*}$.

+ vi: viocáșțe. 2. I0. 4. 7.8I. It. I3. 2. $\mathrm{II}^{\dagger}$.

ví... cáșțe. 7.25.2.

ví cașțe. 4. II. 2 ; I6. 5. 9. I. 5 ; IO. I9. I0. 8. 30 .

ví cakșate. 9. I0. $26^{*}$.

ví calsșva. 5. 20.4. 8.4. $25^{*}$ (1. -șua ?). (cf. vicakșaná.)

+ s a m: sám cakșe. 5. II. 2 . [6-8.

cákşa ṇ a: -am. 5.4.3; 28. 7. I 9. 39. (cf. abhicákșaṇa, praticákṣaṇa, vicakşaṇá, viçvácakșaṇa.)

cákşan: -aṇi (p. -íníti). I0. 2.6.

cákşas: -sā. I3. 2. $2 I^{*}$.

cákşase. I. $5 \cdot \mathrm{I}^{*}$. 6. I9. $3^{\dagger} ; 39.1$; 4I. $\mathrm{I}^{*} ; 68.2 ; 76$. I. I0. 6.8 .

(cf. urucákșas, ghorácalșas, nṛcákşas, viçvácakșas.)

cákṣu: -șos. I9. 6. $7^{*}$.

(cf. sahasracakșu.)

cákșurmantra (p. -ụ̣॰ma-) : -asya. 2. 7.5. I9. 45. I.

cákṣuşmant: -mate. I2. 2. 2I* I9. 49.8 (mss. -tī).

cákșus: 2. $17.6^{2} ; 35.4,5 . \quad 3.22$. 5. 4. 5.4 ; I4. 5 ; 20. 7. 5. 9. 7 ; Iо. 8 ; 13. 4 ; 21. 10; 30. 13. 6. 53.2. 7 . 26. $7^{*}$. 8. I. $20^{*} ; 2.3 ; 3.2 \mathrm{I}^{*}$. 9. 9. I4". I0. $2.29,30 ; 6.35 ; 7.18,33$, 34 ; IO. 24 . II. $3.3 ; 5.25 ; 7.25 ; 8$. $4,26,3$ I. I2. I. $33 ; 3.2 ; 5.9$. I3. I. $45 ; 2.35^{*}$. I4. I. $6^{*}$. I6. 2. 5. I 8. I. IO*; 2. 46. I9. $35.3 ; 43.3 ; 44.5$; 46.3 ; 5I. I ; 53.6; 58. I; 60. I.

cákșuṣā. I. 33.4. 2. 16. 3; 34.3. 5.6. 10; 13. 4 ; 2 1. 2 ; 30. 14. 6. 96. 3. 7.60. 1. 8. 3. $9^{*} ;$ 7. 18. 9. 4. 17. I0. $7.39 ; 8.14$; IO. I5. II. 7.23. I3. 3.6. I4. 2. I2. I6. 1. I2. I8.2. $7^{\dagger}$. cákșușe. 5.4 .7 .6 10.3. 8. 2.4 ;
3. 8*. I 4. 2.35. I 8.3. I0. [12 3. 32 . cákșușas. 4. 9. 6. 5.6.9. 9.2.2. cákșuși (p. -i íti). 9. 5. 21 .

cákșūṇ̦i. 3. I. 6. I I. 2.5.

cákșușām. 5. 24. 9 .

(cf. ághoracakșus, ádabdhacakșus, cākșuṣa, cákșurmantra, cákșușmant.)

c añk a ça in ápracañkaça.

c añkram a in adhicañkramá.

cáṇ da a: -asya. 2. I4. I.

V c at: cattás. 9. 5.9.

cātayāmahe. 4.37.2.

cātáyan. I9. 34. 9; 44. 7 .

(cf. cātana.)

+ nis: níh ... cātayāmahe. 2. I4. 2. cát u ḥ०çrotra: -trā. 5. I9. 7.

c atúr: catvăras. I. 3I.2. I9.47.4. catúras. 4. I5. I 4 ; 34. 7. 8. 9. 24. 14. I. 60. I9. 27.3. [1.60. catvări. 8. 2.21. 9. 10. $27^{*}$. I4. catúrbhis (p. -úhộbh-). 3. 7.2. 4. I4. 9 .

catúrbhyas (p. -úḥobh-). I. I2. 4 ; 3I. I. I9. $45 \cdot 5$.

cátasras. I. II. $2^{2}$. 2. 6.1 ; IO. 3,4 . 3. $22.5 ; 24.6 .5 .3 . I^{*} ; 15.4$. 6. 40 . 2. 8. $5.3 ; 8.22$. 9. 2 . II ; IO. I9. I0. 7. I6. II. $2.10 ; 5.12$. I2. 1. 4 , 55. I3. 3.6. I7. I6. I9. I. 3 ; 10. $8^{*} ; 33.5$.

(cf. turíya, túrīya, cátuḩ̧̣rotra, catúr-catvārinçát.)

c atúr. Ir. 2.9. [32.2.

c aturakṣá (p. -uḥoak-): -ám. 2. caturakșăt. 8.6.22.

caturakșāú. I 8. 2. II", I2* .

caturakșí. 5. 19.7.

caturakșiăs. 4. 20. 7 (mss. -kṣâss).

c aturuttará (p. -uhout-): -răni. 8. 9. r9.

[23. 1 .

c a tu r ṛcá (p. -uḥṛc-): -cébhyas. I 9.

c a turthá: -ás. I3. 4. I6. I5. 15.6;

I6. 4 ; I7. 4 .

caturthám. 8.9.3.

caturthím. I5. 13.4.

cáturdañ șt ra (p. -uḥoda-): -rān. II. 9.17 . 
caturdaca in

caturdą̧arcá (p. -çåṛc-): -cébhyas. I9. 23. II.

c aturdhấ (p. -uḥodhă). 4. 34. 7. 8. 9.24 ; 10. 8 . I0. I0. 29.

L30.

cáturbila (p. -uḥob-): -am. I8. 4 . cát urbhṛșți (p. -uḥobh-): -im. ro. 5. 50 .

c a turmās a in cāturmāsyá.

cáturvira (p. -uḥ॰v-): -am. I9. 45. $3,4,5$.

caturvŗsá (p. -uḥov-): -ás. 5. I6. 4 . cáturh anu (p. -uḥoh-): -us. 5. 19.7. cáturhotṛ (p. -uḥoh-): -tăras. II. 7. 19.

cátușțaya: -am. I0. 2.3.

cátuṣpakşa: -am. 3.7.3 (oiva).

cátuṣpakṣā (p. -uḥop-). 9. 3.2I.

cátuş pa d (p. -uḥ॰p-): -pād. 4. II.

5. 6. 107. I-4. 8. 8. 14. I0. 8. 21 .

I3. $3.25^{*}$. I9. 31.4 ; 34 . I.

cátuṣpadā. 9. I0. 2*. I9. I5. 2.

cátușpade. 6. $27 . I^{*}$; 59. I. II. 2.

28. I4. 2.40*.

cátuşpadas. 4. 2. I* ; 28. I, 6. 6. 28. 3. I 3. 3. $24^{*}$.

cátuṣpādas. Io. 2.6 .

cátușpadas. 3. 2 I. 2. II. 2. I. I2. I. I5. I3. I. 2.

cátuṣpadām. 2. 34. I. $\quad$ 8. 2. 4, 23.

I9. 3 I. 5 .

cátusspadi. 9. IO. $2 I^{*}$. IO. I. 24. II. Io. 6 . I3. I. $42^{*}$.

cátuṣpadìm. I8. 3.40*. [II. c a țu rātrá (p. -uḥorā-): -ás. II. 7. catvārinçát: 5. 15.4. I 9.47.4. caná. I. $20.4^{*}$. 3. I9. $8^{*}$. 4. 5.2; 25.2 ; 26.6 ; 28.5 ; 34. 3. 5. 3. $4^{\text {* } ; ~}$ I9. I0. 6. 57.3 ; 127. I; 130. 3.7 . 7. $1 ; 9.3^{*} ; 37.1 ; 38.4 ; 44.1^{*} .8$. 4. $3^{*}$; 8. 6, I9. 9. 2 . 10, $24 ; 6.52$. 10. 5 . $23 ; 7.37 ; 8.16,44$. II. $4.21,25 ; 9$. I3, 20; Io. I9. I2. I. I8, 23-5. I8. I. $48^{*}$; 2. 24. 32. I9. 46.3 . 20. 127. 14. cánas: 20. 127.14 (mss. vánā).

c andrá: -ás. 2. 15.3. 3. 3I.6. 4. 39. 8. I5.6.2. I9. 27. $2 ; 43.4^{2}$. cándra. 2. 22. I-5. candrám. I. 3. 4. I2.2.53. I3. 3. I0. 14. 2. $10^{\circ}$. 19. 26.2 . candréna. 4. 39.8. candrăya. 4.39. ? $7^{2}$. 19. 43.4. candrásya. I5. 6.2. I9. 27.5. candré. I9. 27. 10.

(cf. candrámas.)

c a ndráma s: -mãs. 5. 24. I0; 28. 2. 6. $83.1 ; 86.2$. 8. I. $12 ; 8.23 .9$. 2. 24 I0. 6 . 10; $7.2,12,33$. II. 4 . $12 ; 6.7 ; 7.2$; 10. I6. 15. I5. $5 ; 18$. 2. $18.4 .89^{\circ}$. I9. $6.7^{\circ} ; 8.1$; 19.4 . candramas. $7.81 .2^{\dagger}$.

candrámasā. I3. 4. 28.

candrámasi. 10. 3.18. I1. 5. 13.

(cf. sūryācandramása, cāndramasá.)

c a ma sá: -ás. 7.73.3. 8. 10. 26. 10. 8.9. I6. 3. 3. I8. $3.53^{*}$. I9. 49.8 ; 58. $4^{*}$. 20. 134.5 (not mss.).

camasám. 6. 47. 3. 18. 3. 53", 54. camaséna. 7. 1 IO. 3 .

(cf. camasădhvaryu.)

c a ma sâd hvaryu (p. -sáoadh-): -yavas. 9. 6. $5 \mathrm{I}$.

c a mû́ : -úos. 9. I0. $12^{*}$.

cá y a na: -nena. I8. 4.37. [II7.I. V car, cal: cárāmi. 3. I5. 5, 6. 6. carāmi. 4. 30. $I^{*}$. 9. IO. I $5^{*}$.

cárasi. 3.6. 4 .

cárati. $4 \cdot 5 \cdot 5^{*} ;$ 16. $2^{2} \cdot 7 \cdot 20.6$. I 8 . 2. 10*. I9. 56.4 .

carati. 3. 10. 4. 4. 8. I, $3^{\circ}$; 10. 7 ; II. 2,$3 ; 39.9 .5 .17 .5^{*} ; 18.13 .9$. I. 4 ; 10. $8^{*}$. I0. 8.12 , I3. II. 2.12 ; 5. I, 23. I2. 4.37 .

caratas. 7.8 I. I*. II. 2.14. I3. 2. $\mathrm{II}^{*}$. 18. 2. $13^{*}$.

cárāmas. 6. I33. I.

cárāmasí. 6. $45 \cdot 3^{\circ}$.

cáratha. 3.9. 4 .

cáranti. 4. 27.4. 6. 5I. $3^{\dagger}$. II. IO. 8. I2. I. 49. I8. 1. 9"; 2. 28. 19.66. I. caranti. II. 5. I3. I2. I. I5; 2.4 I. careyam. I7. 27.

cáret. I2. 4.27.

cara. 3. 2.3. 4. 17.8. 6. 139.2, 4. 8. I. I2. I8. 4.3 I. 
caratu. 9. 2. 14

carata. 6.67.2. 9. 4.24.

cáran. 4. $5.2 ;$ I6. I.

cárantam. 3. 3.4. 4. 29.7. 5. I8.5.

7. $72.2^{*}$. 8. $3 \cdot 5^{*} ; 4 \cdot 8^{*}$.

cárate. I2. I. 3 I.

cáratas. 7.57.1.

cárantas. 3. 30. 5 .

cáratas. 7. I08.2. 8. 2.11 .

cárantĩ. I2. 4. 29, 39.

cárantím. I4. I. 56 .

ácarat. 6. 92. 2.

acarat. 5. 4.4. 19. 39.7.

cacăra. 9. 5.3.

cerimá. 7. 65.2.

ácicarat. 12. 4.28.

caritám. 3. I5.4. 9. I. 3 .

carcarīti. 20. 127.4.

(cf. cara, cala, cáraṇa, Vcaraṇy,

carant, carás, carācará, carita,

carítra, carya, cācala, cācalat, cāra, cārin, cārya.)

+ a nu: ánu carema. 12. I. I7.

anvácaran (p. anuoá-). 12. I. 8.

+ a ntar: antáç carasi. I3. I. 40.

antáç carati. 6. $31.2^{*}$.

antáh ... carati. II. 4. 20.

+ a pi : ápi ... cárāmasi. 6. $45 \cdot 3^{\dagger}$.

+ abhi: abhí cara. 2. II. 3 .

abhiocerús. 5. 30.2. I0. I. 18.

(cf. abhicārá, abhicārín.) [ṇa.

+ pratyabhi: cf. pratyabhicára-

+ a v a: cf. avacarantiká.

+ ã: â... carati. 7.9. $\mathbf{1}^{*}$.

â... cáret. I2. 4 . I6.

ācáran. 20. 127. 8 .

ãocárantam. 2. 34. 5 .

â... cárantam. 9. IO. II ${ }^{*}$.

ācárantī. 7. 73. II*.

(cf. ācāryà.)

+ a bhy ā: cf. abhyācārá.

+ ud ā: udoấcarat. 4. 5. I*.

+ u d: uccáran (p. utoc-). I I. 4. 2 I. uccárantam (do.). 6. 62.3. 8. 4. $24^{*}$. úd acarat. Io. Io. I9.

+ parā: párā ... carati. 7. 9. I*. párā... cárantam. 9. IO. II**

+ pari: pári ... caratas. I8. I. $35^{*}$. (cf. paricará.)

+ pra: prá caranti. 4. I6. 4 .

prá cara. 20. 135.4 (mss. pracára). prá ... caratu. $7 \cdot 73 \cdot 5$.

praocárate. 9. 3. I2.

+ vi: ví caranti. 4. 2 I. $4^{*}$.

ví carā. 20. I27. II. [9. I.

vy àcalat. I5. 2. I-4; 6. I-7, 8, 9;

vyácalat (p. vioá-). I5. I4. I-I2.

(cf. ávicācala, ávicācalat.) [I-I 2.

+ anuvi: anuovyàcalat. I5. I4. anuovyàcalan. I5. $2 . \mathrm{I}-4 ; 6 . \mathrm{I}-7$, $9 ; 9.2$.

+ s a m: sám carati. 8. 9. 22.

sám caratas. 8. 9. I2.

sam.ocáranti. 3. I5.2. 4.38.5. 6.

55. I. I2. I. 47 . I 8. I. $36^{*}$.

sám carete (p. -e íti). 8. 9. I2.

sám carātāi. 3. 4.3.

sám carema. 3. I2. I.

sám cara. 6. 45. I.

sam̉ocárantam. I 8. 4. $28^{*}$.

sám acarat. I3. 2. 41.

sám carat. 13. 2. 40.

+ a nus a m: anuosamcáranti. 3. 2 I. 7. $4 \cdot 38.5$.

anuosámcarema. 19. $58 \cdot 3^{2}$.

anuosamcáranti. 18. 3.4.

c a ra in kucará, divícara, paricará.

cáraṇa: -ṇe. 7. I06. I.

(cf. pratyabhicáraṇa, Vcaraṇy.)

V carany: cf. caranyú.

$+\bar{a}$ : à caraṇyāt. 7. 29. I.

+ u d: úc carạ̣yāt. 7. 29. 2.

c araṇú : -yúvas. 20. 48 . I (mss. -yávas).

carant in avacarantikat.

carama in

c aramatás. 19. 15.3 (p. ca ra-), and c a r a mấj a (p. -maoáj-) :-jām. 5. I8. I I. carás: -se. I3. 2.6.

carācará: -ás. I4. I. II*.

carita in dúçcarita.

carítra: -răni. Io. 2. I2. [4. 16-24.

c arú: -ús. 8. 4.2*. II. I. I6, I8. I 8. carúm. 4. 7.4. II. I. I7; 3. I8

carós. 9. 5.6.

carụtạm. 18. 4. 53 . 
c a rkṛ́t y a : -tias. 6. 98.1 .

cárman: -ma. 4. 12.4. 9. 7. 15. Io. 9. 2, I7, 24. II. I. 8. I2. 3. I, I4. I4. 2. 22,24 .

cármaṇă. 4. 12.4. 5.18.3. [23. cármani. I0. 9.26. I I. I. 9. I4. 2. c arya in brahmacárya.

c a rş a ṇ I: -ṇīnăm. I. 5. 4* (1. -naam).

7. $84.2^{*}$. I3. I. 38 . I9. $5.1^{*} ;$ 13. $2^{*}$.

(cf. prácarșaṇi, viçvácarşaṇi, carşaṇiprá.)

carşa ṇi $\mathbf{0}$ pá: -ás. 4. 24.3.

$\checkmark$ cal, see $V$ car.

c a la in punçcalí.

cākṣusa: I6. 7.7.

cãca la in ávicācala.

cācal a t in ávicācalat.

cātana in amivacătana, arāyacátana, durṇāmacătana, piçācacầtana, bhrātṛvyacătana, yātucấtana, sadānvācătana, sapatnacătana.

căturmāsyá (p. -ụ̣ım-) : -yăni. II. 7. I9.

cāndra masá: -sâs. I9. 9. IO. $\checkmark c \bar{a} y$, see $\gamma$ ci.

[cārá.

cāra in abhicārá, abhyācārá, sahac ārin in abhicārín, bahucārín, brahmacārín, vratacārín.

cấru: -us. 2. $5.1 ; 36.4$. I3. I. 38 . I8. 3. $7^{*}$. I9. $24.6 ; 33.3$.

căru. 2. 13. I. 7. I2. I. I2. I. 56 .

I4. I. 31 . I9. 7.2.

cāry a in ācāryà.

$V$ I, 2 ci: acinvan. I0. 2.4 .

cáyāmahe. I9. 48. I (mss. cayásmāha; p. ca yásmāi āha).

cikyús. Io. 2.4 .

citám. I8. 4. 14, 37 .

cité. 7. 22. 2.

citvă. I0. 2. 8 .

acāyișam. 7.89. I.

cāyituá. 9. I. I.

(cf. cáyana, cítya, cītí.)

+ a dhi: ádhi ... cinotu. II. I. 24.

+ an u: ánu ... cikitām. 6. 53. I.

+ a pa: ápa cikīhi. I. Io. 4 .

(cf. apacít.)
+ ā: â॰citam. 4. 7.5.

+ s a mã: sam॰ăcinuşva. I I. 1. 36 .

+ ni: niocikéşi. I. 10. 2.

niocíkyat. 5. 20. I2.

ní cikyus. 9. 10. $16^{\circ}$.

ní... cikyús. 9.10.16\%"

+ vi: ví cinoti. 7. 50. $6^{\dagger}$.

ví cinotu. 8. $3.4^{\circ}$.

viocinván. I0. 8.12.

viocinvatím. 4. 38.1 .

vi cayat. $7 \cdot 50 \cdot 3^{\text {* }}$.

cikitú: -tvă. 7.52.2.

cikitvāñs in ácikitvāñs.

cikitsú: -sávas. Io. I. I.

c it in acít, apacít, duçcít, vipaçcít.

cit, see cid.

V cit: cetatus. 3.22.2.

cikéta. 7.2. 1 ; 5.5 .

ciketa. 9. 1. 6,7 . I0. $2.2,7 ; 8.4$. cikitvăn. 5. I2. I*. I3. 2.32, 42 . I 8. I. $30^{*} ; 2.37$.

cikitvan. $7 \cdot 97 \cdot \mathrm{I}^{\dagger}$.

cikitúșe. 8. 4.12*. 14.2 .41 .

cikitúșas. 9.9. $7^{*}$.

cikitúșī. 4. 30.2* 7.47.2.

cittám. I. 34.2 . 3. I. $4^{\dagger} ; 8.6 ;$ I9. $5 ; 25.5$. 5. 3. $2^{*} ; 7.8$. 6.9. $2 ; 42$.

$3 ; 43.3 ; 64.2^{*}$. I0. 10. 18 .

citténa. 3.6.8.

cittât. 5. 18.5 .

cittásya. I9. 4. 2.

cittăni. I. 9.4. 2. 30.2. 3. 2. I, 2, 3, $5^{\dagger} ; 25.6$. 5. 2 I. 4-6. 7.77.2 . II. 8. 27.

cittāni. 3. 2.4 (mss. cittắni).

cittébhis. 3. 8.6 .

cetáyantī. 5. 12. $8^{*}$.

cíkitsāt. 9.2.3.

cíkitsatu. 6. 68.2.

cikitsatu. 6. I4I. I. I0. 6.5.

acikitsIs. 5. II. I.

(cf. keta, ketú, cikitú, cikitvăn̉s, cikitsú, cit, cittá, cítti, cittín, citrá, cetaná, cétas, cettŕ.)

+ a p a: ápa cikitsati. I3.2.15.

$+\overline{\mathbf{a}}$ : à ciketa. 9.9. $15^{*}$; 10. $23^{*}$.

à... cikéta. 5. I. 2 .

+ pra: cf. prácetas. 
+ vi: ví cetat. 9. 9. $15^{*}$.

víocittas. I3. 2. 3 I.

(cf. avicetaná.)

cit t a in ihácitta, pứrvacitta, sácitta, cittākūtá, cittín. [I, I3.

cittākūtá (p. -taoāk-): -ám. I I. 9 . cítti: -is. 14. I. $6^{*}$.

cíttyā. 5. 6. 10.

cíttaye. 6. 4I. I.

cíttyām. 5. 24. I-17.

(cf. ácitti, prấyaçcitti.)

cittín: -nas. 3. 30. 5.

cittíobhis. 9. 10. $7^{*}$ (or to cittí).

cíty a: -am. I0. 2. 8.

citrá: -ás. I3. 2. 32, 42.

citră. I9. $7 \cdot 3$.

citrám. 13. 2. 34, $35^{*}$.

citrāú. I9. I3. I (p. -âs).

citrăni. I9. 7. I.

[dhas.)

(cf. sucitrá, citrábhānu-citrárā-

citráobhānu: I3. 3. I0.

citrabhāno (p. -o íti etc.). 4. 25.3.

citráoratha: -as. 8. 10. 27.

citrá $\circ$ rādh as: -dhās. I. 26. 2.

cid. 3. 3.2 ; $16.2^{3^{*}}$. 4. 6.4 ; 21. $5^{*}$, $6^{2 *}$; 28. 2. 5. $2.4^{*}, 8^{\dagger}$; II. 4,$6 ; 27$.

4 ; 30. II. 6. 3.3 ; 20. 1 ; 97. $2^{*}$. 7 .

I4. 4 ; I6. I ; I8. 2 ; 42. I*; 92. I*;

I06. I ; II 7. I*. 8. 4. $7^{*}$. 9. 9. $7^{*}$; IO.

$23^{*}$. I2. $4 \cdot 7^{2}$. I $4.2 .47^{*}$. I8. I. $1^{2 *}$,

$3^{*}, 8^{*}, 20^{*}, 33^{*}, 52^{*} ; 2.14^{*}, 15^{*}, 16^{*}$,

$17^{*} ; 3 \cdot 23^{2 *}, 65^{*}$. I9. $5.1^{*} ; 9.13$; $64 \cdot 3^{*}$.

cití: -ím. 2. $9.4^{2}$.

V cu d: códat. I9. 5. I* $^{*}$.

codáyāmi. $5 \cdot 2 \cdot 5^{*}$.

codayămi. 3. I 5. I.

codaya. 3. $20.5^{*}, 7^{*}$.

codayasva. $7 \cdot 46.3$.

(cf. códana.)

+ pra: praocodáyantã. 5. 12. $7^{*}$. prá codayantām. 19. 7 I. I (mss. praocodáy-).

veṛt: ef. crit.

+ ati: áti cṛtāmasi. 5. 28. I 2.

+ ā: a...crtatu. 5. 28 . 12.

+ pra: prá ... cṛtămasi. 9. 3.6.

+ vi: ví cṛtāmi. 9.3. I8. viocṛtămasi. 9. 3. Io.

ví cṛtāmasi. 9. 3. I, 3, 4, 5, 8 .

ví ... cṛtāmasi. 9. 3. I3, I4.

ví crita. 6. II2. I, 2.

ví cṛtā (p. -ta). 6. 63.2;84.3.

ví cacarta. I4. I. 56.

(cf. vicị́t.)

crit in vicrít.

cetaná: -ním. 9. 4.21.

(cf. avicetaná, sucetaná.)

cétas: 6.64.2 $2^{\dagger}$ 9.7.II.

cétase. 6. 4I. I.

cétasas. 6. II6.3.

cétasi. I I. IO. 2.

(cf. prácetas, sácetas.)

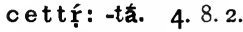

cettăram. 5. 3. $10^{*}$. 6. 99.1 .

cettúr. 6. 73. I.

cé d (p. ca ít). 2. 30. $2 . \quad 4.28 .4$. 5 .

I7. $3^{*}, 8.6 .5$ I. $3^{\dagger}$; I22. 2. 9. 5. 6 .

I2. $2.36 ; 4.18,21,48$. I 8. 2.37 .

$\checkmark$ c eș ț : céșțatas. II. $4.23,24$.

cód a na: -nāya. 7. II6. I.

c y a va in bhuvanacyavá.

cyáva na: -nāya. 7. 116. I.

(cf. duçcyavaná.)

c yãva yi șnú (p. cyav-): -ús. I 9.

V c y u : cyutá. 9. 2. I5.

cyāváyati (p. cyav-). ro. I. 13.

cyāvayantu (do.). 12. 3. 35 .

cyãváyan (do.). I2. I. 5 I.

(cf. cyava, cyávana, cyāvayișnú, cyut, cyuta.)

+ a pa: ápa cyoṣțhās. 6.87 .2 *

$+\overline{\mathbf{a}}$ : â cyāvayantu (p. cyav-). 3. 3.2.

+ pra: praocyávate. 9. 8.3.

praocyávante. 8. 9.8.

prá cyavasva. I8. 3.9.

prá cyavethām. I 8. 4.49.

práocyutas. 6. I2I. 4 .

práocyutām. 8. 9.8.

práocyutās. 4. 1 5.7-9. 5.20.3.

prá cyāvaya (p. cyav-). I0. 4. 25.

prá ... cyāvayatu (do.). I8. 2.54*

c yut in acyutacyút, bāhucyút.

c y uta in ácyuta. 
V ch a d: chādayāmi. 7. 118. I*. (cf. chadís, chad.)

+ antar: antáç chādayasi. 9. 3.14. $+\overline{\mathbf{a}}$ : cf. āchad.

ch a d in maṇichád, āchádvidhāna.

chadís: $3 \cdot 7 \cdot 3$. I4. I. $10^{\circ}$.

$\checkmark$ chand in chándas.

c hánd a ḥ op akşa: -şe (p. -e íti etc.). 8. 9. 12.

chánd as: 8. 10.25. 12.3. 10. I4. I. $8^{*}$. I9. $6.13^{\dagger}$.

chándasā. I I. 7.8 .

chándāṅisi. 4. 34. I. 5.26.5. 8. 9. I7, I9. II. 7.24. I8. I. I 7; 2.6*.

chándobhis (p. -dahobh-). 6. I24. I.

(cf. gāyatráchandas, jágacchandas, trișțúpchandas, bṛhácchandas, chándahpakșa.)

Vchā: + anu: ánu chya. 9.5.4 (l. chia?).

chầy a ka: -kāt. 8.6.2I.

chāyầ: 4.2.2*.

chāyấm. 5. I9.9. 8.6.8. I3. I. 57 . chāyáyā. 5. 2 1. 8.

(cf. abhichāyá, chăyaka.)

$\checkmark$ chid: chinádmi. 6. I4. 2.

chinátti. 12. $2.37 ; 5.43$.

chinatti. I2. 5.38 .

chindhí. 12. 5.5 I. I9. $28.6^{4}$.

chináttu. 5. 29. Io.

chintám. 6. 50. I.

chitthās. 8. I. 4

chinnă. 3.6.7. 9. 2 . 12.

chinnám. 4. 12. 5 .

chinnásya. 4. I2. I.

chidyate. 9. 9. $\mathrm{II}^{\dagger}$.

[chéda.)

(cf. chidyamāna, chidrá, chinna,

$+\bar{a}$ : ầ chinadmi. 7. 74. 2.

à chindhi. 4. I9. I. I2. $5.5 \mathrm{I}$.

+ ud: út ... chindhi. 7. I I3. I. [5I.

+ pra: prá chindhi. I0. 3. I6. I2. 5 .

+ vi: viochídya. 6. 139. 5 .

víochinnam. 6. 139.5 .

(cf. ávicheda.)

+ s a m: sám chindhi. 12. 5.68.

sám achidan. 6. IO4. I.

ch i d y a mān a in áchidyamāna.

chi drá : -ám. I9. 40. I. chinna in áchinna, reşmáchinna, chinnápakşa. [(mss. -apakşấ-). chinnápakşa: -şãya. 20. I35.12 chú buka : -kăt. 2. $33 . \mathrm{I}^{\circ}$.

cheda in ávicheda.

ja in asthijá, ekajá, jarāyujá, tanūjá, tapojá, dvijá, nijá, pūrvajá, prathamajá, samudrajá, sākarnjá, stambajá: and cf. jā. [6. 48.2. já g a c chandas (p. -atocha-): -dās. jágat: 5. I7.7. 6. 12. I; 17.4; 44. I; 77. I；88. I"; I26. I". 9. I0. $\mathrm{I}^{\circ}$. jágatā. 3. 12.7. 9. 10. $3^{*}$.

jágate. I. 3 I. 4 .

jágatas. 4. 2.2*. 7. I7. I. 9.3.17. I2. I. 6. I3. $2.35^{*}$. I9. $5 . \mathrm{I}^{*}$.

jágati. 9. IO. $I^{*}$.

jágatảm. 8. 5. Ix. I9. 39.4.

jágati. 8. 9. 20. I9. 2 I. I (mss. -tI, -tȳāi, -tyāu).

jágatīm. 8. 9. I4. (cf. jágacchandas.)

jag dh a in ájagdhapāpman and ja g d há ○pā pman: -mā. 9. 6. 25.

j a g hána: -am. I4. 1. 36 . (cf. jaghanyà.)

j a g h a n y à : -níām. 7. 74. 2.

jañgi đ̣á: -ás. 2. 4. 2, 3, 5, 6. I9. $34 . \mathrm{I}^{4}\left(\mathrm{ed}^{1}\right), 2,4,7$, Io; $35.2,3$ (ed. -da), 4,5 .

jáñgiḍa. I9. 34.8 (mss. jañgiḍá).

jañgị̣a. I9. $34 \cdot 3$.

jañgiḍám. 2. 4. I. I9. 35. I.

jañgidéna. 2. 4. 4 .

jañgiḍásya. I9. 34.5 .

ján̄ghā: -ghe (p. -e íti). I I. 2. 2. jáñghayos. I9. 60. 2 (mss. ja-). jáñghās. 9.7.10. 10. 9.23. ján̄ghābhis. 4. II. IO.

j a țh ára: -ram. 2. 5. 2. I3. 3. 4 . jațháre. II. I. 25.

j a tú : -túas. 9.2.22.

jatrú: -rávas. II. 3. IO. jatrúobhyas. 14. $2.47^{*}$.

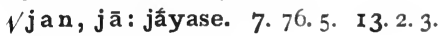
jāyase. $7.8 \mathrm{r} \cdot \mathrm{I}^{\dagger}$ 
jâyate. 8. 3.12* . 9.8.8. I2. 4. I4. jāyate. 5.17.13, I6́; I9.4. II. 4. I4, 20. I2. 4. 9. I3. 2. 25 .

jâyasva. I I. I. I.

jầyatām. 6. I06. I.

jāyatām. I3. I. 54 .

jāyantām. 4. I5. 2, 3.

jầyamānas. 6. I 10. 3. 7. 81. 2*. I3. 3. 22 . I9. 32.9.

$\left[9.4^{*}\right.$. jầyamānam. 3. II.8. 8. 6.25. 9. jấyamānā. 2. I. I (mss. ed. -nās).

I2. 4. I0.

jâyamānāyāi. Io. IO. I.

jấyamānasya. 4. 2.8.

jẫyamānăt. I0. IO. 23 .

jăyamānās. I4. 2. 25.

ájāyathās. 5. 4. 1. 7.84.2*.

ajāyathās. 4. I9.4.

ájăyata. 6. $34.5^{*}$. $\quad$ 12. $1.57 ; 4.24$. ajāyata. 2. 25.2. 6. 39.3. I0. 4 . 7; I0. I8, I9. I I. $8.8^{2}, 9^{2}$. I3. I. 48 , $55 ; 3.26 ; 4.29-33^{2}, 34,35^{2}, 36^{2}, 37$, $38,39^{2}$. I5. 8. I. I8. I. $21^{*}$. I9. 6. $6^{*}, 7^{2^{*}}, 13^{*} ; 30.5 ; 39.6-8 ; 53.10$; 54. 3 .

ajāyanta. I I. 8.3 . I2. $4.34,37,38$. 19. 6. $12^{*}, \mathrm{x} 6$.

jánāt. 6. 8 I. 3 .

jajâna. 3. 10. 12. 6. 38 . I-4. 10. 8. 7, 13. I I. 4. 22 . I3. I. I; 3. I, $\mathrm{I}_{5}$. I 8.4 .54 .

jajāna. 6. 6r.3. 7. 79. 4 ; 80. $3^{\dagger}$. Io. 2.3. I3. I. 6 . I9. 3I. II.

jajñișé. 4. IO. 2. 5. 30. I7. I9. 3I. 9 (m. mss. -sie).

jajñișe. I. 7.6. 4. I0.6. I0. Io. I9. I9. 56.5 (mss. -şé).

jajñé. 4. 24.6 (mss. yaj-). 5. 2. $\mathrm{I}^{*}$. 9. I. I, 3 , 10.

jajñe. 4. I. 6 ; 6. I. 8. 9.5. 9. 2. I9. I0. I0. 20. II. 8.6 , 9. I3. I. 55. I9. 22. 21 .

jajñiré. ro. 7.25 .

jajñire. IO. IO. 21 . II. 7. II, 23-7. 19. 6. $12^{*}, 13^{2 *}$.

jajñānás. $5 \cdot 2 \cdot x^{*}$.

jajñānám. 4. I. I.

jajñānăs. I 8 . I. 50 *. ájijjanas. 5. II. II.

ajijanan. II. I. 3.

jłjjanan. I8. I. 20*.

ájanișthās. II. I. 3 .

ájanișța. 4. I4. I. 9. 5. 13. [47. ajanișța. 6. IIO. 3. 7. 9. $1^{*}$. I2. 3 . jánișța. 4. I. 5 .

janișiya. 9. I. I4.

jātás. I. $24 . \mathrm{I}$; 33. I. 3. 20. $I^{*}$. 4. J. $4 ; 2.7^{*}$; IO. I, $4,5^{2} ;$ II. $3 ; 34$. I. 5. 4. 7,8 ; I2. II $^{*}$; 22. 5. 6. IIO. 2. 9. I. 5 . I0. $6.2 ; 7.36 ; 8.27,28$. I I. 5 . 5. 19.6. $7^{*}, 9^{*} ; 39.5 ; 42$. 1. 20. 34. I6. jātám. I. 28.3. 3. 30. I. 4. 6.8; 9. 9 ; 23.7. 5. 4. 2 ; 28.6. 7.6. I*. 8. 2. 4; 6. I8. 9. I. 5. Iо. ro. 2 I. I I. $5 \cdot 3$, 5, 23. I9. 6. II*; 4I. I ; 44. 3 ; 45 . 3 ; 53.9. 20. 48.2. [8.30. jātă. 5. 13.8. 6. 133.4; I36. I. I0. jāténa. 5. II. 2, 3 . jātâyyāi. Io. IO. I. jātásya. I9. 6.16. jātâyās. 8. 6. I ; IO. I.

jātāú. 8. 9. I.

jātâs. 2. I4. 5 ; 28. 3. 7. II5.3. I0. 2. II. II. $5.20,2$ I; 8. IO. I2. I. I5. I8. 4.57. I9. $6.12^{*}$. jātấsas. I8. r, $32^{*}$.

jātăn. 6. I36.2. 7. 34. I. 8.6. I9. I0. 3. I3-5. II. I. $26 ; 9.6$.

jātăni. I. 16.3. I0. 4. 23. [tấs. jātâ. 8. 9. I6, 2I. I9. $49 \cdot 3$ (mss. jājātắnām. 3. 23. 3 .

janitavíam. 4. 23. 7 .

janayati. 7. I9. r.

janáyathā (p. -tha). I. $5 \cdot 3^{*}$

janáyanti. 3. 23. 4 .

janáyās. 3. 23. 3 .

janáya. 6. I36.2. I3. I. I9. $[24,31$. janaya. 3.23.3. 7. III. I. I4. 2. janáyan. 7.3.1. II. 5.7, 24. I3. I. II; 2. $26^{*}$.

janáyantīs. 4. 2. 8.

ajanayam. 6.61.2, 3 .

ajanayat. 6. 78.3. I9. 36.4 (m. mss. -yan); $53.5 ; 54.3$.

ajanayan. I9. $27.7 ; 34.6 ; 52.3$.

janayat. 14. 2. I4. 
ájanayanta. 13. 3. 1 2, 23. ajanayanta. 9. I. 5 .

janáyanta. 8. 3.12".

(cf. gnă, jána, jánana, jáni, jánitu, janitŕ, janítra, jánitva, jániman, janīna, janū, janús, jantú, jánman, jánya, janyá; ja, jâ, jāta, jātrî, jăna, jāni, jāman, jāmí, jāyâ.)

+ a nu: ánu jāyatām. 3.23.3.

ánu jāyantām. 2. 13. 5 .

+ abhí: abhí jāyate. 12. 4. 10.

+ ā: â...jāyatām. 3.23.2.

â... janayatu. I 4. 2. 40*.

ă janayāvahāi. I4. 2. 7 I.

+ ni: cf. nijá.

+ pari: páriojătas. 3. 6. I. (cf. parijá.)

+ pra: praojáyate. 9.3.20.

prá jãyete (p. -e íti). I 0. 8. 23.

prá jāyante. II. 4. I6, I7.

prá... jâyemahi. 4. 33. 4".

prá jāyatãm. I4. 2. I5, 2 I.

prá jāyadhvam. 3. 14.4, 5. 20. I27.

pră 'jāyata. I5. r. 3.

prá ... jajñé. 4. I. 3.

prá jajñe. 7. 5.2.

práojātam. 9. 9. I8". I9. 26. I.

práojātā. I. 34. I.

práojātena. 6. 89. I.

praojanáyan. I0. 7.26.

prá ... janaya. 3.16.3".

pră 'janayat. I5. I. 2.

(cf. prajánana, prajanú, prajá, ṛtáprajāta.)

+vi: viojâyate. 3. 28. I. 9. 3. I3.

ví jāyate. 9. 3.20. I0. 8. I3.

ví jāyante. II. 4.3.

(cf. vijâ, vijấman.)

jána: -as. I. 8. I. 3. 20. $6^{*}$. 4. 5 . 6*. 5. II. 4 ; 30. 2 . IO. I. 8.20. I27. 10, 13 .

jánam. 4. 5.7. 5.4.8; 7.8;8.7; 22. I2, 14. 7. $84.2^{*}$. I2. I. 45 .

jánāya. 4. 30. $5^{*}$. 8. 4.12".

jánāt. 7. 45. I.

jánasya. I. 29. $6^{*}$. I 8. 2. 30.

jáne. 4. 36.9. 6. 5 I. $3^{*}$. 6.4 . 5. jánitva ${ }^{\dagger}$ : -am. 7.6. I $^{\dagger}$. jánās. 5.19.2. 6. 33. I ; 84. I. 7. 6. I*. 8. 5. 7. I0. 7. IO, $21,25,28$; 9. 7. I4. 2. 59 .

janās. 20. 127. I (mss. já-). jánāsas. $4 \cdot 25 \cdot 3 \cdot$ 5. II. 7,8 . janāsas. I. 32 . I. 4. $21.5^{*}$. 20. 34 . I2, I6, 17 .

jánān. 3. 5.6, 7. 4. 5. I*. 6. 69. 2 ; 74. $3 ; 75.3 .7 .57$. I. 9. I. I9. I2. I. 57 ; 2. 9. I3. 2. $18^{*}, 21^{*}$. I4. 2. $10^{\dagger}$ I8. 2. 13". 19. $26.3 ; 32.7$ (mss. -ās). jánānām. I. 33. 2*. 4. I6. 5 ; 22. 5 . 5. 5. 2. 6. 98.2 . 7. 2 I. I. I2. I. 6 I. I3. $2.46^{*}$. I 8. I. $40^{\dagger}, 49^{* \prime} ; 3$. I3.

jáneșu. 4. 28.4. 6. 33. 3. I 8. 4.30. (cf. itarajaná, tirojaná, devajaná, pañcajana, puṇyajaná, pūrvajaná, pratijaná, janátā, janayópana, janấyana.)

janátã: -ãs. 5. I8. I 2.

jána na: -năt. 6. I09. 2. (cf. prajánana.)

jana॰yópana: -as. I2. 2. I5. [47. jană y ana (p. -naoáy-): -nãs. I2. I.

jáni: -is. 20. 48.2 (mss. jătrīs).

jánaye. 14. I. $46^{\dagger}$ (mss. ed. janá-). jányus. I 8 . 1. $3^{*}$.

jánayas. 5. 12. $5^{*}$. 12. $2.3 I^{*}$.

jánīnām. 7. 49. 2". I3. I. 4.

(cf. jánikāma, janitvá, /janiy janiy.)

jániokãma: -as. 2. 30.5. [tạ̣). jánitu: -tos. I9. 56.2 (mss. -to; p. janitṛ́: -tấ. 2. I. $3^{*}$. 4. I. 7. 9. 4.6 ; IO. I2*. I3. I. I3; 3. I9. I8. I. $5^{*}$. janitấram. 4. 14. I. 10. 4.18 . janitúr. I I. 7. I 5, I6. 20. 34 . I6 (mss. jánitur). (cf. jánitrī.)

janítra: -am. I. 25. I, 2. 6. 46.2 ; I2O. 2. II. I. II. I3. 3. 2 I. I4. 2. 34 . I6. 5. I-6.

janítrās. 2. 28.3 (ed. jánitvās).

jánitrĩ: 3. 10.4. I2. 3.4. 23. jánitrīm. 6. I IO. 3. 9. 5.30. I8. 4. I. jánitrī (p. -īíti). 5. 12.9*. janiotvá: -ám. I8. 3. 2". 
jánitvās. 2. 28. 3 (mss. janítrās).

jániman: -ma. 2. 3I. 5. 6. I2. I. jánimāni. I. 8.4 . I3. I. $37 ; 3.21$. jánimā (p. -ma). 2. 28. 2. 4. I. 3. 5 . II. 5. I 8. 3. $22^{*}, 23^{*}$. (cf. sujániman.)

Vjaniy, janiy: janiyánti. I4. 2. janiyaté. 6.82.3.

jañna in viçvajanina.

j a nú s: -úșā. 9. 4. 24. I4. 2.33*. janúșe. 4. I. 2.

janúșas. 4. 1.5. 7. I15.3. janúșām. I3. I. 4 .

jan $\overline{\mathrm{u}}$ in prajantu.

jantú: -tós. 8. 4. $16^{*}$.

jánman: -ma. 6. 80.3.

jánmanā. $5 \cdot 28.6$.

jánmāni. I3. 2. 22*. (cf. viçvájanman, samānájanman, sarvájanman, sujánman.)

ján y a: -yās. II. 8. I, 2.

janyá: -ám. I3. 4. 43 .

$\mathbf{j a b d h} \mathbf{a}$ in hemantájabdha.

jabhy a: jábhya. 6. 50. 2.

ja mád oag ni: -is. 6. I37. I. I8.3. I 5.

jámadagne. I8. 3. I6.

jamádagnim. 4. 29.3.

jamádagnes. 5.28.7.

(cf. jamadagnivát.)

jam ad agniovát. 2. 32.3.

$\checkmark$ j a m b h: jambhayāmasi. 2. 31. 2, 4. $4.3 .3,4.5 .23 .3,5.6 .50 .3$. jambhaya. I9. 47.9 (muss. -bhâyās). jambhayatām. 5. 23. I.

jambháyat. $4 \cdot 9 \cdot 9$.

jambháyantam. 8.6. I7.

ajjijabham. 7.56.5.

(cf. jabdha, jabhya, jambhá, jámbha, jámbhana.)

+ abhi: abhiojáñjabhãnas. 5.20.6.

já m b ha: -bhe. 3. 27. I-6.

jámbhāis. 8. 3. $3^{*}$.

(cf. tṛșțajambha.)

ja mbhá: -ás. 8. I. I6.

jambhăt. 2. 4. 2.

jám bhan a: -as. Io. 4. I 5 .

(cf. kaṇvajámbhana, piçācajámbhana, maçakajámbhana, yātu- jámbhana, vyāghrajámbhana.)

já y a: -am. 2. 29.3.

(cf. dhanamijayá, parājayá, vi-

jayá, samijayá, sị́ñjaya ?.)

ja yá: -ás. 7.50. 8.

jára: -rāya. 9. 9. $13^{*}$.

jarád oașți: -is. 2. 28. 5. 8. 2. I ;

5. I9, 21 . I 4. I. 50*. I7. 27.

jarádaștim. $5 \cdot 30.5,8$. I2. I. 22. I4. I. 49. I8. 3. I0, I2.

jarádașțī (p. -i íti etc.). 9. 3. 9 .

j ar a n t in jarádaști, ajárant. $\left[24^{*}\right.$.

jarás:-sam. I. 30. 3. 2. I3. I. I2. 2. jarásā. 3. 3I. I. 8. 2. 8.

jaráse. I. 30.2. 3. II. 6. 6. 5.2. 7. 53. 4. I2. 3. 55-60. I4. I. 45. I8. 3. IO. I9. $24.2,3 ; 30.2 ; 33.4$.

jarásas. 5. 30. I7. 6. I22. I, 4. 10. 2. 3 O. I I. 3.56

jarási. 2. IO. 5. I2. 3.6. I8. 2.5 I.

ja rấ: 3. II. 7. II. 8. I9. I2. 3. 55-60. I8. 4.50 .

jarăm. 8.2. 11. 19. 24. 5 .

jarăyāi. 3. I1. $7^{2}$.

(cf. ajára, jarămṛtyu.)

jară $\circ \mathrm{m}$ ṛty u : -us. I 9. 24. 8 ; 26. I ; 30. I (-yu ?).

jarămṛtyum. 2. $13.2 ; 28.2,4$.

ja ră y u: I. I I. 4, 4-6. 6. 49. I. 9.4. 4 . jarăyuṇā. I. II. 5,6 . 6. IO6. 3 . jarầyuobhis. I. 27. I.

(cf. nírjarāyu, jarāyujá.)

jarā y u०já: -ás. I. I2. I.

jaritṛ́: jaritar. 5. II. 8. 20. I35. I, 3, $5,6^{3}, 7^{2}$.

jaritré. I 8 . I. $40^{*}$.

ja rimán: -má. 3. II. 8.

jariman. 2. 28. I.

jarimṇé. 8. 3. 20*.

jarimnás. 7.53.5. I8. 3.62.

jálāşa: -as. I9. 10. 6*.

(cf. jālāşá, jalāşabheşaja.)

jalāșaobheșaja: jálāșabheșaja. 2. 27.6 .

$\checkmark \mathrm{jalp}$ in

jálpi : -is. I9. 56.4 .

javá: -ás. 6. 92.2. 19. 60.2. [2. I5. javám. 4. 27. $3 ; 36.5$. 6. 92. 1. I0. 
javăni. 19. 7.1 .

javas in mánojavas.

já viṣ țh a: -as. 20. I35. 8 (mss. yáv-). jaṣá: -ṣâs. II. 2.25 (s. mss. jakhăs). $\checkmark \mathrm{j}$ a s : cf. jasra.

+ ni: ní jajāsa. 5. 13. 2.

jasra in ájasra.

$\checkmark \mathbf{j} \mathbf{a}$, see 1 jan.

já: 5. I1. $10^{2}$. (cf. jāspatyá.)

jā in abhrajă, indrajâ, upajă, devajă, nakşatrajă, parijấ, prajâ, prathamajâ, manuşyajâ, vātajâ, vijā, sahajâ, somajâ, hiraṇyajâ.

ja or $\mathbf{j}$ a in agnijá, apsujá, oşadhijá, khalajá, çakadhūmajá, sākamijá. $\sqrt{ } \mathbf{j}$ àgr, see $\sqrt{ } 3 \mathrm{gr}$.

jāg ṛtsí: -siás. 19. 34.2 (mss.).

jâtgrvi: -is. 5. 30. 10. 8. I. I3.

jāgrat in

jāgrad duşvapnyá (p. -atodusva-): -ám. 16. 6.9.

jāt a in ájāta, áharjāta, rtájāta, gójāta, devájāta, naktaminātá, purujjātá, ŗtáprajāta, mádhujāta, mánujāta, vaçājātá, sajātá, sújāta, jātávedas.

jātá v vedas: -dās. 3. I. I; 2. I. 4. I5. 10;32. $2^{*} ; 34.2 .5 .11 .2,3.6$. I23. I. 7. 82. 4,$5 ; 84$. I. 8. I. II. 9. 4. 3. I2. $2.8^{*}$. I3. I. I2. I4. I. 49. I8. $4.64,65$. I9. $3.1 ; 4.1$; 6.2 ; 64 . I.

jătavedas. I. 7.2. 3. 10.6. 5. 8.2. 6. $77 \cdot 3$.

jātavedas. I. $7.5,6 ; 8.4 ; 9.3 .2$. 29. 2. 3. I5. 8 ; 22.4. 4. 23. $2 ; 39$. IO ${ }^{2} ; 40 . \mathrm{I}-8$. 5. I2. I"; 27. I2; 29. I-3, IO, I2-4. 6. I40. I. 7. $34.1 ; 35$. I; 74. 4 ; IO6. I; 108. $2^{2}$; II 5.3. 8 . 3. $2^{*}, 4^{*}, 5^{*}, 7^{*}$, II I $^{*}, 25^{2} ; 4$. I4*. II. I. 3,4 ; IO. 4 . I3. I. I5. I8. 2. $4^{*}, 5^{*}$, $8^{*}, 9,35^{*} ; 3.42^{*}, 7$ I ; 4. II. I9. 64 . $2 ; 65.1$; 66. I.

jātávedasam. 4. 23. 4. I2. 2. 7*. I 3 2. $16^{*}$.

jātávedase. I9. 64. I.

jātávedasas. 8.2. I3. I9. $45 \cdot 3$. jātávedasi. 2. 12.8. 10. 3. I9; 6. 35 . I I. I. 29.

jātávedasas (pl.). I8. 4. 12, 13.

jātavedasas. I8. 4. I (mss. jătáv-). jātrt: -is. 20. 48.2 (ed. jánis).

jầna: -am. 7.76.5.

jān a n t in ánājānant, ávijānant.

jāni in ajăni, vijāni.

jầnu: I8. I. $52^{*}$.

jầnuobhyām. 9. 8.2 I (1. -bhiām). Io. jầnunos. 10. 2.2.

(cf. jñu.)

jā $\mathbf{m}$ a $n$ in vijăman.

jāmí: -ís. $5 \cdot 30.5$.

jāmím. 6. I20.2. 7. 99. I. I4. 2. $33^{\dagger}$. jāmí. I8. I. 4".

jāmiāí. 5. I.4. 20. 128. 2.

jāmiàs. 2. 7.2.

jāmáyas. I. 4. I"; I4. 4; I7.I. I4. 2. $6 \mathrm{I}$. I8. I. $\mathrm{II}^{*} ; 4.66$.

(cf. ájāmi, devajāmí, jāmikṛ́t, jāmiçañsá.)

jāmi okṛ́t: 4. I9. I.

jā mi o ç a ñ sá: -săt. 2. IO. I-8.

jāmiçaǹsásya. 9. 4. I5.

jāyă: 3. 30.2. 5. 17. 6*, I2. 6. 22.3. I0. I. 3. II. 8. I7. I2. $3.39,47$. I4. I. $25^{*}, 30 ; 2.3^{\dagger}$. I 8 . I. $8^{*}, 53^{*} ; 2.5$ I. 20. 127.9 .

jāye. I2. 3.39.

jāyăm. 5.17. $5^{*}$. 6.60. I; 78. I, 3 ; 82. 2, 3; II 8. 3. 9.5.30. II. 8. I. I4. I. $56 ; 2 . I^{*}, 39$.

jāyáyā. 12. 3.17. 20. 127.8.

jāyấs. 3. 4.3. 4. 37. I2. I4. 2. 35 .

(cf. brahmajāyá.)

jāyầny a: -as. 7.76 .4 . 9.44 .2

(1. -nias).

jāyānya. 7.76. $5^{2}$.

jāyânyam. 7.76.3.

jārá: -ás. I8. 1. 23 ".

jầla: -am. 8. 8. 5-8.

jâlena. ro. I. 30 .

(cf. akșujālá, áyojāla, indrajālá, bṛhajjālá, jāladaṇụá.)

jāla oda ṇ ̣á: -ám. 8. 8. 12.

jāladaṇụâs. 8. 8.5.

jālāṣá: -ám. 6. 57.2. 
jālāṣénạa. 6. 57. 2.

jālmá: -ás. 4. I6. 7.

jālmâs. I2. $4.5 \mathrm{I}$.

jāṣ k a m a dá: -łấs. II. 9.9.

jā s pat y á (p. -āḥop-) : -ám. 7. 73. 10*. $\sqrt{ }$ ji: jayati. $7 \cdot 50.6^{\dagger}$. 9. $1.23 ; 6.62$. jáyanti. 4. 22. 5 .

jayāti. 2. 27. I. 6. 98. I.

jayema. 5. 3. $1^{*}$. 7. $50.4^{*}, 7^{*}$. 9. 5 . I8. I2. I. 47. I3. I. 22. I 8. 2. $59^{*}$.

jáya. 3. I9. $8^{\dagger}$. 8. 8. 24. II. IO. I 8. jaya. 6. 92. 2. 8. 8.24.

jayatu. 6. $125 . I^{*}$.

jáyatām. II. 9. I8.

jáyatā (p. -ta). 3. I9. $7^{*}$.

jayata. II. IO. 9, I4. I9. I3. $3^{*}$.

jáyantu. 6.65.3.

jayantu. 5. 2 I. 12. 6. I26.3. 8. 8 .

24. I9. I3. II*.

[I8.

jáyan. 2. 29.3 (? mss. -am). II. 9. jáyantam. 5. 2. $4^{*}$. 6. 97.3* . 7. I1 8 . $\mathrm{I}^{*}$.

jáyatām. 3.19.6. I9. 13.10*.

jáyantĩ. 5.5.3.

jáyantīs. II. 9. I9.

jáyantīnām. 19. 13.9*.

ajayat. 7.62. I. 8. $5.3^{2}$, I4. I0. 6. 9, I0, I3. I9. I3. 2*.

ájayan. 7. I10. 2.

ajayan. I0. 6. I6.

jigâya. $4 \cdot 23 \cdot 5$.

jigāya. 3. 10. 4 .

jigyathus. $7 \cdot 44 \cdot \mathrm{I}^{*}$.

jigyus. 5. 29. $\mathrm{I}^{*}$.

jigivăan. 4. 22.6, 7. 8. 5.22.

ájāișam. 2. 14.6. 7.50. 5². 8. 5.8.

ájāişma. I6. 6. I*.

jāișus. 4. 38.3.

jeșyán. 5. 20.x.

jitám. 6. 98.3. I0. 5.36 . I I. 9. 4 . I6. $8 . \mathrm{I}-27$; 9. I. I9. I3. I.

jită. I. 24. I.

jité. I I. IO. 7 .

jitâs. 4. 24.2. II. IO. I5.

jigissati. II. 5 . 18 .

(cf. jáya, jayá, ji, jit, jita, jíti, jișnuú, jétṛ, jétva, jeșa.)

+ a ti : áty ajāișît. I4. 2. 74.
+ a pa: ápā 'jāit. 12. 3. 54 .

+ abhi: abhí ...jayema. I2. 3. I5.

abhí...jaya. 9. 5.6, I2.

abhí... jayantu. 6. 126.3.

abhíojitās. I2. 3.6.

abhiojítya. I2. 3.36. I9. 54.6.

(cf. abhijít.)

+ u d: út... jigãya. 7.80. I. (cf. ujjeșa.)

[44. I*.

+ parā: párā jayethe (p. -e íti). 7 . parāojáyante. 4. 22. 5 .

párā jayātāi. 6. 98. I.

párā ... jayantām. 8. 3.16*; 8. 24. párā jigye. 7. 44. I*.

párāojitā. 3. I. 6.

párāojitās. 5. 2I.9. 8. 8. I9.

párãojitāsas. $4 \cdot 3$ I. $7^{*}$.

(cf. parājaya, áparājita.)

+ pra: prá ... jaya. 6. I26. 3 .

+ vi: ví jaya. 8. 8.24.

(cf. vijayá, vijeșa.)

+ s a m: sám jaya. 8. 8.24.

samojáyan. 5. 20. 4 .

samojáyantīm. 4. 38. I.

sám ajayan. II. IO. 12.

samojítya. Ir. 9. 26.

(cf. samjjayá.)

$\sqrt{ } 2 \mathrm{ji}$, see $/$ jyā.

ji in prtanājí, bhūrji (?).

jigatnú: -úm. 5. 2.6†.

jighatsú: -sú obhyas. 8. 2. 20.

jighatsúam. 2. I4. I.

jighra in anujighrá.

jit in abhijit, abhimātijít, açvajít, ugrajít, gojít, grāmajít, dhanajít, pṛtanājít, prātarjít, rathajít, lokajít, vasujít, viçvajít, samisrșțajít, samigrāmajít, satyajít, samidhanājít, sahojít, svarjít, hiranyajít.

jit a in áparājita, ātmaparājitá.

jíti: -im. I0. 6. I6.

$\sqrt{ }$ ji inv: jínvasi. II. 4. I4, I6.

jínvati. 8. 9. I3. I2. I. 3 .

jínvatha. I. $5 \cdot 3^{*}$.

jínvanti. 9. 4. 18.

jinva. 7. 31. I*.

jinvatāt. ro. 6.34. 
jinvatu. 3. 5. I.

jinvatam. 8. $4 \cdot 6^{*}$.

jínvat. 12. 1. 46 .

jinvitás. 19. 31.7 (mss. jinvátas). (cf. jinvita.)

jinvita in parjányajinvita.

jívri: -is. 8. I.6. I4. I. $2 \mathrm{I}^{\dagger}$.

ji iṣnú: -ús. II. 9. I8. I9. I0. 5 *

jişnúu. 3. rg. I (mss. -ús), 5.

jişṇúnā. 19. 13. $3^{*}$.

jiṣṇáve. 10. 5. I-6.

jihmá: -ás. 12. 4.53 .

jihva: 4. 13. $7^{*}$. 5. 18.8; 30.16. 7 . 29. I, 2. 8. I. I6. 9. 7.3. I0.9.3. II. 3. 36 . 20. 127.4 .

jihvấm. 5. 29.4. 6. 56. 3. ro. 2. 7 ; 7. I9. I1. 8. I5. I9. 32. 4 .

jihváyā. I. 10. 3. 5. 27.9. 6. 56.3. 8. $2.3 ; 3.2 *$ I1. $2.17 ; 3.36^{2}$.

jihvăyāi. II. 2. 6.

jihvầyās. I. 34.2 . 2. $33 . I^{*}$.

jihvâs. 10. I0. 28.

jihvâbhis. 6. ;6. I.

(cf. agnijihvá, dvíjihva, mádhujihva, sujihva, jihvāmūlá, jihvikā.)

jihvāomūlá: -lé. I. 34. 2.

jihvikã in upajíhvikā.

jika in upajikra.

jIta in ájita.

jîmứt a: -tās. II. 5. I4.

jira in

jīrá。dānu: -us. 7. I8.2. I8. 3.61. $\checkmark$ jiv: jivati. 5.5 .2$.

jivati. 8. 5. 25 .

jĩvanti. 9. IO. I9. II. 5. I2. I2. I. 22 ; 2.50 .

jīvāni. 5. I8. 2.

jîvāti. I4. 2. 2*, 63 .

jîvāti. I. IO. 2. 2. 29. 2.

jîvās. 2. 28. 4 .

jīvāt. 18. I. $6^{*}$.

jîvema. 19. 67.2.

jivema. 3. 12.6. I8. 4.70 .

jiva. 2. I3. 3. I9. 24.5, $6 ; 70 . I^{2}$.

jīva. 2. 29.7. 3. II. $4^{*}$; 3I.8. 7.53. 2. 19. $27.8^{3}$.

jivatu. 5. 29. 13 . jivatu. 8. 2. 5 .

jîvatām. 9. 3.9.

jtvata. I9. 70. I (ms . jîvās).

jivan. 5. 8.4. 18. 2. 20. 19. 24.6.

jîvatā. 9.5.7.

jivatas. $5 \cdot 30.7$ (jîtvatạıjojiv-).

jîvantãu. 12. 3. 35 .

jîvantas. I2. $2.23^{\dagger}$. I 8. 2. 29.

jîvatām. 8. 2. 2.

jivantis. 3. 14.6 .

jivyăsam. 19. 69. I, 4; 70. I.

jivyāsam. I9. 69. I-4; 70. I.

jivis. $5 \cdot 13.4$.

jivit. I0. 5.25-35. I6. 7. 13 .

jîvişus. 9. 2. I0.

jivitám. 6. I34. I.

jívitavāí. 6. ıog. I (p. -ta vāí).

jiváyathā (p. -tha). 4. I3. I*.

(cf. jīvá, jîvana, jĩvantá, jĩvalá, jivás, jivătu, jivita.) [32.

+ upa: úpa jĩvati. 3. 29.4, 5. 1 8.4 . upaojívanti. I0. 6. 32 .

úpa jivanti. 8. Io. 22-9. 9. 1. 20. I0. 10. 34 .

úpa ... jîvān. I2. 3.34.

upaojivema. 8. 10. 9. [-vyăs-). úpa jîvyāsam. 19. 69.2 (m. mss. (cf. upajivá, upajívaníya.)

+ s a m: sám jiva. I4. I. 52.

sám jivyaãsam. I9. 69. 3 (mss. sam。 jīvyấ-).

(cf. samjjīvá.)

jĩ á: -ás. 6. 46́. I. 9. 10. 8*. 14. 2. 44. jîvám. 4. 9. I. 6. IOg. $2^{*}$. 9. IO. $8^{*}$. I2. 3. 4. I4. I. $46^{*}$. I 8.4 .5 I.

jīvấm. I8. 3.3.

jīvāú. I4. 2. 43.

jīvăs. 3. 14. 6. 6. II7.2. I2. 2. $22^{*}$. I 8. $2.27 ; 3.67^{*} ; 4.57,87$. 19. 69. I. jîvăsas. I2. 2. 30 .

jīvắn. I 8. 4. 50 .

jîvébhyas. 6. I I 7.2. 8. I. 7, I 5. I 2. 2. $23^{*}$. I8. 4.53 .

jīvấnām. 2. 9. I, 2. I2. 2. 45 .

jivéṣu. I. $35 \cdot 2$. I 8. $2 \cdot 3^{\dagger}, 52$.

(cf. jîvádhanya, jivapură-jivabhójana, jīvaloká, atijīvá, upajīvá, samijīvá.) 
jĩváodhan y a: -yās. 12. 3.25. jîvadhanyās. 12. 3. 4 .

jîvana: -am. 9. 2. $5,16$. jívanāya. 3. II. I* 4. 9. I. 8. 2.25. I2. $2.24^{\dagger}$.

(cf. ájīvana, purușajîvana.)

ji van tá: -ás. I 9. 39. 3 (ed. jivalás). jivantím. 8. $2.6 ; 7.6$.

jivá oputra: -rāu. I2. 3.35.

jiva。purấ: -ăs. 2. 9.3. 5. 30.6.

jIvá。barhis: II. 7.7.

jivaobhójana: -am. 4. 9.3.

jíva lá: -ás. 19.39. 3 (mss. jîvantás). jīvalâ. I9. 39. 3 .

jivalăm. 6. 59.3 . 8. $2.6 ; 7.6$. jivalâs. Io. 6. 3. I2. 3.25. I9. 69. 4 . jIva०loká: -ám. I8. 2.60;3.2*, 4 . jĩvás: -áse. 6. 19.2; 4I. 3 ; 57.2. Ix. $4.9,26$. I8.2. $3^{*}, 23 ; 3.63 ; 4.54$.

jivâtu: -um. 7. I7.2. 8. I.6.

jîvátave. 6. 5.2. 8.2.9.

jĩvita in dāúrjîvitya and

jivita。yópana: -as. I2. 2. 16. jīvitaý́panān. 2. $25.4,5$.

jurya in ajuryá.

$\checkmark$ juṣ: joșase. I9. 49.6.

jușáse. I8. 3.9.

juşeta. $7 \cdot 47 \cdot 2$.

jușásva. 2.5. I. 7.20. $2 ; 46.1^{*}$; 68. I. juşasva. 2. 5.4. 4. 39. IO. 5. 29. I4. I8. 3. 4. I9. $64.3^{*}$.

juşátām. 6. 27.2*.

jușéthām. $\quad 5 \cdot 6.8$.

jușethām. 3. 15.4 ; $17.7^{*}$.

jușádhvam. I8. I. $5 \mathrm{I}^{*}$.

juşadhvam. II. IO. I4. I9. 27. II-3. juṣantām. I. I5. I. 3. 8.2 ; I5.2. 5 . 27. I2. 7. $17.4 ; 28$. I. I $8.2 .35^{\dagger} ; 4$. 13, 40. I9. II. $4^{+}$.

jușámāṇas. I9. 2. 1 .

juşānás. 4. 38.5. 6. 83.4; 1 25. 3* 7 . 72. $3^{*}$; 104. I ; 109. 5 . I0. 6. 35 .

jușānāáú. 7. 29. 2.

jușāṇăs. 7.73. $3 ; 97.4 ;$ I09. 2. 9. 2. 8. ájuşe. 6.6I. 3 .

jujós̨a. 2. 26. I.

jujușțana. 7.77. I*.

jujușānás. I8. 2.21. jușță. 2. 36. I, 4 . juṣțấm. $\quad 5 \cdot 7 \cdot 4$.

(cf. júșța, júșți, jus, joșa, joșas.)

jú șt a: -as. 7.73. $9^{*}$.

júșțam. 4. 30. $3^{*}$.

(cf. [or to juștá] ájușța, bráhmajușta, sómajușța.)

jú șți: -im. 4. 24. 5 .

jus in sajús.

juh tu: - ús. I8. 4.5 .

júhu. I8. 4. 6.

juhúam. 5.17.5*.

[jūtí.

$\checkmark \mathrm{j} \overline{\mathbf{u}}$ in javá, javas, jávișţha, jūta,

jũta in índrajūta, devájūta, bráhmajūta, vătajūta.

jūtí: -ís. I9. 58 . I.

jūtíobhis. I3. 2.15.

(ci. ráthajūti, jūtimánt.)

jūtiománt: -mân. r2. r. 58.

jū r ṇī: jứrṇi. 2. 24. 5 .

$\sqrt{ } \mathbf{j} \overline{\mathbf{r}} \mathbf{v}:$ + ni: niojúrvati. 6. $34 \cdot 2^{*}$. niojúrvathas. 8. 4. $4^{*}$.

niojúrvan. 6. $52 . \mathrm{I}^{\dagger}$.

$\checkmark$ I j rq: járat. I0. 8.6.

járatím. I2. 2. 54 .

járatīs. I4. 2.29 (mss. jar-).

jajâra. ro. 8.26.

jiryati. ro. 8. 32 .

jirnás. ro. 8.27 .

[mán.)

(cf. jára, jarant, jarás, jarấ, jari$\sqrt{ } 2$ j r : járan. 20. I27. I I (not mss.).

jé tṛ̣: -tā. 5. 20. I2. 6. 2.3.

(cf. jāítra.)

jét v a: -tuāni. 6. 125. $I^{*}$.

jeșa in ujjeșa, vijeșa.

$\checkmark$ j e h: jéhamānās. I8. 3.47*

jāítra: -am. I9. I3. $5^{*}$.

jāítrāya. 20. 128. 15 .

joșa, joṣ a s in sajóșa, sajóşas.

jñ a a $n$ a in samjuñápana.

$\checkmark$ j ñ à: jānăti. I 5. I2. 9.

jānīmás. 8. 7.18.

jānăt. 3. 2. 6 .

jānīhí. Io. I. 25 .

jānìtăt. 9. 5. I9.

jānitá. 6. 123.2.

jānīta. 6. 123. I.

jānantu. 7. 60.2, 3 . 
jānIdhvam. II. I. 5 .

jānán. 3. 20. $I^{*}$.

jānānăs. $12 \cdot 3 \cdot 40$.

ajānāt. I I. 8. 17.

jñătăt. I9. I5.6.

jijñāse. I4. I. 56 .

(cf. jānant, jñapana, jñā, jñāta, jñātí, jñātŕ, jñāna, jñāya, năman.)

+ a nu: ánu jānantu. 6. I12.1. Io. ánu ... ajānan. I4. 1. $15^{*}$.

+ ā: cf. ánājānant.

+ u pa: úpa jānate. 4. 36.8.

+ pra: prá ...jānāti. 8. 10. 19, 20. I5. 12. 5 .

praojānán. 2. 26. 2 . 3. 12. 4 ; 20.8. 4. 23. 2. 5. 26.2. 6. I12. I, 2. 7. 9. $I^{*}, 2^{*}$. 8. 9. 22 . 9. $5.1,3$. I2. 2. $8^{*}$. 14. . 59 .

praojānántas. 2. 34.5. 13. 3.17.

praojānatí. I8. 3.4.

praojānatí (p. -í ítỉ etc.). 8. 9. I2.

praojānatís. I2. $2.4 \mathrm{I}$.

pră 'jānan. 9.5. 16.

prá jñeșam. 9. 5. I6.

(cf. prajñá, prajñăna.)

+ prati: práti jānātu. I9. 4. 4. práti ... jānantu. I8. $4.51,52$.

+ vi: ví jānāmi. 9. 10. $15^{*}$. 10. 7.43. viojānăt. 9. 9. $15^{*}$.

ví jānīhi. I0. S. 5 .

viojānán. 4. II. 3 .

viojānată. 12. 5.17. [vijñāya.)

(cf. ávijānant, ávijñāta, vijñắna, + s a m: sám jānāmahāi. 7. 52.2. sám jānīdhvam. 6. 64. $1^{\dagger}$. sám ... jānatām. 6. 64. ${ }^{*}$. sam̉ojānānăs. 6. 64. I*. 7. 19. I. sám ... ájũāsthās. 3. 4.6.

sám jñāyate. 20. I 29. I 2 (not mss.). sám jñapayāmi. 6. 7ł. 2.

(cf. samijñápana, ásamijñā, samjñắna.)

[jñā. j ñ $\overline{\mathbf{a}}$ in ṛtajñá, padajñă, prajñă, ásamjñ àt a in ájñāta, avijñāta.

jñ ātí: -táyas. 4. 5. 6*. I4. I. 26*. jũātín. I2. 5.44 .

(cf. jñātímukha.) jñ̃âtíomukha: -khās. I8. 2.29 (mss. -tim-; s. mss. -khắs).

j j̃ã tṛ́: ttăram. 6. 32. 3. 8.8.21. [na. jñ ã $\mathbf{n}$ a in prajñăna, vijũăna, samjiñă jñāy a in balavijñāyá.

j $\mathbf{n} \mathbf{u}$ in asitajñú. [jman.

jman in urujman, párijman, pṛthuj y a in brahmajyá.

V j y a , j I : jinăti. 6. $1343^{2} \cdot$ I 3. 3. I-25. jiniyat. I2. 4. 15 .

jinatás. 6. I34.3. I2. 5.5, II .

jinatăm. I2. $5 \cdot 56$.

jyeșyán (jeş-?). 5. 20. I.

jítám. I2. 5. 57 .

jîtâya. I2. 5. 57 .

jītásya. 5. 19.13.

jiyáte. I. 20. $4^{\dagger}$. 5. I9.6. I I. 3.56 . jiyate. II. 3. 55 .

jújyāsatas. I. $21 \cdot 4^{*}$.

(cf. jita, jya, jyāni, jyấyas, jyeya, jyéșțha.)

jyă: jiâ. 5. I 8.8 .

jyấm. 4.4.7. 5.13.6. 6. 42. I. jyáyā. I. I. 3 .

(cf. jyākā, jyãghoșá, jyāpāçá.) j y ā kã: jíâke. I. 2. 2.

jy ā॰gh oṣá: -șấs. 5. 21.9 (1. jiā-). jy āni in ájyāni, sarvajyāní.

j y ā॰pã çá: -çāís. I I. IO. 22. [6.3".

jyầya s: -yān. 9. 2. 19-24, 232. 19. (cf. jyăyasvant.)

jy á y a svant: -ntas. 3. 30. 5 .

$\checkmark$ jy ut: jyctáya. 7. 16. I.

jyotaya. 4. 37. 10 (? not p.).

(cf. jyók, jyotaya, jyótis.)

jye ya in brahmajyéya.

jy é ș ț h : -as. 20. I28. 2 (ed. -țhāya). jyéșță. I9. 7.3.

jyéșțham. I9. 22. 2 I ; 53.8 .

jiéștham. 5. 2. $\mathrm{I}^{*}$.

(cf. índrajyeșţha, kắmajyeșțha, bráhmajyeșțha, vãiçvanarájyeşțha, jyeșțhá-jyāișțhya.)

jy eș țhá: -ás. I0.8.28. I8. I. 19*. jyeșțhám. 5. 1.8. 6. I12. I. I0. 7. I 7,$24 ; 8.16$, I9, 20. I I. $5.5,23 ; 8$. 5, 6. I5. I. 3 .

jyeșțháya. 10. $7 \cdot 32-4,36 ; 8$. 1. 
jyeșthásya. I2. 2.35.

jyeșțhatás. II. 3.32. jyeștháotāti: -taye. 6. 39. I. jyeșṭha०vará: -ás. I I 8. I, 2. jyeșt tha ohán: -aghnyấm. 6. I IO. 2. jy āișt hy a in sujyãișțhyá.

jyók. I. 3 I. 4. 4. 2 I. $3^{*}$. 12. 2.49 . jiók. I. $6.3^{*}$; I4. I, 3. 6. 62.3. I 2. 2. I8. I8. 2.29. I9. $24.2,3$.

jyotaya in jyota ya māmaká: -kắn. 4. 37 . jyótiragrà (p. -ị̣ıag-): -rās. 14. 2.3I.

[IO. $4^{*}$.

jyótiranika (p. -iḥoan-) : -as. I9. jyótiṣi om a n t: -mān. I8. 4. I4. jyotiṣkṛ̂t (p. -iḥok-): 13. 2. 19*. jyótiṣ ma n t: -mān. 12.3.6, 16. I3. 2. 33,34 .

jyótișmantam. 9. 5.6.

jyótișmatas. 9.6.62.

jyótişmatī. I9. $40.4^{*}$.

jyótiṣmatīs. $4 \cdot 35 \cdot 5$. I0. $5 \cdot 38$.

jyótis: I. 9. 2 ; 35. 3. 2. II. 5. 4. I4. 3 ; I8. I. 5. 12. $7^{*}$; 13.3. 6. 92. $3^{*}$. 7. $22.1 ; 53.7^{*}$. 8. 1. 8,$21 ; 2.2 ; 5$. I 7 ; 6. I4. 9. 5. 7, I1, 26. I0. I. I6. II. I. 28 . I2. I. $15 ; 3.50$. I3. 2.9 , 36; 3. I I, I7. I6. 2.5. I8. I. $35^{*}$; 3. $64,67^{*}$. I9. $15 \cdot 4^{*}$.

jyótișā. 4. I9. 3. 8. 3. $2 I^{*}, 24^{*}$. Io. 2. 3I. II. 1. 37 . I3. I. II ; 2. 45. I6. 9.3. I7. 27,28 . I8. 3. $7^{*}$.

jyótișe. 6. 6I. I.

jyótișas. 4. I. 5 ; IO. I. 6. 36. I.

jyótiși. I. 9. I.

jyótīnși. 9. 5.8 . 10. 7.40 ; IO. I5. $_{5}$

(cf. dákṣiṇājyotis, híraṇyajyotis, jyótiragra-jyótiṣmant.)

$\checkmark \mathbf{j v a r}$ in jvara; and cf. $/$ jūrv.

jvara in añgajvará.

t a (pron. root): tám. I. I6. 4; I9. $4^{*}$; 2O. 2. 2. I. $3^{*} ; 2.1$ II. 3 ; I2. 3 ; I $3.5^{2} ; 20.1-24.8 ; 35.3$. 3. 3.6; 5 . 3,4 ; I1. $2^{*}, 8$; 16. $5^{*}$; 20. 1 $^{*}$; 21.9 ; $23.3 ; 24.2 ; 27.1-6 ; 28.5,6$. 4. 3 . 5 ; 16.6; 18.2; I9. 5 ; 20. 9 ; 22. 2 ;
30. $3^{*}$ (támotam), $3^{3^{*}} ; 31.5^{*} ; 32.5^{*}$; 36. 2 , 10; 37. II. 5. 4. $6^{3} ; 6.1 \mathrm{I}-4^{2}$; $7.5 ; 8.5 ; 12.9^{*} ; 13.3 ; 14.2,9^{2}$, I $2^{2} ;$ 19. 9, I3, I4; 23. 3 ; 29.4, 10; 30. $12 ; 31.12$. 6. 1. $2 ; 5.3 ; 6.1$; I8. $1 ; 26.2,3^{2} ; 37.3 ; 46.2 ; 54.3$; 75.2; 77.2*; 81. 2, $3 ; 85.1$; I23. I ; I27. 3 ; 132. I-5; 133. $3 ; 134.3^{2} ; 136$. 3. 7. $2 . \mathrm{I} ; 5.5$; IO. I* $; 2 \mathrm{I} . \mathrm{I} ; 3 \mathrm{I}$. $I^{*} ; 40.1 ; 50.6^{*} ; 73.3 ; 74.3,4 ; 77$. $2^{*} ; 88$. I ; S9. I. 8. 1. 10; 3. $5^{*}, 7^{*}$, $8^{*}$, II* I I ; 4. I6*; 5. II, II (mss. ántitam), $\mathrm{I}_{5} ; 6.9,18$; 10.27. 9. I. $5,6^{2}$, I $4 ; 4.3,7,18 ; 5.16$. 10. I. 7 , 8, 28; 2.30; 3.10; 5. $\mathrm{I}_{5}-2 \mathrm{O}^{5}, 2 \mathrm{I}^{3}$, $25-35^{2}, 42^{2}, 43^{2} ; 6.6-10,13-17,18^{3}$, I9, 2 I, 29, 34; 7.4-7, IO-16, I8-20, 22, 23, 39; 8.44 ; IO. I2. II. 2. I3; 3. $22,32-49 ; 4.2 I ; 5 \cdot 3^{2}$. I2. I. I4, 30,$47 ; 2.3^{2}, 4,7^{*}, 9,33^{2}, 43,54 ; 3$. $35,55-60 ; 4$. 50. I3. I. I 7-9, 40,60*; 2. 4,$15 ; 4.6$, I2, 20. I4. I. $3^{8}, 47$. I5. $2 . \mathrm{I}-4 ; 3 . \mathrm{I} ; 6 . \mathrm{I}-9 ; 7.2,4 ; 9$. 2. I6. I. $4^{2}, 5,7 ; 5.1-6 ; 7.5$, 12, 13. 18. 1. $34^{*} ; 2.8^{3 *}, 27 ; 3.4,6^{*}$ $63 ; 4.13,54$. I9. 6. II*; 32 . I 33 $4 ; 34.6 ; 38.1 ; 46.1$ (mss.tád); 53 I, $3^{2} ; 57.3$ (mss. tád), $4 ; 58.4^{*}$. 20. I 29.6 (mss. tam).

tád. I. $16.2 ; 18.3 ; 24.1 ; 32 . \mathrm{I}, 2$, 3, 4 ; 35. I, 3. 2. I. I, 2 ; 3. I, 3-5 ${ }^{2}$; $7.2 ; 25.5 ; 28.2 ; 30.4^{2} ; 3$ I. 5 . 3 . $2.4 ; 4.5 ; 9.2,3 ; 13.2 ; 15.5 ; 22$. I, $5 ; 23 . \mathrm{I}^{2} ; 30.4$. 4. I. $6 ; 7.7 ; 8$. $3^{*}$; IO. $7^{2}$; II. II ; I2. 2 ; I6. 2, 5 ; $17.6,7 ; 18.8 ; 19.6^{2} ; 20.1 ; 37.3$, 4. 5. I. 5,7 ; 2. ${ }^{*}, 6^{*} ; 4$ Iо $6.4^{\dagger}$; 8.2, 6; I1. 6 , 10 $;$ 13.2, 9; 17.9; I8. I4 ; I9. 5, 6, 8 , I2; 22 . II ; 25. 6 ; 27. I0; 28.6; 29.2, 3, 5-9; 30.13. 6. II. $\mathrm{I}^{2}, 2^{3} ; 23 . \mathrm{I} ; 24 . \mathrm{I}, 2$; 29. 2 ; 54. I; 63. I; 69. I, 3; 7I. I, 2 ; 98. 3 ; II6. I; II7.I, 2 ; II8. I; II9. 3 ; 122. 5 ; I24. $2,3^{2}$; I4I. 2 ; 142. 2 . 7. 5. 3 ; 12. 4 ; 24. I；26. $2^{*}, 7^{*} ; 29 . \mathrm{I}$; 44. I* 53. $3^{2} ; 56.1 ; 57.1 ; 65.2,3$; 66. I；70. I, $2 ; 72.3^{*} ; 73.7^{*} ; 76.4$; 77. $1^{*} ; 79.4 ; 80.3^{*} ; 90.2^{*}, 3^{2}$; ror. 
I2. 8. 2. 3, I2, I $3^{2}, \mathrm{I} 6 ; 3.2 \mathrm{I}^{\prime \prime} ; 4.3^{\prime \prime}$, I2* $^{*} 5.5^{3}, 19 ; 6.20,26$; 10. $9,25,29$, $30,32^{2}$. 9: I. $2^{2}, 18,24 ; 2.2 ; 3.2,15$; 4. 4, 20; 5. I3, I9; 6. 7,8, II I I 3,38 , $39,49,50,53,54$; 9. $13^{*}, 21^{*}$; 10. 1", 18 ${ }^{2 *}, 23^{*}$. I0. I. 19; $2.2,3,5,7,27^{2}$, $32 ; 4.25 ; 5.40^{2}, 50 ; 7.8,25,26,28$, $3 \mathbf{1}$; $8.4,7,9, \mathrm{II}^{2}, \mathbf{1 6}{ }^{2}, 24,29^{2}, 33$, 34,4 I, 43;9. 26, 27; 10. 11, 17. II. $3.25 ; 4.5 ; 5.10,15 ; 6.23^{2} ; 7.5,7$, I2, I4, I9; 8.6, I4, I5, I6, I7, 29; 9. I. I2. I. $35,46,58^{2}, 61 ; 2.5,36 ; 3$. I, 3, I2, I9, 22, $39^{2}$; 4. I, IO, I I, 31, $40 ; 5.50,50$ (tă 3 t). I3. I. 44,52 ; 2. $3^{2}$, I4. I4. I. I5*, I6*, 30,$56 ; 2$. I2, 22, 5I, 66, 69. I 5. I. $2,3^{7}, 6$; IO. I ; II. I ; I2. I ; I3. I-5, 9; I 7.2, 9, I0. I6. I. $8 ; 6.2^{*}, 3^{2}$, II; 9. $2^{2}$. I 8. I. $4^{*}, 32^{*} ; 2.26,33^{*}, 52 ; 3.3,24^{*}$, $55^{*} ; 4.31,37,49^{2}, 51,64$. 19. 3.4 ; 6. $6^{*} ;$ 9. $14^{2} ;$ II. $6^{2 *} ;$ I $3.3^{2^{* *}} ;$ I $5 . I^{*}$ (m. mss. tvám); 20.3; 26.2, $4^{2} ; 24$. $8^{3}$; 40. I ; 4I. I ; 44. I ; 52. I * 4, 5 ; $53.9 ; 57.5 ; 59.2^{*}, 3^{*} ; 64.3^{*}, 3.20$. I $28 . \mathrm{I}, 2,3,4 ; \mathrm{I} 32.4 ; \mathrm{I} 33 . \mathrm{I}-6 ; \mathrm{I} 35$. Io; I36. II.

tằm. I. II. 2 ; I4. 3. 2. 25. I. 3. 2. 6 ; I2. I ; $17.4^{*} ; 25.2 .4 .4 .1$; 6.2 ; 20. 4 ; 30. $2^{*} ; 38.1,2$, 4. 5. I4. 6,$7 ;$ I8. 7 ; 22.6, 7; 31. I-9, 10. 6 . $33.3 ; 78.1$; 90. 1 ; 108. 3 ; 109. I; I13. I, 3; I36. I; I37.I. 7. I5. I ; 38. 3 ; II5. 2. 8. 9. 7 ; IO. 9, Io, I8$21,22^{4}, 23^{4}, 24^{3}, 25^{3}, 26^{4}, 27^{3}, 28^{4}, 29^{3}$. 9. I. I, 20. IO. $2.29 ; 8$. IO; IO. 23 . I2. $3.21,54 ; 4.14,24,42^{2} ; 5.5$. I3. I. $23^{2}$. I4. I. $56 ; 2.13,38^{*}, 48,65$, 74. I5. 3. 9. I8. 4.32 . I9. 4.1 ; I7. I-IO; I9. I-II ${ }^{3} ; 40.4^{*} ; 48.6 .20$. I $35.6^{2}, 7^{2}$.

téna. I. $9.3 ; 22.1 ; 29 . I^{*}$ 2. 7.3 , 5; I9. I-23.5. 3.5.8; 6.4 ; IO. I2; I7. $7^{*}$; 22.3. 4. II. 6 ; I4. ${ }^{2}, 6$; I 7 . 8 ; $18.3 ; 20.8 ; 35.1-6 ; 36.5 .5$. 6.11-4; 17. $5^{*} ; 28.12$, 13. 6. 57.2 ; $68.3 ; 74.2 ; 78.1 ; 82.2 ; 92.2$; 100. 2 ; IOI. I, 2 ; 129. 2,3 . 7. 70. 4,5 ; 8I.6. 8. $7.5 ; 8.5,6,7,8$. 9. 2.16 ,
$17 ; 3.15^{2} ; 4.13,24 ; 5.17,18,24$; 6. 9,$19 ;$ 10. 19. 10. 1. 9,$15 ; 3.1$; 5. $15-20 ; 6.6-17,9,12,13,20,21$. I I. $1.37 ; 2.7 ; 3.32^{2}: 35^{2}, 39-43^{9} ; 5$. I2; IO. 13. I2. I. $23-5,46,47 ; 2$. I, $2,47^{2} ; 3.15,22$. I3. 1. $7^{4} ; 2.15$. I4. I. $35,36,48,53,55 ; 2.53-8$. I 5 . I. 3 ; I1. 3-6, 8, 10; 13. I-5. I6. I. 5 ; 7. 1, 12. I 8. 1. $9^{*}, 53^{\dagger} ; 3.56^{*}$. I9. 6. $11^{\prime \prime} ; 9.4 ; 22.21 ; 24.1 ; 27.10$; 30. I; 32. 7, 10; 39.9; 53. $9^{2} ; 72$. I. ténā (p. -na). I. 3. I-5. 3. 7.3; I4 I; I6. $5^{\dagger}$. 4. 5. I" ; 7.I. 6. 7.I-3; I2. I, $2 ; 24.3 ; 80.1,3 ; 82.3 ; 91$ I. 7. $20.4 ; 38.2 ; 79$. I. I8. 2.30 .

téno (p. -o íti). 9. I.20. 18.3. I9. táyā. 2. $25.2 ; 27.5 ; 29.7$; 31. 1; 36. 5. 3. 24.6 ; 25. I, 3. 4. I7. 4; 20. 4. 5. 18. 15; 30. 16 (mss. tváyã) 6. 2.2 ; I08. 4 ; I39. I. 8. 3. I2* 9 2. 5. I I. $3.36^{2}, 49^{2} ; 9.20 ;$ I0. 9,27 I3. x. 22 ${ }^{2}$ I7. I3. I 9. 3. 3; 4. I (not mss.) ; $9.3 ; 55.2$.

tásmāi. I. $5 \cdot 3^{*}$. 2. $12.6^{*}$. 3. 23 . 5. 4. I. 2. 5. 7.2; II. II; I4. $6 ; 25$. 2 ; 28. II. 6. $5.3 ; 20.3 ; 27 . I^{*} ; 28$. 3 ; $55.1 ; 63.2 ; 84.3 ; 87.3^{*}$; I 28 . 4. 7.17.3; 87.1. 9. 2.19-24; 3.12, I5; 6. 45-7. I0. $2.29 ; 6.5 ; 7.32-4$, 36 ; 8. I, I5. II. $2.23,27$ (mss. -syāi); 4. I8, I9, 23. I2. 4. I7, 23. I3. I. 5. I5. 3. $3 ; 4$ I-6; 5. I-7. I6 6. 4. I8. 4. I $4,37,83^{2}, 84^{2}$. I9. I 7 I-5, 7-IO; 56.3. 20. I28. I4 (mss. -smāt).

tásyãi. I. 13.4. 5.7.9, 10. 7. 46. 2*. II. 2. I2, 27 (mss.). I2. I. 26. I8. 3.1 .

tásmāt. 3. I3. I, 2, 3, 4; 29. I. 4 . $9.6 ; 36.7,8$. 6. 5 I. $3^{*}$; I I 4 . I ; I I 5 . I, 2 ; I2O. I ; I 2I. 2 . 7. 5. 4; 54. 2 ; 64. I, 2. 8. 2. IO, 23,27 ; IO. I 8 , I9, 20, 2 I. 9. I. $24 ; 6.37$; IO. IO". IO. $5.22 ; 6.3 ; 8.24$; IO. IO. II. 5.5 , $23 ; 8.32,34$. I2. $2.40 ; 4.9$, I0, 49 , $50 ; 5.17 . \quad$ I3. I. I $4,25,48^{3}, 55 ; 4$. 29-39. I4. 2. 59-62. I6. 7. II ; 8 . I-27. I9. 6. $12^{3^{*}}, 13^{3^{*}}, \quad 14^{*} ; 38.2$; 
44. 8,$9 ; 48.3 ; 53.4$. 20. 128. I4 (mss.). tásya. I. $5.2^{*} ; 24$. I. 2. 27.7 . 3 . 7.6; 22.6. 4. I. 5 ; 2.8; 8. I; 20. $3 ; 2$ I. $4^{*} ; 27.6 ; 28$. I. 5.5.4, $8 ; 6$. $3^{\dagger} ; 8.3 ; 18.5$. 6. $4.2 ; 6.3^{*} ; 24$. 3 ; $39.2 ; 79.3^{3}$; 122. 3 ; 127.2. 7 . 20. 3 ; 81.5 ; 92. $\mathrm{I}^{*}$. 8. $3 . \mathrm{IO}^{2 *}, 17^{*}$; 7.22. 9. 4. II ; 5.20 ; 9. I*, $\mathrm{II}^{*}, 2 \mathrm{I}^{*}$; IO. 24 IO. $5.45 ; 7.40$. II. 3.1 ; 4 . 9. I2. $3.7 ; 4.28 ; 5.47,48,49,50$. I3. I. 56,$57 ; 3 . \mathrm{I}-25 ; 4.8$, I0, 27,28 , 40. I4. I. $3^{*} ; 2.33^{*}, 5$ O. I5. $2.1-4$; 3. I0; I5. I; I8. I. I6. 7. I2;8. I-27. I8. I. $16^{*} ; 3.43^{*}$. I9. $49.9 ;$ 53. . 20. 13I. 2.

tásyās. 3. II. I*. 4. 39.2, 4,6. 7. 20.6. 8. IO. I, I2, 22-9. 9. I. 5 ; IO. $2 I^{*}$. I0. 8.31 . I2. $4.33,44,46 ; 5$. 39. I3. I. $42^{*}$. I5. 3. 4 .

tásmin. 3. 15.6. 4.:8.6. 5.17. I3. 9. $2.3 ; 6.55-9$. I0. 2. $32^{2} ; 6$. $35 ; 7.38,40 ; 8.5,9,43$. II. 5. I, 8 , $24 ; 8.34$. I2. 2. 17 ; 3. $6,8,32,38$, 52. I3. I. 58 . I 8. $3 \cdot 53^{*}, 54^{2}$. I9. I7. $\mathrm{I}-5^{2}, 7-\mathrm{IO}^{2} ; 46.3 ; 53.9 ; 72 . \mathrm{I}$.

tásyām. 4. 18.3. 7.80. I. I0. 2. 3I ; 10. 5. I2. 3.9. I4.2. I4. I5. I3. 9. tāú. 3. 24.7. 4. 25. I-7; 28. I-7; 29. I-7. 5. 24. 5 ; 30. 10. 6. I40. I. 7. 53.3. 8. 9. $\mathrm{I}^{2}$. 9. $\mathrm{x} .7^{2} ; 3.9 ; 5$. 27 ; 6. I2. I0. $4.8 ; 9.25$. II. 5. IO. I2. 2. 32. I4. 2.7 I. I8. $2.13^{*}$. I9. I3. I ; 44. IO. 20. I33. I.

tâ. 9. 1o. 16 *.

té (p. té íti). 4. 26. I-7. 5. 24. 3. 6. I 38. 4. I0. 8. I 2, 20. I I. 5. 8, 9. I 5. Io. 3 .

tâbhyām. 4. 9. 10; 13. $7^{*}$. 8. 3.25. II. 2. I 4 ; $3.33^{2}, 34^{2}, 44-8^{2} ; \quad 9.4$ (1. -bhiām). I8. 2. I2* (l. -bhiām), 56. I9. 68. I.

táyos. 8. 4. 12*. 9. 9. $20^{*}$. I0. 7 . 43. II. 5.9 , II.

té. I. $7.5 ; 30.3 ; 31.2 ; 35.4$ (p.). 2. 12.1 ; 32.5 (mss. te). 3. 3.5 (mss.); 6. 7 ; 15. 2; 21. 10; 22. $2 ; 26$. I-62. 4. $6.7 ; 27 . \mathrm{I}-7 ; 30.4^{*} ; 35.7 ; 36$. 6 ; 40. I-8. 5. 3. 10*; 6. $3^{*}, 9 ;$ I 7 .
I*; 18.'10; I9. $3 ; 23.4$ (s. mss. te); 24. $6, \mathrm{I}_{5}-7 ; 28.3$. 6. 22. $\mathrm{I}^{*} ; 47.3$; 93. I ; II2. 3 (mss. te); II8. 3. 7. 5 . $\mathrm{I}^{*} ; 12.2 ; 28 . \mathrm{I} ; 53.4 ; 60.2,3 ; 70$. 2 ; 77.3; I09. 7. 8. I. $14^{2} ; 4.24^{*}$; $5.5,6$; 10. 24 . 9. 1. $9^{2} ; 2$. 10, 12; 4 . I6; 5.29 ; 6. IO, I4, I5, 5I ; IO. I*, $17^{2^{*}}, 18^{*}$. I0. $2.4 ; 3.9 ; 5.39^{2}, 4 \mathrm{I}^{2}$; 7. I $7^{2}, 25 ; 8.17,35 ; 9.7,9$; ㅇ. 5,31 , 32. II. I. I, $3 ; 5.20,21 ; 6.1-6,8$, 10-22;8. $2^{2}, 4,5,6, \mathrm{IO}^{2}, 13,26$; 10. 2. I2. I. $49 ; 2.14,50,5 \mathrm{I} ; 3.49 ; 4.52$ (mss. te). I3. I. $32 ; 2.27 ; 3.9^{*}$. I4. 2. 9 (mss. te), 73. I5. 15.8; 17.5 . 6. I6. 6. 7. I 8. I. $3^{*}, 44^{*}, 45^{*}, 47$, $5 \mathrm{I}^{*}$; 2. $35^{*}$ (mss. te), $47,55^{*}$; 3. I 9 , $42^{*}, 43^{*}, 45^{3^{*}}, 5 \mathrm{I}^{*}, 68 ; 4.29^{2 *}, 4 \mathrm{O}, 42$, $44,65^{*}, 86,87$. I9. II. $5^{*}$; 18. I-IO ; 20. 3 (mss. te); $27 . \mathrm{II}-3 ; 48.5^{2}$. 20 . I3I. I4

tằn. I. $8.4 ; 30.4$. 2. $12.7 ; 25.4$; 26. 1 ; $34.3,4 ; 35.1$. 3. $1.3,5 ; 2.3$; 6. 2,$3 ; 8.5$. 4. 4.8 ; II. I 2 ; 6.9 ; 22. I ; 36. I, 3, 9. 5.6.10; 8. I, 7 ; 17. 7 ; I8. II ; 23. 5. 6. 22. 3 (mss.); 50. $3 ; 73.2 ; 80.2 ; 103.2^{2}, 3^{2}$; 104. 2; II3. 2. 7. 97. 3; 108. I (mss. tấm), 2 ; II 7. I*. 8. 4.9*; 6. 7, 8, I0, II, I4, 15,$23 ;$ 9. 23. 9. $2.17,18$; 5.2, 30; 9. I5* I $5^{2 *}$. I0. $3.3, \mathrm{I} 6 ; 5.2 \mathrm{I}^{2}$; 7. 24,$27 ; 9.6$. II. I. 5 ; 5. II, 22; $8.3,7 ; 9.22,24$; I0. 23,24 . I2. $x$. 50,$57 ; 2.24^{\dagger}$; 3. I6 (m. mss. tắm) 18 , 36,40 . I4. 2. 10*. I5. I3. $1-5$. I 8 . 2. $14^{*}, 16^{*}, \mathrm{I} 7^{*}, 28^{*}, 34,35^{\dagger}$. I9. $6.14^{*}$; 8.4 (mss.); $35.3,5 ; 49.7$ (not mss.); 65. I ; 66. I.

tăni. I. I8. I. 2. I. 2.4 . I6.5. 6.

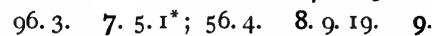
3. 6 ; 9. $19^{*}$; IO. $25^{*}, 27^{*}$. I I. 5.26. I2. 5. II. I3. I. 39. I4. I. $28^{*}$. I5. I7.4. I8. I. I7. I9. 20. 2 ; 37. I; 48. I. tă. 3. 13. I (p. tăḥ). 5. 11.4. 9. 9. I $5^{*}$ (p. tăh ${ }^{\dagger}$ ). I8. I. I I ; 2. $6^{*}$. 20. I28. 6- $\mathrm{II}^{2}$.

tăs. I. $4 \cdot 2^{*} ; 5 \cdot x^{*} ; x 8.4 ; 33.1-4$. 2. I4. 4. 3. $4.7 ; 7.5^{*} ; 13.5 ; 23.6$. 4. $5.3 ; 17.5 ; 2$ I. $3,4^{3 *} ; 39.8$. 5. I 
8; I8. I2; I9. II ; 28. $\mathrm{IO}^{2} ; 2$ 29. I4. 6. $25 . \mathrm{I}-3 ; 9 \mathrm{I} \cdot 3^{*} ; 96 . \mathrm{I}^{*} .7 .4 . \mathrm{I} ; 49$. I"; 74. I ; IO7. I; I09. 3; III. I ; II I. I; II 5.4. 8. $5.9 ; 7.3$, I0, I3, $17,23,24 ; 9.15,18.9 .5 .38 ; 6.5^{2}$; 9. 15 (mss.). I0. $5.38^{2} ; 8.33$. I I. I. 10; $6.9 ; 8.28 ; 9.15$. I2. I. 16, $31 ; 2.41 ; 3.25,26^{2}, 27,41 ; 4.43,47$. I3. I. IO $^{2}$. I4. I. $45 ; 2.7,34^{2}, 49$. I 5 . 15. 7, 9; 16.7. 18. 2.9, 20; 3. $69^{9}$; 4. $26^{2}$. 19. $2.5 ; 8.6$; 13. II"; $17.6^{2}$; 27.3, 9. 20. 48.2.

tébhis. I. $15.3,4 . \quad$ 2. 35.2 . 5. 8 . 2 ; 18.8. 7.55. I; 68.2. II.9.6. I8. 3. $46^{*} ; 4.2,3$. I9. $47.5 ; 50.2$.

tãís. 3. 23.4. 4. 16.9; 36.5. 5. 21. 8. 8. 8. 9. I0. $5.21 ; 6.20$. II. 3 . $37^{2}, 38^{2}$; 5. I4. I3. I. 35. I9. 9. 5, 12. tẩbhis. I. 22. 3. 4.21. $3^{*} ; 37.8,9$. 5. 22. 10. 6. 77.3 . 7. $48.2 *$ 8. 3. 6*. 9. 2. 25 . I3. I. 4 ; 2. $24^{*}$. I 8. 2. $8^{*}$. 19. $3.2 ; 9.14$.

tébhyas. 3. 2 I. I-7; 26. I-6 $6^{2} ; 27$. I-6. 4. 39. 10. 6. I3. I. 7. Iog. 6. 8. I. $14^{2}$; 8. 10. I0. 4.23 ; 9. I2. II. I. 4. I2. 4. 26 . 14. $2.46^{*}$. I 8. 2.29 , $49 ; 3.59^{\dagger}, 72 ; 4.57$.

tăbhyas. 2.2. 4, 5. 9.5.38. 19. 17.6. téṣām. I. I. I. 2. 3. 2 ; 35. I. 3. 9. 6 ; 10. 6 ; 26. I-6. 4. 5.5*. .5. 19. 2. 6. I5. $2 ; 55.1,3 ; 65.1 ; 67.2$; II6. 3. 7. 7.1. 8.3. $15^{*} ; 6.24$. 9. 2.4 , 9 ; 6. 2 I, 52 ; 9. I6*. I0. $4.18^{2}$. II. 3. 53 ; 9. 26 . I2. 3.6 ; 4. I I, 20. I 8 . I. $58^{*} ; 4.68,86,87$. I9. 3 I. 4 (mss. tv èș-).

tầsām. I. 27. I. 3. 24.6. 4. 8.5; 39. 8. 5. 1. $6^{*} ;$ 13. 9. 6. $21.1^{2} ;$ 90. 2. 7. $35.2 ; 43.1$; II5. 3. IO. IO. 28 . II. I. $13 ; 5.13^{2}$. I2. $3.4 ; 4.4$ I. I3. I. 9 . 20. I29. 3 .

téṣu. 8. 9. 19. I2. I. $56 ; 4.26$. I7. 7.

tấsu. 2. 10. 5. I2. 1. 12. 19. 17. $6^{2}$. (cf. tátas, táti, tattvá, tátra, táthă, tadâ, tadânīm, tárhi, tấvant, etá, tadvíd, tè ?, tyá.)

te. I. $3.1-5^{3}, 6-9,7,8 ; 7.5 ;$ I0. 2 ; II. I, 5 ; I3. $\mathrm{I}^{3}, 2,3^{2}, 4$; $3.2,3^{2}, 4^{2}$;
I8. $3 ; 22.1,4^{2 \dagger} ; 23.3 ; 24.3^{2} ; 25 . I$, 2; $35.1,4$ (p. té). 2. $2.1^{2} ; 3.1,2$; $6.2^{2} ; 8.3 .4 ; 9.4^{2} ;$ 10. $1-8,2,3^{2} ; 12$. 7,$8 ; 13.4^{2}, 5 ; 19.1-22.5 ; 29.6,7^{3}$; 30. $I ; 32.5,6^{8} ; 33 . \mathrm{I}-7^{2+} ; 35.4 ; 36$. 8. 3. I. $4^{*} ; 3.4,5$ (mss. té), $6 ; 4.5$, $7 ; 7.3 ; 11.4^{\dagger}, 8 ; 12.6 ; 15.8^{2} ; 18$. $3^{\dagger}, 6^{2 *}, 6 ; 20 . r^{*} ; 22.4 ; 23.2^{2}, 5^{2} ; 24$. $7 ; 29.7 .4 \cdot 3 \cdot 3^{2}, 6 ; 4 \cdot 3^{2}, 7 ; 6.4,6^{3}$, $8 ; 7.1,4 ; 9.8,10 ; 10.7 ; 12.2^{8}, 3^{3}$, 4,$5 ; 13.2^{*}, 5^{2 *} ; 16.6,7,9 ; 17.4,8$; 18. 5 ; 19. 5,$8 ; 22.5,6^{2} ; 30.4^{\circ} ; 31$. $3^{* \prime}, 5^{* \prime} ; \quad 32.1^{*}, 6^{*}, 7^{*} ; 33.4^{2 *} ; 38.6^{3} ;$ 39. 9. 5. r. $3,5,8 ; 2.2^{*}, 5^{2^{*}} ; 4.9 ; 5$. I, $7 ; 7.2,7 ; 8.5 ; 11.6,8,9$, IO $^{2}$; 13. $I^{2}, 2^{4}, 3^{2}, 4^{2}$; I8. I ; I9. I2-4; 20. $2^{2}$, 7 ; 22. 10; 23. 4; 25. 2, 3" $4^{3}, 5^{*}, 9^{2}$; 28. $5,6,7$; 29. II $\mathrm{I}^{*}, \mathrm{I} 4$; 30. $\mathrm{I}^{3}, 2-4,5^{2}$, 9, IO, II, I $5^{2}$; 31. I-9, 2, 4. 6. 8.2 , 3 ; 9. I ; I2. I, 2 ; I3. I, $2^{4}, 3^{3}$; I6. $I^{2}$, $2^{2} ;$ I 7.1-4; I8. I, $3^{2} ; 20.3 ; 29.2$; 30. $2 ; 39.2 ; 42.1,2^{2}, 3 ; 43.3^{2} ; 44$. 2 ; 46. I, 2 ; 49. I ; 56. $3^{3} ; 63 . \mathrm{I}^{2}, 2$; 70. $1-3 ; 72.1,2,3 ; 77.3^{2} ; 79.3$; 8o. I, $3^{4} ; 82.3 ; 84.1,2 ; 85.2,3$; 88. $2^{2 *}, 3 ; 89.1,2^{3} ; 90 . \mathrm{I}, 2^{2}, 3 ; 91$. I, $2^{*}, 3^{*} ;$ 92. I, 2, 3*; 98.2, 3; 102. I, $2^{2}$; 106. I"; III. I, $2^{2}$; II3. I, 3 ; I 25. $\mathrm{I}^{*}$; I26. $\mathrm{I}^{*}$; I27. 2 ; I28. 4 ; I3I. I ; I32. I-5; I36. 3 ; 137. 2,3 ; I $38.4^{2}$, 5; I39. I, 2 ; I42.3. 7.8. I; 9. $3^{*}$; IO. I" ; II.I ; I2. $2^{2}$; 20. 4,6 ; 34.1 ; $35.2^{2}, 3^{2} ; 38.2 ; 43.1^{2} ; 48.2^{*} ; 50$. $5 ; \quad 53.2^{2}, 3^{2}, 6^{2} ; 55.1 ; 56.3,6,8^{2}$; $64.2 ; 68.1,2^{2}, 3 ; 70.4^{2}, 5^{2} ; 74.3^{3}$; 76. 5 ; 78. I; 79. I, 4 ; 80. $3^{*}, 4 ; 82$. $3,6^{2} ; 83.1 ; 90.2 ; 97.6 ; 107.1$; III. $I^{2} ; 114 . I^{4} ; 118 . I^{2 *}$. 8. I. I, $3^{2}$, $5,6^{2}, 7,8$, IO, I $5,20^{2 *}, 2 \mathrm{I} ; 2 . \mathrm{I}^{2}, 2,3^{2}$, $4^{2}, 9$, IO, II, I $3^{3}, 14^{3}$, I5, I $6^{3}, 18,19$, $2 I^{2}, 26 ; 3.1 I^{*}, 19^{*}, 25 ; 4.14^{*} ; 5.22$; 6. I, $18^{2}, 20 ; 7.3,4 ; 8.7$ 9. 1. 10, $20 ; 2.5, I 6, I 9-24,25 ; 3.2,3,4^{2}, 6^{2}$, IO, I2, I3, I4 $, 15, \mathrm{I} 8 ; 4.6, \mathrm{IO}^{3} ; 5.37$ (mss. té) , 38 ; 8. I-5, 2, 7, 9, I 2, I6, 21 , 22. I0. I. $8^{3}$, II $, 16^{2}, 18,20,21 ; 3.2$, 3,$4 ; 4.21,22,24,25 ; \quad 5.45 ; 7.21$; 9. $2^{2}, 3,7^{2}, 13^{3}, 14^{2}, 15,16^{2}, 17^{2}, 18,19^{2}$, 
$20,21^{2}, 22^{3}, 23^{2}, 24,25$; IO. $I^{3}, 7^{2}$, IO, II, 2O. II. I. $6, \mathrm{IO}^{2}, \mathrm{II}^{2}, \mathrm{I9}, 20,25$, $32 ; 2.2^{2}, 3^{3}, 4^{2}, 5^{3}, 6^{3}, 9$, II, I $5^{3}$, I $25^{2}, 3 \mathbf{I}^{3} ; 3.32,35,36,37,44 ; 4 \cdot 2^{4}$, $7^{3}, 8^{4}, 9^{2}$, I 8,23 . I2. I. $11^{2}, 12^{2}, 18$, $23-5,3 \mathrm{I}^{2}, 33,35^{3}, 36^{2}, 46,47,56,6 \mathrm{I}^{2}$, 62 ; 2. $\mathrm{I}^{2}, 3, \mathrm{I} 4,2 \mathrm{I}^{2 *}, 53^{2}$; 3. I, 22,54 ; 4. 45. I3. I. $5^{3}, 8,9^{2}$, IO, I $4,35,37$, $44^{3}, 56,57 ; 2.3,6^{2}, 7,29^{*}, 37 ; 3$. Iо, 2 I ; $4 \cdot 44^{2}, 45,48,55$. I4. I. $5^{*}$, I I $^{2 *}$, I2* $2^{*} 6^{*}$, I $9,2 \mathrm{I}^{*}, 40^{2}, 47^{2}, 48,49,50^{*}$, $5^{\mathrm{I}} ; 2.3^{2 *}, 3^{\dagger}, 24,33^{*}, 34^{2}, 35,59,6 \mathrm{I}$, 62, 75. I5. II. $2^{3}, 6,8$, IO. I6. 5. I-6. I7. $8, \mathrm{II}, \mathrm{I} 2, \mathrm{I} 3^{2}$. I 8 . I. $2^{*}, 3^{*}, \mathrm{I} 3^{2 *}$, I $3,14^{*}$, I $5^{*}, 24^{*}, 32^{*}, 40^{*}, 54^{\dagger}, 59^{*} ; 2$. $7^{*}, 8^{3^{*}}, 9,10^{*}, 12^{*}, 20,21,23,24^{3}, 26^{2}$, $30^{2}, 35$ (s. mss. té*) $36,56,57 ; 3 \cdot 4,7^{2 *}$, $9,24^{*}, 52^{3^{*}}, 55^{*}, 60^{2}, 68^{2}, 69^{3}, 71,72 ; 4$. $9,15^{2}, 26^{3}, 31,33,34,42^{3}, 44,52,56$, $59^{*}, 66,75,76,77,88^{*}$. I9. $2.1^{4}, 2^{3}$, 5 (mss. tắs), $5 ; 3.2,3^{3} ; 4.1$; 8.5 (mss.); $\mathrm{I}_{5} .4^{*} ; 20.3$ (mss.); 26. $4^{2}$; 27.4 ; $28 . \mathrm{I} ; 30 . \mathrm{I}^{2}, 2^{2}, 4 ; 32 . \mathrm{I}, 3$; 33 . $4 ; 34.8,9 ; 39.2,3^{2} ; 44.2 ; 45.3,4^{3}$; 46. I; 47.2, $3^{2}, 5^{2} ; 48$. I, 4,$6 ; 50.2$; 52.5 (m.mss. té); $55 . \mathrm{I}, 2^{3}, 7^{2} ; 64.3^{*}$, 4;66. I. 20. I27. 9, II ; I28. I4; I29. I8 (not mss.); I33. 2.

$\checkmark \mathrm{t}$ a n s: cf. tásara.

+ upa: upátasat. 20. I36. I.

$\checkmark$ t a k: cf. takvan, tan̄ka.

+ nis: cf. nișțákvan.

+ pra: cf. pratáñka.

takmán: -má. 4. 9.8. 5. 22.9. II. $2.22 ; 4$. II. I2. 5.3 I.

tákman. 5.22.6, 7, I2.

takman. I. $25.1-3 . \quad 5.22 .2,5,7$. takmănam. 5. 4. I, 9; 22. I, 3, I3, I4. 9. 8.6. I9. 34. IO; 39. I, 5, 8, IO. takmánā. I1.2.26. [2O. I, 2, 3. takmáne. I. $25.4^{2}$. 5. 22. 4,8. 6 . takmánas. 5.30.16. (cf. talrmanăçana.)

takma。năçana: -am. 5.4.2. takmanāçana. 5. 4. I.

t a k v a $\mathrm{n}$ in niștákvan.

$\checkmark$ t a ks: tákșatī. 9. IO. $21^{*}$.

tatakșa. 2. 5. 6*. I I. 5.8. I4. I. $60^{2}$. tatakșus. 5. 1. 6*.

tașță. II. I. 23 .

(cf. takșaká, tákșan, tașța.) [20. + a pa: apătakșan (p. apaoát-). ro. 7 . + u d: út takșatam. 8. 4. $4^{*}$. [32.3. + nis: nirátakșatam (p. nị̣॰át-). I. nirátakșata (do.). 9. Io. I*.

t a kṣaká: -ás. 8. I0. 29.

t ákṣ a n: -șā. I o. 6. 3 .

t a $\mathbf{n} \mathbf{k}$ a in pratáñka.

t a ñ g a 1 v à : -úāt. 8. 6.2I.

$\checkmark$ t a ḍ: cf. tāọa.

+vi: ví...tāḍhi. 7. 84. $3^{*}$.

t a ṇ du 1 á: -ás. $0.9 \cdot 26$.

tandulám. I2. 3. I8.

tạ̣ụuăs. II. I. 18 ; 3. 5. I2. 3. 30 .

tạ̣uluaís. I2. 3.29.

t a $\mathrm{t}$ a in ánātata, vítatādhvara.

ta tá: tata. I8. 4.77 (mss. tátas).

tatâs. 5. 24. I6.

(cf. tatāmahá.)

tátas. I. IO. I. 3. 4.2, 4. 4.4.3; 9. $4^{*}$; I9. 4,$6 ; 30.7^{*}$. 5. I. $2 ; 24$. I7. 6. I8. $3 ; 89$. I; II3. I, 3; I3I. 3. 7. $56.3 ; 83.1,2 ;$ IO6. I. 8. 9. 6. 9.2. I9-24; IO. $3^{*}$. IO.I. $29 ; 3$. 8 ; 8.25 ; IO. I $8, I 9^{2}, 22$. II. $3.32-$ 49. I2. 4. $7,8,9,3$ I. I3. 2.15. I4. I. $4^{*}$. I5.6.7;8. I. I8. 2.32. I9 3. I (tátaḥota-); $5 . I^{*} ; 6.3^{\dagger}$; I5. I* ; 30. $5^{2} ; 39.6-8 ; 41.1 ; 56.2$ (not mss.); 57.6 .

t a tā m ahá: tatāmaha. I 8. 4. 76 . tatāmahãs. 5.24. I7.

(cf. pratatāmaha.)

táti: I2.3.2.

(cf. tatidhă.)

tatiodhâ. I2. 3.2.

tattvá: -ám. I9. 42.2 (? mss. tátvam, ed. satrám).

t a t $n \mathbf{i}$ in nitatni.

tat $\mathbf{n} \mathbf{u}$ in paritatnú.

tátra. I. 25 . I. 2. $14.3^{2} ; 30.3 .4$. 7. I ; II. II ; I9. $2.5 .4 .3,4,8.6$. II. I ; 22. 2 ; 99. 2 ; IO6. I' $;$ II9. 3 ; I $20.3 ;$ I 23.5 . 7. $5.3 ;$ I $8.2 ; 76.5$. 8. I. 7 ; 2. I5, 24, 25 ; 6. I. 9. I. I8; 3.20. I . I. 8 , I9; $7.8,9 ; 8.4,6$. I I. 
I. 23,35 . I2. 1. $34 ; 3.1$. I3. I. $6^{2}$, 46, 53. I 4. 2.23. I8. $2.7^{*}, 53,55^{*}$; 3. $8,9,52^{\dagger}$. I9. $39.6-8 ; 43.1-8$.

táthã. 3. 4. 5 ; 9. I, 2 ; 28. 2. 4. 5 . $5^{*} ; 8.6$; II. 9. 5.8.8; I7. $3^{*} ;$ I8. $14 ; 29.2,3$. 6. 46.2 . 9. $2.18 ; 5$. I4. I0. 10.27 . I2. 4.4, I 4,33 . I5 I0. $2^{2}, 4$; I 1. $2^{3}, 6,8$, IO. I6. 5. I-6. I 9. 6. $2^{\dagger}, 8^{*} ; 46.7 ; 57.4 ; 64.2$. 20. 133. I-6; I36. 6, 7, I 2 (mss.).

tad声. II. $4 \cdot 4$.

t a d ầñm. I0.8.39. I2. I. 55 . t a duri: -ri. 6. 15.15 . (cf. tādurī.) tad०víd: -de. 9. I. 9 .

v tan, tã: tanváte. I2. I. I3. tanvátām. 4. 15. I6.

tanvānă. 5.26.6.

tanvānâs. I9. 6. I 5 *

atanuta. I8. $3 \cdot 4 \mathrm{I}^{\dagger}$.

átanvata. 7.5.4. I. 6. 6.10*.

tatāna. I3. 1. 6.

tatniré. I4. I. 45 .

tatám. 6. I22. 2.

tāyáte. Io. 8. Io.

tāyámāne. I 8. I. 4I*.

(cf. tata, tatni, tatnu, tán, tanà, tanứ, tántu, tántra, tāna.)

+ a n u: anuotanvánti. 9. 8. I4.

ánv atanuta. I0.2. 16 .

+ a va: áva ... tanomi. 6. 42. I, 2. áva...tanu. 7.90.3.

ávaotatam. 2.7.3.

+ abhyava: abhyávatanomi (p. abhioá-). 8.8.24.

$+\bar{a}$ : ât tanomi. 4. 30. $5^{*}$.

â...tanomi. $4 \cdot 4 \cdot 7$.

à tanoși. 9. 4. 9 .

āotanóti. I2. I. I5.

à tanvanti. I3. 4.7 .

à tanuse. I3. 2. IO.

á tanușva. 5. 2.4".

āotanvānăs. 6. 66.2.

à tatāna. 7.82.5. I9. 22.2I.

à 'tān. 9. 4. I.

àotatas. I3. I. $60^{*}$. I 8. 4. 59*.

àtatam. 7. $26.7^{*}$; 90.3. 20. 132.6. ātátya. 20. 136. 3 (not mss.).

à tāyatām. I0. 2. I7. à tănayā (p. -ya). 4. 4.6. 6. Ior. 2 . (cf. ánātata.)

+ anvã: anuoătatăna. I 8. 2. 32.

+ u d: útotatam. 2. 7.3. 7.90.3

(cf. uttăná.)

+ ni: ní...tanu. 7.90.3.

ní...tanotu. 3. I2. 4 .

(cf. nitatni, nitāná.)

+ pari : ef. paritatnú.

+ pra: praotanvatís. 8. 7.4. (cf. pratāná.)

+vi: ví...tanota. 3. $17.2^{\dagger}$.

ví tanvate. 3.17. I*.

ví tanu. I. I. 3 .

vioteniré. 4. 14. 4.

ví tatnire. 9. 9. $6^{*}$.

víotatas. 4. 2. $4 ; 35.5$. 9. 6.28. I3. 2. I4. I8. 4. 13 .

víotatam. 2. 1. 5 ; 35.5 9. 2.16 ; 3. 8. I o. $8.12,37,38$.

víotatām. I 0. 3. 4 .

vítatău. 20. 133. I.

víotatā (pl.). 6. 124.3.

ví tāyate. I7. I8.

(cf. vítatādhvara.)

+s a m: sám tanoti. 4. 34. 5 . samotanvatís. 8. 7. 16 .

tán: -nā. 8. 4. 10*, I I*.

t a nà̃: -âyās. 7.73.5.

t a nút: -û́s. 2. I3. 4. 4. 32. 5*. 6. 92 . $3^{*}$. I I. 4.9 . I2. 3. 22 . I4. I. $27^{*}$; 2. 50. I7. I3. I9. $3.3 ; 6$ I. I.

tanúm. I 8. I. I $3,14^{\dagger}$.

tanvàm. 7. 3. I (1. -ua- ?). 8. 5. I9. II. 2. $29^{\dagger}$. I2. 3. 54 . I 8. I. I2*. I9. 37.2 . tanúam. I. 2.2. 2. 3 I. 5. 5. I. 3 ; 2. $9^{*} ; 3 . I^{*}$. 6. 9. I; $92.3^{*}$; I IO. I* 8. $4.17^{*}$. I3. I. $34 ; 2.27,33$. I 4 . I. $2 I^{*}, 40$. I 8. I. $3^{*}, 8^{*} ; 2.36 ; 3.9$, $4 I^{*} ; 4.52$. I9. 55.3 .

tanvà. I. 33.4. 7.3.1 (1. -úă ?); I I 5.3 (do.). I6. I. I2. I7. $13^{2}$.

tanúā. 5. 3. $5^{*}$; 30. I4. 8. 4. IO*, I I". I 8. I. I $2^{*}, 13,14^{*} ; 2.10^{*} ; 3 \cdot 7^{\dagger}, 58^{*}$ I9. 50.3 .

tanvè. I. $3 . I-5$; I2. I. 8. 2.16 . tanúe. I. $6.3^{*} ;$ 12. 4 . 5. 3.7. 8. I. 5 . 9. $3.6 ; 5.26$. I2. I. 30 . 
tanvàs. 6.53.3.

tanúas. 2. 29. I. 3. $22 . \mathrm{I} ; 28.5$. 5 . I. 7 ; 4. IO. 6. 4I. 3 ; 49. I; 9I. I ; I 20. 3 ; I 24. 2 ; I40. 3 (l. -vàs ?). 7 . 57. I. I2. I. 12 . I8. 2. 24 .

tanvà̀m. I. I8. 3 . I 9.37 .2 (? mss. -vàm); 6I. I (mss. -và).

tanú (p. -ú íti). 4. 25. 5.

tanvàs. I. I. I.

tanúas. 6.62.2;74. I. 7. 104. I. 8. 9. 2 . 9.2. 25 . I3. 3. $16 ; 4.44$. I4. 2. 32. 18. $2.8^{*} ; 3.59^{*}$. I9. 3. 2 . tanúbhis. 4. I5. IO. 5. 3. $7^{*}$. 6. 53 . 3. I4. 2. 32. I8. 4. IO.

tanúbhias. I. I3. $2 ; 26.4$. tanû́nām. 8. 4. 10*. 19. 13. $8^{\dagger}$. tanû́șu. 7. $42.2^{2 *}$. 19. 20.3. (cf. dușțanu, priyátanu, sárvatanū, tanūjá-tanūvaçín.)

t a ñ̄ $\circ$ já: -ásya. I. 23.4. tanūjăs. 6. +1. 3 .

t a n $\overline{\mathrm{u}} \circ \mathrm{t} y$ áj: -jas. I8. 2. $17^{*}$.

$\tan \bar{u} \circ d \hat{u}$ și: -is. I6. I. 3 . tanūdúșim. I4. I. 38. I6. I. 7.

tán ū。nápātt: $5 \cdot 27$. I. tánūnapāt. 5. 12. $2^{*}$.

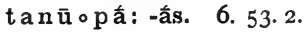
tanūpăs (pl.). 6. 4I.3.

t a n $\overline{\mathrm{u}} \circ \mathrm{p}$ án a: -as. 2. II. 4. 3. 5.8. tanūpănam. 5.8.6. 8. 5.20. $\quad$ I9. 30. 4 .

t a ñ̄o o a lá: -ám. 9.4. 20.

t a n $\bar{u} \circ v$ a çín: -çí. 7. IOg. I. tánūvaçin. I. 7.2. 5. 8.2. tanūvaçin. $4.4 \cdot 4,8$.

tántu: -us. I0.2.17. I3. I. $60^{*}$. tántum. 2. I.5. 6. I22. I, 2. 9.4. I. I2. 3. 52. I3. I. $6 ; 3.19,20$. tántavas. I4. 2.5I. I5. 3.6. tántūn. 9.9.6*. I0. 7.42.

tántra: -am. ro. $7 \cdot 42$.

t andra in átandra: cf. tandrí.

t a n drí: -ís. 8. 8. 9. II. 8. I9. (cf. sambādhatandrî.)

t a n y tú: -ús. 5. I3. 3 . $\checkmark$ tap: tapāmi. 6. 132. I-5. tapasi. I7. I7. tapati. 6. 91. $2^{*}$. 10.8.19. I3. 3 .
I3. I9. 53.6 .

tápanti. I3. 3. I6.

tapāti. 8. I. 5 .

tapa. I I. I. I6. I8. $2.36 ; 4.1$ I $^{2}$.

tapatu. 7.69. I. I2. 3. 43 . I8. 2. $8^{*} ; 4 \cdot 9^{3}$.

tápatam. 8. 4. I*.

tapantu. II. I. I6.

tapasva. I8. 2. 8*.

tápan. I3. 212.

tápas. 18. 2. 36 .

tatápa. 8. 4. $15^{*}$.

tatāpa. 7. 18. 2.

taptás. 4. II.3. 7. 73. 1, 2, 5.

taptám. 7.73.4.

taptăt. 9.5.6.

taptấs. 12. 3.29.

tapyate. 9. 9. II*.

tapyāmahe. 7.6I. 2.

tapyantām. 2. I2. I.

tapyámānas. II 5.26.

tapyámānā. 3. 10. I 2.

tapyámānasya. I9. 56.5 (m. mss. tápya-).

tapyámāne. 2. I2. I.

tāpáyan. I9. 28.2,2 (mss.).

(cf. tápana, tápas, tápiṣṭha, tápus, tapta, tāpa.)

+ ati: áty atapat. I3. 2. 40.

áti tapas. I8. 2. 36 .

+ a nu: ánu tapa. I9. 49.7 (mss. nạ suta。pấ).

anuotapyámānam. 2. 35.2.

anvátapyanta (p. anuoát-). 2. 35. I.

+ abhi: abhiotápan. I9. 28. 3.

abhíotaptam. 4. 4. 3 .

+ ava: áva tapati. I2. 4. 39 .

$+\bar{a}$ : ấ tapati. I2. I. 20.

āotápanti. 12. 3.50.

á tapatu. 8. 2. I4.

āotápantam. 8. 6. I2.

+ upa: upaotapyấmahe. 7.6I. I. úpa tapyāmahe. 7.61.2.

úpa tĩtapāsi. 6. 32. I.

+ ni: niotápan. 19. 28. 3 .

+ pari: pári... átapthās. 9.5.6 (mss. -ptās).

páriotaptās. I. $7 \cdot 5$. 
+ prati: práti tapa. 2. 19-22. I. práti tapata. 2. 23. I.

+ vi: viotápan. 12. 2. 45 .

+ $\mathbf{~ a ~ m : ~ c f . ~ a s a m i n t a ̄ p a ́ , ~ s a ̄ m i n t a p a n a ́ . ~}$

+ a bh is a m: abhiosámtapāti. 2. I2. $6^{+}$.

abhiosámināpaya. I9. 28.2 (mss. abhín samotāpáyan).

tápana: -as. 4. 36.6. tápanam. 4. I8.6. I9. 28. I, 2 (not mss.); 30.4 .

(cf. sāmintapaná.)

tápas: I. 13.2. 2. 19-23. I. 5. 17. $I^{*}$ 6. I33.4. 7.61. $I^{2}, 2^{2}$. 8. 10. 25. I0. 7. I, II, 29, 30; IO. 33 . II. $5.26 ; 7.9,17 ; 8.2,6^{2}$. I2. I. I; 3 . 12. I3. 4. 22. I5. I. 3. I8. 2. I6". I9. $40.3 ; 4 \mathrm{I} . \mathrm{I} ; 53.8$, I0; 54 I.

tápasā. 3. IO. I2. 4. II. $6 ; 32.2^{*}$, $3^{*} ; 35.1,2$. 5. I7. $6^{+} ; 18.8,9 ; 28$. I. 6. 104. $2 ; 122.4 ; 133.3 .7 .61$. 1 ; $77.2^{\dagger}$. 8. 3. $13^{*} ; 9.3$. II. I. 16 ; 5. I, 2, 4, 5, 8, IO, II, I7, I9. I2. I. 39 ; 5. 1. I3. 2. 25 . I7. $24^{\dagger}$. I8. 2 . I6". I9. 43. I-8; 72. I.

tápase. 12. 3.46 .

tápasas. 4. 34. I. 5.6.9. 6. 133 . 4. I0. 7.36. II. I. 26. I3. I. IO. I8. $2.8^{\dagger}$.

tápasi. 10. $7 \cdot 38$.

tápāñsi. 5.26. 7 .

(cf. sutápas, tápasvant, tapasvín, tapojá.)

tá pa s va n t: -vān. $\quad 5 \cdot 2.8^{\dagger}$. tápasvatas. I8. 2. $15^{*}, 18^{*}$.

tapasvín: -ví. I3. 2. 25.

tápiṣtha: -as. II. I.16.

tápișțhena. $7 \cdot 77 \cdot 2^{*}$.

tápișțhās. 8. 3. I9*. I I. I. I6. [3.23*.

tá pura gra (p. -uḥoag-): -rābhis. 8.

tápurvadha (p. -uhov-): -dhãya. 6. 20. I.

tápurvadhebhis. 8. $4.5^{*}$.

tá pus: 8. 4. 2*.

tápușe. 1. 13.3.

tápūnọisi. 2. $12.6^{*}$.

tapojá (p. -paḥoj-): -jâs. 6.6I. I. tapojân. I8. 2. $15^{\dagger}, 18^{*}$. t a p t a in átapta, agnitaptá. $\checkmark$ t a m in támas, támişici, tāmra. támas: I. $21 \cdot 2^{*}$. 8. I. IO, I6, 21; 2 . I, I2, 24. 9. 2. I7, 18. 10. $3.9 ; 7$. 40. I2. $3.18,49 ; 5.26$. I3. I. 32 ; 2. 8, 9. I 4. 2. 48 . I9. 12. I"; 40. $4^{*}$; 47. I.

támasā. 3. 2. 5, 6. 8. 8.8. Io. I. 30. II. 10. 19. I6. 7.1. I8. 3.3. támasas. 2. 10.8. 5. 13.3; 30.11. 7. $53.7^{*}$. 8. 1. 8 . 10. I. 32 .

támasi. 8. 4. $3^{*}$.

támāñsi. 2. 25.5. 9. 2.4, 9, 10; 5 . I, 3,7, II. I3. 2.34 .

(cf. tamasá, tamasvant, tamovị́dh.)

t a m a sá: -sās. II. 9.22.

t a m a svant: -vati. I9. 47.2.

támişĩi: -cayas. 2. 2.5. [4. I*. t a movị́dh (p. -maḥ०v-): -dhas. 8.

$v$ tar, see vtr.

tara (stara) in dușțára.

tara na in pratárana.

taráni: -is. 13. 2. 19".

taráṇim. I3. 2.4, 36.

tára s: -se. 3. 15.3 ".

tárāṅsi. I0. 10. 24.

tárasām. I0. IO. 24.

tarín: -rí. 5.27.6.

t a $\mathbf{r} \mathbf{i}$ tṛ in pratárîtr.

táruṇa: -as. 3. 12. 7.

tárunam. 9. 1. 5. 12. 3.37.

tarutṛ́: -tăram. 7.85. $\mathrm{I}^{*}$.

t a rún a ka: -am. I0. 4.2.

tardá: tárda. 6. 50. 2.

tardám. 6. 50. I.

(cf. tardãpati.)

tardãpati (p. -da॰p-): tárdāpate. 6. 50.3 .

tárdma n: -ma. I4. I. 40.

tárpan a : -am. 9. 6.6.

tarha in çatatárha.

tárhạ̣a: -am. 8. 4. $4^{*}$.

tárhạ̣i. 2. 3I. I.

tárhi. 3. 13.6. II.8.5. I2.4. I3,

ta là çā: 6. I5.3.

ta li d y à: -àm. 7.76.3.

tál pa: talpa. 12.2. 49 . 
tálpam. 5. I7. I2. I4. 2.3I. tálpā. I3. I. I7.

tálpāni. I4. 2.4I. (cf. talpeçayá.)

t a lpeoça yá: -yấs. 4. $5 \cdot 3^{\dagger}$.

tavás: -sam. II. I. I4.

tavásas. $4 \cdot 32 \cdot 3^{*}$.

tavástaram (p. -váḥot-). 19. 24. $7^{*}$.

tavișá: -ásya. 4. 32. $5^{*}$.

tavișấs. 4. I5. 2.

(cf. /tavișy.)

$\checkmark$ tavișy: taviṣyáte. I8. I. 23*".

taviṣyámānas. 20.34. 16 (mss.

stav-).

tá vìy a s: -yān. 4. 32. $3^{*}$.

t as ța in stómatașța.

$\checkmark$ tas, see $v$ tans.

tá s a r a : rāṇi. I0. $7.44^{*}$.

tás k a ra: -as. 4. 3.2; $21.3^{*}$. I9.

47. $7^{2} ; 50.5$.

(cf. ataskará.)

tastúva: -am. 5. I3. $I I^{3}$.

tastúvena. 5. I3. 11 .

tāját. 8. 8.3 (p. tājádbháñgaḥoiva).

tầ a: -am. 19. 32.2.

t ā d u rī: -ri. 4. I5. I4.

$\mathbf{t} \mathbf{a} \mathbf{n}$ a in uttāná, nitāná, pratāná.

$t \bar{a} \mathbf{p a}$ in asamiāpá.

tābúva: -am. 5. 13. $10^{3}$.

tābúvena. 5. I3. I0.

t āmra in

tāmra。dhūmrá: -răs. IO. 2. II.

tā yādará: -ám. 6. 72.2.

tāy ú: -yávas. I3. 2. $17^{*}$.

tārá: -ám. 4. 37.3.

tấrakā: 5. I7. 4 .

[I2I. 3.

tấrake (p. -e íti). 2. 8. 1. 3.7.4. 6.

tấrakās. I 9. 49.8 (not mss.).

tấrkṣy a: -am. 7.85. I*.

tārpyà:-píam. I8. 4.3I.

t ārya in atitāryà (-ríās. 8. 2. 27).

tārșțā ghá: -ghís. 5. 29. I5 (s. mss. -ādhis; p. -șțaoagh-).

vtā v: + vi: viotávati. 12.2.38, 52 .

tầvan t: -vān. 5.22.5. I3. 4.44 .

tấvat. 3.22. 4, 5. 6. $72.2,3$. 9. 6 . 40-3. I2. $1.33 ; 3.2^{2} ; 4.27$.

tăvantas. I9. $6.3^{\dagger}$. tăvatiss. $8.7 \cdot 25,26$.

tigmá: -ás. 13. 2. 33 .

tigmám. 4. 27.7. 7.83. $3^{*}$. [II. tigména. 6. $34 \cdot 2^{\dagger}$. 8. 3. $23^{*}$. I3. I. (cf. tigmátejas-tigméșu.)

tigmá ○tejas: tigmatejas. 6. 63.2. tigmátejasas. I9. 9. Io.

ti g má。çṛñ ga: -as. I3. I. 25.

tig má ○heti: -tī (p. -i íti etc.). 5. 6. 5-7. 8. 3. 25 .

ti g mă y u d h a (p. -máoāy-): -dhāu. 5. 6. 5-7.

[I*.

ti g méṣ u (p. -máoiș-) : -ṣavas. 4. 3I.

$\checkmark$ tij: títikșante. 8.6. I2.

(cf. tigmá, titikșú, tīkṣ̣ná, téjana, téjas.)

titikșú: -ús. I2. I. 48.

$\checkmark$ tir, see $v$ tr.

tira in uttirá.

tíraçciorāji: -is. 3. 27. 2.

tíraçcirājim. 10. 4.17 .

tíraçcirājaye. 6. 56.2. I2. 3. 56 .

tíraçcirājes. 7. 56. I.

tíraçcirājayas. I0. 4. 13, 20.

ti r a ç cìn a :-nā. I9. I6. 2 (mss. -çcīn).

tir a çcyà: -yè (p. -èíti). I 5. 3.5 (mss, -çcyè, -çcè, -çcé, -çce).

tirás. 6. $34 \cdot 3^{*} \cdot 7 \cdot 3^{8} .5 ; 77.2^{*}$. 8. I. 7 ; 10. 28 . I2. $2.23^{\dagger} ; 3.39$. I3. I. 36. I8. I. I*. I9. $40.4^{*}$.

(cf. tiras $+\sqrt[V]{ } \sqrt{ }$ I kṛ, I dhā, bhū ; and tirojaná, tiryáñc tiráçc.)

tirița in

tirītín: -nas. 8.6.7.

ti rojan á (p. -raḥoj-): -ám. 7. 38. 5.

tirodhấ (p. -rặodh-): -ấm. 8. Io. $28^{2}$.

tírodhe. 8. I0. 28.

tiry à: ríam. $4 \cdot 7 \cdot 3$.

tiryág。bila: -as. 10.8.9.

ti r y áñ c, ti rá çc: -ryán. Io. 8. Ig.

II. 4.25 .

tỉriáñ. I0. 2. 28 .

tiryák. I0. $2.24,25$

tiryáñcas. I 5. 3. 6 .

tiráçcīs. 9. 8. I6. I0. 2. II. (cf. tíraçcirāji, tiraçcína, tiraçcyà, tiryágbila.) 
tíl a: -as. I 8.4 .32 (Inss. ed. tilás). tílam. 6. 140. 2.

tílasya. 2. 8. 3 . (cf. tiryà, tāilá, tilapiñô-tilávattila

tilá ○mi çra: -rās. I8. 3.69; 4.26. tilá vats a: -sās. I 8. 4. 33, 34 .

tilpínja: -am. I2. 2. 54 .

tīkş̣̂á: -ás. I9. 33.4.

tĩkṣṇéna. 8. $3 \cdot 9^{*}$. 12.5 .66 .

tīkșṇáotarãs. 3.19.4. (cf. tikş̣náçṛnga-tîkṣnẹşu.)

tīkṣ ṇá o ̧ r ñ g a: -gās. I9. 50.2 (mss. tîkșṇaçrñngās).

tīkṣṇaçṛngit. 4. 37.6.

tīkşṇaçṛngías. 8. 7.9.

thkşṇīy a s: -yāǹsas. 3. $19 \cdot 4^{2}$.

tīkṣṇ éṣu (p. -ṇáoiṣ-): -ṣavas. 3. I9. 7. 5. 18.9.

tĩrthá: -ám. I4. 2. 6*.

tīrthāís. 18.4.7.

tĩvá: -ás. 3. I3.5. I8. I. $48^{*}$. tivrăs. Io. 2. II.

tú. 4. 18.6.

tu pron., see tva.

$\checkmark$ tu in tavás, taviṣá, $/$ taviṣy, távīyas, tĩvrá, turá, tuví, túya. $v$ tuc in toká.

$\checkmark t u j$ : tujáyadobhis. 8. 4. $7^{*}$. (cf. túj, tují.)

túj: tujé. 6. 33.1 .

tuj 1: -jáye. 7. 49. I*.

túṇ dika: -as. 8. 6.5.

tuṇ đ̣éla: -am. 8.6. I7.

$\checkmark$ t u d : tundānă. 6.22.3.

tunnă. 6. 22. 3 .

(cf. tuda, toda, todin, 1 tudāy.)

$+\bar{a}$ : āotutóda. I8. 3. $55^{*}$.

(cf. ātodín.)

$+u t$ : út tudatu. 3. $25 . \mathrm{r}$. (cf. uttudá.)

+ ni: niotudántím. 5. 7.7. (cf. nitodín.)

+ pra: cf. pratodá, pratodín.

+ vi: ví tudantu. 3. $17.5^{\dagger}$. (cf. vi + tudāy.)

+ s a m: cf. samtodín.

tu d a in uttudá.
V t u dāy: + vi : viotudāyási. 2.32.6. $v$ tur, see vtvar.

turá: -ás. 3.16.2\% 6. 102.3.

turéna. I $8 \cdot 3 \cdot 4^{4}$.

turânăm. 7. 50. 2.

[sáh.)

(cf. átura, ătura, turágătu, turā-

turá。gātu: 9.10. $8^{\circ}$.

turāsáh: -rāṣăț. 2. 5. 3.

turipa: -am. 5. 27.10.

turiya: -as. I. I6. I; 31.3. 14. 2. $3^{\circ}$. turiyam. 9. $10.27^{\circ}$.

turfyena. 7. I. I.

turíyā. 8. 9.14.

túrīy a: -am. ro. I0. $29^{4}$.

turmíça: -am. I9. 7.1 (mss.). [3.

tuví: tuvíșțamas (p. tuvíota- $\left.{ }^{\dagger}\right)$. 6. 33. (cf. tuvikșatrá.)

tuviokṣatrá: -răm. 7. 6. 2.

v'tuç: tóçamānā. 3. 17.5.

túşa: -am. I2.3. 19.

túșās. 9. 6. I6. II. 3.5.

túșān. II. I. 29.

túșāis. II. I. I2.

tū pará: -rắs. II. 9.22.

tú y a: -am. 5.12.8*. 18. 1.9*.

$t \tilde{u} \mathbf{r} \mathbf{y}$ in mitratúrya.

t文la: -am. I9. 32.3 (mss.).

$\sqrt{t r}$, tir, tar: tarāthas. I4. 2.43.

taranti. I8. 4. 7. I9. 34. 7 ; 44.6.

tárema. I9. 50.3.

tarema. 7.50. $7^{*}$. 12. 2.48 .

tareyus. I9. 50.3.

tara. 2.6.5.

táran. 7. 4I. I.

tārīt. 2. 7.4. 6. 124.3. 12. 3.17.

tărișús. 2. $7 \cdot 4$.

tīrtvă. 9. 5. I, 3 .

tāráyantas. I 8. 3. 10.

(cf. tara?, tarạ̣a, taráṇi, táras, tarín, tarītṛ, táruṇa, tarutṛ́, tarựnaka, tārá, tārya, tira, tirás ?, tīrthá.)

+ ati: áti tarati. I9. 36.2 (mss. tatrati).

áti tarāṇi. 4. 35. 1-6.

áti ... átaran. 4. 35. 2.

áti ... atārīt. I3. 2. 34 .

(cf. atitāryà.) 
+ a n u: ánu ... taranti. 6. I22. 2.

+ a pa: ápa ... tira. 6. 6. $3^{\dagger}$.

+ ava: ávā 'tirat. 5. I8. II.

avatíryatī. I9. 9.8 (? mss. áva tīryatîs; p. ávatīh yatíh $)$.

+ ud: út tarema. 12. 2. $26^{*}: 27$. utotirán. 6.36.2.

(cf. uttirá.)

+ ni: ní tirāmi. 2. 3I.3. 6. 13I. I.

+ pra: prá tara. I8. 2. 3I. prá taratā (p. -ta). I2. 2. $26^{*}, 27$. prá ... tiratas. I3. 2. 32 .

prá...tirase. $7.8 \mathrm{r} .2^{\dagger}$.

prá... tiráte. I0. 7.42 .

praotiránte. I 4. 2. $36^{*}$.

prá tirāti. I 8.4 .48 .

prá tira. I2. 2. 45. I3. 2.37.

prá ... tira. 7.26.3.

praotirántas. I 8. 2.29 (p. -nte). prá ... tāriṣat. 2. 4. 6. 4. Io.6. I2. 2. I3. I4. 2.67. I9. 34.4 .

pră 'tîtaras. II. 4.6 .

prá ... tāráyantas. I8. 3. Io.

(cf. pratáraña, pratárītr.)

+ upa pra: upaoprátāraya. 2. 36. 5 .

+ s a m: sám tarema. 6. 122. I.

tṛcá: -cébhyas. I9. 23. I9.

tṛ́ṇa: -am. 2. 30. I. 3. 12. 5. 6. 54 . I ; I02. 2 (ed. tṛ́ṇma). 7. 73. $x \mathrm{I}^{*}$.

tṛ́ṇasya. 9.3.4.

tṛ́nāni. 9. 7.22.

tṛnā. II. 7.21.

tṛ́ṇāis. 9. 3.17.

(cf. upatṛnya.)

tṛ́ng a n: -ma. 6. 102.2 (m. mss. tṛnam).

tṛtá: -ás. 5. I. I (s. mss. trit-). 6. II3. I.

tṛtám. I7. I5.

tratásya. 6. II3.3.

tṛté. 6. II3. I. I9. 56.4 (ed. trité). (cf. trịtíya.)

tretiy a: -as. 4. I6. 2. 9. 9. $\mathrm{I}^{*}$. ro. 4. I. I3. 4.16 . I 4. $2.3^{*}$. I5. 5.5 ; I6. $3 ; 17.3$.

trutíyam. 6.47.3.9.5. I, 3, 6, I I. Io. tṛtíyā. I8. 2. 48 .

tṛtíyām. I 5. 13.8. tritíyena. 7. I. I. 18. 3. $7^{*}$. tṛtíye. 6. II7. 3 ; I22. 4. 9. I. I3; 5. 4,8 . I3. I. II. I8. 4.3 . tṛtíyasyām. 5.4.3. I9. 39.6. tritíyebhyas. I9. 22. Io (m. mss. tṛtíyé-).

(cf. vitṛtīyá, tṛ́tíyaka.)

tṛ́ti y a ka: -am. 5. 22. I3. I9. 39. ro (m. mss. tṛtí-).

tṛ́tīyakāya. I. 25.4.

$\checkmark$ tṛ d: tṛndhí. I9. 29. $2^{4}$. [man.)

(cf. tardá ?, tárdman, tṛd, tṛnn-

+ a ti: áty atṛnat. 19. 32.4 (m. mss. atriñ-).

áti ... tatarda. 7.4I. I.

+ an u: ánu ...tatarda. 2. 5. $5^{*}$.

$+\overline{\mathbf{a}}$ : ef. ātṛ́d.

+ ni: ní tṛnadmi. I9. 32. 4 .

ní tṛndhi. 5. 29.4.

+ vi: vioátṛnat. I I. 8. I8. ví tatarda. I0. 2. 6 .

t r $\mathbf{d}$ in ātṛ́.

$\checkmark$ tr.p: tṛpyatu. II. 9. IO.

trpyantu. II. 9.9.

tātṛpus (p. tat-). II. 7. I3.

átṛpam. 3. 13.6 .

tṛptás. ro. 8.44 .

tarpayāmi. 2. 29. 6.

tarpáyati. 13. 3. 4.

tarpáyathas. 4. 26.6.

tarpáyanti. 4. 27.5.

tarpayāti. 9. 5.9.

tarpáyantu. I5. II. 2, 5 .

tarpayantu. 4. I5. I, 5. I8. 4. 39.

tarpayatām. 6. 134. I.

tarpáyantam. 7. 39. $\mathrm{I}^{*}$.

atarpayat. 8. 9. 24.

títṛpsāt. 8. 3. $17^{*}$.

(cf. tárpaṇa, tálpa ?, tārpyà, tṛp, tṛ́ti, tṛpra.)

+ abhi: abhiotarpáyantīs. 18. 4. 39.

+ s a m: sám atitṛ̣pas. 12. 3. 36 .

trap in asutŕp.

tṛ́pti: -tiā. 9. 5.9.

trpra in

tṛpra。dan̉ çín: -ínas. 7.56.3 (s. mss. trip-).

Vtṛṣ: tṛ́şyate. I9. 2. 5 (mss. tṛpy-) 
tātṛşús (p. tat-). $18 \cdot 3 \cdot 47^{*}$.

tṛşat. 2. 29. 4 .

trusţvâ. I9. 34.6 (mss.).

(cf. tṛ́şnā, trişțá, tṛşya.)

tṛ șțá: -ás. I 9. 57.4 (not mss.).

tṛștám. 5. 19.5. 8. 3.12". 14. 1. 29".

tŗștâ. 5. 18.3. 7. 113.2.

(cf. tṛștajambha-tṛșţikă, tārşțāghá ?.)

tŗ șța $\circ$ j a m bh a: tríșțajambhās. 50. 3 .

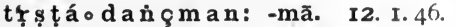
tṛșțá $\circ \mathrm{d}$ ū ma: -am. r9.47.8; 50. I.

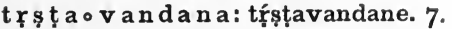
II3. I.

tṛșțiká: 7. II3.2.

tŕsțtike. 7. II3. I.

trusțike. 7. II3. I.

tṛ́ șăa: -ṇayā. 3.31.3.

tṛ́ṣnās. II. 8.2I.

(cf. tṛṣnāāmārá.)

tṛșnāomārá: -ám. 4. 17.6, 7.

trşy a in atrssyá.

Vtṛh: tṛnáhān. 5.8.7.

tṛnéḍhu. 8. 8. II.

tatarha. II. 5.7.

atruam. 2. $31.2^{2}$

tṛ̣̣̣̣huá. I9. 36.5.

tṛhyánte. 5. 17.7.

tṛ̣hyámānānām. I0. 4. 18 . (cf. tarha, tárhaṇa.)

+ vi: ví tṛhyantām. I. 28. 4 : te (pron. $2 d$ pers.), see ta. [136.3.

téj a n a: -am. I. 2.4. 6. 49. I. 20. tejáni. 20. I3I. I I (mss.). (cf. ékatejana.)

téjas: 1. 35.3. 2. 19-23.5. 5. I9. 4. 7. $89.4^{2}$. 9. 1. I7. I0. $3.17 ; 4$. $25 ; 5.36$. I2. $3.2 ; 5.7$ I3. 3.5 . I4. 2. 54. I6. $8.1-27^{2}$. I9. 3 I. $12^{2}$; 53. 4 .

téjasā. 3.5.8. 5. 28. 13. 9. 2.15. I0. $3.17-25 ; 6.27,30$. I3. $4 \cdot 49,56$. I9. $31.3 ; 36.1$.

téjase. I9. 28. I ; 45.6-IO.

téjānnsi. 7. I3. I. I3. I. I4.

téjobhis (p. -jaḥobh-). 13. I. 30. (cf. téjasvant, atejás, agnítejas, ánnatejas, tigmátejas, púruşatejas, bráhmatejas, mánastejas, várunatejas, vắtatejas, vāyútejas, vínaşțatejas, sămatejas, sutéjas, sưryatejas, sómatejas, hiranyatéjas.)

téjasvant: -vat. I 8. 3. $7 \mathrm{I}$

tedanI: 20. I3I. II (mss, tejánI). tãimātá: -ásya. $5.13 .6 ;$ 18. 4 .

tāilá: -ásya. I. 7.2 (mss. tāul-). (cf. tãilakuṇḍá.)

tāil a k uṇ ḍá: -dăt. 20. I 36. I6 (mss. tāílakuṇdam, -umbham).

toká: -ám. I. 28.3.

tokăni. 5. I9. 2.

tokébhias. I. 13.2;26.4.

(cf. ávatoka, sátoka.)

to d a in pratodá, tāúda.

todin in ātodín, nitodín, pratodin, samtodín.

tāú d a: -dĩ. Io. 4.24.

tāulá: -ásya. 1. 7.2 (ed. tāil-).

tāuvilikā: tāúvilike. 6. I6.3.

tmánā. 5.27.II. 6.6.3" (p. vadhatmánā'). 7. 48. $\mathrm{x}^{*}$.

tmány à: -niā. 5. I2. 10".

tyá (pron. stem) : -ám. 7. Ił. I ; 85. I"

(1. tiám). I3. 2. 16". I8. I. $21^{*}$.

tyé. 8. 3. $19^{\dagger} ; 4.20^{*}$. I3. $2.17^{*}$.

$\checkmark$ ty aj: cf. tyaj, tyajás.

tyaj in tanūtyáj.

ty ajá s: -sam. 18. I. $3^{*}$.

tra in gotrá.

trápu: II. 3.8.

trayá: -yần. 4. II.2.

tra y astriǹ çá (p. -yahotr-): -çéna. 8. 9.20.

trayastrinç̧ăsas. I9. 56. 3 (mss. tráyastrinç̧ăsas, -çāsás).

tráy astrinçat (p. -yaḩotr-). 6. I39. I. IO. $7.13,23,27^{2}$. II. 5.2. 12. 3. 16. I9. $27.10 ; 37.1$.

tráyastrinçatam. I I. 3. 52 . (cf. trayastrinçá.)

tráyod aça (p. -yaḥod-). 3.21.5. (cf. trayodaçá, trayodaçarcá.)

tra yo d a çá (p. -yaḥod-): -ás. 5. 6. 4. trayodaçám. I3. 3.8. 
trayodaçarcá (p. -çaoṛc-): -cébhyas. I9. 23. IO.

$\checkmark$ tras: trasantu. 5.21.8. (cf. trāsa.)

+ parā: párā ... atitrasan. 5. 21. 7 .

+ pra: prá trasata. 8. 8. I9.

prá trāsaya. 5.2I. 4-6. (cf. pratrāsá.)

$\checkmark$ trā: trấyase. 5.5.2.

trāyasva. I9. $44.4 ; 49.3$.

trấyatām. 6. 99. 3 .

trắyadhvam. 6.93.3.

trăyantām. 4. I3. $4^{2 *}, 4$. 8. 7. 2, II. trấyamāṇas. 8. I. I 5 ; 7. I4. I 9.10. I0*; 39. 1 .

trăyamāṇam. 4. 9. I. 6. 4. I.

(cf. tra, trātṛ́, trāman, trāyamāṇă, trāvan.)

trātṛ́: -tă. 4. I9.3. I9. I5.3. trātăram. 7.86. $\mathrm{I}^{*}$.

trātúr. 6. 99.3.

trā $\mathbf{m}$ a n in sutrấman.

trāy a māṇă: trấyamāṇe. 6. 107. trāyamānắm. 8. 2.6.

trāyamāṇăyāi. 6. 107. 1.

trā a a in sutrấvan.

trās a in pratrāsá.

trí: tráyas. 4. 3. I; 9.8. 5. 28.3, 8. 6.80. 2 ; II2. 2. 8. 9. I3. 9. 10. $26^{*}$. I0. 6.3I. II. I. IO; 3. 20. I2. 3. 20 . I3. 3.6. I8. 4.4 I9. 47.4 . 20. I29. 8 (mss. tra-). $\left[27.4^{6}\right.$. trîn. 9. $1.8^{+}$; 9. 10* 12. 3. $4^{*}$. 19. tríni. 2. I. 2. 5. I. I; $28 . \mathrm{I}^{3}, 7.7$. 26. $5^{*}$. 8. $2.2 \mathrm{I} ;$ 3. $10^{*} ; 9.3$. 9. 5 . 8 ; 10. $27^{*}$. I0. $7.40 ; 8.4^{2}$. I2. 4 . 47. I3. 3.21 . I8. I. I7; 3. $40^{t}$. I9. 27. 3, 10; 39. 2. 20. 127.3 ; I32. I3. triobhís. 6. II2. 2. I0. 8.43. I2. 3. 42. I9. 6. 2*.

trișú. 7. 26. $3^{*}$. 9. 9. $9^{*}$. I 0. I0. II, tisrás. 3. 24.6 . 4. 20. $2^{2}$. 5. 12. $8^{*}$; I5. $3 ; 27.9 ; 28$. 10. 6. 2 I. I; 75. $3^{2}$; IOO. I. 7. 43. I. 8. 4. II*; 9. I3. 9. 9. IO $^{*}$; IO. $3^{*}$. I0. $8.3^{*}$; IO. 28 . II. 5.3. I3. $3.2 I^{3}$. I9. $27.3^{2} ; \quad 32.4^{2}$. 20. 129.7 .

tísras. $5 \cdot 3 \cdot 7$ (mss. tisrás). tisŕrobhis. 2. 12.4. 7. 4. I. (cf. tṛtá, tritíya, trayá, tráyastrinçat, tráyodaça, trinçát-tryāyușá.)

trinģ̧át: 5. I5.3. 6.31. 3*. 19. 47.4. trinçátā. 7. 4. I.

(cf. tráyastrinçat, triṇçádañga, trinçádara.)

trin̉ çádoañ ga: -am. I3. 3.8.

trin̉ çá d o ar a: -rās. 4. 35.4.

triokakúd: 4.9 .8 .

trikakúdam. 5.23.9. (cf. trāikakudá.)

trí okadruka: -kebhis. I 8. 2. 6". tríkadrukeșu. 2. $5 \cdot 7^{*}$.

triocakrá: -réna. I4. I. 14*.

trị ạ m a n (p. -ionā-): 6. 74. 3 .

tritá, see trịtá.

triodivá: -ám. I0. 9.5 ; 10. 32.17. tridivé. 9. 5. 10.

trionāká: -ké. 9. 5. 10.

trionăbhi: 9.9.2*.

tripañ cāçá: -çís. I9. 34.2 (p. -ñcaoaç-).

tri॰pád: -pấd. 9. 10. 19. 19. 6.3*. trí op ad: -pādam. 13. $2.27^{\dagger} ; 3.25^{\dagger}$. triop rș țhá: -țé. 9. 5. Io. [I0. 2.32. tríopratisthita (p. -tisthi-): -te. tri॰bhúj: -jam. 8. 9.2.

trioyojaná: -ám. 6. I3I. 3.

triovárūtha: -am. 7.6.4. 8. 5 . 20. 9. 2. 16.

triov'́t: 5.28.4,6, II. [27.3. triṿ̛́tam. 8.9.20. I0. 8.17. I9. triṿ̛́tā. 5. 28.2, 8. I9. 27.3 (s. mss. -tās), 9 (mss. -tās, -tāt).

trivị́ti. 5.28.3.

triṿ̛́tas. I9. 27.3.

trivị́dobhis. I9. 27.3, 9 .

tri॰vṛsá: -ás. 6. 16. 3 .

tri॰çatá: -tăs. II. 5.2.

trioçĩşán: -șănam. 5.23.9.

tri॰çóka: -am. 4. 29. 6 .

trís a m dhi (p. tríosa-): -is. II. 9. 23.

trísamdhe. II. IO. 2, I8, I9.

tríșamdhim. II. IO. IO, II.

tríșamdhinā. II. IO. 3, 27.

tríşamidhes. II. IO. $2,4,5,6,7$, I 5 . 
trişaptá (p. triosa-): -tăs. I. I. I ; 27. I.

trişaptắsas. I 3. I. 3 . [6. $4^{8.3}$. triş țú poch an das (p. -istú-): -dăs. trişțúbh (p. triostú-): 8. 9. 20. $\quad$ I8. 2. 6". I9. 2 I. I.

trișțúbham. 8.9.14.

trişțúbhas. 20. 2. $1-4$.

(cf. trāișțubha, trișțúpchandas.)

trís. 5. 2. $3^{*}$. 8. 3. $1 \mathrm{II}^{*}$. I2. 2.29. I4. I. 4 I $^{*}$ I9. $6.15^{*}$. 20. 34.6 (mss. trusțâ); $39.5^{3}$.

trihă y a ṇa in trāihāyaṇá.

tredhă. I. I2. I (l. trayadhă). 4 . I6.6. 5. $28.6,7$. 7.26. I* (1. trayadhâ), $4^{*}$ (do.); 44. I*. 8. 3. IO". II. I. 5 ; 8. 33. I3. 3. 2 I (l. trayadhâ), 21. 18. 4. II. 20. 135. 13 .

trāikaku dá: -ám. 4. 9. 9, 10. trāíkakuda. 19. 44.6 (mss. -dam).

trãíṣțu b ha (p. trāístu-): -am. 9 . Io. $I^{*}$.

trāístubuena. 9. 10. 2". trāíșțubhāt. 9. Io. I".

trāihā y a ṇá (p. -yan-): -ṇăt. ro. 5 . 22. 12. 4. 16.

tr y àr a: tríoare. I0. 2. 32 .

tryāy uşá: trioāyuşám. $\quad$ 5.28. $7^{2}$. tvá (pron. root): tvám. I. 8.4; 9.3; II. 3,$6 ;$ I 7. $2 ; 24.1,3 . \quad 2.3 .2 ; 6$. $5 ; 25.4 ; 28.3 ; 29.7 ; 36.8$. 3. 4 . I ; $5.6,7 ; 12.5 ; 18.5^{*} ; 23.5 ; 31$. I. $4.6 .8 ; 7.6 ; 9.3 ; 10.6^{2} ; 17.8$; I9. 4,$5 ; 20.5 ; 22.1,6 ; 31.3^{*}$. 5. 5 . 4 ; 6. IO; II. 1, 2 ; I3.10, II: I4. I, $2 ; 21.4-6 ; 22.10 ; 29.5$, I4; 30. I7. 6. I6. $2^{2} ; 32.1 ; 59 . \mathrm{I}^{2} ; 63.3 ; 8 \mathrm{I} .2$; 84. $3 ; 92.2 ;$ 105. I-3; 131. 3 ; 133. 5 ; 134. 3 ; 138. I. 7. $38.4^{2} ; 56.4$; 74.4 (mss. tvăm); 76. $5 ; 78.1 ; 8 \mathrm{I}$. 5 ; 106. I ; เо9. 2. 8. $5.15 ; 6.9$, 10; 9. 7. 9. 2. I, $4,9,10,17,18,19-24,25$. I0. $3 . \mathrm{I}, \mathrm{I} 5,16 ; 5.45 ; 6.6-17,20$, 2I ; 8. 27; 9. 2, I2; I0.8, I 9. II. I. $10 ; 3.27 ; 4.14,16 ; 9.5,6,18$; I0. 5. I2. I. $15^{2} ; 2.1,10,17,45 ; 4$. $43 ; 5.55,65$. I3. I. $32 ; 2.29^{\dagger} ; 4$. 47. I4. I. $20^{*}, 43,5 \mathrm{I}, 6 \mathrm{I}^{\dagger} ; 2.50$. I7.
6-I9, 9, II $1^{3}, 12,15,16,18^{4}, 20,21,24$. I8. I. $16^{*} ; 2.35^{*}, 59^{*}, 60 ; 3.6^{*}, 42^{*}$; 4. 3I, 65". I9. I5. I (ed. tád); 28. 2 ; 31. 9, II, 13; 33. 5; 35.3 (not mss.); 44. I ; $46.7 ; 48.3 ; 49.8$ (not mss.); 57.4; 59. I"; 64.2. 20. I28. I3.

tuám. 1. 7. I. $7 ; 11.3 ; 34.4$. 2. 27. 7. 3. $20.2^{*}, 5^{2 *} ; 23.4,5$. 4. I. 7 ; I0. 6 ; 13. 3" ; 18.4 ; 19.7; $32.3^{*}$, $4^{*} ; 33.6^{*}$. 5. 3.2 $2^{\dagger} ; 5.2 ; 8.7$; II. 4, 5, 7; 12. 1", 3"; 20. 2; $28.10 ; 29$. I. 6. $5.3 ; 30.2 ; 65.1 ; 79.2 ; 86$. I-3; $98.2^{3} .3 ;$ I03. 2,$3 ; 104.2 ; 108$. $1^{3} ;$ II2. $2 ;$ II7. I; I28. $3 ;$ I30. 4 . 7. $20.2 ; 38.4 ; 65.1 .8 .2 .16 ; 3$. 1 $9^{2 *}, 20^{*}$. 9. 3. 9. 10. I. $26 ; 6.34$; 8. $27^{2}$; 10. 8 . II. 9.1 I I5, 22, 24 ; 10. I9. I2. I. 6I. I3. $2.21^{*} ; 3.23 .14$. 2. $71^{3}$. I7. IO, I5, I6 . I8. $3.8,42^{*}$; 4. $59^{*}$. I9. 30. $3 ; 31 . \mathrm{II} ; 32.5 ; 33$. $3^{3} ; 35.3 ; 52.2^{2} ; 59 . I^{*}$. 20. 128. I 3 ; I 35. II, 12.

tvắm. 2. 10. $2-8 ; 36.7 .3$ 9.6. 5 . I4. $9 ; 25.2$. 6.63.2; 84.3. 7.38. 2,$5 ; 80.4 ; 82.6$. 8. 2. 23,$27 ; 5.14$. 9. 4. 9. II. I. II; 2. I3;3.27. I3. I. 58 . I 8. I. 15*, I6". I9. 30.2 (mss. tvám: tám?), 2, 3; 31. 13; 48.6; 64.4 (mss. tâbhis).

tuấm. 2.6.3. 3. 4. $2^{2}$. 6. 78. 3. 8. I. 5; 7.26. 9. 4. 9. I7. 14. I8. 4. 75 , 76. 19. 30. $3^{2} ; 33.3$.

tvā. I. 10. 3,$4 ;$ I 2. $2 ; 16.4 ;$ I 8.3 ; 22. I, 2, 3; 23. $2 ; 29.3^{2 *} ; 34.1,5$; 35.4. 2. $2.1 ; 5.2,4 ; 6.1$; IO. $1-8$, I, 5 ; 12. 3 ; $13.5^{2} ; 27.2^{2}, 3 ; 2 S .4$. 3. $3 . \mathrm{I}, 3,5 ; 4 . \mathrm{I}^{2}, 3,4^{2}, 5,6,7 ; 5.8$; 7. $2,5^{\dagger}, 6 ; 9.5 ;$ 10. 3 , I0; I1. I $^{*}, 7^{3}$, $8^{2}$; 12. I ; 15.7; 16.5*; $21.5 ; 23.6$; 24. 6 ; 25. I, I-3, 5 ; 29. 7, 8. 4. 4. $\mathrm{I}^{2}$; $6.3 ; 7.3,4,6 ; 8.4,5,6^{2} ; 9.5 ; 10$. 7 ; $13.5^{*}, 7^{*} ; 15.4 ; 16.9$; 1 7. 1; 20. $6 ; 22.5 ; 32.5^{*} ; 34.5-7^{2}$. 5. 2. $4^{\prime \prime}$; $3 . \mathrm{I} ; 5.2 ; 6 . \mathrm{II}-4^{2} ; 7.7 ; 8.9 ;$ II. $7 ; 13.4 ; 14 . I^{2}, 7 ; 22.11 ; 25.8 ; 28$. $5,9^{2}, \mathrm{IO}, \mathrm{I}^{2} ; 29 . \mathrm{II}^{*} ; 30.2,5,8, \mathrm{I}_{5}$, I7. 6. $9.2 ; 26.2 ; 29.3 ; .45 .1 ; 46$. $2 ; 48.1-3 ; 84.1^{2} ; 87 \cdot 1^{2 *} ; 89.3^{2} ; 92$. 
I ; 99. I' ${ }^{2} ;$ I06. $3 ;$ I09. $3^{2} ;$ I II I. $4^{2}$; II3. I, $3 ;$ I33. 5 ; 136. I; I38. 3 ; 142. I, 2. $7.35 .3^{2} ; 37.1 ; 38.3 ; 45.1$; 50. $5 ; 56.7 ; 71 . \mathrm{I}^{*} ; 72.2^{*} ; 74.4$; 78. $2 ; 82.3 ; 97 . \mathrm{I}^{*}$; IIO. 3 ; II5.I ; II 7. I*; II 8. I ${ }^{2 *}$. 8. I. $3,7,9, \mathrm{II}^{2}, \mathrm{I}^{3}$, $\mathrm{I} 3^{3}, \mathrm{I}^{2}, \mathrm{I} 5^{2}, \mathrm{I} 6^{2}, \mathrm{I}^{2}, \mathrm{I} 9^{3}, 2 \mathrm{O}^{2 *} ; 2.2,4$, $9^{3}, 14,15^{2}, 20,22,26 ; 3.9^{*} ; 5 \cdot 14^{2}, 15^{3}$, $22 ; 6.7,8^{2}, 2 \mathrm{I} ; 7.28 ; 9 . \mathrm{I}, 7$; 10. $3 \mathrm{I}$. 9. I. $2 ; 3.9, \mathrm{II}^{2}, 22 ; 4$. IO; 5. 2 , I5 ; 10. $13^{*}$. I0. I. $7,9^{2}, \mathrm{II}, \mathrm{I} 2,15^{2}, 18,26$, 28. 29; 3. 3, 4, 7, 13-5; 4. 6; 6. $3^{2}, 34$; 7. 29,$30 ; 8.10,34 ; 9.2^{2}, 8 ;$ 10. 7,9 , 10, 22. II. I. I, 3, I3, I4, I6, 22. 25 , $26,32,33,34$; 3. 22, 28, 29, 38, 39, 40, 42,$47 ; 4$. 19, 26 . I2. I. 18, 29, 34, $55 ; 2.5^{2}, 6,16 ; 3.22,23,24^{3}, 35^{2}, 55^{-}$ $60 ; 4.43$. I3. I. $x$, Iо, I $2,5^{3}$, I 7-9, $20^{2}, 36^{2}, 43^{2} ; 2.4,12,23^{*}, 36 ; 4.47$, 50-4. I4. I. $4^{*}, \mathrm{Ig}^{2 *}, 2 \mathrm{O}^{2 *}, 45,5 \mathrm{O}^{*}, 52$, $5^{8^{2 *}} ; 2.7,19,59-62,7 \mathrm{O}^{3}$. I 6. 5. I-6. I7. 8. I8. I. $56^{*}, 57,60^{*} ; 2.21,22$, $25,3 \mathrm{I}, 5^{2}, 54^{2 *}, 55^{3 *}, 57,5^{8^{*}} ; 3 . \mathrm{I}, 29$, $30-5,49^{*}, 66^{*} ; 4.9,33,44,48,5 \mathrm{I}, 52$, $67,88^{+}$. I9. I4. I; 25. I; 26. $2,3^{2}$; 27. $\mathbf{1}^{4}, 2^{2}$, ? $, 5,9 ; 34.6$ (mss. tŕș̣țyā), $6,7^{2} ; 37.2,3^{2} ; 39.2-4,9^{2} ; 44.6,10^{2}$; $46 . \mathrm{I}-7, \mathrm{I}, 2,4^{2}, 5,7 ; 49.5$; 5 I. 2 ; 55 . $3.4 ; 56.2 ; 57.4 ; 64.2 ; 65.1$. 20. 48. I; 130. $14 ; 135.9$ (not mss.); I36. I 2,14 .

tuā. I. I 3. $4 ; 3$ I. $3^{2}$. 3. $3 \cdot 3^{2} ; 12$. 3 ; 17. $8^{*}$. 4. I7. I. 5. $2.4^{*} ; 28.13^{2}$. 8. I. Ir. 9. 3. 24 . I0. $9.7,8,9$; 1 о. 7, I6. I2. 2. 6, I6. I3. I. $2 I^{\dagger} ; 2.5$. 14. 2. $33^{*}$. I9. $37 \cdot 3^{2}$.

tváyā. I. 7.5. 3. 6.4. 4. I5.6; I 7. 6,7 ; 8.8 ; I9. 4 ; 20. 2 ; 3 I. I* $4^{*}$; 32. $\mathrm{I}^{*} ; 37 . \mathrm{I}^{3} ; 2 . \quad 5.2 .5^{*} ; 3 . \mathrm{I}^{*} ; 29$. I; 30. x6. 7. 65.2 (mss. táyā), 3. 9. 5. I6. I I. 2.20. I2. $2.5 ; 5.6$ I. I4. 2. I 7. I8. 4.7 O. I9. $32.3,4 ; 55.6$ (mss. tvám).

tuáyā. 7.50.4*.

túbhyam. I. I3.3. 2. $9.5 ; 28$. I. 3. 23. 5. 4. 8.2. 5. I8. I. 6. $92.3^{*}$; I12. I. 7. $46.3 ; 82.3,6$. 8. I. $5^{2}$; $2.22 ; 7.25$. 9. 5. 38 . II. $2.24^{2} ; 4$.
I9. I2. I. 62. I4. I. $58 ; 2 . I^{*}$. I7 I8 ${ }^{2}$ I9. $48.2 ; 50.7$.

tvát. 3. 7.6. 5. II. $4^{2}$. 6. $87 . \mathrm{I}^{*}$; 9o. I. 7. 79.4 ; 80. $3^{*}$. 8. I. $2 \mathrm{I}^{2}$.

tuát. 3. $23 . \mathrm{I}^{2}$. 6. 30.2. 9. 8. I02 , I9, 20. I2. I. I5. I8. 3. $52^{*}$.

táva. I. I0. $2 ; 23.3$. 2. 29. 2 . 3 . I0. 8 . 4. 9. $7^{*} ; 25.3 ; 32.5^{*} ; 39$. 10 . 5. $5.8 ; 8.9^{2} ;$ 30.8. 6. I5. $\mathrm{x}^{*} ; 44$. I ; 5I. $3^{*}$; 139. I. 7. 9. $3^{*} ;$ 73. 10*; 83. $3^{*}$. $\quad$ 8. $2.3,7$. 9. $4.23^{*} ; \quad 5.38$; 8. II, I9. IO. 4. I8; IO. I8, 20, 2I, 22. II. $2.9,10^{5}, I I, 24 ; 4.9 ; 9.7-I I$, I3, I4, 25. I2. I. I5; $3 \cdot 39^{2}$. I4. I. 51 ; 2.60. I7. 6-19, 24. I8. I. I6*; 3. $2^{*}$. I9. $15.1^{*}$. 20. 136.6 (mss. tava).

tváyi. 4. 25.3. 8. 2.3. I2. I. I5. I3. I. 54. I8. $2.52 ; 3.70$. I9. 3 I. $\mathrm{II}^{2} ; 47.9$.

tué (p. tvé íti). 5. 2.3*.

te, see under ta pron.

(cf. tvádyoni.)

[9. $9^{2}$.

tva (pron. root): tvé (p. tvé íti). 8. $\checkmark$ tvakș in tváșțr.

tvác: -cam. I. $24.2 ; 33.4$. 4. 12. 5. 8. $3.4^{*}$. 9. $4.14 ; 5.4$. I2. 3.21 ; 5. 68. I6. I. I2. I8. $2.4^{*}$. I9. 28.4 . tvacă. 4. I2. 5; 14.9. II. 8. I 5 .

tvacé. II. 2.5 .

tvacás. 5. 14.3. 6. 2 I. I. I2. 3. 53 . tvací. I. 23.4.

tvacăm. I2. 3. $5 \mathrm{I}$. (cf. súryatvac, tvacas.)

tvacas in súryatvacas, híranyatvacas, tvacasyà.

t v a c a s y à: -àm. 2. 33.7.

tvádyo ni: tuádoyonayas. I3. I. 2. $\checkmark$ tvar: tvaráya. I2. 3.3I. (cf. tváraṇa.)

tva ra ṇá: -ṇấs. II. 8. 28.

tváṣṭ̣: -țā. 2. 5. $6^{*} ;$ 26. I. 3.8.2; 20. 10; $31 \cdot 5^{*}$. 5. $25 \cdot 5^{*} ; 26.8$. 6. 4. I; 53.3;78. $3^{3} ; 8 \mathrm{I} .3 ; 92 . \mathrm{I} ; \mathrm{I} 4 \mathrm{I}$. I. 7. 7 7.4. 9. $4.6 ; 6.45 ; 7.7$ II. 8. 8,9, I 8. I2. $2.24^{*}$. I4. I. 53,60 . I8. I. $5^{*}, 53^{*}$. I9. 10. $6^{*}$.

tváṣțar. 5. 25 . Ix. 
tvașțar. 2. 29. 2. 5. 27. 10. 6. 3.3. tváșțāram. 4. 30. 6*. 5. 12.9*. I 1 . 6. 3 .

tváşțã. I2. 3.33.

tváşțur. 9. 4. 10. II. $3.45 ; 8.9,18$. (cf. tvāșțá.)

t vășțrá: -rénaa. 7. 74. 3.

vtviş: tvișitás. 4. 3I. 2".

(cf. tvíși, tveșá.)

tvissi: -is. 6. 38. I, 2. I2. 5.8.

tvísim. I2. 1. 8.

tvíşiā. I0. 6.27.

(cf. tvíșimant.)

[1. 58 .

t víşi ma nt (p. -şiom-): -măn. I 2.

tvisịimantam. I2. I. 21.

tvísimate. 6. 20. 2.

tvíşimati. 4. I9. 2. tveşám. I9.47. I. (cf. tveșáṇ̛mṇa.)

tveșáon ṛmṇa: -as. 5. 2. I"; II. I. $\checkmark$ t s ar: tsárati. 8. 6.8.

tsáran. I2. 3. 13 .

(cf. tsārín.)

tsārín: -rí. Io. I. Ig.

d a in dāyādá, ałomadá ?, prāṇadá; and cf. dã.

$\checkmark$ d à̉ ç: daça. 5. I4. 10.

dașțám. 7.56.3.

(cf. dañça-dáṇșțra.)

+ s a m: cf. samdańçá.

d a ṅ ça in samidanç̧á.

d a ńçin in tṛpradançín.

$\mathrm{d}$ a ṅ ç $\mathbf{m}$ a $\mathbf{n}$ in tṛșțádaņçman.

d a ṅṣṭ̂́: -țâram. I0. 4. 26.

dánșțra: -rāu. $\quad$ 8. 3. $3^{\dagger}$.

dáṅșțābhyām. I $0.5 \cdot 43$.

dáṅșțrayos. 4. 36.2. I6. 7.3.

dáṅșțrās. II 6. 22.

(cf. áyodañșțra, cáturdaṇ̃țra.)

V d a kṣ: dákșamāṇas. I. 35. 3 .

dákșamānās. 2. 4. I.

(cf. dákşa-dákşiṇa.)

dákṣa : -am. 2. 29. 3. 4. 13. 2", $5^{*}$; 25. 5. 5. 28.5. 7. 14. 4. 16. 4. 7. dákșāya. 6. I9.2. I8. 2. 23. (cf. dákşatăti, dākşăyanáa.)

dákşa otãti: -im. 8. 1. 6 .

d a kş a s in pūtádakşas.

dákşiṇa: -as. I5. I8.3.

dákşiṇă. 3. 27.2.

dákşịnam. 4. 14.7. 7.9.4". 12. I. 34. I4. I. 48 . I5. 18.2. I8. 4. 56 . 20. 128. I6.

dáksiṇām. 10. $5 \cdot 37$. I2. 3.8. I5.

$2.2 ; 14.2$.

dákṣiṇăyāi. I2. 3.56.

dákșiṇăt. 7.26.8.

dákșinăyās. 4. 40.2. 5. 10. 2.9. 3. 26. I 5. $4.2^{2} ; 5.2^{2}$. I 8. 3. 26. I 9. I7. $3 ; 18.3$.

dákșiṇe. 4. 20.4. 7. 50. 8.

dákṣiṇăyăm. 3.26.2. 4. 14.7. 15 .

2. 2. I 8. 3. 31 .

(cf. pradakșiṇá, dakșiṇatás-dakşiṇāgní.)

dakșiṇatás. 4. 32. $7^{*} ;$ 40.2. 6. 98. 3. 10.9.8. I1. 6. 18. 12. 3.24. I8. I. $52^{*} ; 4.15$. I9. I6.1. [1. 28. dakṣiṇa os a v yá: -yấbhyām. I2. dákṣiṇa (adv.). I8. I. $42^{\dagger}$ (s. mss. dakșiṇâ"). 19.13.9".

d a kșinat. 9.7.20. I2. 2.34.

dákṣinā: 4. II.4. II. 7.9;8.22. I 8. 4.50 .

dákșināam. 5. 7. I ; II. I. 9. 5. I4. 13. I. 52. 18. 4. $29^{*}$. 20. I35. 6.

dákșiṇayã. 6. 53. I.

dákṣịaãyās. 6. 58. I. 9.9.9".

dálkṣiṇās. 9.6.54. I5. I6. 7.

dákșiṇābhis. I9. 9.6.

dákṣiṇānām. I8. 4. 8.

(cf. çatadakṣiṇa, sahásradakṣiṇa, dákṣiṇājyotis-dakșiṇ̂ya.)

d akși ṇăgní (p. -ṇaoag-): -ís. 9.6. 30. I5. 6. 5. I 8.4 .8 (m. mss. dákşināgnis), 9 (do.).

dakṣiṇāgnés. I5. 6. 5 .

dakșiṇāgnāú. 8. I0. 4 .

dákșina $\bar{a} \circ$ jyotis: -işam. 9. 5.22, 24-6, 28, 3I-6.

dákṣiṇãovant: -vate. I 8. 3.49*. dálș̣iṇāvantas. I8. 3. 20.

dakșiṇîya: -as. 8. I0. 4 . 
d a g d h a in agnidagdhá. $\checkmark \mathrm{d}$ ag $\mathrm{h}$ in

d a g h van in ápaçcādaghvan.

d a ṇ dú: -ás. 9. I. 2 I.

daṇạ́m. 18. 2. 59 .

dandéna. 5. 5.4. I0. $4.9 ; 8.27$. (cf. jāladaṇụá, dáṇ̣̣ana.)

d áṇ dan a: -am. I2. 2. 54 .

d a t t a in ádatta.

d a t t va à in ádattvā.

d a $\mathbf{r a}$ in suvidátra, sudátra.

d a tvánt: -vátām. 4. 3.4.

datvátī. 4. 3.2. 7. 108. 1. 19. 47.8. $\checkmark$ dad, see $\sqrt{ } \mathrm{I}$ dā.

d a d in āyurdád.

$\mathrm{d}$ a d a $t$ in ádadat.

dadí: -ís. 5. 13. I.

$$
\text { (cf. pradadi.) }
$$

d a di $\mathbf{v} \bar{a} \dot{n} \mathbf{s}$ in ádadivāns.

d a dị́ h: dadhṛ́k. I 8. 2. $5^{*}$.

$\checkmark$ dadh, see $/$ I dhā.

da dhán, dádhi: -dhi. 20. 127.9. dadhnâ. 4. 34. 6, 7 .

dadhnás. 3. 12.7. 7. 72. $3^{*}$.

(cf. dadhikrấvan, dádhivant.)

d a dhikrăva n: -vā. 3. I6. 6* (oiva).

dádhiovant: -vān. I8. 4. I7.

d a dhiṣú: -ṣós. I8. 3.2.

dánt: dată. 6. 56.3 .

datás. 5.29.4. 6.56.3.

dadobhyás. II. 2. 6.

datăm. $5 \cdot 23 \cdot 3$.

(cf. ubhayấdant, ṿ̛́ṣadant, çatádant, çyāvádant, datvánt, dánta.)

dánta: -tāu. 6. I40. I, 3 .

dantāu. 6. 140.2, 3 .

dántās. 4.3.6. 5.18.8. 9.7.3. II. 3. 37. I9. 60. I (not mss.).

dántāis. II. $3 \cdot 37^{2}$.

$\mathrm{dabdha}$ in ádabdha.

$\checkmark \mathrm{d}$ a bh, d a m b h: dabhnuhi.

dabhāti. 4. $21 \cdot 3^{*}$. 6. 27. $3^{*}$.

dabhan. 4. 7. 7. 5. 2. $4^{*}$. 8. 3. $9^{*} ; 6$. 25. I3.2.5. I7.8. I9. $27.5,6 ; 46.2$. dadámbha. 5. 29.6, 7, 8, 9 .

dípsati. 4. 36.2. 5. I4.2. 7. 108. I. 8. 4. $\mathrm{IO}^{*}, \mathrm{II}^{*} ; 6.8$.

dípsanti. I0. 3. I6. I9. 49.7;65. I. dipsanti. 8. 4. 20*.

dípsāt. 4. 36. I, 2 (mss. -sat).

dípsa. 5. 14.1 .

dípsantam. 5. I4. I.

dípsatas. 4. 36. 2, 3 .

dambhaya. 7. 90. $I^{*}$.

(cf. dabdha, dábha, dabhna?, dabhrá, dambhana, dābhya, dípsant, dipsú.)

dábha: -bhãya. 4. I. 7 (mss. ed. -āyat).

d a bhn a in duradabhná.

dabhrá : -ám. 8. 4. 10*.

$\checkmark$ d a m: damáyan. 5.20. I. (cf. dam, dáma.)

d a m in dámūnas, dámpati.

dám a: -meodame. 7. 29. I, 2. (cf. purudáma.)

dám $\bar{u}$ n as: -nās. 7.14. $4 ; 73.9 *$ I 9.

dám $\mathrm{m}$ a ti: -tĩ (p. -i íti etc.). I 2.3 .

14, 35. I4. 2. 9, II" 64 . I8. I. $5^{*}$. dampati (do.). 6. I22.3. I2. 3.7. dámpatiobhyām. 12. 3.27.

$\mathrm{d} a \mathrm{~m} b \mathrm{~h}$ a $\mathrm{n}$ a in sapatnadámbhana.

$\checkmark$ day: dayasva. 8. 2. 8.

dayatām. 8. I. 5 .

(cf. dayā.)

+ a v a: áva daye. I6. 7. II.

+ nis: nír dayāmasi. 19. 57.6.

d a y $\bar{a}$ in adayá.

d a r a in tāyādará (?), puramidará.

d arbhá: -ás. 6.43. I, 2. 8. 7.20. Io.

4. 2. II. 6. I5. I9. 30. 5; 32. I, 9, I0;

33. $I$.

dárbha. 19. 33. 2.

darbha. I9. 28. 2-IO; 29. I-9; 30. $\mathrm{I}-4 ; 32.8$.

darbhám. I9. 28. I (m. mss. dárbham); 33.5 .

darbhéna. I9. 32. 2, 7; 33.5.

darbhéșu. I0. 4. I3.

dárvi: -is. 9.6. I7. II. I. 24; 3 . 16. I2. 3.36 .

darve. 3. I0. 7. I0. 4 . 13 .

dárvyā. 4. I4. 7.

d a rçá: -ás. 7. 81.4.

darça. 7. 81.3.

(cf. avasānadarçá, vadhūdarçá.) 
d a rça tá: -ás. 4. 10.6. 7.81.4. darçatám. 18.1.17. (cf. viçvádarçata.)

dávĩyas: 6. I 26́. $\mathrm{I}^{*}$. I0.8.8. dáça: 5. I 5.1, I0; 17.8; 28. I1. 9. 9. $14^{*}$. II. $2.9 ; 7.4 ; 8.3$, 10. 13. 4. 6. 20. I27.2, 3 (mss. daça), 3 .

daçáobhis. 7.4. I. 8.4. 15*. II. 2. 23. (cf. așţādaça, ékādaça, caturdaça, tráyodaça, àvădaça, pañcadaça, șoḍaça, saptadaça, dáçapakșa-dáçaçirșa, daçãngulá, dáçāsya.)

d áça $\circ$ pa kṣa : -şām. 9. 3. 21 .

d a ç a má: -ás. I3. 4. I8.

daçamé. $5 \cdot 25 \cdot$ 10-3.

daçamím. 3. 4. 7 .

dáç a $\circ \mathbf{m} \bar{a} \mathbf{s}$ y a: -sias. 3. 23. 2.

daçamãsia. I. Ir. 6.

d a çarājan in dāçarājñá. [23. 7 . d a ç a rcá (p. -çåṛc-): -cébhyas. I 9. d a ça०vṛkṣa: dáçavṛkṣa. 2. 9. I. d a ça 0 v ṛsá: -ás. 5. 16. Io. d a ça oçat á: -tâs. 5. 18. ro. d áça ०ça l a: -lāt. 8. 7.28. d á ça $\circ$ çā kh a: -khābhyām. 4.13. $7^{*}$. dáça 0 çirşa: -as. 4. 6. I.

$\checkmark$ daçasy: -yet. I8. I. 10*. [6. I* d a çā̄n gu lá (p. -çaঃañg-): -ám. 19. dáçã s y a (p. -çaoās-): -sias. 4.6. I. dáçonasi: -im. Io. 4. I7.

$\checkmark$ das, dàs: cf. das, dasmá, dásyu, dasra, dasvant, dāsá, dăsa.

+ abhi: abhiodăsati. I. 19. $3 ; 21$. $2^{*}$. 2. 27.7 . 4. 19. 5. 6. $6.3^{*} ; 1_{5}$. $I^{*}, 2 ; 54 \cdot 3$. 8. $4 \cdot 7^{*}$.

abhiodásanti. 4. 40. I-8.

abhiodâsāt. 5.6.10; 10. 1-7. 7 . 108. 2. 12. I. 14.

abhiodăsān. I9. I8. I-IO (mss. -sāt). abhiodăsan. 6.66. 1.

abhiodâsantam. 8. 3. 25 .

abhiodăsatas. I. 21.3".

[4. 2.

+ u pa: úpa dasyati. 3. 29. 2, $6^{2}$. I2. úpa dasat. 5.30.15.

úpa dāsayati. I2. 5.27.

úpa dāsaya. I2. 5.52.

(cf. ánupadasvant.) das in riçầdas (?).

d a 8 má : -ám. I8. r.21".

dásy u: -yos. I. 7. I.

dásyavas. I 8. 2.28 (mss. dasyá-). dásyūn. 4.32.6". 9.2.17,18. 10. 3. II. II. I. $2^{*}$. I2. I. 37 . I9. 46. 2. dásyuobhyas. 2. 14.5. [6.20. dásyūnām. 3. 10. 12. 8. 8.5, 7. I0. (cf. dasyuhán.)

d a s y u ohán: -hă. 4. 32.3".

d a sra: dásrā. 7.73. 2.

dasvant in ánupadasvant.

V dah: dáhāmi. 5.23.13. [dahá). dáha. 12. 5.62. 19. $29.8^{4}$ (m. mss.

dahatu. I2. 5.6I.

dáhan. 6. 37.2.

dáhatas. 6. 20.x. 7.45.2 2 .

ádahat. I. 25. I.

dagdhăyām. 4. 18.3.

dagdhấs. I8. 2.34.

[mss.).

dahyante. 12. 4.3. 20. 136.8 (not (cf. dagdha, dahana, dāgha, dāha.)

+ anu: ánu daha. 5. 29. I I*.

anuodáhan. 2.25.4.

+ a p a: ápa ... dáhan. I. 28. I.

$+\overline{\mathbf{a}}$ : ef. ādáhana.

+ ni: cf. nidāgha.

+ nis: níh ... dahati. 9. 5. 3I-6. nír daha. 3. 2.5*. 7. 108. 2. 9. 2. 4 . (cf. nirdahaná, nirdāhá.)

+ anunis: anuonírdaha. 9. 2.9.

+ pra: prá dahati. 4. 34. 2. prá dahāmasi. I3. I. 29. prá daha. 12. 5.62.

prá dahatu. 4. 36. I. I3. T. 29. praodáhan. I0.8.39.

prá dhāk. 8. I. Ir.

+ prati: práti daha. I. 28. 2. 6.32. x. práti ... dahatam. 3. I.3.

práti ... dahantu. 8. 3.19*.

pratiodáhan. 3. I. I ; 2 . I.

+ vi: ví dahas. I8. 2. $4^{*}$.

vidáhyati. 20. 136.8 (not mss.).

viodhalsșyán. I 8. 2. $8^{\circ}$ (mss. ed. -kṣán).

+ s a m: sám daha. I. 28.2. I2. 5 . 62. I8. 3.7I

samoádahas. I $8 \cdot 3 \cdot 6^{*}$. 
+ a n u s a m : anuosám daha. I2. 5.63. d a h a $\mathbf{a}$ in ădáhana, nirdahaná.

V I dă a da d: dádāmi. 5. II. IO. I2. 4. I. I8. 2. 37.

dadāmi. 4.34.7. 5. II.8. 6. 123. 4. 12. 3.47

dádāsi. 7. 48. $2^{*}$.

dádāti. 3.29.3. 4. 21. 3*. 9. 5. 22, 246, 28, 3I-6. ro. 9. 5,6, 10. 14. 2. 41. dadāti. 6.63.2; 84.3. 9.4. 9; 5. II, I2. I 8. I. $55^{*}$; 4. 3 I. I9. $5 \cdot 1^{*}$. dádātas. 9.5.27 (dádatāu ?).

dattás. I4. 2. 42 .

dadati. 8. IO. I9. I2. I. 22.

dadyāt. 3. 28.2. 9. 5. I4.

dehí. 5. II.9.

dehi. I8. 3. 70 . I9. 7.4 (mss.).

dádātu. 7.47. I; 48. I*. [12.1. 44 . dadātu. 6. 33. 3 ; I22. 5 . 7.80.2.

dattám. 14. 2.42.

dattam. 19. 42.4 .

dattá. 6. 24. 3. 7. 50. 9.

dattó (p. -ó íti). I8. 3. 14 .

datta. Ir. 6. 23.

dadatu. 3.5.3. ro. 6.29.

dádat. 3. 16. $3^{*}$.

dádatas. ro. I. I I.

dádatas (pl.). 6. 122. 2.

ádadāt. I4. I. $9^{*}$ (p. ad-).

adadāt. I2. 4.50 .

adadus. 5. $17 \cdot 1^{*}, \mathrm{IO}^{\dagger} ; 18.1$.

dadās. 12. 4.52 .

dadāt. II. I. 27.

dadate. 10. 8. 36 .

dádante. I0. 8.35 .

ádadat. $12 .+23$ (mss. ad-).

dadat. I4. 2. $4^{2 *}$.

dádan. 6. 24 . I.

ádadanta. I4. I. 45 .

dadús. IO. IO. 32 .

dadus. 5. 17. 10*. 10.2.29. I9. 35. I. dade. I0. 2. I6.

dadāvăn. 5. I I. I.

dadivắnsam. 9. 5. 10.

adāt. 3. $29 \cdot 7^{2}$. 6. 100. $1^{3}$. I2. 4 . 49. I 4. I. $52 ; 2.2^{*}, 4^{*}$.

ádus. 5. 25.9. II. I. I 7. [I9. 30.2. adus. 2. 36. 7. 6. 100. $\mathrm{I}^{2}$. 14. $1.50^{*}$. dâs. I 4. 2. I*

dās. 2. 6. 5 ; I 7. I-7; 18. I-5. 3. I2. 5. I4. I. $37^{*}$.

dāt. I8. r. $4 I^{*}$,

dātām. I8. 2. $13^{*}$.

dus. 6. $1 \mathrm{I} 1.4^{2}$.

dāsyán. 6. 71.3.

dattás. 2. 29.4. 3. 5. 4; 29. 1, 2.9. 4. $7 ; 5.7$, II. I2. 3.42 .

dattám. 4. 9.1. 6.71. $2 ; 89.1$; 122. I, 2. I4. 2.4 I. I8. 2.57 . I9. 37. I.

dattă. 5.7.5. I0. 9. I. I8. 4.50. dattăm. 7. IO4. I.

datténa. 2. 4.4.

dattăt. 6. 123. 4 .

dătum. 6. 122.2. 12. 4. 18.

dătáve. 3. 20. $5^{\dagger}$.

dattvă (mss. datvă). 9. 4. I9. Io. I0. 33. I4. 2. $28^{*}, 74$. I9. 7 I. I.

dattuá (do.). 9. 5.29. I I. 8. 10.

dīyámānas. 9. 5.9, 10.

dítsati. 12. 4. 2, I2, I3, 19 .

dítsantas. 5.7.6.

dāpayatu. 3. 20. 8 .

(cf. da, datta, dattvā, datra, dad, dadat, dadí, dadivāñs, dā, dāti, dătu, dātṛ́, dằna, dānu, dāya, dāyin, dāvan, dāsyant, ditsant, dìyamāna, deya.)

+ a n u: ánu dattam. 6. 118. 2. ánu dattām. 6. I 8 8. I. (cf. anudéya.)

$+\overline{\mathbf{a}}$ : à dade. 6.135. I. 7. 12. 3; 13. I, 2 ; II 4. I. I0. 4.24 .

à ... dade. I. 9.4. 2. 12.4. 4. 36 . 4. 7. II $4 . \mathrm{I}^{2}$.

à datse. I2. $5 \cdot 56$.

āodatté. 12.5 .46 .

à datte. 9.5.32-6.

à... dadmahe. 20. 127. I.

à datsva. 5.21. 10 .

à dattām. 3. I. 6 .

à... dadatu. 20. I35. 10 .

āodádānas. I8. 2. $59,60^{*}$.

āodádānā. 4. 38.3.

āodádānam. I2. 5. 52 .

ā॰dádānasya. T.. 5. 5, II . 
à 'dalta. 10. S.21. 15.1 .6 . á... adatta. 2. 5. $7^{\circ}$. āodadé (or pres.). 7. 13. I. 13. 3. 5. a dade (do.). I9. 49.4. ădiși (p. ãoád-). 7. 5 6. 5 .

à 'dişi. I. I4. I. I3. I. 30 . ā॰dâya. I2. 2.35; 5.57.

āodĩyámānā. 12. 5.15 ( V/3 dā ?).

+ pratyā: pratyāaáya (p. -tioād-). I0. I. 27.

+ vyā: vioăttam. 6. 56. r. ro. 4.8 . vioătte. I0. 5.42 .

+ s a mā: samoādăya. 9. 5.23.

+ upa: úpa ... dadāti. 4.21.2*. úpa ... dadāu. I9. 34.8 . upaodádya. I0. 8.18. I3. 3. I4.

+ parā: párā dehi. 14. I. $25^{*}$. párā... dadātu. 8. 3.16*. párā ... dádatĩ. I2. I. 37 . parādadús. 20. I28.5 (mss. -dís). párā dās. 5. 3. $8^{\text {*. }}$

+ pari: pári dadāmi. I. 30.2. 3 . It. 7. 6. I22. I ; I23. I. 7.53.4. pári dadmas. I2. 3.46, 55-60. pári dadmasi. I. I4. 3. 5. 22. I4.

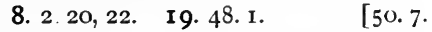
pári dehi. 6. 107. I-4. 19. 48.2; pári dattāt. I $8.2 .5^{*}$.

pári dadātu. I2. 3.55-60. 19. 48. 2. páry adatta. I9. 46.3 (mss. -danta). pári dade. 19. I7. I-10. pári dadat. I8. 2.54*. párittas. 6. 92. 2.

+ pra: praodádātu. 8. 4.9*. prá dadātu. I9. 37. I. praodadúșe. I2. $4 \cdot 35,36$. prấ 'dās. I8. $3.42^{*} ; 4.65^{*}$. praodiyáte. I2. 4.33.40.

(cf. pradadi, pradātŕ.)

+ prati: práti dadmas. 6. II7.2. (cf. ápratītta.)

$+\mathbf{v i}$ : cf. vidatra.

+ s a m: sám datta. I4. 2. 29. sám dadātāi. I2. 324 . sám dadus. I2. I. 53 . sám adus. 3. 22 . I.

V 2,3 d ā: dāntu. I2. 3. 31 . diyate. I2. 4.3 . (cf dăna, dānu, dăman, di, díti.) + a pi: ápi dyāmi. 4.37. 7 (mss. yā-). + ā: à dyati. I2. 5.15 .

â diāmasi. 6. 104. 1 .

à diā (p. dya). 6. 10ł. 2.

à dyatām (1. dia-?). 6. 104. 3 . (cf. ādăna.)

+ 8 a m: sám dyāmi. 6. 103. 2. sám diā (p. dya). 6. 103. 2, 3 . sám diatu. II. I0. 6 .

sámỏoditās. 8.8.4.

(cf. samiăna.)

dā in ātmadấ, āyurdá, draviṇodá, dhanadâ, baladâ, vasudă, svastidâ, havirdấ: cf. da.

d ā or d a in varadá, çușmadá.

d ākșā y a ṇá: -ám. I. 35.2. dākșāyaṇăs. I. 35 . 1 .

da $\mathbf{g} \mathbf{h} \mathbf{a}$ in nāídāgha.

$\mathbf{d} \mathbf{a} \mathbf{t} \mathbf{i}$ in havyádāti.

dât $\mathbf{u}$ in dátum, dătave : see $\sqrt{ } \mathrm{I}$ dā. dātṛ́: -tá. 3. 29. 7. 4. II. 5. II. 3. 25. I9. $55 \cdot 3,4$.

dātắram. $\quad 321.4$. 9.5.9. [27. dātré. 9.3.12; 4. I. I0. 9. I3-24; IO. dātúr. 6. 58.1 . 18. 4. 49 .

dātṛ̣năm. 5. 24. 3 (m. mss. -treṇăm). (cf. pradātṛ́.)

dấdh ̣̣ṣi: -is. 20. 128. 3 (mss. dādṛ-

dăna: -nena. I2. 4. 32.

dănāya. 3. 20. $5^{*}, 7^{*}$.

(cf. ádāna, vasudăna, dănakāma.) dána ( $/ / 3 \mathrm{da})$ : -am. 20. I33. 3 (mss. dvānám, dhanam).

(cf. ādầna, samiắna.)

dănaokāma: -as. 3. 20. 6.

dān a vá: -vắnām. 4.2ł.2. 10.6. Io. dān u in ārdrádānu, jīrádānu, sudănu.

d ānu ( $/ 2$ dā) in dānavá.

$\mathrm{d} \mathbf{a} \mathbf{b} \mathbf{h} \mathbf{y}$ in ádābhya.

dăma n: -ma. 6. 63. I.

dắmnā. 6. I03. 2, 3 .

[dhă-).

dămnas. 7.83. 2 (dămnaḥodā-: mss.

dấmāni. 7.83. I (mss. dhă-).

d ã y a (gerund) in punardáya.

dāya in çatádāya and

dāy ā dá: -ás. 5. I8.6, I4. 
dāy in in rș̣abhadāyín.

dāra in ádārașṛt, udaradārá.

dầru: Io. 4. 2, 4.

dắruni. 6. I21. 2.

dârūṇi. rg. $64 \cdot 3^{*}$ (m. mss. -rụ̣i). (cf. dru.)

dā vá: -ás. 20. I36. 8 (not mss.).

dāvásya. 7· 45. 2.

(cf. antardāvá, viçvadāvyà.)

dā van in baladăvan, viçvadāvan. $\mathrm{d} \mathbf{a} \mathbf{v} \mathbf{y} \mathbf{a}$ in viçvadāvyà.

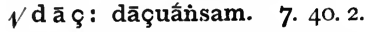

dāçúșe. 7.17.2, 3; 20. I; 40.2; 48. $2^{*}$; I I0. I. I8. I. $4 I^{*} ; 3.43^{*}$. I9. 5. I*.

dāçúşas. 4. 24. I.

(cf. dāę, dāça, dāçuri.)

+ a ti: áti ... dāçasi. I8. I. $38^{*}$.

d $\bar{a} c ̧$ in dūḍăç.

dã ça in purợấça.

dā ça rājñ̃á: -ñé. 20. I28. 12.

dā çu ri in ádāçuri.

dāsá: -ás. 5. II.3.

dāsăya. 5. 2. 2*

dāsásya. 7. 90. $\mathrm{I}^{*}$.

dāsấs. 4. 9.8. 5. 11. 6.

dāst. 5. 13.8. I2. 3. I3; 4.9.

dāsîm. 5. 22. 6 .

dàs a: -am. 4. 32. I*.

d ās y a n t in ádāsyant.

$\mathrm{d} \mathbf{a} \mathrm{h} \mathbf{a}$ in nirdāhá.

$\checkmark$ di, see $\sqrt{ }$ day, $\sqrt{ } \mathbf{2}$ dā.

di in sadamdí.

dík。s a m̧̧ita: -as. Io. 5. 28.

díti: -is. II. 3. 4. I5. $6.7 ;$ I 8.4 .

dítes. 7. 7. I. I5.6.7.

(cf. áditi.)

ditsant in áditsant.

di d y ú: -úm. I. 2. 3 .

didyut: dídyut. 2. 2. 4 .

din a in madhyámdina, sudína.

dipsant in ádipsant.

dipsú: -sávas. 8. 4. 20*.

(cf. rāṣțradipsú.)

$\checkmark$ div, see $V$ div.

dív, dyú : dyāús. 2. 12. $6^{*} ;$ I 5.1 ; 28.4. 3. 9. I; 23.6. 4. 2. 4 ; I6. 3 ;

39.6. 5. 28.2. 6. 3. I ; 6. $3^{*} ; 44$.
I : $53 . \mathrm{I} ; 77 . \mathrm{I} ; 88 . \mathrm{I}^{*}$; IOO. I ; I20. 2 ; I42. 2. 7. 6. $\mathrm{I}^{*}$. 8. I. I $2, \mathrm{I} 7$ (1. diāús ?); 7.2; 9.6. 9. I.2I ; 5.20; 7.2 : IO. I $2^{*}$. I0. $2.24,25 ; 7.3,12$; 8.2 ; I0. 4,30 . II. 2. IO : $3 . \mathrm{II}, 20$; 5.4. I2. I. $53 ; 3.20$. I3. 4.33. I4. 2. 7 I. I5. 4.6 ; I0. $6 ; 17.3$. I8. I. $5^{*} ; 2.48$. 19. $6.8^{*} ; 9.1,14 ; 54.2$. diāús. I4. I. $\mathrm{I}^{*}, 6^{*}$, I0*

díāus. 6. $4 \cdot 3$ (s. mss. ed. dyāús). dyắm. I. 2.4. 4. I. $4 ; 2.7^{*} ;$ II. I ; I4. 4; I6. 4; I9. 6 (mss. and p. yằm); 30. $7^{*}$. 6. 12. I; 60. $3 ; 61.2$, $3 ; 69.3$; 120. I; 126. $x^{*}$. 7.1. $2 ; 6$. $3^{*}$; 95. I. 9. 3. I5; 5. I5; 9. I3*. II. I. 37 . I3. I. 43,$45 ; 2.22^{*}, 45 ; 3.26$. I8. $2.47,49 ; 3 \cdot 5,25-35 ; 4.5,6,28^{\dagger}$. I9. $6.2^{\dagger} ; 49.2$ (not mss.).

diắm. I8. I. $6 \mathrm{I}$.

dívam. 2. 34.5. 3. $21.7 . \quad 4.14$. 3 ; 20. 1,$9 ; 27.4 ; 34.5 ; 35.3 .5$. I9. I. 6. $22 . I^{*}$. 7.97.4. 8. 5.7. 9. 5. 29. I0. $2.8,18 ; 5.27 ; 7.32,44^{\dagger}$; 8. $36 ; 9.3$, IO, II , 25 . II. 5. I, 8, 9; 6. I0 I2. 2.17 ; 3.25. I3. I. 8,9 , I6, $24,25,26.34,45,52$; $2.4,5,8$, 25, 40, 4I; 3. 9*, I3, I6. I4. 2.69. I5. 4. 6 ; I0. II. I7. 8. I8. $2.7^{\dagger}, 9 ; 3$. 64 ; 4. I4. I9. $22.21 ; 32.9 ; 53.5$; 65. $\mathrm{I}^{3}$. 20. I28. 5 .

divă. 4. $30.8^{*}$ I I. 3.40 . I2. I. 63. I8. 1. 10*. I9. 19. 3 .

divé. I. 32.4 . 5. 9. I, 5. 6. IO. 3 ; 20. 2. I9. I1. 6*.

divás. I. II. 2. 2.5. $2 ; 7.3$. 4. I. 4 ; I4. 2. 3 ; I5.10; 16.4 ; 27. 4. 5 . 6. $3^{*} ;$ I3. I ; $24.11 ; 25.1 ; 28.9 .6$. 37.2 ; 52. I ; 86. I; I00. 3 ; I24. I ; I25. $2^{*}$. 7. 9. I* ; I4. 3 (diváḥ๐odivah); 2I. I ; 26. 8; 55. I; 73. I, 4 ; 107. I. 8. $4.4^{*}, 5^{*}, 19^{*} ; 6.12 ; 7.20$. 9. I. I ; 2. $2 \mathrm{I} ; 4.2 \mathrm{I} ; 9.10^{*}, \mathrm{I} 2^{*}$. I 0. 5.27; 7.3;9.5; 10.32. II. 2. 4,27 ; 5. IO. I2. I. $20 ; 2.12 ; 3.26 ; 5.73$. I3. 2. $36,37,4 \mathrm{I} ; 4 . \mathrm{I}, 33$. I6. 7.6. I7. 10. I8. I. $2^{*}, 18^{*}, 61 ; 2.35^{*} ; 3$. $65^{*} ; 4.58^{*}$. I9. 3.1 ; I6. $2 ; 35.4$; 44. 5 ; 47. I ; 54. 5. 20. 127. 2 . 
divas. I9. 47.5 .

diví. 1. 30. $3 ; 32.1 ; 33.3$. 2. 2 . I. 2. 3. $7.4 ; 17.7^{*}$. 4. 10. $4 ; 39$. $5^{2}$. 5. 4. 3, 4. 6. $69.3 ; 75.3 ; 80.2$, $3 ; 92.3^{*}$. 7. $26.7^{*} ; 97.8^{2}$. 9. I. 20 ; 6. $57^{2} ;$ 10. $3^{*}$. I1. $6.13 ; 7.23-7$; I0. 2, 8, 10. I2. 3.50 . I3. I. 39,$44 ; 2$. I, 12. $30 ; 3.16,23.14 .1$. I", II". I5 13. 3. I7. 12 ${ }^{2}$. I8. 2. 50; 4. 59", 89". 19. $6.3^{*} ; 7.1 ; 8.1 ; 27.11 ; 32.3$; 39. 6,7 . 20. 49.2 (mss. dívi). [88*. dyávi. 6. $49 \cdot 3^{*}$. 12. 2. 18. 18. 4 . dyăvā. I8. I. 29*.

dívas. $4.20 .2 ; 34.4$. II. 7. 4 . I3 3. 2 I. I9. $27.3 ; 32.4$ (mss. divás). dyưn. I8. 1. 24*.

dyúobhis. 6. $31.3^{*}$.

(cf. dyăvāprthivî, dyāvābhūmi, áhardivi, pradív, divá-divyá, devá, didyú ?, dyumánt, dyut, vdyut, dyumná, dyus, dyāúsançita.)

[Io.

divá: divéodive. 7.71. I". 20. 135. (cf. tridivá, bṛháddiva, sudivá, dívā.)

dívā. 5.7.3; 29.9; 30. 10. 6. 23. I ; I28.4. 7. 1OI. I. 8. 3. I"; 4. II"; 5. 22. II. 2. 16. 16. 7. 10. I9. 15. $6 ; 39.2-4$. (cf. divākará.)

divāokará: -ás. 4. 10. 5. I3. 2.34. divíccara: -rās. I9. 9. 7.

divioçrít: -tas. II. 7. 23-7.

divişád (p. -viosá-): -das. ro. 9. I2. II. 6. I2.

divișádobhyas. I8. 4.80 .

divișțambhá (mss. diví șța-; p. sta-): -bhéna. 19. 32.7.

divyá: -ás. 2. 2. I. 8. I. II. 9. เo. $28^{*}$. I0. 5.20. I3. 2.9 .

diviás. $7 \cdot 41.2$.

divya. 2. 2. I.

divya. 6. 142. I.

divyám. 4. 14.6. 7.39. I*.

diviám. 7.18. I. 18. 1. 32 ".

divyăm. I I. 2. I9.

divyéna. 2. 6. I. II. 2. 26.

diviăt. 8. 4. $23^{*}$. divyásya. 6.80. I, 3. 7.18.1.

diviásya. $4 \cdot 20.3$.

divié. 7. 82.6.

divyé (p. -éíti). 5. I 2.6 ".

divyăs. $4 \cdot 8 \cdot 4,5,6.7 \cdot 89 \cdot 1^{\dagger}, 8$. 2. $14 ; 7.3,24.9 .5 .14$ 10. 9.6 . II. $5.21 ; 6.8$. I6. I. I. I9. I1. $2^{*}$; 49.8 (mss. -yâ).

diviăs. I I. 2.24. I9. II. 4".

divyănām. I9. 2. 4 (m. mss. -vyà-: 1. -naam).

divyéşu. 7.68. 1 .

$\checkmark$ diç: diçántā. 5.12. 7 ".

dideça. 14. 2. 13.

didiḍ̣̣hi. 7. 46. I".

dișțás. 5. 30. 17 .

dișțám. I2. 3. 55-60.

dișțăt. I0. 3. 16 .

dediçyate. 20. 136.4 .

(cf. díç, dișța, deça, deçya, deşțrá, déșțrī.)

+ ā: à diçatu. I2. 1. 40.

āodídeçati. 6. 6.2.

(cf. ánādișța.)

+ u pa: cf. upadeçyà.

+ parā: párā... didéça. 12. 2. 55 .

+ pra: cf. pradíç.

+ vi: cf. videçyà.

+ s a m: cf. samieçyà. [9.

+ anu s a m: anuosámdiçāmi. 4. 16.

díç: dík. 3. 27. I-6.

díçam. 3.3I.4 (díçam॰di-). I2. 3. 8. I 5. $2 . \mathrm{I}-4 ; 6 . \mathrm{I}-7$; I4. I-5, 9 .

diçé. I2. 3. 55-61).

diçás. 4. 40. I-7. 5. 10. I-6. 6. $9^{8}$. $3^{2}$. 9. 3. 25-30. I5. 4. I-6 ; 5. I-6 2 . I8. 3. 25-8. I9. I7.2-10; I8. I-IO. diçáḥodiças. 4. 15.8. 9. 3.31. 10. 3. I0. I8. 4. 9. I9. 35.4 .

diçí. 3. 26. I-6. 4. I4. $7^{2}, 8^{4}$. II. 2. I 2, I4, 27. I 5. 2. I-4. I 8. 3. 30-5. díças. 4. 8.4; 39.8. 5. $21.9 ; 28$. 2. 6. 88.3 . 8. $5.13 ; 8.5 .22 ; 9.15$. 9. $2.2 \mathrm{I}: 5.2 \mathrm{O}, 37$. $0.2 .28 ; 5.28$, $38 ; 6.9 ; 7.34 ; 8.35 ; 9$. 10. II. 6 . 6. I3. I. $35 ; 2.2,4$ I; 3. 6,$19 ; 4$. 34. I5. 6.8. I8. 4.6, 7. I9. 6.8"; 20. $2 ; 45.3,4 ; 54$. I. 
digobhyás. 4. 40. 8 . I0. 5.28. I3. 4. 34 . diçăm. 4. 40.8. 5. 10. $7 . \quad$ 12. 3 . 9, IO. I3. 2. 2.

dikṣú. 3. 21.7 4. I4. $9 ; 397^{2}$. 5. 11. 8,9 . I 8. 1. $46^{+}$. I9. $8.1 ; 49.5$. (cf. pradíç.)

diṣ ța in ánādiṣṭa.

$\checkmark$ dih: dihănás. 8. 3. $6^{*}$.

ádihan. 4. 6. 7 .

digdhắ. 5. I8. 15 .

+ a bhi: abhíodigdhās. 5. 18.8.

VI dì: + pari: pári dìyā (p. -ya). I9. I3. $8^{*}$.

$\sqrt{2}$ dĩ: dídihí. 7.78.2. [2.18. dĩdihi. 2. 6. 4. 7.74.4;84. I. 12. dĩdáyati. I8. 4. $88^{*}$.

didáyat. I4. I. $37^{\dagger}$.

didāyat (p. -day-). 3. 8. 3 .

didayante. 18. 3. 73 .

+ a ntar: antár dídyati. I0. I0. 28. + s a m: sám ... dỉdihi. 2. 6. I.

dīkșá: II. 7.8. I2. I. I. I5. I6.5. dīkșăm. 9. 6. 4. I4. 2. 52. I9. 40.3; 4I. I.

dìkṣáyā. I2. 5.3. I9.43. I-8.

dīkșăs. 8. 9. I 7 .

dīkșâtbhis. 8. 5. 15 .

(cf. dīkșitá.)

díksitá: -ás. IO. IO. I2, I7. II. 5.6. $\checkmark$ dip: dipyate. I0. 7.2, 4 .

+ abhi: abhiodipáyan. 4. 19. 3.

+ u d: úd dīpayāmasi. I2. 2. 5 . dī y a māna in ápunardīyamāna. dĩ ghá: -ám. I. 35.2. 2. I3. 2. 3. 8. 3. 6. 78.3 . 7. $32 . \mathrm{I} ; 33 . \mathrm{I} ; 8 \mathrm{I}$. $2^{*}$; IO3. I. 8. 2. II. II. I. 34. I2. I. 62 . I3. 2.37 . I4. I. $47 ; 2.39,75$. I 8. 2. $3^{*}$.

dīrghăm. I4. I. $46^{*}$.

dīrghéṇa. I2. 2. 32, 55 .

dīrghăya. 6. 39. I.

(cf. drăghīyas, dīrgháçmaçrudīrghấyus.)

dīrghá。çmą̧ru: -us. II. 5.6. d $\bar{x} \mathbf{g} h \bar{a} y u$ in

dĩghāyuotvá: -tváya. I. 22. 2 ;

35. I. 2. 4. I. 3. 5.4. 4. IO. 7. 5.
28. I. 6.68. $2: 110.2 ; 133.5 .8 .5$. 21. I2 2.6. I4. 2.75. I8. 4.53 . I 9. 28. I. [63.

dĩrghă y u s (p. -gháoāy-): I4. 2. 2*, $\checkmark$ div: didéva. 5. 29. 2.

(cf. dív, divan, divyant, devana, devin, dyūtá.)

+ a ti : cf. átidivan.

+ a dhi: cf. adhidévana.

+ prati: pratiodivyati. 7. I09. 4 . (cf. pratidívan.)

dív, dyúu: dyúvam. 7. 50.9. dyuvé. 7. 109. 5 .

diva $\mathbf{n}$ in átidivan, pratidívan. divy ant in ádivyant.

$v^{\prime} \mathrm{d} u, d \bar{u}$ : dunvanti. 9. 4. 18 .

dūnăs. 2. 3 I. 3 . (cf. dāvá, dūna, doman.)

+ abhi: abhiodunván. 5. 22. 2.

+ vi: ví dunoti. 5. 17.4; 18. 4 .

d ugh a in kāmadúgha, gharmadúgha, sudúgha.

du chúnā: $\quad$ 5. I9.8. 6. 4.3.

duchune. ro. 1.24. [1. 49 duchúnām. 5.17.4. 6. I26. $2^{\dagger}$. 12 . $\checkmark d \mathbf{u d h}$, see $V^{\prime}$ dhū.

dundubhí: -ís. 5. 20. I. 6. I26. 3 . I2. I. 4 I.

dundubhe. 5. 20. $4,6^{2}$, 10; $21 . \mathrm{I}^{2}$, 4-6. 6. 126. $1^{*}, 2^{*}$. [-úbhim). dundubhím. 20. 132. 9 ; 133. I (mss. dundubhínā. 5.21.7. dundubhés. 5. 20.5. dundubhāú. 5. 3I. 7. 6. 33.4. dundubháyas. 5.21.9.

dúr, see dvấr.

durad abhná: -nă. I2. 4. 4, I9.

durarmaṇ I (p. duḥoa-) : -ṇyàs. I6. 2. $I$.

$\checkmark$ durasy: -yáti. I. 29. $2^{\dagger}$.

durasyất. $4 \cdot 36 . \mathrm{I}$.

durasyatás. 4. 36.4. I0. 3. I. durasyatís. 7. I I4. 2.

(cf. durasyú.)

duras y ú: -yávas. 5. 3. $2^{\dagger}$. [5. I 7 . du rādhárșa (p. duḥoā-): -șā. 12. durấhā. 8. 8.24.

duritá (p. dụ̣oi-): -ám. 6. I21. I. 
7. 83.4. 8. $2.7 ; 7.9$. 9. 2.3. 10. I. 25,$32 ; 5.24$. I4. $2.66,67$. durităt. 2. 10.6. 5.6.8. 6. $45 \cdot 3^{\dagger}$. 7. 64 . I. 8. 7. 7 , 19. I0. 5. 22 . 12: 2. 47,48 .

duritásya. 3. II. 3*.

durité. 2. I2. 2.

durităni. 5.28.8. 6.53.2; I IO. 2 ; I12. 3 ; I13.2. 7.63.1. I3. 1. 58 ; 2. 34 19. 33.3 .

durită. 2. 6. 5. 6. $28 . \mathrm{I}^{\dagger}$; 126. $2^{*}$. I2. 2.28 .

dúrişți (p. dúḥoi-): -is. 2. 35 . I.

duréva (p. duhoé-): -văm. 7. 50. $7^{*}$. durévās. 8. 3. $16^{*}, 24^{*}$. $12.2 .26^{\dagger}$. durévāsas. $5 \cdot 2.4^{\dagger}$.

duroṇá: -ṇé. 5. 2. $6^{*}$; I2. I*. 7. I7. $3 ; 7.3 .9^{*}$.

du rgá (p. duḥ̆og-) : -gâ. 12. 4. 23.

durgám. I4. 2. II".

durgăn. 13. 2.5 .

durgấs. I0. I. 16 .

durgấṇi (p. duḥogâni). 7. 63. 1. 9. 5. 9. I 9. 50. 2 .

[6. 12.

durgándhi (p. duḥıg-): -dhīn. 8. durjĩvita in dāúrjīvitya.

du r ṇá ça (p. duḥoná-): -am. 5. ır.6. durṇăman (p. dụ̣onă-): -mā. 8. 6. I, 4 .

dưṇămãnas. II. IO. 2.

dựâumnas. I6. 6.7. I9. $36.4,5$. dưṇằmnām. 2. 25. 2.

dưṇămnīs. 4. $\mathrm{I} 7.5$.

dựnămnīnām. 19. 36.6. [hán.)

(cf. durñāmacătana, durṇāmadurṇāma cất an a (p. durnāma॰c-): -as. I9. 36. I.

durṇāmacătanam. 8.6.3.

durṇāmahán (p. durnāmaoh-) : -hầ. 19. 36.3.

durṇihitāișín (p. durnihita॰eș-):

-inim. I I. 9. I5.

durdhấ (p. duhodh-): -ấm. 5. I7. durbhága (p. duḥobh-): -gām. Io. I. 10 .

d u r bhā ga in dāúrbhāgya.

durbhū tá (p. duḥobh-): -ám. 3. 7. 7. 8. 2. 12. I0. I. 13,32 . du $\mathbf{r m}$ ańg a la in ádurmañgala.

durmatí (p. duhom-): -ím. 14. 2.6". durmatyāí. 6. 13.2.

durmántu (p. duḥom-): I8. 1.34". dú ry a: -yãn. I4. 2. $5^{\text {". }}$

durvàc (p. duhov-): -cas. 4. I7.5. d u rhắrd (p. duḥoh-): -dam. 8. 3. 25. durhắrdas. 2. 7.5. 4.9.6. 10. 6 . 1. I9. $32.4 ; 35.3 ; 45.1,2$. durhắrdas (pl.). 14.2.29. $\quad$ I 9. 28 . 2,5-10; 29. I-9; 32.6 .

dúrhita (p. dúḥoh-): -tān. 4. 36.9.

durhṛnãyú (p. duhoh-): -ús. 7 . 77. 2".

durhṛnāyứn. I 8. I. $6^{*}$.

dú çcarit a (p. dúḥoc-): -am. 9.5.3. d uçcít (p. duhoc-): -tam. II. 10. 26. I2. $5.6 \mathrm{I}$.

duçcítas. 5.31 .5 .

duçcyavaná (p. duḥocy-): -ás. 19. $13.7^{*} ; 32.1$.

duçcyavanéna. I9. $13 \cdot 3^{*}$.

duḥ॰çáṅ s a: -as. 6. 6.2. I9.47.6.

Vduṣ: dūṣáyanti. 8. 4.9*.

dūṣayatā (p. -ta). 6. 10o. 2 .

dūșáyan. 4. 29.7. 8.5.2.

dūșayișyāmi. 3. 9.5.

adū dușam. 4. I8. 5 .

(cf. dúșți, dúșaṇa, dưși, dūṣîkā, doșás, doșâ, doșán.)

duṣkṛt (p. duḥok-): -te. 8. 4. $7^{*}$. IO. I. 23.

duşkŕtas. 8. 4. $3^{*}$. I9. 56.5 . (cf. áduşkṛt.)

duşkṛtá (p. duḥok-): -ám. 4. 25. 4. 7.65.2. II. 8.20. I2. 2. 40. I4. 2. 66 .

duṣkṛtăt. 4. 9.6.

dușkṛtăni. 6. $45 \cdot 2^{*}$.

duṣ ț anu : -no (p. dustano íti duh̆ot-). 4. $7 \cdot 3$.

duṣtára: -am. 6. 4. I.

dús ți: -țyāi. 3. g. 5 .

duṣpratigráha (p. dụ̣ıpr-): -hā. I0. 10. 28

d uṣvápn y a (p. duḥosv-) : -yam. 9 . 2. 2,3 . I2. 5.32. 13. 1. $5^{8}$. I6. 1. II ; 7.8. 19. $57.2^{2}$. 
duṣvápniam. 6. $46.3^{*}$; I21. I. 7 . 83. 4. I 0. 5. 24 . I9. $45 \cdot 2 ; 57 \cdot 1^{*}, 5,6$. duṣvápnyāt. 6. 46.2. I6. 5. I-6. duṣvápniāt. 4. 9.6. 7. 100. I. 16. 6. $2^{*}$.

(cf. dāúṣvapnya, jāgradduṣvapnyá, svapneduṣvapnyá,)

d us in duchúnā, duradabhná ?, durarmaṇì, durādhárșa - duréva, durgá-durmántu, durvắc-duşvápnya, dūọăç.

$\checkmark$ duh: duhanti. I8. 4. 30 .

dhukșe. Io. I0. $8^{2}$.

duhé. 4. II. I2 ${ }^{3}$. I0. IO. 27 . I8. I.

duhe. 4. II. 4. 6. $91.2^{*}$. 8. IO. 16. 9. 5.24 I0. $6.6-17$ I2. $4.18,35$, 36,39 .

duhāte (p. -e íti). 9. I. 7.

duhre. I0. I0. 32 .

duhrate. 9. 9. $5^{*}$. I $8.4 .29^{\dagger}$.

dohat. $7 \cdot 73 \cdot 7^{*}$.

dhukșva. I0.9. I2. I8. 4. 6 .

duhăm. 7. 73. $8^{*}$.

duhām. 3. 10. $I^{*} ;$ I 7. $4^{*}$. 4. 39.2, 4,6. 9. 4.2 I. I2. I. $7,9,45$.

duhāthām. 4. 22.4.

duhātām. I2. I. 36 . I3. I. 5 .

duhrằm. 3. 20. $9^{2}$.

duhrām. 4. 39.8 (m. mss. ed. -hām). 8. 7. 27 . I8. $4.4,5$. [9. I 3-24. duhratām. 7.82.6. 8. 7. I2. Io. dúhānas. 4. II. 2.

dúhānā. 7.79.3. 8. 9. 24 .

dúhānam. II. I. 34. I8. 4. 36 .

dúhānās. 3. 16. $7^{*}$. 4. 2 I. $1^{*}$. I 8 . 4. 34, 39.

adhok. 8. 10. 22-92.

áduhat. 7. I5. I.

aduhat. 2. I. I.

aduhan. 20. I3I.2I (mss. ádūham). aduhran. 8. IO. I4.

duduhé. 8. 9.24.

duduhe. I8. I. I8*.

[2.14.

dugdhám. I0. 6.3I; I0.30, 3 I. I4. dugdhă. I2. 5. 23. 20. 136. I3 (m. mss. dag-).

dugdhásya. 7.73.5.

dugdhă (du.). 8. 9. I. dugdhăni. 20. I30. I (not mss.).

duhyate. 7. 73. 1 .

duhyánte. 7.73.2.

duhyámānā. 12. 5.23.

(cf. dugha, duh, duhitṛ, dogdhṛ́, dóha, dóhas.)

+ prati: cf. pratidúh.

+ vi: ví duhanti. 5. I7. I7.

víodugdhān. 8. 9. 10.

+ s a m: sám duhratām. I2. I. I6.

$\mathbf{d} \mathbf{u} \mathbf{h}$ in godúh, pratidúh.

duhitṛ́: -tâ. 3. IO. I3. 5. I3. 8. 6. I0O. 3 ; I33. 4 . 9. I. 4 ; 2.5 . IO. I. 25. I4. 2.60 .

duhitar. I9. 47.5. [53*. duhitré. 3.31. $5^{*}$. 6. 137. I. I8. I. duhitúr. 9. 10. 12 *.

duhitárāu. 7. 12. I.

duhitaras. 2. 14.2.

d ū ḍ̂ ấ (p. duḥodâ-): -çe. I. I 3. I.

dū tá: -ás. I. 7.6. 3. I. $2 ; 2.1 ; 4$.

3. 4. 13. $3^{*}$. 5. I2. $1^{*}$. 6. $27 \cdot 1^{*}$. I 8 . 2. $27 ; 4.65$.

dûtám. I8. 3. $66^{*}$.

dūtăya. $5 \cdot 17 \cdot 3^{*}$.

dūtāú. 5. 30.6. 6. 29.2. 18. 2. 13*". dūtâs. 8. 8. ro.

(cf. agnídūta, mṛtyudūta, yamadūtá.)

d ū $\mathbf{n}$ a in ádūna.

dūrá: -ám. 3. 15.4 $4^{\dagger}$ 6. 59. 3; 97. $2^{\dagger}$. 7. $42 . \mathrm{I}^{\dagger}$. 8. 7. I4. 9. $2.17,18$; 5. 7, II. II. I. 29 ; 2. 25 . I2. 2.4 , $7^{\dagger}, 8^{*}$, I4. I9. 44. I0; 56.6.

dūrăt. 5. 18.9. 6. 126. I*. 7. 45 . I. I2. 2. I4. I9. 52.3. [8.152. dūré. 3. 3.2; 23. I. 4. 28. 2 . 10. (cf. dūraká-dūrégavyūti.)

dūraká: -ké. ro. 4.9.

dūratás. 4. 38.5 .

dū ráçravas : -se. 20. I35. I I (mss. also puraç-, etc.).

dū ré • anta: -tā. 4. I6.3.

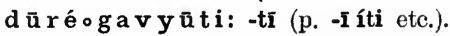

4. 28.3 .

dúrvā: 6. 106. $I^{\dagger}$.

(cf. çāṇụadūrvă.)

dūrçá: -çắni. 8.6. I I. 
dūrçébhis. 4.7.6.

dúg a a a : as. 3. 9.4.

dúşaṇīm. 4. 6.2.

(cf. arātidúşạna, kṛtyādúşaṇa, vișadûșana, vișkandhadúşaṇa.)

dús și: -is. 2. II. I.

dúșyã. I. 23.4.

dúșyās. 2. II. I.

(cf. arătidưși, ātmadúși, kṛtyãdưși, tanūdúşi.)

dū ụt ka a: -kās. I6. 6.8 .

$\checkmark \mathbf{d} \mathbf{r}$ in dara, dāra.

$\checkmark$ d rrinh, dṛh: dṛnhăt. I2. 324.

dứnha. 6. $136.2 ; 137.3$.

drrnha. II. 7.4.

dṛnhatu. 6. 69.3.

dṛnnhatā (p. -ta). I9. 58. $4^{*}$ (mss. dṛ-).

dụnhántam. I2. 2.9.

ádṛnhat. 13. 1.6. 19. 32.9.

adṛnhhat. I3. I. 7 .

dṛ̣̣̂ás. II. 7.4 .

dṛ̣hă. 9. 3. 10.

dṛ̣̣hám. 5. 30. I.

dṛ̣̆hăs. II. 5. II.

dṛdhăn. 9. 3.3.

adṛnhayata. 4. II. 7.

(cf. dïrghá ?, dṛnha-dṛḍha.)

dṛnh a in bhūmidṛnhá.

dŕ̛n h a ṇ a : -ṇāya. 6. I36. I.

(cf. keçadṛ́nhaṇa.)

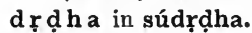

dṛ̂ti: -is. 20. 133. 2 (mss. ŗte).

dṛ́tim. 7. 18. I.

dṛtî. 20. I3I. 23 (mss. datī).

$\checkmark$ drp: adrpat. 20. 136.5 (not mss.).

$\checkmark$ dṛ $q$ : dṛçan. 8. 4. 24 *.

dŗ̧̧ema. I. 31.4.

ádŗçran. 13. $2.18^{\dagger}$.

dárçan. 5. 1.8.

dadárça. 9. IO. 10*.

dadarça. 9. 9. $4^{*}$. I8. I. $7^{*}$.

dadrçé. I0. 8.8. I9. 47.2.

dadŗçe. 9. 10. $26^{*}$. I0. 8.4 I.

dráșțum. II. 5.3.

dṛsțtă. 4. 36.6 (l. -țuá ?). 12. 3. 29 . druștás. 5. 23. 7 .

[țám).

dṛștám. 2. 31.2. 7. 56. 3 (ed. daṣdṛștăn. 5. 23.6. 8.8.15. dṛçé. 1. 6.3*. 2. 1. 5. 4. 37.11. 7.

22. I. II. 9. I, 15, 22, 24. I2. 2.18 .

I3. $2.16^{*}, 20^{*}$.

dŗçyáte. 7. ı1. I.

dŗçyate. ro. 8.25 .

darçáya. 4. 20.6?2.

darçaya. 4. 20.6.

(cf. darçá, darçatá, dṛ́ç, dựça,

dṛçí, dṛçyamāna, dṛşţa, draşţŕ.) + a n u : ánu... dŗ̧̣yate. 20. I 35. 5 (?).

$+\overline{\mathbf{a}}$ : ầ darçati. 5.2. $7^{\dagger}$.

+ upa : cf. upadraștŕr.

+ parā: parāodṛ́çya. 8. 8.2.

+ pari: pári ... dadŗ̧̧răm. 12. 3. 33 .

+ pra: prá darçaya. 4. 20.9. II 9. I, I5, 22, 24 .

+ s a m: sámodṛșțā. I I. 9.2.

(cf. samdṛ́ç, sam̉ dṛça.)

dṛ́ç: dṛçé, see vdṛç.

(cf. İđ̛̣̂, sam dṛ̣̂.)

d ṛça in mádhusamiṛça.

dṛçí: -çáye. 18.2.13*, 46. I9. 10. $5^{*}$.

dŗ̧ y a māna in ádṛçyamāna.

dṛșád: 2. 31. I.

dṛ̛ádā. 2. 3I. I. 5. 23.8. 8. 4.22* dṛșța in adṛsța, viçvádṛșța.

déy a: -yā. I2. 4. Io.

déyam. 9. 5.7 .

(cf. anudéya, vasudéya.)

devá: -ás. 1. 18. 3 ; 28. I ; 29. $3^{*}$; 3I. 3. 2. $34.3,4$. 3. I 3.4 ; $6.5^{\dagger}$; 21. 3,$4 ; 24.2$. 4. 1. 7 ; $2.6^{*} ; 3.1$; 20. 4 ; 32. $2^{*}$. 5. 3. $9^{\dagger}$; II. II ; I2. $I^{*}, 1^{*} ; 25.4 ; 26.2 ; 27.2^{2}, 3 ; 28$. II. 6. I. $3 ; 58 . \mathrm{I} ; 68 . \mathrm{I} ; 85 . \mathrm{I} ; 88$. $2^{*} ; 9^{2 .} 3^{\dagger} ;$ 133. I. 7. 14. $4 ; 63.1$; IO9. 5 ; IIO. 3 . 8. $3.16^{*}$; 10. 26.9 . 2. I4. I0. $2.5,8, \mathrm{I}_{3}, \mathrm{I} 4 ; 3.8 \mathrm{II} ; 8$. $24,28,42^{*}$. I1. $6.4,7 ; 9.4,25$. 12. 2. $8^{\dagger}, 12 ; 5.2$ I. I3. I. $20,2 \dot{4}, 40 ; 2$. $8,9,26^{*}, 30 ; 3.15$. I 4 . I. $49 ; 2.24$, 36. I 5. 5.4. I 8. I. $5^{*}, 29^{*}, 30^{*}, 36^{*}$; 2. $55^{*} ; 4.3 \mathrm{I}, 4^{8}$. I9. 10. $6^{*}, 10^{*}$; II. $3^{*} ; 26.4 ; 3$ I. 8 ; 33. I; 39. I ; 53.2 ; 54. 6 ; 59. $\mathrm{I}^{*}$ (m. mss. -vằs). 20. 2 . 4; 49. I (mss. -vâs); 127. 7 .

déva. 5. 27. 10. 6. $3.3 ; 79.3 ; 99$. 3 ; $125 \cdot 3^{*}$. 
deva. I. 7. I ; 20. I; 25. 2, 3; 28. 2 . 2. 2. I. 3. $20.5^{\dagger}$. 4. 39. IO. 6. I9. $3^{*} ;$ 5I. $3^{*} ;$ I 23.5 . 7. II. I; I4. 3 ; 97. 3. I I. 2. 3 I. I 3. I. 32,$58 ; 2.23^{*}$, 3o. I8. $3 \cdot 42^{*} ; 4.65^{*}, 88^{*}$.

devám. 4. 25.7 . 5. I2. $9^{*}$. 6. I. I ; I 2.2. 7. I4. I ; 53. $7^{*}$. 9. 9. $18^{*}$. IO. 8.22. II. 6.3. I2. 2.33. I3. 2. I6*; 3. I6; 4. 15,24 . I5. 5.4. I 8. I. $54^{*}$. I 9. 24. I. 20. I30. I6 (not mss.).

devéna. I. I. 2.

devăya. 4. 2. I-8*. 5. II. II. devásya. 2. 36.2. 4. I.6. 6. 23. 3 ; 133. I. 7. I7. $2 ; 25.2 ; 70.4 ; 74$. I. 9. 4. 13; 10. $9^{*}$. I0. $5.14 ; 8$. 32. I2. I. 2O. I3. 3. I-25. I8. I. 32 . I9. 6. I6; 49. I ; 5I. 2.

devé. 8. 4. 18 .

devāú. 3. 29.6.

devă. 6. 3.3.

deváyos. 4. 25.7.

devấs. I. 9. I; II. 2; I3.4; I8.2; I9. $4^{*}$; $30.4 ; 33.3 ; 35.4$. 2. I. 5 ; $9.4^{2} ;$ I0. 8 ; I $3.4,5 ; 29.5 ; 35.5$. 3. $3.2 .5 ; 4.4 ; 5.3^{2} ; 8.4 ; 9.4 ;$ Io. 2, I 2 ; 19. 5,6 ; 22. I, 3 ; 26. I-6; 30 . 4,7 ; 3. I, 7. 4. 2. I* 8.2 ; II. 6 ; I3. $4^{*}$; I4. I; I6. I ; I9. 4 ; $23.6^{2}$; 30. $2^{*} ; 35.7 ; 36.5$. 5. 3. $3^{*}, 4^{\dagger}, 5^{*}$, $9^{*} ; 4.3,4 ; 8.3$; I 2. II $^{*}$; I 7. $6^{*}$, IO* $^{*}$; I8. I； I9. I2, I3, I4；21. 7 ; 25. 9 ; 27. I2. 6. 30. I; 47.2; 6I. I; 64. $\mathrm{I}^{*} ; 80.2 ; 85 . \mathrm{I}$; IOO. I, 2 ; IO9. I, 3 ; III. 4 ; II $2 . \mathrm{I}$; II $3 . \mathrm{I}^{2}, 3$; I32. I, 2 . 7. $5 . \mathrm{I}^{2^{*}}, 3,4,5 ; 6 . \mathrm{I}^{*} ; \mathrm{I} 6 . \mathrm{x} ; \mathrm{I} 7 \cdot 3^{2}$; 24. I； 35.I； 70. 2; 79. I, 2 ; 81.6; 89. $2^{*} ;$ IO9. $2 ;$ II $8 . I^{*}$. 8. I. 2,$7 ; 2$. $2 \mathrm{I}, 27 ; 3 . \mathrm{I}^{*} ; 5.5,6$, I0, $\mathrm{I}_{4}, \mathrm{I}_{9} ; 8$. I3; 10. $3,14,20,26^{2}$. 9. I. $5 ; 2.7^{2}$, I 3, I 7, I 8, I9; $4.15,18,20 ; 5.13 ; 6$. 45 ; IO. $18^{*}$. I0. 2.4 ; 3.2 ; 5. 50; 6. 16,$32 ; 7.13,23,24,25,27,38,39$; $8.34,35,40 ; 9.9,12$; Io. $5,26,34$. II. I. $2^{\dagger}, 10,33,37 ; 2.28 ; 3.21 ; 4$. I I ; 5. I, 2, 3. 5, 8, I9: 23, 24; 6. I 2, I3, I 8,$22 ; 7.23-7,27 ; 8.3,10,13^{2}, 17$, I $8,29,3 \mathrm{I}$; IO. II, I2. I4, I5, 27. I2. I. $5,7,53 ; 2.17 ; 3.32,38,50 ; 4.20$,
$22,24,28,41,42,49,5$ O. I3. I. 7,13 , 25,35 ; 2. 13 ; 3. 12, $23,24^{*} ; 4.13,21$. I4. I. I $5^{*}, 32,50^{*} ; 2$. $10^{*}, 32,53-8$. I5. $2.1 ; 3 . \mathrm{I} ; 6.8 ; 17.8$. I6. 6. II. I8. I. $3 \mathrm{I}^{\dagger}$ (mss. devās, dévās, devầs), $32^{*}, 35^{*}, 36^{*}, 47^{*}$; 3. Io, II, 22* $24^{*}, 53^{*}, 68$; 4.2. I9. 4.4 ; 6. 10*, $\mathrm{II}^{*}, \mathrm{I}^{*} ; 9 . \mathrm{II}^{2}, \mathrm{I}^{2}, \mathrm{I}^{2}$; II. $2^{*}$; I9. 10; 20. 3 (mss. deva), 4; 24. 1; 27. 6,7 ; 30. 2 ; 34.6 ; 35. I, 2 ; 4I. I ; 46. $4 ; 564 ; 5$ 8. 6 . 20. I28. 1 ; 135 . 4 , ro (mss. dévās).

devắsas. 3. 22. 2. 7. 28. 1. 20. 136. 4 . dévās. 4. I3. $\mathrm{I}^{2 *}$. 6. $27 . \mathrm{I}^{*} ; \mathrm{r} 23.2$, $3^{2}$; 130. I-3; I3I. I, 2. 7. 97. 7. I9. 70. I.

dévāsas. 6. II4. I.

devās. I. $9.2 ; 3$ O. I, 2, 3; 3I. 2. 2. I $2.2 ; 28.5 ; 29.1 ; 34.2$. 3. 9.1 ; 15 . 5 , 6. 4. I3. $\mathrm{I}^{2 *}:$ I8. 2 ; 27.6 . 5. 8 . $3 ; 14.3 ; 17.5^{\dagger}$. 6. $7.3 ; 27.2^{*}, 3^{*}$;

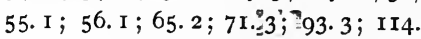
I, 3 ; II5. I; II8.3. 7. 97.4. 8. I. I8; 4. II*. 9. 4.7. I0. 7.23. II 6. I8. I9. $27 . \mathrm{II}-3 ; 59.2^{*} ; 72 . \mathrm{I}$.

devāsas. I. 26. I. 2. 12.5. 5. 3 . $6^{*}$ 8. 5. $2 \mathrm{I}$. I2. 3. 37 . I9. I3. $\mathrm{II}^{\dagger}$; 27. II-3.

devăn. 3. 4.6 ; ro. II ; I5. $5 ; 21.8$. 4. 2 I. $3^{*} ; 34.3$. 5. I2. I $^{*}$ 7. 5.3 ; 38.3 ; 97. 3 ; 109. 7. 8. 4. $14^{*} ; 8.15$; 9. 24 ; IO. 20,26 . IO. $2.22,23 ; 7$. $27 ; 8.18 ; 9.11 ; 10.6$. II. I. $4 ; 5$. 2 ; 6. 19, $20 ; 9.24$; 10. 9 . I2. 3.53 ; 4. I0, 3I, 53. I3. I. 40. I4. 2. $25,69$. I5. I4. I0. I8. I. $30^{*}, 33^{*}, 47^{*}$. I9. 56. 3 ; 63. 1. 20. I28. 4 (mss.), 5 (mss. devăs).

devébhis. 3. 12. 5. 4. 14. 2. 7. 75. 2. devāís. 2. 4.4 ; 16. 4 . 3.17.9. 4. 9. I. 5. I7. II ; 29.2,3. 6. I2. 2 ; I 26. $\mathrm{I}^{*}$. 7.80. I ; 98. I. I2 I. 55 ; 3. I 5 ; 4. 24. I4. 2.4 I. I 8. 3. $28,48^{*}$; 4. I0. I9. I7. I0; 40. I.

devébhyas. 4. 23.2. 5. 4. 7; 8. I ; I2. $4^{*}, 5^{*} ; 27$. I1. $7.3^{8.2}$ (1. -bhias); 8 I. $2^{*} ; 84.2^{*}$. 8. 10. 20 . 9. 3. 25-3I. I 0. $6.5,22-8$. I I. $5.19 ; 8.3$ (l. -bhias), 
IO (do.). 12. 1. 22 ; $2.8^{*}, 50$. 14. 2. $46^{*}$ (1. -bhias). I5. 2. I. I 8. 2. 53 , $54^{*} ; 3.4$ I $^{*}$ (1. -bhias); 4. 5 I. 19. 54. 4 . devănām. I. IO. I; 35.2. 2. I. $3^{*}$; 28. 2 ; 34.2. 3. 5.1 ; 10. 7 ; I6. $4^{*}$. 4. 1. 3 ; 10. 7 ; I1. 2 ; I3. $3^{*}$; I4. 5 ; 30. $3^{\dagger} ; 39.9$. 5. $5.1 ; 7.4 ;$ 1 2. $3^{\text {" }}$, IO*, II"; I 7. $5^{*} ; 28.11 ; 30.17 .6$. 46. I ; 47. $2 ; 85.2 ; 86.3$; IU0. $3 ;$ I08. 2. $7.5 .2 ; 7 . \mathrm{I} ; 46 . \mathrm{I}^{*} ; 47.2 ; 49$. I"; 53. I; 97.2*;. III. I. 8. 2. 9 ; 10. 3. 9. $3.7 ; 4.5 ; 7.6 ; 9.6^{*}$. I0. 2 . 31 ; 4. I. II. I. 5 (l. -naam ?), 5 ; 5 . 23. I2. $2.44 ; 4.2,12,17,2$ I, 29. I 3. I. 27 ; 2. 15, 20* (1. -naam), 25, 34, $35^{*}$; 3. I9, 21 . I 4. I. 33. I5. I. 5 ; 2. I ; 6.8. I6. 7.2. I7. 2 . I8. I. $9^{*}, 25^{*} ; 2.5^{*} ; 3.4,7^{*}, 23^{*}, 25-35,53^{*}$; 4. 16-24. 19. 10. $3^{*}$; 11. $5^{*}$; 13. 10*; $27.9 ; 33.4 ; 46.4 ; 57.3 ; 58.6 ; 59$. 3*. 20. 34 . 16 ; 128. 16 .

devéşu. 3.17. $1^{*}$. 4. 28.5. 5. 27. 2. 6. $21.2 ; 28.2^{*} ; 58.2$. 7. 20. I; 54. I; 73. $3 ; 97.8 ;$ I03. I. 9. 4. II; 5. $17 ; 6.5^{8^{2}}$. I0. 3.25 . I2. 4.6 , 12 . I3. I. $60^{*}$. I5. 12. 6, IO. I8. I. $26^{*}$. I9. $3.3 ; 62.1$.

devi. 2. 25.1. 3. 12. $5 ; 20.3^{*}$. 5 $23.1 ; 25.6$. 6. 3. $2 ; 38.1-4 ; 63.1$; 89. 3 ; 94.3; 136. x. 7. 46.3. 9. 4 . 2. I0. $5.43 ; 8.30 ; 9.11$; IO. I2. II. I. 8. I2. I. 44 I6.6. $5^{2}$. I8. I. $26^{*} ;$ 2. 25. I9. 9. 3. 20. I32. II. devi. I. 13. 4. 2. 25.4 . 4. 4. 6 ; 20. I, 2. 7. 20. 2,$6 ; 46 . \mathrm{I}^{*}, 3 ; 68 . \mathrm{I}^{2}$. 9 . 3. 7. I0. $9.7,25$. I2. I. $55 ; 3.11$; 5. 63,65 . I 8. 1. $43^{*}$.

devim. 3. 8. $2 ; 15 \cdot 3^{*}$. 7.47. I. I3. 2. 5 . I9. 4. 2 .

devyấs. I 4. I. 47 .

deviăs. I4. I. 63 .

devyăm. 6. I36. I.

devĩ (p. -I íti). 4. 26. 2.

devis. I. $6.1^{*}$. 3. $4.2 ; 20.3^{\dagger}$. 5 . 12. $8^{*}$; 17. I*; 27.7, 9. 6. 24. I; 5 I. $2^{*}$; 59. 2. 7. 49. I* $2^{*} ; 82.6$; II2. I. 9. 5. I5. II. 6.22. I4. I. $45 ; 2.9$. I8. 4. 39 . devis (acc.). I. $4 \cdot 3^{*}$. 2. 10.4. 6. 23. I. IO. 9.27. II. 6. 11 .

dévis. 5.12. $5^{*}$.

devis. 2. 2. 4. 3. 13.3. .5. 3. 7. 7. 75 . 2. 10. 5. 7-14. I6. 1. 13 .

devişu. 4. 2. $6^{\dagger}$.

(cf. adevá, ádeva, ánṛtadeva, mahādevá, múradeva, vāmádeva, vídeva, viçvádeva, sudevá, devákāma-devatvá, devápati - devāsurá, devéşita - devya, dāíva, dāivá, dāívya.)

d eváokāma: -as. 7. 50. 6*. [7.28. devaokilbişá: -şăt. 6. 96.2*. 8. deváokṛta: -am. 5. 19. 10.

devákṛtā. 5.7.3; 14.7. 12.4. I1. devákṛte. I4. 1.63.

devákrrte (p. -e íti etc.). 6. I38. 4 . devákṛ̂ās. I2. I. 43 . I9. 35.5 (m. mss. devakṛtăs).

devaokoçá: -ás. IO. 2.27.

devá。gopa: -pã. 7.20. 5. I9. II. $3^{\dagger}$.

deva०janá: -na. II. 9.5 ; 10. 5 . devajanăs. 6. 19. I; 93. I. 9. 7. 16. II. 5.2. I5. 3. 10.

dévajanās. II. 9. 2, 26.

devajanébhias. 6. 56. 1,2.

(cf. dāívajana.)

devaojầ: -ấs. I 0. 6. 31 .

devajấs (pl.). 9. 9. 16".

devá ojāta: -tā. 2. 7. I. [-ajāté-). devájātena. I9. 32.7 (m. mss. d eva ojāmí: -mīnám. 6. 46.2. I6. $5.6 ; 8.6$.

deváojūta: -am. 7.85. I*. dévajūte. 3. 18.2*

devájūtāis. 5 . 18.8.

devátā: 4. I. 5. I0. 8. 25, 3I.

devátãm. 3.22. 3. 4. I 4. I. I 5. I3. $S^{2}$. devátāyāi. I5. I3.8.

devátāyām. I5. I3.9.

deváte (p. -e íti). I 2. 3. I 2.

devátās. I 0. 6.1 7, 29. I I. 7.4; 8 . I9, 30, 32. I2. 3. I6, 35. I5. 6. S. I9. 27. 10.

[3. 33 .

devátābhis. 8. 8,21. II. I. 22. 12 . devátābhyas. 12. $3 \cdot 38,4^{6} ; 4 \cdot 32$ (1. -bhias). 
devátānām. 4. 14. 5. I 5. 6.8. [20. devayūnăm. 8. 9. I3.

devátāsu. 6. I I9. 2. 7. 78. 2. Ir. 4. devaorathá: -ásya. 8. 8. 22.

(cf. sahádevata.)

[tās). devaovadhá: -dhébhias. 6. I3. I.

devátā. 7.82. I*. I9. 4.4 (mss.

d eva ty à: -tíās. I. 22. 3 .

deva。trá. 5. I2.2*. 7.53. $7^{*}$. I2. 4. 40. 18. $3 \cdot 47^{*}$. 20. 127. 6 (mss. dévatrầ).

devatuá: -tvă. 20. I3o. Io (mss. dévatva).

devan a in adhidévana.

devá opatñi: dévapatnī (p. -nīíti etc.). 6. II8.3.

devápatnīs. 7. 49.2*.

devápatnīnām. I9. 57.3 (mss. devănām pát-).

deva。pấna: -as. 7. 73. 3. I 8. 3.53".

deva०pìyú: -ús. 5. I8.5, I3. 19. 57.5 .

$[57.4$.

devapìyúm. 4. 35. 7. I2. 5. I5. I9. devapiyós. 12. 5.60,65. [1.37. devapīyún. 5. I 8.8. II. 2. 23. I2. devá oputra: -re (p. -e íti etc.). 18. I. $25^{*}$.

deva。pură : -ăm. I4. I.64. devapurấs. $5.8 .6 ; 28.9$, 10.

devá oprasūta: -tena. 6. Iоo. 2. deváobandhu: -um. 4. I. 7. 5 . II. II; 18.13. 7. 2. I.

devaomaní: -ís. 8. 5. 20.

$\mathrm{deva} \circ \mathrm{m}$ anuṣy à : -yằs. 8. 10. 9. $\checkmark$ d eva y: devayántam (p. -va॰y-). 12. 3. 18.

devayántas (do.). 7.27. I. I8. I. $4 \mathrm{I}^{*} ; 3.22^{*}, 38^{*}$.

$$
\text { (cf. devayú.) - }
$$

devaoyájana: -as. Io. 5. I 5-20. devayájanam. 9.6.3. I2. 2.42. devayájanās. I0. 5.21. deva०vandá: dāís. I8. 3. $47^{*}$. deva०várman: -ma. rg. 30.3 (m. mss. - varma).

deváoviti: -taye. 7.58. $\mathrm{I}^{*}$.

deva०sád ana: -as. 5.4.3. I9.39.6. devaosenáa: -ấs. 5. 2I. r2.

devasenânām. I9. 13. $9^{*}$.

deváhita: -am. 7.97. 2*. I9. I2. I*.

devá。h ūti: -is. $5 \cdot 3 \cdot 5^{*}$. 8. 10. 3 12. $2.22^{*}$.

deváhūtyām. 5. 24. I-I7.

deváhūtișu. $5 \cdot 7 \cdot 4$.

devaohéḍana: -am. 6. II4. I.

deva०hetí: -Ís. II. 2. I2. I2. 5.29. devahetím. I0. I. 23. II. 2. I9. devahetyăs. 8. 1.12. '

devāñjana (p. -vaoãñj-): dévāñjana. I9. 44.6 (mss. -nam). [3. devãsurá (p. -vaoas-): -rấs. 6. I4I. devãsurébhias. 4. I0. 5 .

devin in sādhudevín.

d e vír: -váras. I4. I. 39.

devịṣu. I4. I. $44^{*}$. (cf. ádevṛhan, devị́kāma.)

d e vṛ́ $\circ$ kã m a: $-\mathrm{ma}$. I 4. 2. $17^{\dagger}$ (s. mss. -vák-"), 18.

d evrrhan in ádevṛhan.

devéșita (p. -váoiș-): -tāt. 8. 7. 2. devāinasá (p. -va॰en-): -sât. 6. III. 3. IO. I. 12.

devya in vāmadevyá.

d eça in antardeçá, deçopasargá.

deçopa os argá: -gấs. I9. 9.9.

d e çy $a$ in upadeçyà, videçyà, samdeçyà.

deṣṭá: -rấya. I4. I. I4*

déșțī: IO. IO. I7. II. 4. I2.

deva。yàna: -as. II. I. 20. I8. 4. I4. devayắnam. 8. 10. 20. I5. I2. 5, 9. devayănāt. I2. 2. $2 \mathrm{I}^{\text {* }}$.

devayấne. I2. 3.3.

devayănās. 3. 15.2. 6. 55. I; II 7.3. devayấnān. II. I. 36. I5. II.3. devayắnāis. 2. 34.5. 9.4.3. 12. 2. I0, 41 . I8. 4. 2 . I9. 27.9 .

deva॰yú: -úm. 4. 21. 2*.

dāiva: -as. 7. II. I.

dāívam. 5. 4. 10.

dāívāya. I6. 2.6.

dāívāt. 4. 26. 7 .

dãívīm. 5. 20.4. 6.61. 2. 7.6. 3*. dāívyā. 8. I. 3 .

dāívīs. 3. 23.6. 6. 98.2. 9. 4.9. II. 4. I6. 
dāívis (voc.). I. 19.2. 5. 3.6t.

dāivá: -ás. 4. 16.8.

dāiva. 20. $135 \cdot 1,3,5$.

dãivăs. $5 \cdot 3 \cdot 5^{\dagger}$. I I. I. 16, 25 .

dāívās. 5.27.9.

dāivănām. I 1. 1. 23.

dãivis. 12. 3. 32 .

dāíva॰jana: -nis. ro. $2.22,23$.

dāívya: -viam. 6. 4. I. 7. 105.1. dāivyyena. r9. 27.6 .

dāíviena. 2. 12. 4. 4.27.6. 7.52. 2 ; 78.2. 8. 3. $2 I^{*}$.

dāíviasya. 2. 2. 2 .

dăíviāyās. 5. 29. I1 ${ }^{*}$.

dāívie. 6. 5 1. $3^{*}$.

dāívyā. 5. 12. $7^{*}$.

dăíviās. 6. 4I. 3. 8. 9.21. I7. 28. dogdhṛ: -dhắras. I0. I0. 5 .

dodhat in vāibādhadódhat.

dom a $\mathbf{n}(?)$ in adomadá, adomadhá.

doșán: -áñi (p. -ĩ íti). 9. 7. 7. 10. 9. 19.

(cf. doșaṇiçríṣ, doṣaṇyà.)

doṣaṇioçríş: -șam. 6. 9. 2.

doṣaṇy à: -àm. 2. $33 \cdot 2^{*}$.

doṣás: -sas. I6. 4. 6.

doṣầ. 6. r. r (-șó: p. -6́ íti). I6. 7. 9.

dóh a: -as. 4. II. 4 .

d6ham. 5.17.17.

dóhās. 4. II. 12. 8. 9. I5.

dohăn. 4. II. 9.

d ó h a s: -sā. I 8. 1. 18*.

dãúrjĩvitya (p. dãúḥoj-) : -yam. 4. 17.5 .

dāú r b hā g y a (p. dāúḥıbh-) : -yāis.

$$
\text { I4. 2. } 28 \text {. }
$$

[4. 17.5 .

dā ú șva pny a (p. dāúhosv-): -niam.

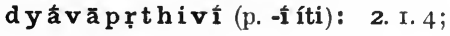
IO. I-8; I2. I; 29.5. 3. 4.5 ; I5. 2 ; 3r. 4. 4. 6. $2 ; 26.7 ; 30.5^{*}$. 5. I 2 . $9^{*} ; 23.1 ; 24.3 .6 .3 .2 ; 8.3 ; 55.1$; 58. I; 62. I; 94.3. 7.30. I; 82.4, 5 ; II2. I. 8. 2. I4; 5. 3, 6, I8; 8 . 2I, 22 . 9. $2.20 ; 4$. I0. I0. $7.35 ; 8$. 39. II. $3.2 ; 7.2$. I3. I. $5,6^{2}, 7,37$; 2. $26^{\dagger}, 35^{*} ; 3.1,4$. I 4. I. 54 . I 9. 10. $5^{*} ;$ I4. I; I 5. $5 ; 20.4 ; 49.1$; 58.3. dyăvāpṛthivī (p. -I íti). 2. I2. 5 ; 16. 2. 4. 26. 2-6. 5. I4. I2. dyāvāpr̨thivi (do.). 2. 29.4. 4. 22. 4 ; 26. I. 6. 40. I.

dyăvāpṛthivibhyām. $5 \cdot 9 \cdot 7.7$. 102. I. II. 3. 33. I9. 17.5.

dyăvāpr̨thivyós. 6. 58.2. 16.8.23. dyăvāpṛthivîs. 8. 9. 16 .

(cf. dyăvāpṛthivivant.) [18.5. dyă vāpṛthivívant:-ntam. I 9 . d yāvā bhūmI: dyấvābhūmi. 18. I. 31 ".

d y ú, see div.

dyút: -utâ. I8. 4. 59*. [22. $\checkmark$ dyut: dyuttám. 4. 12.2. 12. 3 . ádidyutat. 7. I4. 2.

ádyotayan. 4.23. 5 .

dávidyutat. 7.62. I.

(cf. dyút, didyut, vidyút, vidyuta, dyota, dyotana, dyotaní, 1jyut, jyótis.)

+ ā: āodidyóta. 6. 24. 2.

+ vi: ví dyotate. 13. 4.4 I.

ví dyotatām. 4. I5.8.

viodyótamānas. 9. 6. 47.

(cf. vidyút.)

d y u० mán t: -mấn. I 8. I. 24*, 57 .

dyumát. 2. 35. 4. 5. 20.6. 6. I. I.

dyumántam. 4. 31. $4^{*}$. I8. 4. $88^{*}$. dyumántas. 4. I. 5 . I8. I. $57^{2}$.

dyumátas. I8. r. 57 (mss. -mantás, -matás).

dyumátotamā. 5.27. I.

d y umná: -ám. 6. 35. 3.

dyumnâni. 7.73.10*.

dyumnāís. I3. 2. 34 .

dyus in anyedyús, ubhayadyús.

d y ū tá: -té. I2. 3. 46.

dyota in hṛddyotá.

dyot ana in hriddyótana.

dyotaní: -ím. I8. I. $35^{*}$.

d y āú $\circ$ a mọita: -as. I0. 5.27.

drá: -ás. II. 7.3.

(cf. uttaradrá, kṛṣnạadrá.)

dradha in vidradhá.

drapsá: -ás. I 8. 4.28*.

drapsám. I 8. I. $2 \mathrm{I}^{*} ; 4.28^{*}$.

(cf. drapsávant.)

drapsá。vant: -vān. I8. 4. I8.

drava in hăridrava. 
drávina: -am. 2. 29.3. 4. 36.4. 5 . 3. $5^{*}$. 7. 5.2 ; $7.4 ; 67.1$. I0. I. IO; 5. 37-4I. I2. 5.8. I3. I. 34. I4. 2. 74 . I8. 3. I. I9. 7 I. I. dráviṇena. 9. 2. I5. I0.6.26. drávinaasya. I2. I. 45.

dráviṇe. 6. 47.1. I2. I. 6. dráviṇāni. 7.82. $1^{*}$. I9. 31.6 , I1. drávināa. 4. 30. 6†. 7. 78.2. I8.3. I4. dravinas in

draviṇodā (p. -ṇaḥod-): -ấs. Ig. 3.2. 20. 2.4 .

dravitnú: -úm. I 8 . I. $25^{*}$.

draṣṭ̂́: -țăras. I9. 47.3.

- (cf. upadrașț̣́.)

V I drā: drătu. 6. 66. I. dadrúşiṇām. 5. I3.8 (1. -ṇaam). dadrānám. 9. I0. 9*. (cf. drá.)

+ a pa: ápa drāhi. 6. 14.3. ápa drāntu. 6. I29. I-3. I4. 2. II ${ }^{*}$. 12 drā: + av a: cf. avadrāna. drăghiyas: 8. 2. 2. 12. 2. $30^{*}$. drāṇ a in anavadrāná.

drầpi: -im. I3. 3. I. (cf. híraṇyadrāpi.)

$\checkmark$ dru: dravatas. I0. 7.6. (cf. drava, dravitnú.)

+ ati: áti drava. I o. 9. 8, 9 . + u pa: úpa drava. 7.73.6. I8. 2. 23. + nis: nír drava. Io. I. 2 I.

nír dravatu. 9. 8. II.

nír dravantu. 9. 8. 13-8.

+ pra: prá drava. 3. 4. 5. 4. I2.6. I8. 3.8 .

prá dudruvus. 20. I 30. I2 (not mss.).

dru in drughaná, drupadá, droṇa, uttaradrú (?).

drugdha in akṣádrugdha.

d r u g h a ná (p. -uoghan-) : -ás. 7. 28 . I. dru opadá: -dăt. 6. I15.2, 3 . drupadé. 6. 63.3. I9. $47.9 ; 50$. I. druváya: -as. 5. 20. 2.

druváye. II. I. I2 (s. mss. dhru-). vdruh: dudróhitha. 5. 30.3.

drugdhám. I. IO. 2.

(cf. drugdha, drúh, druhú, drúhvan, drogha, droha.)
+ abhi: abhí druhas. 9. 5.4. abhiodudróha. 7.89. $3^{*}$.

(cf. abhidrohá.)

drú h: -hás. 2. I0. 1-8,6. 7.77. 2*; I03. I. I6. 6. I0.

druhás (pl.). 8. 4. $7^{*}$. I9. I 5.2 (ed. drúhas).

(cf. adrúh.)

druhú: -ús. 8. $4 \cdot 7^{\dagger}, 17^{\dagger}$.

drúhvan: -ạas. 4. 29. I, 2.

drogha in ádroghāvita and

droghaovác: -cas. 8. 4. $4_{4}^{*}$. (cf. ádroghavāc.)

drona in

drọ̣aoka laçá: -çấs. 9. 6. I7.

droh a in abhidrohá.

dva, dvi: dvāú. 4. I6. 2. 5.23. $4^{3}$. 8. Io. $13^{2}$. I5. $3.4^{2}$. I9. 47.5 .

duāú. 4. I3. $2^{*}$. 5. $23 \cdot 4^{3}$. I0. 4.8 . 20. I3I. 23 (mss. dāu); I33. I, 2, 3 . dvă. I 8. 2. $33^{*}$.

duă. 9. 9. $20^{*}$.

dvé (p. -é íti). 5. 15. 2. 20. I32. 15 (inss. dvāú).

dué (p. -é íti). 6. 83.2. 8. 2. 21. I8. 2. 28,42 . I 4 . I. 16 ".

duăbhyām. 7. 4. I (1. -bhiām ?).

(cf. dvayá, dvădaça, dvijádviṿ̛șá, dvís, dvyàsya.)

dva yá: -yă, I9. 7.5.

dvayăni. 4. 24. 7 .

(cf. dvayāvín.)

d va yāvín: -nas. I. 28. I.

dvăd aça: 4. II. II. II. 6. 22. duădaça. I 0. 8.4. (cf. dvādaçadhă-dvādaçāhá.)

dvādaçaodhă. 6. II3.3.

dvādaçarcá (p. -çaoṛc-): -cébhyas. I9. 23. 9. [9.12*. dvă d a çākṛti (p. -çaoāk-) : -im. 9. d vă d a çār a (p. -ça॰ar-): -as. 4. 35. 4 . duấdaçāram. 9. 9. 1 $3^{*}$ [7.12.

d vā daçāhá (p. -çaoah-): -ás. II. dvādaçāhéna. 9. 6.43 .

d vầr: duăr. 9. 3. 22.

dvắram. I4. I. 63.

dvắras. $5 \cdot 27 \cdot 7$.

dvāras. 5. 12. $5^{*}$. 
(cf. dvăra.)

d vāra in návadvāra.

dvi, see dvá.

dvijá: -jânām. I9. 71. I.

dvíojihva: -vā. 5. 19.7.

dvita in

dvitiya: -as. 13. 4. 16. I5. 15.4;

I6. 2 ; 7.2 .

dvitiyam. I0. 8. 17.

dvitiyã. II. 5.4.

dvitîyām. II. 1.24. I5. I3.2.

dvitiye. 6. 47.2. 9. I. I2.

dvitíyebhyas. I9. 22.9 (m. mss. -tīyé-).

dvíopakṣa: -șã. 9. 3.21.

dviopád: -păd. 6. 107. I-4.

8. 8 .

I4. I9. 3 I. $4 ; 34$. I.

dvipádā. 9. 10. $2^{*}$. I9. 15.2.

dvipáde. 6. 27. $I^{*}$. II. 2.28. I4.

2. $40^{\text {". }}$.

dvipádas. 4. 2. $I^{*} ; 28.1,6.6 .23$.

3. I3. $3 \cdot 24^{*}$.

dvipădas. I2. I. 51 .

dvipádas. 3. 2 I. 2 . I0. 2.6. II.

2. I. I2. I. 15. I3. I. 2.

dvipádām. 2. 34. 1. 8. 2. 4, 23 (1. dui-?). I9. 3 r. 5 .

[I. $42^{*}$.

dvipádi. 9. 10. $2 \mathrm{I}^{*}$. IO. I. 24 . I3.

dvíopa d: -pād. I3. $2.27^{2+} ; 3.25^{\dagger}$.

dvípadas. I 3. $2.27^{\dagger} ; 3.25^{\dagger}$.

dvípadām. I3.3.25t.

d vibhāga in

d vibhāga d haná: -ám. r2. 2.35. dvíomūrdhan: -dhā. 8. I0. 22.

dviorājá: -jé. 5. 20. 9 .

dviorātrá: -ás. Ir. 7. 10.

dvi०ṿ̛ṣá: -ás. 5. I6. 2.

Vdviş: dvéșmi. 3. 6. I, 3, 5 .

dvéșți. 2. II. 3 ; I9. I-23. 5 . 3.27. I-6. 7. 3I. $I^{*} ; 8$ I. 5. I0. 5. I5-2I, 25-35. 12. 2. 3. I6. I. $5 ; 6.4 ; 7.5$. dvișțas. 5. 18.5.

dvișmás. 2. II. 3 ; I9. I-23.5. 3 . 27. I-6. 6. 26.3 . 7. $3 \mathrm{I}^{\mathrm{I}} \mathrm{I}^{*} ; 8 \mathrm{r} .5$. I0. 5. I5-21, 25-35. I2. 2.3. I6. I. $5 ; 6.4 ; 7.5$.

dvișmas. I9. I4. I.

dvișánti. 9.5.2. 10.3.3. I2. 3. 49 . dvéşat. I 2. I. I 4 .

dvéşāma. 6. 26. 3 .

dveșțu. I6. $7.5^{2}$.

dvişán. I. 19.4. 9.6.24. I7.6. dvişántam. $4 \cdot 35 \cdot 7.45 \cdot$ 1.8. I6. 7. 6.

dvişaté. $5 \cdot 3 \cdot 7^{\circ}$. 6. $46.3^{\dagger}$. 7.115. I. I6. 6.3. I 7. 6. $24^{*}$. I 9. $57 \cdot 2,3,6$. dvişatás. I. $21.4^{*}$. 9. 6.24. I0. 6. I. 31. I9. $28.1,2 ; 30.4$. dvişatás (pl.). ro. 6.6-17, 19, 20, 21 . I I. I. $6,12,2$. 19. $28 \cdot 3,5-10 ; 29$. I-9.

dvişatắm. 5.20.12; 25. 10. 7.13. I, 2. I9. 28.4 .

dvikșat. 3. 30. 3 .

dvikșata. I2. I. I8, 23-5; 2.33.

(cf. dvíș, dvișța, dveșa, dvéșas, dvéşya.)

+vi: viodvișáte. 3. 30.4.

(cf. vidviș, vidveșá.)

dviș: -ișás. 5. 6.4*.

dvíșas. 2. 6.5. 4. 33. $7^{*}$, 6. $34 \cdot 1-5^{*}$. I9. I5. I".

(cf. brahmadvíș, ávidviș.)

dvișța in aghádvișța, kṛtádvișța. dvís: duís. 5. 2. $3^{*}$. 20. 127.2 (mss. dvis).

dvipa in

dvipín: -nam. 4. 18.7.

dvīpínas. 19.49.4.

dvipíni. 6. 38.2.

dveș a in vidveșá.

dvéșas: 6. 4.2. 7. 9I. $\mathrm{I}^{*}$; 92. $\mathrm{I}^{*}$. 8. 4. $2^{*}$.

dvéşāṅsi. I. 2. 2. 5. 22. I. I8. 2.47.

dvéşya: -yas. 9. 2. 14 .

dvéșiā. I. 20. I. 5. 3.6. [19.7.

d v y às y a (p. dvíoās-): dvíāsyā. 5 . dvíāsiāt. 8.6.22.

d h a in adomadhá, nāmadhá; and cf. dhā.

[sás).

dhakṣu: -șo: 19. 64.t (mss. hañdhána: -am. I. $15 \cdot 3,4$. 2. 7.4. 3 . I5. 2, 5,6. 4.31. $7^{*} ; 38.3$. 5. 19.9. 6. 81. I. 7. 50.6 $6^{\dagger} ;$ 109. 5. 8. 5. I6. 
II. I. 28 I2. I. 40. I9. 3I . IO. dhánena. 3. $15 \cdot 5^{2}, 6^{2}$. 7. 33. I ; 81. $3,4,5$. I4. I. $48 ; 2.70$. I8. 3. I 7. 19. $31.7 ; 64.2$.

dhánāt. I2. 2.37.

dhánasya. I9. 31.9.

dhánāni. 7. 50. $7^{*}$.

dhánā. 5. 2.4*. I 9. 35.2; 49.7(mss.

dhánāis. 5.4.2.

dhánānām. 4.22.3. I0. 8.42 .

(cf. dvibhāgadhaná, bhứridhana, mahādhaná, dhánakāma - dhánasāti, dhanya.)

dha $\mathbf{n}$ a in nidhána, pradhána, samidhana.

dhánaokāma: -as. 5. 18. 5 .

dhana okāmyấ: I2.2.5 I (p. -yấ át kr-).

dhanaojít: 5.3. II.

$\mathrm{d}$ h a n a moja yá: -ás. 3. I4. 2. 7. 50.8. dhanaodắ: -ắs. 3. I 5.1 ; 20. 2*.

d hána opati: -is. 4. 22. 3. IO. IO. II. dhanapate. 2. 36.6. 5.23.2.

dhana॰pālá: -ás. I9. 35.2.

dhanaosáni:-is. I8. 4. 38 .

dhanaosă: -ấs. I9. 3I.8.

dhánaosāti: taye. I9. 3 I.8.

dhánus: $4.4 .6 ; 6.6 ; 30.5^{*}$. 6. IOI. 2. 7. 50.9. II. 2. I2. I5. I. 6. I 8. 2. $60^{*}$.

dhánurbhis (p. -uḥobh-). 5. I8.8. (cf. indradhanús, I dhánvan.)

d h a nút: -û́s. I. I 7.4.

dhan ya in jivádhanya.

$\checkmark$ dhanv: cf. 2 dhánvan (?).

+ pra: prá dhanvā (p. -va). 5.6.4*.

I dhánvan: -nas. I. 3.9. 4. 6.4.

5. 13.6. 6. 42.1 .

dhánvani. $4 \cdot 4 \cdot 7$

dhánvanām. II. 9. I.

(cf. abaládhanvan, ugrádhanvan, kșiprádhanvan.)

2 dhánvan: -va. 6. 34. 3*. 7. II 7. 1*. dhánvani. 6. roo. 2.

dhánvan. 5. 13.1.

dhánvāni. 7. 4I. I.

(cf. dhanvanyà.)

dh a n v a n y à :-níās. I, 6. 4. I9. 2.2. $\checkmark$ dham, dhmā: dhámantas. I8. 3. $22^{*}$. 20. 129. Io (mss. -amá-).

(cf. dhama, dhamáni, dhmāna.)

+ u p a: cf. upadhmăna.

+ pra: prá dhamāti. I8. 2.28 . prá... dhamatu. 3.2. 2.

+ vi: ví... dhamatu. 3.2. 2. (cf. vidhamá.)

+ s a m: sám dhamāmi. 8. 2.4. sám dhamantu. 8. I. I9.

dh a m a in vidhamá.

dhamáni: -is. I. I7. 2.

dhamánayas. 6. 90. 2.

dhamánīs. $7 \cdot 35 \cdot 2$.

dhamániobhias. 2. 33.6.

dhamáninnām. I. I7.3 (1. -naam).

d hara na a in vidháraṇa. [36.

dharúna: -as. I6. 3.3. I8. 3. 29 ,

dharúṇam. 4. 32. $7^{*}$. 7. 3. I.

dharúñāya. 6. 92. $3^{*}$.

dharúne. I2. 3. 24, 25.

dharúneșu. 5. 1. $6^{*}$.

dharuṇi: 3. 12. 3 .

d h a r tŕ: -tă. 5. I. I. I2. 3.35. I6. 3. 3. I 8. 3. 29,36 . I9. I0. $3^{*} ; 58,2$. dhartārā. 7. 73. 4 .

dhartăras. 18. 1. 2*.

(cf. vidhartṛ.)

dhá rma: -as. II. 7. I7. I2. 5.7. dhármam. I8. 3. I.

$\mathrm{dh}$ a rma odhṛt: -tas. I. 25. I.

dhárma n: -ạ̣ā. 6. 132. I-5. 7.25. 2. 12. I. 17. 14. I.5I.

dhármaṇi. 7. 14.4 .

dhármāṇi. 5. I. 2. 7. 5. I*; 26. $5^{*}$. 9. I0. $25^{*}$.

dhármā (p. -ma). 6. 5 I. $3^{*}$.

dhármaobhis. $18.2 .7^{\dagger}$.

(cf. nấnādharman, vídharman, satyádharman, dharmadhṛ́t.)

dharșa in durādhárșa.

dh a rș y in anavadharșyà. [liḥ).

d havá: -ás. 20. I3I. I 7 (m. mss. badhavatt. $5 \cdot 5 \cdot 5$.

$\mathrm{d} h$ as in vayodhás, varcodhás.

V I d hā: dadhāmi. 4. 30.6* 7.82, 2. 8. 2.2, 9. I2. $2.23^{*}$.

dádhāti. 5. I. 7 . 
dadhäti. 5. 2.2 $2^{*} ; 17 \cdot 6^{*} \cdot 9 \cdot 5 \cdot 10$, I 8 . dadhmas. 3. $27 . \mathrm{J}-6$.

dadhmasi. 1. 22. $4^{*}$.

dhatté. ro. 7.42 .

dadhate. II. 4.3.

dhehi. 2. $29.2 ; 36.8$. 4. 4.8 ; I 4 . $7^{2}, 8^{4} ; 22.3 ; 32.4^{*}$. 5. $25 \cdot 3^{2 *}$. 6. I. I; 79. $3 ; 82.3 ;$ I33. 4. 7. 20. $4 ; 76$. 6*; 79. I; 89.4. II. I. 2 I; 4. 9; 5 . 25. I2. I. I $2,16,63 ; 2.45$. I 3. I. 12. I4. 2. $6^{\dagger}$. 16. 9. 4. I7. 6-19, 24. I8. I. $43^{*} ;$ 2. I2*; 3. I, 7I ; 4. II. 19. $3.3 ; 4.3 ; 20.3$ (mss. yodhí-); 3 I. I2, I3; 52. I, $2 ; 64.4$.

dádhātu. 6.60.3.

dadhätu. I. I. I. 3. 8. I; 20. $3^{\dagger}$, IO. 5. $25.4,5^{*} ; 28.5$. 6. 47 . I. 7. I7. I, 2,3 ; I. $\mathrm{I}^{2} ; 47.2$. 8. I. 15 ; 5. I8. 9. 4. 21 . 12. 1. $3,4,5,6,8,22,44,52$. 13 . I. 35. I6. 4. 7. I8. $2.55^{*} ; 3.62$. I 9. 3I. 3,$6 ; 43$. I-6, 8 .

dhattam. 2. $29 \cdot 3,5^{2}$. 4. 25.5. 5 . 6.8. 7. $42.2^{*}$. 8. 2. $7 ; 4.2^{*}$.

dhattām. 4.31. $7^{\dagger}$.

dhattá. 2. I3. 2.

dhatta. 2. 34.2. 6. 4I. 3. 7. 82. I"; 97. 3. I0. 5. 7-I4. I8. $3.43^{*} ; 4$ I. dadhăta. 6. 55.2. I4. I. 59. I 8. I. $5 \mathrm{I}^{*}$; 3. I4, $43^{*}, 44^{\dagger}$.

dadhātana. I. 5. I*

dádhat. 9. 4.22. 10. 6.4.

dádhatas. I8. 4. 62 .

dádhānas. I3. I. 2. I8. I. 24 *.

dádhānāu. 7.29. I.

dádhānās. 4. 2.6*; 3 I. $7^{*}$. 12.2. 30*. I8. 3. I7 (mss. āyuḥodádh-), 20. ádadhăt. I 0. 2. 7 .

adadhāt. I0. 2. I2, I4.

ádadhus. 18. I. $35^{*}$.

adadhus. 8.9.14. 9.4.16. I8. 2. $33^{\dagger} ; 4.7$. I9. 56.4 .

dadhete (p. -e íti). 5. I. 3 .

dádhat. 6. II. 3. 7. I4.4.

dadhat. 6. Ir.3. 7. 53.6. ro. 3. 12.

dadhāu. 9. 4. Io. I0. 2.17.

dadhus. I9. 56.3.

dadhișé. I9. 49. 7.

dadhiré. I. $33.1-3$. 8. 4. 18 *. dadhire. 6. $49 \cdot 3^{*}$.

dadhişva. 20. I27. I4 (mss. -idhva, -ídhva).

adhātām. 2. 29.5.

dhām. 7.97.8.

dhăs. 7. 115. 2.

dhăt. 2. I0. 3. 6.6I. I. I6. 9.2. I8.

$3.63 ; 4.54$.

dhīmahi. 7. 7 7.2.

dhătave. 6. 8 r.2.

hitám. 3. I3.3. 8.6.20. ro. 2. 24, $25 ; 8.34$. II. 8. 34. I8.2. $7^{*}$ ( / hã ?).

I 9. 42.1 (mss. antáh̆hite).

hitâ. I0. $2.24,25$. I I. I. $23 ; 7.22$.

hitấs. II. 2.24; 7. II, I5. I2. I. 49.

I3. 4. Io.

(cf. dha, dhána ?, dhā, dhãtṛ́, dhătu, dhāna, dhắman, dhi, hita, dhiti, dheya.)

+ a ti: átiohitam. 7.53.3. I8. 2. 26. + a dhi: ádhi...dádhāne (p. -e íti). 5. 12. $6^{*}$.

ádhiohitā. I I. 3. I4. adhiodhīyámānā. 12. 5.30.

+ antar: antarodádhānās. 5. 28. 8. antár dhehi. II. IO. 4.

antár dadhe. 8. 5.6. I7. 29.

antárohitās. II. 9. I6.

(cf. antardhí.)

+ a pa: ápa ... dadhãtu. 6. 45.2* + a pi i: ápi dadhāmi. 4. 36. 2. 16. 7. 3 . ápi dhatsva. 8. 3. $2^{*}$ (1. -sua?). ápy adhām. 7.35.2. ápi dhāyi. 5. 30. 15.

(cf. apidhăna, apihita.)

+ a bhi: abhí dàdhāmi. 8. 8. 8, 9 .

abhí... dádhāmi. 7. 37. I.

abhyádhatta (p. abhioádh-). 3. I I. 8. abhí dhehi. 4. 16. 7.

abhí dhattam. II. 9. 3 . abhí ... dhattām. 4. 36. Io.

abhí... adhām. 3.18.6".

abhí ... ahita. 3. II.8.

abhiodhăya. 8. 8.5:7. I9. 50. 5.

abhíohitas. 6.63.3.

abhíohitam. 9.3.8.

abhíohitāu. I4. I. II".

abhíohitās. IO. I. 30 . 
(cf. abhidhăna.)

+ av a: áva dadhmas. I9. 72. I.

áva dhehi. 9.5.5.

avaodadhús. 5.31.8.

ávaohitam. 4. 13. I* .

avaodhīyámānā. I2. 5.30.

+ ā: á dadhāmi. 2. 10. 5 ; 12. 8.5 . 25. 2. II. I. 20 . I8. 3.30-5.

à dadhāti. 4. 8. I. II. 5.13. à ... dadhmási. 19. $64 \cdot 3^{*}$ (mss. -masi).

à dadhīta. I8. I. I*.

à dhehi. I. 9.3. 5. I4. $4 ; 25.8$, ro3. 6.8 r. $2 ; \mathrm{I} 33.4$. 7.55. I. I8. I. $42^{*}$. I9. 37.2 .

à ... dhehi. 6. 26. 1. I2. 2.46. à dadhātu. 3. 15.6. 7. 5.2. 19.3 I. 9 . à... dadhātu. 6. 92. I. 8. 4.9*.

á dhattām. 3. 22.4. 5. 25. $3^{*}$.

à dhatta. I6. I. I3.

â dadhatām. 8. 8.2.

à ... ádadhāt. I 3. 3. 22.

à'dhatta. I3. I. 46. [I r. 4. II.

à dadhat. 4. 19.8; 20.4. 5. 25. I.

à dadhāu. Io. 2.5. I 9. 34.9.

āodadhé. I. 28. 3. 5. 25.2. 6. r7. I.

à 'dhāt. 9. IO. I2*. I2. 2. 6 .

à dhās. 6. I26. $2^{*}$.

à ... dhās. 5. 25.7.

à dhāt. 2. 29. I.

ầhitas. 4. Ix.8. 6. I29.3. 7. 50.

8. II. 4. I3; 7. I. I4. I. $2^{*}$. I9. 53. 3.

áohitam. 9. ro. $\mathrm{I}^{2 *}$. I0. 3. I 7, 23, 25 ;

7. I, 29, 30. I4. I. 35. I7. I9. [54. 2.

à̀hitā. I0. 7.3, I2. I I. 7.22. I9.

āodhăya. 8. 6. I3. I3. I. 47.

(cf. ādhí, ādheya.)

+ nirā: nirădadhāu (p. nị̣oăd-). 12. 2.54 .

nirādádhat (p. nị̣॰ād-). I2. 2.39. (cf. ánirāhita.)

[12. 2. $5 \mathrm{I}$.

+ paryā: paryădadhati (p. parioâ-). paryấdhatta (do.). 9. 5.5.

+ s a mā: samoādádhati. 6. 76 I. samoâhitas. 4. I1.8. I3. I. 50. sm oâhitam. I 0. 6.35; 7.29. II. 7. I, 2. I9. $53.7,8$.

samıăhitām. 6. 76.3. samoăhite (p. -e íti etc.). Io. 7. 35 . samoăhitās. I o. $7 . I_{1}, I_{3}, I_{5}, 22$. I I. 7. 8,9 .

[útohitā).

+ u d: úddhitā. 9.3.6. I9. 42.2 (p. úddhitās. I 8. 2. 34 .

(cf. uddhí.)

+ upa: úpa dhehi. 8. 3. $3^{*}$. II. r. 23. úpa dhatsva. I4. 2. 39.

úpa ... adhām. 3. 18.6*.

(cf. upadhắna, upadhí.)

+ tir a s: tiró dhatte. 8. 10. 28.

tiráh ... dadhatām. 12. $2.23^{\dagger}$.

(cf. tirodhă.)

+ ni : ní dadhāti. 4. 21. 2*. 6.76.3.

ní dadhmas. I2. I. 30.

ní dadhmasi. I. 22. $4^{*}$. 3. 23. I. 5 . 2I. I. 8. I. 2 I. I4. $2.65,69$.

niodadhé. 9.5.19. [28, 33 .

ní dadhe. 4. 34.8. 5. 9.7. I I. I. ní dhehi. I2. 1.63.

ní dadhātu. 8. 5. 2 I.

ní ... dhattam. 4. 28.6 (mss. -ttām). niodádhat. I8. $3 \cdot 52^{*}$.

ny àdadhāt. I0. 2. I 7.

ny àdadhus. I0.2.2.

niodadhús. 3.5.3.

ní... dadhișe. 5. 2. $6^{*}$.

ní dadhe. 7. 26. $4^{*}$.

ny àdhus. 19. 20. I (mss. nyá-).

ní dhātu. I8. I. I9*.

ní ... dhāyi. I8. I. $3^{*}$.

níohitas. 6.92.2 ; I40.2. 7.62. I. II. I. 5 , 15. I 2. $3.42 ; 4.14$, 29. I 8. 3. 7 O. níohitam. 6. II3.3. 9. 9. $5^{*}$. 10. 2. I9; 8.6. II. 7. I0. I2. 1. $60 ; 3.48$; 4. I7, 2I. I9. 27.9. [22. níohitā. I. I3.3. I0. I. 29. II. 7. níohitāu. I I. 5. Io.

níohitās. 4. 35.6. 7. 43. I.

níohitā. 2. 1. 2. 9. 9. $3^{*}, 6^{*}$; 10. $27^{*}$. níohitān. I8. 4.4I.

ní dhīyasva. I8. 2. 20.

(cf. nidhána ?, nidhí.)

+ adhini: adhionídadhmasi. 6. 138 . adhionídhehi. 2. 29. 2.

+ pari: pári ... dadhāmi. I3. I. I9. pári dadhmasi. I. $22 . \dot{1}, 3$. pári $\therefore$ dadhmasi. I. 22. 2 . 
pári dadhmas. 6. 99. 2, 3 . pári dhehi. 7. 99. 1. 18. 2. $12^{\dagger}$. [18. pári ... dadhătu. 7.9.4". 13. I. I7, pári dhattăm. I4. I. 53 . pári dhatta. 2. 13.2. 6. 55. I. pári ... dhattana. 19. 24. 1, 2, 3. pári dhatsva. I4. 1. 45. 19. 24.5. páry adadhāt. I0. 2. 15 . pári ... adhātām. 18. 3. I 2. pári ... dhăt. I3. I. 20. pári ... adhithās. 2. I3.3. I9.24. 6. pári... dhimahi. 7. 71. $1^{*}$. páriodhātavāí. 2. 13.2. pariodhăya. 2. 29. 6. páriohitā. 12. 5.3. pári dhāpayāmas. 19. 46.4 . pári dhãpayāthas. 12. 3.5 I.

(cf. paridhăna, paridhí.)

+ puras: puró dadhe. 4. 7.7;27. 2. 5. 30. 12 . 19. 4. 2. purodhatsé (p. -rahıodh-). 5. 7. 2. purodadhiré (p. -rạ̣॰d-). 5. 8. 5.

(cf. purodhă, puróhita.)

+ pra: cf. pradhí.

+ prati: práti dadhmas. 9. 4. 24 . práti dhehi. 8.3.21*. prátiohitām. II. 2. I. prátiohitāyāi. 6. 90.3. prátiohitābhis. I9. I3. $4^{*}$. pratiodhăm. 8. 8.20. II. IO. I6. práti dhīyatām. 7.69. I. (cf. pratidhí.)

+ vi: ví dadhāsi. 7.81. $2^{\dagger}$. [vída-). viodádhat. 7.81 I. I*. I 8.4 .53 (mss. ví dhehi. 8.9.7.

viádadhās. 20! I 28 . I4 (mss. vyàd-). ví adadhāt. I4. I. 53. vy àdadhāt. 10. 2. II. I3. I. I4. ví adadhus. 4. 30. $2^{*}$. vy àdadhus. I0. 2. 4 . ví ádadhus. I9. $6.5^{*}$. ví ... dadhathus. I8. 2.53. viohitas. I8. 4.11 .

víohitā. I0. 2.24, 25 . I I. I. 23. víohitasya. I8. 4.8. víohite (p. -e íti etc.). I2. I. 52. víohitās. I2. I. 36 . víohitāni. 9. 9. 16*. (cf. vidhātŕ, vidhăna.)

+ çradh: çradodádhāti. II. 2.28. çradıdádhānena. 9. 5.7, II. çradodádhānasya. . 4. 35.7. çradıdádhănās. 6. 122.3. 12. 3.7.

(cf. çraddhă, çraddhéya.)

+ s a m: sám ... dadhămi. I2. 3. 23. samodádhāti. 6. 139.5. sám dadhăti. 3. 31. 6 . sám dadhmas. 4. 5. $5^{\dagger}$ [ [3.3 sám dhehi. 4. 12.5. 6.139.5. 8 sám ... dhehi. 4. 4.4. sám dadhātu. I9. 40. I. sám adadhãt. II. 8. I4. samıádhatthās. II. 10. 9 . sám dadhat. 4. 12. 2, 7 . samiodadhāú. I0. I. 8 .

sám adhāt. ro. 5.43. sámohitas. 3. 31.6. 13. 4.26. I9. sámohitam. II. 8. I6. samohitám. 13.3.10. sámohite (p. -e íti etc.). I2. I. 52. sámohitās. 7. 75.2. sám dhỉyatām. 4. 12. 4.

(cf. sam̉hana?, samidhă, sámdhātṛ, samdhí, samhita.)

V2dhā, dhi: dhitám. 7. 56.3. dhátave. 7. 10. $\mathrm{I}^{*}$.

(cf. dadhán dádhi, dhāyas ?, dhārú, dhāsyú, dhenú.)

+ nis: nirodháyanti. 9. 8. I8.

nír dhayet. 9.5.23.

nír adhāt. Io. 4. 26.

dh $\mathbf{a}$ in godhă ?, tirodhă, durdhă, purodhă, pratidhă, yakșmodhă, ratnadhă, retodhấ, vayodhă, varcodhâ, vasudhă, çraddhă, samidhă, sudhă, svadhă : and cf. dha. dhă ñikā:"-ām. 20. I36. 10.

d hầt u: -tave (inf.), see I dhā, 2 dhā. d hā tṛ́: -tâ. 3. 8.2. 4. 12. 2. 5. 3. $9^{*} ; 25.4,5^{*}$. 6. 60. $3^{3}$. 7. I7. I, 2, 3,4 ; I9. I. 8. 1. $15 ; 5.18$. 9. 7. 10, 21. I0. 6. 2 1. II. $8.5,8,9 ; 9.25$. I3. 4. 3. I4. I. $33,34,59 ; 2.13 . \quad 18$ 3. $26 ; 4.48$. I9. 9. I $2 ; 10.3^{*} ; 20$. I; 31.3 .

dhătar. 5. 25. I0. 
dhātar. 7. I8. I. I2. $2.25^{*}$. dhātăram. II. 6.3.

dhātré. 3. IO. 10.

dhātúr. 2. 36.2. I I. 8.9.

(cf. vasudhătṛ, vidhātṛ́, sámidhātṛ.)

$\mathrm{d} \mathbf{h} \overline{\mathrm{a}} \mathrm{na}$ in agnidhăna, apidhắna, abhidhănī, upadhắna, paridhăna, yātudhăna, vasudhắna, vidhāna, vișadhăna, somadhắna, havirdhăna.

d hān ấ: -ầs. I8. 3.69;4. 26;32, 34 (cf. dhānya.)

$\mathrm{d} h \bar{a} \mathrm{n}$ y à : -àm. 6. II 7.2. I I. 3I. 5 . dhāníam. 2. 26. 5. 3. $24.2,4$. 8. 2. 19. I9. 3 I. 10.

dhāníāya. 6. 50. I.

dhāníasya. 2. 26. 3 .

dhāníe. 5. 29.7.

(cf. pứtidhānya, miçrádhānya.)

d hắm a n: -ma. I. I3.3. 2. 1.2. 4 . I.6. 7. 7. I; 29. 2. 8. 9. I0, 25 , 26. I5. 2. I-4; 6. I-9; 8.3; 9.3. I8. I. 7*. dhămnā. 5.27.8. 10. 5.7-14 (l. -manā).

dhắmnaḥodhāmnas. 7.83 .2 (mss.; 1. dhāmanodhāmanas).

dhămaniodhāmani. I2. I. 52.

dhăman. 4. 25. 7. [mss.).

dhămanodhāman. 20. 49. 3 (not

dhămāni. 2. I. $3^{*}$; 14. 6.

dhắmã (p. -ma). 6. 3I. $3^{\dagger}$.

dhắmaobhis. I9. 47. I.

dhắmaosu. 6. 36.3. 7.68. I.

(cf. priyádhāman, sahasradhā-

man, sthirádhāman, dhāmaçás.)

dhāma ○çás. 9. 9. 16*. [yas.

dhāyas in bhứridhāyas, viçvádhā-

d hāra in ādhārá.

dhấrã: -ām. 3. 12.8.

dhắrayā. 7. 50.9. I0. 6.25.

dhấrās. 4. II. 4; 34. 5-7. 7.82. I*;

107. I. 9. 5. I5. I2. I. $45 ; 3.41$.

(cf. bhúridhāra, mádhudhāra, viçvátodhāra, çatádhāra, sahásradhāra.)

dhārú : '-ús. 4. 18.2.

Vdhāv: dhăvasi. 6. 131.3. dhăvatha. 6. 66. 2 .

dhăvanti. 5. 21.5

dhāvanti. I0. 6. I4.

dhāvate. 18. $4.89^{*}$.

dhăvāt. I0. 3.6.

dhăvatu. 6. 92.3

dhāvatu. 5. 20.5. I9. 47.7.

dhāvata. 8.8. I9. I9. 27.6 .

dhăvantu. 5. 2 I. 2.

dhăvantam. 20. I28. I5; I36. II.

dhâvantī. 12. 5. I8.

dhăvamānam. I3. 2. 37 .

+ a ti: áti dhāvata. 5. 8.4.

+ anu: ánu dhāvati. 20. 136. II.

ánu dhāvata. 5. 2 I. IO. II. IO. I.

+ a pa: ápa dhāvata. 4. 37. I2.

+ abhi: abhiodhăvāmi. 6. IIg. 3 .

+ a va: avaodhávati. 2. 3. r.

+ ā: á... dhāvata. 6.2. I ( $/ 2$ dhāv ?).

+ pari: pári dhāvati. 20. 136 . 10.

+ pra: prá dhāvati. 20. 136. I4.

prá ... dhāvatu. 3. $18.6^{2 *}$.

+ prati: práti dhāvatāt. I9. 25. I.

+ vi: ví dhāva. I2. 5.55.

+ s a m: sám dhāvantu. II. 9. I4.

dhās y ú: -ús. 2. I. 4 (l. -siús). 5. I. 2. dhāsyáve. 4. I. 2.

$\checkmark$ dhi, see $\sqrt{ } 2$ dhā.

dhi in antardhí, ādhí, ișudhí, udadhí, uddhí, upadhí, óșadhi ?, nidhí, paridhí, parṇadhí, puchadhí, púramỏhi ?, pradhí, pratidhí, çevadhí, samihí.

dhișáṇa: -am. 2. I4. I.

dhíṣnya: -ṇiās. 2. 35.1. 7.67. I. $\checkmark \mathrm{d} h \overline{\mathbf{I}}(\mathrm{d} \overline{\mathrm{I}} \mathrm{dh} \overline{\mathrm{i}})$ : dídhyatas. I 8. 3. $2 \mathrm{I}^{\dagger}$. dídhiānas. I8. I. I*.

dìdhiānās. I8. 2.47.

(cf. dhî, dhītí, dhîra, dhívan, vdhyā.)

+ a nu: ánu ... dĩdhius. I4. I. $46^{+}$. ánu dídhiānās. 2.34.3.

(cf. anudhyá.)

+ ã : â dīdhĩthām. 2. I2.5.

à dỉdhīthās. 8. I. 8 .

(cf. ādhí.)

+ pra: praodídhiatas. I0. 4. II.

+ vi: ví dĩdhyas. 8. 1. 9 . 
dht: dhis. 18. I. $21^{*}$.

dhíyam. 3.15. $3^{*} ;$ 16. 3". 20. 127.6. dhiyă. 2. 5.4. 6. I9. I. I0. I. 8. 18. I. 18*. r9. 42.4 (mss. dhíyas). dhiyé. 6. 4. $3 ; 4$ I. I.

dhíyas. 9. 2. 25. 20. 48.3 (not mss.). dhībhís. 5. 12. 2"; 20.8. I9. 11. 2". (cf. ādht.)

dhItí: -ís. II. I. II. dhití. 7. I. I. 9. 9. $8^{*}$. dhītíobhis. 9. 10. $17^{*}$.

dhira: -as. 2. 35.3. 3. 21.4 9. 2.6; 9. 22 *. I 0. 8. 44. II. 4. 24. I9. 56. I. dhiram. ro. 9.44.

dhîrās. 3. I7. $\mathrm{I}^{*}$. I I. 9.22.

dhîrāsas. 9. 4.8.

dhîrānām. 20. 128. 4 .

dhíraotaras. 5. II. 4 .

dhtraotarās. 10. I. I8.

dhirit. II. I. I3.

(cf. ádhīra, maryãdhíra.)

dhîvan: -vānas. 3. 5.6.

$\checkmark \mathrm{dh} u$, see $v$ dhū.

$\mathrm{d} h \mathrm{u}$ in vidhú.

dhú r: -ram. 5. I7. 18.

dhură. 9. 9. $19^{*}$.

dhurí. 5. 17. 15. 9.9.9*. I8. 1. 6". (cf. dhura, dhúrya.)

dhura in sádhura.

dhúrya: -am. 5. I. 4.

$\checkmark \mathrm{dh} \overline{\mathrm{u}}$ : dhūnoti. 9.4.13. dódhatas. 12. 1. 58 .

(cf. dhu, dodhat.)

+ ava: áva dhūnute. 5. I9. 7. áva ... dhūnute. I9. 36.4 . áva dhünuşva. 19. 46.2. áva ... adhūșata. I8. 4.6I*.

+ ni: ní dhuvāmi. 3. II. 7 . ní dhūyatām. I. I4. 2.

+ vi: ví... dhūnuhi. 5.22.7. ví dhūnu. II. 2. I9.

vioádhūnuta. 5. 18. 12 (m. mss. vyàdh-); Ig. I I (do.).

ví... dudhuve. I2. I. 57 .

viodhúya. 13. 2.8. (cf. vidhú.)

$\mathrm{d} h \overline{\mathrm{u}} \mathbf{p a}$ in

[I9.6.

$\checkmark \mathrm{d} h \overline{\mathrm{u}} \mathrm{p} a \overline{\mathrm{y}}:+\mathrm{vi}$ : viodhūpáyat. 4 . d hūmá: -ás. 6. 89.2. I8. 4.59". dhūmám. 6.76.2. 8.8.2. 9. 10. $25^{*}$. II. I. $2^{*}$. 12.3 .53 .

dhūmằn. 6. 113. 2.

(cf. tṛşțádhūma, çakadhúma, dhūmáketu-dhūmra.) [9. ro.

dhūmá。ketu: -us. I8. I. $30^{\circ}$. I 9. dhū ma॰çikhá: -khấs. II. 9. I 9 . dhū mākṣá :-ma॰akşî́. II. IO. 7. dhũ mra in tāmradhūmrá.

$\checkmark$ dhūrv: dhúrvantam. 8. 3. $21^{\circ}$.

dhūrvantu. I. I9.4".

dúdhūrşati. 20. I28.2.

$\checkmark$ dh ṛ: dādhắra. $4 \cdot 35 \cdot 3 \cdot 6 \cdot 17 \cdot 2-4$. dādhāra. 4. 2. $7^{*} ; 11 . I^{3}$. 5. I. I. 6. 60. 3. I0. $7 \cdot 35^{3} ; 8$. II. II. 5. I. I 8 . 4. $5^{2}$.

dadhré. I8. 3.63. I9. 26. I.

dadhre. I2. I. 37 .

dhṛthās. 3. 25. I.

adidharat. $6.87 .3^{*}$.

adīdharan. 3. 3.5.

dharişyé. 5. II. 3 .

dhṛtás. 9. 4. 15.

dhṛtă. I2. I. 26.

dhṛtắm. I2. I. I7, 27.

dhriyasva. 12. 3. 35 .

dhriyatãm. 6. 17. I-4; I41. I. 9.

I. I I-3, 16, I7.

dhārayāmi. 8. 2.3. I4. I. 47 .

dhāráyati. I0. 7 . II.

dhärayanti. I2. I. I. I8. $3 \cdot 52^{\dagger}$.

dhāráyante. r8. I. $35^{*}$.

dhārayante. I8. r. $32^{*}$.

dhārayātāi. r8. 3.29.

dhāraya. 6. 79. 2; 87.2*. I9. 31. 12.

dhārayatāt. 3. 5.2.

dhārayatu. 8. 6.20.

dhārayatam. 6. 54. 2.

dhārayatām. 6. 88. 2*.

dhārayantu. I. 9. $\mathrm{I}^{2}$.

dhāráyan. 7.26.5*.

dhāráyantam. 7.78.2. 8. 4. $13^{*}$. ádhārayat. I0. 7.7.

adhārayat. I0. 10.25. I3. 2. I2. ádhārayan. r8.3.68 (mss. adh-). adhārayan. 3. 9.2. 5. I9. I3, I4. 9. 4. I6. I4. 2. 53-8. 
adhārayata. 4. II. 7 .

(cf. dharanaa, dharúna, dhartṛ́, dhárma, dhárman, dhāra, dhúr, dhṛt, dhṛta, dhṛti, dhrī, dhruvá, dhruví.)

+ a dhi: ádhi dhārayāmas. 1. 35. 3. ádhi dhārayā (p. -ya). 7. 82.3.

+ ā: ef. ādhārá.

+ pari: pári...ádhārayan. 19.24. I. + vi: ví dhāraya. 6. 8I.2.

(cf. vidhárana, vidhartín, vídharman, vídhṛti.)

+ s a m: sámodhṛtā. 12. I. 26. d h $\mathbf{r} \mathbf{t}$ in dharmadhṛ́t.

dhṛta in súdhrita and

dhṛtáorāṣțra: -as. 8. 10. 29. and dhṛtáovrata: -as. 7. 83 . I.

dhṛtavratāu. 7.58. $\mathrm{I}^{\dagger}$.

d h r ti in vídhriti.

V dh ṛṣ: dhṛșānás. 6.33.2.

dhṛsitás. 6. 33.2.

dádhṛșanta. 3. 3. 2.

(cf. dharșa, dharșya, dhṛș, dhṛșát, dădhṛși, dhṛșța, dhṛșnú, dhrșya.)

[1. 27.3.

+ abhi: abhí dādhṛșus (p. dadh-).

+ a v a: cf. anavadharşyà.

$+\bar{a}$ : ầ dadharșati. 4. $21 \cdot 3^{*}$. 6.28.2 $2^{*}$. à dadhṛșate. 6. 33.2.

āodhṛ́șe. 6. 33. $2^{2}$ (mss. ed. āodhṛse). (cf. ādharșa, ādhrș, ādhṛșya.)

d h $\mathbf{r}$ ș in ādhṛ̂s (inf.), ánādhṛ̦.

dhṛsát. 7. 76.6*. (cf. dhṛșádvarṇa.)

dhṛșádovarṇa: -am. 7.7I. I*. d h $\mathbf{r}$ șța in ádhṛșța.

dhṛṣnú: -ús. 5. 29. Io. I 8. 2. $58^{*}$. dhṛșṇúm. I. 13.4. 2. I4. I.

dhṛ̦̣núnā. 19. 13. $3^{*}$.

dhṛș̣áve. 7. I.16. I. I8. I. $37^{*}$. (cf. dhṛșụúṣeña.)

[20. 9.

d hṛṣnúṣeṇa (p. -ṇuosen-): -as. 5 .

dhṛșya in anādhṛșyá.

dhenú: -ús. 3. I0. I. 4. 34.8; 89. $2,4,6$. 5. I7. I8. 9. I. $22 ; 2.5 ; 5$. IO. I2. I. $45 ; 3.49$. I3. I. 27 . I 8. 4. 32 .

dhenúm. 3. 10.2. 7.73. $7^{*}$; 104. dhvaní: -náyas. 5. 20.7.

d h y $\bar{a}$ in anudbyà.
I. 9. $4.21 ; 5.29$. II. I. 34. I3. 2. $46^{*}$. I 8. $2.30 ; 4.30$.

dhenós. 7. I. I.

dhenú (p. -úíti). 4. 22.4.

dhenávas. 2. 5. $6^{*} \cdot 3 \cdot 12.3 \cdot 4 \cdot 39.8$.

7. 73.2. 9. 5. 25 . I8. $4.33,34.20$. 48. I.

dhenúobhyas. 6. 59. I.

dhenūnắm. $4 \cdot 27 \cdot 3$.

(cf. ádhenu, dhénukā.)

d hénukā: 3. 23.4.

d h e y a in agnyādhéya, nāmadhéya, bhāgadhéya, ratnadhéya, rūpadhéya, çraddhéya.

$\checkmark$ dhmā, see $\checkmark$ dham.

d h māna in upadhmăna.

$\checkmark \mathbf{d h y} \overline{\mathbf{a}}$ in

$\checkmark \mathrm{dhraj}$ in

dhrâji: -is. 9. 10. $26^{*}$.

dhräjim. 6. I8. I.

dhrăjiā. 3. I. $5 ; 2.3$.

$\mathrm{d} h \mathbf{r} \overline{\mathbf{I}}$ in ansadhrî.

dhruvá: -ás. $\quad 6.87 .1^{*}, 2^{*} ; 88.1^{*}, 3$.

I9. $45 \cdot 4$.

dhruvám. 6. $87 \cdot 3^{*} ; 88.1^{*}, 2^{4^{*}}$. 7 . 94. $I^{*} ; 97 . \mathrm{I}^{2^{*}}$. 9. I0. $8^{*}$. I 4. I. 47 . dhruvă. 3. 12. $2 ; 27.5$. 6. 88. $\mathrm{I}^{2 *}$. I2. 1.45 ; 3 . II.

dhruvắm. 3. I2. I. I2. I. II, I7. 15. 6. I ; I4. 5 .

dhruvéna. 6. 87.3*. 7.94. $\mathrm{I}^{*}$.

dhruvăya. 6. 88.3.

dhruvấyāi. 12.3.59.

dhruvăyās. 4. 40.5. 5. IO. 5. 9.3.

29. I $5.4 .5^{2} ; 5.5^{2}$. I9. I7. $9 ; 18.9$. dhruvắyām. 3. 26.5. 4. I4.8. I8.

3. 34 .

[17.30.

dhruvắs. 2. 26. 4. 8. 7. 8. I2. I. 27.

dhruvăsas. 6. $88 . I^{*}$.

dhruvà̃: I8.4.5.

dhrúve. I8. 4.6 (mss. -uvé).

dhruví: -váyas. I9. 10. 8*.

dhvańsa in apadhvañsá, avadhvañsá.

dhvajá: -jéşu. I9. I3. II*.

$\checkmark d h v a n$ in 
dhvara (?) in adhvará. $\checkmark$ dhvas: cf. dhvansa, dhvasáni. + a p a : cf. apadhvańsá. + av a: cf. avadhvańsá. dhvasáni: -nāu. 9. 10. $7^{*}$. dhvăñ ksa: -as. I2. 4.8 . dhvăñkşãs. II. 9.9.

n a (pron. root): nău. 5. II. 102. 7. 36. I $^{8}$. II. I. 35 . I3. I. I8 (ed. nas). I4. 2. $72^{\dagger}$. I $8.1 \cdot 4^{2^{*}}, 5^{2^{*}}$.

nas. I. $2.2 ; 4.2^{*}, 3^{*} ; 5.1^{*}, 2^{*}, 3^{*}$; 6. $\mathrm{I}^{2 *}, 4^{3} ; 7.3,5,6$; 10. 4 ; I2. I ; I3. 2,4 ; I6. $4^{2}$; I8. I ; I9. I, $3^{*}, 4$; 20. $I^{3} ; 2$ I. $I^{*}, 2^{*} ; 25.1-3 ; 26.3,4 ; 29$. $2^{2^{*}} ; 3$ I. $2,3,4^{2} ; 33.1-4 ; 34$. I. 2. I. $3^{*} ; 3.6 ; 4.2,3,6 ; 5.4 ; 6.3 ; 7$. $2,3,4^{3}, 5$; 12. $4,6^{*} ; 13.2 ; 25.1 ; 27$. $7^{2} ; 29.3,4 ; 35.1,2 ; 36 . I^{2}$. 3. I. I ; 2. I ; $4.2,4$; I0. $I^{*}, 2,3,7,8,13$; I 2 . 4 i $15 . \mathrm{I}^{2}, 4^{*}, 4^{2}, 7 ;$ I6. $3^{*}, 3^{\dagger}, 5^{*}, 7^{2 *}$; I 7. $2^{*} 4^{*}, 8^{2 *}, 9$; I9. 3 ; 20. $1^{*}, 2^{3^{*}}, 2^{\dagger}$, $3^{\dagger}, 5^{2 *}, 6^{*}, 6,8 ; 26.1-6^{2} ; 28.3,5,6.4$. 7.7 ; 9.6, IO; IO. I, $3,4,6$; II. 5 ; 15. I0, 12*; 17. $2 ; 23.1-7,2 ; 24.1-7$; 25. $\mathrm{I}-7,7 ; 26 . \mathrm{I}-7 ; 27.1-7,3 ; 28 . \mathrm{I}-7$, 7 ; 29. I-7; $31.2^{*}, 6^{*} ; 32.2^{*}, 3^{*}, 5^{\dagger}, 6^{2 \dagger}$, $7^{\dagger} ; 33 . \mathbf{I}-8^{*}, \mathbf{I}^{*}, 7^{*}, 8^{*} ; 36 . \mathrm{I}^{2}, 2 ; 38$. $3^{3}, 5 \cdot 5 \cdot 3 \cdot 2^{*}, 5^{\dagger}, 6^{*}, 6^{2}, 7^{2}, 8^{3^{*}}, \mathrm{IO}^{*}, \mathrm{IO}^{\dagger}$, II ; 5.5,9;6.5-7; 7. I ${ }^{2}, 3,6^{3} ;$ II. II ; 12. $2^{*}, 8^{*}$; 18.14； 19. 9 ; 21. 8 , I $; 22.9$, 10; $27.8,9^{2}$, 10; 29. 2 . 6 . I. $3 ; 3.1^{2}, 2^{3}, 3^{2} ; 4.1,3^{2} ; 6.2,3^{*} ; 7$. I, $2^{2}, 3 ; 23.3 ; 24.3 ; 26.1,2 ; 27 . I^{*}$, $2^{3^{*}}, 2^{\dagger}, 3^{*}, 3^{\dagger} ; 28.1^{*} ; 29.2 ; 32.1,3$; 33. 3 ; 34. I- $5^{*} ; 35.1^{2}, 2 ; 37.2^{2}, 3^{2}$; 38. I-4; 39. $2^{2} ; 4$ O. $\mathrm{I}^{4}, 2^{2}, 3^{3} ; 4$ I. $3^{4}$; $45.3^{*} ; 46.2 ; 47$. I, $3 ; 5$ I. $2^{*}, 3^{*} ; 53$. I, $2^{3}, 3^{2} ; 55.2^{2} ; 56.1 ; 57.2,3^{5} ; 59$. $3 ; 62 . \mathrm{I}^{2} ; 63.4^{*} ; 65 . \mathrm{I} ; 77.3 ; 79$. $\mathrm{I}^{2}, 2,3^{2} ; 93.3 ; 96 . \mathrm{I}^{*}, 3 ; 99.2,3$; I04. 2, 3; I06. 2, 3; 107. I- $4^{2} ; 108$. I $^{2}$; II4. I, 2; II5. I ; II6. I, 2, 3; II8. I, $2^{2}$; II9. I ; I2O. I, $2^{3}$; I2I. 2 ; 123. 5 ; I25. $3^{*}$; I26. $2^{*}, 3$; I28. $2^{4}$, 4 ; I3I. 3 ; I33. $\mathrm{I}^{2}, 4^{2}$. 7. 2. I; 5.5; $6.4 ; 9.4^{*} ;$ II. I; I 7. $I^{2}, 4$; I8. I ;
2O. $1,2^{2}, 4^{2}, 6 ; 22.1 ; 24.1 ; 26.3 ; 28$. I ; 3I. I $^{* *}$; 39. I ; 4I. 2 ; 42. I* $^{*} 2^{*}$; 46. $\mathrm{I}^{*} ; 47 . \mathrm{I}, 2^{2} ; 4^{8} . \mathrm{I}^{*}, 2^{*} ; 49 . \mathrm{I}^{3^{*}}$; 50. $3^{*} ; 5$ I. $\mathrm{I}^{2 *} ; 52 . \mathrm{I} ; 53.6 ; 55.1$; 59. ${ }^{2} ; 60.2,3,5 ; 63.1 ; 68.1,3 ; 69$. $1^{4} ; 70.3 ; 73.7^{*}, 9^{*} ; 77.2^{*} ; 79.1^{2}, 3$, $4^{*} ; 80.2,3^{*} ; 82.1^{*} ; 83.2^{2} ; 84.1$;

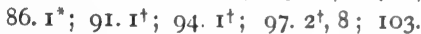
I ; I06. $\mathrm{I}^{2}$; I08. $\mathrm{I}^{8}, 2$; I09. I, $5^{2}, 7$; IIO. 3 ; II2. I ; II5.2. 8. 2. I 7; 3 . $I^{*}, 19^{*}, 20^{*} ; 4.10^{*}, 23^{2 *} ; 5.17^{3} ; 7.17$; 9. $7,17 \cdot 9 \cdot 3 \cdot 6,24 ; 4 \cdot 2,22^{2}, 23^{\dagger}, 24^{2}$; 5. 2, I7, I9; IO. $12^{2+}$. IO. I. $6,20,22$, $29 ; 3.8 ; 5.23,45 ; 6.4,5$. I I. I. I7 ; 2. I, $8^{3}, 1 \mathrm{I}, 19^{2}, 20^{3}, 21^{2}, 26^{2}, 29^{6 *}, 31^{2}$; 4. $5,6^{2}, 9 ; 6 . \mathrm{I}-6,8,9,10-2 \mathrm{I}, 22 ; 9$. 2,23 ; IO. 26 . I2. I. $\mathrm{I}^{2}, 2^{2}, 3,4,5,6$, $7,8,9,10,12^{3}, 13,14^{2}, 16,18^{2}, 22,23-$ $5,30^{2}, 32^{2}, 34,36,40,41,43,44,46^{2}$ $47,52,62 ; 2.3,7^{\dagger}, 13,15^{2}, 18,22^{*}, 33$ 49 ; 3. IO, II, I2 ${ }^{3}, \mathbf{I} 5, \mathbf{I} 6,17^{2}, 26,3$ I, $45,46,48,55-60^{3} ; 4.49$. $\quad$ I3. I. $17^{2}$, I 7-9, 19, 29, 59*; 2.37. I4. I. $34^{*}$, $60 ; 2 . I^{\dagger}, 38^{*}, 40^{*}, 51,67$. 16. 5. 1-6; 6. 4. I7. 6-I 9, 8, 9, IO, I I, I 2, I 3, 24. 18. I. $19^{2 *}, 19^{\dagger}, 25^{2 *}, 26^{*}, 30^{*}, 31^{*}, 33^{*}$, $36^{*}, 39^{2 \dagger}, 44^{*}, 47,50^{2 *}, 51^{*}, 52^{*}, 52^{\dagger}$ $5^{8^{*}}$; 2. $3^{*}, 29,49$; 3. $14,15,16^{2}, 21^{*}$, $22^{\dagger}, 39^{*}, 44^{\dagger}, 45^{\dagger}, 46^{*}, 59,59^{\dagger}, 61,62^{2}$, $63,67^{2 *} ; 4.40,48,50,53,54,62,63$. I9. $3.1,2,4 ; 4.2,3^{4} ; 8.7^{2} ; 9.1,2^{2}$, $3-5,6^{3^{*}}, 7^{2}, 8,9^{4}$, IO $^{2}$, I I, I4 ; IO. $\mathrm{I}^{3^{*}}$, $2^{5^{*}}, 3^{5^{*}}, 4^{4^{*}}, 5^{4^{*}}, 6^{3^{*}}, 7^{5^{*}}, 8^{4^{*}}, 9^{5^{*}}, \mathrm{10}^{4^{*}} ;$ I I. $\mathrm{I}^{4^{*}}, 2^{3^{*}}, 3^{3^{*}}, 4^{*}, 5^{2^{*}} ;$ I4. I ; I5. $\mathrm{I}^{2^{*}}$, $2,3,4^{*}, 5^{2}, 6$; 16. I ; 20. 3 (mss.); 3 I. 2 , $3, \mathrm{I} 3, \mathrm{I}^{2}{ }^{2} ; 32.6,9, \mathrm{IO} ; 33 . \mathrm{I}^{2} ; 34.4$, $5 ; 35.2 ; 40.2,3^{4}, 4^{*} ; 44.4,8,9 ; 45$. $2 ; 47.5,6^{3}$, I0; $48.2^{2}, 3,4,5^{2}, 6 ; 49$. 5,$6 ; 50.2,7^{2} ; 52.5 ; 55.2,3^{2}, 4^{2} ; 56$. $6 ; 57.5 ; 58$. I. 20. I27.8, I4; I30. I4.

(cf. nānā, ana, ena, ná.)

ná (neg.). I. II. $4^{3} ; 20.4^{2 *} ; 27.3^{2} ; 32$. I, $2 ; 34.5 ; 35.2^{2}$. 2. I5. I-6 $6^{2} ; 30$. I; 35. I. 3. $2.6 ; 6.7 ; 8.4 ; 29.2$, $6^{2} ; 30.4$. 4.1.7; 3. $7^{2} ; 5.2^{2} ; 6$. $3^{2} ; 7.3,5,6 ; 9.5^{4}, 7 ;$ II. $3^{2}, 5^{4} ;$ I4. 4 ; 16. 4 ; I8. 6 ; I9. $2 ; 2$ I. $2^{*}, 3^{3^{*}}, 4^{2 *}$; 
$22.5 ; 25.2 ; 26.6,7 ; 28.5 ; 34.2,3$, 4 ; $35.1,4 ; 36.6,7^{3}, 8$, I0. 5. 6. $3^{*}$; I I. $2,3^{2}, 4^{2} ;$ I3. $\mathrm{IO}^{2}, \mathrm{II}^{2} ; 14.9 ; 17$. $3^{*}, 9^{2}, \mathrm{I} 2, \mathrm{I} 3, \mathrm{I} 4, \mathrm{I} 5, \mathrm{I} 6^{2}, \mathrm{I} 7,18^{2} ; 18$. I, 5, 6, 7, 9, I3; I9. I, 4, IO, I5 ; 22. 9 ; 29. II $^{*}$; 30. 8; 3I. II. 6. 8. I-3; I6. 2 (mss. hina); $26.2 ; 27.3^{*} ; 32$. I; $33.2^{2} ; 42.3 ; 43.3 ; 45.1 ; 46 . \mathrm{I}^{2}$; 47. $2 ; 56 . \mathrm{I}^{2} ; 75.2,3 ; 76.3,4^{2} ; 98$. I ; IOg. $2^{*}$; II $4.2,3$; II8. 2 ; I3O. 3 . 7. 7. $1 ; 9.3^{*} ; 18.2^{2} ; 37.1 ; 38.4^{2}$; 44. $\mathrm{I}^{2^{*}} ; 50.6^{*} ; 56.6^{3}, 8 ; 79.4^{*} ; 80$. $3^{*}$; IOI. I. 8. I. 6, IO; 2. 1 $3,24^{3} ; 4$. $3^{*}, 3^{2 *} ; 5.13,19 ; 6.12 ; 8.6,16 ; 9$. 9,26 ; 10. 31 . 9. $2.2^{3}, 12, \mathrm{I}^{2}, 24^{3} ; 4$. I8; $5.23^{2}, 27 ; 6.24^{4}, 26,37,39,52$; 9. $7^{*}, 10^{*}, \mathrm{II}^{2 *}, 15^{*}, 2 \mathrm{I}^{2 *} ;$ IO. $10^{*}, 15^{*}$, I6*, I $8^{*}, 26^{*}, 27^{*}$. I0. I. $26 ; 2.30^{2} ; 4$. $8^{2} ; 7.8,3 \mathrm{I}, 37^{3}, 42^{2}, 43 ; 8.8, \mathbf{I} 4, \mathbf{I} 6$, $25,32^{4}, 44^{2}$. II. I. $33 ; 2.25^{2} ; 3.24^{3}$, $25,30^{2}, 32-49^{3}, 4 \mathrm{I}, 55,56 ; 4$. IO, $2 \mathrm{I}^{6}$, 25,$26 ; 8.22$; 10. 27 . I2. I. $37 ; 2$. I, $25^{*}, 36,37 ; 3 \cdot 4^{3} ; 4.2$, I 2, I 3, I 8 , I9 ${ }^{2}, 27^{2}, 32,43,44,46,49,50$. I3. I. 56,$57 ;$ 2. I $5^{2} ;$ 4. II, I⿰ ${ }^{3}, 17^{3}, \mathrm{I} 8^{3}, \mathrm{I} 9$. 14. I. $3^{*}, 5^{*}, 17,18^{*}, 29^{*}, 30,32,33,57$; 2. 8. I5. 5. I-7 $;$; 6. 7 ; 10. $2^{2} ; 12$. $3^{2}, 6,9^{2}$, II ; 13.7. I6.6. II. I7. 7, I2. I8. I. $2^{*}, 4^{*}, 9^{2 *}, \mathrm{I} 3^{2}, \mathrm{I} 3^{*}, \mathrm{I} 4^{*}, \mathrm{I} 5^{*}$, $36^{*}, 48^{*}, 50^{*} ; 2.32,38-45,50,5 \mathrm{I} ; 3$. $4 \mathrm{I}^{*} ; 4.60^{*}, 89^{*}$. I9. I4. I ; 32. $2^{2}, 9$; 34. $7^{2} ; 36.2 ; 38 . \mathrm{I}^{2} ; 39.2-4$ (not mss.), 8 (do.); 44. $6 ; 46.3 ; 47.2^{2} ; 49$. $7^{2}$, 1о $^{2} ; 50.3,4,6 ; 53.4 ; 56.4^{2}$. 20. I27. I4; I30. 7 (not mss.); I3I. IO (mss. na), I2; 132. 7; I33. I-6; I34. 5 (not mss.); I35. 6 (not mss.) $7^{2}$ (mss. nah $\left.{ }^{2}\right)$; I36. Iо.

nó (p. nó íti). I. 32. I. 3. 18. $3^{*}$; 30. 4. 8. 2. 24 . I8. $2.38-45$.

(cf. ná compar., nákis, naghamārá, naghārișá, nahí, néd.)

ná (compar.). 2. $5.2^{3}, 3^{2} ; 35 \cdot 3.3 .29$. 3. 4. 8.7. 5. I $2.5^{*}$; I3. 3 ; I 7. $5^{*}$. 6. 2.2 ; II6. I. 7. $26.2^{*} ; 72.2^{*} ; 84$. $3^{*}$; II7. I* $^{*}$ 9. 5.9 ; 9. I9*. I0. 8 . $42^{*}$. I8. I. $33^{*}, 39^{2 *} ; 3.22^{*}, 63$ (s. mss. ed. ṇa); $4 \cdot 59^{*}$. I9. I3. $2^{*} ; 49$.
8. 20. $34.16 ; 48.1 ; 127.4^{2}$ (mss. na); 136.5 .

nákis. 2. 3I. 3. I8. I. $5^{*}$

nakulá: -ás. 6. I39.5. 8. 7. 23.

nákta: -am. 5.7.3; 29.9; 30. 10. 6. 23. IO; I28.4. 8. 3. $\mathrm{I}^{*} ; 4 . \mathrm{II}^{*}, \mathrm{I}^{*}$; 5. 22 I6. 7. 10. I9. 15.6. [tan.) (cf. ușāsānáktā, naktamijātá, náknakta mojātá: -tă. I.23. I. náktan: -taobhis. 8. 4. $18^{*}$. Vnakṣ: nakșati. 5.27.3.

nakșatu. 7.73. 5 .

nakșasva. Io. I. I4. nákșamānāas. I 8. 2.29.

+ abhi: abhí nákṣamānāu. 12. 3.8. abhionákṣamāṇās. I8. I. $42^{*}$. [9.9. nákșatra: -am. I0. 2. 22, 23. I9. nákșatrāṇi. 6. I28. I. 9. 7. 15. II. 6. I0. I5. $6.2 ;$ I 7.4. I9. 8. I. nákșatrā. I3. $2.17^{*} ; 4.28$. nákșatrāis. I9. I9.4; 27. 2. nákșatrebhyas. 6. 10. 3 ; 128. 3 . nákșatrānāām. 3. 7.7. 5. 24. 9. 6. 86. 2. 7. I3.I. I4. I. $2^{*}$. I5.6.2. (cf, sunákṣatra, nakṣatrajắnakșatriya.)

nakș atra ojấ: -ấs. 6. IIO. 3 .

nakşatraorāja: 6. I28. 4 .

n a kșa tri y a: nákșatriye. 2.2. 4 .

n a khá: -khắn. 4. 3.3.

nakhébhyas. 2. 33.6 .

(cf. kunakhín, nīlanakhá.)

ná g a : -geșu. I 9. 8. I.

n a gná: -nă. $\quad$ 5. 7.8 .

(cf. ánagna, mahānagná, nágnaka.)

ná g n a k a : -kāt. 8.6.2I.

n a g h a mārá: -ás. I 9. 39.2 (mss. nadyá măras).

na g hãrișá: -ás. I9. 39.2 (mss. nadyâyușas ; p. -dyá ăy-). [7.6. naghärișăm (p. -ghaori-). 8. 2.6; n aghñ in mahānaghnì.

n a ḍá: -ám. 4. I9. I. 6. 138.5. 12. 2. I, 50,54 .

nadé. I2. 2. I9.

naḍăs. 6. $137 \cdot 2,3$. (cf. nāḍí.)

n a t a in súsamnata. 
n a ti in sámnati.

$\checkmark$ n a d: nádatas. 4 I5. I, 5.

ánadatā (p. -ta). 3. I3. I

nănadatĩ. IO. I. I4.

(cf. nadá-nadí, nādá, and $/$ nand.) na dá : -ásya. I8. I. I9".

nad a ni mán: -má. 5. 23.8.

nadi: I. 8.1. 9.7.14. 12. 2.27 .

nadím. $4 \cdot 37 \cdot 3$.

nadyàs. 3. I3. I. I I. 6. I0. I4. 2.7.

nadías. 6. 12. $3 ; 24.3 .7 .38 .5$.

I9. I. I.

nadis. 3. $24 \cdot 3$.

nadíbhis. I9. I9. 7 .

nadînām. 1. 15. 3. 6. $5^{2.2} 2^{\dagger}$ (1. -naam); I 1 3. 2. I4. I. 43 (1. -naam). I8. 3.5 (do.).

nadișu. $4 \cdot 36.5$.

nánāndṛ: -dur. I4. I. $44^{\dagger}$.

nanú. 2. I. 4 . 4. 3I. $3^{*}$. II. 4. 25. 13. 2. 13. I9. 32.9 (mss.).

$\checkmark$ na d : nandanti. I9. 53.7.

(cf. nánāndṛ, nánda-nandin.)

+ abhi: abhionándati. 9. 2. 2.

abhionándan. I9. 8.3.

+ ā: cf. ānandá, ānandín.

+ prati: prationándanti. 3. 10. 2.

práti nandanti. 9. I. $x$.

(cf. pratinándana.)

nán d a: -dān. I 0.2 . 9 .

(cf. ānandá.).

$\mathbf{n}$ and a $\mathbf{n}$ a in pratinándana.

n andin in ānandín.

nápāt: r9. II. $3^{*}$.

napāt. I. I3. 2, 3; 26.3. 6. 3. I, 3 . 14. r. $37^{*}$.

nápātam. I8. I. $\mathrm{I}^{*}, 45^{*}$. I9. 42.4 . (cf. tánūnápāt, naptí, naptí, náptṛ.)

n a ptí: -ís. 9. I. 3 , Io.

napti: -tíam. r. 28.4 .

naptyàs. 7.82 .6 .

naptías. 2. I4. I. I3. $2.24^{*}$.

náptra: -trọobis. I4. x. $22^{*}$.

$\checkmark$ nabh: cf. nábhas, nábhya, năbhi (?).

+ pra: prá nabhasva. 7. I8. x. prá nabhatām. 7.18.2. nábhas: 4. I5.5. 5. 5. I. 7. I8. I.

I3. $4.2,3,9,14,22$.

nábhasã. $5 \cdot 13 \cdot 3$.

nábhasas. 6. 79. I. I8. 4. I4.

nabhasas. 6. 79. 2 .

nábhasī (p. -í íti). 5. I8. 5 ; 20.7 .

I I. 5.8 , I I. I2. $3 \cdot 5,6$. I 7. I6.

nábhāñsi. 4. $15 \cdot 3$.

nábhobhis (p. -bhaḥobh-). 6. 62. I.

(cf. nabhasá-nábhya.)

nabhasá: -ás. 9. 4.22.

nábhasvant: -vatas. 4. I5. I, 5 . nábhasvatis. 4. I5. I.

nábhya: -am. 6. 70.3. I2. I. I 2 . nábhyāni. I0. 8.4.

V $\mathrm{n}$ a m: namantu. 4. 3. I.

namantām. 5.3. I*. 9. 2. II.

(cf. nata, nati, nam, námas, na-

masāná, namuxá, namra, nemi.)

+ pari: pári ... nama. I. 2.2.

+ s a m: sám... namāmasi. 3. 8. 5 .

sám namas. 7. 56.4 .

sám... namas. 6. I3I. 2 (mss. nám-). sám namanta. 3. 16.6* [8.2. sám namantu. 4. 39. I, 3, 5, 7. 5 . sam̊námamānas. 8. 3.6*

samoánaman. 4. 39. I, 3, 5, 7.

sám anaman. 4. 39. I, 3, 5, 7.

sám namayāmasi. 3. 8.5 .

(cf. samnám, sámnati, súsamnata.) + upas a m: upaosámnamantu. 19. 41. I (mss. úpaosá-).

n am in saminnám.

nám a s: I. I0. $2 ;$ I3. $\mathrm{I}^{3}, 2,3^{2}, 4 ; 25$. $4^{3} ; 32.4$. 2. $2.1,4,5 ; 8.4^{2}, 5^{3} ; 35$. $4^{3}$. 3. $26 . \mathrm{I}-6 ; 27 . \mathrm{I}-6^{4}$. 5. I. $5 ; 7$. $\mathrm{I}^{2}, 2,3,9, \mathrm{IO} ; 22.4 ; 28 . \mathrm{II} ; 30 . \mathrm{I2}^{3}$. 6. I3. $\mathrm{I}^{3}, 2^{4}, 3^{4} ; 20 . \mathrm{I}, 2^{6}, 3 ; 28.3 ; 55$. $3 ; 56 . \mathrm{I}, 2^{4} ; 63.2^{2} ; 84.3 ; 90.3^{4} ; 93$. 2 ; I28.4. 7. $32 . \mathrm{I}^{*} ; 87 . \mathrm{I}$; IO9. I; II6. $\mathrm{I}^{2}$. 8. I. I, I4 ; 2. $4^{2}$. 9. 2. I9$24 ; 3.12^{4}, 13,25-31$. I0. $7 \cdot 32-4$, 36 ; 8. I ; IO. $\mathrm{I}^{3}$. II. $2 . \mathrm{I}, 3,4^{2}, 5,6$, $8,9^{2}$, I I , I $2, \mathrm{I} 4, \mathrm{I} 5^{4}, \mathrm{I} 6^{5}$, I 8, I $9,22,23$, $27,30,3 I^{5} ; 4$. I, $2^{4}, 7^{4}, 8^{5}, 23$. I2. I. 26,42 ; 3 . II ; 4. 45. I 3. 4. 48, 55. I 4 . 2. $20,34,35^{3}, 46^{*}$. I5. I8. 5. I6. 2 . 6. I7. $22^{6}, 23^{6}$. I 8. I. $46^{*} ; 2.2^{*} ; 4$. 
$7 \mathrm{I}-4,81^{2}, 82^{2}, 83^{2}, 84^{2}, 85 . \quad$ I9. 8. 2 , 7 ; 11. $6^{*} ; 55.5$. 20. 128. I4.

námasā. 3. 3. I ; I 5. 7. 4. I. 7; 39. 9. 5. 27.4. 7.7.I. I0.4.23. I4. 2. $33^{*}$. I 8.2 .49 .

námase. I4. 2. 35 .

námānsi. I. 25. I.

námobhis (p. -maḥobh-). 3. 8.3. 7. 50. $3^{*}$. I8. 3. 16, $39^{*}$.

(cf. namasāná - námasvant, namovāká.)

n a ma sāná: -năs. 6. 39. 2.

n a m a skārá (p. -maḥok-): -réṇa.

4. 39. 9 .

námaskrta (do.): -tābhias. II. 2. n a m a skŕtya (do.). 7. I02. r.

$\checkmark$ n am as y: namasyántas. I. I2.2. $n$ a m a s y à : -yàs. 2. 2. I.

namasías. 2. 2.2. 3. 4. I. 6. 98. I. namasyè (p. -è íti). 4. 26. 3 .

namasyèbhyas. 6. 93. 2.

ná m a sva nt: -ntas. 9. 9. $8^{*}$.

n a murá: -răt. I3. 4. $46 . \quad$ [4. 26. namovāká (p. -maḥov-): -ké. I3. n a mrá: -ám. 20. I28. I3 (mss. námram, nứmṇam).

[çáñsa.

n a r a in viçvănara, narācí, nárān a rācí: -ciâm. 5. 31.4. [I (mss.). nárāçán s a: -as. 5.27.3. 20. 127. (cf. nārāçañsá.)

naríșțā: 7. I2.2. II. 8.24.

nár y a : -riāni. I9. 49.3.

nála d a : -asya. 6. 102. 3 .

naladi. $4 \cdot 37 \cdot 3$.

náva: -as. 7. 8I. I', $2^{*}$ (návaḥona-).

návam. I2. 3.32. I 4. 2.44 .

návās. I2. 2.4I. I9. 34.7.

návāni. 9.5.25.

(cf. púnarṇava, návĩyas, návya.) náva (num.): 5. I 5.9; I9. II ; 28 . I. 6. 25.3 II. 7. I4. I3. 4. IO. I9. $47.3 ; 57.6$.

naváobhis. 5. 28. I.

(cf. navagát-navavṛșá.)

navaogát: 3. I0. 4 .

ná va०gva: -vās. I $8.1 .58^{*} ; 3.20$.

návagvāis. I4. I. 56 .

$[47 \cdot 3$.

navatí:-ís. 5. I5.9. 6.25.3. I9. navatím. 8. 5. 9. I0. I. I6. 20. 127. I. navatáyas. 5. I9. II.

ná va。dvāra: -rā. Io. 2.3I. návadvāram. I0. 8. 43 .

navaodhá. I3. 4. Io.

náva $\circ$ pa d: -di. 9. I0. $2 \mathrm{I}^{*}$. I3. I. $42^{*}$. n av a má: -ás. I3. 4. 18.

navarcá (p. -vaoṛc-): -cébhyas. I9. 23.6.

n ava०vṛșá: -ás. 5. 16. 9.

náviyas: 7. 72. $3^{*}$. I8. $2.31 ; 3$. I 7. I9. II. $4^{*}$.

nav yá: -ás. 2. 5.2.

návya: -vias. 6. IIO. $\mathrm{I}^{*}$.

$\checkmark$ I n a ç: naçyanti. 4. $36.7,8$.

náçya. 7. II 5.1 .

náçyata. 2. 14. 5,6.

naçyantu. 6. 25. I-3.

nanāça. I8. I. $53^{*}$.

naçanti. 4. $21 \cdot 3^{*}$.

naçat. 20. I36. I2 (not mss.)

neçat. 5. 13.2.

[8. 21.

anīnaçam. I. 23.4. 7. II5.4. 9. aninaças. 9. 8.22.

áninaçat. I. 24. 2.

aninaçat. 2. 3.3, 5. 3. 7. I. 7. 56. I. 8. 6.6. I9. $36 . \mathrm{I}, 3$.

aninaçan. 8. 7.3. I2. 2.14.

naçișyati. 6.83 .3 .

nașțám. 7. 9. $4^{*}$.

nașțéna. 7. $9 \cdot 4^{*}$.

nāçayāmi. 3. 7.6.

nāçáyāmas. 2. I4. I.

nāçáyāmasi. 2. 23. I.

nāçayāmasi. I. I8.4. 3. 7.3. 4 . I7. 5 ; 37. II. 8. 6. II, I2, I4, 23.

nāçáya. $5 \cdot 4 \cdot 9$.

nāçaya. 2. $25 \cdot 3.4$ 4. 37.2. 5. 22. I3. 6. 14. I. 8. 6.9, I3, I5. I9. 35.3 ; 39. I, 5,8 .

nāçayantu. 6. II3. I, 3 .

nāçáyan. 5. 4. I.

nāçáyat. I9. 44. 7 .

(cf. nașța, nāçana, nāșțră.) [2, 3 . + ni s: níh ... nāçayā (p. -ya). I. 23

+ pra: prá ... aninaçat. 8.6.8.

+ vi: ví naçya. 6. ri3. 2.

ví neçat. $5 \cdot 3 \cdot 2^{*}$. 
ví nāçaya. 3. I. 5 ; 2.3. 8.6. 10. nah 1. 3. 18.3". 6. 49. I. 7. IOI. I. I9. I5. 2.

ví nāçayatu. II. I0. 16.

(cf. vínașțatejas.)

$\sqrt{2} \mathrm{n}$ a ç: cf. naça.

+ abhi: abhí naț. 8. 4.23.

$+\mathrm{u}$ d: ún naçat. 9.9.2 $\mathrm{I}^{*}$.

n aça in durnáça.

$\mathbf{n}$ aşț a in ánaşțapaçu, vínaşțatejas,

naşțávişa, nașţăsu.

n așțá $\circ \mathbf{i}$ șa: -şãs. Io. 4. I 2.

n a ș ța s u (p. -țáoas-) : -savas. Io. 4. I2.

nás: nasâ. 2. 27.2. 5. I4. I.

nasర́s. I9. 60. I (mss. násos).

(cf. nasa, nắsã, nasvánt.)

n a s in urūṇasá, pavinasá.

n asvánt: -váti. Io. I. 2.

Vnah: ánahyanta. 19.20.3.

naddhă. 9. 3. ro.

naddhám. 9. 3. 2.

naddhăni. 9. 3. I, 4, 5 .

(cf. nah, náhana, nāha.)

+ a pa: ápa nahyāmi. 7. 70. 5 .

+ a pi: ápi nahyāmi. 1. 14. 4. 7. 70 . 4,$5 ; 95 \cdot 3$.

ápi nahyā (p. -ya). Io. 9. I.

ápi nahyatam. 6. 50 . I.

ápi nahyata. 5.8.4.

ápionaddham. 9. 3. 18.

apionahyámāne. $12.5 \cdot 25$.

+ ava: ávaonaddham. 9.3.8.

+ à: a ... nahya. 6.67.3.

+ paryā: paryănạaddham (p. -rio ăn-). I4. 2. I 2.

+ u p a : cf. upānáh, upanāhá.

+ ni: cf. nīnāhá.

+ pari: cf. parináh.

+ pra: cf. prānāhá.

+ vi: víonaddhā. IO. I. I4.

+ s a m: sám ... nahyāmi. I4. 2. $70^{3}$. sám ... nahyata. 7. 50.9.

sám nahyasva. 14. I. 42.

sám nahyadhvam. I I. 9. 2, 26; IO. I. sam̉onanăha. 6. I33. I.

sámonaddhas. 6. I25. I*. 9. IO. I5. sám onaddhā. I4. 2. 70.

$\mathbf{n} \mathbf{a} \mathbf{h}$ in upānáh, parịnáh.

náh a n a: -nānām. 9. 3.4.
9. 9. $13^{*}, \mathrm{I}^{*}$.

năka: -as. IO. IO. II. I3. I. 7.

năkam. I. 9.2, 4. 3. 29.3. 4. 14 . $2,6,9.6 \cdot 63 \cdot 3.7 \cdot 5 \cdot 1^{*} ; 53 \cdot 7^{4} ; 73$. 6*. 9. 5. I, 3:6. I I. I. $4,30,37$. I3. 2. $46^{*}$. I9. 7.1 .

năkasya. 4. 14.3. 7.80. I. 9.5. IO, I5. II. I. 7. I8. $2.47 ; 4.4,14$. năke. 5. 6.3\%" 6. I 22. 4 ; I23. 5 . 7 . 80. 4. 9. $5 \cdot 4,8$. I0. 7.43 . II. I. 36 . I3. I. II. I8. $3.66^{*} ; 4.3$. nâkān. I9. 27.4 .

(cf. trināká, nālkapālá.) nāka०pālá: -ás. I0. 8. I2.

nā ḍ̂t: -ḍāù. 6. 138. 4 . nāụyàs. I 0.7 . I 5 (1. -ḍías), I6. (cf. nāḍinkâ.)

nā ḍi kă : -ầs. 5. I8.8.

Vnāth: nāthitás. 4. 23.7; 24.7; 26-29. 7. 7. 109. 7. I3. I. I 2. nāthitâ. 5. 20.5. II. I. I. nāthitấs. 3. I. 2.

(cf. nāthá.) [I. I3

nāthá: -ám. 4. 20.9. 9. 2.7. I8. (cf. anāthá, sunātha, nāthákāma, nāthavid.)

nāthá $\mathrm{k}$ āma: -as. I3. 2. 37.

nāthaovid: II. I. I5.

n ā d á: -ám. I 9. 34. 3 (mss. annădam). nādé. I8. I. 19".

$\mathrm{n}$ ā di n in gardabhanādín.

$\sqrt{ } \mathbf{n} \bar{a} \mathbf{d} \mathbf{h}:$ nădhamānasya. I3. 2.44 . nădhamānās. I3. 2.43. I7. 14 . $\mathbf{n} \bar{a} \mathbf{n} \overline{\mathbf{a}}$ in nắnādharman-nắnāvīrya. nă nā॰d harma n: -māṇam. I2. I. 45 .

nānānám. I2. 2.43. [2. 3.

nă nā or ū pa: -pe (p. -e íti etc.). I 3 . nấnārūpās. I4. 2.25.

nằnā०vîrya: -yās. I2. I. 2.

nábhi: -is. I. 13.3. 6. 9. 3; 44. 3; I $25.3^{*}$. 9. I. 4 ; IO. $12^{*}, 14^{*}$. I6. 4 . I'. I 8 . I. $4^{*}$.

năbhim. 3. 30.6. 4. II.6. 5. 27. Io. 9. 10. $13^{\dagger}$ II. 7.4 I 2. 3.40. I3. I. I4, 37 .

năbhyās. I9. 6. 8*. 
năbhiās. 2. 33.4. 9. 8.12. năbhāu. I0. 8.34. I8. 3.40*. năbhā. 7.62. x.

năbhayas. I2. 3.4I.

năbhīs. I9. 53.2.

(cf. anyánābhi, apūpánābhi, trinăbhi, rajatánābhi, sánābhi, sunăbhi.)

nāma $\circ \mathrm{g} \overline{\mathrm{h}}$ á: -hăt. Io. I. I2.

nā má $\circ \mathrm{th}$ à. II. 8. 7 .

$\mathrm{n}$ āma。dhá: -ás. 2. r. $3^{\dagger}$.

nām a odhéy a: -am. 7. rog. 6.

nám a n: -ma. 3. 13. 3 ; 14.1 ; $18.3^{*}$ 4. 8. $3^{*} ; 3$ I. $5^{*}$. 5. 28.12 .6 .76 .4 ; 82. I; 83.2. 7. I. I; I2. 2 ; 20.4. IO I. II ; 2.I $2 ; 7.3$ I. II. 7. I. . I 2.5 9. I8. I. $34^{*}$. I9. $35.1 ; 38.2 ; 48$ $6 ; 53.7$.

nằma (adv.). I. $24 \cdot 3^{2} ; 25 \cdot 2,3 . \quad 2$. 8. I. 3. 7. 4 ; I3. I ; 24. 2 ; 26. I-6. 4. 9.8; 19. 5. 5. 4. $9^{2} ;$ 5. $1,3,6,8$; 6. $4 ; 9.7$. 6. $6.2^{2} ; 44.3 ; 46.1$; I2I. 3. 7. $6.4 ;$ I2. $2 ; 29 . \mathrm{I} ; 45 . \mathrm{I}$; 8I.3. 8. 2.28. 9. 5.3I-62. I0. 4 . $24^{2} ; 7.25 ; 8.6,3$ I. II. $6.4 ; 8.13$, I9; 9. 4. I2. I. $54 ; 4.5$. I5. I5.39. I6. 3. 5. I7. I-5. I9. $39.3^{2} ; 48$. $6 ; 49.7 ; 57.4$.

nắmnā. 10. 7.31.

nấmnī (p. -ĩ íti). 4. 9. Io (1. -mañ) nắmāni. 3.13. I. 5. 4.8. 19. 39. 2. 20. I32. I3.

nằā. 5. r. 3 (p. -ma). 9.9. $3^{\dagger}$.

(cf. nāmagrāhá - nāmadhéya, nāmabibhratî, triṇāman, durṇàman, páñcanāman, purúnāman, mahănāman, yathānāmán, viçvánāman, saptánāman, sahásranāman, sunăman.)

nāma०bibhratì: I5. I3. 6 .

nắraka (p. nár-): -am. I2. 4. 36 .

$\mathrm{n}$ ā $\mathrm{r}$ d a: năradas. 12.4 .24$.

nāradás. I2. 4. 41, 42.

nārada. 5. I9. 9. I2. 4. I6, 43, 45 . nārā çàn sá: -ás. 20. I27. I (not mss.). nārācańsî. I 4. I. $7^{*}$.

nārāçan̉sís. I 5. 6. 4 .

nārāçan̉sìnām. I 5. 6.4. nằi: I. II. I. 2. 36. 3, 4. 5. 20. 5 . I4. 2. I3, I4,63. I8. 3. I. 20. I36. 4 nāri. 3. I2. $8 ; 23.5$. II. I. I3, I4 23. I4. 2. 20,32 . I 8. 3. 2*.

nărīm. I4. I. 53:54, 55, 59 .

nắryāi. I4. 2.2 2 .

nắryās. 5. 25. ro-3.

nầrīs. $4 \cdot 5 \cdot 3^{*}$. I2. $2.3 \mathrm{I}^{*}$.

nārș a dá (p. nārsa-): -déna. 4. 19. 2. $\mathbf{n} \overline{\mathbf{a}} \mathbf{v} \mathbf{a}$ in

nāva prabhránçana: -am. I9. 39. 8 (mss. ná áva prabh-). [16. nāv yà: -víās. 8. $5.9 ; 7$. I5. I0. I. $\mathbf{n} \mathbf{a} c ̧$ a $\mathbf{n}$ in kilāsanăçana, kṣetriyanăçana, takmanăçana, balāsanăçana, yakșmanắçana, roganăçana, vātīkṛtanăçana.

nāṣțrá: -rắs. 8. 2. 27.

nầs ā: -se (p. -e íti). 5.23.3. (cf. năsikā.)

ná s i kā : -kām. I9. 8. 5 (ed. -kā). [r8. 4 . nắsike (p. -e íti). I0. 2.6; 9. I4. I5. năsikābhyām. 2. 33. $\mathrm{I}^{*}$.

nā ha in upanāhá, nīnāhá, prāṇāhá. ní. 3. 12.4. 4. 5. $\mathrm{I}^{*}$; 28.6. 5. 2.6*; I2. $6^{*} ;$ 13. $5 ; 23.8$. 6. $49.3^{\dagger} ; 52$. $2^{4 *} ;$ I3I. $\mathrm{I}^{2}$. 7. 90.3. 8. 4. $5^{*}$, 10* 9. 4.6 ; 10. $7^{*}$, I6*. I0. $8.3^{*}, 7$. I I 4. 22 . I2. 2.9 . I $4.2 .5^{*}$ I $8.1 .3^{*}$. 20. I35. II (not mss.).

(cf. ni $+\sqrt[V]{ }$ añc, añj, 2 as, i, uc, ubj, uș, r, I kṛ, ci, kram, khan, gach, gam, $\bar{a}+$ gam, I gā, 2 gṛ, grah, jas, jā, jūrv, tan, tap, tud, tṛ, tṛ̂d, dah, I dhā, adhi ... dhā,

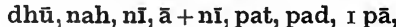
piss, I pre, priyāy, bandh, bādh, budh, bhañj, bhrañç, majj, mi, miș, mìv, 2 mr, mruc, yach, yā, yuj, ram, lip, rī, lì, rudh, 2 vap, vah, vãç, I vid, viç, viṣ, vișt, vṛt, abhi ... vṛt, vyadh, 2 çam çā, çās, çuș, saj, sad, upa. . . sad, sam ... sad, sah, sic, sidh, sev, sthā, svap, han, hā, hū, hṛ ; and nítya, nivát, nyàñc, nikāmá, nikilbisá, nidhána, nímanyu, nivātá, nisvará, nyàrbuda, nyàr- 
budi, nyastiká, nyáhna.)

ni okāmá: -ás. I5. II. 2, IO, II. nikămám. I5. II. IO. nikāmásya. I5. I I. II. nikāmé. I5. II. II.

niokārín: -ínas. 7. 82.3. ni॰kilbiṣá: -ám. 5.17.11". ni०krám a ṇa: -am. I. 34.3 . Vnikṣ: nílsg̣a. I9. 29. $\mathrm{I}^{4}$ (m. mss. nikşá).

(cf. nékşanạa.)

+ an u: anuoníkşanti. 9. 8. 15.

+ vi: ví nikșa. 8.3.25 (mss. ed. -kșva).

vioníkșe. 8. 3. 24* (mss. -kșve).

nikhātaka: -am. 20. 132. 2, 3.

$\checkmark$ nij: cf. nejana.

+ a va: áva nenigdhi. 9. 5. 3. (cf. avanejana.)

+ abhyava: abhyávanikși (p. abhioáv-). I0. 5. 15-21. I6. 1. 4.

+ pra: pră 'ṇāikṣīt (p. prá an-). 2. 7. $\mathrm{r}$.

(cf. pranéjana.)

+ vi: vi anijam. Io. 4. 19.

niojá: -ás. 3. 5. 2.

niṇyá: -ás. 9. Io. 15 ".

niotatni: -ni. 6. 136. r.

niotãná: -nắs. 6. r39. I.

niotodín: -nas. 7.90. 3.

nitodínāu. 7.95.3.

níty a: -as. I 8. I. $30 \%$

(cf. nítyavatsa.)

[4. $2 \mathrm{I}$.

nítya ०vats a: -sām. 7. 104. I. 9. Vnid, nind: níndișat. 2. 12. $6^{\dagger}$.

(cf. nindâ.)

$\mathbf{n i} \mathbf{d} \mathbf{a} \mathbf{g} \mathbf{h}$ in nāidāgha.

niodhána: -am. 9.6.45-8 ; 7. 18.

II. 7. 12. I2. 1. $48 ; 5.3$.

ni॰dhí: -ís. I2. 4. 29.

nidhím. 10. $7 \cdot 23^{2}$. I2. 1. $44 ; 3.42$,

$46 ; 4.17$. 19. 27.9 .

nidhî (p. -ítíti etc.). I I. 5. IO.

nidhín. I8. $4.4 \mathrm{r}$.

nidhíobhis. $7 \cdot 72.2^{*}$.

nidhíşu. I8. $3 \cdot 45^{*}$.

(cf. nidhípati, nidhipă.)

nidhí p ati: -is. 7. 77.4 . ni dhi opấ: -ắs. I2. $3,34,4$ I, 42 .

nin dă : -ầs. II 8.22.

(cf. ánindā.)

ni॰púr: -ras, I8. 2. 28.

níbh a ñj ana: -am. 20. 131.2.

nibhŗşța in ánibhŗșța.

ní $\mathrm{m}$ a $\mathbf{y}$ u: -us. 3. 25.4.

ni॰mís: -ṣas. 4. 16.5 .

ni $\mathrm{m}$ iş a in animişá.

nimeșa in ánimeşa.

niom rúc: -úk. 4. 3.6.

nimrúcas. I3. 3.21.

ni。yắna: -am. 6. 22. I". 8. 2. IO.

13. 3. 9". I8. 4.44 .

ni०y 6 jana: -am. 7.78. r.

nirāhita in ánirāhita. [2. I0.

nírindriya (p. núh̆oin-): -yās. 9.

nírṛti (p. níḥoṛt-): -is. 2. 10.5. 3

6.5. 4. 36. 10. 6. 63. I; $84 . \mathrm{x} ; 124$.

3. 7. 70. I, 2. 9. I0. 10 ${ }^{\dagger}$ I0.2. 10. I I. 8. 19. I2. 3. 17 ; 5.37. I8. I. I2* nírrte. I9. 44.4.

nirṛte. 6. $29.2 ; 63.2 ; 84.3 .7 .64$. 2. 14. 2. 19 .

nírrtim. 6. 97. $2^{*}$; 124. 2. 7. 42. I*.

8. I. $2 \mathrm{I}$; 2. I2. 9.5. I8. I2. 2. 3.

nírụtyāi. $5 \cdot 7 \cdot 9$.

nírṛtiāi. 2. 25. $\mathrm{x}$.

nírụtyās. I. 3 I.2. 2. 10. I-8. 6.

27. I*. 8. I. 3. I0. 3. 7. I6. $5.2 ; 8$.

\begin{tabular}{l} 
2. I8. 3. 26. I9. 44.4 . [II. I. 29. \\
\hline
\end{tabular} nírṛtes. 3. $11.2^{*}$. 7. 53.3. 8. $4.9^{*}$. (cf. nāirrtá.)

nirṛthá (p. niḥoṛth-): -ás. 6. 93. r. I2. 2.14 .

nirṛthám. 8.4.14*.

nirṛthăt. $5 \cdot 3 \cdot 9^{\dagger}$.

ni or $6 \mathrm{~d}$ h a na:-am. I2. 4. I5. [27. I. nírjarāyu (p. níhoj-): -yavas. I. nird aha ná (p. nị̣॰d-): -nt. r4. 2. 48.

nirdāhá (do.): -ás. I6. 1. 3. nirdāhám. 5. 3I. 9

nir bā d ha in nāirbādhyà. [7. I. nírbh ūti (p. níḥobh-): -tyā. I6. nírbhūtyās. I6. 5.4; 8.4. [3.5. nírmukti (p. níhom-): -tyāi. I2. nirhat a in ulkănirhata. 
nírh a st a (p. níhoh-): -as. 6.66. I. nírhastās. 6. 66.2, 3 . nírhastān. 3 I. I ; 2.1 . nírhastebhyas. 6. 65.2. (cf. nāirhastá.)

ni॰lă ya: -am. 4. I6. 2. niolimpá: -pấs. 3. 26.5 . ni。vát: -tā. 5.3.2 $2^{\dagger}$.

nivátas. 6.22.3.

niovártana: -am. 3.6.7. 6. 77. $2^{*}$. 7.38.1. 9. 2. 12.

ni०vātá: -té. 6. 55. 2.

ni०vāçá: -çấs. II. 9. II.

ni०víd: -das. 5. 26. 4 . (cf. nivíd.)

ni०véçana: -as. Io. $8.42^{\dagger}$. nivéçanam. 6. 106. $2^{*}$.

nivéçani. 9. 3. I7. I2. 1.6. I8. 2. ni v eṣy à: -às. 9.7.4 (s. mss. -ás). nị̣oçás: -sā. 6. $45 \cdot 2^{*}$.

nișanga in

niṣañgín: -gíobhis. 19. I3. $4^{*}$.

niș é c a n a (p. niosé-): -am. I. 3. I-5. niṣká: -ám. 5. 14.3. I9. 57.5.

niṣkăs. 7. 99. I. 20. I31. 8.

niṣkắn. 20. 127.3.

(cf. nișkágrĩva.)

nișká。grīva: -as. 5. I7. I4.

nís k a rt r (p. níhok-) : -tā. I4. $2.47^{\dagger}$. níşkrti (p. níhok-): -is. 5. 5.4,6.

nișkṛte. 5.5.6.

nískrtim. 6. 27. I* ; 49. 3†. I 8. 4. 60 nískrtes. 4. 27.6 .

[22. 6.

nișțákva n (p. nih̆ot-): -varīm. 5 . $\mathrm{n}$ ișțtrta in ánișțrta.

[6. $3^{*}$.

níșț a: ttias. I. 19. $3^{*}$. 3. 3.6. 6. nís. I. 8. 3; I8. $\mathrm{I}^{2}, 2^{3} ; 23.2,3.2$. I0. $8 ;$ I $4.2^{4}$. 4. 22. I, 2. 5. I8.4. 6. I4. 2,$3 ;$ I8. $3 ; 75 . \mathrm{I} ;$ 90. 2.7 .76 . 3 ; 115.3 . 9. 5. $3 \mathrm{I}-6$. I2. $2.3^{2}, \mathrm{I} 2$, I6, 42. I6. 2. I; 7.6 . I8. 2. 42. I9. 57.2.

(cf, nis $+V$ Vaks, I aj, 2 as, āl, à $+\mathbf{i}, \mathrm{r} \bar{u} \mathrm{u}, \mathrm{r}, \mathrm{rch}, \mathrm{I} \mathbf{k r}$, abhi . . . krr, krī, 2 kși, khid, cat, tak, taks, day, dah, anu ... dah, dru, $\overline{\mathbf{a}}+$ I dhā, 2 dhā, I naç, ni, nud, pat, abhi ... pat, bādh, bhaj, bhañj, bhid, bhū, math, mantray, I mā, muc, mṛj, $\bar{a}+$ yach, yāc, vac, vad, 2 vap, vah, $\bar{a}+\mathbf{v a h}$, I vā, çañs, I çṛ, sū, sṛj, sṛp, stṛ, sthā, han, vi ... han, hū ; and niștya, nírjarāyu, nírindriya, nírhasta, nihsālá.)

ni०svará: -ás. 12. 2. I4.

nisvarám. 8. 4. $5^{*}$.

nị̣osālá: -lấm. 2. I4. I.

níh: -has. 2.6.5.

V ñ̄i: náyāmi. Io. 4.21.

nayāmas. IO. I. I5.

nayāmasi. I. I8. I. 5. I4. 6, 7.

náyanti. 5. 30. 12. 8. 1.8.

nayate. 5. I9. I5.

náyāti. 3. II. $3^{*}$.

[(do.).

náyāt. 19. 24.2 (mss. nayắm), 3 nayāsāi. 4. 3I. $3^{\dagger}$.

naya. 2. 28.5 . 6. 5.2. IO. I. 26 . nayatu. 2. 36.8 . 6. 59.3 . $\quad$ I2. 2. $24^{\dagger}$. I4. I. $20^{*}$. I9. $43.1-6,8$.

náyata. 8. 8. II.

nayata. 7. 82. I*.

náyantu. I4. 2.10*. [-atu) nayantu. 6.93.2. I9. 43.7 (mss. náyasva. I. 8.3.

náyantī. 6. 92. 3*.

anayam. 18. 3.3.

[ánáy-).

ánayan. 7.1. I. 20. 135.6 (mss. ninăya. 9. 2.17 .

neșța. 3. II. 7 .

neșat. 7. 9. $2^{*}$.

nītăm. 5. $17.5^{*}$.

niyase. $5 \cdot 4.8$.

nīyámānām. 5.7.1. I8. 3.3.

nínīșati. I9. 50.5 (s. mss. ed. níneș-). (cf. ni, nīta, nīti, nītha, netŕ, netrá.)

+ a ti: áti ... náyāti. 3. II. $3^{*}$. áti ... neșat. 6. I I0. 2.

+ an u: ánu neși. I9. I5.4". [úp-*). + a pa: ápa-nītā. 5. $17.6^{\dagger}$ (s. mss. ed.

+ abhi: abhí ... nayantu. 6. 47. 3. I2. 3.26 .

abhí ... nayāsi. 12. 3. I7.

abhí neșa. 12. 3. I6.

+ a va : áva ... nayāmasi. 7.94. I $^{\dagger}$. 
$+\overline{\mathbf{a}}$ : ă nayāmasi. $\quad$ 5. 25.8.

à naya. 9. 5. I.

a...naya. 3. 3. I.

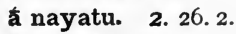

â... nayatu. 2. $26.2 ; 36.8$. 3. 3.4 . ầ nināya. $5 \cdot 17 \cdot 2^{*}$.

+ nyā: nioănayat. 7.38. 5 .

+ u d: ún nayāmi. 3. 19.3.

út ... nayāmi. I. I. I.

ún nayathā (p. -tha). 4. 13. * $^{*}$.

ún nayanti. I3. I. 23.

út... nayāti. 6. II9. I ; I2O. I ; I2I.2.

ún naya. 2. 9. I.

út... naya. 6. 5. I.

unonáy antìm. 8.7.6.

unoninăya. I3. 2.4 .

ún neșyati. 7. 103. I.

[áp-).

+ u pa: úpaonitā. 5. 17.6* (m. mss. upaonáyamānas. II. 5.3.

+ ni : ní neșat. 12. 3.55-60.

+ nis: níh... náyati. 5. I 8.4 . nír anayīt (p. ana-). Io. 4. 26. nirnáyate (p. niḥoná-). II. 2. 22.

+ parā: párā ṇaya (p. na-). 5. I4.4. parāṇîya (p. -rāoní-). 12. 4. 52.

+ upas a mparā: upasámparānayāt (p. upaosám parān-). I 8. 4. 50.

+ pari: pári ... nayāmi. 9.5.2. pári ... nayāmas. 6. 28 . $\mathrm{I}^{\dagger}$. pári ... aneșata. 6. $28.2^{*}$. pariṇīyámānām (p. -rionī-). 18.3.3.

+ pra: prá nayāami (p. na-). 19. I9. I-II.

prá nayati (do.). 9.6.4.

prá ṇaya (do.). 8. 3. $9^{*}$.

prá ṇayantu (do.). $\quad$ I9. 46.4 .

praṇiyánte (p. praoni-). 9. 6.5.

(cf. prániti, pranetri.)

+ prati: práti nayãmi. 8. 8. Io.

+ vi: ví nayanti. I4. I. $46^{\dagger}$.

ví ... nayāmasi. $5 \cdot 7 \cdot 7.6 .43 \cdot 3$.

+ s a m: sám ... náyati. 4. $24 \cdot 7$.

sám nayāmasi. 6. $46.3^{*}$. I9. $57.1^{*}$. samonóyanti. 6. $46.3^{\dagger}$. I9. $57 . \mathrm{r}^{\mathrm{t}}$. sám... náyāthas. 2. 30.2. [yám). sám naya. I9. 45. I (mss. samonasám ... neșa. $7 \cdot 97.2^{\dagger}$.

[ní. $\mathbf{n} \mathbf{I}$ in grāmaṇí, padaní, vaçanț, senā- n I cá : -cāís. 2. 3.3. 3. I9. 3. 4. I. 3. 5. I1.6. 9. 2. I, 9,15 .

nicina: -am. 6. 9I. $2^{*}$.

nícínasya. $7 \cdot 56.5$.

nì ḍa : -ḍé. 5. 1.6* (mss. -ḍe).

(cf. sánị̂ạa.)

n I t a in ásunīta.

nīti in ásunīti, pránīiti, vásunīti.

$\mathrm{n} \overline{\mathbf{I}} \mathbf{h}$ a in sahásranitha.

nìn āhá: -ám. I9. 57.4.

ntla: -am. I4. 2.48. I5. I.7.

ntlena. I5. I. 8.

(cf. nīlanakhá-ñ̄lāgalasẩā.)

nīla n a k há: -khébhyas. 19. 22.4.

nīlaolohitá: -ám. I4. I. 26".

nīlalohiténa. 8.8.24.

nīlalohité. 4. 17. 4 .

nîla I32. I6 (mss. -dá).

nîlaçikhaṇda. 2. 27.6.

nílaçikhạ̣dena. I1. 2.7.

nīlāga lasălā. 6. I6.4.

niví: -ím. 8. 2. I6. I4. 2. 50.

(cf. nīvibhāryà.)

nivíd (p. niov-): -das. II. 7.I9.

nİiobhāry à: -ríāu. 8. 6. 20.

nīsáh: -șaț. 5. 20. II.

nìhārá: -ás. I8. 3. 60 .

nīhārắn. 6. II3. 2.

nú. 2. 5. $5^{*}$. 3. 20.8. 4. I.6; I9. I. 5. I: 8 ; $2.4^{\dagger} ; 6.5$; II. $2,4,9 ; 26.8$, 9 ; 30. I, I4 $4^{2}$. 6. 4.1 ; 60. 2 ; I24. I. 7. $5.4 ; 6.4 ; 26 . \mathrm{I}^{*} ; 86 . \mathrm{I}^{\dagger}$. 8. 9. $25^{2}$. 9. I0. IO*. I0. 2. 2 , I0, $28^{2}$. 12. 2. $23^{*} ; 4.43 ; 5.50$. I4. 2. 29 . I5. 3 . I. I8. 1. $5^{*}, 20^{*}, 48^{*} ; 2.57$. I9. 53 . $2^{2}, 3 ; 54.6$.

(cf. nanú, náva, náviyas, návya, navyá, nưtana, nūnám.)

$\checkmark \mathrm{n} u$ : $+\mathrm{abhi}$ : abhí anūșata. 2. I. I.

+ upa: úpa... nonumasi. 20. 127.

14 (not mss.).

+ pra: prá ṇavati. 20. 135. 5 .

+ s a m: sám navanta. 9. 9. $3^{\dagger}$. sám ... navanta. 5.2.2".

n utta in bráhmanutta, praṇutta.

$\checkmark$ nud: nudămas. 12.3 .43 . nudate. I9. 36.2 . 
nudéthe (p. -e íti). 4. 29. I, 2. nudatu. 6. 75. 2.

nudatam. 6.32.3.

nudata. 6. $28 . I^{*}$.

nudatā (p. -ta). I2. 2. 30 .

nudantu. 6. I24." 2 .

nudásva. 9. 2.4. II. I. 2 I.

nudasva. I2. $3.2 \mathrm{I}$.

nudatām. 9. 2. 15. I2. 5.72. I7. 30. nudéthām. 8.4. I*.

nudán. 3. I5. I. I9. 33.2.

nudișţhās. I2. 1. 32 .

nuttă. I 0. I. 3, I4.

nuttắs. 8. 8. 19.

nuttằn̄m. 9. 2:4.

(cf. nutta, noda.)

+ ati: átionuttas. 8. 7. I5.

+ a p a: ápa nudāmas. IO. I. I, 2.

ápa ... nudantu. I2. 3.49.

ápā 'nudas. 7.84.2*.

[15.

+ nis: nír ṇudāmasi (p. nu-). I2. 2. níh ... nudāmasi. I2. 2. I6.

níh ... nude. 6. 75. I.

níh ... nuda. I2. 2.42 .

+ pa rā: párā ṇuda (p. nu-). 3. I8. $2^{\dagger}$.

+ pra: prá ṇude (do.). 9. 2. 6 .

prá ... nude. 3. 6.8 .

prá ... nudāmahe. 3.6.8.

prá ṇuda (p. nu-). 2. 25. 5 .

prá ṇudā (p. nuda). 7. 34. I.

prá... nudatu. I. $7 \cdot 4$.

prá ṇudasva (p. nu-). 9. 2.4, I7, I8. prá ṇudatām (do.). I2. I. 4I ; 5.73 . prắṇudanta (p. praoánu-). 9. 2. I 7, I8.

práṇuttas (p. práonu-). 9. 2. I4.

práṇuttānām (do.). I I. 9. 20.

(cf. praṇutta, pranóda.) [35. I.

+ prati: práti... nudasva. 7.34. I ; prationudán. 5. 3. 2*.

+ vi: ví ... nudasva. 4. 31. $2^{*}$. 7 . 84. $3^{*}$. I3. I. 27 [ [2.64. + sam: sám nuda. 6. 139. $3^{2}$. I4. nút ana: -am. 7. 21 . I.

nūnám. 4. I. 6. 7.73.2. 8. 4. $20^{*}$. I 8. I. $4^{*}, 46^{*}$.

ṇ̛́: náram. 20. I27. 14 (mss. na-). náras. 3. 17. $6^{*}$. 4. 31. $\mathrm{I}^{*}$. 6. 126.
3. 9. I. 3. I4. I. $46^{*}$ I9. 56.4 . naras. 3. $19.7^{*}$. 6. 22. 2 . 14. 2.9 , I4. I9. I3. $3^{*}$.

n⿳̛̣n. I $8.1 .7^{*}$. ṇ̛́obhis. 3. 16. $3^{*}$. 5. 13.3. I8. 4 . ṇ̛năăm. 2. 9.2. 19. 47.7.

(cf. nara, nárya, nărī, nṛcákṣas, ṇ̛́tama, nṛpáti-nṛșad.)

n ṛ॰cákṣas: -șās. 7. 4I. I, 2. 8. 3 . IO*.

$\left[17^{*}\right.$. ṇ̛cakșas. I. 7.5. 4. 16.7. 8. 3. $9^{*}$, nụcákșasas. 8. 3. $8^{*}$. I3. 2. I.

ņ̣cákșasi. 10. 3.18.

nṛcálsşasāu. 4. 29.2.

nrucákșasā. I8. 2. 12 $2^{\dagger}$.

nṛcálșasas. I8. 4.29*. I9. 47.3.

$\checkmark$ nrrt: nựtyanti. I2. I. 4 I.

anartișus. 6. 49. $3^{*}$.

nṛttắni. I I. 8.24.

(cf. nứt, nṛtí, nứti.)

+ adhi: ádhi nritya. 5. 20. Io.

ádhi nrityatu. ro. 9. 2.

$+\overline{\mathbf{a}}$ : āoṇ̛́tyatas. 4.37.7.

+ pari: parionọ́tyati. 4. 38. 3 .

parionș́tyanti. 8.6. 10.

pári nrrtyanti. I2. 5.48 .

parionútyantios. I0. 7.43 .

+ pra: praonítyantas. 8. 6.II. pră 'nṛtyat. I0. Io. I2.

+ s a m: sam॰ánartișus. I4. 2. 59, 6I. ṇ̛́t: -tas. Io. 2. I7.

nṛ ot a ma: -māya. I 8. I. $37^{*}$.

nṛtí: -táye. I2. 2. 22*.

nứti: -tes. 6. I8. 3 .

n ṛ॰páti : nrpate. 5. I8. I, I5. [4. 6*. nṛpátĩ (p. -tĩ 'vé 'ti nṛpátīoiva'). 8.

n ṛ̣ăna a (p. nựpắn-): -as. I 9. 58. $4^{*}$

n ṛmán a s (p. nṛomán-): -ṇās. I6. 3. 5 .

[5. I-6.

n r m ṇá: -ám. 4. 24. 3. 8. 5.21. Io. (cf. tveşáṇ̛mṇa.)

n rovánt: -ntas. 3. 16. 3*.

n ṛșa d in nārșadá.

nékşạ̣a: -am. 9.6. I7. [na.

nejana in hastāvanéjana, praṇéja-

netṛ: :tâ. rg. 13.9".

netấras. I 0.8 .35 .

(cf. prạ̣etṛ, netrá.) 
netrá: -ám. IO. I0. 22.

néd (p.ná ít). 2.27. I. 6. 50. I. 7. 38. 4. I3. I. I2. I 8. $2.58^{*}$.

nédiyas: 3. I7. $2^{*}$. I0.8.8.

nemi in árișțanemi, ékanemi, sánemi, hiranyanemi.

nãí dāgh a: -as. 9.5.3 1 . nāídāgham. 9.5.31.

[45. 5 .

nāirṛt á (p. nāiḥoṛt-): -tébhyas. I9. nāir bā dhy à (p. nāị̣ıbā-): -dhíena. 6. 75.1 .

nāirhastá (p. nāị̣ıha-): -ám. 6. $65.2,3$.

noda in pranóda.

nodh as in nāudhasá.

nā ú: nāús. 3.6.7. 5.4.4. 9. 2. I2. I9. 39.7 .

năvam. 2.36.5. 5. 19.8. 7.6.3". 9. 2.6. I2. 2. 48 . I7. 25,26 .

nāvă. $4 \cdot 33 \cdot 7^{*}, 8^{\dagger}$.

nầvas. $5 \cdot 4 \cdot 5$.

(cf. nāva, nāvyà.)

nāudhas sá: -ám. I 5. 2.4; 4. $4^{2}$.

nāudhasâya. I5.2.4.

nāudhasásya. I 5. 2.4.

nyá: niás. II. 7.4.

nyagródha: niagródhāt. 5.5.5. niagródhās. 4. 37.4.

n y à ñ c: níañ. 5.22. 2.

níak. 6. 9 I. $2^{3^{*}}$.

nīcâ (adv.). I. 2 I. $2^{*}$. 4. 3. 6 .

nicas. II. I. 6.

nicis. 4. I5. I 2.

(cf. nīcá, nīcína.)

n y áñ can a (p. nioá-): -am.4. 36. 6. niáñcanī. 5.5. 2.

nyá y a na: nioáyanam. 6. I06. 2* (cf. nyấyana.)

n y à r b u d a : níoarbudam. 8. 8. 7. I 0 . 8. 24 . I 3. 4.45.

n y à r bu di : níoarbudis. I I. 9.4. niarbude. II. 9.6, I I, I2, I9; 10. 20,21 .

ny a stikấ: nioastiká. 6. I39. r.

ñ́hna: nioáhne. I8. 4.65.

nyắy ana: niấyanam (p. nioáy-). 6. $77.2^{\dagger}$.

n y ok as in ányokas. nyócana: niob́cani. 14. I. $7^{*}$.

nyocará: nioocarás. 5.22.5.

p a, see 2 pã.

[-tva).

p a k tṛ́: -tấ. Ir. I. I 7, I9 (m. mss. edl.

paktằam. I0. 9. I1, 25. I2. 3. 48 . paktắras. I 0. 9.7. I I. 3. I 7 .

pakvá: -ás. 9. 5. 18. 12. 3. 48. 20.

I27. 10.

pakvám. 3. 17.2". 6. I22.3. II.

I. 28,33 I2. 3.7 , II. 20 I35. I2.

pakvéna. 6. II9. 2. I2. 3. 34, 55-60.

pakváya. I2. 3.8.

pakvăt. 4.35.6. I2. 3.2, 9.

pakvé. 20. 127.4 (mss. -ve).

pakvāú. 20. I29. 15 (not inss.).

(cf. vípakva, súpalrva, pakvaká.)

p a kv a ká: -ám. 20. 130. 6.

pakṣá: -ás. I3. 3. I2.

pakṣāú. 4. 34. 1. 6. 8.2. 8. 9. 14. I0. $8.18 ; 9.25$. I3. 3. I4.

pakșânạām. 9. 3. 4.

(cf. apakșá așțăpakșa. cátușpakșa, chándaḥpakṣa, chinnápakṣa, dáçapakșa, dvípakșa, prācínapakșa, şáțpakṣa, supakșá, híraṇyapakșa, pákṣas, pakșín, pakșya.) pákșa : : -asi (p. -i íti). 8. 8, 22. [33. pakṣín: -ṣ̂́. 4. 37. 4. 7. 76. 4. I3. 2. pakṣínas. I. II. 6 . II. $5.21 ; 6.8$; Io. 8. I2. I. 5 I.

pakșínī. 6. 27. 2", 3".

pakş $\mathrm{a}$ in upapakşyà.

pañtí: -ís. 9. IO. $2 I^{\dagger}$. I3. I. I $5,42^{\dagger}$

I9. 2 I. I.

pañtím. I3. 3.25t.

pañtyá. I3. 3.5.

(cf. păñta.)

$\checkmark$ pa c: pacāmi. 4. 35.7. 6. 123.4.

I2. 3.47 .

pácati. I0. 9.4 . I2. $3.4,5,39$.

pacati. II. I. I.

pácatas. I2. 3. 12.

pácanti. 4.34.3,4. 9.6.30.

pácate. I2. $4 \cdot 38,53$.

pácata. 9. 5.37.

pacatā (p. -ta). 12.3 .27$. 
pácan. I2. 3. 24.

pácatas. II. I. 30 . I2. 3.50 .

ápacat. 4. 35. I.

apacanta. 9. I0. $25^{*}$.

papắca. 4. 35. 2.

ápeciran. 5. I8. II.

[37.

paiktvă. $4 \cdot 34 \cdot 5$. I I. I. I 8 , I9 (-tầ ?),

páktave. II. I. 3 .

pacyámānā. 5. 19.4. $12.5 \cdot 32$.

(cf. paktṛ́, pakvá, pâka, pacya.) p a y a in akrsțapacyá.

páñ ca: I. 30.4. 3. 4. 2; 20. 9; 2 I. $5: 24 \cdot 3^{2}$. 5. $15 \cdot 5$ (m. mss. ed. pañcá). 6. $25.1 ; 75.3 .7 .6 . I^{*}$. 8. 9 . $4,15^{4}, 23$. 9. $5.25^{3}, 26,37$. ro. 8.35 . II. $2.9 ; 6.15,22$. I2. I. 15,42 . I3. I. 18 ; 3.6. I8. 4. 55. I9. $9.5 ; 22$. I ; 47.4 .

pañcáobhis. 4. 14.7. 17.17.

pañcáobhyas. 5.17.9. [dana.)

(cf. pañtí, pañcajana - páñcãupa ñ cajana in páñcajanya.

pañ c a d a ça in pañcadaçá, pañcadaçarcá.

pañ c a。daçá: -ás. II. I. I9. pañcadaçéna. 8. 9. I5, 20.

pañc a da ça rcá (p. -çaoṛc-): -cébhyas. I9. 23. I2.

pañca。dhat. 4. 14.7. 9. 5.8. páñca on ām a n: -mnīm. 8. 9. 15 .

páñ c a $\circ \mathrm{p}$ à da: -am. 9. 9. 12 ". páñcapādāt. 8. 6.22.

páñca。bila: -am. II. 3. I8.

pañcamá: -ás. I3.4. I7. I5. I5.

$7 ; 16.5 ; 17.5$.

pañca०yojaná: -ám. 6. I3I. 3.

pañca $a$ ātrá: -ás. II. 7. II.

pañcarcá (p. -caoṛc-): -cébhyas.

I9. 23. 2.

pañca。vāhín: -hí. Io. 8.8.

pañca०vṛșá: -ás. 5 16. 5 .

páñca oçal a: -lăt. 8. 7.28. [6.4. páñcāñguri (p. -ca॰añg-): -is. 4 . páñcāpūpa (p. -cåap-): -am. 3. $29.4,5$.

páñ cāra (p. -ca॰ar-): -re. 9. 9. II*. pañcāçát: $5 \cdot 15 \cdot 5$. I9.47.4.

(cf. tripañoāçá.) pá ñ cāu dana (p. -ca॰od-): -as. 9. 5. 8, 9, I0, I8, 2I, 3I-6. páñcāudanam. 4. I4. 7. 9. 5. II, I2, 22, 24-6, 27, 28, 3I-6.

paț a rá: -rāís. I3. 3. I6.

pa țāurá: -rāú. II. 9. I4.

páḍīça: -am. 8. I. 4 .

páḍ̉īçe. I2. 5.15 .

[8.27.

páḍbiçāā. 6. 96.2* 8.7.28. I6. $\checkmark$ p a ̣̣ in paṇa, paṇí, pāṇa, pāní.

+ pra: cf. prapaná.

+ prati: cf. pratipaṇá, pratipāná.

p a ṇa in prapaná, pratipaná.

pañi: -ís. 20. I28.4 (mss. -is).

panáyas. 5. I1.6. I9. 46.2.

panín. 4. 23. 5. 5. II. 7.

páan đ̣̣ a g a: -gās. 8. 6. I6.

$\checkmark$ pat: pátati. 4. 20.9. I0. 8. II.

patati. 6. 80. $1^{*}$. 7.76.4.

pátanti. I. II. 6.

pátāti. $5.29 .2,3$.

pata. I. II. 6 .

patatu. 5. 14. 12.

patantu. I. I9. 2. 2. 3.6.

pátantam. 8.3. $5^{*}$. I3. 2. 36 .

pátatas. 10. 8. 18. I3.3.14.

ápaptat. 7.96. I.

paptat. 7. 52. 2.

ápipatat. 7.64. I.

patituâ. 4. I2.'7.

patáyati. 19. 48.3.

patáyanti. 8. 4. I 8 .

patayanti. 8. 4. 20*.

patáyan. I3. 2.3I.

patáyantam. 13. 2.2. I8. 3. $18^{*}$.

pātaya. I. Ig. I. II. 2. 26.

(cf. pata, pátatra, patayālú, patayiṣnuká, patvan, pāta, pātin.) + an u: ánu pātaya. 6. I34. 3. [6. 124. 2.

+ abhi: abhyápaptat (p. abhioáp-). abhy àpaptat. 6. I24. I.

$+\overline{\mathbf{a}}$ : à pata. 3. 3. 3; ro. 7 .

āopátantam. 12. 2.47.

à papatyāt. $6.29 \cdot 3$.

$+\mathfrak{u}$ : út patanti. 6. 22. $1^{*}$. I3. 3. $9^{*}$. ut॰pátantam. I9. 65. I.

út... petatus. 7.95. $\mathrm{x}$.

utopatișyán. I8. 4. 14. 
Gat pātayāsi. I2. 3. 53 .

út pātayătha. 4. 15.5 .

(cf. utpăta.)

+ s amu d: samoútpatantu. 4. I 5 . I. + upa: úpa ... pátantam. 18. 3. 66*.

+ ni: niopátantī. I2. 5. 26.

ní paptam. I2. I. 3I.

níopatitā. I2. 5. 26.

níopatitãyāi. 6. 90. 3 .

+ nis: níh ... pātaya. I. 8. 3.

+ abhinis: abhionişpátan. 7.64. I.

+ parā: parăं॰pátati. 6. I05. I, 2. parā॰pátanti. 6. 105.3.

párā pata. 3. 10. 7 ; 19. 8".

parấpatat (p. -rãoáp-). $\quad$ r. 3.9.

párā 'patat. 5.28.6.

párā ... pātaya. I. 23.2.

+ pra: prá pata. 6. I4. 3 ; 105. I-3.

7. II5. I. I4. 2. I9.

prá patata: 6.83 . I.

pra॰pátan. 6. 8.2. I9. 50.4 (m. mss. prápa-).

prầ 'paptat. 5. 30. 9 .

prá patișyati. $6.83 .3^{2}$.

prá ... pipatişati. 12. 2. 52 .

prá pātaya. I9. 50.4 .

+ vi: ví papāta. 7. 43. I.

ví ... pātayāmasi. 4. 7.4.

ví pātaya. I9. 28. 4.

+ s a m: samopátanti. I2. I. 5 I.

sám patatu. I I. I0. 7, 20.

sám ... patantu. 6. 126. 3 .

sámopatitā. $5 \cdot 5 \cdot 9$.

(cf. sampātín.)

pat a in

p a ta món á :ás. 6.3I. $3^{\dagger}$. 13.2.3I ; pátamina. 6. 50.2 . 13. 2. 30.

pátatra: -rāis. 13. 2. 26".

(cf. patatrín.)

pat atrín: -rí. I4- 2.44 .

patatrínas. I. I5. I. 5.21.6. 8.7.

24. I r. 9.9 ; IO. 24 . I9. I. I.

patatríobhis. I0. IO. I4.

patatríni. 5. 5. 9. 6.29. I.

pat a ȳlú: -lús. 7. I15.2.

patayiṣnu in

patayiṣnu uá: -ám. 6. I8.3.

páti: -is. I. I. I, $3,4^{2} ; 2$ I. I". 2. 2.
I, 2 ; 36.8. 3. 4. I ; I0.8. 4. 2. $7^{*}$. 5. 3. 9"; $7.8,9.6 .33 .3 ; 73.3 ; 79$. I. 7. 17. I. 8. 5.22. 9.4.2, 4, I7; 5.28. 12. $2.39 ; 3.39$. I3. $3.7 ; 4$. 47. I4. I. $26^{*}, 27^{* *} ; \quad 2.2^{*}, 3^{\dagger}, 3^{*}, 63$. 16. $6.6^{\circ}$. I8. 1. $3^{*}$. I9. I0. $5^{*}$, 10*; 20. 2. 20. 127.8 .

pate. I. I. $2^{2}$. 3. 20.2. 4. I9.8. 6. 79.2. 7. 74. $3 ; 81.3 ; 97.8$. 10.5 . $45^{2}$. I3. I. 17-9.

pátim. 2. $36.3^{2}$. 3. $18.1^{*}, 2^{*}$. 5. I. 4. 6. 36. I; 60. I, $3 ; 78.3 .7 .21$. I; 4 6. 3. 9. 5.27 . I I. $5.18 ; 9.8$. 12. 3. 29. I4. I. $6^{*}, \mathrm{IO}^{+}, \mathrm{I}^{*}, 25^{\circ}, 3 \mathrm{I}$, 59 ; 2. 22, 52. I8. I. I I"; 2. 5 I. 20. I27. 9.

pátyā. 2. 36. I, 4. 6. 22.3 (l. -tiā ?). IO. I. 3. II. I. I4. I4. I. 2 I $^{*}, 40,50^{*}$, $52 ; 2.32$ (l. -tiāa).

pátinā. 16. 6. $6^{2}$.

pátye. 3.30.2. 8.6.21. 14.1.9", 49,$55 ; 2.7,24,26,27,3$ I. I 8 . I. $8^{*}$. pátaye. 2. 8. 5. 3. 10. 9, 10.

pátyus. I4. I. 42, 43. I8. 3.2".

pátāu. 3. $18.3^{\dagger}$.

pátĩ (p. -i íti). 6. 3.3.

patī (do.). 6.69.2. 9. I. I9. I4. I. I $5^{*} ; 2.5^{*}, 6^{*}$.

pátayas. 3. 10. 5. 4. 37. 12. 5. 17.8. 6. 62. 2. 7. 79. 4 ; 80. $3^{\prime \prime}$; 91. I"; rog. 6. 9. 7. I4. IO. I. 22 ; 9. 27 . I9. II. I". pátiobhyas. 2. $36.7 .5 .12 .5^{*}$. 14. I. $46^{*}, 6 \mathrm{I}^{\dagger} ; 2 . \mathrm{I}^{*}$ (1. -bhias), 2.

(cf. ápati, átithipati, ádhipati, ánnapati, apsarāpatí, ŗtupáti, gṛhápati, gópati, jāspatyá, tardāpati, dámpati, dhánapati, nidhípati, ṇ̛páti, paçupáti, pușțapáti, prajấpati, bớhaspáti, bráhmaṇaspáti, bhūtapáti, yajñápati, vaghāpati, vánaspáti, viçpáti, vratapati, vrājapatí, çácīpáti, çấlāpati, sátpati, sírapati, sthapáti, svapatí, pátikāma - patihan, pátni, $($ paty.)

pátiokāma: -mā. 2. 30. 5 .

pati oloká: -ám. 14. 2. 40". I8. 3. I. patiloké. I 4. I. 64. 
pati॰védana: -am. 2.36.2. I4. I. 17.

pativédanāu. 8.6.I. patihan in ápatihan. pattatás. 6. I3I. I. pattí: -tín. 7. 62. I.

pátn 1: 2. 12. 1. 3. 10.2. 7. 47.2. I2. I. I. I 4. I. 5 I.

patni. 3. I2. 5. 7.46.3. 9.3.6, 9 . pátnim. 7.6.2. 9.3.2I. I4. I. 49; 2. $2^{*}$.

pátniās. 9.3.5.

pátnis. 2. $26.5,7.49 .1^{*}$. 9. 7.6. I4. 2. 32 .

pátnībhis. 5.26. 4. I I.6. I9, 20. I 4 . 2. 5 I. I9. 58.6 (mss. pat-).

pátnīnām. 9.3.7. I 9. 57.3 (mss.). (cf. ádhipatni, áyușpatni, ékapatnī, gandharvápatnĩ, gṛhápatnī, devápatni, parjányapatnī, vasupátni, vătapatni, viçpátni, sámpatni, sahápatnī, síndhupatnĩ, supátni, súryapatnī.)

$\checkmark$ paty: pátyete (p. -eíti). 7.25. I. pátyamāne (p. -e íti). 5. 27. 8.

patvan in āçupátvan.

patos añgín: -nīs. 5. 2r. IO.

páth: pathă. 3. I8. $6^{*}$. 4. 3.2. 5 . 3I. I0. 6. 7. I; 82.2. I8. I. $61 ; 2$. II ${ }^{*}, 46 ; 4.60^{*}$.

pathás. 5. 30.7. 8. 2. I0. I0. 4.6. I3. I. $59^{*}$.

pathí. I4. 1. 63.

pathás. 5. 12. $2^{*} ; 27.2$. 6. II7. 3 ; I2I. 4. II. I. 36 . I5. II. 3 .

pathắm. 4. 3.5. 5. 1.6*. 6. 26. 2. 7. $9 \cdot I^{*}$.

(cf. patha, pathí, pathyà, pánthā pánthan, panthin páthas.)

p a tha in ápatha, prápatha, vadhūpathá, vipathá.

pathí: -thíbhis. 2. 34.5. 9.4.3; IO. II". I2. 2. IO, 29,4 I. I 8. I. $54^{*}$; 2. $53 ; 4.2,3,62,63$. I9. $27.9 ; 47.7$. pathīnăm. 9. 5. I9. (cf. pathikṛ́t-pathyà.)

pathi०kṛ̂t: páthikṛtā. I 8. 2.53. pathilự́tas. I 8. 3. $25-35 ; 4$. 16-24. pathikŕdobhias. 18. 2. 2*.

pathi orákși : -ṣi (p. -íti etc.). 8 I. 9 .

pathișádi : -dĩ (p. -i íti pathiosá-). I8. 2. $12^{\dagger}$.

páthișțha: -as. 6. 28. $\mathrm{I}^{\dagger}$. páthișțām (p. -iosthā-). I4. 2. 6t. path yà̀: pathía. I8. 3.39".

pathyà̀s. 3. 4. 7 .

pathíās. I8. I. $50^{*}$.

$\checkmark$ p a d: pádyate. 20. I36.3 (mss. șád-). padyantām. 3. I9.3. I3. I. 3 I.

padișța. 7. 3I. I*. 8. 4. Ió".

pannănām. 9.2.9. [I6. 8. I-2].

pādayāmi. I0.5.36. II. I. 12, 21 .

pādayāti. ro. $3 \cdot 3$.

pādayāthas. 9. 2.9.

pādáya. I0. 1. I7.

pādaya. 9. 2. I. I3. I.3I.

pādayasva. 6. 88.3.

pãdáyantam. II. 2. I8.

(cf. pattí, pád, padá, padya, padyamāna, páda.)

+ a nu: ánu padyatām. 6. 26. 2.

+ a p a: apaopádyate. 4. 28. 5 .

+ a va: avaopádyate. 6. 136.3.

ava॰pádyante. 5. 17.7.

áva ... padyatām. I. II. 4-6.

áva padyantām. 8. 8. 20.

avaopádyamānām. 5. I7.4.

áva ... padișța. 8. 4. $17^{*}$.

áva pādi. 8.6.20.

áva patsi. 6. I20. 2 .

áva patthās. 8 . 1. 4 .

áva pādaya. 9.2. 10.

áva ... pādaya. 8. 6. I6.

+ ā: ấ padyantām. 8. 8.18.

ầ 'pīpadāma. I0. $5 \cdot 42$.

āopádya. II. I. 30 .

$+\mathrm{ud}$ : útpanne. 20. I30. I3 (mss. utpánna).

+ ni: niopádyate. 8.6.7.

ní padyate. II. 4.25. I8. 3. I.

ní apadyanta. I4. 2.32.

(cf. anipádyamāna.)

[8. $2^{2}$.

+ pra: prá padye. 5.6. II-4. I9. pra॰pádyante. 9.6.5 I.

prá padyasva. 3. I9. $8^{*}$. II. IO. I8. 


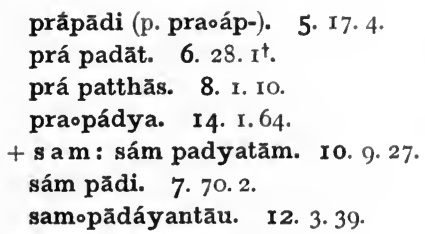

(cf. apád, așțâpad, ékapad, ghṛtápad, cátuṣpad, tripád, trípad, dvipád, dvípad, návapad, prápad, ríçyapad, çitipád, çvápad, șáțad, sárvapad, sahásrapad, pattatás, páḍbiça, patsañgín, padá, păda, padghoșá, padvánt.)

padá: -ám. 2. 12.8. 3. 10.6. 6. 70. $2 ; 76.2,3.7 \cdot 26.7^{*} ; 27 \cdot 3^{*} ; 29.1^{*}$. 9. $9.5^{*}$; IO. $\mathrm{I}^{*}$, I9. I0. I. $26 ; 4.24$; 8.6. 12. $2.30^{*}$. 18. $4.89^{*}$.

padéna. 6. 70. 2.

padăya. 3. $16.6^{*}$.

padé. 5. 6. $3^{*}$ (padé॰pade). 6.63 . $4^{*}$. 7. 27.1 .

padâni. 2. I. 2. 6. 28 . I $^{\dagger}$ 9.9. 9. $6^{*}$; I0. $27^{*}$. I2. 2. 28 . I 8. 3. $40^{*}$.

padă. 7. $26.4^{\dagger}, 5^{*}$. I $0.4 \cdot 7$.

(cf. ápada, adhaspadá, drupadá, prápada, próșțhapada, yajñapadá, çitipadá, çvấpada, saptápada, padajñă-padavt.)

p a d a $\circ \mathbf{j} \tilde{\mathbf{n}}$ à : -âs. 7. 75.2.

p a d a nf: -ts. rr. 2 . I3 (oiva).

pada 0 y 6 ana: -nena. 12. 2.29. padayópanim. 5. I9. I2.

p a d a vãyá: -ás. 5. 18. I4.

padavāyám. 12. 5.4 .

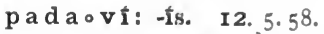

padoghoṣá: -şāís. 5.21.8.

p a d y a mān a in anipádyamāna.

pád yã: -ăbhis. 20. 135.8 (mss. padyă-).

padovánt: -átā. IO. IO. 13.

padvátĩ. 9. 3. I7. I 4. I. $25^{*}$.

padvátinnām. 9. I0. $23^{*}$.

$\checkmark$ pan: pánipnatam. 7. 32. $\mathrm{I}^{*}$.

(cf. pánīyas.)

p anişp a dá: -dă. 5. 30. 16.

pánìyas: -sí. I 8. $4.88^{*}$.

pánthan, pánthā: -thās. 4.2.3. I0. I. I5. I3. I. 23. I4. I. II". I8. 4 .

I4.

pánthānam. I2. I. 47 .

pánthām. 3. 3. 4. 6. 28.3. 8. I. IO; 9. I3; IO. I9, 20 . I I. I. $28,30,3$ I ; IO. I6. I2. $2.2 \mathrm{I}^{*}, 55$. I4. I. $5^{8 ;} 2$. 8, 74. I5. I2.5, 9. I7. I6. I8. I. $49^{*} ; 3.4 ; 4.3$. I9. 59. 3*.

pánthānas. 3.15.2; 31.4. 5.4.5. 6. 55 . I. 7. 55. I. I2. I. 47 . I 4. I. $34^{\dagger}$. (cf. páth etc., paripanthín.)

papivāns in ápapivāns.

pápri: -im. 12. 2. 47.

páyas: I. 4. I*. 2. 29.5. 3. 5. I; I7. $7^{*} ; 29.6 .4 .8 . \mathrm{I}$; II. $4 ; 27.3 .6$. 69. 3. 7. 73. $4,6,8^{*}$. 8. 2 . I9; 3. $17^{*}$. 9. I. 2 ; 6. 32 . I0. 6.31 ; IO. IO, 3 I. II. 5. I4. I2. I. 9, IO; 5. 10. I4. 2. 57. I8. $2.3^{\dagger} ; 3 \cdot 56^{\dagger}, 56^{*}$. I9. 31.5 ; 43. 5 ; 44. 5 . 20. 48.2 (not mss.), 3 ; I $30.2,3,4$.

páyasā. I. 35.4 . 3. I5. 2 ; 7.9 .4 . 8. 5 ; I4. 6 ; I5.6. 5. I. $9 ; 28.3 .6$. 53. $3 ; 62.1 ; 78.2 ;$ I 24.1 .7 .73 .6 ; 79. 3. I0. I. I2; 6.26. II. I. 7. I2. I. 59. I3. I. 8, 9. I 4. 2. $70^{2}$.

páyasas. $7 \cdot 73.5$. I8. $3 \cdot 56^{\dagger}$.

páyāṅsi. I. 9. 3. 5. 26. 10. I8. I. 18". páyobhis (p. -yahobh-). 9. 1. $8^{*}$; 10. 6".

(ef. payasá, páyasvant.) p a y a sá: -ám. 4. I4.6. 7. 39. I . 
páy a sva nt: -vān. 7. 73. $5 ; 89$. I. 9. I. I4; 4 . I, 3.9. I9. 33 I, $2 ; 46.6^{2}$. páyasvat. 3. $24 . I^{*}$. I8. $3 \cdot 56^{*}$.

páyasvantam. 3.24.2. 6. 59.2.

páyasvantas. 7.60. 2.

páyasvatī. 3. 10. I*; I2.2; $17.4^{*}$. 4. 38.3. 9. 3. 16. I2 I. 59 .

páyasvatím. I3. I. 27.

páyasvati (p. -i íti). 6.62. I.

payasvatĩ (do.). 2. 29. 5 .

páyasvatiss. 3. 24. 1. 4. 8. 4, 6. 6. 22.2. 8. 2. 14; 7.17. I8. 3. $56^{*}$.

páyasvatinām. 3. 24. I (1. -naam).

pára: -as. 9. IO. $14^{*}$.

páram. I. 8.3. 7. 35.3. 8. 3. 3* 9. 10. $13^{*}$. I0. 7.3 I 8.8 . II. I. 30 . I2. $2.21^{*}$. I 8. 2.32 . I9. 53.4 .

pare. I. I 7.2.

párām. 3. 18. $3^{*}$.

párena. 4. 3. $2^{3}$. 5. II. 5. 9. 9. $17^{*}$, I8t. I0. I. I6. I9. $47.8^{2}$.

párasmāi. I. 12.4 .

párasmāt. 3. 3. 4 .

[pará-).

párasya. I 3. 3. 5. 20. 34. I6 (mss. párasyās. 6. $34 \cdot 3^{*} \cdot 7 \cdot 26.2^{*} ; 84.3^{*}$. páre. 5. 2.6 $6^{\dagger}$. 9. 9. $12^{*}$.

párasmin. 6. 117.3 .

párāsas. I8. I. $44^{*} ; 3.2 \mathrm{I}^{*}$.

páre. 5. 24. I5. I3. I. 40.

párāis. I 8. $3 \cdot 48^{*}$.

párebhis. 12. 2. 29.

páreșām. 3. I. I ; 2. I, 6. 5. 3. $2^{*}$;

páreșu. 6. 36.3 .

(cf. áparipara, avarapará, parapar a ña in aparāparaná.

para má: -ás. I9. 54.6.

paramám. I. I3. 3 ; 25. I. 2. I. I, 2. 5. II. II. 7. 26. $7^{*}$. 9. IO. $13^{*}$, $14^{*}$. I0. $7.8,2$ I, 28 . II. I. 30 . I4. 2.36 . I8. I. $4^{*}$. I9. 54.5 .

paramám. 6. 75.2. I5. 6. 5 .

paraméṇa. 4. 3.2. I9. 56.5.

paramát. 7.63 .1 .

paramásyās. 3. 4.5.

paramásya. I3. 3. 5 .

paramé. 5. 17.6* 6. 123. I, 2.7. 5.3. 8. 9.8. 9. IO. I8*. I2. I. 8 ; 2. 7*. I3. I. 44. I7. 6-19, 24 . I8. 3 .
$7^{*}, 58^{*} ; 4 \cdot 30$. $\quad$ 9. $53 \cdot 3$.

paramăn. 6. I03. 2.

paramébhis. I9. 47.7 .

(cf. parameșțhín.)

p a r a meș t h í n (p. -meosth-) : -țhí. 4 .

11. 7. 8.5. IO. 9. 3. II; 7. I. I2.

3. 45 . I3. I. $6 ; 3.5$. I5. $6.9 ; 7.2$; I4. 12.

parameșțhin. I. 7.2. I8. 1. I7-9. parameșthínam. 10. 2. 20, 21 ; 7 . I $7^{2}$. I I. 5. 7. I9. 53.9.

parameșthínas. I0. 5.42 . I5. 6. 9. parameșthíni. I0. 3. 24 .

parameșțíni. I9. 9. 3 .

(cf. paramesthína.)

parameșthína (p. -meosth-): -am. I9. 9.4

paraçú: -ús. 7. 28. r. 8. 4. $2 \mathrm{I}^{*}$. paraçós. 3. I9. 4 .

paraçứn. II. 9. I.

páraçu: -us. 7. 28. r.

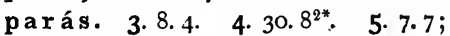
II. $5,6^{2}$. 6. 45 . I. 7. 7. I. 8. 2. I2; 4. $\mathrm{II}{ }^{*}$. 9. 4. $2 \mathrm{I} ;$ 9. $\mathrm{I} 7^{*}, \mathrm{I} 8^{*} ; 10.25^{*}$. IO. 7. 25. II. I. $29 ; 2.1^{2}$; 5. 10. I2. 3. 39 (paráḥoparaḥ). I4. I. 32 . I8. 2. $32 ; 3.7^{*}$. 20. 127. 10.

(cf. parastará-paraḥsahasrá, parókșa.)

p a r a s t a rá (p. -rạ̣ıta-) : -rắm. 5. 22. 7 ; 30.9. 6.67. I.

parástāt. 4. I6.4, 5. 6. 73. 3; 122. I, 4. 8. I. 10. I0. $7.43 ; 8.39$. I3. 2. $8,3 \mathrm{I}$.

parasphána: -as. I9. I 5.3 (mss.). párasvant: -vatas. 6. 72.2. 20. 131. 22 (mss. parasvatás).

(cf. părasvata.)

parahos ahasrá: -rấs. 8. 8. Ir. párā. 1. 23. 2. 2. 2.3. 4. 13. 5*. 5. 19. 6 ; 21.7. 6. 127.3. 7. 9. $\mathrm{I}^{*}$; 53.6; IO0. I. 8. 3. $13^{3 *}, 14^{*}, 16^{2^{*}} ; 8.24$. 9 . IO. II*. I2. I. $37 ; 2.55$.

(cf. parā $+\sqrt[V]{ } 2$ as, i, vi ...i, kram, gam, I gā, car, ji, tras, Idā, diç, dṛç, nI, upasam . . . nI, nud, pat, paç, pū, I pr, 2 pṛ, bhū, bhṛ, mŗ̧, yā, vac, vad, vadh, 2 vap, 
vah, çaǹs, I çr, sic, sū, han; and parāvát, párāñc.)

$\left[\begin{array}{ll}8 & 1.9\end{array}\right.$. párāñmanas (p. -ākoma-): -nās. parācá: -cấs. 2. 10. 5. 6. 97. 2"; I24. 2. 7. $42 . \mathrm{I}^{*} ; 53.3 .8 .9 .2$. I8. 2. 26.

parācṫna: -nāya. II. 4.8.

parācînā. 6. 106.2.

parāj a y a in akşaparājayá.

para ji t a in áparājita, ātmaparājitá. párā ñ c: -ãñ. 6. 29.3；67.3. I 7. 17. párāk. I0. 1. 16. [32-49. párāñcam. 6. 65. I. II. 3.26, 28, párāñcas. 4. 40. I-8. 9. 9. I9*. II. 9. 22.

párācas. 2. 25.5 . 3. 1. 4 *. 9. 9. 19 ". párācīm. 6. 29.3.

(cf. párāñmanas-parācîna.)

p a rā par a ṇ a in aparāparaná.

párāoparāitṛ: :tā. $\quad$ r 8. 4.48 .

parāopúr: -ras. I8. 2. 28.

p a rāobhú : -bhúve. I. 29.4 (inf.).

párā。bhūti: -is. I2. 5. 35 .

párābhūtyā. I6. 7. I.

párābhūtyās. I6. $5.5 ; 8.5$.

p ară y a ṇa (p. -rāoáyan-): -am. r. 34. 3. 6. $77.2^{*}$. 10. 4.7 .

parăyaṇe. 6. I06. I".

parāovát: -tam. 3. 18. 3". 6. 75 . 2. 8. I. 8.

parāvátas. 3. 4. 5. 4. 13. 2*. 6. 35 . I. 7. $26.2^{*} ; 84.3^{*}$.

parãvátas (pl.). 5. 30. I. 6. 75. 3. 8. 5.9. IO. IO. 2,3 . I2. 5.64. I8. 4.4 I. (cf. părāvata.)

parāovāká: -kấya. 6. I3. 2.

parāoçará: -ás. 8. 4. $2 \mathrm{I}^{*}$.

párāçara. 6. 65. x.

parā ○çá s: -sā. 6. 45. $2^{\dagger}$.

parāhat a in áparăhata.

pári. 3. 2.4. 4. 7. 5 ; 2 I. 7*. 5. 6. $4^{2 *}$. 6. I2. I ; 27. $2^{*} ; 28.1^{*}, 2^{2 *} ; 67$. I ; $125.2^{*}$. 7. 9. 4*; 71. I*. 8. 9. 18. 9. $2.5, \mathrm{I} 6 ; 5.6$. II. 2.20. I2. $3.3 \mathrm{I}$, 55-60. I3. I. I 7, I8 $8^{2}, 19,20,25^{2} ; 2$. $3,32,43,44,45^{2}$. I5. I2.7. I8. I. $35^{*} ; 2.58^{*} ; 3$. I2. I9. $24 . \mathrm{I}^{2}, 2,3,6$; $34.5 ; 35.4^{6} ; 44.6$. 20. I29. 8 . (with accus.). 1. 2.2; 17.4; 22.2; 34.5. 2. I. 4,$5 ; 4.2 ; 7.3,4^{3} ;$ I 3 . 3 ; 14.6. 4. $8.3^{\circ}$; I1. I2. 6. 37.2 ; 61.2 ; IOS. 5 ; 123.1. 7. 72. $2^{*}$. 8 . 2. 9,$26 ; 4.6^{*}$. 9. $5.2 ; 9.13^{*}$. I0. 8. 30,36 . 12. $3.25,33$. 20. 132. I 2 . (with abl.). I. IO. I, 4 ; 20. 2. 2. 33 . 3 ; 34.5. 3. 25.5 . 4. 9.9; 10. 1, 4; I5. IO. 5. 4. 2 ; I . $3 ; 30$ II. 6. 89 . I; $111.3 ; 116.3 ; 125.2^{2 *} ;$ I37. 2,3 . 7. $38.2 ; 45.1 ; 53.7^{*} ; 56.1 .8 .4$. $5^{*} ; 9.4,5^{2}$. 9. 4. 10; 8.8, 21. 10. I. $32 ; 7.25$. II. 2.4 . I 2. $3.35,40$, 53. I3. 1.26. 14.2. 44 . 18. 2.27 ; 3. $52^{*}$. I 9. $3.1 ; 26.1 ; 39.1,5 ; 44$. 8,$9 ; 52.4 ; 57.6$.

(cf. pari $+\sqrt[V]{ } 2$ as, ās, i, anu ... i, idh, Iñkh, rș̣, I kṛ, à + kṛ, I kṛt, kram, krī, I kṣi, kṣu, khyā, gam, I gā, grabh, grah, car, jā, tan, tap, I dā, I dI, dṛç, I dhā, ā + dhā, dhāv, dhṛ, nam, nah, ā + nah, ni, nṛt, paç, I pā, bandh, brū, bhū, bhūṣ, I mā, muș, yā, rakṣ, rap, ruj, vac, vad, 2 vas, vah, I vid, 2 vid, viç, viṣ, I vr, sam... vṛ, vṛ̣, vṛt, $\overline{\mathbf{a}}+$ vrrt, abhi ... $\overline{\mathbf{a}}+$ vṛt, vyā, çiş, çubh, 2 çru, sad, sic, sũ, ș̣, sřj, sṛp, skand, stṛ, sthā, sru, svaj, hi, hū, hṛ, hnu ; and parítas, paripanthín, párirathya, parivatsará, parihastá.)

pariokṣa vá: -ám. rg. 8.4 (s. mss. -ichav-), 5 (do.).

parikșavăt. I0. 3.6.

parikșít: 20. 127.8 (mss. -ichít). parikșítas. 20. 127. 7, 9, 10. pariocará: -rấs. I2. I. 9. pariojáa: -ấs. I9. 56. 6.

páriojman: -mā. 7. 14. 4 .

pariotatnú: -únā. I. 34.5.

parítas. ro. $7 \cdot 38$.

pariodhấna: -am. 8. 2. I6.

pariodhí: -ís. 4.9.1. 5.29.2, 3. 8. 2. 25 . I2. 2.44 .

paridhím. 8. 2. 9. 12. 2. $23^{*}$. [6. $15^{*}$. paridháyas. 9.6. 10. I3. 1. 46.19. pariopanthín: -nam. 3. I5. I. 
paripanthínas. I. 27. I. [2. $\mathrm{II}^{*}$. paripanthínas (pl.). I2. I. $32 . \quad$ I 4 . paripạna (p. -riopăn-): -as. 8. 5 . I. I9. 34.7 (p. -ripăn-); 35.3 . paripánạam. 2. $17 \cdot 7^{2} \cdot 4 \cdot 9 \cdot 2^{2}, 3 \cdot 5$ 8.6. I 9. 35.2 .

paripăṇāya. 4. 9. 2.

paripănāat. 4 . 20.8 .

pariobhúa: -ús. 3. 2 I. 4. 4. 33. $6^{*}$. 7. $79.4 ; 80.3^{\dagger}$. I3. 2. IO. I 8. I. $30^{*}$. paribhú (p. -út íti etc.). 4. 25. I. paribhúvas. 9. IO. $17^{*}$. pariomít: -tām. 9. 3. 1. parimita in áparimita. páriorathya: -am. 8. 8.22. pariorāpín: -ínam. 5.7.2. parirāpínas. I2. 4.51 .

pariovatsará: -ás. 8. 8.23. parivatsaráya. $6.55 \cdot 3$.

(cf. parivatsarina.

pariovatsarína: -am. 3. 10. 5 . pari ovargyà: -às. 9. 2. I4. pariovādá: -ám. I9. 8.4 . pári॰veças: -sas. 2. 32.5 . pari॰veṣá: -șát. 9. 6. I2. parioveșțry : -țăras. 9. 6. $5 \mathrm{I}$. pari çrút: -tam. 20. I27. 9 (s. mss. -isrú-).

pariṣád (p. -riosá-): -dam. I8. 3 . pariṣkandá (p. -riosk-) : -dāú. I5.

2. $1-4$.

pariṣkandás. I 5. 3. 10.

pa rișțhà (p. -riosth-): II. 2. 25 .

páriṣvajíyas (p. -riosv-): -sĩ. Io. 8. 25 .

párișvañjalya (p. -riosv-): -liasya. $9 \cdot 3 \cdot 5$.

pariostárạ̣a: -am. 9.6. 2.

pariosrút: -tam. 20. I27. 9 (s. mss.). parisrútas. 3. 12.7 .

pari॰havá: -ám. I9. 8.4.

pariohastá: -ás. 6. 8 I. I. párihasta. 6. 8I. 2.

parihastám. 6. 81.3 .

parīnáh (p. -riṇa- $\left.{ }^{\dagger}\right)$ : -hi. I9. 48. I (m. mss. párĩna-).

parīçāsá (p. -rioç-): -ám. 5. I4.3. paru in yathāparú, paruçás. paru०çás. 9.5.4.

parușá: -ás. 5.22.3.

parușásya. 10. 4. 2.

parușấn. 8. 8.4.

(cf. pāruṣeyá, pấruṣya, paruṣāhvá, páruṣṇi.)

pa ruṣ̄āh vá (p. -șåāh-): -ás. 8. 8. 4. páruṣñi: 6. I2.3.

párus: 4. 12. 2, 3, 7. [3. Io. páruhıparus. I. 12.3. 4. 9.4. 9. párușā. 4. I2. 2, 3, 7. [1. 8, 20. párūnș̣i. 9. 3.3; 6. 1; 8.18. 10. (cf. víparus, sárvaparus, paru, parușá, paruḥsrañsa.)

paru ḥosran̉sá: -ám. 6. I4. I.

paró kṣa: -șāt. I9. I5.6 (not mss.) parka in madhuparká.

parcana in upaparcana.

parjánya: -as. 3. 2I. Io. 4. Ir.4. 6. 4. I. 8. 7. 2 I. IO. IO. 7. I2. I. I2. 19. 10. $10^{*} ; 30.5$.

párjanya. 4. I5. 4 (mss. par-). parjanya. 4: 15.6 .

parjányam. I. 2.I; 3. I. I0. 2.19. I I. 6.6 (1. -niam).

parjányasya. 3. 3I. II.

parjánye. 6. 38.3 .

(cf. vātāparjanyá, parjányajinvita, parjányapatni.) [ $\left[3^{*}\right.$. parjányaojinvita: -tām. 4. I5. parjánya opatnì: 10. 10. 6 . parjányapatniāi. I2. I. 42. parṇá: -ás. 3. 5.4, 8. I 8. 4. 53 . parna. 3. 5.6, 7 . parṇám. 5. 25. I. 8. 7.12. parnất. $5 \cdot 5 \cdot 5$. I0. I. 29.

(cf. achinnaparṇá, áçvaparṇa, áraṭuparṇa, ādhíparṇa, uttānaparṇa, puṣkaraparná, pṛçniparná, çyenáparnaa, sahásraparṇa, suparná, parṇadhí-parṇaçadá.) parṇaodhí: -dhés. 4. 6. 5 .

pa rṇa $\mathrm{m}$ a ñí: -ís. - 3. 5. I, 5 . párṇamaṇe. 3. 5.2.

pa rṇa ça dá: -ás. 20. 135. 2 (mss. párṇaçaphá). [6. I6. par y a stākṣá (p. -taoak-): -șấs. 8. paryāya in 
paryāyiká: -kébhyas. 19. 22. 7 . and

pa ryā y ín:-ínas (p. -rioāyín-). 6. 76. (cf. paryāyiká.)

$[87.2 *$

párvata: -as. I. I4. I. 4.6.8. 6. párvatena. 8. 4. 19*. 12. 2. $23^{*}$. párvatāya. 19. 48.3 (mss.).

párvatāt. 2. 3. I. 5.25. I.

párvatasya. 4. 9. I. I2. $2.4 \mathrm{I}$.

párvate. 2. 5. 6*.

párvatās. 3.21. 10. 6. 12.3; 77. I ; 88. I*. 7.96. I. 9. 7. I2. I2. I. II. 17. 30. 19. 10. $8^{*}$.

párvatān. I. 12.3. 6. 17. 3. 10. 2. 18. II. 6. 10. I3. I. 47,53 . 20. I28. 14. párvatebhyas. 3. 3.3. 6. $52 . \mathrm{I}^{*}$ (1. -bhias). 8. 4. $4^{*}$ (do.).

párvatānãm. 2. 5. 5* 4 4. 9. 8. 5.24. 6. párvateșu. 2. 31.5. 4. 36.5. 8. 7. I7. 9. I. 18.

(cf. parvatíya.)

parvatiy a: -am. 19. 45.3 .

parvatîās. I9.44.6.

párvan: -va. I. 12. 2

párvaṇi. 2. 33. $7^{*}$ (párvaṇiopar-). 19. 48.3 (not mss.).

párvan. 12. 3.3I.

párvāṇi. I. II. I. 8. $3 \cdot 4^{*}$. II. 8. 12. I2. 5. 7 I.

párvā. I2. $5 \cdot 42$.

párvaosu. 2. 9. I. 6. I4. I. (cf. kañkáparvan, çatáparvan.)

párçāna: -ne. 8.4. $5^{*}$.

párçu : -um. I2. 3.3I.

párçavas. 9. 7.6. 10. 9.20. II. 3. I2. (cf. pārçvá.)

p a l a d á: -dăn. 9. 3. 17 .

paladănām. 9.3.5.

pală lá: -liă. 2. 8. 3 .

(cf. palālānupalālá.)

palālānupalālá (p. -lālåan-): -lāú. 8. 6. 2.

pa lă va: -vān. I2. 3. I9.

palāça in açvatthapalāçá, bṛhatpalāça.

palitá: -ás. 9. 10. $9^{*}$.

palitám. I. 23. I, 2.

palitásya. 9.9. I*. (cf. ápalita, pălitya.)

palijaka: -am. 8.6.2.

pálpūlana: -am. I2. 4.9.

pávana: -nena. 4.34.2.

pávanāis. I8. 3. I1 .

pava măn a in pāvamāná.

pavást a: -tāis. 4.7.6.

paví: -ím. 7.84.3.

(cf. ārdrápavi, kşurápavi, supa-

ví, pavinasá.)

p a vi tṛ́: -tă. 6. IIg. 3 .

pavitra: -am. 9.6.16. I9. 33.3. pavítreṇa. 6. I9. $3^{*}$; 5 I. I ; 115.3 .

I 2. I. 30.

pavítrā. 6. I 2 4.3.

pavítrāis. I 2. $3.3,14,25$.

(cf. ārdrápavitra, çatápavitra.)

pavinasá (p. -vion-): -săt. 8.6.2 I.

pavira in

pavírá。vant: -vat. 3. 17.3

$\checkmark$ pą̧, spaç: páçyāmi. 8.7.18. I7. 7 .

paçyāmi. 3. 13.6. 4. 20.4,8.

páçyasi. 8. 3. $5^{*}, 2 \mathrm{I}^{*}$. I3. $2.2 \mathrm{I}^{*}$.

paçyasi. I3. I. 39. I8. 2. 50.

páçyati. 4. 20. I. 6. 76. 2. II. 7. 23. paçyati. 4. I6. I; 20. I. I0. 8.32. paçyămas. I9. 53.3 (msss. páç-). páçyanti. 8. 9.9. 9. I. 3. 10. 8. 14. paçyanti. 7. 26. $7^{*}$. 8. 9.9. I3. I.

$39 ; 2.4$.

páçyāni. 4. 20. 2.

páçyāsi. 10. 3.6.

paçyãsi. I 8 . I. 54".

páçyāma. I. 7.5. I3. 2.36.

páçyat. 9. 9. $15^{*}$

paçyat. 2. I. I.

páçyema. 7.5.3. I9. 67. I.

paçyema. 6. 62.3; I20. 3 .

páçya. I3. 4. 48, 55 .

paçyd. 9. I0. $9^{*}$. I0. 8. 32. I4. I. $28^{*}$. páçyata. I4. 2.28*.

paçyata. I. 33. 4. 7.26. 6". I6. I. I2. páçyan. I2. 2. $7^{*}$. I3. $2.22^{*}$. I 4 . I. 57 .

páçyatas. I 9. 62. I (mss. paçyatá). ápaçyam. 9. IO. II". I8. 3.3.

apaçyam. 9. $9 . I^{*} ;$ I0. $25^{*}$. 
apaçyat. 4. I4. I. I 5. I.2. I9. 56. 2. paspaçé. 7.26.6*.

(cf. paçya, paçyata, spáç, spāça-

+ ati : áti paçyāmi. I 8. 2. 32. áti paçyati. 4. 5.2. I3. I. 45 áti paçyanti. 4. 16.4.

(cf. atipaçyá.)

+ a nu: ánu paçya. 18. 4.3. ánu ... apaçyat. 9. 9.9". anuopaspaçānás. 6.28.3. anu॰paspaçānám. I8. I. 49*.

+ a ntar: antáh paçyanti. 2. 27.3.

+ abhi: abhiopáçyatas. I0. 8.24.

+ ava: áva paçyata. 7.72. I*. 18. 4. 37 .

avaopáçyan. I. $33 \cdot 2^{*}$.

áva paçyate. 9.4. I9.

$+\bar{a}$ : à paçyati. 4. 20. I.

+ parā: párā paçyati. 4. 20. I.

+ pari: pári paçyasi. II. 2.25. pári paçya. 8. 3. 10*.

páry apaçyat. 9. 10. $3^{*}$

+ pra: praopáçyan. I3. I. 4 . pra॰páçyantas. 5.2. $5^{*}$.

+ prati: pratiopáçyati. 9.6.3. práti paçyati. 4. 20. I. 9. 6. 48 . pratiopáçyatha. 7. 13. 2.

práti paçyās. 4. 20. 5 .

práti paçyāsāi. 3. $4 \cdot 3$.

(cf. pratispáçana.)

+ vi: vi॰páçyāmi. I2. I. 33 .

viopáçyati. $4 \cdot 5 \cdot 5^{\dagger} ; 30.4^{*}$. 6. 34 . $4^{*}$. I0. I0. 34 .

ví paçyati. I0. 8. I9. I3. 4. I I, I9. I9. 53.6 .

vi॰páçyan. 9.5.3.

[yaté).

vi॰páçyate. 19. 32.8 (mss. -paç-

+ s a m: sám ... páçyati. 6. 34.4".

samopáçyan. I0. 8. I8. I3. 2.44,

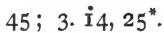

p a çú: -ús. I. I5.2. 8. 2.25. 9.6.6. paçúm. 8. 7. II. I8. 3. I8*. I9.6. I5". paçúnā. 8. 3. I 5 .

paçós. 19. 31. 8.

paçvás. 7. 14.3. I8. 3.23*.

paçávas. 2. 26. I, 2, 3; 34. 4. 3. IO 6; 31.3. 7.40.1; 66.1. 9. I. 20 ; 2. 5,$16 ; 7.26$. I0. 6.33 ; I0. 29. II.
2. 9,$24 ; 4.5 ; 5.21 ; 6.8$. I2. I. 49 ; 3. I6, 5 I ; 5. IO. I4. 2. 25 . I5. 2.2 ; $6.5 ; 15.8$. I6. $4.7 ; 8.1-27$. paçứn. 3. $28 . \mathrm{I}, 2,4,5,6$. 9. 6. 34 . I0. 3. I $2 ; 6.35$. II. I. I7. I5. 5. I-7; I4. 6. I9. 6. $14^{*} ; 48.5 ; 63.1$ (mss. -úm, -úmì); 7I. I (do.).

paçúobhis. 4. 36. 5. 7.8 8 I. 4, 5. 9. 3. I4. II. I. 22 . I2. 4. 2. I7. 6-I9, 2 I, 24 .

paçúobhyas. 4. II.2. I4. 2. I $8^{*}$. I5. paçūnắm. 2. 28.3 ; 34. I. 4. 22. 4 . 5. 24. $12 ; 28.3 ; 31.3$. 9. $4.6 ; 6$. 45-8. I I. 2. 28 . I2. 2. $53 ; 3.21$; 4 . 2I, 40. I3. I. 38 . I5. $2.2 ; 6.5$. I7. 4. I9. 3I. I (mss. -únām), 2: $5^{2}, 6$. paçúșu. I. 30.3. 2. 3I. 5 . I0. 3 . I6. I4. 2.62. I9. $3.2 ; 48.5$.

(cf. ánaștapaçu, álpapaçu, paçupáti-paçuhan.)

p a çu $\circ$ páti: -is. 2. 34. I. II. 2. 28 ; 6. 9. I5. 5.3.

paçupátim. I 5. 5.3

paçupate. I I. 2. 2, 5, 9, I I, I9, 24.

páçupatī (p. -i íti etc). II. 2. I.

paçu०bandhá: -dhăs. II. 7. I9. paçuovíd: Ir. I. I5.

paçuhan in ápaçuhan. [22.

pa çcá: -cấ. Io. 4. II ; 8.7. II. 4 . paçcăt. 4. 40.3. 6. 40.3. 7. 5 I. I"; 8o. I. 8. 3. $19^{*}, 2 \mathrm{O}^{*} ; 5.17 ; 6.15 ; 9$. 9. I0. 8. I0;9.8. II. $2.13 ; 6.18$. I2. I. 31,32 . I3. $2.27^{*}$; 3. II, $25^{*}$; 4. 7. I8. 4.9, II. I9. $6.9^{*} ;$ I5. 3,5 ; I6. I ; 48.4 .

(cf. ápaçcādaghvan.)

paçy a in atipaçyá, ugrampaçyá, māmpaçyá.

p a çy at a: I 3. $4 \cdot 4^{2}, 55^{2}$.

pásas: $4.4 \cdot 6,7$. 6. $72.2^{3}, 3$; IOI. 2 . 20. 136.9 .

pásasā. 20. 136. 2.

p a st y à: -tíānām. 9. 10. $8^{*}$.

VI pā: pāhí. 2. 35.4. 4. 32. 2". pāhi. 2. $16.3,4,5.4 .9 .6$, I0. 6 46. 2. 7. I06. I. I6. 5. I-6. I8. I. $34^{*}$. I9. $48.3,4 ; 55.6 ; 56.6$.

pătu. 6. 3. I, $2^{4}$. 
pātu. 2. $4.3 ;$ 28. I. 4. I0. I, 3, 5 . 5. $28.5,9^{8}$. 6. 4. I; 45. $3^{*} ; 47.1$; 53 . I. 8. $3.1^{*} ; 4.23^{2 *} ; 5.4$. I6. 4.4 . I 8. $2.55^{*} ; 3.25-8,49^{*}$. I9. I 7. I-5, 7 -10;20. $3 ; 27 . \mathrm{I}^{4}, 2^{2}$.

pātám. 6. 3. I.

pātam. 2. I6. I, 2.

pātấm. 6. 3.2, 3 .

pāta. 3. I6. $7^{*}$. I9. II. $5^{*}$.

pātana. 6. 3. I.

pằtu. 6. 3.1; 4. 2.

[19. $17,6$.

pāntu. 5.3. 9*. 7.64. 1. 10. 5. 22. (cf. páti pátñ̄ ?, I pā, pāna, pāyú, pitŕ ?, pītha.)

+ adhi: cf. adhipá.

+ ni: ní pāti. 9. 10. $23^{\dagger}$. ní pāhi. I 9. 47.5 (mss. ná p-).

+ pari: pári pãhi. 4. 19.8. 5. 3. 2* 6. II0. 2 ; II2. I. 7. 84 . I. 8. 3. $20^{*}$; 6.22. 17.9. 18. 4.9 .

pári ...pāhi. 2. 7. 3, 4. I 9. 44.6. pári pätu. 7. 51. I*. 8.6.21. I0. 3. 10. 17. 30. I8. 1. $19^{*} ; 2.55^{\dagger}$. I9. 20. I ; 32. IO; 33. I; 45. 5 .

pári ... pātu. 2. 4. 2. 8. 2. 26. I 9. $34.5 ; 35.4$.

pári pāta. I2. 2. 47

(cf. paripăna.)

$\sqrt{ } 2$ pā: píbāmi. 6. 135.2.

píbasi. 8. 2. 19 .

píbati. 5. 5.2.

pibati. 5. 18.4 .

píbanti. I. $4 \cdot 3^{*}$.

píbāt. 7. 14. 4.

pibāva. 4. 32. $7^{*}$.

píba. 7. 72. $3^{*} ; 73.11^{*}$. I9. 45.5 (mss. ápi vā).

píbā (p. -ba). 2. 5. I.

piba. 5. 25.6. 7.26.3; 76.6".

pibatu. 13. 1. 27. 20. 2.2-4.

pibatam. 7. 58. $1^{*} ; 73.4$.

pibatām. 2. 29. 6 .

pibantu. 20. 2. I (mss. -atu).

píbantis. 4. $21.7^{*}$.

ápibat. 20. 34. 2 .

apibat. 2. 5. $7^{*}$.

apiban. 10. 10. 30 .

papāu. 4.6. I. papiovăn. I4. I. 3".

papiovăñam. I 8 . I. 48 ".

papiovănsas. $7 \cdot 97 \cdot 3$.

apus. 9. 9.5".

päthás. 7.29. I.

pātám. 7. 73.5.

pătave. I2. I. 38 .

pítuâ. 2. 13. I. 10. I0. $3 \mathrm{I}$.

piyáte. 5.19.5.

pāyayāmasi. 8. 7.22.

apãyayat. I0. I0. 9 .

(cf. papi īàns, 2 pă pa, pătŕ, pă-

tra, pắna, pāyin, pāvan, pitú, piba, pĩtí, pîtha, peya.)

+ pra: pra॰píbanti. I4. I. 4 ".

prá pāsta. 12. 3.43.

práopītām. 6. 108. 2.

prá。pītās. 3. 16. $7^{*}$.

(cf. prapá, prapāna.)

+ s a m: sám pibāmi. 6. 135. 2.

sám pibāmas. 6. I35.2.

sam॰páya. 6. 135. 2.

(cf. sampibá.)

$\checkmark 3$ pā: pípānas. 9. 4.2I.

+ ud: utopípānas. 5. 20.7.

utopípānam. I3. I.31.

I p $\bar{a}$ in adhipá, abhiçastipâ, kulapâ, gopâ, tanūpá, nỉdhipấ, vratapâ, svapắ.

2 pā, p a in prapă, sutapá, somapá somapá, haviṣpá.

pän sú: -ús. I2. I. 26.

pānosún. 7. I09. 2.

(cf. pāñsurá.)

pāǹ surá : -ré. 7. 26. 4*.

păka: -as. 9. 9. ó* $^{*}$.

pấkam. 9. $9.22^{*}$. IO. I. 18.

păkena. 8. $4.8^{*}$.

pấkasya. 4. 19.3.

(cf. āpāka, sthălīpāka, păkabali, - pākaçañsá.)

păkabali : -is. 20. I3I. 15.

pāka $\mathbf{k}$ ○̧ańs á: -ám. 8. 4. 9".

pânta: -am. 12. 3. I0.

pấjas: 4. 31. 3".

(cf. pājasyà.)

$\mathrm{p} \overline{\mathrm{a} j} \mathrm{a} \mathrm{s} \mathrm{y}$ à : -àm. 9. 7. 5 .

pājasíam. 4. 14. 8. 
pājasíāt. IO. IO. 20. pấñ caojanya: -yasya. 4. 23. I. pāṭă: -ấm. 2.27.4.

pã ṇa in pratipāṇá.

pāṇí: -ínā. I2. 5.48.

pāníobhyām. 2. 33.6.

(cf. bhứripāṇi, viçvátaspãṇi, híranyapãni.)

$\mathrm{p}$ āta in utpáta.

pātin in sampātín.

pātṛ́: -tṛ̂n. 3. 12. 8.

pầtra: -am. 8. I0. 22-9. II.3. 9. I2.

I. $60 ; 3.8,37,48$.

pătre. 4.17 .4 . 5. 3I. I. I2. 3.25, $33,36,40$.

pătrāṇi. 6. I 42. I. 9. 6. I7.

pătrā. 8. 4.21*.

pătrān. 10. 10. 9 .

pătrāis. I2. 3.30.

pătreșu. IO. IO. II, I2.

(cf. antahpãtrá, ayaspãtrá, alābupātrá, āmapātrá, rajatapātrá, pátrahasta.)

pătra $\circ$ hasta: -tās. 9.6.51.

păthas: 2.34.2. 5. I2.10*.

pầda: -as. I9. 6.3*.

pâdãbhyām. 9. 8.21. I0. 7.39. II.

pấdayos. I 9.60. 2.

pấdān. 14. 1.60.

[vant.)

(cf. ékapāda, páñcapāda, pădapat d a ०vant: -vat. II. 8. II. [ṇa. $\mathrm{p}$ àn a in tanūpăna, nựpănạ, paripápána: -ne. 5.29 .8 .

(cf. devapăna, prapāṇa.)

pāpá: -ás. 5. 18.2. I9. 57.3.

pāpa. I9. 8.5 (mss.).

pāpám. 2. I2.5. 4. 36.8. IO. I. IO; 3.6. I2. $2.50 ; 5.48$. I8. I. I4*. I9. o. 5 (mss. apa॰p-); 9. I4.

pāpáyā. 5. I7. I8. 7. 56.6; 65.2. I4. I. $27^{*}$.

pāpáya. I 3. $4 \cdot 42$.

pāpăt. 7. IOO. I. IO. I. II ; 3.4.

pāpi. 7. II5. I.

pāpís. 7. II5.4. 9. 2. 25.

(cf. bhadrapāpá, manaspāpa, pāpakṛ́t-pāpmán.)

pāpaokŕft: -te. I0. I. 23 . pāpa okṛt yă: -yáyā. 3. 3I. 2.

pāpa $\circ$ kŕt van: -vānam. I9. 35.3. pāpa 10 ká: -kăn. I2. 5.64. pāpa 0 vã dá: -dăt. I0. 3.6. pà pi șt ha: -țhās. 7. 115.3.

pāpmán: -má. 6.26.2. I2. 5.30.

I7. 29. I9. 32.9;36.2.

pấpman. 6. 26. I (mss. pā-).

pāpman. 6. 26. I, 2 ; II3.2. [3.18. pāpmănam. 4. I8.3. 8. 10.28. I2.

pāpmánā. 3. 3I. I-II. I0. 7. 40.

pāpmáne. 5. 14.6.

pāpmănas. II. 8. I9. [man.)

(cf. jagdhápāpman, ájagdhapāppāmán: -mnấ. 5. 22. I2.

pā y in in somapāyin.

pāyú: -yávas. 6. 3.2.

pāyúobhis. I9. 47.5.

pārá: -ám. 3. II. $3^{*}$. 6. I33. I. I9. 47. $2^{3}$.

pāré. I. 27. I. 6. $34.5^{*}$.

(cf. ákūpāra ?.)

pāraṇa in utpărana.

pāra yișnú: -ús. 6. 92.2. 8. 2.28

(m. mss. -núu).

pārayișṇú. 5. 28. I 4.

pārayișṇu (p. -úúti). I9. I3. I.

párasvata: -am. 6. 72. 3 .

párāvata: -tebhyas. 20. 135. II.

pārușe yá: -ás. 5.22.3.

páruṣya: -am. I2. 5.30.

párthiva: -as. I4. I. $3^{\dagger}, 5^{*}$.

pârthivam. 4. I. 4. I9. 47. I.

pấrthivāt. 8. $4 \cdot 23^{*}$.

părthivasya. 2. 29. I

pârthive. I8. I. $46^{*}$.

părthivãs. 9. 5. I4. I0. 9.6. II. 5. 2 I ; 6.8. I9. II. $2^{*}$.

pắrthivāsas. 7.49. I". I9. II. $4^{*}$. pấrthivāni. 4. 25.2. 7. 26. I*

părthivebhyas. I6. 4.4.

părthivānām. 2. 28.3. (cf. pārthivāntarikșá.)

pārthivāntarikṣá: -șât. I9.9.7. (mss. părrthivāntárikșāt; p. -vā an-).

pārçvá: -ám. 4. I4.7, 8. I2. I. 34. pãrçvé (p. -é íti). 9. 4. I2； 5.20. pārçué (do.). 9. 8. 15. II. 8. I4. 
pārçuăbhiām. 2. 33.3. părşțeya: -am. 2. 3I. 4 . pắrṣṇi: -ṇiā. 6. 42.3. 8.6. 17.

părş̣̣ı (p. -1 íti). ro. 2. I. pắrşniobhyām. 2. 33. $5^{*}$. părșṇios. 6. 24. 2.

pắrșṇis. 8. 6. 15.

pāla in apãlă, āçāpãlá, dhanapālá, nākapālá.

Vpălay: + a nu: anuopāláyantí. I8. 3. I.

pálity a: -am. II. 8. I9.

pā va in hiraṇyapāvá.

pãvaká: -ás. 6. 47. I. 8. 3. $26^{\circ}$. pãvaka. I3. 2.2 $I^{*}$. I 8. 4. 59* pāvakấs. I. $33.1,4.6 .62 \cdot 3$. 12 . 2. II, 28 .

pã van in asriłrpăvan, ghṛtapăvan, somapăvan.

pāva māná: -ám. Ir. 7.6.• [-ním), pāvamāním. I9. 7 1. I (mss. -ní, pă ça: -as: 9. 3.2.

[3.24.

păçam. 2. 8. 1. 3. 7.4. 7. 83. $3^{*}$. 9. păçăt. 2. 10. 1-8,6. 4. 36. 10. I4. I. I9*, $58^{*}$. I6. 8. I-27.

pâçe. 2. 12. 2.

păçās. 4. 16.6. 14.2. 49.

păçān. 6. II2. I, $2^{2} ;$ II 7. I ; II 9.2 ; 121. 1. 7. 77. $2^{*}, 3 ; 83.4$. 9. 3. 13, I4. I3. 3. I-25. I4. I. 56, 57. I6. 6. Io. I8. $4 \cdot 70$.

pắçãis. 3. 6.5. 4. I6. 7, 9. 6. I12. 3. I9. 66. I.

[44. 4 .

pắçebhyas. I. 3 I.2. 8. I. 3. 19. pấçeșu. 12. 4. 37.

(cf. kavacapāçá, jyāpāçá, bandhapāçá, mṛtyupāçá, supāçá, pāçín.)

pāçín:-nas. 5.6.3**7. 117. I*. 17.8.

piñgá: -ás. 8. 6. 6, I8, I9, 21, 24.

pínga. 8. 6.25.

(cf. piñgalá.)

piñgalá: -ás. II. 5.25. and piñgalikấ: 20. 136. I4, I6. pi $\mathbf{n} \mathbf{j}$ in tilapiñji.

pitāputrá: -rāú. 6. II2. 2.

pitāmahá: -ás. 5. 5.1. II. 7.16. I5. $6.9 ; 7.2$. pitāmahám. 9. 5. 30 pitāmahásya. I 5. 6.9. $\quad\left[4^{6+}, 59\right.$ pitămahăs. I I. I. I9. I8. 2. 49;3 pitãmahắn. I 8. 4.35.

(cf. prapitāmahá.)

pitú: -ús. $4 \cdot 6 \cdot 3$.

pitvás. 8. 4. 10*. I8. I. $45^{\circ}$.

pitṛ: :tă. I. 24.3. 2. 1. $2,3^{*} ; 9.2$; 13. $\mathrm{I} ; 28.4$. 3. $9 . \mathrm{I} ; 23.6 .4 .5 .6^{\circ}$; 9. 8 ; I5. 12*; 19. 5. 5. 4.9; 5.1, 8 ; 13. $7 ; 24.12 ; 30.5$. 6. $16.2 ; 46.1$; II6. 2 ; $120.2 ;$ I3I. 3 . 7. 6. I*. 8 . 6. 7 ; 7.2. 9. $4.2,4^{2} ;$ 9. I $5^{*}$; 10. $12^{2 *}$. I0. $3.8 ; 6.5 ; 8.28$. II. $4.10,20$; 7. 15,$16 ; 8.18$. 12. I. 12; 3. 5, 12. 13. 3. 19. 14. 2.37. 15.6.9; 7.2. I8. I. $59^{*} ; 3.67^{*} ; 4.56$. I9. 39.3 ; 53. 4,8 .

pítar. 6. 4.3.

pitáram. I. 2.1 ; 3. I-5. 4. I. 7 ; 30. $7^{*}$. 5. I. 8 ; II. II ; I 4. IO. 6. 3 I. I*; IIO. 3 ; I2O. I; I40. I-3. 7. I. 2 ; 2. 1. 8. 9. 7. 9. 5. $30 ; 9.8^{*}, 12^{*}, 18^{*}$, 2I*. IO. I. 25 . II. 2. $29^{*}$. I 4. I. I5t. I8. 4. 35. [57.2* pitré. I. 3I. 4. 5. II.I. 7. 14.3; pitúr. I. I4. 2. 2. I. 2. 3. 25.5; 30. 2. 6. II6.3. 7. 2. 1. 9. 9. $15^{*}$. I5. 6 . 9. I8. I. $I^{*} ; 2.49 ; 3.4^{6+}, 59^{\circ} ; 4.5^{6}$ (mss. -ur). I9. 47. I.

pitárāu. 6. 120. 3 .

pitarāu. I4. 2.37.

pitárā. I8. I. $23^{*}, 31^{*}$.

pitrós. 20. 34. 16 .

pitáras. I. 30.2. 3.27.2. 5. 24 . I5. 6. 116.3. 8. 10. $19,23^{2}$. 9. 2. I9. I0. $6.32 ; 9.9$; IO. 26 . II. I. I9; $5.2 ; 7.27$. I2. 3.34. I4. 2. 73 . I 8. I. $42^{*}, 44^{2 *}, 47,50^{*}, 54^{*}, 55^{*}, 58^{*}$ : 2. $26,29,48,49 ; 3$. 10, $21^{*}, 45^{*}, 46^{*}$, $52^{*}, 59,72 ; 4 \cdot 36,40,44 ; 5 \mathrm{I}, 52,68$, $86^{2}, 87$. I9. II. I*; 56.4 .

pítaras. 2. 12. 5. 6. 123. $3^{2}$. I8. 3. I6. pitaras. 4.15.15. 7.12.1. 9. 5 . II. I2. 2. 33. I8. I. $5 \mathrm{I}^{*}, 52^{*} ; 3 . \mathrm{I} 4$, I9 (mss. -tár-), 43* $44^{*} ; 4.62,63,64$ (mss. -tár-), 812, $82-5^{2}$.

piț̣̂n. 5.30. I. 8. 1. 7; 8.15; ro. 
I9, 23. 9. 9. 10*. I I. 6. I I, I6；9. 24. pípilikāváța).

I4. 2. 69. I5. 14. 7. I 8. I. $45^{*}, 5^{*}$, píppa la (s. mss. písp-): -am. 9. 9. $57 ; 2.4^{\dagger}, \mathrm{II}^{*}, 23,34,46 ; 4.40,4 \mathrm{I}$. pitŕobhis. $6.63 .3 ; 7$ I. 2 . I2. 3.8 . I8. I. $43^{*}, 60^{*} ; 2.21 ; 3.8,58^{*}$. pitṛ́obhyas. 5. 30. I2. 7. 14.4. 8. IO. I9. IO. I. II. I2. $2.32,34 ; 4$. 32. I4. I. $46^{*} ; 2.20$. I8. I. $46^{*} ; 2$. $5^{*}$, 10*, $27,49,54^{*} ; 3 \cdot 42^{*} ; 4 \cdot 39,50$, $5 \mathrm{I}, 65^{*}, 73,78,79,80$.

piț̣năăm. 2. 12.4. 3. 29.4. 5. 24. I4. 6. 44.3 .7 .68 .2 . I0. 5. I3. II. I. 5. I2 2. 9,45 . I8. $3.63,73$.

pitŕșu. I. I4. I, 3. 5. 19.5. 7. 4 I. 2. II. I. 28,3 I. I2. 2. 10. I 8. 2. 25,28 , $52 ; 4.48,49$. I9. 3. 3 .

(cf. pitāputrá, pitāmahá, piț̣́kṛta -pitṛșádana, pítrya.)

pitŕn kṛta: -tāt. 5. 30.4. pitrobandhú: I2. 5.43 . pitŕ $\circ$ m ant: -mate. I8.4. 72, 74 . pitṛ॰yajñá: -ñáya. I2. 2. $7^{*}$.

pitṛyăna (p. -tṛoyăn-): -am. 5. I8. I3. 8. 10. 19. I5. 12. 5.

piț̣yănāas. 6. II7.3.

pitṛyănạais. 12. 2. 10. I8. 4. I, 62.

pitṛoloká: -ám. I8. 4.64. pitṛlokât. I4. 2. 52 . $20^{*}, 21^{*}$.

(cf. supippalá, pippali.)

pippali (s. mss. piṣp-): 6. IO9. I. pippalyàs. 6. ı09. 2.

piba in sampibá.

pí y ā r u :-us. I 9. 57.5 (m. mss. pípā-). píyārum. I9. 57.4 (m. mss. pípā-). píyārūnām. II. 2. 21 .

$\checkmark$ p iç: piñçá. 19. $28.9^{4}$. piñçatu. $5 \cdot 25 \cdot 5^{*}$. ápinçat. 5. 12. 9*. pipeça. I4. I. 60. piçitám. 5. 19. 5. 6. 127. I. piçită. 12. $5 \cdot 36$. pișțás. I 9. 49.8 (not mss.). piçyámānā. I2. $5 \cdot 36$. pépiçāne (p. -e íti). 8. 9. I2. (cf. piç, piçá, piçáñga, piçācá, píçuna, péçana, peças.)

piç in çukrapíç.

pi çá: -ásya. I9. 49.4 (mss. piñsáaya, pișá-).

piçáñ ga: -am. I4. 2.48 . piçánge. 3. 9. 3 . (cf. piçáñgarūpa, piçáñgasamareç.) pi tṛşá d (p. -tṛosá-): -dam. I 4. 2. 33*" pitṛşád a na (do.): -ne. I8. 4. 67. pitṛşádanās. I8. 4.67 .

pittá: -ám. I. 24. I. I8. 3.5.

pítrya: -riam. 6. I22. 2. pítriā. 4. I. 2.

pítriāt. 6. I20.2. I0. I. I2.

pínāka: -am. I. 27.2.

$\checkmark$ pinv: pinvatam. 6.97.2.

pinvata. 6. 22. 2.

pinván. 9. 5.34.

pinvántam. 9.5.34.

pinvatím॰pinvatím. 9. 5.34.

pínvamānas. 4. 34. 8. I 8. 4.35 .

pínvamānā. 3. 17.9 .

pínvamānās. 4. 34. 5-7.

pi pil á: -ás. I 8. 3. $55^{*}$.

(cf. pipílikā.)

pipilikā: -ās. 7.56.7. and

pip I likãvațá: -ás. 20. I34. 6 (mss.

piçáñ a $\circ \mathbf{r} \bar{u}$ pa: -as. 9. 4. 22

pi çáñ ga os a mọ ŗ : -çam. 6. 33. 3.

piçācá: -ás. 5.29.4,6. I2. 3.43. piçācám. 4. 20. 7, 9. 5. 29. 10. [6-9. piçãcấs. I. $35 \cdot 2 . \quad 4 \cdot 36.7,8$. 5. 29. piçācās. 6. 32. 2.

piçācắn. 4 . 20.6;36. 4 ; 37. I0. 8. 2. I2. I2. I. $50 ; 3.15$.

piçācāís. 4. 36.7. 5. 29.5.

piçācănām. $4 \cdot 36.6$.

piçāciâs. I. I6.3.

(cf. piçācakșáyaṇa - piçācajámbhana.)

pi çācaokṣáyaṇa: -am. 2. I8. 4 . piçāca ocătana: -am. 2. 18.4. pi çã ca ojá m b hana:-nís. 5. 29. I4. píçuna: -nebhias. 8. 4. 20*.

$\checkmark$ piș: piṇḍí. I9. 29. $6^{*}$. pinșánti. 20. 136.7 (not mss.). ápīşan. 4. 6.7. piștâás. 12. 2. 53 . 
(cf. péșțra.)

+ ā: à pinașți. 20. I33. I (mss. ā p-).

+ ni: níopișțāsas. I0. 4. 13, 20.

+ s a m: sám pinașmi. 2. 32.3.

sám ... pinașmi. 2.31. I.

sam॰pinşánti. I4. 1. $3^{*}$.

sám pinaşțana. 8. 4. $18^{*}$.

sám。pișțas. 4. 3. 5. 6.6.2. I9. 49.

VI pi, pi: páyate. 9. I. $8^{*}$; 10.6*. (cf. páyas, piyúșa, pívan, pívas, Vpyā, Vpinv.)

+ ã: ầpīnām. 9. 1.9.

+ pra: práopinam. II. I. 34 .

práopinām. 7.15. I.

práopinnās. I2. 3.4 I. I 8.4 .6 .

$\sqrt{ } 2$ pi, piy: piyatas. 5.18. 15.

(cf. píyaka, pĩyu.)

$\checkmark$ pi di: pịdaya. 12. 5. 70.

pItí:-táye. I. 6. $\mathrm{I}^{*}$. 7. $58 . \mathrm{I}^{*}$.

(cf. sómapiti.)

I p I th a in gopithá.

2 pitha in somapithá.

pibas, see pivas.

[7. 3 .

pI b a s phāká (p. -aḥophā-): -ám. 4 . pìy a k a: -kān. I6. 6.8.

pi y u in devapīyú.

pİ úşa: -as. 9. 4. 4 .

piyúșam. 8. 3. $17^{*} ; 9.24$. 20. 131 . 2 I (mss. pūșakam).

pilā: $4 \cdot 37 \cdot 3$.

pîlú: 20. I35.12. (cf. pīlúmant.)

pīlú ○m an t: -matī. I8. 2.48.

piv a n: -vari. 20. I36. I2 (not mss.), I6 (mss. pivarí).

pivarim. 3. 17.3 .

pívas, pìbas: -bas. 9. 7. 18 . pívas. 20. I3I. Io (mss. pīvás).

pivasā. 18. 2. $58^{*}$.

píbasi. I. II. 4 .

(cf. pībasphāká.)

$\mathbf{p u}$ in supú.

pự çcalá: -lì. I5. 2. I-4.

pumosúvana: -am. 6. II.I.

púcha: -am. 9. 4.13; 7.8. I0. 9 . 22. 12. 5.21 .

púchena. 7.56.8.

púche. 7. 56.6. (cf. puchadhí.)

pucha。dhí: -dhāú. 7. 56.8.

puñjişțha in pãuñjișțhá.

puṇ ḍáríka: -am. - I0. 8.43.

(cf. puṇḍárìlkavant.)

p u ṇ ḍ́ ríka pún ya: -yã. 12. 5. 6 .

púṇyam. 8. 10.272. 9.5.16. 19.

$7.3,4 ; 8.5 ; 56.5$.

púṇyās. 7. 115.4 (1. -ṇiās). I5. 13.

I-5. I9. 54.5 .

púṇyān. 19. $54 \cdot 5$.

púṇyānām. 15. 13.4.

(cf. puṇyagá-puṇyajaná.)

p uṇya॰gá: -ás. I9. 8.5 (mss.).

pú ṇy a g a ndhi: -is. 8. I0. 27.

púnyagandhe. 8. 10. 27.

púnyagandhayas. $4 \cdot 5 \cdot 3^{\dagger}$.

púṇagandhīni. I9. 8.5 (not mss.).

pụ̣ya ojaná: -nắn. 8. 8. I5. II. 6. $16 ; 9.24$.

putrá: -ás. I. $25 \cdot 3.3 .23 .2 ; 30$. 2. 4. 39.9. 5.1.8; 14. 10. 6. 46 . 2. 7. I. $2 ; 6 . I^{*}$. 9. 9. $15^{*}$. 10. 8 . 28. I2. I. $12 ; 3.47$. I3. $2.9 ; 3.26$. 14. I. I5*; 2.24. 16. 5. I-6. 19. 53 . $4 ; 54.3$ (ed. mántras). 20. 34.16 (mss. bhúvas); I28. 3, 6, 7.

putra. 4. 16.9.

putrám. I. $11.5 ; 28.4$. 2. 28. I. 3 . 16. $2^{*} ; 23.3,4,5$. 5. 1. $9 ; 20.5 ; 25$. 9 , 10-3; 26.5. 6. 8 1. 2, 3. 9. 5. 30 . I0. 5.44 . II. $4.10,20 ; 9.8$. I3. 2 . 37. I6. $8 . \mathrm{I-27}$. I 8. $2.50^{*} ; 3.50^{*}$; 4. 39. 20. 129. 5 ; 130. 15 .

putrầya. 12. I. 10.

putrăt. 6. II6.3.

[2.35.

putrásya. 6. II. I, 2. I0. 5.36. I2. putré. I6. 7.8 .

putrāú. 8. 7.20.

putrăs. I. 30.2. 3. 4.3. 9.9. 13*. I2. $3 \cdot 34,40$.

putrăsas. $7 \cdot 57 \cdot 2^{*}$. 18.1 . $2^{*}$.

putrāsas. 12. 3.4.

putrằn. 2. 13.1; 36.3. 6. 120.3. 12. $3.12 ; 4.38$. 14. $2.4^{*}$. [1.22*. putıāís. 6. 4. I. I2. 3.6, I7. I4. putrébhyas. 6. 30.3. I0.6.5. II. 
8. I0. I2. 3. II. I8. 3. $43^{*}$ (1. -bhias), $67^{*}$ (do.).

[3. 7. 7. 1 . putrănạăm. 2. 9. 2. 3. 23.3. 6. 131 . (cf. aștáputra, índraputra, jiváputra, deváputra, pitāputrá, çúuraputra, saptáputra, suputrá, sómaputra, pāútra, putraká $-\sqrt{ } /$ putriy.)

putraká: -kắs. 20. 127. 5 (not mss.). putrá。kāma: -mā. II. I. I. putraokām yấ: -miá. 6. 8r. 3 . putra。vídya: -yāya. 3. 23.6. putrín: -ínim. I4. I. 62.

Vputriy: putrioyánti. I4. 2. $72^{\dagger}$. púnar. I. I. 2 ; 24. 4. 2. 24. I-82. 3. I. 6 ; 6. 7 ; 9. I; 10. 7 ; I1. 6.4 4. I2. 2 ; 3 . $\mathrm{I}^{2 *}$. 5.8.7 ; II. 8 ; 14. 4, 5, 7, 8, I0, I2, I3; I 7. $2^{*}, 1^{3^{*}} ; 22.4$, II ; 29. 5 ; 30. 7 ; 31. I-9. 6. 53. $2^{4} ; 63$. $2 ; 75.2,3 ; 77.3 ; 78.1 ; 84.3$; I09. 3 ; III. $4^{4}$; I3I. 3 ; I39. 5. 7. 5. 2 ; 9. $4^{*} ; 53 \cdot 3^{2} ; 66.1 ; 67 \cdot \mathrm{I}^{3}$. 8. 1. $20^{*}$; 2. 1 ; 4. $3^{*}$. 9. 2. I2. IO. I. 24,30 ; 4. 4. II. I. I3. 25 ; 4.14 , 2O. I2. 2.5 , $6^{3}$, 10, 52 ; 3. 20,48 . I3. 2.25 . I4. I. $4^{*} ;$ 2. $2^{*}, 10^{*}, 47^{*}$. I8. 2. $10^{*}, 13^{*}$, $26 ; 3.6^{*}, 58^{*}, 70 ; 4.63,64$. I9. $6.2^{*}$; $8.3 ; 44.10 ; 46.4 ; 49.7 ; 54 . \mathrm{I}, 3$ (not ed.). 20. 132. 12 (púnah-pu-).

(cf. púnarṇava-punaḥsará.)

pún arṇ ava (p. -aḥona-): -as. 8. I. $20^{\dagger}$. I0. $7.33 ; 8.23$.

púnarṇavās. 8. 7.8.

puna rdày a (p. -aḥod-). 5. I 7. II*. punardi y a mā $n$ a in ápunardiyamāna.

pun a r b hú (p. -aḥobh-) : -bhúvā. I. 27. 2. 9. 5. 28.

pún armagh a (p. -aḥoma-): -as. 5 . II. 2. 7. I. 2.

púnarmagha. 5. II. 2.

púnarmagheșu. 5. II. 7.

pún a r v as u: -sū. I9. 7.2 (p. - -ū íti púnaḥov-).

punaḥosará: -ás. 6. I29.3.

punaḥsarám. I0. I. 9. punaḥsarắm. 4. 17.2.

púmāìs, púm s: púmān. $\quad$ I. 8, I.
3. 6. $1 ; 23.2,3.5 .14 .6 .7 .95 .3 .9$. 4. 3. I0. $4.8 ; 7.43^{2 *} ; 8.27$. I2. 3. I. púmāṅsam. 3. 23.3. 5. 25. 10-3. 6. I I. 3. 8. $4.24^{*} ; 6.25$. I I. I. 34 . pừnsé. 5. 30. 3 .

pựás. 3. 6. I. 6. 70. I-3. I2. 3. I. pửíí. 6. II. 2.

pửisás. 9. 9. $15^{*}$.

pựaấm. 4. 4.4. 7. 13. I. 20. 129. 14 (not mss.).

pửosú. I2. I. 25.

(cf. pựçcalá, pựsúvana.)

púr: pứr. I0. 2. 3I.

púram. 5.28. II. 7.7I. I*. I0. 2. 28, 29, 30, 33. I9. I 7. I-IO; 19. I-I I. púras. I0. 6. IO, 20. I2. I. 43. 19. 58. $4^{*}$.

(cf. puramiaará, pūryănạa, purā.) pur in nipúr, parāpúr, púramdhi (?). pura et ̣̂ (p. -raḥoet-) : -tâ. 3. I5. I ; 16. $5^{*}$ 5. 20. I2. 7. 8. I. I0. 3. 2. puramodará: -ás. 8. 8. I.

pú ra mod h i :-is. I4. I. 50*. I9. I0. $2^{*}$. purás. I. 27.4. 6. 31. I*; 40.3； 52. I. 8. $5.17 ; 6.15^{2}$. 10. 8.7. II. 4 . 22. I9. $6.9^{*}$; 15.6 (mss.); 48.4 .

(cf. puras $+\sqrt{ } \sqrt{ } \mathbf{i}$, I gā, I dhā, sr ; and purástāt, purogavá.)

purástāt. I. 7. 5. 4. I. I ; II. 4; 40. I. $5.23 .6^{*} ;$ 29. I. 6. 60. I. 7. 9. $4^{\dagger}$; 5 I. I* I $^{*}$ 8. I. 8. 3. $19^{*}, 20^{*}$. I0. 3. $2 ; 8$. IO. II. I. $32 ; 2.4,17 ; 6.18$. I2. I. $13,32,55 ; 3.24,37$. I3. 3 . II. I8. $2.55^{*} ; 3.49^{\dagger} ; 4.9$. II. I9. 15 . 3,5 ; I6. I, 2 ; I 7. I; 56.6 .

puraḥos ará: -rāú. I5. 2. I-4. pura in jivipurâ, devapurá.

purâ. 5. 30. I7. 6. I 2.2; 33.2; 99. I. 7. $25.2 ; 70$. I. 9.6. I2. I0. 2. $30 ; 3.16^{2} ; 7 \cdot 31^{2}$. II. I. 5,$15 ; 3$. $56 ; 8.3$, IO. I2. 3. 46 . I3. 2. I3. I4. 2. $47^{*}$. I 8. I. $4^{*} ; 2.3^{8-45}, 57 ; 3.30-$ 5 ; 4.56 . I9. 34.8 ; 54.3 (mss. púnạ̣, púraḥ); 56. 2.

(cf. purāṇá.)

p u rā ṇá : -ám. I0. $7 \cdot 26^{2} ; 8$ I 7 . II. 7.24. I5. 6. 4. I8. 3. I. purānásya. I5. 6.4. 
purāṇt. 10. 8.30.

purāṇts. I2. 2.41 .

(cf. purāṇavát, purāṇavíd.)

purānaovát. 7.90. I".

purāna०víd: II. 8.7.

puríkáy a: -yās. II 2. 25.

purítát (p. -riot-). 9. 7. I r. Io. 9.15.

purişa in

purişín: -ínam. 9. 9. 12*.

purīsínas. II. I. 32 .

purú: -ús. I9. 6I. I.

purú. 7.21. I.

purú (p. -rú). 6. 49.3". I8. I. I".

purúnịi. 5. 1.2.

purú (pl.). r9. 49.4.

pūrvis. 4. $21 . \mathrm{I}^{*}$.

(cf. purukṛ́t-puruçăka, puru-

sțutá-purūvị́t, purváñc.)

puruokṛ̂t: $7 \cdot 72 \cdot 3^{\dagger}$.

puruokṣú: 5.3. $8^{+} ; 27$. 10 .

puruojātá: -ás. I9. IO. $2^{*}$.

purú ṇāman (p. -rúonā-): -mānam. 6. 99.1 .

puruotráa. 4. 30. $2^{*}$. 6. I26. I". Io. $2.6 ; 8 . \mathrm{I} 2$.

puruodáma: -māsas. 7.' 73. I.

puruodhá. 7. $5.5 ; 82.5$.

puruomị ḍhá: -ás. I8. 3. 15.

purumiḍhám. 4. 29.4. [I. I7.

puruorúp a: -am. 9. Io. I9. I8. purưứpãs. 4. 2I. I".

puruovártman: -mānam. 5.2. $7^{\dagger}$.

puruoçăka: -as. I3. 3. I5.

púruṣa, púruṣa: púruṣas. 4. 3 . I. 5. 30. 2 . 8. I. I ; 2. 25 . I0. 2 . $28^{2}, 30$. II. $4.14 ; 5$ I3. I2. 3. IO. 19. $6.1^{*}, 4^{*} ; 39.2-4$.

púrușas. 6. IOg. $2^{*}$. I0. 2. $9,18,20$, 2I. I9. 6. $3^{*}, 9^{*} ; 44.8$. 20. I28. I ; I3I. $20 ; 133.1$.

purușa. 5. 30. 6, I7. 8. I. 4,6 , Io. I 8. $4.5 \mathrm{I}$.

pūrușa. 4. 9. $7^{*}$ (mss. -șas).

púrușam. $5.5 .2 ; 7.2 ; 29.1 .6$. 30. 2 ; III. I; I33. 3. 8. 2. 5 ; 7.2, 5,7 , II I I, 22. IO. I. I7, 29. II. 8. I3, I $8,29,32$. I2. 4. I3. I9. 6. $5^{*}, I^{*}, I^{*}$. púrușam. I. 16.4. 5.4.6; 5.4. 6.
138. 1. 7. 76.4. 9. 8.4,6. I2. 4. 25 . púrușena. 7.5 .4 19. 6. $10^{*}$. púruşāya. 9.3.12. 13.4. 42. púruşăt. 5.21.4. 19.6.16. 20. 133. 2 (mss. pứrușān).

púruşasya. $5 \cdot 7.8 ; 28.3 .6 .38 .4$. II. 8.31. I9. 49.4. 20. 128. 3 .

púruşasya. 8. 4. $15^{\circ}$. I O. $2.1,2,4,8$. púruşe. 3. 21 . I. I0. $2.10,11 ; 7$. I $5^{2}, 17.11 .9 .7,14.12 .2 .5 ; 3.5 \mathrm{I}$. púruşe. I0. 2 . I2, I3, If.

púruşās. II 1 . 9.

púruṣās. 2. 26. 3 .

pûruşās. 20. 127. 12 (mss. pứr-).

púruşān. 3. 28.5,6. 9.3. I4. I8. 3. 62 .

pứrușān. 6. 59.2.

púrușāis. $5 \cdot 14 \cdot 7$

púrușebhyas. I. 3I.4. 3. 28.3; 30. 4 (1. -bhias). 6. $27 \cdot 3^{*}$. 12. 2. I6. I 9. 47. Io (1. -bhias).

púrușānāām. 4. 9.2. 8. 7.15.

púruşeșu. 4. I8.5. 6. 38.2. I I. 2. 21. I2. I. I9, $25 ; 2.1$.

(cf. sárvapūruṣa, sahápūrușa, pāúruṣeya, púruṣagandhi - púrușeșita.)

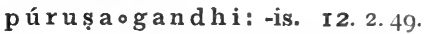
puruşaojivana: -am. I9.44.3.

purusajívanīs. 8. 7.4 .

pữuşátā: I8. I. $52^{*}$.

púruṣa tejas: -jās. I0. 5. 35 .

puruṣaoréṣaṇa: -as. 3. 2 I. 9.

puruṣa ova dhá: -dhấs. I2. 5. I4. puruṣà d (p. -șaoád-) : -das. I 2. I. 49. puruṣāsthá (p. -șaoas-) : -thé. 5. 31.9. [5. púruṣeșit a (p. -șaoiș-) : -tās. 2. I4. purușțutá (p. -ruostu-): -ás. 6.2. 3. puruohūtá: -ás. 5.3. $\mathrm{S}^{*}$. I7. II. puruhūta. 4. 31. 6*. 7. 50. $7^{*}$. 18.3. $67^{*}$. I9. 55.6 (mss. -tya).

puruhūtám. 7. 86. I*. $\left[47^{*}\right.$. purūvásu (p. -ru॰v-): -us. I4. 2. purū vị́t (p. -ru॰v-): -tas. I0. 2. I I. purogavá (p. -raḥog-): -ás. I2. I. 40. I4. I. 8".

purogavấs. I $8.4 \cdot 44$. 
purogaví. 4. 13. $7^{*}$.

(cf. ápurogava, gópurogava.)

pu rog ầ (p. -raḥıg-): -ấs. 5. I2. I1* puroḍaça: -am. I8. 4. 2.

puroḍăçāu. 9.6.12. I0. 9.25.

puroḍăçās. 8. 8.22.

(cf. puroḍăçavatsa.)

puroḍăça ovatsa: -sā. I2. 4. 35 . purodhă (p. -rahı̀dh-): -ăyām. 5 . 24. I-I 7 .

puróhi ta (p. -ráḥoh-): -as. 3. I9. I,

4. 7.62. I. I0. I. 6

puróhitam. II. IO. 18 .

puróhitās. 8. $5 \cdot 5,6$.

p u rváñ c: -rūcîm. I0. 2. 7 .

purūcís. 2. I3. 3. I2. 2.23*. I 8. 2.29. I $9.24 \cdot 5,6$.

$\checkmark$ puṣ: púșyasi. 7. IO. I".

puşyasi. I3. 2 . Io.

púșyati. 4. 32. $\mathrm{I}^{\dagger}$ (ed. pușyati*).

pussyatas. $7 \cdot 57 \cdot 2$.

pușyatam. I4. 2. 37 .

puṣyata. 3. I4. $2,4,5$. 7.60. 7 .

púșyema. I9. 67.5 (not mss.).

púșyate. I 8. I. 22*.

pușema. 5.3. I*. I 9. 55.3.

pușțám. 5. 3.7. 6. 79.2. 7. I9. I ;

79. 3. I2. I. 29. I 8. $2.60 ; 3.6$ I. I9.

3I. 6, Ir.

pușțâya. I 4. 2.27.

puṣté. 3. 10. 7 .

puștaăni. $4 \cdot 24 \cdot 7$.

pușțâ. r9. 49.3 (not mss.).

poșaya. 3. 28.4 .

(cf. puș, pușța, púșți pușțí, púṣpa, pușya, pūṣán, póșa, poṣayiș̣ú, póșya.)

puṣ (?) in púșkara, pușkalá.

púşkara: -am. II. 3.8. I2. I. 24.

(cf. puṣkaraparná-puṣlzarín.)

puṣkara oparṇá: -ám. 8. 10.27.

púșkaraosraj: -jā. 3. 22.4. 5. 25. $3^{*}$.

puṣkarín: -íñi. 5. I7. I6.

puşkarínīs. $4 \cdot 34 \cdot 5-7$.

puṣkalá: -ám. I3. 3. Io.

pușța in

puṣțaopáti: -is. 3. 8.4. 7.19. I;
40. I. I9. 3I. 6, II.

pușțapátim. 7. 40.2. [3.3.

púșți, puṣțí: púșțis. 3. 28.4. I9.

puștís. I9. 3I. I3.

púșțim. 9. 4. I9.

pușțím. I9. 31. 3, 5.

púșțyā. 9. 6.45.

puștiă. I9. 3I. 2, 9, I3; $49 \cdot 3$ (ed. -tă).

púșțaye. ro. 6.29.

(cf. supuștí, púșțikāma.)

púștiokāma: -māya. I9. 3I. I.

púșpa: -am. 5. 4.4 (s. mss. ed. púsyam). 8. 7. I2. I0.8.34. I9. 44 . 5 (ed. -sya-).

(cf. púspavant, puspín.)

púșpa ovant: -atis. 8. 7.27.

puṣpín: -íñi. 6. Io6. $\mathrm{I}^{\dagger}$.

puș y à: -às. I9. 7. 2.

pús y a, see púșpa.

puṣyá: -yăm. 8. 7.6.

$\checkmark$ p̄̄: punāti. I2. 2. II.

punáte. 7.27. I.

punihi. 6. 19.3* 19. 33.3. [3. punātu. 6. I9. I, 2; 62. I; 96. 3 ; I I9. punitām. 6.62. I.

punántu. 6. I9. $x^{3}$. 10. 6.3 .

punantu. 6. 5 I. $2^{*}$. I8. 3. II.

punānás. I2. 3. 54 .

pávate. 4. 24. 4 .

pavate. I0. $7.2,4$. I3. 3. I9. I8. 2. $\mathrm{I}^{\dagger}, 6^{\dagger}, 14^{*} ; 3.54 ; 4.58^{*}$. I9. 54.2. pávante. I3. 3. 2.

pavante. 12. 3.25.

pavatām. 5. 3. 3". 8. I. 5 .

pavantām. 7.82. I*.

pávamānas. 3. 3I.2. 4. II.4. 6. I9. I, 2. 9. 7.8. I0. 2. $26 ; 8.40^{*} ; 9$. 26. I5. 2. I-4; I5. 6 ; I8. 3. I9.6I. I. pávamāne. I7. I3.

pūtvâ. I 4. I. $4 \mathrm{I}^{\dagger}$. [3. I4. pūtás. 6. 5 I. I, 2*. II. I. 25 . 12. pūtám. 4. 39. 10. 6. II5.3.

pūtāú. I2. 3.3.

pūtăs. 4. 34.2. 6. I22.5. II. I. I7, I8, 27. I2. 3. 25 .

(cf. pávana, pavamāna, paviț̣́, pavítra, pāva, pāvaká, pu, pū, pūta, púti, pūtríma, potṛ, potrá.) 
+ abhi: abhí...pavasva. I2. I. I2. + u d: út punāmi. I2. 1. 30 .

+ parā: párā punihi. II. I. II.

+ sa m: sám punăti. I 8. 3.40 $40^{\dagger}$.

pũ in udapú, ghṛtapú, madhuptá, vā-

tapú.

pūta in bráhmapũta and

pūtá od akșa s: -șās. 5. 22. 1. 6. 93. 3 . púti: -im. 8. 8.2.

(cf. pútidhānya, pūtirajjú.)

pútiodhānya: -yā. 3. 12.3.

pūtiorajjú: -ús. 8. 8.2.

pũtúdru: -us. 8. 2.28.

pūtríma: -am. 6. I24.3.

púruṣa, see púruşa.

p $\mathbf{u} \mathbf{r}$ ṇa in súpūrṇa, pāurṇamāsá.

pūrtá: -ám. 9. 5. 13;6.31. II. 7 .

9. I2. 5 . 10, 56 .

pūrtásya. 6. 123.5 .

(cf. abhípūrta, iṣțāpūrtá.)

$p \bar{u} \mathbf{r t i}$ in

púrtiokāma: -as. 7. 103. I.

pūryấṇa (p. pūḥıyăn-): -ṇāis. I 8 . I. $54^{\dagger} ; 4.63$.

pú rv a: -as. I. 7. 4. 5.20.6. 8. 3. 7*. 9. $6.3 \mathrm{I}-6,37$. I 0. 3. 3. I I. 5. 5 . I3. 2.14 . I8. $4.8,9,28^{*}$. I9. 39. 9 . púrvā. 6. 16. 4 ; I33.2. I I. 8.7. I4. 2. 74 .

púrvam. 4. 35.2; 37. I. 8. 1. 1 о. 9. 5.27 . I2. $2.25^{*}$. I4. I. $64 ; 2.20$. I8. $4.15,44$.

púrvām. r6. 7.9.

púrveṇa. I0. 4.3 .

púrvasmāt. I I. $2.25 ; 5.6$.

púrvasya. Io. 1. 27.

pûrue. 4. I. 6.

púrvā. I9. $7 \cdot 3,4$.

púrve. 2. $34 \cdot 5 \cdot 5 \cdot 17 \cdot 6^{*}, 8$. 6. 64 . $I^{*}$; 133.5. 7.5. $I^{*}$. 8.6. I4. 9.6. 5I. II. 2. I $8 ; 3 \cdot 32-49$. I2. I. 5, 39 . I8. I. $50^{*}, 54^{*} ; 2.15^{*} ; 3.72 ; 4.44$. I9. 26. 2 .

pứrvāsas. 18. 1. 46".

púrvās. 19. 34.7.

pûrvān. 5. 30.1. 1 0. 3.13-5.

púrvāis. I $8.3 .48^{*}$.

púrvebhyas. I8.2. 2". pūrviss, see purú.

púrvatamam. 20. 128. I6 (not m8s.).

(cf. apūrvá, anupūrvá, abhipūrvá, pūrvakāmakṛ̂tvan-pūrvyá.)

pūrvakāmaokṛttvan: -ne. 7 . II6. I.

pūrva॰kŗtvan: -vari. I2. I. I4. púrvaocitta: -tās. 7. 82.3. pũ rva ojá: -jébhias. I 8. 2. 2". pū rva。janá: -năs. I2. I. 5 . pūrva。péya: -ye. I2. 1. 3 . pū rva०rū pá: -pấni. I9. 9.2. pūrvá。hūti: -is. 7.25. 1, 2. pūrváhūtāu. r9. 10. $5^{*}$. pūrvăgní (p. -va॰ag-): -năú. 5. 3 I. pūrvāpará (p. -vaoap-): -rám. 7 . 8I. I". I3. 2. II". [1. 27. pūrvāsín (p. -vaoās-): -nam. Io. pūrvyá:-viás. 7.2r. I.

pūrviám. 5. 1. 4. I8. 3.39".

pūrviásya. 4. 1. 6.

pūrviấs. I9. 34.6.

púly a: -yāni. I4. 2.63.

pūṣán: -şấ. I. 9. 1. 3. 14.2; 1 7. $4^{*}$. 5. 28.3 , 12. 6. 67. I; 73.3. 7.9.1", $2^{*}, 4^{*} ;$ 33. I. I4. I. $15^{*}, 33$. I6. 9. 2. I8. 2. $54^{*}, 55^{*}$. I9. 10. $9^{*} ; 20.1$. 20. 127.12 .

púșan. 7.9. $3^{*}$.

pūṣan. I. II. I. 6. I12.3; II3. 2. I4. I. $39 ; 2.38$ (mss. pú-). [I 8. 2. 53 . pūşánam. 3. 66. I". 4. 30. 6". I I. 6. 3. pūṣnás. I9. 5 I. 2.

(cf. índrāpūșáṇā.)

$V$ I pṛ: piparmi. I. 35.4 .

píparti. 9. I0. $23^{*}$. I3. 3. 4. [135.8. piparti. 9. I. 5, 20. II. 5. I, 2, 4. 20. pipṛhí. 7. 35. I.

piprhi. 7. 20.4; 79. I.

pipartu. 6. 53. I.

piprta. 5. 26.5.

prụăti. 6. 22. 3 .

prṇāti. II. 5.4.

prnánti. I 8. 4. 29".

pṛnāt. 20. I27. II.

pṛ̣ihi. I7. 6-I9, 24.

pṛnīá. I. $6.3^{*}$.

pṛnatás. I. 27.4 . 
pṛnántas. 6. 142.3 .

priyāsam. 3. $5 \cdot 4$.

pūrnás. I0. 6.2. I9. 53.3.

pūrnă. 3. IO. 7. 7. 80. $\mathrm{I}^{2}$.

pūrṇám. 3. I2.8. 9. 4.6. I0. 8. $29^{2}$.

I 8. 3. 54 .

pürṇắm. 2.36. 5 .

pūrṇéna. 7. I7. I. I0. 8. I5, 29.

pūrṇát. I0. 8.29.

pūrnăás. $4 \cdot 34.6 . \quad 7 \cdot 60.2$.

pūrṇăn. $4 \cdot 34.7$.

pūrayati. 3. 29. 2.

pūraya. 3. IO. I3.

(cf. paru, párus, párvata, pár-

van, pur, purú, pūrṇa, pūrtá, pūrti, / $/$ pṛn, $/$ prā.)

+ ā: ā॰pṛ̣ắsi. I3. I. 9. I8. 2. 9.

à prināatu. I9.59. $2^{\dagger}$.

ápṛ̣nāt (p. āoáp-). 4. 35.3.

à pūrayāti. I2. I. 6I.

+ ni: niopṛ̣ắmi. I 8. 2. 30; 4.42.

(cf. nipúr.)

+ parā: cf. parāpúr.

$\sqrt{ } 2$ pr: pipartu. 5.28.5. I2. I. I2. píparat. I9. 40. $4^{*}$ (mss. píparid).

pāráyāmi. 8. 2.9.

pāráyāmasi. $8.7 \cdot 7$, Ig.

pārayāti. II. I. 5 .

pārayāt. 4. I7.2.

pārayantu. 5. 28. 2.

(cf. pápri, paraṇa, pārá, pāraṇa, pārayișṇú, pāla, $\vee$ pālay.)

+ a ti: áti parșā (p. -ṣa). 4. 33. 8*.

áti ... parșat. 6. $34.1-5^{*}$. 7.63. I. áty apīparas. I7. 25, 26.

áti pāraya. I7. 25, 26.

áti ... pāraya. 4. 33. $7^{*}$. I9. 50.2 (not mss.).

+ u d: út ... apīparam. 8. I. I9; 2.9. út... apīparan. 8. I. I7.

út pārayāmasi. 8. I. I 8 .

(cf. utpáraṇa.)

+ parā: cf. aparāparaṇá (?).

$\checkmark$ p ṛc: pṛnaliși. 5. I.9.

prñce. 6. I2.3. [pŕñ̃cantīs].

prñoatís. I. 4. $1^{*}$. 20. 48.2 (mss.

apṛkthās. $7.88 . I^{2}$.

(cf. parka, parcana, prec.)

\author{
+ a pi: ápi ... prñoanti. 5. 2. $3^{\dagger}$. \\ ápi ... aprāk. ro. 4.26. \\ + up a: úpa prñ̃ca. 9. $4 \cdot 23^{\dagger}$. \\ upaopŕñ̃catî. I8. 4. 50. \\ (cf. upapárcana.) \\ + s a m : sám papṛcyām. I8. I. I3, I4*. \\ sám piprgdhi. I8. I. I2*. \\ sám apṛkṣmahi. $7.89 .1^{\dagger}$. \\ sám proyadhvam. 6. 64. $1^{\dagger}$. \\ sám ... prọyantām. 6. 74. I. \\ pro in madhupŕc. \\ V pṛ̣: pṛ̣ásva. 2. 5. 2, 4 . \\ pṛ̣asva. 7. 26.8. I9. 6I. I. \\ + à: â pṛ̣nat. 7.57. I. \\ pṛ́tanā: -ās. 5.3. I*; 14.8 ; 20.4 . \\ 6. 97. I. 8. 5.8. I0. 5.36. I3. I. \\ 22. I6. 9. I. I9. 32. 10.
}

pŕtanāsu. 3. 21.3. 4.27.7; 28.7; 32. $4^{*}$. 5. 29. II*. I9. 52. 2 .

(cf. pṛtanājí-pritanyú.)

pṛtanāojí: -ím. 7. 85. It.

pṛtanāojít: -tam. 7.63. I.

Vpṛtanāy: -yatás. I9. 28.5-10; 29. I-9; 32. 6.

p ṛt an ā sá h: -șâț̣. I I. I. 2*. I9. I3. $7^{*}$. pṛtanāșāṭ. 5. 14.8.

$\checkmark$ prrta n y: -yáti. 6. 75. I. I3. I. 29. pritanyăt. I2. I. I4. I9. 46.5 .

pṛtanyắn. 3. 19.3.

prtanyántam. 1. 29. 2*.

pṛtanyatás. 7.70.3.

pṛtanyatás (pl.). I. 21.2*. 7. 93.

I. I9. 32. 10; 46. 2 .

(cf. pṛtanyú.) [II. I.9, II.

pṛtanyú: -yávas. 7. 34. I; 62. I. prtha in viçvátaspṛtha.

pŕthak. 3. I7. I*; I9.6. 4. I5.2, $3^{2}$, 4; 20.2. 5. 20.7. 7.45.2. 9. I. 3 . I1. $5.2, \mathrm{I} 3,22$. I2. $3.2 \mathrm{I}$.

(cf. prapṛthák, prthaksahasrá.) p ṛth akos ah a srá: -râbhyām. Ig. 22. I9. [(p. -isátobh-). pṛthivişád: -dbhyas. I8. 4.78 pṛthivi: 2. I5. I; 28.4. 3. 9. I; 23. 6. 4. $2.4 ; 39.2$. 5. 9. $7 ; 25.2$. 6. I7. I-4; 44. I; 53.I ; 77. I; 88. I*; IOO. I. 7. I8.2. 8. I. I 2, I 7; 4. $23^{*}$; 7.2 ; 10. 24 . 9. I. 2 I; $4.2 ; 7.2$; 10. 
I2", 24. I0. IO. 4, 30. I I. I. 8 ; 2 . IO; 3. II ; $5.4 ; 9.4$. I2. I. I, 2, 5, 21, 22, $37,41,44,45,48,52,53,59 ; 3.20 ; 4$. 23. I3. I. I7. I4. I. $2^{*} ; 2.71$. I5. 10. 6 . I8. I. $5^{* \prime} ; 2.25 ; 3.25-8,30-$ $5,49^{\dagger}, 5$ I $^{*}$. I9. 9. I, I4; $54.2 ; 58.2$. prthivi. 7. I8. I. I2. I. II, I2, I4, I $5, \mathbf{1 6}, 23,24,30,36,46,49,62$. I8. 2 . I9"; $3.50^{*}$.

prthivim. I. 2. I, 4. 3. 8. I; 9. 6; 2I. 7. 4. 2. $7^{*}$; II. I ; I 5. I, 4, 5, 7, 8, $9 ; 27.4 ; 35.3$. 6. 22. $\mathrm{I}^{\dagger} ; 60.3 ; 6 \mathrm{I}$. 2,3 ; I2O. I; I26. I*. 7. 6. $3^{*}$. 8. 2. I5. 9. 3. I5; 5. I5. I0. $5.25,45 ; 8$. II, 36. I I. 2. I0 ; 4. 5, I 7 ; 5. I, 8, 9. I2. I. $I, 7, \mathrm{II}^{2}, \mathrm{I}_{7}, 27,29,43,57 ; 3.22,23$, $25,26,28,40$. I3. I. $25,34,45 ; 2.5$, 45 ; 3. 22. I4. 2.69. I5. I0. 9. I 8. I. $39^{\dagger} ; 2.7^{*}, 49 ; 3.49^{*}, 52^{*} ; 4 \cdot 5,6,28^{\dagger}$, 48. I9. $32.9 ; 58.3^{2}$.

pṛthivyâ. 4 . 30. $8^{*}$. II. 3. 4 I. I2. 3 . 23. I8. I. IO". I9. I9. I.

pṛthivyāí. I. 32. 4. 5. 9.2,6. 6. IO. I ; 20. 2 . I2. I. 26.

pṛthivyás. I. 24.4 . 2. $3.5 ; 7.3$; I0. 8. 4. I. 4 ; 14. 3. 5. $2.7^{\dagger}$; 12. $4^{*}$; I7. II". 6. 43.2 ; 100. 3 ; 105. $2 ;$ I 25 . $2^{*} ;$ I34.2. 7.9. I"; 26.8. 8. 4. $4^{*}$; 9. I. 9. I. I ; IO. $13^{*}, 14^{*}$. I O. 5.25 . II. 2.27 ; 5. II. I2. I. $4,8,12 ; 3$. $35 ; 5.72$. I3. I. I6, 39. I4. I. 47 ; 2. 70. I5. $4.4 ; 7.1,6$. I 8. 2.52. I9. 3. I; 35.4 .

pṛthiviăs. 6. 86. I, 2. I8. 2. 20. pṛthivyăm. I. $3.1-5 ; 30.3 ; 32$. I. 4. $8.5 ; 39 . \mathrm{I}^{2}$. 6. 80. 3 ; 136. I. 7 . 62. 1 ; 97.8. 8. 7. 13 ; 9.25, 26. .9. I. $3 ; 2.14 ; 3.16,17 ; 6.55^{2}$. I0. 3 . I9; 4.22. II. 5. I2, 26;6. I 2 ; I0. 2. I2. I. $\mathrm{I}_{3} ; 3.22$. I3. 2.30 . I5. I3. I. I7. 12, 13. I8. $2.36 ; 4.48$. I9. $27.13 ; 32.3 ; 44.3$.

prithivîs. 4 . 20.2. 6. 2I. I. 8. 4. II". I9. $27.3 ; 32.4 ; 53.5$.

(cf. dyẵāpṛthiví, părthiva, pṛthivișád, pṛthivīprá, pṛthivísamçita.)

pṛthivioprá: -ás. I3. 2.44. prthivíos am çita: -as. I0. 5.25. pŕthĩ: 8. I0. 24 .

pṛthú: -ús. 7. I1. I. I3. 4.52

prrthú. I3. 2.22". 20. 134. 4 (mss.); I35. 9 (inss. pṛ́thus).

pṛthúni. I9. 58.4".

(cf. prrthivi, pṛthujman-prrthuprithuojman: 5. I. 5 .

pṛthú。budhna: -as. I2. 3. 14 .

pṛthú。çiras: -rās. 5. 17.13.

prothustuka (p. -thuostu-): pṛ́thusțuke. 7. 46. I".

pṛ́dāku: -us. 3.27.3.

pṛ̛dākum. I0. 5.17

pṛ́ākave. I2. 3.57.

pứdākos. 7. 56. I.

pṛ́dākāu. 6. 38. I. [129.9. pŕ́dākavas. I0. 4. II, I3, 20. 20. pṛdākús. $5.18 .3,15$.

pṛdākúam. Io. 4.17 (mss. ed. -kvám). .

pṛdākuấs. I ò. 4.5 .

prdākúas. I. 27. I.

pŗฺ̣̂i: -is. 2. I. I. 6. 3 I. I". I0. 5 . 20. I9. II. $3^{*}$.

pŕ̛çne. $5 \cdot 13.5$.

pŕ̛çni. I. II. 4.

pŗ̧̧̣im. 5. II. I, 2, 8; I7. 17. 7. 104. I. 9. 10. $25^{*}$.

pŕ̛çnayas. 8. 7.I.

(cf. pṛçniparṇá-pṛçnihán.)

pṛçnioparṇá: -ṇt. 2. 25. 1, 2.

pŕç̧niparṇi. 2. $25 \cdot 3$. pṛçniparni. 2. 25.4 .

pṛ́çni०bāhu: -us. 8.8.r7.

pṛ́çnibāhavas. 4. 15.12.

pṛ́çniomātṛ: -taras. I3. 3.23.

prçnimātaras. 5.21.11. 8.7.21. I3. I. 3 .

pŕçnimātṝn. $4 \cdot 27.2$.

pṛçniohán: -hă. I0. 4. 15.

pṛşadoājyá: -jiám. I9.6. I4*. and pṛșad ājy ápra nu ut ta (p. -yáopranu-): -tānām. II. Io. Ig.

pṛṣa n t: -ṣat. I. $23.2,3$. pŕṣatī. I3. I. $2 I^{\dagger}, 23$. pŕş̣atĩm. I3. I. 24.

(cf. prṣadājyá.) 
pṛşât ak a: -kāni. 20. I 34.2 (s. mss. -ātakāní).

pṛșātakí. I4. 2. 48.

pṛștí: -tiăm. 6. 102. 2.

pṛșáyas. 4. 3.6. 9. 7.6.

prsțtis. 2. $7.5 ; 32.2$. 5. 23.9. 6. 32. 2 ; 50.1. 8. 3. 10*. 9. 8. I5. I0. 2. 4 ; 9. I9. II. 8. I4. I6. 7. I2. I9. 45. I.

(cf. părșțeya, pṛșțiváh, prșțyāmayá, prṣțí.)

pṛsṭiováh: -văhas. I8. 4. Io (mss. ed. -vāhás).

pṛṣți: -ibhis. I2. I. 34 .

pṛsțy ā m a yá: -țioāmayám. I9. 34 .

pṛṣthá: -ám. 4. 14. 2; 34. I. 9. 5 . 20. I5. I. 7. 20. 128. 15 (mss.).

pṛșthéna. II. 3. $40^{2}$.

[I4.

prsțhăt. 4. I4. $3^{2}$. II. 5. IO. I8. 4 . pṛșthé. 5. 20.6. 7.80. I. 9. 5. 10, I 5 ; 9. 10*; 10. $9^{\dagger}$. 10. $7.3^{8}$; 10. 5 . II. 5. 26. I2. 2.4 I. I 3. 2.37 ; 4 . I. I8. $2.47 ; 4.4,36$.

prșțhẳni. I2. 2. 12. I8. 1. 6 I.

(cf. ghṛtápṛșțha, tripṛșthá, vi-

táprșțha, çukráprșțha, sahás-

raprṣṭha, sómaprșṭha.)

pétva: -as. 5. I9. 2.

pétuasya. 4. 4.8.

pe du in pāidvá.

peya in pūrvapéya, vājapéya.

perú: -ús. I9. II. $8^{*}$.

péç a n a: -nĩs. I0. 2. I.

peç as in supéças.

péṣțra: -am. 4. 12.2. 6. 37.3.

pāidvá: -ás. I0. $4 \cdot 5^{3}, 7$, IO.

pāídva. Io. 4.6.

pāidvásya. Io. 4.II.

\section{potr in}

potrá : -răt. 20. 2. I, 4 (mss. pótrāt). póṣa: -as. 9.4.7.

póşam. $\quad$ r. 9.4. 2. $13.3 ; 29.2$. 3. 20. 10. 4. $25.5 ; 39.2,4,6,8$. 5. 27. I0. $7.40 .2 ; 47.2$. I8. I. $43^{*}$. I9. $24.5 ; 52.1$.

póșeṇa. 3. 10. 3,$8 ; 14.6 ; 15.8 .6$. 5.2. I 9. 55. I, 2.

póșāya. 6. I4I.I. I9. 3I. I3. póșe. 3. 10.7. 9. 4. 2.

póṣās. 2. 34. I. 5.28.3. [4.62. póșāis. 9. 4. 22, 24 . II. I. 34 . I8. (cf. gopoșá, vīrapoșá, sahasrapoșá.)

poṣa y iṣnúu -ús. 3. 14. 6.

poșayișnú. $5 \cdot 28.4$.

póṣya: -ṣiā. I4. I. 52.

pāuñ ișțhá: -ás. Io. 4. I9.

pāútra: -as. II. 7. I6. [4.39.

pāútram. 9. 5. 30. I2. 3. 14. 18. pāútrān. 12. 4.38 .

(cf. pāútrādya.)

[5. 28.

pāútrādy a (p. -traoad-): -am. I3. pãúruṣeya: -as. I. 30. I. [20.I. pāúrușeyam. 8.6. 23. I2. 3.49. I9. pāúrușeyeṇa. 8. 3.15*. [3.4. pāúruṣeyāt. 4. 26. 7. 7. 105. I. Io. pāúruşeye. Ir. 9. Io.

pāurṇa omãsá: -ám. 7.80.2. [I. pāurṇamăsí. 7. 80. 1, 4. I5.2.2; I6. pāurṇamāsîm. I5. 17.9.

V pyā: +āa : à pyāyase. I4. 1. $4^{*}$.

ă pyāyasva. 7.81.5.

à pyāyatām. 5. 29. 12, 13. 6. 78. I. à pyāyantām. I2. 3. 20.

āopyăyamānās. 18.3.17. [çi-). à ... pyāsiṣimahi. 7.81.5 (mss. pyāà pyāyayāmi. I 8. 4.64.

à... pyāyayati. 4. I I. 4 .

āopyāyáyanti. 7.81.6.

à pyāyayantu. 7.81.6.

+ pra: prá pyāyatām. 4. I5. II I $^{\dagger}$. py as a in prapyasá.

prá. I. $3.7 ; 7.4,5 ;$ I8. 2. 2. I. 2 ; $4.6 ; 5.5^{*} ; 6.2$; 10. $5 ; 32.6$. 3. I. $4^{*} ; 2.2 ; 6.8^{3} ; 16.3^{2 *} ; 18.6^{*} ; 20.2^{*}$, $3^{5 *}$. 4. I. $3 ; 7.4$; 10. 6 ; 15.13* $; 25$. $6 ; 27.1 ; 28.4 ; 29.1,2,5,6 ; 33.3^{2 *}$, $4^{2 *}, 5$. 5. I. $4 ; 7.3 ; 22.8 ; 29.4$. 6 . 34. I* I I21. 3 ; I 26. $3^{\dagger}$. 7. 2. I ; 5. 5; $25.2 ; 26.2^{*}, 3$ (prá॰pra); 35.1 ; 50. $4^{*} ; 73.5 ; 78.2 ; 8$ I. $2^{*} ; 83.4$; II4. $2^{3}$; II5. I ${ }^{2}$. 8. $3 \cdot 4^{*}, 24^{*} ; 4 \cdot 17^{*} ; 6$. 8 ; 10. I9, 20. 9. 3.6 ; 5.3. I0. 3 . 2 ; $5.24^{3} ; 8.7$. II. 4.22 . I2. 2. I3, $52 ; 5.60,67^{2}$. I3. $2.31,32,46^{2 *}$. I4. I. I7, I8*, I9*, $58^{*} ;$ 2. 26,67 . I5. I2. 
5. I6. I. $11^{2}$. 18. I. 61 ; 2. $2^{*}, 3^{*}, 39$, $54^{*} ; 3 \cdot 38^{*}, 65^{*} ; 4.29^{*}, 60^{*}$, 70. I9. I3. $7^{*} ; 34.4 ; 49.9^{2}, 10^{2}$. 20. 127. 5,6 ; I36. 4 .

pró (p. -6́́ti). 7. II4. 2.

(cf. pra $+\sqrt[V]{ }$ añj, an, av, 2 aç, ãp, $\mathbf{i}, \mathbf{a}+\mathbf{i}$, anu ... i, upa ... i, sam ...i, idh, sam ... idh, iş, abhi ... iṣ, Ikṣ, Iñkh, Ir, ukṣ, kāç, I kṛ, I kṛt, kḷp, kram, krīạ, 2 kṣi, khud, I gā, grah, car, cit, cud, cṛt, cyu, chid, jan, jā, ji, jñā, tak, tan, tud, tṛ, upa ... tṛ, tras, dah, I dā, diç, drȩ, dru, dhanv, dham, I dhā, dhāv, dhî, nabh, I naç, nah, nij, ni, nu, nud, nṛt, pạ̣, pat, pad, paç, pĩ, pyā, plu, bandh, budh, brū, blī, bhañj, bhā, bhid, bhū, bhṛ, bhrañç, bhrāj, math, mad, man, abhi ... man, mand, I mã, mi, mill, muc, mud, muș, I mṛ, 2 mṛ, mṛç, yam, yach, $\mathbf{a}$... yach, sam ... yach, yaj, yas, yā, anusam ...y $\bar{a}$, I yu, yuch, yuj, anu ... yuj, ric, ruc, ruj, lap, li, ruh, vac, vad, upa... vad, I vap, 3 vas, vah, anu...vah, I vā, I vid, viç, anu ... viç, vī, I vṛ (ūrṇu), $\bar{a}+$ vr, vrrt, vṛdh, vrș, vyath, vyadh, vraçc, çañs, çās, çuc, çr, çru, saj, sad, sah, sā, sādh, sic, sū, sṛ, sṛj, sṛp, stu, stṛ, sthā, snā, sphur, sru, han, has, hā, hi, abhi ... hi, prati ... hi, hr, hrād; and pratará, pratná, prathamá, pravát, prâño, prātár, prakaçá, prácarşạii, prácetas, pradakșiná, pradív, pradhána, prápad, prápada, praprthák, prámanas, právīra, prărtha.)

pra in ākūtiprá, kāmaprá, carșaniprá, prthiviprá.

pra $\mathrm{kaçá:} \mathrm{-ás.} \mathrm{9.} \mathrm{I.} 2$ I.

praokrî: -ís. 4. 7.6. II. 7. I0.

pracañkaça in ápracañkaça.

prá oc arşạ̣i : -ṇi (p. -í íti etc.). 7. práocetas: tās. 5.12. I* 6. 45 . $3^{*}$. 18.2 .27 [3.9. pracetas. $4.32 .5^{*}$. 7. I06. I. 8. prácetasas. 4. 23. L. prácetasāu. 6. 53. 1. [2.46". prácetasas. 6. 68. I. 8. 7.7. I4. (cf. ápracetas.)

1/prach: prechămi. 9. 10. $13^{4^{*}}$. pṛchāmi. 8. 9. 1. 9. 9. $6^{\circ}, 7^{*}$. 10. 8. IO, 34. II. 3. 22 . I2. 4. 43 .

pṛchāmas. 8. 9.7.

prchanti. 12. 5.50 .

prche. 20. I30. 5 (ms8, prcha), 6 (do.). precha. 20. 130. 5 .

pṛchámānāu. I4. 1. 14 *.

áprākşam. 7. 54. 2.

práșțum. 9. 9.4".

pṛșáás. 7. 54. 2.

(cf. praçna.)

+ vi: ví pṛchati. 20. 127.9.

+ s a m: cf. sampraçná.

praojánana: -nāya. 9.6. 44.

(cf. prajánanavant.)

praján a na ova nt: -vān. I 9. 17.9. prajánanavantam. I9. 18.9.

pra。janú: -nvàs. 9.4.6. [prajás. prajas in áprajas, bahuprajás, supra。jấ: 7.35.3. 9.7.13. io. $7 \cdot 33$. I I. I. I9; 332,35 . I2. 5. IO.

prajăm. 1. 8.3. 2. $7.4 ; 29.2$. 3. IO. 3,8 . 4. II. 9 ; I9. I; 39. $2,4,6$, 8. 5. 18. 12; 19. II. 6. 8I. 1. 7. 20. $2 ; 46 . I^{*} ; 68.1 ; 82.2$. 8. $5.16 ; 9$. I3. 9. 4. $22 ; 6.34$. I0. I. I9, 3I; 2 . $29 ; 6.35$. II. I. 9,$17 ; 2.21$. I3. I. 34. I4. I. $42 ; 2.14,24,3 \mathrm{I}, 37,39$, $40^{*}, 7 \mathrm{I}, 74$. I8. 3. I ; 4.62. I9. 3 . I; 7 I. I.

prajáyā. 2. 34.3, 4. 3. 29.8. 5. 3. $7^{*}$; 29.6-9. 6. 5. I ; I4I.2. 7. 17. 4 ; 33. I ; 8 I. $3,4,5 ; 89.2^{*}$. I0. 6 . 23. II. I. I, I4, 2O, 21. I2. 3. 10; 4 . 2. I 4. I. $32,33,48,53,54 ; 2$. I*, I 3 , $64,70$. 18. 3.17. I9. $24.8 ; 31.7$; 6.4. 2.

prajâyāi. I. I8. 1. 5.3.7, 8*; 25 . 8. 8. 6. $2 \mathrm{I}$. 9. 3. II. I4. I. $2 \mathrm{I}^{\dagger}, 47$. I8. $3 \cdot 4 \mathrm{I}^{\mathrm{*}}$. 
prajāyās. 9. 6. 45-8.

prajầyām. 6. 55.2. I4. 2.62.

prajâs. 2. 35.2. 7. I9. I ; III. I. 9. I. I, $24 ; 4.20$. I0. $8.3^{*}, 37,38$. II. 4. IO, I9. I2. I. I6. I3. I. I9. I5. I4. II ; I5.9. I6. 8. I-27. I9. 53. 7, 10 . prajăbhis. I9. I9. II.

prajăbhyas. 4. I5. IO. 9. I. 24. I3. 4. II. I9. 10. $10^{*} ; 20.2$.

prajănām. 5. 24. 13. 9. I. 4; 6. $44^{2}$. I0. I. 21 . 17. 3 .

prajấsu. 3. $15 \cdot 7$.

[jas.)

(cf. prajăkāma-prajāvid, praprajăokāma: -māya. 7. 17.3. prajāta in ritáprajāta.

prajầpati: -is. 2. 34.4. 3. I5.6. 4. 4. 2 ; II. 7; I5. II; 35. I. 5. 25. 5*. 6. II. 2,$3 ; 68.2$; 69.3. 7. I7. 4 ; I9. I; 24. I. 8. I. I7; 5. IO. 9. I. $24^{2}$; 3. II ; 7. I, 24 ; IO. 24 . IO. 7. $7,8,4$ I ; 8. I3; 10. 30 II 3.52 ; 5. $16^{2} ; 7.3 ; 8.30 ; 9.25$. I2. I. 43 , 6I. I3. $2.39 ; 3.5$. I4. 2. I3, 40*. I5. I. $2 ; 6.9 ; 7.2$; I4. II. I7. I8. I9. 9. $6^{\dagger}, 12 ;$ I 7.9; I9. II; 20. $2 ; 46.1$. prájāpate. 5.25.13. 7.80.3*. 9. I. 24.

$[5.45$.

prajāpate. 3. 24.7. 9. I. IO, 20. 10. prajâpatim. I0. 7. I7. II. 4. I2; 5 . 7 ; 6. II. I5. I. I. I9. I8. 9; 53. I0. prajăpates. 3. 10. 13. 4. II. II. 7. I2. I. 9.6.29. I0. 5.7-I4. I5. 6 . 9. I6. 8.8. I7. 27. I9. 53.8. prajấpatāu. I0. $3.24 ; 7.40$. I I. 5 . I5. I2. 4.47 .

prajăpati (p. -i íti etc.). I I. I. 2 I (mss. ed. -jāva-).

(cf. prājāpatyá, prajăpatiș̣sța.)

prajăpatioṣ̣șta: -as. Io. 6. I9. prajām ṛtatvá (p. -jāoam-): -ám. II. I. 34 .

prajáovant: -vān. 6.68.3. prajăvantam. 7.20.3.

prajấvat. 6.97.2. I2. 4. I. I4. 2.73. prajầvantas. 7.74.4. 19.26. 2. prajấvati. II. I. 14. I4. 2. I8, 32. prájāvati. 9. 3. I3, I4. [ávati). prajāvati. I 4 . I. 52 (s. mss. -ắvatī, prajắvatĩm. I4. 2. 7 .

prajâvatīs. 4. $2 I \cdot I^{*}, 7^{*}$.

prájāovíd: II. I. I5.

praojñẫ: -ănām. I3. 2. 2.

pra。jñâna: -nāya. II. 3. 53 .

prajñănis. ro. $7 \cdot 34$.

práñiti (p. práon-): -taye. 6. 23.2. pránīitis. 7. I05. $\mathrm{r}$. (cf. supráninti.)

prạ̣utta in prșadājyápraṇutta, bṛ́haspátipraṇutta, vāibādhápraṇutta, sã́yakapraṇutta.

prạ̣éjan a (p. praon-): -ne. I9. 2. 4. prạ̣etṛ (do.): pránetar. 3. 16. $3^{*}$. prạ̣óda (do.): -am. 6. 28. I* $^{*}$.

pra०táñka: -am. 4. 16.2. 5. 13.8. praotatãmaha: I8. 4.75 .

pra॰tará: -ám. 5. I. 4. 6. 5. $2 ; 4$ I. 3. 8. 2.2. II. I. 2 I. I2. $2.30^{*}$. I 8 . I. $\mathrm{I}^{*} ; 2.3 \mathrm{I} ; 3 . \mathrm{IO}, \mathrm{I} 7,63 ; 4.54$. [49. praotárạa a: -as. 6. I25. I*. 12. 2. pratáranam. 19. 44. I.

pratáraṇi. I4. 2. 26.

(cf. āyuṣpratáraṇa.) [-ītāḥ̣ ${ }^{\dagger}$. praotáritṛ: -tã. I8. 4. $58^{*}$ (p. pra。tāná: -nás. 6. I39. I.

práti. I. 28.2. 2. II. 3. 3. I. $3 ; 3$. 5 ; 10.6. 4. I 8.4. 5. I4. I2; $29.4,14$. 6. $31.3^{*} ; 125 \cdot 3^{*}$. 7.29. I, 2 ; 34. I; 35. I; 58. $I^{*} ; 73.3 ; 82.5^{4}$. 8. 3. $19^{*}$, $23^{*}$. 9. 8. I3. IO. I. $15,27,28$. II. I. I4. I3. 2. $46^{*}$. I 8. 2. $37 ; 4.5$ I, 52. I 9. 42. $3 ; 49.8$. 20. 130. I0, I2; 135. I0. (cf. prati $+\sqrt{ }$ Varc, 2 as, ah, i, ud $+i$, İsș, I ūh, ṛ, kāç, kḷp, kruç, khyā, 3 gr, grabh, grah, cakș, abhi + car, jñā, tap, dah, I dā, $\bar{a}$ +dā, dīv, duh, I dhā, dhāv, nand, nī, nud, pạ̣, paç, budh, brū, bhañj, bhūș, manyũy, I mā, mi, muc, muh, mṛç, rakṣ, rih, I vid, viç, 2 vṛ, vṛt, I çI, çuc, çuș, çṛ, çru, à + çru, șthīv, su, sṛ, sthā, à +sthā, smṛ, han, $\bar{a}+$ han, I hṛ, hary, pra +hi; and apratí, pratikāmá, pratikúla, prátiprāça, prativartmán, prátiçatru, pratyákșa, pratyáñc.) 
pratiokāmá: -ám. I 8. 3. 46". pratikāmăya. 2. 36.7 .

pratiokā m yà:-mías. 2. $36.5,6,8$. pratikămíam. 6. 60.3.

pratiokt́la:-am. 5. 14. I3. 10. I. 7. prati॰kroçá: -çé. 4. 36.3. [5. pratiograhitṛ́: -tâ. 3. 29. 7. 4. II. pratiocákşaṇa: -ṇe. I. I8.3. pratiojaná: -năs. 3. 3.5. pratiodivan: -vne. 7. 109.4. pratiodúh: -dhúk. 9. 4. 4. [IO. 16. pratiodhă : -ấm (inf.). 8. 8. 20. II pratiodhí:-dháyas. I4. I. $8^{*}$. prationándana: -am. 7.38. I. pratiopaṇa: -ás. 3. 15.4. pratiopāṇá: -năya. I9.52.3. práti॰prāça: -as. 2. 27. I-6. pratiomá: 8. 9.6. 9.4.2. pratimăm. 3. 10. 3. I 8.4 .5 . pratiomăna: -am. 5.2. $7^{\dagger}$. pratiomít: -tām. 9. 3. I. pratiovartmán: -má. Io. I. 9. prátioveça: -çăs. 3. 15.8. 19.55. I, 2.

práti॰çatru: -ravas. 4. 22.6. prati॰çIvan: -vari. I2. I. 34 . pratișțhă (p.-tiosth-): I2. I. 6. Ig. 6o. 2.

pratișţhăm. 6. 32.3. 8. 8.21. 9. 6.44. I0. 2. I. I8. 4. 5. I9. I I. 6*. pratișțháyā. I I. 3. 49. I 9. I 7. 9 (mss. -țhăyā, p. -ầyāḥ).

pratișțháyām. 5. 24. I-I7.

pratișţhé (p. -é íti etc.). 4. 26. I, 2. pratișțhăs. I2. 3.25.

pratiş ț $\mathbf{h} \bar{n} \mathbf{n}$ in apratișthāná.

pratișțita in trípratișțita, súpratișthita.

pratiosará: ás. 2. II.2. 8. 5. I, 4 . pratisaréna. $4.40 .1-8$.

pratisarāís. $8.5 \cdot 5,6$.

pratisutvan in prātisutvaná. pratiospấçana: -am. 8. 5. II. pratiohárạ̣a: -ṇena. 5. I4.8. pratika in ghṛtápratika, vyāghrápratīka, sinhápratīka, suprátīka. pratíkāçá (p. -tiok-): -ás. 9. 8.6. pratíciká: I9. 20.4. praticina: -as. 9.3.22. I0. I.6. pratícínäya. II. $2.5 ; 4.8$.

(cf. praticinaphala.)

pratic Iná: -ás. 4:32. 6".

praticina。phala: -as. 4. 19.7. 7. 65.1 .

pratita in ápratíta.

pratitta in ápratitta.

pratípá: -ám. 20. 129. 2 (m. mss. prátipam). [13.

pratíbodhá (p. -tiob-): -ás. 8. I. pratíbodhéna. 8.6.15. 19. 35. 3 . (cf. bodhapratibodhá.) [ 16

pratívartá (p. -tiov-): -ás. 8. 5.4, pratīhārá (p. -tioh-): -ás. II. 7. I2. pra॰todá: -ás. 15. 2. I-4. pratodin in çronipratodín.

pratná: -ás. 6. IIO. I*. pratnăsas. I 8.3 .21 ". pratnắn. 6. 136. 2.

pratyákṣa (p. -tioák-): -am. 9.6. I. I0. $7.24,29,30$. II. 8.3 .

pratyáñ c: -áñ. 3. 20. $2^{*}$. 4. I I. 8 ; I9. 7. 6. 5 I. I. 9.7.2I. II. 1. 22 . I3. I. $56 ; 2.3,20^{3 *}$. I5. 18. 5. I8. I. $29^{*}$. I9. 53.3 .

pratyák. 4. I8. 2 ; I9. 5, 6; 40. I-8. 5. I3. 4 ;30. 5. 8. 3. $14^{*} ; 5.2,15.10$. I. 5 .

pratyáñcam. 7. 40.2. 8. 3. $17^{*}, 25$. I I. $3.26,29,32-49$. I2. 2.55 .

pratyáñcas. II. 7. 13.

pratícas. 3. I. $4^{\dagger}$. 5. 8. 7. 6. 32.3 . 7. 108. 2.

pratî́cás. 8. 3. $6^{*}$.

pratícI. 3. 27.3. 7. $38.3^{3} ; 46.3$; I08. I. I2. 3. 9 .

pratícim. 9. 3.22. II. IO.26. I2. I. 34. I5. $2.3 ; 14.3$.

pratícyāi. I2. 3. 57 .

pratícyās. 4. 40. 3. 5. I0. 3. 9. 3. 27. I2. 3.24. I5. $4.3^{2} ; 5 \cdot 3^{2}$. 18. 3. 27. I9. I7. 5 ; 18.5 .

pratîcyām. 3.26.3. 4. I4.8. I5. 2. 3 . I 8. 3.32 .

pratî́cìs. I. 28.2 . 8. 5.5,6. I0. I. 6 . (cf. pratīka, pratīcikă, pratícína, pratīcīná.) 
pratyabhicárạ̣a (p. -tioabh-) : -as. 2. II. 2.

praotrāsá: -ám. 5.21.3. pratrāséna. 5. 2 I. 2.

$\checkmark$ prath: prathasva. II. I. I9. prathatām. 3.22. I. I 2. 1. $2 ; 3.38$. práthamānā. I2. I. 55 . práthamānās. I I. I. 32 . áprathethām. 4.26. I. paprathé. I9. 3.3. paprathāná. I2. I.6I. pratháyate. 6.72. I. pratháya. I2. 3.37. pratháyasva. 6. IOI. I. áprathayas. 20. I28. 2 (mss.).

(cf. pṛ́thak, prọtha, pớthī, prọthú, prothivî, práthas, práthiștha.) + vi: ví... prathate. 5. I2. $4^{*}$.

prathamá: -ás. I. I2. I; 24. I. 4 . 6. $\mathrm{I}^{2} ; 14.5 ; 24.6$. 5. I. $2^{2} ;$ I $7.2^{*}$; 28. II. 6. 28.3 . 7. $82.4,5$. 9. 2. I9. I 0. $2.8 ; 4 . \mathrm{I}, 6 ; 8.28$. I I. 5.9 I 3 . I. 55. I4. I. 55 . I 5. I 5. 3; I6. I ; I 7 . I. I8. I. I $9^{*}, 30^{*}, 50^{*} ; 3.13^{2}, 73$. I9. 4. I; I3. I ; 22. 2 I 32. IO; 53.2. prathamám. 4. I. I; $3.4 ; 6.3 ; 39$. $2,4,6,8$. 6. 59. I; 65.3. 8. 9.24. 9. 9. $4^{*}$. I0. $4.18 ; 7.3$ I. I2. 3. I. I4. 2. 3. I8. 2. 57 . I9. $42.4 ; 46$. I; 52. I*. prathamá. I. $24.2 ; 27.4$. 2. 25.2 . 3. I0. I, 4. 4. 30. $2^{*}$. 6. 108. I. 7. 80. 4. 9.3. 22 ; I0. $23^{*}$. I0. 9. I. prathamám. 6. I8. I; I08. 2. 7.74. 2. I9. 4. I.

prathaména. II. 8.33 .

prathamáya. 4. 1. $2^{2}$. 7.14.3.

prathamásya. 4. $21.5^{*} ; 23.1 ; 24$. 6. I8. I. $7^{*}$. I9. $25 . \mathrm{I}$. prathamásyās. 6. I8. I. prathamá. $4 \cdot 32.7^{*}$. 5. 12. $7^{*}$. prathamé (p. -é íti). I 8. I. $29^{*}$. prathamás. $5 \cdot 17 \cdot I^{*} \cdot 7 \cdot 50 \cdot 7^{*}$. 10 . Io. 8 . prathamấni. $\quad 2.5 \cdot 3^{*} . \quad 7 \cdot 5 \cdot \mathrm{I}^{*} . \quad 9$. prathamá. $4 \cdot 7 \cdot 7$.

prathamébhyas. I9. 22. 8. [syà.) (cf. prathamajá - prathamavāprathama。já: -ás. 4. 4. 5 . prathamajám. I. 35.2 .

prathamajấs. 5. I7. $I^{*}$. 10. 7.14. prathamajá. 8. 9. I6, 21 .

pratham a०jă :ấs. 4. 35. I. 6. I22. I. 9. IO. $15^{*}$. I2. I. $6 \mathrm{I}$.

prathamajăm. 2. I. $4 ; 5 \cdot 7^{*}$. [5. prathama。vāsy à: -síam. 2. I3. práthas: I3. 4.53.

(cf. sapráthas.)

práthișța: -am. 8. 3. I* $\left[50.3^{\dagger}\right.$. praodakșiṇá: -ám. 2. 36.6. 7. p r a d a di in ápradadi, súpradadi.

pra。dātŕ: -tă. 3. 29. 4, 5 .

pra०dív: -dyāús. I8. 2.48. pradívas. I. I5. I.

praodíç:-çam. I2. 3. 7 . pradíçā. 5. $12.4^{*}, 7^{*}$. 9. IO. $17^{*}$. pradíçi. I. 9. 2. 4. 23.7 ; 28. I. 7. 25.2 .

pradíças. I. II. 2 ; 30. 4. 2.6.I ; I0. 3,4 . 3. 4 . I, $2 ; 20.9 ; 22.5 ; 24$. 3. 4. $2.5^{*}$; II. I ; I 5.1 ; 20. 2 ; 35 . 5. 5. 3. $\mathrm{I}^{*} ; 28.2$. 6. 40.2. 8. 5.3. 9. 2. II, 2I; IO. I9. Io.6. I9; 7. I6, 35. I I. 2. IO; 5. I $2 ; 6.22$. I2. I. 4,3 I, $55 ; 3.30$. I3. I. $38 ; 2.33,34$; 3. I, 20. I7. I6. I9. I. 3 ; 10. $8^{*}$; I4. I ; 20. $2 ; 33.5 ; 45.3$.

pra。dhána: -neșu. I8. 2. $I 7^{*}$.

praodhí: -ís. 6. 70. 3 .

pradhāú. 6. 70.3. I 8. $2.14^{\dagger}$.

pradháyas. Io. 8.4 .

pra。paṇá: -ás. 3. I5. 4 . prapanám. 3. I5.5,6.

prá。patha: -the. 7.9. $\mathrm{I}^{3^{*}}$. I8. 2. $55^{*} ; 3.49^{\dagger}$.

prá opa d: -dos. 6. 24. 2.

prá opa da:-dena. 6. 42. 3 .

prápadābhyām. 2. 33. $5^{*}$ (1. -bhiām).

I I. $3 \cdot 47^{2}$.

prápadāni. 8.6. is

pra०pá: 3. 30.6.

prapāṇa in aprapāná, suprapāṇá.

pra。pitāmahá: -hấn. I8. 4.35. pra。pitvá: -tvé. 3. I6. $4^{*}$. [I. 27. pra。prethák. 6. I22. 5. I0.9.27. I I. pra。pyasá: -sấs. Io. 7. I6 (ed. prathamăhạ). 
pra॰pharvi: -víam. 3. $17.3 . \quad 5$. 22. 7 .

pra०búdh: -dhãm. 5. 3. 2".

pra。bhá : tús. 9. 4.2. 13.4. 47.

prabhú. 20. I 35.9 (mss. -ús).

prabhvís. 12. $3.27 .18 .3 .69 ; 4.26$. práobhṛti: -is. 2. 35.5 .

práomati: -is. 7. 20.5. I8. 3.63. prá०m a d(?): -dā. I9. 56 . r.

prá $\circ$ a n a s: -nās. 2. 28 . I. pra $\circ$ m a d a ná: -nt. 4. 37.3. pra॰mayú: -ús. 8. r. I6. pra。mấ: 10. $7 \cdot 32$.

pram ā da in ápramāda.

pramāy uka in ápramāyuka. pra。mãrá: -réṇa. II. 8. 33 . praomilín: -nam. 8.6.2. [I. I3". pra。múd:-das. II. $7.26 ; 8.24$. I 8 . pramocana in unmocanapramocaná.

pra०móta: -am. 9. 8. 4 . pra॰modín: -nim. 4. 38. 4 . pra॰yáj: -ákșu. 5. 27.5,6. pra० yājá: -jấs. I. 30. 4 . prayāṇa in anuprayậa. prayā va in áprayāva. prayuchant in áprayuchant. pra॰yúj: -jas. II. 8.25. praorúh: -has. I3. I. 8, 9. praolá yana: -am. I. 23.3. praolāpá: -pâs. II. 8. 25 .

praovát: -tam. 6. 28.3.

pravátā. 3. I. 4 ".

pravátas. 4. 25.6 .

právatas. 1. 13. 3 .

pravatas. I. I3. $2 ; 26.3$.

pravátas (pl.). I0. I0. 2,3 . I2. I. 2. I3. 2. 28,33 . I8. I. $49^{*} ; 4.7$.

praovadá: -ás. 5. 20.9.

pra॰vartá: -tāú. I5. $2.1-4$.

pra०vấ: -ấm. I2. 1.5I.

pra。vāy y à : -vāyíam. 6. I05. I.

pravāhín: -ínas. 20. 127.2 (mss. -văhi-).

prá。vira: -as. I9. 13.5*.

praveda in

pravedaokŕt: $\quad$ 5. 20.9.

praçasta in supraçastá. práçasti: -ti॰bhis. I. $4 \cdot 4^{\dagger}$.

prą̧işţa in ŕşipraçişţa. [4.27.

pra॰ ९́is: -íşam. 4. 2. I". 13. 3. $24 "$ ";

praçíşā. 6. 133.4. .14. 1. 53.

praçíşi. 5. $12 . \mathrm{II}^{\dagger}$.

praçíşas. I I. 8.27.

prą̧ o can a in uchocanapraçocaná.

prą̧na in sampraçná.

práști: -is. 13. r. $2 \mathrm{I}^{*}$.

práş̧̨im. 20. 128. 15 (not mss.).

práşțayas. ro. 8. 8 .

praosavá: -vé. 3. 20.8. 6. 92. I. 7. 6. 4. 8. 9.8. I9. 5 I. 2 .

prasavănām. 5.24 . I.

praosâd ha ana: -as. I3. I. $60^{*}$. [46".

práositi: -im. 8. 3. I I", I4". I4. I. prásitāu. 8. 4. $13^{*}$.

pra०sút: -ús. 3. 23.4 .

prasúas. 19. I0. $7^{*}$.

(cf. prasúmant.) [tiprasūta. pras ūta in deváprasūta, bṛ́haspáprastúmant: -matīs. 8. 7.27.

pra ostará: -ás. I6. 2.6.

prastarám. I8. 1. $60^{*}$.

prastarấya. I6. 2.6.

prastarana in rukmáprastaraṇa. prastha in

prasthăovant: -vat. 3.17.3.

pra。hâa: -ầm. 4. 38.3. 7. 50.6*.

pra o hā y y à : -yàs. I 5. 3. IO.

pra॰hāsín: -nas. 8. 6. I4.

prahita in áprahita.

praohé y a: -yã. 5.17. $3^{\dagger}$.

prahrāda in prâhrādi. $\quad\left[\mathrm{I}^{\dagger}\right.$.

V prā: piprâyasva ( $/$ prī?). 6. I IO. (cf. pra.)

+ ã: ầ paprāu. I9. 49. I.

a papre. II. 2. 27.

ấ 'prāt. I 3. 2. $35^{\dagger}$.

à ... aprāyi. 19. 47. I.

prāktás. 8. 4.19†. I8.3.3.

prācína: -am. 4. I1. 8. 5. 12. $4^{*}, 7^{*}$. (cf. prācínapakṣa, prācīnopavītá.)

prā cín a opakṣa: -ṣā. 3. 25.3.

prācīnopavitá (p. -naoup-): -ás. 9. I. 24.

prāc yà : -cíam. 4. 7.2. 
prājā p a tyá: -ás. 9. 6.28. prājāpatyám. 3. 23.5. I8. 4. I2, I3. prājāpatyăbhyām. I9. 23.26. prājāpatyás. II. 5.22.

prẫ̃ c: -ăñ. 3. 4. I. 9.7.20； 10. I6*. I0. 8. Io. I3. 2.3. I5. I8. 5 . prăk. 20. I28. I ; I34. I-6.

prâñàm. 8.3.9. [7. I5. 3.6. prăñcas. II. 6. I8. I2. 2. $22^{*}$. I3. 4 . prấcī. 3. 27. I.

prăcīm. 7. I7.2. I2. 3.7 (prấcīm。 prā-). I5. 2. I ; I4. I.

prấcyāi. I2. 3.55.

prắcyās. 4. 40. I. 5. 10.1. 6. 98. 3. 9. 3. 25 . I5. $4 . \mathrm{I}^{2} ; 5 \cdot \mathrm{I}^{2}$. I8. 3 . 25. I9. I8. I.

prăcyām. 3. 26. I. 4. 14.7. 5. 4 8. I5. 2. I. I8. 3. 30 .

prấcīs. 5.28. II. I2. I. 3 I.

(cf. prāktás-prācyà.)

pránjan a (p. praoánj-): - nat. prāná: -ás. 2. 28. $3.5 \cdot 9 \cdot 7 ; 30$ I I5. 6. 5.3. 2 . 7. 3I. $\mathrm{I}^{*} ; 53.3,4 . \quad 8$. I. 3,15 . 9. I. 2,$4 ; 2.5,16 ; 5.2$ I. IO. 2. 27,$30 ; 5.25-35$. II. $3.56 ; 4.3$, 4: $5, \mathrm{IO}^{2}, \mathrm{II}^{3}, \mathrm{I}^{3}, \mathrm{I}^{2}{ }^{2}, \mathrm{I} 5, \mathrm{I} 7,24$; 9. $2 \mathrm{I}$ 12. 5. 9. I3. I. I7-9. I 5. I 5. 3-9. I6. $4.3 ; 7.13$. I8. $2.26,46 ; 4.5^{8+}$. I9. 44. 5 ; 5 I. I ; 537 ; 58. I, 2 ; 60. I. prằna. II. $4.26^{2}$. I9. 44.4 .

prāna. 2. I5. I-6. I I. $4.2^{3}, 7,8,9^{2}$, I4, I6, 18, I9, 23.

prāṇám. 2. 34.5. 4. 5.4; I5. 10. 5. 8.4. 7. 53.6. 8. 2.3, 13. 9.6. I9. I0. 2 . 13,$29 ; 5.35,36$. II. $3 \cdot 54,55$; 4. II, I2 ${ }^{2}, I_{5} ; 8.3$ I. I2. I. 22 . I3. 3. 5. I5. II. 5 ; I4. II. I6. 8. I-27. I9. $27.5 ; 6 ; 44.4 ; 46.3 ; 58.2 ; 63$. I; 7I. I.

prāṇéna. 3.13.5; 29.8; 31. 6, 7,8, 9. 5. 30. 14. 6.62. I. 7.8I.5. 8. $2.4 ; 9.9$ I0. 8 . 19. II. $4.6 ; 7.23$. I3. 3. 4. I5. I4. II. I9. $27.2,7^{3}, 8$. prāṇấya. 5.4.7. 6. 10. $2 ; 4$ 1.2. 8. 2. 4. II. $2.3 ; 4$ I. I9. 45.6-IO. prānăt. 6. 31. $2^{*}$. I0. 5.35. 19.6. $7^{*}$. prānásya. 5. 30. 10. [152. prāṇé. 9. 6. 22 . I0. 5. 44. II. 4. prāṇấs. 6. I04. I. 8. I. I. II. 3. 28. I5. 15.2. I7. 30 . 19. 46. 5 . prānăan. 2. 12. 7. 3. 31.6. 5. 28. r. 6. I35.2, 3. II. 5. 22. I2. 5.27. I9. 43. 2.

prānéșu. 3. I5.7.

(cf. aprāná, sahásraprāṇa, svadhăprāṇa, prāṇada--prāṇāpāná.)

prāna a dá: -ás. 4. 35.5. (cf. prānaadávant.)

[-dầ-). prāṇadá ovant: -vān. 4. 35.5 (ed. prāna nt in áprāṇant.

prāṇáosam çita: -as. I0. 5.35.

prāṇāpāná: -nāú. 5. 10.8. 7.53. 2. 8. 2. II. IO. 7.34 . II. $4.13 ; 5$. $24 ; 7.25 ; 8.4,26$. I6. 4.7 .

prănāāpānāu. 2. I6. I. I6. 4.5. prānāāpānāu. 3. II. 5,6. 7. 53.5. prāṇāpānăbhyām. 2. 28.4 prāṇāpānăs. II. 3. 2, 38 . prāṇāpānăn. II. 9 II. prānāpānāís. II. $3 \cdot 3^{2}$. I2. 3. 28 . prānāhá: -ásya. 9.3.4.

prātár. 3. I6. I $^{6 *}$. 4. II. I2. 6. 108. 5 ; I28.2. 7. I0I. I. 9.3.I8. II. 2. I6. I3. 3.13. I9. 55.3 (prātáḥo prātaḥ), 4 (do.).

(cf. sāyámprātar, suprātár, prātarjít, prātahsavaná.) [2* prātarjít (p. -tahojo): -tam. 3. I6. prātaḥosavaná: -né. 6. 47. I. 9. I. II.

prātisutva ná: -ám. 20. I29. 2 (mss. prâtisutvánam).

prādús. 9. I. 24

prấpti (p. práoāp-): -is. II. 7.22 (l. práāp-).

prābandha in késaraprābandhā. prāyá (p. praoāy-): -ám. 4. 25. 2. prāy a ña in suprāyaná.

prấy açcitti: -im. I4. I. 30.

prărtha (p. praoár-): -as. 5. 22.9. prāvi in suprāví.

prāvị́ṣ: -șā. I9. 6. I I†.

prāvị́sii. I2. I. 46.

práą: -çam. 2. 27. I-6, I, 7.

prāçí. 2. 27.7.

(cf. prāça.) 

prā ça in prátiprāça. $[25,32$.
prā çit tṛ (p. pra॰aç-): -tăras. II. I. prầhrādi: -is. 8. 10. 22.

priyá: -ás. 2. 36.4. 4. 22. $4^{2} ; 37$. II. 6. $58 . \mathrm{I} ;$ I 30. 2 . 8. Iо. 3 . 9. I. II, I2, I3 ; 6. 44. I5. II. 7 ; I5. 8 . I7. $2,3,4,5$. $18.3 .7^{\prime \prime}, 53^{\prime \prime}$.

priyám. 2. $28.5 ; 34.2$. 3. 5.3. 4 . 3I. 5*. 6. 47.2. 7. I4. I; 29. $2 ; 32$. I*. 9. 2. 2 . II. 4. IO. I2. I. $7 ; 2$. $34^{2} ; 3.32$ (mss. -yắm), $49 ; 4.40^{2}$.

I4. I. $2 I^{*}$. I5. 2. I-4; 6. I-9;8.3; 9. 3 ; II. $2,6^{2}, 7$. I9. $32.8 ; 62 . I^{3}$.

priyâ. I0. 8. 25. II. 4.9 ; I0. 5 , I5. 12. 3. I.

priyăm. 4. I8.4. I8. $3.4 \mathrm{I}^{*}$.

priyásya. I5. II. 7.

priyé. 12. I. 52.

[2. 5*.

priyăs. 7. 61. I. 9. $5.30 ; 6.23$. I4.

priyăn. r8. $4.6 \mathrm{I}^{t}$.

priyạni. 13. I. II.

priyănāām. 12. 3.49.

priyéşu. r8. $3.45^{*}$.

priyáotamas. 5.30 .17 .

priyáotamam. 5.28.6.

priyáotamā. I4. 2.50.

priyáotame (p. -e íti etc.). 7. 9. I*.

(cf. ápriya, sámpriya, súpriya, priyátanu-priyấvant.)

priyátanu: -nos. 5. I8.6 (oiva). priyáodhāman: -mā. I7. Io.

priyaovādín: -ni. 325.4 .

priyāpriyá (p. -yaoap-): -yânịi.

I0. 2. 9.

V priyāy: priyāyámānās. I9. 27 . Io (mss. priyầya mấnā).

+ ni: nipriyāyáte ( $\mathrm{p}$. ni॰priyay-).

I2. 4. II, 2 I, 25.

[18.4.

priyăvant (p. -yáov-): -vate. 4. V prí: piprấyasva ( $/$ prā ?). 6. I Io. $\mathrm{I}^{\dagger}$.

prîtăs. 10. 9.4 . [préyas.)

(cf. priyá, pri, prinnāna, prení ? $+\overline{\mathbf{a}}$ : ef. āprí.

pri in āprí, ghrtaprí.

prịnā $\mathbf{n}$ a in prāināná (?).

$\checkmark \mathrm{pru}$ in prut.

prut in udaprút.

V pruṣ: prușántas. 20. I34. 2 (mss. prúşá-, púruşa-).

(cf. pruş, pruşva.)

$+\mathbf{v i}$ : cf. vipı ús.

prus in viprús.

pruşa a: 18. 3.60.

preñkhá (p. pra。Iñ-): -khăs. 4. 37

pre ní: -ṇiás. 6. 89 . I.

pré y a s: -8I. II. 4.9.

prāiṇāná: -ás. 5. 27.3. [II. 7. I8.

prāişá (p. praoeş-): -şấs. '5. 26.4. prāişāís. 16.7 .2$.

prokşa na (p. praoúk-) : -ṇis. 10. 9. prókşaṇībhis. 5. 26.6.

prost ha in

prósțha०pada: -dā. r9. 7.5. and proşţheoçayá: -yấs. 4.5. 3".

pla kşá: -şăt. 5.5.5.

plavá: -ám. r2.2.48. (cf. áplava.)

plāęí: -ís. I o. 9. I7. plāçés. 2. 33. 4. plāçáyas. 9.7. 12.

plīhán: -hắnam. 3.25.3.

plīhnás. 2. $33 \cdot 3^{\dagger}$.

$\checkmark$ plu: plavasva. 4. I5. I4. (cf. plavá, pluta.)

$+\bar{a}$ : à plavante. 20. I29. I. [2. I2. + pra: prá plavantām. 3.6.7. 9 . plut a in udaplutá.

ps ar a s in apsarás (?).

V psā: psātás. ro. 3. I4.

psāhi. ro. 3. I4.

psātu. I0. $5 \cdot 43$.

pháț. 4. 18. 3.

pharva in prapharvi.

phál 20: I35. 3 .

phála: -am. 6. I24. 2.

phálasya. 20. 136. 9.

(cf. aphalá, pratícínaphala, phálavant-phalikkáraṇa.)

[3I. 3.

phála ova nt: -vatīm. 7. 50. 9. I 9.

phalín: -nam. 3. 15.4.

phalínis. 8. 7.27 .

phalíokárạ̣a: -ṇās. II. 3.6.

phálg una: -nyāu. I9. 7.3.

phálgunișu. I4. I. $13^{\dagger}$. 
phāka (sphāka) in pībasphāká.

phàla: -am. I0. 6.6-Io.

phálena. I0. 6.33 .

phălāt. I0. 6.2.

(cf. suphālá.)

phéna: -am. I. 8. I. I2. 3. 29.

phénān. 6. II3. 2.

bajá: -ás. $\quad$ 8.6.6, 7, 24 .

bajám. 8.6.3.

bát.. I 3. 2. $29^{2 *}$.

b a ṇ á: -déna. 7.65.3.

baṇdáyā. I2. 4. 3 .

batá: -ás. I8. I. 15 *

bata. I8. I. $15^{*}$.

báddha (bádva?): -dhe. I3. 4.45 (mss. -ddhe, -ddhve, -dhve).

báddhāni. I3. $4 \cdot 45$.

b a d dha in subaddhá and

báddhaka: -am. 6. I2I. 4.

(cf. baddhakamócana.)

[3.

bad dhaka omócana: -am. 6. I2I. ba d h in ābádh.

$\checkmark$ b a dh, see $/$ bādh, $/$ vadh.

b a dhirá: -ás. II. 3. 33 .

badhirấs. II. 9. 22.

ba d hú

bádhya: -dhias. I8. 2. 3I. [madh-). badhyatás. I2. I. 2 (m. mss. $\checkmark$ b a nd h: badhnămi. II. 4. 26.

badhnāmi. I. 35 . I. 3. 5. 8. 4. Io. 7 . 5. 30. I. I 9. 28 . I ; 32. I ; $33.4 ; 46.1$. badhāna. I0. 5.44 . I9. 57.4 (not mss.).

badhnātu. 8. 5.22.

badhnantu. 8. 5. ro.

ábadhnāt. I 0. 6.6-I7, 22-8. I4. I. I9*, $58^{*}$.

abadhnāt. I9. 46. I.

ábadhnan. I9. 6. I5*.

abadhnata. I0. $6.18^{2}, 19^{2}, 20^{2}$.

bedhise. 6.63 .3 .

baddhvă (mss. badhvă). 7·38.5. 8 . 8. 10. I0. 6. I8 (1. -dhuá).

baddhás. 2. I $2.2 ; 35.3$. 6. III. I. 20. I35. I3.

baddhám. 7.12. $4 ; 42.2 *$. baddhă. 5. 30. I6.

baddhắnäm. 6.84. I.

badhyáse. 6. I2I. $2^{2}$.

badhyáte. 9.6.6. I8. 4. 70.

badhyate. 8. 5. I. I4. I. 26*. I9.

3I. I $4 ; 45.4$.

[37.

badhyatām. I. I4. $2 ; 29.4$. I2. 4 . badhyantām. 3. I7. 6*.

badhyámānam. 2. 34.3.

(cf. baddha, badh, bandhá, bándhana, bándhu, bandhra.)

+ a nu: anuobadhnánti. 5. I9. I2.

$+\overline{\mathbf{a}}$ : á badhnanti. 3. $9 \cdot 3$.

à badhnāt. 6. 8 I. 3.

ábadhnan (p. āoáb-). I. 35.3.

āobabándha. 6. 63. I ; I33. I.

āobedhús. 9.3.6.

āobedhé. 5. 28. II

āobádhe. 5. 28. 11 .

+ upa: úpaobaddhān. I. 7.7.

+ ni: ní badhnimas. 4. 38.7.

+ pari: pariobedhiré. 6. 133.5 .

+ pra: cf. prābandha.

+ vi: víobaddhas. 5. 20.2. 6. I12.3.

b andhá: -ás. I0. 5.44. I9. 56.2

(mss.).

bandhám. 5. I4. IO.

bandhăt. 6. I2I. 4 .

bandhébhyas. I9. 45.5 .

bandhéșu. I4. I. 26*.

(cf. kábandha?, paçubandhá, prābandha, bandhapāçá.)

bándhana: -am. 6. I4. 2. [1.17. bándhanāt. 3.6.7. 9. 2. I2. I4. (cf. híranyabandhana.)

b a nd ha $\circ \mathrm{pa}$ çá: -çắn. 6.63.2; 84.3. bándhu: -us. 2. $1.3^{\dagger}$. 4. I. 3. 5 .

II. IO, II. 9. IO. 12*. IO. IO. 23.

bándhu. 5. 13.7; 22.8. I0. I. 3.

bándhunā. I9. 56.5 (mss. bandhú-). (cf. abandhú, devábandhu, pitrbandhú, mātṛ̂andhú, víbandhu, sábandhu, subandhú, bandhukṛt.)

bandhukrt in ábandhukṛt.

bandhúr: -ras. 3. 9.3.

bándhura: -rā. 3.9.4.

bándhuram. I0. 4. 2.

b a nd hra (-nddhra) in abandhrá. 
b a bhri: bábhre. II. I. 32 . babhrés. II. I. 31 .

b a bhrú: -ús. 5. 23.4. 6. I6. $3 ; 93$. I. II. 5.26.

bábhro (p. -o íti). 5. 13.5 .

bábhru. 6. 139.3 .

babhrúm. I2. I. II.

babhrúnā. 4. 29.2. 5.7.5.

- babhráve. 6. 20.3; 56.2. 7. 109. I. babhrós. 2.8.3. 5. 13.6.

babhrávas. 8.7 .1 .

babhrún. 7. 109. 7 .

(cf. ajababhru, babhrúkarṇa.)

babhrú。karṇa: -as. 5.23.4. 6 . I6. 3 .

b a rja h y à : -yè (p. -è íti). I I. 8. I4. b a rh a in mușkābarhá, vĩbarhá.

barh a ṇ a in upabárhạ̣a, mūlabárhana.

b a rh i șá d (p. -iosá-): -das. I 8. I. 45*" bárhișadas. I8. I. $5 \mathrm{I}^{*}$.

b a rhiṣy à : -ṣíeșu. I 8. 3. $45^{*}$.

barhís: 5. 12. $4^{*}, 8^{*} ; 22.1 ; 27.9 .7$. 98. I. 8. I. I6. 9. 4. Jo; 6.8. Iо. 9. 2. I2. $3 \cdot 32,33$. I $8.4 \cdot 51,52,68$. 20. $49 \cdot 3$.

barhíșā. $\quad$ 5. 26. 6.

barhíși. 7. 58. 2*. I0. I. I 8 ; IO. I 2 , I 7. I 8. I. $42^{*}, 59^{*} ; 3.20,44^{*}$. [yà.)

(cf. jivábarhis, barhișád, barhiș-

bál a: -am. I. $35 \cdot 3$. 2. 1 7. $3^{2} ; 26.4$. 3. I9. I, 2 . 4. 24. 2 . 5. 9. 8 ; 30. I3. 6. $6.3^{*} ;$ 126. $2^{*} ;$ 135. 1. 7. $54.2 ; 56$. 6. 8. I. $15 ; 7.5,22$. 9. I. $17 ; 7.9$. I0. $2.15 ; 5 . \mathrm{I}-6 ; 6.7$; IO. 20 . II. 7. I7;8. 20. I2. I. $8 ; 5.7$. I5. I4. 2. I 8. 4.53. I9. $33.4 ; 37.1$ (m. mss. balám), 2 (do.); 4I. I ; 43. 6; 46.3; 6o. I.

bálena. 3. 5. I. 4. 25.4. 5. 30. I4. 6. 92. 2. 7. 82.2. 9. 2.6 I3. I. 6. I5. I4. 2. I8. 2. 59, 60

bálāya. I. 35.1 . 3. I5. $3^{*}$. 4. IO. 7. 6.63. I. II. IO. II. I9. 26. 3 ; $37.3 ; 46.1$.

bále. 2. 29. I. II. 7.17.

bálā. I. I. I.

(cf. abalá, tanūbalá, yathābalá, sábala, hṛdbalá, baladă-balavijñāyá, balín, báliyas.)

balá: -ám. 2. 5.3. 4.23.5. 9.3.2. I9. 28. 3 .

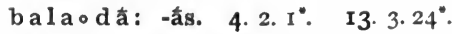
b a l a $\circ$ dăv a n: -vā. 4. 32. $5^{\dagger}$.

bála。vant: -văn. 6. 92.2.

bálavatotamas. 5.4.1.

bálavatotamām. 3. I8. I".

bala。vijñāyá: -ás, 19. 13. $5^{\circ}$.

balats a : -as. 4. 9.8. 9. 8. 10.

balăsa. 6. I4. 3 ; 127.2 .

balầsam. 5. 22. II. 6. I 4. I, 2.9 . 8.8. 19. 34. I0.

balâssena. 5. 22. I 2.

balăsasya. 6. I27. I.

(cf. abalāsá, balāsanăçana, balāb a lāsa

balāsín: -nas. 6. 14. 2.

balí: -ís. II. IO. 5 . 20. I3I. I7 (m. mss. ed. dhaváḥ).

balím. 3. 4. 3. I 0. 7.39; 8. I5. I I 4. I8, I9. I9. $45.4 ; 55.7$ (m. mss. ed. bálim).

balínā. 6. I I 7. I.

(cf. păkabali, çákabali, balihārá, balihṛ́t.)

balín: -lî. 3. I5. I.

balínas. 14. I. $2^{*}$.

ba li ohārá: -rắya. II. I. 20. [I.62.

baliohŕt: -tas. II. I. $6 ; 4$. I9. I2.

bálíy as: -se. 3.29.3.

bálbaja: -am. I4. 2.22, 23.

balça in çatábalça.

bálhika: -kān. 5.22.7,9.

bálhikeșu. 5. 22. 5 .

b a șká y a: -ye. 9. 9.6".

bast $a$ in

bastaovāsín: -nas. 8. 6. I2. and bastābhivāsín (p. -ta。abh-): -nas. I I. 9.22 .

bahís. I. 3. I-5,6-9. 9. 8. I-9, I I, I3-8. I9. 44.2 (m. mss. barh-). (cf. băhya.)

bahú: -ús. 6. I42. I. 7.60.3. bahú. I. IO. 3 . 3. $5.4 ; 24.2$. 4 . 28. 4 ; 34. 2. 5. 2 I. 5 . 6. I II. 2.8. 8. 20. I0. 8.22. II. 5.26 ; IO.4. I2. 
I. 2. I 8. I. I2*. I 9. 44. 8; 60. I (not] + a pa : ápa bādhatām. 5. 22. I. [8*. mss.). 20. 135 . I 2 (mss. -ús).

bahúm. 3. $4.3 ; 24.7$. 6. 5. I.

bahávas. I. 27.3 . 2. 13.5. 3. 15. 2. 6. 55 . I. I2. I. 47 ; 2.2 I. I3. 3. I7. 18. 3. 61 .

bahứn. I9. 32.6 (m. mss. -húm). bahúobhis. 4. 1. 6. 7.26.8. [49*. bahúobhyas. 5.20. 9. 6. 28.3. I 8. I. bahūnằm. 4. 31. 4*.

bahvis. 6. $96 . I^{*}$. II. $4.3 . \quad$ I3. 2. $4,6,7$.

(cf. bahucārín-bahusúvan.)

b a hu०cārín: -rí. II. 3.46.

bahuodhà. I. 33. 3. 2. 34. 4. 3. 4. 7. 4. I5. I6; 23. I. 5. 20. 4,$9 ; 26$. 7,8 , IO, II. 6. 7 I. I. 9. I. $3 ; 5 \cdot 1,3$; IO. $28^{*}$. I0. $4.23 ; 8.13$. II. 2. 17. I2. I. $4,44,45 ; 3.21,54 ; 4.29$. I3. 3. I7. I7. 6-19, 24. I8. 2.57. I9. 53.3. [10*. bahu $\circ$ prajás (or -jấ): -jấs. 9. ro. bahulá: -ám. 4. 15.6. 8. 5. I9. I2. 3. 8 .

bahulăm. II. I. I7.

bahulé. 7. 52. 2.

bahulấs. 3. 14.6. 4. 18. $3 ; 38.6$.

bahulăni. I9. 20. 2.

bahulâ. I0. 2. 9. I9. $58.4^{*}$.

bahulăn. 12. 3. 29.

bahulâbhis. 7.31. I*.

bahu०stúvan: -vari. 7. 46. 2*.

bāṭyá: -yấs. I9. 44.6 (mss. bāhyầs, băhyās).

băna: -as. 3.23.2. 6. I05.2.

bānáá: -ám. I0. 2. I7.

(cf. vănịi.)

$\checkmark$ bảdh: bādhe. 5.13.3.

bădhate. 3. $18.1^{*}$.

bādhate. I. 16.3. 2. 4:3. I9. 36 . 2. 20. $1_{3} 6.1_{5}$.

bădhasva. 8.6.25.

bădhatām. 7. 9I. I* .

bădhethām. 6. 97.2 $2^{\dagger}$ 7.42. $\mathrm{I}^{\dagger}$.

bắdhamānas. 6. $126.2^{*}$. 9. 5. 18 . I7. 17 .

babādhé. 9. 2. I8.

(cf. bādha, Vvadh badh.) apaobădhamānas. 12. 3. 15. 19. I3. ápa bādhaya. I2. I. 49 .

+ a va: áva bādhe. 4. 35. 7 .

áva bādhāmahe. 5. 3. 10*.

áva bādhasva. 4. 22. 7 .

+ ni: ní bādhathās. I8. 3.50*.

+ nis: cf. nirbādha.

+ vi: ví bādhase. $4.9 \cdot 4^{\dagger}$. ví bādhate. 20. 136.12 (mss. ba bādh-), I4.

ví ... bādhate. 8. 5. 7.

ví bādhete (p. -e íti). 8. 2.18.

ví bādhatām. I0. 3. II.

viobabādhé. 8. 96 .

(cf. víbādha.)

+ s a m: sám bādhișța. I8. 2. 25 . (cf. sambādha.)

bā d ha in nirbādha, víbādha, sambādha.

bầrhat a : -tāis. I4. I. 5 .

bārhatos̄am a: -me. 5. 25.9.

bārhaspatyá: -ás. 9. 4. I.

bâl. I. 3. I-5, 6-9. I8. 2. 22 .

I bầl a: -lāt. I 0. 8. 25.

2 bă l a: -lās. 9. 7.8 (s. mss. vầ-). 10. 9. 3, 22.

bălān. 12. 4. 7 .

bălebhias. ro. IO. I. (cf. vắra.)

bāhú: -úm. I8. I. II*.

bāhāú. 2. 27.3.

bāhúu (p. -û́ íti). 4. 2.5* 6.65. I ; 99. 2, 3. 7. 70.4, 5. 9. 4. 8; 7. 7. 10. 2. 5 ; 9. 19. 19.6. $5^{*}, 6^{*}$; 13. 1 ; $15.4^{*}$. bāhúobhyām. 2.33.2*. I3.2. $26^{*}$. I9. 5 T. 2 .

[hvos).

bāhvos. 7. 56.6. 19. 60. I (mss. băbāhávas. 3. I9. $7^{*}$. II. 9. I, I3.

bāhû́n. 3. Ig. 2. 6. 65.2. 8. 3.6* I I. IO. I6.

(cf. ugrábāhu, pŕ̛çnibāhu, vájrabāhu, çitibăhu, sahásrabāhu, subāhú, bāhucyút - bāhuçardhín, bāhvan̄ká.)

bāhu०c yút: -tā. 18. 3.25-8, 30-5. b āh u o mánt: -măn. I. 7.4. 13.1.30. bāhuoviry à: -ríe. 5. 21 . 10. 
bāhu०çardhín: -dht. 19. 13. $4^{*}$. budh in prabúdh, subúdh.

băh y a: -hiam. 2. 30. $4^{2}$.

băhyās. 19. 44.6 (s. mss. bāhyăs). bāhvañká: -huoañkāís. II. 9. 12. bindú : -ús. 9. I. 2 1. I0. 10. 19. I9. 30.5 (m. mss. bíndus).

bindún. I2. 3.29.

bi bhI vãns in ábibhivāns.

bibhyat in ábibhyat.

bibhrat in nāmabibhratí.

bíl a: -am. 7. 35.2. 9.8. I1, 13-8. I9. 68. I. 20. 127. 10.

bíle. I2. 3.13 .

(cf. koçabilá, cáturbila, tiryágbila, páñcabila, vastibilá.)

bilvá: -ás. 20. 136. 13 (not mss.), I 5 (mss. bilvas, bilvas).

bișkalā: -le. I. II. 3 .

bís a: -am. 4.34.5. 5.17.16. bija: -am. 3. 17.2* 10.6.33. I4. 2. $14,38^{*}$.

bîjāni. 3.23.4.

b I bhats ú: -ús. 9. 9. 8*.

bībhatsāú. II 8.28.

b I ça in páḍ̂iça.

$\mathbf{b} \mathbf{u} \mathbf{d} \mathbf{d} \mathbf{h}$ a in ghóşabuddha.

$\checkmark$ budh: bódhatu. 7. 48. $1^{*}$.

bódhantu. 8. 7. 19.

búdhyema. 19. 67.3 (mss. búdhe-, búddhe-, búdhre-).

búdhyamānā. I4. 2. 31, 75 .

búdhyamānāu. I4. 2. 43 .

bodhi. 4. 32. 6".

ábodhi. I3. 2. $46^{*}$.

abūbudhat. 20. 127. II (mss. áb-). bodhaya. I0. I. I7. 19.63. I.

(cf. buddha, budh, bodhá.)

+ a nu: ánu ... budhyate. 9. I. 24. ánu ... budhyasva. 9. 1. 24. ánu ... ábhutsata. I2. 4. 1 .

ánuobuddham. 4. 24.6. I0. I. I9.

+ ni: ní bodha. I9. 49.5 .

+ pra: prá budhyasva. 14. 2. 75 . (cf. prabúdh.)

+ prati: pratiobúdhyamānās. I2. I. 62 .

prátiobuddhās. $4 \cdot 37 \cdot 3,4$.

(cf. pratībodhá.)

budhná: -ás. I9. 56.2 (not mss.). budhné. 2. 14. 4 . I2. 3. 30 .

(cf. ūrdhvábudhna, prthúbudhna, mahăbudhna, budhnyà.)

budhny à: -nías. I9. II. $3^{*}$.

budhnyằt. 4. I. 5.

budhniás. 4. I. I.

$\checkmark$ bŗh : cf. barha, barhaṇa, barhís, bṛh, bṛhánt, bráhman, $\sqrt{ }$ vrrh.

+ upa: úpa barbṛhi. I8. I. II*.

(cf. upabárhaña.)

+ s a m: sám bṛhatam. I I. 9. II.

sám babarha. 9.3.3.

brrh in bṛ́haspáti.

b r há c ch a nd a s (p. -átocha-): -dās.

3. 12.3 .

[mss.).

b r háchravas: -vās. I9. 56.3 (not

bṛh ajjālá (p. -atojā-): -léna. 8. 8. 4 .

bŗhát: 4. 34. I. 8. 9. 4 ; I0. 13, I6. II. 3. I6. I2. I. I. I3. 3. II, I2. I5.

2. I; 3. $5 ; 4 . I^{2}$.

bṛhată. 8. 10. 14 .

bṛhaté. I5. 2 . I.

bṛhatás. 8. 9. 4. I5. 2. I.

brhati: 8. 9.4 $4^{2}$ I3. I. I5. I9. 2 I. I.

bṛhatim. 3. 3. 2.

bṛhatyấs. 8.9 .4 . (cf. bărhata.)

[30. 3.

bṛhatopalāça: bṛ́hatpalāçe. 6 .

bṛhátosāman:"-mānam. 5. 19. 2. (cf. bārhatsāma.)

bṛh a d o arká: -kím. 8. 9. 14.

b ṛhád gāva: -vā. I9. 56.3 (mss. bṛhád gầvã; ed. bṛháchravās).

bṛhádodiva: -as. 5.2.8*, $9^{*}$.

bṛhánt: -án. 4. I6. I. 6. 53. I; 82. 3. 9. 4.5. I0. $8.3^{\dagger}, 40^{\dagger}$.

bṛhát. 3. 8. I ; 22. I, 4. 4. $21.6^{*}$. 6. I. I；33. I; 55.3. 8. 5. I9;8.6, 7. I I. 5. I 2 ; 8.20. I8. I. $7^{*} ; 2.6^{*} ; 3.24^{*}$, 73. 20. 135.9 (m. mss. ṿִhas).

bṛhántam. 4. 14. 6. 6. 1 22. 4. 7. 39. I*. bṛhată. 5. I0. 8. 8. $3.24^{*}$. I3. 2 . 9. I8. $3.65^{*}$. I9. 52 . I.

bṛhaté. 2. 4. I. I4. 2. 30,72. 19. II. 6*; 64. I. [6. 16.

bṛhatás. 6. х24. I. 8. 8.6,7. 9. 
bṛhántā. I $9 \cdot 15 \cdot 4^{*}$.

bṛhántas. I $0.7 \cdot 25$.

bṛhánti. 8. 9.3.

bṛhatăm. 7. 7. 1 .

bṛhatí. I. 17.4 . 4. 16.3.

2. I5. I3. I. 22 . I9. 47 . I.

bṛhatîm. I5. 6. 4 .

bṛhatì (p. -í íti). 5. I2.6* I9. Io.

bṛhatís. 9. 7.5. I3. $2.8,+2$.

bṛhatis. 5. $12.5^{*}$.

(cf. bṛhácchandas - bṛháddiva.)

bṛ́h a s páti : -is. 2. I $3.2 ; 26.2 ; 29$.

I. 3. II. $4^{*}, 8 ; 12.4 ; 14.2 ; 20.3^{*}$; $26.6 ; 27.6$. 4. :. 5. 5. $17.5^{*} ; 25$. 4 ; 28. I2. 6.73.1: 88. $2^{*}$; 103. I. 7. 8. I; 33. I; 51. I* $; 8$ I. 6 ; IIO. $3^{*}$ 8. 5.5 ; 10. 25 . 9. $3.2 ; 4.10 ; 6.45$ 7. 5. I 0. 6. 6-I 7, 22-8. I I. 3. I; 8 . 5 ; IO. 10, 12, 13. I2. 4.38 . I4. 1 . $52,54,55$. I5. I0. 6 ; I4. 9 . I6. 3 . 5. I8. I. $47^{*} ; 3.4 \mathrm{I}^{\dagger} ; 4$. I5. I9. $4^{\circ}$ 4; 9. $6^{*}$, II ; 13. $9^{*}$; I 7. IO; 20. I; $24.8 ; 26.4 ; 3$ I. 5 ; 40. I; 58. 2 .

bṛ́haspate. I. 8.2. 5. 26. 12. 7. 16. I ; 53. I. I4. 2. 42 . I9. I3. $8^{*}$.

bṛhaspate. II. 10. 9, I3. I2. 4.44 , 46. I3. I. 31. I4. I. 62 . I9. 4.3 . bṛ́haspátim. 3. 20. $4^{*}, 7^{*} ; 2$ I. 8. 4 . I. 7. 9. 4. 5. I I 6. I. I 5. IO. 4. 5 , 9. I9. I8. Io.

bṛ́haspátinā. 7. 104. I. II. 3. 32 . I4. 2. 53-8.

bṛ́haspátaye. 2. 35.4 . I2. 3.60.

bṛ́haspátes. 9. 4. I3. I4. I. 53. I6. 8. 7 .

(cf. bārhaspatyá, bṛ́haspátipraṇutta, bṛ́haspátiprasūta.)

bṛ́haspáti praṇutta (p. -tiopranu-): -tānām. 8. 8. I9.

[I*

b ̛̣ haspátiopras ū ta: -tās. 6. $96^{\circ}$.

bodhá: -ás. 8. I. I3.

[dhá.)

(cf. pratībodhá, bodhapratĩbobodhaopratībodhá: -dhāú. 5 . 30. 10.

bradhná: -ás. 7. 22. 2.

bradhnám. I9. 49.4 .

bradhnásya. I0. I0. 3 I. II. 3. 50, 5I. I3. I. I6. bradhnằn. I9. $27 \cdot 4$.

(cf. bradhnáloka.)

bradhnáoloka: -as. II. 3. 5 I.

brava in anavabravá.

brahmaokilbiṣá: -șé. 5. 17. I*.

brahma०gavi: 5. 19.4. I2. 5. I2, I $5,27,38,4 \mathrm{I}, 44$.

brahmagavim. I2. $5.5, \mathrm{II}$.

brahma。cárya: -am. 7. Io9. 7. brahmacáryena. I I. $5 \cdot 17^{2}, 18^{2}, 19^{2}$.

brahma。cārín: -rí. 5. 17. 5 * 6. I33. 3. I I. 5. I, 4, 5, 6, 7, 8, 9, IO, I I, I 2, I $3,15,16^{2}, 24,26$.

brahmacārínam. II. 5.2, 3, I7.

brahmacārínas. II $5 \cdot 20,2 \mathrm{I}$.

brahmacāríni. II. 5.22.

[8.

brahmacāríobhis. 6. 108.2. I9. I9.

brahmaojāy â: 5. I 7. $3^{*}, 4,7,12-7$. brahmajāyằm. 5. 17.2*, 10*, $11^{*}$.

bráhma。juṣṭa: -am. 2. 36. 2 .

bráhma。jūta: -tām. 6. I08. 2.

brahma。jyá: -ya. 5. Iy. 12-4. brahmajyám. 5.19.15. 12. 5.15, $38,4 \mathrm{I}, 52,63$.

brahmajyásya. 5. I9. 7. I2. 5. 16, 27, 44,60,65. I3. 3. I-25 (l. -jiásya).

brahmaojyéya: -am. I2. 4. II.

bráh ma ojyeṣt th a : -țā. I9.22. 21.

bráhmaṇaspáti (p. -ṇah p-): -is. 6. $4.1 ; 5.3 ; 74.1 ; 87.3^{*}$. 7. 30. 1 . I I. 9. 25 . 12. 2. 6 . I3. I. 5 I ; 3. 7 . bráhmaṇaspate. I4. I. $3 \mathrm{I}$.

brahmaṇaspate. I. 29. I*. 4. 4. 6. 6. $6.1 ; 45.3^{*}$; IOI. 2 ; I 40. I. 7. 56 . 4. 8.6. I5. I9. 8.6;24.1;63. I. bráhmaṇaspátim. 3. I6. I*. II. 6. 4. 19. 30. 3 .

bráh mạ̣ovant: -vati. 8. I0. 25. bráhmaṇvatīm. 6. Io8. 2.

bráhma ot eja s: -jās. Io. 5.31 .

brahma。dvíș: -șam. 2. 126 *. brahmadvíșe. 4. 30. $5^{*}$. 8. 4. $2^{*}$.

bráhman: -ma. I. Io. 4 ; $19.4^{*}$; 32. I. 2. $12.6^{*} ; 15.4$ 3. I9. I; 20. $5^{*}$; 30.4. 4. I. I, 3; II. II ; 34. I; 35. $2 ;$ 40.8. 5.8.6. 7. I00. I. 8 . 2. 10,$25 ;$ Io. $25^{2}$. 9. $2.16 ; 6.1 ; 7$. 9 ; 10. 19. I0. $2.2 \mathrm{I}^{4}, 23^{4}, 25^{2}, 29,33$; 
5. 40; 7.10.11.17, 19,24;10.33. II. 3. I ; 5. 5, 7. 10, 22, 23, 24 ; 7.4;8. 2 . $23,30,32$. I2. I. I; 5.4.8. I3. 1 . $33 ; 2.13 ; 4.22$. 14. 1. $54.64^{4}$. I5. 1. $3 ; 3.7 ; 6.3 ; 10.3 .4 .5,7,8,9 ; 14$. 12. I6. 8. I-27. I8. 1. $37^{*} ; 3.39^{*}$. 19. $9.12 ; 11.4^{*} ; 10.7^{*} ; 19.8 ; 22$. $2 \mathrm{I} ; 40.2 ; 42 . \mathrm{I}^{2}, 2^{2} ; 43.8 ; 53.8,9$ : 54. I.

bráhmañā. I. $8.4 ; 9.3 ;$ IO. I ; I4. 4 ; 23. 4. 2. 2. I; IO. I-8; I $2.7 ; 32$. 3. 3. $6.8 ; 15.3^{*} ; 19.3 .4 .37$ II. 5. $2.5^{*} ; 20.10 ; 26.12^{2}$. 6. I13.1, 3 ; 133.3. 7. I. I; 78.2. 8.8.19. 9. 3.8, 19. I0. I. 12,$14 ; 2.25 ; 5.15-$ 21,$42 ; 6.30,35 ; 8.19 ;$ 10. 4 , 6. I I. I. $18 ; 3.15,35 ; 4.24 ; 8.30 ; 10.9$. I2. I. $29 ; 2.32 ; 3.22 ; 5$. I. I3. I. $9,33,48,49$. I4. 2. I2, 35. I5. I4. I2. I7. $12,14,27,28$. I 8. $4.8,52$. I9. 9 . 5 ; $27.1 ;+2.1,2 ; 54.6$.

bráhmaṇe. I0. $7 \cdot 32-4,36$; 8. I. I9. 22. 20 (m. mss. brahmá-); 23.29 (do.). bráhmaṇas. 4. I. 3. 5. 6.9. 8.9. 7. I0. $2.28,29,30$; IO. I9. II. 5.5 . I2. 5. 54. I5. 6.3. I9. $42 . \mathrm{I}^{2} ; 72 . \mathrm{I}$. (and see bráhmanaspáti.)

bráhmaṇi. 5. 24. I-I 7 .

bráhmāṇi. 8. 4. 6".

bráhma. 5. 2. 8*.

bráhmaobhis. I0. 10. 23.

bráhmaṇām. 7.97.2 $2^{\dagger}$.

(cf. brahmán, brāhmá, brăhmaṇa, brähmaná, brahmakilbișábrahmadvís, bráhmanutta brahmāudaná.)

brahmán: -mâ. 2. 7.2. 5. 17.8 ; 18.8. 6. 50. 2. 8. 9.3. 9. I. $6 ; 4$. I I IO. I4". I0. 7.24 ; IO. 22 . I2. 2. 6,39 . I 4. I. $28^{*}, 29^{*}, 30$. I8. 4. 15 . 19. $9.12 ; 22.21 ; 43.8^{2}$. 20. 2.3 .

brahmấṇam. 3. $20.4^{*}$. 4. 30. $3^{*}$. 5 . 8. 5 ; 19. 8. [(mss. bráhma-). brahmánā. IO. IO. 25 I 9. 22. 2 I brahmáṇe. 3. 28. 2. 4. 35. I, 2. 9. 5 . 7, 9, IO, I I, I2. I4. 2. 4I, 42. I9. 43.8 . brahmánas. 20. 128.7 .

brahmănas. 2. $6.2 ; 9.4$. I2. 1. 35 ;
$431.14 \cdot 1 \cdot 3^{\circ}, 16^{\circ}$.

brahmāṇas. 6. 63.3.

bralımáobhis. 6. 12.2. 10. I. 3 .

brahmáobhyas. $12,2.34 ; 4.1$, I0, 30, 33, 34. 40, 47 (1. -bhias). I 4. I. $25^{*}$. brahmáṇām. 5.18.7. 6. 122. 5. 10. 9. 27 I I. I. $25,27$.

(cf. ábrahman, súbrahman.) bráhmaonutta: -am. I0. I. I3. bráh ma opūta: -tās. I 3. 1. 36, 43 . brahma०bhāgá: -ám. I 4. 2.42 brahma。y०gá: -gắs. I0. 5. I. brahma orājany à: -yà̀bhyām. I9. 32.8 (s. mss. -yăbh-).

brahmaoloká: -ám. I9. 71. I.

brahmaovarcasá: -ám. I9.7I. I. (cf. brahmavarcasín.)

brah ma ovarcasín: -sí. 8. 10. 25. I5. 10. 8 .

brahma。vādín: -nas. II. 3. 26. I5. I. 8.

brahma०víd: -das. I0. $2.32 ; 7$. 24,27 ; 8. 43. I9. 43. I-8. 149. bráhma ovṛddha: -dhāu. I3. I. bráh ma $\circ$ u mb hit a: -as. 4. 24. 4. bráhmaos a m̧̧ita: -tā. I9. 9.3. bráhmasamçitam. I9. 9. 4 . bráhmasam̧̧̧ite. 3. I9. 8*. bráhmasamçite (p. -e íti). 8. 3. 25. bráhmasamç̧itās. II. IO. 10.

bráhmāhuta (p. -maoāh-): -tāu. I3. I. 49.

bráhmed dha (p. -maoid-): -dhāu. I3. I. 49-5 I.

brahmāudaná (p. -ma॰od-): -ás. II. I. 20.

brahmāudanám. 4. 35. 7. II. I. I, 37. brahmāudanăya. II. I. 3 .

brahmāudanásya. II. I. 23.

brahmāudané. II I. I. 26.

brāhmá: -măs. Io. 2. 29.

brầh m a ṇ a: -am. 7.66. I; 67. I. Io. 7. I7; 8. 20, 33, 37, 38 . II. 5. 5, 23 . 12. 4.20.

brăhmaṇena. 12. 3. 20.

brăhmaṇāt. 20. 2. 3 .

brăhmaṇasya. II. 5. IO. [maṇăs). brắhmaṇās. 12.4. I 5 (s.mss.ed. brāh- 
brăhmaṇim. 5. I8. I 2; I9. II.

brāhmạ̣á: -ás. 4. 6. I. 5. I7.9, I8; I8.6; I9. 6 . 9. I. 22 . I2. 5. 4 . I9. $6.6^{*}$.

brāhmanám. 5. I8.4, I3; I9. 2, 3, 6. II. 3. 48 . I2. 5.5 , I I. I3. 3. I-25. brāhmaṇéna. 4. 19. 2.

brāhmaṇásya. $5.17 \cdot 6^{*} ;$ I 8. 1, 2, 3 . I0, I5; I9. 9, I0. I2. $3.44 ; 5.46,5^{8}$. brāhmañé. 6. 38. I. 9. 4.9, I8; 5. 19. brāhmaṇăs. 2.6.3. 4. $15 \cdot 13^{*}$. 5. 18 . 9. 9. I0. $27^{*}$. I2. 4. I 5 (m. mss. brăhmaṇās), I6, 22, 26 . I4. I. 39. I9. $34.6 ; 35.2$.

brāhmạ̣ās. I2. $4.4^{8}$.

brāhmạ̣ăn. I0. $5.4 \mathrm{I}$. I 8. 3. $55^{*}$

I9. $59 \cdot 2^{*}$.

brāhmaṇāís. I2. 4. 25.

brāhmaṇébhyas. 6. 13.3. 9. 4. I9. IO. IO. 33. I2. 4. 2 I.

brāhmaṇănām. I 2. 4. 12, I4; 5. I 7 brāhmaṇéṣu. 4. 34. 8. II. I. 28.

(cf. ábrāhmaṇa, yajamānabrāhmaṇá, sábrāhmaṇa, súbrāhmaṇa, brāhmanavarcasá.)

brāhmạ̣aovarcasá: -ám. ro 5. 37-4I. I3. 4. 14, 22.

[I7. $2 \mathrm{I}^{\circ}$. brāhmaṇavarcaséna. I3. $4 \cdot 49,53$. bru va in vrātyabruvá.

bruvant in ápratibruvant.

$\checkmark$ brū: brávĩmi. I3. $2.44,45$.

bravīmi. 8. I. IO. I2. $2.2 \mathrm{I}^{*}$.

bráviși. 5. II. 7.

brūmás. II. 6. 2, 3.

brūmas. II. 6. I, 2, 3, 4: $5^{2}, 6^{2}, 8,9$, IO, I1 ${ }^{2}, \mathrm{I}^{2}, \mathrm{I} 5, \mathrm{I}^{2}, \mathrm{I} 7, \mathrm{I} 9,20,21$.

bravas. 7. $2.1 ; 5.5$. I8. I. $7^{*}$.

bravātha. 7.56.7.

brūyāt. II. 3.24. I2. 4. I. I5. 1 I.

2 ; 12. 2.

brūhi. Io. $7 \cdot 4,5-7$, 10-6, I8-20, 22.

brávitu. I. $7 \cdot 4$.

bravitu. 9. 9. $5^{*}$.

brūta. 4. II. 5. 8. 9. I7.

abravis. 5. II. I.

abravit. I. 6. 2* 5. I3.9; I9. IO. 6. II. $2 ; 82.2$. 9. 4. I2. I0. 4. 4. I2. 4. 42. I3. I. 54. I5.3.2. 20. I 28.
3 (mss. áb-); 132. 14; 136. 6.

abrūtām. I5. I0. 3 .

abruvan. 5. I9. 12. 8. IO. 9. 9. 4. I4 ${ }^{2}$. I2. 4. II, 22. I 5. 3. I. 20. I28. I4. (cf. brava, bruva, bruvant.)

+ a dhi: ádhi bravat. I. I6. I. 6. $5.3 ; 87.3^{*}$; r4 I. r.

ádhi brūhi. 8. 2, 7,8.

ádhi ... brūhi. 2. 27.7. II. 2. 20 ádhi bravitu. I2. I. 59 .

ádhi ... brūtam. 4. 28.7 .

ádhi brūta. 3. 26. I-6.

ádhi bruvantu. I 8. 3. $45^{*}$.

ádhi ... bruvantu. 4. 27. I.

ádhi bruvan. 4. 8.2 (s. mss. brav-). + a pa: apaobrávat. 6. 57. I.

+ a va: cf. anavabravá.

+ up a: úpa bruve. 5. 22 . II.

úpa brūte. I4. 2. 63. 20. 136. 7. 8, 9 . + pari: pariobrávimi. I9. 32. 2-4 (mss. pári bra-).

+ pra: prá bravìmi. 5. Ir. 6 .

prá... brūmas. 5.22 .8 .

prá brūhi. 8. 3. $8^{*}$.

prá ... brūhi. I. 7. 5 .

praobruván. 5. I7.9.

praobruvānaăs. I. $7 \cdot 5$.

+ prati: cf. ápratihruvant.

$\checkmark$ blĩ: + pra: práoblīnas. II. 9. I9.

b h án s a s : 20. 136.3 (not mss.).

bhánisasas. 2. 33. $5^{*}$. 8. 6.5. 9.8. 21 . bhakti in

bhaktiovấns: -sas. 6. 79.3.

$\checkmark$ bhakș: bhakșayati. 9. 6. 55-9

bhakșáyanti. 7.81.6. I8. 4.3.

bhakșáyantas. 2. 35 . I.

(cf. bhakșá.)

bhakṣá: -ás. 4. 2 I. 5*. 8. 7 . 12.

bhakșám. I. 33.3. 9. 4. 5 ; 9. 22†.

I3. 2. 15. I $8.3 \cdot 54$

(cf. sahábhakșa.)

bhága: -as. 2. 30. 7. 6. 129.3. 7 . 5O. 2 . I2. I. 25. I 4. 2. 55.

bhágam. I. I4. I, 4. 2. 36.2. 3. 16. $2 *$ I2. I. 5 . I4. I. 3 I. I8. I. $23^{*}$. I9. $7 \cdot 5$. 
bhágena. 2. 3 0. $5 ; 36$. I. 3. 22.6 . 6. I29. I, 2. I9. 45.9 .

bhágāya. 7. 15.1 .

bhágasya. 19. 4.3.

bhágāsas. 2. 30. 2.

(n. pr.): bhágas. I. 26. 2. 3. I2. 4 ; I6. $5^{*} ; 20.3^{\dagger}$. 4. 2 I. $5^{*}$. 5. 26.

9. 6. $4.2 ; 21.2 ; 53.1 ; 74.1 ; 82$. 2 ; 103. I ; III. 4. 8. I. 2. I2. I. 40. I 4. I. $20^{\dagger}, 50^{*}, 5 \mathrm{I}, 53,54,59,6 \mathrm{O}^{2} ; 2$. 13. I9. 10. $2^{*} ; 45.9$.

bhága. 3. $16 \cdot 3^{5 *}$.

bhaga. 3. $16.5^{2 *}$

bhágam. 3. 16. $1^{*}, 2^{*}, 6^{*}$. 4. 30. 6*. 5. 7.4. II. 6.2.

bhágena. 14. I. 34.

bhágasya. 2. $29.1 ; 36.4,5$. 6. 74 . 2 ; 102.3. 9. 4. I2. I4. 2. 15, 21 . I9. 49. I.

(cf. abhagá, àbhaga, durbhága, subhága, bhágavant, bhagín.)

b há g a ○ va n t: -vān. 3. 16. 5. 4. 13.6*. bhagavas. I9. 34.8 (mss.).

bhágavantas. 3. $16.4^{*}, 5^{*} \cdot 7 \cdot 73$. II". bhágavadobhias. 5. 3I. II.

bhágavatĩ. 7.73. $\mathrm{II}^{*}$.

bhágavatĩ (p. -1 íti). 2. 8. I. 6. I 2 I. 3. bhágavatotaras. 4. 13. 6*.

bhágavatotamas. 2. 9.2.

b ha gín: -nam. 6. I29. I, 2, 3. 7. 12.3.

b h a ñ gá: -ás. 8. 8.3 (p. tājádbháñgahıiva). I I. 6. I5.

bhañgura in [tas. 7.7 I. $\mathrm{I}^{\dagger}$. b hañgurávant (p. -ráov-): -vabhañgurăvatas (pl.). 8. 3.23*; 4. $7^{*}$. $\checkmark$ b h aj: bhajemahi. 20. I36. 9 (mss. bháj-).

bhajantu. r9. 8.2.

bhajadhvam. I2. 3. 4 .

abhajanta. II. IO. II.

bhájanta. I 8 . I. $45^{*}$.

bhejiré. I2. I. 23.

bhejānás. 3. I3. 6.

abhakși. 2. 25. I.

bhakși. 3. $16.2^{*}$.

bhakșimahi. I9. 8.5 (mss. -máhi). bhaktuá. 5. I7. II $\mathrm{I}^{\dagger}$.

bhājayata. I. 5. 2*. (cf. bhakti, bhága, bhãj, bhāgá, vbhaks, /bhiks.)

$+\bar{a}$ : à ... bhaja. 4. 22. 2 .

à ... bhájata. 6. 55.2.

à bhajāt. I9.50.7.

à babhāja. 9.9.8".

(cf. ăbhaga.)

+ nis : níh ... bhajāmas. I0. 5.2535. I6. 8. 1-27.

níh ... bhaja. 4. 22. 2.

níh ... bhajāma. I6. 7.6.

nírbhaktam (p. níḥobh-). 2. 35.2.

+ vi: ví bhajāmi. II. I. 5 .

viobhájante. 3. 29. I.

viobhájāsi. I8. I. 26".

ví bhajāsi. r9. 24.6 .

ví bhajāmahāi. 6. 66.3. 7. 90. $2^{\dagger}$. ví bhajā (p. -ja). 3. 4. 2, 4. I4. I. 25*". ví bhajasva. 4. 3I. 2* [janti). viobhájantr. I9. 50.6 (mss. ví bhaviobhejiré. ro. 7.27 .

ví bhejire. 5. 4.8. II. 8.3I.

víobhaktās. I. 30. 4. II. 2. 9.

viobhajyámānā. I2. 5. 28 .

viobhăjya. II. I. I3.

+ s a m: sámobhaktās. 8. 7. I2.

$\checkmark$ bhañj: bhanálzti. Io. 3. I3.

bhañdhi. I0. 3. I3.

bhañján. II. 9. 5 .

bhañjatî. IO. I. I5.

bhajyantām. 8. 8. 3, 4.

(cf. bhañgá, bhañgura, bhañjana.) + a bhi: abhiobhañjatīnăm. I9. I3. $9^{*}$.

+ ni: cf. níbhañjana.

+ nis: niroábhanas. 3.6.3.

nír bhañdhi. 3. 6.3.

+ pra: praobhañján. I9. I3. $8^{*}$.

+ prati: práti bhañdhi. 8. 3. $6^{*}$. práti bhanaktu. II. I0. I6.

$\mathrm{b} h$ a ̃̃j $\mathbf{a} \mathbf{n}$ a in níbhañjana.

- b ha drá: -ás. r4. 1. 39. 20. 136. I3, I 5 , I 5 (mss. -ras).

bhadrám. 4. I8.6; 21. I*, 6*. 5. 31. II. 7.18.2; 78.2. 8 4.9". 9. 4 . I, I7. I.4. I. $7^{*}$. I6. 2. 4. I8. 2. I $3^{*}$, $52 ; 3$ I4, 24*. I9. 7.2 ; fI. I ; 44 3. 20. 127.10. 
bhadră. 3. 1 I. 7. 7. 20.5. 12. 2. 22* I8. I. $20^{*}$. I 9. 49.8 .

bhadrằm. 6. 108. 3 .

bhádre. I9. 47.2 .

bhadre. I0. 10. 7. 19. 47.7.

bhadréna. 20.127.14.

bhadréñā (p. -ṇa). 7. 60.7.

bhadráyā. 3.30.3. 4. 12.2. 9.4. II. I2. I. 52,63 . I3. 4.43. I8. 2. 52 . bhadrằya. I 3. 4. 42.

bhadrăt. $5 \cdot 5 \cdot 5^{2}$. 7.8 . I.

bhadrásya. 6. 26. I. 20. 128. 3 .

bhadré. 2. 10. 7 . 6. $55 \cdot 3^{*}$. 7.92. I*. I8. I. $58^{*}$.

bhadré (p. -é íti). 4. 9. 10.

bhadrấs. 3. $13.5 ; 16.7^{*}$. 9. 2. 25 . I0. 10.17 .

bhadrăṇi. 3. 23. 4 .

bhadrấ. I. I 8. 1. 7.82. 1*. I0. 10. 15 . bhadrăbhis. I9. 49. 2 (mss. [ánu。 sāma] drăhimim).

(cf. subhadra, bhadratás - bhadrāhá, bhándișțha.)

bhadratás. I 8. 4.50.

bhadra opāpá: -ásya. I2. I. 48 .

bhadrapāpăs. I2. 1.47 .

bhadra。vāc: -cas. 4. $21.6^{*}$.

bhadra॰çrút: -tāu. I6. 2. 4.

bhadráosvapna: -as. I9. 57. 3 (mss.).

b h a drāhá (p. -raoah-) : -ám. 6. I28. $\mathrm{r}, 2^{4}, 3,4$.

$\checkmark$ bhand, bhad: see bhándișțha, bhadrá.

bhándișțha: -as. 4. 33. $3^{*}$.

bhayá: -ám. 4. r9.2. 5. 2 I. I. 8. I. 10;8.2, 18. I9. 3. 4 .

bhayăt. I0. $3.4,7$. (cf. ábhaya.)

bhára: -āya. II. I.I3. bháre. $7.50 .4^{*}$ (bháreobhare). bháreșu. 4. 29. I, 2.

(cf. viçvambhará, çakambhará.)

bháraṇa: -ṇyas. I9. 7.5.

bharata in bhăratī.

b harád ovāja:-as. 2. 12.2. I9.48.6. bháradvāja. I8. 3. 16.

bharádvājam. 4. 29.5 . bharant in bharádvāja.

bháras: -sā. 2. 16. 5 . (cf. sábharas.)

bhar ũjĩ: bhárūji. 2. 24.8 .

bhárga s: 9 I. 4 (s. mss.). I9. 37. r. (cf. bhárgasvant.)

b hárgasva n t: -vatīm. 6.69.2.

bh a rtṛ́: -tâ. I I. 7.15. I8. 2. 30.

bhartrí. 5. 5. 2.

$\checkmark$ bharts: bhartsiămi. 3. 9.5.

$+\mathrm{ud}$ : úd abhartsatha. 20. I34. I (mss.).

bhala. 7.56.7.

bhal a in sambhalá.

bh a va in abhibhavá, sãyambhavá.

bhavá (n. pr.): -ás. 8. 8 . I7 (mss. bhávas). I I. $2.8^{2}, 27^{3}$. I 5. 5. I, I-7. bháva. II. 2. 28 .

bhava. II. $2.3,5,25$.

bhavám. I 5. 5. 1 .

bhavấya. 6. 93.2. II. 2.9, I6. bhavásya. II. 8. II.

(cf. bhavārudrá, bhavãçarvá.)

b há va d ०v a s u : -us. I3. 4.54.

bhavant in bhávadvasu.

b havã ru drá: -rāú. II. 2. I4.

bh a vã ça rvá: -vãú. 4.28.7. Io. I. 23. II. 6.9. I2. 4. I7. [2.1. bhávāçarvāu. 4. 28. I. 8. 2. 7. I I. bhavítra: -am. I9. 10.9*.

bhávya: -as. I3. I. 55. bhávyam. 2. I5.6. 6. I2.2; II5. 2. 9. 10. $24^{2}$. I0. $7.22 ; 8$. I 2 . II. 4. 15, 20. I3. 4.23. I7. 19. I9. 9. $2 ; 53.5 ; 54.3$.

bháviam. I0. 8. I.

bháviena. I7. 29.

bhávyāt. I9. 35.4.

bhávyasya. 6. 36.3.

bháviasya. I2. I. I.

bhávye. I7. I9.

(cf. asambhavyá, bhūtabhavyá.)

$\checkmark$ bhas: bábhasti. 9. 2. 2.

babhasti. 6. 49. 1, 2. (cf. bhásman.)

bhas ád: 9.4.13； 7.8. 10. 9.2r. bhasádam. 4. I4. 8.

(cf. bháńsas, bhasadyà, bhăsada.) 
b h a s a d y à : -àm. 2. $33 \cdot 5^{\dagger}$.

b hásma n: -ma. II. 3. 8. [ [ bhās. $\checkmark$ bhã : cf. bhā, bhānú, bhăma, bhăs, + a ti: atiobhăti. I0. 3.17 .

+ a bhi : cf. abhibhă.

+ à: ầ bhāsi. I3. 2.19".

àobhăti. 13. 2. 2.

â... bhăti. II. 7. I4.

à bhāhi. 2.6.1. I9. 33.5 .

+ pra: prá bhāti. I 8. 4. I4. prá ... bhăti. I $8.3 \cdot 65^{\dagger}$.

+ vi: ví bhāsi. 13. 2. 10, 28. I7. I6. viobhăti. I3. $2.42 ; 3.17$ (mss. vío bhă-).

ví bhāti. I3. I. II; 3. I6.

ví... bhāti. 8. 3. $24^{*}$.

viobhātí. Io. 8.30. I9. 49.4 (mss. viobhātiss. I $4.2 .43,44$. I $8.3 .24^{*}$. I9. 10. 10".

(cf. vibhā, vibhăvan.)

bha in abhibhă, vibhă, sabhă (?).

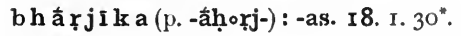
bhāgá: -ás. 6.84.2; 140.2. 7.73. 4. 9. 4.5. I0. 5. 7-I4, I5. II. I. 5, 15. 12. $2.9 ; 3.45$. I4. 2. $33^{*}$. I 8. 2. $8^{*} ; 4.54$.

bhāgám. 2. 34. I. 5. I9. I3, I4. 6. 64. $1^{*}$; 122.1. 7. 72.1 $1^{*}$; 81. $2^{*} .8$. 3. $16^{*}$. 9. 5.2 ; 10. $15^{*}$. II. I. 16, 29. 12. 4. 2 I. I4. I. 33. I8. I. $26^{*}, 43^{*}$. I9. 54.4 .

bhāgé. 8. I. I.

(cf. abhāgá, annabhāgá, karmabhāgá, durbhāga, dvibhāga, brahmabhāgá, mádhubhāga, yathābhāgá, sabhāga, subhāga, stríbhāga, hutábhāga, bhāgadhéya.)

b hãgaodhéya:-am. 6. III. I; i 16. 2. 7. 79. I. II. I. 29 . I2. 2. I, 53". I8. 2.3 I. I9. 58.6 .

b hãj in ardhabhăj.

bhānú: -ús. I9. 7.2.

bhānúm. I8. 3. 29.

bhānávas. $4.33 \cdot 5^{*}$. I3. $2.46^{*}$. (cf. citrábhānu, svábhānu.)

b hà m a : -as. 4. 32. 4*.

bhămāya. I4. 2.35. I 8.4 .82 . (cf. bhāmín.)

bhāmín: -nas. 18. 1. $6^{\circ}$.

bhārá: -ás.9.3.24. bhārám. 9. 10. $23^{\circ}$.

(cf. bhưribhāra, sambhārá.)

bhatratI: $5.12 .8^{\circ} ; 27.9$.

bhāv yà: -víam. Iß3. 1. 54. I9. 6. 4.

V bhās: + vi: víbhāsati. 13. 4. 7. viobhắsāsi. I 9. 26. 3 .

bhăs: 7. 14. 2.

(cf. bhặ̂jikka.)

bhatsa d a: -am. 2.33. $5^{\dagger}$.

$\checkmark$ bhiks in

bhikṣăa: -ăm. II. 5.9.

$\checkmark$ bhid: bhinádmi. 2.32.6. 4. 37 .

7. 5. 23. 13 .

bhinadmi. 6. $138.4,5$.

bhindánti. 6. 138.5 .

bhindyāt. 9. 5.23.

bhindhí, 7. 18. I. I9. $28.4,5^{4}$.

bhindhi. 3.6.6. 8.3.4". I9. 28.3 .

bhinattu. 6. 138.2 .

bhindán. 5.28.14. 8.4.21".

bhindántas. I 8. 3.2 $\mathrm{I}^{*}$.

bibhéda. 2. $5 \cdot 3$.

bibhidus. I0. 6.20.

bhinnắm. 5.19.8.

(cf. bhíd, bhidya, bhinna, bhedá.)

+ ava: áva bhindanti. 5. İ.. 9 .

+ ud: udobhindatím. 4. 38 . I.

út ... bhideyam. 9. 2. 2. [9. 1 .

údobhinnam. I0. 5.36. I6. 8. I-27; (cf. udbhíd.)

+ nis: nír bhindhi. II. 1.9.

+ pra: prá ... bhinadmi. I. 3. 7 .

prá... abhinat. 2. 5. 5*.

+ vi: ví ... bhinadmi. I. 11.5.

ví bhindhi. 4. I9.5. [ábh-).

ví... abhinat. 20.128. 13 (mss.

viobhindán. 4. 19.5 .

viobhindatí. 4. 19. 5 .

ví bhidyate. 20. 131. I (not mss.).

+ s a m: sám bibheda. I0. 4.5 .

bhid in udbhíd.

bhidy a in çirșabhídya.

b hinna in abhinná.

b hiyás: -sam. 5.2.2*.

bhiyásā. 5. 13.2. 
b hi y ásāna: -ne (p. -e íti). 4. 2. 3 . bhiṣáj: -șák. 5. 29. I. I0. 4. I5.

bhișájā. 2. 9.5. 7.53. I.

bhişág。bhyām. I0. 6. 12.

bhișájas. 2. 9.3; 29.7. 8. 7.26.

bhișág。bhyas. 19. 2. 3 (l. -bhias); 56. 2 (mss. bhișágbhyaorūpam).

bhișájām. 6. 24. 2.

bhișákotarās. I9. 2. 3 .

(cf. çatábhișaj, súbhișaj, bheșajá.) $\checkmark$ bhi: bibhítás. 2. 15. I-6.

abibhet. 8, I0. I.

bibhes. 2. I5. I-6. 5. 30.8. 8. 2.23, bibhīta. 7. 60. 1 .

bibhitana. 7.60. 4,6 . 18. 3.64.

bíbhyatas. 5. 2 I. 2.

bíbhyatām. 8. 8.20.

bíbhyatīs. 5. 2 I. 5 .

bháyāmahe. I9. 15. I*.

[50.

bibhāya. 5. II. 4. I0. 8.44. 14. 2.

bhāișīs. I0. 9. 7 .

ábhāișma. I6. 6. 2*.

bhītás. I3. 2. 37.

bhìtă. 5. 20. 5 .

(cf. bibhivāñs, bibhyat, bhayá,

* bhiyás, bhiyásāna, bhì, bhīmá, bhīruna, Vbhyas.)

bhî: bhíyam. 6.67.3.

bhiyâ. II. 9. I2.

bhíyas. 4. 31. $7^{\dagger}$.

bhīmá: -ás. 7.26. $2^{*} ; 84 \cdot 3^{*}$. 8. I. 10. 9.8.6. I9. $13.2^{*}$.

bhīmà. 3. 25. I. 5. $17.6^{*}$. I0. I 29. I2. $4.48 ; 5.12$.

bhīmám. II. 2. I8. I8. I. $40^{*}$.

bhīmăm. 12. 4. 4 I.

bhīmấs. $4.37 .8,9 . \quad 5.22$. 10.

bhīmáotamā. I2. 4.45 .

bhirunga in abhîruna.

bhu in abhibhú, mayobhú, vibhú, çambhú.

b húk. 20. I35. I.

$\checkmark$ bhuj: bhunajāmahāi. 6. 24. 3. bhojaya. I9. 50.6 .

(cf. bhúj, bhujișyà, bhujișțha, bhóga, bhogá, bhógya, bhójana, bhojas.)

+ s a m: samobhuñjatî. 3. 10. 7 . samobhuñjatíbhias. II. 2. 31 .

bhúj: -jam. 8. 2. 8.

$$
\text { (cf. tribhúj.) }
$$

b h ujișt $h a$ in ábhujișța.

b huji ș y à : -àm. I2. I. 60 .

$\checkmark$ bhuraṇy:-yántam. I3. 2. $2 \mathrm{I}^{*}$. (cf. bhuraṇyú.)

b hura ṇy ú: -úm. I 8. 3.66".

bhuríj: -jos. 20. I27. 4 (mss. bhúri-).

b húvana: -am. 3. 3I. 5. 4. II. I. I0. $7.35 ; 8.7$, I3. II. 4.22 . I3. 3. I 5 . I8. I. $53^{*}$.

bhúvanasya. 2. 2. 1,$2 ; 34.2 .5 .3$. 9*. 7.81.6. 9. 9. $22^{*}$; I0. $13^{*}, 14^{*}$, I $7^{*}, 2 \mathrm{I}^{\dagger}$. I0. $7.38 ; 8.15$. I2. I. 57 . I3. I. $14,37,42^{\dagger} ; 2.2 ; 3.7$. I8. 2 . $54^{*}$. I9. 20. 2 [7. I bhúvane. I2. I. 31. I8. I. I7. I9. bhúvanāni. 2. I. $3^{*}, 5$. 3. 20.8. 4 . $25.3 ; 26.5$; 30. $7^{*}, 8^{*}$. 5. II. 4 ; 12 . $9^{*}$. 7. 26. $3^{*} ; 87.1$; I I0. 2. 9. 9. I I*, I4* I0. 8. I8. II. $2.11 ; 5.9$. I3 2. 9 ; 3. I, 3, I4. I9. 53. I, $2,3,4^{2}$. 20. 34. 17.

bhúvanā. 2. I. $3^{*}$. 4. II.2. 6. 34 . $4^{*}$. 7. 8 I. I*. 9. I. $5 ; 9.2^{*}$. 3.2 . II*. I7. I6. [2.7.

bhúvaneșu. 5. 2. I*. 9. Io. II*. 10. (cf. bhāuvaná, bhuvanacyavá, bhuvaneșthă.) [13.10*. bhuvanaocyavá: -vănām. Ig. bhuvaneṣt háa (p. -neosth-): -ấs. 2. I. 4. 4. I. 2.

$\checkmark$ b h u : bhavāmi. 5. II. 2. 6. I I 7. I, 2. bhavasi. 7. 8 I. $2^{\dagger}$. 10. 8.27 . I2. 3. 2 I.

bhávati. 2. I. I. 3. 22. 4 (mss. bhav-). 5. 18.8. 9. I. II-3；2. $25 ； 5.31-6$. II. 3. 54. 20. 128.3 (mss. bhav-).

bhavati. 5. $17.5^{*}$; 18.13. 6. I1. 2 . 8. 5.12 ; 10. $2-7,22-9$. 9. I. $22,23^{2}$, $24 ; 5.24,28 ; 6.44-8$. I0. 8 . II. I I. 3. II, 5 I. I2. $2.37 ; 4.40 ; 5.45 .13$ 3. $13^{2}$. I4. I. $26^{*}, 27^{*}$. I5. $2 . \mathrm{I}-4 ; 6$ I-9; 8. $3 ; 9.3$; IO. 8, IO； II. 7,9 , II ; I2. 6, IO; I3. 9. I9. 26. I, 2.

bhavatas. 18. 1. $29^{*}$.

bhavatha. I. $4.4^{2+}$. I9. 2.4 . 
bhávanti. 1. 33.3. 5. 2. 3* . 2.2.25". bhavanti. 5. 27. I. 9. 5. 25,262 . I I. 5. I, 8. I3. 4. I3, 2I. I5. 3. II.

bhávāsi. 3.23.3.

bhávāti. I8. 1. 2", I2", 26", $34^{*}$.

bhavati. 2. 36. 3. 6. I 20. 2. I8. 2. 5". bhavāthas. I4. 2. 37 .

bhávāma. I 9. 49. 6 .

bhavet. I9. 6r. I (not mss.).

bhávema. I9. 67.6 .

bháva. 3.23. 5 .

bhávã (p. -va). I9. 24. 5 .

bhava. 2.6.3. 3. 4. I; I6. $5^{*}$; 17. $8^{*} ; 20.2^{*} ; 23.4 ; 28.3,4 ; 31.9 .4$. 31. 5*. 5. 20. 10; 30. I. 6. $84.2 ; 86$. I-3; 92. I; 98. I; I23. 5 ; I33. 2 ; I42. 1. 7. 68.3. 8. 2. 26 . 9. 3. 6 , 24. IO. I. 29 . I I. IO. 6 . I2. I. 32 ; 5. $58,59^{2}$. I 4. 2. $27^{2}, 40^{*}$. I7. IO. I8. 2. $19^{*} ; 3.50^{*}$. I9. $4.3 ; 25.1 ; 64.4$. bhavā (p. -va). 2.6.3. 4. 32. $7^{*}$.

bhávatu. 9. 8. Io.

bhavatu. I. 20. I. 2. 13.4. 3. 14. 5 ; I5.5; 30.2. 4. 3.6; I5. I6. 6. 9I. $2^{*}$. 7.9I. I*. 9. 8. IO. I0. 9. 2. 14. I. 40. I8. 3.60. I9. 9. $6^{*}$; I0. $3^{*}, 7^{*}, 9^{*}$, I0* ; II. $3^{*}$.

bhávatam. 4. 26. 2-6.

bhavatam. I 8. 3. 39*.

bhávatām. 7.20. I.

bhavatām. I9. ro. I".

bhavata. 5. 12. $5^{*}$. 12. 2. 20.

bhavatā (p. -ta). 7.60.7.

bhavantu. I. 6. I*; 9. 2,$4 ; 33 . \mathrm{I}-4$. 2. 3.6 ; I0. 3.3 .4 .3 ; I9. 3 . 4. 15. I6; 27. 3. 5. 11.6. 6. 23.3. 7. 69. I. 9.2.7. I2. I. $3 \mathrm{I} ; 2.2 \mathrm{I} ; 3.3 \mathrm{I}$. I4. I. $40 ; 2.9$ I $8.3 .61 ; 4.33$. I9. 9. 9 , I3; ro. $5^{*}, 7^{*}, 8^{2 *}, 9^{*}$, IO $;$ II. $\mathrm{I}^{2 *}$, $2^{*}$; I3. II*; I4. I; I5. $6 ; 40.3 ; 45.4$. abhavas. 4. 6. 3 .

ábhavat. I9. 6.4.

abhavat. 3. IO. I, I2. 5. I2. II". 7. I. 2. 8. $4.2 \mathrm{I}^{*}$. 9. I. $5 ; 4.5 ; 5.20$. I0. I0. $24,26,29,34$. II. $5.16 ; 8$. I, 2. I2. I. 60 I 3. $2.39,40$ I 4 . I. 9*. I5. I. $3^{7}, 4^{2}, 5,6 ; 7$. I. I8. $4 \cdot 32^{2}$. I9. $6.2^{*}, 6^{\dagger} ; 53.4$. ábhavatam. 4. 26. I, 2.

ábhavan. I0. $7 \cdot 18,34$.

abhavan. IO. IO. 20, 24 .

bhavat. 10. 8.22. 14. 2.24.

bhavan. 20. 130. I9.

bhávan. 3.29.2. 9.6.47. I8. 4 . 5 I (mss. bhav-).

bhávantas. 6. 62.3. 12. $2.11,28$.

bhávantr. 9. I0. 7".

bhávantiss. 3.14.6.

babhứtha. I I. 2. 28 .

babhưvitha. I. 7. I. 3. $23 . \mathrm{I}$.

babhūvitha. I2. I. I8.

babhưva. 2. 36.4. 3.22. 6 ; 23. 6 . 4. 2. $2^{*}$; I5. I0; $35.5,6$. 6. 133. 4 . 7. 20.5. 8. 7.2, I2. 9. 4.2. I0. 2 . 3. I3. 3. 7. I9. 46.4 .

babhūva. 4 . 8 . I ; 10. 7. 5. $5.7 ; 28$. 6. $7.5 \cdot 2^{2} ; 20.6$ 9. 10. 24 . I0. 7. $8 ; 8.7$ I2. 3. I0, 50 . I3. 2.25. babhūváthus. 4.25. I.

babhūvathus. I9. 58. 3 (mss. -áthus). babhūvús. 9. 2.22. I0. 8.9.

babhūvúșī. 9. IO. $21^{*}$. I3. I. $42^{*}$. ábhūs. 2. 13.3. I9. 24.6 .

abhūs. 5. 3. II. I8. 4. 52 .

ábhūt. 2. 9.2. 5. 22.9. I2. 2. 22*. I8. $2.37 ; 4.65$.

abhūt. 6. 8I. I. 8. I. 2 I. I0. 4. 26. I3. I. 5 .

ábhūtam. I4. 2. $5^{*}$.

abhūtām. I9. I4. I. [6. I* ábhūma. I2. 2. 13. I4. 2.67. I6 abhūma. I 8. 3.24*.

abhūtana. $4 \cdot 37 \cdot 3,4$.

abhūvan. 2. 3 I. 3 .

bhūs. 6. 98. 2 .

bhūt. 7. I08. I. 8. 4. 7*.

bhūtám. I 8. 3. I9 (-tá?).

bhúvas. 3. 1 7. $8^{\dagger}$. 6. 106.3.

bhuvas. I $8.3 .60^{\dagger}$.

bhúvat. I. 22. 2. 3. 20.6. I0. 8. I I. bhuvat. 3. 3. I. 5. 30. I4. 7. 1. $2^{2}$. I 9. $26.4^{2}$.

bhūyấsam. I. 34.3.

bhūyāsam. 3. 5.2. 6. 15.2, 3. 7. 50. $8 ; 8$ I. 4. I3. I. 38 . I6. $3.1 ; 4$. I; 9.4. I7. I-5. I8. 2. 45. I9. 55. 5. 
bhūyấs. 5.22. 2. 6. I25. I* 7. 73. I1 $1^{*}$. bhūyāt. 4. 22. 4 .

bhūyāsma. 7.61. I. I8. 4. 87 .

bhūyāstha. I8. 4. 86 .

abūbhuvas. 20. $136.7,8$. [26.

bhavișyasi. Ir. $3.33,34,45,46 ; 4$.

bhavișyáti. 8. Io. I (s. mss. -yati).

bhavişyati. II. 4.5 .

bhavișyán. I2. 3. 19, 53 .

bhavișyát. 4. II. 2. I0. 7.9. I I. 4 . $20 ; 7.17$. I3.3.7. I5. 2. I.

bhūtá, see the word.

bhūtvă. 3. 18. $5^{\dagger}$; 28.2 ; 30. 3. 4 . 34. $4^{2}$. 5. 5.9; r9.7. 6. 42. 1. 8 . 4. $18^{\dagger} ;$ 6. 7. 9. 2. 9. IO. I. $24 ; 8$. $2 \mathrm{I} ; 9.3$. II. 5.7, I 5. I2. $5.4 \mathrm{I}, 55$. I3. 3. $13^{2}$. I $4.1 .25^{\dagger}, 42$. I5. 7. I, 2 , 4; I4. I-I2. I8. 4. IO. I9. 32. 5 . bhūtuâ. I. 7.6. 3.3.3. 4. 37. 11 . I0. IO. I6. II. 5.7. I9. 53.9.

bóbhuvatī. $5 \cdot 7 \cdot 8$.

(cf. bhavá, bhavant, bhavítra, bhávya, bhāvyà, bhúvana, bhứ, bhu, bhūtá, bhứti, bhứman, bhứmi, bhūya, bhứyas, bhứri, bhva, bhvan.)

+ antar: antár abhūs. 6. $87 . \mathrm{I}^{\mathrm{t}}$.

+ a pa: ápa ... bhavantu. 4. 35.7. 5. 3. $10^{*} ; 22 . \mathrm{I}$.

ápa bhūs. I 8 . I. $25^{*}$.

(cf. ápabhūti.)

+ a pi : ápy abhūs. 2. I0. 7 .

ápi bhūma. 7.20.3.

+ abhi: abhibhávantīm. 9.5.36 (abhibhávantīmoabhibhav-). abhyábhavas (p. abhi॰á-). 6. I29. 2. abhí bhūt. $7 \cdot 35 \cdot 3$.

abhí ... bhūt. 5. II. 7.

(cf. abhibhavá, abhibhùu, abhíbhūti, abhibhứya.)

+ $\bar{a}$ : āobhávan. 3.29. 2.

à 'bhavat. 7. I. 2.

āobabhúva. 5. I. I. [s. mss. -vắn 3$)$. à babhūva. 7. 5.2. I0. 2. 28 (-vānn3; āobabhútha. 4. 3I. 5*.

à babhūvitha. I9. 56. I, 2.

āobabhūvús. IO. 4.23.

ầobhūtas. II. 4. 20. (cf. àbhūti, ābhưka.)

$+\mathrm{ud}$ : cf. udbhú.

+ tiras: tiró bhūt. 8. r. 7 .

+ nis: cf. nírbhūti.

+ parā: parāobhávet. I2. 4. 45.

párā 'bhavat. I2. 4. I9. [II. párā 'bhavan. 5. 18. 10, I2; I9. I, párā bhāvayati. I2. $5 \cdot 43$.

párā 'bhāvayat. 8. 5.3.

(cf. parābhú, párābhūti.)

+ pari: pári bhavanti. 9. 10. $17^{*}$. pariobhávan. 20. 34. 12 (not mss.). páry abhavat. I0. 2. I8.

pári ... babhúva. 12. 3.31. I3. I. 25 ; 2.44 .

pári ... babhūva. xo. 8. 30, 36 .

pári ... bhūtu. 8. 4. 6*.

(cf. paribhú.)

+ pra: praobhávan. 3.29. 2. (cf. prabhú.)

+ vi: cf. vibhú.

+ s a m: sám bhavati. II. 3. 32-49. sám bhavāthas. I2. 3. 2, 9 .

sám bhavāva. 14.2. 71. [55-60. sám bhavema. 6. II9.2. I2. 3. I0, sám bhava. I4.2.32.

sám ... bhava. I 9. 64.4 (not mss.). sám ... bhavatu. 4. 12.3.

sám ... bhavatā (p. -ta). I2. 3. 29. sám bhavantu. I8. 4.48.

samoábhavas. 19. 34.8 (not mss.). sám abhavat. 4. 19.6. 8. 10. 18-21. I0. 8.2 I. II. 8.8 . I9. $6.9^{\dagger}$.

sám abhavan. I9. 54. I (mss. -vat), 3. sám babhūva. 4. 30. 8*.

samobabhúva. 3.22. I, 3. 4. 35.6. 10. 7.31. 12. 1. $23 ; 3.3$.

sám babhũva. 3.28. I. I2. 3. 5 I. I9. 32. 10.

sám babhūtha. I8. 3.2*. samobabhưvitha. 4. 19.7. sám babhūvitha. 9. 5.6. sám babhūvima. 3. 20.8. samobabhũvús. 6.74 .3 . I2. I. 3 , 4, I 2 ; 3.40. I3. I. I0, I8. I9. 4.4 (m. mss. sámobabhūvus). sámobhūtam. I2. 4. 33. sámobhūtā. 6. 100.3. 
samobhutya. Io. 8. II. (cf. asambhavyá.)

+ abhis a m: abhiosámbabhūva. 3 abhiosambhưya. 5. 28.8.

b h tá: bhuvas. I0. $5.45^{2}$.

bhúvas. I3. 4.52. I8. 2. 32. 20. 34. 16 (mss.).

(cf. bhu, akṣibhú, abhibhú, ābhúka, udbhú, parābhú, paribhú, punarbhú, prabhá, mayobhú, vibhú, çambhú, subhú, svayambhứ.)

b hū tá: -ás. 4. 8. I. I I. 4. I, 20². I 3. I. $55 ; 3.7$.

bhūtám. 2. I5.6. 4. II.2. 6. I2. 2 ; II5.2. 8. 9. I8. 9. 10. $24^{2}$. 10. 6. I8, 2 I ; 7. 9, 22, 3I; 8. I, I2. II. 4. $15 ; 6.21 ; 7.2$, I7. I3. I. $54 ; 2$. $41 ; 4.23$. I5. 2. I. I7. $19^{2}$. I9. 6. $4^{*} ; 9.2 ; 53.5 ; 54.3$.

bhūténa. 6. 78. I. I7. 29.

bhūtăt. 6. 133.3. I9. 35.4 .

bhūtásya. I. 3I. I; 32.2. 3. I0. 9, I0. $4.2 .7^{*}$. 5.25.7. 6. $36.3 ; 39$. 3 ; 86. I ; 95.3. IO. I. 22. I2. I. I. I3. I. 45. I4. 2. $46^{*}$.

bhūté. I7. I9.

bhūtăni. I. 29.3* 4. I3. $4^{*} ; 20.2$. 6. I9. I. I0. 5. 6. II.6.2I. I5.3. IO, II. I 8. 4. 7. I9. 6. $3^{*} ; 53.6$. [12. bhūtă. 6. 80. I†. 8. 9. I6, 21. I3. 2. bhūtằnām. 4. 8. I. 5. 25.2. 6. I7. I. II. 6.2I. I9. 22. 2 I.

bhūtéșu. 4. 8. 1. 19. 48.5 . (cf. durbhūtá, subhūtá, bhūtakŕ̛t -bhūtabhavyá.)

bhūta $\circ k$ ṛ́t: -tas. 3. 28. I. 4. 35. 2. 6. I08. 4 ; I35. 5. II. I. I, 3, 24 . I2. I. 39. I9. I6. 2.

bhūtakṛ́tām. 6. 133. 4.

b hūta॰páti: -is. 2. I4. 4. bhūtapátim. I I. 6.2I. bhứtapatī (p. -I íti etc.). II. 2. I.

bhūta०bhavyá: -ám. II. 5. 20.

bhtuti: -is. II. 7.22;8. 2 I.

bhúte. 6. 84. 2 .

bhútim. I0. $3.17-25 ; 6.9$. I2. 4 . 28. I9. 53. 6 (mss.). bhưtiā. Io 6.24 .

bhưtyās. 9. 6. 45-8.

bhưtiām. I2. 1. $63 ; 4.44,46$.

bhattiobhis. I0. 6.28 ,

(cf. ábhūti, ápabhūti, abhíbhūti,

âbhūti, nírbhūti, párābhūti, sahabhūti, súbhūti.)

bhú man: -ma. I3. 2.3.

bhūmán: -má. 5.28. $3^{3}$.

bhūmănam. 3.24.7. I9. 3I. 4,8 .

bhūmné. 6. I4I. I.

bhú mi: -is. I. 32.3. 3. 29.8. 4. I6. 3. 5. I8. I2; I9. II; $28.2,5$. 6. 18. 2 ; 2 I. I ; 84. I ; I 2O. 2. IO. 2. 24,25 ; $7.3,12,32 ; 8.2$. II. $3.20 ; 8.7$. I2. I. $3,4,6,8,9$, 10, I 2, I3, 22, 26ㅇ, 40, 4 I, 52, 59. I3. 1. 46,$53 ; 4 \cdot 35$ (mss. bhūmís). I4. I. I", 6* I $5.4 .5 ;$ 6. I ; 17 . I. I9. $6.8^{*} ; 9.8^{2}$.

bhúme. I2. I. 33,63 .

bhūme. I2. I. I4, I 8, 25, 29, 31, 32, $34^{2}, 35,36,50$. I8. $2.50^{*}, 51 ; 3.50^{*}$; 4. 66 .

bhứmim. 3. $17.5^{*}$. 4.5.2; 15.2, 3,6 ; Í́. 4 ; 20. I, 3,$9 ; 40.5$. 5. II. 6. 8. 7. I6. I0. 2.18 ; 9. IO. II. 2. 25 ; 5.9 ; 6. IO. I2. I. 7, I I, I 7, 29. I3. I. 52,$54 ; 2.40,4$ I. I5. 4. 5. I 8. 3. $49^{*}$. I9. 6. I" $^{*} 9^{*} ; 33.3 ; 53.6$ (not mss.).

bhứmyāi. I2. I. 42.

bhứmyās. 4. 19.6. 5.28.9. 9.9. 4". I0. I. I3. I2. 3. 26 . I9. I6. 2 ; 28. 4 .

bhứmiās. I. II.2. 2. 30. I. 5. 20 . 6. 6. 89.3 . I4. I. 48 .

bhúmes. I3. 4.35 (mss. bhūmés). I 5. 6. I. I8. 3.9 (mss. -me).

bhứmyām. II. 7. 16. I2. I. I3, I9, $22^{2}, 4 \mathrm{I}$.

bhứmiām. 2. 9.4. 6. 8.2 ; 121.2. 9. I. IO, 20. IO. 9. I2. II. 4. 4; IO. 23. I2. I. $28,52,54,56$. I9. 34.6 .

bhứmāu. II. 5. I2. I2. 3. I2. I8. I. $39^{\dagger}$. I9. 8.1 .

bhû́mis. 2. 27.8. II. 7. I4. (cf. dyāvābhūmi, bhúmigṛha, bhūmidṛnhá.) 
bhtúmi g g ̣̣ha: -as. 5.30. I4. bh ū mi od ṛnhá: -ás. I9. 33. 2. bhūmidṛnhám. 5.28. 14.

b h ū y a in abhibhứya, amutrabhúya, vasyobhúya.

b hứ y a s: -yān. I 3. $4 \cdot 46^{2}, 47$.

bhứyas. 3. I 5. 5. 9.6. I 8 (bhứyấ3s), I9. I3. $2.27^{*}, 27 ; 3.25^{*}$. (5-I7. bhúyaḥobhūyas. 4.21. $2^{*}$. 10. 6 . bhứyānsas. 7.60 .7 .

bhứyasīm. I8. 4. 27.

bhựyasīs. I 9. 67.8 (mss. -sī). (cf. ásthibhūyas.)

bhû́ri: 4. 22. $4 ; 30.2^{*}$. 5. 2. $3^{\dagger} ; 22$. 6. 7. 14.3 . 18. 2.60 .

bhưrayas. I 8.4 .55 .

bhứri (pl.). 4. 32. $7^{*}$. 5. 2. $5^{*}, 6^{\dagger}$; II. 7. 6. I. 3 .

bhúriobhis. I8. I. 22*

(cf. bhưyas, bhúridhana - bhúristhātra, bhưryojas.)

bhû́riodhana: -nās. 7. 60. 4 .

bhû́riodhāyas:-sam. I. 2. I.

bhứridhāyase. 6. 4I.2.

bhúuriod hāra: -rā. I2. I. 9.

bhû́riopāni i: -is. 5.27. I.

bhúuriobhāra: -as. 9. 9. II*.

bhû́ri॰mūla: -as. 6. 43.2.

bhúrioretas: -tās. I9. 53. I.

bhứriretasā. 8. 9. 12 .

bhû́riovarpas: -sam. I. 2. I.

bhứriosthātra: -rām. 4. 30. $2^{*}$. b h ū rji (p. bhūḥoj-): -jayas. I8. I.6I. bhứrṇi: -ṇayas. 5. 6. $3^{*}$.

bhúryojas (p. -rioo-): -riojās. 5 . 2. $2^{*}, 7^{\dagger}$.

$\checkmark$ bhūṣ: bhứṣema. I9. 67.7 (mss. bhūyé-).

+ $\bar{a}$ : āobhúș̣ati. 7. II. I.

à... bhūșati. I 8 . 1. $24^{*}$.

+ pari: pári ... abhūṣan. 4. $8 \cdot 3^{\text {* }}$.

+ prati: práti bhūșa. I4. 2. 25 .

$\checkmark$ bhr: bibharmi. 4. 30. $1^{*}, 6^{*}$. Io. 3. I2.

bibharși. 4. 31. 6*. 7. 43. I ; 56.6.

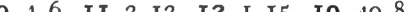
bíbharti. I. $35 \cdot 2$. 4. 9.5. 8. 5. I2, + a va: cf. avabhṛ́tha. I3. 9. 9. 4*. II.7.I5. I2. I. 2, 4. I9. + ā: â bharāmi. 8. 2. I; 7. 26.
26. I (m. mss. bibhá-), 2 (do.); 53. 9. bibharti. 9. 2. $15 ; 4.3,7$. I1. 5.3 , 24. I8. $4 \cdot 35^{2}$.

bibhṛthás. $4 \cdot 26.4^{2}, 5$.

bibhrmas. 2. 4. I.

bíbhrati. 4. 38.4 (mss. -tī). 8. 6 . II, I3. I2. I. 23 .

[19.

bibhrati. 3. 13.5. II. 5.22. I2. I.

bibharat. I. $35 \cdot 3$.

bibhṛhi. I8. 4.56.

bibhartu. I3. I. I.

bíbhrat. 5. 28. 10. 7.60. I. 8. 5 . 14. 9. 4.1 ; 9. 10*. 10. 6. I0, 13. 12. 2. $49^{2}$. I9. $31.4 ; 33.5$. 20. I28. I6. bíbhratam. 14. 2.30. 19. 32. 9 .

bíbhratas. I. I. I. 4. 14.2. 7.32. I*. 8. 6. I4. I0. 6. I6.

bíbhratī. I. 27.2.9.3.16;9. $17^{*}$ I O. IO. I4, I5. I2. I. $6,44,45,48$. I4. 2. I4.

bíbhratīm. I2. I. 29.

bíbhratīs. 3. 14.3. I0.6.14.

ábibhar. 6. 8 I. 3. 8. 5.14. I8. 2. $57 ; 3.54 ; 4.56$.

bhárati. $8 \cdot 3 \cdot 15^{*}$.

bharāmasi. 9. 3.24.

bháranti. I 8. 2. 28.

bharanti. I0. 8. I5.

bharema. 3. 15.8 .

bharantām. 8. 3. 16 6 .

bhárantam. I0. 8. I4.

bhárantas. I9. 33. 3; 55. I.

bhárantī. IO. I. 25.

bháramāṇās. 7.97 .4 (mss. -ṇā).

abharat. 6.6I. I. I8. 2. $33^{*}$.

jabhắra. 7.95. 3 .

bhártave. 3. 5.3. 18. 4.31.

bhártavāí. I9. 30. 2.

(cf. bibhrat, bhára, bhárana, bharata, bharant, bháras, bharūji, bhartị́, bhala, bhārá, bhārya, bhṛt, bhṛti, bhṛta, bhṛtenya, bhṛtya, bhṛtyâ, bhṛtvan, bhṛtha, bhrătr.)

a nu: ánu ... jabhāra. II. 5. 12. 
a. ... bharati. 9.10.23*.

ấ bharāmasi. 6. II. I.

a bhare. 3. 24. I.

à bhara. 3. I0. 7. 5. 29.5. 6. 63 .

$4^{*}$. I I. I. I 5. I 8. $3.67^{*} ; 4.88^{*}$.

à bharā (p. -ra). 4. 22.6; 32.3*. 7 . 73. 9".

à... bhara. 5. 7. I.

à bharatām. 5.7.6.

āobhárantīm. 8. 9. 14 .

âbharat (p. āoábh-). II. 8. II.

à 'bharat. 6. I37. I. I0. 8.21. II. 5. I9; 3. $12^{2}, 16,17$. I 3. 2.39. I8. I. $21^{*}$. 19. 53.4 .

âbharan (p. āoábh-). 4. 23.6.

à jabhāra. 5. 3I. 10. II. 5. 9 .

à 'bhărșam. 6.52.3.

à 'bhārişam. 4. 13. $5^{\dagger}$.

ầbhṛtas. 2. 4.5. 4. IO. 4. 9. 4. Io. à。bhṛtam. 6. I 25. $2^{*}, 2^{\dagger}$. 7. 45.1 . I0. I. 19. II. $5.14,22$. I3. I. 55 ; 4. 2,9 .

â॰bhŗte (p. -e íty etc.). IO. 2. I.

ầbhṛtās. I. 6. 4. 8. $5.9 ; 7.8,25$. 19. 2. 2 .

ăobhŗtābhyas. 8. 7.15.

+ s a mā : samoábhṛtam. 5. 25. I.

+ u d: úd bharāmi. 8. 2. 23 .

út ... bharāmasi. 8. 1. 3 .

úd bharanti. 2. 3.4.

úd bhare. 6. 102. 3 .

út ... bharantu. 8. I. 16.

udobhárantī. II. I.9.

udoábhaxāma. I9. 72. I.

új jabhāra. 4. I. 3 .

údobhṛtam. 2.3.5. 6. $125 \cdot 2^{*}$. 7

údobhṛtā. I. 24.4 .

+ upa: úpa bharasva. 5. 20. 4 . (cf. upabhŕt.)

+ parā: párāobhṛtam. 5. 29. 5, 12. 7. 4I. 2.

+ pra: prá bharāmi. 3. I2. 9. 18. prá bhare. 7. 50. $3^{*}$. 19.42 .3 .

prá bhara. 3. 12.8.

prá bharasva. 5. 20. II.

prá ... bharasva. 20. 127.6.

prá ... bharan. I8. 3. $38^{*}$.

práobhṛtā. 5. 2. 2* . (cf. prábhṛti.)

+ vi: ví jabhāra. Io. $7 \cdot 43^{\dagger}$.

víbhṛtas. I9. 3. I (mss. bíbh-, bíbhratas).

+ s a m: sám ... bharati. I3. 2. $26^{\dagger}$. samobháranti. 9. I. If.

sám bharatam. I4. 1.31.

sám bharantu. I5. 3. 2 .

sám bharasva. I 8. 3.9; 4. 52 .

sam॰ábharas. I. 9. 3 .

sám abharat. I0. 2. 5 .

samoábharan. II. 8, I3.

sám abharan. I 5. 3.3.

samiojabhăra. 9. 3. II .

sám ... jabhāra. 5.31. 10 .

sam̉ ojabhrús. I2. I. 24.

sámobhṛtas. 5.20. I ; 21.3 .

sámobhṛtam. 2. 36.2. 4. 14.9. 7. 56.1 ; 90. 2*. 8. 7.18. 9. 4.8. I0. 2. I. I9. 6. 14 *

sámobhṛtā. I0. I. 2, 24.

sámobhṛtām. 3.12.8.

sámobhṛte. I0. 3. 20.

sámobhṛtā. I9. 22. 2 I.

(cf. sambhalá, sambhārá, sambhṛta, sambhṛtvan.)

b hṛ́g u: -us. 2. 5. 3 .

bhŕ̛gum. 5. 19. I.

bhŕgavas. I 8. I. 58*.

bhṛ́guobhis. 4. 14. 5 .

bhŕguobhyas. I9. 39. 5 (not mss.).

bhṛ́ñ $\mathrm{a}$ : -ās. 9. I. 22.

b h ṛ t in ișubhựt, upabhṛ́t, kṣatrabhṛ̂t, gurubhṛ́t, rāșțrabhṛ́t, viçvabhṛ́t.

b h r t a in sámbhṛtaçrī, súbhṛta.

bhrrti in prábhṛti.

bhṛtenyà: -nías. I9. 35.5 (mss. vabhr-; ed. mártyebhyas).

bhṛty a in rāṣtrabhṛ́tya.

bhṛtyá: -ăm. I8. 1. 6".

bhrtvan in sambhŕtvan.

bhṛtha in avabhṛ́tha.

b hṛmal á: -ás. I2. I. 46.

b hṛsța in ánibhṛșța.

bhṛṣṭi in kṣurábhṛșți, cáturbhṛșți, sahásrabhṛsți.

bh edá: -ás. I2. 4. 50.

bhedám. I2. 4 . 49 . 
(cf. an̉hubhéda, añgabhedá.) bheș ajá: -ám. I. $4 \cdot 4^{*} ; 5 \cdot 4^{*} ; 6.3^{*}$. 2. 3. I, $3-5,4$. 3. 7. I, 6. 4. I3. $3^{*}$. 5. 30. 5. 6. 2 I. I; $24.3 ; 57 . \mathrm{I}^{2}, 2,3^{2}$; 83. I; 91. $3^{*} ;$ ro6. 3 ; III. 2,3 ; 127. 2. 7. 38. I; 45. I; 76. 4. 8. 2. 5, 28 ; $6.3 ; 7.5,22,26$. I0. 4 . I0, I4. II. $4.9 ; 6.23^{2}$. I 9. 35.1 ; 44. I (mss.). bheșaja. 8. 6. I6.

bheșajásya. 5. 29. I. I9. 38. I. bheșajāú. 8. 6.20; 7. 20. [42. 2*. bheșajấni. 2. 3. $2 ; 9.5$. 6. 44. 2. 7 . bheșajă. I. 6.2*. II. 6. I4. bheșajébhias. 6. 13.3.

bheșajănām. 4. 17. I. 6. 2 I. 2. bheșají. 7 . 56. 2.

bhesajim. 6. Io9. $3^{2}$. 8. 7. 23 .

bheșajis. 3. $7 \cdot 5^{2}$. 6. 9I. $3^{2 *}$. 8. 7.8 . (cf. atividdhabheșajá, āsrāvabheșajá, āhrutabheșajá, kilāsabheșajá, kṣiptabheșajá, jalāṣabheșaja, viçvábheșaja, súbheșaja, haritabheșajá, hṛddyotabheșajá.)

bhóg a: -gãya. I2. 4.7.

bhóge. I2. I. 60.

(cf. vaçābhogá.)

bho gá: -gấya. I9. 44. IO. bhogébhis. II. 9.5.

bhógya: -gias. I0. 8.21, 22.

bhójana: -am. I0. 8.2 I. 20. 34 . I 2 (not mss.).

bhójanāni. 4. 22.6, 7. 7.73.9*. (cf. ihábhojana, jīvabhójana.)

bhojas in viçvábhojas, subhojas. bhāuva ná: -nâs. 3.21.5.

$\checkmark$ bhy as in

bhy a s a in udbhyasá, svabhyasá.

$\checkmark$ bhrańç: bhraçat. 6. $87 . \mathrm{I}^{*}$.

bhrașțás. 20. 136. 7, 8 .

(cf. bhṛșța, bhrançana.)

+ ava: áva ... bhrańçat. 20. 133. 6.

+ ni: cf. ánibhṛșța.

+ pra: cf. prabhranç̧ana.

b h r a ṅ ça $\mathbf{n}$ a in nāvaprabhráṅçana. bhraj in mṛtábhraj: cf. bhrajás.

bhrajás: 7.90.2.

(cf. vătabhrajas.)"
V bhrāj: bhrăjat. II. 5. 24.

bhrăjatā. I7. $20^{2}$.

bhrăjantas. I3. 2. I, I8*. I9. 27.6.

bhrăjamānas. 5. I. I. I 3. I. 24 ; 2 . IO.

bhrăjamānam. I3. 2. 4, 36; 3. I6.

bhrājyāsam. I7. 20.

[já.)

(cf. bhárgas, bhṛ́gu, bhrșțị, bhrā+ pra: praobhrăjamănăm. 10. 2. 33 .

+ vi: viobhrăjan. I3. $2.33,45$.

bhrājá: -ás. 2. II. 5 . I7. $20^{2}$.

b hràtṛ: -tā. 3. 30. 3. 4. 4. 5. 5. 30. 5. 6. I20. 2 . 8.6.7. 9.9. $\mathrm{I}^{*}$. 18 . I. $12^{*}, 13^{*}, 14,19^{*}$.

bhrâtaram. 3. 30. 3. I I. 9. 8 .

bhrătrā. 5. 22. I2.

bhrătur. I. 14. 2. 6. I16.3.

bhrătaras. 2. 13.5. I0. 3.8.

bhrătṛobhis. 6. 4. I.

(cf. abhrătṛ, hatábhrātṛ, bhrătṛvya, bhrātṛhan.)

bhràtṛya: -as. 8. IO. I8.

bhrátṛ̂yyam. 8. I0. 33. I5. I. 8.

bhrâtṛvyenaa. 5. 22. I 2. [6. I.

bhrătṛvyasya. 9. 5. 31, 32-62. Io.

bhrătṛvyās. ro. 3. 9. [vyahán. (ef. bhrātṛvyakșáyaṇa - bhrātṛbhrätṛvyaokṣáy aṇa: -am. 2 . i8. I.

[I.

bhrätrvyaocattana: -am. 2. I 8 . b hrātṛvyaohán: -yaghnit. ro. 9. I.

bhrātṛhan in ábhrätṛhan.

bhru $\mathbf{r} \mathbf{a}$ in

[II3. 2.

bhrū ṇaohán: -ṇaghní. 6. I12. 3 ;

$b h v a$ in abhvà.

bhvan in mātaríbhvan.

m a (pron. root) : mắm. I. $34.4,5.2$. 27. 7 ; 30. 1. 3. 6. I, 3,5 ; 18. $6^{*}$; 22. 3, 6. 4. 30. $4^{*}$. 6. 8. I, I-3; $9.1 ; 82$. 2 ; 89.2 ; 102. I ; IOS. 4 ; I24. I; 130. I-4; I3I. I, 2 ; I 33. 5 ; I39. 2, 3, 4 . 7. I2. 3 ; $36.1 ; 79.2$. 10. 6.31 . II. 3. 30. I3. I. $57,58$. r6. 4.3 (mss. mām). r8. 3. IO, II, 12. I9. 52.4 (mss. upa。 mám). 20. I36. I I, I 2,13 .

mā. I. 33.4 . 2. $4.5 ; 12.5^{2} ;$ I6. 
I-5. 3. $5.1,5 ;$ 10. 7 ; $13.5,6^{2} ; 15$. 2,4 ; 20. 10 ; 22.2 ; 25.4. 4. 19. 8 ; $20.6 ; 24.1 ; 26.7 ; 30.2^{*} ; 36.9 .5$. $3.4^{\dagger} ; 9.8^{2}$; 10. I-7; II. 8 ; 24. I-I 7; 28. 2, 14; 29.6-9. 6. I9. $\mathrm{I}^{2}, 2 ; 26$. $\mathbf{I}^{2} ; 39 . \mathbf{I} ; 48 . \mathbf{I}-3 ; 55 . \mathbf{I} ; 58 . \mathrm{I}^{2} ; 69$. 2; 71.2; 96.2*; 99.3; 107. I-4; II 52,3 ; II9. 3 ; I29. I $^{2}, 2,3$. 7. 12 . $\mathrm{I}^{2} ; \mathbf{I} 3.2 ; 33 . \mathrm{I}^{2} ; 50.9 ; 54.2 ; 64 . \mathrm{I}$, $2 ; 67 . \mathbf{1} ; 75.2 ; 81.3 ; 89 . \mathbf{1 ,} \mathbf{2}^{*} ; 97.4$; IO2. I ; II 5. 2. 8. I. $8^{*} ; 4 \cdot 7^{\dagger}, 8^{*}, \mathrm{II}^{\dagger}$, $15^{*}, \mathrm{I}^{*} ; 5.20 ;$ 7. I3. 9. I. $14^{*}, \mathrm{I} 9$, 24 ; $9.22^{*}$; IO. $15^{*}$. IO. I. IO; 3.10 , I 7-25; 5. 6, 22; 6. 2, 2I-8, 3I, 32 . II. $4.24 ; 6.7$. I2. I. $21,22,23,24$, 30 (p. mâ), $4 \mathrm{I}, 58,63^{2} ; 2.40 ; 3.17$; 4. 37. I3. I. I2, I3 I I , 57; 4. 48, 55. I6. I. $12 ; 2.5 ; 3.2-4^{2} ; 4.4,5,7 ; 9.2$. I 7. 6, 6-I9, $7^{2}, 24,25,26,28,29,30$. I 8. 3. $\mathrm{IO}^{2}, \mathrm{I} \mathrm{I}, \mathrm{I} 2^{2}, 25-8,56^{*}$. I9. I6. $\mathrm{I}^{2}: 2^{2} ;$ I7. $1-10^{3} ;$ I8. I-10; 20. 4 ; $31.2,7^{2}, 12,13^{2} ; 32.8 ; 35.4^{5} ; 43.1-$ 8,$7 ; 44.6 ; 45.6-10 ; 49.2$ (not mss.) ; $52.4 ; 62 . \mathrm{I}^{2} ; 72 . \mathrm{I}$.

máyā. 3. 5.8; 14.5, 6. 4. 30. $4^{*}$. 7. 60. 7. I 4. I. $48,50^{*}, 52$. I9. 7 I. I. máhyam. I. 29.4. 2. I2.2. 3. 5. 6 , 7 ; I5. I; 22. I. 4. 36. 10 ; 39. I, 3, 5,7. 5. 3. $1^{*}, 3^{*}, 4^{*}$; 13. I. 6. 24. I ; 61. $\mathrm{I}^{4} ; 63.2 ; 7$ I. $3 ; 82.3 ; 84.3 ; 89$. $3^{3}$. 7. 38. 5. 9. $2.7,8, \mathrm{II}^{3}$. I0. 6.2 , 29. II. I. 20. I2. I. I6, 3I ; 3. II. I4. I. $50^{*}, 52 ; 2.4^{*}$. I7. $6,24^{*}$. I 9. 8.6 ; 31.6 ; 7 I. I. 20. 48.3 ; I3I. I3.

me. I. I. I ; 6. $2^{*} ;$ I $2.4^{3}$; I5. I, 2, 3,$4 ; 16.2 ; 30.2 ; 33.4 ; 34.2,3^{2} .2$. 2. $3 ; 5.4 ; 7.4 ; 15.1-6 ; 17.1-7$; I8. I-5; 30. 3. 3. 6.6 ; 8. 2 ; I5. 5 , 6; 16. $6^{+} ;$17. $7^{\dagger} ;$ 18. $2^{2 *}, 5^{*} ;$ I9. I ; 20. $3^{\dagger}, 9$, 10; 22. 4. 4. I 3. $6^{3^{*}} ; 20.4$; 2I. $5^{*}$; 22. I ; 25. 5 ; 26.2-6; 27. I ; $34.8^{2} ; 35 \cdot 7^{2} ; 36.4 ; 39.2,4,6,8.5$. $3.4^{*} ; 4.6^{2}, 7 ; 6.11-4 ; 8.1,2^{2} ; 9.7$, $8^{2}$; IO. I-7; II. $3,8,9^{3}$; $3.3,5^{2}$; I5. $\mathrm{I}-\mathrm{IO}^{3}, \mathrm{II}^{2} ; 23 . \mathrm{I}^{2} ; 28 . \mathrm{II}$. 6. $2 . \mathrm{I} ; 4$. I ; 6. I ; 9. I, 3; 24. 2 ; 45. I ; 50. 3 ; 53. I; 54.3; 71. $2 ; 94.3^{2} ; 95.3$; III. I; I22. 5 ; $130.2^{2} ;$ I38. I. 7. I2.
2 ; 30. $1^{2} ; 32.1 ; 33.1 ; 34.1 ; 50.8^{2}$; 57. $1^{2} ; 89.2^{4} ;$ IOI. I; IOg. $3^{2}$. 8. 2. $20 ; 5.5,6,18^{8}$, I9. 9. I. II-3, 16, I 7 ; 2. $2^{2}, 7,15 ; 9.15^{*} ;$ 10. 24 . I0. 1. 28 ; 3. I, $8^{3}, 9, \mathrm{II}^{2}, \mathrm{I}^{2}, \mathrm{I} 3, \mathrm{I} 4, \mathbf{I} 7-25 ; 4$. $-10,16,17 ; 5.6,37-4 I^{2}, 50 ; 6.19,30^{2}$; 9. 27 . I I. I. $27,28^{2}, 33$; IO. 4. I 2. I. I0, $33,44,45,53^{2}, 59$. I3. I. I 2,32 , 43. I4. 2. $9,42,50^{2}, 63$. I5. 3.2. 16 . I. $12 ; 2.3 ; 3.5,6 ; 4.7^{2}$. I8. I. I 2 ", I4, $3 I^{*} ; 2.32 ; 3 . \mathrm{II}^{2}$, I $2 ; 4.40,55$, 89*. I9. 4. 2, 4; 7.2 (not mss.), 2, 3, $4^{2}, 5^{4} ; 8.2,3^{2} ; 9.5,12^{3}, 13^{5}, 14^{2} ; 14$. $\mathrm{I}^{2}$; I6. 2 ; 20. $2,4^{2} ; 28.5-\mathrm{IO}^{4} ; 29 . \mathrm{I}-$ $9^{4} ; 31.1,3.5,9,10,12 ; 32.6 ; 37.1$, 2 ; 40. I; 42.4 (mss. te); 43. I-6, 8 ; 49. 8 ; 5 I. I $^{6}$; 55.6 ; 60. I, 2 ; 6I. I ; 64. I, 3 .

mát. I. 34.5. 2. 7. I ; 30. I. 4. 19. 7. 6. $8.1-3 ; 118.3 .7 .60 .1 ; 65.1$. I0. I. 10, I3. I8. I. $9^{*}, \mathrm{II}^{*}, 13^{*}$.

mat. II. $4.26^{2}$. 12. 3.46 .

máma. I. $6.3^{*}$; I2. 4 ; I9. 2, 3, 4* ; 34. $2^{2}$. 3. $8.6^{3} ; 18.4^{*} ; 25.5^{2}, 6.4$. 30. $7^{*} ; 36.8$. 5. 3. $\mathrm{I}^{*}, 3^{2 *}, 4^{*} ; 7.2$; 8. 3 ; 23. 2. 6. 9. $2^{3} ; 37.1 ; 42.3$; 43. $3 ; 65.3 ;$ I30. 3 ; I39. I. 7. 20. I; 37. $\mathrm{I}^{2} ; 38.4 ; 50.2$. 8. 7. 7, I9. 9. 2. I, $4,5,7^{2}, 9$, IO, II I I 6, I 7, I $8 ; 4$. I2. I0. $3.15 ; 8.25$. I2. 3.47 . I3. I. 28 I 4. I. 52 I $8.2 .37^{2} ; 4.49$. I9. $8.1 ; 15.6 ; 49.7 ; 57.3 .20$. I27. II ; 136.8 (not mss.).

máyi. 1. $1.2^{2}, 3^{2}$. 2. 12. $1 ; 26.4$. 3 . 5. $2^{2}$; 10. 6 ; 14. 2,4 ; 22. 5. 5. 3. $5^{3^{*}}$. 6. $69.1,3^{2} ; 73.2,3 ; 102.2 ; 108.3$; 139. 2. 7.12. 4 ; I9. I; 79. $2^{2} ; 82$. $2^{4}$; 89. 4. 9. I. I8. I0. 6.33. II. 4. $26 ; 7.3,5,12,14$. I2. 2.33. I4. I. 57 I6. I. I3;9.4. I7. 30 . I 8 . 2. $52 ; 3.6$ I. I9. 3 I. 6, I 2 .

(cf. mattás, māmaká, māmpaçyá ; and áma, imá, samá, sma.)

$\checkmark \mathrm{m}$ a n h, m a h: māmahe. 20. 127.3. mahayantu. 4. I5.2, 3 .

(cf. mán̉hișțha, maghá, máh, mahá, mahán, mahánt, mahā, máhas, máhi, mahimán, mahişá, 
Jmahīy, mahmán.)

mánhișț a: -as. 20.49.2.

mákaka: -kān. 8. 6. 12 .

mákșā: -ās. 9. I. I 7.

$$
\text { (cf. mákșikā.) }
$$

mákși kā: II. 9. IO.

mákșikās. II. $2.2 ; 10.8$.

makhá: -ás. I8. I. $23^{*}$.

ma gád h a: -dhebhias. 5.22. I4.

$$
\text { (cf. māgadhá.) }
$$

ma g und ì: -dyās. 2. I4. 2 (p. -dyā). mag há : -ghă. 20. I 30. I 2 (mss. mághā).

maghāís. I8. I. $38^{*}$.

(ef. púnarmagha, maghávan, maghávant, maghă.)

$\left\lfloor 47^{*}\right.$.

m a ghá ov a n: -vā. 2. 5. 7*. I4. 2. mághavan. I9. I5. I*.

maghavan. 2. 36.4 . 3. I. 3 ; $16.4^{*}$; I9. 6. 7. 3I. I" ; 50.4*. 8. 4. 19*. I3. 4. 44. 20. 128. I3.

maghávānam. 3. I9. 3 .

maghávānas. 20. 128.5.

maghónas. I8. 1. 38*.

magháovant: -

maghấ: -ầs. I9. 7.2.

maghăsu. I4. I. I3*. [gála, and

mañgala in ádurmañgala, sumañmañgaliká: -kébhyas. I9. 23.28. $\checkmark$ majj: cf. majján, majmán.

+ ud: unomájya. 10. 4. 4 .

+ ni: niomájya. Io. 4.4 .

[9. 18.

majján: -jầ. 4. 12. 3, 4. 9. 7. I8. 10. majjănam. II. 8. II, I2. I2. 5.70. majñă. 4. I 2. 3, 4. [-jjanás). majñás. 2. 12. 7. 9.5.23;8. 8 (1. majjáobhias. 2. 33. 6 .

majjáosu. I. II. 4.

m aj má n: -ni. I3. I. I4, 37 .

maṭm a țá: -țâs. 8. 6. I5.

mañí:-ís. I. 29.4. 2. 4.2,6. 4. IO. 4, 5. 8. 5. I, $2,4,16$; 7. I4. I0. 3. I, $2,3,6$, I0, I7-25; 6.2, 4, 5, I9, 22-8, $25,3 \mathrm{I}^{2}, 32$. I5. 2. I-4. I9. 3 I. 2,6 , $7^{2}, 8$, I0, I4; 33. I; 36. I (mss. -ím),

3,5 .

máne. 10. 6. $34^{2}$.

$[\mathrm{I}-9$.

mane. 3.5.8. I9. $28.3,4,5$-I0; 29 . maním. 2. 4. I. 3.5.3; 9.6. 8. 5 . 7, IO, I2, I3, I4, 22. I0. 6. 6-10, 10, I I-7, I3, I 4, I 5, I6, I 7, $29^{2}$. I2. I. 44 . I9. $28.1 ; 30.4 ; 31.4 ; 45.5$.

manínā. I. 29. $I^{\dagger}$. 2. 4.4. 8.5.3, 8. I0.6. I2. I9. 3I. I.

mañāú. 6. 30. I. I9. 46.5 .

maṇinăm. I9. 3I. II.

(cf. amaní, devamaní, parnamaṇí, sumaṇí, maṇichád.) [mss.).

mañichád: -das. 20. 130. 9 (not

ma nqút ka: -am. 7. II6.2.

maṇdúkās. 4. 15. 12, $13^{*}$.

mandūūt. I8. 3.60†.

maṇụuki. 4. I5. I4.

mand $\bar{x} r a$ in $\quad$ [mss.).

mandūrikā: -ke. 20. I3I. I3 (not

mát a sna: -ne (p. -e íti). I0. 9. I6. mátasnābhyām. 2. 33. $3^{*}$.

matí: -ís. 7. 22. 1. 8. 4. $6^{*}$. I0. 2. 10. matím. 6. 133.4. 7. I4. I.

mati. I8. 1. 23*.

matyāí. 6. 4I. I.

matés. 2. 5. I. $\left[63 ; 4.58^{*}\right.$.

matinắm. I3. 1. $33 ; 3.19$. I 8. 3 . (cf. ánumati, durmatí, prámati, sumatí.)

mattás. 6. 20. I.

maty à: -tíam. 8. 8. II. II. 2. Ig.

mats a rá: -ám. 4. 25. 6.

matsarắs. $7 \cdot 77 \cdot 3$.

máts y a: -yās. II. 2. 25.

(cf. mātsyá.)

$\checkmark$ m at h, ma n th : mathnāmi. 2. 30 .

I. 7. 50. 5 .

mathnita. 5.8.4.

mathnantu. 7.70. 2.

mántha. 19. 29. $5^{4}$.

manthatu. 8. 8. I.

manthantu. II. I. I.

mamătha. I0. 9. 26.

máthat. 7.50. 5 .

(cf. mathavyà, mathi, manthá, mántha, mánthitr, methi, / mathāy.)

+ $\mathrm{n}$ is: niromathyáte. I0. 8.20.

+ pra: prá mathișțana. I9. 40.2.

$\mathrm{m}$ a th a v y à : -yần. 2. 35. 2. 
V mathāy: mathāyáti. 2. 3o. I. + ud: ún mathāyati. 20. 132. 4 . $\mathbf{m}$ a th $\mathbf{i}$ in havirmáthi.

$\checkmark$ mad: mátsva. 2. 5.4.

madasi. 19. 56.5.

mádanti. 3. 28.5 .4 .8 .5 . 6. 120. 3. 7. 73. 2 ; IOg. 2 . I8. $2.11^{*} ; 4.10$. madanti. 7. I09. 3. I4. 2.34 .

mádema. 7. 5.3. I9. I2. $\mathrm{I}^{*}$, [28. madema. 6. 122.4. 7. IOg. 5. I2. 2. madeta. 9. 1. 6 .

mádantāu. I8. 1. $54^{\dagger}$.

mádantas. 6. $28.1^{*} ; 62.3$.

mádanti. I8. 1. 43*.

mádantīm. I 8. 4. 30 .

amadat. 20. 130. 16 (not mss.).

mamáttana. 7. 72. $1^{*}$.

mamádat. 7.14. 4.

amimadas. 4.6.3.

ámimadanta. I8. 4. 6I*.

madáyanti. 9. 8. 19.

mādáyante. I8. 1. $35^{*}$; 2. $35^{*}$.

mādayāthas. 4. 25.6.

mādaya. 5. 8. I.

mādayasva. I8. I. $59^{*}, 60^{*}$.

mādayethām. 7.58.2*.

mādayadhvam. 5. 3.6 . 9. 2.8. I 8 .

I. $42^{\dagger} ; 3.20 ; 4.64$.

mādayantām. I 8. 3.53*. I9. 58.6.

(cf. mad, matsará, máda, madita, mádișțha, mádya, māda, mādayiṣnú, mādya, medín, $/$ mand.)

+ anu: anuomádanti. 5. 2. $4^{*}$.

ánu ... mádanti. 5. 2. $\mathrm{I}^{*}$.

ánu madantu. 7. I6. I ; 35. I.

ánu... madantu. 7. IIS. I".

(cf. anumădya.)

$+\overline{\mathbf{a}}$ : á madat. 20. 49.2 (mss. -da).

+ ud: únomattam. 6. III.3.

únomaditam. 6. II1.3.

ún mādayā (p. -ya). 6. 130. 4 .

út ... mādaya. 6. 130. 4 .

ún mādayata. 6. 130. 4.

(cf. ánunmadita.)

+ pra: prá madas. 8. I. 7 .

(cf. prámad, pramāda.) [ma-).

+ vi: viomádan. 20. 49. 3 (mss. víví... amímadam. 7.74. 3 . (cf. vimadá.)

+ s a m: sám ... madate. 4. 34. 3 .

sám... madema. 7.80. I.

sám ... mádasva. I 8. 3.8. [I, 2. sám ... mádantas. 3. 15. 8. I 9. 55 . sám ... amadat. 20. 49. I (mss. -dan).

m a d in prámad, samád.

mád a: -as. 6. 30. 2.

mádam. $4 \cdot 7 \cdot 4$.

mádāya. 2. 5. I.

máde. 2. 5.3.

mádās. 2. 5. 2.

mádeșu. 5.2.2".

(cf. ukthāmadá, vimadá, madâvant, madín.)

[16.2.

ma dá va nt (p. -dá॰v-): -vatí. 6. madāvati. 4. 7.4.

$m$ a dit $a$ in ánunmadita.

madín: -ínotamas. II. 7.7.

mádiṣt ha: -as. 4. 24. 3 .

m a dú g h a: -ghāt. I. 34.4 .

madúghasya. 6. I02. 3 .

má d y a: -diam. 7.58. I*

mádhu: I. 34. 2. 2. I3. I. 3. I4. 3. 5. $2.3^{*} ;$ I5. I-II. 6. $12.3^{2} ; 22.2$; 69. I. 7. 73. I. 9. I. $14^{2}, 16,17,18^{2}$, 22 ; 6. 42 . I0. $6.5 ; 9.12-24$. I2. I. 7, I6;3. 44. I 8. 2. I4*; 4. 3 .

madhús. 7. 56. 2.

mádhunā. I. 4. I*; 34. I. 3. 17.9. 5. $2.3^{*} ;$ 12. $10^{*} ; 28.14$ 6. 30. I; 69. 2 ; 97. 2 ; II6.2. 9. I. I9. I2. 3. 4 I. I8. 3. IO, I4, $18^{*}$.

mádhvā. 5. 12.2*. I 8 . I. $31^{*}$.

mádhuā. 5. 27.2,3. 6. I2. 3 .

mádhvas. $4 \cdot 32.7^{*}$. 7.3. I.

mádhos. I. 34. I, 4. 5. I. I, 2. 7. 73. 5.

8. 7. I2. 9. I. 5. I0.6.25.

mádhāu. 9. I. I6, 17. [22.

mádhūni. 7.97.3. 8. 9. I8. 9. I.

mádhuotaras. I. 34.4 .

(cf. mădhva, madhvád, madhu-

kaçă-madhứlaka.)

m a d h u ०k açă : 9. I. I, 2, 3, 4, IO.

madhukaçấm. I0. 7. I9.

má d hu०kū la: -lās. 4. 34. 6.

madhu०kṛ́t: -tas. 9. I. I6. 
mádhu॰jāta: -tā. I. 3ł. I. 7. 56.2. madhyám dina: -as. 9. 6. 46 .

mádhuojihva: -vās. 5.6. $3^{*}$.

mádhuodhāra: -rā. I8. 4.57 (m. mss. madhú-).

madhuoparká: -ké. I0. 3.21. $\mathrm{madhu} \circ \mathrm{p}$ út: - tús. I8. 3.37.

ma dhu opṛ́c: -cām. 3. I3. 5. mádhu。bhāga: -as. 6. II6.2. mádhuomant: -mān. 9. I. 22, 23 . I2. 3.6. I8. I. $48^{*} ; 4.22$. I9. 33.2 ; 46.6 .

mádhumat. I. $34 \cdot 3^{3} \cdot 4 \cdot 34 \cdot 5-7 \cdot 6$. 6I. I; 7I. 3 ; II6. I. 7.82. I*. 8.7. I $2^{5}$. 9. 1. 23 . I2. I. 58 . [4. 42 . mádhumantas. 7.68.2. I8. 3.68; mádhumatas. I. 34. I. 9. I. 23. mádhumatī. I6. 2. I.

mádhumatìm. I. $34 \cdot 4 \cdot 3 \cdot 30.2$. 5 . 7.4. 8. 7.6. I6. 2.2. I8. 4. 30. I9. 3I. I4.

mádhumatīs. 4. 23.6. I 0. 9.27. I 4 . I. $37^{*}$. I6. 2.2 . I 8. 4.39 .

mádhumatotaras. I. 34.4 .

mádhumatotamam. r8. 2.2*.

mádhumatotamasya. 7. $58.2^{*}$.

madhulá: -lá. 5. I5. I-II. 7. 56. 2. (cf. madhúlaka.)

madhu。çoút: 7. 56.2.

madhuçcútas. 9.5.15. I8. 2. 20. mádhuosa mkāça: -çe (p. -eiti etc.). 7. 36. I.

mádhu०sa món dŗa: -as. I. $34 \cdot 3$. madhút laka: -am. I. 34. 2.

mádhya: -am. 4. II. 8; I4. 8. 5 . 23.3. 6. 89. 3 ; 137.3. 7. 72.2 $2^{\dagger} .8$. 7. I2. 9. $5.8,20$. ro. 4.19 . I2. I. 12. I9. $6.6^{\dagger} ; 44.7$.

mádhyena. 8.8.13. I9. 36. 2. mádhyāt. 4. I. 3. 5. 28.9. mádhye. I. $33 \cdot 2^{*}$. 3. I6. $4^{*}$. 4. I5. I4, I5. 5. 19. 3. 6. 106. 2. 9. 10. $8^{*}$. I0. $7.38 ; 8.15,17$; 10.28 I3. 2 . 36. I8. I. $19^{*} ; 2.35^{*}$. $19.13 .9^{\dagger}$.

(cf. madhyatás-madhyamá.)

madh yatás. 4. 14.8. 7. 5I. I*; $56.6 ; 80$. I. I0. 2 . I. I2. I. 2 (s. mss. ed. ba-). I3. 3. I3. I4. I. 60, 64. I8. $3.73 ; 4.9$. I9. I5. 3 . madhyámdinam. 4. I1. 12. 6 I08. 5. madhyámdine. 6. I28. 2.

(cf. mădhyamdina.)

m a dh y a má: -ás. 9. 9. I*.

madhyamám. 5.13.2. 7.83.3* 10. 7. 8 . 20. 136.5 (not mss.).

madhyamă. I8. 2. 48 .

madhyame. I. 17.2.

madhyamám. 7.74. 2.

madhyamé. 20. I33. 3 (mss. mádhyame).

madhyamás. I. I7.3. I 8. I. $44^{*}$.

madhyamằn. 6. 103. 2. [șțhâ.)

(cf. madhyamaçî, madhyame-

m a d h y a m a çî: -î́s. 4. 9. $4^{*}$ (oiva). madhyameșţhă (p. -meosth-): -ấs. 2.6.4. 3. 8. 2 .

m a גhvá d: -dhu॰ádas. 9. 9. 21*.

$\checkmark$ man, mnā: mánye. 3. 13.6.

manye. 4.36 .9 . 7. $45.1 ; 72.3^{2 *}$. Io. 8. 16.

mányase. 20. 133. I-6. [7. 12. 4. 6. mányate. 4. I6. I ; 20. 9. 5. 18. 4. manyate. II. 8.32. I4. I. $3^{*}$.

manyante. I0. 7.2I.

manyeta. I0.8.20. II. 8.7.

amanyata. I5. 6. 7.

mányamānas. 2. $35 \cdot 3 \cdot 3 \cdot 16.2^{*}$. 5 . I8. 5 ; 19. 6 . 12. $4.37,3^{8}$.

mányamānā. 8. 9. 22.

manvé. 4. 26. I; 28. I ; 29.1 .

manve. 4. 23. I ; $27 . \mathrm{I}$.

manmahe. 4. $24 . I^{2} ; 25 . I$. ro. 4 .

manávate. I8. I. $34^{*}$.

manvita. I2. 4.48 .

amanvata. 7.I. I.

amīmāñsanta. I2. 4. 42 .

mímāñsamānās. 9. I. 3 .

mīmāñsámānasya. 9.6. 24 (-syá-?). mīmāńsitásya. 9. 6. 24.

mānayet. I5. IU. 2.

(cf. matí, mánas, manīșâ, mánu, mánus, mantu, mántra, mánman, manyú, māti ?, múni.)

+ a ti : áti...mányate. 2. 12.6*. [35. atyámanyanta (p. atioám-). 10. 8. + a nu: ánu ... manyasva. 6. 131. 2. 
ánu manyatām. 4. 8. 1. 7.20.3. I $8.3 .69 ; 4.26$.

ánu... manyatām. 7. 20. I.

ánu manyantām. $\quad$ I. 35.4 . 5. 28 . II. 8. 2. 2 I. 9. $4.2 \therefore$

anuományamānas. 7.20.3.

anuományamānău. $\quad$ 14.2.42.

ánu... máñsase. 7. 20. 2,6.

ánuomatam. 6. 71.2. 7.20.4.

ánuomatā. 3. 17.9.

(cf. ánumati.)

+ a bhi: abhiományate. 6. 6. I. abhí ... mányate. 5. 19. 9.

abhí maństhãs. 9.5.4 (s. mss. mã-). abhí maństa. 8. I. I 2.

abhí māñsta. I I. 2.8.

(cf. abhímāti.)

+ pra: cf. prámati.

[84. I.

+ abhipra: abhioprámanvate. 6 .

mán a ḥoşa ș ț h a: -țhāni. I9. 9. 5 (mss. mánaḥ șașțhăni).

mánas: 1. 11. $6 ; 21.4^{*} ; 27.2$. 2 . 12. 2,3 ; 30. 1,4 . 3. $4.4 ; 18.6^{*}$. 4 . I5. $15 ; 38.6$. 5. 10. 8 ; 30. 13. 6. 8 . 2,$3 ; 18.2^{2} ; 45.1 ; 64.3^{*} ;$ 70. I, 3 , I-3; 7I. $2 ; 89.2^{2} ;$ IO2. I, $2^{2}$; I05. I; III.2. 7. 12. $4^{2}$; 36. I. 8. I. 3 , 7 ; 2. 3. 9. $4.19 ; 9.18^{*}$. 10. 2. 19, 27 ; 7. 37. II. $5.24 ; 8.4$, 26. I2. 4 . 30. I3. I. I9. I4. I. 10* I5. 2. I-4; I4. I. I8. 1. $3^{*}, 15^{*}, 16^{*}, 19^{*} ; 2.21$, 23,$24 ; 3.9 ; 4.66$. 19. 9. 4 ; 28. 2 ; $43.4 ; 52.4 ; 53.7$.

mánasā. I. I. 2 . 2. $34.3 ; 35.5$. 3. $6.8 ; 8.6$; 20.9; 21.5. 4. 21. $5^{*}$; 39. IO. 5.6. IO; II. I ; 2 I. 2 ; 30. 6 . 6. $53.3 ; 83.4^{2} ; 93.2 ; 96.3 ;$ I 19 . 3 ; 122. 4. 7. I. I ; 2. I ; 5. 3,5 ; 52 . $2^{2}$; 70. I ; 73. $8^{*} ; 97.2^{*}$. 8. $4.8^{*}$; Iо. 3I. 9. 4. IO; 9. $6^{*}, 8^{*}$; IO. I5* I I ${ }^{*}$. I 0 . 8. I4. II. I. $23 ; 9.8$. I2. I. I4； 2. $52 ; 4.31$. I3. I. IO, I3; 3. I9. I4. I. $9^{*}, 56,57 ; 2.6$. I5. I4. I. I8. 2. 21 . 19. 25.1 .

mánase. 6. 4I. I.

mánasas. 2. 35.4 . 5. 3. $4^{*} ; 6.9 .6$. 74. 2 ; 105. I. 7. 97.8. 8. 3. 12*. 9. 2. 2. I4. I. 57. I8. I. I4. I9. $6.7^{*}$;
40. I; 52. I"; 56.5 .

mánasi. 7. 73.2. 10.8.28. I8. I. 3". I9. 4. 2.

mánān̊si. 3. 8. 5,6. -6. 64. 1*; 74 . I. I4. I. 32 .

(cf. ămanas, ṇ̛mánas, párānmanas, prámanas, mahămanas, mṛtámanas, vimanas, sámmanas, sumánas, mánahṣaşţ̣a, manaská $-\checkmark$ manasy.)

m a na s ká (p. -aḥok-): -ám. 6. I8. 3 . manasketá (p. -ahok-): -tāís. 6. I05. I.

[5. 28.

mánastejas (p. -aḥıt-): -jās. ro. m a n a s pã pa (p. -aḥ॰p-): 6. 45. I. m a n s má y a :-am. I4. I. I2*.

Vmanasy: + abhi: abhiomanasyéta. II. 3. 25 .

(cf. V/sumanasy.)

manișă: -ấm. 5.9.8. 19.42. 3 . manīsáyā. r $8.4 \cdot 5^{4}$.

manișâ. 20. I27. 5 . (cf. manīsín.)

manișín: -ṣt. 8. 5.3 .

manīṣínă. 8. 5. 8.

manīṣínas. 3. 5.6. 9. 4.8 ; I0. $27^{*}$. I1. 6. I3. I2. I. 8 .

mánu: -us. 7. 82.6. 8. I0. 24.

mánunā. 3. 9.2. I4. 2. 41 .

mánave. I8. I. $20^{*}$.

mános. Ig. II. $5^{*}$.

mánavas. 6. I9. I. I9. 26. 2.

(cf. mánujāta, mānavá.)

má nuojāt a : -tena. 7.37. I.

m a nu ș y à: -yàs. 8. 10. $21,24^{2}$. 9. 7. 16; 10. $27^{*}$. 10.6. $32 ; 8.34 ; 9.9$; I0. 26 . II. 7.27. I2. I. 22.

manuṣians. 3. 4. 6. 5. 17. 10*. 6. 51 . $3^{*}$; I4I. 3. 8. I. II ; 7. 26. I0. IO. 34. I2. 2. 17. I $4.2 .38^{*}$.

manuṣyàn. 4. 26. 4. 8. 9. 23, 24; IO. 2 I, 24 . I5. I4. 8.

manuṣyāìs. 6. 71.2.

manuṣyèbhya . 8. I0. 21. I6. 4. 4. manuṣyàn̄ām. I2. 2. 44 (1. -ṇaam). manuṣíānām. 6. 86.3 (1. -ṇaam). manuṣíeșu. 3. 22. 3. 4. II. 3. 6. II3 I. I9 3.3 . 
(cf. devamanușyà, manușyajămanuşyeșu.)

m a nu ș y a ojà : -ấs. r 4. 2. 3*. [43. manuşyajầs (pl.). II. 4. I6. I2. 4 . ma nușyát. 5. 12. $8^{\dagger}$ (ed. -șvát*).

manuşyeșu (p. -yaoiș-) : -șieșavas. I. I9. 2 .

manuṣyāinaś (p. -yåen-): -șiāinasăni. 6. I I 3. 3 .

mánus:-ușas. 5. 12. I*, $7^{*}$. I 8 I. $22^{*}$. (cf. manușyà, manuṣyát, mănușa.)

[92. I.

mánojavas (p. -naḥoj-): -vās. 6. m a nom ú h (p. -naḩom-): -has. 2. 2. 5 . manoyúj (p. -nạ̣॰y-): -jā. 5. 7.5 ; Io. 8 .

manoyújā (du.). 6. 65. I.

m a no hán (p. -naḥ̆h-) : -hă. I6. I. 3. manohánam. 5. 29. 10.

mantu in amantú, durmántu, sumántu.

má n tra: -as. 6. 64. 2*. I 5. 2. I (mss. mítras), 2 (ed. mitrás). I9. 54.3 (not mss.).

mántram. 5. 20. II.

mántrās. 18. I. 60*.

(cf. asanmantrá, ŕ̛dhan̄mantra, cákșurmantra, $/$ mantray.)

mantrạ̣a in āmántraṇa.

$\checkmark$ mantray: mantráyete (p. -e íti).

4. I6. 2.

mantráyante. 9. 9. 10*.

(cf. mantrana.)

$+\bar{a}$ : cf. āmántrana.

+ nis: nír mantrayāmahe. 9. 8. I-g. $\sqrt{ }$ manth, see $/$ math.

manthá: -ám. 2. 29. 6. I8. 4.42

(mss. mántham). 20. 127. 9 (mss. mánthām).

manthéna. I0. 6.2.

manthé. 5. 29. 7.

[thám).

mánthā: -ām. 20. 127. 9 (ed. manmánthitṛ: :tā. 8. 8. I.

$\checkmark$ m and: mandasva. I6. 7. I2.

(cf. mandana, mıandasāná, mandrá.)

+ pra: ef. pramandaná.

$\mathrm{m}$ and a $\mathrm{n}$ a in pramandaná. ma n d a sāná: -nắ. I4. 2. 6.

m a ndrá: -ás. I 8. I. 30*.

mandră. I2. I. 57 .

mandrāís. 7. $117.1^{*}$.

mandrắsu. $5 \cdot 27 \cdot 6$.

mánm a n: -mani. 18. 1. $36^{*}$.

mánmāni. 5. 12. 2*.

mány ā: -niās. 6. 25. I.

manyú : -ús. 4. 31. $7^{*} ; 32.2^{3^{*}}, 2^{\dagger} .6$. 40. $2 ; 65.1$; II6.3. 7. 74.3. 9. 7 . I3. II. 8. I.

mányo (p. -oíti). 4. 32. 6*.

manyo (do.). 4. 3I. I* $2^{*}, 3^{*}, 4^{*}, 5^{*}$, $6^{*} ; 32.1^{*}, 2^{*}, 3^{*}, 4^{*}, 5^{*}$. 9. 2.23.

manyúm. I. $21.3^{*}$. 5. 3. $2^{*}$. 6. 42. I, $2^{2}, 3$. I5. 14. I0.

manyúnā. 5. 18.9. 7. 70.4, 5 ; 93. I. I2. 2. 5. I5. I4. IO.

manyáve. I. IO. 2 . I2. 4. 12, $5 \mathrm{I}$. I8. 4.82 .

[8. 3. $12^{*}$.

manyós. I. IO. I. 5. 13.6. 6. 43. I.

(cf. ámanyuta, nímanyu, vímanyuka, çatámanyu, manyutásل/manyūy.)

manyuta (?) in ámanyuta.

manyutás. 2.7.2.

manyu。mánt: -mát. 8.4.3*.

manyumántam. I9. 40. I.

manyumátotamās. 7. 22. 2.

m a n y oçáma na: -as. 6. 43: I, 2. $\checkmark \mathrm{many}$ y $\mathrm{x}$ + prati: in ápratimanyūyamāna.

m a mri in ámamri.

máyas: I. 13. $2 ; 26.4$. 6. 57.3. I4. I. $46^{*}$. 19. 2.5 .

(cf. mayobhú.)

ma y u in pramayú.

ma yứk ha: -khās. I0. $7 \cdot 44^{*}$. (cf. șáṇmayūkha.)

ma yúra: -ūrías. 7. 56. 7 .

(cf. mayúraroman.) [ $\mathrm{I}^{*}$.

ma yúraroman: -maobhis. 7. II 7. mayobhú, mayobhú (p. -yaho bh-): -ús. 5. I7. I*. 7. 10. I*. I9. 46. 6.

mayobhúvā. 2. 4.4.

mayobhúvas. I. 5. $\mathrm{I}^{*}$. 7.60. 2. mayobhứn. I8. 1. $6^{*}$. 
máríci: -cayas. 5. 21 . IO.

márícis. 4. 38.5. 6. 113. 2.

marI mŗ̣̣á: -ám. 8. 6. 17.

marút: -tas. 2. 29.5. 3. 1.6 ; 3. I ;

$4.4 ; 12.4 ;$ I9. 6 . 4. II. $4 ; 27.2,3$,

$4,5,7.5 \cdot 3 \cdot 3^{\prime \prime} ; 24.6 .6 .3 .1 ; 4$.

$2 ; 22.3 ; 30.1 ; 47.2 ; 92.1 .7 .24$.

I; 33. I; 77.3. 8. 1. 2. 9. 7.3. 10. 9. 8 , I. II. I. $33 ; 9.25$. I3. 3.23 . 14. 1. 33,54 . 18.2.22. I9. 10. 9"; 13. 9"; 45. I0. 20. 2. I (mss. máru-). márutas. I. 26.3. 7.77. I".

marutas. I. 20. I. 2. $12.6^{*}$. 3. I. 2 ; 2.6. 4. I5.5; 27.6. 5. 21 . II ; 26. 5. 6. 22. $2^{2} ; 93.3 ;$ 130.4. 7 . 77. $2^{*}$. 8. 4. $18^{*}$. I3. I. 3.

marúdobhis. 2.29.4. 3.17.9. 4. I5. 7-9. 6. 74.3. 7.98. I.

marútām. 4. I3. $4^{*}$; I5. I $5 ; 27.1$. 5. 24. 12. 6. $125 \cdot 3^{*}$. 7. 50. $3^{*}$. 9 . I. 3 , I0; 4.8 . I9. I3. IO".

(cf. măruta, marútvant.)

marútva nt: -vān. 6. 104. 3 ; I 22. 5. II. I. 27 I2. 3. 24 I 8.3 .25$. 19. 17.8 .

marutvan. 4. 3I. $\mathrm{I}^{4}$.

marútvantam. I9. 18.8.

marútvate. 7.57.2*.

márt a : -as. $7 \cdot 77.2^{\dagger}, 9.3 .20$. mártasya. 4. 21. 4*.

mártāsas. I2. I. 20 . 18. $3 \cdot 23^{\dagger}$.

mártān. 8. 3. $20^{*}$. I8. I. $29^{*}$.

mártya:-yas. I2. 4.21.

mártias. 6. 49. I. I2. 2. 38 . I8. 4. 37. 19.49 .9 .

martya. I 8. I. 3 .

mártyam. I9. 8. 3 (mss. amártyam). mártiam. I 1. 8. 13, I8.

mártienā (p. -yena). 9. 10. $8^{*}, 16^{*}$. mártiāya. I8. 3.43*.

mártyasya. I2. 2.36.

[I. $3^{*}$.

mártiasya. 7. II5.3. I0. 8.26. I8. mártyās. 9. 2. I9. I2. I. 4I.

mártiās. 8. 5. I3. I2. I. I 5, 22. mártyān. 6. 41.3. I9. 56. I. [7. mártiān. 4. 37. 12. 9. I0. 7. 20. 127. mártiebhyas. I2. I. I5. I8. 2.33*. I $9.35 \cdot 5$ (-bhias : mss. vabhṛtenyàs). mártiānām. II. I. 5. 18. 3. 13. mártieşu. 5. 18.13. 9. 1. 4. 12. 2. 33. I6. 4. 2. 19. $26.1 ; 59.1$ ".

(cf. ámartya.)

márma n: -ma. 12. 1. 35 .

mármaṇi. 5.8.9. 8. $3.17^{\dagger} ; 8.20$.

márman. 8. 3. $14^{*}$.

mármāṇi. 7. 118. I*.

(cf. marmāvídh.)

marmāvid h: -dham. II. 10. 26. márya: -as. 14. 2.37. I8. 4.60".

marya. 20. 128. 13.

(cf. maryādhíra.)

ma ryăd a: -am. 5. I. 8.

máryāde. 6. 8r. 2.

maryầdās. 5. I. 6*.

maryāodhíra: -rebhyas. 5. 3r. marçan a in çivábhimarçana.

mála: -am. 2. 7. . 7. 39. 3. I0. 5 . 24. I2. 2. 20 . I4. $2.67,68,6$ 9.

málāt. 6. II5.3.

ma la gá: -ás. 12. 3. 21 .

ma limlú: -ús. I9. 49. I0.

malimlucá: -ám. 8.6. 2.

malvá: -ás. 4. 36. I0. 5. 18. 7.

malvám. 12. 1. 48 .

ma çáka: -asya. 7. 56.3.

maçákās. 4. 36. 9. I I. 3.5.

(cf. maçakajámbhana.)

m a ç a ka ०já m b h a na: -nI. 7.56.2.

m a ș mașâ. $\quad 5 \cdot 23.8$.

$\mathrm{m}$ a $\mathrm{s}$ in candrámas.

mastíṣka: -as. 9. 7.2.

mastíşkam. I0. 2. 8.

mastíṣāt. 2. 33. I*. I0. 2. 26.

$\checkmark \mathbf{m a h}$, see $/$ manh.

má h: mahé. I. 5. I". 2. 5.4. 5. II. I. I0. 6.8. I9. $24.2,3$.

mahás. 4. I. 6. 5. 2. $8^{*}$. 7.26.8. I0. 7.2. I8. I. $2^{*}, 53^{*}$.

mahí. 1. 17. 2. 2. 3I. I. 4. 2. 4. 5 . 7.10; $25.2 ; 27.9$. 6. 6. 3": 17. I-4. 9. 10. $12^{*}$. 10. $7.14 ; 8.30$. II. I. $8 ; 7.20 ; 8.15 ; 9.4$. I4. I. $2^{*}$. I8. 2. 25 . I9. $5+2^{2}$.

mahím. 6. 54. I. 7.6. 2, 4. 8.8. 13. I0. 2.7 I I. $4.5,17$. I3. 1. 45 .

mahyāí. 3. 5.5. 8. 5.20. 
mahî (loc.: p. -ítíti). I 8. I. $39^{\dagger}$. mahí (p. -ííti). 4. I. $4^{2}$. 5. I. 5 . mahis. 3. 13.4. 4.8.4. 8. 8.5. I 8. 1. $49^{*} ; 4.7$.

mahá: -ás. 6. g2. $3^{\dagger}$. (cf. tatāmahá, pitāmahá.)

mahaṛșabhá (p. -hăoṛṣ-): -arșabhásya. 4. I5. I, 5. [9. II. m ah aṛși (p. -hāoṛṣ-): -arșáyas. I9. mahatokāṇ ạa: -ḍâya. I9. 23. I8. m a há n: -hnă. 9. 10. $3^{*}$. I0. 2. I8. I $8.3 \cdot 63$.

ma há nt: -hăn. I. 20. $4^{*}$. 4. I. 4. 5. 2. $9^{*}$. 8. 8.8. 9. I. 4 ; 2. 19-24. II. 3 . 22. I2. I. $18^{2}$. I3. 2. $14,29^{3 *}, 29^{\dagger}$. I5. I. 4. 20. I28. I4 (mss. -hán); 136. $13,15^{3}$.

mahát. I. 20. $3 ; 2$ I. $4^{\dagger} ; 32$. I. 2. 3. 3, 5. 3. $29.6,8.4$. $8.3^{*}$; I9. 6. 5 . I. 5 . 9. I. 2 . I0. $7.38 ; 8.6,15,20$, $33,37,38$. I I. 8.3 , I6. I2. I. 18; 4 . 39. I5. I. 3. I9. 7.5. mahăntam. 4. 15. I6*. I I. 2. 29*. mahatâ. 2. 3I.3. 5. 3I. I2. 6. 66. I. 8. 4. I6". 9. 2. I. II. I. I9. I3. I. 8. mahaté. 2. 6.2. 3. I2. 2. 4.8.7. 5. 28. I4. 7. I6. I; 73. 8*, 10*. II. I. 3, 7. I7. 9

mahatás. I. IO. 4. 6. 7 I. 3. 8. 8. 8. 10. 8. 9. I2. 5.72 . I3. I. $26 ; 2$. 29. 20. I36. I2, I4, I5.

mahatí. 3. 6. 3. I I. 8. 2,6 .

mahăntas. 3. 10. 4 . 19.36.3.

mahănti. 9.5. I. 10. 4. 23.

mahatăm. 9. 4. 4. I9. 33. 2.

mahatí. 5. 7.9. I2. I. I8.

mahatím. II. IO. I5.

(cf. mahatkāṇ̣̣á.)

máh a s: 4.25 .5 . 6. 80. I, 3. 9. 5 . 24. I0. 6.4 , I2. II. $4.5 ; 7.22$. I3. 4. 50. I8. 2. I6".

[2. 43 . máhasā. 6. I42. I. I0. 6. 24. I4. máhāǹsi. 7. 73. 10*.

(cf. mitramahas, máhasvant.) máh a svant: -ntam. 4. 25. 6. m a ha $\mathbf{a}$ in maharşabhá, maharsí, mahāgaṇá - mahăsya, mahendrá, mahónmāna. mah ā०g a ṇá: -nébhyas. I9. 22. 17. mahãodevá: ás. 5. 2 I. II. 9. 7. 7. I2. 5. I9. I3. 4. 4. I5. I. $4 ; 5.6$. mahādevám. I5. 5. 6 .

mah $\mathbf{a} \circ d h a n a ́:$-ásya. 4. 31. 6*. m a hān a gná: -ám. 20. 136. I I. mahānagnt. 20. $136.5-1 \mathrm{r}$. mahãnagni. 20. I 36. I 2 (mss. -ắnagnirr), I4 (do.).

mahāonaghnt: -nyấs (-gnyās ?). I4. I. 36 .

ma hắonāman: -mnīs. II. 7.6.

mahăbudhna: -as. I. I4. I (oiva). mahấ ○m a na s: -sãm. I9. I3. I0".

mahãoy a má: -ás. 13. 4. 5.

m a hāovṛkṣá: -ṣấs. 4. 37. 4 .

mahāovṛṣá: -șấs. 5. 22. 5 .

mahāvrșăn. 5. 22. 4, 8 .

mahāovratá: -ám. II. 7.6.

mahăsya (p. -hấoās-): -siebhias. I I. 2.30 .

máhi: 5.3.7. 7.29. I, 2. 12.3. I4. I3. 2. $3^{2}$.

máhi (pl.). 4. 22. 3.

(cf. mahitvá, máhivrata, $/$ mahiy.)

ma hi otvá: -ám. 7. 29. I. I2. I. 55. mahitvă. 4. 2. 2*, 4, 5*. 5. II. 3. 7. 79. I ; 80. I. 8. 3. $24^{*}$; 9. 2. 9. 10. $3^{*}, 9^{*}$. I2. 3. 5. I4. 2. 32 . I9. 49. I. m a himán: -mă. 6. 80. 3. II. 3. 22. I3. $2.29^{*}, 45 ; 4.44$. I5. 7. I. I9. 3. 2,$3 ; 34.5$.

mahimắnam. 3. IO. 12. 5. 27. 5. I I. 3. 23. I7. I2. I8. 4.8. I9. 56. 3 . mahimnâ. 4. 30. $8^{\dagger} ; 35 \cdot 3$. 6. 7 I. 3. II. I. I9. I3. I. 8.

mahimné. 9. 3. 25-31.

$\left[3^{\dagger}\right.$. mahimănas. 3. 10.4. 7. 5. I*. I9. 6.

máhi。vrata: -asya. I3. 2. I. máhivrate (p. -e íti). 7. I I2. I.

mahiṣá: -ás. 5. 3. $8^{*} ; 26.2$ 6. 3 I. 2*. 7. I5. I. I2. 3. 38 . I3. 2.30 , $32,33,42,43,44$. I $8.3 .65^{*}$.

mahișa. 2. 35.4 .

máhișĩ. 2. 36. 3. 20. I 28. I0, I I. $\checkmark$ mahiy: mahiyate. 5. I 7. 15. 20. I28. 16.

mahtluka: -kā. 10.'io. 6. 
mahen drá (p. -hāoin-) : -ás. I 3. 4. 2, 9. 17.18.

mahónmã na (p. -hăoun-) : -nā. 5 . mahmán: -mănam. 10. 2. 12. 20. 48.3 (not mss.).

mahmáni. I0. 2. 6 .

mầ (prohib.). I. I. 4 ; I9. I ; 20. I $^{2}$; 30. $1^{2}$. 2. $6.2^{2} ; 7.4^{2} ; 15.1-6 ; 28.1$, $3^{2} ; 29.4^{2}, 7$ 3. 11. 6 ; 12. 6 ; 15. 5 , 8 ; $19.8^{*} ; 25.1 ; 28.5,6 ; 29.8^{3} ; 30$. $3^{2}, 5 ; 31.8,9$. 4. 7.7;8.2; 16.7; 20. 5,$7 ; 21.7^{2 *} ; 34.8 ; 37.12 ; 38$. 3; 39. 9. 5. 2. $4^{*} ; 3.4^{*}, 6^{2}, 7^{3 *}, 8^{2 *}$; 7. $1^{2}, 2,6^{2} ; 8.3^{2}, 4 ; 9.8 ;$ II. 7,8 ; 13. 4,$5 ; 18.1,2,3 ; 19.9 ; 22.1^{2}$; 29. $1 I^{*} ; 30 . I^{2}, 6,8,14^{2}, 15.17 .6 .27$. $3^{*} ; 32.3^{2} ; 41.3 ; 51.3^{*} ; 56.1 ; 57$. 3 ; 73. $3 ; 87.1^{*}, 2^{*} ;$ I 10. $3^{2}$; I12. I ; I18. 3 ; 120. 2 ; I23. 4 ; I24. 3 ; 127. I; $134.2 ; 140.2,3 ; 142.1 .7 .11$. $\mathrm{I}^{2} ; 20.3 ; 35.3^{2} ; \mathbf{5}^{2} .2^{3} ; 53.2,4 ; 54$. 2 ; 60. 1, 4,6, 7; 68. 3 ; 70.2; 82. 3 ; 99. I; IO2. I; 108. I; II 7. I*. 8. I. $4^{2}, 5,7^{4}, 8,9^{3}, 10^{2}, \mathbf{1 1}, 12,15,16^{3}, 18$ $19^{2} ; 2.1^{2}, 5^{2}, 7,17,23,24,26 ; 3.9^{*}$, $17^{*} ; \quad 4 \cdot 7^{*}, 23^{*}, 24^{*}$; 6. I, $3^{3}, 20,25^{2}$; 8. $19,20,21^{2}$. 9. 2 . Io; 3. 16,$24 ; 4$. 24 ; $5 \cdot 4^{2}$. I0. I. $7,16,17,26,29,31$; 5. I5-2I, 23, 25-35; 9. 7, II. II. I. $22^{2}, 25,32 ; \quad 2 . \mathrm{I}^{4}, 2^{2}, 7,8, \mathrm{I} 7, \mathrm{Ig}^{2}, 2 \mathrm{O}^{3}$, $21^{2}, 26^{3}, 29^{6^{*}} ; 4.26 ; 9.13,20,21$; 10. 9 , I4, 16, I9. I2. I. 1 $8,23-5,28,3$ I, $32^{4}, 33,34,35^{2}, 46$; 2. 10, $18,23^{*}, 33^{2}$; 3. $14,17,18^{2}, 22,23,43,46^{3} ; 4.52$. 13. I. $12,59^{3 *} ; 2.5,37$. I4. I. $22^{*}$, 48,63 ; 2. 9 , I1 I $^{*} 16^{*}, 19,50,69^{5}$. I6. I. $4 ; 2.5 ; 3.2-4^{2} ; 4.3,5^{2} ; 7.13$; 8. I-27. I 7. $6,8,24^{\dagger}, 28^{2}, 29^{2}$. I 8 . I. $52^{*} ; 2.4^{4^{*}}, 24^{5}, 25^{2}, 31,36^{2} ; 3.9,38$, 50*, 53*,64, 73; 4. I2 (p. mā), I3 (p. mā), 30. I9. I5. $2 ; 20.4 ; 27.5,6^{3}$, $8^{2} ; 33.5 ; 40.2^{2}, 3^{3} ; 46.2 ; 47.6^{3}$, $7^{2} ; 55.1,2 ; 58.4^{*}$. 20. 127. 13 (mss. ná), $13^{2}$; 130.14 .

mó (p. -ó íti). I. 19. I ; 20. I. 2. 28. $3^{2}$. 5. 3.6; 11. 7 ; 30.15. 6. 124.3. 7. 53.4 ; 108. 1. 12.3.17. 16. 4. 3 . 18. 3. $9,52 ", 62$ (l. mấ u ?). 20. 127. 13 .

\section{(cf. măkis.)}

/'I mā: mimimahe. 18. 2. 38 . mimate. 4. 36. 5. 9. 10. $2^{\circ}$. mímānas. 4. 31. 2". - 10. 7.2. 13 2. $22^{*}$; 3. I9 (ms8..ed. mimă-). 19. 56. I.

mímānā. 5. 12. 7".

amimita. 7.14. 2.

ámimātām. I2. I. IO.

mame. Io. 2. 20, $2 \mathrm{I}$.

ámãsi. 12. 3. 30. 18. 2.45.

mấsātāi. I 8. 2.38-45.

mitâ. 8. 9. 4. I I. I. 6.

mităs. 12. 3. 30 .

mìyámānā. II. I. 6.

(cf. mas, mā, mātŕ, mătrā, măna, māyâ, I māyú, măs, măsa, mita, méya.)

+ a n u: cf. anuméya.

+ a pa: ápa ... mimimahe. 18.2. 40. apaomáya. I9. 57.6 (not mss.).

apaomítya. 6. 117. 2.

(cf. apamítya.)

$+\overline{\mathbf{a}}$ : à mimīyāt. 6. $92 \cdot 3^{\dagger}$.

+ u d: út... mimimahe. I8. 2. 43 . ún mimiyāt. I8. I. IO*.

(cf. unmāna.)

+ n is: niromímite. 13.3.8.

níh ... mimimahe. I 8. 2. 42.

nír amimita. II. 3. 52 .

níromitas. 4. 35.4 .

níromitam. 8. 9. 4 .

níromitā. 8. 9. 5 .

níromitās. 4. $35 \cdot 4$.

níromitā. 8. 9. 4 .

+ pari: páriomitã. 9. I0. $27^{*}$.

+ pra: prá... mimimahe. 18. 2. 39 . (cf. pramâ.)

+ prati: práti mimite. 9. 10. $2^{*}$. I8. $3 \cdot 40^{\dagger}$.

(cf. pratimá, pratimắna.)

+ vi : ví mimite. 4. II. 2 . I0. 7. 2. ví ... mimimahe. I8. 2. 4 I.

ví mimissva. I3. I. 27.

viomímānas. I3. 2. 5 .

ví amimìta. 5. I2. II.

viomamé. 7. 26. I".

víomitam. I3. 3. 8 . 
víomite. I0. 7. 39 .

víomitā. I3. I. 7.

(cf. vimăna.)

+ s a m: sám mimīte. 5. 28. I. sám ... mimimahe. I 8. 2. 44 .

sámomitas. I2. 3. 33 .

sámomitam. 3. 29. 3, 5 .

sámomitās. I2. 3. 20, 28 .

sámomitāsas. I2. 3. 27.

[mí-).

sámomitā. 20. I28. 6-I I (mss. samV 2 mā : mímāti. 9. I. $8^{*}$; 10. $6^{*}, 7^{*}$. mimāya. 9. ro. $2 \mathrm{I}^{*}$.

ámímet. 9. 9. $9^{*}$.

amimet. 9. 10. $6^{*}$.

mătavāí. 9. 10. 6*.

(cf. 2 māyú.)

$\mathbf{m} \overline{\mathbf{a}}$ in pramă, pratimá.

māñ sá: -ám. 4. I2. 4. 5. 29. 5, I 5.

6. 70. I. 8. 6. 23 . 9. 6. 39,43 . Iо.

2. I ; 9. I8. II. 8. II, I2. I8. 4.42 .

māñséna. 4. I2. 4.

māñsásya. 4. 12. 3

mānnsé. I. II. 4. 4. I 7.4. 5. 3I. I. māǹsấni. 2.24. I-8. II 3. 3. 7. I2. 5. 69 .

(cf. māñsávant.)

mā ñsá ○va n t: -vān. I8. 4. 20. măkis. I8. I. $25^{*}$. I9. 47.6 .

māg a dhá: -ás. I5. 2. I-4 māt a ríbhvan, see mātaríçvari. mātarí çvan: -vā. 5. 17. I $^{*}$. 8. 1 . 5. I0. $7.2,4 ; 8.39,40 ; 9.26$. I2. I. 5 I. I3. 3. I9. I4. I. 54. I5. 2. I-4. I6. 3. 4 . I9. 20.2.

mātaríçvānam. 9. 10. 28*. I I. 4. 15 . mātaríçvanā. 5 . 10. 8 .

mātaríçvan. II. 5. I3.

mātaríçvarī (p. -ĩ íti). 5. 2. $9^{\dagger}$ (mss. -íbhvari ?).

mātaríçvanas. I9. 27.4 (m. mss. -tári-).

mătali: 8. 9.5. II. 6.23. I8. I. $47^{*}$. māti in abhímāti.

mātṛ́: -tâ. I. 24. 3. 2. 28. I, 4, 5. 3. 9. $1 ; 23.3,6$. 4. 5. 6* 5. 5. I; 13. $7 ; 26.5 ; 30.5$. 6. $16.2 ; 30.3 ; 46$. I ; I20. 2. 7.6. I*; 74. I. 8.6. I ; 7.2. 9. I. 4,$5 ; 9.8^{*}, 9^{*}$; IO. $12^{*}$. IO.
3.8 ; IO. $18{ }^{2}$. I2. I. IO, I2; $3.5 ; 4$. 33. I4. 2. 37 I 8. I. $53^{*} ;$ 2. $50^{*}$; 3. $50^{*}$. I $9.4 .2 ; 39.3 ; 49.5$.

mătar. I9. 48. 2.

mātar. 12. 1. 63

mātáram. I. 2. I; II. 5. 4. 18. 2. 5 . 2. $6^{\dagger}$. 6. 3I. I*; IIO. 3 ; II 2.2 ; 120 . I; 140. I-3. 7. I. 2 ; 6. 2, 4. 9. 5. 30 . I I. 2. $29^{*}$. I2. I. I7. I8. $3.49^{*}$.

mātră. 3. 30. 2.

mātré. I. 3 I. 4.

mātúr. I. 14. 2. 3. 25.5 . 6. I16 2, 3. 7. 2 I. 8. 9. 5. 9. IO. IO*. I 2.4 . 32. I4. 2. 25. 18. 2. 52. 20. 133. 2.

mātári. II. 7.6 .

mātárā. 5. I. 4.

mătáras. I. 5. 2* 6. 9. $3 ;$ 51. 2*. 19. 40. 3 .

mātr̆́s. 9. 9. $10^{*}$.

(cf. pṛ́çnimātṛ, saptámātṛ, sammātṛ́, hatámātṛ, mātaríbhvan, mātaríçvan, mātṛ́kṛta - mātṛmánt.)

mātṛ́ $\circ$ ṛ̣t a: -tāt. $\quad 5 \cdot 30.4$.

mātṛ०bandhú: 12. 5.43

māt r mánt : -mádobhyas. I2. I. 60.

mătrā: 8. 9.5. II. I. 6 .

mătrām. I 8. 2. 38-44, 45 .

mătrayā. 9. I0. I9.

mătrāyās. 8. 9. 5 .

mătrās. 3. 24. 6 .

(cf. atimātrá.)

māt s y á: -siás. I9. 39.9 (mss. āts-). mā da in pramāda, sadhamăda.

mā d a yi ș̣̣ú : -ṇávas. 7.77.3.

mà dy a in anumădya.

mă dhy a mdina: -asya. 7. 72. $3^{*}$. mădhyamindine. 7. 76. 6*.

mă d h va: mádhvi (p. -i íti). 7. 73. 4 . mầna: -am. 20. 135.8.

mănasya. 9.3.5, 21 .

mănasya (with voc.). 3. I2. 5 .

mānasya. 9. 3. 6 (mss. mă-), 9 (do.)

(cf. unmāna, pratimăna, vimána.)

mān a vá:-văs. 3. 2 I. 5 . I I. IO. 2.

I2. I. I5. I8. 4.55 .

mānavébhias. 5.17.9.

mānavănām. 4. 22. 5. I2. I. 2. 
mānavis. 3. 24. 3 .

mânușa: -as. 4. 16.8. 12. 4. 20. mănuşam. 20. 128. 12 (ed. ámã-). mănuşe. 8. 5.14 . mănuṣās. 6. 23.3. r 8. 3. 38 . mănuṣāsas. $7 \cdot 77 \cdot 3$. mănuşāṇām. 4. 14. 5 ; 30. $3^{\dagger}$. 7. III. mấnuṣeșu. 4. 28. 5 . mânuşis. $4.32 .2^{*}$. 13.2.20†. 17. mănușibhis. 7.84. 1 . mănuşīṣu. 5. 11. 8, 9. (cf. ámānușa.)

mã m a ká: -ám. I. $29 \cdot 5^{\dagger}$. 3. $24.1^{*}$. 4. 4. 2. I 8. $3 \cdot 56^{*}$.

māmakăn. 3. 6. I, 5. 13. 1. 30 . (cf. jyotayamāmaká.)

mā mop a ̧̧ yá: -ám. 7. 38. r.

mã yấ: 8. 9.5.

mâye. 8. ro. 22.

māyăm. 2. 29.6. 8. 10. $22^{2}$.

māyáyā. 4. 38.3. 6.72. I. 7. 81 . I*. 8. 4. $24^{*}$. I0. 8.34. I3. 2. $3, \mathrm{II}^{*}$. I9. 68. I.

māyăyās. 8. 9. $5^{2}$.

māyầs. 4. 23.5. 8. 3. $24^{*}$.

māyăbhis. I2. 1. 8 .

(cf. asuramāyă, vătamāȳa [yín.)

māyín: -yit. 5. II. 4.

mãyínas. I 9. 27.5,6; 66. I.

I māy ú : -úm. I9. 49. 4 .

māyãú. 6. 38. 4.

māyû́ (p. -t̂́ íti). I 8. 4. 4.

2 māyú : -úm. 9. 1. $8^{*} ;$ 10. $6^{*}, 7^{*}$.

mā y u ka in ápramāyuka.

māra in aghamārá, kṣudhāmārá,

tṛṣṇāmārá, naghamārá, pramārá, çinçumăra (?).

märuta: -as. I3. 4.8.

mărutam. 4. 27.7. I5. I4. I.

mărutena. 4. 27.6.

mărutās. 4. 15.4.

mā $\mathbf{r g}$ a in apāmārgá.

mărta。vatsa: -am. 8. 6. 26.

mārtyavá: -ás. 8. 10. 23.

mầsa: -am. 6. 140. 2.

măşās. 12. 2. 53.

(cf. mășājya.)

mấșājy a (p. -șaoāj-): -am. 12. 2. 4. mâ s: măsí. 5. 25. 10-3. 8. 10. $19^{2}$. I8. r. $35^{\circ \prime} ; 4.63$.

māsás. 8. 9. 17.

mādbhyás (p. -ātobh-). 3. IO. Io. 19. 27.2.

măsăm. I. $35 \cdot 4$.

(cf. mas, măsa, māsya.)

mats a: -as. 5.6.4. I4. 1. 4 ".

măsam. 13. 3. 8.

măsāya. 1 3. 2.12 (mss.).

măsāu. I 5. 4. I-62 .

mâsās. $4 \cdot 35 \cdot 4$. I $0.7 \cdot 5$. I I. $7 \cdot 20$.

I5. 6. 6 .

măsān. 3. 10.9. I1. 6. I 7 .

măsānām. I5. 6.6. I6. 8. I9.

(cf. ardhamāsá, pāurṇamāsá, sũryāmāsá.)

mãs y a in úpamāsya, cãturmāsyá, dáçamāsya.

V mi: mitás. 7.83. I (mss. mithás). mită. 9. 3. $9,16,17$.

mităm. 9. 3. I9.

mităs. I9. 42. I (mss. avāmitâ).

miyánte. 4. 24.4. I2. I. 13.

(cf. mít, mití.)

$+\overline{\mathbf{a}}$ : â minoti. 20. I3I. I (not mss.).

+ upa: cf. upamít.

+ ni: ní minomi. 3. I2. I.

ní minoti. 4. 16. 5 .

ní minotu. 3. 12.4 .

niomimâya. 9. 3. Ir.

níomitā. 3. 12.5. 9. 3. I6.

níomitām. 9.3.192.

niomiyáte. 9.3.21. I2. I. 38.

+ prati: cf. pratimít.

mikṣa(?) in āmíkşā.

mít: -tas. I8. 3. $5 \mathrm{I}^{*}$.

(cf. upamít, parimít, pratimít.)

mit a in ámita, áparimita.

mití: -táyas. I9. 10. $7^{*}$ [1.33*.

mitrá: -ás. 2. 5.3. Ir. 5. 15. 18.

mitrám. 5. 19. 15. 8. 3. I*. I9. 15.6.

mitréna. 2. 6.4.

mitrăt. I9. I5. 6 .

mitrâs. 2. 28.3. 3. 3.5. 6. 7. I.

mítrās. I I. 9. 2, 26.

mitrănịi. Ir. 9. 2.

mitrāís. 5. 20.8. 12.3 .48 . 
mitrăṇām. 9. 2.14.

(n. pr.): mitrás. I. 9. I ; 18.2. 2. 28. I, 2. 3. 8. I; 22.2. 5. I7. 2*. 6. 4 . 2 ; I03. I. 7.30. I. 9. 3. I8; 4.12 ; $7.7,23$. I0. 4.16 . II.9.25. I3.3. I3. I5. 2.2 (mss. mántras). I 8. I. $36^{*}, 39^{*}$. I9. 9. $6^{*}, 7$; I9. I; 44. I0; 49. 2.

(29. 5 .

mitra. 2. 28.5 (p. mitraorājan). 4 mitrám. I. 3.2. 3. 2 I. 8. 9. I0. $28^{*}$. II. 6. 2.

mitréṇa. 3.6. 2.

mitrăya. I2. $4 \cdot 26$. I4. 2. $46^{*}$.

mitrásya. 6. $85.2 ; 125.3^{*}$. I3. 2 . $35^{*}$. I8. I. $7^{*}$.

(cf. amítra, viçvămitra, mitratúrya-mitríya.)

mitraotúrya: -riāya. 5. 20. 7 .

mitraodhâ. 2.6.4.

mitraomahas: 5. 12. ${ }^{*}$.

mitra॰várdhana: -as. 4. 8.6. mitravardhana. 4. 8.2.

mitră várụ̣ a : -ṇāu. 4. 29.7. 5 . $24.5 ; 25.4$. 6. 89.3; I32.5. I3. I. 20. I6. 4.7. I9. 10. $4^{*}$.

mitrăváruṇā. 3. 4.4; I6. I*. 4. 30. I*. I4. I. 54. I 8. 3. I 2 (m. mss. mítrāvaruṇā).

mítrāvaruṇāu. 4. 29.6. I3. I.31. mítrāvaruṇā. $\quad 4 \cdot 29 \cdot 3,4$.

mitrāvaruṇāu. 1. 20. 2. 3.25.6. 4 . 29. I. 6. 32.3.

mitrāvaruṇā. 6. 97.2. 9. 10. $23^{*}$. I9. II. 6*.

mitráváruṇayos. I0.5. II. II. 3 . 44. I6. 8.25.

mitrín: -ínas. II. 9. 2 I.

mitríy a: -yeṇa. 7.60. I. 14.2. I2. mitríyāt. 2. 28. I. [mss.).

1/mith: ámethayat. 20. 128. 2 (not (cf. mithás-mithuyă.)

mithás. I. 28.4. 3.30.4. 5. I7. 7. 6. 32.3. 7. 83. I (mss.). 8. 8.2 I. (cf. mithoyodhá.)

mithuná: -ám. 6. I4I.2.

mithunâ. 8. 3. $12^{*}$. I4. 2. $5^{*}$. 18 . I. $10^{*} ; 2.33^{*}$.

mithunā. I2. 3.2, 9. mithunăs. $8.4 \cdot 23^{\dagger}$.

mithunấsas. 9.9.13*. (cf. mithunatvá.)

mithunaotvá: -ám. 8. 9. 10.

mithuyá. 4. 29.7; 39.9. 8.4.13*. mithoyod há (p. -thaḥoy-): -ás. I2.

5. 24.

$\checkmark$ m i d : medyatām. I9. 8. 5 (not mss.). medayathā (p. -tha). 4. 21. 6*. (cf. médas, medín.)

miçrá: -ám. I2. 3. 44 .

miçrăs. 4. I4.2. I2. 3. 4 I. (cf. tilámiçra, miçrádhānya, āmíkșā.)

miçráodhānya: -nie. 5. 3r. I.

$\checkmark$ miṣ: miṣántam. 9. 10.6".

mișată. I0. 8.30 .

(cf. miș, mișa, meșa.)

+ ni: ní mișanti. 5. 6. $3^{*}$. 18. 1. $9^{*}$. niomișát. I0. 8.2, II.

niomișatás. 4. 2. 2*. 9.2.23.

(cf. nimíș, nimișa, nimeșa.)

miṣ in nimís.

mișa in animișá.

$\checkmark$ mih: méhati. I3. I. 56 .

méhanti. 12. 5. 22.

mekṣyămi. 7. IO2. I (mss. -ṣấmi). (cf. mị̣ha, mị̣̂hvănis, meghá, médhra, méhana.)

+ abhi: abhí mehatām. I9. 8.5 (p. me hatām).

$\checkmark$ mĩ: mināti. I4. I. 33 .

mimāya. 5. II.3.

meșta. 12. I. 33 . (cf. mayu, māyuka.)

$+\bar{a}$, ud: á mimiyāt, ún mimīyāt, see $\sqrt{ }$ I $\mathbf{m a ̄}$.

+ pra: prá mināti. I8. $4.60^{*}$.

prá minanti. I8. I. $5^{*}$.

praominăma. 19. 59.2*.

prá minīt. 6. I I0. 3 .

prá meși. I6. $4 \cdot 5$.

prá meșțhās. 8 . I. 5 ； 2 . I.

(cf. pramayú, ápramāyuka.)

mi d ha in purumiḍhá.

mi ḍ̂ h váns : miḍhvas. I4. I. I $8^{*}$. mīạhúșas. I3. 2. I.

$\checkmark \mathrm{mil}:$ + pra: cf. pramílín. 
mIlin in pramilín.

$\checkmark$ mI v: cf. mūta.

+ ni: niomivantīm. 5.7.7.

mukti in nírmukti.

mú kh a: -am. 2. 35.5. 4. 3. 3; 34 . I. 5. 23. 13. 6. 50. 1. 8. 2. 17. 10. 2. $6 ; 7.19 .20 ; 9.13$. II. I. $3 \mathrm{I}$; $3 . \mathrm{I}$; 8. 14 , 15. I2. $3.5 \mathrm{I} ; 4.20$. I3. I. I3; 2. 39. I9. $6.5^{*}, 6^{*} ; 57.4$.

múkhena. 7.64. 2. II. $3 \cdot 35^{2}$. 12.4 . múkhāya. II. 2. 5.

múkhāt. I9. 6.7".

múkhasya. 7. II4. I.

múkhe. 6. 6.2. I2. 5.25.

múkhāni. 7. 56. 4. I 0. 9. I.

múkhā. 6. Io6.2. 8.6.15.

(cf. áyomukha, açrumukhá, áş̧ñmukha, ékamukha, jñātímukha, rathamukhá, vikan̄katímukha, viçvátomukha, sūcímukha, svápnamukha, mukhatás, múkhya.)

mukhatás. II. 3.33.

mú k h y a: -ām. 6. 43. 3 .

$\checkmark$ mu c: muñcắmi. I. Io. 3,4 . 3. II. muñcāmi. 2. I0. I-8. 6. I8.3.

muñcatas. 8. 2. 18.

muñcāsi. 6. 121. 4. [19. 44. 8, 9 . muñcá. I. I2. 3. 2. 9. I. 6. 84.2. muñca. 6. II2.2. 7.83.22. I9.44. 4 . muñcatu. 4. 23. I-7; 24. I-7. 7. 83 . I. II. 6.7.

muñcátam. 7. 42.2*.

muñcatam. 4. 25. I-7; 26. I-7; 28 . $1-7$; 29. $1-7$.

muñcatām. 6. II5.2.

muñcáta. I. 31. 2.6 II4. 2.

muñcata. 6. I14. I ; I15. I. 8. 7.5. 14. 2. $16^{*}$.

muñcántu. 6. $23.2 ; 96.2^{*}$. 8. 2 . 27. I0. I. I2. II. 6.7.

muñcantu. $3 \cdot 7 \cdot 5^{\dagger} \cdot 4 \cdot 27 \cdot 1-7.6$. 96. $1^{*}$. 7. II2. I. 8. 7. I3. I0. 1 . II. II. 6. $\mathrm{I}-6,8, \mathbf{1 0 - 2}$.

muñcántas. 2. I0. 8.

ámuñcas. 7. 53. I (mss. am-). mumugdhi. 6. III. I.

mumuktám. 5.6.8. mumucānás. 6. I15.3.

mumucānăs. 8. 7. 16 .

ámok. 12. 2 . 12.

amukṣi. I4. 2. 44.

ámukthās. 2. I0. 6.

mukşata. 5. 29. I $x^{*}$.

ámoci. I3. 2. 8.

moci. 3. 19.8. 4. 16. 7. 5. 8.4. 8. 8.

I9. II. 9.20 ; IO. I9. I6. 8. I-27.

mucyáse. 8. 8.16.

mucyáte. I0. I. 32 .

mucyate. 4. 36. ro.

múcyātāi. 8.8.6 (ed. mucyắ-).

mucyātāi. 4. I6. 4 .

mucyatām. I. 3. 6-9.

mucyámānas. I2. 2. I2.

(cf. mukti, muc, muci, moka, molyya, mocana.)

+ ava: avaomuñcán. 8. 2.2.

avaomuñ cámănas. 8. I. 4.

$+\mathrm{u} d$ : ún muñca. 6. II2. 2.

úd amuñcat. 3. II. 8.

un॰muñcántīs. 8. 7. 10.

úd amukthās. 2. Io. 6.

úd amucye. I4. I. 57.

(cf. unmocana.)

+ nis: cf. nírmukti.

+ pra: prá ... muñcāmi. I4. I. I7, I $8^{* \prime}, 19^{\prime \prime}, 58^{*}$.

prá muñcati. 3. 29. r.

prá muñcā (p. -ca). 2. 35.3.

prá... muñca. 7.83.4. I8.4.70.

prá muñcatu. 7.64.2.

prá muñcatām. I 4. 2. 59-62.

prá muñcantu. $7 \cdot 77 \cdot 3$.

pra॰muñcán. 7.84. I.

praomuñcántas. 2. 34. 2.

prá mumoktu. 2. $34 \cdot 3,4$.

prá mumuktam. 3. II. I". 6. 97.

$2^{\dagger}$. 7. 42. $\mathrm{x}^{\dagger}$.

(cf. pramocana.)

[6.30.

+ prati: práti muñcāmi. 9. 2. 2. 10. práti muñca. 8.6.26. 9.2.3. I3. 3. $\mathrm{I}-25$.

práti muñcata. $5.14 \cdot 3$.

práti muñce. I9. 31. 13.

práti muñcatām. $7 \cdot 77 \cdot 2^{\dagger}$. I9. 45 $2 ; 57 \div 5$. 
práty amuñcata. I0. 6. 6-9, I5, 21 . práty amuñcanta. I0. 6.17. pratyámucam (p. -tioám-), I0.6.34. práti mucas. 9.3.24. práti ... amukthās. 19. 49. 8 .

+ vi: ví muñcāmi. 5. 13.6. ví... muñcāmi. 7.78. 1. ví muñcāt. 6. 133. I. ví muñca. 7. 4. 1 .

ví ... muñ catām. 2. 8. I. 3. 7.4. ví ... muñcantām. 6. II2.3.

víomuktas. 9.7.24.

(cf. vimúc, vimoká, avimokyá.) muc in an̉homúc, vimúc. $\mathbf{m u c I}$ in ámuci.

mú ñj a : -as. I. 2. 4 . $\lfloor 39,43$. $\checkmark$ m u d : módamānāu. I4. I. 22*; 2. modișișțhās. 2. 29.6. [modín.)

(cf. mud, muda, mudrá, móda, + abhi: cf. abhimoda.

+ pra: prá modate. Ir. 4.4 . praomódante. 4. 38.4. prá modante. II. 4.5 .

(cf. pramúd, pramodín.)

+ s a m: cf. sammúd.

mud in abhímodamúd, pramúd, sammúd.

m u d a in kúmuda (?), hasāmudá.

múdgala: -am. 4. 29. 6.

mu drá: -ám. I8. 3. I9.

múni: -nes. 7.74. I.

(cf. múnikeça.)

múni॰keça: -am. 8. 6. I7.

mulālit: 4. 34.5.

$\checkmark$ muṣ: moṣis. 7.99. I.

(cf. $\sqrt{ }$ mușāy, mușita.)

+ pari: pári muṣnāāi. 4. 34. 4 .

+ pra: prá moṣis. 8. 2. I7.

$\checkmark$ muṣā y: muṣāyati. 4. 21. $2^{*}$ (mss. mukhā-).

muşita in ámuşita. [20. 136. I, 2. muṣká: -kāú. $\quad$ 4. 37: 7. 6. 127. 2. muṣkăbhyām. 8. 6.5.

mușkáyos. 6. $138.4,5$.

(cf. muşkará, muṣkābarhá, kumbhámuşka.)

muşkará: -ám. 6. 14.2. [9.2. muş̧ ābarhá (p. -ka॰āb-): -ás. 3 . muṣtí: -ís. 6. 126. 2*.

$$
\text { (cf. muṣțihán.) }
$$

muṣțiohán: -hă. 5.22.4.

músala: -am. II. 3. 3. I2. 3. 13 .

músale. I0. 9. 26.

(cf. ulūkhalamusalá.)

V'muh: múhyantu. 667. I. II. 9. 13 ; 10. 20.

muhyata. 3. 2.4 .

amūmuhat. 3. 2. 2.

mūụhăs. 6. 67.2. I I. IO. 2 I.

mugdhấs. $7 \cdot 5 \cdot 5$ (p. -dhă).

moháyanti. 9.8.17.

mohaya. 3. 1. 5. 5. $21.4-6$.

mohayatu. 3. I. I, 6; 2 . I.

moháyan. 3.2.3.

(cf. muh, múhus, mū ḍha, mógha, móha.)

+ prati: pratiomoháyantr. 3. $2.5^{\dagger}$. $\mathbf{m u h}$ in manomúh. [10".

múhus. II. 5.6. I2. $2.38,52$. I8. I.

múja $\circ$ vant: -ntas. 5. 22. 5 .

mújjavatas. 5. 22. 7,8 .

mújavadobhyas. 5. 22.14 . $\mathbf{m} \overline{\mathbf{u}} \mathbf{d} \mathbf{h} \mathbf{a}$ in agnímūạha.

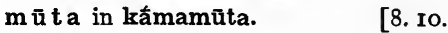

mútra: -am. I. 3.6-9. 6. 44.3. 9.

múra: -am. I. 28.3.

(cf. sahámūra, múradeva.)

mú raod eva: -vās. 8. 4. 24".

múradevān. 8. 3.2*, $13^{*}$. [ăm-).

$\checkmark \mathrm{m}$ ū r c h : ámūrchat. 20. 34. I2 (mss.

mū rdhatás. I0. 6. 3I, 32.

mūrdhán: -dhă. I6. 3. $1^{2}, 2$.

mūrdhănam. 3.6.6. 9. 8. 13; 10. 6*. I0. $2.26 ; 7.32$.

mūrdhnás, I9. 6 . 6 .

mūrdhán. 4. 30. $7^{*}$.

(cf. ékamūrdhan, dvímūrdhan, mūrdhatás.)

múl la: -am. 2. 7.3. 3. 23.6. 6. I4.2;

I37.3. 8. 3. IO*; 7.2. I2. I3. I. 56, 57. I9. $7.3 ; 32.3$ (mss. túllam).

múlena. 7.74. 1. 19. 36. 2.

múlāt. 6. 44.3. 7. 59. I. I2. 5.63. múlāni. I2. $5 \cdot 42$.

múlebhyas. 6. 13.3.

(cf. amūlá, jihvāmūlá, bhưrimūla, 
sámūla, sahásramūla, múra, mūlakṛ́t-mūlín.)

mũ laokṛt: $\quad$ 4. 28. 6.

[II2. I. mūlaobárhạ̣a: -ṇāt. 6. I1o. 2 ; mūlabárhañi. I2. 5.33 .

mūlín: -nam. 5. 31. 12.

V I m ṛ: mamăra. 9. 10.9*. 18. 3. 13. mamāra. I0. 8.32 .

mamrúșas. 6. 18.2.

amrrta. I0. 4. 26.

$[27.8$.

mṛthăs. 3. 31.8, 9. 5. 30. I7. 19. mrita. 8. 2. 5 .

murīya. 8. 4. $15^{*}$.

marișyasi. 5. 30.8. 8.2. $24^{2}$. II. 3. 43,49 .

marișyati. II. $3 \cdot 32,35,36$.

marișyatas. II. 3.44

mạtás. 6. 46. 1 .

mṛtám. 2. 10.8 (mss. ṛtám). 5. 19. I4. 6. I8. 2 .

mụtăya. 5. 19. I2.

mṛtăt. 6. 18. 2.

mṛtásya. 9. 10. 8*. 18. 2.60*.

mṛté. 12. 2.5 .

mṛtấs. I2. 2. 45 . I $8.4 \cdot 48,57$.

mṛtāís. 12. $2.22^{*}$ *

mṛtébhyas. I 8. 3.3 (mss. ṛt-).

mriyáte. 12. 2. 39 .

mriyante. 8. 2. 24 . 12. $4.7,8$.

mriyásva. 5.13. 4.

māráyati. 18. 3. 3.

märáyanti. 8.6. I9.

māráyāti. 8. 6. I8.

(cf. mamri, márta, mártya, māra, mṛta, mṛtyú, $\sqrt{2}$ mṛ mṛ̣.)

+ pra: cf. pramārá.

$\sqrt{ } 2 \mathrm{~m} \mathrm{r}, \mathrm{m}$ ṛ̣ : mṛ̣ịhí. 6. 142. I. 10. mṛnán. 4. 31. $3^{*}$. I6. I. 2.

mṛnántam. I I. 2. I8 (s. mss. mṛḍá-). mṛnasi. 5. 29. II".

mṛná. I9. 29. $4^{4}$.

mrṇáta. 3. I. 2.

ámìmṛnan. 3. I. 2.

mūrṇấs. 4. 3. 6.

+ ni: ní mṛnịihi. Io. I. I7.

+ pra: prá mṛ̣inihi. 4. 37. 10. 6. 88 . 3. I0. 3. I.

prá... mṛṇinhi. 5. 29. 4 . prá mṛnita. 5. 2 I. II. 13. I. 3.

praomṛnán. 3. I. $4^{*}$; 5. I. 4. 3I. $3^{*}$. 5. 23. 6. II. 2. 23. I6. I. 2. I9. I3. $8^{4} ; 66$. I.

praomṛnántam. 6. 97. 3*.

prá mṛna. 8. 4. $22^{*}$. 10. 3. 2.

prá mṛnat. 9. 2. 14.

práomūrṇam. 12. 5. 6I.

mṛgá: -ás. 4. 3.6. 7.26. 2"; 3ิ4. 3". I0. I. $26 ; 3.6 .20 .136 .10$.

mṛgám. 3. I5. I. 5. I4. 12.

mrịăya. 12. 1. 48 .

mṛăt. 19. 38.2 (not mss.).

mrrgásya. 4. 3. 6.

mṛgăs. 5. 21.4 . 8. 7. 24 . II. 2.

$24 ; 6.8$. 12. I. 49 .

mṛăăsas. 6. 52. $2^{*}$.

mṛ̣ănāăm. 2. 36. 4. 3. 22.6.

mrrgéșu. 3. 2 I. 2. I2. I. 25.

mrgí. 5. 14.11.

(cf. sumṛgá, $\sqrt{ }$ mṛgay, mṛgáçiras.) $\checkmark$ m ṛ g y : mṛgáyāmahe. ro. 5. 42. mrrgáyante. 4.36.3.

(cf. mrrgayú.)

m ṛga॰yú: -ús. Io. I. 26.

mṛgáoçiras: I9. 7. 2.

$\mathrm{m} \mathbf{r} \mathrm{g} v a \mathrm{n}$ in vimứgvan.

$\checkmark$ m ṛc: marcayasi. I3. I. 40.

marcáyatā. 8. 2. 17.

$\checkmark$ m r j: mṛjmas. 4.17 .8 .

mrje. I6. 7.8 .

mrijmáhe. I4. 2. 66.

mrjmahe. 12. 2. 13. I3. I. 58.

mṛkṣva. 6. II2. 3 ; II3. 2.

mṛḍ̣hvam. 12. 2. $19^{2}$ (mss. mṛḍ hv-). mṛjānăs. 18. 3. I 7 (mss. mṛjă-, mựjā-). ámṛjata. 12. 2 . I7.

amrijata. 6. I13. I.

mamrje. 6. I13. I.

mṛșțaă. 12. 2. 17, 20 (1. -țuâ ?).

marmrijyánte. 4. 8. 7.

(cf. mārga, mrrgvan.)

+ a n u: ánu ... mārṣțu. 6. 53.3.

+ a pa: ápa mrjmahe. 4. 17.6, 7; 18.

8. $7 \cdot 65 \cdot 2,3$.

ápa mṛḍ̣hi. II. I. 29.

ápa mārșțu. 4. 18. 7.

ápa ... mrịjethām. I8. 4 . 49 . 
ápaomrstam. 6. II3.3. apaomŕjya. 4. :8. 8.

$$
\text { (cf. apāmārgá.) }
$$

+ ud: unomamắrja. 8. 6. I. unomṛjānás. I8. 3. 73 (s. mss. ed. -ằnas).

+ nis: nír mṛḍhi. I 8.4 .56$.

+ vi: ví mṛḍ̣hi. II. I. $3 \mathrm{I}^{2}$.

(cf. vimứgvan.)

+ s a m: sám mãrșțu. I o. 9. 3 .

v mrd: mrdāti. I. I2. I. 7. IOg. I. mṛạat. 2. 2. 2 .

mṛḍa (p. -ḍá). I 8. I. 40*

mṛda. I. 13. 4. 5. 3. $8^{\dagger} ; 4.7 .6$. 30. 3 ; 57. 2. II. 2. II, $28^{2}$. I2. I. 46 , 47. I7. 8, II. I9. 44. 4 ; 55. 2. mrduatāt. II I. I. 20.

mṛdátam. 8. 2. 7. II. 2. I.

mrḍatam. 5. 6. 5-7.

mṛḍáta. I. 26.4.

mṛạátā (p. -ta). I. 20. I. I8. 3. I6. mṛdata. 3. $26 . \mathrm{I}-6$.

mrdantu. 7. I09. 7.

mṛḍayāsi. 5. 22. 9. 6. 26. I. mṛạáyā (p. -ya). I. 13. $2 ; 26.4$. mṛdayantu. IO. 1. 22.

(cf. mṛ̣itị̂, mṛ̣̣īka.)

m ṛ ḍitŕ: : tâ. I0. 1. 22. I2. 3. 9. m r ḍi $\mathbf{i} \mathbf{a}$ in sumṛḍiká.

$\checkmark \mathbf{m} \mathbf{r} \mathbf{n}$, see $\boldsymbol{V} \mathbf{2} \mathbf{m r}$. [vatsa. m ṛta in amṛ́ta, mṛtábhraj-mṛtámṛtáobhraj: -je. 4. 4. I.

m ṛtá $\circ \mathbf{m}$ an a s: -nās. 6. 18.2. mṛtámanastarā (p. -naḥıt-). 6. 18. 2. m r táovats a: -sām. 8. 6. 9. Io. I. Io.

(cf. mărtavatsa.)

m ṛtyú : -ús. 3. II. 8. 4. 2. $2^{*} ; 8$. I. 5. 2 1. II; 24. 13. 6. 46.2 ; 93. I. 8. I. 5 ; $2.23^{2}$. 9. IO. 24 . Io. 2 . I 4 ; 7 . I5. II. 4. II; 5. I4; 7.3. I2. 5. 2 I, 55. I3. 4. 25. I6. 5. I-6. I7. 29. I8. $2.27 ; 3.62$. I9. 9. Iо.

mị́tyo (p. -o íti). 8. 2. 5 , Io. mrrtyo (p. -o íti). 6. 13. I, 2, 3. 8. 2. 4, 8. I2. 2. $2 \mathrm{I}^{*}$.

mṛtyúm. 4. 35. I-6, 2. 5. 28. 8. 6. 32. 3. 7. 53. I. 8. I. 2 I ; 2. II ; 8. 2 I.
I0. IO. 26 I I. 5. I9. I2. 2. $2,3,9$ $23^{*}, 29,30 ; 3.49$. I8. 3. $4 \mathrm{I}^{*}$.

mṛtyúnā. 7. 70. 1. II. 10. I8.

mrrtyáve. 5. 8. 5 ; 30. 12. 6. 28. 3; 37. $3 ; 63.2 ; 76.3 ; 84.3$. 7. 102. 1 . 8. I. I; 8. 10. I2. $3.55-60$.

mrrtyós. 2. 16. I. 3. 6.5 ; II. 2* 5 . 30. II, I5. 6. I33. 3. 8. I. $4,17,18$, 19; 2. 9, 23; 7. 13;8. 10, 18. I0. 3 . 7 ; 9.44. I2. $2.30^{*} ; 4.37$; 5. 15. 16. 8.27. I9. 20. $1 ; 27.8$.

mṛtyávas. 2. 28. I. 3. I I. 5, 7. 8. 2 27. I2. 5.13 .

mṛtyún. I. 30. 3. II. 6. I6.

mṛtyúobhis. 6.63.3.

mrityúobhyas. I3. 4. 46 .

(cf. jarămṛtyu, mārtyavá, mṛtyudūta, mṛtyupāçá.)

m ṛtyuodūta: -tās. 8. 8. Ir.

mṛty uopā çá: -çấs. 8. 8. 16.

mṛtyupāçắn. 8. 2.2. 17.30.

mrtyupāçāís. 8. 8. Io.

$\checkmark$ m ṛ d: mṛditás. I I. 9. I9.

mṛditám. II. 10. 26. I2. 5.6I. (cf. mṛdú, mradas.)

m ṛ dú: -ús. 3. 25.4 .

mṛdúm. 5. 18. 5 .

$\sqrt{ } \mathbf{m r} \mathbf{r} \mathbf{h}$ in mṛ́h, mṛdha.

m ṛ dh: -dhas. I. 2 I. $2^{*}, 3^{*}$. 4. 3I. $2^{*}$. 5. 20. 12. 6. 2. 2. 7. $84.3^{*}$. 8. 5.8. I3. I. 5,27 . I 8. 2. $59^{\dagger}$. I9. I5. I*.

m r d ha in vimrdhá.

V mṛ : : mṛçántīm. 8. 9. 9. (cf. marīmṛçá, marçana.) [13. $7^{\dagger}$. + abhi: abhí mṛçāmasi. 3. 24.6. 4. (cf. abhimarçana.) [64.2.

+ av a : avămṛkșat (p. avaoám-). 7 .

+ parā: párāomṛștā. I2. 5. 2.

+ pra: praomṛçántam. 8.6.6.

+ prati: pratiomṛăt. 8. 6. 18 .

+ vi: ví ... amŗ̧at. I3. I. 8.

V m ṛș: mīmrșas. 3. $15.4^{*}$. (cf. mứșā.)

ṃ̛́șā. 5. 18.9. 6. 45. $3^{\dagger}$.

mékh a lā: -ām. 6. I33. I.

mekhale. 6. $133.2,4,5$.

mékhalayā. 6. 133.3. II. $5 \cdot 4$.

meghá: -ghấs. $4 \cdot 15 \cdot 7,8,9$. 
meḍ́: -ís. II. 7. 5 .

médhra: -am. 7.95. 3.

methr:_is. 14. 1. 40.

methím. 8. 5. 20.

mé d a s: :sā. 4. 27. 5. I 8. 2. 58*".

(cf.jvarṣámedas, médasvant.)

méd as va nt: -vatā. 6. Ir4. 3 .

medín: -di. 3.6.2. 4. 31. 6*. 5. 3 . I I ; 8. 9 .

medínã. 6. 65.3 ; 129. I. I2. I. 33 . medínāu. 6. ro4. 3 .

medínas. I0. 6.20.

medínis. 8. 7. 7 .

(cf. índramedin.)

m é d h a: -dhãn. I2. 3. I6. (cf. arkāçvamedhá, medhas-médhya.)

medhas in sumedhás.

medhat: 9.7. 11 .

medhe. 6. 108. 1 .

medhằm. 6. 108. $2,3^{3}, 4,5^{4}$; 133. 4 . I0. 2. 17. I1. 5. 24. I2. I. 53. I 8 . 3. I1. I9. 40. 2,3 ; 43.1 (m. mss. -ầ); 64. I.

[4. 6*. medháyā. 5. II.4. 6. ro8.4. 8. (cf. medhāvín.)

[29.6.

médhātithi (p. -dha。at-): -im. 4 . medhāvín: -nam. 6. 108. 4 . medhāvínas. 6. ro8. 4 .

medhin in grhamedhín.

médhy a: -dhias. I 8. 4. 51, 52. médhyam. 5. 29.13.

médhiam. 18. 4. 12, 13 .

médhiāsas. 4. I4. 1 .

mení: -ís. 2. II. I. 5.6.9. I2. 5. $16,23,39,59$.

menyà. 5. 6. 10. I0. 5, 15-21.

menyấs. 2. II. I. 5.6.9. (cf. amení.)

méy a: -yās. 6. 137.2 .

(cf. anuméya.)

meșá: -ás. 6. 49. 2.

meşa in ánimeșa.

méhana: -am. I. 3. 7 ; I1. 5 .

māitrāvaruṇá: -ám. 5. 19. r5. moka in vimoká.

moky a in amolxyá, avimokyá.

mógh a: -am. 6. 29. $\mathrm{I}^{*}$. 8. 4. $14^{*}, 15^{*}$. mocan a in unmocana, pramocana, baddhakamócana.

mota in pramóta.

mó da:-dās. II. 7. 26; 8. 24.

(cf. abhimoda.)

modin in pramodín.

$\mathrm{mó} h \mathrm{a}:$-as. 8. 8. 9.

mradas in turnamradas.

vmruc, mluc: cf. malimlucá, mruc, mroká.

+ a nu : ef. anumroka.

+ ni: niomrócan. 2. 32. r. (cf. nimrúc.)

m ruc in nimrúc.

mroká: -ás. I6. 1.3.

mróka. 2. 24. 3 .

mrokám. 5. 31. 9. 16. 1. 7 .

(cf. anumroka.)

V m lā: mlāpáyāmi. 7.90. 2.

mlāpayāmasi. 6.66.3.

$\checkmark \mathrm{mluc}$, see $/$ mruc.

y a (pron. root): yás. I. $5.2^{*} ; 8.1$; I2. I, $2,3^{3} ;$ I $5.2 ;$ r9. $3^{3}, 4^{3} ; 20.2$; 21. $2^{*} ; 25.4 ; 29.2^{*} ; 30.1$; 31. 3 35.2. 2. I. $2,3^{*} ; 2.1,2 ; 5.3 ; 7.2^{2}$ 5 ; 9.5 ; II. 3 ; I2. $2,3,6^{2^{*}} ;$ I4. 3 ; I9. $\mathrm{x}-23.5 ; 24 . \mathrm{I}-8 ; 25.3 ; 27.7$ $32.6 ; 33.7 ; 34 . \mathrm{x}^{2} ; 36.5,6,8$. 3. 3 . $6^{2} ; 6.4 ; 11.8 ; 14.2 ; 16.2^{*} ; 21.1^{2}$ $2^{6}, 3,4^{2}, 9 ; 23.5 ; 24.2,2$ (yáḥ॰yah); 27. $\mathrm{I}-6 ; 29.3$. 4. I. 3,7 ; 2. $\mathrm{I}^{2 *}, \mathrm{I}^{\dagger}$, $2^{*} ; 3.5 ; 5 . \mathrm{I}^{*}, 5^{3^{*}} ; 6.4 ; 9.5 ;$ 10. 2 ; II. $3,5,9$, II ; I 5.10 ; I6. I, $2^{4}, 4,6$, $8^{6} ;$ 18. $2,3,6,7 ;$ 19. 5 ; 20. $4,9^{3} ; 22$. 2,$5 ; 24 . \mathrm{I}, 2^{2}, 3,6,7^{2} ; 28.6,7 ; 30$. $4^{3^{*}} ; 32 . \mathrm{r}^{*} ; 35 . \mathrm{r}, 3^{3}, 5,6 ; 36 . \mathrm{r}^{2}, 2^{2}$, 10. 5. I. $1,2^{2}, 3 ; 3.9^{*}, \mathrm{II}^{2} ; 4 . \mathrm{I} ; 5$. 2,$8 ; 6.10^{2}$; 10. $1-7 ; 12.9^{*} ; \mathrm{r}_{4} .2$, 9 ; r8. 4,5 (p. yé), 7,13 ; 19. 6, 9; 22. 2,$3 ; 23.3^{3} ; 28 . \mathrm{Ir} ; 29.2,6,7$, I5; 30. 9, IO, I2; 3I. II. 6. 1. 2 ; 2 . I; 6. I, 2, $3^{2 *} ;$ I4. I ; I 5. I*, 2; I6. $2 ; 20.3 ; 26.2 ; 28.3^{3} ; 30.2 ; 34.2^{*}$, $3^{*}, 4^{*}, 5^{*} ; 37.3^{2} ; 42.2 ; 43.2 ; 46 . \mathrm{r}$; 54. $3 ; 6$ r. $3 ; 73.2 ; 75.1 ; 76.3,4$; 77. $2^{3 *} ; 82.3 ; 84.2 ; 85.1 ; 92.2^{2}$; 
99. 2 I III. I ; I 23. $3 ;$ I $27 \cdot 3^{3} ;$ I 28 . 4 ; $129.3^{2} ;$ I $33 . \mathrm{I}^{3} ;$ I $34.3^{2} ;$ I $36.3^{2}$.

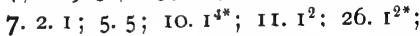

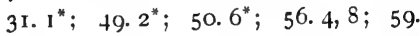
$\mathrm{I}^{2} ; 70.3 ; 73.3 ; 74.3 ; 76.3 ; 77.2^{*}$; 8I. $5 ; 87 . \mathrm{I}^{4} ; 95.3$; IO8. $\mathrm{I}^{2}, 2$; IO9. I, $4,5^{2}$; II 6. 2. 8. 3. $8^{*}, \mathrm{II}^{*}, \mathrm{I}^{3^{3 *}}: 4$. $7^{*}, 8^{*}, \mathrm{IO}^{2 *}, \mathrm{II}^{2 *}, \mathrm{I}^{*}, \mathrm{I}^{2^{*}} ;$ 5. $12, \mathrm{I} 3$; $15^{3} ; 6.5,7,8^{2}, 9,16,18$; 9.2 ; 10. $2-$ 7. 17-29, 33. 9. I. 6, 22, 23, 24; 2. 3; 3. $2,9,1 \mathrm{I} ; 4.2,9,1 \mathrm{I}, 17,18 ; 5.22$, $24-6,28,3 \mathrm{I}-6^{2}$; 6. I, 6, 24, 27-9, 302, 3 I-6, 40-4, 44, 45-8, 62; 7. 26;8. 4, 7,$22 ; 9 \cdot 5^{*}, 7^{*}, 15^{2 *}, 18^{*}, 21{ }^{*} ;$ Io. $10^{2 *}$, I $8^{*}$. I0. I. $7,8,28 ; 2.8,28,29,30$; 5. $15-2 \mathrm{O}^{2}, 2 \mathrm{I}, 25-35 ; 7.17^{2}, 24,32,33$, $34,36^{2}, 41$; 8. $1^{2}, 5,20,22,26,36,37^{2}$; 9. $4,5,6$, I0, I 5 (mss. yát), I $7^{2}, \mathbf{1} 8$ (mss. yát), $26^{2}$; 10. $2^{2}, 24,27$. I I. I. $5^{2}, 15,28,31 ; 2.13,23,28 ; 3.22,23$, $32-49,5$ I, 54; 4. I, I8, I9, 23, 24; 6. $4,9,21$; 7. I $2 ; 8.3,7, \mathrm{I} 8$; 9.4 ; го. $22^{3}, 26$. I2. I. $14^{4}, 23,24,25^{3}, 30,46$; 2. I, $3,7^{*}, \mathrm{I} 4, \mathrm{I} 5^{3}, \mathrm{I} 6,2 \mathrm{I}^{*}, 33,35,39$; 3. $6,16^{2}, 50^{2} ; 4.2,6, \mathrm{I} 1,12,13,17,18$, $23,28,38,44,46 ; 5.46$. I3. I. $\mathrm{I}^{2}, 2$, $25^{2}, 29,56,57,5^{8}, 60^{*} ;$ 2. $2,14,26^{2+}$; 3. $\mathrm{I}^{2}, \mathrm{I}-25,3,4^{2}, 5,6,7^{3}, 8, \mathrm{I}_{5}, 22,24^{2 *}$, $24^{\dagger} ;$ 4. I 5,24 . I 4. I. $29^{*}, 30,37^{*}, 38$; $22^{*}, 4 \mathrm{I}, 47^{*}, 55,58,68$. I 5. 2. I- $4^{2}$, I-4 (not mss.); 3. II ; 4. I-6; 5. I-7; 6. $\mathbf{I}-9 ; 7.3,5 ; 8.3$; 9. 3 ; I0. 9 , II ; II. 7, 9, II ; I2. 4, 7, 8, II ; I3. 9; I4. I-I2; I5.3-9; I6. I-7; I7. I-7; I8. $3^{2}$. I6. I. $5,7,8 ; 0.4$ (mss. yát); 7 . 5; 8. I-27. I8. 1. $6^{*}, 14^{*}, 24^{*}, 34^{*}$, $59^{*} ;$ 2. IO* $^{*}, 26,30,3 \mathrm{I}, 37,53 ; 3 . \mathrm{I}^{2}$, $53^{*}, 55^{*}, 6 \mathrm{I}, 63,70,73 ; 4.28^{*}, 54$. I9. 3. $2^{3}, 3$; 15.6 (mss.); 20. 2 ; 26. $1^{2}, 2$; $31.2 ; 32.1,9^{2} ; 39.10 ; 44.2 ; 46.4$, 5 ; 49. 9, 10; 50. 4,$5 ; 53.8 ; 56.6$; 57. 3 (mss. ayas), 4 (not mss.); 59. 2 . 20. 34. I2, I6 (not mss.), I $7^{3}, 17$ (not mss.); 127. 7; I28. I, 2, $4^{2}, 6,7,8,9$, $14^{3} ; 136.10$.

yát. 1. $2.3 ; 3.6^{2} ;$ I0. $3 ;$ I $3.3 ;$ I 8 . $3^{2} ; 20.3^{2} ; 23.1,4 ; 25.1 ; 32.3 ; 35$. I. 2. I. I, $2 ; 3.1 ; 7.2,4 ; 12.3 ; 19$.
$\mathrm{I}-23,5 ; 30.3,4^{2} ; 32.2 ; 34.2 ; 35$. 3, 4. 3. 2.4 ; 3. 2 ; $7.2,3,6$; 13. I, 2; 14. I, 2 ; I7. $7^{*}$; 22. I, 4 ; 29. I. 4 . I. $5 ; 3.7^{2} ; 7.2 ; 9.9 ; 12.2^{2} ; 13.2^{*}$, $3^{*} ;$ 16. $2,5^{2} ;$ 19. $4 ; 23.7^{2} ; 26.7$; 28. I, 2 ; 33. $3^{*}, 4^{*}, 5^{*}$. 5. I. $4,5,7$; 2. $1^{\dagger}, 3^{*} ; 3.7 ; 5.4^{3} ; 6.1 \mathrm{I}-4 ; 8.3,6$; II. $3,9, \mathrm{IO}^{2} ;$ I3. 2 ; $7.7,8$; 19.5 ; 22. IO; $23.9 ; 25.6^{3} ; 28.8,12 ; 29$. $5^{2}, 12^{2} ; 30.2^{2}, 3,4^{2}, 5^{2}$. 6. 12. $2^{4} ; 18$ 3 ; 22. 2 ; 24. $2^{2} ; 27 . \mathrm{I}^{*} ; 29 . \mathrm{I}^{2^{*}} ; 45$. $2^{2^{*}}, 3^{*} ; 49.2,3^{\dagger} ; 5$ I. $3^{*} ; 53.3 ; 61.2$, $3 ; 63 . \mathrm{I}^{2} ; 69.1,3 ; 71 . \mathrm{I}^{2}, 2,3 ; 72.3$; 74. 2 ; 80. I, $3 ; 83.4 ; 89.1 ; 96.3^{3}$; I00. 2 ; I07. I-4; II4. I, 2 ; II5. $\mathrm{I}^{2}$; II6. I, $2^{2} ;$ II7. I, 2; II8. I, 2; II9. I, $3^{2} ;$ I 2O. I ${ }^{2}$; I 2 I. $2^{4} ;$ I 22. 3 ; 124 . 2 ; I28. I : I3I. 3 ; 133. 3 ; I35. I, 2, 3. 7. $5.3,4^{2} ;$ 12. $4^{2} ; 20.4,6^{2} ; 24$. $\mathrm{I}^{3} ; 25.2 ; 41.2 ; 42.2^{*} ; 44 . \mathrm{I}^{*} ; 53$ I, $3 ; 54.2 ; 57 . \mathrm{I}^{2}, \mathrm{I}$ (m. mss. tát) 6I. I; 64. I, $2 ; 65.2^{3}, 3 ; 66.1 ; 68$ 2 ; 70. $\mathrm{I}^{2}, 2 ; 73.4 ; 79.1 ; 83.2^{2} ; 89$ $3^{3^{*}} ;$ 90. $3^{2} ; 97.1^{*}, 2^{*}$; IOI. 1 ; 106. I; Iоg. $7^{3}$. 8. 2. 3 , 10, 12, 16, 17. $19^{4}$ 3. $12^{2^{*}} ; 4.12^{*} ; 5.19 ; 6.20 ; 7.5^{2}$ 10. 9,32 . 9. 1. $18^{3}, 24 ; 2.2^{2}, 16,25$; 3. $2, \mathrm{I}_{3}, \mathrm{I}^{2}: 4.5, \mathrm{I}_{4}, \mathrm{I}_{5}, 23^{\dagger} ; 5.3,2 \mathrm{I}$ 3I-6; 6. 3, 4, 6-1 3, 18, 19, 23, 37, 39 $49,50,51,53,54^{2}, 55-9 ; 9.4^{*}, 21^{\dagger} ; 10$. $\mathrm{I}^{2 *}, \mathrm{I}^{*}$. IO. I. IO, II ; 2. $3,26,32$; 3. $8^{4} ; 4.22^{2}, 25 ; 5.22,45 ; 6.3 ; 7$. $8^{3}, 9,3 \mathrm{I} ; 8.2^{2}, 7, \mathrm{II}^{3}, \mathrm{I} 3,38,43 ; 8$. 39 ; 9. $13^{2}, 15,16^{2}, 17,18^{3}, 22^{2}, 24$; IO. 9-II, 16, 22. II. I. $30 ; 2.10 ; 3$. $50 ; 4.3,4^{2}, 9,10^{2}, 21,22 ; 5.15$ (yáto yat); 6. $23 ; 7.23^{2} ; 8.1,16,22,23$; 9. I, I3. I2. I. $12^{2}, 25,34^{2}, 35.40,46$ (yátoyat), 46, 47, 55, 56, 58 2 60, 61 ; 2. $5,19,36^{3}, 39,40^{3} ; 3.3$ (yátoyat), 7, I3, I3 (yátoyat), 22 (do.), 30, 39 (yátoyat), 43, 48, 52 $2^{3} ; 4.7,8$, 9. 15 , $22,33,40^{2} ; 5.5$ O. I3. I. $44^{2}, 54^{2}, 55$; 2. $3^{2}, 5,14,28,36,42,44,45 ; 3 . \mathrm{IO}^{2}$, I2, I 7,$23 ; 4.7, \mathrm{II}^{2}, \mathrm{I}^{2}, 43^{3}$. I4. 1 . $3^{*}, 4^{*}, 6^{*}, 9^{*}, 10^{*}, 14^{*}, 15^{*}, 16^{*}, 27^{*}, 35^{3}$, 56 ; 2. I $2,48,5 \mathrm{I}, 53,54,56,57,6 \mathrm{I}^{2}$, $62^{2}, 65^{2}, 66^{3}$. I5. I1. $3-6,8$, I0; I4. 
I-I $2 ; 17.9 ; 18.2^{2}$. I6. I. $8 ; 7.9^{3}$, IO ${ }^{4}$, I I. I 8. I. $2^{*}, 4^{*}$, I $2^{2 *}, 14,20^{*}, 22^{*}$, $26^{2 *}, 29^{*}, 31^{*}, 32^{*}, 34^{*}, 52^{*} ; \quad 2.26,33^{*}$, 36,$57 ; 3.3,19,24^{*}, 38^{*}, 55^{*}, 56^{\dagger}, 66^{*}$; 4. $7,42,49,56,64,83^{2}, 84^{2}, 88^{*}$. I9. 5 . I*; 6. $4^{3^{*}}, 5^{*}, 6^{*}, 10^{*}, 15^{*} ; 9.4,8,14^{3}$; I3. I ; I5. 4 ; 20. $3^{2} ; 26.1,2,4^{2} ; 27$. IO; 30. I, 5 ; 3I. 4,$5 ; 38.2^{2} ;$ 40. $\mathrm{I}^{2}$, $3 ; 44.9^{2} ; 45.2^{3}, 3 ; 47.2 ; 48.3^{3} ; 50$. 6,6 (ed. tát); 52 . I*, 4,$5 ; 57.2$ (mss. yáta; p. -tah), $5^{3} ; 59.2^{*}, 3^{*} ; 64.3^{*}$. 20. 49.1 ; I $28.2^{2}, 3$, I 2 ; I 36 . I, 3,4 yă. I. I 5.2 (p. yăha); 28. $3^{3}$. 2. 9 . I; 26. 3; 3I. I; 35. I. 3. 2.6; Io. 2,4 ; $18.4^{*} ; 24.6$; 25. I, 3. 4. 38 . 3. 5. 7.9. 6. $4.3 ; 38 . \mathrm{I}-4, \mathrm{I}^{2}, 2^{3}$; 73. 2. 7. 42. I"; 46. I", $2^{*}, 3$; II 5. 2. 8. 3. $12^{*} ; 4.17^{*} ;$ 9. I4. 9. I. $8 ; 3$. $2 \mathrm{I}^{2} ; 5.27$. I0. 8. $\mathrm{IO}^{4} ; 9.19,2 \mathrm{I}$; 10. 28. II. $49 ; 7.25 ; 8.4,7,17,26$, 30. I2. I. $2,4,8,37 ; 3.29$ (mss. -ya), 54; 4. 44, 46, 48. I4. 2. I9, 22, $38^{*}$ (p. yăh $\left.{ }^{\dagger}\right), 48,50,74$. I7. I3 $3^{4}$. 18. I. $43^{*} ;$ 2. 31. I9. $3.3^{2} ; 93 ; 40.4^{*}$ (mss. măt ${ }^{\dagger}$; 55. 2, 2 (mss. vă-). yó (p. yó íti). r r. 4. 9 (l. yă u).

yám. I. 26. I. 2. II. 3 ; I9. I-23. 5. 3. $5.3 ; 15.4^{*} ;$ I6. $2^{2 *} ; 2$ I. $3,4^{2}$, 5 ; 27. I-6. 4. 2. $3^{*}$; 23. I; 24. 5 ; 30. $3^{*} ; 35.1,2^{2}, 4 ; 36.7,8$. 5. 7. 2 , 5 ; 8.5. 6. $2.2 ; 26.3^{2} ; 65.2 ; 81.3$; 109. $2^{*}$; I18. 3 ; 123. I ; I32. I-5. 7. 3I. I*; 8I. 5, 62. 8. I. II ; 5. II. 9. 5. I9. I0. 5. $15-21,25-35,42 ; 6.6-$ I $7,22-8,32 ; 7.23 ; 9.26$. I I. I. 7 ; 6. 7 ; 10. I2, I3. I2. I. $23^{3}, 24 ; 2.3$, $37 ; 3.4^{2}, 5^{2}$, I 2 . I 3. I. $2 \mathrm{I}^{\dagger}, 5 \mathrm{I}^{2} ; 2$. $4^{2}, 6,7,36$. 4 . I. $3^{*}$, I $3^{*}, 37^{*} ; 2.22$, 42. I6. I. $5 ; 6.4 ; 7.5$. I8. 2. 30 ; 3. $6^{*}, 54 ; 4.42^{2}$. I9. 20. I; $27.9 ; 32$. $9 ; 35.1,2 ; 38.1 ; 39.9^{4} ; 46.3$ (not mss.). 20. 136. I6 (mss. yás).

yằm. I. 13. 4. 3. 10. 2, 3. 4. 4. I ; I $7.4^{3}$; $18.5^{3}$. 5. I7. 4 ; I8. 9 ; I9. 12; 3I. $1^{3}, 2^{3}, 3^{2}, 4^{2}, 5^{2}, 6^{3}, 7^{3}, 8^{2}, 9^{2} .6$. 78. I ; 90. I; 108. $3^{3}, 4 ;$ I 33. 5 ; 137 . I. 7. 15. 1. 8. $2.16 ; 4.6^{*} ;$ 9. 8.9. I. 9 ; 2. 5. IO. I. I, I8 $8^{2}$ II. I. 24 ;
8. 7 ; 10. 9,27 . I2. 1. $7,8,1^{2}, 51,60$ 4 I9, 45. I4. 2. 65 . I8. 2. 30. I 9 . 4. I, 2.

yéna. I. 9. $3 ; 29 . I^{*} ; .32 .1$. 3. 15 . 5,$6 ; 22.3^{8} ; 23.1 ; 30.4$. 4. I1. 6 ; $22.5 ; 23.5^{3}, 6^{3} ; 24.2^{2}, 6 ; 26.7$ (yéna॰ye-); 35.2. 5. I9.14 $4^{2}$. 6. 7. I, 2 , 3 ; 30. 2 ; $57.1 ; 68.3 ; 82.2$; IOI. $2^{2}$; I17. I; 129.2. 7. IO. $1^{*}$. 8. I. IO; 3. $2 \mathrm{I}^{*} ; 4.4^{*}$. 9. $2.17^{2} ; 3.9 ; 5$. 17 ; 10. $7^{*}$. 10. 4.6 II. 1. $2^{*}, 30$, 37 ; 3. 32, 35, 39-43; 8. I6; IO. II. I3. I. $23 ; 2.6 ; 3.17^{2}$. I4. I. $19^{*}, 30$, $36^{3}, 48,58^{*}$. I $8.4 .3,7$. I9. $9.4 ; 24$. I; $34.5 ; 49.5$.

yénā (p. -na). I. I3. I. 3. 9. 4. 7. 12. I; 38. 2. 9. 5. I 7. 13. 2. $2 \mathrm{I}^{*}$. 18. I. $54^{\dagger} ; 4.44$.

yáyā. 3. I8. $\mathrm{I}^{\text {y* }}$ I0. 8 . IO; I0. $4^{3}$. II. $3.36,49$; IO. I5. I4. 2.9. I 7. 13. I9. 4. I (not mss.); 9. 3 .

yásmāi. 4. $24 \cdot 3 \cdot 4^{2} ; 35 \cdot 5 \cdot 5 \cdot 30.17$. 6. I 18. 3. 8. I0. 30. I0. $6.34 ; 7.39^{2}$; 8. 26. I9. $32.2,8 ; 39.2-4$.

yásmāt. 4. 35. $4^{2}, 6$. 6. 7 I. 2. 9. 3 . 20. 10. $7 \cdot 20^{2}, 3$ I. I2. 3.45 . I3. $3 \cdot 2^{2}$, 3. 16. 6. 2". I9. 72. I. 20. 34. 17.

yásya. I. $5 \cdot 3^{\#} ; 20.4^{*}$. 2. 1 $3.5 ; 24$. I-8. 4. 2. $\mathrm{I}^{2^{*}}, 2^{2^{*}}, 3,4^{3}, 5^{3^{*}} ; 9.4^{*} ;$ I I. $5 ; 23.7 ; 24.3,4,5,6 ; 35.5$. 6. 5 . $3 ; 33.1 ; 76.2 ;$ II8. 3 ; I33. I. 7 . I4. $2 ; 25.2 ; 26.3^{*} ; 40 . \mathrm{I}^{3} ; 76.5 .9$. 6. $I^{2}, 2,25,26 ; 8.3,6$. I0. $6.31 ; 7$. I3, I 5, I6, 1 $8^{2}, 19^{2}, 20,23,27,32,33$ (l. yásia ?), 34 ; 8. I. I I. 2. 22; 3. 21 ; 4. I. I3. I. $37 ; 3.16,24^{2 *}$. I5. IO. I ; II. I ; I 2. I ; I 3. I-5, 6. I 9. 4. 4 ; 56. 5. 20. 127. 2.

yásyās. 6. 62.2;84. 1. 7.6.4;27. I. 8. 9. 8. 9. 3. 10. I0. 2. $28,30$. II. I0. 27 . I2. I. $2,4,8,42,43^{2}$. I 9. 47. 2 .

yásmin. 4. 24. $5^{2} ; 35.6 . \quad 5 \cdot 2.6^{\mathrm{m}}$; I 7. I 2-7. 8. 9. $3^{2}$. 9.6.30; 9. $\mathrm{II}^{\dagger}$, $14^{\dagger}, 21^{*} ;$ IO. $18^{*}$. I0. $7.7, \mathrm{I}^{2}, 14$; 8. $19,37,38$. II. 2 . I I ; $3.20 ; 4$ I, I8. I2. 2. $17^{2} ; 4.14,24$. I3. 3. I, 5 , 6, I0. I4. 2. 8. I8. I. $35^{*}, 36^{*}$. 20. 34. I2. 
yásyām. I2. I. $3^{3}, 4,5^{2}, 9$, Io, $13^{3}$, 27, 37, 38 $8^{4}, 39,41^{3}, 42,51,52$ (1. -siām); 3. 9. I 4. 2. $38^{2^{*}}$. I 8. 2. 48 .

yãú. 4. 25. $\mathrm{I}^{3} ; 28 . \mathrm{I}^{2}, 2,4,6^{2} ; 29$. I, $2^{2}, 3^{4}, 4^{2}, 5^{3}, 6^{4}$. 6. 29.2 ; 127.2 ; I 40. I. 7. $25 . \mathrm{I}^{2}$; I IO. 2. 8. I. $9 ; 6$. I. 9. I. 7. IO. I. $21 ; 9.13,14,17$, I9 $9^{2}, 2$ I. I8. 2. I $2^{2} ; 4.50$ (mss.).

yé (p. yéíti). 3. 7. 4. 4. 26. I, $4^{4}, 5^{2}$, $6^{7}$. 6. $138.4 \cdot 8 \cdot 3 \cdot 25$. I0. 9. $13,14^{3}$, I6, I9, 2 I.

yăbhyām. 2. 32.6. 4. 25.2: 26.6. 7. $54 . \mathrm{I}$; IIO. 2 . I0. $2.3 ; 8.20$. II. 3. $33,34,44-8 ; 9.4$. I9. I3. I.

yáyos. $4.25 .2^{2} ; 26.5$; 28. I, 2, 5 ; 29.7. 6. 138.4. 7.25. I.

yé. I. I. I ; $7.3 ;$ I $5.3,4 ;$ I6. I; I9. $2^{2} ; 30.2^{2}, 3^{3} ; 3$ I. 2. 2. I 2. 2 ; 26. I ; 28. I, $3^{2}$; 31. 5 ; 32 . I, $5 ; 34.3 .4 ; 35$. I. 3. $5.6^{2}, 7^{2} ; 6 . \mathrm{I}, 3,5 ; 8.5$; 10. 6 ; I5. 2 ; 19. 3 ; 2 I. $1^{4}, 7^{3}$, I0; $26.1-6$. 4. $4.8 ; 6.7^{4} ; 7.7$;1. I2; r4. 4 ; I6. $6 ; 22.6 ; 27.2^{2}, 3,4^{2}, 5^{4} ; 34.3,4$; 35. $7 ; 36.3,5^{2}, 9 ; 40.1-8$. 5. 3. 10*; 6. 9 ; I 7. $6^{*}, 7^{2}$, I 7; I8. Io, II ; I9. 2, $3^{2}$; 21. 7,$8 ; 23.5^{3} ;$ 30. 12. 6. 3. 2 ; I3. I; 4I. $3^{2} ; 47.3 ; 50.3^{2} ; 55.1$; 63. 3 ; 66. I, 2 ; 76. I; 80. 2 ; 103. 3 ; I04. I, $2 ;$ II 7. 3 ; I2I. $\mathrm{I}^{2}$. 7. I. $\mathrm{I}^{2} ;$ I2. 2 ; 34. I; 55. I; 62. I; 80. $4 ; 83.4^{2}$; 97. 4. 8. г. 8,$11 ; 2.27 ; 4.9^{2^{*}}, \mathrm{r} 8^{2^{*}}$, $23^{\dagger} ; 5.7 ; 6 . \mathrm{IO}^{2}, \mathrm{II}^{2}, \mathrm{I} 2, \mathrm{I}_{3}, \mathrm{I}^{2}, \mathrm{I}_{5}$, I $9,23^{2}, 24 ; 8$. IO; 9. 2 I. 9. I. $9 ; 2$. 4,5 , I0, I I, I6, I 7, I $; 4.8^{2} ; 5.2,14^{2}$, 30; 6. 14; 8. I9; 9. $3^{*}, 1^{2 *}$; 10. $1^{*}$, I $8^{*}, 27^{*}$. IO. I. $9 ; 2.4 ; 3.3,16^{2} ; 4$. $9^{2}, 23^{2} ; 5.21 ; 7.17^{2}, 21,25,38 ; 8.4$, $9, \mathrm{I} 7,35^{2}, 4 \mathrm{I} ; 9.6^{2}, 7^{2}, 9, \mathrm{r2}^{3}, \mathbf{2 0}, \mathbf{2 2}^{2}$, 23 ; I0. $5,30,3 \mathrm{I}, 32$ (p. yás). II. I. 9 III $2.2 ; 5.2 \mathrm{I}^{2} ; 6.8, \mathbf{I 2}^{3}, \mathbf{2 2}^{2} ; 7$. II, I 5, 26, 27; 8. IO, I3, 24, 25 ; 9. I, I6 $6^{2}, 17,22^{4}$; Io. $2^{3}, 8^{2}, 14,23^{3}, 24^{3}$. I2. I. $37,47,49,50^{2}, 56^{2}, 57 ; 2$. $26^{*}, 27,45,5 \mathrm{I} ; 3.6,40,42,5 \mathrm{I}$; 4. II, 5I, 52. I3. I. I $8^{2}, 28,35$. I4. I. $46^{*} ;$ 2. $9^{2}, 10^{*}, \mathrm{II}^{*}, 46^{*}, 5 \mathrm{I}^{3}, 73$. I5. 13. I-5. I7. 8 . I8. I. $9^{*}, 44^{*}$, $45^{*}, 46^{4 *}, 47^{*}$; 2. $11^{*}, 15^{*}, 16^{3^{*}}, 17^{3^{*}}$,
I $8^{*}, 28^{2}, 34^{4}, 35^{2 *}, 47,49^{4} ; 3.20^{2}, 25-$ $35,46^{*}, 46^{\dagger}, 47^{*}, 48^{*}, 59^{3}, 72^{2} ; 4$. I6$24,29^{*}, 40,44,57^{4}, 68,75,76,86$, 86 (mss.), 87. I9. 6. II*, I2*, I4*; 7. 4 (mss. de-); II. $4^{*}, 5^{*} ;$ I8. I-IO; 27. II-3; 3I. 4 ; 34. 2 ; 35.5 (mss. yáh), 5 (p. yáḥ); $36.3^{2} ; 42.2 ; 47$. $3 ; 48.5^{3} ; 49.7 ; 50.2 ; 55.6 ; 58$. $6^{2} ; 65.1 ; 66.1$. 20. 128. $5^{2}$.

yấni. 2. $5.5^{*} ; 6.1$. 3. 2.2 ; 23.4 . 4. 7.7. 5.3. $4^{*}$; 19.13. 8. 9. 3. 9. 3. $6 ; 6.15$ IO. $7.40 ; 9.2,24$. II. 2. 5. I4. 2. 7. I9. 8. $\mathrm{I}^{3} ; 9.5,13 ; 20$. $2^{2}$; 31. 4 ; 37. I; 48. I, I (p. yằn。 iva); $49.3 ; 64.3^{\dagger}$.

yă. I. I6. 3 ; I8. I; 20. I. 2. 3. 2. 5. 3. 6. 6. 44. 2. 9. 9. I9*. II. 9. 2 (p. yăh). I 4. 2. 7 .

yâs. I. $4.2^{*} ; 6.4 ; 17.1 ; 22.3^{2} ;, 29$. $2^{*}$; $33.1-3,3,4$. 2. $2.4,5$; I0. 4 . 3 . 24. 3. 4. $5.3^{2^{*}} ; 8.5 ; 21.5^{*} ; 32.2^{*}$; $38.4,5^{2}$. 5. I. 8 ; 13. 9 ; 18. 12; 19. II；2I. 9. 6. 21.1 ; 22. $3 ; 24.3 ; 25$. I-3; 90. 2 ; 96. I*. 7. $35.2 ; 48.2^{*}$; 49. $\mathrm{I}^{2 *} ; 76.2^{3} ;$ III. $\mathrm{I}^{2} ;$ II 5. 4. 8 . 2. $27 ; 5.9^{4} ; 7 . \mathrm{r}^{2}, 4,8, \mathrm{IO}^{2}, \mathrm{II}, \mathrm{I} 7, \mathrm{I} 8^{3}$, $23,24^{5}$. 9. $2.25 ; 4.6^{2} ; 5.19 ; 6.5$; 8. 13-8. Iо. 9. $16,20^{3}, 23^{2}$. II. 2 . 3 ; 4. I7; 6. 9, 22; 8. 21, 27, 28, 302; 9. I. I2. I. $12,3 \mathrm{I}^{4}, 56 ; 3.4 \mathrm{I} ; 4.5$, 4I, 43. I3. I. $2,9^{2}$, IO; 3. I. I4. I. $45^{3} ;$ 2. $7^{2}, 29^{2}, 49^{2}$. I7. 28. I 8. 2. $8^{*}$, 9,$20 ; 3.69 ; 4.26$. I9. $2.2 ; 8.6$; I3. II I $^{*}$ 34. 2 (mss. jā-, ed. akșa-), 7. yăn. 2. $35.1,2$. 3. $6.1,3,5$; 11.5 , 7; 23. 3 (mss. yấm). 5. 8. $7^{2}$. 7. 97. 3. 8. 8. 16. 12. 2. $38,50,52 ; 4$. I9 (mss. ed. yắm). I7. $7^{2}$. I 8 . 1. $47^{*}$; 3. 68 .

yāís. 5. 21. 8 . II. 3. 37: 38 . 2 2. I. 47 I $8.4 .2,70^{2}$. I9. 9. 5 .

yébhis. 6. II2. 2, 3. 7. 55. I. 10. 8. 35 . I4. I. $34^{*}$.

yăbhis. I. $4.2^{*}$. 4. $21.3^{*}$. 5. 4. 5 . 7. $48.2^{*}$. 9. 2.25 . I3. I. 9. I4. I. 37". I8. 2. 9 .

yébhyas. II. 2. 25. I2. I. 15. I8. 2. $14^{*}$. I9. 58.6 . 
yéşām. 1. $30.4^{2}$. 2. $26.1^{2}$. 3. 19 . I, 4. 6. 122. 2. 7. 60. 3. 8. 6. 15 ; 9. 3. 10. $2.6 ; 4.23$. 19. 56.4 . yăsām. 1. $33 \cdot 2^{*}, 3 \cdot 3 \cdot 23 \cdot 6 \cdot 4 \cdot 38$. 5. 6. 9. 3. 8. 7. 2, 16. 12. 3. 31 . yéșu. 7.60.3. 8.2. 22.

yăsu. 1. 33. $1^{2}$. 4. 2. $6^{\dagger}$. 8. 7. 18 . (cf. yátkāma, yatamá, yatará, yátas, yáti, yátra, yáthā, yadă, yádi, yăt, yăvant, tyá.)

y ajká n, yákr̨t: yákṛt. 9. 7. II. ro. 9. 16.

yalknás. 2. $33 \cdot 3^{*}$.

y a kṣá : -ám. 8. 9. 8, 25, 26. I0. 2. $32 ; 7.38 ; 8.15,43$. Ir. 2.24. yakșăni. I 1. 6. 10.

yákşima : -as. 2. 10. 5. 5. 30. 9. 6. 85. I. 8. 7. I5. 9. 8. 3. 12. 2. $\mathrm{I}^{2} ; 4.8$. yákșmam. 2. 33. $1-7^{*}$. 4. 9. $4^{*}$; 13 . 5*. 5. 4.9 ; 30. 8, 16. 6. $85.2,3$; 1 27 . 3. 7. 53.6. 8. 1. $21 ; 2.18 ; 7.3 .9$. 8. 7. I2. $2.2,14$. 14. 2.69. 19. 36. $2 ; 44.2$.

yákṣmeṇa. 3. 31. I-II. [máya). yákșmãya. 20. 128. 12 (mss. yakṣyákṣmāt. 2. 10. 6 . 8. 7.2, 5 . yákṣmās. I4. 2. 10*. 19. 38. 1, 2. yákșmāsas. 9.8. 19. 19. 36.3.

yákșmān. 19. 36. I, 4 .

yákṣmāṇām. 9. 8. 10-2, 19, 20.

(cf. ayakṣmá, ajñātayakșmá, rājayakșmá, yakșmanăçana, yakṣmodhá.)

y a kş miå̀ nă ça n a : -nIs. 3. 12. 9. y a kşmod hờ (p. -mạ̣ıdh-) : -ấm. 9. 8. 9 .

$\checkmark \mathbf{y}$ a ch, see $\sqrt{ }$ yam.

$\checkmark$ y aj: yajāmi. I. 3I. 3 .

yajasi. 5. 12. $\mathrm{I}^{*}$.

yajati. 18. I. 18 t.

yaja. 6. $125 \cdot 2^{*}$.

yaje. 3. 10. $9^{2}$, 10, I1. 6. 123. 4 .

yájate. 4. 2I. $3^{*}$.

yajate. 9. 4. 18 .

yajāmahe. 4. 33. 2*. 7. 54. I; 8o. 2. I4. I. I7. I8. 3. 25-35; 4. 16-24. yajāt. 19. 59. $3^{*}$.

yajantām. 5. 3. $4^{\dagger}$. yájamānas. 6. I 23. I, 2. I 5.2.2; 6. 5 . yájamānam. 2. 34. I. 5. 3. 9*. I I. 6.14. 19. 63.1. 20. 34. 12 (not mss.). yájamānena. 18.4.6.

yájamānāya. 2. 34.2. 4. 30. 6*. 5 . 26. I2. 6.6. I; 54.3.7.17. 4; IIO. 3. 8. 9. I4. 9. 4. I; 5. 2. II. I. $9 ; 2$. 28. I5. 2.2. I8. I. $43^{\dagger} ; 4.4,5,7$. 19. 52. I, 2.

yájamānasya. 7.99. 1. 9.5.2. 10. 9. I. I5. $2.2 ; 6.5$. 19. 42.3 .

yájamāne. 10. 3.23.

yájamānās. 4. 14. 5. 6. I I4. 3 .

áyajanta. $7 \cdot 5 \cdot 3,5$. 20. 128. 5 .

ayajanta. 7.5. $1^{*}$, 5. I9. 6. II*.

Ijāte (p. -e íti). I3. I. 47, 49-5I.

ijiré. $7 \cdot 5 \cdot 4$.

ijānás. I 8. 4. I4.

Ijānám. I8. 4. I, I0, 13.

jijānăs. I8. 4. 2.

İjānănām. 9.5. 8, I2.

yakși. 5. 12. $3^{*}, 9^{*}$.

yakșat. 3. 4. 6. 5. 27.5 .

yakṣyámānāa. 20. 135. 5 (?).

yájadhyāi. 5.12. $7^{*}$.

ișțấ. 9. 6. 40-3. I2. 2. 54 .

ișțám. 9. 5. 13; 6. 31. II. 7. 9. 12.

5. I0, 56 . I9. 72 . I.

ișțásya. I 8. 1. 19*.

ișté. 7. 14. 4.

iṣțăni. 9. 9.16*.

ișțâ. $5 \cdot 3 \cdot 4^{\dagger}$.

íyakșati. 18. 1. $23^{*}$.

íyakșamāṇās. 4. $14 \cdot 5$.

(cf. ij, ișța, ișți, yakșá, yaj, yajatá, yájatra, yajátha, yajana, yajamāna, yájiyas, yájus, yajñá, yájvan, yāj, yāja.)

+ a n u : cf. anuyājá.

+ ava: áva ... yaja. I9. 3. 4 .

(cf. avayăj.)

$+\bar{a}$ : à yajasva. 6. I IO. $I^{*}$.

à yajantām. $5 \cdot 3 \cdot 5^{*}$.

āyejé. r9. 4. I (not mss.).

+ pra: cf. prayáj, prayājá.

y aj in prayáj.

y aj a tá: -ás. 2. 2. 2.

yajată. I 8 . 1. 26*. 
yajaté (p. -é íti). 5. I2. 6*; 27.8.

yáj a tra: -as. I3. 2. 44, 45 .

yajatra. I8. I. 26*.

yájatrās. I9. Ir. $5^{*}$.

yájatrās (voc.). 6. II4. 2.

y a játh a: -thāya. I 8. I. $29^{*}$.

y a jana in devayájana.

y a jam ã $n a$ in

[6. 18.

y a ja māna brāhma ṇá: -ám. 9.

yá jị y a s: -yān. 5. 12. $3^{*}, 9^{*}$. 18. I. $30^{*}$.

$[38$.

y a jurvíd (p. -uhov-): -das. I2. I.

y a juṣ y à : -às. I0. 5. I 5-20.

yajușyà̀s. I0. 5. 21 .

yáju s: 7. 54.2. 9.6.2. I0. 7. I4, 20. I I. $7.5 ; 8.23$. I 8 . I. $32^{*}$. I9. 6. $13^{*} ; 54.3$.

yájușā. 7. 70. I. I I. 7.24.

yájūnșịi. 5. 26. I. I I. 6. I4. I5. 3. $6 ; 6.3$.

yájușām. I5. 6. 3.

(cf. yajurvíd, yajușyà.)

y ajñ á: -ás. 4. Ir. 4, 5 ; 34. I. 5. 26. I2. 6. 97. I. 7. $5.2 ; 73.3 ; 97.6 .9$. $5.2 \mathrm{I} ; 6.28$; IO. 14 . . $0.7 . \mathrm{I} 6 ; 8$. IO; 10. $20,27,29$. II. I. 14, 15; 8 . 2O. I2. I. I. I3. I. 48,$55 ; 4.39,4 i^{2}$. I5. $2.2 ; 6.5 ; 7.4,5 ;$ I6. 6 . I6. 8 . I-27; 9. 4. I7. I8. I8. 2. I"; 3. I4; 4. I3, I5. I9. I3. $9^{*}$; I9. 6 ; 42. I (mss. -ñăs).

yájña. 7.97.5.

yajñám. I. $9.4 ;$ I5. I. 2. 35.5 . 3. 20. $5^{*}$. 4. I4. 4 ; I5. I6; 23. 2 . 5. 3 . II ; 6. 8; I2. $2^{*}, 7^{*}, 8^{*}$, II $^{*} ; 26.6$, I 2 ; 27. 3,8 , I2. 6. 35.2 ; II4. 2 ; 122. 4 . 7. $2 . \mathrm{I} ; 5 . \mathrm{I}^{*}, 4,5 ; 20 . \mathrm{I}, 4,5^{2} ; 27 . \mathrm{I}$; 28. I; 47. 2 ; 54. I; 73. $9^{*} ;$ 79. I; 82. $\mathrm{I}^{*} ; 97 . \mathrm{I}^{\dagger}, 5,8$. 8. $3.9^{*} ;$ IO. $\mathrm{I} 5$ I7. 9. 4. 7; 5. I7, 22. I0. 2. I4, I9; 5. 3 I ; 6. 4 ; I0. 25 . I I. I. IO, 34,36 ; 3. 53 ; 6. I4. I2. I. I3, 22. I3. I. I4. I8. I. $42^{*} ; 2.35^{*} ; 3.4 \mathrm{I}^{*} ; 4.2,40$. I9. I. I, $2^{2}, 3 ; 6$. IO* $\mathrm{II}^{*}, \mathrm{I}^{*} ; 54.4$; 58. 6.

yajñéna. $7.5 . I^{*} . \quad$ I2. I. $39 ; 4.32$. 13. 3. I7. I9. 63.1 yajñăya. I5. 2. 2. yajñăt. I0. $5.3 \mathrm{I}$. I2. $4.4 \mathrm{I}$. 13. I. $59^{*} ; 4.39$. I8. 2. 28 . I9. 6. I3*, 14*. 20. $135 \cdot 7$ (? ed. jájñā).

yajñásya. 2. $35.3,5$. 6. $36.2 ; 48$. I-3；69.3. 8. 9. I4. 9.6. $38^{2}$. I0. IO. 2,3 . II. 7.6 , 10. I3. I. I3, $60^{*}$; 3. $6 ; 4.40$. I5. $2.2 ; 6.5$. I9. 42 . 2 (not ed.).

yajñé. I. 20. I. 4. 24.6 (ed. jajñé). 5. 26. I, 2, 3, 4, 5, 7-I I. 7. 47. I; 97. I*. 9. $5.2 ; 6.5$. IO. I. II ; 3.23 ; I0. I8. I2. 5.3 .

yajñăs. 8. 9.8. I0. I0. 24 I I. 7. 8, II, I5, I9. I3. I. 36,43 . I9. Io. $7^{*}$. yajñấn. 3. 10. 7 .

yajñāís. 6. 124. I. 7. 70. I; 80. 4 . 8. $3.6^{*} ; 5.15$.

yajñănām. $4 \cdot 34 \cdot 5$. I3. 2. 39 .

yajñéşu. I9. 59. I*

(cf. pitṛyajñá, yajñákāma yajñíya.)

y a j ñ á $\circ \mathbf{k} \mathbf{a} \mathbf{m}$ a: :-as. 7. 103. I. yajñákāmās. 7. 28. I.

y a jñ a 0 kŕt: -tas. r8. 4. 7 .

y a j ñ a kratu in âhṛtayajñakratu.

y a jũá

yajñapate. $7 \cdot 97.6$.

yajñápatim. 2. 35. 2. 7. 26. $3 ; 97.5$. y a j ñ a

yajñárta (p. -ñaoṛt-): -as. 8. Io. 4 (s. mss. -nárt-).

y aj $\tilde{\mathbf{n}} \mathbf{a} \circ \mathbf{v}$ a cá s: II. 3. I9.

yajña०vardhana: I0.6.34.

y a jñ $a \circ v \bar{a} h$ as: -sas. 6. II4. 2.

y a jñ a०vị́ d h: -dham. 4. 23. 3 .

yajñ áos a m̧̨ita: -as. ro. 5. 3I.

yajñ $\mathbf{y}$ ajñ a in

y aj ñ ā y ajñíy a: -am. 8. I0. I3, I 7 .

I5. $2.2 ; 3.5 ; 4.2^{2}$.

yajñãyajñíyena. 8. 10. 15 .

yajñāyajñíyāya. $\quad$ 5. 2.2.

yajñãyajñíyasya. $\quad$ 5. 2.2.

y aj ñ ā y u d há (p. -ña॰āy-): -dhắni. I8. 4. 2.

yajñāyudhāís. 12. 3.23.

y a jñ íy a: -as. II. I. I6. I8. I. I8*. yajñíyam. 2. 34. I. 6. II6. I. yajñíyā. 6. 108. 1. 7. 80. 4. 10. 9.3. 
yajñiye. 7.80 .4 .

yajñíyasya. 7.92. I".

yajñíye (p. -e íti). 6. 62. r.

yajñíyās. 2. 12. 2. 6. 122. 5. 7 . 28. I. II. I. I0, I3, I7, I8, 27. I2. 2. $13,20.14 \cdot 2.10 ", 67$. 18. 4.57. I9. 58. 6 .

yajñíyāsas. I9. II. $4^{*}, 5^{\dagger}$.

yajñiyāsas. II. I. I 2 .

yajñíyān. II. I. 4. I8. I. I8".

yajñíyāis. I 8. I. $59^{\dagger}$.

yajñíyānām. 4. 30. 2*. 6. 55. 3* 7 . $97.2^{*}$. I8. I. $58^{*}$. 19. 42.4 . (cf. ayajñiyá.)

[vâ).

yájvan: -vā. 20. I28. I (mss. yajyájvane. 4.21. 2*.

yájvanas. 4. 21.4 ".

yájvanām. 12. 3.6.

(cf. áyajvan.)

$\checkmark$ y at: yatete (p. -e íti). 7. 57. 2*. yatasva. 2. 6:4.

yátamāne (p. -e íti). I $8.3 .38^{*}$.

yátamānās. 12. 2. 24 *

(cf. yatana.)

+ ā: à yatantām. I7. 30 .

à̀yattās. Ir. 7.3.

(cf. āyátana.)

$+\mathrm{vi}$ : ví yetire. 18. I. I7.

ví yātayantām. 5. 29. 6-9.

y a t a in súyata.

y a t a n a in ãyátana.

y a t a má: -ás. 4. II. 5. 5.29.2, 4, 7-9. 6. 55. I. 8. 3. $8^{*}, 17^{*} ; 9.17$. I0. 2.8 .

yatamát. 5. 29. 5 .

yatamá. 12. 3. I.

yatamásyām. II. 2. I2, I4, 27.

yatamé. I I. I. 26, 32. I2. 3. 49.

yatamắs. II. I. I3.

yatamắn. II. I. IO.

y a tará: -át. 8. 4. 12*.

yatară. I0. 7.43 .

yáta s. I. I3. 2. 2.2.3. 3. 20. I* 4. 6.8 ; 3I. $5^{*}$. 5. 2. $1^{*}$. 6. $75.2,3$. 7. $26.6^{*} ; 56.3^{2} ; 76.5$. 8. $4.3^{\dagger}$. 9. I. 2 ro. I. 19,$28 ; 8.16,29$. I4. 2 . 10*. I9. 3. 4 ; I5. I".

yáti. 10. 3.6. 12. $2.24^{*}$. (cf. yatidhă.)

yatiodhà. 8. 9.7. 10. I. 20.

yát。kāma: -as. 6. 122.5. 10. 9.

27. II. I. 27.

yátkāmãs. 7. 79. 4; 80.3".

yátra. 1. $4.3^{*} ; 8.4 ; 25.1 .2 . r$. I, $5 ; 25.5$. 3. $13.7 ; 28 . \mathrm{r}^{2}, 6 ; 29.3$. 4. II. $8 ;$ I9. $2 ; 37.4^{3}$. 5. I7. 4,18 ; 19. 6,8 . 6. 98. 3 ; 1 24. 2 ; 142. 2.7 . 5. I"; I8.2. 8. $2.25 ; 3.5^{*}$. 9. 5.5 , 9 ; 9. $2^{*}, 3^{*}$. 10. I. 29 (yátra॰ya-); 7 $4,5^{2}, 6, \mathrm{IO}^{2}, \mathrm{II}^{2}, \mathrm{I} 2, \mathrm{I} 4, \mathrm{I} 5, \mathrm{I} 6,22^{2}, 24$, 26 ; 8. I6, 33, $34^{2}, 39 ; 9.5$; IO. I I7. I4. 2. $36^{*}$. I8. I. II"; 2. $55^{2 *}$, 57 ; 3. $9 ; 4.3$, IO, I5. I9. 3. I (yátra॰ya-); $39.8^{2}$; 43. I-8. 20. I 29. 7 . yátrā (p. -ra). 3. 28. 5, 6. 6. 22. 2 ; I20. 3. 9. 9. $22^{*}$. I8. I. $50^{*}$.

\section{(cf. yatrakăma.)}

\section{y atraoka ma: -am. 9. 3. 24.}

yáthā. I. $2.4 ; 3.9$; II. $6^{3} ;$ I6. 4 ; 22. 2 ; 29. $3^{*}, 5,6^{*} ; 34.5^{2}$. 2. 3.1 ; I5. I-6;28. 4,$5 ; 3$ O. $\mathrm{I}^{3}, 3,5 ; 3 \mathrm{I} .3$; 36. 4. 3. $2.6 ; 5.5 ; 6.3,6 ; 8.2 ; 9$. I ; II. $3^{*} ;$ I 5.2 ; I 7. $8^{2 *} ; 20.6^{*} ; 25$. 5. 4. I. $7 ; 4.3 ; 5.5^{*} ; 8.6 ; 13.4^{*}$; 23. $2^{2}$; 39. $1,3,5,7$. 5. $8.7,8$; 14. 4 ; 2I. $4,5,6^{2} ; 25.2$; 29. I, 2,3 . 6. 8 . I-3 3 ; 9. 2 ; I5. 3 ; I7. I-4; I8. $2^{2}$; 2 I. 2 ; 29. 3 ; 33. 2 ; 42. I, 3 ; 43. 3 ; 46. $3^{3^{*}} ; 58.2^{2} ; 64 . I^{*}, 3^{* \prime} ; 69.2 ; 70$. $\mathrm{I}^{4}, 2^{2}, 3^{4} ; 72 . \mathrm{I}, 2 ; 74.3 ; 8 \mathrm{I} .3 ; 85$. 3 ; 97. I ; IO2. I, 2 ; IO5. I-3; III. 2 , 4 ; 130. 3 ; 138. 5 ; $39.4,5$; 4 I. $3^{2}$. 7. I3. I; 37. I; 38. 2 ; 50. I, 5 ; 90. 3; 94. $\mathrm{I}^{\dagger}$; II $3 . \mathrm{I}, 2$. 8. 2. I3; 4. $2 \mathrm{I}^{*}$; 5. I9, $21 ; 7.7,19,22 ; 8.1,6, I_{4}, I_{5}$. 9. I. II-3, I6, I7, I9; 2. I $8^{2}$. IO. I. $5, \mathrm{I} 3,32$; 3. I3, I4, I5, I $7^{2}, \mathrm{I} 8, \mathrm{I9}$ $25^{2} ; 6.33$. I1. 4. I9;9. 23 . 12. 2 . $25^{3^{*}} ; 3.54 ; 4$. I4, I5, 34; 5. 64. I4. I. $18^{*}, 20^{*}, 43,50^{*} ; 2.75$. I5. II. $2^{3}$, 6, 8, I0. I6. 6. II. I7. 20, 2 I. I8. I. $18^{*}, 6 \mathrm{I} ; 2.38-45,50^{*} ; 3.2 \mathrm{I}^{*}, 5 \mathrm{O}^{*}$, $67^{*}, 70 ; 4.55^{2}$. 19. $2.5 ; 24.2,3 ; 26$. 3 ; 3 I. $9 ; 46.7 ; 49.7^{2}$ (not mss.), IO $^{2}$; 50. 4,$6 ; 57 \cdot \mathrm{I}^{3 *} \cdot$ 20. 48.2 ; I33. I-6; r36. $6,7,8$. 
yathā. 6. 14. 2, 3. 13. 2. $17^{*}, 18^{*}$. 20. I34. I (not mss.); 136. 4 .

(cf. yathān̄gá-yathāukasá.)

y a thāñ gá (p. -thāoañ-): -ám. 6. IOI. I.

y a thāonāmán: -má. 4. 38.7.

y a thā $\circ$ parú: 9.5.4. r8.4. 52 (mss. -purú).

y a thāobalá: -ám. 3. 20. 9. y a thā॰bhāgá: -ám. 7. Iog. 2. y a thā॰y a th á: -ám. I0. 8. 33; 9. 4 . y athāoloká: -ám. II. 9. 26.

y a thāovaçá: -ám. 3. 13.4. 7. 104. I. I 8. 3. $59^{*}$.

yathāosthāmán: -má. 7.67. I. y a thā ukasá (p. -thā॰ok-): -ám. I2. I. 45 .

yadä. 3. I3.6. 6. III. I, 3. 8. 7. 2I. 9. IO. I5*. II. 4. 5, I4, I6, I7; 8. II, I8. I2. $3.2 ; 4.29,30$. I4. 2. 20. I8. $2.4^{*}, 5^{*}$. 19. 34.8 (not mss.). 20. 136.2.

yadó (p. -ó íti). I $8.2 .5^{\dagger}$.

yádi. I. $16.4^{3} ; 25 \cdot 2^{3}, 3^{3}$. 2. $14 \cdot 5^{3}$. 3. II. $I^{*}, 2^{3 *}$. 4. 9. IO $^{2} ;$ I2. $7^{2} ; 27$. $6^{2}$. 5. 2. $4^{\dagger} ; 8.6 ;$ I4. $6^{2}, 7^{2} ;$ I6. III. 6. III. 2 II3. I, $3 ;$ II5. $2^{2}$; II6. $3^{2}$; IIg. 2 ; I24. $2^{2}$. 7. 38. $5^{2} ; 66 . \mathrm{I}^{4}$; 72. $\mathrm{I}^{2 *}$. 8. $4.14^{*}, 15^{2 *}$. 9. 8.8. ro. I. 24,$30 ; 3.6$. I2. $2.4^{2} ; 3.30 ; 4$. 53. . 13. $2.6,7 ; 4.45$. 14. 2. $59,60$. 18. 2. $7^{*}, 35^{\dagger}$. 20. I32. 10 .

yádĩ (p. -di). I 8. I. 2I*, 32*. [yant. y ant in astamyánt, āyant, samy a ntṛ: -tâ. 6. 8I. I.

$\checkmark$ yabh: yábha. 20. I36. II-3.

(cf. yabhya.)

y a bhya in áyabhya, súyabhya.

$\checkmark$ y a m, y ach: yachati. 19. 32.2. yachatas. 7. 54. I.

yachātha. I. 26. 3 .

yácha. I8. 2. I9*.

yacha. I. $21.2^{*}$. 2. 28.5 . 6. 59 . I. I2. 3. 14. I7. 12, 13. 19. 47. 10. yachatu. 5. 3. $8^{t}$. 6. 59.2. 7. I7. I. I0. $5 \cdot 37,40$. I9. 9. I2 $2^{2}$; I. I-II. yachatam. 8. 2. 7 .

yachatām. I9. I6.2. yachata. 5.3.7. 6.7.3. yachantu. 7. 49. $\mathrm{I}^{\dagger}$. 8. 7.25. Io. 5. 38, 39:41. 14. 2.73. I9. 9. $13^{2}$. yáchamānam. 20. 34. I 2 (mss. yája-). (cf. yata, yantŕ, yama, yāma.) $+\bar{a}$ : ầ... yacha. 6. $137 \cdot 3$. ā॰yáchantas. 6. 66. 2. à ... yamat. 6. 35.3 .

à yame. I8. 2. $3^{\dagger}$.

á yayāma. 9.3.3.

áoyatā. 6. 65. I.

ầyatām. II. 2. I.

à॰yatāyām. 6. 38. 4 .

+ u d ā: udoấyachatu. 5. 30. I5.

+ nir ā: nirấyachati. 20. 133. 3 (mss. nírāyachasi).

+ vyā : cf. vyāyāmá.

+ u d : úd yachadhvam. I4. I. 59. údoyatas. 4. 24.6. 8.8. I2. I2. 3. I8. úd。yatam. 20. I36. 5 (not mss.). údoyatāni. 5. II. 9. udoyátya. 8. 8. I2.

+ upa: úpa yacha. 12. 3. I9.

+ ni: ní yachāt. 7.6.4; 24. I; 4 I. 2 ; 47. I. 12. 3. 8. 9.3 I. 5 , I4. ní yachān. I8. 4. 40 (mss. -āt). ní yacha. 2. 26. 2. 3. 20.8. 7. II5. 3. II. I. 3, II. I9. 3I. I3. ní ... yacha. 9. 4.6.

ní yachatu. I. I. 3. 2. 26. I. Io. 3. 17-25. I9. 31.6, 8 .

ní yachatam. 4. 25.6. 7. 52. I. ní yachantu. I8. 3. II.

+ pra: prá yachāmi. 8. 8. 10. prá yachasi. 12. 5. 57 . pra॰yáchanti. I0. 7.39. prá... yáchanti. I8. 4. 29*. prá yachān. 12.3.38. prá yachet. I2. 4.47 . prá yacha. 12. 3. 31 . prá ... yacha. 3. 20. 2*. prá yachatu. 19. 64. I. prá ... yachatu. 3. 20. $3^{*}$. prá... yachatām. 6. 121. 3 . prá yachata. I8. 3. 43 . praoyáchantas. 6. 122. 2. prấ 'yachat. I. I6. 2. 2. I3. 2. 5 . I 7. $2^{*}$. IO. 2.15 . II. 5.15 . 
pră 'yachan. 6. I28. I. II. 8. 31. prá。yatas. 13. 2. 31 . prá。yatãm. 5. 20. 5 . práoyatāni. I8. 3. $44^{*}$. práoyatā. I8. 3.42"; $4.65^{*}$.

+ ā pra: āopráyacha. 7. 26.8. [45. + s a m p ra: samopráyacha. I0. 5 . + vi: ví ... yacha. I. 20. $3 ; 21.4^{*}$. ví yamas. $4 \cdot 3 \cdot 7^{2}$.

vi yaman. 7. $117 . \mathrm{I}^{\dagger}$. víoyatāu. I0. 8.18 . I3. 3. I4. ví ... yāmaya (p. yam-). 6. 137. 3 . + s a m: samoyámas. 4. 3. $7^{2}$. sám yamat. 6. 56. I. 10. 4. 8. sámoyatam. 6. 56. I. I0. 4. 8 . y a ma in suyáma.

y a má: -ás. 4. 34.4. 5. 24. 14 . 6. 46. I; 62.2; 84. 3; 93. I. 8. 10. 23. 9. 7. I, 20. I2. 3.8. I5. 14.7. I6. 4. 4. I8. I. $47^{*}, 50^{*}, 55^{*} ; 2.32,37$; 3. $41^{*}, 46^{*}, 52^{*}, 63,69 ; 4 \cdot 26,54$. 19. 20. I.

yáma. 18. I. 59*. [12*, $15^{*}, 18^{*}$. yama. I. 14.2. I8. I. $15^{*}, 60^{*} ; 2$. yamám. 4. 40.2. 9. 10. 28*. I 4. 2. 69. I8. I. $49^{*}, 54^{*} ; 2 . I^{*} ; 3.13,62$. yaména. 6. $32.2 ; 63.3$. I8. 2. I I", $2 \mathrm{I} ; 3.5^{*}$.

yamăya. 5. 30. 12. 6. 28. $3 ; 63.2$; 84. 3 ; I33. 3. I2. 3. 56 . I8. $2 . \mathrm{I}^{2 *}$, $2^{*}, 3^{*} ; 4 \cdot 55 \cdot 74$.

yamásya. 2. 12.7. 3. 29. I. 5. 5. 8; 30.6. 6. 29. 3 ; 46. 2 ; 96. $2^{*}$; II0. 2 ; II7. I ; II8. 2 . 7. 53. I. 8. I. $9 ; 7.28 ; 9.23$. I0. 5.12 I2. 2 . 54. 16. 5. I-6. I8. 1. $8^{*}$, 10*, $34^{*}, 53^{*}$; 2. $13^{*}, 27,56 ; 3.66^{*}, 70 ; 4.31,32$. 19. $56 . \mathrm{I} ; 57.3$.

yamé. 3. 10. 1. 4. 34. 3. I 8. 2. 6", 32. yamé (p. -é íti). I8. 3. $38^{*}$.

yamăs. 9. 9.16*. 10. 8. 5 .

(cf. mahāyamá, yāmá, yamadūtá-yamt.)

y a ma od ū tá: yámadūtās. 8. 8. I I. yamadūtấn. 8. 2. II. [2. 46 .

y a má $\circ$ rã ja n: -jñas. I2. 2. $8^{*}$. I 8. yamárājasu. I8. 2. 25 (s. mss. p. yama răj-). y a ma $\circ$ râjjya: -ye. 12. 3.1 ; 4. 36 . yamarâjieşu. I2. 3.3.

y a má • çreșțh a: -țhān. I I. 6. I I. y a m a sã daná (p. -maosad-) : -năt. I2. 5.64 .

y a mín: -íni. 3. 28. I, 5,6 . yamini. 3. 28. 4 .

y a m t: -1s. I8. 1. 10*.

yami. I8. 1. 13 (mss. yá-), 16".

yamíam. I8. 1. 8*.

y a mu uã in yāmuná.

y a yú: -ús. 4. 24. 2.

I yáva: -as. 8. 7.20. 9. I.22. II. 6. 15. 20. 127. 10 (s. mss. váyas). yava. 6. I42. I. yávam. 6. 30. I ; 9I. I ; I40. 2 ; 142. 2. yávena. 7. 50. $7^{*}$. yávasya. 2. 8.3. yáve. II. 4.113. yávās. 9. 6. 14 . yávān. 6. 50. I, 2. (cf. vrīhiyavá, yávasa.)

2 yá va: -as. 9. 2.133. (cf. yavayâvan.)

yavan a in āyávana.

y a va o yấva n: -vānas. 9. 2. 13.

yá va s a: -sā. I8. I. $22^{*}$. (cf. sūyávasa.)

yá viṣt ha: -as. 20. 135.8 (mss.). yaviștha. 5.29. 4. 8. 3. $8^{*}$. yávișțhās. I8. $4.6 \mathrm{I}^{\dagger}$. (cf. yavișțya.)

yavișthya: -țhia. I9. 64. 3 .

y áç a s: 3. 22. I. 6. 39. I; 69. I, 3 . 8. 4. $1 \mathrm{I}^{*}$. 9. 6.35 . I0. 3. $18,19.20$, $21^{2}, 22^{2}, 23,24 ; 8$. 9. I I. $5.25 ; 8.20$. I2. 5. 8. I3. $4.14,22$. I4. 2. 56 . I5. 2. $1-4^{2}$. I9. $37.1 ; 58.3$. 20. 132 . 15 (not mss.).

yáçasā. I0. 2. 33; 3. 17-25;6. 27. I2. 5. 2. I3. $4.49,56$. I9. $56.6 ; 58$. 3 (mss. -sām).

yáçobhis (p. -çahıbh-). 6. 39. 2. (cf. sváyaças, yaçás-yaçasvín.) y a çá s: -çās. 6. 39. $3^{4}$. I 3. I. $3^{3}$. yaçásam. 6. 39. $2 ; 58.1^{3}$. yaçáse. 3. 21.5 . yaçásas. 2. 6. 2. 6. 39. 2 ; 58.2. 20. 
48. 3 (not mss.).

yaçásotamas. 6. 39.3.

$\checkmark$ y a ça y in

y a ç a s y ú: -yávas. 4. II. 6.

y á ç a s v a n t: -vān. 6. 58. 2.

yáçasvati. I8. I. 20*.

yáçasvatīs. 6.58.2.

y a ça svín: -ínam. 6. 39.2.

yaçasvínas. I9. 56.6 .

$\checkmark$ y as: yayastu. 8. 4. $2^{*}$. (cf. $\sqrt{ }$ yeṣ.)

+ pra: praoyásyantī. I2. 5.31. prá。yastā. I2. 5.3I.

y ahvá: -ás. I8. 1. 18*. yahva. 5. 12. $3^{*}$. yahvầs. I3. 2. $46^{*}$.

$\checkmark \mathrm{y}$ à: yăsi. I 3. 2. 3 .

yāsi. I 3. I. $2 I^{\dagger}, 38$. I 9. 56. I.

yăti. I. 33.2*. 3. 21.3 . I3. I. 23.

yāti. 10. 8. 18. 13. 2. $24^{*} ; 3.13,14$.

20. I3I. 3.

yằnti. I9. 43. I-8.

yāhi. 2. 34. 5. 5. 20. 12. 6. 92. I. I8. I. $9^{*} ; 4.2,3$. 19. 66 . I.

yātiăs. I4. I. 12*.

yātấm. I8. I. 33".

áyāt. 14. 1. 6*, 10*.

áyātam. 14. I. $14^{*}, 15^{*}$.

yayătha. I8. I. $43^{*}$.

yayús. I8. 2. 16*".

yāsyán. I3.2. 28.

yătave. 12. 1. 47. 13. 2.8.

yātám. 3. 8.6. 10. 8.8.

(cf. yā, yāta, yātṛ, yāna, yắma, yăman, yāvan?.)

+ a ti: áti yãhi. 13. 2. 5 .

+ a pa: ápa yāhi. 19. 56. 6.

ápa yāta. 6. 73.3.

+ a pi: ápi yāmi. 4.37.7 (ed. dyāmi).

+ av a: cf. avayātŕ, avayăna, ánāvayā (?); and avayăj.

+ abhi: abhioyăti. 4. 29. 7.

abhí yāhi. IO. I. I5.

abhí yātu. 6. 40. 2.

abhí yātam. II. 2. I.

abhíoyātas. II. 2. I3.

$+\bar{a}$ : ầ yāti. 6. 60. I.

[26. I2.

à yāhi. 2. 5. 1. 5. 8.2; II. 8 ; 12. $3^{*}$; à... yāhí. 7. II 7. I* (mss. -hi'). â... yāhi. I8. $3 \cdot 47^{*}, 48^{*}$.

à yātu. 3. 8. I.

à...y yātu. 6. 73. $\mathrm{I}^{2}$.

à yātam. 5.26. I 2 .

à yāta. I. 15. 2. 18. 4. 62,63 (p. ayāta).

à ... yāta. I8. 3. I4.

$+\mathbf{u}$ : : cf. udyắna.

+ up a: úpa yāmi. 8. 3. I*. I3. 2. 37.

I9. 3. 4 .

upa॰yăsi. I8. I. 22*.

úpa yāti. 4. 34. 3.

úpa yāhi. 7. 73. $9^{*} ; 97 . \mathrm{I}^{*}$. 12.3 .

I9, 53. I8. 4. 8 .

úpa yātu. 7. 58. It. I8. 2. Iot.

$+\mathrm{n}$ i: cf. niyầna.

+ parā: párā yāta. 18. 3. 14; 4. 63 .

+ pa ri: parioyấsi. I3. 2. 6 .

pári yātas. 7.8I. I*. I3. $2 . \mathrm{II}^{*}$.

pári yāhi. 8. 3. $3^{*}$.

parioyăntam. I3. 2. 4,5 .

+ pra: prá yāhi. 7.72. $2^{*}$.

prá yātu. 6. 35. r.

prá... yayús. I8. I. 6r.

(cf. prayăna.)

+ anus a mpra: anuosampráyāhi.

I I. I. 36 .

+ vi: ví yāti. 3. 3I. $5^{\dagger}$.

+ up a s a m: upaosámyāta. 6. 73. I.

y ă in ánāvayā.

$\checkmark$ y āc: yấcāmi. 5.7.5.

yãcāmi. I. 5. $4^{*}$. 15. 13. 8 .

yắcati. 9. 6. 4, 48 .

yācanti. I2. 4. 26.

yắceyus. I2. 4. 22, 48 .

yắcadobhyas. I2. 4. I, 2, I2.

yắcamānas. 6. II8. 3; II9.3.

yăcamānasya. 7. 57. I.

áyācan. I2. 4. 20, 24.

yắcitum. I2. 4. 3I.

yācitás. I2. 4. 48, 50.

yācităm. 12. 4. I3, I9, 25, 36 .

yācáyate. 12. 4. 38 .

(cf. yācñyá.)

+ nis: niroyăcan. 6. 133.3.

yã c ñ yá: -yấya. I2. 4. 30.

y $\mathbf{a} j$ in avayáj. 
y āj a in anuyājá, prayājá, çatayăja. yàt. I2. I. 57 .

y āt a in áyāta.

y ātú: -távas. 2. 24. 1-8. I0. 7.18. I3. 4. 27.

yãtún. 4.9.9.

yātūnăm. 5. 29. 8, 9. 8. 4. $2 \mathrm{I}^{*}$.

(cf. áyātu, úlūkayātu, kókayātu, ĝ̛̣dhrayãtu, çuçulúkayātu, çáyātu, suparnáyātu, yātucătana-yātuhán.)

yātuocătana: -am. I. I6. 2.

ya t uojám bhan a: -am. 4. 9. 3.

y a tuod hấna: -as. 4. 28.6. 8. 3. $8^{*}, \mathrm{II}^{*}, 14^{*}, 15^{*}, 17^{*} ; 4.15^{*}$.

yấtudhāna. 8. 4. $15^{*}, 16^{*}$.

yătudhănam. " I. 7. 1. 4. 3.4; 20. 8. 8. $3.5^{\dagger} ; 4.24^{*}$.

yātudhănasya. I. 8. 3. 8. 3. $4^{*}, 10 *$ yătudhănās. I. 7. 3. 7. 70.2. 8. 3. $9^{*}, 16^{*}$. 19. 46.2.

yātudhānās. 6. 32.2.

yătudhănān. I. $7.2,5,6,7 ; 8.1$; 28. 1, 2. 4. 18.8; 20.6. 5. 14. 2 ; 29. II $I^{*}$ 8. $3 \cdot 2^{*}, 3^{*}, 6^{*}, 7^{*}, 12^{*}, 13^{*}, 21^{\dagger}$.

yātudhắnebhyas. 6. 13.3.

yātudhānís. I. 28.4.

yātudhānías. I. $28.2,4 . \quad 2.14 \cdot 3$. 4. 9.9 ; 20.6. I9. 36.2 ; $39.1,5,8$; 47. 7 .

yātudhānís (pl.). 4. 18. 7 .

(cf. Yātudhānakṣáyaṇa.) [32. I. y ātudhāna okṣáy.ạ̣a: -am. 6. ya tu o mánt: -mắn. I. 7. 4 .

yātumádobhias. 8. 4. $20^{*}, 25^{*}$.

y ātuomatvant: -vat. 8. 4. $23^{\dagger}$.

yāt uoh án: -hă. I. I6. I.

y $\mathbf{a}$ tr in avayātŕ.

yần a: -nān. 5. 12. 2*.

(cf. ajayắna, avayấna, udyắna,

devayăna, niyăna, pitruyăna, pūryăna, prayāṇa, rathayắna.) y ãm a in vyāyāmá.

y ã má: -ám. 6. I16. I.

yằm a: -am. I0. 2. 6 .

yămeșu. 6. 2 I. 2.

y àm an : -ni. r 8. 3. $67^{*}$.

yấman. 4. 23. 3 (yấman॰yā-). (cf. çatáyãman, suyāman.) y ā mi n in áyāmin, súyāmin. yām uná: -ám. 4. 9. 10. y $\mathbf{a} \mathbf{v}$ in áprayãva.

yãvachreșţhá (p. -vatoçre-): -țhăbhis. 7. $3 \mathrm{I}$. $\mathrm{I}^{\dagger}$.

yãvatosábandhu: 18.4 . 37. yā

yãvan in yavayâtran.

yā $\mathbf{v}$ a in çapathayăvana.

yăv a n t: -vān. 4. II. 8.

yẫvat. 3. $15.3^{*} ; 22.4,5^{2}$. 4.6. 2. 5. $19.4 ; 22.5$. 6. $72.2,3 ; 75.3 .8$. 9. 6. 9. $2.20^{2} ; 6.40-3$. I0. I0. 34 . II. 3. 25. I 2. I. $33 ; 4.27$.

yăvantāu. I2. 3. I.

yăvantas. 6. I16.3. 7. I3.2. I2. 3. $36,40,50$. I4. 2. 49. I9. 58.6 .

yăvatas. 13. 2. 42 .

yăvatī (p. -ííti). 4. 6.2. 9. 2. 20. yăvatīs. 8. 7. I3. 9.2. $2 \mathrm{I}^{2}, 22^{2}$. I4 2. 49,5 I.

yăvatīnām. 8. $7 \cdot 25^{2}$.

yâvatișu. 8. 7.26.

[na.)

(ef. yãvachreșțhá-yāvadañgíy ā çu in ayāçú.

y u (pron. root): yuvám. I. 20.2. 3 .

I. 3 ; I I. $6.4 .25 .3 .7 .42 .2^{\text {" }} ; 52$. I. 8. $4.5^{*}$. I $4.1 .31 ; 2.42$.

yuvós. 7. 58. I*.

yūyám. 1. 26. 3; 30. 1. 3. 1. 2; 16. $7^{*}$. 4. $21.6^{*} ; 27.6 ; 37.12 .5 .21$. II. 6. II4. I; II5.I. II. I. I $2 ; 9$. 2, 26. I3. I. 3. I8. 4. I0, $86^{2}$. I 9. II. $5^{*} ; 40.2$.

yuṣmắn. I 8.4. 86. 20. I 35. IO (mss.). yuṣmăkam. 8. 9. 22.

yuṣmé. 20. 135. 10 (mss. -mănà).

V I y u: yāumi. 2. 2. I.

yutām. II. IO. I6.

yutăs. I3. 4. 6.

yćyuvat. I9. 47.2.

(cf. yavana, yāva, yuta, yóni.)

$+\overline{\mathbf{a}}$ : à yavan. 3.17. $6^{+}$.

(cf. āyávana.)

$+\mathrm{u}$ d: údoyutam. 6. III. 2.

+ pra: ef. áprayāva.

$\left[4^{*}\right.$.

+ s a m: sámosam ... yuvase. 6.63. 
sámoyutam. 6. 30. I.

$\checkmark 2$ y u: yuyoma. 7.68. 3.

yuyotu. 7. 92. I*.

áyuvanta. 4. 23.5.

yūșam. 6. 123. 4 .

yāvayās (p. yav-). 7.65. I.

yāváya (do.). 6. 4. 3 .

[I. 50.

yāvaya (do.). I. 2.3. 5. 22. 6. 12. yāvayā (p. yavaya). I. 20. $3^{2} ; 21$. $4^{\dagger}$. 4. 19.7. I2. I. 32 .

yāvayatam (p. yav-). 1. 20. 2.

yāvayantu (do.). 9. 2. 13.

yāvayat (do.). 6. 4. 2. [vana.)

(cf. yayú (?), 2 yáva, yāvan, yā-

+ ví: ví yūyās. 8. 4. $5^{*}$.

ví yãuștam. I4. I. 22*.

ví yāụsța. 3. 30. 5 .

ví yoșatas. 9.5.27.

y ukta in

yuktá。grāvan: -vā. 9. 6.27.

y ukti in sváyukti.

y u gá: -ásya. I4. I. 40, 4I*.

yugé (p. -é íti). 8. 2. 21 .

yugăni. I8. I. I I*

yugă. 3. I7. I*, 2*.

(cf. Ișāyugá, udyugá.)

$\checkmark$ y u ch: + pra: cf. áprayuchant. $\checkmark$ y uj : yunájmi. 4. 22. 5. 7. 78.2. I9. 25. I.

[2. 56.

yunajmi. 3.30.6. I0. 5. I-5. I8.

yunakti. 3. 3 I. $5^{\dagger}$.

yuñjanti. 3. 17. $1^{*}$. 9. 9. $2^{*}$. 20. 128. I6 (mss. -ánti).

yuñte. I8. 1. 6*.

yuñdhi. I I. I. 9 .

yunáktu. 5.26. 2.

yunaktu. 5. 26. I, 3, 7, 8, $9^{2}$, I0, I I.

yunákta. 3.17. 2*.

yuñjántu. 3. 3. I. 6. 92. I.

yujé. 6. 54. I. 18. 3. $39^{*}$.

yukșvā (p. -va). I8. I. $25^{*}$.

yuyója. 6. I33. I.

yuyukșé. 8. 9. 7 .

áyukta. I3. 2. $24^{*}$.

ayukta. I3. 2.8 .

yokșye (l. -șie). I 9. I 3. I (rnss. -șe). yuktvâ. 6. 37. I (l. -tuâ). 20. 128 I6 (not mss.). yuktás. 5. I7. $15 ; 29.1$. 9. 7. 24. I3. 3. I9.

yuktám. 8. 9.7. I8. I. 15*.

yuktấ. 9. 9. $9^{*}$.

yuktăs. 5. 26. 4, 5. 9. 9. $14^{*}, 19^{*}$. I0. $5.6 ; 8.8$. I 8.4 . I.

yujyáte. 8. 9.3. 10. 8. $10^{2}$.

yujyate. 10. 2. 3 .

yujyánte. 12. 1. 38 .

yujyátām. I4. I. 64. [I. 39†.

yujyámānas. 6. 92. 1. 9. 7. 24. 18.

(cf. yukta, yukti, yugá, yúj, yújya, yóktra, yóga, yógya, yójana.)

+ abhi: cf. abhiyúj.

$+\overline{\mathbf{a}}:$ cf. āyúj.

+ ud: udoyujé. 7. 70. 2.

(cf. udyugá.)

+ u p a : úpaoyuktam. 4. 23. 3.

+ ni: ní yuñdhi. 8. 3. IIt.

ní yujyatām. 2. 12. 2.

(cf. niyójana.)

+ pra: prá yunakși. 19. 56. I. (cf. prayúj.)

[13.

+ anupra: anuopráyuñkșe. II. 2. anuopráyuñtām. I2. I. 40.

+ vi: vi॰yunákti. 8. 9. 3 .

(cf. viyúj.)

yúj: yưjâ. 4. 23. $5 ; 31.4^{*} ; 32.1^{*}$, $3^{*}$ 5. 21. 11 . 7.50. $4^{*}$. I3. I. 3.

yujé. 6. 54. I, 2.

yújas. 6. 33. I. II. 8. 25.

(cf. abhiyúj, açvayúj, āyúj, prayúj, manoyúj, viyúj, sayúj, suyứj, svayúj.)

y új y a: -jias. 5. II. 9, Io. 6. 5I. I. 7. 26. $6^{*}$.

y ut a in áyuta, ayúta.

$\checkmark \mathrm{y} \mathrm{ud} \mathrm{h}$ : yúdhyante. I2. I. 4 I (mss. ed. yudhyá-). I8. 2. $17^{*}$.

yutsmahi. 7. 52. 2.

yuddhâya. $4 \cdot 31.4^{\dagger}$.

yúyutsati. I I. Io. 26.

(cf. yúdh, yudha, yudhi, yudhénya, yodha, yodhya.)

+ abhi: abhí yodhīs. 5. 2. $3^{*}$.

$+\bar{a}$ : cf. áyudha.

+ u d: úd yodhanti. I2. 3. 29 . 
yú dh : -dham. 6. 66. I; 103.3. yudhă. I. 24. I. I0. 6.16 . yudhé. 4. 24. 7.

yúdhas. I0. 10. 24. 19. 13. $3^{*}, 4^{*}$. yudhām. 7.81. 3 .

yutosú. 19. 13. 7".

y udha in ayudha.

y u dhi in

[-íng-).

y u d h i ṁ g a má : -ás. 20. I28. 1 I (mss. (cf. áyudhirngama.)

y u d hé n y a : -niāni. 5. 2. $5^{*}$.

vyup: yuyopimá. 6. 5 I. $3^{*}$.

yupitám. 4.25. 2.

yopáyantas. 12. 2. $30^{*}$.

(cf. yūpa ?, yopana.)

yuvatí: -ís. r9. 49 . I, 8 (mss. -ím). yuvatím. r8. 3. 3 .

yuvati (p. -i íti). ro. $7.6,42$.

yuvatáyas. I4. 2. 29,61 .

[1.

yúvan: -vā. 6. 2.3. 10. 4. I5. I3. 1. yúvānam. 6. I. 2. 7. 2. I; 32. I*. 9. 4. 24 ; 10. $9^{*}$. 10. 8. 44. I1. 5. I8.

(cf. yāúvana, yuvatí, yávișțha.) y us mát $\mathbf{k} \mathbf{a}$, see yu pron. y $\overline{\mathrm{u}} \mathrm{t} \mathbf{i}$ in gávyūti(?).

yūthá: -thé. 5.20.3. 9. 9. 17*". yūthă. 18. 3. $23^{*}$.

y túpa: -as. 12. I. 38 . yúpe. 9. 6. 22.

yựān. 13. 1. 47.

y évāṣa: -as. 5. 23.8.

yévāșāsas. 5. 23.7.

$\checkmark$ yeș: yéșantam. 4.7.4.

y6ktra: -am. 7. 78. I.

yóktre. 3. 30. 6.

yóktrănịi. 14. 2. 16 .

yó g a: -am. I9. 8. $2^{3}$.

yógāya. 10. 5. 1-6.

yóge. 19. 13. I ; 24. $7^{*}$ (yóge-yoge). (cf. apsuyogá, așțāyogá, indrayogá, kşatrayogá, brahmayogá, șaḍyogá, somayogá.)

yó g y a : -giam. 8. 9. 7 .

y ój a n a: -nāni. 4. 26. I.

yójaneșu. 9. 9. 9".

(cf. triyojaná, niyójana, pañcayojaná.)

yodha in mithoyodhá. yodh in: -nas. 19. 20. 3 (not mss.) yodhy a in ayodhyá.

y $6 \mathrm{ni}$ : -is. 3. 20. $1^{*}$. 4. 30. $7^{*}$. 9. 10. 12*. 13. 1. 17.15 .15 .7$.

yónim. I. II. $3,5 . \quad 3.23 .2,5.4$. I. I. 5. I. I, $2 ; 25.5^{*}, 9.6$ 6. 8 1. 2 . 7. 97.5 . 8. 9. 2,12 . 10.5 .23 . 12. 2. $3 I^{*}$. I3. 2.25 . I8. 4. $28^{2 *}$.

yónes. 5. 25.1. 7. 35. 3. I 4. 2. 43 . yónyās. 6. 121. 4.

yónāu. 2. 1. 5. 3. 17. $2^{*}$. 5. 12.6". II. 5. 7. 14. I. 19*. 18. 1. $8^{*} ; 3.66^{*}$. I9. 56. I. 20. 34 . 12 (not mss.).

yónā. 9. 10. 10".

yóniām. 5. 25. 8.

yónişu. 13. 1. 19.

(cf. aștáyoni, ghṛtayoni, tvádyoni, çatáyoni, sáyoni.)

yopana in janayópana, jivitayópana, padayópana, çapathayópana.

yóṣạ̣ã: 18. 1. 19*.

yóṣaṇe (p. -e íti). 5. 12. 6*. (cf. yóșā, yoṣít.)

y 6 șā: 12. 3. 29. I4. I. 56 . I8. I. 4*. 19. 49. I.

yóșām. 14. 2.37.

yóșās. I $8.4 .60^{\dagger}$.

yoșit: -tam. 6. Ior. I.

yoșítas. I. 17. I. 6. 122. 5. II. I. $14,17,27$.
[11. 6*. yós. I. 6. I*. 18. I. $51^{*}$. 19. 10. $I^{*}$; y āúvana: -ne. I8. 4.50 (mss. yāú váne).

$\sqrt{ } \mathbf{r} \mathbf{a} h$ in rańhas, ránhi, raghu, laghú, lághīyas.

$\mathbf{r a n h}$ a s in vâtarañhas.

ránh h : -hayas. I8. 2. 9.

Vrakṣ: rakșasi. I9. 30. 3 .

rakșati. 8. 9. I3. IO. IO. II. II. 5. 8, I0, 22. I2. 1. I 8 .

rákṣathas. 4. $25 . \mathrm{I}$.

rakșathas. 4. 25.3. [48.5.

rákșanti. I0. 7.23. I2. I. 7. I9.

rakșanti. 5. 27.7. I3. I. 23.

rakșase. 17.16. 
rákșa. 6. I07. I-4. 8. 6. 25 . rákșā (p. -șa). I9. 47.6 (ed. rakșâ). rakșa. $4.38 .6,7.8 .3 \cdot 9^{*}$. 20. I36. II. rakșā (p. -șa). 8. 3. $19^{*}$.

rákșatu. 8. I. II, I $2^{2}$.

rakșatu. 8. I. II, I2; 5. I6, 22 . I2. 3. $24^{2}$. I8. 3. 62. I9. I6. 2 ; I 7. I-5, 7-IO; 27. 2 ; 34. I; 35. 2.

rakșatām. 8. I. I2, $13^{3} ; 2.15 ; 6.20$. 9. 3. I9. I0. I. 2 I. I9. 16. 2 .

rákșata. I. 30. I.

rakșata. II. IO. I5.

rákșantu. 8. I. II.

rakșantu. 5. 28. ro. 8. I. I4. 9. 5. 38. I4. 2. 7. I6. 16. $2^{2} ;$ I 7.6; 27. 3,9 . rákșan. 4. 38. 5. I9. 46.2 (mss.).

rákșantas. 8. 2. I0.

rákșamāṇās. 3. 30. 7. I8. 4. 70. rakșīs ( $\sqrt{ } 2$ rakṣ ?). 5.7 .1 .

rakṣitás. I4. I. $5^{*}$

(cf. rakși, rakșiț́, rákșas ?.)

+ a bhi : abhí rakșati. I0. 2. 27.

abhí rakssatas. Io. 6 . I2.

abhiorákșatha. I0. 7.23.

abhí rakṣāti. 3. I2. 8 .

abhí rakșa. 4. Ig. 8 . I2. 3. II. abhí rakșatu. 3. I7. $4^{\dagger}$. 4. IO. 7. 6. 79. I. 10. 3. 13-5. I9. 46. 1-7. [33. abhí rakșantu. 5.3. $4^{\dagger}$. 8. I. 7. I I. I. abhí rakșatām. 2. 4. 5 .

abhí rakșatāt. 2. I3. I.

+ pari: pári rakșata. 8. 2. 20.

+ prati : práti rakșanti. I0. 8. 36 .

+ vi : ví rakșati. Io. 6 . I8. II. 5 . I7. I3. 2. 4I.

rákșas: I. $21.3^{*}$. 4. I 7. $5 ; 37.2$. 7. 70. 2. 8. 2. $12 ; 3.10^{*}, 13^{*} ; 4 . I^{*}$, $4^{*}, 13^{*}, 22^{*}, 23^{*}$. 9. 4. I 7. II. I. 2 I, 32. I2. I. 49 ; 3. I $4,15,43$. I3. 4 . 25. I4. I. 59. I9. 36. 2 .

rákșasas. 2. 9. I. 6. III. 3 .

rákșānsi. I. 35. 2. 2. 4. 4. 4. Io. $2 ; 25.4 ; 37 . \mathrm{I}$ 5. 29. II". 6. 32. I ; $34.2^{*} ; 52.1 ; 8$ I. 1. 8.3. $9^{*}, 26^{*} ;$ 6. I3; 7. I4. 9. 7. I7. I1.6. I6; 9. I6 I2. I. 50. I 4. 2. 24,4 I. I 9. $34.9 ; 36$. I, 4,5 . rákșānsi (voc.). I I. IO. I. [4. 25*. rákșobhyas (p. -șaḥobh-). 8. 3. $24^{\dagger}$; (cf. rakșás, rakșasvín, rakșohán, rākșasá.)

rakṣás: -ṣấs. 8. 4. I6*. 19.47 .6 (not mss.).

rakșásas. 4. I9. 3. I4. 2.7.

rakșásas (pl.). 2. 3.6. 8. 3. $23^{*} ; 4$. $7^{*}, 17^{*}, 18^{*}, 19^{*}, 2 \mathrm{x}^{*} ; 5.8$.

rakșásām. 2. 3. 6 .

rakșa s vín: -ínīs. 6. 2.2. 7. 114. 2. r a kși in pathirákși.

r akșitứ: -tă. 3. 27. I-6. I4. I. $4^{*}$. I9. $15.3 ; 34$. I.

rakșitré. I2. 3. 55-6o.

rakșitărāu. I8. 2. I2*.

rakșitṛ́obhyas. 3. 27. I-6.

rakṣohán (p. -ṣaḥoh-): -hắ. I. 28. I. 8. 2. 28 . I9. I3. $8^{*} ; 33.4 ; 44.7$. i akșoháṇam (p. -șaḥ̆ohán-). 4. 23. 3. 8. 3. $I^{*}$.

ragháț: -țas. 8. 7. 24 .

ra g h u : cf. raghuṣyád, laghú.

r a gh us y á d (p. -uosy-): -das. 3. 7. I. raghușyádas (pl.). I3. 3. I6.

$\checkmark \mathbf{r a j}$ : arajyata. I5. 8. I.

rajaya. I. 23. I.

(cf. rajatá, rajani, rájas ?.)

+ u d: út ... rărajîti. 6. 7I. 2.

r aj a tá: -ám. I3. 4. 5 I.

rajaté. 5. 28. I.

(cf. rajatánābhi, rajatapātrá.)

rajatá n a b hi: -is. 8. Io. 28.

raja ta०pātrá: -ám. 8. 10. 23.

raja ni : -ni. I. 23. I.

ráj a s: 4. I. 4 ; 25.2. 6. 33. I. 8. 2. I. I0. I. 32 ; 3. 9. I2. I. 57 . I3. 2. $22^{*}$; 4. 5 I. I9. $47 . \mathrm{I}$.

rájasā. 9. 9. 14 *.

rájasas. 4. 2.3. 5. II. 5,6 . 6. 34 . 5*. 8. 2. 9. 9. 3. 15 ; 9. 19*. 10. 8. $3^{\dagger}, 40^{\dagger}$. I3. 2. 8. I9. 10. $5^{*}$. [1. $46^{*}$. rájasi. I2. I. 6. I3. I. II; 2. 43. I8. rájāñsi. 7. 25. I; 26. I*; 4I. I. 9. 9. $7^{*}$. 12. I. 5 I. I3. I. 7 ; 2. $28 ; 3.2$ I. (cf. rajasá.)

raja s á: -ám. 8. 2. Io.

rajasấs. II. 2. 25 .

raj í: -ím. 20. I28. I3 (mss. ravih)).

rájj u : -us. 4.3.2. I9. 47.8. 
rájjuā. 3. Ir. 8 (mss. rájvā). rájjvām. 6. 12I. 2 (mss. rájvām). rájjuni. 20. 133.3 (not $\mathrm{mss}$.).

(cf. ádhirajju, pūtirajjú.)

rá ṇ a : -ṇāya. I. 5. I*. 2. 4. I ; 5.4. ráneorạ̣e. $5 \cdot 2.4^{\dagger}$.

ráneşu. 5.2. $5^{*}$.

$r$ a n $i$ in árani (?).

rán y a: -ṇiām. I2. I. 43 .

r a ̣ny y à -ṇíâya. 9.3.6.

r a ṇvá: -ás. I 8. I. 22*.

[2. 53 .

rátna: -am. 5. 1. 7. 7. 14. 4. 18. rátnā. 7. 29. I. I 8. I. 26*. [ya.)

(cf. surátna, ratnadhă, ratnadhé-

ratnaodhấ: -ấm. 7. 14. I.

ratna odhé ya: -yãya. 6. I 40.2.

rátha: -as. 4. 12.6; 29.7. 5. 14. 5, I3. 7. $58 . \mathrm{I}^{*}$. 8. 8.23. ro. $4 \cdot \mathrm{I}^{3}$. ratha. $6.125 \cdot 3^{*}$.

rátham. 3. 16. 6*. 6. 37. I ; 125. 2* 8. I. 6. 9. 9. $2^{*}, 3^{*}$. II. 2. I8. I3. 1. 24 ; 2.7 I 8 . I. $25^{*}$. I 9. I3. $5^{*}$. ráthena. I4. I. $20^{*}$. I9. I3. $8^{*}$.

ráthāya. 13. 2.6.

ráthasya. 4. I2. 7. I0. I. $8 ; 4$. 2. I2. I. 47. I3. 2. $24^{*}$. I4. I. $4 I^{*}$. 20. I27. 2. ráthe. 4. 10.6. 6. 38.3. I0. 3. 20. I3. I. $2 \mathrm{I}^{*} ; 2.8,23^{*}$.

[thyâ).

ráthãs. 3. 9.5. 20. I3I. 6 (mss. raráthān. 5. 13.6.

ráthāis. 7. 50.3".

ráthānām. 7. 85. I*.

(cf. arathá, citráratha, devarathá, sarátha, rathakārá--ráthya.) rath a okārá: -răs. 3. 5.6. rathaokritá: -ám. II. 6. 23. rathaojít: -tām. 6. I30. I.

(cf. rāthajiteyá.)

ráthaojūti: -im. r9. 44. 3 . rat h a mot a rá:-ám. 8. I0. I3, I6. Ir. 3. I6. I 3. 3. II, I2. I 5. 2.1 ; 3. 5 ; 4. I I $^{2}$ rathamiaréna. 8. Io. 14. rathamitarâya. I5. 2. I. rathamiarásya. I5. 2. I. rathamiaré. 9. 10. $3^{*}$.

ratha०mukhá: -ám. 8. 8.23. ratha y ắna: -ne. 4. 34. 4 . ratharví: -viás. ro. 4.5 . rathaovăhana: -am. 3. 17.3.

rathin: -nas. 6. 126.3 ". II. IO. 24. ratht (or rathín): -1. 4. 34.4. 7.62. I; 73. I.

[8. 23.

rat hopasthá (p. -thaoup-): -ás. 8 .

ráthy a: -thiā. I 8. I. $8^{*}, 9^{*}$.

$\sqrt{ } \mathbf{r}$ d: radantām. II. IO. 8.

rádantam. 20. I36. I6 (mss. ród-). radité. I I. 9. 7-I I, I3, I4, 25.

$\checkmark \mathbf{r a d} \mathbf{h}$, see randh.

$\checkmark \mathbf{r}$ a : rạáyantu. 4.21. $1^{*}$.

(cf. rána, ráṇya, rạ̣yà, rạ̣vá, ránti ?, rántya.)

ránti: -is. 3. Io. 6 .

ránty a: -tiam. 6. 33. I. [24* $\sqrt{ } \mathbf{a n d h}, \mathbf{r} \mathbf{d} \mathbf{h}$ : radham. I7. 6 , radhāma. $5 \cdot 3 \cdot 7^{*}$.

rádhyatu. 17.6.

randhayāmi. I 9. 66. I.

randháyāsi. 6.7.2.

randhayāsi. 6. 6. I ; 54.3. [I4. randhaya. $4 \cdot 22$. I, 2. 8. 3. $8^{*}$. I2. I. randhayantu. 7. I09. 3 .

randháyan. I7. 24 .

arandhayat. Io. 4. I0, I6, I7.

1'r a p: rapāmi. I8. I. I2*.

rapema. I8. I. $4^{*}$.

rápat. I8. I. I9*.

(cf. Vlap, rāpin.)

+ pari: cf. parirāpín. [3*;9I. I, $2^{*}$.

rápas: 4. 1 3. $2^{*}, 3^{*}$. 5. 4. 10. 6. 57. (cf. arapás.)

$\checkmark$ r a p ç: cf. rapçin. -çate).

+ vi: ví rapçante. 20. I 28. 5 (mss. (cf. virapçín.)

$\mathbf{r}$ a $\mathbf{p}$ in in virapçín.

Vrabh: rabhasva. II. I. I4.

(cf. $\sqrt{ }$ labh, rabhi ?, rambhạ̣a.)

+ a n u: ánu... rabhasva. 9. 5. 2.

$+\bar{a}$ : à rabhe. 4. 20.6. 6. $48 . \mathrm{I}-3$; 76. 2. I9. 5 I. 2 .

à rabhāmahe. 4. I7. I. 5. 8.9.

à ... rabhāmahe. 8. 1. 8 .

a rabhasva. 1. 7.6. 8. $2.1 ; 3.8^{*}$.

9. 5. I. I0. 3. I, 2. I8. 3. 7 I.

à ... rabhasva. 8. 3. 2 .

à rabhatām. I. 7. 4 .

ầ rabhethām. I I. 9. 3. I 2. 3. 7 . 
à rabhadhvam. 2. I2. 5. 6. 62.2, 3. 12. 2. 28 .

ă rabhantām. I 8. 4. I 2. āorábhamānāa. 4. 30. $8^{*}$. à rabhathăs. 8. 2. 7 . àorebhé. I. 28.3 . āorebhăthe (p. -e íty etc.). 4. 28. 4 . āorebhāṇăn. 8. 3. $7^{\dagger}$. ăorabdhas. 5.18.4. àorabdhān. 8. 3. $7^{\dagger}$.

(cf. $\overline{\mathbf{a}}+\sqrt{ } \mathrm{labh}$, anārambhaṇá.)

+ a nvā: anuoărabhethām. I2. 3. 20. 6. I 22.3 (l. anvâ-). I2. 3.47 (do.). anvărabhadhvam (p. anuoăr-). I 2. 2. $47,4^{8}$.

+ s a m: sám rabhasva. 2. 6. 4. I9. 3. 2 (s. mss. bharasva). $\left[26^{*}\right.$. sám rabhadhvam. 6. 97. 3*. I2. 2. sám rabhantām. I I. IO. 8 .

sámiorabdham. I3. I. 4 . samorábhya. Ig. I. 3 .

[122.3.

+ a n u s a m: anuosámrabhethām. 6 . rab hi in surabhí.

$\checkmark$ ram: ramase. 3. I8. $3^{\dagger}$. 5.22.9. ramate. I0. $7 \cdot 37$.

ramatām. 7. 12. 4

rámadhvam. 7.60. I.

rámantām. 7. I 15.4.

ramantām. 7. III. I. 8. I. I.

aramsata. I. $17 \cdot 3$.

ramisthās. I4. 2. I9.

(cf. ránti ?, ramáti, rámati, rătrī ?.)

+ ni: ní ... ramadhvam. 5. I2. 5 .

ní ... aramsata. I4. 2. $5^{\dagger}$.

ní ramaya. I. I. 2 (s. mss. rām-).

ramáti: -is. 6. 73.2, 3 .

rámati : -tayas. 7.75.2.

$\mathbf{r} \mathbf{~ m ~ b h}$ a ṇ a in anārambhaṇá.

rayí: -ís. I. I5.2. I9. 3I. I2.

rayím. 2. 6. 5. 3. 5.2 ; I 2. 5; 20. $\mathrm{I}^{\dagger}, 3^{\dagger}, 5^{\dagger}, 8 . \quad 4.2$ I. $2^{*} ; 25.5 ; 33 . \mathrm{I}^{*} ;$ 39. $2,4,6,8$. 6. 33.3 ; 54. 2 ; 65. I. 7. 17. I; 20. 3,$4 ; 47.1 ; 76.6^{*} ; 79$. I $80.2 ; 82.3 .9 .4 .2$ I. II. I. 3, I1. I2. $2.4^{6}$. I 4. I. $42 ; 2.4^{*}, 6^{*}$, 37. I 8. 3. I I, I4, $43^{*}, 44^{*} ; 4.29^{\dagger}, 40$. I9. $3.3 ; 7.5 ; 3$ I. 12, I3, I4.

rayyà. 3. I4. I. 6. 78. 2 . rayịnăm. 3. 10. 5. 6. 62. 2. 7. 40.2 ; 79. 4 ; 80. $3^{*}$; 109. 6. 10. 9. 27. II. I. 34 I6. 3. I; 4. I.

(cf. rayișțhă, rayișțhăna.)

ra yiṣthấ (p. -iosth-): -ăm. 7. 39 . I; 40. 2.

rayișthăna (p. -iosth-): -as. 7. 76 . rarivāns in árarivāns.

raru in aráru (?).

ráva: -as. 5. 13. 3.

r açantă: I0. 9. 2 .

raçanăm. 7.78. I.

(cf. $\sqrt{ }$ raçanāy.)

$\checkmark$ r a ça n ā y : -nā॰yámānā. I 4. 2. 74. raçmí: -máyas. 6. 105.3. 7. 107. I. IO. IO. 20. II. 5. II. I3. 2. $18^{*}$. raçmin. $4 \cdot 38.5 \cdot 7 \cdot 82.4$, 5. I3. 2. Io. racmíobhis. 2. 32. I. 5. 30. 15. 6. 62. I; IO8. I, 5. 7. II. I. 9. 8. 22. I2. I. 15. I3. 2. 2,$40 ; 4.2,9$.

(cf. rjúraçmi, saptáraçmi.)

rás a: -as. I. $5.2^{*}$. 3. I3. 5 ; 28.4. 4. 4 5. 6. I6. I. 9 4. 5. I0. 4 . I8. I2. 5. IO. I4. 2.58 .

rásam. 2. $26.4,5 . \quad 4.27 .2,3.5$. I3. 2, 3. 8. 4. IO*. 9.6.32. I9. 31. 5 . rásena. 3. 3I. Io. 4. 35. 3. 6. 78 . I; I24. I. 7.89. I*. I0.6.2, $22 ; 8.44$. rásāya. I8. 4. 8I.

rásasya. I. 28.3. I8. 2. 24 .

ráse. 2. 29 . I.

rásās. 4. 15. 2. I9. 3 I. 4.

rásebhias. 2. 4.5 .

(cf. arasá, gárbharasa, rásavant.) rás a ○vant: -vān. I8. I. 48*; 4. 23. ra să : -ấm. 4. 2. $5^{\dagger}$ [ [79.3. V rā, rās : rāsva. 6. 39. 2 (1. -sua ?); rarāsva. 7. 20.2; 68. I. [33. rárāṇas. 5. 27. II. 7. II5. 2. I3. 2. rárāṇā. I. I8. 2. 7. 48. 2*. 9. I. 2. rātă. 7. 46. 3 .

rāsatām. I 9. 7.4; 40. $4^{\dagger}$ (ed. -athām). rāsantām. I9. 7. 4 (mss. -atām); I I. 5*. răsamānā. 12. I. 44. [rāya, rākâa ?.)

(cf. rarivāǹs, raru?, rāta, rātí, + s a m: samorarānás. 2. 34. 3, 4. 7 . I7. 4 . I8. 3. $46^{*}$.

rākà : rāke. 7. 48. 2". 
rākằm. 7. 48. I".

rākşa sá: -astbhis. 20. 34.12 (mss, rakş-, rákş-; ed. çácIbhis).

V $\mathbf{r} \mathbf{a} \mathbf{j}$ : răjati. I0. IO. 28 .

rājatas. 7. 54. I; 57.2".

árăjan. 5. 18. 10.

rājayātāi. 6. 98 . I.

(cf. rằj, răjan, rāja, rājñi, rājya, răștrí, rāșțá.)

$+v$ i: vi rājati. I. ro. 1. 6. $31.3^{*}$; 36. 3. 7. 73. 6*. 8. 5. I3. I I. 5. I6. 20. 49.3 .

viorăjăni. I. 29. $6^{*}$.

ví rāja. 3. 4. I. 6. 93. 2. I I. 1. 22. I4. I. 64 .

ví rājatu. 2. 36. 3 .

viorâjan. 3. I2. 6 .

viorăjantam. I9. 42.4. (cf. virăj.)

+ s a m: cf. samrăj.

rầj : răț. 7. 49. $2^{*}$.

(cf. ekarăjj, virăj, samrắj, svarăj.)

rāj a in adhirājá, gṛharājá, dvirājá, nakșatrarāja.

$r \bar{a} \mathbf{j} a \circ k \underline{́} \mathrm{t}$ : -tas. 3. 5. 7 .

răja okṛta: -tā. Io. I. 3 .

răja n: -jā. I. 33. 2". 2. 32.4; 36 . 3. 3. $3.3 ; 4.5 ; 12.4 ;$ I6. $2^{*} ; 22$.

3. 4. 2. $2^{*} ; 8.1$; I6. 2,$5 ; 22.2,3$, 4. 5. I7. $2^{*} ;$ I9. 6, I0; 2 I. II ${ }^{2} ; 25$. $6 ; 88 . \mathrm{I}^{*}, \mathrm{2}^{*} ; 98.3 ;$ 104.3. 7. 83. I ; II8. I*. 8. $7.16,20$; 10. 23,25 . 9 . I. $22 ; 7.2$ 22. IO. I. $22 ; 3.1$ I ; 6 . I 5. II. 5. I7. I 4. I. 49.59. I5. 2. 3,4 ; $4.3,4,7$. I8. I. $33^{*} ; 3.69$; 4. 26,53 . I9. $5 . \mathrm{I}^{*} ; 20 . \mathrm{I} ; 26.4 ; 33$. $4 ; 49.6$.

rājan. I. IO. 2 ; I4. 2, 3. 2. 28.5 (p. mitraorā-). 3. 4. 1. 4. 22. 6. 5. 3. $7^{*}$. 6. $99.3 ;$ 123. $5^{2}$; 128. 3.7 .83 . I, 2. II. I. $26 ; 2.28$. I 8 . I. $60^{*} ; 2$. 12*; 4.70 (mss. rầ-). I9. 44.8.

răjānam. 3. $20.4^{*}$. 6. I28. I. II. 6. 2. I 8. I. $40^{\dagger}, 49^{*} ;$ 3. I3.

răjñe. 2. I3.2. 6. 20. $2 ; 93.2$. I5. 2. 3,4 . I8. $2.3^{*}$.

răjñas. I. IO. I, $3 ; 25 \cdot 3 \cdot 4 \cdot 16.3,4$. 6. $68.1,3.9 .2 .6$ I0. 5.44 . I 4 .
2. 49. I5. 2. 3,4 ; I0. I. I6. 8. 26 . 19. 6. 16; 13.10". 20. $127.7,9$.

răjani. 6. I16. I.

răjānāu. I $8 \cdot$ I. $54^{\dagger}$.

răjānas. 3. 5. 7; 29.1. 5.17.10".

I9. 57.2.

răjñām. 2.6.4. 4.22.5. 6. 40. 2. răjaosu. 6. 98. I 7.50. $7^{\dagger}$. I9. 6,2.1.

(cf. daçarājan, yamárājan, sindhurājan, sómarājan, svarăjan, rājñīi, rājya, rãja-rājāçvá.)

rāj a n y à : -nyàs. 5. 17. 9. 12. 4. 32 . I5. 8. I.

rājanías. 5. 18.2. 19. 6.6*.

rãjanya. 5. 18. 1, 3 .

rājanyàsya. I0. 10. I8. I2. 4. 33 . rājaníe. 6. 38.4.

(cf. brahmarājanyà.) [5.22.

rāj a $\circ$ y a kṣ má : -ás. I I. 3. 39. I 2. rājayakṣmăt. 3. $\mathrm{II} . \mathrm{I}^{*}$.

rāja०vadhá: -dhébhias. 6. I3. I. rāja osúy ya: -am. 4. 8. I. II. 7.7. I9. 33. I.

rājāçvá (p. -ja॰aç-): -ás. 6. IO2. 2. $r \bar{a} j i$ in tíraçcirāji.

rāj ñ I in samrấjñi, and síndhurājñī, sómarājñĩ.

rājyá, rājy à, rắj y a: -yám. 4 . 8. I (s. mss. răjyam).

rājyàm. 12. 3. $3 \mathrm{I}$.

rājyăya. I9. 20. 3 (not mss.).

rājíāya. 3. 4.2.

răjie. I8. 4. 31, 32 .

rājyăni. II. 6. 15.

(cf. yamarăjya, vedarăjya, sămrājya, svarăjya.)

$r$ àt $\mathbf{a}$ in

rātá $\circ$ a vy a: -am. 3. 3. I.

rātáhavyā. I9. IO. I".

rātí: -ís. I. 26. 2. 3. 8. 2. 7. 17. 4 .

rātím. I9. $3 \cdot 4$.

rātāú. 6. 39. 2.

rātáyas. II. 8.21.

(cf. árāti, rātiṣấc.)

rātișăc (p. -tios-): -cas. I 8. 3. 20. I9. II. $2^{*}$.

rātra in atirātrá, ahorātrá, ekarātrá, catūrātrá, dvirātrá, pañca- 
rātrá, șaḍrātrá, saptarātrá. rátrì, rầtri: -ris. I 3. 4. 30. rătri. 2. 8. 2 ; 15.2. 4. I8. I. 5. 5. I. 6. 12.1 ; $128.2 .7 .69 .1 ; 79.3 .9$. 3. I7. II. 4. 2 I. I5. 2. I-4, 3. I9. 49. I, 2,4 (ms. rātri), 9 .

rătri. 3. I0. 7 I 9. $47.2,5 ; 48.2$; 49. 6,7 (mss. rătrīi).

rātri. 3. 10. 3. I9. $47.1,3,8,9 ; 4 \mathrm{~S}$. 3,$6 ; 49.3$ (mss. râ-), 8; 50. I, 2, 4, 6, 7. rătrim. I. I6. I. 3. 10.2. 5. I7. I8. 8. 9. 2 I. I0. I. 32 . I5. I3. I-4. I6. 7. 9. I7. 25,26 . I9. $48.5 ;$ 49. 5 ; 50. 3 (rătrimorã-); 55. I (do.). rătryā. II. 2. I6. I5. 18. 5. rătraye. 8. 2.20.

rătryās. I3. 3. 26; 4.30. I9. 56. 2. rătrīs. 4. II. II. II. 5.3. I5. I3. 5 . rătrībhis. I 8.1 . $10^{*}$.

rătrīṇām. 4. 5.4. 7. 80. 4. (cf. rātra.)

rāthajit e yá: -yínām. 6. 130. I (p. rāthaojite yínām).

ră d dhi: -is. IO. 2. IO. II. 7.22. $\checkmark \mathrm{r} \overline{\mathrm{a}} \mathrm{d} h$ : rắdhyatām. I2. I. 2.

rădhyamānasya. II. 3. II.

arātsīs. 5. 6. 5 .

rātsyasi. II 3. 4 I.

rādhayāmi. II. I. IO.

(cf. răddhi, rādha, rādhana, rādhayant, rădhas, rādhi.)

+ a nu: ánu rãdhyāsma. I9. I5. 2.

(cf. anurādhá, anūrādhá.)

+ a p a: ápa ... arātsīs. 5. 6. 7. ápa...rarắdha. 2. 35.2.

ápaorāddhas. 6. II6. 2.

+ a v a: áva ... arātsīs. 5. 6.6.

+ vi: ví rādhiși. I. 1. 4. 3. 29.8 .

(cf. virắdhana, ávirādhayant.)

+ s a m: saṁorãdháyantas. 3. 30. 5. $\mathbf{r} \overline{\mathbf{a}} \mathbf{d} \mathbf{h}$ a in anurādhá, anūrādhá. $\mathbf{r} \overline{\mathrm{d}} \mathbf{h}$ an $\mathbf{a}$ in virădhana.

$\mathbf{r a} d \mathbf{h}$ a y an $t$ in ávirādhayant.

rầdhas: 5. II. I1. I9. 5. I $^{*} ; 7.3$ (mss. -dhe). 20. $135.9^{3}$.

rădhase. $7 \cdot 46.3$.

(cf. arādhás, citrárādhas, viçvárādhas, satyarādhas.) rā d hi in krsțárädhi.

$r a \bar{p}$ in in parirāpín.

rā má : răme. I. 23. I.

rāmăyām. 12. 2. 19.

(cf. rāmāyaṇá ?.)

rām à y a ñá: -ṇt. 6.83 .3

rā m y ă: I9. 49. 7 (mss. çámyā).

rã y a in arấya.

rāçí: -çáyas. 6. 142.3

$r$ ã șț in in râțțí.

rāṣț á: -ám. 3. 4. I ; 8. I ; I9. $2,5$. 5. 17. $3^{*}, 4 ;$ 19. $6,7,8^{2}$. 6. $39.2 ; 87$. $I^{*}, 2^{*} ; 88.2^{*} ;$ 128. I; 134. I. 7. 35 . I. 8. 9. I3. I0. 3.12 ; IO. 8 . II. 5 . I7; 7. I7, I8. I2. 3. I0; 5.8. I3. I. I, $4,5,8,20,34,35$. I9. 4I. I.

rāṣțréna. 6. 78. 2.

rāṣtrăya. I. $29 \cdot 1^{*}, 4$. I3. I. I. I5. IO. 2. I9. 24. I.

rāṣțrásya. 3. 4. 2 ; 5.2. 5. 19. 4. 6. 54. 2.

rāṣțré. 5. 17. 12-7; 19. I0. 12. 1. 8. I3. I. 9. 20. 127.9, 10.

rāṣțắni. I9 30.3 .

(cf. abhírāșțra, dhṛtárāșțra, rāṣțradipsú-rāșțrabhŕ̛tya.)

rāṣtraodipsú: -sávas. I0. 3. I6.

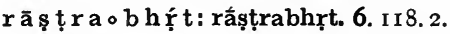
rāșțrabhṛ́tas. 7. 109.6. I0. 8. I5. I3. I. 35 .

rāṣtraobhṛtya: -yāya. I9. 37. 3 (mss. -țrábhrrt-).

rășțĩ: 4. I. 2; 30. $2^{*}$. [ṇā). rā h ú : -úñā. I9. 9. Io (mss. çarāhurikta in

rikta。kumbhá: -bhăni. r9. 8.4 (mss. -bhăn).

Vric: riréca. 5. I. 3 . riricyām. I8. 1. 8*. (cf. rikta.)

+ a ti: áti ricyate. 8. 9. 26 . áty aricyata. I9. 6. $9^{*}$. átioriktas. 8. 9. 17 .

$+\overline{\mathbf{a}}$ : ầ rireca. I8. $3.4 \mathrm{I}^{\dagger}$.

+ pra: prá ririce. 9. 10. $3^{*}$. [pas $\checkmark$ rip: cf. $/$ lip, ríp, ripú, riprá, reríp: -pas. 8. 4. I8*.

ripú: -ús. 8. 4. 10*. 19. 49.9. 
riprá: -ám. 6. 51. 2". 10. 5.2ł. I2. 2. II, 40. I6. I. IO. I8. 3. 17. riprăt. 12. 3. 5 .

riprăni. 12. 2. 13. (cf. ariprá, ripravāhá.)

ripra०vāhá: -ás. 12. $2.8^{*}$. $\checkmark$ riph: riphatí. 3. 28.1 . Vriç: rişțám. 4. 12. 2. + vi: víorișțam. 6. 53. 3. 7. 57. I. riçă : -ăm. II. 9. I5.

ri çă d a s : -dās. 2. 28. 2. riçādasas. $7 \cdot 77 \cdot \mathrm{I}^{*}$.

riç y a: cf. ŗ̣́ya, ríçyapad.

rí ç y a ० p a d: -dím. r. 18. 4. $\checkmark$ riş: ríşyati. I4. I. $30 ; 2.8$. ríşyatas. 2. 15. I-6. ríșyās. 8. 2. 13. rișyāti. 6. 109. $2^{*}$. rișyema. $7 \cdot 9 \cdot 3^{*}$. 20. 127.14. rișam. I 8. 3. 52* (mss. -şan). ríşat. r9. 49. Io (mss. áçişas). rișat. 19. $39 \cdot 2-4$ (m. mss. ŗșat). 20. 127. 13 (mss. ririşat).

rișāma. 3.15.8. I3. 2. 37. I4. 2. 50. I9. 55. I, 2.

rișan. 2. 6.2. 3. 12. 6. I I. I. 25,32 . rīrișas (p. rir-). 5. 3. $8^{*}$. 6. 5 I. $3^{*}$. II. 2. $29^{*}$.

reşaya. II. I. 20.

(cf. ríş, rișa, rișța, riṣyant, reșaṇa, reşmán.)

+ a bhi: abhioréşāt. 4. 35. I.

ríṣ: rișás. 8. 3. $\mathrm{I}^{*}$.

ri șa in naghārișá.

rișț a in árișța.

riș y ant in árişyant.

$\checkmark$ rih: rihanti. I8. 3. $18^{*}$.

rihānée (p. -é íti). 5. I. 4.

rérihatím. II. 9. I5.

(cf. Vlih, rerihá, rehạ̣a.)

$+\overline{\mathbf{a}}$ : cf. āréhaṇa.

+ prati: práti ... rihanti. 7. 73. 3. $\checkmark \mathbf{r} \mathbf{i}, \mathbf{r}$ i: riyate. 12. $2.26^{*}$.

rị̣ās. 20. I 35 . II.

rinán. I3. I. $2 \mathrm{I}^{*}$.

(cf. $\sqrt{ } \mathbf{l} \mathbf{i}$, reṇú, rétas.)

+ ni : ní rị̣āmi. 5. 13. I. ní riṇāti. $5.2 . I^{*}$.
V ru: rutám. 5. 5.6.

róruvatam. I 1. 10. 26.

(cf. ráva.)

+ abhi: abhí ruva. $5,20.3$.

$+\overline{\mathbf{a}}$ : à ... roraviti. I $8.3 .65^{\circ}$.

rukmá: -má. 9. 5. 25, 26.

(cf. surukmá, rukmáprastaraṇa, rukmavakşas.)

[30.

rukmá oprastara na: -am. I4. 2.

$\mathrm{rukma} \circ \mathrm{kaksas:-asas.} \mathrm{6.} \mathrm{22.2.}$

Vruc: rócase. 13. 2. $30^{4}$. I 8. 4. $59^{\circ}$. rócate. II. 8. 16.

rocate. I0. 8.24 . II. 5. 26 .

rócamānas. 3. 5.4. 5.20.6. 13 .

2. 28,42 .

rócamānam. II . 5.23.

árocathās. 3. 20. 1 ".

rucișiya. I7. $2 \mathrm{x}$.

rocaya. I4. I. 3 I.

(cf. rukmá, rúc, rúci, rocá, rocaná, rocis, rúçant.)

+ a ti: áti rocase. I3. I. 36 .

atiorócate. 6. 34. $3^{\prime \prime}$.

+ ava: avaorócate. 3. 7. 3.

$+\bar{a}:$ āorocáyan. 13. 2. 32 .

+ u d: úd arocathās. I3. 3.23.

+ pra: prá rocaya. I2. I. I8.

+ vi: viorócate. 4. 23. $7 ; 28$. I. 7 . 25. 2. I3. 1. 55 .

(cf. virócana.)

rúc: rucé. Io. 2 . I6.

(cf. akṛttaruc, sưúc.)

rúci: -is. I2. I. 25. I3. 4. 23. I7. 2 I. rúcim. 3. 15.6.

rúcyā. 13. 2. 30 (l. -ciā). I7. 21.

(cf. vásuruci.)

$\checkmark \mathbf{r}$ u j : ruján. I. I2. I. 4.3 $1.3^{*}$. I6. I. 2.

(cf. ruj, rujá, róga, rogana.)

$+\bar{a}$ : āorujántas. 4. 31. I".

ā॰rurója. 4. 24. 2.

(cf. äruj.)

+ pari: parioruján. I6. r. 2.

+ pra: prá ... ruja. 7. 50. $4^{*}$.

+ vi: viorujánti. 9. 8. 13,18 .

ví ... ruja. I. 2 I. $3^{*}$.

vioruján. I9. 28. 3 (mss. -jám).

$r u j$ in āruj.

rujá: -ás. I6. 3.2. 
$\checkmark \mathrm{rud}:$ rudanti. I4. I. 46.

rudan. 8. I. Ig.

rudatyàs. II. 9. I4.

árudat. I 4. 2. 60 .

(cf: rund, róda, roruda)

+ a b hi : ef. abhirorudá.

rud in agharúd.

ru d rá: -ás. I. I9. 3. 3. 22. 2.6. 32. 2 ; 90. I; I4I. I. 7. 77. I. 8. 5 . IO. I3. $4.4,26$. I5. $5.5 ;$ I4. 6. I 9 . Io. $6^{*}$.

rúdra. 227.6.

rudra. 6. 9o. 3 . I I. $2.3,13,15,26$, 29*. I8. I. $40^{*}$.

rudrám. 3. I6. I*. I I. $2.17 ; 6.9$.

I5. 5.5 .

rudréna. II. 2.7.

rudrăya. 4. 30. $5^{*}$. 6. 20. 2. 7.87. I. I9. $55 \cdot 5$.

rudrásya. 4. 2 I. $7^{*}$. 6. 44. $3 ; 57.1$; 59. 3. I I. 2. 12, 30. I 2. $2.47 ; 4.52$. rudrấs. $5.3 .9^{\dagger}, 10^{*} .6 .68$. เ. 8. 8. I2. I0. 7.22. II. 6. I3. I2. 2. 6 . I9. 9. IO, II ; II. $4^{*}$. 20. I35. 9. rudrāís. I9. I7. 3.

rudrébhis. 4. 30. $I^{*}$. I9. 10. $6^{*}$. (cf. bhavārudrá, somārudra, rudrávant.)

rudrá ova nt: -ntam. 19. I8. 3. [55. $\checkmark \mathrm{rudh}$ : ruṇáddhi. 7. 50. $6^{\dagger}$. II. 3 . runaddhi. II. 3.54 .

rundhí. 19. 29. $3^{4}$.

[dhate.)

arundhata. I9. 38. I (mss. árunarãut. I0. 4. 26.

(cf. I rudh, rundhant, rodha, rodhana.)

+ a nu: cf. anuródhana.

+ a pa: ápa rudhmas. I2. 3. 43 . ápa ... arudhan. I8. 2. 27.

ápaoruddham. 3.3. 4 .

+ ava: avaorundhé. 9.6.40-3. áva rundhe. 9.5.22;6.9, 40-3. I2. 3. 4I. I5. II. 3, 4, 6, 8, IO; I3. I-5. áva rundhate. I3. 2.15 .

$+\bar{a}$ : ầ rundhām. 3. 20. 10 .

ấ rurudhre. 4. 31. $3^{*}$.

+ ni: niorundhānásya. I2. 4. 36 . niorudhyáte. 5. 17. 12-7. (cf. niródhana.)

+ s a m: samorúdham. 7. 50. 5 .

I $\mathbf{r} \mathbf{u d h}$ in samrúdh (infin.).

$2 \mathbf{r u d h}$ in vīrúdh.

rudhirá: -ám. 5. 29. Io.

$\mathrm{rund}$ hant in arundhánt.

$\checkmark \mathbf{r u p :}$ arūrupas. 4.6. 3 .

rũrupas (p. rur-). 4. 7. 3; 5, 6 .

(cf. Vlup, ropaṇá, rópi.)

$r$ ú p ?, see 2 rūpá.

$r$ ú ç a n t, r u çá n t: rúçantam. I4. I.

rúçantas. 4. 16.6.

rúçati. 3. 28. I. I4. I. $27^{*}$.

rúçatím. I2. 3. 54 .

ruçántis. $4,21.7^{\dagger}$.

$\checkmark \mathrm{ruh}$ : róhati. I0. 6.33 .

róhanti. 8. $7.8,17$.

róhāt. I I. I. 30 .

róhema. I9. 67.4.

róha. 13. 1. $34^{3}$.

roha. I3. I. $34^{3}$. [3.6*

rohatu. 4. 12. $4^{3}, 5$. 6. IO6. $\mathrm{I}^{\dagger}$. 18 .

arohat. 19. 6. $2^{\dagger}$.

arukșat. I2. 3.42 .

ruróhitha. 7.65. I.

rurohitha. 6. I39. I.

ruroha. I0. 2 8. I3. I. 4,26 ; 3. 26.

ruruhus. 4. $14 . \mathrm{I}$.

rū ḍhuâ. I3. I. 8 .

roháya. 4. I2. I.

rohayatu. 13. I. 13 .

(cf. 2 rudh ?, rúh, rū ̣̣ha, rodha?, róha, róhạ̣a.)

+ adhi: ádhi rohati. 13. 3. 26 .

ádhi roha. 3. 12.6. II. 1. 7.

ádhi rohatu. I0. $6.3 \mathrm{I}, 32$.

ádhi ... aruhat. I9. 49. 2 (mss.

ávi ...).

ádhy arukșat. II. I. I3, I6.

ádhi rohaya. I. 9.2, 4. 6.63.3. II.

I. 4 , 30. I4. 2. 37 . I8. 3.4 .

+ anu: ánv arohat. I8. 3.40'.

+ a pi: ápi rohati. 8. Io. 18.

ápi rohatu. 4. 12. 3. 12. 1. 35 .

+ a va: ávaorū ̣̂hāu. 6. I40. I.

$+\mathrm{u} d$ : út ... róhantas. 7. 53. 7 .

$+\overline{\mathbf{a}}$ : ầ rohasi. $5 \cdot 5 \cdot 3$.

à rohati. I0. 9.5 . 
ầ rohanti. 19. 53. I.

à... rohanti. 4. 14.4 .

á roha. 2. $36.5 .3 .20 . I^{\dagger}$. 8. I. 8 .

9. 5. 9. I2. 2. I; 3. I4. I3. I. 2. I4. I. $6 \mathrm{I}^{*} ; 2.24,3 \mathrm{I}, 39$. I 8. $3.73 ; 4.6$, 51. 19. $33.2 ; 65.1$.

a... róha. 8. I. 6 . I 8. I. $60^{\dagger}$ (mss. à...roha. 5. 28.14 .

ầ rohatu. I4. 2. 22.

à rohata. 7.97. 4. 12. 2. $24^{*}, 4^{8}$. I 8. $3.64 ; 4.1$.

a rohantu. I2. 2. $3 I^{*}$.

ā॰róhan. 3.6.6. 13. 1. $43 ; 2.42$. I7. I0. 19. 36 . I.

ā॰róhantas. 4. I4. 6 . II. I. 37.

太 'rohat. I4. I. I 2*; 2.30. I5. 3. 9.

à rurohitha. 4. 20.3 .

á ruroha. I3. I. $4,33,45$.

a.... ruroha. 13. 1. $15^{3}$.

āoruruhús. 4. 11.6 .

a 'ruham. 4. 14. $3^{2}$.

a'ruhas. 19. 65. I.

à 'ruhat. I2. 2. I2. I3. 1. 26 ; 2. 8, a... aruhat. I9. 49.2 (not mss.).

ấruhan. 20. 49. I.

à 'ruhan. I8. I. $6 \mathrm{I}$.

ấ ruhemā (p. -ma). 7. 6. $3^{*}$.

a. ... ruha. 12. 2.17 .

á 'rukșas. I7. 25, 26.

à 'rukşat. I8. 4. I4.

â... arukșat. 3. 5.5. 8. 5. 20.

á ... arukșāma. ' 4 4. 2.8 .

ầ rukşas. 17.8 .

āorúhya. 8.5.7.

ăorūdhas. 6. II. I.

â rohayāmi. I 8.4 . I.

(cf. ārúh, āróhaṇa.)

+ a nvã: anvắrohāmi (p. anuoắr-). 6. I22. 4 .

+ a bh yā: abhyấrohati (p. abhioăr-).

3. 29. 3 .

(cf. ánabhyārūḍ̂ha.)

+ a dā : udoăruhan. I8. I. 6I (s. mss. p. úd 育'r-).

+ pra: cf. prarúh.

+ vi: ví roha. 6. 30. 2.

ví rohatu. I0. 6.33.

viorohatas. $4.4 \cdot 3$. (cf. vĩrúdh ?.)

rúh: -has. I3. I. $4.8,9,26 ; 3.26$. (cf. ārúh, prarúh)

rũ kşna in árūkṣna.

$\mathbf{r} \overline{\mathbf{u}} \mathbf{h} \mathbf{a}$ in ánabhyārūộha.

I rū pá: rūpám. 1. 24. I. 2. 29. 6. 5 . 29. $15.9 .4 .7 ; 5.24 ; 7.15$; 10. 26 *. I0. 2.12 I I. 7. 1. I2. $3.33 ; 5.9$. I4. I. 56,57 . I9. 49. 8 (mss. gó rūpam); 56.2 (mss. bhişágbhyaorápam).

rūpámorūpam. 1. 22.3. I9. I. 3.

rūpéṇa. 4. I1.7. 5. 25. 10-3. I0. 8. $3 \mathrm{I}$.

rūpăya. I O. IO. I. II. 2. 5.

rūpé. 9. 9.7.

rūpé (p. -éíti). I3. 2. 28, 42.

rūpáyos. I0. 8. 23.

rūpânịi. I. I. I; 24.4. 4. 20. 5. 5. 25. 5* 6. 20. 3. 7. 60. $7 ; 79.4 ; 80$. $3^{\dagger}$. 9. 4 I. I2. 3. $21 ; 4.29$. I3. I. I I ; 2. IO. I4. I. $28^{*}$; 2. 30. I9. 49. 4 . rūpă. 5.26 .8 (p. -ăḥ).

rūpāís. 5. 12. $9^{*}$.

rūpănām. 9. 4. 6.

(cf. 2 rūpá ?-rūpaçás, agnírūpa, áparūpa, abhírūpa, ékarūpa, klībárūpa, gorūpá, nằnārūpa, piçáñgarūpa, pururúpa, pūrvarūpá. vírūpa, viçvárūpa, víșurūpa, sárūpa, sárvarūpa.) [pás"). 2 r ū pá: -ás. $\quad$ I8. $3 \cdot 40^{\dagger}$ (s. mss. rurúp a ka: -kãs. II. 9. I5.

rū pa odh é y a : -yāni. 2. 26. I.

$r \bar{u}$ pa०çás. 9.9. $16^{*}$.

r $\bar{u} \mathbf{r}$ á: -ás. 5. 22. Io.

rūrám. 5. 22.13.

rürăya. I. 25.4. 7. II6. I.

re, see rāí.

$\checkmark$ rej: réjante. 20. 34.17 .

rejante. 9. 9. $16^{*}$.

réjamāne. I. 32.3 .

rẹú : -úm. Io. I. I3

(cf. renúkakāța.)

renú $\circ k$ a kāṭa: -as. 4. 2 I. $4^{*}$.

réta s: 2. 28. 5: 34.2. 4. I5. $\mathrm{II}^{\dagger} ; 34$.

4. 5. 28.6 . 6. II. $2 ; 49.3^{*}$. 8. 9 . 13. 9. I. $2 ; 4.4,7,23^{\dagger}$; IO. $13^{*}, 1^{*}$, 
I7*. I0. 2.17 ; IO. 29. II. 5. I 2, 25 ; 8. 29. 12. 3. 3. 14. 2. I4. I9. 52. I* rétasā. 8. 7.21. I3. I. I5.

rétasas. 14. 2. 37 .

(cf. bhúriretas, retodhă.)

r et o d hầ (p. -taḥodh-): -ấs. 5. 25. I. re pas in arepás.

rebhá: rebha. 20. 127. 4 (mss. ré-), rebhé. 8. 3. $2 \mathrm{I}^{*}$.

rebhăs. 8. 3. 12 *

rebhāsas. 20. 127.5 (mss. -ấsas). (cf. rāíbha.)

rerihá: -ám. 8. 6. 6.

$[8,9$.

revánt: -vắn. 20. 128. 4 (mss. de-),

revátī. I9. 7.5.

revati. I9. 47.4

revátīs. 3. 4. 7. 9.7.3.

révatīs. 6. 21.3 .

revátībhis. I3. I. 5 .

reș a ṇa in purușaréșaṇa.

reșmáochinna: -am. 6. I02. 2.

reṣmán: -mă. I5. 2 I-4.

(cf. reșmáchinna.)

re h a n a in āréhana.

rāí: rāyấ. I4. 2. 36 .

rāyé. I 8. 2. 37.

[19. 24. 5 .

rāyás. 2. 13. 3. 7.50. 6t. I8. 4. 62. rāyás póşa. I. 9.4. 2. 29. 2 ; 34. I. 3. I0. 3,8 ; I4. 6 ; I5.8. 5. 27 . 10. 6. 5.2 . 7. $40.2 ; 47.2$. 9. 4. 22,24 . II. I. 34 . I8. I. $43^{*}$. I9. 3 I. I3; 52 . I ; $55 . \mathrm{I}, 2,7$.

rấyas. 19. 10. $2^{*}$.

rāíbh a: -bhĩ. I4. I. $7^{*}$.

róga: -as. 6. 44 . I.

rógam. I. 2.4 . 2. $3.3,4,5 . \quad 3.28$.

5. 6. I20. 3. 9. 8. I-5, $2 \mathrm{I}, 22$.

(cf. roganáçana.)

rog a ña in árogaṇa.

rog a on ăçan a: -am. 6. 44. 2.

rocá: -ás. I $7 \cdot 2 I^{2}$.

roc a ná: -ás. 4. Io. 6. I4. I. 38. rocana. 13. $2.19^{\dagger}$.

rocanám. I3. 1. 39.

rocanéna. 2. 6. I.

rocané. $7 \cdot 73.4$.

rocanăni. I9. 7.1 .

rocană. 6. 3 I. $2^{*} ; 75 \cdot 3$. rocanănām. 4. 10. 2.

(cf. virócana, rocanấvant.) [3. Io. roc a nă vant (p. -náov-): -vat. I3. rocis in svárocis.

ród a: -am. 8. 6. 26.

ródena. I4. 2. 59-6I.

r 6 d a s : -asi (p. -i íti). I. 32.3. 3. 3 .

I. $4.1 .4 ; 2.3 ;$ I $4.4 ;$ I6. 5 . 5. I.

9. 8. 9.6. II. 5. I. I3. $2.32 ; 3$. 6. I8. I. $25^{*} ; 3.65^{*}$. I9. I0. $3^{*}$.

rodasi (p. -1 íti). I8. I. $3 I^{*} ; \cdot 4.89^{*}$. (cf. ródasi.)

ró d a s I: 7. 49. 2t.

rod h a in nyagródha, ródhacakra.

ródhaocakra: -re (p. -e íti etc.). 5. I. 5 .

[na.

rod h a $\mathrm{n}$ in anuródhana, niródha-

rop a ṇá: -ṇấs. 9. 8. I9.

(cf. ropaṇăkā.)

rop a ṇ̂ ấ kā: -āsu. I. 22. $4^{*}$.

rópi:-payas. II. 2. 3 .

rópis. 5. 30. 16.

rom a n: ef. lóman, mayúraroman.

rorud a in abhirorudá.

ró ha: -hān. 4. I4. I.

róhāis. I3. I. 13.

ró h a ṇ a: -ṇi. 4. I2. $\mathrm{I}^{3}$.

(cf. āróhaṇa.)

róhiṇi: I3. I. 22, 23. I9. 7.2.

róhinim. I2. I. I I.

róhiñ (p. -I ́́ti). 6. 83. 2.

róhiṇis. I. 22. $3^{2}$. 8. 7. I. I8. $4 \cdot 34$. (cf. lóhiniñ, rāuhị̣á.)

rohít: -tam. 4. 4. 7

róhita: -as. I3. I. I, 3, 4, 5, 6, 7, 8, Io, II, I3, I4. I5, I8, $21^{*}$ (mss. rohitas, rohita), 24, 25, 26 $2,35,46,52,54$; 2. $25.39^{4}, 40^{3}, 4 \mathrm{I} ; 3.26$.

rohita. I3. 3. I-25.

róhitam. I3. I. I3; 3. 12, 23.

róhitena. I3. I. 34,55 .

róhitāya. I3. I. I3.

róhitasya. I. 22. I. I3. I. 9, 22, 23, $47,48,49-5 \mathrm{I}$.

róhite. I3. I. 37. I4. 2.23.

róhitāu. 5. 23. 4.

róhitāis. I. 22. 2.

[hité-). róhitebhyas. I9. 23. 23 (m. mss. ro- 
(cf. lóhita, róhị̣I, rohít.)

rāuhiṇá: -ám. 20. 128. 13 (mss. rãúhinam).

$\checkmark$ l a k in lákşman, lakşmt.

1 ák \$ ma n: -ma. I. 23.4. 6. 141. 2 , 3. 12. 4. 6.

(cf. sálakşma.)

[5.6.

laks mt: -Is. 7. II5.2. II. 7. 17. 12. lakşmi. 7. I15. I. lakşmíam. I. 18.1 . lakşmías. 7. II5.3. lakşmis. 7. 115.4 .

lá ghiyas: -asi. IO. I. 29.

la g hú : -ús. 9.3.24. (cf. raghu, lághiyas.)

V l a p: lapită (-tvă ?). $\quad 4 \cdot 36.9$

lălapîti. 6. III. I. (cf. $/$ rap, lap, lapant, lāpa.)

+ abhi: cf. abhīlāpa.

+ ā: cf. ālāpá.

+ pra: cf. pralāpá.

+ vi: ví lapantu. I. 7.3.

violápan. 6. 20. I.

vi lāpaya. I. 7. 2; 6 .

la p in abhilāpaláp.

1 a pant in álapant.

$\checkmark 1 \mathrm{a} \mathrm{b} \mathrm{h}$ : lábhet. 20. I36. I6 (mss. la-).

labdhvâ. I. 8. 2. 5.8.8.

lipsethās. 20. 134.5 (not mss.). (cf. 1 rabh.)

+ ã: āolábhe. 7. 109. 7 .

āolebhiré. I0. I. 9 .

(cf. $\overline{\mathbf{a}}+\boldsymbol{V}$ rabh.)

+ up a: upaolípsamānās. 6. I I8. I. lay a $\mathrm{n}$ in praláyana.

l alăța: -am. 9. 7. I. I0. 2. 8.

la lầma: -am. I5. I. 3 .

lalāmíam. I. I 8. I, 4 . (cf lalămagu.)

1 a lầm a g u : -um. 20. 136. 4 .

l a vạná: -naăt. 7.76. 1.

1 āks̄a : -se. 5. 5. 7 .

lầng a l a: -am. 3. 17. 3, 6*.

lângalebhias. 2. 8.4 .

lā p a in abhīlāpa, ālāpá, pralāpá.

1 a y a in nilấya. /likh: likhat. 20. I32.8.

likhitám. I2. 3. 22.

+ a pa: ápa ... likhāt. I4. 2. 68

+ s a m: sámolikhitam. . 7.50. 5 .

li g a in âliga, víliga.

$\checkmark$ li p: cf. lipta, limpa.

+ ni: ní limpāmi. II. IO. I3.

ní... alipsata. 6. 52. 2 ".

(cf. nilimpá.)

+ vi: cf. viliptt.

lipt a in viliptí.

1 líbujā: 6. 8. I. I8. I. I5*, I6*.

1 i m pa in nilimpá.

$\checkmark$ lih : cf. liḍha.

+ vi: cf. vilidht.

$\checkmark 11$ : cf. $\vee$ rì, layana, lāya.

+ ni: nioláyate. II. 2. I3.

ní layantãm. 4. 3I. $7^{*}$.

níolinas. 4. 16. 3 .

(cf. nilấya.)

+ pra: cf. praláyana.

+ vi : víliyate. 20. I 34. 3, 4 (not mss.).

$\mathbf{1} \mathbf{d} \mathrm{h}$ a in viliḍht.

$\checkmark \mathbf{l}$ u p : cf. $\checkmark$ rup.

+ a pa: apaolupyáte. 5. 17. 7.

$+\bar{a}$ : ãolumpệt. I2. 4. 34. [6.

+ u t: úlluptas (p. útol-). I 9. 33. $2 ; 46$. úlluptam (do.). 5. 28.14.

+ s a m: samolúpya. Io. I. 30 .

$\checkmark l u b h:$ cf. lubhyant.

+ s a m: samolobháyantas. 6. 28. $\mathrm{I}^{\dagger}$.

$\mathbf{l u b h}$ y a t in álubhyant.

loká: -ás. 3.28.6. 5.30. I7. 8. 8. 8. 9. $5.5,9 ; 7.4$. I I. I. 7 ; 7. 1. I2. 2 . I $3.47 ; 5.3$. I3. $2.40 ; 4.53$. I5 7. 4,5 . I7. 18.

lokám. 2. 9. I. 3. 28. 5,6. 4. II. 6,$9 ; 14.6 ; 34.2$. 5. 18. 13. 6. 119. I ; I2O. I ; I II. I, 2, 4; I22. 3 ; I 23. 2. 7. $83.4 ; 84.2^{*}$. 8. 9. 15. 9. 2. II ; 5. I, 6, I2 $2^{2}, 16^{2}, 22,26 ; 6.9,23$, 6I. II. I. 8, I 7, 1 8, 31, $37^{2} ; 5.7 ; 8$. IO, I1. I2. I. I ; 2. $45 ; 3.7,16,17$, I9, 26, 38, 39, 53; 4. 36. I4. I. 58, 6I"; 2. 13. I8. 1. $55^{*} ; 2.8^{*}, 25,47,53 ; 3$. 4, I $3,38^{*}, 73 ; 4.2,7$, Iо, I3, 44 . I9. I5. $4^{*} ; 54.5^{2}$.

lokéna. 3. 29.3-5. 
lokăya. I0. 5. 7-14.

lokât. 6. 120. 2. 8. I. 4 ; 9. I. 9. 2. I 7 , I8. I2. $3.45 ; 4.53 ; 5.38$. I9. 56. I.

loké. 2. Io. 7. 3. 29.4. 4. I I. $4 ; 34$. 2, 5-7. 6. 26. I; II7. 3 ; II8. 2 . 7. 99. x. 8. I. I. 9.5. 7, II I I8, I9. Io. 7 . 28. II. I. I9, 35; 4. II, I8; 8. IO. I2. $2.9 ; 3.3 ; 4.35 ; 5.57$. I4. I. 19*. I5. 12. 7 , II. I6. 9. 2 . I8. 2. 20; 3. 7I; 4. I, II, 67. I9. 9. II.

lokâs. $4 \cdot 35 \cdot 5 \cdot 6$. II7. 3. ro. $6.3 \mathrm{I}$; 7. 22, 29, 30. II. 3. I9. I2. 3. 20. I5. 6. 6 (mss. lókās); I3. I-5. I8. 4. 4, 5,67. I9. 9. 12 ; 54. 4 .

lokấn. 4. 38. 5. 9. I. 23 ; 5. 14, I8; 6. 62. 10.6. 16; 7. 7, 10, $36 ; 9.6$, 10; IO. 33 II. $3.52 ; 5.4,6$; IO. I2. I2. 3. $6,15,25,36$. I3. I. I6; 2 . I0, 42 . 19. $6.8^{*} ; 54.5,6$.

lokânām. 4. 35. I. I5. 6.6 (mss. lókā-).

lokéṣu. 9. 6. $59^{2}$.

(cf. urúloka, jīvaloká, patiloká, pāpaloká, pitṛloká, bradhnáloka, brahmaloká, yathāloká, samānáloka, lokakṛ́t, lokajít, lāukyá.)

[24.

loka $\circ \mathbf{k}$ t: $:$ tas. I 8. 3. 25-35; 4. 16loka ojit: -tam. 4. 34.8 .

logá: -ám. I8. 3. 52*.

16 ma n: -ma. 4. I2. 5. I2. 4.8.

lómnā. 4. I2. 5 .

lómniolomni. 2 33. $7^{\dagger}$.

lómāni. 9. 6. 2; 7. 15. 10. 7. 20; 9 . 2, 24. I2. 5. 68 .

(cf. roman, lómavant, lomaça.)

16 mava nt: -vati. 20. 133. 6 (mss. lomáv-).

lom aça in

lom aça०vakșaṇa: lómaçavakşaṇe. 5.5.7.

lohá: -hé. 20. 134. 5 (not mss.).

lóhita: -am. 9. 7.17. I0. 9. I8. II. 3. $7^{2} ; 5.25$. I 4.2 .48 . I5. I. 7 . lóhitena. 6. I4I. 2. I5. I. 8. lóhitasya. 6. I27. I. (cf. róhita, nīlalohitá, vilohitá,

\section{lóhitakșira-lóhinI.)}

lóhit a okşira: -rās. I9. 9. 8.

16 hit a०vāsas: -asas. I. I7. I. [12. ló hitāsya (p. -taoās-): -siān. 8.6.

16́hinI: 12.3 .54 .

lóhinim. I2. 3. 21 .

lóhinis. ro. 2. II.

lóhinīnām. 7. 74. I.

(cf. róhiṇi, lóhita.)

$1 \bar{a} u \mathbf{k}$ yá: -yăs. Ir. 7.3. I 5. 6.6. lāukyấnām. I 5.6.6.

v a (pron. root): vayám. I. 18. 3; 27. I; 3I. I; 35.4. 2. 4. I; II. 3; I9. $\mathrm{I}-23.5$; 33. 7. 3. 6.4 ; I0. $5, \mathrm{II}^{2}$; I5. 7 ; $6.2^{*}, 4^{*}, 5^{*} ; 24.2$; 27. $1-6 ; 31$. II. 4.3 .4 ; 4.1 ; $5 . I^{*}$; I 7. 6,7 ; 18 . 8 ; 3I. $4^{*} ; 32 . \mathrm{I}^{\dagger} ; 33.4^{*} ; 37.2 .5 .2$. $5^{*} ; 3 . \mathrm{I}^{*} ; 7.3$; $4.7,9$. 6. $26.2 ; 4 \mathrm{r}$. I, $2 ; 47.2 ; 55.3^{*} ; 58.2 ; 62.2 ; 85$. 2; 90. I, 2; II4. I; II5. I; I35. 2, 3 . 7. 9. $3^{*} ;$ I7. $2 ; 20.3 ; 34.1 ; 50.4^{*}$, $7^{*} ; 53.7^{*} ; 61.2 ; 65.3 ; 68.2 ; 71$. $I^{*} ; 73 . I_{1} I^{*} ; 74.4 ; 79.4 ; 80.2,3^{*}$; 8I. $5^{2} ; 83.3^{*} ;$ 90. $2^{*} ; 92.1^{*} ; 93.1$; 109. 6. 8. 9. I8. I0. $3.8 ; 4.6^{2}$, II, I2; 5. 15-21, 25-35, 42; 9. 27. 12. I. 62 ; 2. I3, 33. I3. I. $29,59^{*} ; 2.43$; 4. $47,50-4$ I $4.2 .36,50,66,67,69$. I6. I. $5 ; 6.1^{*} ; 7.5$. I8. I. $36^{*}, 58^{*}$; 2. $59^{*} ; 4.87^{2}$. I9. $15.2 ; 50.3 ; 55$. 3 ; 58. I, 2 (mss. hvay-); 59. 2*. 20. 1 $27.14^{2} ; 136$. 10 (mss. ay-).

vas. I. $5 \cdot 2^{*}, 3^{*} ; 17.4 ; 30.2^{2}, 4^{2}$. 2 . $2.4 ; 14.2^{2}, 6 ; 23.1-5 ; 24.1-8^{2} ; 32$. 3. 3. $2.2^{3} ; 8.4^{2}, 5^{2}, 6$; 13. I, $2,3^{3}, 4$, $6,7^{2} ;$ I4. $I^{2}, 2,4,5^{2}, 6^{2}$; I9. $7^{*} ; 26$. $I-6^{3} ; 27 . I-6$; 30. I, $4,5,6^{2}, 7^{2}$. 4. 7 . $7^{2} ; 15.7,9 ; 21.6^{*}, 7^{2 *} ; 37.4,12 ; 38$. 7. 5. $8.4 ;$ 13. 7 ; 26. I. 6. $24.3 ; 32$. $2^{3} ; 55.2 ; 64.1^{*}, 2^{*}, 3^{4 *} ; 66.2 ; 67$. 2 ; 73. $2^{3}, 3^{3} ; 74.1^{3}, 2^{2} ; 83.1$; 100. 2 ; IO3. I ; II4. 3 ; I22. 5 ; I23. I. 7 . I2. $4^{3} ; 97.4 ;$ 109. $6^{2}$. 8. $7.5^{2}, 21 ; 9$. $22^{2}$. 9.2. I4; 4. 24 ; 5. II. IO. $5.1-5$, 7-I4, 15-20; 21,$23 ; 9.27$. II. I. $5^{2}$, $15^{2}, 18,27 ; 9.2,25^{3}$; 10. 2,5 . I2. 2 . 
$24^{\dagger}, 47,48 ; 4$. 48. I3. I. 3. I4. I. 32 , $33^{2}$; 2. 14, 16". 16. 1. $6,8^{2}, 9$. I 8 . I. $5 I^{*}, 52^{*} ; 3.14,19,64 ; 4.1,48,64^{2}$, $81^{2}, 82^{2}, 83^{2}, 84^{2}, 85^{2}, 89^{*}$. I9. I9. I-

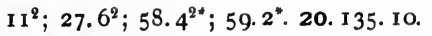
vām. 2. 29. 4 ; 30.2. 4 26. 1, 5 ; 28 . $1^{2}$; 29. 1. 6. 78. 3; 122. 3; 1 40. 2, 3. 7. 29. $1^{2}, 2^{2} ; 5^{8} .2^{*} ; 73.1^{2}, 2,4,5^{2} .8$. 4. $3^{*}, 6^{2^{*}}$. 9. 10. $23^{*}$. II. 2. I. 12 . 3. $1,2,3,4,5,7: 8,35$. I4. I. $14^{*}, 15^{*}$; 2. $5^{*}, 39,40^{\dagger}$. I 8.I. $31^{*} ; 3 \cdot 38^{*}, 39^{*}$; 4. 49.

v a ṅ çá: vaņça. 3. 12.6 . vañçănām. 9. 3. 4 .

váǹ s a g a: -as. 18. 3. $3^{\text {f. }}$

vakţ̣́: -tâ. 8. 4. 8*.

vaktári. 2. I. 4.

(cf. apavaktŕ.)

vakrá: -ás. 7. 56.4 .

vakrăt. 4.6 .4 .

vakră. 7.56. 4 .

vakşán̄ā: -ās. 2. $5 \cdot 5^{*}$.

vakşánābhyas. 7. I14. I. I4. 2. 14. vakșáṇāsu. 9. 4. I; 8. I6.

(cf. lomaçavakșaṇa.) [vakșas.

$\mathbf{v}$ a kșas in rukmavakşas, híraṇyavághā: -ās. 9. 2. 22.

(cf. vaghãpati.)

va ghā $\circ$ a ti : vághāpate. 6. 50. 3 . $\checkmark v$ ac: vívakti. I8. I. $23^{*}$.

vivakti. 2. 28.2 . 4. I. 3 .

uváktha. I. Io. 3 .

uvắca. Io. I. 7 .

ūcimá. 7.83.2. I9.44.9.

ūcús. I 8.4 .49 (mss. -us).

ávocat. 5. 2. $9^{*} ;$ 1 $7.3^{\dagger}$.

avocāma. 5. 1. 9.

vocéyam. I3. I. 14, 37.

vocat. I8. I. $36^{*}$.

vocan. 5. II. 7,8 .

vakşyāmi. 4. 9.7.

uktám. I. 30. 2 . 4. 30. $4^{*}$.

uktâ. I2. I. 55 .

ucyáse. 4. 9. 10. 12. $4.4 ; 5.53$.

ucyase. I9. 44. I (s. mss. -ate).

ucyáte. 9.6.2. ro. 2. 28,30 .

ucyate. 3. 13. 4. 4. $21.6^{*}$. 5. 18.

14. 6. $43.1,2$. 9. 2. 5. I0. 2. 22 ,
23. II. 4. $13^{2}, 15 ; 8.34$. I3. 4. 16 , I 7, 18.

ucyetet. 19. 6.5 (s. mss. -yate).

(cf. ukta, ukthá, vaktr̂́, vácas, vãká, văc, vãcana, vãcas, vivakșú.) + a dhi: ádhi vocata. 6. 7.2.

(cf. adhivāká.)

+ a n u: cf. anuvāká.

+ a pa: cf. apavalktŕ, apavãcana.

+ u d : cf. udvắcana.

+ upa: upociré (p. upaoūc-). 5. 8.6.

(cf. upavāká.)

+ nis: níx avccam. 4. 6.4. 52. 5. 30.

8, 16. 9. 8. 10-2, 19, 20.

+ parā: cf. parãvăká. $\quad$ [2.

+ pa ri : páryuktā (p. -riouk-). 4. I9.

+ pra: prấ vocam (p. prá v-). 2. 5 . 5*. 7. 26. $\mathrm{I}^{*}$.

prá ... vocas. 7.2. $1 ; 5.5 ; 78.2$. prá vocat. 7. $73 \cdot 7^{\dagger}$. 9. 9. I $8^{*}$. 18. I. $7^{*}$. prá ... vocet. 2. I. 2.

$+v i$ : ví vocati. I8. I. I9*.

vácas: I. $2 \dot{9} .5^{\dagger}$. 3. $8.2 ; 24.1 .4$. 4. 2. 6 2. I; 4. I. 7. 105. I. I0. I. 28. 13. I. 43. 20. 128.3 .

vácasā. 2. 31. 2, 4. 4. 7. 4, 5. 5. 8. 4 ; 13.3 ; 23.2. 6. 85. 2 ; 108. 5 . 7. $6.4 ; 21.1 ; 74.3$. 20. 127. 14 \%.

vácasas. $8.7 .7,19$.

vácasi (p. -I íti). 8. 4. 12*.

vácānsi. I9. 32.4 .

vácobhis (p.-caḥobh-). 5. 2. $5^{*}$; 13 .

I. 8. $4.8^{*}$. I9. 3.4

(cf. adhóvacas, yajñavacás, vacasyà.)

v a c a s y à: -àm. I4. 2. $6^{\dagger}$

$\checkmark \vee \operatorname{aj}($ (?): vājáy anti. 6. IOI. 2 (s. mss. -ayá-).

vājáyadıbhis. $7 \cdot 50.3^{\dagger}$.

(cf. ugrá, ójas, ójiyas, ojmán, vájra, văja.)

váj ra: -as. 2. 3.6. 3. I. $4^{*}$. 4. 24. 6. 6. I34. I. I2. 5. I8, 54. I9. 66. I. vajra. $4.31 .6^{*} ; 32.1^{*}$. 6. 13.4. 3 . vájram. 2. $5 \cdot 6^{*}, 7^{*}$. 4. 28. 6. 6. I 25 . $2^{*}$; I35. I. IO. 5.50 ; 9. I. II. IO. I2, I3.

vájreṇa. I. $7 \cdot 7 \cdot$ 2. I4. 4. 4. 3. 5 ; 
28. 7. 5. 22. 6 ; 29. 10. 6. 6.2 ; 134 . 2. 8. 5. 15. II. 10. 3,27 . 12. 2. 9 ; 5. 66. I3. I. 30 . vájrāt. 3.19.7.

(cf. vájrabāhu, vajrín.)

vájra०bāhu: -um. 6. 97. 3*. vájrabāhū (p. -ū íti etc.). 7. x 10. 2. vajrín: -rí. 2. $5 \cdot 5^{*}$.

vajrin. $4 \cdot 32 \cdot 6^{*}$. 7. 72. $3^{*}$.

vajrínā. Io. 4. 12.

vajríne. 6. $2.3^{*}$. $18.1 .37^{*}$

$\checkmark$ V a ñ c: vañcasi. ro. 8.27 .

váñcati. 4. 16.2

váñcate. 20. I 35 . 12 (mss. va-).

vacyásva. 20. 127. $4^{2}$ (mss. vácya-, vacya-).

(cf. vakrá, vañcana.)

+ upa : ef. upavañcana.

v a ñ c an a in sūpavañcaná.

vaníj:-jam. 3. 15. I.

$\checkmark$ vat: + a pi: ápy avivatan. 7. 57.

vatsá: -ás. 3.12. 3, 7; 13. 7. 4. 18.

2 ; $39.2,4,6,8$. 8. 9. 2 ; ro. 12, 22-

9. 9. $4.4 ; 9.9^{*}$. I0. 5. I7. I3. I.

I0, $33 ; 2.13 ; 3.26$. I 8. 4.32 .

vatsám. 3. 18. $6^{*} ;$ 30. 1. 4. 2. 8. 7 . 73. $8^{*}$. 9. 9. $17^{*}$; 10. $6^{*}$. I3. 1. 10, 33 . 20. 48 . $x$.

vatsắm. 4. 38.6, $7^{2}$.

vatséna. $4 \cdot 39 \cdot 2,4,6,8$. I8. 4. 6 . vatsé. 6. 70. $1-3$. 9. 9. $6^{*}$.

vatsāú. 8. 9. 1 .

vatsấs. I3. 4. 6. 20. 134. 2.

vatsằn. I 2. 4. 7 .

vatsănām. 9. 4.2, 4 .

(cf. anupūrvávatsa, tìlávatsa, nítyavatsa, puroḍáçavatsa, mṛtávatsa, vatsápa, vatsara.)

vatsá opa: -as. 8.6. I.

v a t $\mathbf{s}$ a r a in idāvatsará, parivatsará, saminvatsará.

V vad: vádāmi. 6.6r. 2, 3. 12. 1. 58. vadāmi. I. $34 \cdot 3$. 4. $34 \cdot 3^{*}, 4^{*}$. 5. 30. 2-4. 7. 38. 4. I2. I. 58 .

vádati. 6. 29. $\mathrm{I}^{*}$. 12. 1. 4 r.

vadati. 20. 127. 8 (mss. vád-).

vádanti. I0. 8. I7. I I. I. 7. I2. 4.5 I.

vadanti. 9. ro. $27^{*}, 28^{*}$. I0. 8.33 .
II. 3. 26 . I5. I. 8.

vadāni. 7. 12. 1 .

vádās. 12. 3. 52².

udeyam. 3. 20. 10. I6, 2. 2.

vadet. II. 8.3 .

vadema. I2. I. 56 . I8. $3.24^{*}$. váda. 5. 21. r. 7. 38.4. 8. 2. 3 .

vada. $5.20 .6^{2} ; 21.3$.

vadatu. 3. 30. 2 . I4. I. 3 I.

vadata. 3. 30. 3 .

vádantu. 4. 15. 12.

vádan. 18. 3. 70 .

vádantam. 4. 16.6. 8. 4. 13 *.

vádatas. 7. 57. I.

vádantāu. I4. I. 3 r.

vádantas. 3. 30. 5. 6. 47. 2. I8. 1. $4^{*}$

vádantím. 5. 20. 5 .

vádantīs. I0. 8. 33 .

ávadan. 7. 1. 1 .

avadan. 5. $17 . \mathrm{I}^{*}$.

avadanta. 5. 17.6*

ūdimá. I0. 5. 22.

avādișam. $5 \cdot 7 \cdot 4$.

vādișus. 6. 118.3 .

vădișas. 6. $42.3 ; 43.3$.

vadișyati. I. 32 . 1 .

uditâ. 7. 68. 2.

udyámānam. 7. 66. I.

vāvaditi. 20. I35. 13 .

vāvaditu. 6. 126. $3^{\dagger}$.

(cf. udita, udya, vada, vadya?, vāda, vādin, vādya.)

+ a ch a: áchā vadamasi. I 9. 2. 3 (p. ácha v-; ed. achăv-).

áchā vada (p. ácha). 3. 20. $2^{*}$.

+ a ti : áti vadet. I I. 3.25 .

(cf. anatyudyá.)

+ antar: antár vadati. 5. 30. r6.

+ abhí: abhiovádati. 9.6. 4 .

abhí vadati. 9. 6. 48 .

$+\bar{a}$ : à vadāmi. 8. 7.4. I2. I. 29.

āovádāni. 6.69. 2. 9. I. 19.

à vadāsi. 8. I. 6. I4. I. $20^{*}, 2 \mathrm{I}^{\dagger}$.

ầ vadema. I2. 2. 22, 30 .

à vada. 1. 10. 4.4 . 15.14.

+ a c hã : achăvadāmi (p. achaoăv-). 6. $59 \cdot 3$.

[2. achāvádāmasi (p. acha॰āv-). 6. I42. 
achăvadămasi (p. acha॰ấv-). 7. 38. 3. 8. 7.1 IO. IO. 4 I2. I. 27.

+ u d: úd vada. 5. 20. II.

+ upa: upaovádati. I5. 2. I-4.

+ nis: nír avădişam. 4. 6. 2.

+ parā: párā vada. 6. 29. 3 .

+ pari: pári vadanti. I0. 8. I7.

páry avadan. 12. 4. 49.

(cf. parivādá.)

+ pra: prá vadati. 12. 2.38 .

praovádanti. 4. 24. 3 .

prá vadãsi. 5. 20.6. I2. 3. 18 .

prá vadāti. 5. 20.8. I2. 3. I5.

prá... avādişus. 4. $15.13^{*}$.

(cf. pravadá.)

+ u pa pra: upaoprávada. 4. 15.14 .

+ vi: viovádat. 3. 3. 6 .

viovăvadat. 9. 4.II.

+ s a m: samovádanti. $4 \cdot 37.4$. sám avadanta. 6. Iog. 2 .

sám avãdiran. Ir. 4. 6 .

samoúde. 8. I. I5 (sammúde?).

$\mathbf{v}$ a d a in pravadá.

$\mathbf{v}$ a d y a in avadyá (?).

$\checkmark v a d h$, badh: vadha. 6. 6. $3^{\dagger}$ (? mss. vadhatmán̄a).

vadheyam. I0. 5. 15-2I.

avadhișam. 7. 70. 4, 5 .

ávadhit. 9. 2. II.

vadhis. 7. II. $I^{2}$. 8. 2. 5. IO. I. 29.

vadhit. 6. 56.1 ; I I0. 3 ; II 2.1 ;

I42. I.

vadhișus. 2. 28.3 .

badhyāsam. 7. 50. I.

(cf. $\sqrt{ }$ bādh, vadhá, vádhaka, bádhya.)

[úpā-).

+ u p a : upắvadhït. 20. 136.2 (mss.

+ parā : parắvadhīt (p. -rāoáv-). Io. 6. 3 .

vadhá: -ás. I. 20. 2 ; 30. I. 6. 99. 2. vadhám. I. 20. $3^{2} ; 2$ I. $4^{2 *}$. 4. I9. 7 . 8. $4.4^{*}, 20^{*}, 25^{*} ; 8$. I8. II. IO. IO, I 2 , 13. I2. I. 32 . I9. 20. I.

vadhéna. 2. 31.3. 5. 31. I2. 6. 66. I. 8. 4. I6*. I2. I. I4.

vadhăya. 5. 14. 9. 17.28.

vadhăt. 4.28 .5 .6 .93 .3 . I0. 3. 7 . vadhăs. 6. 13. I. vadhāís. 8. $8.3,4$. $10.5 \cdot 42$.

vadhănăm. 5.20. 5. II. 10. 25.

(cf. tápurvadha, devavadhá, puruşavadhá, rājavadhá, çatávadha, vádhaka, vadhatmán.)

vádhaka: -as. 8. 8. 3,4 .

va dhat mán: -nã. 6. $6.3^{\dagger}$ (mss.).

vadhú: : tús. I. I4. 2.3 . IO. 4.4 . 20. 3. I I. 8. 17. I4. 2. $20,28^{\circ}$. vadhu. I4. I. $5^{8} ; 2.7$.

vadhúm. 9. 3. 24. I0. I. 1.

vadhvāí. I4. 2. 9 (1. -dhuāí), 73.

vadhvàs. I4. I. $27^{*} ; 2$. 10".

vadhúas. I4. $2.4 \mathrm{I}, 42$.

badhúas. 8. 6.14 .

(cf. vadhūdarçá-vadhūyú.)

v a dh $\mathbf{u} \circ d$ a r ̧̧á: -çăs. I4. 2.73.

va dhū opathá: -ám. I4. I. 63.

vadh túmant: -ntas. 20. 127.2 (mss vádhū-).

$\checkmark \mathbf{v a d h} \overline{\mathbf{u}} \mathbf{y}$ in

va dh $\bar{u} \circ$ y ú: -ús. I4. I. $9^{*}$.

vadhūyós. I4. 2. 42.

(cf. vădhūya.)

vádhri: -is. 4. 6. 7,82. I6. 6. Ir. vádhre. 6. 138.3 .

vádhrim. 3.9.3. 6. 138.3 .

vádhri. 3. 9. 2.

vádhrayas. 4. 6.7,8. 5.20. 2 .

(cf. saptávadhri, vadhryaçvá.)

vadhry açvá: -rioaçvám. 4. 29.4.

$\checkmark v$ an: vanve. 6.82. I. 8.2. I3 (1. -nue).

vanuté. 12. 2. 36 .

vanute. 7. 103. I.

vanușva. I2. 3. 53 .

vanutām. 4. I5. 10.

vanudhvam. 4. I5. 15 .

vanvatām. 6. $126 . I^{\dagger}$.

vanvānás. 5. 20. 9.

avanvata. 5. 4. 3, 4 .

vananti. I2. I. 58 .

vánās. I. 34.4.

vanișat. 20. I32. 6, 7. [I6. 9.4. vańsișīya (mss. vańçi-). 9. r. r4. (cf. vana, vanana, vaní.) [9.3. + s a m: sám vānayantu (p. van-). 6.

(cf. saminánana.) 
vána: -am. 6. 33. I. 8. 4. $2 \mathrm{I}^{*}$. vánāt. 20. 127.14 (ed. cánas). váne. 8. 6. II. II. 2.24. I2. I. 49. I 8. I. $39^{*} ; 4.50$ (mss.).

vánāni. 6. 30. 2 ; 45. I.

vánā. I4. 2. 7 .

váneșu. 2. 31. 5. I8. 2. 36. I9. 3. 2. (ef. vanín, ványa.)

$\mathbf{v}$ an a in [mss.).

van a ṁkará: -ám. 20. 136. I3 (not vanana in samvánana.

va n a r gú: -gúobhis. 4. 36. 7 .

v a $\mathbf{n}$ a in vanargú, vánaspáti.

ván a spáti: -is. 4. 3. I. 5. I2. 10* 6. 85 . I. 8. 7. I6. I0. 3.8 , II. II. 5. 20. I2. 3. I5.

vánaspate. 5. 27 . II. 6. I25. I*. 7 . 2. 10. I2. 3.33 .

vanaspate. 2.9.1. 6. I27. I. I4. 2. 50. I8. 3. 7. I9. 3 I. 9 ; 34.9. 20. I $36,6,7$.

vánaspátāu. 3.5.3.

vánaspátayas. 8. I0. I8. I5. 6. I. I9. 9. I4.

vánaspátīn. I. I2. $3 ; 24$ I. 3. 2 I. I. 4. 26. 5. 6. I7. 2 . 8. 8 . I 4 ; 10. I8. 9. 3. II. I0. 3. I3, I4. II. 6. I ; 9. 24 .

vánaspátiobhyas. 6. IO. I ; I25.2*. I9. 3. I.

vánaspátīnām. I. $35 \cdot 3.4 \cdot 4 \cdot 5$ (l. -naam). 5. 24. 2 ; 25. 7. 8. 10. 18. I2. I. 57. I5. 6. I. I6. 8. I5. (cf. vānaspatyá.)

vaní: -ís. $5 \cdot 7 \cdot 3$.

vaním. 5.7.2,6. I2. 4. II. (cf. vasuváni:)

vanín: -ínas. I9. 10. $5^{*}$.

vaniṣthúu: -ús. 9. 7. I2. I0. 9. I7. vanișțhós. 2. 33. 4*. vanișthāú. 20. I3I. I 2 (mss. vániș$\checkmark \mathbf{v}$ a nd: vánde. I9. 49.5 .

vándāmahe. 3. $17.8^{*}$.

vándamānas. 3. $15 \cdot 3^{*}$. 7.60. I. vándamānās. I9. 7 I. I (mss. veda。 mătã).

vanditás. I. 7. I.

(cf. vanda, vándana, vándya.) vanda in devavandá.

vánd ana: -as. 7. 115. 2.

(cf. trușțavandana.)

vánd y a : -dias. 5. 12. $3^{*}$. 6.98. I.

vándyas. I8. 4. 65 .

vándye. I9. 49. 3 (mss. vánde).

ványa: -niāya. 6. 20. 3 .

$\checkmark$ I va p: vápasi. 8. 2. 17.

vapate. 9. 10. $26^{*}$.

vapatu. 6. 68.2.

vapata. 6. 68. I, 3 .

ávapat. 6.68. 3 .

(cf. váptṛ.)

+ pra: prá vapanti. I9. 32. 2 .

$\checkmark 2$ v a p: vapāmi. I 8. 4. 55 .

vápanti. I4. 2. $38^{*}$.

vapata. 3. $17.2^{*}$. I4. 2.14.

ávapan. I 8.4 .55 .

uptâs. 8. 8. I6.

(cf. vapana, vapant.)

+ anu: anuovápate. 12. 2. 50.

+ apa: ápā 'vapat. 8. 8.5. 19.36. 4.

+ a pi : ápi ... vapāmi. 12. 3. 22.

$+\bar{a}$ : à vapa. II. I. 26, 29, 32.

opyámānās (p. āoup-). I2. 3. 28.

(cf. āvápana, āvapantikă.)

+ ud: út... vapatu. 3. I7. 3 .

úd avapan. 6. 109. 3 .

+ ni: ní vapantu. I8. I. $40^{*}$.

+ nis: niroupyánte. 9. 6. 14. [34.

+ pa rā : pároptās (p. -rāoup-). I 8. 2.

vapana in ãvápana.

v a p a nt in ãvapantikâ.

v a puṣt a ma (p. -uḥot-): vápuşțame. 5. 5.6.

vápus: I9. 57.4 (mss.). [49. 8 . vápūńsi. 5. I. 2, 8, 9. 6. 72. I. 19. (cf. vapușțama.)

vá p tṛ: : tā. 8. 2. I7.

v a y á m, see va (pron. root).

I vá y a s: I. 22. 3 (váyaḥova-). 2. 10. 3. 4. $21.6^{*} ; 27.5$. 6. 36. 2 . 9 . 4. I0. I1. I. 30. I2. 3. I, 47,49 (váyahova-). I8. 3.73. I9. I. 3 (váyahova-); 37. I, 2. 20. 127. IU.(s. mss. ed. yávas).

váyāñsi. 5. 2. $5^{*}$. [yodhă.) (cf. viçvávayas, vayodhás, va- 
2 váy a s: 7.96. I. váyase. 6. 59. I.

váyasas. I2. I. 5 . váyānisi. 8. 7.24. II. 2. 2, 24; 10. 8. I 2. I. 5 I.

váyobhyas (p. -yaḥobh-). 6. 10. 2. váyaḥosu. 3. 2 I. 2.

(cf. vāyasá.)

v a y ấ: -ấm. I3. 2. $46^{*}$.

v a ýu a: -nāni. 2. 28. 2. 4. 39. 10. 5. 20. 9 .

[1. 19.

va yodhás (p. -yaḥodh-): -ásas. 8.

va yodhấ (p. -yaḥodh-) : -ấs. 5. II. II. 7. 4 I. 2. 9. I. $8 ; 4.22$. I2. 3 . I4. I3. 2. 33. 18. $4.38,50$. 19. 46.6 . I vára: -as. I 3. 4.53 .

váre. 7. 8. I. [(mss. ấsuram).

2vára: -am. 12. 3. 9. 20. 135. 10 váramovaram. 3. I9. 8. 6.67.2. II. 9. 20; IO. 2 I.

várãya. 7. 3. I.

várās. II. I. IO.

várān. I6. 6. Io.

(cf. varadă ?.)

v a rá : -ás. 2. 36. 5,6 .

varám. 2. 36. 6 .

vară. I4. I. 8*, 9*.

varăs. II. 8. I, 2.

varéșu. 2. 36 . I.

(cf. jyesțthavará, vareyá.)

vara náa : -ás. 6. 85 . I. 10. 3. I, 3, 4, 6,7 , IO, II, I3-5, I7-25. I9. 32.9 (not mss.).

varana. 10. 3. 16.

varanám. 10. 3. 12.

varanéna. 10. $3.2,9$.

(cf. samuváraṇa, varaṇávant.)

vara ṇ ấva nt (p. -ṇa॰v-): -vatiām. 4. 7. 1 .

varatrá: -tráyā. 20. 135. 13.

varatrấs. 3. 17. 6*. I1. 3. 10. [-dá). vara dầ (or -dá): -dâs. I9. 7 I. I (p. varāhá: -ás. 8. 7.23.

varāhéṇa. I2. I. 48.

várimatas. 6. 99. I.

va rimán: -mănạm. 7. 14. 3 .

varimṇâ. 4. 6.2. 9.2. 20.

varimṇás. I2. $5 \cdot 72$. váriman: -mã. 4.25.2.

váriy as: 1. 2. $2 ; 20.3 ; 21.4^{*}$. 3 . 4. 7. 4. $19.7 .5 \cdot 12.4$. 6. 53.3. 7 . 50. $4^{\dagger} ; 5$ I. I I $^{\dagger} 65.1$; I18. I". 94. I9. I2. I. 32 . I9. 7.5 .

varĩv ṛt á: -tắt. 8.6. 22.

váruna: -as. 1. 9.1; 16.2; 18.2; 33. $2^{*}$, 2. 28.2 . 3. $3.3 ; 4.5 ; 8.1$; 22. $2 ; 27.3$ 4. 16. $2,5,8^{3} ; 3$ I. $7^{*}$; 32. $2^{*}$. 5.13. I; 17. $2^{*} ;$ 19. $10 ; 21$. II ; 22. I ; $24.4 ; 25.6$. 6. $4.2 ; 2$ I. 2 ; 73.1;88.2*; 93.3.7.81.6; II8. I*. 9.7.7. I0. $4.16 ; 6.15$ II. 5 . I4, I5. 12. 3. 24. I3. 3. I3; 4. 4. I5 2. 3 ; 14. 3. I 8. I. $18^{*}, 39^{*}$. 19. 9. 6", 7; 10. $6^{*} ; 17.4 ; 20.1 ; 26.4 ; 44$. I0. 20. I3I. 3.

váruna. 7.83.2. 19. 44.9.

varuṇa. 1. 10. 2 ; 20.3. 2. 28. 5. 4. I5. I2; I6. 6, 7; 29.5. 5. I. 9; II I, 4, 5, 6, 7, IO, II. 6. 5 I. $3^{*}$. 7. 83 . I, $2^{2}, 3^{*}, 4$. I3. $2.2 I^{*}$. I 4. I. 62 . I8. 4. 70. I9. 44.8 .

váruṇam. I. 3.3. 3. 2 I. 8. 4. 40. 3. 5. I. 9. 7. 25 I, 2. 9. I0. $28^{*}$. II. 6. 2. I8. I. $54^{*}$. I9. I8. 4 .

váruṇena. 2. 29. 4. 3. 5. 4; 6.2; I3 2. 7. I04. I. 9. 3. I8. 19. 56. 4.

váruṇāya. 4. 4. I. 6. 20. 2. I2. 3. 57; 4. 26. I4. 2. $46^{*}$. I5. 2. 3. I8. I. $36^{*}$.

váruṇāt. I. IO. 3 .

váruṇasya. I. IO. I; 25. 3. 2. I0. I-8. 4. 16. $3^{2}, 4$. 6. $38.3 ; 68.3 ; 85$. 2 ; $125.3^{*}$; 132. 1-5. 7. 90.2. 9. 2. 6 ; 4. 8. 10. 4 . I; 5. 10, 44 ; 10. 22 , 28. I3. $2.35^{*}$. I4. 1. 19*, $57,5^{*} ; 2$. 49. I5. 2.3. I6. 8. 26. I8. I. $7^{*} ; 3$. 66*. 19. I3. 10".

várunāis. 3.4.6.

(cf. índrāvárụ̣a, mitrắváruṇa, vivaruṇá, vāruṇá, váruṇatejas -varuṇyà.)

váruṇa ot ejas: -jās. I0. 5.33.

varuṇaní: 6. 46. I. 7. 49. $2^{*}$.

v a r u ṇ y à : -níāt. 6. $96.2^{*}$.

várūtha: -am. 1.6.3". 5.6.14. 20. I28. I2 (not mss.). 


\section{(cf. trivárūtha.)}

várẹny a: -as. 7.14.4.

váreṇias. $7 \cdot 53.6 ; 73 \cdot 6^{*}$. I9. 15.3 . (cf. várenyakratu.)

váreṇya kratu: -us. 6. 23. I (1. -niakr-).

vare yá : -ám. I4. I. I5*, 34*.

varg a in abhivargá.

varg y a in parivargyà.

várcas: I. 9.4 ; I4. I. 2. 29. I. 3. 22. $4^{3}$. 5. 3. I* $^{*}$ I8. 4. 6. 69. 3 ; I24. 3. 7. I2. 3 ; I3. I, 2 ; II4. I. 9. I. II3, I6, I7. I0. 5. 7-14, 36; 6. 8. I2. I. 5,$25 ; 5.8,56$. I4. I. $35^{2} ; 2.29,53$. I6. I. I $3 ; 8$. I-27. I8. 3. I2. I9. 37 . I, $2 ; 49.4 ; 58.2^{2}, 3$.

várcasā. 2. I3. 2. 3. 4. I; 5.1 ; 13. 5 ; 20. 10; 22. $2,3^{2}, 6$. 4. 8. 5,6 . 6 . 5. I; 38. I-4; 53. 3 ; 68. 2 ; 129. 2 . 7. $82.2 ; 89.1,2^{*}$. 9. I. $14^{*}$. I0. 6 . 2, 22. I2. I. 7 , 9. I3. I. I 5 , I 7, I 8 , I 9 , 20; 3. I6. I4. I. $34,35,36 ; 2.2^{*}$. I7. $6,7,27,28$. I 8. 2. $59,60^{\dagger}$; 3. IO, II. 19. $26.2 ; 3$ I. 7,$12 ; 33.5 ; 36$. I. 20. 48. I, 2.

várcase. I. 35. I. 2. 28.5 . 4. 10. 7. 5.28. 13. 6.62. $3 ; 63$. I. I2. 2.28. I9. $26.3 ; 45.6-10 ; 46 . \mathrm{I}$.

várcasas. I9. $58.1,3$.

várcāñsi. 4. 22. 3 .

(cf. avarcás, brahmavarcas, brāhmaṇavarcas, sahásravarcas, suvárcas, sūryavarcas, sómavarcas, hatávarcas, hastivarcas, varcasa-varcodhă.)

varcasa in brahmavarcasá, brāhmaṇavarcasá, hastivarcasá.

v a r c a s y à : -síam. I 9. 26. 4.

várcas vant: -vatim. 9. I. Ig.

varcas vín: -ví. 5.28. IO. I9. 40. 2. varcasvínam. 3.22.3. [21.5. varcodhás (p. -caḥodh-): -se. 3 . varcodhă (p. -caḥodh-): -ấs. 2 . II. 4 .

va rjivā ǹs in ávarjivān̉s.

várṇa: -as. I. 23.2. II.3.8. várṇam. II. 8. I6, I7.

várṇena. I. 22. I. várṇāis. I. 22. 2.

(cf. anyávarṇa, dhṛşádvarṇa, sávarṇa, suvárṇa, sūryavarṇa, híraṇyavarna.)

v a r a in abhivartá, pravartá, pratīvartá, çvavartá.

vartaka in kuçavartaka (?).

vartana in ãvártana, nivártana, vyāvártana.

vartaní: -ís. 7. 21. I.

vartaním. I9. I2. I.

(cf. kṛ̣ș̣̣avartani.)

vártman: -ma. I2. I. 47.

vártmabhyām. 20. I33.6(not mss.).

vártmāni. 6.67. I.

(cf. ánuvartman, prativartmán, puruvártman, satyávartman.)

vártra: -am. I. 3. 7 .

vart syant in avartsyánt.

várdh a: -dhāya. I8. I. $3 \mathrm{I}^{*}$.

várdhana: -am. I9. 30. 4 .

(cf. keçavárdhana, kşatravárdhana, mitravárdhana, yajñavárdhana.)

várdhra: -rān. 14. I. 60.

várpas in bhứrivarpas.

várman: -ma. I. I9. $4^{*}$. 5. 6. 13. 8.

2. 10; 5. 10, I4, 185, I9. 9. 2. $16 ; 5$.

26. I0. 6. 2 . I4. 2. 21 . I8. $2.58^{*}$;

4. 9. I9. 16. 2 ; I9. I-II ; $203,4^{4}$; 30. I (mss.), 3. [46. 4 .

vármanāa. 7. II8. I* I7. 27, 28. I9. vármāṇi. 5.8.6. 8.5.7. I9. 20. 2; 30. 2 .

vármā. I9. $58.4^{\dagger}$ (p. -ma*).

vármaosu. I9. 30. I (mss.).

(cf. avarmán, açmavarmán, devavárman, çatávarman, suvárman, varmín.)

va rmín: -ínam. I9. 30. I.

varmínas. II. IO. $23^{2}$.

varşá: -ám. 3. 27.6. 4. 15. 6, 9, ro, I4, I5. 5. 19. I5. II. 5. I3; 7. 21 . I2. 3. 53. I3. I. 53 . I5. 7.2, 3 . varṣéna. I I. 4.5 I 7. I2. I. 52 . I3. I. 52. I8. 2. 22 .

varșăya. 12. 3. 60 .

varșásya. 4. 15.2, 3, 4. 9. 7. 14. 
varşăni. 8. 2.22. 12. 1. 36 . varşâs. 6. 55.2. I 5. 3. 4 . (cf. vărșika, varşámedas - varsăjya, varsyà.)

varşáomedas: -ase. I2. I. 42. varṣá vṛddha: -am. 12. 3. I9.

várşavr̨ddhe. 6. 30. 3 .

varşấj y a (p. -șáoăj-): -yāu. I3. I. 47. várşişțha: -as. 4. 9. 8.

várşișțham. I9. 49.2.

várşi y a s: -yānosam. 9.6. 19. I5. II. 5 .

várşìyasas. 6. 136. 2.

várşman: -ma. 4. 22. 2.

várşman. 3.4. 2.

varşmán: -má. 20. 127. 2.

varşman. $5 \cdot 2.7^{\dagger}$.

varșmắṇam. $7 \cdot 14 \cdot 3$.

varşmánā. 4. 30. $7^{*}$.

varş y à : -síăs. I9. 2. I.

val a gá: -ás. I2. 5. 39.

valagám. 5. 3I.4. I0. I. I8.

valagás. I9. 9.9 (m. mss. valgăs). (cf. valagín.)

valagín: -ínam. 5. 31. I2. valagínas. I0. I. $3 \mathrm{I}$.

$\checkmark \mathbf{v}$ alg: cf. valgú.

+ a bhi: abhí valganti. I2. 3. 29.

+ s a m: samoávalgata. 3. I3. 2.

valgú: -ús. 2. 36. I.

valgú. 3. 30. 5. I2. 3. I8, 32 .

vavrá: -ám. 8. 4. $17^{\dagger}$.

vavré. $8.4 \cdot 3^{*}$.

vavrí: -ím. 9. 9. $5^{*}$; 10. $7^{*}$. (cf. vavrívāsas.)

vavríovāsas: -asam. 8. 6. 2. $\checkmark$ vaç: vașți. I 8. I. $2^{*}, 3^{*}$.

uçánti. I8. I. $3^{*}$.

uçán. I8. I. $56^{*} ; 3.46^{*}$.

uçántam. I8. I. 20".

uçántas. I4. 2. $38^{*}$. I8. I. $56^{2 *}$.

uçatás. 7. 97. 3. I8. I. $56^{\prime \prime}$.

uçádobhis. I8. 3. $46^{*}$.

uçatấm. 18. I. 20*.

$[4,8$.

uçati. 7. 47.2. 14. 2. $38^{*}$. I 9. 49.2, uçatís. I. $5 \cdot 2^{*}$. 7. 49. I". I4. 2. 52 . vaça. 3. 4.7 (vasa?).

vaçet. I2. 4.27 (vaset?). (cf. I váça, vāçitã ?, váçiyas.)

I vá ç a : -as. I 5. I I. 2, 8, 9 (mss. vaçás). váçam. 4. 31. 3". 5. 19. 15. I5. 11 . 8 (mss. vaçám). I9. 27: 8 .

váçasya. I1. 8. 17.

váçe. I. 8.2. 3. 25.6 . 9. 10. $24^{2}$. II. 4.1 ; 10. 4 . I3. 4.28 .

váçās. I. 10. I.

váçān. 6. 72. 1. 9. 4.24.

váçeşu. 3. 8.6.

(cf. avaçá, yathăvaçá, vaçant, vaçín.)

2 vá ça: -am. 8.9.24. 9.4.21.

vaçá t a m a: -má. 12. 4. 42.

v a ça $\mathrm{n}$ Î: -Îs. I8. 2. $5^{*}$.

vaçă: 7. I13.2. Io. 1o. 6, 12, 13, I4, I $5,17,18^{2}, 23,24,25^{2}, 26,28,30^{3}, 34$. I2. 4. IO, I4, 22, $25,29,30,33,35,36$, $37,39,42,44,45,46,47$. 20. 136. 13. vaçe. Io. 10. $7^{2}, 8^{2}, 9$, 10, 11, 16, 19, 2O, $21,22$.

vaçấm. I0. 10. $2,4,5,26^{2}, 27,32,33$, $34^{2}$. I2. 4. I, I5, I6, I8, 20, $21,22,23$, 24, 3I, 34, 38, 48, 49, 50, 53 .

vaçấyās. IO. IO. I8, 29, 30, 31. 12. 4. 4, 32, 40, 5 I. 20. 130. 15 .

vaçấyām. I0. I0. 25 .

vaçấs. I2. $4 \cdot 41,43$.

vaçăsas. $4 \cdot 24 \cdot 4$.

vaçănām. I2. 4. 42 . I9. 24.6 (mss. vāpinắm).

(cf. ávaçā, sūtávaça, vaçátama, vaçājātá-vaçābhogá.)

v a çāojātá: -tấni. I2. 4. 47. [6". vaçấnna (p. -çấoan-): -nāya. 3.21.

vaçā०bhogá: -ás. I2. 4. I3.

vaçín: -çí. I. 2 I. I*. 4. I 7. $8 ; 24$. 7 ; 31. $3^{*}$. 5. 22. 9 . 6. 5.2 ; 26. I; 36.2 ; 36. 2 . 8. $5.4,7,22$. Iо. 1о. 24. II. 5. I6; 6. 21. I5. II.9. I9. 13. 4"; 46. 7 .

vaçínām. I5. I 1.9 .

vaçíni. I4. I. $20^{*}$.

(cf. tanūvaçín.)

váçīy a s. I 8. 4.49 (vásīyas ? ed. vaçấya).

váṣaț. I. II. I. 7.97. 7². 8. 10. 20. (cf. vașațkārá, váşaţlụta.) 
vaṣaț०kārá: -ás. II. 7.9. I3. I. $15 ; 4.26$.

vașațkārám. I5. I4.9. [14.9. vașaṭkāréṇa. 5. 26. I 2. 9. 6. 22. I5. vașațkāré. 10. 3. 22.

váș a ț॰kṛta:-am. 9.5. I3. Ir. IO. I4. vas (pron.), see va (pron. root).

VI vas, uch: uchántu. 3. I2. 4 (ukșá:?).

uchantu. 3. 16. $7^{*}$.

uvāsa. I8. I. $20^{*}$.

avasran. I $8 \cdot 3 \cdot 24^{*}$.

(cf. Vuṣ, úṣ, uṣás, uṣți, uṣ̣á, usrá, ūṣmán, oṣá, vásiștha, vásiyas, vásu, vástu, vásyas, vāsa, vivasvant.)

+ a pa: ápo 'chatu. 6.83. x.

ápa ... uchatu. 2. 8. $2-5,2$. 3. 7 . 7. 4 4. 2. 48 . I6. 6. $2^{*}$.

ápo 'chantu. 2.8.2. 8. $4.23^{\dagger}$.

ápa ... avãsayas. 19. 50.5 (not mss.). (cf. apavãsá.)

+vi: ví uchatu. 7.69. I.

ví uchet. II. 4. 2 I.

viouchántiss. I7. 30. I9. 49.6 .

vioāúchat. 3. Io. 4 .

ví uvāsa. 3. ro. I.

ví avāt ( $V_{\text {I }}$ vā ?). 8. I. 2 I.

(cf. vyús, vyùști, vyòșa.)

$\checkmark 2$ vas: váste. I0. 8.36 . I3. 3. I. vaste. I3. I. $16^{2}$.

vasáte. I9. 20.2 (mss. vasaté).

vásānas. 4. 8. 3*. 9. 4. 7; IO. II*. I 0. 2. 7. II. $5.5,6$. I4. 2.44 . I 8 . 2. $\mathrm{IO}^{*} ; 4.3 \mathrm{I}$.

vásãnã. 3. 12.5. 9.3.17.

vásānām. 9. I. I.

vásāne (p. -e íti). I3. 3. I I.

vásānās. 6. 22. I*. 7. 40.2. 9. 9. $5^{*}$. 13. 3. $9^{*}$.

ávasta. I4. I. 56.

(cf. vasantá ?, vástra, vāsana, vàsas, I vāsya).

[II.

+ a n u: ánu vaste. II. 4. Io. I3. 3 . ánu vastām. 7. 27. I ; II8. I*.

+ a bhi: cf. abhivāsín (?).

+ upa: cf. upavấsana. [13. 2. 32 .

+ pari: pári...vásãne (p. -e íti).
+ s a m: 'sam̉ovásānāu. I2. 3. 52.

$\checkmark 3$ v a s : vásati. 5. 17. 18. 15. 13. I-5.

vasati. 10. 8 . 15 .

vasāmasi. 19. 47.9.

vaset. I 2. 4. 27 (mss. ed. vaçet).

vasa. 3. 4.7 (mss. ed. vaça).

vasatu. ro. 6.4 .

ūṣimá. 7. rog. 7 .

avātsīs. I5. II. 2, 3.

vāsaye. I5. 13. 8.

[2 vãsya.)

(cf. vasatí, vasatha, vãsin, văstu,

+ ã : â vasanti. 7.79. 2.

(cf. ãvasathá.)

+ u d: úd vãsayãthas. 12. 3. 35 .

+ pra: praovásan. 7.60. 3 .

+ vi: ví vasantu. 4. I. 5 .

+ s a m: sam̉ovásantas. 7.79. I; 80. I.

vasatí: $-\mathbf{i m}$. 7.96. I.

vasatés. 6. 83. $\mathrm{r}$.

(cf. văsateya.)

vas a tha in ãvasathá.

vas a ntá: -ás. 6. 55.2. I2. 1. 36 .

I5. 3. 4. 19. 6. 10*.

vasantám. 20. I36. I6 (mss. vasántam, ed. kṛçitám).

vasantáya. 8. 2. 22.

vasantăn. 3. II. 4 ".

(cf. vãsantá.)

va sávya: -yāis. 7. 26. 8.

vásiṣtha: -as. 6. IIg. I. 7.53.2. vásiṣtham. 6. 21.2 ; 44. 2.

(n. pr.) vásișțham. 4. 29. 3.

vásișțha. I 8. 3. I6.

vásiṣthās. I8. 3. $46^{*}$.

vá s I y a s: r 8. 4.49 (mss. váçiyas, ed. vaçấya).

vásu: 1. 9. 1. 3.14.2. 6. 79.2. 7. 4I. 2 ; 79. 3; 90. $2^{*}$; II5. 2. 10. 8 . 20. I2. I. 44. I4. I. $25^{*}$; 2. 8. I6. 9 . $4^{2}$. I8. 2. 60. I9. 50.6. 20. I35. II. vaso (p. - o íti). 7. 55. I.

vásum. 7.97.4.

vásunã. 5.28.4. 7.98. I.

vásos. I. I. 2. 9. 4. 3. I2. 3. 4r. 19. 55. 2,3 (vásoḥova-), 4 (do.).

vásvas. I8. 3. $43^{*}$.

vásūni. 2. 35. I. 3. 4. 2, 4. 4. 32. 3*. 5. 7.6. 6. $63.4^{*}$. 7. $48.2^{*} ; 97.3$ 
4. 12. I. 44. 19. 5. $\mathrm{r}^{*} ; 24.6$.

vásūnām. 4. 26. 1,2 ; 30. $2^{*}$. 7. 73 . 8*; 76. 6"; 79. 3. 10. $8.42^{*}$.

(n. pr.) vásavas. 1. 9. I. 3. I. 2. 5 . 27. 6. 6. 68. 1. 8. 1. 16; 8. 12. I0. 7 . 22 ; 9.8 ; IO. 30,3 I. II. 6. I3. 12. 2. 6. I9.6. II"; 9. II ; II. $4^{*}$. 20. I35.9. vásavas (voc.). I. 30 . I.

vasavas. 4. 27.6. 7. 77. $2^{*} ; 97.3$. vásuobhis. 2. 12.4 . 4. 30. $\mathrm{I}^{*}$. 5 . 12. $3^{*}$. 6. 73. $1 ; 74.3$. 19. 10. $6^{*}$; I7. I. 20. 13I. 3 (not mss.).

vásuobhyas. 8. 3. 9*.

vásūnām. 9. 1. 4.

(cf. āyádvasu, idádvasu, púnarvasu, purūvásu, bhávadvasu, vājinîvasu, viçvâvasu, saṃyádvasu, sámbasu, svávasu, vasávya, vásișțha, vásiyyas, vásyas, vasujít-vasūyă.)

vasuojít: 5. 20. 10. vasujíti. I3. I. 37.

v a suodă : -ấs. I2. I. 44 . $19.55 \cdot 3$ (p. -ănas), 4 (do.). [3 (mss.), 4 (do.). vasuodâna: -as. 6.82.3. I9. 55 . vasuodé y a: -yãya. 3. 4. 4 .

vasudéye. 12. 4. 26.

$\mathbf{v} \mathbf{s} \mathbf{u} \mathbf{d} \mathbf{h} \overline{\mathbf{a}}$ in

vasuodhattara: -as. 5. 27.6.

vasuodhăna: -as. II. 2. II.

vasudhẳĩ. 12. 1. 6 .

vás u०nIti: -is. I2. 2. 6 .

vasuopátnì: 7.73. 8*.

vásuom an t: -mān. I6. $9 \cdot 4^{2}$. vásumantam. I8. I. 26".

vásuoruci: -is. 8. 10. 27.

vasuováni: -is. 7. 60. I. I3. 4. 26. vásuovant: -ntam. I9. I8. I.

vasuovíd: I8. 4.48 .

vasuvídam. 3. 16.6". 20. 127.6.

$\checkmark$ vasu y in

vasū y â (p. -suoy-): 4. 33. $2^{*}$.

vastí: -ínā. I2. $3 \cdot 43^{2}$.

vastāú. I. 3.6.

(cf. vâsteya, vastibilá.)

vastiobilá: -ám. I. 3. 8.

vástu: -tos. 5. I2. $4^{*}$. 6. $31.3^{*}$.

vástra: -am. I4. 2. 4I, 42 . vástrẹ̣a. 18.2. 52.

vástrāṇi. 5. 1. 3.

vástrā. 9. 5.25. 12. 3. 21 .

vasná: -néna. 12. 2. 36 .

vás y as: 6.47.3. 7. 103. I.

(cf. vasyobhúya.)

[16. 9. 4 .

vas y o b h ta y a (p. -yaḥobh-) : -yãya.

$\checkmark v a h:$ váhasi. 4. 23.2. 9. 5. 17.

váhati. 13.1.21".

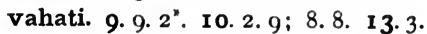
I9. I9. 53. I, 2.

váhanti. I3. 2. 4,6, 7, 23*.

vahanti. 8. 9.16. 9. 9. $3^{*}, 14^{*}, 19^{*}$. I3. I. $24,36,43 ; 2.1^{\dagger} ; 3.16$. I 8.4 . 44.

váhase. 7. 4. I.

váhāti. 6. 55. I. I8. 2. 53 .

vahātha. I. 30. 2. I8. 4. IO.

vaha. 5. 8. I; 29. I. 7. I09. 2.9. 5. 17. I0. 9. 25 . I8. 2. 8*.

váhā (p. -ha). I8. I. $30^{*}$.

vahatu. 9. 4.3. 12. 2. 8*. I9. 4. I.

váhatam. I. 27.4.

vahatam. 3. II. 6.

vahata. 5. 26. 4 .

vahantu. 7.53.4. I4. 2.74.

váhantam. II. 2. $29^{\dagger}$.

váhamānas. I 8 . I. $24^{*}$.

váhamānās. $7 \cdot 97 \cdot 4$ (p. -nā).

ūháthus. 6. 82. 2.

ávāṭ. I8. 3. 42*; 4. I.

vākșit. 5. 8.3.

vakṣyatás. II. 2. 29.

vóḍhave. I8. 2. 56 .

uhyámānam. I4. 2. 9 .

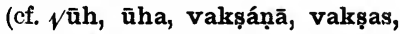
vah vāh, váha, vahatú, váhiṣțha, váhni, vahyá, vāhá, vāhín, vāhana, vāhas.)

+ a n u : anūhiré. r 8. 3. 46* (mss. anu。 jahiré).

[mss.).

+ a pa: ápā 'vahat. 20. I30. I (not

+ abhi: abhyùụhas (mss. -yút-; p. -ioú-). I5. $15 \cdot 5$.

$+\overline{\mathbf{a}}$ : ā॰váhāt. 6. I23. I.

à vahān. 2048.3 (mss.?).

à vaha. I. 7. I, 7. 4. 23. 2. 5. 4.6. I8. I. $56^{*}, 57$;2. 34 . 20. I28. I5. 


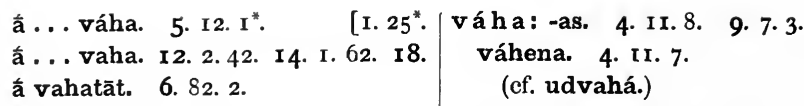
(cf. udvahá.)

+ ni : ní ... vaha. 20. I35. I I (mss.?).

+ nis: nír vahata. I8. 2. 27.

nír vakșat. I2. $2.47,48$.

+ parā: párā vaha. I6. 6. $3^{2}$. párā vahantu. I0. 4. 20. I6.6. 7, II. + pari: páry avahan. I4. 2. I". pariouhyámānā. I 8. I. $53^{*}$. [5.3. páryūọhā (p. -rioū-). I I. 3. I5. I2.

+ pra: praováhanti. 6. 5 I. $2^{*}$. prá vaha. 2. 5. I.

prá vahatām. I4. I. 20*.

prá vahata. 7.89.3.

prá...vahantu. I0. 5.24. I6. I. II ${ }^{2}$. prāúḍhas (p. praoúḍh-). I5. I5. 4 . (cf. pravāhín.)

+ anupra: anuoprávoḍhum. I9.

+ vi: ví uhyate. I4. I. $13^{\dagger}$.

(cf. vivāhá.)

+ s a m: sam̉ováhanti. I3. 3. I 7.

sám vaha. 6. 48 . I- 3 .

sám ... vákșathas. 2. 30. 2.

sámoūụham. 7.26. $4^{*}$.

vahatú: -ús. I4. I. $13^{*}$.

vahatúm. 3. 3I. $5^{*}$. I4. I. $14^{*}, 6 \mathrm{I}^{\dagger}$, $6 \mathrm{I}^{*} ; 2.9,10^{*}$, I 2,73 . I8. I. $53^{*}$.

vahatúnā. I4. 2. I*.

vahatāú. I0. I. I. I4. 2.66.

vá hiṣt ha a: -as. 4. 34. 5 (mss. bah-). váhișțam. 4. 23.3 (mss. bah-).

váhișţhās. I3. 2.6, 7 .

$\left[23^{*}\right.$.

váhni: -is. 5. 27.4. 13. 3. 19. 18. I. váhnim. I2. 2.47 .

váhni (p. -i íti). I8. 2. 56. (cf. suváhni.)

v a h y á: -ám. 4. 20. 3. I4. 2. 30. (cf. vahyaçivan.)

v a h y a oç I va n: -varis. 4. 5. $3^{\dagger}$. vā (conj.). 1. $4.2^{*} ; 9.2 ; 18.3^{2} ; 25$. $2^{2}, 3^{2} ;$ 30. I, 4 ; 32. 2. 2. I2. $6^{*} ;$ I 4 . 5 ; 28. 2, 3. 3. II. $2^{*}$; 13.6. 4. 8. 5 ; 9. 10; 12. $7 ; 18.5 ; 26.7 ; 27.5 ; 38$. 5. 5. I. $7^{2} ; 5.4 ;$ I $4.6,7^{2} ;$ I9. 3 ; 22. 2,7 ; 25.6; 3I. 2, 4, 8. 6. 7. I ; 29. $\mathrm{I}^{\dagger}, 2$; IO6. $\mathrm{I}^{2+}$; II3. 2 ; II6. 2, 3; I20. I. 7. I. $\mathrm{I}^{2} ;$ I2. $4^{2} ; 26.8 ; 38$. $5^{2} ; 50.7^{\dagger} ; 65.2 ; 66.1 ;$ 108. I, $2^{2}$. 8. 3. $5^{*} ; 4.9^{3^{*}}, 14^{2 *}, 15^{*}, 16^{*}, 18^{*} ; 6.18 .9 .6$. $39^{4} ; 8.20$; 10. $\mathrm{I}^{2^{*}}$. IO. I. I I, I $8^{2} ; 8.17$, $27,28^{2} ; 9.26^{2}$. 12. 2.4 ; 3. $13,39,52$. I3. I. 5 I, $54 ; 2.6,7 ; 4.42^{3}, 43^{3}, 45$. I4. I. $36 ; 2.62,65$. I8. I. I6 $2^{* *}, 22^{*}$; $4^{*} ;$ 2. $7^{*}, 17^{*}, 31 ; 3.55^{*}$. 19. 9.4 (mss. vām); $38.2 ; 39.9 ; 48$. I (mss. iva). 20. $132.15, x 6$.

V I vā: vāti. 6. 91. $2^{\dagger}$.

vātas. $4.13 \cdot 2^{*}$.

vătu. 4. I5. I6.

vātu. 7. 69. I. 8. 2. 14.

vāntu. 4. 15. 8. I2. 3. 12. I8. I. $39^{\dagger}$.

(cf. vā, văta, vāyú, vāyya.)

+ a ti: áti vāti. 4. 5. 2.

+ a nu: ánu vāti. I2. I. 5 I.

+ a pa: apaovấn. 19. 50. 4 (? ed. áparam).

+ a nus a m: anuosámvahanti. Io. + a bhi: abhí vātu. I9. 10. $4^{*}$.

vah, vāh in anaḍváh, prșțivăh, $+\bar{a}:$ â...v vāhi. 4. 13. $3^{*}$.

havyavâh. āovătu. 4. 13. $2^{\dagger}$. 
+ up a: úpa vāntu. I8. 2.21. (cf. upavá.)

+ nis: nír vāpayāmasi. 6. I8. I. nír vāpayā (p. -ya). 18. 3. 6*.

+ pra: prá vãmi. 4. 30. $8^{*}$. praováti. I0. 8.35 .

(cf. pravă, pravāyyà.)

+ vi: ví... vāhi. 4. 13. $3^{*}$

ví ... vātu. 4. $13.2^{\dagger}$.

ví avăt. 8. I.2I ( $\sqrt{ } \mathrm{I}$ vas ?).

$\mathbf{1}^{\prime} \mathbf{2} \mathbf{v} \mathbf{a}, \mathbf{v e}, \mathbf{u}$ : vayati. ro. $7.43^{\dagger}$.

vayatas. I0. $7 \cdot+2$

avayat. 10. 2. 13.

ávayan. I4. I. 45 .

utám. I 4. 2. 5 I.

vătave. I0. $7 \cdot 44^{\dagger}$.

ótavāí. 9. 9. 6*.

(cf. uta, 6tu.)

$+\bar{a}:$ ótā etc., see $\mathfrak{V}$ u.

ótam (p. àou-). I I. 7. IO.

ótās (do.). I $\quad$ o. $8.37,38$.

+ s a mā : samoótās. I I. 5. 24 .

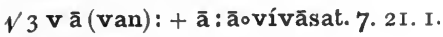
āovívāsatām. 8. 4. 2I*.

$\mathbf{v}$ a in upavă, pravá.

vāká: -ám. 9. 10. $2^{2 *}$.

vākéna. 9. Io. $2^{*}$.

vākăs. 6. 25. I-3.

vākāís. I9. 3.4.

(cf. adhivāká, anuvāká, upavā .

ká, cakravāká ?, namovāká, pa. rāvāká, sūktavāka.)

vāg vín: -ví. 5. 20. I I.

văc: văk. 2. 12. 8. 3. 13.6. 5. I8.

8. 6. 3 I. $3^{*}$. 8. 8.22. 9. I. 10, 20 ; I0. $24,27^{*}$. I I. $8.4,26$. I2. 5. 7. I6. 2. I; 6. 5. I9. 9. 3 ; 60. I.

vắcam. 2. I. 4. 3. 20. IO; 30.2, 3 . 4. 6. 2 ; $15.13^{*}$ (mss. vătam). 5. $\mathrm{I}$. 2 ; $7.4,6$; 10. 8 ; 20. I, $4,5,6,8$, II. 6. $34 . I^{*} ; 49.3^{*} ; 6$ I. $2 ; 69.2 ;$ II 8 . 3. 8. 9. 3. 9. I. I9; $2.5 ; 9.10^{*}$. I0. 2. 7. II. I. $2^{\dagger} ; 5.24$. I2. 3. I5. I 4 . I. 31. I6. 2.2. I9. 4. 4. 20. 127. 5 . vācă. I. I8. $3 ; 34.3$. 2. 3 I. $3 ; 35$. 5. 5. 7. 5; 30. 2-4, 9. 6. $85.2 ; 96$. 3; I2I. 2. 7. 70. I. 8. I. $3 ; 3.6^{*}$. 9. 3.2. I0. 7.39. I3. I. I3. I6. 6.5.
I 8. I. 30". 20. 49.2 (not mss.), 3 (do.). vãcás. I. I. I, $3,4^{2} \cdot 4 \cdot 13 \cdot 7^{*}$. 7. I. I. 8. 3. $12^{\circ}$. 9. 10. $13^{\circ}, 14^{\circ}, 15^{\circ}, 27^{\circ}$. 12 . I. $16 ; 3.5$. I6. $6.6^{2}$. I7. 29.

vắcas. I 3. I. I 7-9.

vãcas. I. I. 2.

văcí. 5. 12. II".

vắcas. 7. 43. I. I0. 8.33 . 20. 49 . I (mss. -am).

(ef.anŗtavăc, durvăc, droghavăc, bhadravāc, satyavắc, suvắc, vāgvín, vãcăstena.)

vã c a n a in anapavãcaná, udvắcana. vā c a s in vívãcas, sávācas.

vācăostena: -am. 8. 3. 14 *

vă ja: -as. I I. 7.3. I3. I. 2. I8. I. $33^{*}$. văjam. 4. 27. I. I4. 2. 70. I8. I. 22". I9. I2. $I^{*}$.

văjāya. 7.6.4.

văjasya. 3. 20.8. 7.6.4. [vāje). văje. 6. $38.3,4$. I9. $24.7^{*}$ (văje。 văjās. 4. 4. 8. I9. 3I. II.

văjān. I2. 2. $26^{*}, 27$. I3. I. 22.

(cf. vājapéya-vājinīvasu.)

vāja $\circ$ péy a: -am. Ix. 7.7.

$\checkmark \mathbf{v} \mathbf{a} \mathbf{j}$ a y, see $\boldsymbol{V} \mathbf{v a j}$.

văja 0 sāta: -te. 4. 27. I.

vâjaosāti: -taye. 5. 6. $4^{*}$. 7. 49 . $I^{*}$. I4. 2. 72 .

văjjasātāu. I9. IO. I*

vājín: -jí. 5. 29. 10. 8.5.2. 9. 2. 7. I9. $13.5^{*}$.

[I. I. vājin. 4. $38.6,7$. 6. 92. I, 2, 3*. I3. vājínam. 3. 20. $7^{*}$. 7. 80. $2 ; 85.1^{*}$. 8. 3. I*. I3. 2. 7 .

vājínā. 4. 4.2. II. 2. 7 .

vājínas. 6. 72. 3 .

vājínā (du.). 8. 4. 6*.

[2. 4 .

vājínas (pl.). r. 4. $4^{*}$. 3. I6. 6*. I9. vājíobhis. I9. 27. I.

vājini. I9. 47.4 .

vājínīs. I. 4. 4.

(cf. văjina, vājínīvant, vājinĩva-

văji in a: -am. I0. 6. II.

văjināni. 3. I9. 6. 12. 3. 2.

vājínī。vant: -vān. 4. 38. $5^{2}$.

vājinīvan. 4.38.6, 7 .

vājínivate. I8. 3.54. 
vājínīvatas. 8.8.6. I0. 4.7. vājiñ̄॰vasu: -sū (p. - -ũ íti etc.). I4. 2. $5^{*}$.

$\checkmark \mathbf{v} \bar{a} \mathbf{n} \mathrm{ch}$ : vấñcha. 6.9. $\mathrm{I}^{3}$.

vāñchantu. 4. 8.4. 6. $87 . \mathrm{I}^{*}$.

văni: -ṇis. 9. 10. 2*.

vāt a in vātīkārá, vātîkṛta.

vâta: -as. I. II. 6. 2. Io. 3 ; 30. I. 3. 2 I. 10; 26.4 . 4. 5.2 ; I5. $16 ; 30$. 8*. 5. 3. $3^{*} ; 5.7 ; 9.7 .6 .62 .1 ; 91$. 2*. 7.69. I. 8. I. 5 ; 2. $14 ; 6.19$. 9. 2. 24 I0. I. 13,$17 ; 3.13,14 ; 7$. I $2,34,37 ; 8.35 ; 9.26$. II. $3.4 ; 4$. I $5 ; 7.2 ; 8.3$ I. I2. I. 5 I. I3. I. 5 I. I 5. 2. I-4. I9. IO. $4^{*} ; 27.2,7 ; 44$. $5 ; 54.2 ; 55.2$ (mss.). 20. I32. 4 (mss. vāta).

vāta. 4. $13 \cdot 3^{2 *}$.

vătam. 3. 20. $7^{*}$. 4. 15.13 (ed. văcam $\left.^{*}\right)$. 6. 89. 2. II. 6.6. I8. 2. $7^{*}$.

vătena. 6. 72. 2. I0. 3.15 ; IO. I4. vătāya. 10. 6 . I I-7.

vátāt. 4. Io. I. 8. 2.3. 9. I. I, 3, IO. vătasya. 3. I. 5 ; 2.3. 9. 4. 13. I 2. I. 5 I.

văte. 3. 2 I. 7 . 6. $38.3 ; 92.2$. 7 . 66. I ; 97. 8. I 8. 2. 26 (p. vă te). I 9 . 8. 6 (p. vătah).

vătāu. 4. 13.2".

vătās. I. I5. I. 4. I5. 8. I2. 3. I2. I3. 3. 2. I 8. I. I 7, $39^{\dagger}$; 2.21. I9. I. I. (cf. nivātá, vătagopa - vātāparjanyá.)

vat taogopa: -am. 2. I2. I.

vāta $a \circ$ ấ: -ấs. I. 12. 3 .

vătaojūta: -tāni. 4. I5. I.

vàta otejas: -jās. I0. 5. 29.

văta $\circ$ patni: -is. 2. Io. 4 .

vāt $a \circ p$ út: -ús. I 8. 3. 37 .

vātaobhrajas: -jās. I. I2. I.

vầtam。āy as: -yās. I3. 2. 42.

văta $\circ$ ranh as: -hās. 6. 92. I.

vătaran̉hasas. I I. 10. 3. [mss. -yà).

vātā parja nyấ: -nià. Io. 4. I6 (s. vātāparjanyáyos. 6.93. 3 .

vātĩokārá: -ásya. 9. 8. 20.

vātîn krta: -asya. 6. Iog. 3 . (cf. vātīkṛ̂tanăçana.) vātíkṛtaonăça na: -nt. 6. 44. 3 . vā d a in parivādá, pāpavādá, vādin. vā di n in priyavādín, brahmavādín, satyavãdín.

vā d y a in ekavādyá.

vấd h ū y a: -am. I4. I. 29*; 2.41, 42.

vānaspatyá: -ás. 5. 20. I; 21.3. 12. 3. 18 .

vānaspatyăs. 3. IO. 5. I2. I. 27. I5. 6. I. [9. 24

vānaspatyắn. 3. 6.6. 8.8. I 4. I I. vānaspatyắnām. 15. 6. 1. I6. 8. 16. vānaspatyéșu. I4. 2. 9. [çănām). vāpí: -pĩnăm. I9. 24. 6 (mss. vavāmá: -ám. 4. 22. 4. 6. 92. 3. 7. 84. $2^{*}$. I4. 1. $46^{*} ; 2.9$.

vāména. 7: 60. 2.

vāmásya. 4. 25.6. 9. 9. $\mathbf{I}^{*}, 5^{*}$. (cf. vāmádeva.)

vāmá。d eva: -as. I8. 3. I5.

vămadeva. I8. 3. I6. (cf. vāmadevyá.)

vāma。devyá: -ám. 4. 34. I. 8. I0. 13,17 . I5. $2.2 ; 3.5 ; 4.2^{2}$.

vāmadevyéna. 8. 10. 15 .

vāmadəvyáya. I5. 2. 2.

vāmadevyásya. I 5.2.2.

vāy a in padavāyá. [-ăn).

vā y a v y à: -yăn. I9. 6. I4* (m. mss. vāyavyầni. 9.6.17. [sas). vāyas sá: -ás. I9. 39. 9 (mss. vā văvāyú : -ús. 2. 26. I; 34.4. 3.8. I ; I2. 4 ; 20. IO. 4.25 .5 ; 29. 4. 5. 24. 8. 6. 53.1 ; 124.2 ; I4I. I. 8. I. 15. 9. $7.4,8$. I1. 10. I6. I2. $5 \cdot 72$. I3. 4. 3,32 . I4. I. $4^{*}$. I6. 4.4 . I9. 6 . $7^{*} ;$ 10. $9^{*} ;$ I 7. $2 ;$ 19. $2 ; 27.1 ; 43.2^{2}$. vầo (p. -o íti). 20. 20. $1-5$.

vāỵo (do.). 4. $25 \cdot 3,4,6 . \quad 6.68$. I. 7. 4. I.

vāyúm. 4. 25.7; 40.6. I8. 4. 29*. I9. I8. 2.

vāyúnā. $4 \cdot 39 \cdot 4$.

vãyáve. 4. 39. $3^{2}$. 6. I0. 2. I9. 43. 2. vāyós. 4. 25. I. 6. 5 I. 1. 9. 4. 10. I3. 4. 32. 20. I3I. 4 (not mss.).

(cf. indravāyú, vāyavyà, vāyútejas, vāyumánt.) 
vāyú ot eja s: -jās. I0. 5. 26. vāy u mánt: -mádobhis. I2. 2.29. $\mathbf{v}$ ā y y a in pravāyyà.

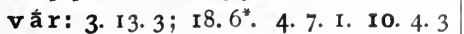
(m. mss. vār), 4 (do.). I8. r. $32^{*} .20$. 135. I 2 (?).

vấra: -as. 10. $4.2^{2}$. 20. 129. 18 . (cf. băla.)

[vāra.

vāra in abhiviăra, viçvávāra, çatávāra ṇá: -ṇt. 5. I4. II.

vāru ṇá: -ṇăs. 6. J2r. I. 7.83.4. vă r y a : -as. 19. 45.4 (mss. cā "ryàs). vấrie. I9. 49.3 (mss. várye).

văriam. I8. I. $4 \mathrm{I}^{*}$.

văriāṇi. 7. 10. $1^{*}$; 14. 3 .

văriā. 7. 17.3.

văriānaam. I. $5 \cdot 4^{*}$.

vắrșika: -am. 4. 19. I. 5. 22. 13. vấrṣikāu. I5. $4 \cdot 3^{2}$.

vắrşikis. I. 6.4 .

$\mathrm{v}$ à $\mathbf{l a}$, see băla.

vā vattā: 20. I28. I I (mss. văvātâ). $\checkmark \mathbf{v}$ ă Q̧: văçyamānā. I2. 5. 20.

vāvaçānâ. 9. 1. $8^{*}$; 10. $6^{*}$.

(cf. vaçă, văça, vāçrá.)

+ ni: cf. nivāçá.

$\mathbf{v}$ à ç a in nivāçá.

v ā çi t ấ: -ắm. 5. 20. 2 (mss. ed. vāsi-). vă çì : -çiā. Io. 6.3 (mss. ed. vâsyāa). vā ç rá: -rấ. 12. 3. 37 .

vãçrăs. 2. 5. 6*. 4. 15. I, 5 .

$\mathbf{v} \mathbf{a} \mathbf{s}$ a in apavãsá.

văs ateya: -as. 8. I0. 4 .

$\mathbf{v} \mathbf{s}$ an $\mathbf{a}$ in upavásana.

vās a ntá: -tāú. I 5. 4. I ${ }^{2}$. (cf. văsantika.)

văs a ntika: -am. 20. 136. 3 (mss. văsantikám).

vāsavá: -ásya. 6.82. I.

vấs a s: 2. 13.2, 3, 5. 8. 2. 16. 9. 5 . I4, 29. I0. 2.15 . 12. 3.51 . I4. I. $7^{*}, 30,45,53 ; 2.4 I, 42$, 5 I. I 5. 2. I-4. I8. $2.57 ; 4$. 3 I. I 9. $24.5,6$.

văsasā. 7. 37. 1. I4. I. 27. I8. 2. 5 I. văsasas. 6. 124.2. 14. 2. 50 .

văsānnsi. 9. 5. 26.

(cf. agnívāsas, lóhitavāsas, vavrívāsas, suvăsas.) vã sit tă, see vāçită.

văs in in bastãbhivāsín, kharvavăsín, bastavāsín, savāsín.

vàs I, see văçí.

vástu: 7. 108. I.

văstos. 6. 73. 3 .

văstūni. 9. 2. 4, 9 .

văstuşu. I 2. 5. 49 .

(ef. avāstú.)

vầsteya:-yis. II. 8. 28 .

I vās y a in prathamavāsyà.

2 vāsya in amãvāsyà.

$\mathbf{v} \overline{\mathbf{a}} \mathbf{h}, \operatorname{se} \theta$ vah.

vāhá: -ás. 6. IO2. 1 .

vāhắs. 3.17. 6".

vāhăn. 3.17. $5^{\dagger}$.

(cf. udavāhá, ripravāhá, vivāhá, vipathavāhá, çatavāhá, havyavāhá, vāhín.)

$\mathbf{v} \mathbf{a} \mathbf{h}$ a $\mathbf{n}$ a in kavyavăhana, rathavăhana, svastivâhana, havyavăhana.

$\mathbf{v} \overline{\mathbf{a}}$ a s in yajñavāhas.

vāhín: -ínī. IO. I. 15 . (cf. pañcavāhín, pravāhín.)

ví (prep.). I. II. I, $3,5^{5} ; 20.3 ; 2$ I. $2,3^{4^{*}}, 4^{*}$. 2. 8. I. 3. $2.2,4 ; 7.4$; II . 5,7 ; $7.2^{*} ; 25.6 ; 3 \mathrm{I} . \mathrm{I}-\mathrm{II}^{2}, \mathrm{I}^{2}, 2^{2}$, $3^{2}, 4^{2}$. 4. 1. 1,$4 ; 7.4 ;$ 13. $2^{+}, 3^{*} ; 3$ 1. 2*. 5. 7. 7; I2. $4^{*} ;$ 22. 7. 6. 2.2 ; 43. $3^{2} ; 49.2$ III. 3 ; 137. 3. 7. 25. $2 ; 44.1^{*} ; 72.2^{\dagger} ; 73.6^{*} ; 74.3 ; 78$. $\mathrm{I}^{3} ; 83 \cdot 3^{*} ; 84 \cdot 3^{2^{*}}$. 8. $3 \cdot 24^{*} ; 5 \cdot 7,8$. 9. 3. 13,$14 ; 9.7^{*}$. 12. I. $57 ; 2.22^{*}$, 32,55 . I3. I. 8,$27 ;$ 2. $18^{*}, 22^{*} ; 3$. 22. I8. I. $8^{*}, 55^{*} ; 2.4 \mathrm{I}, 53 ; 3.39^{*}$. I9. I5. $\mathrm{I}^{2^{*}} ; 44.7$. 20. I28. I $3 ;$ I 35.4 . (cf. vi $+\sqrt[V]{ }$ añc, añj, an, r aç, 2 aç, 2 as, āp, āl, i, parā $+\mathbf{i}, \overline{1} r, \bar{I} r t s$, uch, ud, ubj, ūrṇu, rș, kas, kāę, I krr, $\overline{\mathbf{a}}+\mathbf{k r}$, , I kṛt, adhi . . . kṛt, kḷp, kram, anu ... kram, krī, klid, kșar, kșubh,' khan, 'khyā, gach, gad, gam, gāh, grah, ghas, caks, car, anu...car, ci, cit, crt, chid, jā, ji, jñā, taḍ, tan, tap, tāv, tud, tṛd, tṛh, dah, I dā, $\overline{\mathbf{a}}+\mathrm{da}$, diç, du, duh, dyut, dviș, dham, 
I dhā, dhāv, dhī. dhū, dhūpāy, dhṛ, I naç, nah, nikș, nij, ni, nud, pat, paç, prach, prath, pruş, bandh, bādh, bhaj, bhā, bhās, bhid, bhū, bhṛ, bhrāj, mad, I mā, muc, mrj, mṛç, yach, yat, yam, $\overline{\mathbf{a}}+$ yam, yā, yu, yuj, rakș, rapç, rāj, rādh, riç, ruc, ruj, 2 rudh, ruh, lap, lip, lih, li, vac, vad, I vas, 3 vas, vah, I vā, vic, I vid, vișt, I vṛ, vṛt, $\bar{a}+\mathbf{v r q t}$, anu ... vṛt, vṛh, vyadh, vraçc, ças, çās, çr, çrath, çri, çru, saj, sah, sā, anu ... sic, sṛ, sṛj, sṛp, skabhāy, stabh, stim, stṛ, sthā, spṛ, sras, han, nir + han, hā, hū, hṛ, hvṛ; and vitará, vină, viṣu, vikarná, vikeçá, vigada, vígrivaa, víjāni, vitṛtiyá, vídeva, vidradhá, vípakva, vipathá, víparus, víbandhu, vimanas, vímanyuka, vimrdhá, vírūpa, víliga, vilohitá, vivaruṇá, vívācas, vívrata, viçaphá, víçākha, viçăkhha, viçāla, víçikha, visalyá, víșkandha, vihálha, víhṛdaya, vyàñga, vyadhvá, vyadhvará, vyàlkaça, vyàdhī, vyāmá, vyāla, vyènas, vyāilaba, vyòman.)

Ví: -ís. I8. I. $2 I^{*}$.

vím. 7. $117.1^{*}$.

vés. 9. 9. $5^{*}$.

váyas. 6. 2.2. 8. 4. $18^{*}$.

v i ǹ ça in așțāvinçá, ekavinçá.

vin çatí: -ís. 5. 15. 2. 9. 9. $13^{*}$. 19. 23. I7 (m. mss. -átis); 47.5 .

vinçatím. 4.3.3.

vinçatyă. 7.4. I.

(cf. vinç̧a, ekonaviñçatí.)

vikañkata in vāikañkatá and

vikañkatí $0 \mathrm{mukha:} \mathrm{-khās.} \mathrm{II.}$ Io. 3 .

vi॰karṇá: -ás. 5. I7. 13.

vík asuka: -as. I2. 2.14.

viokeçá: -ás. 6. 30. 2.

vikeçt. 5. I7.4. I I. 9. 7. I4. 2.60. vikeçías. I. 28. 4. II. 2. II; 9. I4.

vi॰kramá: -mấn. 9. 6. 29. viokrám a ṇ a: -am. I8. I. $45^{*}$. vikrámaṇeșu. 7.26. $3^{*}$.

viokrayá: -ás. 3. 15.4.

vioklíndu: -us. 12. 4. 5 .

víokledíy as: -asīs. 7. 76. I.

viokṣará: -ám. 6. 105.3. [22.6.

viga da: vígada (? p. ví gada). 5 .

víogríva: -vāsas. 8. 4. $24^{*}$.

vígrivān. 4. 18.4 .

vioghasá: -sé. II. 2.2.

$\checkmark v i c:$ viveca. 6.61. 2 (Vvyac?).

+ a pa: ápa ... vinaktu. 12. 3. I9. ápā 'vinak. II. 3. 4 .

+ vi: ví vicyadhvam. II. I. I2.

viocakş a ná: -ás. I8. 4. 58*.

vicakșanám. 10. 2. 19; 10.3. 13. 2. $23^{\dagger}$. I8. I. $2 \mathrm{I}^{*}$.

vicakșaṇé. 9. 9. $1^{\dagger}$.

(cf. çatávicakșaṇa.)

vi ocr̂́t: -tam. 6. II7. I; IIg. 2 (inf.). viçŕtāu. 2. 8. I. 3. 7. 4. 6. 121. 3 . vicŕtos. 6. 110. 2.

$\checkmark v i j$ : vijante. 8. 7. I5.

vijámānā. 12. 1. 37 .

(cf. véga.)

+ u d : úd vijantãm. 4. I5.3.

+ s a m: sam̉ovijánte. 5. 2 I. 4,6 .

sám vijante. 8. 7. I5.

sám vijantām. II. 9. I2.

vi॰ja yá: -yâya. 4. 31. $4^{*}$.

vijayásya. I0. 2. 6 .

vija in vijāvant.

víojāni: -is. 5. I7. 18 .

vi jầma n: -mni. 7.76.2.

vijā॰vant: víjāvati. 9. 3. 13, 14 .

vijeşa in

vijeşa०kŕt t: 4. 3I. $5^{*}$.

$\mathbf{v i j} \tilde{\mathbf{n}} \mathbf{a} \mathbf{t}$ in ávijñātagada.

vi०jñă na: -am. 7. 12. 3. I5. 2. I-4. (cf. suvijñāná.)

vijõ ā y a in balavijñãyá.

vitata in

vít atādhvara (p. -taoadh-): -as.

9. 6. 27.

viotará: -ám. 5. I2. 4*.

viotṛti yá: -ám. 5. 22. I3.

vitta in

vittaokām yấ: 12. 3. 52 . 
vitti in ávitti. [uras).

vithurá: -ás. I6. 6. I I (mss. víthvithurāú. 7.95. I.

$\checkmark$ I vid: vidátha. I. 32.1 .

vidyatt. 9.6. I. I0. $7.24 ; 8.20$, $37^{2}$; 10. $2^{3}, 27$. I I. $3.23 ; 8.3,7$. I 2 . 4. 16.

vidyăt. 7. 89.2*: 8.9.3. $\quad$ ro. 8. 20, 37. 12. 4.24 .

vidyāma. 10. 8. 29.

vidyús. $7.89 .2^{*}$.

viddhí. 5. 29. I. 6. 123. 5 .

viddhi. II. I. 30 . I 4. 2. $33^{*}$.

vettu. I2. 3. 12.

vittám. I8. $4.89 *$.

vittam. 4. 28 . 1 .

ávet. I0. I0. 22.

védas. 7. 54. 2.

védat. I4. I. 57.

véda. 2. I. $2 ; 26.1$. 3. $7.6 ; 24.2$. 4. II. 9, II. 5. 7.7; II. IO; $25.6^{2}$; 30. 12. 6. 76.3 ; 127.2. 8. 7. 18; I0. $2-7,17-29,33$. 9. I. $22,23,24$; 5. 3I-6;6. 45-8,62;7. 26;9. 5* I8 $^{\dagger}$, $2 \mathrm{I}^{*}$; IO. $\mathrm{I}^{*}$. I0. $2.28,29,30 ; 7$. I $7^{2}, 4 \mathrm{I} ; 8.38$; Io. 3 . I I. 3. 32-49, $5 I ; 4.18 ; 6.23$. I2. 4 . I8. I3. I. 44; 4. I5, 24. I4. I. $29^{\dagger}$. I5. 2. I-4 ${ }^{2}$; 3. II ; 4. I-6; 5. I-7; 6. I-9; 7.3, 5 ; 8.3 ; 9. 3 ; I0. 9 , II ; II. $7,9,1$ I ; I3. 9 ; I4. I-I2. I8. I. 5*. I9. 26. I, $4^{3} ; 39.9 ; 48.6$.

veda. 2. I. $3^{t}$. 4. I6. 2. 6. II9. 2. 7. I. 2. 8. $7.23^{2}$; 10. 9. 9. 10. 10*. 10. 7. $23,29,30 ; 8.3^{8}$; 10. $3^{2}$. I8. I. $7^{*}$, I8*; 4. 41. I9. 48.6 . 20. 34. I6. véttha. I. 8.4. 5. II. $5 ; 30$. I4. I2. 4. 43.

vettha. 4.9 .3 . 5. II. 4. 6. II7. I. I3. I. 39. I8. 2. $35^{*}$.

vidmá. I. 13. 3. 5. 13. 7. 6. 46. 2. 7. 1 $2.2 ; 76.5$. 8. 7. 18. I6. 5. I-6. I9. $56.6^{2}$.

vidmă (p. -má). I. 2.1 ; 3. I-5. 4 3I. $5^{*}$. IO. I. 20. I3. 3.21 .

vidmó (p. -6 íti). I. 2. I.

vidma. 4. II. I2. II. I. 29. I3. 3 . 21. 18. 1. $36^{*}$. 20. 136. 10 (mss. -má). vidá. 6. 123. 2.

vidús. I. 32.2. 5. 4. 2. 6. 108. $3^{3}, 4$. 8. $7.23,24^{3}, 26$. 9. 10. $I^{*}, 18^{*}$. I0. 7. 10, $17^{2}$. I1. 8. 7. 14.1. $3^{*}$. 19.9. 13. vidus. 4. 11.9; 16. I. 5. 18. 14. 9. I0. $27^{*}$ I0. $2.32 ; 7.17,21,27,28$; 8. 14, 43 ; IO. $5.13 .1 .40 ; 2.13 .14$. I. I6 $6^{2 *}$ I9. $34.6 ; 56.4$.

vidvăn. 2. 1. $2 ; 28.2 ; 35.3$. 3. 1 . I, 2 ; 2. I. 4. 39. 10. 5. I1.6; 12. $9^{*} ; 20.9 ; 29.5 ; 30.7 .6 .68 .3 ; 76$. 4; III. 2, 3; 122. I. 7. 73. $9^{\circ}$; 108. I. 9. $3.3 ; 6.24,40-4,44 ; 9 \cdot 7^{*}$. I0. 5. $50 ; 8.20,44$. II. I. $4 ; 5.10 ; 8$. 32. I2. $2.9,39$. I4. I. 56 . I5. 10. I; Ix. I; I2. I; I3. I-5. I7. I6. I8. 2. $54^{*}, 57$. I9. $15.4^{*} ; 56.1 ; 59.2^{*}, 3^{*}$. viduăn. 4. 1. $3 ; 9.7$. 10. 8. 1 2 . vidvăñsam. 9. $9 \cdot 4^{*}$. I0. 8. 17. 12. 4. 43. I3. 3. I-25. I5. $2.1-4$.

vidúṣā. I5. I2. $4,7,8$, I I.

vidúșe. 8. 10. 30 I0. 10. 32 . 12. 4. 23,45 .

vidúșas. II. 3. 54. I2. $4.22 ; 5.46$. vidvănisas. 6. II 5 . I.

vidúșām. I9. 59. 2*.

vidúși. II. I. 24.

viditám. 4. 27.7. 6. 12. 2.

viditāú. 4. 28.2.

(cf. $\sqrt{ } 2$ vid, vid, vidátha, vidman, vidyấ, vidván, vidvalá, vidvānss, véda, véditr, védya.)

+ a nu: ánu veda. 7. 9. 2*. anuovidvăn. I2. 2. 38, 52 .

+ ni: cf. nivíd, nīvíd.

+ pari: pári veda. 6. 84 . I.

+ pra: prá veda. 8. 9. 10. 9. 1. 6, 7 . pra॰vidvân. 5. 26. I, 3, 9. 7. 97. $\mathrm{I}^{\dagger}$. II. I. 3 I. I2. 2.55 .

(cf. praveda.)

+ prati: práti vedayāmi. 6. IIg. 2. 12. 3. 44 .

+ vi: ví veda. I8. I. $33^{*}$.

+ s a m: samiovidmá. II. 6. 9. [57.4. sám vidma. 6. 46. 2. I6. 5. I-6. I9. samovidús. 3. 2 I. 5 . I0. 8.41.

sám ... vidus. 12. 3.50 .

samovidvắn. I. $25 \cdot 1-3$. 
(cf. sam + 2 vid, sámvidya.)

+ anus am: anuosámvidus.

17,26 .

$\sqrt{2} \mathbf{v i d}, \mathbf{v i n d :}$ vindati.

vindanti. I8. 4.89 *.

vindáte. 9.5.27. I2. 2. 36.

vindate. II. 5 . I8.

vindante. 4. 36.6 .

vindatu. $5 \cdot 7 \cdot 5$.

vindásva. 3.23. 5 .

vindasva. 3.23. 4 .

ávindat. I3. 2. 36 .

viveda. I 4. I. 59 . I 8. I. $50^{*}$.

ávidam. 8. I. $20^{*}$.

avidam. 8. 1. 20"; 2. 3 .

ávidas. 2. 10. 7 .

ávidāma. 8. 5. II.

avidāma. I8. I. 15 *.

ávidan. 2. 9. 4 .

avidan. 2. 9. 4 .

avidanta. I8. 2.47.

vidat. I. $20 . I^{2}$. 5. 3. $6^{2}$. 8. I. I6. 20. I3O. I4 (mss, vidan). [II*. $^{*}$. vidan. I. I9. $I^{2}$. I2. I. 32 . I4. 2. vidata. I8. 2. 3 I. [2 (p. av-). vidanta. 6. 32.3. 8. 8.2 I. II. 2 . vidé. I2. 3.54 .

vidéyam. I9. 4.2 (mss. víde yám). videma. I0. 6.35 .

videșța. 2. 36.3 .

vidānás. 5.20 .3 .

vídāne (p. -e íti). I 8. 3. $38^{*}$.

vidyáte. I9. $49 \cdot 7^{2}$.

vidyate. 20. I36. 3 (not mss.).

véttave. 2. 36.7 .

vittvá (mss. vitvă). 7.97. 7. 9.5. 27 (l. -tuâ). I 8. 2. 25 (do.).

vittă. I2. 5. I.

vitté. I9. 48. 6.

(cf. vitta, vitti, vid, vidya, vin-

na, védana, védas.)

+ an u: ánv avidāma. Io. I. I9.

anvávindat (p. anuoáv-). I9. 27.9.

ánv avindat. 2.27. 2. 5. 14. I; $17.5^{*}$. anvávindan (p. anuoáv-). 4. 23. 6 ; 35. 2.

ánv avindan. 13. 1. 4, 7. [nú...). ánu... vivéda. I9. 32.9 (mss. na- anuovidyáte. I9. 50. 4.

$+\overline{\mathbf{a}}$ : â... avitsi. I8. I. $45^{*}$.

+ pari: páriovittas. 6. I12. 3 .

+ s a m: samovindáte. 3. $18 . \mathrm{I}^{*}$.

sám ... vide. 4. 36. 5 .

sám vitsva. 8. 2. 3 .

sám vidām. 5. 30. 13 .

sam̉ovidānás. 3. 4.6. 4. I5. 1o. 5 . 29. 2,3 . 6. 63.3 . I2. 3. 8. I3. I. 35 . I6. 6. $6^{2}$. I8. I. $60^{*} ; 3.8$. I9. 40. I. saṃ。vidānă. $\quad$ 6. $38.1-4 . \quad 7 \cdot 70.1$. I2. I. 48,63 . I6.6. $5^{2}$.

samovidānám. 5. 28. 5. [2.14. sam̉ovidānāú. 2. 28. 2. 3. I5.4. II samovidāné (p. -é íti etc.). 2. 28.4 . 7. 12. 1. ro. 7.6 .

[7. 5 .

sam̉ovidānăs. 3.4.7. 5. 28. 2. I0. (cf. sam + I vid, samvíd.)

vid in annavíd, gātuvíd, govíd, tadvíd, nāthavíd, nivíd, nivíd, paçuvíd, purāṇavíd, prajāvíd, brahmavíd, yajurvíd, vasuvíd, viçvavíd, viravíd, samvíd, sarvavíd, svarvíd, hotrāvíd.

vida in

vida $\circ$ g ạ á: -ṇébhyas. I9. 22. 18. vidatra in suvidátra.

vidátha: -am. 8. I. 6 . I2. 2.22 , 3o. I4. I. $20^{*}, 2 I^{*}$. I7. I5.

vidáthāya. I 8. I. $20^{*}$.

vidathasya. 7.73.4.

vidáthe, I 3.4 I 8 I. $35^{*} ; 3$

vidáthāni. 4. $25 . \mathrm{I}$.

[3. 70 .

vidáthā. 5. 20. 12. 9.9.22*. 18 . vidátheșu. 5. I2. 7 . (cf. vidathyà.)

vid a th y à : -thías. 20. 128. I (mss. -áthyas).

víodeva: -as. 20. 136. 14 (mss.). vídevam. I2. 3. 43 .

vi o d e ç y à: -às. 4. I6. 8.

vid d h a in atividdhabheșajá.

vid $m$ an in

vi d m a năp as (p. -nắap-). 7.47. I.

vid y a in putravídya, sámividya.

vi d yă : -yáyā. 6. II6. I. I I. 7. 10. vidyấs. II. 8.23.

(cf. ávidyā.) 
viodyút: 4. 15.9. 9. I. 21 ; 2. I5; 7. 3; I0. $7^{*}$. I I. 3. 40. I5. 2. 4. 20. I34. 4 (ed. viprúț).

vidyútam. 3. 2 I. 7. I0. I. 23. I1. 2. vidyútā. 7. II. I; 59. I. 8. I. II. 19. 30. 5 .

vidyúte. I. I3. I. II. 4. 2.

vidyútas. 4. IO. I. I0. 4. 23. vidyútas (pl.). 9. 2. 14. I0. 10. 7 . II. 7. 21 . I8. $4.89^{\dagger}$.

vidyútām. I9. 44. 5 . (cf. savidyutá.)

vi०dradhá: -ám. 6. 127.3. vidradhásya. 6. 127. 1. 9. 8. 20.

vidván: -ánas. 9. 9. $7^{\dagger}$.

vidvalá: -lâs. Io. I. 9 .

vidvān s̀ in ávidvānos, súvidvāns. vidviş in ávidviṣ.

vi॰dveşá: -ám. 5. 2 I. I. (cf. ávidveșa.)

$\checkmark v$ idh: vidhéma. I. 3I. I. 6. 4I. I, 2. vidhema. I. 12. $2^{2}$. 4. 2. $1-8^{*}$. 6 . 39. 2 ; 80. I, 3 ; 97. I. 7. 79. 3 ; 109. 6. I0. 4. 23 . I8. 2. 49 .

ávidhat. 4. 32. $\mathrm{I}^{*}$.

$\sqrt{ } 2$ vidh, see $\sqrt{ }$ vyadh.

vidh in marmāvídh, çvāvídh, hṛdayāvídh.

viodhamá: -mám. r. 18. 4.

viodháraṇa: -ṇi. 9. 7.4 .

viodhartị́: ttă. 3. I6. 2*. ro. 8 . 36. I3. 4.3 .

víodharman: -mā. I6. 3. 2. vídharmanā. I6. 3.6. vídharmani. 7. 22. 1. 9. 10. $17^{*}$.

vidh a va in avidhavá.

viodhātŕ: :tâ. 5. 3. $9^{\dagger}$. vidhātré. 3. Io. Io.

vidhāna in āchádvidhāna.

vi॰dhú: -ús. 9. 8. 22.

vidhúm. 9. 10. 9*.

víodhṛti: -is. 4. 35. I.

vídhṛtís. I9. 54.5 (s. mss. -tīns).

vínașțaotejas: -asas. I9. 34.2 (mss. vinaktaoté-).

vină. 20. 136. I3 (not mss.).

vinna in áviçvavinna.

$\checkmark v i p$, vep: vépate. I8. 1. $23^{*}$. vépamānā. I9. 9.8 (mss. vepyamānăh).

avepanta. IO. IO. 23 .

ávepayas. 5. 22. 10.

(cf. vip ?, vípra?, vepáthu.)

+ u d: udovépamānās. 5. 21.2 (p. -mānā).

ud॰vepáyati. 9. 8.6.

úd vepaya. I1.9. I2, I8. I3. 3. I-25. $v$ i p in vipaçcít.

víopakva: -ve. 5. 29.6.

viopathá: -ám. I5. 2. 1-4.

(cf. vipathavāhá.)

vipathaovāhá: -hău. I 5. 2. I-4.

víoparus: 7. 56.4

vi paçcít (p. -aḥ॰c-): 8. 9. 3. 9. 5 .

I3. I3. 2. 3I. I4. I. 59.

vipaçcítam. 6. 52.3. 9. 4. 2 I. I I. 2.

I7. I3. I. $39 ; 2.4$.

vipaçcitā. 6.97.2.

vipaçcítas. 9. 10. $17^{*}$. 19. 53. 1.

vípra: -as. 5. II. II. 6. 27. 2*. 9. 5. 13. 20. 1 28. 3 (mss. viprás). [(mss.). vipram. 3. 3. 2. 7. 71. I* 19. 44. I víprāya. 5. II. II. 20. I35. II.

víprasya. 9.5. I3. I8. I. $22^{*}$.

víprās. 4. 1. 5. 5.2. $4^{*}$. 9. 10. $28^{*}$. I8. $4.6 \mathrm{I}^{*}$. I9. 2.3 .

víprāsas. I4. I. $37^{*}$. [dyút).

vioprús: -út. 20. 134. 4 (mss. vi-

viprúșas. 9.5. I9.

víobandhu: -uşu. I8. 2. 57.

víobā dha: -as. 19. 34.7 . (cf. vāibādha.)

vibhā(?) in [bhăv āos-).

vibhă vanti -vā. I9. 52. 2* (mss. vio

vibhāvari. I9. $48.2,4 ; 49.6 ; 50.7$.

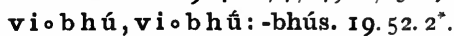

vibhús. 7. 2 I. I. I3. 4. 47. I5. I5.6.

vibhúm. 4. 23. 4.

vibhúam. I8. I. $2 I^{*}$.

vibhú. 20. I35. 9.

vibhvís. 18. 3. 69 .

vi०m a dá: -ám. 4. 29. 4.

viman as in vāimanasyá.

vimany $\mathbf{u}$ in

víomanyuka: -as. 6. 43. I.

vímanyukasya. 6. 43. I. 
viomấna: -as. 4 . 2. 3. ro. $8.3^{\dagger}, 40^{\dagger}$. vimănam. 9. 3. 15 .

viomúc: -cas. 6. II2. 3.

vi०m rŕgvan: -vari. I2. I. 37 .

vimrgvari. I2. I. 35 .

vimứgvarim. I2. I. 29.

vi $\circ$ r r dhá: -ás. I. 2 I. I*. 8.5.4, 22. viomoká: -ás. I6. 3. 4. (cf. vimokya.)

vi mok y a in avimokyá.

viyúj: -úg。bhis. 7.4. I.

vi॰rapçín: vírapçin. 6. 2. 2. virapçínam. 5. 29. 13.

viorăj : -râț. 4. II. 7. 7. 84. I. 8. 5. 10;8. $23 ; 9.8,9$; I0. I. 9. 5. 21 ; I0. $24^{5}$. II. $4.12 ; 5.16 ; 8.30$. I2. 3. II. I3. 3. 5. I4. 2. I5, 74. I5. 6. 8. 19. 6. $9^{*}$.

virăjam. 8. $9.7,9.9 .2 .5$. 10.7 . I9. Ir. 5. 7. I5. 14. 5 .

virăjā. I5. I4. 5 .

virăje. I7. 22, 23.

virăjas. 3. $17 \cdot 2^{\dagger}$. 8. $9.1,2$, IO. I3 I. 33. I5. 6.8. I9. 6.9*.

(cf. vāirājá.)

vi०rădhana: -am. II. ro. 27.

virā d h a y a $\mathrm{t}$ in ávirādhayant.

víor ūpa: -as. 20. I28. I2 (mss.).

vírūpam. 6. 7I. I.

vírūpāu. 5. 23. 4.

vírūpe (p. -e íti etc.). ro. $7.6,42$.

vírūpās. 2. $34.4 \cdot 3 \cdot 4 \cdot 7$. I 8. 4.33 . (cf. vāirūpá.)

vi oróc ana: -as. 8. Io. 22.

víoliga: -gi. 5. 12. 7 .

violipti: I2. $4.46,47$.

viliptíam. I 2. 4. 4 I (mss. tyám, -tím). viliptiăs. I2. 4.44 .

vi०liḍhi: -dhíam. I. I8. 4 .

violohitá: -ás. I2. 4. 4.

vilohitám. 9. 8. I.

vivakṣú: -șávas. 2. 30. $3^{2}$.

viovarựá: -năs.s. 8. 7. 10.

vivásvant, vívasvant: -vásvān. I8. $2.32^{2} ; 3.61,62$. I9. 9. 7. vivasvantam. I I. 6.2. I8. I. 59*. vívasvate. I8. 2. $33^{*}$.

vivásvatas. I 8 . I. $35^{*}$. vívasvatas. I8. I. $53^{*}$.

(cf. văivasvatá.)

víovācas: -asam. I2. I. 45.

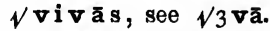

[66.

vi॰vāhá: -hé. I2. I. 24. I4. 2.65, vivāhăn. 12. 5. 44 .

vi॰vyādhín: -ínas. I. Ig. I.

vívrata: -tās. 3. 8. 5.

$\checkmark \nabla$ iç: viçáthas. 4. 25. 1.

viçantu. 12. 3. 32 .

aviçat. Io. 10. 25 .

veçáyāmi. 3.13.7.

(cf. víç, veça, veçana, veçantá ?, veçás, véçman, veçya.)

+ a p a: ápa veçayā (p. -ya). 9. 2.25

$+\bar{a}$ : à viçati. 7.76. 4 .

à ... viçánti. 6. 2. 2 .

ā॰viçé. 4.36 .7$.

ā॰viçáte. 4.36 .8 .

à... viçate. I4. I. $25^{*}$.

à viçāti. I2. 3.48 .

à viça. 7. IIO. 3. I4. 2. $40^{*}$.

à viçata. I9. Ig. I-II.

à viçantu. I3. I. Io.

â... viçantu. 2. 5.4 .

à ... viçatām. I. 23. 2.

ā॰viçán. I8. $4.58^{*}$.

à ... aviçat. 12. I. 55 .

à 'viçan. II. 8. I3, I8, 29.

āovivéça. 3. 2 I. I, 2. 7.42. I"; 87. I. I2. I. $24 ; 2.33,55$. I6. I. 8. I 8. 3. $55^{*}$. I9. $3.3 ; 59.2$.

ā॰vivéçā (p. -ça). I. I2. 3 .

â viveça. 3. 29. 7. 4. II. I ; 30. $5^{*}$; 34. 5. 5. I. 2. 7. 82.4. 9. 9. 22*; Iо. I0*. I0. $2.33 ; 7.35 ; 8.3^{*}, 40^{*}$. 12 .

2. 43 . I3. I. 24

āoviviçús. 2. 3I. 5. I8. 2. 49 ; 3. 59 . à viviçyās. I 8 . I. $3^{*}$.

ă。viștas. 3. 2I. 2. 6. 85 . I. [4. 48 . â veçayāmi. 7. 53. 3. I2. 3. 22. 18 . à veçayāmasi. 6. 108. 3 .

à veçayāmahe. 6. 108. 5 .

à veçaya. 2. 25.4 . I3. I. 2.

á veçayantu. I8. 2. 26.

āoveçáyantī. 7. 79. 3 .

ā॰veçáyantas. 4. 30. $2^{\dagger}$.

ă॰veçitam. 20. I36. 9 (mss. āvéç-). 
+ upa: upaovíçya. 14.2. 23.

+ ni: ní viçate. I9. 47.2 ; 54. I. nioviçánte. 9. 9. $21^{*}$.

ní viçante. $4.25 \cdot 3$.

ní... aviçanta. 10. $8.3^{\dagger}$.

ní ... avikşata. 6. $52.2^{*}$.

nívişțas. 7. 40. I. I8. 2. 32.

nívișțam. 9. 1.2. 10.8.24. I8. 3. 9.

(cf. nivéçana.)

+ pari: cf. páriveças.

+ pra: prá viçāmi. 5. 6. II-4.

prá viçāva. I5. 10. 3 .

prá viça. 6. II3.2. I3. I. I.

prá ... viça. I 4. 2. 26.

praoviçátu. I5. I0. 4 (sanh. mss. prāviçátu, prāviçatu).

prá viçatam. 3. I1. 5. 7. 53.5.

prá viçata. II. I. 18. I9. I9. I-II. prấviçat (p. pra。áv-). ro. 7.8 .

pră 'viçat. I0. 10. 7. II. 8. II, 23, 30. I5. I0. 5 .

pră 'viçan. I I. 8. I9-2 I, 22, 24, 25, 27.

pra॰vivéça. I2. 2. 4, 7".

prá viveça. Io. $7 \cdot 8,9^{2}$.

prá viveçā (p. -ça). II. 4. 20.

praviçiovănisam. 4. 23. I.

praovíçya. I. 25.1 . I2. 5.4 I.

práovișțas. 4.39 .9 . $\quad$ I0. $8.28,40$.

I4. 2. 55,58 .

práovișțā. 3. 10. 4. 6. 73. 2.

práovişțam. I4. 2. 53, 54, 56, 57.

práovișțām. I2. 1. 60. I9. 4. 2.

práovișțās. 7. 80.4 1 10. 8.40. I 8. 2.28. prá veçayet. 9.5.23.

pră 'veçayat. I I. 6.23. [10.22.

+ anupra: anuoprấviçathās. Io.

+ prati: cf. prátiveça.

+ s a m: sám viçātha. I4. I. 33 .

sám viçema. 3. IO. II.

sám viçantu. I8. 2. 29.

sám viçasva. I8. 3. $7^{*}$. 19.24 .8 .

sám viçadhvam. I2. 3. 4 .

samov eçáyan. 3. 8. I.

(cf. samivéçana, samineçyà.) [9.

+ a n u s m: anuosámviçasva. 18.3.

+ a bhis a m: abhiosamiviçánti. 15 .

7. 9.

abhiosáminviçasva. 9. 2. 25. abhiosám viçadhvam. 3.3.4. 6. 64. $2^{\dagger}$. 8. 5. 20, 21 .

víç: víçam॰viçam. 4. 31. 4".

viçé. I4. 2. 27.

viçí. 3. 3. 5 . I3. I. 9.

víças. $3.3 .3 ; 4.2,6.4 .8 .4 ; 22$. 7; 23. I (víçah̆ vi-); 33. 2". 5. I. 3. 6. $61.2 ; 87.1^{\circ} ; 98.2$. 7.94. I". 9. 4. 9. I0. $2.22,23$. I2. 5. 8 . I3. I. 2, 10 ; $2.20^{*}$. I5. 8.2 ; 9. I. I8. I. $2 I^{*}$. I9. 45.4 (mss.).

viḍıbhyás. 3.3.3.

viçắm. I. 2 I. I $I^{\dagger}$. 3. 4. I. 4. 22. I, 3. 6. 88. I". 7. 50.2. 8. 5. 22. I5.8.3. viçām. 3. 20. $2^{\dagger}$. vikşú. 2. 2. I. 8. 3.10"; 4.18". 9.5. (cf. viçpáti, viçpátnI, víçya, vāíçya.)

vi॰çaphá: -ásya. 3. 9. I.

vi çará: -rât. 2. 4. 2.

víoçarîk a: -am. I 9. 34. Io.

vi。çás a na: -am. I4. I. 28*.

vi०çastṛ: -tar. 9. 5.4.

ví。çā k h a: -khās. 8.7.4.

vi。çâkha: -khe. I9. 7.3.

viçāla in vāiçāleyá.

víoçikh a: -khān. 4. 18. 4.

vi०çís: -íşas. II. 8.27.

viçpáti:-is. $4.5 .6^{*} ; 22.3$.

viçpátim. 9. 9. I".

viçpátni: 7.46 .3 .

viçpátniāi. 7. 46. 2.

víçy a: -yānām. 6. 13. I.

viçravaṇa in vāiçravaná.

víçva: -am. I. Io. 2 ; 3 I. $4 ; 32.4$. 2. I. I. 3. 3I. 5*. 4. 2. $6^{*}$; II. I ; 32 . I". 5. 2. $8^{+} ;$I1. 8. 6. 44.1 I $51.2^{*}$; 57. 3 ; 77. I; 88. I*. 7. I. 2 ; II. I; 20. 6 ; 55 . I (1. -çuam). 8. 9. 9. 9. 3. $20 ; 5.21 ; 7.4 ;$ 10. $19,26 *$ I0. 6. I7; 7.35:8.7, I3. II. 4. 22; 7. I, 2. I3. I. I, $52 ; 2.3, \mathrm{I9}^{*}, 20^{*}, 31,44^{2}$; 3. I5. I4. I. $22^{*} ; 2.64$. I8. I. 18*, $53^{*} ; 3.24^{*}$. I9. $47.2 ; 55.6$.

víçvena. 2. I6. 5 . I7. $24^{\circ}$.

víçvāya. I3. 2. 16". [2.44. víçvasmāt. 6. 96. $2^{\dagger}$. 8. 7.28. I 4 . víçvasya. 2. 3 I. I. 3. $7 \cdot 5^{\dagger}$; II. $3^{\text {". }}$ 
4. 25. I (1. -çuas-). 6. 39. 3 ; 86. I ; 91. $3^{\dagger}$; 95. 3. 8. 3. $14^{*} ; 4.16^{*}$. 9. 9 . $22^{*}$; IO. $13^{\dagger}, \mathrm{I}_{4}^{\dagger}$. II. $4.23 ; 7.15$, I6. víçve. $4.2 .5^{\dagger} ; 8.3^{*}$. 5. $2 . \mathrm{I}^{*} ; 27$. 7. 6. II5.3. 7. 2 I. I; 50. $7^{\dagger} ;$ 73. 3. 9. $9.21^{*}$. I8. 1. $52^{*} ; 3.39^{*}$.-víçve devăs. I. 9.1 ; $13.4 ; 35.4$. 2. I3. 5 ; 29. 5. 3. 3. 5 ; $4.4 ; 8.4$; 19. 5 . 4. 2. $\mathrm{I}^{*}$ 5. 3. $4^{\dagger} ; 27.12$. 6. 47.2 ; 6I. I；III. 4 ; II2. I ; I32. 2. 7.6. I*; I6. I; 24. I; 35. I. 8. I. 7 ; 2 . $21 ; 5.19 ; 8.13 .9 .2 .7 ; 418 ; 6$. 45 ; IO. $18^{*}$. IO. 5.50 . II. I. $33 ; 5$. 24 ; 6. I8. I2. I. 53 . I3 3. $24^{*}$. I4. I. $15^{*}, 32 ; 2.53-8$. I5. 2. I. I8. I. $32^{*}$; 3. I1. I9.9. 13. I4; $20.4 ; 30.2$. víçue devâs.s. 2. 9.4 ; 13.4 . 3. 22. I. 7.17 .3 .

víçve devās (voc.). I. 30. I. 2. I2. 5 ; 28. 5. 5. 3.6* 6. 93. 3 ; II5. I. viçve. 6. II4. 3 (s. mss. ví-).

víçvās. 2.6.1. 5.7.9; 23.2. 6. 22. 3 ; 97. I. 7. 73. $9^{*}$; 84. 1. 8. 4 . II ${ }^{*}$. I0. $5.36 ; 8.36$. I3. I. $22 ; 2$. 28, 33. I6. 9. I. I8. 2. $59^{*}$.

víçvāni. I. 6. $2^{*}$. 4. 39. Io. 6. 45 . $2^{*} ; 63.4^{*}$. 7. 41. 1. 8. 3. $24^{*}$. I0. 5.6. I5. 3. IO, II. I9. 49. 2.

víçvā. I. I. I; I6. $3 ; 29.3^{*}$. 2. I. $3^{*}, 5 ; 6.5$ (p. -vāh); 28.2. 3. 20. 8 . 4. I. $3 ;$ I $3.4^{*} ; 26.5 ; 30.7^{*}, 8^{*} ; 32$. $3^{*}$. 5. II. 4,$5 ;$ I2. $9^{*} ; 28.8$. 6. 19. I; 20. 3 ; $34.4^{*} ; 36.2 ; 53.2$; 80 . $I^{*}$; I IO. 2 ; I42. I. 7. IO. $\mathrm{I}^{*}$; 26. $3^{*}$; 42. $2^{*} ; 60.7 ; 63.1 ; 79.4 ;$ 80. $3^{*}$; 87. I ; IIO. 2. 9. I. 5 ; 4. I; 9.2*, II*, I4*. I0. 8. I8. II. 2 . II ; 5.9. I3. I. I I ; 2. 9, IO, I 2, 32, 34; 3. 3, I4. 14. 2. 30. I7. 16. 19. $6.3^{*}$; 53. I, $2,3,6$. 20. 34.17 .

víçuā. 7. 17.3; 8I. $\mathrm{I}^{\dagger}$. I3. $2 . \mathrm{II}^{\dagger}$. víçvān. 3. 8. 3; 21.8. 5. 22. 2. 7 . 38. 3 (l. -çuān). I I. 6. 5, 19.

víçvāis. 2. 16.4. 3.17.9. 12. 3 . I0. I8. 3.28. I9. I7. IO; 40. I.

víçvebhis. 4. 9. I. 5. 29. 2, 3. 7. 105. I. víçvābhis. II. 6. I9.

víçvebhyas. I5. 2. I. víçveşãm. 4. I. 7. I5. 2. I

víçveşu. 6. 58. 2.

[-çuā-). víçvāsu. 5. II. 8, 9. I9. 49. 5 (1. (cf. viçvákarman-viçvăhā.)

vi çváokarman: -mā. 2. 34.3 ; 35. I, 2. 4. II. 5. I2. 1.60. I9. I7.7. víçvakarman. 2. 35.4 . 6. 122. I. viçvakarman. 2. 35.3 .

viçvákarmānamam. I9. I8. 7 .

viçvákarmạ̣ă. 2. 35.5 .

viçvákarmạ̣e. I3. I. I4.

viçvákarmāṇas. I2. I. I3.

(cf. vāiçvakarmaṇá.)

viçvaokŕt: 6. 47. r.

viçvá。g a rbh a: -bhām. I2. I. 43. viçváogotrya: -as. 5. 21.3 .

viçváocakşaṇa: -am. I8. r. I7. viçvá。cakṣas: -ṣase. I3. 2. $17^{*}$. vi çvá。carṣaṇi: -is. 4. 32. $4^{*}$. I3. 2. $26^{\dagger}$. 19. 33.4 .

viç va oj a n İ a: -nāt. 7. 45. I. viçvajanínasya. 20. 127. 7 (mss. -jánī-).

viçvá。janman: -nas. II. 4.23. viçvaojít: 4. II. 5. II. 7. I2. I7. II. víçvajit. 6. 107. I, 2, 3 .

viçvajítam. $4 \cdot 35 \cdot 7$.

viçvajíte. 6. 107. 2.

viçvátas. 2. $4.2 ; 7.3$. 3. 16. $7^{*}$, 4. $33.5^{*}, 6^{*}$. 5. 3. $2^{+}$. 7. 50. $2 ; 53.6$. 8. $4.6^{*} ;$ 5. 22 . 9. 10. $17^{*}$. 10. 8. 10. II. 2. 8. I7. 30. I9. $6 . \mathrm{I}^{*}$; 20. 3 ; 32. I0; 33. I; 34. $5 ; 44.6$.

(cf. viçvátaspāṇi--viçvátovirrya.) viçvátaspạni (p. -aḥ॰p-): -is. I3. $226^{\dagger}$.

$\left[26^{+}\right.$.

vi çvátaspṛtha (do.): -as. I3. 2. vi çvát od hāra (p. -aḥodh-): -am. 4. I4. 4. [10.8.27. I3. 2. $26^{*}$. viçvátomukha (p. -aḥm-): -as. viçvatomukha. $4 \cdot 33 \cdot 6^{*}, 7^{*}$. 7.65.2. viçvátomukham. I9 27.7. [-yāḥ). viçvátovīrya: -yā. 6. 32. 2 (p. viçvátovīryam. 3. 31.7 .

viçváodarçata: -as. I3. 2. $19^{*}$. viçva。dănim. 7. 73. II*. I2. I. 7. 18.3 .54 .

viçva。dāvan: $4.32 .6^{\dagger}$. 
viç va०dāv y à: -vías. 3. 21. 3, 9 . I0. 8. 39 .

viçváodrsța: -as. 5.23. 6". 6.

viçváodeva: -vās. I9. I1. 2".

viçvádevāis. 4. 30. I*.

viçvádevebhis. 7.98. 1.

viçvádevebhyas. 19. 39.5.

(cf. vãiçvadevá, viçvádevavant.)

viçvádeva ovant: -ntam. I9. I 3 . Io.

viçvád hã. 6. 85.3 . (cf. viçvadhãvīrya.)

vi çvá odhã y a s: -asam. 12. 1. 27. viçvádhāyasas. 3.22.2. [39. 10.

vi ̧ vadhāovirya: 5. 22. 3. 19 .

vi çváon āma n: -mnīs. 7.75.2 (l. -manis).

viçva०bhṛ́t: 4. II. 5. 5. 28.5.

viçváobheşaja: as. 2. 4.3. 4 . 10. 3 ; 13. $6^{*}$. 10. 3. 3. I9. $35.5 ; 39$. $5,8,9$.

viçvabheșaja. 4. $13 \cdot 3^{\dagger}$.

viçvábheşajam. I9. 44. I (not mss.). viçvábheșajim. 6. 52.3.

viçvábheșajya. 6. 136. 3 .

viçvábheșajiss. 8.7. 26.

viçvá。bhojas: -asam. 4. 35. 3 . I8. 4.6.

vi çvá o mitra: -ās. I 8. 3. 63. viçvamitrās. I8. 4.54 (s. mss. viçvám-).

(cf. viçvămitra.)

viç va m。inva: -vās. 5. 12. 5*. viçva mobhará: -râ. 12. 1. 6 . viçvambhara. 2. 16. 5 .

vi çvá $\circ \mathbf{r}$ dh as: -asas. 7. 17. 2.

vi çvá $\circ$ ru pa: -as. 4. 8. $3^{*}$. 9. I. 5 ; 4. 22. I8. I. $5^{*}$.

viçvárūpā. 4.34.8. 9.5. 10. 10. I. $2,15,24$. I4. 2. 32 .

viçvárūpam. 2. 32. 2. 4. 14.9. 9. I. 2 (l. viçuár-); 6.55-9; 7.25. 10. 7. 8; 8. 9, II. I3. I. 8. I4. I. $6 \mathrm{I}^{*}$; 2. 12 .

[I.II.

viçvárūpām. 6. 59. 3. I I. I. I. I2. viçvárūpãs. 2. 34. 4. 3. 10. $6 ; 28$. I. 4. $15.2,3 ; 35.6 .5 \cdot 23 \cdot 5 \cdot 9 \cdot 7 \cdot 26$. viçvárūpān. I3. I. 22. viçvárūpăis. 17. 6-19, 24.

viçvárūpānăm. 2. 30. 4 .

viçvaorūpíam. 9. 9. 9".

vi çvá o v a y a s:-yãs. 19.56.2 (mss.).

vi çvá。vã ra: -as. "5.27.3.

viçvavāre. 7.20.4; 79. 1. 9. 3.2,

4. I2. 3. 11 .

viçvávãram. 7·47.1.

viçvávārãm. 7. 15.1.

viçvávārāyãs. 9. 3. 1.

viçva॰víd: -das. 9.9.10 $10^{\dagger}$.

viçva vinna in áviçvavinna.

viçvá ovedas: -dās. 7.91. I".

viçvávedase. I. 32.4 . [27.6.

viçvávedasas. 3.3. 1. 6. 92. I. I 9.

viçvavedasas. 6.93.3.

viç vá ov y a c a s: -cãs. 9. 7.15. 12. 3. I9, 53. I9. 49. I (not mss.); 56. 2 (do.).

viç vá ○ç a m b hū : -ūs. 6. 47. I. viçváçambhuvam. I. 6.2*. [34. Io.

vi çvá。çā ra d a: -am. 9. 8.6. I 9.

vi çva०sút: -súam. I2. I. I7.

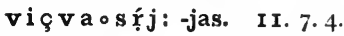

vi çváhā. 5. 27.7. 9. 2. 19-24. I2. I. $17,27$. I9. 50.2. (cf. viçvăhā.)

viçvāñ gá (p. -va॰añ-): -gám. I 9. 49. 8 (not mss.).

viçvāñgāís. 12. 3. 10. (cf. viçvāñgyà.)

viç vāñg yà (p. -va॰añ-): -gíam. 9. 8.5 .

vi çvấd (p. -va॰ád): 3.21. 4. I8. 3. $55^{*}$. I9. 59.2 (mss.).

viçvànara: -re. 4. II. 7 . (cf. vāiçvānará.)

viçvānná (p. -va॰an-): -ám. 9. 3.

viçvấmitra: -aṣ. I8. 3. I5.

víçvāmitra. I8. 3. I6.

viçvămitram. 4.29. 5 . (cf. viçvámitra.)

viç vat y u s (p. -váøāy-): I 8. 2. $55^{\text {". }}$

viçvá vasu (p. -váova-): víçvāvaso (p. -oíti etc.). I 4. 2. 35 .

viçvāvaso (do.). I4. 2. $33^{*}$.

viçvăvasum. 2. 2. 4. [28.

vi çvās á h : -vāṣăț. I 2. I. 54. 1 3. I. 
viçvấhā. 3. 15.8. 7.50. I; 74. 4. I8. $3.5 I^{*} ; 4.34$.

(cf. viçváhā.)

$\checkmark$ viș: veveșțu. 2. 12.8.

vévișat. $5.17 .5^{*}$.

viddhí. 2. $5 \cdot 4$.

(cf. víșa, vișá ?, veșa, veșț̣, ve$+\mathrm{n}$ i: cf. niveșyà.

+ pari: pári veveșmi. I5. I3. 8 . pári vevisyăt. I5. I3. 8 .

pariovíşya. 9.6.53.

páriovișțam. 6. 122.3. 12. 3. 7 .

(cf. pariveșá, pariveșț̣́.)

víșa: -as. 5 . I7. 5 .

vișá: -ám. 4. 6. I, 4, 5², 6, 8; 7. I, 2. 5. I3. I $^{2}, 2,4^{2}, 8,9$, I0, I I : I9. Io. 6. I2. I, 2 ; 100. 2 , 3. 7. $56.1,3,5,7,8$; 88. $\mathrm{I}^{2}$. 8. 3. I6"; I0. $29^{2}, 32,33$. 9 8. IO-2, I9, 20. I O. $4.3,4$, I 9, 20, 2I, $22^{2}, 26^{4}$. I2. $4.39 ; 5.3$ I.

víșa. 4. 6.3 (mss. -șas).

vișéna. 5. 13. 4. 8. 3. 23". I I. 2. 26. vișásya. 4. 6. 2. 5. 18.4. I0. 4. 25. vișé. 5. 13. 5. 7. 88. I. I0. 4. 26. vișâni. 6. 90. 2.

vișébhis. I 9.56 .6 (p. dviș-).

vișâ. 7. 113. 2.

(cf. avișá, aghávișa, āçivișá, kāndāvișá, nașțávișa, vișagirí-vișávant, vișātaká.)

vișa girí: -ís. 4.6.7. [4.24.

vişaod tús aña: -am. 6. IOO. I. I0. vișadúșañīs. 8 . 7. 10.

vișa 0 dhăna: -as. 2. 32.6 .

vișá v a nt: -vat. I4. I. 29*.

vísavati. 8. 10. 29.

vișăna (p. viosăn-): -nā. 6. I2I. I. víșāṇe. 3. 7. 2.

vișânạaya. $3 \cdot 7 \cdot 1$.

(cf. vișānạakâ.)

v iș ā n a ká (p. viosāna-): 6. 44. 3 .

vișāt a ká: -kí. 7. II3. 2.

vișāsahí (p. viosas-): -ís. I. 29. 6*. I2. I. 54 . I9. 33. 4 .

vișāsahím. I7. I-5.

visāsahyāí. I9. 23. 27.

víșit a ost u p a (p. vísi-) : -as. 6.60. I. v iș u in vișurūpa-vișūvị́t, vișváñc. vís u $\circ$ rū p a : -pā. I8. I. $2^{*}, 34^{*}$.

víșurūpam. I9. 5. I".

viş ū ctna: -am. 3. 7. I.

vișūcinā. 9. 10. $16^{*}$.

vișūcînān. 8. 6. 10.

$[15$.

vișū vánt (p. -ṣu०v-): -ntam. II. 7.

vișūvátā. 9. I0. $25^{*}$.

vișūváti. 9.3. 8.

viș $\bar{u} v$ ŕt (p. -şu०v-): -tas. I0. 2. II.

vís k a ndha (p. viosk-): -am. I. I6. 3. 2. $4.3,4$. 3. 9. 2. 4. 9.5. I9. 34. 5 . víşkandhāt. 2. 4. 2, 5 .

víşkandhāni. 3. 9. 6.

(cf. vișkandhadúșana.)

vișk andhaodúțạna (p. visk-): -am. 2. 4. I. 3. 9.6. I9. 35. I.

$\checkmark v$ ișț: veșțatām. 6. IO2. 2.

+ ă : àovișțitā. 5. I8. 3 . àovistitāni. 5. 28. I. [I-27.

+ ni: ní veștayāmi. ro. 5. 36. I6. 8 .

+ vi: ví veștaya. I2. 5.68 .

vișțáp: -pam. II. I. 7 .

vișțápi. I0. I0. 3I. II. 3.5I. I3. I. 16. I 8.4 .4

(cf. vișțápa, vāișțapá.)

visttápa: -am. II. 3. 50

vișț a m b há: -bhăs. 13. 4. 10.

vișțāin: -rí. 4. 34. r.

vișțãrínam. 4. 34 3, 4, 5, 8. [-ená).

vișțimá: -ména. 20. I35. 5 (mss. - (cf. vișțīmín.)

vișținin: -ínam. 20. 136. 4 .

vișthat (p. viosth-): 7. 3. I. I2. I. 5 . vișțhás. 4. I. I. 5. I. 8 . I8. 4. 4 .

víṣnu: -us. 3.27.5. 5. 3. $3^{*} ; 25$. $5^{*} ;$ 26. 7. 6. 3. I. 7.17. 4 ; 26. $2^{*}$, $4^{*}, 5^{*}$. 8. 5. 10. I0. I0. 30 I2. I. IO. I3. 2.3I. I4. 2. 15. I5. I4. 5 . 18. 3. I1. I9. 9. 6*; 10. $9^{*}$.

vișṇo (p. -o íti). 7. 26. 3, $8^{2}$; 44. $I^{*}$. I7. 6-I9, 24.

[6. 2 .

víṣnuum. 3. 20. $4^{*}, 7^{*}$. 7. 25. I, 2. II. víșnave. 12.3 .59$.

víṣnos. 7. 26. I*, 6*, 7*; 46. 3. 9. 2. 6 ; I0. I7*. I0. 5. 25-35. I8. I. $45^{*}$. (cf. agnāvișṇu.)

vís v a ñ c: -vañ. II. 8. 33. I9. 6. 2*. víşvañcam. 2. 33.7. 
víşvak. I. 27.2. 3. I. $4^{\dagger} ; 6,6$.

víşvañcău. 20. 136. 2.

víşvañcas. I. I9. 2 . I9. 38.2 (l. víşua-).

víşũcas. 3. $1.5 ; 2.3$.

víşūci. I. 27.2 .

víşūcīm. 6. 90. I. 7.42. I".

víşūcis. I. I9. I. 9. 2.21; IO $11^{*}$ I9. $8.6 ; 15.2$.

(cf. vișūcína.)

vi०sargá: -gé. 5. 1. 6*.

viosalyá: -yásya. 9. 8. 20. (cf. visályaka.)

viosály a ka: -as. 6. 127.3. 19.44.2. visályakam. 6. 127.3 . 9. 8. 2, 5 . visályakasya. 6. 127. I. [sra-) viosrás: -ásas. 19. 34.3 (mss. vívi०hálha: -as. 6. 16. 2

vi०havá: -vé. 5.3. 3*, II. vihavéșu. 5. 3. I".

vi०hávya: -as. 2.6.4 vihávyena. $7 \cdot 5 \cdot 4$.

víohãy a s: -yās. I7. 27.

víohṛdaya: -am. 5. 21. I.

vihruta in ávihruta.

$\checkmark \mathbf{v i}:$ vithas. 7. 29. 2.

vihí. 6. 83. 4 .

vihi. 19. 52.5 .

vìtāt. I 8. I. 26".

vítám. 7.73. 5 .

viántu. 7.49. $2^{*}$.

vyantu. 7. 49. 2* (l. via-?).

(cf. váyas, vayúna, vi, I vīta?, vīti, vīrá.)

+ u d: údovìtā (?). I2. 5. I8.

+ pra: prá viyante. II. 4. 3 .

praoviyámānā. 12. 4. 37.

vi in ãvaya (?), padaví, prāvĩ (?), ratharvi (?),

vîci: -ciā. I 8 . I. $7^{*}$.

V VI ḍ : vị̣áyasva. 6. I 25. I"; 126.2". (cf. vidú.)

vị̃̂́: -ús. I. 2. 2.

(cf. vịứharas, vị̣̂̀ànga.)

vi dú $\circ$ h ar a s: -rās. 5. 17. I*

vi dù àn $\mathrm{g}$ a: -dúoañgas. 6. I25. I*. I vit a in vitáprșțha, vítáhavya. 2 vit a in prācinopavitá. vitáoprșțha: -țhăs. 6. 62.2. vi tá $\circ$ h a y a: -as. 6. 137. I.

vIti in devávíti.

vidhrá: -ré. 4. 20.7. 9. I. 24.

v I barhá (p. viob-): -héna. 2.33. 7.

vĩrá: ás. 3. 5.8; 23.2. 5. 19. 4. 6.

I10. 3. 8. 5. I, 2. I3. 2. 9. I4. 2. 8 .

19. 31. 14. 20. 127. 5 (not mss.).

vira. II. I. 10.

vîrám. 6. $97.3^{\dagger} .7 .47 .1 ; 4^{8 .} 1^{*}$.

vīréṇa. 3. 5.8.

virằya. 8. 5. I. I9. 31. 14.

vīrầs. 2. $26.4,5 \cdot 5 \cdot 17 \cdot 7 \cdot$ 9. $5 \cdot 2$; I0. $25^{\circ}$. I2. 2. 2 I. I6. 8. I-27. I8. I. $2^{*} ; 3.6 \mathrm{I}$. 19. $33.11^{*}$.

vĩuăn. 4.7.7. 6. 93. I. I9. 36.4 (m. mss. -ră).

vīrāís. 8. 4. $15^{*}$.

vīrănāām. I. 29. $6^{\dagger}$. 3. 19. 6 .

vīréşu. I2. I. $25 ; 2$. I5.

vīráotamā. 7.25. 1.

(cf. vāíra, abhívīra, árișțavīra, ekavirá, cáturvīra, právīra, çúuravira, sárvavira, sahávīra, suvîra, vīrapoșá-vīrahán, vīryà.)

vĩraopoșá: -ám. I3. I. I2.

Vviray: viráyasva. 5. 25. 8.

vīráyadhvam. I2. 2. $26^{\dagger}$.

virá。vant: -vatis. 3. I6. $7^{*}$.

viraovíd: II. I. I5.

vīraostú: -ús. I4. 2. I $7^{*}$, I 8 .

vìrastầra: -am. 20. I27. 6 (mss.).

virahat y a in avāirahatyá.

vĩrahán: -raoghni. 6. I33. 2.

vīrúdh: -út. I. 34.1 . 2. $7.1 ; 8$. 2-4. 6. 32. 2 . 7. 56. I, 2.

vīrúdham. 6. 52.3. 8. 7.23 (s. mss. -dhām).

vīrúdhã. 6. 136.3 .

vīrúdhas. I. 32.3. 2. 9. 3, 4. 3. 27. 5. 4. I5. 3. 7.87. I. 8. 7. 4, II, I8; 8 . I4. IO. I. I $2 ;$ IO. 21 . II. $4.17 ; 6$. I; 7.21; 9.24. I2. 3. 3I. I5. 6. I. vīrúdobhis. 5.28.5. 8. 7. I5. vīxúdobhyas. I9. $35 \cdot 4$. vīrúdhām. 3. I8. $1^{\dagger} ; 23.6 .4 .37$. 5. 5. 4. I; 24. 7. 6. I38. I. 8. 7.2, I2, I4, 20. II. 6. I5. I 5.6. I. I9. 33. I. 
vīrudhām. 4. 49.8.

(cf. vírudha.)

vîrudha: -dhānaam. 6. 2 I. 2.

virtsă (p. vioīr-): -sấyāi. 5. 7. I.

viry à: -yàm. 4. 24. 6. 10. 5. I-6.

II. 7. I7. I2. 5.6.

vīríam. I. 7.5. 3. I9. I, 2. 5. 8. 2. 8. 7. 5. 9. $4.23^{\dagger}$. I0. 2. 5. I9. 34.8 . vīryèna. I9. I9. 9 .

viríeṇa. 5. 28. 4. 9. 2. I. IO. I. I2. 19. 72. $\mathrm{I}$.

viríāya. 10. 6. 7. I I. I. 3,$7 ; 2.14$. I9. $37.2 ; 46.1$.

viríāni. I. $35 \cdot 3 \cdot$ 2. $5 \cdot 5^{*}$. 5. 26 . I I. 7. $26.1^{*}, 2^{\dagger}$. II. 9. I. I2. 3. 2. I3. 2. 32. I7. 6-I9, 24. I9. 22. $21 ; 27$. IO $^{2}$; 30. $2 ; 33.5 ; 37.1 ; 46.5$.

vīríāis. 7. 25. I. I9. 30. I.

(cf. amitavirya, kṛtávĩrya, nănāvirrya, bāhuvīryà, viçvátovīrya, viçvadhāvīrya, çatávirya, sahásravīrya, suvírya, viryàvant.)

viryàovant, viryàvant (p. -yà॰v-): viríavãn. 8. 5. I.

vīríāvãn. I4. I. $37^{\dagger}$.

vīriāvatā. 4. 37. I J. I0. I. I4.

vỉriãvatị. $4 \cdot 37 \cdot 5$.

vīriāvati. 6. I39. 5 .

vīryàvatotaras. I8. 4.38.

V I v ṛ, ū r ṇu: ávṛmịidhuam. 6. 7.3. ūrṇotu. I8. 4. $59^{\dagger}$.

āurṇot. 7. 1.2. 10. 2. 18.

vṛtă. I2. I. 52 .

vṛtvă. I9. 6. $1^{*}$.

avīvaran. 6. $85 . \mathrm{I}$.

ávivarata. 3. 13. 3.

vāraye. 4. 7. I. 6. I2. I, $2 ; 85.3$. I9. 36.6 .

vārayāmahe. 6. 85. 2 .

vārayātāi. 4. 7. I. 6. 85. I.

ávārayanta. 10. 3. 2.

vārayișyate. ro. $3 \cdot 4,6,7,8$.

(cf. úras, urú, I vára, varaná, váriman, varimán, várīyas, váruṇa, várūtha, várṇa, vártra, várman, vắra?, vāraṇá, vị́t?, vṛtrá, vrá, vavrá, vavrí.)
+ a pa: ápa vran. 18. 3. $21^{*}$. aporṇuván (p. apåūr-). 9. 3. I 8.

+ a b hi : abhí... ūrṇomi. I8. 2. 52. abhioūrṇuté. I4. $1.27^{\dagger}$.

abhí... ūrṇuhi. 18. 2. $50^{*}, 51$; 3 . $50^{*} ; 4.66$.

[10. I6.

abhívṛtā (p. abhíov-). 9. 10. $7^{*}$. 10. (cf. abhìvăra ?.)

[17. 27.

$+\bar{a}$ : ầvṛtas. I0. 2. 3I. I3. 4. 2, 9. ăovṛtā. 9. 3. I 7. 12. I. $52 ; 5.2,12,53$. ăovrtam. 9. 9. I4*. I0. 8.43. II. 9. 4. I2. I. 8.

ăovṛtām. I0. 2. 29.

ấvṛtās. IO. I. 30 (p. -tā). [15.

+ prā: prāvị́tya (p. praoāv-). Ir. 8 . prầṛ̂tā. 12. 5.2. I8. 3.3.

+ pa ri : pári vāraya. I I. 9. 5; I0. I9. párīvṛtas (p. -riov-). I7. 28.

párīvṛtā (do.). 10. 8.31. I2. 5. 2.

+ sa m pari : sampárivịtãm (p. -m。 páriv-). 10. 2.33 .

+ pra: pró "rṇoti. I5. I. 8. pró "rṇuhi. 4. 14. 9.

pró "rṇuṣva. I8. 2. 58 ".

+ vi: ví... ãvar. 4. I. I.

ví var. 4. I. I.

ví ūrṇotu. I. II. 3 .

vy ùrṇuvantu. I. II. 2.

ví... ãúrṇot. I3. 3.22.

+ s a m: cf. samivárana, samvít.

$\sqrt{ } 2$ v r.: vṛne. Io. 4. 2 I.

ṿ̛nịșé. 9. 2.25. II. I. IO.

vṛnáte. I8. I. $2 \mathrm{I}^{*}$.

vṛate. 2. 6.3.

ṿ̛natām. 3. 4.2.

vṛ̣ānás. 2. 13.1. 7. 105. 1.

vṛnānă. 12. I. 37 . 18. 3. I.

ṿ̛nānăs. 12. 2: 24 *

avṛṇita. 2. 5. $7^{*}$. 9. 4. 5. I4. I. $15^{*}$. I8. 3. $4 \mathrm{I}^{2 *}$.

ávṛ̣imahi. 7.97. I*.

(cf. 2 vára, vará, váreṇya, vāra, vầrya.)

+ ā: á... vṛṇe. 7. 15. I.

āvṛnānás. I9. 42.3 (mss. mā vṛ-). + prati: práti ... avrșata. 3. 3. 5 . ṿ̛́ka: as. 4. 3. I, 2. 5. 8.4. 6. 37 , I. 7. 50. 5. I2. 4. 7. I9. 47.6 . 
vf̣kam. 4. 3.4. 12. I. 49. vị́kăt. 5. 21.5 .

vịkasya. I9. 47.9; 50. I. vị́kāu. 7.95. 2.

ṿ̛̂kās. I2. $5 \cdot 49$. (cf. avṛká, sālāvŗká.)

vŗkká: -kāú. 7.96. 1. 9. 7.13. vṛná, see $\mathbf{v}$ vraçc. [2.25.

ṿ̛ksáa: -ás. 4. 7. 5. 7. 59. I. 18. vŗkşám. I. 2. 3. 2. 12. 3. 5. 5.3 (vŗkşámovṛkşam). 6. 2.2; 8. 1; 37 . 2. 7. 50. I; 109. 4 ; I1 5. 2. 9. 9. $20^{\circ}$. 18. I. $15^{\circ}, 16^{*}$.

vṛkșât. I. 14. I. 6. 124. 2. 8. 6. 26. vṛkşásya. 3. 6.8. 4. 6.6. I0. 7 . 38. 20. 136. 9 (mss. vị́kşa-). vṛksé. 9.9.21*. 20. 127.4 . vṛkşăs. 5. 19. 9. 6. 15. I*; 44. I. 10. 3. 15 ; 8. 3I. I2. I. 27 20. I3I. I4. vŗkşắn. 5. 5.9. 6. 45. I ; 129.2. 10. I. 17 ; 3. I3, I4. I2. I. 5 I. vṛkşănāām. 6. 15. 2, 3 .

vłkşéşu. 6. 129. 3. 7.66. I. (cf. daçavṛkșa, mahāvṛkṣá, vṛkşasarpa.)

v rk\$a०sarpá: -pías. 9. 2. 22.

V vrjj: vṛkṣi. 6. 30. 2.

vrjyate. 5. 12. 4 (mss. -ase).

varivarjáyanti. I2. 5. 22. (cf. úrj etc.?, varga, vargya, varjivāǹs, ṿ̛j, vṛjana, vṛjaní, vṛjiná, vrajá ?, vrājá ?.)

+ an u: cf. anūví̛j.

+ a pa : ápa vṛñjāte (p. -e íti). Io. 7.42. ápa vṛñkşva. 3.12. 6.

ápā 'vṛk. 13. 2. 9.

+ abhi: cf. abhĩvargá.

$+\overline{\mathbf{a}}$ : cf. āvrj.

+ pari: pári vṛndhi. I. 25. I-3. 5 . 22. 10. 9. 2. 5 , 16 .

pári ... vṛñndhi. 6. 37. 2. I I. 2. 20. pári vṛnaktu. I. 30. 3. II. 2. $8^{2} .4$. 21. $7^{\dagger}$. 6. $27 \cdot 2^{*}$. 8. 2.9. 9. 2. 5,16 . pári vrñnjantu. 6. 93. I.

páriovṛktā. 7. 113.2. 20. 128. 10 (mss. pári vṛktă).

pári varjaya. Io. 4.25.

(cf. parivargyà.) v ŗj in anūvị́j, svăvŗj.

vrjan a in suvrijána, vrjant.

vrjjan 1: -nibhis. 7. 50. $7^{\dagger}$.

vrjanişu. 9.9.9.

v ŗji ná: -ám. I. 10.3. 8. 3.14"; 4 . I3. I I. 8. 20.

ṿ̛jină. I. 20. I. 5. 3. 6.

vṛjinăni. 2. $12.6^{\circ}$.

vŗjină. $7 \cdot 56.4$.

$\checkmark$ vrt: vartate. I0.8.7. II. 4. 22.

vartatām. $5 \cdot 14 \cdot 5,13$.

vāvṛtús (p. vav-). 5. 19. 13.

vartáyatam. 8. $4.4^{\circ}, 5^{\circ}$.

várvartti. 9.9.13..

(cf. varivṛtá, varta, vartana, vartaní, vártman, vartsyant, vṛt, vṛtta, vráta, vratá, vratáti, vrăta ?.)

+ a nu : anuovártate. I2. 2.37.

ánu vartatām. I I. 9. 2 I.

ánu vāvṛte (p. vav-). 7. 21 . I. anuovartáyan. II. IO. 18 .

+ abhi: abhiovŕtya. I. 29. 2*.

abhyávartayan (p. -i॰áv-). I2. I. 5. (cf. abhīvartá.)

$+\overline{\mathbf{a}}$ : a vartate. 12.2 .52 .

à... vartate. I9. 47 . I.

āvartsyán. I5. 6.7 (? p. av-).

à vavṛtsva. $4.32 .6^{\circ}$.

â... vavṛtyām. I8. I. I".

à 'vavṛtran. 6. 22. I'. 12. $2 \cdot 22^{*}, 4 \mathrm{r}$.

13. 3. 9".

à 'vìvṛtāma. I4. 2. 36 .

àovṛttas. 9. 7.23.

â vartayāmasi. 7. 12.4.

â varīvartti. 9. IO. II". I0. 2.7 (1. varv-?).

āovárvṛtatas. 5. 1. 8 (mss. -rvrat-). (cf. āvártana, āvị́t, ánāvṛtta.)

+ anvā: anvăvarte ( $p$, anuoấv-). I0. 5.37 [2. 34 . + a pā: apāvṛ́tya (p. apåãv-). I2. + abhyā: abhyầvarte (p. abhi。 áv-). 10. 5. 38-41. [1. 22. abhyăvartasva (do.). 7. 105. I. II. abhyăvavṛtsva (do.). 3. 17. 9.

+ u pāa upávartata (? mss. ed. úpā 'v-). I9. 56.3. 
(cf. upāṿ̛́t.)

+ paryā: paryăvarte (p. -rioấv-). 7. I00. I. I2. I. 34 . paryầvartethām (do.). I2. 3. 8. paryằṛtas (do.). II. 4. 26.

+ abhipary $\bar{a}:$ abhioparyávartanta. I5. 7. 4 .

+ Vyā: vioăvṛttas. I0. 7.40.

(cf. vyāvártana.)

+ ni: nívṛttas. 20. 133. 2 (mss.). niovítya. Io. I. 17.

ní vartaya. 6. $77 \cdot 3$.

(cf. nivártana.)

+ abhini: abhionívartasva. ro. I.

+ pari: pariovártamāne. 9. 9. I I*.

+ pra: prá vartaya. 8. 4. 19*.

(cf. pravartá.)

+ prati: cf. prativartá.

+ vi: ví vartatām. Io. I. I9. ví vãvṛte (p. vav-). 9. 9. $144^{*}$. ví... avṛtan. 3. 3I. I (ed. acṛtan). ví vartaya. II. 2. 2 I.

vioávartayat. I0. 7.26.

+ anuvi : anuovyàvartayanta. I5. 7. 2.

+ s a m: sám ... vártate. 6. IO2. I. sám... vartatām. 6. IO2. I.

sám avartata. 4. 2. $7^{*}$. I 9.6. 8*; 52. I*. sám vṛtas. 8.6.3.

sám vartayati. I9. I2. I*.

sam.vívrtsati. 8.6. I6.

(cf. samiń̛t.)

vị́t: -tam. 7. 50. $4^{*}$.

v ṛt in āvṛ́t, upāvṛ́t, ekavṛ́t, triṿ̛́t, purū vị́t, vișū vị́t, samvị́t, suṿ̛́t.

v ṛtta in ánāvṛtta, akṣávṛtta.

v ṛtrá: -ás. 6. 85.3.

vṛtrám. 2. 5. 3. 8. 5. 3. 12. 1. 37.

vṛtrăt. 4. I0. 5 .

vṛtrásya. I. 21. $3^{*}$. 6. I34. I ; I35. I. 20. 128. 13 .

vrrtré. 3. 2 I. I.

vṛtrặni. 4. 32. $7^{*}$. 5.6. $4^{*}$. 7.93. I ; I IO. I.

(cf. vṛtrahátya, vṛtrahán.)

vṛtraohátya: -yena. I8. I. 38*

vịtra。hán: -hă. I. 21. I*. 4. 32.

$3^{*}$. 5.25.6. 6. 75.2. 7.76.6*. 8.
5. 22. IO. IO. IO. II. IO. 27. I8. I $38^{*}$. 19. $15.3 ; 26.4 ; 27.2$. 20. 128. I4 (mss. -hán).

vrtrahan. I. 2 I. $3^{*}$. 3. I. 3. 5. 8. 7, 9. 6. 98. 3. II. 9. 23.

vṛtraoghnă. 3.6. 2.

vṛtraoghnás. 4. 24. I. 6.82. I.

ṿ̛trahánā (p. -traohán-). 4. 28. 3. 7. I I0. 2.

vṛtrahánotamā. 7. I I. I.

ṿ̛́thā. 20. 127. 5 (mss. ṿ̛́șâ).

(cf. vṛthāsáh.)

[mss.).

v r thā sá h: -thāşăț. 20. 128. I3 (not

v ṛddha in ghṛtávṛddha, bráhmavṛddha, varșávṛ̂dha, vṛddhávṛșnạa.

vṛddháovṛṣ̣a: -as. 7. 62. I.

$\checkmark \mathbf{v} \mathbf{d} h$ : vardhatas. 20. 136.2 (mss. vár-).

vardhase. 5. 1. 9.

várdhante. 8. 2. 22.

vardhantu. 18. 3. I0.

várdhasva. 6. IOI. I.

vardhatām. 2. 28. I. 6. 39. $1 ; 72$.

2,3 ; IOI. I. $7.53 .5 ; 73.8^{*} ; 82.3$. vardhantām. 5. 29. 12. 6. I37. 2,3 . várdhamānas. 3. II. $4^{*}$. 5. I. I. 6. IIO. 3. 7. 53. 2.

várdhamānā. I2. 1. I3 (mss. vardhamānă).

várdhamänam. 2. 1 3. 5.

avardhata. I5. I. 4.

avardhanta. 5. I9. I.

vṛdhāma. 5. I. 9.

vavardha. 18. 3. $65^{*}$.

vāvṛdhús (p. vav-). I8. I. $47^{*}$.

vāvṛdhé (do.). I4. I. $37^{*}$.

vāvṛdhe (do.). 7. 5. 2.

vāvṛdhéte (p. vavṛdhéte iti). 5. I. 5. vāvṛdhānás (p. vav-). I. 8.4. 5. 2. $2^{*}$; 28. 4. I3. I. 9. I7. 12. I8. 1. $47^{*}$. vāvṛdhănám (do.). 8.4.4*. 19. 45.3. vāvṛdhānăm (do.). I2. I. 29. vāṿ̛dhānāú. 7. 29.2. 13. 1. 49. vāṿ̛dhānắs. 7. I. I.

vāvṛdhántas (p. vav-). I 8. 3. 22†. ávivṛdhas. 13. 4.43 (mss. av-). vṛddhắsu. I1. 8.34 . 
vṛdhé. II. 2. 24. I 8. 3. 23 ". vardhayāmi. 3. 19.5 . vardhayāmasi. I9. 64.2 . vardháyanti. 5. 2. 9*. vardhayanti. I3. I. 33 . vardhayātha. I4. I. 32 . vardháya. 6.3.3. 7.16. I. vardhaya. I. 9. 3. 3. 20. $5^{*}$. 4. 22 . I. 5. 28. 4. 6. 39. I. II. I. 21 . I9. 63 . I; 64. 2.

vardhay $\bar{a}$ (p. -ya). 3.20. $I^{*}$. 6. 5.3; vardhayatā (p. -ta). I. 15.2. I9. I. I, 2 .

vardhayantu. 2. 6. I. I4. I. $54 ; 2$. 13. I8. 3. 12. 19. I. 3 .

vardháyan. 4.21. 2*. 19. 27.5.

vardháyantāu. 5. 26. I 2.

vardháyantas. 17.14 .

vardháyanti. I9. 58. I.

vardhayat. 12. I. 13.

(cf. $\sqrt{ }$ rọh, ūrdhvá, várdha, várdhana, várdhra, vṛddha, vị́dh.)

+ a b hi : abhí vardhatām. 6. 78. I, 2. abhí ... vardhatām. 6. 78. 2.

abhiovāvṛdhé (p. -vav-). I. 29. I ${ }^{\dagger}$. abhí ... avivreqhat. I. 29. $3^{\dagger}$. abhí...vardhaya. I. 29. $\mathrm{I}^{\dagger}$.

+ pra: práovṛddhe (p. -e íti etc.). 4. 26. 2.

prá vardhayāmahe. 19. 32. 3 .

prá ... vardhaya. 2.6.2.

$\mathbf{v}$ ṛ̛ $\mathbf{d} \mathbf{h}$ in vṛdhé (inf.), and āhutĩvị́dh. ritāvị́dh, tamoví́dh, yajñaví̛dh, suvị́dh.

vị́nta: -tāt. 8. 6. 22.

ṿ̛́çcika: -as. I2. I. 46 .

ṿ̛́çcikam. Io.4. 9.

víçcikasya. I0. 4. I5.

V v ṛṣ: várșasi. I3. 4. 43.

varşanti. 9. I. 9.

várșantu. 4. I5.4, 7.

varșantu. 8. I. 5 .

várșan. 9. 6. 47.

várşate. II. 4. 2.

várșatas. 4. 15. 4 .

vrstée. 3. 24. 3 .

varșáyanti. 4. 27.5 .

varşayanti. 9. I. 9 . (cf. varșá, vársişţha ?, várşiy yas ?, várşman?, varşmán?, vṛş, vṛşa, víș̣an, vṛşabhá, vṛșțí.)

+ abhi: abhí varşati. 5. 19. 15. abhyàvarşit (p. abhìoá-). I I. 4. 5, I 7 . abhíovṛşţās. II. 4. 6.

+ ã: ấ vrṣasva. $7 \cdot 76.6^{*}$.

à vŗşethăm. 7.58.2*.

+ pra: cf. prăvị́s.

v rọ in prāvíng.

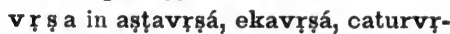
şá, trivrş̣á, daçavrşá, dvivŗşá, navavṛşá, pañcavṛşá, mahãṿ̛şá, şaḍṿ̛șá, saptavṛsáá.

$\checkmark$ v rִs a ṇy: -yatás. 6. 70. I-3.

vrşaṇyánti. $5 \cdot 5 \cdot 3$.

vł̧̧ạ̣yántyãs. 6.9 . I.

v ŕşa o d a nt: -atīm. I. 18. 4 .

ṿ̛̂s a n: -șā. I. I2. I ; $21 . I^{*} ; 29.6^{\dagger}$. 3. 7. 2. 4. 36. I. 5. 13. 3 ; I9. 4 ; 20 2,$3 ; 25.8$. 6. $48.3 ; 67.3 ; 86.1^{4}$.

8. 5. 12, 22. 9. I. IO, 20. IO. 3. I. II. 7. I6. I4. 1. 43 . I8. I. I8; 4. $58^{*}$. I9. 27.1 ; 3I. 2, II. 20. 49.1 ; 127. 5 (mss.); I 28. I3 (not ed.).

vṛșan. 6. 63. $4^{*}$.

ṿ̛́ṣnā. 4. 4. 2. I9. I3. $3^{*}$.

ṿ̛́ṣne. I2. I. 37 . I8. I. 18 *

vị́ṣnas. $4.8 .3^{*}$; $15.11^{*}$. 7. $58.2^{*}$. 9. 10. $13^{*}, 14^{*}$. 19. $13.10^{*}$.

vị́ṣanạas. II. 2. 22.

vị́şaṇāu. I9. I3. I.

ṿ̛́șaṇā. 7. IIO. 2.

vṛșaṇā. 7. 58.2 (mss. vị́ș-); 73.1, 2. 8. 4. $\mathrm{I}^{*}$.

vṛșanas. II. I. $2^{\dagger}$.

(cf. vṛșa-vịṣadant, vṛṣabhá, vṛșāy, vṛ̣̣na, vṛṣnya.)

v ṛșabhá: -ás. 4. 5. I"; 24. 3. 6. 98.

3. IO. 5. I8. II. I. 35. I3. I. I2, 25, 33. I6. I. I. I8. 3. $65^{*}$. I9. I3. $2^{*}$.

vrșabha. $7 \cdot 84 \cdot 2^{*}$.

vrșabhám. 7.39. I $^{\dagger}$ 80.2. I9.42.4. vṛșabhăya. 6. 3.4. I". I2. I. 37. I 8. I. I I".

vṛșabhásya. I2. 2.41 .

vṛșabhāú. I9. 13. 1 .

vṛșabhăs. 9. I. 9 . 


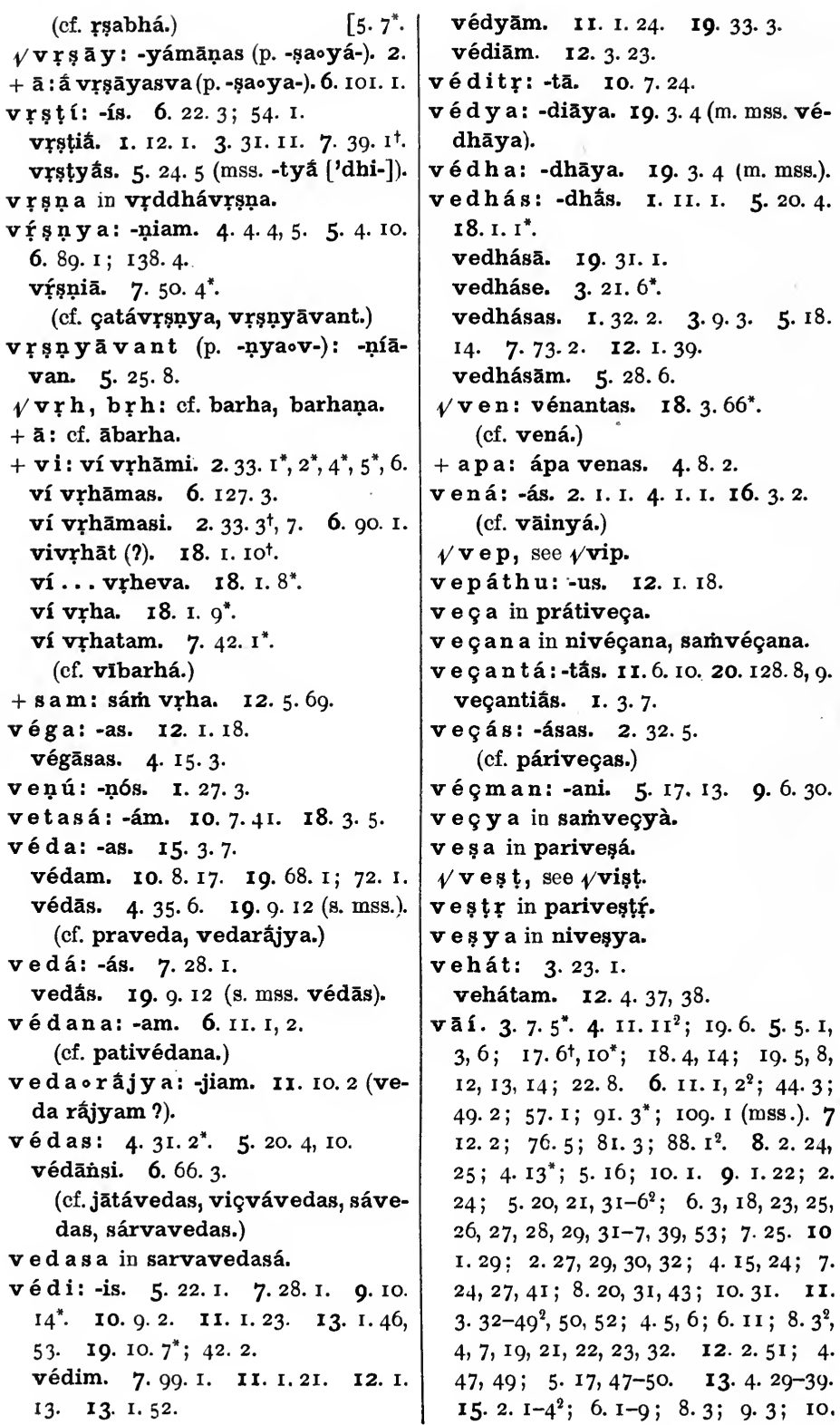


$3,4,5,6,7 ;$ I 7.8. I8. I. I4*; 2. 50, $51 ; 4.32,60^{\dagger}$. 19. 14. I; $48.6^{2} ; 53$. 3, 4. 20. 133. I-6; 134. 4 ; $136.13,15$. vāikañkatá: -téna. 5. 8. I. [r. vãita $\circ$ ha v yá: -yắs. 5. 18. 10; 19. vãitahavyắn. 5. I 8 . II.

vāinyá: -ás. 8. 10. 24 .

$v$ āibādha in

[2. and

vāibãdha०dódhat: -tas. 3. 6 . vāibādháprạ̣utta (p. -dháo pran-). 3.6. 7 .

vāiman as yá: -ám. 5. 2 I. I.

vāíyāghra: -as. 8. 7. 14 .

vãíyāghre. 4. 8. 4.

vāíra: -am. IO. I. I9. I2. 5. 28. (cf. avāirahatyá.)

vāirājá: -ám. r5. 2. 3; 4. 32.

vāirājầya. 15. 2.3.

vāirājásya. I5. 2. 3 .

vāirājăs. 3.26.3.

vāir ū pá: -ám. 15. 2.3; 4. 32

vāirūpăya. I5. 2. 3 .

vāirūpásya. 15.2. 3 .

vāirūpāís. I8. 1. 59".

vāivasvatá: -ás. 6. ıi6. 2. 8. Io. vāivasvatám. I8. I. $49^{*}$; 3. I3.

vāivasvaténa. 8. 2. II.

va̋ivasvaté. 6. I16. I.

vāiçāle yá: -ás. 8. 10. 29. [6.6*. vāíçy a: -as. 5.17.9 (1. -çias). 19. văiçravaṇá: -ás. 8. 10. 28.

vai ç va ok a r m a ṇá :-ṇăs. I3. I. I8.

vāiçva०devá: -ás. 9.7.24.

vāiçvadevi. 7.27. I. 12. 5. 53 .

vāiçvadevím. 12. 2. 28 .

vāiçvadevís. 8. 7.4.

vāiçvānará: -ás. 3. 21. 3. 4. 36. I. 6. $35.1,2,3 ; 47.1 ; 53.2 ; 62.1$; IIg. I, 3. 8. I. II; 5. IO. IO. 7. I8: 12. 5.18 . 13. 3. 5 .

vāiçvānara. 2. 16.4. 3. 15.7. [1.6. vãiçvānarám. 4. 23. 4. 6. 36. 1. 12. vāiçvānaréna. 6.85.3. 7. 108. 2. vāiçvānarăya. 6. IIg. 2.

vāiçvānarăt. 1. 10. 4. 8.2. 27 ; 7. 16. vāiçvānarásya. 4. 36. 2. 6. 71. 3 . 8. 9. 6. 10. 5.43 . 16. 7. 3. 20. 127. 7 . vāiçvānaré. 4. I1. 7. I8. 4. 35 . vāiçvānartm. 6.62. 2, 3.

(cf. vāiçvănarájyeșţha.)

vāi çvānará oj y eș ț ha: -țhebhias. 3: 21.6 .

văișț a pá: -pấn. í. 27.4 .

v y àn $\mathrm{g}$ a : víoañgas. 7. 56.4 . víoañga. 5.22. 6.

v y a c in uruvyác.

vyácas: 4. 19.6. 6.61. I. 8. 10. 14, 16. 9. 3. 15 . 10. $2.24,25$. 12. I. 53 . 3.4 .53 .

vyácasā. I1. $3 \cdot 39^{2}$.

vyácasas. I9. 68. I (mss.).

(cf. ávyacas, uruvyácas, viçvávyacas, vyácasvant.)

vyá casva nt: -vatis. 5. 12. $5^{\circ}$.

$\checkmark$ vy a th: vyathantām. 4. 40. I-8. vyathișthăs. I2. 3. 23 . I4. I. 48 .

r9. 33. 5 .

vyathișmahi. 12. 1. 28.

vyatháyã (p. -ya). r3. I. 3 I.

vyathayis. $5 \cdot 7 \cdot 2$.

(cf. vithurá, vyathí.)

+ pra: práovyathitās. io. 3. 9 .

vyathí: -is. 4. $21.3^{\dagger}$. 6. 33. 2.

v y ád va n: vioádvari. 3. 28. 2. [ [2 $\checkmark$ v y a d h, vid h: vídhyāmi. 7. 74 . vidhyāmi. 3. $25.1,3$. 7. 74. I. I6. 7. $1^{6}$.

vidhyati. 5. I 8.8, I5. I5. I. 8.

vidhyāmas. I. 16. 4 .

vídhya. 5. I4.9. I I. 9. I2. I9. 28. IO ${ }^{4}$ (s. mss. vidhyá).

vidhya. 3.2. 5. 5.8.9; 20.3. 8. 3. $5^{*}, 6^{*}, 12^{*}, 17^{*}$.

vidhyatu. 3. 25. 2. 5. 3I. I2.

vidhyata. 3. 2. 6 .

viddhás. 2. 29.7.

viddhà. 3. $25 \cdot 4$.

viddhásya. I0. I. 26 . II. 2.13.

(cf. viddha, vidh, vyadhana, vyādha, vyādhin, vyādhya.)

+ ati: atiovídhyanti. 8. 5. Ig.

(cf. atividdhabheșajá, anativyādhyà.)

+ a bhi : cf. abhivyādhín.

$+\bar{a}$ : cf. anāvyādhá.

+ ni : ní vidhya. 5. 29. $4^{2}$. 
ní ... vidhyatam. 8. $4.5^{*}$. ní vidhyatām. 8.6.24. níoviddhā. 9. 9. $8^{*}$.

+ pra: prá vidhya. 8.6. I7. prá vidhyatam. 8. 4. 3 *. praovídhyantas. 3. 26. 4 .

+ vi: ví vidhyatu. I. I9. 3 . ví vidhyatam. I. 8. 2. ví vidhyatām. Ir. 9.23. ví vidhyata. I. I9. 2. víoviddhas. 6. 66. $\mathrm{x}$. víoviddhā. II. IO. 25. (cf. vivyādhín.)

vy adh an a in krtavyadhana.

vyadhvá: vioadhvăyăs. 4. 40. 6. vioadhvé. I3. 2.31.

vyadhvará: vioadhvarám. 2. 3 I. 4 . vioadhvarăs. 6. $50.3^{2}$.

vyanant in ávyanant.

v y àlka ça: víoalkaçā. I 8. 3. 6*. vyasta okeçá: -çías. 8. I. I9 (1. via-). $\checkmark \mathbf{v} \mathbf{y} \bar{a}, \mathbf{v}$ ye: cf. vita.

+ a pa: ápa vyaye. 6. 9I. I.

+ a pi: ápi vyayāmasi. I. 27. 2.

+ u pa: cf. prācīnopavĩá.

+ pari: pári vyayāmasi. 6. 106.3. pári ... vyayasva. I8. 2. $58^{*}$. páriovĩtas. 9. ro. 10*.

[1. 45 .

+ sam: sám vyayantu. 7.17.3. I4. + upas a m: upaosámvyayasva. 2 . 13. 3. I9. 24.5 .

v yā ghrá: viāghrás. 4. 3. $1 ; 8.4$; 36. 6. 8. 5 . II, I2. I9. $39.4 ; 46.5$. víăghra. 4. 3.3 (mss. vyā-; ed. vyấ-). viāghrám. 4. 3. $4 ; 8.7$.

viāghrásya. I9. 49.4 .

viäghré. 6. 38. I; I ro. 3 (-ghryé ?). viāghrāú. 6. 140. 1. 12. 2.43.

vyāghrấs. I2. r. 49 .

(cf. vāíyāghra, vyāghrajámbhana-vyāghryá.)

[3. 7 . vyāghra,ojámbhana: -am. 4 . vyāghráopratīka: -as. 4. 22.7. v yāghryá: viāghryás. 12. 2. 4 . vy àdha in anāvyādhá. [dhín. vyādhin in abhivyādhín, vivyāv y à dhĩ: víoādhias. 7. I14.2. vyā dh y a in anativyādhyà. v yāná (p. vi̊ā-): -ás. I5. 17. I-7. 19. 5 r. $\mathrm{r}$.

viānás. I 4. 1. 12*. 18. 2.46. viānám. I0. 2. 13. II. 5.24. viānăya. $5 \cdot 4 \cdot 7 \cdot 6.4$ r. 2. vyānăs. 15. 15. 2.

(cf. vyānodāná.)

v y ā nod ā ná (p. -naoud-): -nāú. I I. 8. 4 (l. viā-), 26 (do.).

v y à pti (p. víoā-): víāptis. Ir. 7. 22. víāptim. 9. 5.12.

v y ā má (p. vioā-) : viāména. 6. 137. 2. viămé. 18. 4. 70.

(cf. vyāmyà.)

v yã $\mathrm{m}$ y à : vioāmyàs. 4. 16. 8.

v yā yāmá: vioāyămé. 2. 4. 4 .

vyāla: víoāla. 5.22. 6 .

v yā várt a n a (p. vi॰ă-): -ne. 6. 26. 2 .

v y ús: vioúșas. 13. 3.21.

v y ù șt i: víouṣțīs. 8. 9. ro, 15 .

vy r̀ d d hi (p. víoṛd-): -is. 8. 8.'9 (l. vírd-). 12. 5. 29.

vírddhayas. 4. 2. 49

(cf. ávyrụdhi.)

v y èn a s: víoenasāu. 14. 2. 16t.

vyeşyant in ávyeşyant.

v yāì la ba: víoāilabās. r2. I. 4I.

vyòm a n: víooma. 9. 10. $13^{*}, 14^{*}$. II. I. 30 .

víooman. 5. 17. 6*. 6. 123. 1, 2. 7 5. 3. 8. 9. 8. 9. 10. $18^{*}$. 12. 1. 8. 13. r. 44 . 17. 6-19, 24. I8. 3. $58^{*} ; 4$. 30. 19. 53.3.

v y òs a: víooșā. 3.25. 3 .

víooşayā. 3. 25.4 (m. mss. vioóș-). vrá: -ás. Ir. $7 \cdot 3$.

vrắs. 2. I. I.

$\checkmark \mathrm{vraj:}$ vrajata. I9. 7 r. I.

vrajá: -ás. 4. 38. 7.

vrajám. 3. II. 5. 7.53. 5. 19.58. $4^{*}$. vratá: -ám. 4. Ir. Ir. 5. Ir. 3; 27. 7. 6. $64.2^{\dagger}$. 7. 40. x. 9. 1. $8 ; 6.38$; 7. II. IO. 7. I, II. II. 7.9. I8. I. $33^{*}$. vraténa. 4. I1.6. 7.27. I; 74. 4 ; 9o. 2. I8. $3 \cdot 40^{*}$.

vratásya. 6. 133. 2.

vraté. $4 \cdot 25 \cdot 3 \cdot 7 \cdot 9 \cdot 3^{*} ; 40 . I^{2} ; 49$. $\mathrm{r}^{*} ; 83.3^{*}$. 8. 9.8. 
vratăni. 4. I1. 2. 7.26.6*. I8. I. 5*. I9. 59. 2*.

vrată. 2. 30. 2. 3. 8.5 . 6. 74.1 . 20. 34.16.

vratébhis. I9. I0. 9.

vratéṣu. 7. 68. I.

(cf. avratá, ánuvrata, ápavrata, dhṛtávrata, mahāvratá, máhivrata, vívrata, sávrata, suvratá, vráta ?, vratacārín, vratapativrátya.)

vráta: -as. 5. 1. 7.

vrataocārín: -ínas. 4. 15.13 ".

vratáti: -tes. 7.90. $1^{*}$.

vrataopati: -te. 7.74. 4.

vrata。pă: -ăs. I9. 59. I".

vrátya: -yās. 4. II. II.

$\checkmark \mathbf{v a c ̧ c , ~ v r ̣ c ̧ c : ~ v r ̣ c ̧ c a ̆ ́ m i . ~ 2 . ~ I 2 . ~}$ 3; 25.2 (mss. -cā-). 3.19.2. 6.65. 2. ṿ̛çcāmi. 2. I2. 7 . I 3. I. 56,57 . vŗ̧cati. I2. 5. 42.

vịçcanti. I2. 4. 28.

vṛçcá. 12. 5.62. I9. $28.7^{4}$.

vrçca. 8. 3. $10^{*}$.

vŗ̧̣cáte. 6. 136. 3. 8. 10. 18.

ávṛçcan. I2. 4. 50.

vṛșțâ. 8. 3. $2^{\dagger}$.

vṛkṇám. 8. I0. I8.

(cf. vị́ka ?, ví̛çcika, vraska.)

+ a pi : ápi vṛçcămi. 2. 32. 2. 5. 23. 9. I0.6. I.

ápi vŗçca. 7. 90. $I^{*}$. 8. 3. $15^{*}$.

ápi ... vṛçcatu. I. 7.7.

+ ã : ầ vṛçcate (i. e. -cyate). I2. 4 . 26, 34. I5. 2. I-4; IO. $2^{2}$; I2. 6.

á ... vṛçcate. I2. 4.6 , 12. I5. I2. 10. à vṛçcante. I2. $2.50 ; 4.5 \mathrm{I}$.

à vṛçcantām. 8. 3. $16^{\dagger}$. (cf. anāvraská.)

+ pra: prá vṛçca. I2. 5.62.

+ vi: ví vṛçcanti. 7.56.7.

+ sam: sám vṛçca. 12. 5. 62.

v ras k a in anāvraská.

vrājá: -ám. I. I6. I.

(cf. vrājapatí.)

vrāja॰patí: -ím. 7. 72. $2^{\dagger}$.

vrâta: -am. 2. 9. 2.

vrătya: -as. I5. I. I; 3.9; IO. I;
II. I； 12. I; I3. I-5; 18.5 .

vrătya. I 5. 3. I ; II. $2^{6}, 3,4,5,6,8$, Io; I2. 2.

vrătyam. 15.2.1-4; 17.8.

vrătyena. I5. I 2:4, 7, 8, II.

vrătyāya. I5. 3. 3; 18.5.

vrătyasya. $15.15 .1 ; 18.1$.

(cf. ávrātya, ekavrātyá, vrātyá, vrātyabruvá.)

v rãtyá: -yăbhyãm. 19. 23. 25.

vratya०bruvá: -ás. I5. I3. 6.

vrîhí: -ís. 8. 7.20. 9. I. 22. II. 4. 13.

vrìhím. 6. 140.2.

vrĩháyas. 9.6.14. (cf. vrīhiyavá.)

vrîhi ○y a vá: -vāú. 8. 2. I8. II. 4. I3. I2. 1. 42. 20. 129. I 5 (not mss.), I6 (do.).

vrīhiyavăbhiām. I0. 6. 24 .

$\checkmark$ ça ǹ s : çan̉sasi. 6. 45.1 .

çańsati. 2. 12. 2.

çánsantīm. 14. 1. 9".

çastám. 19. 11. 6*.

(cf. çánsa, çańsin, ças, çasta, çasti, çãs.)

+ a b hi : abhíoçastā. 5. 18. I4. (cf. abhíçasti.)

+ av a: cf. avaçás.

+ ā: ā॰çáńseta. I2. 4. 44, 46 .

ầ çańsaya. 19. 64. 4 (not mss.). (cf. āçás.)

+ nis: ef. nihçás.

+ parā: cf. parāçás.

+ pra: prá çańsati. 20. 135. 13 .

+ s a m : cf. samçās.

çán s a : -as. 19. 10. $2^{2 *}$.

(cf. agháçańsa, jāmiçańsá, duḥçáṅsa, nárāçáṅsa, pākaçańsá, suçáñsa.)

ça ṅsin in suçańsín.

$\checkmark$ çak, çikş: çaknoti. 5. 18.7.

çaknuvánti. 4. 26.6.

çaknávāma. I9. 59. 3*.

çagdhi. I9. I5. I".

áçakat. I2. 4. I8. 
çakan. 8. 8. 20 . II. IO. I6. çakema. 5. 8.2. I8. 2. 29. çaçăka. 4. I8.6. 5. 3I. II. çikșāmi. 7. I09. I. 9. 2. I. çíkșā (p. -șa). 18. 3.67*. çíkșān. 6. 122. 2. çíkşan. 9. 4. I. çíkșate. 4. $21.2^{\dagger}$. çíkșantas. 6. I I4. 2, 3 . çíkşantīs. I2. 3. 27 (mss. āpaḥ॰çík-). (cf. çákti, çakrá, çákvan, çagmá, çáci, çāka, çikva, çikşant.)

+ upa: upa॰çekimá. 6. II4. 2 (m. mss. úpa॰çekima).

úpa çekima. 6. II4. 3 . úpa ... çikşāt. 7. I2. I. úpā 'çikṣan. I I. 8. I7.

+ s a m: sám çaknomi. $4 \cdot 3^{6.7}$. sám açakan. I. 27. 3 . çáka, çakán, çákṛt: çákā. 3 . çákṛt. I2. 4. 9. çaknă. 20. 129. 12 (not mss.). çaknás. I2. 4.4 .

(cf. çakadhutma - çakambhará.) ça ka o d hú ma : çákadhūma. 6. I28. 3,4 . çakadhứmam. 6. I28. I. (cf. çakadhūmajá.) ça ka dh ūma ojá (or -jâ): -jầs. 8 . ç a kán, see çáka.

çákabali: -is. 20. I3I. I6. ça ka omáy a: -am. 9. Io. $25^{*}$. ça k a mobhará: -rásya. 5. 22. 4 . çakala, çakalya in [25.2. çakalyeșín (p. -lya॰eș-): -șí. $x$. çakuná: -ás. 6. $27.2^{*}$. 12. 3. I3. I8. 3. $55^{*}$. 20. I 27.4 (mss. -únas). çakunám. I8. 3. $66^{*}$.

çakunấs. II. 2. 24. I2. I. 5 I.

(cf. suçakuná, çakúni, çakúnta.) ça kúni: -is. 7.64. I, 2.

çakúnes. 2. 25.2. I0. 3.6. çakúnayas. II. 9.9.

(cf. kṛ̣ṇaçakuní.)

Ç a kú n t a: -tān. I I. 6. 8. [-lāu). ça ku lá: -lāú. 20. I36. I (m. mss. çák rẹt, see çáka.

çákt i: -im. 20. I36. 5 (mss. çákti). çálstiobhis. 2.27.7. 3. I3.3. çakrá: -ás. 3. 2 I. 4 ; 3I. 2. 4. II. 2. 5. I. 7. 8. 4. $20^{*}, 2 \mathrm{I}^{*} ; 8.1,5,7$. 9. 4.5 . çakra. 2. 5. 4 . çakrám. 7. 86. I*. 20. 49. I (mss. -kră), 2 (mss. -krás), 3 (do.).

çakrăya. I2. I. 37 . çakrásya. 8. 8.6, 8. çakrấs. 5. 28. 8. I I. 6. I2, I8. çákvan: -vari. 7.27.1.

çákvarīs. I 6. 4. 7 .

çakvarīs. 3. $13 \cdot 7$.

çákvarỉbhis. II. 2. 23. I3. I. 5. (cf. çākvará.)

ça g má: -ás. I8. 4. 8.

çagmă. I4. 2 . I7.

çagmấs. 4. 27. 3. I8. 2.21.

çagmấni. I9. 8. 2.

(cf. çagmíya.)

ç a g míy a: -am. 5. I. 9.

çañ kú: -kávas. I0. 8.4.

(cf. çān̄kurá ?.)

çañ khá: -ás. 4. 10. I, 3, 4 .

çañkhéna. 4. 10. $2,3^{2}$.

çañkhébhyas. I9. 22. 8-10.

çác I: -cyās. I3. 4.47.

çácĩbhis. 5. II. 8. 7.25. 2 ; 53. I. 9. 10. $26^{*}$. I I. 4.20 . 20. 34. 12 (not mss.).

(cf. çácīpáti.)

çácIopáti: -is. 3. Io. 12. 6. I34. I ; I35. I. I I. 9. 20. I2. I. I0. I9. I6. I. çacīpate. 6.82. 3. 7.54. 2. I I. 9. 23. ça ṇá: -ás. 2. 4. 5 .

V çat: çātaya. I2. 5.69. çātáyan. 6. I35. I.

+ a p a: ápa ... çātaya. I9. 34. 3.

çatá: -ám. I. I0. 2 ; 30. 3. 2. 3. 2 ; 9. 3 ; I3. 3,4 ; $28 . \mathrm{I}, 4$; 29. 2 . 3. II. $4^{4 *}, 5,7 ;$ 12. 6. 4. 37. 8, 9. 5. 15. 10, II; 30. I6. 6. 44.2 ; 77. 3 ; 90. 2 ; I39. I. 7. $35.2 ; 53.2$. 8. $2.2 \mathrm{~J} ; 8$. 7. I0. 8.24 ; 10. $5^{3}$. I2. $2.23^{*}, 28$; 4. 22. I3. $2.6,7 ; 4.44$. I4. I. 52 ; 2. $2^{*}, 63$ I9. 13. $2^{*} ; 24.5,6 ; 30.2$; $34.2 ; 36.4^{2}, 6^{3} ; 46.3 ; 67.1-7.20$. I27. 3 ; I31. 4-8. 
çaténa. 4. 16. 7; 19.8.

çatăt. I9. 67.8 .

çatásya. I. 17.3.

çaté. I 8. 2. 38-45.

[20. 127.3.

çatăni. 9. 9. 13". 10. 8.4. 18. 4. 70.

(cf. ékaçata, daçaçatá, triçatá, çatákāṇụa-çatāúdana.)

çatá okã ṇ ḍ a :-as. I9. 32. 1, 10;33. I. ৎ̧átákratu: -us. 6. 3o. I.

çatakrato (p. -o íti etc.). I4. I. $41^{*}$. çatákratos. 6. 32. I.

çat aotárha: -am. I. 8. 4 .

cataodakşina a: 10. 6. 34 .

६̧atá odant: -an. I4. 2. 68.

çatáodāy a: -am. 7.47. I; 48. I*. ৎ̧atáodhāra: -as. II. I. 20. I2.3. 5. çatádhãram. 3. 24.4 . I8. 4. $29^{*}$, 35,36 .

çatádhărā. I 8. 3. 72. [5.66. çatá oparvan: -anā. 8. 5. I5. 12. çatá opavitra: -rās. I4. I. 40. çat á b a l ça: -çā. 6. 30. 2.

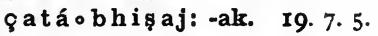
६̧atá $\mathrm{many}$ u: -us. I9. 13. $7^{*}$. ६ata。yája: -am. 9. 4. I8. çatá ○y à man: -anā. I8. 4. 60'. ६atá。yoni: -is. 7.41.2. I9. 46. 6. ६̧atá $\circ$ adha: -dhā. I2. 5. I6.

çatávadham. II. 2. I2.

çatá ○ varman: -ma. I9. 30. I (mss. çatám vármaosu).

çatá ○vāra: -as. 19. 36. 1, 3. çatávāreṇa. I9. 36. 6.

(cf. çātavārá.)

̧̧ata。vāhá: -hí. 5. 17. 12. ९ a tá $\circ$ vicakşa ṇ a: -ṇās. 6. 96. I". çatá vĩrya: -rienaa. 3. II. $3^{\dagger}$.

çatáviriasya. 8. 8.7.

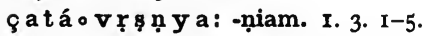
çatá ○̧̧alya: -yām. 6. 57.r. çata०çás. 6.66.3. çat á @̧ākh a: -khā. 4. I9. 5 . çatá ○َ̧ārada: -as. IO. 3. I2.

çatáçāradāya. I. 35. I. 3. 5.4; II. 2". 4. I0. 7. 5. 28. I. 6. I I0. 2. 8. 2. 2 ; 5. 2 I. I2. 2.6 . I4. 2. 75 . 18. 4. 53. I9. 37. 2, 3 .

çataoséy a: -yãya. 3. I5. 3".
Ça t a ०h a st a : çátahasta. 3. 24. 5. Çatá。hāyana: -as. 8. 2. 8; 7.22. ९̧a tá ○h i ma: -măs. I9. $12.1^{\circ} ; 55$. 4 (mss. -támoh-).

C a tă n I k a (p. -tá。an-) : -kãya. I. 35. I. ç a tă på șţha (p. -táoap-): -țhām. 5. 18.7 .

$\left[4^{\circ}\right.$. ६̧ a t ă y u s (p. -táoāy-): -uşā. 3. I1. $3^{\circ}$, ça tấritra (p. -táoar-): -trām. I 7 . $25,26$. [9. 1 .

ç a tã úd a n a (p. -tá॰od-): -nā. Io. çatãudane. I0. $9.3,7,11,24$. çatāúdanām. Io. $9.4,5,6,10$. çátru: -us. 2. 27. I. 5.2. $2^{\circ}$. 6.66. I çátrum. 4. 22.2 (s. mss. -trūn), 3. 6. 4. 2.

çátros. 3.6.6.

çátravas. 4. 3. I ; 3I. $7^{\circ}$. 5.20.3. 6. 66.3 (mss. çat-).

çatravas. 6. 66. 2.

çátrūn. 2. $5.3 ; 27.5$. 3. I. $1,4^{*}$; 2. $5^{\dagger}$; 6. I, 3, 5; 10. I2; I2. 6. 4. 22. 7; 31. $2^{*}, 3^{*} ; 32.3^{*}$. 5. $2.1^{*} ; 21.11$. 6. 88.3 ; 126. I". 7. $84.3^{*}$. 8.8.6. I0. 3. I, 3, II. I3. I. 3. I9. $13.8^{+}$; 46. 2,5 .

çátrūṇām. 3. 19. 2. 5. 20.4 (1. -ṇaam). 6. 65. 2. 7. 50. $4^{*}$. I9. 28.2 .

(cf. açatrú, āréçatru, prátiçatru, çatrușáh-çatrūy.)

çatruṣáh: -rūṣaț. 5. 20. I I.

६̧ a truohá: -ás. I. 29. 5. 6. 98.3. $\checkmark$ ç a $\operatorname{tr} \bar{u}$ y (p. -ru॰y-) : -yatás. 6. 88. 3 . çatrūyatăm. 4. 22.6, 7. 7.73.9", 10*. çatrūyatím. 3. I. 3. .

VI, 2 ç a d: çatsyanti. I I. 3. 37.

(cf. çátru ?, çada.)

çãçadmahe. 5. 2. 5 \%

çăçadānas. I. IO. I.

çâaçadānām. 8. 4. 24".

ç a d a in parṇaçadá.

çá mot a m a : -as. I7. I0.

çámintamā. 7.68.3.

çámintamena. I8. I. $5 \mathrm{I}^{*}$.

çámintamāni. 7.68. 2.

çámintamãbhis. I 8. 4. 10. [tãte). çám tā ti : -im. I9. 44. I (mss. çam̉çámāātiobhis. 4. I3. $5^{*}$. 
ça $\min i$ in

ça min ti॰vá: -vấ. I2. I. 59.

çàntivăm. 3. 30. 2 (mss. ed. -văn).

$\checkmark$ ç a p: çápātas. 8. 3. $12^{*}$.

çápāti. 1. 19. 4.

çápāt. 2.7.2. 6. $37 \cdot 3^{2}$. 7. 59. I. çápate. 16. 6.3.

çápatas. 6. 37.3. 7.59. I.

çaçắpa. I. 28. 3 .

çepé. 7. 89.3 .

çepișé. 5.30 .3 .

çāpayā (p. -ya). 4. 18. 4.

(cf. çapátha, çápana, çápant, çap-

ça páth a : -as. 2. 7. $2^{2}, 5.4$ 4. 9. 5 ; I8. 7. 5. I4. 5. 6. 37 . I. IO. I. 5 . II. I. 22. I9. 38.1 .

çapatha. 6. 37.2.

çapáthăs. 8. 3. $14^{*}$.

çapáthān. 2. 7. I. 4. 19.7. 7. 65. I. çapáthebhis. 3. 9. 5 .

(cf. çapathayăvana - çapathyà.) ça patha०y ávana:-anim. 4. 17. 2. çapatha॰yópana: -ani. 2. 7.I. $\checkmark$ ça pathIy (p. -thi॰y-): -thiyaté. 5. 14. 5. I0. I. 5 .

ça pa th ey y à: -eyíam. 5. 3I. 12. ç a p a th y à : -thíát. 6. 96. 2*. I I. 6. 7. çá p a na: -nena. I. 28. 3 .

ça pant in áçapant.

ça p tṛ́: -tăram. 2. 7.5. 6. 37. I, 2. ç a p há: -ám. 6. 46. $3^{*}$. I9. 57. I* $^{*}$.

çaphé. 20. I31. Io (mss. -éna). çaphấs. 8. 8. 22. 9. 7. 10. I0. 9. 23. çaphấn. 9. 4. I6. 12. 5.19.

çaphāís. 9. 5.3.

çaphébhias. I0. IO. I.

(cf. ékaçapha, goçaphá, viçaphá, çáphaka, çaphārúj.)

çá p h a ka: -as. 4. 34. 5 .

ç a phārúj (p. -phåār-): -jas. 8. 3 . ça bála: -as. 8. I. 9 .

çabále. 5. 29.6.

çabálāu. I8. 2. II*.

ça bda in

ça bdín: -ínas. I9. 36. 3 .

VI ç a m: çaçamānás. I8. I. 22*. çaçamānám. 2. 34.2. 12. 2. Io. çaçamānăs. I 8. 2. 47. $\sqrt{ } 2$ ç a m: açīçamam. 3. 21.9. açīçamas. 9. 8. 22.

açiçamat. 2. 3. 4 .

açīçaman. 3. 2 I. Io (mss. -mam).

çāntás. 3. 21. $9^{2}$.

çāntám. 19. 9. 1, 2², 14

çāntă. I9. 9. $\mathrm{I}^{2}$.

çāntấs. I9. 9. $I^{2}$.

çāntâni. I9. 9. 2, I3.

çamayāmi. I9. 9. 14 (not mss.). çamayāmasi. 7. 74.3.

çamaya. 7.45.2. 18. 3. $60^{\dagger}$.

çamayantu. 3. 2 I. 8 .

çamitâya. I9. 42.2.

[çắnti.)

(cf. çám ?, çaminti, çamana, çamitṛ, + ni: ní çamayat. 6. 52. 3 . ní çamayatu. 6. III. 2.

çá m. I. 3. I-5;6. $1^{2 *}, 4^{4} ; 12.4^{4} ; 33$. I-4. 2. 3. 6 ; IO. $2^{2}, 3^{2}$; 25. 1. 3. 23. $5^{2}$. 6. 12. $3 ; 23.3 ; 27.1^{2 *} ; 57.3$; 120. 2 . 7. 20. $2 ; 69 . \mathrm{I}^{5}$. 8. I. $5 ; 2$. $14^{2} ;$ 7. I7. I 4. I. $40^{6} ; 2.40^{2 *}$. I 8. I. $5 \mathrm{I}^{*} ; 2.36 ; 3.6 \mathrm{O}^{2^{*}}, 6 \mathrm{O}^{\dagger} ; 4.9^{2}, \mathrm{II}^{4}$, I2. I 9. $2 . \mathrm{I}^{4}, 2^{4}, 5$ (not mss.); 7. 2 (m. mss. sám); 9. $2,6^{5 *}, 6,7^{5}, 8^{4}, 9^{6}, \mathrm{ro}^{4}$, II ${ }^{7}, 13^{2}, 14$; IO. $1^{5^{*}}, 2^{6^{*}}, 3^{6 *}, 4^{5 *}, 5^{4^{*}}$, $6^{4 *}, 7^{7 *}, 8^{5^{*}}, 9^{6 *}$, I0 1 $^{*} ;$ I I. $1^{5^{*}}, 2^{6^{*}}, 3^{5 *}$, $6^{*} ; 44.1$.

(cf. áçam [2. 25. I], çámíntama, çám tāti, çamópya ?, çam̉bhúu.)

ç a m a $\mathbf{n}$ a in manyuçámana.

çáma la: -am. 7.65.2. I2. 2. 40; 3. 52 . I3. I. 58 . I4. 2.66.

çámalāt. 4. 9.6. I2. 3. 5 .

ça mit ţ̣: -tâ. 5. 12. 10*; 27.11 .

çamităras. I0.9.7.

çamitāras. 9. 5.5.

ç a m I : çami. 6. 30.2, 3 .

çamim. 6. II. I.

ç a m॰ó p y a : -piāt. I. I4. 3 .

ça m ba in çambín.

çám b a ra : -am. 20. 34. I2, I 7 .

ça mbín: -bí. 9. 2. 6 .

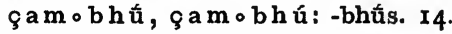
2. 26 . I9. 46.6 .

çambhús. I9. IO. 10*.

çambhú. Io. 1. 9 .

çambhúvam. I 0.6 . I5, I7. 
çambhúbhyas. I 9. 39. 5 (? mss. çămbuobhyas; ed. bhŕgubhyas).

(cf. viçváçambhū.)

çá m y ã: 19.49 .7 (mss.).

çámyayã. 6. 138. 4. 20 136. 10. çámyās. 14. 2. 16*.

ç a y a in talpeçayá, proşțheçayá. çá y a na: -ne. 3. 25. I. 5. 59. 8, 9. I8. I. I4.

(cf. upariçayaná.)

६ a y u in álpaçayu.

çará: -ás. 8. 8.4.

çarám. 1. 2. 3. 4. 7.4.

çarásya. I. 2. I; 3. I- 5 .

(cf. parāçará, viçará.)

çára: -as. Ir. 3.6 (s. mss. çíras).

ça ra ṇá: -ṇă. 3. 12. 5 .

çaraṇé. 6. 55. 2.

çaraṇâ. 19. 15.4".

çarạ̣ấs. 18. 3. $5 \mathrm{I}^{*}$.

ça rá ṇi : -im. 3. I5. $4^{*}$. 6. 43.3.

çarád: 6. 55.2. I2. I. 36 . I5.3. 4 . I9. 6. Io*.

çaráde. 8. 2. 22.

çarádas. I. IO. 2. 2. 13. 3,$4 ; 29.2$, 7. 3. II. $3^{*}, 4^{*}$; 12. 6.7 . 53. 2. I2. 2 . $23^{*}$. I4. I. $52 ; 2.2^{*}, 63$. I8. 2.29. 19. $24.5,6 ; 67.1-7,8$.

çarádām. I8. 4. 70 (mss. -dam). çarátosu. I2. 3. 34, 4I. I 8. 2. 38-45. (cf. çāradá, viçváçārada, çatáçārada.)

ça rabhá: -ás. 9.5.9.

乌aravyà : 8. 3. I2*. II. IO.6. 12. 5 . 25, 59 (l. -víā).

çáravye. 3. I9. 8*. çaravyàm. 5. 18.9. çaravyàyã. I. 19.3. çaravíãs. I. 19. I.

çarika in áçarikka, víçarikka.

Çáríra: -am. 2 12.8. 3.11.6. 4. II. 6. 5.9.7; 10. 8 ; 30. 13. 7. 53 . 2. 8. 2. 26,28 . 9. 4. 5. I I. 8. II, 16, I9-22, 23, 24, 25, 27, 30, 34. I2. 3. 2. 18. 2. $4^{*} ; 3 \cdot 9,7 \mathrm{I}$.

çáríreṇa. I I. 8. 26.

çárirre. 5. 29. 5. I I. 8. 30 .

çárīrāṇi. II. 2. 2. çárîrăis. 2. 34. 5. 18. 2. $7^{\circ}$.

çáru: -um. 1. 2. 3. 6.65.2. 12.2.47. çáruā. 8. 3. $5^{*}$.

çárave. $4 \cdot 30.5^{\circ}$.

çárău. 5. 25. I (msss. ed. sárāu).

çáravas. I. 19. 2. 8. 3. $14^{\circ}$.

(cf. çaravyằ, çarvá ?.)

çárka ra: -rās. II. 7. 2 I.

çár ku : -um. 8. 6.2.

çarkóța: -țasya. 7. 56. 5.

(cf. çărkroța.)

çardís: I8. 3. I6 (s. mss. çárdis).

$\checkmark$ ̧̧ a d h: çárdha. 7. 73. 10*.

(cf. çárdhas, çardhin.) [10*

çárdhas. 4.27.7. 15.14.1. 19.13. çardhin in bãhuçardhín.

çárman: -ma. 1. 20. 3; 21. 4*; 26. 3. 2. 28.5 . 5. 3. $7,8^{*} ; 6.12$. 6. 7 . $3 ; 59.1,2 ; 92.3^{*}$. 7.6. $4 ; 49.1^{\circ} .8$. 2. 7 ; 3. $1^{*} ; 7-25$. 9. 2.16 . I2. 3 . 8, I4. I4. 2. 2 I, 73. I7. I2, I3. I 8. 2 . I9*; 4. 9. I9. 9. $12^{2}, 13^{2} ; 16.2$; 9 . I- II ; 32. 2 ; 47. IO. 20. I35. I I (mss. çarmá).

(cf. suçárman.)

çarvá: -ás. 6. 93. I. I2. 5.36. I 5. 5. $\mathrm{I}-7,2$.

çárva. 8. 8. 17, 18,

çarvám. 15. 5. 2.

çarvăya. 6. 93.2. II. 2. I6.

(cf. bhavāçarvá.)

çarvara in atiçarvará.

çál. 20. r35. 2.

çala in dáçaçala, páñcaçala.

ça la ka kầ: 20. 130. 20 (mss. çalok-). çal ún a: -nān. 2. 3r. 2.

ça lyá: -ás. 2.30.3. 4. 66 .

çalyám. 7.107. I.

çalyatt. 4. 6.4 (l. -liăt), 5 .

çalyắn. 8. 3. $6^{*}$.

(cf. kấmaçalya, çatáçalya.)

çáv a s: 6. $33.2^{2}$. 8. $4.3^{*}$. I I. $8.34^{2}$. 20. I32. I 5 (not mss.).

çávasā. 5. 2. $2^{*}, 7^{*}, 9^{*} ; \quad 27.4$. I3. 2. 3 I. I8. I. $38^{*}$.

çávișţh a: çavișţha. $7.97 . I^{\dagger}$. çávișţhā. I9. 49. 2 (not mss.). çáviṣţhā (du.). 7.25. I. 


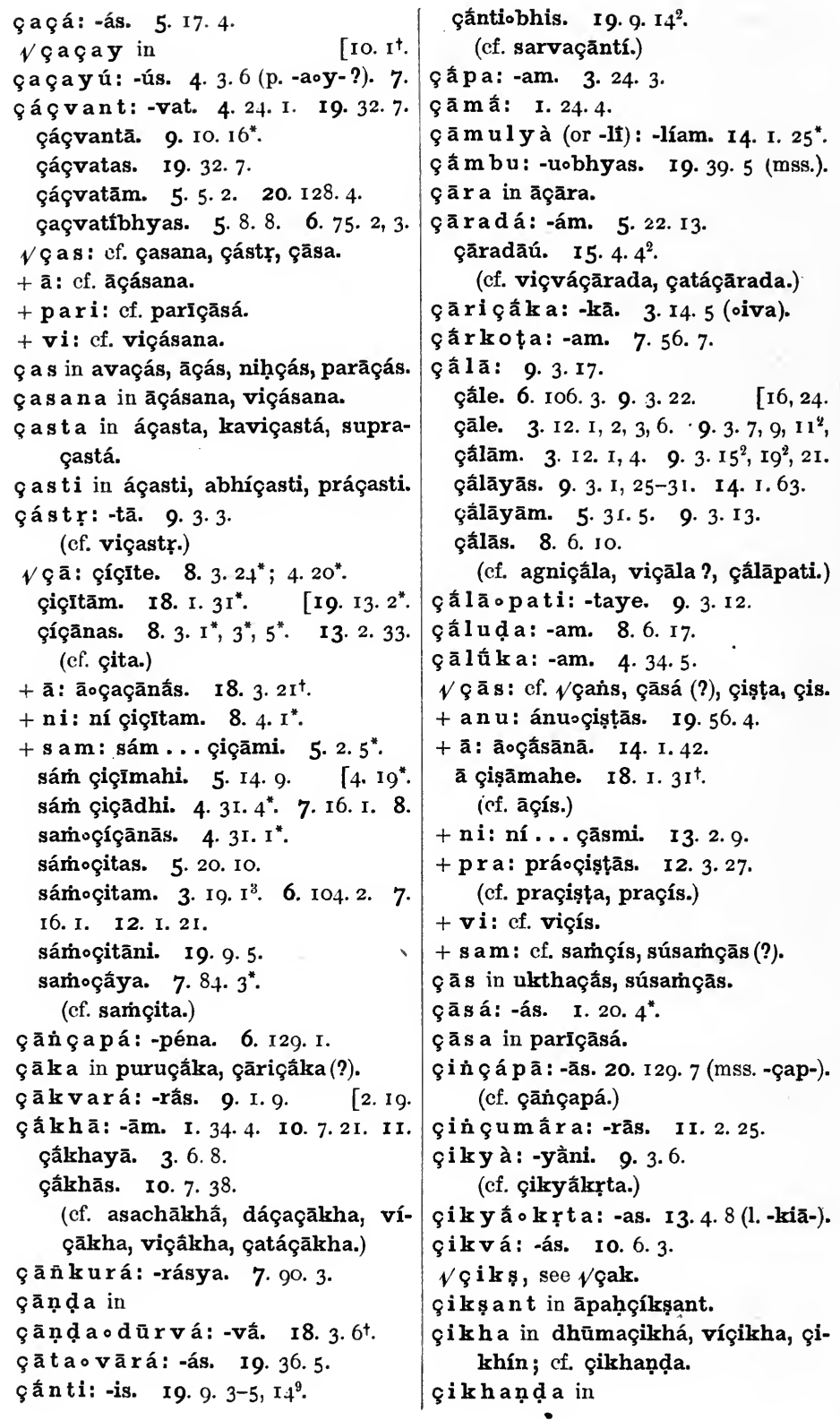


çikh a ṇ̣ dín: çikhạ̣ḍin. I1. 2. : 2. çikhạ̣dínas. 4. 37. 7 .

çikhaṇúínas (pl.). 4. 37.4. (cf. nillaçikhaṇdin.)

̨̧ikhín: -khíobhyas. I9. 22. 15 (m. mss. çişí-).

$\checkmark$ çiñj: çiñte. 9. 10. $7^{*}$.

çit a in samçita, sómaçita.

çiti in çitikákṣa-çitibăhu.

çitiokákşa: -şâs. 5.23.5.

çitimgá : -ás. II. 5. I2.

çitiopád: -păd. 3. 29. I, 2, 6 .

çitipłdam. 3. 29.3, 4, 5 .

çiti op a dá: -dí. I I. 10. 6, 20.

çitiobath u: -havas. 5.23. 5 .

çit hirá: -ám. I0. 2. 3 .

çipavitnuká: -kăs. 5. 23. 7.

çibhrá: -ám. 7·90. 2.

Çímidā: $12.5 \cdot 36$.

çímidām. 4. 25. 4 .

çi $\mathbf{m I}$ in

çímI०vant: -vatas. I8. I. $6^{*}$.

çíras: 2. $25.2 ; 32.2$. 4. I4. 7. 5. 23. 9,13 ; 29. 10. 6. 49.2 ; 50. 1; 89. I. 9. $5.21 ; 7.1$. I0. $2.27^{2} ; 4.5 ; 6$. I; 7. 18; 9. 13 ; 10. 2 , 3. I1. 3.1 ; 8 . I4, I5. I2. $5.60,67$. I3. 4. 40. I5. I8. 4. I9. $28.4 ; 39.8 ; 49.9 ; 50.5$. 20. 128 . 13 .

[șan.)

(cf. prthúçiras, mṛgáçiras, çīrçilat: 12. I. 26.

çivá: -ás. 2.6.3. 3. I4. 5. 6. 27. $2^{\dagger}, 3^{\dagger}$; II6. 3. 7. 4 1. 1. 8. 9.22. 9. 4. $7 ; 5.12$.

çivắm. 6. 71. 3. 7. IOI. I. 8. 2. I6. I0. $6.30,34$. I2. 1. 46,47 . I8. $2.9 ; 4$. 84. 19. 9. $14 ; 64.3$.

çivă. 3. $28.2,3^{4}$. 7.68.3. 9. 3.6. I2. 3. I1. I4. I. $64 ; 2.13,18^{*}$. 19. 7. 3 ; 8.5 (mss.).

çivằm. I2. I. I7. I9. 49. 5 .

çivéna. I. 33. 4. 6.53. 3. I3. I. 10. I4. 2. $6^{\dagger}$. I6. I. I2.

çiváyā. I. 33. 4. I6. 1. I2.

çivāú. 6. I40. I. 8.2. I8.

çivé (p. -é íti). 2. IO. I-8. 3. 4. 5. 8. 2. 14. I9. I4. I.

çivăs. 1. 6.4. 2. 3.6. 6. 3.2; 22.2;
23. 3. 7. 43. 1 ; I15.3. 8. 2. I4, I5; 7. 17. 9. 2. $25 ; 4.6$ I1. 6. 9, 22. 12. 3.12. 18. 2. $8^{*}$. 19. $2.5 ; 40.3^{2} ; 45.3$. çivăn. 12. 2. 27 . I6. 1. 13.

çivăni. 19. 8. 1, 2.

çivăbhis. 2. 29.6. 7.84. I. I7. Io. çiváotamas. 1. 5. 2".

çiváotamăm. 14.2. $38^{\circ}$.

çiváotamãs. I9. 8.6.

çiváotamābhis. 18. 2.9. [çana.)

(cf. áçiva, çivãpará, çivăbhimarçi vāp a rá (-va॰ap-): -ám. I2. 2. 43. çivăbhimarçana (p. -váoabh-): -as. 4. 13. $6^{*}$.

çíçira: -as. 6. 55.2. I2. I. 36 . (cf. çāiçirá.)

çíç u: -çave. 7.57.2*

çíçū (p. -ūíti). 7.81. I*. I3. 2. II". çíçavas. I2. 3. 40. 20. 132.15 (mss.).

(cf. çiçulká, çinç̧umăra ?.)

çi çuká: -ás. 6. I4. 3.

çi çná: -ám. 4.34. 2.

çi çlikṣu in áçiçlikșu.

$\checkmark$ çiṣ: çișțás. 2. 29. 4. 3. 5.4.

çiștăăs. 5. 26. 4 .

çișțăn. 2. 31.3 .

çișyate. I5. I2. II.

(cf. çișța, çéșaṇa, çéşas.) [3I. $+u d$ : úc chişas. 6. 127. I. IO. I. I7, utoçíșātāi. 2. 31. 3 .

úc cheși. II. 9. I3.

útoçișțas. II. 7. 15, 16.

útoçișţam. 9.6.48.

útoçișțāt. II. 7. II, 23-7.

útoçișțe. II. 3. $21 ; 7.1^{3}, 2^{2}, 3^{2}, 4,5^{2}$, i-10, I2, 13, 14 ${ }^{2}, 1$ 7-22.

+ pari: pári ... çișyate. I5. I2. 7 . çi șța in áçișța, ŕṣipraçișța.

çis in āçís, praçís, viçís, samoçís.

VI, 2 ç I: çéșe. 5. 30. 4 .

çáye. ro 8.26. I2. I. 46 . 20. I3I. I9 (not mss.).

çaye. 9. 10. $8^{*}$.

çayāte (p. -e íti). 8. 4. $13^{*}$.

çére. 10. 3. 15.

çáyīya. I8. I. I4 (mss. ed. çay-).

çetām. II. 10. 25 .

çayām. 6. I34.2. II. 9. 19; 10. 22. 
çáyānas. 8. 9.2. I2. I. 34. çáyānam. 5. 29. 8, 9. II. IO. 26. çáyānām. 7. 99. I. çáyānāyām. 20. 133. 4 (mss. çayānăyāi).

áçayat. II. 8. I6.

çaçayānăs. 4. $15 \cdot 3^{*}$.

(cf. çaya, çáyana, çayu, çI, çIvan, çeyya.)

+ adhi: adhioçémahe. I2. I. 34 .

+ an u: anuoçérate. 8. 6. I9.

+ a va : áva çìyatām. I8. 3.60.

$+\bar{a}$ : à çaye. 5. I7. I2. 9. 3.2 I. I2. 4. 19.

à çayām. $5 \cdot 25 \cdot 9$.

+ a nvā: anuoăçaye. I0. 7. 9.

+ u pa: úpa çeșe. 18. 3. $2^{*}$.

+ prati: cf. pratiçIvan.

ç I in madhyamaçí.

çI tá: -ás. 5. 22 . Io.

çî́ám. 5. 22. I3. I8. 2. 22. çîtăya. I. 25.4. 7. I16. I.

çităn. 8. 9.17.

(cf. çîtáhrada, çîtikā.)

çItá ○ hra d a: -dã. 6. Io6. 3 .

çI ti kā: çitike. I 8. 3. $60^{*}$.

(cf. çitikāvant.)

[6o*. çitikā॰vant: çítikāvati. I8. 3 . çi pālā: 6. 12. 3 .

çI ṕdru: -us. 6. 127.2. [2.3, 5 . ç Ib ha: -am. 3. I3. 2. 5.20. 7, I2. I3. (cf. çibhrá?.)

ç I m a in suçíma.

ÇIrṣá : -ám. 4. 34. I.

çİșé. 7. 56.6. I4. I. 55 .

(cf. dáçaçîrșa.)

çirşa०kapālá: -lé (p. -é íti etc). I5. 18.4.

çIrşaktí: -ís. I2. 5.23.

çīrșaktím. 9. 8. I. I2. 2. I9, 20.

çirșaktyấs. I. I2. 3 .

Çİrṣ a ṇ y à : -yàm. 2.33.1*. 9. 8. 1-5. çîrşaṇíam. 2. 3I. 4. I4. 2.68.

ÇIrṣa ṇ॰vánt: -vátí. Io. I. 2. çIrșatás. 6. I3I. I. I0. 2. 26.

çİṣán: -rṣṇă. 6. 49.2. II. 3. $32^{2}$. 20. 136. I0.

çirșnás. I. I4. 3 (l. -șaṇás). 6. 137.
2, 3. 9. 8. $21,22^{2} ; 9.5^{*}$. $9.6 .8^{*}$. çIrșáni. 3. 7. 1. 6. 138. 3. I0. 2.6. çİrșâni. 1. 7. 7. 8. 3. $15^{*}$. 10. 4. 19. (cf. açirșán, ékaçirșan, triçirșán, çirșá - çīrșatás, çīrșabhídyaçirșāmayá.)

çIrșa०bhíd ya: -yāya. I0. 5. 50. çIrşa०çoká: -ám. I9. 39. 10 (mss. -șalo-).

çI rşā m a yá (p. -șaoăm-): -ám. 5 . 4. 10. 9. 8. I (1. -şaām-).

çI van in uttānaçívan, pratiçivian, vahyaçivan.

$\checkmark$ ç u : cf. çávas, çávișțha, çivá (?), çíçu (?), çuná, çūnya, çưra, çéva, çevas, çvan, $\downarrow$ ¿̧vā.

çú $\mathbf{k} \mathbf{a}$, see súka.

çukrá, çuklá: -rás. 2. II. 5.4 . 24. 4. 6. $34.5^{*} ; 53$. I. I3. $2.8,34$, 42. I7. 20. I8. 4. $59^{*}$.

çuklás. 3.29. 3. [3. I6. çukrám. 4. I. 5. I0. 5.7-14. I3. çuklám. 5. I9. 3.

çukrāú. I4. I. 10*.

çukrấs. 8. 7. I. I I. 8. 28. I2. I. I3; 3. 27 . 13. 2. I.

çuklăni. I. 23. 2.

çukrâ. 5. 27. I.

(cf. çukrapíç-çukráçocis.)

çukra॰píç: -çam. 5. I2. 6*.

çukráopṛsṭ ha: -as. I3. I. 33 .

ç u krá ○ç०cis: : 8. 3. 26*.

çuklá, see çukrá.

ç uñ ga in ékaçuñga.

V çu c: çócatā. 2. 12. 3.

çucántas. 18. 3. 22*.

çocáyāmasi. 6. $89 \cdot 2^{2}$.

çocayāmasi. 6. 89 . I.

çóçucatas. 8. 3. $13^{\dagger}, 19^{*}$.

çóçucānas. 4. II.3. 8. 3. $7^{*}$.

çóçucãnam. 6. I32. 1--5. 8. 3.9*".

çóçucānās. 5. 22. I.

(cf. çúka ?, çukrá çuklá, çúc, çúci, çóka çoká, çoca, çocana, çocayișṇu, çocí, çocís.) [I, 2.

+ a n u : ánu çocatu. 6. I30. 1-4; I31. + a p a : ápa... çóçucat. 4. 33. $1^{*}, 1-8^{*}$. + abhi: abhioçócati. 4. 26.7 . 
abhí çūçucas (p. çuçu-). I 8. 2. $4^{\dagger}$.

(cf. abhiçoká, abhiçocá, abhiçócana, abhiçocayișṇú.)

+ ã: à ... çuçugdhí. 4. 33. I".

+ u d: uchocáyan (p. ut॰ço-). 5.22. 2. (cf. uchócana.)

+ pra: cf. praçócana.

+ prati: práti çoca. 2. 19-22. 4 . práti çocata. 2. 23. 4 .

ç ú c : ̧úk. I2. 5. 34.

çúcam. 4. 38. 4 .

çucă. 3. $25 \cdot 4 \cdot$ 5. 20. 3 .

çúcas. 7. 100. I.

申úci: -is. 2. 9. 5. 6. $51.2^{*}$. 7. 73 . 3. 8. $3.26^{*} ; 4.16^{*}$. II. I. I6. çúci. I8. 3. $2 \mathrm{I}^{*}$.

çúcim. 4. 34. 2. 10.6. 3 .

çúcaye. 3. 16. 6*.

çúci. (p. -i íti). I4. I. I2*.

çúcayas. I. 33. I, 4. 4. 34. 2. 5. I. 3. 6. 62. 3. I0. 6. 3. 12. 2 . I I, 28 ; 3 . $27,28$.

(cf. çucitvá.)

çuciotvá: -ám. I2. 3. 28.

ç $\mathbf{u} \mathbf{d} \mathbf{d} \mathbf{h} \mathbf{a}$ in

çu d d há o ha st a : -tãu. r2. 3.44. $\checkmark$ çudh, çundh: çuddhám. 7.73. II*. 20. I36. I6 (mss. súdam, çúnam).

çuddhă. I0. 9. 3 .

çuddhăm. II. I. 23.

çuddhắs. 4. 21. $7^{*} ; 34.2$. 6. 62. 3 ; 122. 5. I I. I. 17, 18, 27. I2. I. 30 ; 2. II, $13,20,28$; 3. 26 . I4. 2.67. çuddhāís. 9.5. 3 .

(cf. çuddha, çundhyú.)

çuná : -ám. 3.15. $4^{2 *} ; 17 \cdot 5^{2}, 6^{5 *}$.

(cf. áçuna, duchúnā, çúnāsīra.)

çú nās İra: -rā. 3. I7. 5, $7^{*}$.

çundhyú: -yúvas. I3. 2. 24". [I. $\checkmark$ ç u b h, ç u m b h : çumbhāmi. 6. 54 . çumbhati. I4 I. 28t.

çumbhata. 12. 3. 13. [3. $56^{6 t}$. çumbhantu. 6. II5. 3. I2. 2. 40. I8. çumbhāti. I2. 3. 2 I.

çúmbhan. 8. 2. I7 (mss. ed. -am). çúmbhante. 12. 3. 26.

çúmbhantām. r8.4.67. çúmbhamānās. 5. 12. $5^{\circ}$. II. I. I4. (cf. çúbh, çubhrá, çúmbha, çúmbhana, çumbhita.)

+ pa ri: parioçúmbhati. I3. I. 5 I.

+ s a m: sám çobhayà̄masi. I 4. I. 55 .

६̧ú b h: çúbham. I4. I. 32 .

çubhă. I 3. I. $21^{\dagger}$.

çubhé. 7. 106. 1. I4. I. 53.

çubhás. 6. 3. 3 .

çubhas. 6.69.2. 9. 1. 19. I4. 1. $15^{*} ; 2.5^{*}, 6^{\circ}$.

६̧ubhrá: -rấs. II. I. I7.

çubhríyas. 20. 48.2 (mss. çru-).

çú $\mathbf{m b ~ h}$ a: -am. 8. 2. 17 (mss.).

çú mbhana: -anI (p. -I íti). 7. I1 2. I.

çumbhit a in bráhmaçumbhita.

çuçuluk $\mathbf{k} a$ in

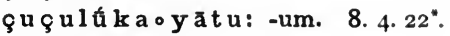

V çu ş: çúṣyatu. 6. I39. 2.

çușyatu. 6. 139. 2.

çuşyantu. 6. 9. I.

çoşayãmi. 6. 139. I.

çoșáyati. 3. 25. 3.

(cf. çușá, çúșka, çúṣna ?.)

+ an u: ánu çuşyatu. 7.59. I.

+ a pa: apa॰çúşyati. 6. 139. 4.

+ ni: ní çusya. 6. 139. 2,4

+prati: práti çușyatu. 8.4. II.

çușá: -ásya. 5. 1.4.

çú ș ka: -ke. I9. 49. Io.

(cf. çúş̧āsya.)

çú ș kā s y a (p. -kaoās-): -siā. 3. 25.

4. 6. I39. 2,4 .

(cf. çāușkāsyyá.)

çú ș ạa: -am. 20. 34. 17 .

çú ș ma: -as. I. 12. 3. 5. 20. 2. 6.

73.2. 9. 4.22. I8. 2. 36 .

çușma. 5. 1. 9.

çúșme. 5. 5.7.

çúșmam. 3.9.3. 6.65. I. 9. I. I0, 20. çúșmeṇa. 4. 4. 2.

çúṣme. 6. 38.3 .

çúșmā. 4. 4. 4 .

(cf. çuṣmadă-çuṣmín.)

Ç uṣ m a dă (or -dá): -dấs. I9. 40.2 (mss. çușyadă).

çúṣmavant: -vatotaram. 4. 4. 3 . çuṣmín: çuşmin. $5.2 .4^{\dagger}$. 
çușmínas. 6. 20. I.

çū drá: -ás. 4. 20.4. I9. 6. 6*.

çūdrám. 4. 20. 8.

çūdrăm. 5. 22. 7 .

çūdrấya. I9. 32.8 (mss. sūryăya).

çūdré. I9. 62. I (m. mss. -rám).

(cf. çūdrákṛta.)

ç ū d ráokṛta: -tã. Io. I. 3 .

çū $n a, c ̧ \bar{u} n y a$ in

çū nyāișá (p. -yaoeș-): -şî. I4. 2.

I9 (1. -yaeș-).

çứra: -as. 8. 8. I.

çūra. 2. 5.1. 7. $31.1^{*} ; 76.6^{*}$. 8. 5. 17 ; 8. 7 . I8. I. $38^{*}$.

çúram. 7. 86. I*.

çû́rāsas. I8. 2: $17^{*}$.

(cf. çưraputra, çúravīra.)

çû́ra p putra: -rā. Ir. I. II.

çúraputrām. 3. 8. 2.

çứra०vĩra: -as. 8. 5. I.

çúurpa: -am. 9.6. I6. Ir. 3. 4. I2. 3. I9, 20. 20. I36. 9 (çứrpamçū-: mss. -peçū-).

çúxpe. I0. 9. 26.

(cf. çūrpagrāhá.)

ç ūrpa。grāhá: -hí. II. 3.4.

ç $\overline{\mathrm{u}} \mathrm{l}$ a in karṇaçūlá.

çū șá: -ám. 5. 2. 8*.

$\checkmark$ ç ṛ: çṛ̣ắmi. 2. 32.2. 5. 23. 9.

çṛnihi. 8. 3.10*.

çrṇatu. 6. I34. I.

çaçré. 4. I8.6. 5. 3I. II.

áçarāit. 6. 32. 2.

(cf. çará, çaráṇi, çarīka, çáru, çarvá, çala ?, çalúna, çalyá.)

+ a pi: ápi çṛnìmasi. 2. 7. 5.

ápi çṛnīhi. I6. 7. I2.

ápi çṛnātu. 6. 32. 2.

ápi ... çṛnịtam. 6. 5 O. I.

ápi çṛ̣a. I9. 45. I.

ápioçīrnāas. 4. 3.6.

$+\overline{\mathbf{a}}:$ in àçarīka.

+ nis: níh çrṇihi. 3. 6.2. 8. 8. 3.

+ parā: párā çṛnīihi. 8. 3. I $3^{*}$. párā ... çṛ̣nihi. 8. 3. $13^{2 *}, 13^{\dagger}$. párā çṛnītam. 8. 4. I* .

párā ... çṛnantu. 8. 3. $4_{4}^{*}$.

párā 'çarīt. 6. $75 . \mathrm{I}$.

párā 'çarāit. 6. 66. 2 (s. mss. -rìt). (cf. parāçará.)

+ pra: prá ... çṛ̣āmi. 2. 32.6 . praoçṛ̣ăti. 7.76.3.

prá ... çṛ̣inhi. 8. 3. 4". T0. 3. 2. prá çṛnātu. 6. I34. I. I0. 5.50.

+ prati: práti çṛ̣ini. 8. 3. 10*. práti ... çṛ̣inhi. 5. 29.4.

+ vi: ví çarāis. 12. 3. I8.

(cf. viçará, víçarīka.)

+ s a m: sam̉oçaçré. 4. 12. 7.

sám çīryante. I2. $4.3,5$.

çŕñ g a : -am. 20. I29. I0.

ç̛̣̂ngāt. 4. 6.5.

çŕ̛ñge (p. -e íti). 2. 32. 6. 8. 3. 24*, 25. 9. 7. I. I0. 9. I4. 20. 130.13 (mss. -ga ut-).

çŕ̛ñgābhyām. 9. 4. I7. I9. 36.2.

çṛ́ngāṇi. 8.6. I4.

(cf. ajaçrñnga, tigmáçrñnga, tīkṣṇáçrūnga, sahásraçṛnga, híraṇyaçr̄̄nga.)

çr ta in súçrta.

çe p a in çepahársaña.

çépas: 4. 37.7. 5.25. I. 6. 72.1 ; IOI. I; I38. 5. 7.90.3. 9. 7. I3. II 5. 12. I4. 2. $3^{8+}$.

(cf. çepa, çepyávant.)

ç e p a h árs a ṇ a (p. -paḥohá-): -ṇīm. 4. 4. I.

çepyấ。vant: -piávate. 7. Ir3. I. çey y a in sahaçéyya.

çerabha: çérabha. 2.24. I.

(cf. çerabhaka.)

çerabhaka: çérabhaka. 2. 24. I.

çév a: -vā. 8. 9. 22.

(cf. suçéva, çevadhí.)

çevaodhí: -ís. 7.53.5. 12. 4. I4.

çevadhím. 5. 22. I4. 6. I23. I. 12.

3. 46.

çevadhíobhyas. 9. 3. I5.

çé va la : -am. I. II. 4.

çevas in suçévas.

çevṛh a: çévṛdha. 2. 24. 2.

(cf. çevr̆dhaka.)

çevṛdhaka: çévṛdhaka. 2. 24. 2.

çéș a ṇ a: -am. 7. 109. 5.

çéșas: I 8. 2. 10*. 
çaiçirá: -rāú. I5. 4. $6^{2}$. ६̧ $6 \mathbf{k a :}$-am. 6. I8. I. I8. I. $39^{\prime \prime}$.

çókāya. 5.1.3.

çólkāt. 4. 14. I. 9.5.13.

çókāis. 3. 2. $5^{*}$.

(cf. çoká, abhiçoká, kaçóka?, triçóka, çIrşaçoká.

çoká: -ás. I. 25. 3.

çoca in abhiçocá.

९ocana in abhiçócana, uchócana, praçocana.

çoc a y iş ṇu in abhiçocayişnú.

çocí: -cáyas. I8.2.

çocíşkeça (p. -íhok-): -am. I 3. 2. cocís: I. 25.2. 2. 19-23.4. I0. 4. 2. I8. 2. 8*.

[I7. I6. çocíşā. I. I2. 2. 6. $34.2^{*}$. 8. 3. $23^{*}$. çocişe. I. $25 \cdot 4$. çocinșịi. 5. 27.1 .

(cf. çukráçocis, çocíşkeça.) ç ọ̣a in áçoṇa. [9. 21 . ç ā u ş kãs y á (p. -kraoās-): -ám. II. çсut in ghṛtaçcút, madhuçcút.

ç maçāná: -né. 5. 31. 8. I0. I. I8. çmáçru: 6.68.2.

çmáçrūṇi. 5. 19. I4.

(cf. keçaçmaçrú, dīrgháçmaçru.) $\checkmark$ $\mathbf{y} \bar{a}:$ cf. çîtá.

६̧ȳ̄má: -ás. 8. I. 9.

çyãmám. I I. 3. 7 .

çyāména. 9. 5.4.

६ y āmâka: -as. I9. 50. 4 (mss. -myấk-).

[mā-).

çyāmăkram. 20. 135. 12 (mss. çyăÇ y āvá: -ás. 5. 5.8.

çyāvāú. 7.95. I.

(cf. çyāvádant, çyāvăçva.)

çyāváodant: -datā. 7.65.3.

çyāvádatas. II. 9. I7.

ç y ā vá ç v.a (p. -váoaç-): -as. I 8. 3 . I5 (l. -çuas?).

çyāvăçvam. 4. 29.4. II. 2.18.

çyet a in çyāitá; cf. çyéni.

६̧ ye ná: -ás. 3. 3. 3, 4. 5. 30. 9.6. 48. I. 7. 4I. I, 2. 9. 7. 5. I8. I. $2 I^{*}$. çyenăt. 5. 21.6.

çyené. 6. 92. 2.

çyenāú. 7. 70. 3 . cyenầs. II. $9.9 ;$ I0. 24 .

(cf. çyenáparṇa.)

çy e náparṇa: -ṇI. 20. 129. I9 (not mss.).

申̧yénI: 6.83.2. 20. I29. I9 (mss.).

çyénIs. I 8. 4. 33 (1. çié-), 34. [4. $4^{2}$.

ç y āitá (s. mss. çāi-): -ám. I 5. 2. 4 ; çyāitấya. I5. 2. 4 .

çyāitásya. I5.2. 4 .

çraǹ ça yitvă, see $v$ sras.

Vçrath, çrathāy: çrathnānás. I4. 1. 57 .

çratháyā (p. -ya). I. 11. 3 .

+ ava: áva ... çrathāya. 7. $83.3^{\circ}$.

+ ud: út ... çrathāya. 7. 83.3 .

+ vi: ví.. çrathãya. 7. $83.3^{*}$.

ví çrathaya. I2. 5.7 I.

çraddhà: $5 \cdot 7 \cdot 5$. 9.5.21. IO. 7 . I, II. I I. $7.9 ; 8.22$. I3. 4. 23. I5. 2. I; 7.2, 3, 4, 5; I6. 4 . çraddhám. Io. 2. I9;6. 4. I9.64. I. çraddháyā. I2. 5.3.

çraddhầyās. 6. I33. 4 .

(cf. áçraddhā, açraddhá.)

çradodhéy a: -am. 4. 30. $4^{\dagger}$.

çradh (?): cf. $\sqrt{ }$ I dhā + çradh, çraddhă, çraddhéya.

$\checkmark$ çra p: see $V$ çrā.

$\checkmark$ çra m: çrắmyatas. Ir. I. 30. áçramat. 6. 60. 2. çrāntám. 6. 74. 2.

çrāntă. 4.20. 3 . (cf. çráma, çrānta.)

çrám a: -as. 8.8.9. II. 7. I7. çrámeṇa. 4. II. IO; 35.2. 6. I33. 3. I I. 5. 4. I2. 5. I.

çrámāt. I $0.7 \cdot 36$.

çray a in apaçrayá.

çrávạ̣a: -as. I9. 7.4

(cf. viçravaṇa.)

çráva s: 6. 28. 2*; 33.2. I3. 2. 3 .

(cf. uccāiḩ̧̣ravas, dūráçravas, bṛháchravas, suçravas, çravasy.)

$\checkmark$ çravasy: ef. çravasyú.

çravas yú: -ús. 6. 98. 2.

çravasyúm. 3.9.3.7.40.2 (1. -siúm). çravasyavas. 3.9 .4 .

çráviṣt ha: -ṭ̂ās. I9. 7. 4 . 
V çrā, çrí: çrịnantu. 4. I. 2. çṛtás. 9. 5. 5 .

çṛtám. 4. I4. 9. II. I. 25. I8. 2. $4^{*}, 5^{*} ; 4$. 12. I3. çrātám. $7 \cdot 72 \cdot 1^{\dagger}, 2^{*}, 3^{2 *}$ çrapáyan. II. I. 4. (cf. çŗta, çrāta, çrī.) ç $\mathbf{r} \overline{\mathbf{a}} \mathbf{t} \mathbf{a}$ in áçrāta.

çrānta in áçrānta and çrānta。sád: -dāu. 7.95.2. çrāntasádām. I. 32. 2. çrā va in abhiçrāvá.

$\checkmark$ ̧̧ri: çraye. I9. I7. I-10. çrayate. II. $3.5 \mathrm{I}$. çrayante. I0. 7.38. II. 5. II. çrayātāi. 12. 3.33 çrayasva. 3. 4. 2. çrayatām. 5. 28. 4 . çrayethām. I2. 3.9. çrayantām. 5. 28. $3^{2}$. çiçriyé. 4. 24. 5 . çiçriye. 13. 1. 6. çiçriyānás. I2. I. 3 I. çiçriyāṇám. I.I2.2. 2. 5. 6*. açiçriyat. $6.3 \mathrm{I} \cdot 3^{\dagger}$.

çritás. 7.76 .3 . I2. 2.44 . 3.3. 5. I4. I. I*. I8. I. $3^{8^{\dagger}}$ (s. mss. çrt-) çrită. 9. 10. $7^{*}$. 12. 5.1 . çritám. I. 32. 4. 6. I8. 3. I0.8. 19. I3. 2. 14 .

çrité (p. -é íti). I3. I. 37. çrităs. 6. 80.2 . I0. 8. 34. I I. 3.20; 6. I $2 ; 7.4,14$ (s. mss. çrt-). I3. 3. 6. I8. 4.4 .

çrită. II. 7.21.

(cf. çaraná, çárīra ?, çárman, çāra, çraya, çrit.)

+ a dhi: ádhi ... çrayāmi. 9.5.5. ádhi çiçrāya. I0. 2. 7,13 . ádhioçrite. I5. 12. I.

+ a pa: ápa॰çritāu. 6. 127. 2. (cf. apaçrayá.)

+ abhi: abhí ... açrāit. I3. 2. 9.

$+\bar{a}$ : à 'çrayan. II. IO. IO. (cf. āçāra.)

+ u d: úc chrayātāi. I2. 3. I5. úc chrayasva. 3. I2.2. 6. I42. I, 2. úchritam (p. útoçr-). I3. 4.3.
+ u p a : úpa... çráyantām. I 8. 3. $5 \mathrm{I}^{*}$.

+ vi: ví çraya. 9. 5.4. vioçráyāti. I4. 2. $38^{\dagger}$.

ví çrayasva. 9. 5.8. I8. 4.3.

ví çrayantām. 5. 12. $5^{*}$. [3.6, 7.

+ s a m: sám çrayethām. 6. 122. 3. I2. sámoçritā. II. 7.2I.

çrit in diviçrít, sūryaçrít.

$\checkmark$ çri ș: cf. çriṣ, çreșa, çreşiṇa, çreşman, $\sqrt{ }$ çliș.

+ a bhi: cf. abhiçríş (infin.).

$+\overline{\mathbf{a}}$ : cf. āçréşa.

+ s a m: cf. samộreșiṇá.

çriṣ in abhiçrís, doşaṇiçrís, hṛdayaçríş.

ç $\mathbf{r} \mathbf{i}$ in abhiçrí.

ç II: çrîs. II. 7.3. I2. 5. 7 .

çríyam. 4. 8. $3^{\dagger}$. 5. 12. $6^{*}$. 6. 54.1 ; 73. I. 9. $5.31,32-6 ; 6.36$. 10. 6. 1o. çriyá. I0.6. 26. I I. I. I2, 21. I2. 5. 2 . çriyătm. I2. 1. 63 .

(cf. sámbhṛtaçrī, çrīra, çlīla, çréyas, çréșțha.)

çrIr a in açrīrá.

$\checkmark$ çrīv, see $\boldsymbol{V}$ sriv.

$\checkmark$ çu: çṛ̣omi. 3. 13. 6 .

çrnóti. 4. 30. $4^{*}$. 9.4.17.

çṛ̣ávat. 6. 2. I. II. 4. I9.

çṛú. İo. 1. 28.

çṛ̣u. 5. 8.2.

çrṇuhi. 2. 12. 3 .

çṛ̣ótu. 7.47.2; 48. I*. [10. 6*.
[1. çṛ̣otu. 5. 3. II. I3. 2. 44, 45. I9. çṛ̣utám. I8. I. $3 \mathrm{I}^{*}$.

çṛuuta. I. 30. 2. 2. 12. 2. I4. 2. 9. çṛ̣vántu. 4. 35.7. I8. 3.39*. I9. Io. $4^{*}$.

çṛ̣vantu. I8. 3. 45 .

çṛ̣ván. I4. I. $5^{*}$.

çrṇvaté. I2. 2. $2 \mathrm{I}^{*}$.

çṛ̣vántas. 7.6r. 2.

[1 28. 4 .

çuçruma. 7. 74. I. II. I. 29. 20.

çuçrumā (p. -ma). 8. 9. r8.

áçravan. 7. 66. I (mss. ed. ásr-). çrūyāsam. I6. 2.4.

çrudhí. 4. 30. $4^{*}$.

çrudhì (p. -dhí). 2. 5. 4. I8. I. $25^{*}$.

çrutvă. 5. 4.2. 12.4 .27 . 
çruta. 4. 30. $4^{*}$.

çrutám. I. I.2, 3. I5. 2.4. I8. I. 40". çrutăm. 6. 52.3 .

çruténa. r. I. $4^{2}$.

çrutăya. 6. 4 I. 1 .

çrutásya. 7.61. x.

çrutăni. 7.6r. 2.

(cf. çravaṇa, çrávas, çrávișțha, çrāva, çrut, çrúti, çrúșți, çlóka, çrótra.)

+ a nu: ánu çuçrāva. II. 4. 25.

+ abhi: abhioçrută. 6. I38. I.

(cf. abhiçrāvá.)

+ ã: â... çrṇavat. I3. r. 3 .

a... çrṇotu. 7. 49. 2".

â... çrṇuta. 5.13.5.

à çṛota. 6. 50.3. I8. 3. I9.

ลै çṛ̣otā. 20. 127. 7 (mss. suno-).

āoçrṇvatí. 5. 20. 5 .

āoçṛ̣vántam. 6. 142. 2.

à... açrṇvan. r9. 52.3 .

à çrāvayati. 9. 6.49 .

āoçrāváyantas. 5. 13.5.

+ pratyã : pratyăçrāvayati (p. -ti。

ăç-). 9.6. 50 .

+ u p a: upaoçṛ̣uuyatt. I2. 4. 27.

úpa çruta. 20. I27. I.

upa॰çrútya. I2. 4. 28.

(cf. úpaçruti.)

+ pari: cf. pariçrút?.

+ pra: prá çṛ̣ve. I8. I. 24 *.

+ prati: pratioçrṇóti. 9. 6. 50 .

+ vi: víçrutam. I5. 2.4 .

(cf. viçravaṇa.)

+ s a m: sámoçrutam (-sru-?). I. 3.6. çrut in pariçrút, bhadraçrút, suçrút, çrútkarṇa.

çúti: -is. II. 7. 20.

(cf. úpaçruti, súçruti.)

६ rútokarṇa: -ṇāya. I9. 3. 4.

çrústi: -is. 3. $17.2^{\dagger}$.

çrúşțim. 8. 2. I.

çréyaḥoketa: -as. 5. 20. ro.

çréyas: 5. 20. 9. 7. 8. I. 8. 9. 22. I0. 6.5 (çréyahı̧̣re-). I9. I4. I (mss. utoçré-).

çréyāṅsam: 2. II. I-5. I5. IO. 2. çréyasim. I2. 2.45 .

\section{(cf. çréyaḥketa.)}

çreşa in āçréşa.

çreșiṇa in samçreşiṇá. $\quad\left[7^{*}\right.$.

çréşth a: -am. 6.21. 2 ; 44.2. 7.73.

çréşţhena. 5.25. io-3.

çréşthās. 4. 25.7. 18. 4. 86, 87.

çréşţha॰tamā. 6. 138 . I.

(ef. yamáçreştha, yãvachreșțhá, sómaçreştha, çrāiş̧thya.)

çreş $\mathbf{m}$ a $\mathbf{n}$ in açreşmán.

çrāis șthya: -yāya. 8. 6. 31, 32, 34. çrãișțhye. 1. 9.3.

çróṇi: -ṇi (p. -I íti). 9. 4. I3; 7. 9. I0. $2.3 ; 9.21$.

çróniobhyām. 2. 33. 5*. 9. 8.21.

(cf. çroṇipratodín.)

६̧rọiopratodín: -nas. 8. 6. I3. çrótra: -am. 2. 17. $5^{2}$. 5. 10.8. II. $5.25 ; 7.25 ; 8.4,26$. 12. 5. 9. I9. 51. I; 58. I; 60. I.

çrótreṇa. 2. 35. 5. 10. 7.39. I3. I. 13. I8. 2. 59 .

çrótrāya. 6. IO. I. I0.6.8. I9.24.3. çrótrāt. I9. $6.8^{*}$.

çrótre. 19. 24. 3 .

çrótre (p. -e íti). II. 3. 2. I4. I. $\mathrm{II}^{\dagger}$. çrótrābhyām. II $3 \cdot 33^{2}$.

(cf. cátuḩ̣rotra, çrótriya.)

६rótriya: -as. 9. 6. 37.

çrótriyam. IO. 2. 20, $2 \mathrm{I}$.

çla kṣ̣̣á: -ám. 20. I33. 5 (mss. çlákș̣nam), 6 (do.). [ṇã-). çlakșṇăyām. 20. 133.5 (mss. çlákş(cf. çlakṣṇiká.)

çlakṣṇiká: -kăyām. 20. I33. 5 (mss. çlákṣṇikā-).

çlakha in uchlakhá. [mss.).

$\checkmark$ çliș: çiçlikșate. 20. 134. 6 (not

(cf. çiçlikșu, çleșa.)

+ ā: cf. āçleșá.

çli la in açlílá.

çleşa in āçleșá.

çlóka: -as. I8. I. $33^{*} ; 3.39^{*}$.

çlókam. I6. 2.4.

(cf. çlokakṛ̂t.)

çloka०kṛ t: 5.20 .7 .

çloṇá: -ṇáyã. 12. 4. 3.

(cf. áçloṇa.) 
Çva०kişkín: -ínas. 8. 6.6.

Çva。ghnt: 4. 16.5. 7.50. 6".

$\checkmark$ Çvañ c: + ud : úc chvañcasva. I8. $3 \cdot 50^{*}$.

$\left[5 \mathrm{I}^{*}\right.$.

uchváñcamānā (p. ut॰çv-). I8. 3 .

çvan in mātaríçvan.

çván: çvă. 4. 5. $6^{*}$ (mss. svă); 37. II. 20. I35. I (mss. svâ).

çúnā. 7.5.5.

çúne. I. II.4. 6. 37.3. II. 2. 2. çúnas. 6. 80. I, 3 .

çuânāu. 8. I. 9. I8. 2. II*, 12*.

çvănas. 4. 36.6. I I. IO. 23.

çuănas. II. 2. II.

çúnas. 4. 5. 2.

çváobhyas. II. 2. 30 .

çúnām. 3. 9. 4 .

çunyấs. 4. 20. 7 .

(cf. çvakișkín, çvaghnt; ఢ̧vànvant-çvavartá, çvắpada, çvāvídh.)

çvàn॰va n t: -vatīs. II. 9. I5. çvànvatīnām. I9. 36.6 (? ed. çván-; mss. çaçvanvát-).

ç vápa d, see çvăpada.

çvá。yātu: -um. 8. 4. 22*. çváyātavas. 8. 4. 20*.

çva。vartá: -tébhyas. 9. 4. 16.

çváçura: -as. I4. I. 39.

çváçurāya. I4. 2. 26.

çváçurāt. 8.6.24.

çváçurebhyas. 14. 2.27.

çváçureșu. I4. I. $44^{\dagger}$.

(cf. çvaçrú.)

६̧ v a ç r ú: -ruāí. I4. 2. 26. çvaçruăs. I4. $1.44^{\dagger}$.

ç vá s : çuás. 5. 18.2. II. 4. 2 I.

çuáh̆çuas. I0. $3.2 ; 6.5-17$.

$\checkmark$ çvas: çvasihí. 6. roI. I.

çvásantu. 4. I5. 12.

(cf. Vçuș, çúṣma, çūșá ?, çvasa, çvāsa.)

+ a va: cf. avaçvasá.

+ u d: cf. uchvāsá.

+ u pa: úpa çvāsaya. 6. 126. I*. (cf. upaçvasá.)

çvas a in avaçvasá, upaçvasá. ६̧văpada, ६̧văpad, ६ vápad: çuăpadas. $18.3 \cdot 55^{*}$. çuăpadam. II. 9. Io.

çuâpadas. Ir. I0. 8 .

çvápadām. 8. 5. II. I9. 39. 4 .

६̧vāvídh: -vít. 5. 13.9.

çvās a in uchvãsá.

$\checkmark$ çvit in çvitrá, çvetá.

çvitrá: -ás. 3. 27.6.

çvitrám. I0. 4. 5, 13 .

çvitráya. 12. 3.60.

६̧vetá: -ás. 5. 17. 15. 20. 135.8 (mss. çvétas).

çveta. 10. 4. 3 .

çvetám. I. 23.4 .

çvetăs. 20. 128. x6 (mss. çvétās).

șáţ p a kşa: -șā. 9. 3.21.

şáṭ $\circ$ p a d: -das. I3. 2. 27.

șa ț os a hasrá: -râs. Ir. 5.2.

șádoara: -re. 9. 9. $12 *$

ș a d a há: -ám. 8. 9. I6 (mss. șád ahám).

șa ̣̣oṛcá: -cébhyas. I9. 23. 3 (m. mss. -darc-).

șa ḍ ○y g gá: -ám. 8. 9. I6.

șaḍyogébhis. 6. 91. I.

șa ̣̣०rātrá: -ás. Ir. 7. II.

șa ḍ०vṛșá: -ás. 5. I6. 6.

șáṇm a y $\overline{\mathbf{u}} \mathbf{k h a}$ (p. șáțom-): -am. I0. 7.42.

șá ş (or şákş): şáţ. 4. II. I ; 20.2. 5. 15. 6. 8. $9.7,16^{4}, \mathrm{I7}^{2}, 23$. 9. 2 . $\mathrm{II}$; 9. $7^{*}, 16^{*}$. I0. $7.35 ; 8.5$. II. 3.21 ; 7. I8. I3. I. 4 ; 3. I,6. I8. 2. 6*. I9. 47. 4 .

șaț. 5. 3. 6*.

șaḍobhís. I2. 2. 48 .

(cf. șáțakşa- \$̧ánmayūkha, saştí-şoḍaçín.)

șa țí: -ís. 5. 15.6. ro. 8. 4. I9. 47.4 . șaștím. 20. 127. I. şașțyấm. 12. 3. 34, 4I.

șa șțhá: -ás. I3.4. I7. I5. I5. 8 ; I6. $6 ; 17.6$.

şașţám. 8. 9.6.

şașthăya. I9. 22.2.

șașțhatt. 8. 9. 4, 6 . 
(cf. mánaḥşașțha.)

s o d a ça in şoḍaçá-şodaçín. şo đa açá: -ám. 3. 29. I. [19. 23. 13. şo ̣a a ̧arcá (p. -çaoṛc-): -cébhyas. şo đ̣a çín: -çí. II. 7. II.

$\checkmark$ șthIv: + prati : pratyáşţhivan (p. -tioáș-). 5. I9. 3.

s a (pron. root): sás. I. 8.1 ; 12.1 ; 16. I; $25 . \mathrm{I}-3 ; 3$ I. $3 ; 35.2$. 2. I. $2,3^{2 \dagger}$; 9. $5^{3} ; 12.2 ; 34.1$. 3. I. I; 2.1 ; 4 . $5^{2}, 6^{3} ; 6.1$; 7. I ; 15. $\mathbf{1}^{2}, 7$; 16. $5^{*}$; 29. 3. 4. I. I, $4^{2}, 5 ; 2.7^{*} ; 3.5 ; 6 . \mathrm{I}^{2}$, $8 ; 7.3 ; 8 . \mathrm{I}^{2} ;$ IO. I, 4,$5 ;$ II. 2,3 , $7^{2} ; 12.6 ; 14.1,9 ; 15.10 ; 16.4 ; 18$. 6 ; $21.5^{*} ; 23 . \mathrm{I}-7 ; 24 . \mathrm{I}-7 ; 30.4^{*}$; $33.8^{*} ; 34.8 ; 36.10 ; 38.5 ; 39 . \mathrm{I}, 3$, 5,7 , 10. 5. $3.8^{*} ; 4.7,8 ; 8.4,5 ; 9$. 7; 10. I-7; II. 4 ; I2. $3^{*}$; I6. II ; I7. $5^{*}, 8 ;$ I8. 2,4, I3 $; 22.9 ; 24.1,2,4$, $7-14 ; 25.7 ; 27.5 ; 29.2,3 ; 30.17$. 6. I. $3 ; 2.3 ; 6.2 ; 15.1^{*} ; 16.2 ; 33$. $3 ; 34.1-5^{*} ; 36.2 ; 39.2 ; 46.2 ; 47$. I ; $63.4^{*} ; 76.3 ; 83.3 ;$ Iog. $2^{*}$; I IO. 3; II2. I, 2; II9. 2; I22. 2, 5; 123. $3,4^{4}, 5 ; 124.2$; $125.3^{*} ;$ I $26 . I^{*} ;$ I 33 . $\mathrm{I}^{2}$. 7. I. $2^{7} ; 3 \cdot \mathrm{I}^{2} ; 5 \cdot 2^{5} ; 6 . \mathrm{I}^{2^{*}} ; 9$. $2^{*}$; 12. I ; I 7. I ; 2I. I; 31. I"; 4 I. $2 ; 63.1 ; 73.4 ; 76.4 ; 77.2^{*} ; 80.2$; 92. $I^{*} ;$ IOg. I, 5. 8. 2. 23,$24 ; 3 . \mathrm{I}^{2 *}$, $8^{*} ; 4.10^{*}, I^{*}, 15^{*} ; 5.4,12,22 ; 9.1$, 2, 22, 25. 9. I. 5, 6, $7^{2} ; 4.7,9$, I8, I9; 5. 9,$12 ; 6.6^{2}, 24,30^{3}, 40-4,55-60$; 9. $15^{2 *}, 22^{*} ;$ 10. $7^{*}, 9^{*}, 10^{2 *}, 1^{2^{*}}, 24$, 28*. I0. I. $26 ; 2.7,8 ; 3.3,11,12$; 4. $15 ; 5.25-35,44,50 ; 6.5,6-17,21$, $22-8,31,32 ; 7.4-7$, 10-6, I 8-20, 22, $24,3 \mathrm{I}, 39,40,4 \mathrm{I} ; 8 . \mathrm{I} 3, \mathrm{I} 8,2 \mathrm{O}^{2}, 2 \mathrm{I}$, $26^{2}, 28,37 ; 9.4,5,6$, 10; 10. $2,22,23$, 27. I1. I. 5,$27 ; 2.8,11 ; 3.23,54$; 4. $\mathrm{I}_{4}, 2 \mathrm{O}^{2}, 2 \mathrm{I}, 22 ; 5 . \mathrm{I}^{2}, 2,6,26 ; 7$. 16; 8. 3, 7. 12. 1. 12; 2. $4,7^{*}, 18.33$, 47,$48 ; 3.5, \mathrm{I} 5,16 ; 4.2 .6,12,13,47$, 49. I3. I. I, I3, 55 ; 2. 9, I 2, $25^{3}, 37$; 3. $13^{4}, 14,15,26 ; 4.1,3^{3}, 4^{4}, 5^{3}, 8$, II, I2, I9, 20, 25 $, 26,29-39,40^{2}, 4 I^{3}$. I 4 . I. $29^{*}, 30 ; 2 . \mathrm{I}^{\dagger}, 33^{*}, 36,4 \mathrm{I}$. I 5. I. I,
$2,4^{8}, 5^{2}, 6^{2} ; 2.1-4^{4} ; 3.1 .2 ; 6 . I-9^{2}$; 7. I; 8. I, 2. 3; 9. I, 3 ; I $2.3,4 ;$ I 4 . $1-12 ; 15.3-6 ; 16.6 ; 17.7 ; 18.2^{2}$, $3^{2}$. I6. $1.8 ; 5.1-6 ; 7.5,13 ; 8 . \mathrm{I}-$ 27. I7. $8,1 \mathrm{I}, 12,20,21$. I8. 1. $6^{\circ}$, $16^{*}, 18^{2^{* *}}, 24^{2^{* *}} ;$ 2. $3^{*}, 31^{2}, 54^{* \prime} ; 3.63$; 4. $35,41,54$. 19. $4.4 ; 6.1^{*}, 9^{\circ} ; 13$. $4^{8^{*}} ; 15.3^{4} ; 17.1-5^{2}, 7-10^{2} ; 26.1 ; 31$. II, I3, I4; 32. 9, IO; 33. I; 34. 5 ; $35.2 ; 39.5,8 ; 46.5 ; 49.10 ; 52.1$ (mss.); 53. $2^{2}, 3,4^{2} ; 54.6 ; 57.3,4$; $58.4^{*} ; 59.3^{40} ; 64$. I. 20. $34.12,16$, 17; I27. IO; I28. I2, I6 (not ms8.); I29. I 2.

să. I. 13.4; 14. $2 ; 24.3 ; 28.3$; 34. I. 2. 29.7 . 3. I0. I, I*, 2, 3, 4 , 8 ; $17.4^{*}, 9 ; 18.4^{*} ; 23.4 ; 28.1,5$, 6. 4. 20. $3 ; 38.3^{2}: 39.2,4,6.5$ 5. I, $4,5,9^{2} ; 14.12 ; 17.4 ; 18.9,15$; I9. 4, 7. 6. I5. $2 ; 38.1-4 ; 59.3 ; 100$. $3^{2}$; 124. 3 ; 133. 4, 5. 7. 6. 4 ; 20. 5 ; 47. $1 ; 56.2 ; 73.8^{*}$. 8. 4. $17^{*} ; 9.8$; I0. $2-7^{2}, 8,18-2 \mathrm{I}^{3}, 22-9^{2}$. 9. I. $20 ; 2$. 5 ; 9. $8^{*}, 17^{*} ;$ 10. $7^{*}, 2 \mathrm{I}^{*}$. IO. I. I, 2 , $24 ; 5.37^{2} ; 8$. 10, 25,$30 ; 9.8,9,25$; IO. 28 . II. I. $24 ; 8$. I 7. I2. I. I, 3 , $4,7-10,13,18,22,26,40,41,52 ; 3$. II ; 4.35 ; 5. I $2,15,162$. I 3. I. 42 * I4. I. $60 ; 2.6^{\dagger}, 14,50,70,7$ I. I5. I6. I-5; 17. I, 3. I6. 7.4. I8. 1. $4^{\circ} ; 2$. $52 ; 4.88^{\dagger}$. I9. 4.2 ; I9. I-I I ; $48.4^{3}$, $6 ; 55.2 .20$. I 29. 19; 134.4 (not mss.). só (p. só íti). I 8. I. 20".

(cf. eșá.)

s a in satrâ, sádam, sádā, sadha, sahá, sánā (?), sám, sākám; and sakŕ̛t, ságaṇa, sácitta, sácetas, sajātá-sajóṣas, sátoka, sadyás (?), sádru (?), sádhura, sadhryàñc (?), sánābhi, sánīạa, sánemi, sapátna(?), sapráthas - sábharas, sabhă(?), sabhãga, sàmád, sámūla, sayúj, sáyoni, sarátha, sárūpa, sálakṣma, sávarṇa—savãsín, savidyutá, sávedas, sávrata, sásūnu, sáhṛdaya, sākṣá, săñga, sãtman, sằntardeça.

s a ṁ yá dov a su: -us. I 3. 4. 54 . 
s a myant in ásamyant, samyádvasu.

s a mór ú dh (inf.), see $\sqrt{ } \mathbf{r u d h}+$ sam. s a movát: -tam. 6. 29.3; 105.2. s a m $\circ v$ a ts a rát : -ás. 3. 10. 8.4 . 35. 4. 8. 8. 23. I0. 6. I8. II. 5. 20; 7. IS. I 5.17 .7 ; IS. 4 .

samivatsarám. 4. 15.13*. I0. 2. 20 , 21. I5. 3. I; I7.8. I9. 58. I. sambvatsaréna. I0. 7.5. samivatsarăya. 6.55.3. saḿvatsarásya. $\quad$ I. 35.4 . 3. 5.8 ; I0. 2,3 . 5. 28. I3. II. 6. 22. samvatsaré. 8. IO. I $\delta^{2}$. 9. IO. $26^{*}$. saminvatsarầs. 2. 6 . I.

saminvatsarắn. 3. 10. 9. I I. 6. I 7. samivatsarébhias. 3. Io. Io.

(cf. samvatsarina.)

s a movatsarinat: -am. 8. 3.17*. samvatsaríñās. 7. 77.3.

s a mován a n a: -am. 6. 9. 3 . samíánanena. 3.30. 7 . samivánani. 6. $139 \cdot 3$.

s a movára ṇa: -ṇe. 2. 6. 3 . sám $\dot{\text { m }}$ a su: -savas. 7. 109. 6 . s a movíd: -dam. 9.6. 36. I8. 1. 16*. samínídas. 3. 5. 5. [săm-). sámovidy a : -am. I2. 4.4 (s. mss. s a mov samvị́tas (inf.). I8. 3. 30-5. s a mo $\bullet$ é ça na: -ne. I 8. 3. $7^{*}$. $\mathrm{s}$ a ṁ॰ ve ȩ y à : -çíam. 3. 8. r. $\mathbf{s}$ a mọ $\mathbf{a} \mathbf{s}$ in susamçās.

s a m çit a in antárikșasamçita, apsúsamçita, àçāsamçita, r̂́ksamçita, óṣadhĩsamçita, kṛşísamçita, díksamçita, dyāúsamçita, prāṇásamçita, pṛthivísamiçita, bráhmasamçita, yajñásamçita, súsamçita.

s a mo ̧̧ís: -íşas. II. 8.27.

s a mo ocresin ná: -ṇé. 8. 5. I4. samosád: -das. 7. I2. 3 . $\mathrm{s}$ ámos a m a ka: -am. 6. 72 . I. s a mosíc: -cas. II. 8. I3. s a mos r̂́j: -ji. 4. 31. 6*. samsrsțaojit: $19.13 .4^{*}$. sámosk andha: -am. I9. 34. 5 . s a mskṛtaotrá: -ám. 4. $21.4^{*}$. s a msthit a in ásamsthita.

s a mos p parçá: -çé. 8. 2. 16 .

s a mos phắn a: -as. 6. 79. I.

sam̉sphāna. 6. 79.3.

sá mos r a șț r : -țā. I9. I3. $4^{*}$.

s a mo $\circ \mathbf{x}$ ā vá: -vāís. I. I5. 3, 4 . (cf. saminrāvyà.)

[r. 2.

s a mos $x$ ã v a ṇ a: -ñās. I. I5. 2. I9.

s a mosrā và : -víena. I. I5. I. 2. 26. 3. I9. I. $\mathrm{I}-3$.

s á moh a nu: -us. 8. I. I6. sámhanu. 5.28. 13.

[2.3. sám hitānt a (p. -taoan-): -am. ro. s a ká: -kấ. I0. 4. 14 .

s a $\circ k$ ṛ́t: -tãu. II. I. 10.

sakti in āsaktí.

s a k thán, sákthi, s a kthí: sákthi. 20. 136. 5 (mss. saktum, -tu). sakthnă. 20. 136.4 (mss. sakulă etc.). sakthíāu. 6. 9. I. sákthiobhyām. IO. IO. 2 I.

s a kṣán ṇi : -is. 5.6. $4^{*}$.

sák hi : -khā. I. $20.4^{*} ; 26.2^{2}$. 5 . 4. 7 ; II. 9 , IO, I1. 6. 5 I. I. 7. 26. 6"; 5I. I*. 8. 3. $20^{\dagger}$. I8. I. $2^{*} ; 4$. 60*. I9. 52. $2^{\dagger}$ (mss. āosakhe). 20. 130. 14 .

sákhāyam. 5. I. 9. 8. 3. $20^{*}$. I 8. I. $I^{*}$. 20. I28. 2.

sákhyā. 7.41. I.

sákhyus. 5. 13. 5. I8. $4.60^{*}$. sákhāyāu. 6. 42. I, 2.

sákhāyā. 6. 61.3. 9. 9. 2".

sákhāyas. 7.72. $2^{*}$. I4. I. $34^{*}$. sákhāyas (voc.). 7. 60. 4. 18. 1. $37^{*}$. I9. $24 \cdot 7^{*}$. $\left[26^{*}, 27\right.$. sakhāyas. 6. $97 \cdot 3^{*}$. II. I. $2^{*}$. I2. 2 . sákhīn. 5. 22. II.

sákhiobhis. 7. 105. I. I4. I. 56.

sákhiobhyas. 7.51.1"; 106. 1. 8.9.7.

(cf. asmátsakhi, índrasakhi, $\sqrt{ }$ sakhīy, sakhyá.)

$\checkmark$ sakhiy: -yaté. I9. 52.2*.

s a kh y á: -khiám. 7. ro4. I (s. mss. yàm). 18. 1. 2*.

sakhiă. I8. I. I*.

sakhiâya. 3. 3. 2 (s. mss. -yằya). 
sakhyé. 8. 9. 22. I3. 1. 17-9 (1. -khié).

sá $\circ$ g a ṇa: -ṇãs. 7.77.3.

s a mokal pá: -ásya. II. 8. I.

samikalpăs. II. 8.27. I5. 3. 10.

samkalpân. r6. 6. 10.

(cf. samklalpákulmala.) [25. 2.

s a mka lpáokulma la: -lām. 3 .

sám $\mathbf{m} \circ \mathbf{k}$ a u k a : -as. I2. 2. 12, 14 .

sámkasukam. I2. 2. II.

sámkasuke. 5.31.9. 12.2. 13, 19.

sámkasukāt. 8. 1. 12. 12. 2. 40.

sám

(cf. mádhusamikăça.) [13.2*]

s a mokránd an a: -as. 5. 20. 9. I9.

samkrándanena. 19. 13. 3*.

$\mathbf{s} \mathbf{a} \mathbf{n} \mathbf{g}$ in sañgin.

sámo g a ti: -tyām. 3. 20. 6".

s a mó g a má: -ás. 6. 24. I.

s a mo gám a na: -as. I0. $8.42^{*}$.

sam̉gámanam. I8. 1. $49^{*} ; 3.13$.

samínámane. 9. 5. 19.

saminámani. 4. 30.2*. 7.79.3.

s a mog a rá: -ás. 6. Jig. 2.

samingarám. 6. II9. 3 .

$\mathrm{s}$ a mỏ $\mathrm{g}$ a vá: -ás. 9. 6. 46 .

$\mathbf{s}$ añ $\mathbf{g}$ in in nișañgín, patsañgín.

s a mogirá: -ás. 6. 135.3. I8.4.60t.

s a mogr gáh a ṇa: -nī (p. -ííti etc.). I9. 58. 3 .

s a ṁ̀ g rā má: -ám. II. 9. 26. samingāmásya. 5.21 .7$. san̉ngrāmấs. I2. 1. 56 . samingrāmăn. 4. 24. 7 . (cf. samingāmajít.)

s a m grāmaojít: 5.20 . 10 . (cf sắngrāmajitya.)

$\checkmark$ sac: sacase. 5. 7.8.

sácate. 5. 1. 7. 12. 3. 50. [3.2. sacate. 4. 2 1. $3^{*} ; 34.3 ; 37.11$. I2. sácadhve. 2. 2.4 .

[sac-).

sácante. 6. Ir6.3. I2. 3.40 (mss. sacante. 6. 122. 3. 12. 3. $7,16,26^{2}, 28$. sácāvahāi. 6. 42. 1.

sacāvahāi. 6. 42. 2.

sacevahi. I4. 2. 72.

sacasva. I2. 2. 53 .

sacatām. I. 12. 3 . sacethām. I2. 3. 9 .

sacadhvam. 3.14.6. 4. 37. 12 (1.

-dhuam). 18. 3.19.

sacantām. 2.34. I. 4. 15.2. 8.4.

14. 12. 3. 43 [ábhac-).

ásacanta. 19. 56.5 (mss. áşac-, ápac-, sacanta. $7 \cdot 5 \cdot \mathrm{I}^{*}$.

(ef. saçcat, săc.)

+ anu: ánu secire. 8. 9. 23.

+ a bhi : abhí ... sacatãm. 9. 4. 22. abhí... sacadhvam. 6. 41.3. 9. 4. 24 . I8. 4.62 .

(cf. abhişăc.)

+upa: úpa... sácante. I8. 4. 40. sá o citt a : -tăs. 6. 100. I.

s á oc et a s: -sāu. 2. 29.3. 4. 26. I ; 29. I, 2.

sácetasas. I. 30.2. 5.21.12. 6. 68. 1. 7.22. 2.

$\checkmark \mathrm{s}$ a j, s a ñj: saktám. 5. 13. I.

(cf. saj, sakti, sañga, sañgin.)

t. a ti : átiosalktā. I2. 3. 23.

+ a n u : cf. ānuṣák.

+ ã: à sajāmi. I4. 2. 48 .

â sajāmasi. 7. I15. 1 .

à sajantu. 5.21. 10. II. 10. 3 .

âosaktam. I9. 48.3 (mss. -yā sá tvám).

(cf. āsaktí.)

+ ni: cf. nișañgín.

+ pra: praosalktás. 7. 50. $3^{\dagger}$.

+ vi : víșaktam (p. viosa-). 12.3. 13 s aj in ānușák (?).

sa०jātá: -ás. I. 19.3. 3.3.6. sajātám. I3. I. 31 .

sajātấs. $\quad 3 \cdot 4 \cdot 3$. [4.37. sajātās. 3. 3.4. 6. $73 \cdot 1,2,3$. I8. sajātăn. I. 10. 4. II. I. 6.

sajātāís. 3. 8.3. II. 1. 7.

sajātănām. I. 9. 3. 2. 6. 4. 3. 8 . 2. 6. 5.2. I9. 46.7 .

$\mathrm{s} a \circ j \mathbf{u} \mathbf{s}$. 6. 35. 2 ; 126. $x^{*}$. 8.2. 13.

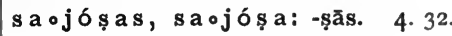
$2^{*}$. 5. 12. $3^{*} ; 28.5$. 7. 108. 2 . 12. 2. $24^{*}$.

[17.3.

sajóṣās (pl.). 3. 22. 1. 4. 14. 5. 7 . sajóşasas. 6. II5. I.

$\checkmark$ s a ñ j, see $\sqrt{ }$ saj. 
s a moj a yá: -ás. 8. 5. I6.

s a mojojivá: -vắs. I9. 69. 3 .

s a moj ñ ápana: -am. 6. 74. $2^{2}$.

s a m j j̃̃ $\bar{a}$ in ásamiñ̃ā.

s a moj ñána: -am. 3. $14.4 ; 30.4$. 7. 52. $\mathrm{I}^{3}$. II. I. 26.

sát: 8. 4. 12*. 10. 7. 10. I7. I9. satás. 4. I. I.

satí. I7. I9.

(cf. ásant, sátpati, satyá.)

sá otoka: -kān. 6. 56. I.

s attṛ in upasattṛ́.

s a ttrá (mss. satrá): -ám. I7. I4. I 9.

42. 2 (not mss.).

sattréna. I2. I. 39.

sattrăni. II. 7.8.

(cf. sattrasád, sattrasádya.)

sattra०sád: -das. I. 30. 4 .

sattraosádya: -yena. 9. 6. 42.

sát opati: -is. 7.62. I.

satpatI (p. -i íti etc.). 7. 73. 4.

s a tyá: -yá. 5. 3. 4*.

satyám. 2. $15.5 ; 35.4$. 3. I. $4^{*}$. 4 . 9. 7 ; 18. I ; 34. I. 5. II. $3^{2}$; 17. 10* 6. $61.2,3 . \quad 8.3 \cdot 21^{*} ; 4.12^{*}$. 9. 2 . $25 ; 5.2 I^{2}$. I0. $2.14 ; 3.25 ; 6.15$; 7. I, 37. II. 7. I7; 8. 20. I2. I. I; 3. $12 ; 5$. 10. I5. I. 3 ; 6. 2 .

satyéna. 2. 36. 2. 7.70.2. I0. 8. I9. II. 3. 42. I2. I. 8 ; 5. 2. I4. I. I* satyăya. I2. 3.46.

satyăt. 7. 70. I.

satyásya. 3. II. 8. 6. I. 2. I5. 6. 2. I9. IO. $2^{*}$; II. I*. 20. I36. 4 . satyé. II. 3.49. I3. I. 50. satyăs. I. IO. I. 19. 42.3 . satyăsas. I 8. 3. $48^{*}$.

satyă. 2. 6. I.

satyāís. I $8.3 \cdot 47^{*}$.

(cf. susatyá, satyajít-satyāújas.)

s aty a ojít: -tam. 4. I7. 2.

satyá odharman: -mā. 7. 24. I.

Io. $8.42^{*}$.

satyádharmanas. I. Io. 3. [16.3* s at y a $\circ \mathbf{r a ̄ d h}$ a s: sátyarādhas. 3 . s a tyá $v$ artman: -mā. 4. 29. 7. satya $\circ$ và c: -cā. 5. I. 9. 18. I. 29*. s atya०vādín: -dí. 4. I6. 6. satyavādínam. II. 4. II. [20. s a t yá os a m d ha: -dhān. I I. 6. I9, satyá os ava: -am. 7. I4. I.

satyásavām. 7. 15. I.

satyānṛtá (p. -yaoan-t): -té (p. -é íti etc.). I. $33.2^{*}$.

s at yằa n (p. -yáov-): -vānam. 4. 29. I, 2.

s a t y ā új a s (p. -yá॰oj-): -jās. 4. 36. I. s atră. I7. 25, 26. and s a trā s a h in sātrāsāhá.

sátv a n: -vānas. 6. 65.3. II. 5. I4. sátvanas. $5 \cdot 20.8$.

sátvanām. 5. 20. 8 .

(cf. abhísatvan, 1 /satvanāy.)

$\checkmark$ s a t v a nā y: -āoyán. 5. 20. x.

$\checkmark$ s a d: sidasi. I9. 33. 3 .

sida. II. I. 25,35 .

sī datā (p. -ta). I I. I. I 2.

sídantu. 4. 21 . $I^{*}$.

sídat. I8. I. $29^{*}$.

sídatas. 12. 3.30.

ásadat. 6. 3 I. I*.

ásadan. 7.96. 1 .

sadata. I8. 3. $44^{*}$.

satsi. 6. IIO. $\mathrm{I}^{\dagger}$.

sannăn. 6.76. 4 .

sādayāmi. 6. I22. 5. I0. 9.27. II .

I. 27. 14. 2. 49 .

sādaye. 10. 5. 7-I4.

sādayāthas. 12. 3. 52 .

sādaya. II. I. 23.

asādayan. II . 8. 28, 29.

sādayitvă. I2. 2. 20. I4. 2.67.

(cf. sattr, sattrá, sád, sádana, sádas, sadi, sádman, sadya, sāda, sădana, sādín, sedí.)

$+\bar{a}$ : āosídanti. I4. 2. II*.

à sIda. I2. 3. 33. 1 9.61. I (mss. me s-). á ... sidatu. I 8. 4. I6-24.

â sĩdatam. I8. 3. $38^{*}$.

āosasăda. 6. 28.3. 12. 3. 13.

à ... sasăda. 5. I. 2.

à sasadyāt. 6. 29.3.

á... asadas. I 8. 4. 52 .

â sadat. 20. 49. 3 (mss. āsánan, āsáran).

â... sadantām. 5. $12.8^{\dagger} ; 27.9$. 
ăsannās. 20. 1 34 . I (not mss.). ằsannānăm. 9. 6.21.

āosádya. 7. 58.2*. I8. r. $42^{*} ; 3.20$. à sādayāmi. I 8. 4.67 .

ầ sādayati. 9.6.20.

(cf. āsád, āsādá.)

+ u d: útosannās. I 1. 7.8.

+ upa: upaosidanti. 9. I. 9 . úpa sIda. 14. 2. 24, 25. úpa sIdantu. Ir. I. 25. upaosidān. II. I. 26, 32 . úpa sadema. $7 \cdot 74.4$. úpa... sadema. 3. I4.6. I I. I. 34. upaosádyas. 3.4. I. 5.30. II. 6. 98. r.

(cf. upasattṛ́, upasád.)

+ ni: ní şidati. 20. 127. I2. ní şidema (p. sId-). I2. r. 29. nişedús (p. niose-). 5. 17.6*. 9. I0. $18 *$.

ní ședus (p. sed-). 8. 9. I7. I7. 14. ní... asadan. 6. 52. $2^{*}$.

ní... sadatăm. 5. 12. 6*.

níșattās (p. níosat-). 18. 1. $46^{*}$. nișádya (p. niosá-). 12. 3.32. 18. I. $52^{*}, 59^{*}$.

+ upani: upaníședus (p. -aoníse-). I9. 4I. I.

+ sa min i: sam̉onişádia. 4. I6. 2.

+ pari: parị̧ı̇danti (p. -riosî-). 6. 76. $x$.

(cf. pariṣád.)

+ pra: prá sĩdāmi. 3. I2. 9 .

prá sIda. II. I. 25.

+ s a m: cf. samisád.

sá d: sádā. 4. 4. 7.

(cf. antarikşasád, apsuṣád, svāsád, ātmasád, upasád, gartasád, gharmasád, divișád, nṛșad, parișád, pitṛșád, pṛthivișád, barhișád, çrãntasád, samisád, sattrasád, sabhāsád, susáa, somasád 2.)

sádana: -am. 2. 2. 3. 7. 40. 2.9 . 3. 7. II. I. 34 .

sádanăt. 6. $22 . I^{*}$ 13. 3. 9*. sádane. 7.96. I. I8. I. $25^{*}, 35^{*}$. sádanā. 7.97. 4 . (cf. devasádana, pitrşádana, hotŗ̧̧ádana, sădana.)

s a d a mod í:-1s. 19. 39. I0.

sadaríním. 5. 22. 13.

sád a m. 1. 15.3. 3. 15.8; I6. $7^{\circ}$. 7 . 18.2. I1. 1. 34. I3. 3. II.

(cf. sadaundí.)

sád a s: 7.75.2.9.3. $7^{2}$, 19. 13. 1. 23. sádaḥosadas. 5. 1. 4. 18. $3.44^{\circ}$.

sádasi. 7. 54. r.

sádāñsi. 19. 47. I.

(cf. sadohavirdhāná.)

sá dã. 2. 4. 1. 3.16. 7*. 4.27.2. 6. 1 28.4 7. 26. $7^{*}$. 10. $6.14 ; 7.39$. I I. $6.9,22$. 13. I. 24. 18. I. 22". I9. II. 5*; 58. I (mss. sáodevãs).

s a dầnvā: -vās. I6. 6.7.

sadânuās. 2. 14. $x, 4$. 4. 10. 3 .

sadānuās. 2. 14. 5 (mss. -dă-), 6 (do.).

(cf. sadānvākșáyaṇa, sadānvācătana.)

s a dān vãokşá y a ṇa:-am. 2. 18. 5 . s a dānvāocâtan a: -am. 2. 18. 5 . s a dohavirdhāná (p. -daḥ॰ha-): -né (p. -é íti etc.). I2. I. 38.

sadohavirdhănăni. 9.6.7.

s a d $\mathbf{i}$ in pathișádi.

s ád m a n: -ma. 4. I. 4.

sádmani. 5. 31. 8 .

s a d y a in upasádya (see $/$ sad + upa), sattrasádya.

s a d y a h. $\circ \mathbf{k} \mathbf{1}:-1$ s. II. 7. 10.

s a d y ás. 2. I. $4 ; 2.3 .4 .3$ S. 5.5 . 2. I"; I2. II". 6. 8.3 ; 23. 2 . 8. IO. 2I. II. $2.25 ; 5.6$. I3. 2.6 .

(cf. sadyaḥkrt.)

sá d ru: -us. I5. 7. I.

s a dh a in sadhamàda, sadhástha.

s a d h a $\circ \mathrm{m}$ à d a: -am. 6.62. 3; 122 .

4. 7. 109. 3, 5. I4. 2.34. I8. 2. II"; 4. 10.

sadhamádeșu. 6.62.2. 7.73. I.

sadháostha: -am. 2. 2. I. 6. 80. 3. 7. $26 . I^{*}$ I2. I. 18. I3. I. 44. 14. 2.36 .

sadhásthāt. 7.63. I.

sadhásthe. 3.4.6. 7.82.6;97.3. 12. 2. $7^{*}, 30$. 18. 1. $25^{*} ; 3 \cdot 7^{\dagger}, 8$. 
sadhásthe (p. -eíti etc.). 7. 9. $\mathrm{I}^{*}$. sádhasthãs. 6. 123. 2. sadhasthās. 6. I23. I.

sá odhưra: -răs. 3. 30. 5 . s a dhricin a: -nān. 3. 30. 5, 7 . $\mathrm{s}$ a d h ry à ñ c: -ríañ. 6. 89. 2. sadhrîci (p. -ĩ íti). I3. 3. I2. sadhricis. 6.88.3. 9. 5. 37 ; 10. $\mathrm{II}^{*}$ I0. 8.35 . 19. 8.6 .

(cf. sadhrícina.)

$\checkmark$ s a n, s ã : sanávāni. I9. 32.7 (mss. ed. sánav-).

ásanam. 19. 32. 7 (mss. ed. -nām). ásanāma. r6. 6. $x^{*}$ sanéyam. 4. 9. $7^{*}$. sanema. 5. 29. I. I9. I2. I". sasaovăn. I8. I. 22*. sanișan (p. -şam). 5. 3. $5^{\dagger}$. siṣāsati (p. -sã-). I3. 2.14 . sișāsatha (do.). 6. 2 r. 3 . síșāsatis. 20. 49. I (mss. -sathas). sĩṣatî (?). 4. 38.2. [ṣãsú, seya.)

(cf. saní, sásni, sā, sāta, sāti, si+ ã : ầ... sanuhi. I4. 2. 70 .

sána: -am. I0. 8. 30.

(cf. sanátna, sanā, sanăt.) s a nátn a: -tni. I0. 8. 30.

s a $\mathbf{n}$ ā in sanātána.

sanăt. 5. 29. II*. 6.Iro. I*. 9. 9. II* s a nātána: -am. I0. 8.22, 23.

sáonābhi: -is. I. 30. I. 6. 6.3". 9 . 9. $\mathrm{XI}^{*}$.

s aní: -ím. I9. 3I. I4.

(cf. gosáni, dhanasáni.)

s a ni şy a dá (p. -niosy-): -dấs. I9. 2. I (mss. -ádās).

s a nisra sá: -ás. 5.6. 4 . (cf. sanisrasākșá.)

s a nisrasākşá (p. -sa॰ak-): -șébhyas. 2. 8.5 .

sá on I ḍa : -ḍās. I 8. 2. 26.

s a nutár. 7. 92. $\mathrm{I}^{*}$.

sáonemi: 9. 9. $14^{*}$.

s a n t, see sát.

s a m t a pan a in sămtapaná.

s a mot ará: -ám. 7. I6. I.

s a motodín: -ínāu. 7.95. 3.

s a miod a ń çá: -çắnām. 9. 3·.5. s a mod ăn a: -am. 6. 103: $1^{4}$. samdănena. 6. 104. I. (cf. ādānasamiāná.)

s a mod ̣̂́ ç: -çe. II. 2. 5 . samírças. 7. 68.3. 8. 1. 4. samiŕçi. I2. I. 18. (cf. piçáñgasamdṛç, samirça.) s a m dr ç a in mádhusamiṛça.

s a m̊ $\mathrm{d} e$ ç y à : -às. 4. I6. 8. samindeçyàt. Io. I. II, I2. samdeçíebhias. 2. 8.5 . $\mathbf{s}$ a m $\mathbf{d} \mathbf{h}$ a $\mathbf{n}$ a in

s am dh anājít (p. -naoj-): samdhanäjit. 5.20.3.

samihanājítam. I7. I-5. sam̉hanājíti. I3. I. 37 .

s a modhă : II. 8. I 5 . samidhăm. I I. IO. 9 , I 5 . samiháȳa. II. 8. I6.

(cf. indrasam̉hă, satyásamindha.)

s á mod hă tṛ: -tā. 14. 2. $47^{*}$.

s a modhí: -ím. I4. 2. $47^{*}$.

sam dhí (p. -ítíti etc.). ro. 2. 2.

s a m $\mathrm{n}$ a $\mathrm{t}$ in súsamnata.

sámonati:-is. II. 7. I3.

s a mon

s a pátna: -as. I. 19. 4. 6. 75. I. sapátnam. 7. Iog. 3 .

sapátne. 9. 2. 2.

sapátnãs. I. 9. $2,4.4 \cdot 22.6 ; 35.7$. 5. 3. 10*; 20. 2. 9. 2. 4, I0, II, I7, I8. sapátnān. I. 29. $2^{*}$. 2. 29. 3. 3. 5 . I ; 6. 4. 5. 20. I; 28. I4. 7.34. I ; 35. I. 9. $2 . \mathrm{I}, 5,6,9, \mathrm{I} 4, \mathrm{I} 5, \mathrm{I} 6$. Iо 3. $13, I_{4}, 15 ; 6.30$. II. I. 6 . I2. I. $4 \mathrm{I}$; 2. 46. I 3. I. 28, 29, 30, 3I, 32. I7. $24^{\dagger}$. I9. $28.5-10 ; 29.1-9 ; 30$. I ; $32.5 ; 33.2 ; 66.1$.

sapátnebhyas. I. 29.4 .

sapátnānām. 7. 13.2. 19. 28.3, 4 . sapátneṣu. ro. 9. I.

sapátnI. 3. $18.4^{*}$.

sapátnIm. 3. $18.1^{*}, 2^{*}, 3^{*}, 5^{*}$

(cf. ásapatna, asapatná, sāpatná, sapatnakárçana-sapatnahán.)

s a patna okárçana: -as. 8. 5. 12. s a patna kṣá y a na a: -as. I. 29.4, 6t. I0. 3. I. 
sapatnakşáyaṇam. 2.18.2.19.30. 4. s a pt a d a ç a in

sapatna०cătana: -am. 2. 18.2. saptadaçarcá (p. -çårc-): -césa patnaodámbhana: -am. Io. 6. 29 .

bhyas. I9. 23.14.

s a pta。d hấ. 8. 9.23 .

s a pa t na bán: -hă. $\quad$ I. 29. 5 . 2 . 6. 3. 4. 8.2. 8. 2.28 ; 5. I, 2 . Io. 5. 25-35; 6. 30. I9. $31.8 ; 32.10$; 46. 7 .

sapatnahánam. 9. 2. I.

s a par in

$\checkmark$ s a pary : saparyāmi. I 9. 7. I (mss. -yămi).

saparya. I4. 2. 18.

saparyatu. I4. 2. 23 (s. mss. -yata). saparyata. 3.30.6. I 8. 1. $49^{\dagger}$; 3.13. ásaparyāit. I4.2. 20.

s a ptá: 2. 12. 7. 4.6.2; I1. $9 ; 16.6$ (saptáosapta); 39. 10. 5. 1. 6*; 15.7. 6. 3. I; $25.2 ; 61.2,3.7 .29 .1 ; 57$. $2^{*} ; 107.1$; 112. I. 8. 9. $17^{3}, 18^{5}, 19$, 23. 9. I. $22 ; 9 \cdot 2^{*}, 3^{4 *}, 6^{*}, 13^{*} ;$ 10. $2^{*}, 17^{*}$. I 0. $2.6 ; 8.9 ;$ IO. $2^{2}, 3$. I I. 9.6. I2. I. $39 ; 2.29 ; 3.16$. I3. I. 37 ; 2. $4,6,7,8,23^{*}, 24^{*} ; 3$. IO. I 5 . I5. $2^{3}$. I 8. $4.28^{*}$. I9. 6. $15^{4 *}$, I6; 34 . $3 ; 47.3$ (m. mss. ed. sápta); $53.2^{2}$. saptānấm. 3. 10. 6 .

(cf. trișaptá, saptarşí-saptáhotṛ.) s a pt a o rq sí (l. -tarş-): -şáyas. 4. I I. 9. 5. 17. $6^{*}$. 8. I0. $25^{2}$. I I. I. I (s. mss. -rş-), 3 (do.), $24 ; 3.2$. I 5. 2.4 (s. mss. -rș-). I 9. 9. I2, I 3 (s. mss. -rş-). saptarşin. 8 . I0. 25 . I 0. 5.39 (s. mss. -rş-). II. 6. 1 I (mss. -rș-).

saptarșíobhis. I I. $3 \cdot 38$ (s. mss. -rṣ-). I5. 4.4 (mss. -rş-). I9. I7. 7.

saptarşíobhyas. 7. 53.4 (s. mss. -rş-). I5. 2.4 (mss. -rș).

saptaṛșiṇăm. 6. 40. I (s. mss. -rṣ-). I 5. 2.4 (mss. -rş-).

(cf. saptarşívant.)

s a pta r\$ \$í vant: -ntam. I9. I8. 7 . sa pta。g rạdhrá: -răs. 8. 9. I8.

s a ptá co kra: -am. 9.9.3*. saptácakre. 9.9. $12^{*}$. [47.3. s aptatí: -ís. 5. I5. 7. 6. 25. 2 . 19. saptatís. I9. 6. I6.

saptátha: -am. 9. 9.16*.

s a p tá

s a ptá pada: -as. 5.11.9, 10.

saptá。putra: -am. 9.9. I".

s a ptamá: -ás. I3.4.17. I5. 15.9; 16. $7 ; 17.7$.

saptamám. 9. I. 22.

(cf. saptamāsțamá.)

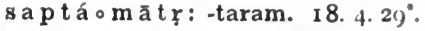

s a pt a māş ţa má (p. -ma॰aş-): -mấbhyām. I9. 22.3.

s a ptá ra çmi: -is. I9. 53. I. saptáraçmāu. 9.5. 15. I I. 1. 36 .

s a pta。rătrá: -ás. II. 7. II.

saptarcá (p. -taoṛc-): -cébhyas. I9. 23.4 .

s a ptarsí, see saptarșí.

s a ptá。vadhri: -im. 4. 29.4.

s a pta。v rạá: -ás. 5.16. 7 .

s a ptá hotṛ: -tā. 4. 24. 3 .

sa práthas: -thãs. I8. 2. $19^{\dagger}$.

sapráthas. I. 26.3 (mss. -thās).

sá $\circ$ b a n dh u : -us. 6. $15.2 ; 54.3$.

sábandhū (p. -ū íti etc.). I 8. I. IO*.

sábandhavas. Io. 3.9.

sábandhūn. I5. 3.2.

sábandhuobhyas. 8. 2. 26.

sábandhūnām. I5. 3.3.

(cf. ásabandhu, yāvatsábandhu.)

s á。bala:-le (p. -e íti etc.). I3. 3. 12.

sá $\circ$ brā hm a ṇ a: -ṇān. I 2. 4. IO, 53 .

s á bharas: -rās. 3. I7.2*.

s a bhă: 7. I2. I. I5.9. I.

sabhe. 7.12.2.

sabhăm. 8. IO. 5. I9. 55.6.

sabhăyãs. I5.9.3.

sabhăyām. 5.31.6. 7.38.4. 8. 10. 5 .

sabhăs. I2. I. 56 .

sabhăsu. 4.21. 6*.

(cf. sabhéya, sábhya, sabhāsád.) $\mathbf{s} \mathbf{a} \mathbf{b} \mathbf{h} \mathbf{g} \mathbf{g}$ in

$\checkmark \mathrm{sabh} \bar{a}$ ga y : -gáyati. 9.6.54.

sabhāgayati. 9.6.54.

s a b hāosá d: -das. 3.29. I. 7. I 2. 2. I9. 55.6 . 
s abhé y a : -as. 20. I28. I (mss. sabhé yás).

sábhy a: -as. 8. I0. 5. [-yás). sábhya. I 9. 55. 6 (mss. sabhyá, sábhyās. I9. 55.6 (mss. sabhyăs, -yás).

sám. I. I. 4 ; I5. $\mathrm{I}^{3}$. 2. 2. 3 ; 6. I, 2 ; 26. $3^{3}, 4 ; 30.2^{5} ; 31.1 ; 35.2$. 3. 4 . $6 ; 8.5^{3} ; 14.1^{3}, 2^{4} ; 15.8 ; 16.6^{*} ; 19$. $2^{2}$; 3I. I-II. IO. 4. 4. 4; I2. $3^{4} ; 15$. I, 7, 9; 24. $7 ; 25.4^{2} ; 28.7 ; 34.3$; 36. 4 , 5. 5. 2. $2^{*}, 3^{*}, 5^{*}, 7^{\dagger} ;$ I $8.5 ; 30$. 14. 6. $4.3 ; 5.1 ; 21.1 ; 34.4^{*} ; 49$. $2 ; 53.3^{3} ; 56.3^{4} ; 63.4^{*}$ (sámosam), 64. I $^{*}$; 74. I $^{5}$; 102. I $^{2}$; 103. $2^{2}$; 124 . I ; $126.3^{*}$; 131. 2 . 7.9. 4 ; 33. $1^{4}$; 50. 6*, 9; 52. 2 ; 73. 10*; 80. 1; 89. $2^{3 *} ; 97.2^{5^{*}} ; 98.1^{4}$. 8. $4 \cdot 2^{*}, 4^{*} ; 8$. 21. 9. 8. $22 ; 9.8^{*}$. I0. 4. I9; I0. $13^{2}$, $14^{2}, 15^{2}$. I2. 2. $32,55: 3.3^{3}, 17,21$, $23,29,39,5$ O. I3. I. 8 ; 2. $26^{2 *}$. I4. I. $34^{3}, 52 ;$ 2. $17,37,70^{3}$. I6. 9. 3 . I8. 2. $2 \mathrm{I}^{2}, 44,58^{*} ; 3.8^{2}, 5^{8^{2 *}} ; 4$. I. I9. I. $I^{3} ; 3$ I. $2 ; 53.4^{2} ; 55.1,2 ; 57$. $2^{3}, 2$ (mss. sás). 20. 49. I.

(cf. sam $+V /$ añc, añj, an, am, av, I aç, 2 as, āp, ās, $\mathbf{i}, \bar{a}+\mathbf{i}$, pra $+i$, anu ... i, abhi ... i, upa... i, idh, pra +idh, ìsṣ, ir, ukș, ubj, us, I ūh, r, rdh, rss, edh, kas, kāȩ, I krr, à + krr, 2 krr, I krț, krss, klp, krand, kram, anu ... kram, kruç, 2 kṣi, khyā, gach, gam, abhi ... gam, ā + I gā, I gṛ, 2 gṛ, grabh, $\overline{\mathbf{a}}+$ grabh, cakș, car, anu ... car, ā + ci, chid, ji, jĩv, jñā, tan, tap, abhi...tap, tud, tṛ, tṛp, daņ̇, dah, anu ... dah, I dā, $\bar{a}+$ dā, 2 dā, diç, anu... diç, 2 dì, duh, dṛç, dham, I dhā, à +dhā, dhāv, dhṛ, nam, upa...nam, nah, nī, upa ... parā + nī, nu, nud, nurt, pat, ut + pat, pad, paç, 2 pā, piș, pū, pṛc, prach, bādh, bṛh, bhaj, bhid, bhuj, bhū, abhi ... bhū, bhr, $\bar{a}+$ bhṛ, mad, I mā, mud, mrj, pra +yach, yam, anu ... pra + yā, upa ... yā, r yu, rabh, anu ... rabh, rā, rāj, rādh, rudh, likh, lup, lubh, vad, van, valg, 2 vas, 3 vas, vah, $\overline{\mathbf{a}}+\mathbf{v a h}$, anu... vah, $\bar{a}+2$ vā, vij, I, 2 vid, anu... I vid, viç, anu ... viç, abhi ... viç, I vṛ, pari + vṛ, vṛt, vyā, upa ... vyāa, vraçc, çak, çā, çās, çubh, çr, çri, çriș, çru, sad, ni+ sad, sā, sic, sīv, sṛj, stu, sthā, sprẹ, sphā, sru, svaj, svar, han, $\overline{\mathbf{a}}+\mathbf{h r}, \mathbf{h} \overline{\mathbf{u}}$; and samvát, samvatsará, sám ’asu, saminsūkta, sámskandha, sámbhanu saringavá, samigrāmá, samitará, samidhana, samá, samaka, samakṣá, sámagra, sámañga, sámana, sámanta, samaha, samāmá, samudrá, samușyalá, sámpatní, sámpriya, sámmanas, sammātṛ́, samrăjan.)

s a m á : -ám. 2. I I. I-5. 4. I8. I. I2. I. 2. samá. 5. $11 . \mathrm{IO}^{3}$.

saméṣu. 8. 7. I7.

[vant.)

(cf. ásama, sámā, ásamāti, samăs a m a k a in sámsamaka.

s a moakṣá: -ám. 5. 14. 4. 8. 3. $1 \mathrm{I}^{*}$. sám。agra, s a m。a grá: sámagras. 7. $81.4^{2}$.

samagrắs. 8. 7. 19. I2. I. 16.

s a mo an ká: -ám. 6. 50. I.

saman̄kắn. I. I2. 2.

s á mo añg a: -as. I8. 4.8.

s a moáñ jan a: -am. 7.36. I.

s a $\circ$ má d: -dam, 4. 30. $5^{*}$. II. I. 32

samádas. 5. 20.12.

sá m a n a: -am. 6. 60. $2^{2}$.

sámane. 6. 92. 2.

sámaneșu. 2. 36. I.

(cf. sāmaná.)

sám。anta: -as. 7. 8I. $4^{2}$.

sámante (p. -e íti etc.). I0. 8. I 2.

sámantās. 4. 34. 5-7.

(cf. samantá.)

s a m a n tá : -ám. 6. 8. 1 ; 99. 2, 3.

s a moa yá: -yé. 2. 35.3.

s a moa rá: -ré. 5. 20. 5. 7.76.6*.

I0. $8.42^{*}$. I I. IO. 25 .

s a maha. 5. 4. 10. 6. 24. I.

s á mā: -ām. 3. 10. $1^{*}$; I 7. 4*. I2. 1. 33 . 
sámās. 2.6. 1. 3. 10. 9. I1.6. 17. sámābhias. 5.8.8. 6. 75.2, 3 . sámānām. I. 35.4 . I4. I. 4 *. s a ma ti in ásamāti.

I s a moāná: -ám. I0. 2. I3.

$\mathbf{s}$ a mā ná: -ás. 6. 64. $2^{\circ}$.

samānám. 6. $64.2^{2^{*}}, 3^{*} ;$ 1 39. 3. 8 9. I2. 9. 9. 20". 12. 3. I, 52 . I3. I. 40. I5. I7.8. I 8. 4. $23^{\prime \prime}$.

samānă. I9. 58. I (s. mss. samană). samānéna. 6. 64. 2".

samāné. 2. 1. 5. 3. 30.6. I8. I. 8*. samānă. 6. $64 \cdot 3^{*}$.

samānắn. II. I. I2, 2 I. I5 5. I-7. samānébhyas. 8. 2. 26.

samānănām. I6. 3. 1; 4. 1. I7. 5 . samānt. 3. 30.6. 6. 64. 2*, 3*. 12.3. 22. samānis. I2. I. 9 .

(cf. samānájanman, samānáloka.) s a māná oj a nman : -mā. 8. 9. 22. s a mānáoloka: -as. Ir. 5. 28.

sám。āpti: -is. Ir. 7.22.

s a moāmá: -mé. I8. 4. 70.

(cf. samāmyà.)

s a moā myà: -às. 4. I6.8. [18. r. s amấvant (p. -máov-): -vatí. 4 . sámoiti: -is. 5. 19. I5. 6.64. 2*; 88. 3. 7. 12. I. I5. 9. 2. I8. I. $26^{*}$. sámitim. 8. ro. 6 .

sámites. I5. 9. 3.

sámitāu. 8. I0. 6 .

sámityām. I2. 3.46, 52 .

sámitayas. I2. I. 56 .

sámitiss. 18. 2. 56 .

(cf. sāmityá.)

s a moíd h: -ít. 7.89 .4 I0. 5.43 . I I. 5. 4. I8. $4.88^{*}$. I9. 64.4 (mss.). samídham. 6. 76.3 . II. $5.13 ; 8$. 29. I9. 64. I.

samídhā. 8. 3. $8^{*}$. II. I. $4 ; 5 \cdot 4^{2}, 6$. I3. 2. $46^{*}$. I 8. I. 30". I9. 64.2.

samídhâu. I I. 5.9.

samídhas. 5. 22. I; 26. I; 27. I; 29. I4, I5. 8. 9. I8. 9. I0. $3^{*}$ Ig. $6.15^{*} ; 64.4$.

s a mu drá: -ás. 3. 23. $6 ;$ 29. 6.6. 86. 2 ; I35. 2,3 ; I42. 2. 8. 7. 2 . Io. 7. 15 ; 10. 16. II. $3.20 ; 7.2$. I2. I.
3. I5. 7. 1. 16. 3.6. 19. 11. 3*; 19.7. samudrám. 2. 5. $6^{\circ}$. 3. 29. 7. 4. 8.7. 6. 43.2 I I0. $5.23 ; 10.13,15$. I I. 5. 6. I3. I. $36 ; 2.14,40,4 I, 45$. I3. 3. 22. I6. I. 6 .

samudréna. II. 3. 43 .

samudrât. 2. 3.4. 4. 5. I*; I0. 2 , 5 ; $15.11 ; 27.4$. 9. I. I ; 2. 23.

samudrásya. I. $3.8 ; 32.3$. 6. 105. 3 ; 106. $2^{*}$. 9.1.2. I3. 3.4 .

samudré. I. 13. 3. 2. 2. 3. 4. 2. $5^{\dagger}$; 30. $7^{*}$. 6. 80.3 I0. I0. I4. II. 2 . 25 ; 5. 26. 19. 30. 5 (mss. -drás).

samudrāú. 4. 16.3. 9. 5.20. 13. 2. 10, 30.

samudrắs. 9. I0. 2 I*. I I. 6. 10;7. 14. I3. I. $42^{*} ; 3.2$.

samudrắn. I9. 27. 3, 4.

(cf. samudrajá-samudríya.)

s a m u d ra ojá: -ás. 4. 10. 4 . [jás). s a mu dratás. 4. 15.5 (s. mss. -ras a mu drí ya: -am. 7.7. I. I9.38.2.

samudríyās. 7.107. I.

s a mou ș y a lá: -lâ. 6. 139. 3 .

sá $\circ \mathrm{m} \overline{\mathrm{u}} \mathrm{la}$ : -as. 6. 136.3 .

s a moū há: -ás. 3.24. 7 .

s a m r d d ha in ásamrrddha, súsam. riddha.

sámoṛd dhi: -is. 6. I24. 3. I0. 2. Io. II. 7. 18 .

sámṛddhyā. I2. 3.21.

sámṛ̂ddhīs. I I. I. Io.

(cf. ásamṛddhi.) [savị́-)

$\mathrm{s}$ a $\mathrm{m} \circ$ ṛ $\mathrm{d} h$ : -dhe. 3. Io. Io (s. mss.

sám $\circ$ p a tni: I4. 2. 25 .

sámpatnyāi. I 4. 2. 73 (s. mss. -tyāi). s a m pātín: -ínāu. 7.70. 3 (oiva).

s a mopibá: -ás. 6. 135. 2.

s a mopra çná: -ám. 2. I. 3 ".

sám

$\mathbf{s} \mathbf{a} \mathbf{m} \mathbf{a} \mathbf{d h a}$ in asambādhá and

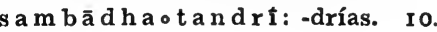
2. 9 .

s a mobhal á: -ás. 2. 36. I. I4. I. 3 I. sambhalásya. I4. 2. 66 . sambhalé. I4. 2.67.

(cf. sahásambhala.)

s a mbhav ya in asambhavyá. 
s a mobhārá: -râs. 9. 6. I.

sambhārắn. I I. 8. I3.

$\mathrm{s} a \mathrm{mbhr} \mathbf{t a}$ in

sám。bhṛ̂t a çrĩ: -iss. I9. 49. I (s. mss. -tahçr-).

s a mobhṛ́t van: -vã. 3.24.2.

s ám。ma n a s: -nās. 3. 30. 2.

sámmanasāu. 6. 42. I.

sámmanasas. 3. 30. 5,7 . 6. 73. I ; 74. 3 ; 83. 3. 7. I9. I; 94. It. 9. 5 . 37. II. 5. I, 8.

(cf. sāmmanasyá.)

sámomātr : -tā. I3. I. IO.

s a m mātŕ: -tárāu. 13. 2. 13 (oiva). sammātáras. 8. 7.27 (oiva). [úde). s a m。mú d : -de. 8. I. I 5 (mss. sam。 (cf. svādúsammud.)

s a m y áñ c: -yák. I8. 4. II. samyáñcam. I3. 3. 20.

samyáñcāu. 5. 1. 5 .

samyáñcas. 3. 30. 3,6 .

samícis. 7. 22. 2.

s a mor à j: -ráț. 4. I. 5. 6. 36. 3; 86. 3 . samrăje. 17. 22. 23.

(cf. samrăjñ̃I, sămrājya.)

s a morâjñ I: r4. I. $43,44^{4 *}$.

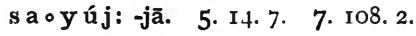
sayújāu. 7.53.2.

sayújā. 9. 9. 20*. II. I. 9; 2. I4. sá。y○ni: -is. 3. 5. 8. 6. 122. 4. 9. I0. $8^{*}, 16^{*}$. I2. 3. I9, 53 . I9. 52 . I. sáyonayas. 7. I9. I.

s ará: -râ. $5 \cdot 5 \cdot 9$.

(cf. atisará, punaḥsará, puraḥsa-

rá, pratisará, svásara ?.)

s a ra $\mathbf{g} \mathbf{h}$ ã in sāraghá.

sara na, $v$ saraṇy in

s a ra ṇ yú : -yû́s. 18. 2. $33^{*}$.

s aoráth a: -am. 3. 21.3 . 4. 3I. I*.

9. 2. 9. I 8. I. $43^{*} ; 3.48^{*}$. 19. 56 . I. (cf. sắrathi.)

s a rá mā: -māyāi. 9. 4. 16.

(cf. sārameyá.)

s a r a s in

sár a s v a n t : -ntam. 7.40. I, 2. 9. 4. 9. sárasvatī. 5. 23. I ; 25.6; 27.9. 6. 3. $2 ; 89.3 ; 94.3 .7 .57 .1$. I6. 4 . 4. I8. I. 4 I* $^{*}$ I9. II. $2^{*} ; 3$ I. 9 , IO. sárasvati. 7. 10. ${ }^{*}$; 68. I. I8. I. 43". sarasvati. 4. 4.6. 5. $25 \cdot 3^{*}$. 6. 94. 3 . 7. 68. 2, 3. I 4. 2.15.

sárasvatīm. 3. 20. $7^{*}$. 5. 7. 4. 18 . I. $41^{3^{*}}, 42^{*}$. I9. 40 . I (mss.).

sárasvatyā. 5.7 .5 ; 10. 8 .

sárasvatyāi. 6. 41. 2. 14. 2. 20.

sárasvatyām. 6. 30. I.

sárasvatis. 5. 12. $8^{\dagger}$. 6. I00. I.

sarit: -tas. I2. $2.4 \mathrm{I}$.

s a rís r pá: -ám. 3. 10.6. I9. 48. 3. sarisụ̣̂ăni. 19. 7. I.

s á ru : -rāu. 5. 25. I (çárāu ?).

s a ru in somasatsaru (?).

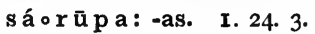

sárūpā. I. $24 \cdot 3$.

sárūpam. I. 24. 3 .

sárūpām. I. 24. 2.

sárūpāu. 5.23.4.

sárūpās. I $8.4 \cdot 33$.

(cf. sarūpakŕt, sarūpamikárạ̣a.)

sarū paokṛ́t: $\quad$ I. 24. 3 .

s a r ū p a mok káraṇa: -ṇi. $\quad$ 1. 24. 4.

s á r g a : -gās. 4. I 5. 2, 3, 4.

(cf. upasarga, visargá.)

s a r $\mathbf{j}$ a $\mathbf{n}$ a in avasárjana. [3.55*.

s a rpá: -ás. II. 3.47. I2. 1. 46. 18.

sárpa. 2. 24.4 .

sarpám. 12. I. 37.

sarpấs. 8. 7.23 ; I0. $29^{2}$. I I. 9. I6.

sárpās. II. IO. I. [9. 24.

sarpắn. 8. 8. 15; 10. 29. I1. 6. I6;

sarpébhyas. I0. 4.23 .

(cf. anusarpa.)

s a r p a in vṛkșasarpá.

s a r p a n a in sūpasarpaná. $\quad[45$.

s a rp ís: 9. 6.41. I0. 9. I2-24. I2. 3 .

sarpíșā. I2. 2. $3 I^{*}$.

sarpíșas. I. I 5.4 .

sárva: -as. I. $7.4 ;$ I5.2. 3. 16. $5^{*}$; 20. $6^{*}$. 8.2.25. 9.6.25, 26 . 16. 4 . 6. I8. 4. 8. I9. 5I. I. 20. I27. II. sárvam. I. I8. 3. 2. 7. 2 ; 3I. 5 ; 36. $6.3 .7 .3,7.4 .5 .7$; 16. I, 5 ; 17. 6,7 ; 18. 8 ; 20. I, 4,8 ; 22. 2.5 . 4. 9 , 10;8. 6 ; 18. 4. 6. 6. I; I4. I; $24.2 ; 46.3^{*} ; 54.3 ; 57.3$; 107. I-4. 7.20. $6 ; 65.3 ; 76.3$; IOI. I ; II 4.1 . 
8. I. $20^{2 *}$; 2. I2, I9; IO. I, 28.9 .4 . $20 ; 5.19,23 ; 7.24 ; 8.1-5$. 10. 1. 10, $13,25,32 ; 6.16,18 ; 7.29,30 ; 8$. I, 2, 6, 2I, 30; 9.27 ; I0. 26,34 . II. 2. IO; 4. $\mathrm{I}^{2}, 4, I_{5} ; 8$. I $3, \mathrm{I}_{5} ; 9 . \mathrm{I}, \mathrm{I}$. I2. $2.2,24^{\dagger}, 36 ; 3.28,52$. I3. I. 54 , 55 ; 2. 4I, 45. I9. 6. 4"; 9. 2, 14; 34 . I ; $39 . I, 5,8 ; 44.2 ; 52.5 ; 57 . I^{*}, 2$ (not mss.), 6; 61. 1; 64. 3; 69. I-4; 70. 1 .

sárvām. I I. 2. 25.

sárveṇa. 3. 3I. I-II. 5. 30.6. Io. IO. 13,15 .

sárvasmāi. 3. 28. 3. 4. I7. 1. 9. 4. 2. II. 4. 8. I3. 4. I9. I9. 32.8 . 20. I28. 12 .

sárvasyāi. I 4. 2. 47. [4;5.22. sárvasmāt. 7.64. I. I0. I. II ; 3 . sárvasyās. 7.12.3.

sárvasya. II. 4. I, IO, 24. I2. I. 34. I9. $53.8 ; 62$. I.

sárve. I. $7.5 ; 19.4 *$ 2.32. 5.3 . 22. I (l. -rue?). 4.6. 7 ; I6.6. 5. 3 . $3^{*} ; 7.6 ; 8.1 ; 21.7 .6 .55 .1 ; 73.1$. 7. 40. I; $56.7 ; 74.4 ; 79.2$. 8. 5. 10, 19; 7.24. 9. 1. $20 ; 2.7,10 ; 4.15$. 10. $7.13,22 ; 8.14^{2}, 17 ; 9.4,7,9$; IO. 23 . II. I. 33 ; 3. I9; 4. I 2,18 ; $5.2,5,22,23 ; 7.11,13,23-7 ; 8$. I 7 , 25,27 ; IO. I4, I5. I2. $3.5 \mathrm{I}$; 5.13 , 14. I3. 4. $21,27$. I4. I. 33. I5. 6. 8. 19. $9.13,14 ; 46.4$.

sárvās. 2. I4. I, 3. 3. 4. I, $7^{2} ; 20$. 9. 4. 5. $2,3^{*} ; 8.4 ; 9.9 ;$ I $7.2,5$; I8. $5,7,8 ; 22.7 ; 34.5-7 ; 35.5$. 6 . 24. 3 ; 25. I-3; 87. I*; 88.3. 7. 9 . 2*; 43. I; 74. I. 8. 5.8, I3; 7. I, I9; 9. 22. 9. I. I; 5.37. IO. I. $30 ; 2$. 28. II. 4.6, I9; $6.6 ; 8.21,32 ; 9$. I5. I2. 3. 4 I. I3. I. 20,$26 ; 2.2,4$ I ; 3. I9, 20. I5. 6.8. I8. 4.6. I9. 3 . 2; 15.6 ; 34.9; 39. I, 5, 8; 44. 7; $45.4 ; 53.7 ; 56.6$.

sárvāṇi. 10. 7.40. 12. 5 . II, I3, I4. I9. 8. I, 4 (mss. -vāis); 9. I3.

sárvā. 2. I. $3^{\dagger} ;$ 4. 4. 4. 5.4; II. 2 ; 20.2. 6. 124.3. 7. 83. I. 8. 7. I4. I0. 5. 50. II. I. 3 I ; 6. 2 I. I2. I.
$50 ; 5.42,71$. I3. 4. 28 . I4. 2. 24. I 8. 2.6* I 9. 31. II ; 60. 2 (m8s. -vān). sárvān. 2.7.1; 14.6;31.2. 3. 5. 6,$7 ; 6.3$; 10. 7 ; 29. $2 ; 30.7$. 4. 3 . $3 ; 9.9 ; 16.9 ; 19.7 ; 20.6$; 22. 1 ; $36.3,4 ; 37.2$, 10; 38.5 . 5. 23. 6,8 . 6. $50.3 ; 80.2 ; 112.2$; $117.1,3$; II9. 2 ; I21. 4. 7.65. I; 83. 4. 8. 2. I I ; 8.6,8, 9. 9. 2. I5. I 0. $7.7,36$; 8. 18; 9. 10; 10. 33 . II. I. 12, 21; 5. 2,$22 ; 6.20 ; 9.22,24 ;$ IO. 9, 12, 23,24 . 12. 2.46 ; $3.15,36,40 ; 4.35$, 36; 5. 44. I3. 2. 10; 3. I4. I 4. 2.69. I5. $6: 9 ;$ I4. I2. I 8. $2.34 ; 4.70$. I 9. 28. 2, 5-10; 29. I-9; 32. 6; 34. 2 ; $35.5 ; 36.3,4,5 ; 46.2,5 ; 48.5 ; 50$. $7 ; 54.6$.

sárvāis. I. I 5.3, 4. 4. I4. 9; I6. 9 . I0. I0. I4. II. 9.6. I7. 29.

sárvābhis. I0. 6.28. II. 6.20. sárvebhyas. 1. 30.2. 15.5. $7^{2}$. 19. 22. 18.

sárvābhyas. 4. 40.8.

sárveșām. 5. 23. I3. 6. 85.2; II6. 3. 9. 8. 10-2, I9, 20. I0. 4. 20. II. 9. 26. I2. 4. 20. I5. 6.8. I9. 3I. I.

sárvāsām. 4. 8. 5 ; I7.8. 5. I3.8; 23. I3. 6.83.2; 90.2. 7.35.2. I5. 6.8 . sárveșu. 6. 58.2 .

(cf. sarvaká-sárvātman.)

s a rva ká: -ám. I. 3. 6-9.

s a rva okeçaká: -ás. 4. 37. II.

sárva。g aṇa: -as. I6. 4.6.

sárva。gu: -us. 5.6. II-4.

s arvá。janman: -anas. II. 4.24.

s a rva॰jyāní: -ís. I2. 5. 22.

sarvajyāním. II. $3.55,56$.

sá rva ot a nū : -ūs. 5.6. II-4. II. 3. $32-49^{2}$.

sarvátas. 3. 2.2 ; 20. 10. 4. 10. 5. 5. 13. 7 ; 28. 10. 6. 67. I; 84. 1. 8 . 5. 4, I9, 22. Io. 8. IO. I I. 7. 4. I4. I. 64. I9. I6. 2.

s a rvá otāti: -taye. 6. 3. 3. s a rva dấ. I. 32.3. 9.6.27. I0. 6. $32 ; 7.23 ; 9$. I2. I2. 2. 50, 5 I. I8. 4. 29.

sárva op a d: -pād. ro. 10. 27. 
sárva oparus: II. 3. 32-492. sárvapūrușa (p. -vaopur-): -as. 5. 6. II-4. Io. 3. Io.

sárva०rūpa: -am. 9.7.25. sárvarūpās. 9.7.26.

sarva०víd: I7. II. sárvavid. 6. 107. 4. sarvavíde. 6. 107. 4 .

sárva०vira: -as. 7.9.2*.

sárvavīram. 3. 20. 8. 7. 8. I. II. I. 3, II. I4. $2.6^{\dagger}$. I8. 3. $14,44^{*} ; 4$. 40. 19.3I. I3, 14 .

sárvavīrās. 3. 12. I, 6. I2. 2. 28. I9. 49.6 .

(cf. ásarvavira.)

sár va०vedas: -sas. I9. 49. 6. (cf. sarvavedasá.)

s a rva०veda sá: -ám. 9. 5. I 7. sarvaçāntí: -tíobhis. I9. 9. I4 (mss. sárva çắntio).

sárva ohăy a s: -yās. 8. 2. 7 . sárvahāyasas. I0. 5.23. sarva ohút: -tas. I9.6. $13^{*}, 14^{*}$. sárva०huta: -tam. 18. 4. 13. sárvāñga (p. -vaoañ-): -as. 8. 2. 8. I I. $3 \cdot 32-49^{2}$. sárvāñga. 8. I. 20*.

sárvātman (p. -vaoāt-): -mạ. 5 . 6. I I-4. I9. 60. 2 (mss. sárvān mâ). sá。 la kṣma: -mā. I8. I. $2^{*}, 34^{*}$. salilá: -ás. 5. I7. I*. salilám. 8. 9.2. I2. I. 8.

saliléna. I7. 29.

salilăt. 4. I5. II. 8. 9. I. II. 4. 2 I. salilásya. 9. 10. $9^{\dagger}$. 10. 7. 38. I I. 5 . 26. I8. $4 \cdot 36$.

salilé. ro. 7.4 I. I7. 8 . I8. 3. 8 . salilâni. 9. IO. $2 \mathrm{I}^{*}$. I0. 8.40 .

s a ly a in visalyá.

s a vá: -ám. 7. 73. 7*.

savéna. 6. 19. $3^{*}$. 9. 2.6 .

savé. 6. 23.3.

(cf. prasavá, satyásava.)

sávana: -am. 6. 47.3. sávanasya. 7. 72. $3^{*}$.

sávane. 6. 47. 2. 7. 76.6*; 97.4. 9. I. I2, 13 . [tahsavaná.)

(cf. adhișávaṇa, abhiṣávaṇa, prā- sáova rṇa: -ṇām. I8. 2. $33^{*}$.

sá $\circ \bar{a}$ cas: -asas. 7. 12.2.

s a ○ vāsín: -ínāu. 2. 29. 6. 3. 29. 6.

s a vit tŕ: -tấ. I. 18. 2, 3; 26. 2; 29. $3^{*}$; 33. I. 2. 26.1 ; 36.8. 3. 8. 2 ; II. $4^{*}$; I2. 4 ; 15.6. 4. 8. 6 ; 25. 3 , 4, 5. 5. 3. $9^{\dagger} ; 24.1 ; 26.2 ; 27.3 .6$. I. 3 ; 40.I, 2 ; 53.I; 58. I; 6I. I ; 68. I, 3 ; 103. I. 7. 14. $4 ; 17.4 ; 24$. I; 30. I; 73. $6^{*}, 7^{*}$. 8. I. $15 ; 3.16^{*}$; 5. 5 , 10; 10. 26 . 9. 4. 10; 6. $45 ; 7$. IO, 2 I. I0. $6.13 ; 8.42^{*}$. I3. I. 20 , 38; 3. 13; 4. I. I4. I. 9*, 13*, 19*, $33,47,49,50^{*}, 5 \mathrm{I}, 53,58^{*} ; 2.12,39$, $59-62,75$. I8. I. $5^{*}, 36^{*} ; 2.55^{*} ; 3$. I2, 29; 4. 3I. I9. IO. 10*; I6. I; 20. I ; 24.8 ; 3I. I, 5 ; 45. 4 ; 46.7 .

sávitar. 5.25.12. 7. I6. I.

savitar. 2. 29. $2.4 .4 .6 ; 25.6 .6$. I9. $3^{*}$; 99. 3. 7. I4. 3; I5. I; II5. 2. I0. 8.5. I4. I. 62 . I9. 8.4 .

savităram. 3. 8. 3 ; 20. $7^{*}$; 2r. 8.4 . 25. 7. 6. I. I. 7. I4. I. II. 6. 3. I3. 2. 36. I9. 24 . I.

savitúr. 4. 25. I. 6.23.3. 9.2.6. I0. 5. I4. II. 3. 47 . I2. 2.48 . I9. 49. I ; 5 I. 2.

(cf. sāvitrá.)

s a ०vi d y u tá: -ám. 4. I5. 16.

sávím an: -ani. 7. 14.2.

sá。vedas: -asas. 12. 2.14 .

s a v ý: -ás. 15. 18. 3 .

savyám. I2. I. 34. I5. 18. 2.

savyăt. 7. 26. 8 .

savyé. 7. 50. 8 .

(cf. dakṣiṇasavyá, savyașțhă.)

s a vyaṣt țhá (p. -yaosth-): -ầs. 8. 8. 23.

sáovrata: tās. 3. 30. 3.

s a ç c a t in asaçcát.

$\checkmark$ s a s: sasán. 4. I. 6.

sáos ū nu: -us. $\dot{5} \cdot 27$. I.

sásni: 5. 2. 2*.

sas yá: -ám. 7. II. I. 8. 10. $24^{2}$.

Vs a h: sáhe. 4. 36. 4 .

sahe. 4.36 .3 .

[I 8. I. $48^{*}$. sahate. I. I6. 3. 2. 4. 3. 5. I7. 18 sahāmahe. 2. 4. 4 . 
sahante. I. 35.2

sahãvahāi. 3. $18.5^{\prime \prime}$.

sáhasva. 2. 25.3. 3. 6.6. 4. 3I. $3^{*}$; 37. 10. 19. $32.6^{8}$.

sahasva. 4. 31. 2" (m. unss. sáh-). 5 . I4. 8. I9. 31 . II.

sahatām. 8. 6. 7 .

sáhadhvam. 3. 1. 2.

sahadhvam. I9. 13. 3".

sáhamãnas. 3.6.4. 5.20. II. 8.

5. 2 . I2. I. $54 ; 2.46$. I3. 2. 28 . I9. 13. $5^{*} ; 32.5$.

sáhamānam. 7.63. I. I7. 1-5 2 .

sáhamānā. 2. 25.2 ; 27. 1. 3. 18. 5 ". sáhamānām. 3.18. 6". 4. 17.2. 8. 2. 6. sahamānās. 8. 7.5.

ásahanta. I I. I. 2" (m. mss. as-).

sasahé. 2. 5.3 (mss. -he).

sāsahé. I9. 34. 5 (mss. sāsáha).

sasahe. I. 16. 3 .

sāsahānás (p. sas-). 3. 6. 4.

sāsahānám (do.). I 7. I-5.

sāhyăma (p. sah-). 4. 32. I".

sahișivahi. I9. 32. 5 (mss. -ima-). '

sahișimahi. 3.6. 4 .

sākşe. 2. 27.5 (-şye?).

sālkșiya. I9. 32. I0.

sāḍhás. 5. 30. 9 .

(cf. sakșáni, sah sāh, saha sāha, sahantya, sáhas, sahásra ?, sáhīyas, sáhuri, sāọha, sāsahí.)

+ a b hi : cf. abhiṣáh.

+ ni: cf. nișáh.

+ pra: prá... sahate. 8. 3. 24". I 3 . prá... sáhasva. 7.3 35. I.

prá sakșati. 5. 2. $7^{\dagger}$.

+ vi: ví şahāmahe (p. sah-). 4. Io. 2. ví şahasva (do.). I 9. 46. 2.

ví așahanta (p. as-). 3. 10. I 2. (cf. vișāsahí.)

s a h, s $\mathbf{a} \mathbf{h}$, in abhīṣáh, turāsáh, nīșáh, pṛtanāsáh, viçvāsáh, vṛthāsáh, çatruṣáh, satrāsah. [trasāhá. $\mathbf{s} \mathbf{a} \mathbf{h} \mathbf{a}, \mathbf{s} \overline{\mathbf{a}} \mathbf{h}$ a, in abhimātișāhá, amisahá. I. I. $2 ; 4.2^{*}$. 2. 7.5 ; 10. $2^{2}$; 30. 5 ; 36. I. 3. 4.1 ; 5.3 ; $12.7,9$; 13. 5 ; 30. $6^{2}$. 4. $21.3^{*} ; 31.6^{*} ; 38$. $5,6,7$. 5. 6. II-4; 21.8 ; 22. 10, 12 $2^{2}$;
29. 2,3 ; 30.6. 6. 59. $2 ; 64.2^{*}$; II 9 . 2 ; 129. 2; 132.1-5. 7. 36. I; 60. 7 ; $65.3 ; 82.2 ; 89.2^{*} ;$ I05. I. 8. I. I, II ; 8.21. 9.3.14. I0.6.2, 22, $23^{2}$, $24^{2}, 25,26^{2}, 27^{2}, 28,30 ; 7.5$; 10. 13 , 25. II. I. I, 7, 22 $;$;. $2 ; 6.19,20$; $7.8,11,20,24 ; 8.30 ; 9.5 ; 10.1,2$, 5,6 . I2. I. 39,$59 ; 3$. 10, $15,17,32$, $39^{2}, 55-60 ; 4.24$. 13. 1. 15; 3. 5; 4. 28 . 14. 1. $4^{8} ; 2.1^{2 *}, 2^{*}$. 17. $24^{\circ}$. 18. $2.59,60^{\dagger} ; 3.56^{\circ}$. I9. $6.4^{\dagger} ; 8$.

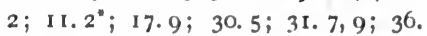
I ; 40. I; 43. I-8; 58.6 (mss. saháo pat-); 61. I (mss. sahé; ed. bhavet). 20. 131.14.

(cf. súsaha, sadha, sahákaṇţhika - sahádevata, sahápatnI-sahaçéyya, sahásambhala, sahásũktavāka.)

sahá oka ṇţhika: -kā. ro. 9. 15.

s a ha०cãrá: -ám. 2. 26. 1 .

s a h a ०jầ: -âs. 4. 31. 6".

s a há odeva ta: -tã. I2. 4. 23.

s a hanty a in sāhantya.

s a há op a trn I: -niāi. I4. I. 58.

sahápū ruṣa (p. -háopur-) : -ṣān. 6. 56.1 .

s a há obhakṣ a : -șās. 6. 47. I.

sahaobhūti: -te. 4. 31. $6^{\dagger}$.

s ahá om ū ra: -rān. 5. 29. I I".

saháovíra: -am. 2.6.5. 3. 12. 5. s a ha ०çé y y a: -yiāya. I8. I. 8*.

sáhas: 2.17. $2^{2}$. 3. 5.4. 4. 31. $6^{*}$; 32. $I^{*} ; 36.8$. 6. 4.1 ; $125.2^{*}$. 8. 7 . 5. I 0. 5. I-6. I 1. $6.15 ; 7.13$. I2. 5. 7. I3. $4.12,20,50,5$ I. I 8.4 .53$. I9. $37.1,2 ; 52.2$.

sáhasā. 2. 29.3. 4. 32. I*; 36. 3, 4. 5.20.3. 6. 72. I. 7.35. I. I9. 13. 7"; 52. 2.

sáhase. 8. 4. 3". 19. 37.3.

sáhasas. 9.5.13. I8. I. $24^{*}$.

sáhobhis (p. -haḥobh-). 7. 25. 1, 2. (cf. sáhaskṛta, sahasyà, sáhasvant, sahojít, sáhovan.)

s a há os a m bh a la: -lāyãi. I4. I. 19. saháosīktavāka: -as. 7.97.6. sáhas。kṛta: -am. 6. 39. I. 
sáhaskṛtena. 4. 32. $1^{*}$.

s a ha s y à: sahasya. 7. 7I. I*

sahasyènā (p. -na). 4. 5. $\mathrm{I}^{*}$.

s ahásra: -am. I. IO. 2. 2. 9. 3. 5 . I5. II ; I8. I0. 6. $44.2 ; 63.3 ; 77$. $3 ; 78.3$. 7.22. I; 35. 2 ; 44. I*. 8 . 8. 7 . 9. 4.9 ; 5. 17. 10. 8.24 ; 10. 9. I2. I. 45 . I3. I. 37 I7. 30. I8. 3. $47^{*}, 5 \mathrm{I}^{*}$. I9. $30.2 ; 46.5$.

sahásrena. 4. I9. 8.

sahásrasya. I. I7.3.

sahásrā. 20. 127. I, 3 .

(cf. parahsahasrá, pṛthaksahas-

rá, șațsahasrá, sāhasrá, sahásrakāṇụa-sahasrāhṇyá.)

sahásraokāṇ ạa: -ḍena. 2. 7.3.

I9. 32. 3 .

s ahásra॰kun a pa: -pā. II. IO. 25. sahasraoghní: -ím. II. 2. I2 (s. mss. -ghnyám).

s a h a s ra oc a kş u : -șo (p. -o íti etc.).

4. 20.5. I9. 35.3 .

sahásraodakșiṇa: -as. 20. 127. I 2 (m. mss. sáhas-).

sahásradakșin̄ās. I8. 2. I7*

s ahasraodhă. ro. 7.9 .

s a hasraodhāman: sáhasradhāman. 4. 18.4 .

sahásra。dhāra: -am. 3. 24. $4^{2}$.

I7. 15. I 8. 4.36 .

sahásradhārãm. 7. I5. I. I0. 10. 4. sahásradhãre. 5.6. $3^{*}$.

sahásradhārāu. 9. I. 7 .

s a hás ra o nā ma n: -mnīs. 8. 7.8 (l. -manīs).

s a hásrạ̣ith a (p. -raoni-): -thās. I8. 2. $18^{*}$.

[6. I*.

s a hásra p pa d: -pād. 7. 41. 2 . I9. sahásra。parṇa: -as. I9. 32. I.

sahasraparniat. 6. I39. I.

sahasraparnías. 8. 7. I3.

[20.

sahásraoprșțha: -as. Ir. I. 19, s a h s ra०poṣá, sah asrā poṣá

(p. -ra॰p-): -rāpoșám. 7.48. $2^{\dagger}$.

sahasrapoșâya. 6. 141. 3.

sahasrāpoșásya. 6. 79.3.

s a há s r a prāṇ a: -as. I9.46. 6 (mss. -ram prānáh ). s a hásra $\mathbf{b} \bar{a} h u$ : -us. 19.6. It. sahásraobhṛști: -is. 19. 66. I (mss. -raohṛș-).

sahás ra०mūla: -as. I3. 3. 15 .

s ahásraovarcas: -asā. 6. 78. 2.

sahásraovirya: rias. 2. 4. 2.

sahasraviria. I9. 44. 8, 9.

sahásravīryam. 6. 39. I.

sahásravīriam. 4. I7. I. 8. 5. I4. sahásraviryeṇa. 8. I. I 8.

s a hasra oçás. 3. 24. I. 8. 8. I, I6.
II. 9. 23.
[I. 12.

s a hás ra o çṛng a: -as. 4. 5. I*. I3.

s ahásraosāt a ma: -mā. 3. 28.4 .

s a há sra stuka: -kā. 7. 46. 3 .

sahasra $\circ$ há: -ás. 8. 8. I7. [24.5. s a h s ra oh a s ta: sáhasrahasta. 3 .

s a h a srākșá (p. -raoak-): -ás. 4 . 20. 4. 6. $26.3 ; 37$. . 10. 3. 3. 19. 6. $\mathrm{I}^{*} ; 53 . \mathrm{I}$.

sahasrākșám. 9.3.8. I I. 2. I7.

sahasrākșéna. 3. II. $3^{*}$. 11 . 2.7 .

sahasrākșăya. Ir. 2.3 .

sahasrākșāú. 4. 28. 3.

sahasrākșăs. 4. I6. 4 .

s ahás rākșara (p. -raoak-): -am.

I0. 8. 7. I I. 4.22.

sahásrākșarā. 9. IO. $2 I^{*}$. I3. I. $42^{*}$.

s a h s rā poṣá, see sahasrapoșá.

s a hásrāyus (p. -raoāy-): I7. 27 (l. -raãy-).

s ahas rārghá: -ás. 19. 33. I (m. mss. ed. sahásrārghas). [ar-).

sahasrārghám. I8. I. $43^{*}$ (1. -ra。 sahasrārghásya. 8. 8. 7 .

s a h a s rāhṇyá (p. raoahny-): -ám. I0. 8. I8. I3. 3. I4.

sáhas s a nt: -vān. 2.4.6. 8.5.2. 9. 2. I5. II. I. 6. I9. 13. $5^{*} ; 32.5$, Io (mss. -vanā); 34.4 .

sáhasvat. 4. 27. 7.

sáhasvatā. 4. 32. I*.

sáhasvatas. $4 \cdot 33 \cdot 5^{*}$.

sáhasvantāu. I9. 32. 5 .

sáhasvati. 3. 18. 2*.

sáhasvatīm. 2. 25. I. 8. 2. 6 .

sáhasvati (p. -i íti). 3. 18. $5^{*}$.

sáh ì y a s: -yān. 4. 32. $4^{\dagger}$. 5. 20. 10. 
sáhiyāñsam. I7 I-5.

sáhìyasi. I0. 5.43 .

sáhiyasim. 3. 18. 6".

sáhīyasīs. 8. 7. II.

sáhuri: -is. 4. 32. $4^{*}$.

sahure. 4. 3 I. $2^{*}, 5^{*} ; 32.6^{*}$.

sá $\circ$ hṛ d y a: -am. 3. 30. I.

sahojit (p. -hahoj-): 19. 13. $5^{\dagger}$. sahojítam. I7. $1-5$. V I s ă, s i : sinămi. 6. 133. 3 .

sinătu. 3.6. 5 .

sinántu. 4. I6. 6 (mss. çi-, chi-).

sităs. 8. 8. 10 .

sétave. $5.6 .3^{\dagger}$.

(cf. sãna, sita, siti, sīmáu ?.)

+ a b hi : abhí șiāmi (p. syã-). 4. 16. 9.

+ a va: áva syanti. 9. 2. I4.

áva syatam. 7.42. 2".

(cf. avasăna.)

+ udava: udoávasyati. 9. 6. 54.

+ u d : útsitas. 6. II2. 3 (s. mss. útthi-).

útsitãs. 6. I I2. 2 (do.).

+ pra: cf. prásiti.

+ vi: ví șyāmi (p. sy-). 6. 63. I. I4. I. 57. I9. 68. I (p. víşy-).

ví şya (do.). 3. 7.2. 5. 27. 1o. 6. I2I. I (l. șia?).

ví șiā (p. sya). 7. I8. I.

víşitam (p. víosi-). 1. 3.8.

víşite (do.). 4. I. 6.

vișitãs (do.). 4. I6. 6.

(cf. vișănạa ?, vișita.)

+ s a m: sám siāmi. 3. I9. 5 .

sám ... siāmi. 3. rg. 2.

$\checkmark 2 \mathrm{~s} a \bar{a}$, see $/$ san.

[șấ.

$\mathbf{s} \overline{\mathbf{a}}$ in dhanasă, sahásrasātama, svars āka moj já: -jấnām. 9. 9. I6".

sãkám. I. I0. 2 ; I I. 6 ; I7. 3. 4 .

I. $6 ; 28.4$. 5. 28.8. 6. 6I. 2 ; I 29.

I. 7. I I5.3. I0.8.9. II. I. $7 ; 5$. 5,23 ; 8. 3. I2. $2.1,25^{\dagger}$. I3. 3. IO.

I4. $2.4 \mathrm{I}, 42$. I8. 4.6 . I9. 7. I; I3. $2^{*} ; 39.5,8$.

(cf. sākam̉já.)

sā kṣá (p. saoak-): -șât. I2. 5 . I2.

s ā ñ gá (p. sa॰añ-): -gấs. I 8. 4. 64. [I I.

sắng rāmaojity a : -yāya. 5. 20. s ã c in abhişắc, rătişăc.

8 ă $\mathbf{d} \mathbf{h}$ a in aşặ̂há.

s a t a in rtásăta, văjasāta, sātahán.

s ã t a há n: -taoghnás. 3. 15.5 .

să ti in dhánasāti, vằjasāti.

sāt ma ot vá: -tvăya. 9. 6. 38.

$\mathbf{s}$ à $\mathbf{m}$ a $\mathbf{n}$ in sătmatvá.

sātrāosāhá: -ásya. 5. 13.6.

s ã d a in asãdá, āsãdá, sădín. [2. 56.

s ấd a n a (p. sád-): -am. 2. 12. 7. 18.

sădanāya. I9. I1. 6".

sădane. I 8. 3. 70 .

sădană. I $8 \cdot 3 \cdot 52^{*}$.

(cf. yamasādaná.)

sā ín: -ínas. II. IO. 24.

$\checkmark$ s ã d h : cf. sấdhana, sãdhú, sādhyá.

+ pra: prá sādhaya. 1. 24. 4 .

(cf. prasấdhana.)

sā d hú: -ús. I6. 6. II. "

sădhúm. 20. I29. 5 (mss. sădhum). sādhú. II. I. 9. I8. 4. 3. 20. 136.12 (mss. sādhu-), I4 (do.), I 5 (do.).

sãdhúnā. I8. 2. II I $^{*}$

(cf. sādhudevín, sādhuyă.)

sādhuodevín: -ínim. 4. 38. I, 2.

sã d hu०yà. I0. 4. 2 I.

sā dhyá: -yấs. 8. 8. I2.

sādhiấs. 7.5. I*; 79.2. I0. IO. 30, 3I. I9. 6. $\mathrm{II}^{*}$.

sādhyănām. 9. 10. 24.

s ã $\mathbf{n}$ in avasăna, vișănạa.

săn u: -nãu. Ir. 5•.12.

sănuṣu. ro. 4. I4.

(cf. snu.)

s ām

sāmọntapanăs. $7 \cdot 77 \cdot 3$.

sắmtapanās. 7.77. I". [5.37.

s án t a r d eça (p. sá。ant-): -çās. 9

sã patná: -ás. 2. 7.2.

sā ma $\circ$ gá: -gébhis. 2. I2. 4 .

sá ma $\circ$ t eja s: -jās. ro. $5 \cdot 30$.

sắma n: -ma. 7.54. I, 2. 8.9. 16 (sấmaosā-). 9. I0. 2". I0.7.14;8. 4I. II. $7.5 ; 8.23$. I4. 2.7 I. I 5. 3. 8. sắmnā. I0. 8.4 I. II. 3. I5. I2. I. 38 . sămnas. II. 7.5 .

sắmāni. 8. 9. 4, I6. 9. 6. 2. 10. 7. $20,44^{*}$; IO. I4. I I. 6. I4; 7. 24. 
15. 6.3. 19. 6. $13^{*}$.

sắmnām. r 5.63.

(cf. sāmaná?, ṛksāmá, bṛhátsāman, sāmagá, sămatejas.)

s ā m a ná : -nāú. 14. 1. $11^{*}$.

sāmoit y á: -ás. 8. o. 6.

sāmityāís. I3. I. I3 (p. -yāí).

s āmoma na syá: -ám. 3. 30. I.

sấmorājy a: -am. I4. I. 43 .

să y a ka: -am. 2. $57^{*}$.

sāyaka. 4. 31. $6^{*} ; 32.1^{*}$.

(cf. sâyakapraṇutta.)

săy a k a prạutta (p. -kaopranu-): -tānām. 9. 2. 12.

sāyám. 3. I2. 3. 4. II. I2. 6. 108. 5 ; I 28. 2,4 . 8. 6. I0. II. 2. I6. I3.

3. 13. 18.4 .65 .

sāyámosāyam. I9. 55.3,4.

(cf. susāyám, sāyámprātar, sāyambhavá.)

[2-4.

sāyámoprātar. 3. 30.7. I9.39. sā y a mobhavá: -ám. Io. 2. I6.

sà̀r a: -rā. 4. 4. 4 .

sār a g há : -ghéna. 6. 6g. 2. 9. I. I9. sāráñ ga: -am. 2. 32. I. 5.23. 9 .

sărathi: -is. 8. 8. 23. I5. 2. I-4. sāra me yá: -yāú. I8. 2. II*.

sāla in nị̣sālá, alasălā ?, nīlāgalasầā ?, sālāvṛ̂á ?.

sālāvṛká: -kắn. 2. 27. 5 .

sāvitrá: -trí. I4. 2. 30

sāvitrím. 6. 82. 2 .

sās a hí (p. sas-): -ís. 3. 18. $5^{*}$. I 9 .

sāsahím. 3. 21.3.

(cf. vișāsahí.)

$\mathbf{s} \overline{\mathbf{a}} \mathbf{h}$, see sah.

s ā ha , see saha.

sāhantya: 6. 7.2.

s āhasrá: -ás. 9: 4. I, 7.

sāhasrám. I 8. 4. 35 .

sāhasré. 9. 4. 2.

$\mathbf{s} \overline{\mathbf{a}} \mathbf{h} \mathbf{n}$ in

sāhnātirātrá (p. -na॰at-): -rāú.

II. 7. 12.

$\checkmark$ si, see $\sqrt{ } \mathbf{l}$ sā.

sin há : -ás. 5. 20. 1, 2. 8. 5. 12.

sinhám. 4. 8. $7 ; 36.6$.

sinhásya. 5.21.6. 8.7.15. I9.49.4. sinhé. 6. 38. I.

sinuhăs. I2. 1. 49 .

(cf. sinhápratīka.)

sinhá opratika: -as. 4. 22.7

sík a tā: -ās. 7. I09.2. II. 3.12;7. 21. síkatāsu. 20. 136. 2 .

(cf síkatāivant.)

síkatāovant: -vatí. r. 17.4.

$V$ sic: siñcati. II. 5 . 12.

siñcáthā (p. -tha). 6. 22. 2.

ásiñcat. 6. 132. 3 .

ásiñcatām. 6. $132.3,5$.

ásiñcan. 6. 132. 1, 2.

ásiñcata. II. IO. I2, 13

sicyate. 10. 8. 29.

sicyámānāyām. 6.69. 1. 9. 1. 18.

(cf. síc, secana.)

+ a n u : ánu șicyate (p. si-). 6. I I. 2.

+ abhi: abhioșiñcămi (p. -si-). 6. I22. 5 . I0. 9. 27 . II. I. 27. abhí șiñcãmi (p. si-). 3. 22. 6.4 . 8. 5. 6. 136.3 . [-ntis). abhí... siñcánti. 20. 48. I (mss. abhioșiñcét (p. -si-). 8. 10. 30. abhí şiñcet (p. si-). $\quad$ r6. I. 9. abhí șiñca (do.). 4. $15.16^{t}$. abhí ... siñca. 19. 31. I2. abhí șiñcata (p. si-). 6. 57. 2. abhí ... asiñcan. 4. 8.6. abhíșiktas (p. -ísi-). 19. 31. I2. abhyáșicyanta (p. -i॰ási-). 14. 1. 36. + ā: āosiñcánti. 4. 27. 2.

à siñca. 9.5.5. I2. 3. 45 . à ... siñca. 7.73 .6 . à siñcatu. $5 \cdot 25 \cdot 5^{*}$. ấsiñcan (p. āoás-). 6. 100. 2. ăosiktam. 4. 7. I. ăosiktās. 12. 3. 25 .

+ u pa: úpa siñcatam. 3. 17. $7^{*}$. úpa siñcata. 6. 57. 2.

upaosícya. 9. 6. 40-4, 44 . (cf. upasécana.)

+ ni: nișiñcán (p. niosi-). 4. 15. 12*. (cf. nișécana.)

+ pa r ã:párā ... sicyate. 5. 19. 6. [2*

+ pari: párișiktam (p. -riosi-). 7. 58 . parișicyáte (do.). I0. 8. 29. 
+ anuvi: anuvíşicyate (p. anuovisi-). 8. 10.33.

+ s a m: sám siñ̄āmi. 2. 26. 4 . sám ... siñcatu. 7.33. I. sám... siñcantu. 7. 33. I. sámosiktās. 2. 26. 4 . samosícya. II. 8. 1-3. (cf. samsíc.)

síc: sicấ. 18. 2. 50"; 3. 50". sícas. II. 9. I8; 10. 20. 14. 2. 51 . (cf. samsíc.)

sit a in víşitastupa.

siti in prásiti.

$\checkmark$ sidh: sedhati. 8. 3. $26^{*}$. (cf. sedha.)

+ a pa: ápa sedhāmi. 8. 2. II. ápa ... sedhasi. 6. $8 \mathrm{I}$. I. ápa sedhati. 20. 135. 13. ápa sedhanti. 5. 19. 9. ápa sedha. 6. I26. $1^{*}, 2^{\dagger}$. ápa ... sedhatam. 4. 25. 4 . apaosídhya. 8. 2.7.

+ ni: ní ședha (p. se-). 3. 15.5 sinivālit: 2. 26.2. 6. I1.3. 19.31.10. sínivāli. 7. 46. I*. I 4. 2. I5, 21 . sinīvāli. $5 \cdot 25 \cdot 3^{*}$. sinivālyāí. 7. 46. 2*. sinivālyăs. 9. 4. 14 .

sindhu: -us. I2. I. 3. I4. I. 43 . síndhum. 4. 33. $8^{*}$. 9. 10. $3^{*}$. síndhos. 4. 13. $2^{*}$. 10. 4. 19. 18. 3. 18 *. 19. 44.5 (mss. -dho). síndhāu. 6. 1. $2 ; 24$. 1 . síndhavas." I. I5. I. 4. 3. I; 6.2 ; 24. 2. I0. 4. 20. I9. 10. $8^{*}$.

sindhavas. 3.13. I. 6.3.1. síndhūn. 6.61.3. 12. 3.50. síndhuobhyas. r. $4 \cdot 3^{*}$. síndhūnām. I8.4. $58^{*}$. [dhusị́tya.) (cf. sāindhavá, sindhutás-sinsindhutás. 4. 10.4. 7.45. 1 . síndhuopatnĩ: -nis. 6. 24. 3. síndhuorājñi: -ñis. 6. 24. 3 . sindhuos ŕtya: -yāya. ro. 2 . II. silācî: 5.5.1, 8.

silẵnjālā: 6. I6.4. $V$ siș $\mathbf{s}$, see $V$ san.

s ișā sú (p. sisā-): -sávas. 6. 2I. 3. $\begin{aligned} \text { s It ā: } & 3.17 .9 . \\ \text { site. } & 3.17 .8\end{aligned}$

site. 3. 17.9.

sîtām. 3. $17.4^{*}$.

sităs. I I. 3. I 2.

8 I má n, 8 I má n t: :-mănam. 9. 8. 13. simántam. 6. 134.3.

sĩmatás. 4. I. I.

sîra: -am. 8. 9. 16.

sînā. 3.17. I*, 2*

(cf. çúnāsİra, sÍrapati.)

siraopati: -is. 6. 30. I.

$\checkmark$ siv, sy ū: sivyatu. $7.48 .1^{\circ}$. sivyadhvam. I9. $58.4^{*}$ (mss. -dhvám).

(cf. sútra ?.)

+ s a m: samosivya. 10. 2.26 .

si ș a ti, see 1 san.

sis a: -am. I. 16. 2. I2, 2. I, 53 .

sÍsena. I. I6. 4.

sîsāya. I. 16. $2^{2}$.

sîse. I2. 2. I9, 20.

sú. I. 2. I ; 17. 4*; 24. 4. 5. I. $5 ; 2$. $3^{*} ; 6.4^{*}, 5-7$; II. 7. 6. 32. 1; 84. 3. 7.6. $2 ; 72.2^{*} ; 73.7^{*} ; 85.1^{*}$. I4. 2. 9. 18. 1. $16^{*}, 37^{*} ; 3.51^{*}, 60^{*}, 62$. 19. 24. 5 ; 49. Io (p. suoápāyati).

(cf. sumna, sukárman - sujyāişțyá, sutápas, sutéjas - sutrăvan, sudátra-sumatí, sumánas —sumedhás, súyata - surabhí, surukmá, surúc, suvárcas - sușțutí, susamç̧ās - suhūti, sūktá, sūnar?, sūpasarpaná, sūpāyaná, sūyávasa, sūșás, svañgurí, svadhvará, svápas, svàbhyakta, svàramkṛta, svaritrá, svarká, svardha, svastaká-svastí, svăkta, svāyasá, svăvrịj - svăhā, svitá, svìșți.)

$\checkmark \mathrm{su}$ : sunóta. 6. 2. I.

sunótā (p. -ta). 6. 2. $3^{*}$. [IIO. 3. sunvaté. 4. 30. 6*. 6. 6. I; 54. 3. 7 . sunvatás. II. I. 30.

sutám. 4. 29.2. 7. 58. I". [34. 12. sutásya. 2. 5. 1, 2, 7". I 8. 1. $45^{*} \cdot 20$. sutăs. I 9. 71. I (mss. stută).

sutăsas. 2. 5. 4 . 
(cf. sávana, suta, suti, sútvan, / u u c a krá: -ás. 4. 12.6. sóma.)

+ adhi: cf. adhiṣávana.

+ abhi: cf. abhișávaṇa.

$+\bar{a}$ : āsunótā. 20. 127. 7 (mss.). (cf. āsutí.)

+ prati in prātisutvaná.

s ú ka: -keșu. I. 22. $4^{\dagger}$.

suokárma n: -māṇas. 18. 3.22* su०kálpa: -am. 12. 2. 5 .

su०kin̉ çuká: -ám. I4. I. 6I*.

suokŕt: 5.27.3.

sukṛ́tam. 7. 47. I.

sukṛ̂te. I8. 4. I4.

sukṛtas. 4. 24. I.

sukṛtāu. I2. 3. 44 .

sukṛ́tas. 3. 28. 5. 6. I2O. 3. 7. 79. 2 ;

80. 4. I2. 3. 9 . I8. I. $4 \mathrm{I}^{*} ;$ 2. $55^{*}$; 3. $20 ; 4.3,7$. I9. II. I*; 56. 5 .

sukứtām. 3.28.6. 6. I24. I. 9. 5. I, $5,8,9$, I2. II. I. I 7, I 8,35 . I8. 2 . $8^{*}$; 3. 7I ; 4. I, II, 44. I9. IO. $4^{*}$.

súokŗta: -as. I7. 27.

súkṛtam. 12. 3. 33 .

suokṛtá: -ásya. 2. IO. 7. 4. II. 4,

6; I4.6. 6. II9. I; I2O. I; I2I. I,

2. 7. 83 . 4. 9. 5. I9. Ir. I. 8 , I9, $37^{2}$. I4. I. I9*. I6. 9.2. I8. 3. 54.

sulkṛté. I4. I. 59.

sukṛtăni. r9. 10. $4^{*}$.

sukưtāís. II. I. 36 .

suokrátu: -us. 7. 14. 2.

sú。kșata: -asya. 7.76.4.

suksetra in

suokṣetrá tā: -tāyāi. 7. 20. 5. and

suokṣetriyâ: 4. 33. $2^{*}$.

su०khá: -ás. 5. 14. 5, 13. I9. 7.3 . sukhám. 8. I.6. I3. I. $24 ; 2.7$.

suogá: -ám. 3. 3. 4. 7. 50. $4^{*}$. 8. 4. $7^{*}$. I4. I. $5^{8} ; 2.6^{\dagger}, 8$.

sugéna. I4. 2. $\mathrm{II}^{\dagger}$.

sugă. 7. 97.4 .

suogàtu: -tave. 6. I. 3 .

(cf. sugātuyấ.)

$\mathrm{su} \circ \mathrm{g} \overline{\mathrm{a}} \mathrm{tu} \mathbf{y} \bar{a}^{\dagger}:$ 4. 33. $2^{*}$.

$\mathrm{s} u \circ \mathrm{g} \overline{\mathbf{a}} \mathbf{r h}$ a patyá: -ás. 12. 2. 45 .

s u०g ú : -gú (p. -ú íti etc.). I 4. 2. 43 .

s u०gṛ̂há: -hāú. I4. 2. 43. sucakrám. I4. I. $61^{*}$.

suocitrá: -răm. 7. 15. I.

su cetaná: -ám. 20. I35. IO (mss. súcetanam).

s u०jánim a n: -mā. I2. 2. 24*.

s u ०já n m a n :- -mā. 5. I. I. [20. 5 .

sú $\circ \mathbf{j} \bar{t}$ a: -am. 2. I3. 5. 4. 23. 4. 7 . sújāte. I9. $49 \cdot 3$.

(cf. sujāátátā.)

suojātátā: I9. I2. I*.

su०jihva: 5. I2. 2*.

su०jyāișțhyá: -țhiás. I4. 2. 24. suta in

s u ta॰p a: -pāu. 7. 58. I*.

s u ot á p a s : -asāu. 4. 26. 3 .

suti in āsutí.

s u otéj a s: -asā. 8. 2. I 7 .

s u otrá̀m a n: -mā. 7. 9I. I"; 92. I*. I8. $3.6 \mathrm{I}$.

sutrắmāṇam. 7.6. $3^{*}$. [-ávṇe). sutrắmṇe. 19. 42.3 (m. mss. ed. (cf. sāutrāmaṇá.)

s u ot $x$ ầ a n: -vṇe. I9. 42.3 (s. mss. -ămṇe).

s ú t v a n: -vā. 20. I 28. I (mss. sutvă). (cf. prātisutvaná.)

suodátra: -as. 7. I0. $I^{*}$.

suodầnu: -us. r8. 3. 61 .

sudânu. $7 \cdot 20.4$.

sudănavas. $4.15 \cdot 2,7,9$. 6. 30. I. I4. 2. $72^{*}$.

sudānavas. I3. I. 3 .

suodína: -ne. I7. 17 .

su०divá: -ám. I9. 8. 3.

s u ○dú g h a : -ghā. I2. 4. 35. I 8. 4. 50. sudúghām. 7.73. $7^{*}$; I04. I. 9.4.21. sú。dṛ ḍ a: -am. I0. 2. 3 .

s u o de vá: -ás. 20. I36. I2 (mss. súdevas).

s u०d hă : -ấyām. I 7. 6-1 9, 24.

sú。dhṛta: -as. I3. 2. I2.

su०nákşatra: -am. I9. 7.3.

suonātha: -thās. I2. 3.27.

su०natbhi : -is. 4. I2. 6 .

s u० nằ m a n: -mã. 8. 6. $4^{2}$.

sú p akva: -ve. 5. 29.6.

s uopa kṣá: -ám. I3. 2. 2. 
suopátnI: II. I. I4. supátnIs. I2. 2. $3 I^{*}$.

s u०parṇá: -ás. I. 24. r. 2. 27.2. 4.6.3. 5. I4. I. 6. 8. $2 ; 83$. I. 7. 41. 2. 9. IO. $28^{*}$. I2. 3. 38. I3. 2. 9, 32. I $8.4 \cdot 89^{*}$. I9. 65. I. suparṇám. 4. I4.6.7. 39. I". I3. 2 . 36, 37. I 8. 3. $66^{\circ}$.

suparnásya. 4. 20. 3.

suparṇă. 9. 9.20".

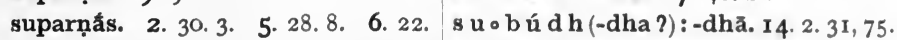

I"; 49. 3". 8. 7.24; 9. I7. 9. 9. $2 I^{*}$, sú brah man: -mā. 20. I 28. 7 (mss. 22. I I. 2. 24 . I2. I. 5 I. I3. $3.9^{*}$. I 8. 4. 4 . suparṇāís. II. IO. 26.

(cf. sāúparṇa, suparnáyātu, suparṇasúvana.)

su parná y ātu : -um. 8. 4. 22". suparṇaosúvana: -ne. 5. 4. 2. su०pavi: -ís. 4. I2. 6.

s u०pāçá: -çáyā. 3. I I. 8 .

s u०pip pa lá: -lấs. 3. 17. 5 .

su०pú: -únā. I2. 2. I1.

suoputrá: -ră. I4. I. I8*.

suputrāú. I4.2.43.

suopug̨tí: -ím. I9. $7 \cdot 4$.

sú。pūrṇ a: -ṇā. 3. 10. 7 .

s u०pé ças: -asas. 7. 48.2*. $[23,74$.

su०prajás: -jăs. 4. I1.3. I4.2.22,

suprajásam. I4. I. 49 .

suprajásas. 3. Io. 5 . I 8. 4.63 .

(cf. sāuprajāstvá.)

supráñiti (p. suopráni-): -is. I9. 4. 4 (mss. -tās).

supraṇite. 5. I I. 5. 7. 20. 4 . supránitim. $7.6 .2,3^{*}$. supranitayas. I $8.3 .44^{*}$. súpratișțita (p. súopratisthi-) :

-am. I2. I. 63.

suoprátika: -as. 5. 27. I. suprátilkam. 4. 21.6 . suprátīkās. I0. $5 \cdot 24$.

s ú pra d a d i : -is. 20. I 28. 9.

s u pra pāṇá (p. suoprapān-): -ṇám. I4. $2.6^{\circ}$.

suprapānắ. 20. 128. 9 . suprapāṇé. 4.21. 7 .

suopraçastá: -ám. 5. II. II. su०prảtár. $\quad$ 9. 8. 3.

s u prā y a ṇá (p. suoprāyan-†) : -ṇăs.

5. 12.5 .

s u prāvî (p. -ra॰av-): -víā. 4. 30.6 .

sú。priy a : -yă. 7. 38.2.

su०phalá: -1â. 3. $17.8^{\dagger}$.

su०phālá: -lăs. 3.17. $5^{\dagger}$.

s u०ba d d há:-dhầm. I4. I. $18^{*}$.

su०ba ndhú: -úm. I4. 1. I7.

s u०bāhú: -ús. 7. $46.2^{\circ}$. sub-).

sú。brāhm a ṇ a : -ṇãs. Ir. I. 26 .

s u०b há g a : -gã. 2. 36. 3. 5. 7. I0. 6. 3. 2 ; $38.1-4.7 .48 . I^{*}$ I 0. 9. I I. I 4. I. $18 \%$

súbhage. 3. I8.2* 5.5.6, 7. 6. 30 . 3. I9. 49.3 .

subhage. 3.17.8*, 7.20.4; $48.2^{*}$; 79. I. I 8. I. I I", I2*. I9. $49.5 ; 50.6$. subhágām. 2. 36. 3. 6. 59.3. I4. I. 49. I9. 4. 2 .

subháge (p. -e íti etc.). 3. 7.4.

subhage (do.). 4. 26. 2.

subhágās. 7.60.6.

(cf. sāúbhaga.)

sú ○ b h dra: -rām. I8. I. 16".

s u b hā g a (p. suobhag-) : -gās. 9. 4. 24. (cf. sāúbhāgya, subhāgam̉kárạ̣a.) s u b hāg a m kárạ̣a (p. -bhagam。 k-): -aṇi. 6. I39. I.

súbhiș a j : -şakotamas. 2.9. 5 . súbhişakotamās. 6. 24. 2.

s u०b hú : -ús. I 3. 4. 52 . subhúvas. 4.8 .7 .

s u०bh ū tá: -ám. I. 3I. 3, 4. 6. 40 . 2. I2. I. 55 .

sú。bhūti: -tiā. 3. I4. I. súbhūtaye. I9. 45. 6-10 (mss. subhūtáye).

sú。bhṛta: -am. 6. 39. I. I3. I. I. sú。bheșaja: -am. 2. 3. I.

su०bhoj a s: -asāu. 4. 26. I. [34. 7. s u०m añ gá l a: -las. 8. 5. r, r6. I9. suman̄gálam. I4. I. 30 . sumañgálāu. 6. I40. 3 . $[25,26$. sumañgalí. 3. 10.2. I4. I. $60 ; 2$. 
sumañgalís. I4. 2. 28*.

s u m a ñ í: -ís. 20. I28. 7 (mss. súmanis).

s u०m atí: -ís. I4. 2. $5^{*}$.

sumatím. 2. 36. I. 4. 23. 2 ; 25.6 . 6. 22.2. 7. I5. I; I 7. 2. I0. 6. 35. I7. 7. I8. I. $24^{*}$. I9. 7. I; 42. 3 . sumatyāí. 6. 13.2.

sumatāú. 3. 10. 7 ; 16. $4^{*}$. 5.8.9. 6. $47.2 ; 55.3^{*} ; 93.3 .7 .20 .3,6$; 92. $\mathrm{I}^{*} ; 97.2^{\dagger}$. I3. 2. 37. I4. 2. I5, 21. I7. 8, II. I8. I. $5^{*}$.

sumatáyas. 7.48. 2.

s u m a d in

s u mád॰gu: -us. 5. I. 7 .

s u०mána s: -nās. 3. 4. 7 ; 12. 5 ; 17. $8^{\dagger} ;$ 20. $2^{*}, 6^{*}$. 6. 123. 5. 7. $48.2^{*}$; 60. I; 74. 4. I9. 49.3.

sumánasam. 6. 99. 3 .

sumánasas. 3. 4. 3. I2. 2. 49. I4. 2. (cf. sāumanasá, $\sqrt{ }$ sumanasy.)

$\checkmark$ su०mana s y: -yámānas. 7. 19. I ; 43. I. I3. I. 35. I 4. 2.39. sumanasyámānā. II. I. 8. I2. I. 44. I4. 2. 17, 31.

sumanasyámānam. 5.28. 5 . sumanasyámānās. $\quad$ r. 35 . I. 2. 35 . 5. I3. I. I3.

su○mántu: I8. I. $34^{*}$.

s u०mṛgá: -ám. I9. 8.3.

s u $\circ \mathbf{m r ̣}$ ḍ İá: -ás. 7. 9I. I*.

sumṛ̣̣ilză. 7. 68. 3.

sumṛ̣̣īké. 7.20.3.

s u $\circ \mathrm{medh}$ á s, -dhă : -dhắs. 5. I I. I I. 7. 60. I. 9. I. 6 (mss. ed. sumédhās).

sumedhắm. 4. 30. $3^{*}$.

sumedhásas. 7.61. I, 2.

s u m n a in ántisumna, $\sqrt{ }$ sumnay.

$\checkmark$ sumnay in sumnayă, sumnayi, sumnayú.

sumna。y â: 7.55. I.

sumnay i: -yi. I9. 47.4 .

s u mna॰yú: -ús. 7. 10. $\mathrm{I}^{\dagger}$.

sumnayāú. 3. $17 \cdot \mathrm{I}^{\dagger}$.

$\mathrm{sú} \circ \mathrm{y}$ a ta: -as. 6. III. I.

s ú y a b h y a: -yā. 20. I28. 9 .

suoyám a : -am. 7. 73. 10* ; 82.3. suyámā. 14. 2. $17,18^{\dagger}$.

suyámasya. I 9. IO. 2 (mss. -mastu). suyámãn. 4. 27. I.

su०yāman: súyāman. I6. 7.7.

s ú yā m in:-mi. 20. I28. I (not mss.).

s u० y új: -jāu. 6. I40. 3 .

suyújas. 5.26. 3, 7-I I.

suorátna: -nās. I2. 2. $3 I^{*}$.

s u rabhí: -ís. I2. I. 59 . I4. 2. 44.

I9. $38 . \mathrm{I}$.

surabhi. 6. I24. 3 .

surabhím. 12. 1. 23, 24.

surabháyas. I8. 3. 17.

surabhîs. II. 4.6 .

surabhịni. 18. 3. $42^{*}$.

súrā: 6. 70. I. I4. I. 36. I5.9. 2. súrām. Io. 6.5 .

súrāyās. I5. 9.3.

súrāyām. 6.69. I. 9.'I. I8. I4. I. 35. (cf. súrodaka.)

suorukmá: -mé (p. -éíti etc.). 5 . 12. $6^{*}$.

s u $\circ$ r ú : -cam. 4. I. 2.

surúcas. 4. I. I. I8. 3. $22^{*}$.

s ú ro d a k a (p. -rāoud-) : -kās. 4. 34. 6.

s u v a $\mathbf{n}$ a in pửsúvana, suparnasúvana.

s u०várc a s: -cãs. 2. 29. 6, 7. I3. I. 22. I4. I. 47 ; 2. 18*. I 8. 2. $10^{\dagger} ; 3.58^{*}$. su०várṇa: -am. I 5. I. 2. I9. 26. 2. suvárṇā. I3. I. 22.

suvárṇās. I. 33. I-3. I2. 3. 28.

suvárnaais. I3. 3. 16.

s u várm a n : -ma. I9. 30.. I (mss. osu várma).

su०váhni: -im. I3. 2.7 .

s u०vắc: -cā. 5. 12. $7^{*}$.

suvăcas. 2. 5.2 .

s u ०v ấ s a s: -sās. I4. 2.44.

s u०vijñāná: -ám. 8. 4. 12*.

suvitá: -tâya. I9. I0. I*.

s u०vidát ra : -as. I3. $2.44,45$.

suvidátram. I. 31.4 .

suvidátrās. 18. 3. 19 (msss. -datrằs). suvidátrān. I $8.1 .45^{*} ; 2.1 \mathrm{I}^{*}$. suvidátrebhis. I8. 3. $48^{*}$.

(cf. suvidatríya.)

$\left[54^{*}\right.$. suovidatríya: -yebhyas. I8. 2. 
sú。vi d vāñ s: -ñsas. 4. I4. 4 . su०vira: -as. 6. IIO. 3 ; I25. I". 8 . 5. 2. II. I. $2^{*}$ I 2. 2.49 . I3. I. 12. 19. 24.8 .

suviram. 3. I9. 5 (m. mss. ed súvI-). 7. 20.4 ; 79. 1 .

suvîrās. 3. 10. 5 ; 12. I. 5. 3. $5^{*}$. I8. 2. $59^{*} ; 3.24^{*} ; 4.63$. I9. 12. $1^{*}$. suvîrāsas. 12. 2. 22.

(cf. suvirrátā, suvîrya.)

s u०vĩrát ā: -tāyāi. 6.29.3.7.20.5. suovirya: -as. 7.97.6.

suvtriasya. 7.91. ${ }^{*}$.

s uov ṛjána: -nāsu. 18. 1. 46".

su०vị́t: -tam. I4. I. $6 I^{\prime \prime}$.

s u०ṿ̛ dh (or -vṛ́dha): -dhā. 2. I3. 5. su०vratá: -tânām. 7.6. 2.

su०çánís a: -as. 19. 10. 6*.

su॰ç a ṅ sín: -ínas. 6. 6.2 (mss.susanç̧ínas).

[nam).

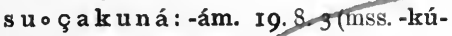
suoçárman: -ma I9. 7.5.

suçármāṇam. 7.6.2, 3*.

suoçim a: ám. 3. 17.3. súoçṛt a: -am. 7.72. $3^{\dagger}$.

su०çéva: -vā. I3. I. I7. I4. 2. I7, 26. I8. 2. 31 .

suçévam. 4. 25.5. 6. I. 2.

suçévām. I8. 3. $49^{*}$.

suçévāu. 5. 6.5-7.

s u ० çé va s : -vās. 2. 2. 2. I 4. I. $19^{\dagger}, 5^{8^{\dagger}}$. su०çravas: II. 4. Ig.

su०çrút: 8. 2. 8 .

suçrútāu. I6. 2. 4 .

s ú ○̧ruti: -is. I6. 2. 5 .

s us a tyá: -ám. 20. 135. 4 (mss.).

s uṣád (p. suosá-): -dam. 20. I35. 4 (not mss.).

suşádā. 2. 36.4. 3. I4. I.

suṣádām. 3. 22. 6.

s u șú m a (p. suosú-): -mā. 7.46.2* suṣțutí (p. suostu-): -ím. 7. 82. I".

20. 127. 7 (mss. súșțutim).

sușțutyâ. 7.29. 2.

sușțutî. 7. 48. I".

sușțutí (p. -í íti etc.). 6. I. 3.

sușțutis. 6. 35 . I. [5. 1 2.6* ; 27.8.

s us vá y a nt (p. susv-); -ntĩ (p. -I íti). s u०s a mí çā s: súsamçāsas. 18.3. I6. s ú ○s a mọ it a :-as. 6. 105. 2.

sú $\circ$ a món a t a : -tā. 3.25. 3 .

súsaminatām. 3.25. 2.

s ú o $\mathrm{s}$ a m r d d h a: -dhena. 9.6.40-3. sú。s a ha. 6.64. 3".

s u०sã yám. I9. 8. 3 .

s us ráj: -jam. 20. 128. 15.

suosrás: -ásas. 7.76, $1^{2}$.

suoháva: -as. 7. IO. $\mathbf{I}^{\dagger}$. 19.4. 3 . suhávam. 7.20.4; 86. I". I7. II. 19. $7.2 ; 8.3$

suhávā. I9.4. $2 ; 7.3 ; 49.1,5$.

suhávā (instr.). 3.20.6*7.47.1; 48. I'. II. I. 26.

suhávās. 7. 49. I $I^{\dagger}$.

suhávāni. 19. 10. $3^{*}$.

suohásta: -as. 7. 73. $7^{\circ}$.

suhástãs. I9. II. I*.

suohărd: 2. 7.5 (m. mss, -ăd).

suhắrdas. 3.28. 5. 6. 120.3. I 9. 32.6 . suhắrdām. 3.28. 6.

sú ○hit a: -tā. II. IO. 4.

súhira ṇy a vant: -vān. 20. I28. 7 (mss. -vas).

sú。hut a: -am. 6. 7I. I, 2. I0. 9. 26.

suohũti: -te. 7.4. I.

$V$ I, 2 s $\overline{\mathrm{u}}$ : suve. 4. 30. $7^{*}$.

sūte. 9. 9. 17 ".

súvate. 9. 9.2 $\mathrm{I}^{*}$,

súvānā. 2. 36.3.

suva. I9. 8.4 .

suvāti. I4. I. 33 .

sasûva. 10. IO. 23.

suṣuvé. I 4 . I. 43.

sâvis. 7. 14. 3.

sãvișat. 6. т. 3. 7.73. $7^{*}$.

sưtave. I. II.2. 5. 25. IO-3.

sútavāí. I. II. I.

sávitave. 6. I 7. I-4.

(cf. savá, savitŕ, sávīman, suvana, sū, sūta, sũti, sưtu, sūtrî, sūná, sūnú, sūma, sūya, sūvan, sūșaṇā, suṣá.)

+ a p a: ápa . . . suvāmi. 6. I I9. 3 .

+ $\overline{\mathbf{a}}$ : à ... suvāmasi. 7. 53.6.

à suva. 2. 29. 2.

à suvā (p. -va). 7. 14.3 . 
ầ suvatām. 4. $25 \cdot 5$.

+ nis: níh ... suvãmasi. I. I8. I.

nih șua (p. sva). 6. I2I. I (m. mss. ní șv-). 7.83. 4 (mss. ní șv-).

níh ... suvāma. I9. 57.2.

níh ... sāviṣak. I. I8. 2 (ed. -ṣat).

+ parāa párā ... suvāmi. 4. 13. $5^{*}$. 7. 53.6.

párā ... suvāmasi. 6. 127.3. párā suva. 5. 22.3. 19. 39. 10. párā ... suva. I9. 8. 4 (mss.). [23. + pari : parișūtám (p. -riosū-). I I. 5 .

+ pra: prá suvāmi. I. Io. 2.

prá suvāmasi. 12. 2. 3 .

prá ... asāvișus. I. I8. 2.

práosūtas. 3. I. $4^{\dagger}$. 6.63. I. I9. 5 I. 2. práosūtās. I2. I. 62 .

(cf. prasavá, prasú, prasūta.)

$\mathbf{s} \tilde{u}$ in asú, asūsú, prasú, viçvasú, vīrasú.

s ūkará: -ás. 2. 27. $2 . \quad$ 5. I4. r. sūkarâya. I2. I. 48.

[tena). s ū kt á: -téna. 20. 127. I \& (mss. súk(cf. asaminsūktagilá, sahásūktavāka.)

$\mathbf{s} \overline{\mathbf{u}} \mathbf{k}$ ta $\mathbf{v} \overline{\mathbf{a}} \mathbf{k} \mathbf{a}$ in sahásūktavāka.

sū cî: -cyâ. 7. 48. I*.

(cf. sūcímukha.)

s ūcí $\mathbf{m} \mathbf{u k h}$ a: -khās. II. IO. 3 . s ū tá: -tăs. 3. 5. 7 .

sūta in prasūta and

s $\bar{u}$ tá $\circ$ v a ça: -çā. I2. $4.44,46,47$.

$\mathbf{s} \overline{\mathbf{u}} \mathbf{t} \mathbf{i}$ in

sû́tikā: -ās. 8.6. I9. (cf. asútikā.)

sút u: -us. 7.35.3. sútum. 6. I7. I-4. sútave, sútavāí, see $\mathfrak{V} /$ sū. sútau. I. I I. I (or to sūti).

sút ra: -am. ro. $8.37^{2}$. sútrasya. I0. $8.37,38$. sútre. 3.9.3.

sūtrí: 9. 7. I4.

$\checkmark$ s ū d: suṣūdáta (p. susū-). I. 26. 4 . sūdayatu. I. I8. 3 .

sūdayantu. 6. 5 I. $2^{\dagger}$.

s ū ná: -nắnām. 5. 17. 14. s $\overline{\mathbf{u}} \mathbf{n}$ a r, s $\mathbf{u} \mathrm{n} r$, in sūnọ́tā. sūnú: -ús. 6. I. 2. 7. I. 2. sūno (p. -o íti). I 8. I. $24^{*}$. sūnúm. I2. 3. 23. (cf. sásūnu.)

[19. 7. 2.

s ū n⿳̛̣ tā: 3. 20.3*. Ir. 7. 13. 12. 5. 6. súnṛte. 8. Io. II.

sūnứtām. 6. 62.2 . 10. 6.13 . (cf. sūnứtāvant.) [I. I, 20.

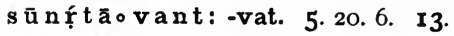
sūnứtāvate. 3. 21.5 .

sūnứtāvantas. 7.60 .6 .

sūnụtāvatĩ. 3. I2. 2.

[3. $50^{t}$. s ū pa s a r pa ạá (p. suoup-): -ṇâ. 18. s ū p à y a n á (p. suoup-) : -nă. 18. 3. 50*. $\mathbf{s} \overline{\mathbf{u}} \mathbf{m} \mathbf{a}$ in suṣúma.

s ū y a in rājasúya, strāíșūya.

s ū yá vas a (p. suoy-): -se. 4. 21. $7^{*}$. s ū y a vasád (p. suyavasaoád): 7 . 73. $I^{*}$.

sû́ra: -as. 4. 2. 4. 6. 6r. I. 7. 72. 2*. I3. 2. $24^{*}$. I8. $4.5^{8+}, 59^{*}$.

s ūrí: -ís. 2. II. 4. I3. I. 22 . I8. 3. 39†. 20. 34. I 7 (mss.).

sūrím. 3. I9. 3. 9.5. 2.

sūráyas. $4 \cdot 33 \cdot 3^{*}, 4^{*}$. 7. 26. $7^{*}$. sūríobhis. 7.97. 2*.

s ū r t a in asúrta.

súrya: -as. 2. I0. 4 ; I 5. 3; 29. I. 5. $9.7 ; 17.9 ; 23.6^{*} ; 24.9 ; 28.2$; 30. II, I5. .6. 75. $3 ; 83.1$; IO0. I. 7. $13.1,2 ; 82.4$. 8. I. I2; $2.14 ; 5$. 7 ; 6.8. 9. $2.24 ; 6.46$. ro. 1. 32 ; 3. 17 ; 6. 9 ; 7. I2; 10. 34 Ir. 4.12 ; 7. $14 ; 8.3$ I. I2. I. 15,$53 ; 5.73 .13$. I. $45^{4} ; 2.8,34,35^{*}$. I5. 6. 2 . I6. 4 . 4. I7. 30. 19. $6.7^{*}$; 10. $8^{*}$; 17. 5 ; I9. $3 ; 33.5 ; 43.3^{2} ; 44.5$. 20. 128. 5 . súrias. I. $4.2^{*} ; 9.2 ; 29.5^{*}$. 4. 4 . 2. 5. I3. 3. 6.8. 3 ; I2. I; 52. I; 9I. 2*. 7. 69. I. 8. I. 5 ; 5 . I8. ro. 7 . 33 ; 8. I6. I3. 2. I4; 4. 5. I9. 20. 4 ; $27.2 ; 53.6 ; 54.1$.

súrya. 2. 16. $3 ; 21.1-5$. I3. 2. I2 (mss. súryā). I9. 70. I.

súria. I7. 26.

sūrya. I3. 2. 5, 6, 37 .

sūria. I 3. I. 32,$58 ; 2.7$ (mss. sú-), I9*, 22*, 23*, 29*. I7.6, 7. I9.65. I. 
súryam. I. 22. I. 2. 10. 8. 331 . 7. 4. 20. 7 ; 40. 7. 6. 62.3. 8.6. 12. I0. IO. 25 I I. 6. I. I 3. I. 25,3 ), $56 ; 2.2,32$. 18. 2. $7^{*}$. I9. I $8.5 ; 27$. 7. 20. I2S. I.

súriam. I. $3.5 ; 6.3^{*} ; 3$ I. 4. 3. 20. $4^{*}$. 6. 60.3. 7. 38. $3 ; 53.7^{*} ; 109$. 3. 8. $4.24^{*} ; 5.6$. 9. 10. $3^{*}$. 12. 2 . 18. I3. 1. $35 ; 2.16 ", 43$. 14. 2. 34. I8. 2. $18^{* \prime}$ 50. 20. I 30. Io (mss. -as). sûryeṇa. $4 \cdot 36.5$. I2. I. 33. I 4. I. $1^{*}$, súrieṇa. 4. I8. I. I0. IO. I5. I9. 26. 2. súryāya. 6. 10. 3. I9. 32.8 (mss. sūryâ-; ed. çūdráya); 43. 3 .

súriãya. I8. 2. 13*, 46 .

súryāt. 5. 10. 8. 8.2.3; 6.24. 10. 7.3I. sứryasya. 4.38 .5 . 6. $105.3 ; 108$. I, 5. 7. 82. 5; 107. I. 8. I. I, 4. 9. 9. I4". I0. 5. 37 . I3. I. 24. I 5. 6. 2. 18. I. 10". 19.27.5. [II. I. 16.9.3. súriasya. 3. $16.4^{*} ; 22.4$. 7. 5.3: sutrye. II. 5. I3. I8. I. $35^{*}$. súrie. 1. $4.2^{*}$. 6. $3^{8.1}$. I0. 4. 22. súryās. i 3. 3. 10.

súryān. I9. 27.4.

(cf. anusúrya, otsūryá, súryaketu-sūryāmāsá.)

súrya。ketu: -tavas. 5. 2 I. I2. sú ry a ot ejas: -jās. I0. 5. 27.

$\mathbf{s}$ tú $\mathbf{y}$ a ot vac: súriatvak. 2. 2. 2. súriatvacam. I4. I. $4 \mathrm{I}^{*}$.

sú ry a ot va cas: -asas. I. 26. 3 .

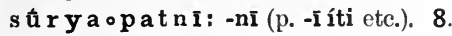
9. I2.

súrya ovant: -vatas. 9. 5. I8. s ū y a va rcas in sāuryavarcasá. s ĩ r y a o va r ṇa : súryavarṇe. 5. 5.6. sūrya oçrít: sūriaçrítas. 6. 49. $3^{\dagger}$. s ū ryă : I4. I. 12*; 2. 30, 32 .

sūriă. 14. 1. 6*, 10*.

sūrye. I4. I, 6I*.

sūrie. I4. I. I6* (mss. súrye).

sūryấm. I 4. I. $9^{*}, 53 ;$ 2. I".

sūriấm. 6. 82. 2. I4. I. $15^{*}, 29^{*}$.

sūriâyaai. I 4. 2. 46".

$\left[28^{*}\right.$.

sūryấyās. 9. 4. I4. I4. I. $7^{*}, 8^{*}, 13^{*}$, sūriâyãs. I2. I. 24. I4. I. $14^{*}, 55^{*}$. sūryăbhyām. I9. 23. 24. s ũ r yācandramása: -sãu. 8. 2. 15. I1. 3. $2 ; 65$.

sũryācandramásãbhyăm. 6. 128 . 3 (1. -bhiām). II. 3. 34 (mss. -masăbhyăm).

s ū r y ã mā 8 á: -sáyos. 3.29. 5. sũryāmãsăya. 13.2.12 (? mss. sûryã mằsāya).

$\mathbf{s u} \mathbf{v}$ a $\mathbf{n}$ in bahusâvan.

s ū sุa ṇa ã: -ṇe. I. II. 3 .

sū şás: suouşăs. I6. 4. 2.

s ū şă: I. II. 3 .

V s ṛ: sísratām. I. II. I.

sasrúșis. 6. 23. $I^{2}$.

sarşat. 4. II. 3 .

(cf. sará, saraṇyú, sarámã ?, saras, sarít, sáru?, sắra, ș̣t, sṛtí, srrtya.)

+ a ti: cf. atisará.

[ran?).

$+\overline{\mathbf{a}}$ : ăsaran. 20. 136.5 (mss. anāsa-

+ u d: út... sarişyatha. 3. 9. 5 .

+ pari: pári... asaran. 2. I4. 6 . pári ... sasratus. 6.67. I.

+ puras: cf. purahsará.

+ pra: prá ... sisrate. I 3. $2.46^{*}$. praosársrānam: 6. 39. I.

+ prati: ef. pratisará.

+ vi: ví... asaran. 3. 31. 3 .

s ṛ ká: -ám. 7.84.3*.

ṣ̛́kv a n: -vāṇam. 9. 10. $6^{*}$.

$\checkmark$ s r j: srrjante. I3. I. 25.

sṛjá. 5. 16. 1-10 8. 2.7.

srjat. 8. 4. $20^{*}$.

asrijata. 8. 5. I4. II. 3. 53. I9. 53. 6, ásṛjanta. I. I3.4. 3. 28. I.

sárjatas. 5.30 .5 .

sasrjjé. I0. 7.8 . I9. $9.3,4,5$.

saşrje. 2. 29. 7 .

sṛștás. IO. $2.28^{2}$ (-tắ3s).

sṛșțâ. I 2. 5. I.

sṛșțám. 4. 15.6.

sṛșțằs. 8. $3 \cdot \mathrm{I}^{\dagger}$.

(cf. sárga, sarjana, sṛj, sṛșța, sŕ̛ṣți, srașț̣, sráj.) [ [ . 1.

+ a ti : áti sṛjāmi. I0. 5. 15-21. I6. áti ... sṛjāmi. I6. I. 7 .

áti srija. 15. 12. 2.

áti ... sruantu. 4. I6. 6. 
atiosrijét. I5. 12. $3^{2}$.

átiosrșțtas. I5. 12.4, 7. I6. I. I. átiosrișțās. I6. I. I.

(cf. ánatisrșța.)

+ abhyati: abhyátișrjāmas (p. abhioát-). I0. 5. 15-21. I6. I. 5.

+ abhi: abhí ... srrjánti. 4. 27. 4. abhí srās. II. 2. 19.

+ a va: áva srja. I 8. 2. 10*. áva srjjā (p. -ja). 5.27. II. [26. I. áva... srja. I. II. 3. 4. 15. I2. 6. avắsṛjat (p. avaoás-). I4. I. 13*. avăsrạjan (do.). 4. 6. 7.

áva ... asṛkșata. I 4. 2.52.

ávaosṛșțā. I. 3. 9. 3. I9. $8^{*}$.

ávaosṛșțām. I4. 2. 53-8.

ávaoș̣șțās. I 7.28 (p. -țā).

(cf. avasárjana.)

+ abhyava: abhyávasrijāmi (p. abhioáv-). I6. I 6. [5.12.10*. + upāva: upắvasrija (p. upaoáv-).

$+\mathrm{u} d$ : út srijate. 6. 36. 2.

út srjatā (p. -ta). 12. 3. 46 .

+ up a: ef. upasarga.

+ nis: níh ... asrujan. 2. Io. 8.

+ pari: páriosrșțam. 8. 6. 20. [-to).

+ pra: prá srjate. 20. 136. 12 (mss. prá ... ásrāșțam. 4. 28. 4 (mss. -tram).

+ vi: ví sṛjatām. I2. I. IO.

ví srāșțam. II. 2. I.

ví áș̦șța. I8. I. 39*.

víoș̣șțās. 2. 3.6. 4. I5. 16.

viosṛjyámānāyāi. 6. 90.3.

(cf. visairgá, visárjana, vísṛști.)

+ s a m: sám ... sṛjāmi. 12. 2. 32, 55 . samosṛjáti. 4. 24.7. [-jāti). sám sṛjati. I0. IO. 24. I9. 26. 2 (ed. sám ... srujati. 7. 50. $6^{*}$.

sám ... sṛjáthas. 4. $25 \cdot 4$.

sám sṛjāmasi. 3. I4. I, 5. I 4. 2. 53-8. samosrijánti. 4.27.5.

sám srọjanti. I 9. 27. 7 (mss. -jati). sám ș̣jāti. 6. I16.2. I9. 33. I. sám srija. 3. 10. 3,8 . 5. $28.4 ; 30$. 14. 6. 5.2. 7. 89. I*. 9. I. I4. II. 9. 12. 12. 1. 25 .

sám... ș̣ja. 6. 5. 1. 7. 89. 2. sám ... sṛjā (p. -ja). 5. 2. $3^{*}$.

sám ... srijatu. 2. 35. 2. 3. I4. 2.

14. I. 34. I 9. 3I. 2 (mss. sá mā sṛj-). sám... srajatam. 4. 28. 7.

sám srijantu. 6. ıog. 3. [37.

sám ... sṛjethām. 12. 3. 39. I4. 2.

sám srās. II 2. 26.

sám srijyante. 12. 2. 39 .

sámosṛșțam. 4. 3r. $7^{*}$.

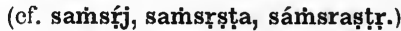
s r $\mathbf{j}$ in viçvasí́j, samsín.j.

s ŕñ j a y a (p. sị́noj-): -yās. 5. I9. I. s ṛnit: -ṇiás. 3. 17. 2*.

s r $\mathbf{t}$ in ádārasṛt.

sríi: - -ím. I0. 3. 6 .

s r ty a in sindhusiŕtya.

V s r p : sárpat. I2. I. 46.

sárpantam. 4. 20. 7 .

(cf. sarīsṭpá, sarpá, sarpa, sarpana, sarpís.)

+ a ti: atiosárpati. 4. 20. 9. atiosárpāt. 4. I6. 4.

+ anu: anuosárpati. 9. 8. 7 . anuosárpanti. 9.8. 7 .

(cf. anusarpa.)

+ abhi: abhí sarpa. 3. 25.4 .

+ a va: áva sarpantu. II. I. I 7 .

ávā 'sṛpat. I9. 44. 7.

áva sṛpas. 8.6. 3 .

+ u d: út sṛpat. 6. I34.2.

+ up a: úpa sarpa. I 8. 3. $49^{*}$.

úpa sarpantu. 5. II. 6.

upaosárpatas. 7.56. 5.

úpa sṛpas. 8.6.3.

úpa sṛpat. I2. I. 46 .

(cf. sūpasarpaṇá.)

+ nis: niḥosípya. II. I. 25.

+ pari: pariosárpati. 5.23. $3^{2}$.

pariosárpanti. 8.6. 24.

+ pra: praosárpasi. 4. 9. $4^{\dagger}$.

praosárpatas. 8.6. 22.

+ vi: ví... sarpata. I 8 . I. $55^{*}$.

vioásarpas. I2. I. 55 .

sṛșța in ánatisrșța, prajấpatisrșsța, samsrstajít.

sứṣti : -țyā. 3. 28. I.

sứșțis. I3. I. 25.

s ec an a in upasécana, nișécana. 
sedí: -ís. 2. I4. 3. 8. 8.9 I2. 5.24. sedím. 4. I I. IO. 8. 8. I8.

sedha in goședhá.

sénā: 3. 2.6. 4. I9.2. I I. IO. 4, 25. 15. 9. 2 .

sénām. 3. I. I, 5,6 . 8. 8. 2, 5, I3, I4, I5, I7, I8. II. 9.5 ; I0. 13 .

sénayā. 3. I9. 6. 6. 93. I. 8.8.7. I1. 9. 4, 5, 6, I9; 10. 5, 6, 7, 18, 2 I. sénāyās. 8. 8. I. I 5. 9. 3 .

sénāyām. 5. 31. 7.

sénās. 5. 21.9. 6.67. I. 8. 8. I. II. 9. 3 ; 10. 20 . 19. 13. $2^{*}, 7^{*} ;$ I5. 2.

sénābhis. 6. 66. I.

sénābhyas. II. 2. 3 I.

(cf. amitrasenă, devasenă, dhrsnúușeṇa, sénya, senānt.)

sen $\bar{a} \circ \mathrm{n} \mathbf{1}$ : -is. 4. 3I. 2*.

sén y a: -nias. I. 20.2. 6. 99. 2. sényam. I $8.1 .40^{+}$.

s e y a in çataséya.

$\checkmark$ sev: sevasva. 5.30 .5 .

+ ni : ní șevate (p. se-). I I. 8. 33 .

séhu: -hos. 7. 76. I.

sāind havá: -ám. 19. 39. 2.

s6bhari: I8. 3. I5.

s $6 \mathrm{ma}$ : -as. I. $6.2^{*} ; 29.3^{*}$. 2. 10. 2 ; 36. 3. 3. 3.3 ; $15.6 ; 27.4$. 5. I7. $2^{*}$; 18. 6, I4；21. I1；22. I； 24. 7; 26. I0; 29. I0. 6. 3.2; 5.3; 15. 3 ; $21.2 ; 39.3$; 40. I ; 5 I. I ; 53. I ; 73. I; $87.3^{*} ; 96.3 ; 97.1$; 104. 3. 7. 18. 2 ; II 4.2 ; I I8. I*. 8. I. $2 ; 4.9^{*}$, I2*, I $3^{*} ; 5.5 ; 7.20 ; 10.25$. 9. I. II, I , 13; $2.13 ; 7.2,22$; IO. 14 *. IO. I. 22 ; 4. $26 ; 6.8$; 10. 7. I1. $5.14 ; 6.7 ; 8$. 8, 9. I2. 3. $9,24,3$ I. I4. I. I*, $2^{*}, 9^{*}$, 49,54 ; 2. $4^{*}$. I5. 2.4 ; I4. 4 . I6. 9. 2. I8. $2 . \mathrm{I}^{\dagger}, \mathrm{I}^{*} ; 3.28,55^{*} ; 4.60^{*}$. I9. 10. $7^{*} ;$ I3. $9^{*} ;$ I 7. 3 ; I9. 5 ; 20. I ; $24.8 ; 27.2 ; 43.5^{2} ; 45.8 ; 58.2$; 59. $2^{*}$ (mss. sómasya).

sóma. 6. 99. 3. I I. I. 26.

soma. I. 20. I. 5. 3. $7^{*}$. 6. 6. $2,3^{\dagger}$; 7. I, 2. 8. 4. $25^{*}$. 9.9. $19^{*}$. I $4 \cdot 1 \cdot 4^{\dagger}, 5^{*}$. sómam. 2. 5. $7^{*}$. 3. 8. 3 ; I6. I*; 20. $4^{*}$. 4. 6. 1 ; 30. $6^{*}$; 40.4 (mss. somám). 6. 2. $1,3^{*}$. 7. I4. 4 ; 38. 3 ;
58. $1^{*} ; 76.6^{*} ; 94.1^{*} ; 97.1^{*}$ 10. 2. 19; 7.36 ; 10. $3,9,12,32$. I2. 1. 38 . I3. I. 2,27 . 14. I. $3^{2 *}$. 19. 18. $3 ; 24$. 3. 20. $2 . \mathrm{I}-4$.

sómena. $5.7 .5 ; 17.5^{\circ}$. 6. 89. 1. 9. 4. 6. I O. IO. I3. II. I. 25. I4. I. $2^{2 *}$. 18.3 .8 . $19.39 .5-8$.

sómāya. 2. 13.2. 12. 3. 58 . I5. 2. 4. I8. 4. 72. 19. 43. 5 .

sómāt. 4 10. 6 (mss -mã). I r. . . 9. sómasya. 2. 5.3. 3. 5.4. 4.4.5; 21. $5^{*}$. 5.4. $7 ; 28.6 ; 29.13 .6 .68$. I, 3. 7. 58.2"; 81.3. 9. 4. 5, 15. 10. 5.9. II. I. I8. I 4. I. $4^{*}$; 2. $3^{\dagger}$. I5. 2. 4. I9. 6. 16

sóme. 3. 21.2 .

(cf. agníşóma, agnīşomá, índrāsóma, sāúmya, sómakāma-somyá.)

s $6 \mathbf{m}$ a kām a: -as. 20. 34. 17 . s $\circ \mathrm{ma} \circ \mathrm{j}$ à : -ầs. 4. 3. 7 .

só m a oj uşț a: -am. 2.36. 2.

s $6 \mathrm{~m}$ a $\circ$ te j a s: -jās. I 0.5 .32

soma $\circ \mathrm{dhắn}$ a: -as. 7. III. I. 9. I.6.

som a $\circ \mathrm{pá}, \mathrm{s} \circ \mathrm{m}$ a $\circ \mathrm{pá}$ : -pâs. I. 21 . I". 8. 5.22. I9. I 3.4 ".

somapa. 1. 8. 3. 2. 12. 3 .

somapăs (pl.). 5. 25. 9 .

sómapãs. 18. 3.64.

somapăn. 2. $35 \cdot 3$.

[3. 64 . soma $\circ \mathbf{p a ̄ y}$ in: sómapãyinas. 18. s o ma opàva n: -vne. 6. 2. $3^{*}$ (l. -vane).

sóm a॰piti: -taye. I7. 10.

soma p pithá: -ám. I8. 3.46*.

somapithé. I0. 3. 21 .

s om a ॰p utra: sómaputre. 3. I0. 13.

s $6 \mathrm{~m}$ a $\circ$ pṛ țh a: -as. I3. I. I2.

sómaprṣțhā. 7. 27. 1 .

sómaprșțhāya. 3. 21. 6".

sómaprșțhās. 3. 2I. Io.

s o m a $\circ$ y $\mathrm{g}$ á: -gāís. I I. 5.4 .

$\mathrm{s} 6 \mathbf{m}$ a $\circ \mathrm{r} \bar{a}$ j a n : -jñîs. 6. g6. I". 8. I. I 7 . s $6 \mathbf{m}$ a va n t: -vadobhyas. 18. 4.73.

s $6 \mathrm{~m} \mathrm{a} \circ \mathrm{v}$ arc a s: -asas. I4. I. 32.

s $6 \mathrm{ma} \circ$ çit a: -am. 8. 4. $19^{*}$.

s ó m a ○ çreşț ha: -țhāni. II. 6. I 5 . somasátosaru: 3. 17.3 . 
s o mā r u d ra : sómārudrāu. 5. 6. 5-7. sómārudrā. 7. 42. I", 2*.

so mín: -ínas. I3. I. 59*.

somínas (pl.). 4. 24. 5 .

so m y á: -miám. 3. I4.3. 9.3. 19. I8. 3. I9.

somyăs. 9.5. I 5 .

somiầsas. I 8. 1. $44^{*}, 58^{*} ; 3$. 10, $45^{*}$; 4. 62, 63 .

sómiāsas. 2. I2. 5 .

somiébhis. $4 \cdot 34 \cdot 3$.

somiănām. I8. 3. $53^{*}$.

sāutrām a ṇá: -ṇyấ. 3. 3. 2.

sāú parna: -am. I6. 2.5.

sāuprajāstvá (p. -āḥotv-): -ám.

2. 29.3 .

s āú b h a g a : -am. 2. 36. I. 6. I IO. I*. sāúbhagāya. I. 18. 2. 2. 6. 2. 3. I2. $2 . \quad 4.8 .7$ 5. 2 S. I $4 . \quad 7.16 .1$; 35. I; 73. $8^{*}, 10^{*}$. I 4. 2. 30. I7. 9 (cf. sāubhagatvá.)

sā u b ha g a ot vá : -tvấya. I4. I. 50*. s ā ú b hā g y a m: -giam. I4. I. 42; 2 . $28^{*}$.

s ā u ma n as á: -ás. 3. 30. 7. 7. 60. 3 . sāumanasám. I3. I. I9: I4. I. 42. sāumanasásya. I9. $55 \cdot 3,4$. [I. $58^{*}$. sāumanasé. 6. 55. 3*. 7. 92. I*. I8. s ā ú m y a: -yena. I9. 45. 8 .

s ā u r ya。varcasá: -ás. 8. Io. $27^{2}$. $V$ sk a nd: caskanda. I8. 4. $28^{*}$ (p. ca sk-).

(cf. skanda.)

+ a d hi: ádhi skanda. 5. 25. 8. ádhy askandat. 10. 10. 16 .

+ abhi: abhioskándan. 5. I4. II (? mss. ed. -dam).

abhiocaskánda. 7. II5. 2.

+ pari: cf. parișkandá.

s k a n d a iu abhiskánda, parișkandá.

sk a n dhá : -dhăs. 9. 7.3. I 0. 9. 20.

skandhẳn. 6. I35. I. I0. 2. 4. I2.5.67.

(cf. víșkandha, sámìskandha, skándhya, skándhas ?.)

skándhas: I0. 7. 38 .

skándh y. a : -dhiās. 6. 25.3.

$\checkmark \mathbf{s k a b h}, \mathbf{s k a b h a ̄ y : ~ c a s k a b h a ̄ n e ́ ~}$ (p. -é íti). 4. 2. $3^{\dagger}$. skabhità. 7.25 .1 .

áskabhāyat. 7. 26. I*.

askabhāyat. 4. 1. 4. 9. 10. $3^{\dagger}$.

(cf. skambhá, $\sqrt{ }$ stabh.)

+ a p a: ef. apaskambhá.

+ vi: ví... áskabhāyat. 4. I. 4 .

skambhá: -ás. 4. 1. $6^{*}$ 10. 7.8 , $9^{2}, 26,28,35^{3}$.

skambhám. Io. $7 \cdot 4-7,10-6,17,18$ 20, 22, 29, 39 .

skambhéna. ro. 8. 2.

skambhásya. ro. 7.2 (1. -sia ?), 25 , skambhé. Io. $7.29^{3}, 30,35 ; 8.2$.

(cf. apaskambhá.)

$\mathbf{s} \mathbf{k}$ a $\mathbf{v}$ in avaskavá.

Vsku: + ava: cf. avaskavá.

$+\overline{\mathbf{a}}$ : āoskunóti. I2. 4. 6 .

$\checkmark$ s t a n: astānīt. 5. 20. 2.

stanáyati. 8. 7.21. 9. I. 24.

stanayati. I3. 4. 4I.

stanáya. 4. 15.6. 5.20.7.

stanáyan. I. I2. I. 9.6.47. II. 5. I2.

(cf. stanáthu, stanayitnú.)

+ a b hi : abhí ștana (p. sta-).6. 126. $2^{\dagger}$. abhí tañstanīhi. 5. 20. I.

stána: -as. 7. I0. $\mathrm{I}^{*}$.

stánāu. 8. IO. I3. 9. 1. 7. I0. 2. 4. stánās. 9. 7. 14. 10. 9.22 ; 10. 7 .

stánān. 12. 4. 18 .

stánebhyas. I0. IO. 20.

(cf. $/$ stanasy.)

st a náth u: thos. 5. 21.6. 8. 7. 15.

st a n y itnú: -ús. 7. II. I. 9. I.

IO, 20; 7. 14. II. 7.20. I5. 2.4.

stanayitnúnā. 4. I5. II*. II. 4. 3.

stanayitnáve. I. I3. I. II. 4. 2.

stanayitnún. 9. 2. 15 .

$\checkmark$ stanasy in

s t a n a y ú: -úm. I2. 3. 37.

s t a p (?) in vișțap.

V s t a bh: stabhăná. 9. 5. I 5 .

ástabhnāt. 4. 35. 2. 19.32. 9 .

tastámbha. 6. 85.3.

stabdhvâ. ro. 7. 7 .

stabhitám. I3. I. 7 .

(cf. stambha, $\sqrt{ }$ skabh.)

+ u d: út ... stabhnāmi. I 8. 3. $52^{*}$ úttabhitā. I4. I. $\mathrm{I}^{2 *}$. 
+ u pa: úpa tastabhus. I0. $7 \cdot 44^{\dagger} \cdot[25$.

+ vi: vișțabhnăti (p. viosta-). I3. I. ví ... tastámbha. 9. 9. 7 ".

víșțabhitas (p. víosta-). II 2.23.

víșțabhite ( $\mathrm{p}$. vístabhite íti víos-). I0. 8. 2 .

(cf. vișțambhá.)

st a m bá: -bé. 8.6. I4.

(cf. stambajá, stambín.)

s t a m ba ॰já: -ás. 8. 6. 5.

st a mbín: -ínis. 8. 7. 4 .

[bhá.

st a mb ha in divișțambhá, vișțamst ara in upastára, prastará.

staraṇa in āstárana, upastáraṇa, paristárana, prastaraṇa.

stāmán: -mânam. 5. 13. 5.

stāyánt: -át. 4. 16. 1. 7. 108. I.

st $\mathbf{a} \mathbf{r a}$ in vīrastăra, stārin?.

stārin in vișțārín.

s t $\mathbf{a} \mathbf{v} \mathbf{a}$ in ghṛtastáva.

$V$ s ti in stāyánt, stená, stéya.

$\mathrm{s}$ ti in abhíști, upastí.

$\checkmark$ stĩ, st y ā: ef. stīmá, stīmin.

+ vi: ef. vișțīmín.

stĩmá : -măsu. I I. 8.34.

(cf. vișțīmá, stîmin.)

sti m in in viștịimín.

Vs tu : stāúmi. 4. 23-29. 7 .

stávāma. I3. 2.2.

stuhí. 6. I. I. I8. I. $40^{*}$.

stuhi. 6. I. 2.

stușvá. 5. 2. $7^{\dagger}$.

stuvatām. I. 8. I.

stuván. 4. 28. 3 .

stuvaté. 5. I I. I I (mss. -te), 20. 135 .

stuvānás. I. 8.2.

stuvānám. I. 7. I.

stuvānásya. I. 8. 3 .

stávānas. I8. I. 40*.

ástoșata. I8. 4. $6 \mathrm{I}^{*}$.

stuşé. I8. I. $37^{*}$.

stavişyate. 20. 127. 1.

stavișyámāṇas. 20. 34. 16 (mss.)

stutuâ. 9. 2. 2.

stutám. II. $7 \cdot 5$.

[ma.)

(cf. stuta, stuti, stotṛ́, stotrá, stó-

+ abhi: abhí șțuhi. 20. 49. $2^{2}$ (not mss.), 3 (do.). abhíşțutas (p. -ístu-). 9. 2. 1.

abhíșțutās (do.) 8. 7. I1.

+ upa: úpa... stumas. 3. $15 \cdot 7$.

úpaostutas. I9. $5 . \mathrm{I}^{*}$.

+ pra: prá stāuti. 9. 6. 45-8.

prá stāutu. I3. 1.27.

prá...stavate. 7.26. 2".

práostutam. II. 7.5.

+ s a m: sám stãutu. 9. 4. I1.

sám ... stuşvá. 5.27.

st úkā: -ām. 7. 74. 2.

(cf. prothușţuka, sahásrastuka.)

s tut a in ŕşișțuta, purușțutá.

st uti in sușțutí.

s t u pa in vísiitastupa.

$\checkmark$ s t u b h : ef. stubh.

+ anu: cf. anuşțúbh.

s t u b h in anușțúbh, trișțúbh.

V stṛ: stṛnāmi. I 8. 4.5 r.

stṛnạāmahāi. I0. $5 \cdot 42$.

stṛnita. 12. 3. 32. [tastiré).

tastriré. I9. 46. 3 (mss. tasthiré,

strusiya. 10. 5. 15-21 (s. mss. striş-).

stīrnám. I2. 3. 33.

stárítave. 2. 27.3,4. [strita.)

(cf. stara, staraṇa, stāra, stārin, + ā: cf. āstárana.

+ u pa: upaostṛnīthána. I 4. 2. 22. upaostṛ̣ánti. 9. 6.8.

úpa stṛ̣inihi. I2. 3. 37. I4. 2. 23.

úpā 'starīs. I2. 3. 38 .

(cf. upastára, upastáraṇa.)

$+n$ is: cf. ániṣțtrta.

+ pari: pári stṛ̣ịihi. 7.99. I.

(cf. paristáraṇa.)

+ pra: praostṛnatís. 8. 7. 4 .

(cf. prastará, prastaranaa.)

+ vi : cf. vișțārín.

s tṛ t a in ástṛta, astṛtá, ánișț̣̂ta.

s te gá: -ás. I8. I. $39^{*}$.

stená: -ás. 4. 3. $5 ; 2: 7^{*}$. 8. 4. $10^{*}$.

I9. $47.6,7 ; 49.7,9$. 20. 1 27.13 .

stenám. 4. 3. 4 . I 9.47 .9 (mss. té-

na); 5 o. I (do.), 5 .

stenāís. $4 \cdot 36.7$.

(cf. vācăstena.)

st é y a: -am. II. 8. 20. I4. I. 57.

(cf. steyakṛ̂t.) 
steyaokṛt: 8. 4. $10^{*}$.

stoká: -ás. 6. I24. I.

stokăs. $4 \cdot 38.5$. $\quad$ 12. 3. 28.

stokăn. 2. 35. 2.

stotṛ: :túr. 6. 2. I.

stotăras. $7 \cdot 9 \cdot 3^{*}$. I9. 48.4

stotŕobhyas. I $8.4 .88^{*}$.

s totrá: -ám. 5. II. 8.

stotrắni. 5. I1.9.

stóm a: -am. 6. 35.3. 7.50. 3". I7.

II. I9. 27.3 .

stómasya. I9. 49. 5,6. [I. $\delta^{*}$.

stómās. 4. 24. I. 8. 9. 6, I9. I4.

stómeșu. 8. 9. I9.

(cf. agnișțomá, stómatașța.)

s tó m a ot a ș ț a : -țāsas. I 8. 3.47*.

strí: 1. 8. 1. 5. 14.6. 7.95.3. 10. 4 .

$8 ; 8.27$.

stríyam. 8. $4 \cdot 24^{*} ; 69,16,25$.

striyāí. 5. 30.3.

striyấs. 5. I7. 8. I2. 2. 39 .

striyắm. 6. I1. 2 ; 70. I-3.

stríyas. 4. 5. $2,3^{*} ; 37.11$. 6. 138 .

5. 9. 9. $15^{*}$.

strịnăm. 7. 13. 1. 8. 6. 13.

strīşú. 6. I I. 1. 7. 90. 3. 12. I. 25.

(cf. stríkṛta-strāíșûya.)

stríkrta: -tā. ro. I. 3 .

strî́bhāga: -gãn. 8. 6. I9.

strīs ū y a in strāíșūya.

strāína: -am. 4. 34.2. 8.6.4.

(cf. astrāiná.)

strāíș y y a: -am. 6. II. 3.

sth a in apāșțhá, avasthá, svăsastha, upástha, goșțhá, páthișțha, sadhástha, sthapáti ; cf. sthā.

sthapáti: -is. 2. 32.4 .

sthávira: -as. 9.4.3. 19. 13. $5^{*}$. sthávirasya. 19. 15.4".

sthávirāu. I9. 13. I.

V sthã : tiṣţhasi. 9. 3. I7. I4. I. $5^{*}$. I5. 3. I.

tíșthati. I. I6. 2. 4. 16. 2. 6. I38. 4. 7. 20. 6. IO. 8. II. II. 2.23 .

tișțhati. I0. 7. I, $3^{4}$. I9. 39. 5-8.

tíșțhatas. 6: I27.2. II. IO. II.

tișțhatas. I0. 8.2. [I. 27.

tíșțhanti. 4. 16.6. 10. 7. 12, I6. 12. tișțhanti. 9. I0. $17^{*}$. I4. I. I*. 18. I. $9^{*}$ 20. I3I. I4 (mss. -ati).

tișțhe. 9. I. 24.

tișțhāsi. I9. 45.4

tișțhāti. 3. I2. I.

tíșţhāt. I. I7.2. 6. 44. I.

tisstha. I. I7. $2^{2}$.

tíșțhā (p. -tha). 4. 7.5.

tiștha. I. I7.2. 6. $87 . \mathrm{I}^{*}, 2^{*}$.

tișțhatu. I. 15.2. I8. 3. $5 \mathrm{I}^{*}$.

tíșțhata. I. I7. 4*.

tíșțhantu. I. I7. I.

tísthan. 4. 5. $5^{\dagger}$. 7. IO2. I. 9. 7. $20^{2}$, $2 \mathrm{I}^{2}$. I2. 2. 49. I 9. 46.2 (mss. -anta). tíșţhantam. 8. 3. $5^{*}$. I0. 7. 4I. I I. I. 36 20. I33. 4 (mss. -nteva).

tísțhate. 3. I5. 8. II. 2. I 5; 4. 7.

I 9. $55.1,7$.

tíșţhatas. 9. 2.23.

tíșțhantas. 7.60.2. 12. 1. 28.

tísțhatas. 7. 108. 2.

átișțhas. I0. I0. I6.

átișthat. 9. 9. $9^{*}$.

atisthat. 8. I0. 8. I I. 5. 26. I5. 3. I.

átișțhan. 5.27.6. 10. 8.39.

tișțhas. 8. 1.9. I0. 1. 26.

tasthãu. 5. 1. $6^{*}$. 9.9. 10*. 10. 8. $3^{*}, 40^{*}, 42^{*}$.

tasthathus. I4. I. I4*.

tasthișe. 4. 9. 2.

tasthe. 5. $17.3^{*}$.

tasthiovầnsam. 4. 8. 7 .

tasthúșas. I3. 2. $35^{*}$.

ásthāt. 2. $34 \cdot 2.6 .44 \cdot \mathrm{I}^{3} ; 77 \cdot \mathrm{I}^{3}$.

ásthus. I. I7.3. 6. 44. I.

asthus. 6. 77. 1. 7.96.1. [96.1. atișțhipam. 6. 77. I (p. atisthi-). 7.

(cf. stha, sthā, sthávira?, sthānú ?, sthātṛ́, sthātra, sthāna, sthăman, sthālí, s' hita, sthin, sthirá, sthựnā?, sthūri?, sthūlá?.)

+ a ti: áty atișțhat. 19. 6. I*. atișțhăyā (p. atiostháya). 19. 33. 5 . (cf. atisthăvant.)

+ a dhi : adhiotísțhati. I0. 8. I.

ádhi tișţhati. I0. 7. I.

ádhi tișțhatas. I9. 54. 5 .

ádhi tișțha. 12. 3. 1. 13. 2.7. 
ádhi tişțhatu. 2. 14.4. adhiotíşțan. I3. 2. 31 . ádhy aşţhām (p. asth-). I2. I. II. ádhy așţhăt (do.). I0. 10. 13. ádhi ... asthāt. I3. I. II. ádhi tasthús. 9. 9. 2*. 14. 2.9. ádhi ... tasthus. 9.9. $3^{*}$.

(cf. adhişțhătŕ, adhișțhăna.)

+ a nu: ánu tişţhati. I 5. 5. :-7.

ánu tișțhatas. 15. 4. 1-6.

anuotíșţhanti. II. 10. 27. I9. 48.5 .

ánu tișțhatu. II. 4. 24 .

ánu tișțhase. I7. I6.

anuotíșthate. 9.6.54.

ánu ... ásthāt. 20. 34 . 16 (not mss.). (cf. anuṣţhātŕ.)

+ antar: antás tíșțhati. I. 2. 4 . antás tişțhatu. I. 2.4 . antás tișțhāti. 6. 53. 2. antáh sthus. I3. I. $59^{*}$.

+ a p a : cf. apāșțhá.

+ a pi: ápy atișțhat. 3. I3. 4. ápi șțhāta (p. sthā-). 5. 13. 5.

+ a bhi : abhí tișţhāmi. 6. 42. 3. [5. abhí tișța. 5. 8.9. 7. 73. 10". 19. 46. abhí ... tiștha. 1. 29. $2^{*}$.

abhy àșțhām (p. asth-). 10. 5. 36 . I6. 9. I.

[20. $135 \cdot 3$

abhíșthitas (p. -ísthi-). 5. I4. IO

+ a v a: avaotísțhati. 6. 43.2. 7.76.3. (cf. avasthá.)

+ ã : à tișthati. II. 5 . II.

à tiștha. 2. I3. 4. 4. 8. 2. I4. I. 47 . 19. $13.5^{*}$.

āotíșţhantam. 4. 8. 3*.

ãotíșthantas. 5. 1. 4 .

à ... tasthāu. 4. 8. $3^{*}$.

āotasthátus. 7. I I0. 2.

āotasthús. 9. $9 . \mathrm{II}^{\dagger}, \mathrm{I}_{4}^{\dagger}$.

à... tasthus. 9. 9. I3.

ăosthitam. 4. 17.8. 6. 14.1 .

à ... sthāpayāti. 7.39. I.

à sthāpayata. $5 \cdot 2.6^{\dagger}$.

(cf. āsthātṛ́, āsthăna.)

+ pratyā: pratyātíșţhantī (p. -tio ātí-). 5.5.3.

+ u d : út tișțha. 4. 12.6; 14. 9. 10. I. 20. II. I. I4; $9.5,6$; IO. 5 . I4.
2. $19^{2}, 33^{\dagger}$. 18. 3. 8. 19.63.1. 20. 127. I1.

út ... tişțha. 2. 6. 2.

út tişţhatam. II 9. 3. [10.1. út tişțhata. 7. 72. I". II. 9.2, 26; út tişţhatā (p. -ta). 12. 2. 27.

úd atişțhat. II. 5. 5. I 5. 2. I-4.

úd atişțhatãm. I5. 10. 3 .

uttasthiovănsas. $6.93 . \mathrm{I}$.

úd asthāt. 9.9.17. 19.13.10\%.

úd asthāma. 3. 3I. II.

udoásthus. I. I6. I

út thus (p. sthus). 7.52. 2.

utthăya. 19. 31. I 2 (mss. ukthyăya). útthitas. 6. 43.2. 9. 7. 19.

útthitā. 6. 44.3 .

útthitam. 3. I5.4.

út thāpayāmasi (p. sthā-). ro. I. 29. út thāpaya (do.). I2. 3. 30.

úd atișthipam. 7.95.2.

(cf. utthătŕ.)

+ abhyud: abhyúdatișțhat (p. -bhioúd-). I5. 8.2.

+ u pa: úpa tișțhati. I2. 4. 35 . upaotísțhanti. I7. 8.

úpa tișthanti. I 3. 4. 6. I9. $5^{8} .3$. 20. 130.7 (not mss.).

úpa ... tișțhanti. 9. 7. 26.

upaotísțhante. 7. 40. I. 8. 9. 8.

úpa tișthatu. ro. 1. IO. I9. 43. 7 .

úpa tișțhantu. I0. 5.6. I8. 4. 33 .

úpa ... tișțhantu. 4. 34. 5-7.

úpa tișţ̧hatām. I8. 2.37.

upaotíșthantī. I2. 5.24.

upaotíșthamānas. 13. 3. $25^{*}$.

upaotíșțhamānām. 8. 9.8.

upătișțhas (p. upaoát-). 10. I0. 9.

úpā 'tișțhe. 2. I. 4.

úpa ... asthita. 7.27. 1 .

úpa... asthiran. 4. 25.7.

úpa stheșus. I6. 4.7 (m. mss. -șu). (cf. upástha, upasthá.)

+ ni: níșţhitas (p. níosthi-). 19.32. 3. níșthitam (do.). I4. 2.62. I9. 34. 6 .

+ $\mathrm{n}$ is: nís tișțasi. 5.5.5.

+ pari: pári șțhās (p. sthāḥ). 5. 7. I. pári ... sthāpayāmasi. $4 \cdot 7 \cdot 5$.

(cf. parișțhâ.) 
+ pra: prá ... tișthata. I8. 2. 2*. praotíșthantīm. I0. 7.21.

prá tasthāu. 4. 1. 3 .

prá ... sthāpayāmasi. $4 \cdot 7 \cdot 4$.

(cf. prasthävant.)

+ prati: práti tișthanti. 8. 9. I9. práti tișţha. 3. 12. 2. 4. 12. 6; I4. 9. 6. I23. 5. I4. 2. 15. [2. $7^{*}$. práti tișțhā (p. -șțha). 2. 34. 5. I8. práti tișthatu. 5. 30. 13. 6. 123. 5 . pratișțaáya (p. -tiosthắ-). I I. 3.49. prátișțitas (p. -tiosthi-). II. 4. I8.

I9. 52. 2 .

prátișțhitā (do.). $\quad$ 12. 5.3.

prátișțitam (do.). I0. 7. I, 30; 8 .

6. II. 4. I, I5. I7. $19^{3}$. I9. 53. 9. prátișţhitās (do.). I0. 7. 22. 19. 54. 4 . (cf. pratișțhá, pratișțhāna, pratișthita.)

+ vi: ví tișthe. 4. 30. $7^{*}$.

ví tișțhase. I9. 47. I. [5 (do.)

ví tișthate. I9. 49.2 (not mss.); 53. ví tișțhadhvam. 8. 4. I8*. I I. 9. 26. ví tișțhantām. I4. 2. 25.

ví tașthe. 9. IO. I9 (s. mss. ed. caste ${ }^{*}$; p. tasthe).

ví tașthire (p. tasthi-). 4. 6. 2.

ví āsthan (?). I3. I. 5. [I26. I*. víșthitam (p. víosthi-). 6. I7. 4 ; víșthitās (do.). 6. 90. 2. 7. II5. 4 (p. vísthitāhoiva).

víșțitā (do.). 3. 9. 6.

(cf. vișthă.)

+ s a m: sámosthitas. I8. 4. I5.

(cf. samsthita.)

s th $\mathbf{a}$ in añgeșțhá, atișțhā, rtasthă, girișțhă, páthișțhā, parișțhă prasthā, pratișthă, bhuvaneșțhă, madhyameșțhă, rayișțhá, vișțhă, savyașțhá.

s th $\mathbf{h}$ or stha in āpākesthá, upasthá.

sthānú ú: -úm. Io. 4. I. I4. 2. 6*. sthāṇāú. I4. 2. 48, 49. I9. 49. 10 (mss.).

s thātṛ́: -tré. 9. 9. I6*.

(cf. adhiṣțhātṛ, anuṣṭhātṛ́, āsthātŕ, utthātŕ.)

s thātra in bhúristhātra.
( $\mathbf{s}$ thā $\mathbf{n}$ a in adhișthắna, āsthăna, pratișțhāna, rayișțhăna.

st hă ma n : -ma. I. 32.2. 12. 4. 29, 30. sthấmni. 4. $7 \cdot 5$ (1. -mani). 6. 77.

I. $7.96 . \mathrm{I}$. (cf. yathāsthāmán.)

sthālî: -ím. 8. 6. I7. (cf. sthălīpāka.)

s thầlípāka: -as. 20. 134. 3.

sthit a in pratișthita, samsthita.

st hin in paramesthín.

sthirá: -ás. II. 7.4.

sthirám. 5. 2. $4^{*}$.

sthiréna. 6. 65.3.

sthirásya. 10. 4. I1. [dhāman.) (cf. ásthira, gavísțira, sthirásthiráodhāman: -mnas. Io. 4 . I I (l. -manas). [(mss. -ūṇăm).

s thứṇā: -ăm. 3. 12. 6 . I 8. 3. $52^{*}$ sthúne (p. -e íti). I4. 1. 63.

s th $\mathbf{u} \mathbf{r} i$ in asthūrí.

s thūlá: -ám. 20. I36. I. sthūléna. 20. 136. 2. sthūlás. I I. 8. 28.

(cf. sthūlabhá.)

st hu ù la bhá : -ám. 6. 72. 2.

snápana: -nis. I4. I. 39.

V s nā: snāhí. I9. 45. 5 .

snātás. I I. 5. 26.

snātvă. 6. 115.3.

snapayāmasi. I0. I. 9 .

snapáyanti. 5. 19. 14.

(cf. snápana, snāna.)

+ pra: práosnapitām. Io. I. Io.

s $\mathbf{n}$ ā $\mathbf{n}$ in āsnăna.

s nà̀va n: -va. II. 8. II, I2.

snăvnā. 7.50 .9 .

snăvāni. 12. 5.69.

snăvaobhyas. 2. 33.6 .

s $\mathbf{n} \mathbf{u}$ in ghṛtasnu.

snușâ: 8.6.24.

$\checkmark$ spand in paniṣpadá and [sya-). s p a d a ná: -nă. 8. 6. I7 (mss. ed. spárana : -ṇi. 5.5.3.

s p a r ça in saminsparçá.

$\checkmark$ s p a ç, see $V$ paç.

s pá ç: -ças. 4. 16.4. 5.6.3*. I8. 1. 9". s pā çan a in pratispăçana. 
V spṛ: spṛnuhi. 8. 3. $7^{*}$.

áspārșam. 3. 11.2" (mss. -rçam).

$$
\text { (cf. spáranaa.) }
$$

+ vi: ví sparat (p. spa-). 6. 56. 1. 10.

Vs pṛdh: spárdhamānā. 3. 2. 5 .

spárdhitum. 19. 22. 21.

paspṛdhāte (p. -e íti). 8. 4. 12".

ápaspṛdhethām. 7. 44. 1*.

$\checkmark$ s pŗ̣ : áspṛkşat. 6. 124. 2.

sprşțás. 2. 2. 2.

sprșța. 20. 134.4 (not mss.).

(cf. sparça, sprȩ.)

+ a p a : ef. ánapasprȩ.

+ u d: út... asprçan. 5. 19. I.

+ u p a: úpa sprçāmi. 4. 30. $7^{*}$.

úpa spŗ̧̧a. 8. 3. 2*.

úpa spŗ̧̧ata. I. 33.4. I6. I. I2. úpa sprçāt. I4. 2. 5 I.

(cf. upaspŕç.)

+ $\mathrm{s}$ a m: sám spŗ̣asva. I3. I. 34. 14 . I. $2 \mathrm{I}^{\dagger}, 40$.

sám spŗ̧̣antām. I 2. $2.3 \mathrm{I}^{\dagger} ; 3 \cdot 30$.

sám aspŗ̧̧anta. 14. 2. 32.

(cf. samsparçá.)

s pŗ̣ in ánapaspŗ̣, upaspŕç, uparispṛ́ç.

V s p hã : cf. sphāka, sphātí, sphāna. + s a m: cf. saminsphăna.

s phāka in píbasphāká.

sphātí: -ís. 2. 26. 3.

sphātím. 2. 25.3. 3. $24.3,5,7.9$. 6. 33. I9. 3 I. I, 8 (mss. -tís; m. mss. sphătis), 9 (m. mss. sphătim).

(cf. gáyasphāti, sphātimánt.)

sphātimán t: -mátotamā. 3. 24. 6.

s phān a in gayasphăna, samisphăna, parasphăna.

V s phu r: sphuráti. I3. I. 56 .

(cf. sphura, sphurant.)

+ anu: cf. anusphurá.

+ a p a: cf. ánapasphurant.

+ pra: prá sphuratam. I. 27.4.

sphura in anusphurá.

sphurant in ánapasphurant.

Vsphū rj: sphūrjáyan. 8. 3. II".

+ abhi: abhí sphūrjati. 12. 5. 20.

sphyá: -yāú. II. 3. 9.

sma. I. 8.2. 3. $17.7^{\dagger}$. 4. 4.3; I8.
4. 5. 22. $10,11^{2}$. 6. $123 \cdot 1,2^{2}$. 8. 3 . 23 . I 2. 3. $4^{6 .} \quad\left[1.33^{\circ}\right.$. smā (p. sma). 10. 4.6. 12. 3.3. 18. s m a rá: -ás. 6. 130. I. [1-5. smarám. 6 130. 1-3; 131. 1, 2; 132. $\checkmark$ s m r : smárăt. 6. 130. 3 .

smaratăt. 6. 130. $2^{2}$.

(cf. smará, smṛti.)

+ prati: práti smarethām. 8. 4. $7^{\circ}$. s m rạti in ásmŗti.

s y a d in raghuşyád.

$\checkmark$ sy and: syandate. I2.2.27.

syandadhvam. 19. 60. 2 (m. mss. syannadhvam).

syándamānās. 2. 5. 6". 3.13.3,4. sişyadús (p. sisya-). 9. 2. 20.

(cf. sanişyadá, syad, syandaná, syédu.)

[5. 9. + abhi: abhí sişyade (p. sisya-). 5 . + ā: āosyándamānās. 3. 12.3.

s y a n d a ná, see spandaná.

s y é d u: -us. I2. 1. 30 .

s yo ná: -ám. I2. I. I1. I3. 2. 7. 14. I. I9, 30, 47,61",63; 2. 12, 5 I. 18. 2. $29 ; 4.84$ I9. 6r. I. [53. sionám. 2. 10. 7. 5. 12. 4*, 8*. 18. 2. syoná. 3. 28. 2. I2. I. 59. I4. I. 64 ; 2. $17,18,26,27^{4}$. 18. 2. $19^{*}$. sionă. 3. 12. 5. 13. I. $17^{2}$. syonăm. 12. I. 17 .

sionăt. I 4. 2.43.

syonāú. 6. 140. 3 .

sioné (p. -é íti). 4. 26. 2-6.

syonăs. I2. I. 3I. I4. 2. 9. 18. 2. 21 ; 3. II.

sionás. I. 33. I-4. $4 \cdot 27 \cdot 3 \cdot 18 \cdot 3 \cdot 5 \mathrm{I}^{\dagger}$. syonăni. 8. 2. 22.

syonăn. 12. 2. 27 .

$\checkmark$ sran s : asisrasan. 7. 107. I. srańsayitvă. 4. 16. 7 (mss. ed. çrañçay-).

(cf. sanisrasá, sraṅsa, sras.)

+ vi: víosrastam. 4. 12. 3 .

ví srańsayāmi. 9. 3.2.

(cf. visrás.)

s r a ń $\mathbf{s}$ a in asthisrañsá, paruḥsrañsá.

sraktyá: -ás. 2. 11.2.

(cf. srāktyá.) 
sráj: -jam. I. I4. I. 8. 6. 26. srájas. 20. 127.3.

(cf. púṣkarasraj, susráj, háritasraj, híranyasraj.)

sravát: -tām. 6. 86. 2.

sravant in ásravant.

s r a șț ṛ in sámỏsrașț̣.

s r a s in visrás, susrás, svayaminsrás.

srāktyá: -tiás. 8. 5. 4.

srāktiám. 8.5.7.

srāktiéna. 8.5.8.

s r $\mathbf{a}$ ṇa in aruḥsrấna.

s rā má: -ás. II. 3. 45 .

(cf. ásrāma.)

s rā va in āsrāvá, samọsrāvá.

$\mathbf{s} \mathbf{r} \mathbf{v}$ a ṇ a in samsrāvana.

$\checkmark \mathrm{sridh}$ in

srídh: -dhas. 2. 6.5 (mss. ed. sựdhas).

sríma: -mās. 8. 6. Io.

Vsrīv: srīvayāmi. 6. 73.2 (mss. ed. çrīv-).

V'sru: ásravan. 7.66. I (mss. ed.). susruvus. 7. II2. I.

susros. 12. 3. 22.

susrot. I9. $58.4^{*}$.

srutăt. I3. 2. 4 (mss. stu-?).

(cf. sravát, sravant, srāva, srāvana, srut, sruvá, srotas, srotyá.;

+ abhi: abhí sravantu. I. 6. I*.

$+\overline{\mathbf{a}}$ : ầ sravati. 5. I9. 8 .

ă susrot. 2. 29.7 .

(cf. āsrāvá.)

+ pari : cf. parisrút.

+ pra: prá sravanti. 6. 24. I.

+ s a m: samosrávanti. I. I5.3, 4. sám sravantu. I. 15. I (sám sám sr-). 2. 26. 2, 3 (sám sám sr-). $\quad$ I9. I. I (do.).

sámosrutam. I. 3. 6 (mss. ed. -mçr-). sám srāvayāmasi. I. I 5. 3, 4 .

(cf. saminsrāvá, saminsrāvaṇa.)

sruk॰kārá: -réṇa. 9. 6. 22.

s rúc: srúk. 9. 6. I7.

srúcam. II. I. 24.

srucă. 6. II4.3. 9. 6. 22.

srucás. I2. 4.34 .

srúcas. 5. 27. 5. I8. 4.2 (mss. ed. srucás). I9. 42.2 (s. mss. ed. srucás). (cf. srukkārá.)

s rut in parisrút.

s ruvá: -véna. I 8. 4.6.

srotas in

s rot a s y à : -síānaam. I 9. 2. 4 .

srotyă : -tyás. 8. 7. 15. I0. I. I6. srotiâs. I. 32. 3. 4. 26 4. 6. 98. 3 .

s vá : svás. I. 23. 2.

suás. I. I9. $3^{*}$. 5.30. 2 . 7. 108. I. suá. $4 \cdot 32.5^{*}$.

svám. I0. I. 25 . I2. 4. I5. I4. I. 27*. I8. $3.38^{*}$.

suám. 4. $21.2^{*}$ 6. 49. I; 92. $3^{*}$; 107. I-4. I0. 8.24. I2. $4.3,6$. 18. I. $29^{*}$.

svắm. 5. 2. $9^{*}$. 6. 83. 4. 7.97. 5. II. 2. $29^{\dagger}$.

suăm. 6. I 10. $\mathrm{I}^{*}$. 10. 5.23.

suéna. 2. 6.4. 6. 142. I.

sváyā. 7. 3. 1.

suấya. 6. 43. I.

suăt. I4. 2. I9.

svásya. I2. 4. I0.

suâyās. 3. 28. 5. 6. I20. 3 .

sué. 2. 6.3. 3. $4.6 ; 25$. I. 7. 97.

3. 9. 4. I9. II. I. 22.

svắs. 5. I. 3. I8. I. $50^{*}$.

suás. I 0. 3. 8. I8. 2. 29; 3. 73.

svă. 2. 24. I-8. 7. 97. 4 .

suăn. 3. I9. 3. I I. 5. I 5 ; 9.8. I 8. 2. 23 (m. mss. svắm).

suébhis. 7. 52. I.

svânām. 9. 2. 14 .

(cf. svayám, svávant, svaga, svadhă, svádhiti ?, svapātí, svapă, svábhānu, svabhyasá, sváyaças - svayúj, svarăj - svarâjya, svárocis, svásara, sváhotṛ, svấvasu.)

s v a g a in ásvaga.

s vañgurí: suoañgurís. 7. 46. 2*.

Vsvaj: cf. svajá, svajiyas, svañjalya.

+ pari: pári șvaje (p. sva-). I9. x. 3 . pári șvajātāi (do.). I 8. I. $15^{\dagger}, 16^{\dagger}$. pári şvajasva (do.). 6. 8. I; I33. 5 . I4. 2. 39 . 
parişasvajé (p. -riosas-). 6. 8. I. pári șasvajāte (p. sasvajāte íti). 9. 9. $20^{*}$.

[4. 8. 7 .

parişasvajānăs (p. -riosas-). I. 2. 3 . parişváje (p. -riosv-). 14. 1. $46^{*}$.

(cf. párişvajiyas. párişvañjalya.) + s a m: sám svajasva. I2. 3. I2.

svajá: -ás. 3.27.4. 5. I4. Io.

svajám. I0. 4. I 7 .

svajăya. 6. 56.2 . I2. 3.58 .

svajásya. I0. 4. I0, 15.

$\mathbf{s} \mathbf{v}$ ajI y a $\mathbf{s}$ in párișvajiyas.

$\mathbf{s} \mathbf{v} \mathbf{a} \mathbf{j}$ a ly a in párișvañjalya.

V s v a d: svádantu. 5.12. 10*. [-áyā). svadayā (p. -ya). 5. 12. 2* (mss. svadayatu. 5. 27. II.

(cf. svātta. svădiyas, svãdú.)

svadhă: 3. 29. I. 6. 53. I; 97.2. I0. IO. I7. II. 7. I3. I 3. 4. 23. I8. 2. $52 ; 4.71-80,85$.

svádhe. 8. Io. II, 23.

svadhe. I0. IO. I 8 .

svadhăm. 2. 29. 7. 8. 10. $23^{2}$. 12. 2. 32. I 8. 4. 39. I9. 31. 3.

svadháyā. 4. 34.8. 6.96.3. 9. 10. 16*. 12. 1. $22 ; 5.3$. 13. 2. 3. I 8 . I. $45^{*}, 54^{*} ; 2.35^{*}, 35^{\dagger} ; 3.42^{*} ; 4.65^{*}$. svadhăyām. I 8. 3. 30-5.

svadhầs. 4. 1. 3. 18. 2. 20.

svadhăbhis. $7 \cdot 50.6^{\dagger}$. $8.4 .9^{*}$. 9

I0. $8^{*}$. I8. 1. $43^{*} ; 3.8 ; 4.36$. I9. Io. $3^{*} ; 49.2$.

(cf. svadhākārá-svadhăvant.)

s vadhā okã rá: -ám. I 5. I4. 7.

svadhākāréṇa. I2. 4. 32. I5. I4. 7.

s va d hà oprã ṇ a: -ṇā. Io. Io. 6. [10†.

s vadhầvant: -vān. 4. I. 7. I8. 2.

s vadhāvan. 5. II. 4, 5, II.

svadhāvas. I8. I. 26".

svadhăvat. $7 \cdot 4 \mathrm{I} .2$.

svádhāvantāu. $\quad$ 5. 9.8.

svadhăvantas. I8. $3.68 ; 4.42$.

svadhấvatis. I8. $369 ; 4.26$.

svá。dhiti: svadhite. 9. 4. 6.

svádhitim. I8.2. $35^{\dagger}$.

svádhitinā. 6. I41. 2.

svádhityā. I2. 3. 33 .

svadhvará: suoadhvarás. I 8. I. sva yamosrás: -ásas. 7. 76. 2. $\checkmark$ s va p: sváptu. $4 \cdot 5 \cdot 6^{\text {st. }}$

svápantu. $45.0^{\dagger}$.

svapán. 6. I15. 2 (mss. svápan).

svapántim. 8.6.8.

svapántas. 6. 45.2*; 96.3. [ási). svapişyămasi. I9. 47.9 (p. -yăm suptvă. ro. 3.6.

suptás. 16. 7. I0.

suptám. II. 4.25 .

suptăn. 7. 108.2.

suptănām. 7.13.2.

suptéşu. II. $4 \cdot 25^{2}$.

svāpayāmasi. 4. 5. 3*".

svāpáya. 4. 5. 2, 7.

(cf. svápna.)

+ ni : ní ... svāpayāmasi. 4. 5. I". ní șvāpayā (p. svāpaya). 4. 5.7.

svapatít: -ím. 8.6. I6. [24.

s vápas: su॰ápasas. 5. 12. 8*. 18. 3 .

(cf. 1 'svapasy.)

Vsva pas y: -yáte. I8. I. 23*.

s va०pă: suapăs. 3. 3. I.

svápna: -as. II. 8. I9. I9. 57.3 (msss. bhadráosva-).

svápna. 4. 5. 7. 19. 56 . I (mss. -nam). svapna. 6. $46.1,2^{3}$. I6. 5. I-6 $6^{3}$. I9. $56.2,6 ; 57.4^{2}$

svápnam. I0. $2.9 ; 3.6$. I9. 56.4. svápnena. I9. 56. 5 (mss. asvá-).

svápnãya. I9. 56.3 .

svápnāt. 7. 1oo. I (mss. ed. -nyāt). svápne. 7. IOI. I. 8.6.7.

(cf. asvapná, ūrdhvásvapna, bhadrásvapna, svápnamukhasvápnya.)

svápna。mukha: -khãs. 7. 100. I.

svapna y at. 5. 7.8.

s v a pnābhikára ṇa (p. -naoabh-): -nena. $4 \cdot 5 \cdot 7$.

svapneduṣvapnyá (p. -neodusva-): -ám. I6.6.9.

s vá p n y a : -nyāt. 7. Ioo. I (mss.).

(cf. dușvápnya.)

s váobhānu: -navas. I8. 4. 6r".

s và b h y a k ta: súabhyaktas. 20 . I28. 7 (mss. svabhyaktás) 


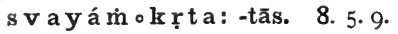
s v a yá m. 4. 30. $3^{*}$. I2. 4. 27. I 4. I.

57. I 5. II. 2 ; 12.2. [svayambhú.)

(cf. svayaminsrás, svayámlkrta,

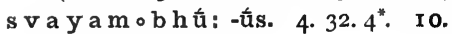

8. 44. I9. 53. IO.

svá。 y aças: -sas. I8. 3. 19. svá y u kti : -tiobhis. I3. $2.24^{*}$. sva yú j: -úg॰bhis. 2. 5. 4 .

$\checkmark \mathrm{I}, 2 \mathrm{~s}$ v a : svaráyantam. I3. 2. 2.

(cf. sưra, sūrí, súrya, svàr, svára, sváru.)

+ a bhi: abhiosváranti. 9. 9. 22*.

(cf. abhisvará.)

+ s a m: sám asvaran. 5. 6. 3*.

s và r: 2. II. 5. 4. I4. $6 ; 23.6$. 5. 26.

12. II. I. 37 . I6. 8. I-27;9. $3^{2}$. I8. 2. 45. 20. 127. ro (not mss.).

súar. 2. 5. 2. 4. II. 6; I4. 2, 3, 4, 5. 6. 3 I. $\mathrm{I}^{*}, \mathbf{2}^{\dagger} ; 33 . \mathrm{I} ; 35.3 ; 47.3$. 7. I. 2 ; I4. 2 ; IIO. 2.8 9. I4. 9. 5. I7. ro. 6. $13 ; 8.1,21$. Ix. 5. 14, I9. I2. 3. 34 . I3. I. 7, I6; 2. 20*, 39 ; 4. I. I8. $2.16^{*}$. I9. I3. I ; I5. $4^{\dagger} ; 52.3 ; 56.3,5$.

[svarșâ.)

(cf. svargá, svarjít, svaryà svára: -as. II. 7.5 .

(cf. abhisvará, nisvará.) [1. 25. s và r a m̉ kṛt a : súoaramikṛtā. Io. s va or á j: -ât. I 8. 3. $59^{*}$.

svarăjam. 8.9 .9 .

svarăje. I 7. 22, 23

svarăjas. 9. I. 9 .

(cf. svarăjan, svarăjya.)

sva

sva。rájya: -am. ro. $7.3 \mathrm{I}$.

svaritrá: suoaritrắm. 7.6. $3^{*}$.

s váru: -ravas. 4. 24. 4. I2. I. I3.

18. 3. I2. I9. 42. I (mSS. svàr avāmitâ).

svárūṇām. I9. 10. $7^{*}$.

sváorocis: 4. 8. $3^{*}$. [19. 10. $9^{*}$. svarká: suoarkăs. 7. 24. I ; 77. 3 . svargá (p. -aḥog-): -gás. 9. 5. 16; 7.4. I3. 4. 23. I8. 4. I4.

suargás. 6. I22. 2. I0. 2. 3I. II. I. $7,20,28.3 \mathrm{I}, 35$. I2. $3.5 .38,4 \mathrm{r}$, 42, 54. I9. $3 \cdot 3$ (ed. -gé). svargám. 2. 34. 5. 9. 6. 9, 23. 12. 3. 26 . I8. 4.56 .

suargám. 4. 34. 8. 9. 5. 26. ro. 8. I 8 ; 9.5. Ir. I. 30. I2. 3. I6, I7, 34, 44. I3. 3. I4. I8. $3.4 ; 4.2,3$, I0, I3. svargăt. 20. 2. 1 -4. [64. I9. 6r. I. svargé. $4.34 \cdot 5-7$. 9. 5.18. 18. 4 . suargé. 4. 34. 2. 6. I20. 3. I9. 3. 3. svargás. I 8.4 .5 .

suargấs. I2. 3.6. I 8. 4. 4 .

suargăn. I2. 342 .

s va rjít (p. -aḥj-): suarjít. 13.2. 30 . suarjítam. I7. $1-5$.

$\mathbf{s v a r d h a ~ i n ~}$

svardhín (p.suoar-): -dhí. 5. 20. 7. s vary à : -ríam. 2. 5. 6*. 8. 4. $4^{*}$.

s vàrvant (p. -àḥ̆ov-): súarvatī. I8. 1 . 20*.

[24.3.

svarvíd (p. -ạ̣ov-): suarvid. 4 . suarvídam. I7. I5. I $8.4 .29 *$.

suarvíde. 4. 24. 4 .

suarvídas. r3. 1. 47-5r.

suarvídi. I7. 13 .

suarvídas. 2. I. I. I9. 4I. I.

s varșâ (p. -ahıs-): suarșấs. 5. 2. 8*

svalpikâ: 20. 136. 3 (l. sual-: mss. svàlpikā). [9I. I*; 92. I* s vá ○ a nt (su-ávas ?): suávān. 7 . svá s a ra: -am. 7. 58. I*.

svásare. 7. 22. 2.

s vá s ṛ: :sā. 3. 30.3. 5. 5. I, 7. 6. 100. 3 ; I33. 4. 7. $46 . \mathrm{I}^{*}$. I8. I. I2*. svásāram. I. 28.4. 3.30.3. I8. I. I4* svásrā. 5. 22.12.

svásur. I8. I. I4. I9. I2. I*.

svásārāu. 5. 2. $9^{\dagger}$.

svásāras. 9. 9. $3^{*}$.

(cf. hatásvasr.).

[2.64.

s vastaká: suoastakāú. I4. 1. $22^{\dagger}$;

svast a mitá : -ám. I9. 8.3 (mss. svastí tám).

s vastí: suastís. 7.28. $\mathrm{I}^{2}$.

svastí. I. 3 I. $4^{2}$. 6. 4 O. $2 ; 48$. I-3. 7. $53.4 ; 86 . \mathrm{I}^{*}$. Ir. $2.3 \mathrm{I}$. I3. 2.6 . I6.4.6. I8.2. 12. I9.8.7. 20. 136.9. suastí. I. 30. 2 . 4. 14. 5. 6. 123. I, 2. 7. 28. I. 8. 2. II. I0. 6.35 12. 1. 32. 13. 2. 5. I9. $8.3,3$ (mss.); 
15. $4^{*}$. 20. 128. 15 .

svastiă. 20. 128. IO (mss, -tià) , II suastyâ. 7.97.2

svastáye. I9. 45.6-10.

suastáye. 2. $13.3 ; 35.3$. 4. 33. $8^{*}$.

5. 1. 8. 7. 6. $3^{*} ; 85.1^{*}$ 8. 1. 2,16 . 12. 2. I1. I7. 10, 25, 26 . I8. 4. 30. I $9.24 .6 ; 33.4$.

suastíobhis. 3. 16. 7". I9. I1. 5". (cf. svastidă-svastyáyana.)

svastida â: suastiodăs. I. 21. r". 7 . 9.2*. 8. $5.22 *$.

[14. 2.8.

s vastivăhan a: suastiovăhanam. svastyá y a na: -nam. I 9. 9.12 (p. -tyáyan).

svá ohotṛ: -tā. 7. 73. 5 .

svăkta (p. suoăk-): -am. 7. 30. $\mathrm{r}^{3}$, I (l. suấk-).

svătí: -ís. r9. $7 \cdot 3$ (mss. -tí). s v ātt a in agniṣvātta.

svâdiyas: 5. 2. 3". 9.6.39.

s vā dú : -ús. I 8 . I. $48^{*}$.

svādú. 5. r8.7. 9. 9. 20*, $2 \mathrm{I}^{*}$. svādúnā. 5. 2. 3".

svād6s. 5. 2. 3*.

(cf. svãdúsammud.)

svã dú $\circ$ s a m mu d: -das. 7. 60. 4. svādusammudas. I3. I. 3.

s vāya sá: su॰āyasắs. Io. r. 20.

svăva su (p. svá。v-): -um. 7. 50 . $3^{\dagger}$ (l. suáv-).

svầv r.j: -vṛk. I 8. I. $32^{*}$.

s vāçú : suāçús. 20. 128. Ir.

suoāçávas. 19. 50.2 .

s vāsád: suoāsát. I6. 4. 2.

svấsastha: suoắsasthe ip. -e íti etc.). I 8. 3. $39^{\dagger}$.

svăhā. 2. I6. I-5; 17. I-5; I8. I-5. 3. 26. I-6. 4. $38.7 ; 39.2,4,6,8$. 5. 6. 5-7, 10;9. 1-6; 21. 12;24. 1-17; 26. I-I2 (I, 5, 6 l. suă-); 27. 12. 6 . I0. $\mathrm{I}-3 ; 48 . \mathrm{I}-3 ; 83.4 ; 84.2 .7 .82$. $2 ; 97.5,6,8^{5} ; 98$. 1. 8. r. $1_{4} ; 8.24^{2}$. 9. 3. 25-31. I4. 2. 52. I9. 4. I; I 7 . I-IO; 22. I-20; 23. I-29;42. $2 ; 43$. $\mathrm{I}-8$; 45. 6-10; 52. 5 .

(cf. durăhā, svāhākārá-svāhyà.)

svāhāokārá: -ám. I5. I4. 8. svāhākāréna. $15 \cdot 14.8$.

s văhã $\circ \mathbf{k r q t a :}$-as. 7. 73.3.

svăhăkṛtam. 5.12.11

s vāh y à:-yèbhyas. 9. 3. 25-31.

svitá: suoité. 6.55.2.

svid. 9. $9.4^{*}, 7^{\circ}, 17^{2^{\circ}}$. Io. $2.2 ; 4$

18: $7.4-7$ (m. mss. svid), 10-6 (do.), 18-20(do.), 22 (do.), 39(do.), 18 . J. 33".

$\checkmark$ svid: svinnás. 6. I15.3.

s vìșți (p. sú-iṣ-): -im. 2. 35. 1 .

súișțim. 6. $47 \cdot 3$.

súișțaye. $\quad 5 \cdot 27 \cdot 9$.

ha. 2. 27.3. 3. 10.1. 4. 20. $3 ; 34$ $4^{2}$. 5.1. 6"; 5. 7,8. 6. $21.1,3 ; 24$. I. 7. $5 . \mathrm{I}^{*} ; 38.5 ; 76.5$. 8. 9. 5 , I $8^{2}$. I0. $7 \cdot 3 \mathrm{I} ; 8.3^{2 *}, 5,28,40^{\circ}$. II. 4. $10, \mathrm{II}, \mathrm{I} 2, \mathrm{I} 3, \mathrm{I}^{2}$; 5. 7, I9; 8. 6, 9. 12. $4.22,30,31,34,39$. I3. I. $55 ; 2$. 27; 3. 21, 26. I7. 19. 18. 1. $4^{\circ}, 29^{\circ}$; 2. $1^{*}, 4^{8} ; 3.29 ; 4.8 S^{*}$. I9. 6. 12*, I $3^{\dagger} ;$ 22. 21 (mss. utá); 49.7; 53. 5 (mss.), 5 (mss. havís), 6, 8, 9; 54. 3 . 20. $135.6^{3}, 7^{2}$; I 28 . I 2 .

(cf. gha, hí.)

h a in arätihá, çatruhá, sahasrahá.

h a ñ sá: -ás. II.4.21. I9.64. 4 (mss.). hańsám. I0. 8. I7.

hañsăt. 6. 12. I.

hańsásya. I0. 8. I8. I3. 3. I4.

hañsăs. 8. 7.24. I I. 2. 24. I2. I. 5 I. h a t a in áhata, áparāhata, ulkábhihata, ulkânirhata, hatábhrāț̣hatásvasr.

hatá ○bhrātṛ: -tã. 2. 32. 4 .

h a tá $\circ \mathrm{ma}$ tṛ: :tā. 2. 32. 4 .

hatá $\circ$ varcas: -cās. I2. 2. 37.

hatávarcasas. I. I7. I.

h a tá os v a s r : - sā. 2. 32.4 .

h a tnu in upahatnú.

h a t y a (gerund) in ánihatya.

haty a in virahatya, vṛtrahátya.

h a t y a in anāgohatyá, upahatyâ.

$\checkmark$ h a n: hanmi. 2. 31. 3. 5 ; 32. 3. 4. $36.4 ; 40.1-8$. 5. 13. $4^{2}$. I0. 4.9 . II. IO. I3.

háṅsi. I. 16. 4 . 
han̉si. I I. 2. 25.

$\left[12^{*}, 13^{2^{*}}\right.$.

hánti. 5. I8.4, 5. 7. 50. I. 8.3. II*; 4 . hanti. 5. 19. 3. 9. 4. I7. I0. I. 27 ; 4. 5. I4: $2.24,4$ I.

hatás. 7. I10. I.

ghnanti. 6. 76. 4. 8. 5. 13. I0. 8. 24. hanas. $7 \cdot 76.5$.

hánat. 5. I4. 4. IO. I. 5. 20. I32. IO. hanat. 20. I32.9, IO, II ${ }^{2}$, I6 (mss. -as). hánāva. 4. 32. 6*.

hánāma. 8. 8. I. II. 9. 23.

hánan. 8. 8. I4, I5.

jahí. I. $8.3,4 . \quad 3.1 .4^{*}$; 19. 8.8. 4. $22^{*}, 24$. 9. 2. IO. II. IO. 21 . I9. 29. $9^{4} ; 3+9$.

jahi. 2. 27. I-6, 7. 4. I7.4. 5. I4. 2,$9 ; 23.2 ; 29.10 .6 .6 .2 ; 26.3$; 37. 2 ; IOI. I; I34. 3. 7.88. I; 109. 4. 8. 5.15 . I0. I. 6,$31 ; 4.13 ; 6$. $6-17,20,21 . \quad$ II. 2.21 ; IO. 2 I. 16. 7. 12. I9. 30. I.

hántu. 8. 8. 3, 4. I0. I. I9. I3. I. 29. hantu. 2. $32 . \mathrm{I}^{2}$. 3. 6. I. 4. 3. 5. 5. 29. I0; 3I.I2. 6. 67.2. 7. 70. I; II4. $2^{2}$. 8. $3.4^{*} ; 4.16^{*} ; 8.16$. II. 9. 20 ; 10. 27 . I3. I. 28.

hatám. 7. 50. I. 8. 4. $1^{*}, 7^{*}$.

hatam. 8. 8. I 7,18 .

hatām. 7. 70. 3 .

hata. 3. I9. 7. 5.8. 4 .

hantanā (p. -na). 7. 77.2* [8.20. ghnantu. 3. I. 6. 7. 70 2. 8. 4. $17^{*}$; ghnán. 5.23. 6.

ghnántas. 7.93. 1. 8.8.13.

áhan. 2. $5 \cdot 5^{*}, 6^{*}, 7^{*}$.

ahan. 8. 5.3.

aghnata. 8. 10. I8-2I.

jaghằna. 2.5 .3 .4 12.7. 8. 8. 7 . I0. 4. I2. I8. 2.31 . 20. 34 I 7 .

jaghāna. 4. 37. I. 7. 18.2. ro. 4. I8. jaghnimă (p. -má). I0. 4. I2.

jaghnús. 4. 37. I.

hanișyasi. II $3 \cdot 48$.

hanișyati. II. $3 \cdot 39,40,42,47$.

hántavāí. 4. 30. $5^{*}$.

hatvă. 4. 10.2. I9. 36.4 (1. -tuă). hatvăya. 4. 31. 2*.

hatás. 2. $32.4^{3}$. 5. 23. $8^{2}$. 7. 59 .
I. II. 9. I9. 20. I3I. I9.

haté. 3. 13. I. II. 9. 7, I4.

hatăs. 2. 32. 5. 5. 23. 2,4 . 0.4 . I2, 13, 20 .

hatắsas. 2. $32 \cdot 5^{2}$.

hatăn. II. IO. 23, 24 .

hanyáte. I. $20.4^{*}$.

hanyánte. I4. I. $13^{\dagger}$ (ed. -ante*).

hanyátām. 5.23.7.

hanyatām. 5.23.7.

hanyantām. 8. 8. II.

hanyámānā. 5. I8. II. I2. 5. 25.

jíghāṅsati. 4. 18. 3. 7. 87.2*. 8.

5. I5. I2. 4.29 (-gāin-?), 30 (do.).

jíghān̉san. 6. 99.2 (mss. -sam).

jan̄ghanāva. 4. 32. $7^{*}$.

(cf. Vhinss, ghaná, ghanāghaná, ghātin, ghătuka, ghni, ghnī, ghnya, ha, hata, hatnu, hatya, hatyā, han, hanana, hanas, hántṛ, hantṛ́, hanman.)

+ a ti : cf. atighnyà.

+ a pa: ápa hanti. 9.5. 7, I I.

ápa hanmas. I. I8.3. 8.6.4.

ápa hanmasi. 8. 2. $12 ; 6.5$.

ápa ... hanātha. I4. I. 59.

ápa hantu. 2. 3.6. 6. 134. 1. 8. 7 .

I4. I2. 3. I4.

ápa ... hatam. 14. 2. 6*.

ápa hata. 12. 2.47 .

ápā 'ghnata. II. 5. I9.

ápa ... hatám. I0. 7.40 .

+ abhi: abhí jahi. 8. 4. $19^{*}$.

abhí ... hatām. 19. 8.5 (mss.).

abhíohatas. II. IO. 22.

+ ava: áva ... hanmi. I2. I. 58 .

áva jahi. 5. 14. 2 . I3. I. 30.

áva ...jahi. 5. I4. I, 2 ; 2 I. I. 10.

4. 3. I3. I. 32 . I9. 65.1 .

avaoghnati. II. I. 9 .

ávaohatas. 6. I 34.2.

áva jañghanīhi. 5.20.8. [50. I (do.).

+ à : à ...jahi. I9. 47.9 (not mss.);

à ghnate. I9. 32. 2.

ă॰ghnānăs. II. 9. I4. I2. 5.48.

àohatas. I 4. I. I2*.

àohatam. I. II. 4 .

àohatās. I0. 8. 4 . 
(cf. āhánana, āhanás ?.)

+ prat yã : pratyăhanmi (p. -tioăh-). 8. 10. 31 .

pratyāhánti (p. -tioāh-). 8. 10. 32. pratyăhanti (p. -tioăh-). 8. 10. 32 . pratyāhanyăt. (p. -tioāh-). 8. 10. 31 . pratyăhanyāt (p. -tioăh-). 8. 10. 30, $3 \mathrm{I}$.

+ u d: út... hantu. I4. 2.16*.

+ upa: cf. upahatnú, upahatyâ.

+ ni: ní hanmi. 6. 8. 2.

niəhánti. 6. 8. 2.

ní hanti. 10. I. 27.

nioghnánti. 20. $136.6(\mathrm{~m}$ mín

ní jahi. 8. 3. $7^{*}$. 11.1 .9 .

nioghnatás. IO. 1. 27.

nioghnántas. 19. 46.3 .

niohanyáte. 6. 70. I-3.

ní hanyatām. 6. 70. 1-3.

. (cf. ánihatya.)

+ n is : nír hanti. 5. 19. 4 .

nír jahi. 3. 2. 4. 12. 5. 70. I 9. 50. I (mss. jahyās).

nír hantu. 19. 44.2 (mss. ahantu). (cf. ulkănirhata.)

+ vinis: vionírhate. 7.52.2.

+ parā: cf. áparāhata.

+ pra: prá... hanat. 19. 49. 9. prá ... jahi. 12. 5.60, 67 .

+prati: práti...jahi. 8. 3. $23^{\dagger}$.

pratioghnānă. I I. 9. 7 .

pratioghnānăs. II. 9. I4.

+ vi: ví... hanmi. 8. 5. 8 .

ví jahi. 4. 32. $3^{*}$.

ví ... jahi. 1. 21. $2^{*}, 3^{*}$. 6. 2. 2. I9.

ví ghnatām. I. 28.4 .

vioghnänăs. 6. 32.3. 8. 8.21 .

viohátya. 7.73. 9".

+ s a m: sám ... hanmi. 6. 56. 3 .

h a n (f. ghní) in adṛșțahán, amitra-

hán, jyeșțhahán, dasyuhán,

dưṇāmahán, devṛhan, patihan, paçuhan, prȩ̣nihán, bhrātṛhan, bhrātṛvyahán, bhrūṇahán, manohán, mușțihán, yātuhán, rakșohán, vīrahán, vṛtrahán, sapatnahán, sātahán.

b a n a $\mathbf{n}$ a in āhánana. h a n a v y à : -yăm. 6. 43.3.

$\mathrm{h}$ a $\mathrm{n}$ a s (?) in ăhanás.

há n u: -nuã. 6. 56. 3 .

hánū (p. - -̄̃ íti). I. $21.3^{*}$. 6. 56.3.

10. 9. 13. 19. 47.9 .

hánvos. I 0. 2. 7, 8 (1. -nuos).

(cf. adharahanú, uttarahanú, cáturhanu, sámhanu, hanavyà.)

hánt a. II. 8. 22.

hántr: : tã. 5. 18. 14.

hantŕ: -tâ. 1. 7. 1. 3. 10. 12. 4. 19. 3. 7.71. $1^{\circ}$.

han m an in áçmahanman.

hár a ṇ a: -ṇāya. 1. 28.3.

(cf. pratiháraṇa.) [19.27.6.

háras: 2. 19-23.2. 18. 2. 36; 3. 71 .

hárasā. 2. 12.4. 5. 5.4. 6. 93. 2.

8. 3. $4^{*}, 10^{*}, 13^{*}, 15^{*}$. 18. 2. $5^{*}$. 19.

65.1 ; 66. 1. .

hárasas. 2. 2. 2.

(cf. vĩụúharas, hárasvant.)

hárasvant: -ntam. 19. 40. I (nss. sárasvatím). [mss.).

hári: -is. 19.65.1. 20. 130. II (not háraye. 5.11.1.

háres. 10.8.18. I3. 3.14.

hárỉbhyām. 2. 5.1. 3.1. 4*.

háryos. 20. 128. 15 (l. -rios: mss. haryós), 16 (mss. hắryo, hắryor).

hárayas. 6. 22. I*. I3. I. $24,36,43$; 3. $9^{*}, 16$.

háriobhis. 7.117. $1^{*}$.

(cf. haridrava - harivant, háryaç-

hárikṇikā: 20. 129. 3; I 30. II (not mss.).

hárikṇike. 20. 129. 4.

h arịná: -ás. 3. 7.2.

hariṇásya. 3.7.1. 5.21.7.

hariṇásyā (p. -sya). 6. 67.3. (cf. háriṇī)

há r iṇi I: -īm. I0. 2. 33 .

háriṇis's. 10. $8.3^{\dagger}$. 18. 4.34 .

harít: -tas. Io. $8.40^{*}$. I3. $2.4,6$, $7,8,11^{\dagger}, 23^{*}, 28 ; 3.17$.

hárita: -as. I0. $3.3 ; 8.3^{\dagger}$.

háritam. 5. 28.9. 7.99. I. II. 2. I $2 ; 3.8$.

háritena. 5.28. 5 . 
haritasya. I. $25 \cdot 2,3$.

hárite. 5. 28. 1.

háritāu. I5. 2. I-4.

háritās. 4. 37.4. I0. 8.31 .

háritā. 6. 20. 3 .

háritān. 5. 22. 2.

háritebhis. 6. 49.2.

háritebhyas. I9. 22.5 (m. mss. harité-).

(cf. hárikṇikā, háriṇi, áharita, haritabheșajá, háritasraj.)

harit a०bheșajá: -ám. 4. 9. 3.

háritaosraj: -jas. ro. 8. 3 I.

haridrava in hăridrava.

harimán: -mă. I. 22. I. I9.44. I. harimănạam. I. 22. $4^{2 *}$. 9. 8. 9.

hariovant: -van. 7.97. $2^{\dagger}$.

h a rm yá: -miám. 4. 5.5 . I8. 4. $55^{2}$. $\checkmark$ h ary : cf. haryatá.

+ abhi: abhí haryata. 3. 30. I.

+ prati: práti haryāsi. I2. 3. 23 .

práti harya. I0. 6. 35 .

práti haryatam. I. 7.3.

práti haryata. I. 8.2. 5.7.6.

práti haryantu. 3. 8.2.

h ary at á: -ás. I8. I. $23^{*}$.

háry açva: háriaçvas. 20. 34. I7 (mss. -va).

harioaçva. 5. 3. 8*, II.

$\mathrm{h}$ arș an $\mathbf{a}$ in çepahárșaṇa.

$\mathrm{h}$ arsin in uddharsín.

hálīkṣ na a: -ṇāt. 2. 33.3.

$h$ a llh a in vihálha.

háva: -am. I. 15.2 . 2. $5.4 ; 30.3$. 3. 3. 6. 4. 24. I. 5. 8. I, $2,3^{2}$. 6. 2. I. 9. 2. 7 .

háve. $5 \cdot 3 \cdot 8^{*}$. 7.86. I* (háveoha-). háveșu. I8. I. $44^{*}, 47$. I9. II. I*, 13. II*.

(cf. anuhavá, āhavá, parihavá, vihavá, suháva, havín.)

$\mathbf{h}$ a va $\mathbf{a}$ in āhavanìya.

havín: -nas. 3. 4. 3 .

havirád (p. -ih̆ó-): -das. I 8. 3.48*. h aviradá (p. -iḥoad-): -dăn. 4 . $37.8,9$.

havirdá (p. -iḥod-): -ấs. 5. 1. 7 . havirdằm. 7. 78. 2. havirdhăna (p. -iḥıdh-): -am. 7. I09. 3. 9. 3. 7. I 4. 2. 34 .

(cf. sadohavirdhāná.) [8. 4. 2I". havirmáthi (p. -iḥom-): -thinām. havișkŕt (p. -iḥok-): -tam. 9.6.13. havişkị́tas. 7. 28. I. I9. 4. I (not mss.); 42. 2 .

haviș pâ (p. -iḥop-): -ấs. I 8. 3. 48*. h a vís mant: -ntam. 6. 39. I.

havíșmate. 4. 30. $6^{*}$.

havísmati. 6. 84. 2.

havís: 1. $4.3^{*} ; 7.3 ; 8.1$. 3. 10. 5. 5. I2. II"; 27. II. 6. 5. $3 ; 27$. $2^{*} ; 39.1 ; 50.2 ; 97.1 .7 .46 .2^{*} ; 54$. $2 ; 68.2 ; 70.4,5 ; 72.2^{*} ; 76.5 ; 77$. $\mathrm{I}^{*}$; 98. I; rog. 5. 8. 7. 20. 9. 5. 38 ; 6. 2 . II. I. $4 ; 7.18$. I2. $2.37 ; 4$. 40, 48. I8. I. $5^{2^{\dagger}} ;$ 2. $\mathrm{I}^{*}, 3^{\dagger} ; \quad 3.64$; 4. $2,35,63$. 19. $27.11-3 ; 42.1 ; 52$. $5 ; 53.5$ (mss.).

havíșā. I. 12. $2^{2} ; 15.1 ; 3$ 1. 1, 3. 2. 26. 3. 3. II. $1^{*}, 3^{*}, 4^{*}$; I5. 5 ; I7. 5 ; 19. 2 4. $2 . \mathrm{I}-7^{*}, 8$. 6. 4 O. I; 4I. I, $2 ; 64.2^{*} ; 65.2 ; 73.2 ; 75.1 ; 78.1$; 80. I, $3 ; 87.3^{*}$; 125. $2^{*}$. 7. 5. 3, 4; 70. $1 ;$ 79. 3 ; 94. $\mathrm{I}^{*} ; 98.1$; 109. 6 . 9. 2. I. I2. 1. $60 ; 2.32$. I8. I. $49^{*}$; 2. 29 ; 3. 13. I9. I. I-3; 6. 10*; 58. I. havíse. I 8 . 1. $56^{*}, 57 ; 2.34$.

havíșas. 6.47.2. I8. I. 60+. I9. 52. 5 . havínși. 4. 26. 4. 5. 12. 10*. 7. 46. 3. 9. 6. 20. I8. $3.42^{*}, 44^{*}, 46^{*} ; 4.65^{*}$. havírbhis (p. -íhobh-). I8. 3.63; 4 .

54 .

havíșām. 6. 15.3 .

(cf. havirád-havísmant.)

háv y a: -as. 6. 98. 3. 20. I35. II (mss. havyám).

hávyā. 7.47.2.

(cf. upahávya, vihávya.)

h a vyá : -ám. 3.3.4; 15. $3^{*}$. 4. 23. 2 ; 39. Iо. 5.8. 3 ; I2. 10*; 27 . เ1. 7. 20. 2 ; 46. I* ; 68. I, 2. 8. 9. 2 I. II. I. 25 . I2. I. $22 ; 2.8^{*}, 53$. I 8. I. $30^{*}$. I9. $4 . \mathrm{I}^{2} ; 42.3 ; 58.6$. havyăni. $18.3 .42^{*}$.

havyá. 3. 10.6. 6. 125.3*. 7. IOg. 2. I8. I. $5 \mathrm{I}^{*} ; 4$. I. 
(cf. rātáhavya, vítáhavya, havyádāti-havyavăhana.) [rog. 2. havyáodāti: -im. 6. 125. 3". 7 . havya०vah: -văham. 4. 23.4. 12. I. 20 . I8. 4.41 .

[-văhas).

havyaovāhá: -ás. I 8. 4. I (mss. havyaovăhana: -as. 7. 20. I.

$/$ h a s: ef. hása, hasá, hasya, hāsin. + abhi: cf. abhihásya.

+ pra : ef. prahāsín.

hás a : -as. I5. 2.3 .

hásāya. 12. 2. $22^{*}$. (cf. hasāmudá.)

h a s á: -ás. I I. 8. 24.

ha sāmu dá: -dãú. 14. 2.43.

hasāmudăs. 7.60 .6 .

hásta: -as. 4. 13. 6*. I9. 7.3.

hástam. 5. 17. 8. 7. 9. $4^{*}$. I2. 3. 17. I4. 1. $48^{2}, 49,50^{*}, 51^{2} ; 2.39$. I8. 4.56 . hástena. 5. 17. 3". 9.6.22. I0.6.3. hástāt. I 8. 2. 59, 60". [II. I. IO. háste. 4. 20.4. 7. 50. 8. 8.6. I4. hástāu. 6. 8 I. I. 7. 26. 8 ; I09. 3 . 8. I. 8. II. 8. I4, I5. I9. 49 . I0. hástābhyām. 3. II. 8. 4. I3. $7^{*}, 7^{\dagger}$. 6. 102. 3 ; II8. I. I0. 7.39 . II. 3 . $48^{2}$. I9. 5 I. 2.

hástayos. I. 18. 2. I8. 3. I 2.

hásteşu. 4. 14. 2. 6. 122. 5. 10. 9. 27. II. I. 27.

(cf. hástakṛta-hastín, antarhastá, ārdráhasta, íṣuhasta, nírhasta, parihastá, pătrahasta, çatahasta, çuddháhasta, sahasrahasta, suhásta, híraṇyahasta.)

hást a $\mathbf{k}$ ṛ̣t a: -tām. ro. I. I.

hasta。gŕhya. 5. I4. 4; I 7. 2"; 20. 5. I4. 1. $20^{*}$.

hast a $\circ \mathrm{g} \overline{\mathrm{abh}}$ á: -ásya. I8. 3. 2*.

hás t ā: -ām. II. I. 24.

hast āvanéjana (p. -taoav-): -am. II. 3. 13 .

hastín: -tí. 3. 22. 3,6. 6. 70. 2. Io. hastínam. 4.36 .9 .

hastínas. 3. 22. 4 . 20. 131. 23.

hastíni. 6. 38. 2.

hastíșu. 12. 1. 25.

hastíni. 9. 3. 17 . hastiniằs. 6. 70.2

(cf. hăstina, hastivarcasá.)

h astiovarcasá: -ám. 3. 22. I, 5.

h a s y a in abhihásya.

V I, 2 hā: jahămi. Io. I. 32 .

jáhāsi. 6. 26. 2.

jáhāti. 10. 1. 32 . 12. 2. II, $25^{*}$.

jahāti. I0. 2. $30 ; 8.32$. I 1. 3. 56 .

jahimas. 6. 26.2 .

jáhāni. I3. I. 12.

jahyus. 6. 47. 2.

jáhātu. 5. 29. 15 .

[7. 13.

jahātu. 7.31. I*. I0. 5. 25-35. I6.

jahîtāt. II. I. I3.

jahitam. 7.53.2.

jahita. I2. $2.26^{4}, 27$.

ájahāt. I8. 2. $33^{*} ; 4.64$ (mss. aj-).

âhās. 2. 10. 7 .

hāsta. I 8. 2. 24.

hāsmahi. 5.3.7". [13.1.12. 16.4.3.

hāsit. 2. 28.3 . 7. 53. 4. 8. 1. 15 .

hãsișțam. r6. 4. 5 .

hāsișțām. I6. 2. 5; 3. 2-4.

hāsișța. 9. 4. 24.

hāsişus. 6. 4I. 3. 8. 2. 26.

hāsyanti. I I. 3. 28, 29, 38 .

hiyate. I0. 8.15 .

hitám ( $V$ dhā ?). I8. 2. $7^{*}$.

hitvă. 4. Ix.6. 5.20.3. 6. 28 . I*.

I7. 8 . I8. $2.47 ; 3.5^{8^{\dagger}}$.

(cf. hā, hāyas ?, heya ?.)

+ a n u: anūjahiré (p. anuoj-). I8. 3. $46^{\dagger}$ (ed. anūhiré").

anuohâya. 5. 18. 9 .

+ apa: ápa hāsthās. I 8. 3. 73.

+ a va: avaohăya. 7.53.4. I6. 4. 3.

$+\mathrm{ud}:$ új jihIdhve. 8.7.2I.

ujojíhānās. I3. 2. 46".

+ ni: ní ... hìyatām. 8. 4.10* ní jihișate. 20. I 27. 2 (mss. -hịdate).

+ pra: prá jihíte. 20. 127. 10 .

(cf. prahā, prahéya.)

+ vi: ví jihite. I2. I. 48 .

ví jihīọva. 5. 25.9. 6. I 2 I. 4 .

ví ... jihatām. I. 1 I. I.

ví hãyi. I 8. 3.9.

viohâya. 3. 28.5. 6. 120. 3 .

ví ... hāpayāmasi. I. II. 3 . 
$\mathrm{h} \overline{\mathbf{a}}$ in prahă.

hā y a ná: -ás. 6. I4. 3. I9. 39. IO. hāyanắn. 3. Io.9. 8. 2. 2 I. I I.6. I 7. hāyanıิs. 12. I. 36 .

(cf. trāihāyaṇá, çatáhāyana.)

hā y a s in sárvahāyas, víhāyas.

h ā y y a in prahāyyà.

hā $\mathbf{r a}$ in aghahārá, nİhārá (?), pratihārá, balihārá.

hấridrava: -veșu. I. $22.4^{\dagger}$.

$\mathbf{h} \mathbf{a} \mathbf{r} \mathbf{d}$ in durhărd, suhărd.

hầrdi: -im. 6. 89. I, 2. I8. $4.5^{8+}$.

hārya in āhāryá.

$h$ āsin in prahāsín.

hâstina: -am. 6. 72.3.

hí. I. $5 . I^{*} ; 7.1$; 10. 1,$2 ; 35.2$. 2. $6.5 ; 9.3 ; 25.1 ; 36.3$. 3. I. $2 ; 4$. $6 ; 9.5 ; 13.3 ; 22.6$. 4. I. 4 ; 3. I; 13. $3^{*}$; 14.1 ; 19. 7 ; 25.4; 26. I, 2 ; 32. $4^{*} ; 33.6^{*}$. 5. 4.2 ; 5.2 ; II. 5,7 , II； I3. I； I8. 6 ；22. $2^{2}$. 6. I6. 2 (mss. hina); 27. 2*; 51. 2*; 106. 3 ; I 10. 1"; II2. 3; I25. I*. 7. 3. I; 7 . I; I4. $3 ; 20.5,6 ; 56.5 ; 65.1$; 73 . I, II*; IOg. 6 ; IIO. I. 8. I. $6 ; 8.6$; 9. 7 , 24. 9. I. I, 3 , 10; 2. 9 ; 3. 22 ; 5. $13 ; 9.8^{*} ;$ 10. $7^{*}$. 10. I. $28 ; 2.7$; 4. I9; 9. 4 ; IO. I3-5, 22, 23 ${ }^{2}, 27,33$. I I. $2.28 ; 8.32$. I2. $2.55 ; 4.4 ; 5$. I6 $6^{2}, 53$. I8. I. $33^{*}, 38^{*}, 60^{*} ;$ 3. I 9 , 5 I"; 4. 59", 6I*. I9. 7.4 (mss. dehi); 49. 7 (mss. hi); 58. $4^{*}$.

(cf. nahí, hina.)

Vhi: hinoti. 4. I.6. 8. 4. $13^{*}$.

hinvánti. 5.2.9* 6. IOI. 2.

hinvanti. 4.8 .7$.

hinvantu. I. $4 \cdot 2^{*}$.

ahyam. 4. I. 2.

hitás. 5.4.7. I3. 3. 23. [heya ?.)

(cf. hāyya, 2 hita, hetí, hetú,

+ pari: parihinóómi (p. -riohinó-). 8. $4.6^{*}$.

+ pra: prá hiṇomi (p. hino-). 5.22. 4. I0. 5. 23 . I2. $2.4,8^{*}$, 10. prá hị̣masi. 5. 3: Io. 10. I. 30 . prá hiṇmas. 7. I I5. 3. I0. I. I5. I9. 57. 3 .

prá hiṇutāt (p. hinu-). I8. 2. $4^{*}$. prá hị̣uta (do.). 6. I30. I-3; I3I I, 2. I8. 4.40. prăhāit (p. praoáh-). 2. 24. I-8. práohitas. 2. 29. 4 . I8. 4.65. práohitāu. 6. 29. 2. práohitān. 8. 2. I I.

(cf. prahāyyà, áprahita, prahéya.) + abhipra: abhiopráhitãm. I0. I. I5.

+ pratipra: pratiopráhiṇmas. 10. $\checkmark$ hin s: hinásti. 2.12. 2, 3. 5.18.13. hinasti. 5. 17.7. I5. 5.1-7. hínsanti. 5. I9.8.

hínste. 12. 4. 13.

jihinssimá. 6. I20. I.

jíhinsiss. I2. 3. 18 .

hinsīs. 9. 3. I6. I0. 9. II. II. 2. 20, $29^{\dagger}$. 12. 1. 34. I8. 4.30.

hinsit. 3. 28. 5, 6. 6. $27 \cdot 3^{*}$. 7. 54. 2. hinsișțam. 5. 9.8. 6. I40. 2, 3. II. 2. I. I4. 1.63 .

[-țam). hinssișța. 18. I. 52*. 19. 40.3 (mss. hinsișus. 2. 28. 1. 7. IO2. I. I4. 2. 29. hińsitásya. 5. 286 .

hinsitvâ. 5. I8. I2; 19. I, I I.

(cf. hinsant, hinssitavyà, hiñsrá.) hins a $\mathrm{nt}$ in áhinsant.

hinsitavyà: às. 5. 18.6.

hiñsxá: -ás. 8. 3. $3^{*}$.

hinssrat. 8. 3. $4^{*}$.

hinssrám. 8. 3.9".

[kārá.

hín : see $\sqrt{ }$ I kr + hiñ, abhi ... kṛ, hiñ-

hìn $\circ \mathbf{k a ̄ r a ́ : ~ - a ́ s . ~ I I . ~ 7 . ~} 5$.

I hit a $(V$ dhāa $)$ in apūpăpihita, ánirā-

hita, dúrhita, deváhita, puróhita, sáminhiānta, súhita.

2 hit a $(v$ hi) in áprahita.

h ina. 6. I6. 2 (ed. hí ná).

h i má: -ás. 7. 18.2. I3. I. 48.

himám. I3. I. 46,47 .

himásya. 6. 106. 3. 19. 49. 5 .

(cf. himávant, hímā, çatáhima, heman, hemantá, hāyaná.)

himáovant: -vatas. 4.9.9. 5. 4 . 2,8. 6. 24. I. I9. 39. I, 8 .

himávantas. $4 \cdot 2.5^{*}$. I2. I. II.

himávatām. 6. 95.3.

(cf. hāimavatá.) 
h ím ā: -ās. 2. 28.4. I2. 2. 28. (cf. çatáhima.)

hír a ṇ y : -am. I. 9. 2; 25. 1, 2, 3. 2. 36. 7. 5. 1. $3 ; 28.6^{2}$, II. 6. 7 I. I ; 124. 3. 9. 5. 14, 29. 10. 7. 28. II. I. 28 . I2. I. $44 ; 3.50$ I 4 . I. 40. 18. 4. 56. 19. 26. I, 2 ; 27. 9, 10. 20. 132 . 14 (mss. hiraṇyatyéke).

hírạyyena. 10. 10. 16 .

híranyasya. 12. 1. 18.

híranye. 6. 38. 2; 69. I.

híraṇyãnām. 4. 10. 6.

(cf. hiraṇyáya, hāiraṇyá, hírạ̣yakaçipu-híranyahasta.)

híra ṇy a ok a çipu: -us. 5. 7. 10. hiraṇya okę̧ a: -çiāí. 5. 7.9.

hiraṇyaogarbhá: -ás. 4. 2. $7^{*}$. I0. 5. 19 .

hiraṇyagarbhám. 10. 7.28.

hir a ṇy $\mathrm{y} \circ \mathrm{j}$ à: -ấs. 4. IO. I, 4 .

hiranyaojit: 7.50.8.

híranyaojy otis:-ișam. ro. 9. 6. hira ṇya otéja s: -asā. I9. 26. 3.

híra y ya otvacas: -asas. I3. 2. 8. hírạ yaodrāpi: -paye. 5. 7. 10. hiranyaonemi: -mayas. I8. 4 . $89 *$.

híranya opakșa: -am. I8. 3.66*. híra ṇya opān i: -is. 7. 14. 2.

híraṇyapānim. 3.21.8.

hirạ̣ya pã vá: -vấs. I8. 3.18*. híraṇyaobandhan a: -nã. 5.4 . 4. I9. 39. 7 .

hiraṇyáya: -as. 4. 2.8. 6.82.3. 7. 83. I. 9. I. 2 I. I0. 2.31 ; 3. 3. I9. 30. 5 .

[II. 2. 12. 20. 129. 5 . hirạ̣yáyam. 7.99. I. I0. 7.4I. hiraṇyáye. I0. 2.32 ; 10. $12,17$.

hiraṇyáyās. 5. 4. 5. 20. I3I. 5-8. hiraṇyáyā. $5 \cdot 4 \cdot 5$.

hiraṇyáyI. 5. 4.4. 19. 39.7.

hiraṇyáyim. Io. 2.33. [6. 10. hiraṇyáyis. 4. 37.9. 5.4. 5. 10. hirạ̣yáyIbhis. 10. 4. 14.

hír a ṇ y avakşa s: -ṣās. I2. 1. 6. híranyaovakșase. I2. I. 26.

h ir a ṇ y a va $\mathrm{t}$ in áhirạ̣yavant, súhiraṇyavant. híraṇ y o varṇa: -as. I9 24. 8 híraṇyavarṇã. 5.7. 10. 9. 1. 4.

híranyyavarnam. I4. I. $6 \mathrm{I}^{\circ}$.

híraṇyavarṇe. $5.5 .6,7$.

hírạ̣yavarṇăs. I. 33. I.

híraṇyavarnaass (voc.). 3. 13.6.

híraṇ y o çrñga: -as. 19. 36. 5 .

hírany a o sraj: -ak. I0. 6.4.

hírany a $\circ$ h a t a: -as. 7. I I5.2.

hirẫ: -âs. I. 17. 1. 7.35. 2.

hirăṇăm. 1. 17. 3.

híruk. 4. 3. $\mathrm{I}^{8}$. 9. 10. 10*.

$\checkmark$ hI ḍ: jihịạa (p. jih-). 4. 32. $5^{\dagger}$.

jihidée. 6. 116. 2.

ájihidatat. I2. 4. 8.

hị̣itâs. I2. 4. 28,49 .

(cf. héda, heḍana, héḍas.) [şate). + ni: ní jihidate. 20. 127. 2 (ed. -hI$\checkmark$ h u : juhómi. 3. 15. $3^{\circ}$ (mss. -homi). 4. 32. $7^{\circ}$. 6. 83. $4 ; 84.1$.

juhomi. I. 15.1 ; 3I. 3. 2. 26.3 ; 35. 5. 4. 39. 9, I0. 6. 64. 2*; I I6. I. 9. $4.10 ; 5.38$. 12. 3. 54 . I3. 1. I3. I8. 4. $28^{*}, 35$. I9. I. $1-3$.

juhoti. 7. 70. 1, 2. 15. 12. 4, 7, 8, I1. juhoti. 9. 6.21.

juhumás. 7.79. $4^{*} ; 80.3^{*}$.

júhvati. 4. 40. I-8.

juhvati. 17.18 .

juhuyát. I5. 12.3.

juhuyāt. I5. I2.3.

juhutā (p. -ta). 6. 32. I.

juhótā (do.). I8. 2. 2".

juhbtana. 7.72. I*.

juhotana. 7. 46.2* I8. 2. $3^{*}$.

júhvatas. 3. I0. II. 6. II4.3. I7. I8. hoșyămi. 15. 12. 2.

hutás. 18.4. I5. [15.12.6; 13.9. hutám. 3. 21. I-7. 6. 71.2. 9.4. 3. hutắm. 12. 4. 53 .

huté. 5.21. 2. II. 9.6. I5. I4. 4. hutébhyas. 7.97.7.

hutănām. I 8. 4. I5.

(cf. juhû, havana, havís, havyá, hut, huta, huti, hotrá, hótrā, hóma.)

+ abhi: abhíohutā. 6. 133. 2.

+ ā: āojuhóti. 9.4. 9, I8. 
āojúhvānas. $5 \cdot 12 \cdot 3^{*}$.

àohutas. II. IO. 5. I8. 2. 10".

āohuta. 6.5. I. 12.2. I8.

à。hutam. 7. 20. 2 ; 46. $\mathrm{I}^{*} ; 68.1$; 73. 4. I3. 1. $60^{*}$.

àohutā. 6. I 33. 2.

(cf. āhavana, āhuta, ăhuti.)

$h$ u $t$ in agnihotrahút, sarvahút.

huta in áhuta, āhuta, sárvahuta,

súhuta and $[25-35 ; 4.16-24$.

hutá ○bhãga: -gãs. I. 30. 4. I8. 3 . hu ti in âhuti.

$\checkmark \mathbf{h} \bar{u}, \mathrm{~h} v a \bar{a}:$ hávāmahe. 7. 73. 1.

havāmahe. 3. I6. $\mathrm{I}^{*}, \mathrm{I}^{\dagger}, 2^{\dagger} ; 20.4^{*}$, $6^{*} ; 21.8 ; 24.2$. 4. 23. 4. 5. 3. II; 7. 4. 7.6. $2 ; 40 . \mathrm{I} ; 63 . \mathrm{r}$. I3. 2.43 . I6. I. I3. I9. 15. $2 ; 24.7^{*}$.

hávante. 4.24. 5 .

havante. I8. I. $4 \mathrm{I}^{*}, 4 \mathrm{I}^{\dagger}, 42^{\dagger}$.

huvé. 3. 8. 2, 3. 7. 86. $\mathrm{I}^{\dagger}$; log. 7 .

huve. 4. 26. 3 ; 28. 3 ; $38.1,2,4.5$. 25. 2 . 6. 77. $2^{*} ;$ 99. 1 ; 108. 2. 7 . 48. I"; I 10. 2. 8. 2. 6; 7.6, 23, 24. II. Io.9. I 8. I. 59*. I9. 42.4 (mss. -vé). huvema. 7. 40. 2.

hváyāmi. 6. 99. x. 8. 7.4. I8. 2.21. hváyati. 9.6.49.

hváyanti. 9.6. 13 .

hvayanti. 9.6.13.

hvayatu. $3 \cdot 3 \cdot 3^{3}$.

hváyantu. 3.3.5.

hvayantu. 3.4. I, 4, 7.

hvayasva. 12. 3. 1 .

ahvayat. I0. IO. 10.

ahvayan. 5. 1. 8 .

áhvayethām. 4. 2. 3 .

ahvat. 3. $4 \cdot 5,6$.

ahve. 4. 27. I. 6. 80. 2 .

hve. I7. $1-5$.

hūtás. 4. 31. 2*.

hūyámānā. I0. 10. 9.

hūyámānās. I8. 3. 19.

jóhavimi. 2. 12.3. 3. 21.3.

johavimi. 3. 16. $5^{\dagger}$. 4. 23. 7 ; 24. 7 ; 26-29. 7. 7. 47. I. I I. I. 26. I9. 4. I. johavìti. I0. 7.31 .

(cf. háva, havín, hávya, jihvă, hūta, hūti, hótr [or to $/$ hu] , hva.) 8. 1. 15.

ánuohūtas. $5 \cdot 30.7$.

ánu ... johavitu. 6. 73. 3 .

(cf. anuhavá.)

$+\overline{\mathbf{a}}$ : a huvema. 7.85. $\mathrm{I}^{\dagger}$.

(cf. āhavá, āhva.)

+ u d: úd ahvayat. ro. ro. 22. úd ahvam. I 8. 2.23.

+ ú pa: úpa ... havāmahe. 19. 58. 2. úpa hvaye. I. $4.3^{*}$. 6. 23 . I. 7 . 73. $7^{*}$. 9. $5 \cdot 30$.

úpa hvayāmahe. 5. 10.8. 7.60.3. úpa hvayāmahāi. 8. 10. 9.

úpa ... hvayatām. I. I. 4. I 9. 58.2. úpa ... hvayethām. 12. $3.3,40$.

úpā 'hvayanta. 8. ro. ro, 22-9.

úpaohūtas. I. I. 4. 7.60.5. 9.6. $55-9^{2}, 60^{2}$. I6. 2. $3^{2}$.

úpaohūtãu. 6. 140. 3 .

úpa.hūtās. 6. 122. 4. 7. 60. $4,5^{2}$. I 8. 3. $45^{*}$. I9. 40.2 (mss. -tas).

(cf. upahávya.)

+ ni: ní hvayasva. 5. 20.8.

+ n is: nír hvayămasi. 7.56.3.

níh ... hvayāmasi. 6. 90. 2.

+ pari: cf. parihavá.

+ vi : cf. vihavá, vihávya.

+ s a m: sám ahvi. 4. I7. 2.

$h \bar{u} t a$ in puruhũtá.

h $\bar{u} t i$ in deváhūti, pūrváhūti, suhūti.

V I h ṛ: harāmi. 12. 2. $7^{*}, 9,43$.

hárati. 20. 136. Io.

harati. I4. I. 30.

harāmasi. 5. 14.8.

hárāmas. 2. 13. 5 .

hárāt. 4. 18. 2.

harān. I I. 4. 18, I9.

hárantas. 19. 55. 7 (mss. harantás).

áharat. I0. I0. IO.

háras. I8. 2. 36 (or to háras).

hṛtám. 5. 29. 5, 12.

hṛtâ. 12. 5. 29.

hriyámāṇā. I2. 5.29.

jíhîrșati. 2. 25.3. 5. 29. 15 . [hṛt.)

(cf. háraṇa, háras, hāra, hārya,

+ abh i: abhí harantu. I9. 45. 4 .

$+\bar{a}$ : â harāmi. 2. 26.5 . 3. II. $2^{*}$. 
ă ... harāmi. 8. 2. 2 .

āoháranti. 9. 6. 6, 9-12.

āohárāṇi. 3. $15 \cdot 2$.

â harāṇi. 20. 127.9.

à hara. 12. 3. 31. 14. 2. 21 .

a ... harantu. I4. I. 39 .

à ... áharat. ro. ro. $\mathrm{I}$.

â... aharat. I0. 10. 12 .

à 'hărşam. 2. 26.5. 3. II. $3^{*}, 4^{\dagger}$. 8 . I. 20 . I9. 64.1 .

ă ... ahārșam. 6.87. I".

à ... ahārşit. I3. I. 5 .

à 'hār. 7.53.3. 13. 1. 4 .

ăohṛtãs. 2. 26.5 (m. mss. àhūtãs). (cf. āhāryà.)

[I. I9.

+ upã: upăhṛtam (p. upa॰ăh-). ro.

+ s a m ā : samoăhara. 3. 24. 5. 5. 29.12.

+ u d : úd dharet. 20. 136. I6.

úd dhara. 4. 14.7. 9.6. I9. 12.3.36. új jaharus. 3. 9.6 (1. -hrus).

út ... ahārșam. 8. 2. $15 ; 7.28$.

úddhṛtā. 12. 5.34 (s. mss. údhṛ-).

úddhṛteșu. I 5 . I2. I (s. mss. údhṛ-). uddhṛ́tya (p. utohṛ́-). 19. 68. I (l. -tia ?).

[ri-).

uddhriyámānāa. 12. $5 \cdot 34$ (mss. udh-

+ u p a : upaohárati. 9. 6. 27-9, 40-4, 44 . úpa harati. 9.6. 20, 48 .

úpa haranti. 8. 10. 24.

úpa ... haranti. 8. 10. 24.

úpaohṛtā. 12. 5.35.

upåhriyámānāa. 12. 5. 35 .

+ ni: ní harāmas. 6. 117.2.

(cf. nihhārá ?.)

+ pari: páry ahār. 6. ro3. 2, 3 .

+ pra: prá harāmi. I0. 5. 50 .

praohárasi. 7. 56.8 .

praohárema. 14. 2. $3^{\dagger}$.

praohárantas. 19. 46.3 .

práohṛtas. 4. 12. 7 .

+ prati: práti harāmi. 5. 3I. I-9. práti harati. 9. 6. 45-8.

práti hara. 2. 19-22. 2.

práti ... hara. 4. 18.4.

práti harata. 2. 23. 2.

(cf. pratiháraṇa, pratīhārá.)

+ vi: viohárante. 8. 4. 9".

ví hara. 5. 20. 9 . víohṛtam. 5.29. 5.

$\sqrt{ } 2$ h r: hṛnişe. 8. 4. $14^{*}$.

(cf. hṛ̣̣āyu, hṛniyamāna.)

b r ṇa $\mathbf{a} u$ in durhṛnāyú.

h ṛṇ I y a mãn a in áhṛniyamãna.

$\mathrm{h} r \mathrm{t}$ in balihrít.

hṛttás. I8. 1. 23".

hŗtsvás:-suoásas. 18. I. $6^{\circ}$

h r̂́ d: hṛdă. 2. 12. 3. 4. 2 I. $5^{\circ} ; 39$.

10. 18. 3. $66^{\circ}$. 20. 48.2 .

hṛdé. 6. 12. 3. 8. 2. 14; 7. I7.

hṛdás. 3. 25.6 . 6. 42. I; 74. 2. 7 .

95. I. 9. 1. $6 ; 8.8$. I2. 3. 32 . 18.

I. I4. I9. $28.1,2,3 ; 30.4$.

hṛdí. 3. 2. 2, 4 ; 7.2; 25. I, 2, 3. 6. 9 . $3 ; 18.3 .7 .36 .1$. I1.9. 1, 13. 19.9.5. hrrdobhís. 9. 1. I. [14. 2. $5^{\circ}$. hṛtosú. 3. 2. $5^{\prime \prime}$ 8.8.2. 12.2. 33 . (cf. hārd, hărdi, hṛttás, hṛtsvás, hị́daya, hṛddyotá-hị́dya.)

hṛ́d a y a: -am. 2. 29.6. 3. 13. 7. 5 . 20. 3 ; 29. 4. 6. 139. I, 2, 3. 9.6.2; 7. II ; 8. I 4. I O. $2.26 ; 4.25 ; 9.15$. II. 5. 24. I2. I. 8,35 . I6. 3.6. I 8 . I. $15 "$ 19. $28.4 ; 52.4$.

hựdayena. 3. 20.9. 5. 2 I. 2.

hṛ̛dayãya. 6. 90. I.

hṛ̛dayāt. 2.33.3. 6. 76. I. 7. II4. I. 9. $8.8,12$. I9. 52.4 .

hṛ́dayasya. 9. 8. 22.

hṛ́daye. 5. 18. 5. 8. 3. $6^{\circ}, 12^{*} ; 6.24$. hṛ́dayāni. 3.8.6. 6.64.3". I1.9.21. hṛ́dayeşu. 4. 3I. $7^{*}$. 6. 73. 2.

(cf. víhṛdaya, sáhṛdaya, hṛdayaçríş-hṛdayyà.)

hṛda yaoçríṣ: -şam. 6. 9. 2.

h ṛ̣ a yāma yá (p. -yaoām-): -ás. 5.30. 9 .

hṛdayāmayám. 6. I4. I; 127.3.

hṛ dayāvídht: -dham. 8. 6. 18.

h r d a y y à : -ayíam. 6. I8. 1.

hṛdd y otá: -ás. r. 22. I (mss. ed. hṛdyo-; p. hṛodyo-). [sajá.)

(cf. hṛddyótana, hṛddyotabheh ṛd d y ót an a: -as. 5. 20. I 2 (mss. ed. hṛdyó-; p. hṛodyó-).

hṛd d yotaobheșajá: -ám. 6. 24" I (mss. ed. hṛdyo-). 
h ṛ dobalá: -lāís. 5. I8. 8.

hṛ d y a: -as. I6. 3. 5 .

Vh ṛṣ: hárṣamānāans. 4. 3 I. $I^{\dagger}$.

hṛșităsas. 4. 3I. $\mathrm{I}^{\dagger}$.

járhṛșānas. I8. 2. $5^{\text {* }}$.

(cf. harșaṇa, harșin.)

+ a n u : ánu harșadhvam. 6. 97. $3^{\dagger}$.

+ u d: úd dharṣantām. 3. r9. 6 .

úd dharșaya. 5. 20. 8 .

(cf. uddharșín.)

h é đ̣ a : -am. I2. 4. 20, 21, 32.

$\mathrm{h}$ e d a $\mathrm{n}$ a in devahéḍana.

héḍ as: I9. 3. 4 .

héḍasi. 7. 20. 3 .

hetí: -ís. I. 26. I. 2. II. I; 24. I-8. 4. $21.7^{*}$. 6. $27.2^{*}, 3^{*} ;$ 29. I. 8. 2. 9. I0. 5. 43. II. 2. 22. I2. 5. I9. hete. 5.6. $9^{4}$.

hetím. 5.7.7. 6.59.3. I2. 4. 52. hetáye. I. 13.3.

hetyăs. 2. II. 1. 4. 10. 5. 5. 29. $11^{*}$. hetáyas. 3. 26. I. 4. 37. 8, 9. 5. 22. 10.

[mánt.)

(cf. tigmáheti, devahetí, hetihetiománt: -ntas. 5. 18. 9.

hetú: -tós. 9. 8. 3 .

h e m a $n$ in hāimaná.

hemantá: -ás. 6. $55 \cdot 2$. I2. 1. 36 .

hemantâya. 8. 2. 22.

hemantấn. 3. II. $4^{*}$.

(cf. hemantájabdha.)

hemantá。jabdha: -as. 12. 1. 46. hey a in prahéya.

hāí. 7. 50. $2^{3}$. I8. 4. 66.

hāim a ná: -nāú. I5. 4. 5 .

hāima。vat á: -tís. I9. 2. I.

hāiraṇ yá: -yāís. I3. 2. II $1^{\dagger}$.

hotṛ: :tā. I. II. I. 2. 28.2. 4. 32.

$2^{*}$. 5. 12. $3^{*}$; 17. $2^{*}$. 6. 71. I, 2 ; 1 10.

I*. I0. 9.26 ; 10. I9. I 8. I. $29^{*}, 30^{*}$;

4. I5. I9. 42.1 ; 59. $3^{*}$.

hótar. 3. 15.7. 7.97. $\mathrm{I}^{*}$.

hotar. 5. $12.9^{*}$.

hótāram. 3. 21 . 5. I 8. I. $20^{*}, 2 x^{*}$. hótur. 5. 12. $\mathrm{II}^{*}$. 9. 9. $\mathrm{I}^{*}$.

hótārā. $5 \cdot 12 \cdot 7^{*}$.

hótāras. 5. 3. $5^{*}$.

hótāras (voc.). 5. 27. 9 . (cf. áhotṛ, cáturhotṛ, saptáhotṛ, sváhotr, hotṛșádana.) [99. I. h ot ṛşád an a (p. -tṛosá-): -am. 7 . h otrá: -réna. 9. 2.6.

(cf. agnihotrá, agníhotra.)

hótrā: -ām. 8. 4. 6".

hótrās. I I. 6. 14; 7.19. I8. 4. 28*. hótrābhis. I 8. 1. 22*.

(cf. hotrāvíd.)

hotrāovíd: -das. I8. 3. $47^{*}$.

hó $\mathrm{m}$ a: -as. 8. 8. I7.

hómam. 4. 38. 5 .

hómās. 8. 9. 18 .

homās. 19. I. 2 (mss. hó-).

hómāis. 6. 93.2. 10. 6.35.

$\checkmark$ hnu : + pari: párihṇutā (p. -rio hnu-). I2. 5.40.

h yás. 9. 1o. $9^{*}$ (1. hiás).

h ra dá : -ás. 6. I06. It.

hradám. 6. 37. 2.

hradásya. 4. 15. 14. 6. 106. 2.

hradé. 20. 133.6 (mss. hṛdé).

(cf. ghṛtáhrada, çitáhrada.) [kā. $\checkmark$ h rā d: cf.' hradá (?), hrāda, hlādi+ pra: cf. prăhrādi.

hrā d a in prăhrādi.

hrút: hrutás. 6. 5 I. I.

(cf. abhihrút.)

[hruta.

hrut a in áhruta, āhrutabheşajá, ávi-

hruti in ábhihruti.

h r ú ḍ u (? mss. hrúḍu, hựạu, hrúdru, rúụu): -us. I. 25. 2, 3.

h lā dikā: hlădike. I8. 3. 60*.

(cf. hlādikāvant.)

[60*. h 1 à di k à $\circ v$ a n t: hlădikāvati. I 8. 3 . hva in paruṣāhvá. [1.33*.

$\checkmark$ h v a r, h u r, hru : juhurānás. 18. (cf. hrút, hruta, hruti, hvārá.)

+ abhi: cf. abhihrút, ábhihruti, abhihvārá.

$+\overline{\mathbf{a}}$ : cf. āhrutabheșajá.

$+\mathbf{v i :}$ ví jihvaras. I8. 3. $53^{*}$.

víohrutam. I4. 2. $47^{*}$.

víohrutasya. 7.56.2.

(cf. ávihruta.)

$\checkmark$ h va (hve), see $\sqrt{ } \mathbf{h u}$.

h vārá: -ám. 4. I. 2.

(cf. abhihvārá.) 


\section{INDEX BY FINALS}

\section{of Declinable Stems (not compound), Indeclinables, and Roots.}

In the following Index are presented, in reversed alphabctic order. in the first place, the great body of Atharvan simple declinable stems, whether of primary or of secondary derivation, along with such as, though not thenselves oceurring, are implied in their derivatives. It did not seem worth while to burden the list in addition with the compound stems, since these are everywhere given above under

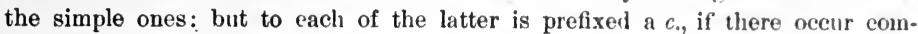
pounds of it; and a $d$. is likewise prefixed if it forms derivatives, although such derivatives are also given in their alphabetie place. If a stem is found only in composition or derivation, these signs are enclosed in parenthesis.

In the second place, the same Index includes the indeclinables and the roots, the former indicated by the sign "ind.", the latter by the root-sign $\mathbf{1}$, as emplnyed above. With these also are used the signs $d$. and $c$., and in the same way, as with the stems; moreover, a $p$. before a root indicates that it occurs combined with prepositions; and $p d$. and $p c$. denote the occurrence of derivatives and com. pounds which admit of being regarded as coming from a root + preposition. (so, for example, atidívan, adhivāká, etc.). A question-mark shows that, on account of the readings of the manuscripts or the edition, the word as given is not to be taken as Atharvan material without referring to what is reported of it it the Index above. Words, finally exhibiting no oceurrences that are not also RigVeda occurrences, have an asterisk (") before them.

All comparative and superlative stems are duly entered here in their alphabetic place; but feminines in $\overline{\mathbf{a}}$ and $\mathbf{i}$ and $\overline{\mathbf{u}}$, of which the corresponding masculines appear in the Index, are not given separately in it. but will be presented by themselves farther on.

The stems of verbal irflection, whether of tense or mode or secondary conjugation, will be given later, in another method of arrangement. But all verbal declinable stems (participles) are included here, as well as the verbal indeclina. bles, or gerüds (distinguished by a prefixed "g."). Stems having forms used as infinitives are also marked (with "inf."). And denominative stems are (as above) indexed as roots in final $y$.

If a stem occurs only as final member of a single compound, the latter is sometimes, for convenience, given instead of the simple stem. A stem of which the accent is plainly derivable from its compounds is usually (in participles, etc.) marked with the accent, the prefixed signs showing in every ease on what authority the accentuation rests.

I have not ventured to adopt Grassmann's ingenious device and management or a hyphen, final or inserted between primitive and added ending, because of the many drawbacks to its successful use-as, the separation, after all, of stems with a ploneticaliy altered ending from others of the same formation, the impossibility of always dividing the ending from the final of the primitive, and, especially, the arbitrariness and uncertainty of division in very many words on account of doubtfil etymology. In a purely alphabetic arrangement one knows, at any rate, just what one has to expect and for low much to make allowance. 


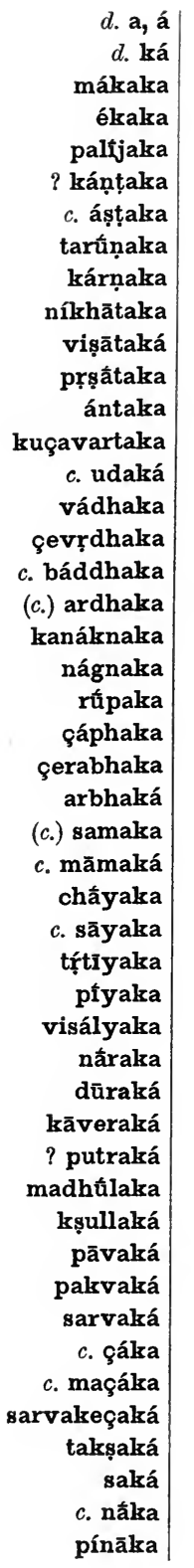

\begin{tabular}{|c|c|}
\hline c. păka & (pc.) māyuka \\
\hline (d.) apāka & vímanyuka \\
\hline (c.) āpāka & urvāruká \\
\hline upáka & "tríkadruka \\
\hline (c.) ? phāka & mahíluka \\
\hline (c.) ? sphãka & ? çúka \\
\hline ? çyāmáka & çiçuká \\
\hline yușmăka & "sukiḿnçuká \\
\hline d. asmăka & ? súka \\
\hline anāsmāká & (pc.) kasuka \\
\hline pc. c. vāká & mạ̣dúk ka \\
\hline cakravāká & d. ánūka \\
\hline (c.) çāka & kambüka \\
\hline çāriçăăka & ābhưka \\
\hline ? ṛkșâka & çālúkka \\
\hline ? ārkșăka & c. úlūka \\
\hline ṿ̛́çcika & (c.) "çuçulūka \\
\hline sahákaṇṭhika & c. vớka \\
\hline túṇ̣ikika & "sṛká \\
\hline ? ámaṇika & d. c. éka \\
\hline ? çlakșṇiká & c. kóka \\
\hline kāirātiká & c. toká \\
\hline antiká & stoká \\
\hline ? văsantika & (pc.) moka \\
\hline nyastiká & pc. mroká \\
\hline paryāyilká & d.c. loká \\
\hline karkariká & c. çlóka \\
\hline man̄galiká & pc. c. çóka \\
\hline ? ávika & çoká \\
\hline vărșika & kaçбka \\
\hline bálhika & vṛkká \\
\hline (c.) jîka & d. c. añká \\
\hline "bhărnjīka & (c.) kan̄ka \\
\hline (c.) mṛḍika & (pc.) tan̄ka \\
\hline āṇụika & ejatká \\
\hline (c.) pratīka & avatká \\
\hline d. c. ánika & c. arká \\
\hline kumbhíka & (c.) parka \\
\hline d. puṇ̣árīka & (d.) kișka \\
\hline$(p c$.$) çarìka$ & mastíșka \\
\hline alīka & c. niṣká \\
\hline dūṣika & d. c. mușká \\
\hline *káṭuka & c. çúşka \\
\hline patayișṇuká & manaská \\
\hline ghătuka & aṇiyaská \\
\hline çipavitnuká & $(p c$.$) vraska$ \\
\hline ? alăbuka & c. khá \\
\hline *chúbuka & d. c. nakhá \\
\hline
\end{tabular}

"makhá

uchlakhá

(d. c.) çikha

d. ukhá

d. c. múkha

c. mayutkha

çan̄khá

( $p c$.) Iñkha

(c.) I, 2 ga

páñạaga

nága

d. c. bhága

d. sāubhaga

malagá

d. valagá

váñsaga

(c.) āga

c. bhāgá

(pc.) liga

c. yugá

d. c. mrrgá

"stegá

véga

c. bhóga

bhogá

c. yóga

c. róga

"logá

ind. añgá

d. c. I áñga

2 áñga

bhañgá

sāráñga

c. piçáñga

(d.) sañga

çitimgá

d. piñgá

(c.) çuñga

c. çrínga

ádga

(pc.) varga

pc. sárga

(pc.) mārga

ind. gha

d. c. aghá

d. c. maghá

sāraghá

tārșțāghá 
to the Atharva-Veda. -lavana

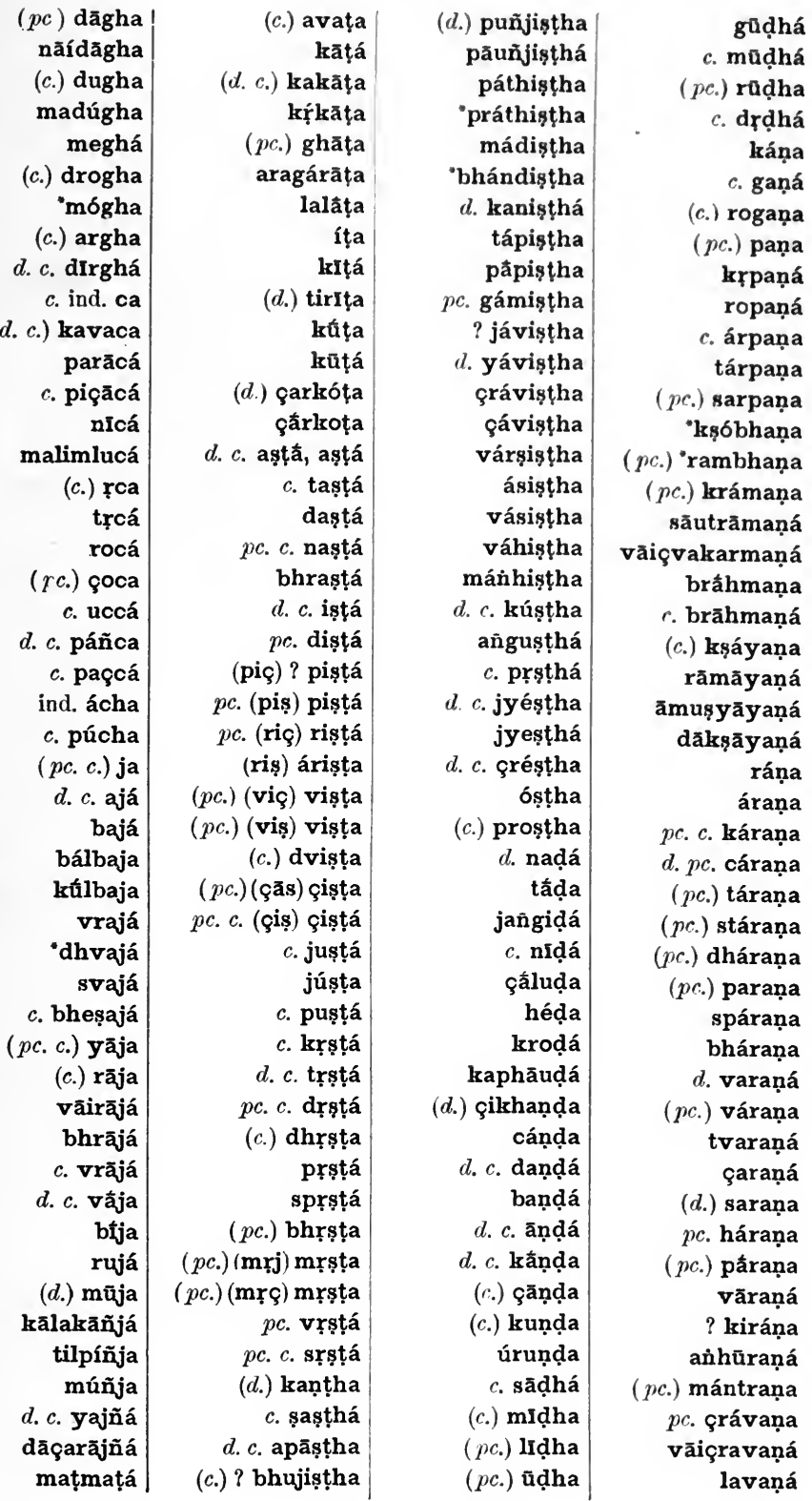




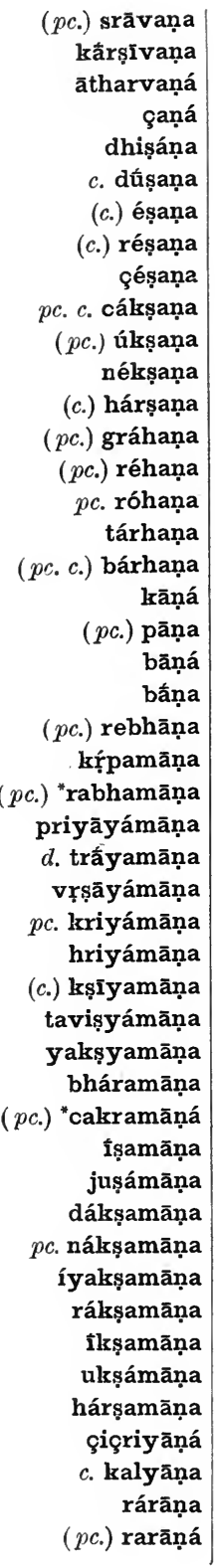

$$
\begin{array}{r}
\text { (pc.) Írānạa } \\
\text { d. c. purānaá } \\
\text { *juhurānáá } \\
\text { (pc.) drāṇa } \\
\text { "dadrānáa } \\
(c .) \text { srāṇa }
\end{array}
$$$$
\text { (pc.) sársrāṇa }
$$$$
\text { (pc.) bruvāná }
$$$$
\text { kurvāná }
$$$$
\text { jușānáá }
$$$$
\text { jujușānáá }
$$$$
\text { dhṛșānáá }
$$$$
\text { *járhṛșāṇa }
$$$$
\text { rihāṇá }
$$$$
\text { hariṇá }
$$$$
\text { írina }
$$$$
\text { drávina }
$$

(pc.) çreșiṇa

d. c. dákșiṇa

? rāuhiṇá

parivatsarina

saḿvatsarína

(pc.) kṣiña gụá arụá karúnạa táruna

dharúna

d. c. váruṇa māitrāvaruná vāruṇá abhiruna

(c.) bhrūṇa c. rṇá d. tṛ́na c. strāína duroná

(c.) droṇa c. çloná

(c.) çoṇa vṛkná

c. nựmná

d. c. kárṇa karnáa

c. parná sāúparna

c. várna

(c.) girṇa

$$
\begin{aligned}
& \text { jīrṇá } \\
& \text { stirnáá } \\
& \text { (pc.) çîrṇa } \\
& \text { (c.) "ūrna } \\
& \text { c. pūrná } \\
& \text { pc. mūrṇá } \\
& \text { ușnáá } \\
& \text { çúș̣̣a } \\
& \text { d. c. kṛṣnáá } \\
& \text { kŕ̛ṣna } \\
& \text { (c.) vrṣṇa } \\
& \text { d. ? çlakșnáá } \\
& \text { d. c. tilkṣná } \\
& \text { háliksșna } \\
& \text { árūkșna } \\
& \text { kắrṣna } \\
& \text { d. c. tá }
\end{aligned}
$$

d. vikan̄kata

vāikañkatá

pc. c. gatá yajatá

c. rajatá

tatá

$p c$. tatá

( $p c$.$) nata$

(c.) pata "batá

(pc.) mata

(pc. c.) yata

"haryatá paçyata

(d.) bharata bhắrata

d. c. vratá vráta

hāimavatá părāvata āirāvatá

d. párvata părasvata vāivasvatá d. c. çatá c. darçatá (c.) kșata pc. c. hatá bărhata

pc. c. d. khātá pc. c. jātá pc. $c$. jũătá snātá

(pc.) pāta

tāimātá

pc. c. yātá

(pc.) khyāta

c. rātá

(d.) kirāta

d. kāirāta

vrăta

c. çrātá

c. văta

(c.) vāta

(c.) sāta

(pc. c.) ita

pc. likhitá

$p c$. citá

yācitá

$p c$. jitá

(pc.) ubjita

(pc.) viștita Iḍitá hiditá

(pc.) patita

? ántita

(pc.) vyathita nāthitá

(pc.) sthita

(pc.) dita

(pc.) madita

raditá

viditá

c. uditá

mrịditá

vanditá

(pc.) snapita gupitá yupitá

pc. árpita gușpitá skabhitá

$p c$ stabhitá

(c.) çumbhita pc. c. $(\mathbf{m} \bar{a})$ mitá

pc. (mi) mitá

çamitá

c. caritá

c. hárita 


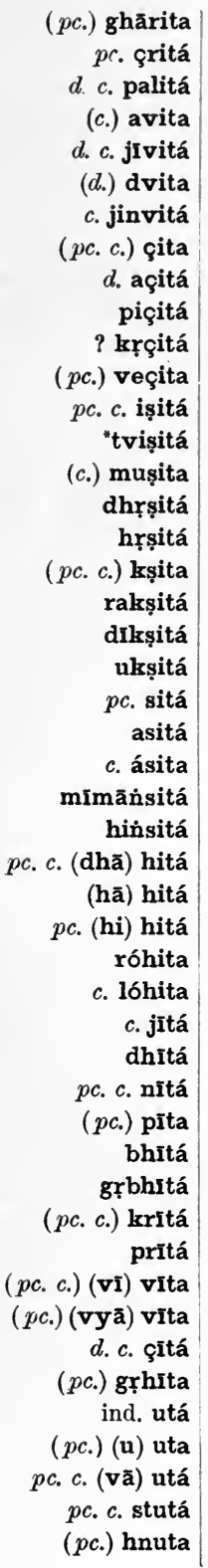

\begin{tabular}{|c|c|c|}
\hline ádbhuta & ( $p c$.$) bhakta$ & klptá \\
\hline pc.c. yutá & pc. saktá & kartá \\
\hline$p c . c$. cyutá & $(p c . c$.$) rikta$ & (c.) garta \\
\hline savidyutá & (pc.) sikta & márta \\
\hline ámanyuta & pc. $c$. uktá & $(p c . c$.$) varta$ \\
\hline rutá & (pc.) mukta & pc. c. pûrtá \\
\hline măruta & $p c, c$. yuktá & asûrta \\
\hline pc. çrutá & $(p c$.$) vŗkta$ & d. c. ásta \\
\hline pc. srutá & pănta & $p c$ astá \\
\hline (pc. c.) hruta & $(p c.) \mathrm{tta}$ & (c.) basta \\
\hline (c.) pluta & cattá & $(p c$.$) yasta$ \\
\hline$c$ sutá & c. dattá & $(p c$.$) srasta$ \\
\hline pc. c. hutá & (pc.) matta & pavásta \\
\hline (c.) jūta & $(p c$.$) yatta$ & pc. c. çastá \\
\hline c. dūtá & $(p c$.$) "satta$ & d. c. hásta \\
\hline c. pūtá & (c.) "svātta & nāirhastá \\
\hline$p c . c$. bhūtá & pc. c. cittá & ind. átha \\
\hline (c.) "mūta & pittá & "yajátha \\
\hline jĩmúta & pc.c. vittá & "saptátha \\
\hline dyūtá & pc. c. nuttá & d. vidátha \\
\hline$(p c . c$.$) sūta$ & dyuttá & (c.) patha \\
\hline sūtá & (c.) kṛtta & d. c. çapátha \\
\hline pc. c. hūtá & nṛttá & d. c. rátha \\
\hline d.c. rrtá & (pc. c.) vṛtta & $(p c$.$) vasatha$ \\
\hline$(p c$.$) rta$ & d. c. ánta & c. nāthá \\
\hline pc. c. kṛtá & dánta & ( $p c$.) githa \\
\hline d.c. ghṛtá & c. hemantá & (c.) "nitha \\
\hline d. tṛtá & ? jīvantá & (c.) r pitha \\
\hline$(p c . c$.$) stṛta$ & veçantá & (c.) 2 pitha \\
\hline pc. c. dhṛtá & d. vasantá & yūthá \\
\hline (pc. c.) bhṛta & d. vāsantá & c. várūtha \\
\hline c. mṛtá & ind. hánta & (pc.) rtha \\
\hline nāirṛtá & pc. krāntá & (c.) pritha \\
\hline pc. vṛtá & c. çrāntá & (pc.) bhṛtha \\
\hline varivrụtá & çāntá & d. c. ukthá \\
\hline c. çrtá & çakúnta & c. açvatthá \\
\hline pc. hṛtá & galuntá & manthá \\
\hline d. etá & ṿ̛́nta & c. ártha \\
\hline eta & pc. c. taptá & tīrthá \\
\hline (c.) keta & d.c. saptá & caturthá \\
\hline (d.) çyeta & (pc. c.) āpta & $(p c . c$.$) stha$ \\
\hline çvetá & (pc.) lipta & (c.) astha \\
\hline çyāitá & c. kșiptá & (c.) da \\
\hline c. kapóta & uptá & (c.) ada \\
\hline pramóta & c. guptá & (c.) gada \\
\hline (c.) dyota & (pc.) lupta & "nadá \\
\hline (pc.) akta & suptá & $c$. padá \\
\hline c. nákta & tṛptá & paniṣpadá \\
\hline
\end{tabular}




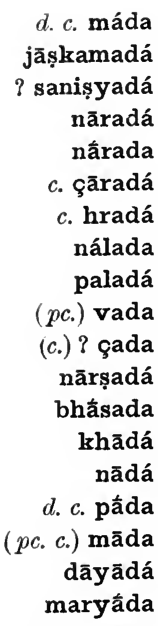

(pc.) hräda

(pc. c. c.) vāda

(d. c.) sāda

(c.) vida

kákuda

trāikakudá

(pc.) tuda

(c.) arbuda

(c.) muda

kúmuda

(pc.) roruda

( $p c$.) cheda

c. bhedá

pc. c. véda

vedá

(d. pc.) toda

(pc.) noda

$p c$. móda

róda

tāúda

(pc.) skanda

pc. nánda

pc. kránda

klandá

(c.) vanda

(c.) kānda

*upabdá

(d.) çabda

c. tardá (c.) dha

ind. ádha

d. magádha

māgadhá

vidradhá

d. c. vadhá

(c.) ind. sadha

"gādhá

(pc.) bādha

(c.) vāibādha

(pc.) vyādha

( $p c$.) rādha

(pc.) yudha

c. àyudha

vírudha

vimṛdhá

d. çevṛdha

d. c. médha

? védha

(c.) sedha

pc. c. bodhá

(c.) yodha

(c.) rodha

kródha

c. jagdhá

c. dagdhá

pc. digdhá

$p c$. dugdhá

mugdhá

c. drugdhá

pc. naddhá

? báddha

$p c . c . d$. baddhá

(pc.) rāddha

$p c . c$. iddhá

$p c$. viddhá

(pc. c.) buddha yuddhá

( $p c$.$) ruddha$

kruddhá

c. çuddhá

( $p c$.) rddha

$p c$. c. vṛddhá

andhá

d. c. skandhá

gandhá

c. bandhá

kábandha kúsindha

kukúndha

(c.) jabdha

(c.) dabdha

(pc.) rabdha árdha

d. c. ardhá

*várdha

na

c. ind. ná aná

khaná

c. ghaná

d. jaghána

"ghanāghaná

ind. caná

( $p c$.) vắcana

(pc.) sécana

(pc.) *ócana

(pc. c.) mócana

pc. d. rocaná

(pc.) çócana

$(p c$.$) áñcana$

(pc.) parcana

d. c. jána

(c.) yájana

dāívajana

(c.) vrọána

c. téjana

( $p c$.$) néjana$

$c$. bhójana

pc. c. Yójana

( $p c$.$) áñjana$

(pc.) bhañjana

( $p c$.) sárjana

(c.) héḍana dánụana

( $p c$.) yátana

(c.) cắtana

sanātána

nútana

pc. c. cetaná

(c.) dyótana

(pc.) kártana

(pc.) vártana d. stána

c. sádana

c. sădana c. védana

c. odaná

khódana

códana

(pc.) nándana

? spandaná

(pc.) mandana

(pc.) krándana

c. vándana

d. c. dhána

(pc.) dhana

(c.) vyadhana

(pc.) rấdhana

(pc.) "sădhana

edhána

(pc.) ródhana

c. bándhana

c. várdhana

pc. jánana

(pc.) vánana

(pc.) hánana

(pc.) jñápana

pc. tápana

sāmintapaná

snápana

(pc.) vápana

çápana

gópana

(c.) yópana

c. jambhana

(c.) dámbhana

çúmbhana

( $p c$.) gámana

(c.) çámana

anāmaná

"sāmaná

hāimaná

pc. c. áyana

cáyana

(pc.) láyana

c. çáyana

c. hāyaná

pálpūlana

d. vána

(c.) vana

pávana

( $p c$.$) yávana$

c. cyávana 
pc. c. sávana $(p c$.) havana

(c.) yăvana c. jivana

d. c. bhúvana

(c.) súvana

(pc.) dévana

bhăuvaná

? yãúvana

? prātisutvaná

c. áçana

(c.) năçana

(pc.) spăçana kứçana péçana

(pc.) véçana

( $p c$. ) bhránçana

c. karçaná

(pc.) "marçana d. sána ásana

(pc.) çásana àsana

( $p c$ ) vấsana

( $p c$.) dahana náhana gláhana

(c.) văhana méhana

c. dứnhana (pc.) ăna cakāná

mumucāná çóçucāna jầna

(pc.) sasvajāná zjāná

pc. mṛjāná bhejāná

(pc.) jñăna jajñāná iḍāna

(d.) prīnāna gṛ̣āaná pc. vṛnāaná prāiṇāná gṛhṇāná (pc.) tāna paprathāná (pc. c.) sthắna

c. I dăna

pc. 2 dăna

( pc.) dádāna

çăaçadāna

$p c$. vidāná

tundāná

(pc. c.) dhăna dádhāna

( $p c$.) idhāná

vāvṛdhāná índhāna

(pc.) rundhāná pc. jānāná punāná

( $p c$.) ghnāná çrathnāná (pc.) snấna c. păna

(c.) păna pc. pípāna

(pc. c.) sphắna (pc.) jáñjabhăna pc. măna cakamāná yăcamāna rócamāna ( $p c$.$) "çváñcamā-$

(pc.) muñcámāna ? yáchamāna ichámāna *prchámãna c. yájamăna pc. bhrấjamāna vijámāna réjamāna

(pc.) tíșthamāna *yátamāna

(pc.) dyótamāna

(pc.) "vartamāna práthamāna módamāna

$p c$. syándamāna vándamāna nădhamāna $p c$. bădhamāna $(p c$.)krañsyámāna spárdhamāna | ? mimãñsyámãna várdhamăna ( $p c$.) nahyámãna

khánamāna pc. uhyámāna

$p c$. vépamāna duhyámăna

kálpamāna d. pávamăna

çúmbhamāna dhăvamāna

(pc.) ámamāna pãvamāná

( $p c$.) námamāna pínvamăna

(pc.) náyamăna çaçamăná

tóçamãna

samåná

răsamāna

jâyamāna

raçanāyámāna

(pc.) pyăyamāna

İyamāna

(c.) hṛṇiyamāna

pc. c. dīyámāna

(pc.) dhīyámăna

pc. nìyámāna

mìyámāna

( $p c$.) vīyámāna

"kaviyámāna

(pc.) manyūya-

māna

(pc.) acyámåna pacyámāna sicyámāna mucyámāna

(pc.) bhajyámāna yujyámāna

(pc.) sṛjyámāna pátyamāna

( $p c$. ) kṛtyámāna

(pc.) pádyamāna

(c.) chidyamāna udyámāna badhyámāna rădhyamāna ( $p c$.) búdhyamāna

pc. mányamāna hanyámāna $p c$. tapyámāna

(pc.) upyámāna açyámāna piçyámāna

(c.) dṛçyamāna sumanasyámāna mimãñsamāna (pc.) lípsamāna váhamāna sáhamāna

(pc.) găhamāna

( $p c$.) gûhamāna pc. mímāna

(pc.) jagmāná

(pc.) dhmầna

pc. $c$. yăna çáyāna

pc. dìdhyāna "stávāna

kṣṇuvāná stuvāná súvāna kṛ̣̣vāná pc. tanvāná vanvāná

(pc.) *júhvāna ānaçāná

(pc.) paspaçāná çmaçãná

*vāvaçāná

(pc.) çaçāná pépiçāna $p c$. çíçāna ìçāna "párçāna (pc.) sắna mandasāná namasāná bhiyásāna $p c$. vásāna (pc.) çăsãna sāsahāná 


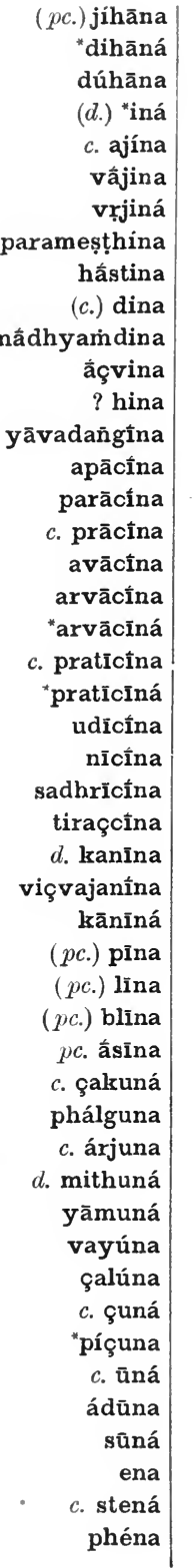

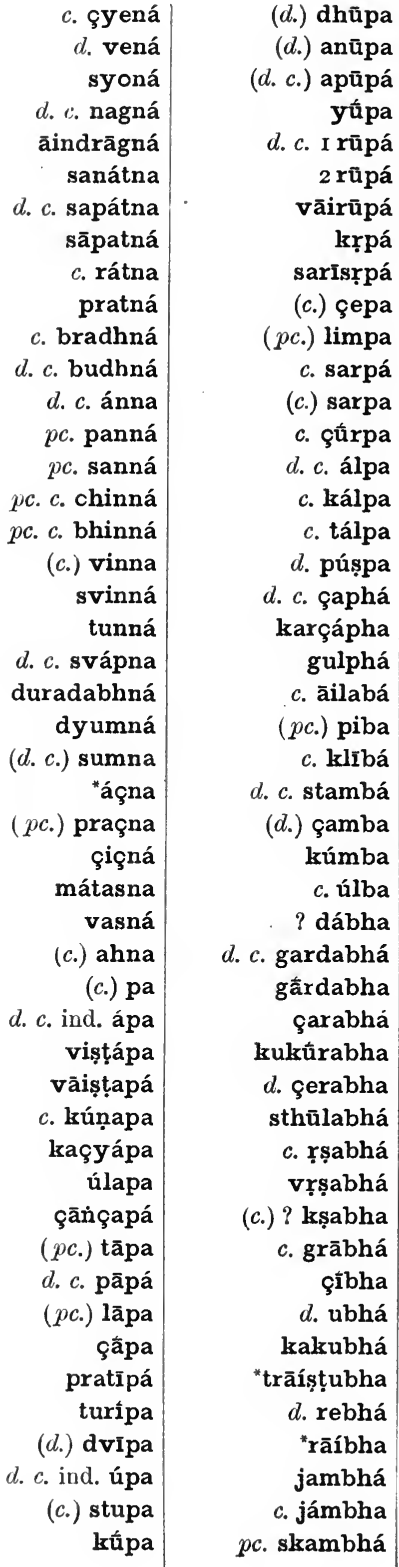

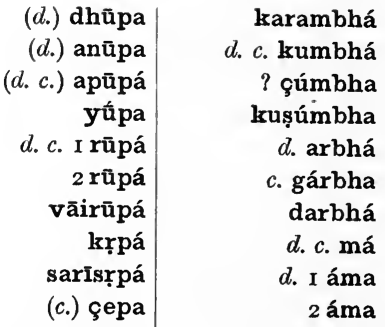

karambhá

d. c. kumbhá

? çúmbha

kușúmbha

d. arbhá

c. gárbha

darbhá

d. c. má

d. I áma

2 áma

(pc. c.) gama pañcamá

c. așțamá

tuvíșțama

vapuștama

katamá

çréșțhatama

*inátama

bhīmátama

yatamá

priyátama

vīrátama

çivátama

? púrvatama

vaçátama

"nị́tama

gótama

súbhișaktama

"mádhumattama

dyumáttama

manyumáttama

bhágavattama

bálavattama

c. uttamá

çámintama

madíntama

c. saptamá

yaçástama

c. prathamá

c. dáma

( $p c$.$) dhama$ adhamá upamá

d. c. yamá

(c.) yama

c. madhyamá

(d. c.) carama vṛtrahántama 
c. paramá kāuramá pc. kráma

( $p c$.$) cañlzrama$

çráma

avamá

navamá

daçamá

ruçáma

ksamá

d. c. samá

(c.) āma

c. āmá

d. c. kằma

d. bhắma

yāmá

yắma

(pc.) yāma

d. çyāmá

d. rāmá

(pc.) krāma

d. c. grằma

c. srāmá

c. lalấma

c. vāmá

(c.) kṣāma

imá

khanitríma

pũtríma

krrtríma

sríma

d. c. himá

d. c. stímá

d. bhimá

suçima

*úma

d. c. dhūmá

(c.) *sūma

d. kșéma

c. stóma

d. c. sóma

hóma

c. rukmá

d. çagmá

c. tigmá

c. idhmá

c. gharmá

dhárma

\section{Irmá \\ kūrmá \\ jālmá \\ d. grișmá}

d. c. çúşma

grāíşma

c. yákşma

(c.) lakşma

ind. sma

"dasmá

brāhmá

jihmá

yá

$p c$ áya

purilkáya

"başkáya

c. gáya

gáya

pc. c. jáya jayá

ṣ̛́ñ̄jaya

cátușțaya

(c.) ? jyotaya

d. c. hị́daya

c. bhayá

d. c. ubháya

"çakamáya

(c.) āmaya

? gomáya

"manasmáya

ayasmáya

hiraṇyáya

(pc.) kraya

trayá

(pc.) çraya

āvayá

druváya

d. dvayá

(c.) çaya

c. kșáya

(pc.) āya

? kãyá

(c.) gãya

(pc.) "jñāya

(pc.) g. sthằya

(c.) dāya

$p c . c$. g. dăya

(pc.) g. dhằya (pc.) g. pầya

(pc.) g. mấya

c. arầya

? (pc.) g. ghrăya

(pc.) lăya

kulâya

(c.) vãya

g. gatvằya

g. "hatvăya

(pc.) g. "çấya

(pc.) g. hăya

c. yajñiya

yajñāy ajñíya

çagmíya agriyá

"suvidatríya kşatríya

nakşatriya mitríya

c. kșetriyá çrótriya

samudríya

d. c. indriyá

d. c. priyá

abhriya

usríya

"rtvíya

ŕtviya

āmantraṇiya

dakșinịya

parvatiya

dvitiya

d. c. tritiya

(pc.) g. niya

āhavantya

upajivaniya

agnișomíya

túriya

turíya

*tūya

(pc.) g. dhứya

vădhūya

(pc. c.) bhứya

(pc.) g. bhūya

strāíșuya

(c.) súya

d. c. súrya

pắrṣteya văsateya

rāthajiteyá

c. stéya

văsteya

pc. c. déya

( $p c . c$.) dhéya

âsneya

(c.) péya

? sabhéya

$p c$. méya

"sārameyá

( $p c$.) khyéya

(c.) jyéya

vāiçāleyá

'vareyá

pārușeyá

pāúruşeya

c. ārșeyá

(c.) séya

( $p c$.) héya

c. çikyà

anūkyà

(pc. c.) mokya

lāukyá

sakhyá

úkhya

múkhya

sãúbhāgya

dāúrbhāgya

bhógya

yógya

áñgya

(pc.) vargya

(pc.) g. "ácya

(c.) pacya

adharācyà

prācyà

(pc.) g. sícya

udícyà

"apícyà

anūcyà

tiraçcyà

(c.) jya

(pc.) g. májya

c. ăjya

(pc.) g. bhājya

- rājyá

rājyà 


\begin{tabular}{|c|c|c|c|}
\hline c. răjya & d. c. vrătya & (pc.) mādya & udāpyà \\
\hline svarăjya & vrātyá & (c.) vādya & samāpyà \\
\hline sămrājya & (pc.) g. ítya & (pc.) g. chídya & kupyá \\
\hline ărtvijya & cítya & (c.) bhídya & $(p c$.$) g. lúpya$ \\
\hline yújya & $(p c$.$) g. jítya$ & (pc. c.) vídya & anūpyà \\
\hline$(p c)$ g. mứjya & sắngrāmajitya & talīidyà & ( $p c$.$) g. sị́pya$ \\
\hline - yācñyá & d. ādityá & (pc. c.) udya & çamópya \\
\hline bāṭyá & c. nítya & hựdya & tārpyà \\
\hline níștya & (pc.) g. mítya & ? védya & sphyá \\
\hline *yavișţhya & apamítya & vándya & jabhya \\
\hline (c.) jyāișțya & sāmityá & bádhya & nábhya \\
\hline çrāíșțya & pălitya & úbadhya & (c.) yabhya \\
\hline idya & dāúrjīvitya & d. c. mádhya & (pc.) g. rábhya \\
\hline karmaṇyà & (pc.) g. çrútya & nāirbādhyà & sábhya \\
\hline ráṇya & $(p c$.$) g. ŕtya$ & (pc.) vyādhya & (c.) dābhya \\
\hline raṇyà & (pc. c.) g. kứtya & sādhyá & (pc.) g. gựbhya \\
\hline d. áraṇya & (pc.) g. (kr) kṛ́tya & ( $p c$.$) g. sídhya$ & (pc.) g. krámya \\
\hline āraṇyá & (c.) krítya & (c.) kșudhya & (c.) kāmya \\
\hline d. c. hírạ̣ya & carkŕtya & gŕdhya & kămya \\
\hline hāiraṇyá & (c.) bhṛ́tya & médhya & samāmyà \\
\hline *doșaṇyà & (pc.) g. vị́tya & (c.) yodhya & vyāmyà \\
\hline çirrșaṇyà & (pc.) g. (vṛ) vị́tya & skándhya & grāmyá \\
\hline *niṇyá & (c.) sị́tya & nyá & kșemyá \\
\hline c. púṇya & (pc.) g. hṛ́tya & d. c. anyá & somyá \\
\hline *varuṇyá & d. sraktyá & ánya & sāúmya \\
\hline upatṛnya & srā] & jaghanyà & harmyá \\
\hline c. váreṇya & rántya & janyá & hṛdayyà \\
\hline kárṇya & (d.) sahar & jánya & pravāyyà \\
\hline dhíșṇya & sāhantya & pâncajanya & prahāyyà \\
\hline d. c. ṿ̛́ṣṇya & tyá & c. rājanyà & çapatheyyà \\
\hline tyá & c. mártya & c. parjánya & "sahaçéyya \\
\hline$(p c$.$) g. gátya$ & agástya & (c.) dhanya & *aryá \\
\hline ? (pc.) g. tátya & ? vidathyà & ványa & (c.) cárya \\
\hline d.c. ápatya & çapathyà & dhanvanyà & nárya \\
\hline c. gấrhapatya & "ráthya & adānyá & c. márya \\
\hline prājāpatyá & ukt & c. dhānyà & "svaryà \\
\hline ádhipatya & ind. adyá & jāyănya & ărya \\
\hline vānaspatyá & (c.) ádya & (c.) çūnya & kāryà \\
\hline bārhaspatyá & $(p c$.$) g. dádya$ & ? bhṛtenyà & ācāryà \\
\hline "jāspatyá & $(p c$.$) g. pádya$ & "yudhénya & $(p c$.$) tārya$ \\
\hline matyà & (d.) apadya & sénya & vărya \\
\hline$(p c$.$) g. yátya$ & *mádya & vāinyá & āhāryà \\
\hline vrátya & d. c. avadyá & (c.) ghnya & írya \\
\hline khâlatya & $(p c . c$.$) sádya$ & budhnyà & tiryà \\
\hline devatyà & $(p c$.$) g. sádya$ & dāúșvapnya & $(p c$.$) g. girya$ \\
\hline d. c. satyá & bhasadyà & c. svápnya & d. c. viryà \\
\hline$(p c$.$) g. "hátya$ & ādyá & (c.) ahnya & suvírya \\
\hline (c.) hátya & c. ādyà & "apya & ajuryá \\
\hline
\end{tabular}




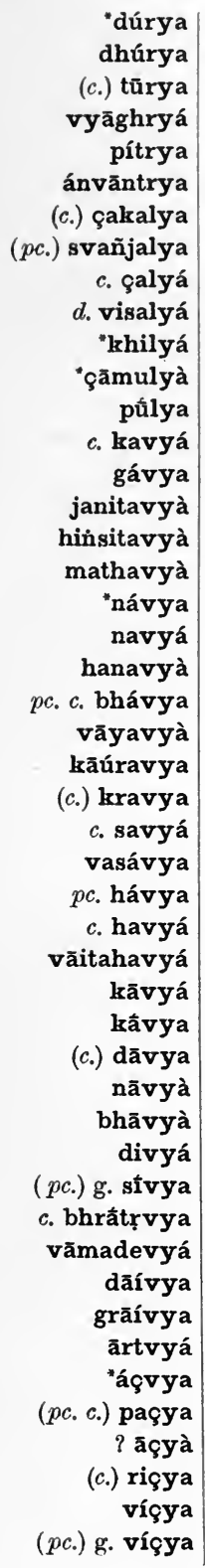

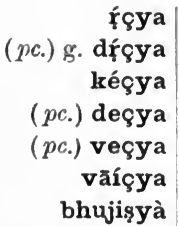

$$
\begin{array}{r}
\text { ? mātsyá } \\
\text { utsyà } \\
\text { barjahyà } \\
\text { c. vahyá } \\
\text { băhya } \\
\text { 'grāhyà } \\
\text { svãhyà }
\end{array}
$$

(pc.) g. úhya gúhya

(pc.) g. rúhya

(c.) g. gł̣̆hya gŗ́hya (pc.) ara c. ará $p c . c$. kará karúkara sūkará çárkara

d. c. púşkara muşkará

c. táskara ākhará

(pc.c.) gara gárgara

(pc. c.) cara

"carācará

nyocará

"jára pațará

"ávidușțara jațhára

(c. ?) tara katará

tīkṣṇátara yatará pratará açvatará

vasudhătara c. Ítara "vitará kavítara mádhutara

bhișálstara mádhumattara ávattara "bhágavattara çúșmavattara vĩryàvattara ásattara

d. c. úttara

uttará

ántara

ratharntará

samintará

(pc.c.) stara

mṛtámanastara

parastará

"tavástara

(c.) dara

tāyādará

c. udára

d. c. ádhara

(c.) nara

c. vāiçvānará

d. c. pára

c. ápara

úpara

tūpará

çámbara

d. udumbára ãúdumbara

c. bhára smará

d. c. vará I vára

c. 2 vára

c. ávara çākvará

(c.) jvara

d. c. adhvará

kárvara

atiçarvará c. İ̧̧vará

$p c$. svára gáhvara çára pc. çará

(pc. c.) kşara

"anṛkșará

pc. c. sará

'tásara

svásara

(c.) kesara matsará

(c.) vatsara d. c. ārá 


\begin{tabular}{|c|c|c|c|}
\hline udārá & kurkurá & ind. átra & astrá \\
\hline (c.) kāra & (d.) bhañgura & atrá & vástra \\
\hline ? āgārá & c. turá & yájatra & c. drá \\
\hline (pc. c.) cāra & c. ătura & ind. tátra & d. c. bhadrá \\
\hline *jārá & vithurá & d. pátatra & chidrá \\
\hline tārá & sádhura & "samskṛtatrá & mudrá \\
\hline (d. c.) stāra & bándhura & $(p c . c$.$) datra$ & d. c. samudrá \\
\hline (c.) dāra & $(p c$.$) sphura$ & (c.) vidatra & d. c. rudrá \\
\hline (pc.) dhāra & amura & c. ind. yátra & kșudrá \\
\hline c. pārá & namurá & c. gãyatrá & c. çūdrá \\
\hline pc. c. bhārá & çváçura & ind. anyátra & c. candrá \\
\hline (pc. c.) māra & c. kșurá & d. c. kșatrá & átandra \\
\hline d. kumārá & d. c. ásura & d. c. nálsṣatra & mandrá \\
\hline çinçumăra & āsurá & gătra & d. c. índra \\
\hline kāúmāra & "pāṅsurá & (c.) "sthātra & āindrá \\
\hline karmăra & "añhurá & c. pătra & c. ārdrá \\
\hline vấra & khaḍutura & (c.) rātra & *ādhrá \\
\hline (c.) vāra & (d.) maṇụūra & c. citrá & ăgnidhra \\
\hline çātavārá & d. c. dūrá & janítra & viddhrá \\
\hline (c.) dvāra & c. múra & d. c. mitrá & c. gṛ́dhra \\
\hline$p c$. hvārá & c. mayưra & āmitrá & (c.) bandhra \\
\hline (c.) āçāra & rūrá & c. áritra & várdhra \\
\hline sắra & krūrá & carítra & d. c. ind. prá \\
\hline$(p c . c$.$) hāra$ & c. çứra & c. pavítra & (c.) pra \\
\hline$(p c$.$) gira$ & súra & "bhavítra & c. riprá \\
\hline c. ajirá & d. kúbera & sāvitrá & vípra \\
\hline$(p c$.$) tira$ & c. vāíra & çvitrá & c. kșiprá \\
\hline çithirá & c. ghorá & d. c. putrá & (c.) tṛpra \\
\hline c. sthirá & kiçorá & c. ind. amútra & d. c. abhrá \\
\hline c. khadirá & paṭãurá & mútra & "dabhrá \\
\hline badhirá & c. cakrá & sútra & çibhrá \\
\hline rudhirá & vakrá & c. vṛtrá & çubhrá \\
\hline sthávira & çakrá & netrá & ? namrá \\
\hline d. çíçira & c. çukrá & d.c. kṣétra & (c.) tāmra \\
\hline çāiçirá & d. c. ágra & jāítra & (c.) dhūmra \\
\hline iṣirá & c. ugrá & d. gotrá & vrá \\
\hline (c.) jira & vāíyāghra & stotrá & vavrá \\
\hline c. dhíra & d. c. vyāghrá & ? potrá & tĩvrá \\
\hline gabhīrá & (pc.) jighra & d. c. çrótra & vāçrá \\
\hline c.) gambhīrá & d. c. vájra & c. hotrá & c. miçrá \\
\hline çárira & c. rāṣțrá & c. pãútra & ájasra \\
\hline d. kurîra & tvāșțrá & yóktra & dasra \\
\hline *açrīrá & úșțra & c. sattrá & d. c. sahásra \\
\hline d. c. vīrá & "deșțrá & tántra & sāhasrá \\
\hline (d.) pavïra & péșțra & d. c. mántra & d. usrá \\
\hline d. c. kṣirá & c. dáñṣțra & $d$. āntrá & "hin̉srá \\
\hline c. síra & méḍhra & kártra & puṣkalá \\
\hline çān̄kurá & (c.) tra & vártra & c. khála \\
\hline
\end{tabular}




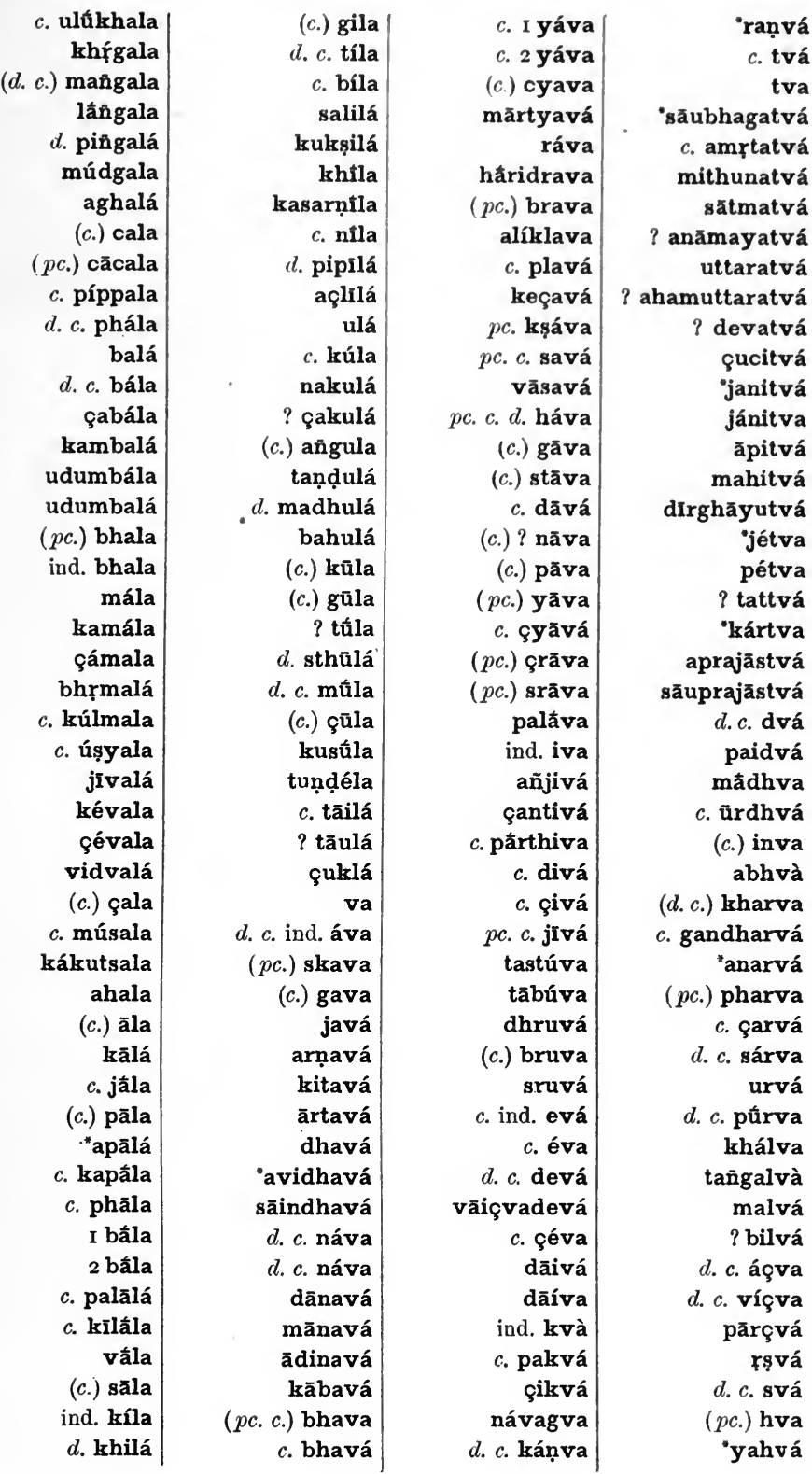




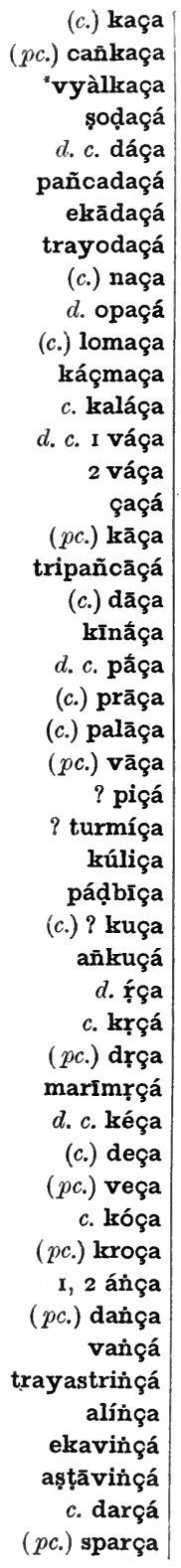

\begin{tabular}{|c|c|}
\hline ārçá & c. póşa \\
\hline dūrçá & c. akşá \\
\hline (c.) $\mathrm{abalça}$ & I ákşa \\
\hline káṣkașa & c. 2 ákṣa \\
\hline jașá & d. c. kákşa \\
\hline ? àșa & d. dákṣa \\
\hline c. măssa & d. c. pakșá \\
\hline c.) kalmáșa & c. bhakșá \\
\hline d. c. jálāșa & yakșá \\
\hline jālāṣá & plakșá \\
\hline yévāşa & (pc.) mikșa \\
\hline ? ișá & d. c. antárikşa \\
\hline c. kílbișa & (c.) ŗ̣ș̣a \\
\hline (pc.) mișa & c. āukșá \\
\hline (c.) rișa & dhvăñkșa \\
\hline d. c. vișá & (pc.) dharşa \\
\hline víşa & d. c. varșá \\
\hline d. tavişá & c. çIrșá \\
\hline mahișá & (d. c.) sa \\
\hline ușṇiș̣a & d. sá \\
\hline (d.) karișa & (c.) okasa \\
\hline (d.) purișa & (pc.) ghasa \\
\hline (c.) ghușa & (c.) varcasa \\
\hline túṣa & sāuryavarcasá \\
\hline c. mănuşa & rajasá \\
\hline (c.) āyușa & vetasá \\
\hline aruṣá & (c.) vedasa \\
\hline d. c. parușá & nāudhasá \\
\hline d. c. púrușa & (c.) nasa \\
\hline çușá & sāumanasá \\
\hline cākşușa & (c.) ānasa \\
\hline kán̄kūṣa & (c.) enasa \\
\hline pīyúșa & nahhasá \\
\hline "çūșá & c. camasá \\
\hline (c.) vrșa & tamasá \\
\hline (pc. c.) eşa & cāndramasá \\
\hline eșá & payasá \\
\hline (pc.) jeșa & c. àyasa \\
\hline (pc.) meșa & ? vāyasá \\
\hline meșá & ? prapyasá \\
\hline (pc.) çreșa & $(p c . c$.$) bhyasa$ \\
\hline (pc.) çleșa & d.c. rása \\
\hline (pc.) veşa & ān̄girasá \\
\hline c. treșá & c. sanisrasá \\
\hline (pc.) dveşa & c. "yávasa \\
\hline c. oșá & ? āuccāiḥçravasá \\
\hline d. c. ghóșa & upakvasa \\
\hline sajóșa & $(p c$.$) çvasa$ \\
\hline
\end{tabular}

? rākşasá

hasá

c. hása

(c.) $I, \imath 2,3$ ãsa

àsa

kāsá

ghāsá

dāsá

"dăsa

c. mása

pāurṇamãsá

(pc.) trāsa

d. c. balâsa

c. kilấsa

(pc.) vāsa

(pc.) çvāsa "çāsá

(pc.) çāsa bísa

sisa

c. ánisa

kańsá

ghrañsá

(c.) srańsa

(pc.) dhvańsa

c. çánisa

nārāçañsá hañsá

d. māñsá

d. c. vatsá

mártavatsa

d. útsa

kútsa

d. drapsá ind. ha

(c.) ha

ind. áha

(c.) aha

c. mahá

ind. samaha

c. gráha

gláha

pc. váha

c. ind. sahá

(c.) sāha, saha

(pc.) dāha

(pc.) nāha

kâhābāha 
varāhá

(c.) grāha

pc. c. d. vaha

(c.) sāha

sātrăsāhá

$c$. ind. ihá

rerihá

kúha

(pc.) ūha

c. gṛhá

ehá

dóha

móha

róha

(pc.) droha

? lohá

c. sinhhá

(c.) dṛnha

(c.) tarha

(pc.) barha

vihálha

$d$. c. ind. $\mathbf{a}$

, $\mathbf{k a m}, \mathbf{k a ̄}$

çalākakấ

c. áșțakā

vișāṇakâ

tărakā

(c.) avakā

"ropanăăkã

jyākā

"rākầ

çāriçăkā

pratīcikâ

kakățikā

trusțiká

kanișțhikầ

kúșțhikã

dhấṇikā

háriknikā

? çlakṣṇikă

kāirātikâ

d. çîtikā

c. sútikā

? iyattiká

kŕ̛ttikā

āvapantiká

d. "hlādikā

kaninikā gavinikã

c. alpikâ

kumārikă

? maṇḍurikā

pingalikà

tãuvilikă

c. piptlikā

khárvikā

? upajíhvikā

mákșikă

kăsikã

năsikã

năḍikă

iṣ̂tkā

dūṣtkāa

ŗ̣ş̣̂kā

c. stúkā

dhénukã

mahílukā

ișukâ

kárkandhūkā

"kṣvíñāa

c. ulkầ

$\checkmark$ khan, khā

khāimakhā

khaṇvakhā

c. çầkhă

d. ukhă

p. d. V I ga

p.d. $\sqrt{ } 2 \mathbf{g a}$

(pc.c.) gā

bhựñgā

maghá

(d.) saraghã

c. vághā

ján̄ghā

(p.) v/chā

$p . d . / \mathrm{jan}, \mathrm{jā}$

pc. c. jấ

ajâ

(c.) kakajā líbujā

ūrjă

p. $d . \uparrow^{\text {jjñāa }}$

(pc. c.) jñā pāțâ

(c.) așțá, așță naríșțā

\section{? kăş̧ţhã}

? gășțhă

iḍă

sũşañā

yóşană

c. vakşánăa

trāyamānă

vişănăa

ind. dakşiṇă

ind. dákṣiṇă

d. c. dákşiṇă

sthứñã

c. trígnnāa

p. Vtan, tā

d. síkatā

asvagátā

"sujātátã

janátā

anapadyátā

suvirátā

sukģetrátā

c. devátā

ind. devátã

*puruşátã

? vāvătā

? vāçitâ

? vāsitâ

sittā

d. sūnứtã

agótā

aprajástā

hástã

ind. kathă

ind. táthā

ind. nāmáthā

c. ind. yáthā găthā

ind. rtuthă

c. ? ind. viŕthā

ind. óthā

ind. itthá pánthā

? mánthā

p.d. $\sqrt{ }$ sthā

(pc.c.) sthā

p. $d . \vee$ I dā

$p . d \cdot 1 / 2 \mathrm{da}$

(c.) $\mathbf{d} \bar{a}$ ind. kadă

ind. tadă

ind. yadá

ind. sarvadă

ind. sádă

maryădā

$(d . c$.$) ind. idă$

çímidā

gúdă

c. nindă

p. d. V I dhă

f. d. 1/dhi, 2 dhă

(pc.) inf dha

(pc. c.) dhā

ind. ekadhă

ind. pañcadhă

ind. aşțadhă

ind. saptadhă

ind. mitradhă

ind. sahasradhă

ind. navadhầ

c. ind. viçvádhā

d. c. svadhâ

ind. dvādaçadhă

anurādhă

iud. katidhă

ind. tatidhă

ind. yatidhă

ind. purudhă

ind. bahudhă

d. medhă

ind. tredhă

godhă

(d.) ind. addhă

ind. caturdhă

tană

d. c. pŕtană

ind. tmánã

d. raçaná

uçánā

(d.) ind. sanā

d. dhănă

(d. c.) ind. nānā

? ind. vină duchúnã

(d.) yamunã

d. c. sénā

"gnà 
p.d. $\sqrt{ } \mathbf{s n} \bar{a}$

p.d. V I pā

p.d. $\sqrt{ } 2 \mathbf{p a}$

p. $\sqrt{ } 3 \mathrm{pa}$

(pc. c.) I $\mathbf{p} \overline{\mathbf{a}}$

(pc.c.) 2 pā

çinçápā

(d. pd.) $\mathbf{1}^{\prime}$ sphā

$\left(p . d_{0}\right)$ / bhā

(pc.c.) bhā

d. c. sabhá

p. d. 1/ I mā

d. ${ }^{*} \sqrt{ } 2 \mathrm{ma}$

(pc.) $\mathrm{m} \overline{\mathrm{a}}$

c. ind. má

c. ind. amá

d. sarámā

sámā

çāmáa

c. hímā

(pd.) $/$ dhmā

$p \cdot d \cdot \sqrt{ } / \mathbf{y} \bar{a}$

anāvayá

(c.) dayā

ind. svapnayá

sumnayá

gamayà

"vayá

d. c. chāyà

c. jāyá

d. c. māyá

"sukșetriyá

ind. "urviyá

"sugātuyá

ind. mithuyá

ind. sādhuyà

ind. amuyâ

"vasūyá

p.d. / khyā

d. $\sqrt{ } \mathbf{j} \mathbf{1}, \mathbf{j y} \mathbf{a}$

d.c. jyá

(pc. c.) hatyā

c. I, 2 kṛtyâ

*bhṛtyá

srotyá

"pastyà

pathyà

? pádyā

$$
\begin{aligned}
& \text { c. vidyà } \\
& \text { (pd.) } \sqrt{ } \text { dhyā } \\
& \text { (pc.) dhyā } \\
& \text { kanyà } \\
& \text { mányã } \\
& \text { ind. tmányā }
\end{aligned}
$$

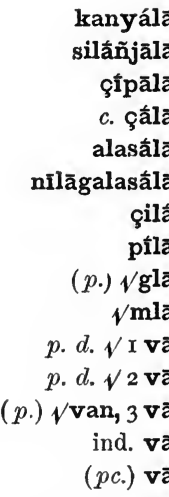

\'çȳā

irşyầ

p.d. $\sqrt{ } \mathbf{r a}$

rchárā

c. jarầ

ind. antará

d. c. ind. párā

urvárā

c. apsarâ

c. dhărāa

d. c. írā

hirâ

$d$. ind. purấ

(c.) purā

c. súrā

$(p . d$.$) V ghrā$

*áșțrā

nāṣțrá

d. 1 trā

varatrá

ind. devatrá

$c$. ind. satrá

c. mătrā

ind. purutrá

c. hótrā

p.d. V I drā

(pd.) $\sqrt{ } 2$ drā

p. d. 1 prā

d. v çrā

kalá

bișkalā

mékhalā

"khargálā (c.) *vidhavā

$c$. ind. dívā

c. ámīvā

d. c. griva á dhruvá

g. ișțvà

? g. trustutvá

g. dṛsțtáa

g. mrssțtà

g. vrșțtiá

g. rūḍhvá

g. trụ̂hvă

g. gatvá

g. hatvấ

g. snātvà

g. citvá

g. patitvă

? g. lapitvá

g. sādayitvá

(pc.) g. arpayitvá

g. kalpayitvâ

? g. srańsayitvá

g. cāyitvá

g. hinsitvâ

g. hitvâ

g. grubhïtvá

g. pītvá

g. krītvá

g. grhitvá

g. stutvá

g. çrutvá

g. pūtvá

g. bhūtvâ g. rtváa

g. krrtvâa

g. "vṛtvá

g. paktvá

g. bhaktvă

g. yuktvâ

c. g. dattvá

g. vittvá

g. suptvâ

g. tīrtvấ

g. jagdhvấ

g. baddhvâ

g. stabdhvâ

g. labdhvá

c. sadănvā

apváa

c. dúrvā

prușvá

p. d. $\sqrt{ }$ hū, hvā

d. c. jihvá

p.d. $\sqrt{ }$ ça

c. káçā

d. c. vaçă

c. àçā

āçấ

talâça

riçá

Içâ

ind. maṣmașấ

ișá

rjīșá

d. manișáa

snuṣáa

sūșá

ind. mứșā

ind. doșấ

yóșā

$p . d . \sqrt{ } \mathbf{k s ̦ a ̄}$

d. mákșā

lākṣā

bhikșá

āmíkșāā

d. dîkșá

p. d. $/ \mathrm{s} \overline{\mathrm{a}}$

d. $\boldsymbol{V}$ san, sā

(c.) $\mathbf{s} \bar{a}$

ktkasā

rasá 


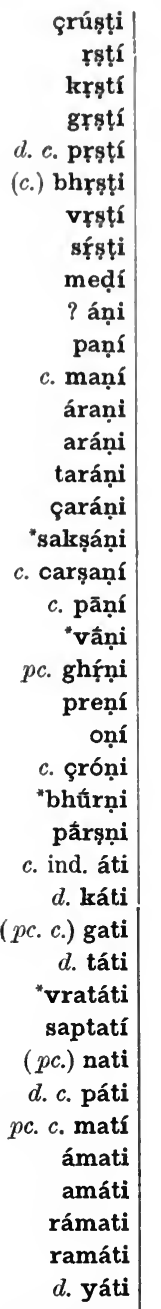

(d.) khalati

c. ind. práti navatí yuvatí

d.c. vinçatí

d. vasatí

c. jñātí

ariștátāti

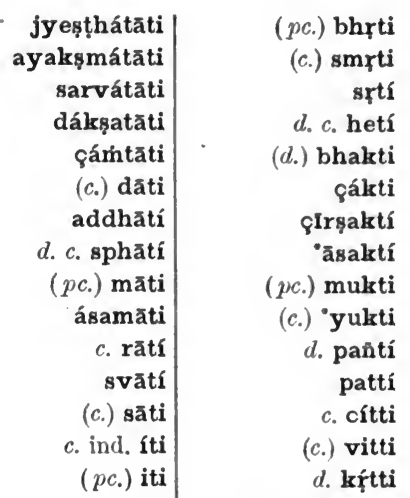

(pc.) bhrti

(c.) smrti şrtí

d. c. hetí

(d.) bhakti

çákti

çIrşaktí

"āsaktí

(pc.) mukti

(c.) 'yukti

d. pañtí

pattí

c. cítti

(c.) vitti

d. krị́tti

d. c. ind. ánti

ránti

(d.) ̧̧anti

c. çằnti

naptí

(pc.) āpti gúpti tṛ́pti

d. kirtí

(c.) pūrti

(d.) $/$ sti

(pc.) sti

(d. c.) asti agásti

d.c. vastí (pc. c.) çasti

d.c. pathí

(c.) mathi vyathí udārathí sărathi

c. átithi methi sákthi sakthí granthí

d. c. ásthi asthí pc. dadi ind. yádi (d.) kladi (c.) sadi prăhrādi 


\begin{tabular}{|c|c|}
\hline c. árbudi & jálpi \\
\hline védi & "ambí \\
\hline sedí & d. c. ind. abhí \\
\hline sadamiń & surabhi \\
\hline upabdi & c. năbhi \\
\hline hắrdi & dundubhí \\
\hline$\sqrt{ } 2$ dhä, dhi & gṛ́bhi \\
\hline$(p c . c.) \mathrm{dhi}$ & p.d. $\sqrt{ } \mathrm{mi}$ \\
\hline c. ind. ádhi & c. jāmí \\
\hline d. c. dádhi & c. bhứmi \\
\hline c. óșadhi & kń̛mi \\
\hline (c.) rādhi & (c.) nemi \\
\hline (c.) yudhi & ūrmí \\
\hline răddhi & c. raçmí \\
\hline (pc.) r্ rddhi & c. rayí \\
\hline (c.) gandhi & ári \\
\hline d. c. ind ní & arí \\
\hline khaní & d. karkarí \\
\hline d. c. jáni & d. c. ind. pári \\
\hline ăjani & d.c. ind. upári \\
\hline${ }^{*}$ dyotaní & d. c. hári \\
\hline c. vartaní & gandhằi \\
\hline dhamáni & c. girí \\
\hline c. vaní & c. añgúri \\
\hline dhvaní & (c.) dāçuri \\
\hline açáni & "sáhuri \\
\hline c. saní & ? asthūrí \\
\hline *dhvasáni & c. bhứri \\
\hline (c.) jāni & sūrí \\
\hline (c.) jyāni & d. c. trí \\
\hline c. çakúni & d. átri \\
\hline c. múni & d. rătri \\
\hline c. mení & ádri \\
\hline c. yóni & c. vádhri \\
\hline d. c. agní & pápri \\
\hline (c.) ghni & c. ábhri \\
\hline$(p c$.$) tatni$ & babhrí \\
\hline aratní & (c.) mamri \\
\hline ărtni & c. vavrí \\
\hline c. pŕ̛çni & jívri \\
\hline "sásni & $p . d$. V̧̧ri \\
\hline c. váhni & káli \\
\hline c. ind. ápi & kalí \\
\hline kapí & c. balí \\
\hline d. āpí & kalmalí \\
\hline c. drắpi & d. añgúli \\
\hline ? vāpí & ululí \\
\hline rópi & a. $c$. ind. ví \\
\hline
\end{tabular}

\begin{tabular}{|c|c|}
\hline ví & tilapiñji \\
\hline d.c. ávi & (c.) rājñ̃ \\
\hline d. c. kaví & prșțti \\
\hline c. paví & d. nāội \\
\hline c. nīví & d. āṇḍ̂t \\
\hline (d. c.) tuvi & vilị̄ht \\
\hline "dhruví & bháraṇi \\
\hline jăgṛvi & arșaṇ̂ \\
\hline (d. c.) dvi & indrāṇît \\
\hline dárvi & háriṇi \\
\hline "kāąí & d. róhiṇi \\
\hline răçí & dharuṇi \\
\hline plāçí & "sṛṇt \\
\hline dṛçí & eñî \\
\hline d. tvíși & jūrṇi \\
\hline c. dưși & párușṇi \\
\hline d. c. ŕși & jágatI \\
\hline d. c. krșíi & d. bṛhati \\
\hline ? dădhṛși & naptí \\
\hline p.d. $V$ I kși & vilipti \\
\hline p.d. $\sqrt{ } 2 \mathbf{k s s i}$ & $\left(p d . d_{.}\right) \sqrt{ }$ sty $\overline{\mathbf{a}}, \mathbf{s t i}$ \\
\hline c. ákși & rathi \\
\hline (c.) rakși & pṛthi \\
\hline d. kukșí & $(p .)^{*} \sqrt{ } \mathbf{I} \mathrm{d} \mathbf{I}$ \\
\hline$V$ I sā, si & p. $\quad \sqrt{ } \mathbf{d} \mathbf{I} \mathrm{d} \mathbf{I}, \mathbf{2}$ di \\
\hline así & nadí \\
\hline dáçonasi & $\mathbf{k} \bar{u}$ dí \\
\hline c. ind. hí & magundi \\
\hline p.d. $\sqrt{ } \mathbf{h i}$ & p.d. $\sqrt{ }$ dĩdhi, dhi \\
\hline c. ábi & $p c$. dhit \\
\hline d. c. máhi & d. c. óșadhi \\
\hline pc. sāsahí & $p . d . \boldsymbol{v} \mathbf{n} \mathbf{I}$ \\
\hline grậhi & (c.) $\mathbf{n} \mathbf{I}$ \\
\hline c. vrīhí & rajani \\
\hline ráṅhi & vŗjant \\
\hline ind. tárhi & ? tedanit \\
\hline d. c. $\mathbf{1}$ & varuṇāní \\
\hline arātakî & c. abhidhắni \\
\hline vișātakí & araṇyānt́ \\
\hline karkí & hastini \\
\hline c. çáci & lóhinì \\
\hline narācí & d. gavint \\
\hline silācí & çuni \\
\hline "kadríci & énī \\
\hline (c.) $\mathbf{m u c I}$ & çyéni \\
\hline c. sūcí & ásikni \\
\hline$d$. ฟjyā, ji & (c.) ghni \\
\hline bharūji & mahānaghní \\
\hline
\end{tabular}




\begin{tabular}{|c|c|c|c|}
\hline$(p c.) \operatorname{tatn} \overline{\mathbf{I}}$ & (c.) gavi & $(p c$.$) çoca yişn̨u$ & 'jantú \\
\hline c. pátnI & suprāví & (d.) patayişnu & tántu \\
\hline d. $\sqrt{ } \mathbf{p} \mathbf{i}, \mathbf{I} \mathbf{p} \mathbf{I}$ & d. c. prithivi & mădayiş̣ú & (c.) 'mantu \\
\hline d. $\sqrt{ } \mathbf{p} \mathbf{I} \mathbf{y}, 2$ pi & ratharvi & pārayişṇú & inf. 'hántu \\
\hline d. $\sqrt{\mathrm{bhI}}$ & $p d$. । ç̄ & cyāvayişṇú & d.pc. inf. kártu \\
\hline bhi & (c.) "çI & poşayişṇú & nc. inf. bhártu \\
\hline p.d. $/ \mathbf{m I}$ & "urváçI & c. vís̨ṇu & $p . d .1$ stu \\
\hline ami & (c.) $\mathbf{a} c ̧ \mathbf{I}$ & "kravişṇú & vástu \\
\hline yami & ? văçì & c. dhṛşṇú & c. văstu \\
\hline çami & máhiş̨ & 1 kşnฺu & ejáthu \\
\hline (d.) *çimI & (d.) ulkuşI & (d.) $) / \mathrm{tu}$ & stanáthu \\
\hline lakșmt & akş1 & ind. tú & vepáthu \\
\hline sumnayi & ródasi & edhatú & d. c. prthú \\
\hline "agnăyI & ? văsi & tanyatú & p.d. $\mathrm{d} \tilde{\mathrm{a}}, \mathrm{du}$ \\
\hline arāyi & ? jăgṛtsî & c. krátu & c. svădú \\
\hline p.d. $\sqrt{ } \mathbf{r i}, \mathbf{r I}$ & $(p.) \mathfrak{v} \mathbf{u}$ & vahatú & mrrdú \\
\hline sóbharI & c. ind. $\mathbf{u}$ & c. gātú & $\left(d_{.}\right)$pedu \\
\hline urvárĩ & d. c. ku & inf. datu & syédu \\
\hline nấri & pṛ́dāku & $p c$. inf. dhătu & Índu \\
\hline taduri & kṛkavăku & inf. * (2 dhā) dhătu & bindú \\
\hline tãduri & íkșvāku & inf. pătu & viklíndu \\
\hline$p . d . / \mathbf{k r} \mathbf{I}$ & d. çañkú & inf. "mătu & vidhú \\
\hline$(p c . c.) \mathbf{k r} \mathbf{i}$ & çárku & inf. yâtu & d. c. mádhu \\
\hline āșțrî & $(p \cdot p d.) \sqrt{ } \mathbf{s k u}$ & d. c. yătú & d. c. sādhú \\
\hline rășțrī & àkhú & inf. vătu & c. krrdhú \\
\hline déşțri & (c.) $\mathrm{gu}$ & jivătu & (d.) karkandhu \\
\hline ? jātrî & bhṛ́gu & cikitú & c. bándhu \\
\hline d. rătrì & vanargú & inf. yăcitu & d. c. síndhu \\
\hline jánitri & valgú & inf. spárdhitu & $(p),. / \mathbf{n u}$ \\
\hline sūtrí & (c.) raghu & jánitu & d. ind. nú \\
\hline bhartri & d. laghú & pitú & c. ind. ánu \\
\hline d. c. strí & c. rịú & inf. sávitu & ind. nanú \\
\hline c. tandri & c. rájju & inf. jívitu & d. c. mánu \\
\hline ansadhrí & (c.) jñnu & inf. stárìtu & d. c. hánu \\
\hline$p d . d . \vee$ pri & $?(c$.$) arațu$ & sútu & d. jănu \\
\hline (pc. c.) prI & inf. dráșțu & inf. sútu & (c.) I dānu \\
\hline$(p c$.$) çrI$ & inf. "práşțu & d. c. rrtú & (d.) 2 dānu \\
\hline d. c. çrít & vanișthú & $p c$. inf. étu & $c$. bhānú \\
\hline$(p . p d.) \sqrt{ } \mathbf{l} \mathbf{I}$ & ind. anuṣțhú & d. c. ketú & d. sănu \\
\hline mătali & c. vị̣ú & inf. sétu & c. sūnú \\
\hline pippalí & ? hrựdu & hetú & d. c. dhenú \\
\hline (c.) phalI & alăṇ̣u u & ótu & ? gatnú \\
\hline c. sthālì & $p c$. inf. vóḍhu & inf. "ótu & jigatnú \\
\hline mulāli & d. aṇú & aktú & $(p c$.$) tatnu$ \\
\hline sinivālî́ & sthāṇú & inf. páktu & (pc.) "hatnu \\
\hline$(p.) \sqrt{ } \mathbf{b l i}$ & c. reṇú & inf. áttu & stanayitnú \\
\hline p.d. $\sqrt{ } \mathbf{v} \mathbf{I}$ & veṇú & inf. véttu & "ánāmayitnu \\
\hline (c.) $\mathbf{v} \mathbf{I}$ & jișṇú & inf. gántu & "dravitnú \\
\hline
\end{tabular}




$$
\begin{aligned}
& \text { (c.) *snu } \\
& \text { (p.) } / \text { hnu } \\
& \text { (c.) } \mathrm{pu} \\
& \text { trápu } \\
& \text { ripú } \\
& \text { c. kaçípu } \\
& \text { d. c. alâbu } \\
& \text { ? çămbu } \\
& \text { kásāmbu } \\
& \text { (pc. c.) bhu } \\
& \text { ŗbhú } \\
& \text { d. amú } \\
& \text { yú } \\
& \text { p.d. } \sqrt{ } \mathbf{I} \mathbf{y u} \\
& \text { p.d. } \sqrt{ } 2 \mathrm{yu} \\
& \text { mrigayú } \\
& \text { sumnayú } \\
& \text { c. ābayu } \\
& \text { (pc.) mayu } \\
& \text { yayú } \\
& \text { amitrayú } \\
& \text { devayú } \\
& \text { (c.) çayu } \\
& \text { çaçayú } \\
& \text { c. *āyú } \\
& \text { aghāyú } \\
& \text { p.d. vcyu } \\
& \text { caranyú } \\
& \text { "saranyú }
\end{aligned}
$$

$$
\begin{array}{r}
\text { avișyú } \\
\text { Irșyú } \\
\text { c. dásyú } \\
\text { stanasyú } \\
\text { durasyú } \\
\text { çravasyú } \\
\text { yaçasyú } \\
\text { dhāsyú }
\end{array}
$$

p. d. $\sqrt{ } \mathbf{r u}$

carú

(d. c.) paru

aráru

sváru

d. çáru sáru

somasátsaru

kārú

cấru

d. dâru

dhārú

píyāru

$d$ : urvārú

d.c. urú

(d.) kuru

c. gurú

d. c. purú

ūrú

kurúru

éru

"perú

ágru

jatrú

d. c. çátru

$p . d . \sqrt{ } \mathrm{dru}$

d. c. dru

sádru

pūtúdru

çīpúdru

(d.) 1 pru

kábru

c. babhrú

p. d. V̧̧ru

c. áçru

c. çmáçru

p.d. $\mathbf{v}$ sru

p. d. / hvar, hru

patayālú

d. pilú gúggulu

p.d. $\sqrt{ }$ plu

malimlú

(d.) $\vee$ çu

c. paçú

paraçú

páraçu

d. c. āçú

(c.) yāçu

d. çíçu

abhîçu

d. c. añçú

d. párçu

d. c. ísu

dadhișú

(d. c.) ind. vișu

(d. pd.) $\sqrt{ } \mathbf{k s ̦ u}$

d. c. kșú

c. ákșu

c. cákșu

? dhakșu

vivakșú

ikşú

titikșú

? (c.) çiçlikşu

d. c. ind. sú p.d. $\sqrt{ } \mathrm{su}$

$d$. c. ásu

d. c. vásu

sișāsú

d. pāǹsú

jighatsú

bībhatsú

cikitsú

c. dipsú

$p$. d. $\sqrt{\text { hu }}$

d. c. bahú

d. c. bāhú

? rāhú

druhú

séhu

(d. c.) anhu

(d. pd.) $/ \mathbf{k} \overline{\mathbf{u}}$

(d.) $\sqrt{ } \mathbf{j} \overline{\mathbf{u}}$

jatú

p.d. $v \mathrm{du}, \mathrm{d} \overline{\mathrm{u}}$

p.d. $\sqrt{ } \mathrm{dh} \overline{\mathbf{u}}$

badhú d. c. vadhú

prajanú

c. tanú

dhanú

p.d. $\sqrt{ } \mathrm{p} \overline{\mathrm{u}}$

(c.) $\mathrm{pu}$

kyămbū

p. d. $\sqrt{\mathrm{bhu}}$

pc. c. bhứ

"camú

dív, dyú

p. d. V bru

çvaçrút

p. d. $\sqrt{ } / \mathrm{s} \overline{\mathrm{u}}$

(pc. c.) sर̄

p. d. vhvā, hū

kuhú

juhú

p. d. $\sqrt{ } \mathbf{r}$

p.d. $\sqrt{ } \mathbf{~} \mathbf{k r}$

p. d. $\sqrt{\mathbf{k i r}, 2} \mathbf{k r}$

d. $\sqrt{ } 3 \mathrm{kr}$

$\checkmark \mathrm{I} g$ ?

p. d. V $\mathbf{g i r}, 2$ gr

p.d. $\gamma^{\mathrm{jä} g r,} 3 \mathrm{gr}$

d. $\sqrt{ } \mathrm{x} \mathrm{jr}$

? $\sqrt{ } 2 \mathrm{jr}$

pc. drașț́r

(pc.) srașțr

d. tváșțr

(d.) rāștr

(pc.) veșțr

kroșțr

dañṣṭ́

p.d. $\sqrt{ } \mathbf{t r}$ jñātŕ

- (pc.) sthātŕ

pc. dātŕ

pc. dhātŕ

pātṛ́

d. c. mātị

(pc.) yātṛ

trātṛ

d. c. bhrâtrr

idịị

mrdití

anvartitŕ

mánthitṛ 


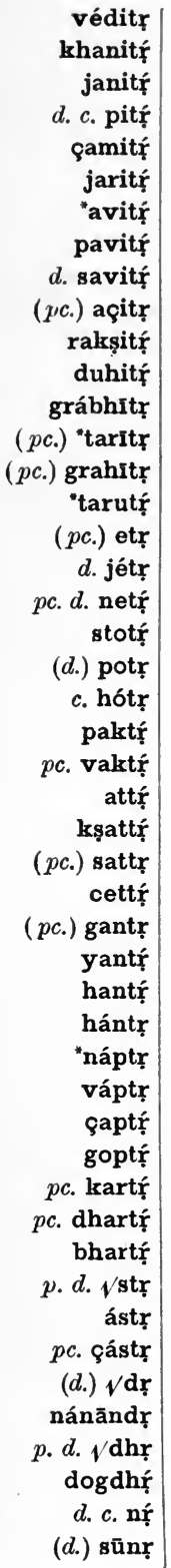

$$
\begin{aligned}
& \text { p.d. / I pr } \\
& \text { p.d. / } 2 \text { pr } \\
& \text { p.d. / spr } \\
& \text { p.d. / bhr }
\end{aligned}
$$

d. pd. $\sqrt{ } \mathrm{I} \mathbf{m r}$

p. $/ 2 \mathbf{m r}$ p.d. 1 smr p. d. $\mathbf{1} \mathbf{I} \mathbf{v r}$ p.d. $\boldsymbol{V} 2 \mathrm{vr}$ c. devị $p . d$. । p. $d$. $\mathbf{s p r}$ cátasr

c. svásr tisér

p.d. $\mathrm{I}^{\prime} \mathrm{I} \mathrm{hr}$ d. $1 / 2 \mathrm{hr}$ ind. rté inf. "yájadhyāi rāí

ind. vāí ind. hāí

d. c. gó

d. nāú glāú asāú

(pd.) $\downarrow^{\text {tak }}$ c. ind. prithak

(c.) ind. rdhak p.d. $\mathfrak{i}$ çak ind. gabhișák ind. "ānușák ind. bhúk ind. híruk ind. jyók p. Jlikh (p. pd.) $\sqrt{\overline{\mathbf{i}} \mathrm{n} k \mathrm{k}}$ p. 1 ing (p.d.) $/$ valg

(d.) $/$ dagh

c. ind. hín d. 1 pac

(c.) vyac p. d. $1 \mathrm{vac}$

d. c. tvác p.d. v sac $p d . \sqrt{ } \mathbf{y} \bar{a} \mathrm{c}$ d. $c$ vắc

$$
\begin{array}{r}
(p c . c .) \text { sãc } \\
p . \text { tric } \\
p . \text { v vic } \\
p . d \text { /sic } \\
p c . \text { síc } \\
(p . d .) \text { Juc } \\
(d .) \text { vtuc } \\
p . d . \text { t muo } \\
(p c . c .) \text { muc } \\
p . d . \text { ruc } \\
\text { inf. rúc } \\
\text { (c.) rúc }
\end{array}
$$

(d. pd.) 1 /mruc

(pc.) mruc c. srúc

(d.) itmluc

p. d. I çuc çúc

d. c. r̊́c

p.d. $\sqrt{ }$ prc

(c.) prac

$\checkmark$ mrc

(p. d.) V $\mathrm{ac}, \mathrm{añc}$

(pc. c.) añc

$d$. údañc

d. pratyáñc

d. nyàñc

(d.) apyañc

samyáñc

d. c. tiryáñc

$d$. sadhryàñc

d. $p d .1$ vaño

$d$. anváñc

urváñc

purváñc

(p.) "V̧̧vañc

$d$. víşvañc ghṛtáñc

d. ápāñc

(d.) upāñc

$d$. adharăñc

d. c. párāñc

d. prấñc

d. ávāñc

d. arvâño

p. $d$, re, arc

p.d. tvraçc

$p$. $\sqrt{\text { gach }}$ p. Vyach

p.d. 1/prach

p. i ich

p. uch

(p.) 1/yuch

p. 1 r $\mathrm{rch}$

$/$ văñch

vmurch

p.d. vaj

áj

p. d. v bhaj

p.d. 1/yaj

(pc.) yaj

(d.) ityaj

(c.) "tyaj

p.d. 1 raj

(d.) $/$ dhraj

(c.) bhraj

$\checkmark$ vraj

c. sráj

d. 1 vaj

(p.d.) 1/svaj

(pc.) inf. "svaj

d. c. bhișáj

p.d. / $/$ sañj, saj

(pc.) saj

(c.) bhāj

(pc.) yāj

p. d. $\backslash \mathbf{r a ̄ j}$

pc. c. ră j

p. d. / bhrāj

vaníj

d. 1 tij

(p. pdl.) $/$ nij

? bhuríj

p.d. $v \mathbf{v i j}$

d. ritvíj

d. $v$ tuj

túj

$p . d . /$ bhuj

c. bhúj

p.d. । у уиј

pc. c. yúj

p.d. $\mathbf{v} \mathbf{r u j}$

(pc.) ruj

i kūj

p.d. $1 \mathrm{mrJ}$

p.d. 1 vrij 


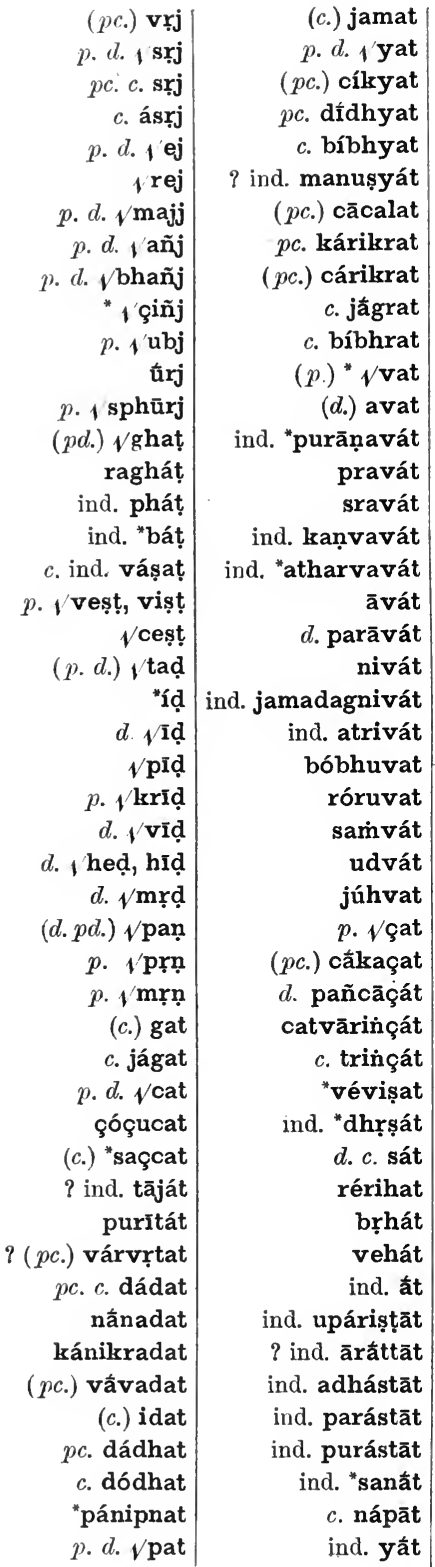

ind. "purānavát

p.) * $/$ vat

(d.) avat

pravát sravát

ind. kanvavát ind. "atharvavát āvát

d. parāvát nivát

ind. jamadagnivát ind. atrivát bóbhuvat róruvat saminát udvát júhvat p. V̧̧at (pc.) căkaçat d. pañcāçát catvārinçát

c. trinçát

"vévișat

ind. "dhṛșát

d. c. sát

rérihat

bṛhát

vehát

ind. at

ind. upárișțāt

? ind. ārăttāt

ind. adhástāt

ind. parástāt

ind. purástāt

ind. "sanăt

c. nápāt

ind. yăt

ind. uttarăt ind. adharăt p.d. v cit (pc.c.) cit $(p c . c$.$) jit$ $p c$. mít sarít harít

(c.) çrit

(d.) V̧̧vit yoșít

( $p c$.$) kșit$ rohít

(pc.) yáchant $p c$. ichánt (pc.) uchánt

( $p c$.) yuchant

(pc.) bhájant

(pc.) rấjant pc. bhrăjant

pc. rujánt

kújant

d. éjant

(pc.) *añjánt $p c$. bhañjánt

(pc.) bhuñjánt ubjánt

(c.) cyut

d. Vjyut

p.d. vdyut $p c$. dyút didyut

d. marút

(c.) prut

(pc. c.) çrut

(pc.) srut

pc. hrút

(c.) hut

p. d. $v$ I krt $\sqrt{ } 2$ krrt

(c.) krrt yákṛt çákṛt

(p. pd.) V crat (pc.) inf. crrt

(c.) dhṛt p.d. $\sqrt{\text { nrrt }}$ nút

(pc. c.) bhṛt p. d. v vṛt pc. c. vị́t

(c.) srrt

(c.) hrt pácant

pc. yắcant "çucánt

(pc.) mrócant

(pc.) "siñcánt

$p c$. muñcánt

pc. pruñcánt

$p c$. gáchant céșțant

pc. tísțhant krídant

"rinánt gṛnánt

(pc.) stṛnánt pṛnánt

pc. mṛnánt iṣnánt

pc. gṛhṇánt $p c$. pátant kṛntánt d. c. dánt

(c.) adant nádant

pc. mádant

? rádant

vádant

khădant

( $p c$. ) khidánt sidant

( $p c$.$) tudánt$

pc. nudánt rudánt

? ( $p c$.$) skándant$

( $p c$.) nándant

(pc.) krándant $p c$. bhindánt (pc.) undánt vāvrdhánt

(c.) rundhant *ṛndhánt $p c$. anánt pc. jānánt 


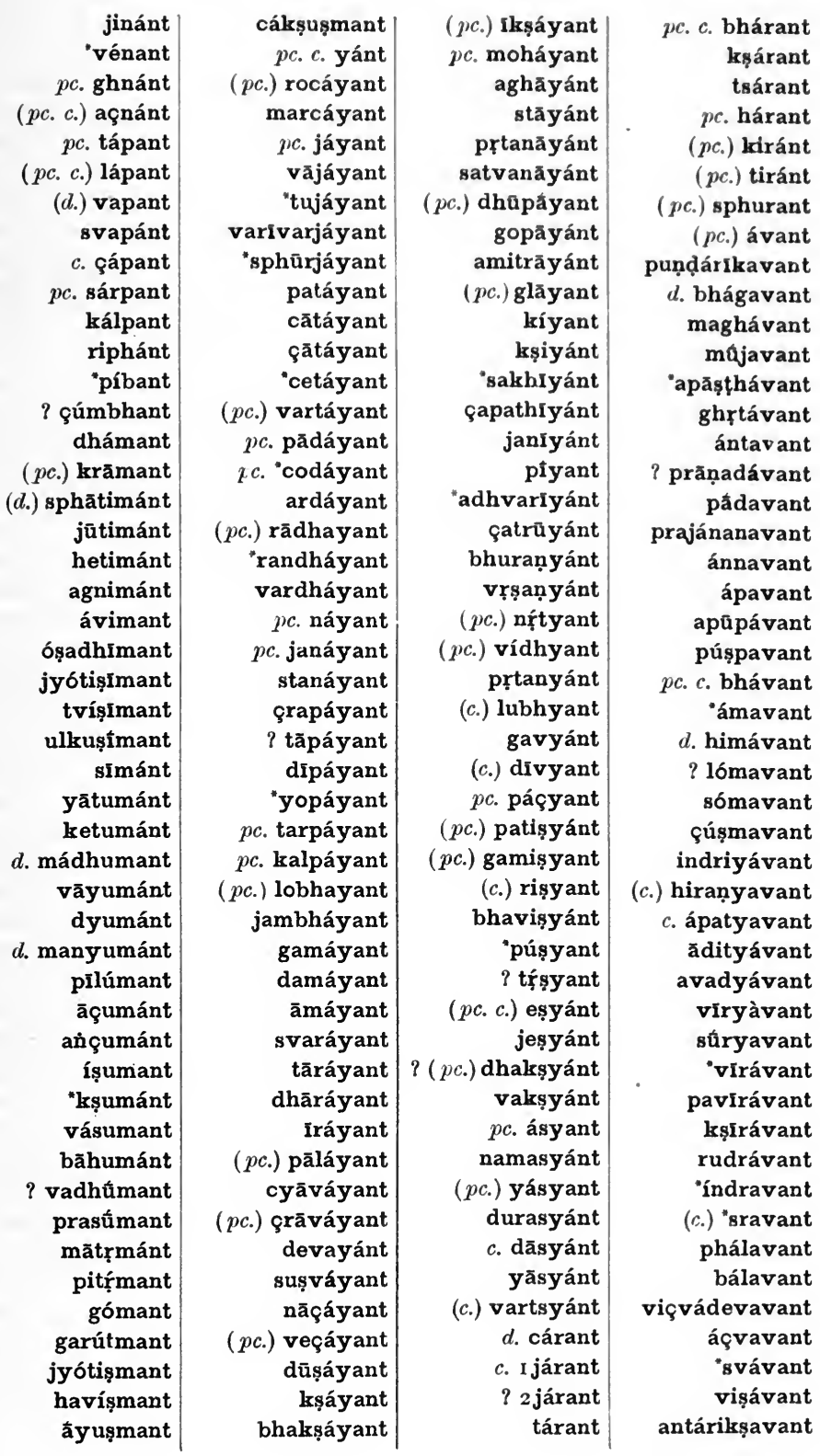


rásavant māñsávant drapsávant "çítikāvant "hlādikāvant prajăvant vijāvant ișțăvant atișthăvant varaṇăvant dákșiṇāvant tăvant síkatāvant açitâvant sūnứtāvant etăvant

prasthăvant madăvant

dhấvant svadhăvant rocanăvant samávant yātumắvant c. yăvant priyăvant vṛṣnyāvant çepyầant viryàvant uttarăvant d. írāvant

bhañgurấvant áçvāvant dádhivant harivant saptarsívant jívant așțhivánt kladívant vājínīvant (pc.) mívant dyầ-] "çímivvant vāpṛthivívant kakșivant

( $p c$.) ūrṇuvánt stuvánt

(pc.) bruvánt vásuvant vișūvánt

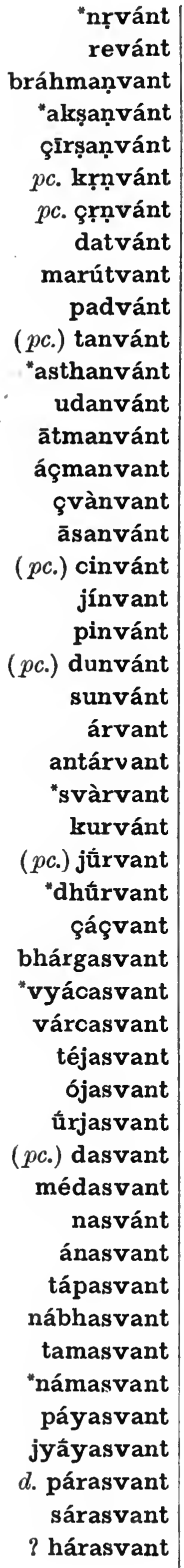

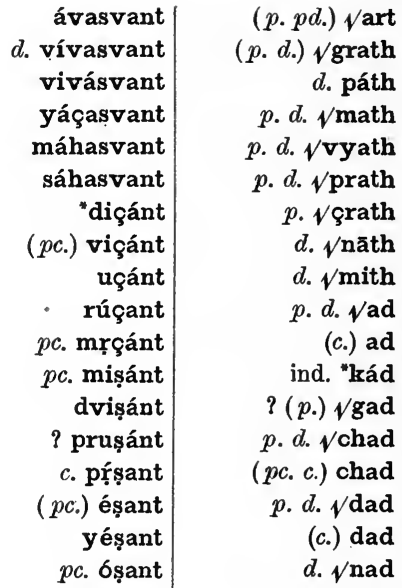
"tákșant rákșant

c. çíkșant

(pc.) ukșánt

(pc.) kárșant várșant sánt

(pc.) vásant sasánt

(pc.) dấsant

( $p c$.) vívāsant

? síșāsant "çáṅsant

? jíghānnsant

(c.) hinsant

c. dítsant

(pc.) irtsant

c. dípsant

$p c$. Ipsant

$p c$. dáhant

c. mahánt

váhant

(pc.) thhant

d. c. brhánt méhant

( $p c$.) róhant drunhánt

(pc.) bhănt pc. yănt

? ( $p c$.$) vănt$ p.d. $\checkmark$ pad

d. c. pád

p.d. $/ \mathrm{mad}$

(pc. c.) mad

(c.) sumad

(c.) syad $\checkmark \mathbf{r a d}$

d. çarád

p.d. $\checkmark \mathrm{vad}$

d. $/$ svad

d. Vçad dŗşád

d. $\downarrow$ kșad

p.d. $/ \mathrm{sad}$

pc. c. sád

$d$. bhasád

d. $\sqrt{\text { khād }}$

(d. pd.) $\sqrt{ }$ hrād

c. ind. íd

p. $d .1$ khid

? ( $p c$.) inf. khid

ind. cid

p. d. vohid

p.d. $/$ bhid

(pc.) bhid

d. $\sqrt{ }$ mid

(pd.) $\sqrt{ }$ klid

p. d. V I vid

p.d. $/$ vind, 2 vid

(pc. c.) vid 
ind. kuvid 1 svid

ind. svid

p. c. ind. úd

p. d. vund, ud

$(p c$.$) inf. úd$

d. c. kakúd

p.d. 1/khud

p. d. voud

p.d. vtud

p.d. $/$ nud

p. d. $\sqrt{ }$ mud

(pc. c.) mud

pd. $d$. / rud

c. rud

(d.) Vkṣud $\checkmark$ sūd

p.d. 1 trrd

(pc.) inf. "tṛ̂́d

d. $1 / \mathrm{mrd}$

d. c. hṛ̛

ind. céd

ind. néd

p.d. $/$ skand

(d.) $\sqrt{ }$ chand

p.d. $/$ nand

(d.) $\sqrt{ }$ spand

(d.) $\sqrt{ }$ bhand

pd. $\sqrt{ }$ mand

p. d. vsyand

p.d. $\sqrt{\text { krand }}$

d. $\checkmark$ vand

d. $\checkmark$ nid, nind

$\checkmark \mathbf{r d}$, ard

(c.) härd dadh

( $p c$.) inf. bádh

p. $d . v$ vyadh

(c.) ind. çrádh

p. d. V vadh /nādh

p. d. Vbādh

p. $d . \sqrt{ } \mathbf{r a ̄ d h}$ $p . d . \sqrt{ }$ sādh

p.d. Vidh

$(p c)$ idh

(d.) $\sqrt{ }$ sridh

? srídh

$$
\begin{aligned}
& \checkmark \text { vidh } \\
& \text { (c.) vidh } \\
& \text { p.d. } / \text { sidh } \\
& \text { vdudh }
\end{aligned}
$$

$$
\begin{array}{r|r}
\text { aryamán } & \text { c. dhárman } \\
\text { vijăman } & \text { c. márman } \\
\text { stāmán } & \text { d. c. várman } \\
\text { c. sthăman } & \text { c. çárman } \\
\text { dăman } & \text { d. c. áçman } \\
\text { d. c. dhăman } & \text { véçman } \\
\text { d. c. năman } & \text { (c.) daņ̧̃man } \\
\text { pămán } & \text { uşmán } \\
\text { c. yăman } & \text { c. reşmán }
\end{array}
$$

c. trāman

"kşăman

d. co sắman

c. jániman

nadanimán

jarimán

varimán

váriman

harimán

mahimán

sávìman

sìmán

bhúman

bhūmán

(d.) heman

(pc.) oman

(c.) doman

(c.) roman

d. lóman

klomán

c. takmán

(pc. c.) jman

ájman

majmán

ojmán

? tŕnman

? vadhatmán

d. c. àtmán

pc. c. vártman

sádman

(c.) vidman tárdman

c. jánman

mánman

(c.) "hanman

c. pāpmán

(c.) arman

d. c. kárman

cárman (c.) ̧reşman

d. lákşman

várşman

varşmán

bhásman

mahmán

d. c. bráhman

d. c. brahmán

d. iran

p.d. $/$ van

maghávan

rităvan

(c.) dāvan snăvan

(c.) pāvan

vibhăvan

(c.) yāvan

satyăvan

(c.) "krāvan

c. grăvan

? (c.) trāvan

(pc.) divan dhivan

pivan

(pc. c.) çivan

(d.) krṣivivan

d. yúvan

(c.) "súvan sáhovan

(pc.) tákvan

d. çákvan

"ŕkvan

"sị́kvan

( $p c$.) mŕgvan

(c.) daghvan

c. yájvan

(c.) pátvan

d. c. sátvan

(c.) ítvan 


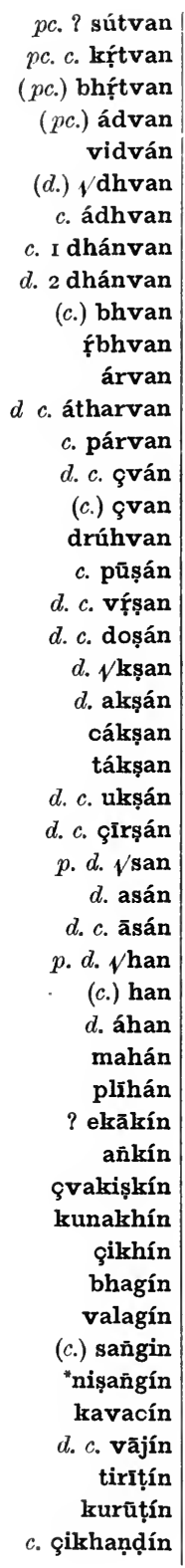

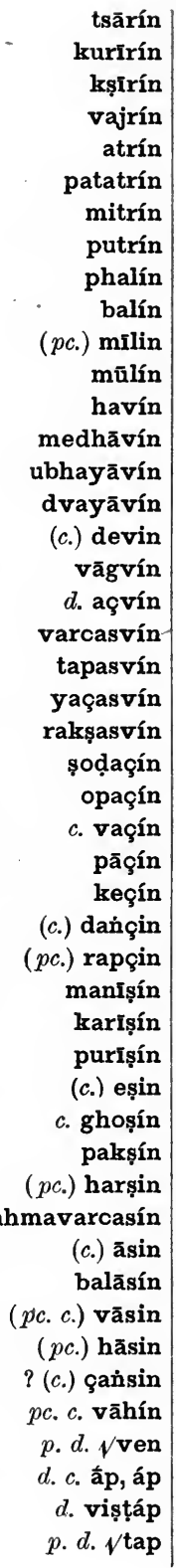

$p d . d . v$ rap

p.d. Vlap

(c.) lap

p.d. VI vap p.d. $\sqrt{ } 2$ vap

p.d. $v$ svap

d. V̧̧ap

p. d. $\mathrm{f}^{/ \bar{a} \mathrm{p}}$

d. c. áp, âp

(d.) $\sqrt{ }$ rip

*ríp

(p. pd.) Vlip

$\checkmark$ vep, vip

(c.) vip

p. d. $\sqrt{\text { kșip }}$

p. $\sqrt{ }$ dip

(d.) $\sqrt{ }$ kup

d. Vgup

d. $\sqrt{\text { yup }}$

d. $\sqrt{\text { rup }}$

? rúp

(p.) Vlup

d. $\sqrt{ }$ krap, krrp

"kíp

p.d. V tựp

(c.) trpp

? vdrp

p.d. V $\mathbf{s r p}$

p.d. $\sqrt{\mathbf{k l p}}$

$\checkmark$ vip, vep

(d.) $/$ jalp / riph

d. pd. $v$ skabh

p.d. $\sqrt{ }$ stabh

d. Vdabh

(p.d.) $\sqrt{ }$ nabh

d. $\sqrt{ } \mathbf{y a b h}$

p.d. $\sqrt{ } \mathbf{r a b h}$

p.d. Vgrabh

p. labh

(p.) $\sqrt{ } \mathrm{ubh}$

d. kakúbh

(pd. d.) $/$ stubh

(pc. c.) stubh

p. 1lubh

$p$.d. V çubh çúbh

p.d. 1 kșubh 
p.d. /jambh p.d. vam d. $\mathbf{k a m}$ ind. kam, kám c. ind. sākám p.d. vgam (d.) 1 tam ind. kathám ind. itthám d. $\checkmark$ dam (c.) dam c. ind. sádam idám p.d. 1 dham p.d. /nam ( $p c$.) nam ind. nānānám ind. nūnám p.d. $/$ yam ayám

svayám

c. ind. sãyám

$p$. d. 1 ram $c$. ind. áram p.d. 1 kram d. $\downarrow$ '̧ram ind. álam ind. evám $\checkmark$ I çam p. d. $\sqrt{ } 2$ çam d. c. ind. çám (p. d.) / ksşam kşám

d.c. ind. sám c. ahám ind. Im

ind. tadănīm ind. viçvadănim ind. *idấnim $\checkmark$ sabhāgay d. 1 mrgay $\sqrt{k i r t a y}$

p. $d$ day

(d.) / sumnay $\checkmark$ viray

(d.) Vamitray p. $d .1 /$ mantray (p.) 1'pālay

$$
\begin{aligned}
& \text { d. Vdevay } \\
& \text { i'suşvay }
\end{aligned}
$$

p. V mathāy

(p.) * V̧̧rathãy

( $p$.) vtudãy

$\checkmark$ pṛtanāy

/ satvanāy

iraçanāy

(d.) ? / kupāy

(p.) Vdhūpāy Vgopāy

p. 1/skabhāy

p. V grbhãy

p. V priyāy

Vamitrāy

* /musaãy

p. V vrşāy 1 arātiy Vjaniy t putriy

- Asakhiy

(d.) \'arātíy

$\checkmark$ çapathiy h hrụiy ijaniy

- Vadhvariy " lkaviy $\checkmark$ mahiy

(d.) I/vadhūy (p.) 1 manyūy 1/̧̧atrūy

(d.) * vasūy (p.d.) $\sqrt{ }$ caranyy (d.) * /sarany $d$. " bhurany v vrsany $\checkmark$ paty

d. 1 prtany / sapary

(d.) 1/adhvary p.d. 1 hary /gavy

(d.) Vavișy $\checkmark$ tavisy i'uruşy (d.) IIrşy

(d.) 1/stanasy

(p.) 1 manasy I'sumanasy

- /svapasy t namasy

d. 1 durasy

(d.) I çravasy * ídaçasy

(d.) $/$ yaçasy

(p.d.) I ghar p.d. icar c. ind. prătár ind. 'sanutár

d. c. ind. antár (c.) vanar

c. ind. púnar

(d.) sapar

(d.) I jvar

d. 1 tvar

p. $d .1$ svar

d. c. svàr

(p.d.) \ hvar

p. d. 1 kșar

d. vtsar

c. áhar vấr

d. dvắr gír

$p . d .1^{\mathrm{Ir}}$

(p.) 1 gur

d. c. catúr

ind. catúr

(d.) dur

d. dhúr

bandhúr

(pc.c.) pur

d. c. púr

p.d. 1 sphur Vhvar, hur (p.d.) ical ind. phál ind. çál (p.) 1/a $\mathbf{l}$ ind. băl p. 1 il

(pd.) $)_{1 / \mathrm{mIl}}$ p.d. 1'av (p.) , tā v p. Idhăv

d. c. dyú, dív p.d. $/ \mathbf{j I V}$

(p.) isthIv p. d. $1 \mathrm{dIV}$ dya, div

(p. d.),$/ \mathrm{m} / \mathrm{v}$

p. 1 sIv

? I criv

? 1 sriv

p. $\mathbf{1}^{\text {'sev }}$

(p.d.) d dhanv

d. inv

ijinv

i pinv

(p.) ijüurv $1^{\prime d h u a r v}$

$p . d .1 / \mathrm{I}$ ą

p.d.1'2 ac

p. $d .1^{\prime}$ I nac

$(p . d$.$) 1/2 naç$

p.d. ı pac

p.d. I'spac

spáç

d. 1 vaç

(p.d.) $1 \mathbf{k a ̄ c}$

$p . d .1$ dãą

(c.) dā̧̧

d. prăç

d.pd. $\mathbf{v} \mathbf{v a ̄} ̧$

p.d. ' diç $p c$ díç

d. $ı$ piç

(c.) "piç

p. ' rị̧

p. d. Ivi६

d. c. vį́

$d .1$ Iद̧ 1 tue

p. $d .1$ krue

$d .1$ krq

$p . d .1$ dre

pc. $c$. inf. dŕç

p. $d .1$ spre

(pc. c.) sprȩ

p. $d .1 \mathrm{mr \varphi}$

$p d . d$. , dańç 


\begin{tabular}{|c|c|}
\hline p.d. 1 bhrañç & d. 1 daks \\
\hline ? \'çrañç & p. $/$ naks \\
\hline$(p . p d .)_{1}$ rapç & d. t bhaks \\
\hline (p.) , kaş & 1iyaks \\
\hline d. c. șáş & $p . d . \sqrt{\text { raks }}$ \\
\hline$p . d .1$ is & (d.) 1 laks \\
\hline & (d.) ptvaks $^{\text {to }}$ \\
\hline p.d. 1 pis & p.d. niks \\
\hline p.d. $1 \mathrm{mis}$ & ( $p c$.$) inf. "niks$ \\
\hline$(p c.) \mathrm{mis}$ & (d.) $\sqrt{\text { bhiks }}$ \\
\hline p.d. 1 ris & p. 1 çiks \\
\hline "ríş & p. 1 Iks \\
\hline$(d . p d .)_{1} /$ çriș & p.d. $/$ uks \\
\hline (pc.) inf. "çris & $p . d . v 1$ as \\
\hline (c.) çriş & $p \cdot d \cdot 1^{\prime 2}$ as \\
\hline pd. ^'çliş & (c.) as \\
\hline p.d. i vis $^{\prime}$ & $(p . p d),. \mathbf{k a s}$ \\
\hline d. 1 tviş & d.c. ókas \\
\hline p.d. $/$ dviş & d. c. àgas \\
\hline pc. c. dvíș & d. bhárgas \\
\hline p.d. / çiş & $p d . d . \sqrt{ }$ ghas \\
\hline$p \cdot 1$ Is & d. c. vyácas \\
\hline$p . d$. us & d. c. vácas \\
\hline$p c$ ús & (d. c.) tvacas \\
\hline (d.) 1 ghus & (c.) vācas \\
\hline d. vjus & d. c. várcas \\
\hline d. V duș & $(p . d .)_{1 / \mathrm{jas}}$ \\
\hline d. $/$ puss & "tyajás \\
\hline (c.) pus & d. rájas \\
\hline$p . d .1$ mus & (c.) prajas \\
\hline$p d .1$ prus & c. bhrajás \\
\hline ( $p c$. ) prus & d. păjas \\
\hline$p . d .1$ çus & d. c. téjas \\
\hline$p .1$ bhüş & d. c. ójas \\
\hline p.d. $\sqrt{ } \mathrm{rs}$ & (c.) bhojas \\
\hline p.d. 1 krss & "áñjas \\
\hline d. $1 / \operatorname{trs}$ & (d.) ūrjas \\
\hline p.d. v dhrs & héḍas \\
\hline (pc.) inf. dhrss & (c.) draviṇas \\
\hline d. $1 / \mathrm{mrqs}$ & ind. átas \\
\hline p.d. $\mathbf{v} \mathbf{v r s}$ & ind. mukhatás \\
\hline$(p c.) \mathbf{v r r s}$ & ind. jyeșțhatás \\
\hline$p . d .1$ hṛs & ind. dakşiṇatás \\
\hline$p . d$. tess & ind. karṇatás \\
\hline 1/yess & ind. tátas \\
\hline (p.) $/$ aks & ind. pattatás \\
\hline$(p . d$.$) , caks$ & ind. antatás \\
\hline p.d. t taks & ind. mūrdhatás \\
\hline
\end{tabular}

ind. "abhipatás
ind. caramatás
várimatas
iud. yátas
ind. ? badhyatás
ind. madhyatás
ind. anyátas
ind. ãsyatás
ind. uttaratás
ind. dūratás
ind. agratás
ind. bhadratás

ind. samudratás

ind. sarvátas

c. ind. viçvátas

ind. çirṣatás

ind. itás

ind. abhítas

ind. parítas

ind. kútas

ind. sindhutás

ind. amútas

ind. manyutás

pc. c. cétas

c. rétas

(d.) srotas

ind: udaktás

ind. apāktás

ind. prāktás

ind. mattás

ind. "hṛttás

c. práthas păthas

$c$. ind. mithás

(p.d.) 1/das adás

(c.) mradas c. sádas riçădas

d. c. médas

c. védas

d. ródas

c. chándas

"krandas

(c.) dhas

$d$. c. ind. adhás

c. rădhas

tudhas édhas

(c.) medhas

vedhás

(d.) nodhas

ándhas

skándhas

çárdhas

d. nás

d.c. ánas

? cánas

d. c. mánas

(c.) vanas

"āhanás

arcanănas

dámūnas

d. c. énas

ind. amnás

c. ápas

apás

d. c. tápas

c. rápas

(c.) repas

d. çépas

(c.) varpas

c. pibas

d. 1 bhas

d. nábhas

ámbhas

(c.) mas

d. c. támas

d. c. námas

p. 1 yas

d. c. áyas

d. páyas

c. máyas

c. I váyas

d. 2 váyas

(c.) dhãyas

d. jyatyas

(c.) prāyas

(c.) häyas

bhiyás

lághiyas

drăghiyas

"yájiyas

(pc.) svájiyas

f́jiyas

ojIyas 


\begin{tabular}{|c|c|c|c|}
\hline & inf isvas & & \\
\hline ttkşiyas & ptvas & d. kăs & (c.) varjivāńs \\
\hline svầdiyas & (c.) ̧̧evas & $\left(p, d_{.}\right){ }_{1}^{\prime}$ das, dãs & bhaktivấns \\
\hline nédiyas & c. ind. kŕtvas & $(p)$, bhăs & $p c$. tasthiváns \\
\hline c.) klediyas & $(d . p d$.$) / dhvas$ & c. bhăs & pc. c. dadivănós \\
\hline kán & p.d. / ६ cuas & d. mầs & c. papivăhs \\
\hline "pán & ind. çvás & $p$. | rã, răs & $\left(p c_{.}\right)$"Iyivắns \\
\hline vár & (d. $p d$.$) । '̧as$ & (p.d.) / '̧̧ăs & (c.) rarivăn̉s \\
\hline yas & $(p c$.$) cas$ & $(p c . c$.$) çās$ & dadrivăns \\
\hline "táv & ind. anIkaçás & (c.) "rocis & mamrivấnss \\
\hline dáv & ind. ardharcaças & c. çocís & ( $p c$. ) viçivāñs \\
\hline náv & ind. çataçás & arcís & jakşivăhs \\
\hline ? váçiyas & (d.) daças & d.c. jyotis & jiglvăhns \\
\hline várşiyas & ind. "rūpaçás & chadís & (c.) bibhívāns \\
\hline ? vásiyas & ind. "dhāmaçás & çardís & babhưvắns \\
\hline sáhiyas & d.c. yáças & d.c. ind. nis & c. cakŗvắńs \\
\hline c. bháyas & yaçás & sarpís & sasŗvătno \\
\hline préyas & ind. agraçás & ind. tris & miḍhvăńs \\
\hline c. çréyas & ind. sahasraçás & d. kravís & c. cikitvắns \\
\hline ind. sadyas & ind. rtuçás & d. c. havis & pc. c. vidvăàs \\
\hline (d.) $\sqrt{ }$ bhyas & ind. paruçás & ind. ãvis & $p c$. jaganvănns \\
\hline c. vásyas & (c.) "peças & ind. dvís & dăçvatans \\
\hline ind. "hyás & pc. veçás & $(p c$.$) cis$ & d. 1 hins \\
\hline inf. carás & c. ușás & d. ind. bahís & c. purns \\
\hline jarás & dvéșas & d. c. barhís & p. 1 bharts \\
\hline táras & "çéşas & (c.) jus & $p \cdot 1^{\prime a h}$ \\
\hline c. ind. parás & (c.) joșas & d.c. yájus & p.d. \\
\hline c. bh & doșás & (c.) ind. dus & p.d. 1 nah \\
\hline (d.) $\mathrm{s}$ & c. cákşas & ind. prādús & (pc.) nah \\
\hline d. c. apsarás & (c.) dakșas & janús & d. $\{$ mańh, mah \\
\hline d. c. $\mathrm{h}$ & pákşas & c. dhánus & máh \\
\hline d. c. án̄g & d. c. rákșas & d. mánus & p.d. I'grah \\
\hline c. ind. $\mathrm{t}$ & rakşás & tápus & p.d. / vah \\
\hline c. çíras & (c.) vakşas & d. vápus & (c.) $\mathbf{v a h}$ \\
\hline úras & isas & d. c. àyus & anaḍváh \\
\hline (d.) duras & pásas & (c.) ind. dyus & p.d.1 sah \\
\hline c. ind. purás & c. văsas & c. árus & pc. c. sah \\
\hline$p . d .1$ tras & bháṅsas & d. c. párus & $(p . d .)_{\text {i }}^{\prime} \mathrm{gāh}$ \\
\hline$(p c . c$.$) sras$ & ápsas & d. c. cákșus & (c.) vāh \\
\hline$p . d . \sqrt[V]{\mathrm{I}} \mathbf{v a s}$ & $(d . p d$.$) has$ & ind. múhus & $(p c . c.) \mathbf{s a n h}$ \\
\hline p.d. $\sqrt{2}$ & c. áhas & ind. sajús & d. uşṇíh \\
\hline p.d. $\sqrt{ } 3$ & d. c. máhas & "yós & $p \cdot \mathcal{I}^{\prime}$ dih \\
\hline ind. a & d. c. sáhas & $(p . d.) \sqrt{ } / \tan s$ & níh \\
\hline d. c. ávas & (c.) vāhas & ghráns & p.d. $/ \mathrm{mih}$ \\
\hline$c$. javas & (c.) ehas & p.d. 1'srańs & p.d. , rih \\
\hline tavás & "dóhas & p.d. $/$ çañs & $(p d$.$) , lih$ \\
\hline d. c. çrávas & c. ánhas & púmāñs & (d.), $\mathbf{I h}$ \\
\hline & (c.) rañhas & "sasavấns & p.d. iguh \\
\hline
\end{tabular}




\begin{tabular}{|c|c|c|c|}
\hline p.d. / duh & $p c . \mathbf{r u ́ h}$ & $p . d . v \operatorname{trrh}$ & ${ }^{*} /$ jeh \\
\hline$(p c . c$.$) duh$ & $p . d . \vee$ druh & "dadṛ̣h & d. $\quad$ mah, man \\
\hline p.d. 1 muh & c. drúh & $(p . d.) \sqrt{ } \mathbf{b} r \underset{h}{h}$ & (d.) $\sqrt{ } \mathbf{r a}$ \\
\hline (c.) muh & $p . d . V(\mathbf{I} \overline{\mathbf{u}} \mathbf{h}$ & (c.) bṛh & \\
\hline$p . d$. ruh & $p \cdot \sqrt{ } 2 \overline{\mathrm{u} h}$ & $(p . d.) \sqrt{ } / \mathbf{v r} \mathbf{h}$ & \\
\hline
\end{tabular}

OMitTed in THEIR PROPER PLACE ABOVE.

\begin{tabular}{|c|c|c|c|}
\hline c. ástaka & írtsamāna & arasátama & arasátara \\
\hline trāihāyạ̣á & *jéhamāna & sahásrasātama & c. vrrkş \\
\hline ? staviṣyámāṇa & vișūcína & sphātimáttama & avacarantikấ \\
\hline tŗhyámāṇa & c. dūná & bārhatsãma & $\mathbf{k s}$ \\
\hline hūyámāna & (c.) stambha & karúma & durarmaṇt \\
\hline văçyamāna & "ábhayatama & dhiratara & āsandf \\
\hline
\end{tabular}

\section{LISTS OF FEMININE STEMS

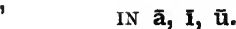

While regarding it as undesirable, in an index of declinable stems, to pass unnoticed the feminines having a form of their own, differing from that of the masculines to which they belong, I have yet thought it better to present them by themselves, in a classified order, rather than to include them in the general alphabetic Index. They are accordingly thus given below. Since, however, it is not practicable to draw a strict line between those feminines which have independence enough to require to be treated as separate stems and those which attach themselves to masculines, the lists following should be examined in connection with the stems having corresponding finals in the preceding Index; a few words are found in both places.

\section{A. Feminine Stems in ā.}

These all belong to masc.-neut. stems in a.

1. From participles in ta. The participles in ta, whether simple, combined with prepositions, or in other compounds, make their feminines in $\mathbf{a}$, and constitute the largest class of such feminines (over a hundred separate stems); they are so common and so regular as not to be worth reporting in detail. The only apparent exceptions are vilipti and vilị̂hí, which are words specialized in accent and meaning, as well as in ending.

2. From participles in na: chinnă, tunnă, bhinnă, -vinnā, pūrṇấ, -çîrṇā, -pīnā. Feminines in $\mathbf{I}$ of perhaps participial origin are jūrnị, -nagnĩ (but nagnâ), -naghni.

3 From participles in ãna : içā̄nā, dúhānā, rihāṇă, vásānā, vidānă, çăsānā, çáyānā, súvānā, ghnānă ; dádānā, dádhānā, rárāṇā; kṛ̣̣vānă, kưvāṇă, tanvānă; gṛ̣ānă, gṛhṇānă, vṛ̣ãăă; tundānă ; jagmānă, paprathānă, mumucānă, vāvaçānă, vāvṛdhãnă, sasvajānă ; pépiçānā, çăçadānā, çóçucānā to which may be added ăsīnā, and bhiyásānā, mandasānă. 
4. From participles in māna: ikşamãnāa khána-, gúha-, pínva-, prátha-, bhrăja-, rábha-, răsa-, vépa-, várdha-, çúmbha-, çváñca-, sáha-, tíş̧̧ha-, spárdha-, syánda-; ukșámānā, vijá-; jằyamānā, padya-, búdhya-, mánya-; kriyámāṇă, kṛtyá-, chidya-, tapyá-, tṛhyá-, diyá-, duhyá-, dhiyá-, niyá-, pacyá-, piçyá-, bhajyá-, miyá-, uhyá-, viyá-, sicyá-, słjyá-, hanyá-, hũyá-, hriyá-; yakşyámānāa ; hṛṇiyamānā, pátya-, raçanāyá-, sumanasyá-.

5. From words of comparison in ra, ma, ișţha: ádhară, ápară, avară, itarā, úttară, yatară ; avamă, uttamă, upamă, katamă, yatamă; paramă, madhyamă ; arasátarā, ásattarā, tilkṣṇátarā, parastară, bhişáktarā, mṛtámanastarā; dyumáttamã, priyátamā, bálavattamă, bhimátamā, manyumáttamā, vapuşțamā, vaçátamā, virátamā, çámtamã, çivátamā, çréşţhatamā, sahásrasãtamã, súbhişaktamā, sphãtimáttamă; prathamă ; jyéşţhă, păpișţhã, çréşţhã, çrávişţhā, páthişţhă. An (apparent) exception is açvatart.

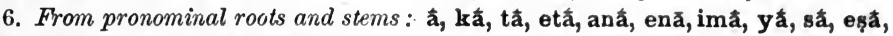
ékā (and ékāikã), sakă, svă.

7. From adjectives of various ending:-

a. Verbal derivatives in a: viçvaminvā, vyòşā, klandă, kșamă, ãgamā, paricarâ, ajárā (or poss. comp'd), dughã (in kāmadúghã, sudúghã), vidhamă, prābandhă, ugrampaçyă, prapyasâ, viçvambhară, naghārişă, talpeçayă, proșţheçayâ, punaḥsară; and, from intensively reduplicated roots, adhicañkramă, panișpadă, sanişyadá. Compare the feminines of such derivatives in I (below, B. III. 1).

b. Vṛddhi-derivatives in a: only părthivā (-vã or -vi in Rig-Veda), bārhatsãmā; all others of this class make their feminines in I (see below, B. 1II. 3).

c. Adjectives in ana. Stems of this form having the accent on the final regularly make their feminine in $\overline{\mathbf{a}}$ : thus, tvaraṇă, çarană, spandană. Those accented on the root-syllable as regularly make it in I (below, B. III. 2), except in possessive composition (below, A. 8, end): an exception is abhicákşaṇā; and visănāa, if it comes from $/$ sā.

d. Adjectives in ka: nyastikâ, rúpakā, avacarantikă, kumbhìkā, pāvakăa; for others, see the stems in kã in the Index of stems.

e. Adjectives in ya (the so-called gerundives first): anădyà, atitāryà, déyā, dvéşyā, anumădyā, áyabhyā and súyabhyā, ayodhyă, anavadyă, ekavãdyâ, vắryā, aghnyă, prahéyā ; múkhyā, bāṭ̂ă, ráṇyā, púṇyã, devatyà, satyă, skándhyā, anyầ, jaghanyà, jivádhanyā, dhanvanyà, budhnyà, ápyā, anūpyà, somyă, ăryā (to āryá), pítryā, gávyā, hanavyà, nāvyà, divyă, dāívyā, grāívyā, puṣyă, póşyā, kakșyà, upapakṣyà, varṣyà, utsyà, namasyà, srotasyà, amāvāsyà, băhyā, gúhyā, yajñíyā, samudríyā, priyầ (and sámpriyā, súpriyā), nakṣatriyā, abhriyā, usríyā, ṛ̂tviyā (to ṛttríya), turíyā, tritíyā, dvitíyā. The only exception is anudéy

f. Adjectives in ra: párā, sară, ișiră, gambhīră, tură, bándhurā, ghoră, ugrấ (also ugrí), citrầ (and sucitră), bhadrầ (and súbhadrā), mandră, víprã, çūdră, ārdrăâ, tīvră, vāçră, miçră (and tilámiçrā), usrầ, hin̉sră.

g. Adjectives in la: samușyală, jĩvală, açlīlâ, madhulă, bahulă, sthūlâ.

h. Adjectives in va: návā (and púnarṇavā), çantivă, çivầ (and áçivā), jıvâ, dhruvă, çévā (and suçévā), dvă, ūrdhvă, sárvā, pứrvā, víçvā.

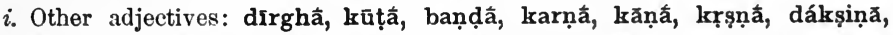
arună (also arụ̣i), çlakṣṇă, çloṇă, yajată, ámanyutā, duradabhnă, vṛịină, syonâ, pāpá (also pãpí), ubhă, khanitrímā, bhīmăa, çagmă, yamă (also yami), samă, stīmă, rāmă, vişâ, ujijeşā, vatsă. 
8. Possessice adjectives having an a-stem (or ā-stem) as final member (arranged in alphabetic order of the latter) : sahásrākșarā, jyótiragrā, tápuragrā, samagrăa, dưréantā, sámantā, sắntardeçā, çatâpāșțhā, anamitră, anamivâ, çatăritrā, svaritră, vyàlkaçā (?), anasthă, durādhárșā, anāmayă, anāvyādhắ, dvyàsyā, çúṣkāsyā, súrodakā, avákolbā, anṛkșară, índrarșabhā, dưévã, çatāúdanā, sahákaṇțhikā, deṿ̛́kāmā, pátikāmā, putrákāmā, sahásraku- . ṇapā, samikalpákulmalā, mádhukūlā, tuvikşatră, açvakșabhă (?), 16́hitakṣīrā, ávijñãtagadā, viçvágarbhā, urugúlā, saptagṛdhră(?), devágopā, uccāírghoșā, așțấcakrā, ródhacakrāâ, sácittā, ajárā, dvíjihvā, ávatokā, sahádevatā, navádvārā, pútidhānyā, bhưridhārā, mádhudhārā, çatádhārā, sahásradhārā, sunāthā, așțăpakșā, cátuṣpakșā, chándaḥpakṣā, dáçapakșā, ḋípakșā, prācínapakșā, șáț̣akșā, ādhíparṇā, uttānaparṇā, bṛhatpalāçā, çatápavitrā, apãlă, supāçấ, supippalâ, așțáputrā, indraputrā, deváputrā, çứraputrā, suputră, somaputrā, vitáprșțhā, sómaprșțhā, duṣpratigráhā, suprátIlkā, aprānăa, svadhăprāṇā, aphală, suphală, çatábalçā, dưrbhágā, subhágā, ábhayā, subhāgā, ékamukhā, svápnamukhā, amūlă, sumṛ̣ịkấ, suyámā, surátnā, arașa, gárbharasā, aripră, surukmâ, abhírūpā, pururúpā, viçvárūpā (also viçvarūpî), víșurūpā, sárūpā, sálakṣmā, lomaçavakșaṇā, anupūrvávatsā, tilávatsā, nítyavatsā, purợaç̧avatsā, mṛtávatsā, çatávadhã, vivaruṇă, anyávarṇā, sávarṇā, suvárṇā, sūryavarṇā, híraṇyavarṇā, sūtávaçā, viçvávārā, aghávișā, nănāviryā, viçvátoviryā, suṿ̛jánā, ánuvratā, máhivratā, kămaçalyā, çatáçalyā, asachākhă, víçākhā, çatáçākhā,

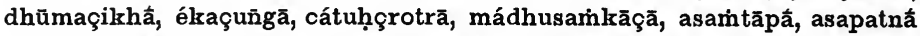
(but sapátñ), triṣaptă, sahásambhalā, satyásavā, ántisumnā, suṣúmā, pṛthușțukā, sahásrastukā, bhứristhātrā, suhávā, ārdráhastā, çītáhradā.

The possessive compounds of stems in ana may be best mentioned by themselves, since these stems in their other uses, simple and compound, make their feminines in I (see below, B. III. 2): they are sūpāyană, suprāyaṇă, çatávicakṣaṇā, ékatejanā, aprapānăa, suprapānầ, híraṇyabandhanā, mahónmānā, tṛșțavandanā, anapavācană, sūpasarpanăa With them perhaps belongs uttānă ( $\left.\mathfrak{1}^{\mathrm{t}} \mathbf{\mathrm { a }}=\tan \right)$, which at any rate can hardly be a participle.

A number of a-stems (including three of the above-parna, mukha, rūpa) form feminines in $\mathbf{I}$ in possessive composition: see below (B. III. 5).

9. Other compounds. Descriptive compounds having a stem in $\overline{\mathbf{a}}$ as final member of course show the same form: examples are caramăjā, ekāṣțakă, çāṇḍadūrvă (possessive?), avidhavă. Of a root in $\overline{\mathbf{a}}$ shortened as final of a compound and taking a feminine in $\overline{\mathbf{a}}$ the only examples are durgă, svāsasthă. Of prepositional compounds making a feminine occur only vyadhvă, nị̣sālă.

\section{B. Feminine Stems in $\mathbf{I}$.}

The feminines in $\overline{\mathbf{1}}$ are to be divided according to the ending of the masculine from which they are made or to which they correspond. The great majority of them come from consonant-stems.

I. From consonant stems.

1. From participles in ant and at: yántī (also yatì), svapántī (transfer to á-class?); hinsantī ; járantĩ (and járatī), óșantī, kárṣantī, krắmantí, krídạtī, kṣáyantī, gáchantī, cárantī, jáyantī, jîvantī, dhăvantī, náyantĩ, pátantī, píbantī, bhájantī, bhávantī, bhárantī, mádantī, méhantĩ, mívanti, vádantī, çáṅsantī, çíkșantī, tíșțhantī, sravantĩ ; ichántī, ukşántī, kirántí, 
khidánti, tudántĩ, muñcántI, mṛçánti, uchánti, sphurantI ; ásyanti, nựtyantI, yásyantĩ ; IpsantI, IrtsantI ; cetáyantI, janáyantı, tarpáyantı, moháyantı, rădhayantI, veçáyantı, vardháyantı, varıvarjáyantı; pāláyanti,

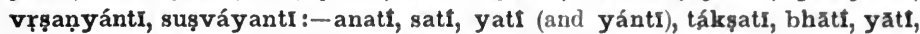
riphatí, rudatí, uçatí, ghnatı ; dádatı, bíbhyatı, bíbhratI ; kṛ̣vatı́, cinvatı,

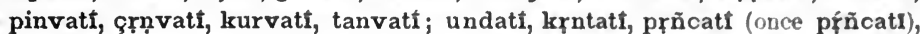
bhañjatî, bhindatí, bhuñjatî, rundhatí; açnatí, jănatí, stṛnatí ; síşāsatı (2); kárikratī, jâgratí, nănadatí, bóbhuvatî, rérihatı; durasyatı́, ̧atrayatt.

To these may best be added the other words in ant and at: kíyatı, jágatı, p̛̣şati, bṛhatí, mahatí, rúçati (and ruçántı), çaçvatı (to çáçvant), járatı (and -járanti); jivantî is rather feminine to jivantá; compare also datí (in víşadati) from dánt, and naptí from nápāt.

2. From possessives in mant and vant: 6șadhimati, tvíşimati, ançumáti, íșumatí, ketumátI, kşumátI, pilúmati, mádhumati, prasúmati, gómatı, jyótişmatí, havíșmatí, áyuşmatí - avadyávati, ghṛtávatı, púşpavati,

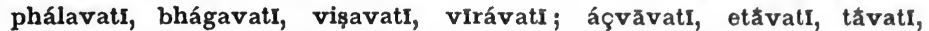
madăvatí, yăvatí, varạ̣ăvatí, vīryàvati, samăvatí, írãvati, prajăvati, vijāvatı, çı̂tikāvatĩ, síkatāvatĩ, sūnị́tāvati, svadhăvatí, hlādikāvatı; revátĩ ; datvátĩ, padvátī; áçmanvatī, bráhmaṇvatī, çvànvatí, àtmanváti, udanvátĩ, çirşaṇvátĩ, árvatī, svàrvatĩ ; ánasvatĩ, ánupadasvatí, turjasvatí, tamasvatĩ, nábhasvatī, páyasvatī, bhárgasvatĩ, yáçasvatí, várcasvatí, vyácasvatī, sárasvatĩ, sáhasvatĩ, nasvátí.

3. From possessives in in and vin: aghārịñ̄, açvíni, karīṣiṇi, karṇinI, kăn -

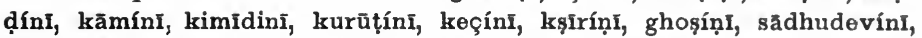

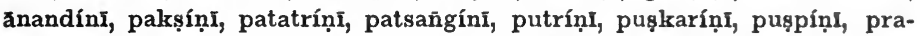
modíni, phalínī, medínī, yamíni, vaçínī, vājíni, priyavādínI, kharvavăsínI, vāhíni, stambínī, hastíni (and hastint); rakșasvínI.

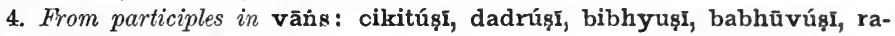
ruși, vidúṣị, varjúșī, sasrúși.

5. From comparatives in yas: víklediyasĩ, páníyasi, préyasi, bhâyasI, lághìyasī, çréyasī, sáhīyasī, párişvajīyasĩ.

6. Feminines in varī (reckoned as belonging to masculines in van): agrét-

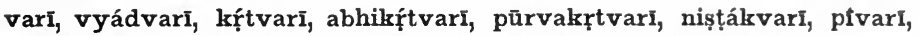
vibhāvarī, vimrígvarī, çákvarī, uttānaçî́varì, pratiçîvarī, vahyaçîvarī, mātaríçvarī, bahusứvarī ; ṛtávarī.

7. From noun-stems in an. Here occur only rājñ̄ (in samrâjiñ̄ and the possessive compounds síndhurājñ̄i and sómarājñ̄i), and the possessives kīlálodhnī, dựnămnī, páñcanāmnī, mahănāmnī, viçvánāmnī, sahásranāmnī, ékamūrdhni. With them may be mentioned çunt. The word durarmant is probably corrupt.

8. From roots and root-words. Apart from the feminines of adjectives in añc

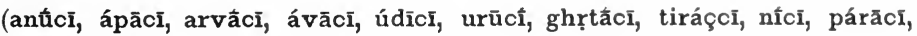
purūct, pratî́cī, prăcī, víșūcī, sadhrî̀ī, samícī), which are of disputed character, we have from roots only mucī (in ámuci) and ghnī (in jyeșțhaghni, ádevṛghnī, ápatighnī, ápaçughni, ábhrātṛghnī, bhrātrłoyaghnì, vīraghní, áviraghnī); of essentially kindred character is maht; and the compounds of pad (așțăpadī, ékapadī, ghṛtápadī, cátuṣpadī, dvipádī; návapadī, ríçyapadí; yajnapadì and çitipadí more probably belong to masculines in -pada) are best classed with them, as well as vị́şadatí. 
II. From $\mathbf{r}, \mathbf{u}$, and $\mathbf{i}$-stems.

1. From stems in ṛ: jánitrī, jātrí (mss.). déșțri, bhartrí, rășțrī, sūtrí.

2. From stems in $\mathbf{u}$ : urvit, pūrvi, prthivt, bahvi, bhvī (in udbhvi, prabhvi, vibhvî).

3. From stems in i: only kṛmî (to kị́mi), since pátnī (to páti) is no direct formation.

III. From a-stems.

1. From verbal nouns with suffix a : annādí, çūnyāișt, avakrāmî, çūrpagrāhî, pumçcalî, çatavāhì, vṛkșasarpí, udahārì.

2. From verbal nouns with suffix ana. Verbal derivatives in ana with accent on the radical syllable make feminines in $\mathbf{i}$, both when simple and when compounder (except in possessive composition: see above, A. 8, end). The examples are áraṇi, âñjanī (?), úkșaṇi (in prókșaṇi), ócanī (in nyó-), kárạ̣i (in ayakșmamkk-, sarūpamkk-, subhāgamik-), gámañ̄ (in sam̉g-), gráhañ (in saṃ-), cătanI (in amīvac-), jámbhañ̄ (in kaṇvaj-, piçācaj-, maçakaj-), jîvan̄i (in puruṣaj-), táraṇi (in prat-), tárhaṇī, dựșaṇi (and kṛtyād-, vișad-), dứnhaṇī (in keçad-), dháraṇi (in vidh-), năçañ̄ (in kṣetriyan-, balāsan-, yakşman-, vãtīkṛtan-), péçani, bárhaṇi (in mūlab-), bhárạ̣i, yăvanī (in çapathay-), yópani (in paday-, çapathay-), róhạ̣i, vánani (in samv-), vápañ (in ãv-), várdhanĩ (in keçav-), véçani (in niv-), vyadhanī (in kṛtav-), çúmbhanī, sávanī (in abhiṣ-), snápanī, spáraṇī, hárșaṇi (in çepah-), jñănīi (in praj-), dhănī (in abhidh-, vasudh-; yātudhãnt is specialized in accent and meaning), dhmă$\mathbf{n} \mathbf{I}$ (in upadh-); and probably ajani in âjani (instead of ájani). The two words nirdahant and pramandant are probably of the same formation, but specialized as proper names; uttarāñjant is conjectural; arșaṇ̂ and cetaní perhaps belong to a different suffix ; edháñ̄ (mss.) and tejánī (mss.) are doubtful.

3. From vṛddhi-derivatives with suffix a: āngirasî, ātharvaṇi, āmitrí, àyasī,

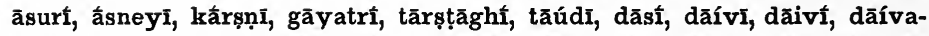
janĩ, nārāçaǹsí, pāvamānt, pāurṇamāsí, brăhmaṇi, bhăratī, mādhvĩ, mā-

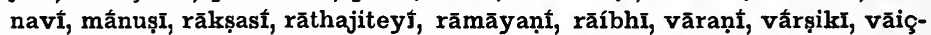
vadeví, vāiçvānarí, sāvitrí, sāutrāmaṇi, hāyaní, hāimavatì. Two exceptions, pậrthivāa and bārhatsāmā, were noticed above (A. 7. b). The only feminines to vṛddhi-derivatives in ya are văsteȳ (from an i-stem) and dāívyã (Rig-Veda also dāívī).

4. Of derivatives with other secondary suffixes, forming classes with feminine regularly in $\mathbf{i}$, there are but few: namely, ayasmáyī; sanátnī; and the ordinals caturthì, așțami, daçamì, tripañcāçí.

5. Of possessive compounds with an a-stem as final member there are, as noticed above (A. 8), a few making feminines of this form: dhūmākṣi, caturakṣi, bṛhadarkit, vikeçî, vyastakeçi, hiraṇyakeçi, kṛdhukarṇi, prę̧niparṇi, çyenáparṇi (?), sahasraparṇi (to sahásraparṇa), anhhubhédi, viçvábheşajī,

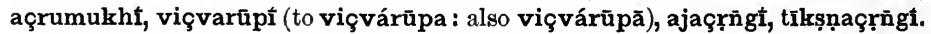

6. From stems of various formation (in part, with change of accent): arāyí (to arấya), arụ̣̂t (and aruṇâ), árjunī, ugrí (and ugrâ), ubháyĩ, kalyāṇî (and ákalyāṇī: to kalyăṇa, not in AV.), kumārî, kumbhí, kévalī, gandharví, gardabhí, deví (and ádevī), dharuṇî (to dharúna), dhīní (to dhíra), naladí (to nálada), palālí, pāpí (and pāpă), pippalí (to píppala), piçācí, purāṇí, prssāatakí (to prșâtaka), prapharví, phálguni, sumañgalí (to sumañgála) and ádurmañgalí, bheşají (and atividdhabheşají, āhrutabheşají ?, kşiptabhe- 


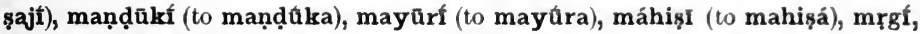
yamí, lalāmí (to lalâma), âligī and víligī, vişătakf́, jîvantí, veçantí (and veçantă), çubhrī (?), sapátnī (and asapatnă, possessive), samănt, hiraṇyáyĩ (-yī or -yā in RV.); and, in composition, vikankatí (in -tímukha: to víkañka$\mathrm{ta}$, not in AV.).

Already mentioned above are the forms of participial character or aspect viliptî́, vilị̣̄hí, jūrṇī, mahānagnî and mahānaghní; the feminines throughı derivatives in a from monosyllabic stems gavī (in purogaví, brahmagaví) and padì (in yajñapadí, çitipadí); the quasi-comparative açvatarí; the solitary gerundive in $\mathbf{y} \mathbf{i}$ anudéȳi ; and yātudhāní, with altered accent.

7. Feminines differing otherwise than in ending from tho masculine: ásikni (to ásita), énī (to éta, not in $\mathrm{AV}$.), páruṣñ̄ (to paruşá), róhị̣i (to róhita), 16hinī (to lóhita), cyénī (to çyetá), harikṇi (in hárikṇikă) and hárinĩ (to hárita). The feminines in vari to masculines in van wero given above (B. I. 6); also pátnī, to páti (B. II. 3).

\section{Feminine Stems in ū.}

These are extremely fow: namely, agrú (to ágru), aghāyú, guggulú (to gúggulu), caraṇyú (?), jighatsú, patayălú, pṛdākú (to pṛ́dāku), madhú (to mádhu), çundhyú, saraṇytú.

There may be mentioned, finally, the two numeral feminines in $r$, tisś and cátasr.

\section{LISTS OF TENSE-, CONJUGATION-, AND MODE-STEMS.}

Below are given all the stems of verbal inflection found to occur in the Atharvan (not excluding those from which only participles, and not actual personal forms, are made). They are arranged, under each sub-division, in the alphabetic order of the roots from which they come. Accents are added, provided that accented forms occur, wherever it seemed worth while, as helping to determino the charaeter of the stem. The bases of derivative or secondary conjugation are put next after the present-stems, with which they are essentially akin; then follow the other tense-stems; and the mode-stems come last of all. The mark of interrogation and asterisk are used as in the Index above.

\section{Present Stems.}

1. Root-class: ad, an, I as, ās, i, ị̂, īr, īẹ, I kṛ (kárṣi), kṣnu, cakṣ, takș", taḍ*, 2 dā, dih, duh, drā, dviș, ı pā, psā, brū, bhā, mrrj, yã, ı yu, rih, rud, rudh (only rudhmas?), vaç uç, 2 vas, vā, I vid, vī, çās, çiñj”, çî, çvas, sas, sū, stu, snā, svap, han; and, only in the imperatively used $2 d$ sing., nī", yaj", sad".

2. Reduplicating class: iyar, jígā, jighar*, jighrā, ciké ciki cikī, dádā, didiç* (or perf.), dīdi, dádhā, dīdhĩ, pípā, I pípṛ, 2 pipṛ, pip̣̣c, bábhas, bibhī, bíbhṛ, mamád, mimĩ, mímā* (2 mā), yayas", yuyo, rarā, vívac, çiçā çiçī, sísṛ, jáhā jahī jahi jihī, juhú.

3. Nasal class (in the weak form, if the strong does not occur): anaj, indh, und, ṛnadh, kṛnt, gṛ̣ath, chinad, tund, tṛnad, tṛnahah, pinaş, pṛnac, bhanaj, bhinad, bhunaj, yunaj, rụ̣adh, vinac, vṛ̣ajaj, hinas. 
4. Nu and u-classes: akṣnu, açnu, āpnu, ṛ̣u, ṛdhnu, kṛ̣nu, kṣiṇu, cinu, dabhnu, dunu, dhūnu, minu, ūrṇu, çaknu, çṛ̣u, sunu, skunu, stṛ̣̣u, spṛ̣u *, hinu ;-kuru, tanu, manu, vanu, sanu.

5. Nā-class (in the weak form, if the strong does not occur): açnā, ișnāa, krinĩ, kṣināa, gṛnīi, gṛnā (2 gṛ), gṛbhṇā gṛhṇā, jānā, jinā, punā, pṛṇā, badhnā,

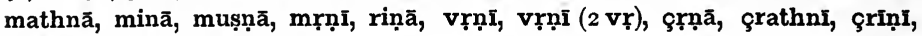
sinā, stabhnā, stṛ̣̣ā, hṛnī*.

6. Unaccented a-cluss: ája, añca, áca, ána, áma, árca, arda, arha, áva, āla (?), áya, ínva, íkșa, íșa, óșa, túha, oha, arșa, éja, édha, éșa, kașa, kasa, kứja, ḳ̛́pa (or to 7), kárṣa, kálpa, kránda, kráma krăma, krị́̂a, kroça, kșada, kṣâma(?), kṣára, kṣáya, khána, khăda, gácha, gada(?), găha, gưha, cára, cala, cáya (?), ceta*, códa*, céșța, cyáva, jáya, jínva, jíva, júrva, jára, jára (? 2 j̣̣), jéha*, takșa, tápa, tấva, tóça, tára, trasa, tsára, daça, dákșa, dabha, daya, dâsa, dáha, dáda, dāça*, ḍ̛́nhha, dyóta, drava, dhanva*, dháma, dádha, dhăva, dhứrva*, nákșa, náda, nánda, nabha, náma, naça, nădha, níkșa, náya, nava, páca, páta, píba, pínva, páya*, páva, prñoca, prátha, plava, bădha, bódha, bhája, bhăsa, bháya*, bháva, bhúșa, bhára, bhrañạa, bhrăja, mántha, máda, manda, méha, míva, móda, mūrcha, mróca, yája, yáta, yábha, yácha, yăca, yodha, yéșa, rákșa, rada, rápa*, rapça, rábha, ráma, răja, rắsa, réșa, róca, róha, réja, lápa, lábha, láya, váñca, váda, vadha, vána, vánda, vápa, vápa (2 vap), valga, vaça (?), vása, váha, văñcha, vépa, veșța, várta, várdha, várșa, véna, vyatha, vraja, çáṅsa, çíkșa, çápa, çárdha*, çaya, çóca, çúmbha, çráya, çváñca, șțhiva, sáca, saja, sída, sáha, sedha, sara, sárja, sárpa, seva, skánda, stana, stava*, tíșțha, spárdha, sphūrja, smára, syánda, sráva, svaja, sváda*, svára*, háva, hára, hárșa.

7. Accented á-class : aná, rida*, ichá, ukșá, ubjá, umbha, ṛcha, rșá, kirá, kṛntá, kṛ̣á, kṣiyá, kṣipa, khidá, khuda, gura, gṛná, gíra(?), cṛtá, juṣá, tudá, tirá, diçá, dṛnhaá, dhuva, nudá, pinçá, pṛná, pṛchá, prușá (?), bṛha, mișá, muñcá, mṛná, mṛạá, mṛçá, yuva, yuva (2 yu), yucha, yujá, ruva, rujá, likha, limpa, lumpá, uda, uchá, vijá, vindá, vidhá, viçá, vṛșa*, vṛha, vṛçcá, çṛ̣a, siñcá, suva sva, sṛjá, spŗ̧̣a, sphurá, huvá.

8. Ya-class: ásya, f́ya, iṣya, ucya, kupya, krúdhya, gâya, glāya, chya, jầya, jīrya, tīrya (?), tṛpya, tṛ́șya (?), trắya, dasya, dáhya(?), dya, dīya*, dīpya, dívya, dháya, náçya, nahya, nứtya, pádya, páçya, píya, púşya, pyãya, búdhya, mánya, medya, múhya, yásya, yúdhya, rajya, rádhya, rădhya, ríṣya, rīya*, lubhya, vaya, văçya, vídhya, vyaya, çìya, çúșya, çrămya, sya, sívya, harya, hváya.

9. Passive or accented yá-class: acyá, ajya*, açyá, asya, idhyá, rdhya, kriyá, kṛtyá, kṣīyá, gamyá, gṛhya, chidya, jñāya (?), jìyá, tāyá, tapyá, tṛhyá, dahya, dīyá, dīya (2 dā), duhyá, dṛçyá, dhīyá, dhūya, dhriya, nahyá, nīyá, pacyá, pīyá, piçyá, proya, badhyá, bhajyá, bhajya (bhañj), bhidya (?), mathyá, mīyá (māi), mīyá (mi), mucyá, mriyá, yujyá, ricya, rudhyá, lìya (?), lupyá, ucyá, vacyá, udyá, upyá, uhyá, vicya, vidyá, viyá, vṛ̣ya, vṛçcya (?), çiṣya, çīrya, sicyá, sṛjyá, hanyá, hīya, hūyá (hū), hriyá; - mīmāñsyá (?).

10. Intensives (including those found in derivatives only): cākaç, cañkaç (in d.), karikṛ carikṛ, carkṛ (3 kṛ), carkṛș, kanikrad, jañgah, jāgr, carcar carācar (in d.), cācal (in d.), jañjabh, davidyut, nānad, nenij, nonu (?), panipn*, pepiç, barbṛh*, bobhū, marīmŗ̣ (in d.), maliml (in d.), malimluc (in d.), yo- 
yu, răraj, rerih, roru, rorud (in d.), lălap, vãvad, vevig̨, varṿ̧t varîṛt, çăçad, çoçuc, sanişyad (in d.), sanisras (in d.), sarış̣p (in d.), sarsł̣, taństan,

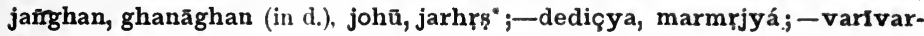
jáya.

11. Desideratives: ipsa, Irtsa, cikīrg̨a, jigāñsa (?), jighatsa, cikitsa, jigIşa, jijñāsa, jijyăsa*, titikşa, titṛpsa*, dipsa, ditsa, dudlıŭrşa, ninı̨̧a (?), pipatiģa, břbhatsa (in d.), mImānsa, iyakşa, yuyutsa, lipsa lipsa (?), vivãsa, vivakşa (in d.), vivṛtsa, çiçlikşa (?), sişãsa, jighānsa, jihıșa (?), jihırşa.

12. Causatives: anaya, āmaya, ardaya, āvaya, iñgaya;, ilaya, Ikşaya, Ińkhaya, Iraya, ardhaya, kāmaya, kāçaya, kalpaya, krandaya, krodhaya, gamaya, ghāraya, cātaya, cetaya", codaya, cyāvaya, chādaya, janaya, jambhaya, jîvaya", jyotaya, tānaya, tāpaya, tujaya , tāraya, tarpaya, trăsaya, tvaraya, dambhaya*, damaya, dãsaya, dípaya, dūşaya, dṛnhaya, darçaya, dyotaya, dhāraya, namaya, nāçaya, pataya pātaya, pãdaya, pāyaya, piḍaya, poşaya, pūraya, pãraya, pyāyaya, prathaya, bãdhaya, bodhaya, bhakșaya, bhăjaya", bhojaya, bhāvaya, mahaya, madaya mādaya, mānaya, methaya (?), medaya*, mohaya, māraya, marcaya, mṛdaya, yãtaya, yāmaya, yācaya, yāvaya, yopaya*, rajaya, rạaya*, randhaya, ramaya, rājaya, rādhaya, reșaya, rocaya, rohaya, lāpaya, lobhaya, vājaya, vānaya, vāsaya (? I vas), vāsaya (3 vas), vedaya, vepaya, veçaya, veșțaya, viḍaya*, vāraya, varjaya, vartaya, vardhaya, varşaya, vyathaya, çańsaya, çātaya, çāpaya, çamaya, çocaya, çobhaya, çoșaya, çrathaya, çrāvaya, çvāsaya*, sādaya, sādhaya, sūdaya, stanaya, sphūrjaya*, srañsaya, srivaya (?), srāvaya, svadaya, svāpaya, svaraya, harșaya; arpaya, kṣăpaya, glăpaya, jñapaya, dāpaya, dhāpaya, mlāpaya, vāpaya (I vã), çrapaya, sthāpaya, snapaya, hāpaya;-varīvarjaya.

13. Denominatives (accented): aghāyá, adhvariyá, amitrāyá, arātiyá, urușyá, kavīyá, kīrtáya, gavyá, gopãyá, gṛbhāyá, carạ̣ya, janiyá janiyá, taviṣyá, tudāyá, daçasya*, durasyá, devayá, dhūpăya, namasyá, pátya, pāláya, putriyá, pṛtanāyá, pṛtanyá, priyāyá, bhurạ̣yá, mathāyá, manasyá, mantráya, manyūya, mahiya, mușāya*, mṛgáya, raçanāyá, viráya, vṛṣạ̣yá, vṛşāyá, çatrūyá, çapathīyá, çrathāya, sakhīyá, satvanāyá, saparya, sabhāgáya, sumanasyá, suṣváya, skabhãya, svapasyá*.

\section{Perfect Stems.}

Of the perfect stems both strong and weak forms are given. if there is anything special in either formation. They are: ān", ānṛc, āv $\mathbf{a}^{*}, \bar{a} n a n c ̧$ ānac, ās, āh, āp,

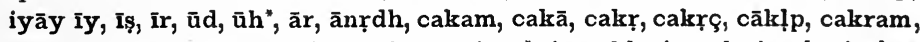
cukșubh, cakhn, jagam jagm, jugup, jagr", jagrabh, jagrah jagṛh, jaghas jakș, cacar cer, ciki, cikit, cacṛt, jajan jajñ, jajas, jigi, jujuş, jajṛ, tatakș, tatan tatn ten, tatap, tutud, tatṛ̂, tātṛ̣, tātṛș", tatṛh, dadambh, dadā, dāç (pple), didiç, didīv, duduh, dadŗ̧̣, didyut, dadrā, dudru (?), dudruh, dadhā, dudhū, dādhṛ dadhṛ, dādhṛ dadhṛș, nanaç*, nanah, ninī, papac, papat pet, paspaç, papā, pipiç, papṛc, paprath, paprā, babandh bedh, babādh, babṛh, babhaj” bhej, bibhid, bibhī, babhū, jabhṛ, māmah, mamath, mamã, mimī" (2 mā), mimi, mīmĩ (mĩ), mumuc, mamr, mamṛj mamārj, Ij yej(?), yet, yayam, yayā, yuyuj, yuyop*, rebh, rarādh, riric, ruruj, rurudh*, ruruh, lebh, uvac ūc, ūd, uvas (I vas), ūṣ (3 vas), ūh, vāvaç", vivic, vid, vivid, viviç viç, vṛj (pple), vāvṛt vavṛt, vāvṛdh vaṿ̛dh*, çaçak çek, 
çaçap çep, çaçam, çaçā, çaçī", çuçuc* , çaçr, çiçri, çuçru, sec, sasad sed, sasa* (san), sāsah sasah, sasū sușū, sașr, sasł̣j, caskand, caskabh, tastambh tastabh, tastṛ (?), tasthā, paspṛdh*, siṣyad, susru, sasvaj, jaghan jaghn, jahā (?), jihiñs, jihīẹ jîhī ̣u, jahṛ, juhur* ;-jāgṛ.

\section{AORIST STEMS.}

1. Root-aorist: I aç, idh, rddh, kṛ, kṛp*, gam, gā, 2 gṛ, grabh, ghas, chid, juș, I dā, dṛç, I dhā dhi hi, 2 dhā, dhṛ, dhṛș (?), naç, pad, 2 pã, prā, bhū, muc, mṛ, yam (?), yuj, rudh (?), I vas*, 2 vid(?), vṛ, vṛj, vṛt, çru, sah, sthā sthi, spr, hā (?); and, in "precative" forms only, jīv, I pr, bhrāj, 2 yu*, rādh, vadh ; in single imperative forms only, budh*, mad, rā, viș, çak*.

The passive aorist $3 d$ persons are as follows: dhāyi, pādi, prãyi, bodhi*, moci, çeși, hāyi.

2. A-aorist: astha ( 2 as or sthā), āpa, ara, rdha, kara, krudha, kșudha, khya, gama, gṛdha, tasa, tṛpa, tṛșa, tṛha, dasa, dṛpa (?), dŗ̧̣a, druha, neça, nija, papta, pada, pișa, pușa, bhida, bhúva, bhraça*, mátha, muca, radha, rișa, ruha, vocá, vidá, vṛdha, çaka, çișa (çās), çíșa (çiș), çucá*, çrama, sada, saná, șrpa, hya, hva. Of these, neça and voca, as well as papta, are regarded as involving a reduplication; pada (if the reading be allowed to stand) may perhaps be regarded as root-aorist with double mode-sign; mátha may be rather a present-stem.

3. Reduplicated aorist: amama, arpipa, cīkḷpa, cikrada, cikșipa, jīgama, jagrabha, cīcara, jíjana, jījabha, tītapa, tītara, tītṛpa, titrasa, dū duṣa, didyuta, dīdhara, nīnaça, pīpata, pīpada, pípara, būbudha, būbhuva, mīmada, mūmuha, mīmṛna, mīmṛsa*, rīrișa*, rūrupa, vīvata*, vĩvara, vīvṛta, vīvṛdha, çiçama, çūçuca, çiçriya sușū dá, tișțhipa, sisrasa, jīhiḍa, jihvara* ; and, without union-vowel, mimi $\overline{\mathbf{r}}^{*}(\mathbf{m} \mathbf{m} \overline{\mathbf{a}})$ and susru (unless they are to be reckoned as pluperfects instead): jagrabha is in form pluperfect, although its use is aoristic.

4. S-aorist (strong and weak forms, when occurring, given together): kārș (3 kṛ̂), kramins, kṣeș (2 kṣi), cyóș, chits, jāiș, jñās, tāns (in atān), taps (?), dhākṣ, diṣ (I dā), dhūṣ", nāikṣ nikṣ, neș, nūṣ, pats, pās, prākṣ pṛ̂ṣ̣ (pṛc), prākṣ (prach), bhuts, bhakṣ, bhāiș, bhārș, man̉s mān̉s, mās (I mā), meṣ (mi), mukș, yakș, yūṣ yāuṣ yoṣ (2 yu), yukș (or to 1), yuts, rams, rāts, rāuts, lips", vāts (I vas ?), vāts (3 vas), vākṣ vákș, vits*, vikṣ" (viç), vṛș (2 vṛ), vṛkṣ, çrāiṣ, sākṣ sakṣ, sarș, srākṣ sṛkș, stoṣ*, stṛṣ, spārṣ" (?), hās, hāị̣, hārṣ.

5. Iș-aorist: aniṣ, açiș (2 aç), aviș, edhiș, kramiș, kṣaṇiṣ, grabhị grahīṣ, cāyiș, jániș, jīviș, tāriș, níndiș, nayiș, nudiș, nạtiș, bādhiṣ, bhāriș, mathiṣ, modiș, moșiș, yodhiș゙, rakșiș, rādhiș, ruciṣ, vâdiș, vadhiṣ, vaniș- varșiș,

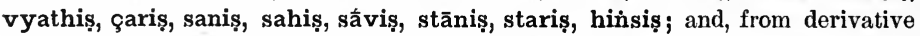
conjugations, irtsiș, cikitsiș, ilayiș, vyathayiș, saparyiṣ.

6. Siș-aorist: pyāsiṣ (?), vañsiș (?), hāsiṣ.

7. Sa-aorist: dvikșa, mṛkșa (mŗ̣), rukșa, spṛkșa.

\section{Future STEMS.}

The future stems are as follows: eșya, kartsya, kramsya, gopsya, jeşya, jyeşya (?), dhakșya(?), dāsya, neșya, mekșya(?), yakșya (?), yãsya, yokşya (?), rātsya, vakșya (vac), vakṣya (vah), çatsya, sākșya (?), hāsya, hoşa; [v]artişya, karișya, gamișya, dharișya, naçișya, patişya, bhavișya, marişya, vadișya, sarișya, stavișya, svapișya, haniṣya ; and, from secondary conjugation-stems, dūṣayişya, vãrayișya. 


\section{Subjunctive Mone-Stress.}

The subjunctive stems are here presented in the order of the tense and conjugation stems as given above. They are all accentuated, if accented forms from them occur.

A. From present-stems:-1. ádā, ása ásā, ăsā, áya áyā, doha', dvéşa, brava bravā, yava, véda, stáva, hána hanã;-2. dỉdáya dĩdāya, bibhara, mamáda, jáhã ;-3. ṛnádha*, tṛ̣áhă, bhunaja;-4. açnáva, kṛnáva kṛṇavã, çaknáva*, çrnáva, stṛnava; karava karavă, manáva , sanáva;-5. jānă ;6. éjā, gáchā, carā, jánā, jáyā, jîvā, tapā, tarā, dabhā', dăsã, dadā (dad), dṛnhhā, dhamā, dhăvā, náyā, pátã, padā, píbā, bhájā, bhăsā, bhávā, yajā", yachā, rakșā, răjā̄, réşă, róhā, vádā, vánă, váhā, çíkşă, çápā, çumbhā, çráyā, sácā, sîdā, sahā”, sárpā, tíșțhā, smárā, svajā, hvayā, hárā;-7. ichā,

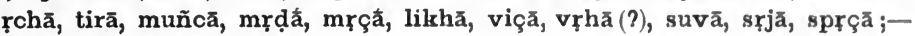
8. páçyā, ríşyā, haryā;-9 (passive). mucyă (?).

B. From derivative conjugation-stems :-10 (intensives). căkaçā, jāgara jāgarã, yóyuva;-11 (desideratives). cíkitsā, dípsā;-12 (causatives). ardayā, iñkháyā, kalpayā, janáyā; tarpayā, dhāpayā, dhārayā, pātayā, pādayā, pūrayã. pārayā, mādayā, māráyā, mṛ̣ayā, yãvayā, randháyā, rājayā, vārayā, vardhayā, sādayā, sthāpayā;-13 (denominatives). arātiyă, kīrtáyã, caraṇyā, durasyă, pritanyă.

C. From perfect-stems: cākḷpa, dídeça, dadharşa* dádhŗ̧̦a.

D. From aorist-stems :-1. kára, gara, caya ${ }^{*}$, joşa, dárça, naça*, yáma, spara;-2. gamā, voca*, çíșā ;-3. tîtapāa-4. neșa, parşa, máñsa, mằsa, yakşa, yoșa, vákșa, sakṣa, sarṣa ;-5. tārișa, níndișa, vădișa, vaniṣa, sanișa, sāviṣa.

\section{Optative Mode-Stems.}

These stems are given in the same order with the preeeding division. The socalled precative forms, or those actually showing a sibilant between optative-sign and ending, are put together at the end.

A. From present-stems:-1. adyā, syă, brūyā, vidyă, hanyă ; çaȳi ;2. dadyā, mimiyā, jahyā, juhuyă ; dadhَ" ;-3. bhindyā ;-4. çṛ̣uyă ; manvī;-5. açnīyă, gṛhṇịyã. jinīyă ;-6. kṣaye, gache, cáre, jaye, jíve, táre, bhaje, bháve, bhúse, bhare, máde, yache, yáce, rape", róhe, labhe, vade, vadhe, vaçe (?), vase(?), çánse, sace, sĩde, háre;-7. iche, kṣiye, khidé, jușe, lumpé, ude, uche, vidhé, viçe, vṛhe*, siñcé, srjé, huve;-8. jâye*, dhaye, páçye, púșye (?), búdhye (?), manye, riṣye.

B. From derivative conjugation-stems:-10 (intensives). vevișyā;-11 (desideratives). lipse (?);-12 (causatives). mānaye, veçaye;-13 (denominatives). daçasye*, manasyé.

C. From perfect-stems: jagamyā, papatyā, papṛcyā, riricyā", viviçyā", vavrty $\bar{a}^{*}$, sasadyā.

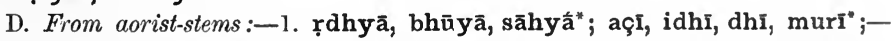
2. ápe (āpe ?), rłdhe, game, dṛçe, pușe, bhide, ruhe, vocé, vidé, çake, sade,

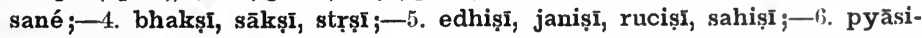
și (?), van̉siṣī (?).

Precative forms: ṛdhyầs, jīvyăs, priyās, bhūyăs, bhrājyās, yūyās", rādhyās, badhyās, çrūyās; videṣ; padīṣ", modișīṣ. 
There are, of course, among the above a certain number of forms of doubtful classification, as to which opinions will differ, until criteria shall be found for fixing their place finally. And there are left a few residual words, of too uncertain character to go properly under any head. Thus, jñeșam, geșma, and stheșus (?) are the Atharvan examples of a formation of questionable belongings (see the author's Sanskrit grammar, $\$ 894$ c). The forms çarāis and açarāit and ásaparyāit have been reckoned as iṣ-aorists (as if equivalent to çaris etc.), and the isolaterl dhimahi as root-aorist optative; imahe has been put nowhere; avãdiran and ápeciran seem to be anomalous aorist-forms (unless the latter is better viewed as pluperfect). The $2 \mathrm{~d}$ sing. perf. iyátha (for iyetha or iyayitha) shows a mutilation also made in the Rig-Veda; in didhyus (Rig-Veda has dídhiyus) is

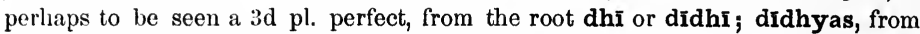
the same, is still more questionable. For minit is probably to be read mināt; and āitat, aṛnavat, ajāgan(?), cetatus equally call for amendment; sākșe has been treated as if sākşye (fut.) ; yame must be yamat or yamet; vidátha also needs emendation. The form bhartsyāmi (four syllables) is most probably bhatsyãmi (fut. of bhas); and abhartsatha (mss.) a corruption. Piprăyasva (for RV. piprayasva) seems to be trying to belong at once to prī and to prā; as made from the latter, it would be an example of a "double-stem" form. Double stems may be suspected in the forms classed above as perfect subjunctive, and are certainly to be seen in the participle vāvṛdhánt (RV. vavṛdhánt), and in neșa and parșa*, imperatives of the a-form from an s-aorist stem. Of the middle 1st persons sing. pres. from an s-aorist stem the only Atharvan example is stusé*. The participle sīsatî appears to belong to the root san or sā, but has no known parallel elsewhere.

\section{ADDITIONS AND CORRECTIONS.}

Below are given the results of an extensive series of verifications of the Index as printed. They include a further selection, for the first eighteen books, from the cases of discordant readings in the manuscripts--without, however, claiming fully to exhaust the list; that can on!y be properly done, in connection with conjectural emendation, in critical notes on the text, which I trust will not very much longer have to be waited for.

The material is given in the briefest intelligible form, with indication of page and column ( $\mathbf{a}$ or $\mathbf{b}$ ), and of line when the addition appears to be called for.

Page 14a. ágravas. 18. 2. 47 (m. mss. ed. agrá-).-16̂b. níoaktām (s. mss. ed. -tam).-17b, l. 2. insert: a ti $\circ \mathrm{tā} \mathbf{r}$ y à : -ríãs. 8. 2. 27.-do. atyāyám. ro. 8. $3^{\dagger}$--19b. ádbhutas. 5. 27. Io (s. p. mss. átobh-).-24a. anūpíâs. add I. 6.4 . -27a, 1. 47. $a d d$ sthā.-27b. áparāsas (s. mss. úp-").-34a. arárus (s. mss. ára-). -37b. avayắs (p. -yā).--do. dele avartsyánt.-39a. prầ "çis. I I. 3. 26 (prấçî́3s), 27 (do.).-do. 1. 35. insert: á ç a m. 2. 25. r.-42b. asnă. 5 [not 4]. 5. 8 . -do. ásatotarās.-48a, l. 27. add in the par. devāñjana.-50a, 1. 7. insert: a p p y a in samāpyà.-54b. yatís. 2. 5. 3.-55b. abhí ... etu (s. mss. eti*).-56a. āís (p. à éḥ, à âín).-68b, 1. 14. add dhmā, nah.-69a. dele upavañcana.-70b. 
ululáyas (s. mss. ulual-).-78b. oşám: add 8. 8. 18 (mss. āg̨-; ed. óg̨am).-79b. 1. 26. read -kata twice.-81a. lkartám (s. mss. kártum).-do. 1. 10. read kartṛ̂n. -86b. cakre. I. 24. I (mss. cák-).--87b, 1. i 6. reud hiñkụṇvatīt.-93b. kg̨ṇuvānás (m. mss. kşuṇuv-).-94h). nị̣ıkhídam (mss. -dan).-96h), ăgaman (p. à ag-).-97b. galuntás (s. mss. -lan-).-101a. gó t a m a (s. mss. gãút-).-do. read gó p a n a.-109a. citám. 18. 4. I4 (s. mss. ed. cittám).-112a. jajñisé. 5. 30. 17 (p. puruşaoja-).-113a. prá...jajñé (m mss. yaj-)--113b, 1. 33, insert: j a n i t a v y à, see under 1/jan.-116h. read jighatosúam.-123b. te. 5. 23. 4 (8. mss. té). 8. 2. 2I, 2 I (p. té).-124b. reud tatni, nitatni.--126b. tapyámăne (p. -e íti).-131a. read tṛ̣huâ.-132b. triṿ̛șás. 5 [not 6]. 16. 3--147a. devis. 6. 59. 2 (nom. sing. ?). - 151a, 1. 1. add in the par. dúrya.-155a. pári dadhmas ( 8. mss. dadm-).-156a, 1. 5. dele vasudhațr.-163a, 1. 8. insert: udoănaț. 6. 77.

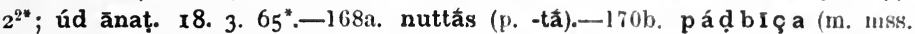
-ḍvī-).-172b, 1. 42. insert: + u pa: úpa padyatām. 4. 18.2.-175b, 1. 27. add çās.-177a. palăvān (s. mss. -vām).--181a. anuopāláyantĩ (s. mss. -pādá-).184a, 1. 37. read: -bhúvās. I. 27. 2 ; punarbhúvã. 9. 5. 28.-188a. prṇakṣi (8. mss. -nák-).-190a, 1. 13. dele ed.-193b. pratyáñcam. I I. 3. 26 (-áñcẳ3m).197a. priyăn (s. mss. apr-).-201b. budhnyât (s. mss. -nầt).—208b. bhavatha. I. 4 . 4 (m. mss. bháv-), 4.-223a. mâ. 5. 18. 3 (s. mss. sầ)--225a. mãyă (p. -yăh).-228a. ví ... muñcantām (s. mss. ed. mucyantām).-241b. ã yavan. 3. 17. $2^{\dagger}[$ not 6].-242a, 1. 40. dele 6. 54. 1.-244a. rakşatām. 8. 1. 12 (s. mss. rák-):-249a. riçâdās (p. -dā).-250b, 1. 16. insert: r u çá ma: -meşu. 20. 127. I.-251a. à rukșas (s. mss. aru-).-256a. dele 11. 18, 19.-257a. upaoprávada (s. mss. úpa).-do. viovádat. 3. 3. 7 [not 6].-259b. váruna. 7. 83. 2 (p. -ṇah).-260b. dele 1. 19.—267a. vắsasā. 14. I. 27 (m. mss. -asasł).-27la. vidhús (s. mss. vidús).-274b. vi ç vá tovīry a (p. -taḥov-).-276b. ăovișțitāni (p. -isti-).-279b, 1. 28. dele (? p. av-).-280b. vṛdhāma (s. p. mss. ávivṛdh-).-281b. read abhyávarșīt.-283a, 1. 11. add -ttānām.-284a. vioadhvarăs (s. mss. -adva-, -addhva-, etc.).-285b. çaknuvánti (p. -nu॰vá-).-289b, 1. 42. insert: çavartá, see çvav---293a. çumbhantu. 18. 3. $5^{6^{\dagger}}$ (s. mss. -atu, -ata).-294b. ví çarāis (s. mss. -rīs).--296b, 1. 38. read çruvantu. I 8. 3. 45*.-298a. ६̧vavartébhyas (s. mss ça॰v-) - -299 b, 1. 34. read (cf. eșá, saká.).--304a. sánīās (m. mss. -dāt).-304b. read s a ॰ pá tn a ---305a. saptá. 6. 25.2 (m. mss. od. sápta.).-307a, 1. 23. insert: s a moā p y à: -píãs. I 1. 3. 19.-31ib. suphală (p. lăḥ).-325a, 1. 13. add dușțará ?.—325b, l. 3. read stumás.--326b. tíșțan. 7. 102. I (mss. tiṣ-).-328a. prátișţhitā (p. -tāh ).-do. ví taşțhe (s. mss. cașțe ; p. ed. tasthe).-330b. suâs. I8. 2. 29 (? p. svănaḥ).--335b. hántā (s. mss. hantâ).-337a. hásas (s. mss. hasás).-337b. ní ... hīyatām (s. mss. ví).— 338a. read parihinómi.-342a. hṛșităsas (s. mss. dhṛṣ-). 
11964

94 
2 


v 
PK

3409

W5

1881
Whitney, William Dwight Index verborum

\section{PLEASE DO NOT REMOVE}

CARDS OR SLIPS FROM THIS POCKET

UNIVERSITY OF TORONTO LIBRARY 

